\title{
DIE BEDEUTUNG DER SCHULE FÜR DIE „HEIMATFRONT“ IM ERSTEN WELTKRIEG
}

Sammlungen, Hilfsdienste, Feiern und Nagelungen im Deutschen Reich

\section{DISSERTATION}

zur Erlangung des Philosophischen Doktorgrades an der

Georg-August-Universität Göttingen

\author{
vorgelegt von
}

Martin Kronenberg

aus Berlin

Göttingen 2010 
VORWORT 4

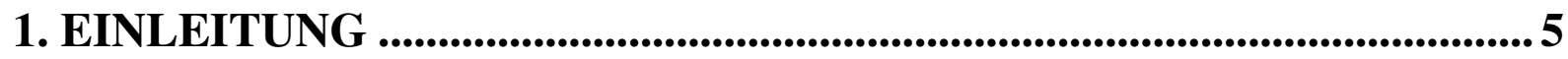

1.1 AllgEMEINE SitUATION DER SCHULEN IM KAISERREICH VOR DEM ERSTEN WELTKRIEG 5

1.1.1 Möglichkeiten und Grenzen staatlicher Schulpolitik ............................................ 5

1.1.2 „, Geistige Mobilmachung “ in den Jahren 1890 bis 1914 ...................................... 14

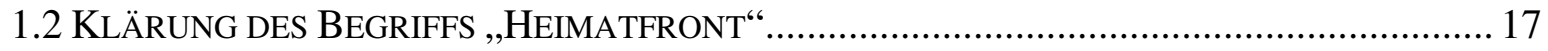

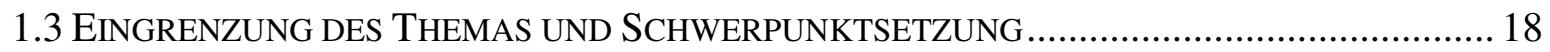

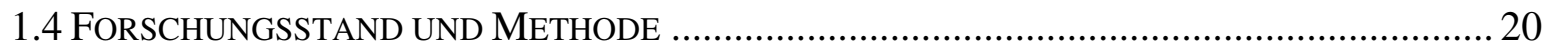

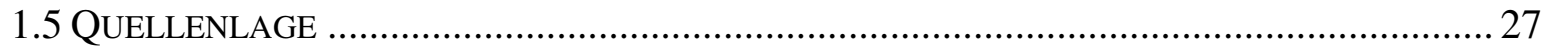

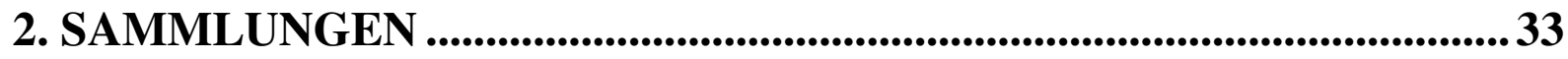

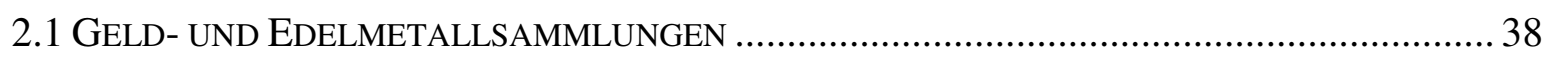

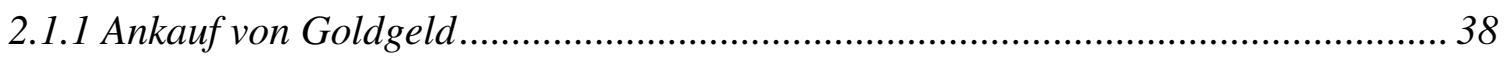

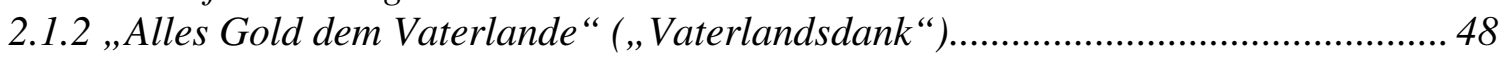

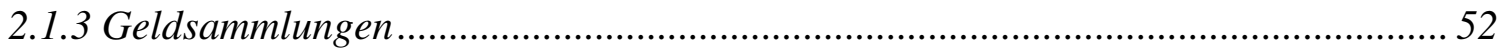

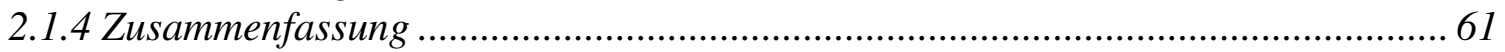

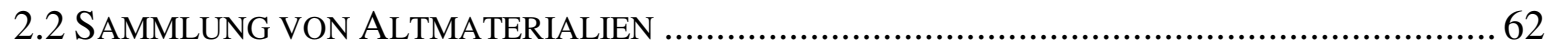

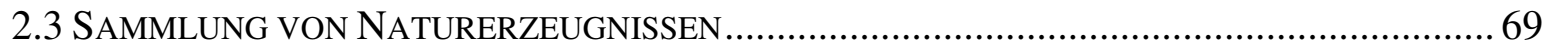

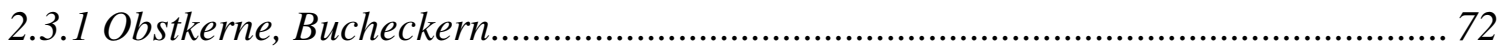

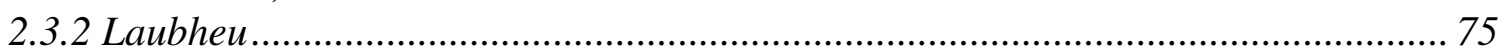

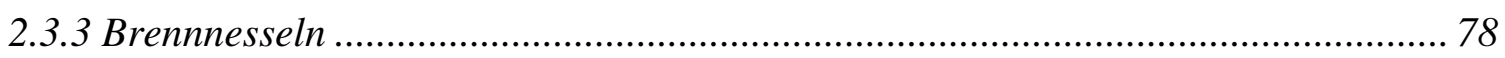

2.3.4 Kaffee- und Tee-Ersatzmittel ...................................................................... 83

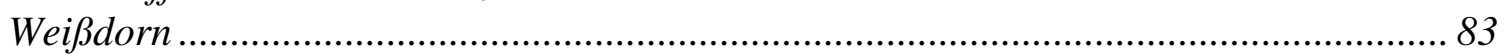

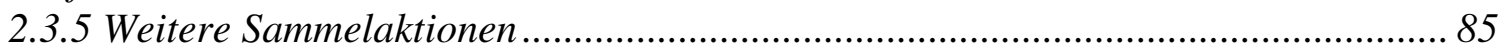

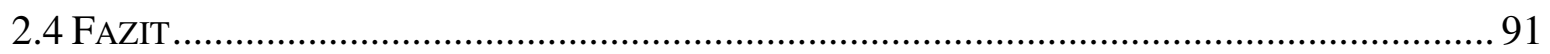

3. KAUFS- UND VERKAUFSAKTIONEN ..............................................95

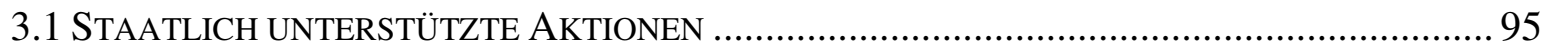

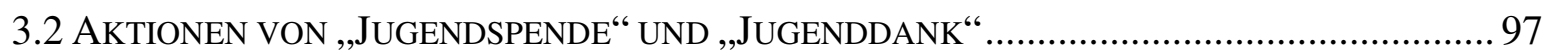

3.3 AKTIONEN VON ALLGEMEINEN WOHLFAHRTSVERBÄNDEN UND EINZELNEN SCHULEN . 103

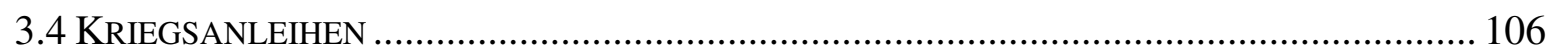

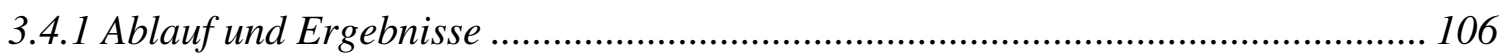

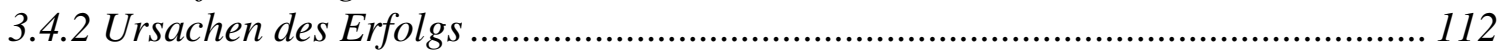

3.4.3 Vorbehalte, Kritik und Widerstände ..................................................................... 120

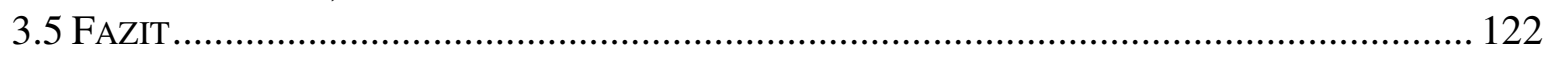

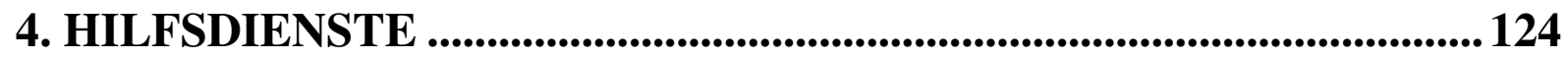

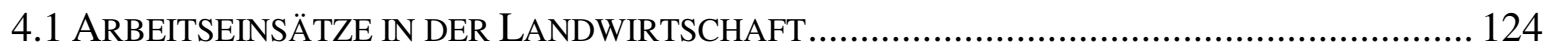

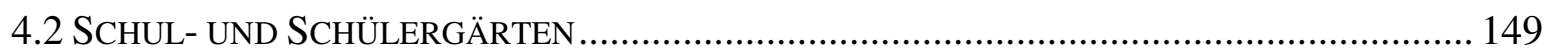

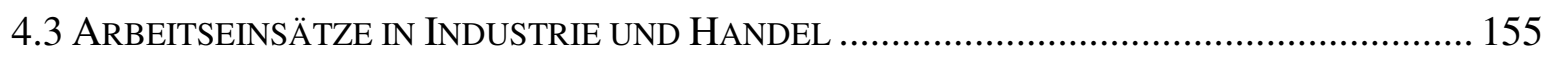

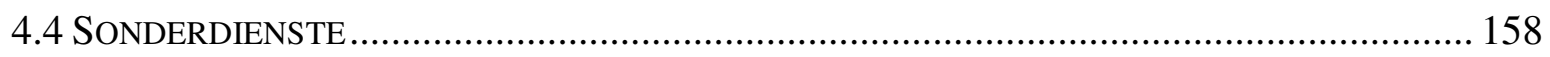

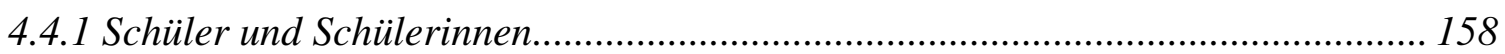

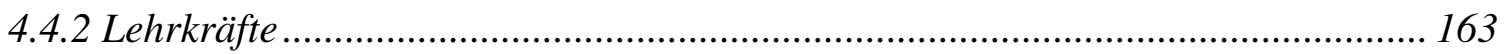

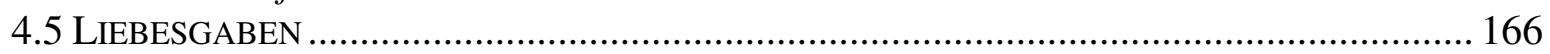

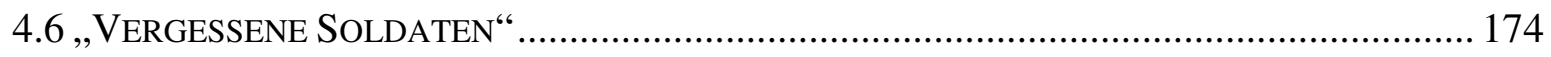

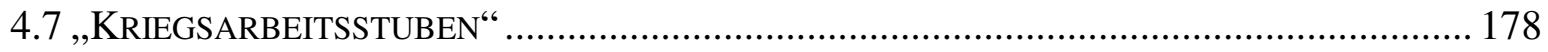

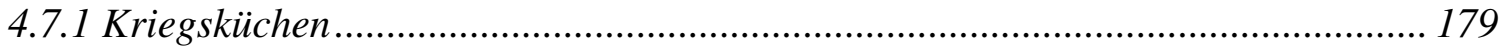

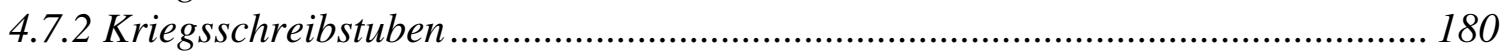

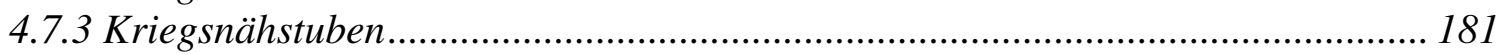

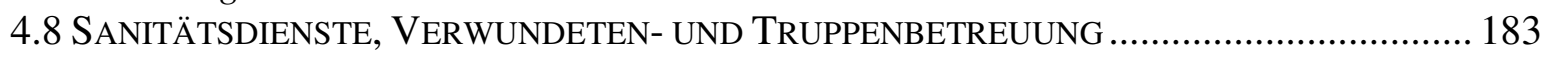


4.9 FAZIT 190

5. PATRIOTISCHE FESTE UND FEIERN

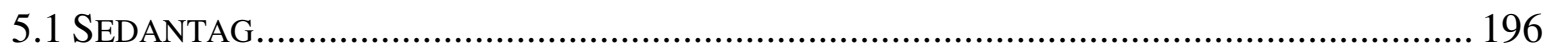

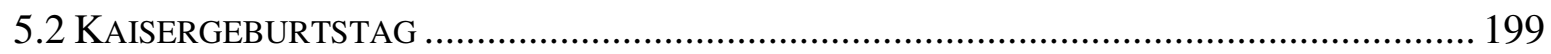

5.2.1 Vorbereitung und Ablauf................................................................................ 204

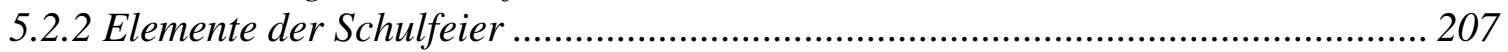

5.2.3 Reaktionen der Teilnehmer und Berichterstattung in der Presse ......................... 211

5.2.4 Entwicklung der nationalen Schulfeiern im Krieg ......................................... 213

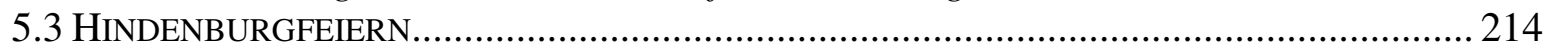

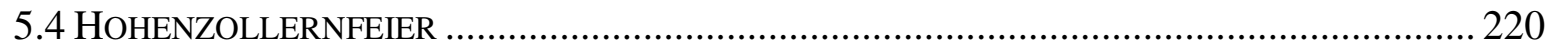

5.5 400JÄHRIGER GEDENKTAG DER REFORMATION (31. OKTOBER 1917)........................... 223

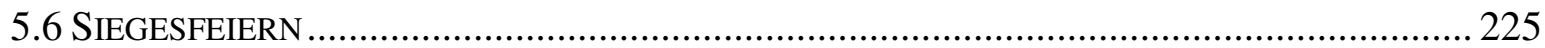

5.7 GEDENKFEIERN FÜR GEFALLENE SCHÜLER UND LEHRER ........................................... 234

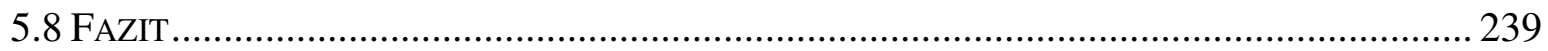

6. VERANSTALTUNGEN ZU WOHLTÄTIGEN ZWECKEN .................. 241

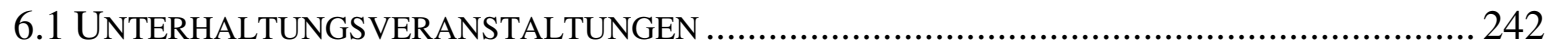

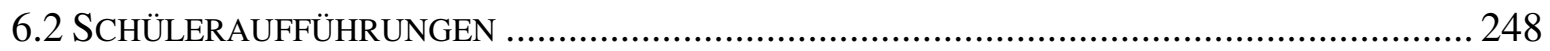

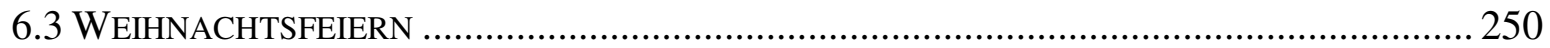

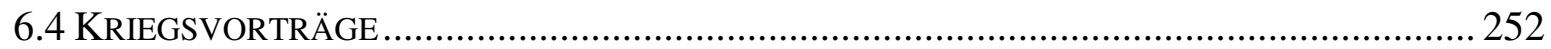

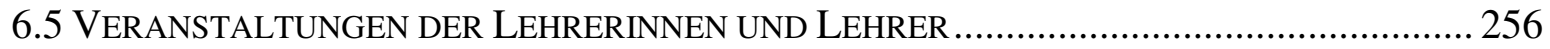

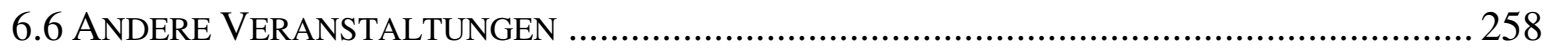

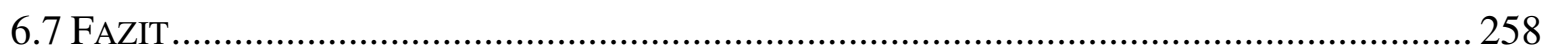

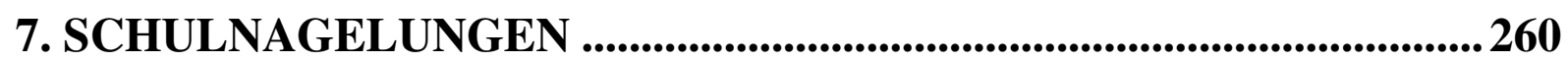

7.1 ALLGEMEINE NAGELUNGEN - URSPRÜNGE UND ENTWICKLUNG BIS 1918 ....................260

7.2.1 „Verein Jugendspende für Kriegerwaisen “......................................................... 266

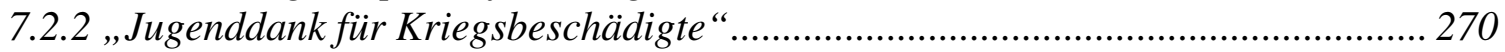

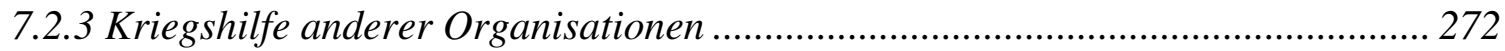

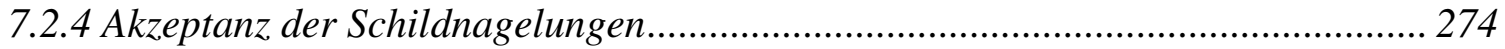

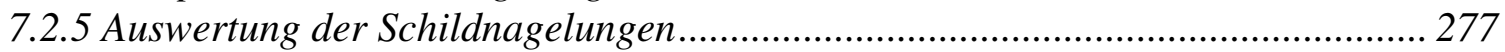

7.2.6 Individuelle schuleigene Nagelobjekte ............................................................. 281

7.2.7 Einweihungsfeiern und Ablauf der Nagelungen................................................ 287

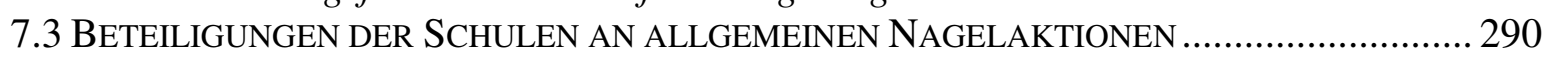

7.3.1 Schulleiter und Lehrer in Arbeits- und Festausschüssen .................................... 290

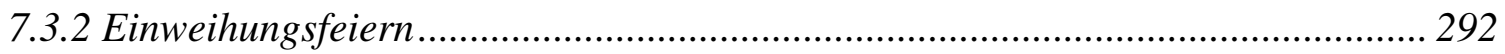

7.3.3 Finanzielle Unterstützung von Schülern ........................................................... 304

7.3.4 Nagelungstage und andere Aktionen der Schulen.............................................. 307

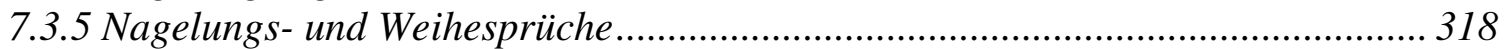

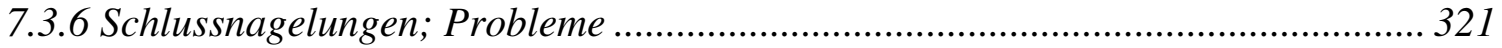

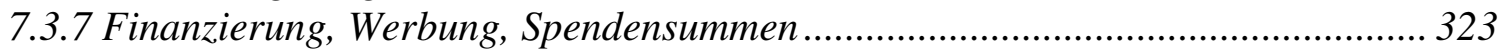

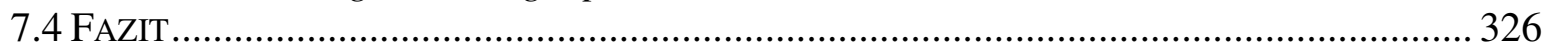

8. SPAREN UND EINSCHRÄNKUNGEN...................................................329

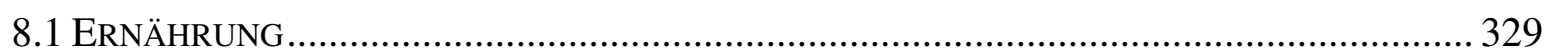

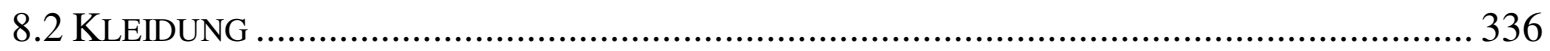

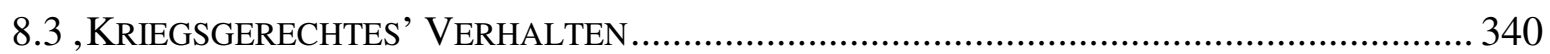

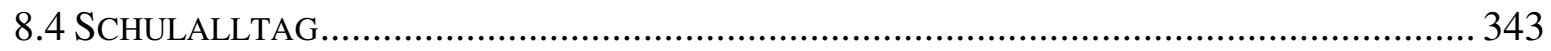

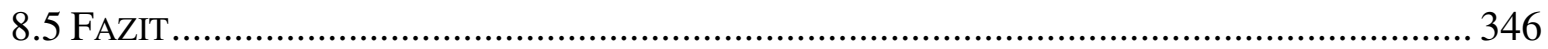


9. KRIEGSUNTERRICHT

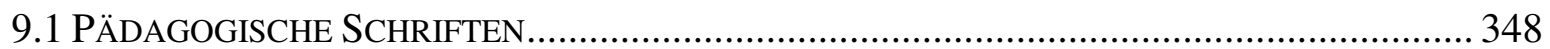

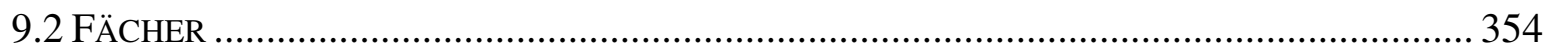

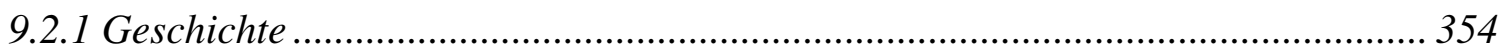

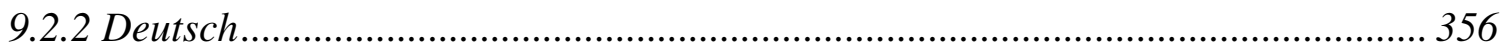

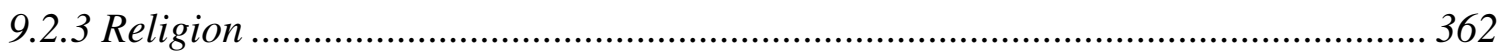

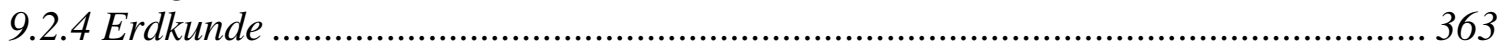

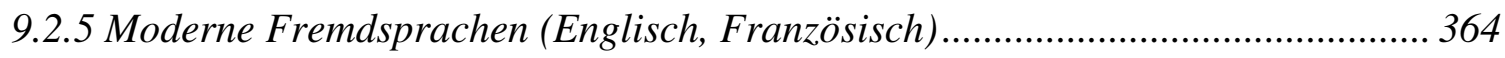

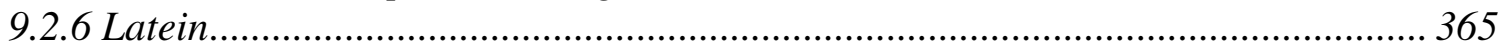

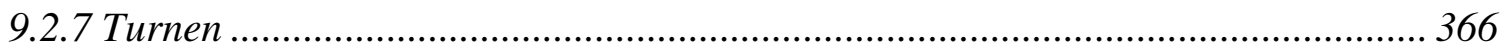

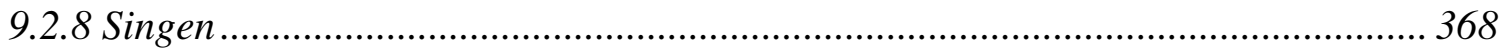

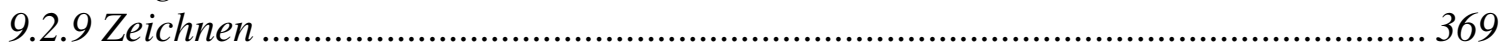

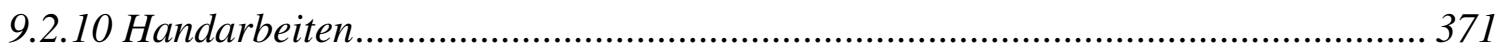

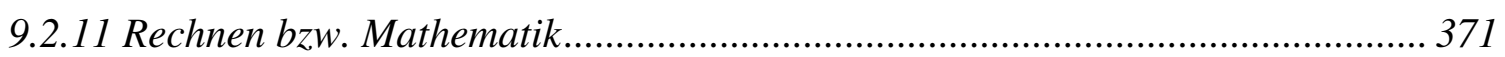

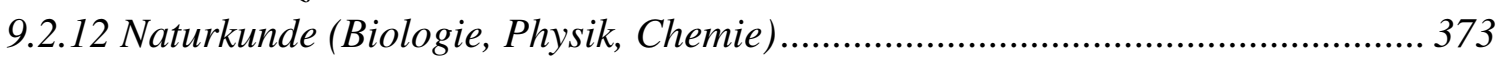

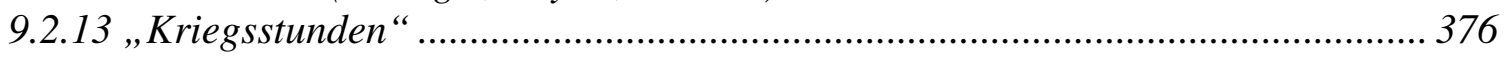

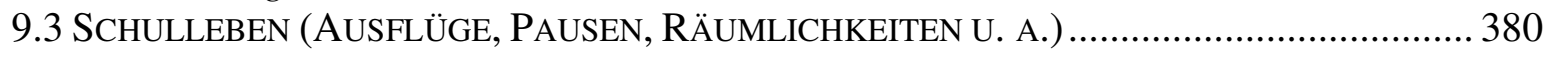

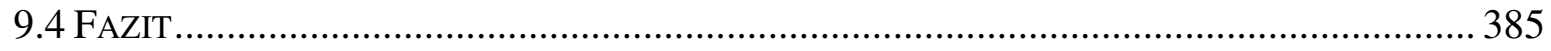

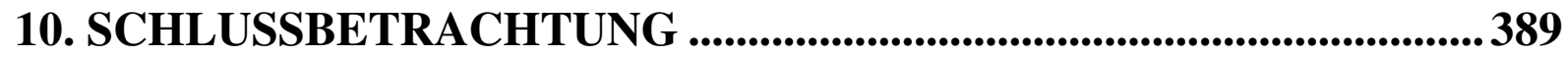

QUELLEN- UND LITERATURVERZEICHNIS .....................................400

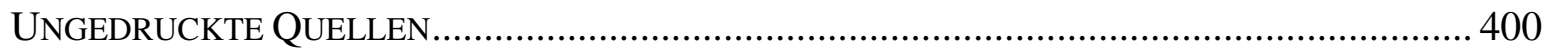

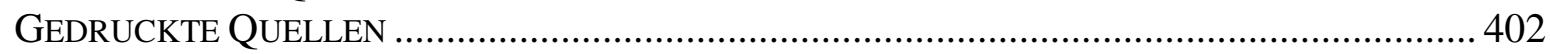

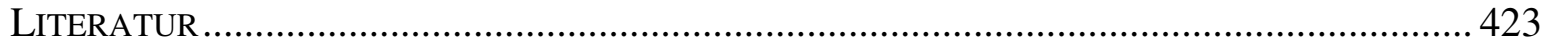

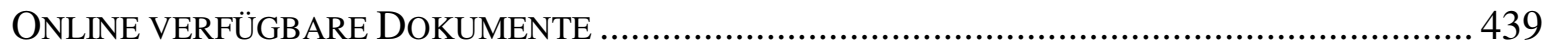

ABKÜRZUNGSVERZEICHNIS.................................................................. 445

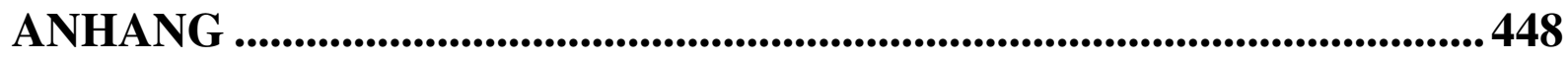




\section{Vorwort}

Seit Jahren habe ich über das weitgehend unbekannte Gebiet der Nagelfiguren im Ersten Weltkrieg geforscht, insbesondere auch über die Nagelungen in den Schulen, soweit mir meine Tätigkeit als Gymnasialdirektor dazu Zeit ließ. Deshalb lag es nach meiner Pensionierung nahe, die Arbeit zu intensivieren und die Ergebnisse im Rahmen einer größeren wissenschaftlichen Abhandlung darzustellen.

Für die Idee, das Thema zu erweitern und neben den schulischen Spendennagelungen auch Sammlungen, Hilfsdienste und andere patriotische Bemühungen der Schulen im Rahmen der „Heimatfront“ zu untersuchen, danke ich Herrn Prof. Dr. Michael Sauer ebenso wie für die stets hilfreiche und angenehme Betreuung. Er begleitete den Fortgang der Arbeit mit vielen Hinweisen und Anregungen.

Ein besonderer Dank gilt auch Herrn Prof. Dr. Gerhard Schneider, dessen grundlegende wissenschaftliche Veröffentlichungen zur Erinnerung an die weitgehend vergessenen Kriegswahrzeichen geführt haben, für seine Bereitschaft, die Arbeit als Zweitgutachter zu begleiten, ebenso für seine vielen Ratschläge und den langjährigen fruchtbaren Gedankenaustausch über die Kriegsnagelungen.

Ich danke ebenfalls Herrn Dr. Pust (Stuttgart) und Frau Dr. Munzel-Everling (Wiesbaden), die mir häufiger interessantes Bildmaterial zukommen ließen.

Teilweise konnte ich bei meinen Untersuchungen über die schulischen Kriegsnagelungen auch auf die Ergebnisse von umfangreichen Recherchen meines letzten Leistungskurses im Fach Geschichte (Abitur 2006) zurückgreifen, wofür ich den ehemaligen Schülerinnen und Schülern danken möchte.

Mein letzter Dank gilt meinen Freunden und besonders meiner Familie für das Interesse an meiner Arbeit sowie die vielfältige Unterstützung. Durch Vermittlung meines Sohnes Prof. Dr. Felix Kronenberg war es z. B. im Herbst 2008 möglich, im Rahmen einer Fortbildung einen Vortrag im Pomona-College in Claremont (Los Angeles), wo er damals beschäftigt war, einige Ergebnisse meiner Arbeit vor Studenten und Professoren vorzustellen.

Für das Korrekturlesen danke ich in erster Linie Herrn Klemens Weilandt. Mein Dank gilt aber auch besonders meiner Frau, Dagmar Kronenberg, meinen Kindern Marion Fiene, Florian und Felix Kronenberg, meinem Bruder Axel Kronenberg und meiner Schwester Dr. Uta Scheidemann sowie Christian Fauth von Kreitmayr, Adolf Ludy, Anneliese Niehus, Hans Tegtbauer und Andreas Randt. 


\section{Einleitung}

\subsection{Allgemeine Situation der Schulen im Kaiserreich vor dem Ersten Weltkrieg}

\subsubsection{Möglichkeiten und Grenzen staatlicher Schulpolitik}

Im Gebiet des Deutschen Reiches war die Bedeutung der Schule nach den erfolgreichen Freiheitskriegen gegen die Napoleonische Herrschaft in den ersten zwei Dritteln des 19. Jahrhunderts ständig gewachsen. Nach Thomas Nipperdey hatten sich die Gesellschaft „zu einer Schulgesellschaft“" und der Staat zu einem „Schulstaat“ entwickelt. Die Schule war ein „wesentlicher Teil der politisch-sozialen wie der kulturellen-moralischen Ordnung ${ }^{\text {‘2 }}$ geworden. Sie spiegelte einerseits den Zustand der Gesellschaft wider und formte ihn andererseits entscheidend mit, indem sie die zukünftigen Generationen mitprägte. Deshalb war es für das 1871 neugegründete Deutsche Reich von existenzieller Bedeutung, wer die Rahmenbedingungen, Unterrichtsinhalte und Lernziele setzte sowie das Lehrpersonal ausbildete, einstellte, normierte und kontrollierte.

\section{$\underline{\text { Volksschulen }}$}

Neben dem Staat waren es vor allem die Kirchen und die Gemeinden, die Bestimmungsrechte für sich beanspruchten, und zwar in erster Linie über die Volksschulen. Sie wurden von der überwiegenden Mehrheit des Volkes besucht ${ }^{3}$ und entsprechend groß war nach der Einführung des allgemeinen, gleichen, geheimen und direkten Wahlrechts zum Reichstag ihre politische Bedeutung, denn in ihr wurde die große Mehrheit der zukünftigen Wähler erzogen. Deshalb war die Frage, wer den entscheidenden Einfluss auf die Volksschulen haben sollte, für die Schulpolitik von zentraler Bedeutung. Stärker als früher war der Staat z. B. auf „soziale Disziplin und politische Loyalität der Massen“ angewiesen. Während die ältere Forschung die Volksschulpolitik einseitig als Versuch der „,Perpetuierung’ (...) der ,gesellschaftlichen Machtverhältnisse”“ deutete und in den Schulen „Untertanenfabrik(en)“4 sah, in denen die Schüler zu gehorsamen Untertanen erzogen und auf einen Krieg vorbereitet wurden, kommen Historiker seit den 80er Jahren verstärkt zu differenzierteren Ergebnissen.

\footnotetext{
${ }^{1}$ Nipperdey, Wie modern war das Kaiserreich? (1986), S. 531.

${ }^{2}$ Nipperdey, Wie modern war das Kaiserreich? (1986), S. 531.

${ }^{3}$ Im Jahre 1911 waren es z. B. auf dem Land 84\%; siehe: Müller/Zymek/Herrmann, Datenhandbuch zur deutschen Bildungsgeschichte (1987), S. 300.

${ }^{4}$ Kuhlemann, Niedere Schulen, in: Berg (Hrsg.), Handbuch der deutschen Bildungsgeschichte IV (1991), S. 179.
} 
So habe beispielsweise die Volksschulpolitik durch die Alphabetisierung die „kulturellen und politischen Partizipationschancen breiter Bevölkerungsschichten unstreitig erhöht" ${ }^{* 5}$. Betont wird auch, dass die Schule trotz entsprechender Bildungsvorgaben ,weder den Aufstieg der Sozialdemokratie noch den generellen Linkstrend der Wählerschaft im Kaiserreich habe verhindern können“. Auch die Frage, warum die staatliche Bildungspolitik, die auch eine Politik der Disziplinierung der Bevölkerung war, so wenig erfolgreich war, wird immer wieder gestellt. Im Folgenden soll vor allem am Beispiel Preußens ${ }^{6}$ zunächst auf die Frage nach der Wirksamkeit der staatlichen Schulpolitik und möglichen Gründen für deren Begrenztheit eingegangen werden, da die faktischen Einwirkungsmöglichkeiten des Staates für die Beurteilung des schulischen Einsatzes an der „Heimatfront“ während des Ersten Weltkriegs von groBer Bedeutung sind.

Das preußische Volksschulwesen hatte sich ,seit jeher in lokalen und regionalen Varianten sowie in Abhängigkeit von diversen provinziellen und örtlichen Sonderregelungen entwickelt“" und alle Versuche des Staates, es durch ein für Gesamtpreußen gültiges Unterrichtsgesetz zu vereinheitlichen, scheiterten. Neben den Schulen in staatlicher Trägerschaft existierten in großer Zahl Konfessions- und Gemeindeschulen, sodass hinsichtlich der Volksschule nicht von einer „Staatsschule“ gesprochen werden kann, sondern eher von einer „Gemeindeschule“6 Streit gab es immer wieder um die Finanzierung der Schulen, da der Staat sich bei der Finanzierung der Volksschulen nur widerstrebend engagierte. So betrug beispielsweise 1901 der Staatsanteil an der Finanzierung der Volksschulen auf dem Land lediglich $37 \%$ und in den Städten nur 11,3\%. Auch wenn aufgrund des Schulunterhaltungsgesetzes (1906) und vielfältigen gesellschaftlichen Drucks der Staat sich finanziell stärker an der Schulunterhaltung beteiligte, so ist die These vom „überragenden Einfluss des Staates“, die insgesamt von der älteren Forschung vertreten wurde, schon aufgrund der Finanzierung der Volksschulen falsch. ${ }^{9}$

Recht groß war auch der Einfluss der Kirche als weiterem „Schulinteressenten“, der dem staatlichen Einfluss in der Volksschule Grenzen setzte. Da sich die im Kulturkampf errichte-

\footnotetext{
${ }^{5}$ Kuhlemann, Niedere Schulen, in: Berg (Hrsg.), Handbuch der deutschen Bildungsgeschichte IV (1991), S. 179.

${ }^{6}$ Die Darstellung der Schulgeschichte orientiert sich weitgehend am Beispiel Preußens. In den anderen deutschen Ländern verlief die Entwicklung ähnlich, auch wenn die süddeutschen Länder teilweise Sonderwege beschritten. Wohl aufgrund der Größe Preußens und der durch die Personalunion von Landesherr und Kaiser engen Verzahnung der preußischen Politik mit der Reichspolitik beschäftigen sich die meisten entsprechenden wissenschaftlichen Untersuchungen mit Preußen. Für Württemberg liegt allerdings eine ausführliche Geschichte der Volksschule im 19. Jahrhundert vor: Friederich, Die Volksschule im Württemberg im 19. Jahrhundert, in: Führ/Mitter (Hrsg.), Studien und Dokumentationen zur deutschen Bildungsgeschichte (1991).

${ }^{7}$ Kuhlemann, Niedere Schulen, in: Berg (Hrsg.), Handbuch der deutschen Bildungsgeschichte IV (1991), S. 180.

${ }^{8}$ Im Jahre 1901 waren $75 \%$ aller Volksschulen formal Gemeindeschulen (siehe: Nipperdey, Deutsche Geschichte (1994), Band 1, S. 532).

${ }^{9}$ Die Mittelschulen waren noch stärker von den Gemeinden abhängig, da sie in der Regel überhaupt keine staatliche Unterstützung bekamen; siehe: Kuhlemann, Niedere Schulen, in: Berg (1991), S. 182.
} 
ten „Simultanschulen“ nicht hatten durchsetzen können, dominierten bis zum Ende des Kaiserreichs in Preußen die Konfessionsschulen, die kirchlich geprägt waren und in der Regel auf Orts- und Kreisebene geistlicher Schulaufsicht unterstanden. Daran hatten nach FrankMichael Kuhlemann auch das Schulaufsichtsgesetz von 1872 und der sog. „Schulkompromiss“ von 1904 nichts ändern können. ${ }^{10}$ Dem Staat war es nicht gelungen, den geistlichen Einfluss entscheidend zurückzudrängen.

Ein weiterer Grund für die Begrenztheit staatlichen Handelns lag in der Kinderarbeit, die auch im Kaiserreich durchaus noch existierte. Zwar war die Fabrikarbeit in der zweiten Hälfte des 19. Jahrhunderts gesetzlich eingegrenzt worden, in erheblichem Maße arbeiteten allerdings schulpflichtige Kinder in der Heimindustrie, in gewerblichen Kleinbetrieben und vor allem in der Landwirtschaft. Beispielsweise sollen im Jahre 1898 in Preußen 269.598 Kinder gewerblich tätig gewesen sein und 1904 im Deutschen Reich 1.769.803 Kinder in der Landwirtschaft gearbeitet haben (insgesamt etwa $20 \%$ aller schulpflichtigen Kinder ${ }^{11}$ ). Die sporadische Teilnahme dieser Kinder am Unterricht belastete das schulische Lernen in erheblichem Maße. Neben Staat, Gemeinde und Kirche war aber auch die Schule selbst als Institution von Bedeutung, denn „sie hatte ein Eigengewicht, das über Schulverwaltungsbeamte, Seminardirektoren und -lehrer, pädagogische Wissenschaft und pädagogische Öffentlichkeit und zuletzt über die Lehrerverbände zur Geltung kam“"12. Großen Einfluss auf das Schulleben hatte vor allem die Schulbürokratie, die ,eine Art dynastischer pädagogischer Provinz “13 war. Zu diesem System, in dem die „kleine Schulpolitik vor Ort“, die mit der staatlichen nicht immer übereinstimmte, gemacht wurde, gehörten neben den genannten Einflussfaktoren die geistlichen Schulaufseher, die städtischen Magistrate, Schulpatrone, die Eltern der Schulkinder, die Parteien und die Volksschullehrer. Da vor allem die Lehrer für die Umsetzung der staatlichen Bildungsvorgaben von Bedeutung waren, soll auf ihre Stellung und Einstellung zum Staat näher eingegangen werden.

Die Lehrer stammten zum größten Teil aus der kleinen Mittelschicht und ländlichen Unterschicht. Sie absolvierten nach dem Volksschulabschluss die Präparandenanstalt, der ein dreijähriges Seminar folgte. Ihr Berufsstand war wenig angesehen und ihre Tätigkeit wurde schlecht bezahlt. Erst im letzten Drittel des 19. Jahrhunderts verbesserte sich ihre wirtschaftliche und soziale Lage deutlich. Im Jahre 1895/96 wurden sie z. B. mit den Absolventen der Sekundareife gleichgestellt und damit zum einjährig-freiwilligen Militärdienst zugelassen,

\footnotetext{
${ }^{10}$ Kuhlemann, Niedere Schulen, in: Berg, Handbuch der Deutschen Bildungsgeschichte (1991).

${ }^{11}$ Kuhlemann, Niedere Schulen in: Berg (1991), S. 182.

${ }^{12}$ Nipperdey, Deutsche Geschichte (1994), Band 1, S. 533.

${ }^{13}$ Zitiert nach: Herrlitz/Hopf/Titze/Cloer, Deutsche Schulgeschichte von 1800 bis zur Gegenwart (2005), S. 123.
} 
was ihnen die Möglichkeit bot, zum Reserveoffizier zu avancieren. Die Entwicklung von einem ,problematischen, semiprofessionellen, ungesicherten zu einem konsolidierten und pro-

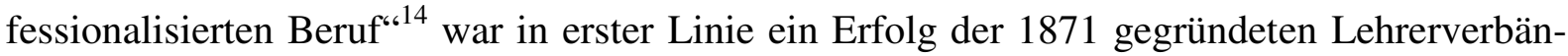
$\mathrm{de}^{15}$, die einen sehr hohen Organisationsgrad aufwiesen. Nachdem sie zunächst dem Staat gegenüber oppositionell eingestellt waren, wurde ihr Verhältnis pragmatischer und sie betrieben eine sehr erfolgreiche Interessen- und Statuspolitik.

Im Vergleich mit anderen Staatsbeamten jedoch blieben die Volksschullehrer trotz der Statusverbesserung hinsichtlich des Einkommens, des Sozialprestiges und der Eigenverantwortlichkeit benachteiligt. Sie waren von Gemeinde, Kirche und Staat abhängig und standen als Unterrichtsbeamte unter ständiger Kontrolle. Ihre berufliche Existenz, und zwar nicht nur in materieller Hinsicht, war vom politischen und religiösen Wohlverhalten abhängig; so durften sie z. B. keine Sozialdemokraten sein. Waren die Volksschullehrer anfangs mehrheitlich dem bürgerlich-monarchischen System gegenüber oppositionell eingestellt, so waren sie nach 1871 wie die Mehrheit der Deutschen national gesonnen. Sie verstanden sich gern als Sieger von Königgrätz (1866) und Sedan (1871) und trugen den „Konsensnationalismus““16. Diese Haltung war für ihre Einstellung zum nationalen Militarismus, zum Weltkrieg und sicher auch für ihren Einsatz an der „Heimatfront“ von großer Bedeutung. ${ }^{17}$ Trotz der o. g. Abhängigkeiten vom Staat, der Schulbürokratie, den Gemeinden und der Kirche, die die Lehrer insgesamt als „unerträgliche Zumutung für den gesamten Stand“"18 empfanden, besaßen sie insgesamt durchaus Gestaltungsmöglichkeiten und blieben bei der Umsetzung der staatlichen Bildungsund Lernziele ein wichtiger Faktor. Dieses traf besonders auf die Gruppe der Hauptlehrer zu. Sie wurden von der Behörde auf Lebenszeit eingesetzt und ,herrschten' häufig als Vorgesetzte in ihren Schulen, wie die „Instruktion für die Lehrer und Lehrerinnen an den öffentlichen Volksschulen in Hamburg“ von 1872 und 1882 zeigt: „Der nächste Vorgesetzte der Lehrer ist der Hauptlehrer, dessen Anordnung in allen den Unterricht und die Disziplin betreffenden Gegenständen sie pünktlich zu befolgen, dessen Weisungen und Erinnerungen sie mit

\footnotetext{
${ }^{14}$ Nipperdey, Deutsche Geschichte (1994), Band 1, S. 545.

${ }^{15}$ Deutscher Lehrerverein 1871, Landesverein preußischer Volksschullehrer 1871, Bayerischer Lehrerverein 1871.

${ }^{16}$ Nipperdey, Deutsche Geschichte (1994), Band 1, S. 545.

${ }^{17} 1912$ dienten im Deutschen Reich 46\% aller eingezogenen Volksschullehrer freiwillig (siehe: Kuhlemann, Niedere Schulen, in: (Hrsg.), Handbuch der deutschen Bildungsgeschichte IV (1991), S. 359). Auch die Tatsache, dass von den vielen Lehrern, die im August 1914 Soldaten wurden, darunter allein $~ 40.000$ preußische Volksschullehrer, ein großer Teil sich freiwillig gemeldet hatte, zeigt die loyale und patriotische Einstellung zum Staat.

${ }^{18}$ Kuhlemann, Niedere Schulen, in: Berg (Hrsg.), Handbuch der deutschen Bildungsgeschichte IV (1991), S. 368.
} 


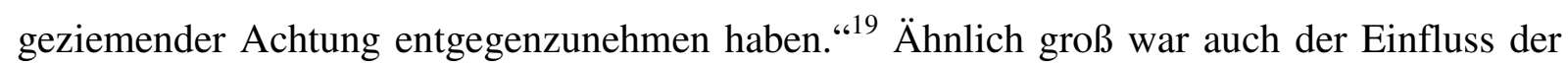
Rektoren und der Schulleiter der anderen Schulformen. Da sie im Deutschen Reich „eindeutig als verlängerter Arm der Schulbürokratie“ ${ }^{60}$ fungierten, hatte der Staat durch sie große Einflussmöglichkeiten auf das Verhalten der Lehrer.

Zusammenfassend kann zur Situation der Volksschullehrer vor dem Ersten Weltkrieg festgestellt werden, dass sie als Stand „sozial abgesichert und politisch zuverlässig“‘21 in der Gesellschaft verankert waren.

Im Folgenden soll dargestellt werden, inwieweit der Staat durch den Unterricht die zukünftigen Untertanen auf ihre Rolle im nationalen Obrigkeitsstaat und in einen möglichen Einsatz im Krieg vorbereitete. Da nur wenige neuere Arbeiten über die Entwicklung der Volksschulgeschichte in den außerpreußischen Staaten vorliegen, stehen Unterricht und Lernhalte der preußischen Schulen im Zentrum der Betrachtung. Über die pädagogischen Ziele der Schule bestand weitgehend Einigkeit: Sie sollte,,sozial disziplinieren, konservativ-monarchisch und bürgerlich prägen und binden, antisozialdemokratisch vor allem, sie sollte Pflicht und Gehorsam, die ,richtige“ Gesinnung und Loyalität verbreiten und festigen, sollte die Zöglinge gegen Systemkritik immunisieren, die soziale Differenzierung der Gesellschaft legitimieren.“ ${ }^{\text {22 }}$ Bei der Umsetzung der Ziele kam vor allem den Fächern eine wichtige Bedeutung zu, die auf besonders auf Gesinnungs- und Charakterbildung zielten. Neben Deutsch und Religion als gesinnungsbildenden Fächern war es vor allem Geschichte, das für die nationale und vaterländische Erziehung eine besonders wichtige Rolle spielte. „Kein anderes Fach war so gut geeignet, die Ideologie und den Nationalgedanken in die Herzen der Kinder einzupflanzen, wie der Geschichtsunterricht.“ ${ }^{23}$ Auch wenn die „Allgemeinen Bestimmungen von 1872“ für die Volksschulen Geschichte noch nicht als eigenständiges Fach mit festen Wochenstunden vorsah und geschichtliche Themen häufig im Deutschunterricht behandelt wurden, ist vor allem nach dem Kaisererlass von 1889 die Bedeutung geschichtlicher Erziehung ständig gewachsen. So sollten den Schülern die Verdienste preußischer Herrscher der jüngsten Geschichte noch deutlicher gemacht und den Schülern das Gefühl vermittelt werden, und Mitglieder einer groBen mächtigen Kulturnation zu sein. In den Methodischen Weisungen vom 31. Januar 1908 wird beispielsweise verlangt,“ wie dies bereits die Lehrpläne für

\footnotetext{
${ }^{19}$ Zitiert nach: Lehberger, Schule in Hamburg während des Kaiserreichs, in: Stephan/Winter (Hrsg.), "Heil über dir, Hammonia" (1992), S. 435.

${ }^{20}$ Zitiert nach: Herrlitz/Hopf/Titze/Cloer, Deutsche Schulgeschichte von 1800 bis zur Gegenwart (2005), S. 123.

${ }^{21}$ Kuhlemann, Niedere Schulen, in: Berg (Hrsg.), Handbuch der deutschen Bildungsgeschichte IV (1991), S. 368.

${ }^{22}$ Nipperdey, Deutsche Geschichte (1994), Band 1, S. 537.

${ }^{23}$ Kuhlemann, Niedere Schulen, in: Berg (Hrsg.), Handbuch der deutschen Bildungsgeschichte IV (1991), S. 206.
} 
Lehrerseminare und Präparandenanstalten vom 1. Juli 1901 festgesetzt hatten, für die Zukunft eine noch eingehendere Berücksichtigung der „,neuere(n)vaterländische(n), insbesondere der preußische(n) Geschichte“, der „um so mehr Zeit gewidmet werden (kann), je mehr bei der älteren und mittleren Geschichte Beschränkung eintritt، ${ }^{\text {24 }}$. Darüber hinaus wurden in verschiedenen Handbüchern für den Geschichtsunterricht die Lehrer angehalten, ihren Schülern ein „obrigkeitlich-konservativ geprägtes Bewußsein von ihren Rechten und Pflichten als Staatsbürger ${ }^{25 ، ~ z u ~ v e r m i t t e l n . ~ D a z u ~ g e h o ̈ r t e ~ a u c h ~ d i e ~ B e r e i t s c h a f t, ~ d e m ~ V a t e r l a n d ~ z u ~ d i e n e n ~}$ und im erforderlichen Fall sogar sein Leben zu opfern. In der Vorkriegszeit wurde also bei den Schülern gezielt eine Wehrbereitschaft aufgebaut und verstärkt. Die Lehrer bereiteten sie im Unterricht ideologisch auf den Kampf an der „Heimatfront“ und ihren späteren Einsatz als Soldaten vor.

\section{Gymnasien}

Im Gegensatz zu den Volksschulen standen die höheren Schulen ${ }^{26}$ nicht im Mittelpunkt der politischen Auseinandersetzungen. Die Gymnasien beispielsweise waren in der Regel Staatsschulen, die der staatlichen Bürokratie unterstanden, und deshalb dem Einfluss der Kirche weitgehend entzogen. Die Freiheit der einzelnen Schule und der Lehrer war recht gering, da sie ,in steigendem Maße der bürokratischen Zentralisierung und Bürokratisierung“ unterlagen. Zwar gab es auch städtische Gymnasien, die die Städte selbst finanzierten, die staatliche Dominanz beim Personal und bei den Lehrplänen war aber in Preußen recht groß. ${ }^{27}$ Das Gymnasium galt als Eliteschule, die wichtige Berechtigungen verlieh (z. B. die Zulassung zum Studium und das militärische Einjährigenprivileg), und wurde im zweiten Drittel des 19. Jahrhunderts von den Kindern „der traditionellen Elemente der Gesellschaft “ ${ }^{28}$ besucht. Die Gymnasiallehrer („,Oberlehrer ${ }^{\text {‘29}}$ ) waren Beamte und damit dem kommunalen, kirchlichen

\footnotetext{
${ }^{24}$ Schneider, Der Geschichtsunterricht in der Ära Wilhelms II., in: Bergmann/Schneider (Hrsg.), Gesellschaft Staat Geschichtsunterricht (1982)., S.157. Schneider zitiert Ullmann, M./Fischer, E., Methodische Werke zur unterrichtlichen Durchführung der Allgemeinen Bestimmungen vom 15. Oktober 1872 und der „Weisungen“ vom 31. Januar 1908, Breslau 1917.

${ }^{25}$ Kuhlemann, Niedere Schulen, in: Berg (Hrsg.), Handbuch der deutschen Bildungsgeschichte IV (1991), S. 206.

${ }^{26}$ Zum höheren Schulwesen in Preußen gehörten gegen Ende des 19. Jahrhunderts Gymnasien, Realgymnasien und Oberealschulen. Um die Jahrhundertwende besuchten etwa 60\% aller höheren Schüler das Gymnasium. Aufgrund dieser Gewichtung und wegen der gesellschaftlichen Bedeutung der Gymnasien wird hier lediglich auf diese Schulform eingegangen. In den anderen deutschen Ländern war das höhere Schulwesen ähnlich organisiert (siehe: Kuhlemann, Niedere Schulen, in: Berg (Hrsg.), Handbuch der deutschen Bildungsgeschichte IV (1991) 251-252).

${ }^{27}$ In Bayern und in Sachsen war das staatliche Übergewicht noch größer (siehe: Nipperdey, Deutsche Geschichte (1994), Band 1, S. 547).

${ }^{28}$ Nipperdey, Deutsche Geschichte (1994), Band 1, S. 557.

${ }^{29}$ Bis zu einem Drittel konnte in Preußen den Professorentitel erlangen.
} 
und elterlichen Druck nur in geringem Maße ausgesetzt. Seit 1872 waren sie pensionsberechtigt.

Sie waren fast zu $100 \%$ im „Verband akademisch gebildeter Lehrer“ (seit 1921 „Philologenverband“) organisiert, der sich erfolgreich gegen die Angriffe auf die privilegierte Position $^{30}$ der Gymnasien zur Wehr setzte und politisch bürgerlich-konservative Positionen vertrat. „Das kollektive Statusstreben des Berufsstandes nach mehr Ansehen und Gehalt, vor allem nach voller Gleichstellung mit den akademisch gebildeten Beamtenklassen hatte nur deshalb Erfolg, da sich die Standesangehörigen mit den dominierenden Werten und der Privilegienstruktur der Gesellschaft identifizierten, an der sie teilhaben wollten. “31 ${ }^{31}$ Der nationalliberale Abgeordnete Dr. Röchling fasste den Anspruch und das Selbstverständnis der Oberlehrer 1907 folgendermaßen zusammen: „Ihre hohe Bedeutung liege darin, dass sie ,die Führer' zu erziehen hätten, die im Kampfe der Zukunft dem deutschen Volke die Feldzeichen voranzutragen hätten. “32 Von Lehrern mit einer dem Staat gegenüber derart loyalen Einstellung war zu erwarten, dass ihr Unterricht nationalem, monarchischem und patriotischem Geist geprägt war und sie sich in besondererem beim Einsatz an der „Heimatfront“ engagierten. Trotzdem ist es ein Klischee, dass es gerade das Gymnasium gewesen sei, das eine spezifische, nationalistisch prononcierte Staatsgesinnung durchgesetzt habe. Der Geschichtsunterricht z. B., der durch „Wissens-Positivismus“ bestimmt war, hatte durchaus die Tendenz zu Sachlichkeit und den Sachen, Irrationalismen der Zeit hatten keinen Ort, und in den ,Gesinnungsfächern ‘ wurde Gesinnung doch vom historischen Wissen neutralisiert. ‘33

Auch wenn im letzten Drittel des 19. Jahrhunderts die überragende Bedeutung von Latein und Griechisch abnahm und der Deutschunterricht neben Religion und Geschichte als ,der ethisch bedeutsamste in dem Organismus unserer höheren Schulen“ emphatisch propagiert wurde, blieben die Lehrpläne angesichts der geweckten Erwartungen weitgehend unverändert und traditionsorientiert. Der Literaturunterricht beispielsweise „,blieb eher eine Anstrengung des Intellekts als ein die Gemütskräfte ansprechender Gegenpol ${ }^{\text {‘34 }}$.

Auch in Geschichte wurde nach der durch den Kaisererlass von 1889 hervorgerufenen Neuorientierung großer Wert auf die Vermittlung von soliden Grundkenntnissen gelegt. So sprach sich 1893 der erste Historikertag gegen eine einseitige Gesinnungsbildung durch den Ge-

\footnotetext{
${ }^{30}$ So verdiente um die Jahrhundertwende z. B. ein Oberlehrer etwa doppelt so viel wie ein Volksschullehrer.

${ }^{31}$ Kuhlemann, Niedere Schulen, in: Berg (Hrsg.), Handbuch der deutschen Bildungsgeschichte IV (1991), S. 356.

${ }^{32}$ Kuhlemann, Niedere Schulen, in: Berg (Hrsg.), Handbuch der deutschen Bildungsgeschichte IV (1991), S. 356.

${ }^{33}$ Nipperdey, Deutsche Geschichte (1994), Band 1, S. 558.

${ }^{34}$ Kuhlemann, Niedere Schulen, in: Berg (Hrsg.), Handbuch der deutschen Bildungsgeschichte IV (1991), S. 258.
} 
schichtsunterricht zulasten einer faktenreichen Gründlichkeit aus. „Geschichtsunterricht sollte nicht auf eine bestimmte Gesinnung abzielen, auf historisches Wissen und historischen Sinn komme es an. “35 Die Lehrer wollten die Schüler lieber von der Gegenwart fernhalten und sich z. B. mit antiken Themen beschäftigen. Deshalb war die Akzeptanz der kaiserlichen Initiative bei den Gymnasiallehrern war insgesamt recht gering.

Trotzdem nahm in den letzen Jahrzehnten vor dem Ausbruch des Ersten Weltkriegs die wissenschaftliche Objektivität des Unterrichts in den Gesinnungsfächern Religion, Geschichte und Deutsch ab und der „neue Nationalismus von Kaiser und Reich hatte in den Gymnasien seine Hauptbastion“. Dieser nahm allerdings vom Nordosten zum Westen und Süden ab. ${ }^{36}$ Allerdings waren alle Gymnasien im Deutschen Reich geprägt von einer Atmosphäre des Nationalismus, die dazu führte, dass die älteren Schüler sich 1914 freiwillig für den Militärdienst meldeten und die jüngeren auf den Dienst an der Heimatfront vorbereitet waren.

\section{Höhere Mädchenschulen}

Die höhere Mädchenbildung im Kaiserreich war von zwei unterschiedlichen Zielsetzungen bestimmt. Zum einen ging es um die Vorbereitung der Schülerinnen auf ihre zukünftige Rolle als Ehefrau und Mutter, zum anderen jedoch sollten die Mädchen für eine mögliche Berufstätigkeit ausgebildet werden. Zwischen diesen beiden Polen spielte sich die politische Auseinandersetzung um die Reform der höheren Mädchenschule in Preußen und auch in den anderen deutschen Ländern ab. Im Jahre 1872 trafen sich die Lehrerinnen und Lehrer, die an höheren Mädchenschulen unterrichteten, zu einer ersten Hauptversammlung in Weimar, um ihre Ziele zu formulieren und über die Durchsetzung ihrer Forderung nach einer Normierung zu beraten. Die Ergebnisse wurden in der „Weimarer Denkschrift“ veröffentlicht. In ihr wurde „das Idealbild einer im patriotischen und religiösen Sinne gebildeten Frau, die dem Mann Ergänzung und Unterstützung bietet" gezeichnet und die gleiche wissenschaftliche Ausbildung für die Lehrerinnen und Lehrer an höheren Mädchenschulen gefordert. Mit Helene Langes „Gelber Broschüre“ (1887), der Begleitschrift einer Petition Berliner Lehrerinnen an das preußische Abgeordnetenhaus, bekam das Problem einer Normierung eine neue politische Brisanz, nachdem es jahrelang nahezu ergebnislos öffentlich diskutiert worden war. Um die in der Broschüre artikulierte Forderung, zum Beispiel nach Bildung von „Anstalten zur Ausbil-

\footnotetext{
${ }^{35}$ Kuhlemann, Niedere Schulen, in: Berg (Hrsg.), Handbuch der deutschen Bildungsgeschichte IV (1991), S. 261.

${ }^{36}$ Siehe Nipperdey, Deutsche Geschichte (1994), Band 1, S. 559.
} 
dung wissenschaftlicher Lehrerinnen für die Oberklassen der höheren Mädchenschulen“‘37, wirkungsvoller vertreten zu können, gründeten die Lehrerinnen unter Führung von Helene Lange, Marie Loeper-Houselle und Auguste Schmidt 1890 den „Allgemeinen Deutschen Lehrinnenverein“, dessen Publikationsorgan die Zeitschrift „Die Lehrerin in Schule und Haus“ wurde. Dass die Mitgliederzahl schnell stieg und um die Jahrhundertwende bereits $\sim 16.000$ betrug, zeigt die Bedeutung dieses Vereins.

Nachdem wichtige Forderungen in einigen deutschen Ländern, vor allem in Baden und in Württemberg, bereits am Anfang des Jahrhunderts berücksichtigt worden waren, wurden 1908 auch in Preußen die höheren Mädchenschulen neu gestaltet und ihre administrative Gleichstellung mit den höheren Knabenschulen kodifiziert. Es entstand die abgeschlossene zehnjährige Mädchenschule (ab 1912 Lyzeum) genannt, die als „höhere Schule“ im amtlichen Sinne anerkannt wurde. Auf ihr bauten für die Schülerinnen, die das Abitur machen wollten, „Studienanstalten“38 sowie das „Oberlyzeum“, das die Aufgabe der Lehrerinnenausbildung übernahm, auf. Heftigen Widerstand der Lehrerinnen gab es gegen die für die höheren Mädchenschulen festgelegte geschlechtsspezifische Quotierung, nach der zu einem Kollegium männliche und weibliche Lehrkräfte in annähernd gleicher Zahl gehören sollten. Deshalb blieben sie aus berufspolitischer Sicht der Neuordnung gegenüber ambivalent eingestellt, obwohl, z. B. mit der Abiturregelung, wichtige Forderungen erfüllt worden waren.

Ähnlich wie ihre Kollegen an den Gymnasien waren auch die Lehrerinnen und die Lehrer an den höheren Mädchenschulen in politischer Hinsicht bürgerlich gemäßigt, im kaiserlichen Staat verankert und ihm gegenüber loyal eingestellt. In ihrem Kampf um die Akademisierung ihres Berufsstandes, die Gleichstellung mit den männlichen Lehrkräften und die Normierung der höheren Mädchenschulen waren vor allem die Frauen darauf angewiesen, sich mit dem Kaiserstaat zu identifizieren, um ihre Forderungen durchsetzen zu können.

Die ,gesinnungskundlichen“ Fächer Deutsch, Geschichte (mit Kunstgeschichte), Religion und auch Erdkunde, die sich für die Vermittlung nationaler Bildung und die Erziehung zum patriotischen Staatsbürger besonders eigneten, spielten in den höheren Mädchenschulen eine noch größere Rolle als in den Gymnasien und Oberrealschulen. So entfielen z. B. im Berliner Normallehrplan von 1886 auf die genannten vier Fächer etwa 1 1⁄2 Mal so viele Stunden wie den entsprechenden Knabenschulen. ${ }^{39}$ Hinzu kommt, dass bei den Mädchen die formale

\footnotetext{
${ }^{37}$ Zitiert nach: Kraul, Höhere Mädchenschulen, in: Berg (Hrsg.), Handbuch der deutschen Bildungsgeschichte (1991), S. 282.

${ }^{38}$ Entsprechend den Schultypen für Jungen entstanden gymnasiale, realgymnasiale und oberreale Studienanstalten.

${ }^{39}$ Siehe Stundentafeln: Kuhlemann, Niedere Schulen, in: Berg (Hrsg.), Handbuch der deutschen Bildungsgeschichte IV (1991), S. $302 f$.
} 
Schulung des Geistes, die bei den Jungen eine großer Bedeutung hatte, weniger wichtig war. Da bei den Mädchen ,eher das einfühlsame Verständnis von Phänomenen angestrebt “40 wurde, konnten die Lehrer gerade die Mädchen im Sinne vaterländischer und monarchischer Gesinnung beeinflussen und damit auch auf den Dienst an der „Heimatfront“" vorbereiten.

Betrachtet man abschließend die Möglichkeiten des Staates, die intendierte Bildungspolitik durchzusetzen, so kann festgestellt werden, dass die direkten Einwirkungsmöglichkeiten durchaus begrenzt waren, da vor allem mit den Gemeinden und der Kirche weitere ,Schulinteressenten' Einfluss nahmen. Allerdings konnten die staatlichen Gremien über die Schulverwaltungsinstanzen, die ihnen unterstanden, wirkungsvoll in die Verwaltungs- und Unterrichtsabläufe bis ins einzelne eingreifen, um bestimmte politischen Wirkungen zu erzielen. Nach Folkert Meyer ,wurde das Personal der Schule (...) zum bloßen Gegenstand des bürokratischen Zugriffs, (um) die jeweilig erwünschte politische Haltung auf dem Wege der Ge-

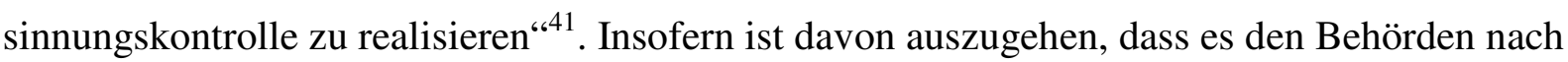
Ausbruch des Ersten Weltkriegs gelungen ist, die Schule für den Einsatz an der „Heimatfront“ erfolgreich zu mobilisieren, zumal die Lehrerschaft insgesamt national eingestellt war. ${ }^{42}$

\section{1 .2 „Geistige Mobilmachung“ in den Jahren 1890 bis 1914}

Mit dem Regierungsantritt Kaiser Wilhelms II. erfolgte sowohl in außen- als auch in innenpolitischer Hinsicht eine Neuorientierung des Deutschen Reichs. Die Veränderungen betrafen auch den schulpolitischen Sektor und waren für die künftige Entwicklung der Schulen von entscheidender Bedeutung. Vor allem in Preußen wurden die Weichen sowohl für die Bekämpfung sozialistischer Ideen durch die Schulen als auch für die sich im Kaiserreich latent und offen ausbreitende Kriegserziehung gestellt. Vorrangiges Ziel der neuen Jugend- und Schulpolitik („Neuer Kurs“), dessen wichtigstes Dokument die „Allerhöchste Ordre“ von 1889 darstellte, war es, den Schulen im Kampfe gegen Sozialdemokratie und Umsturz eine wichtige Rolle zuzuweisen. Den Schülern als den zukünftigen Untertanen sollten „die traditionellen Sozialisationsziele ,Gottesfurcht` und ,Liebe zum Vaterland”“43 von neuem eingeschärft werden, und zwar besonders in den ,Gesinnungsfächern` Deutsch und Religion:

\footnotetext{
${ }^{40}$ Kuhlemann, Niedere Schulen, in: Berg (Hrsg.), Handbuch der deutschen Bildungsgeschichte IV (1991), S $291 \mathrm{f}$.

${ }^{41}$ Meyer, Schule der Untertanen (1976), S. 200.

${ }^{42}$ Wie viele andere Wissenschaftler kommt auch Heinz Lemmermann zu dem Ergebnis, dass die deutsche Lehrerschaft nahezu geschlossen dem Königshaus, dem Staat und der Regierung loyal gegenüberstand (Lemmermann, Kriegserziehung im Kaiserreich (1984), S. 284).

${ }^{43}$ Schneider, Der Geschichtsunterricht in der Ära Wilhelms II., in: Bergmann/Schneider (Hrsg.), Gesellschaft Staat Geschichtsunterricht (1982), S. 134.
} 
„Schon seit längerer Zeit hat Mich der Gedanke beschäftigt, die Schule in ihren einzelnen Abstufungen nutzbar zu machen, um der Ausbreitung sozialistischer und kommunistischer Ideen entgegenzuwirken. In erster Linie wird die Schule durch Pflege der Gottesfurcht und der Liebe zum Vaterland die Grundlage für eine gesunde Auffassung auch der staatlichen und gesellschaftlichen Verhältnisse zu legen haben. Aber ich kann Mich der Erkenntniß nicht verschließen, daß in einer Zeit, in welcher die sozialdemokratischen Irrthümer und Entstellungen mit vermehrtem Eifer verbreitet werden, die Schule zur Förderung der Erkenntniß dessen, was wahr, was wirklich und was möglich ist, erhöhte Anstrengungen zu machen hat. Sie muß bestrebt sein, schon der Jugend die Überzeugung zu verschaffen, daß die Lehren der Sozialdemokratie nicht nur den göttlichen Geboten und der christlichen Sittenlehre widersprechen, sondern in Wirklichkeit unausführbar und in ihren Konsequenzen dem Einzelnen und dem Ganzen gleich verderblich sind [...].“44

Die Schule sollte also im Kampf gegen die Sozialdemokratie für die Interessen des obrigkeitlichen Staates instrumentalisiert werden. Nach Auffassung Kuhlemanns darf die Wirkung der Initiative des Kaisers allerdings nicht überschätzt werden, „da sich die agierenden Parteien und die Verwaltung von ganz anderen Interessen leiten ließen (...).

Unabhängig von der kaiserlichen Ordre gab es ab 1890 schulpolitisch verstärkte Bemühungen, im Unterricht vermehrt nationalistische, monarchistische und militaristische Themen zu behandeln, und zwar vor allem in den Fächern Deutsch und Geschichte. ${ }^{45}$ Heinz Lemmermann spricht vom „Unterrichtsprinzip, das verschiedenste Fächer durchdrang. Kriegserziehung erfolgte auf mehr oder weniger sublime Art, vor allem in den Fächern Turnen, Geschichte, Deutsch und Gesang “46. Auch außerhalb des Unterrichts machte sich in zunehmendem Maße im Schulleben eine Militarisierung bemerkbar, z. B. bei Schulfeiern, politischen Festen und vaterländischen Gedenktagen. Dazu gehörten die jeweils am 2. September inszenierten patriotischen Erinnerungsfeiern an den Sieg über Frankreich, die groß angelegten Kaisermanöver, Kaisergeburtstagsfeste, Denkmalseinweihungen und andere dynastische Gedenktage sowie weitere nationale Feiertage, bei denen die Schulen engagiert beteiligt waren. Dass auch dem „Patriotischen Schulfestspiel“47 bei der Kriegserziehung eine wichtige Bedeutung beigemessen wurde, zeigt die folgende zeitgenössische Formulierung der politischen Zielsetzung: ,(Ihre Aufgabe war es,) das jugendliche Gemüt mit dankbarer und treuer Gesinnung gegen das Herrscherhaus zu erfüllen, in den Kindern das Gelöbnis unwandelbarer Treue

\footnotetext{
${ }^{44}$ Zitiert nach: Herrlitz/Hopf/Titze/Cloer, Deutsche Schulgeschichte von 1800 bis zur Gegenwart (2005), S. $98 f$.

${ }^{45}$ Siehe: Schneider, Der Geschichtsunterricht in der Ära Wilhelms II., in: Bergmann/Schneider (Hrsg.), Gesellschaft - Staat Geschichtsunterricht (1982).

${ }^{46}$ Lemmermann, Kriegserziehung im Kaiserreich (1984), S. 8.

${ }^{47}$ Mit dem Beginn des Zweiten Kaiserreichs wurden an den preußischen Schulen im Rahmen von patriotischen Schulfeiern, die an den staatlich vorgeschriebenen Gedenk- und Erinnerungstagen stattfanden, erstmals Schulfestspiele aufgeführt. Sie sollten ein zusätzliches Mittel sein, „die vom Staat propagierten Indoktrinationsziele, die der Herrschaftssicherung und der Förderung affektiver Dispositionen zum Krieg dienten“ (Schroeder, Chronik des Weltkriegs (1990), Einleitung, Seite XI), zu erreichen und die politische Bewusstseinsbildung der Kinder und Jugendlichen ,zeitgemäß' zu prägen. Für den Zeitraum von 1871 bis 1914 sind etwa 450 patriotische Schulfestspiele bekannt, die teilweise von Lehrern stammen.
} 
und freudigen Opfermuts für Kaiser und Reich zu erwecken und sie zur Nachahmung der vor Augen geführten Tugenden zu begeistern. “48

Die staatlich angeordneten Aufführungen waren also mehr als Huldigungen an das Herrscherhaus, denn sie dienten - nach 1890 - in zunehmendem Maße der „Mobilmachung auf der Bühne“ und der „Erzeugung einer Kriegsmentalität" “49. Durch sie sollten bei den Schülern besonders auch affektive Dispositionen zum Krieg gefördert werden. Das zeigte sich z. B. darin, dass man im Gymnasium teilweise Uniformen trug und paramilitärische Exerzierübungen durchführte. Die Indoktrination im Schulalltag wurde ergänzt durch die politische Sozialisation im Alltag, in dem alles Militärische bewundert wurde. So gehörten Paraden, Aufmärsche mit Musikkapellen und marschierende Kolonnen zum Alltag der Kinder. Häufig liefen Jungen und Mädchen, in der Hand eine Fahne oder ein Holzschwert, begeistert nebenher und bewunderten die Uniformierten.

Christoph Schubert-Weller spricht von einem ,grundlegenden Wandel des militärischen Mentalitätsklimas, wie er seit der Jahrhundertwende offenbar wurde und sich spätestens seit 1911 auch ganz praktisch in der vormilitärischen Jugendpflege niederschlug““50. Als im August 1914 der Erste Weltkrieg ausbrach, war der Kriegsbegeisterung, die auch die Schüler und Lehrer erfasste, ,eine Militarisierung des Bewusstseins und der Mentalität vorausgegangen: absichts- und planvoll, im Zusammenwirken aller wichtigen Instanzen und Medien, die der öffentlichen Gesinnungspolitik zur Verfügung standen bzw. in die sozialisierenden Inszenierungen des Militarismus einbezogen werden konnten“651.

Waren die Kinder und Jugendlichen aber nicht nur auf den glorifizierten Kampf der Soldaten an der militärischen Front, sondern auch auf ihren Einsatz an der „Heimatfront“ mental vorbereitet? Hatte die Schule im Krieg tatsächlich ihren eigentlichen Bildungsauftrag verloren und „erfüllte nun die Funktion einer Rekrutierungs- und Mobilisierungsstelle, welche die Schüler als billige Arbeitskräfte hinter der Front am Kriegsgeschehen beteiligen sollte ${ }^{\text {“52 }}$ ? Auch wenn viele Quellen keinen Aufschluss darüber geben, ob Schüler bei ihrem Einsatz für die „Heimatfront" aus freien Stücken gehandelt haben oder ob sie auf Druck der Eltern oder Lehrer sich an Aktionen beteiligten, so geht aus den in der Arbeit angeführten zeitgenössischen ÄuBerungen und Erinnerungen von Zeitzeugen eindeutig hervor, dass die „Anziehungskraft des

\footnotetext{
${ }^{48}$ Zitiert nach: Schröder, Chronik des Weltkriegs, Einleitung, Seite X.

${ }^{49}$ Siehe: Schröder, Chronik des Weltkriegs, vor allem das Kapitel 2.1, S. 284-291.

50 Schubert-Weller, Vormilitärische Jugenderziehung, in: Berg (Hrsg.), Handbuch der deutschen Bildungsgeschichte (1991), S. 515.

${ }^{51}$ Herrmann, Ausblick, in: Berg (Hrsg.), Handbuch der deutschen Bildungsgeschichte (1991), S. 523.

${ }^{52}$ Bendick, Kriegserwartung und Kriegserfahrung (2003), S. 130. Die Formulierung wirkt allerdings übertrieben zugespitzt.
} 
Krieges“533 auf Kinder und Jugendliche und „die Faszination des kriegerischen Spiels““54 für sie sehr groß gewesen ist. Wie die Untersuchungen von Stéphane Audoin-Rouzeau zeigen, waren die Kinder und Jugendlichen nicht nur in Deutschland, sondern vor allem auch in Frankreich erfolgreich für den Kampf an der „Heimatfront“ mobilisiert worden, wobei die ideologische Integration in Frankreich noch umfassender war. ${ }^{55}$

\subsection{Klärung des Begriffs „Heimatfront“}

Der Erste Weltkrieg unterscheidet sich von früheren Kriegen sowohl durch die Intensität der Kriegsführung und durch seine räumliche Ausdehnung als auch durch die Verringerung der Grenzen zwischen militärischem und zivilem Bereich, zwischen Front und Heimat. Für Roger Chickering, für den gerade die Verzahnung von Front und Heimat das Hauptmerkmal war, beginnt deshalb mit diesem Krieg die Epoche „totaler Kriege“ ${ }^{\star 56}$. Er wurde mit riesigen Massenheeren geführt, was den Einsatz moderner Transport- und Waffentechnik voraussetzte. Dieses führte zu einer Industrialisierung des Krieges und zu einem bis dahin kaum vorstellbaren Einsatz von Material und Menschen. Um dies zu ermöglichen, war eine umfassende patriotisch-nationale Mobilisierung von Soldaten und Zivilisten erforderlich, denn neben den Soldaten an der Front wurden große Teile der Zivilbevölkerung benötigt und als Soldaten des ,Heimatheeres' mobilisiert.

Im Deutschen Reich wurde die Heimat zur ,zweiten’ Front erklärt, zur „Heimatfront“, wie es

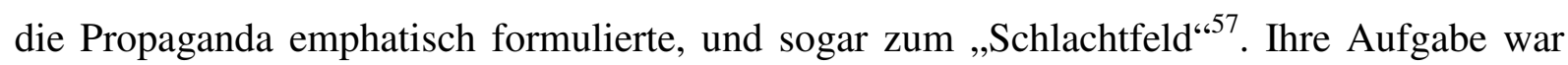
es, Menschen und Material für den Krieg an der, ersten' Front auf den Schlachtfeldern bereitzustellen und zugleich deren Verluste in materieller, personeller und mentaler Hinsicht zu verarbeiten. Dazu gehörten neben der Arbeit in der Industrie materielle Opfer und das Engagement in der Kriegsfürsorge.

„Heimatfront“ ist ein gängiger Begriff der historischen Weltkriegsforschung und gilt als ein wichtiges Charakteristikum moderner Kriegführung. Vielfach finden sich im zeitgenössischen Diskurs ähnlich konnotierte Bezeichnungen. Sowohl die Kampffront der Soldaten als auch das Hinterland der nicht eingezogenen Männer, Frauen und Kinder galten 1914 bis 1918 als

\footnotetext{
53 Audoin-Rouzeau, Die mobilisierten Kinder: Die Erziehung zum Krieg an französischen Schule, http://www.erster-weltkrieg.clio-online.de/ Rainbow/documents/keiner\%20f\%C3\%BChlt\%20sich\%202/audoinrouzeau.pdf (18.01.2009), S. 139; siehe: auch Audoin-Rouzeau, Die mobilisierten Kinder, in: Hirschfeld/Krumeich/Renz (Hrsg.), Keiner fühlt sich hier mehr als Mensch (1993).

${ }^{54}$ Haffner, Geschichte eines Deutschen (2002), S. 20.

${ }^{55}$ Die Ergebnisse einer Untersuchung über die Situation der Schule in Tirol im Ersten Weltkrieg (Auer, Kriegskinder [2008]) und eigene umfangreiche Quellenstudien, zeigen, dass die Mobilisierung in Österreich-Ungarn ähnlich intensiv und erfolgreich wie in Deutschland und Frankreich war.

${ }^{56}$ Siehe: Chickering/Ameskamp, Das Deutsche Reich und der Erste Weltkrieg, S. 14-52 (2002).

${ }^{57}$ Roerkohl, Schlachtfeld Heimat, in: Schlanstein/Wolter/Karwath (Hrsg.), Der Erste Weltkrieg (2004).
} 
Kriegsgebiet; deshalb musste auch Letzteres für den Krieg mobilisiert werden. Neben „Heimatfront“" entstanden Begriffe wie „Frauenfront“" oder „Kinderfront“" und auch „,Schulfront" ${ }^{\star 58}$. Der Begriff „Heimatfront“ wurde aber nicht nur in Deutschland benutzt, sondern diente ebenfalls sowohl dem verbündeten Österreich-Ungarn ${ }^{59}$ als auch den Kriegsgegnern zur Beschreibung der Situation der zivilen Gesellschaft im eigenen Land. ${ }^{60}$

\subsection{Eingrenzung des Themas und Schwerpunktsetzung}

Ziel dieser Arbeit ist es, den Beitrag, den die Schule zu wichtigen Aktivitäten der „Heimatfront" leistete, zu erforschen. Sie orientiert sich vorrangig an der Beantwortung der folgenden Fragen:

1. Worin bestanden die Leistungen der deutschen Schule an der „Heimatfront“ ?

2. Was bedeutete die Schule im Rahmen ihrer Tätigkeit an der „Heimatfront“ für das Leben in der Heimat und den Verlauf des Krieges?

3. In welchem Umfang konnte die Schule für den ,Kampf“ an der „Heimatfront“ mobilisiert werden?

4. Inwieweit veränderte sich im Laufe des Krieges die Einstellung der Schüler und Lehrer zu ihrem Engagement an der „Heimatfront“?

5. Welche Bedeutung hatte der Krieg für die Schule, insbesondere für Erziehung und Schulausbildung der Schülerinnen und der Schüler?

Es würde allerdings den bereits sehr weit gesteckten Rahmen dieser Arbeit sprengen, wenn alle Bereiche des Themas „Schule im Ersten Weltkrieg“ gleichermaßen intensiv untersucht werden würden. Deshalb sollen zunächst einige thematische Einschränkungen und dann Schwerpunktsetzungen vorgenommen werden.

Im Zentrum der Darstellung steht die Bedeutung der Schule für den Kampf der „Heimatfront“ also der Kampf der Schüler und der Lehrer an der „Schulfront“. Während das Bildungswesen jener Zeit und die pädagogischen Theorien in dem entsprechenden Zeitraum nicht thematisiert werden, da der direkte Bezug zum Thema dieser Forschungsarbeit fehlt, wird die unterrichtliche Situation im Krieg in einem eigenen Kapitel behandelt. ${ }^{61}$ Die „Kriegsstunden“662 sind darüber hinaus dann Thema der Untersuchung, wenn in ihnen Aktionen und Sammlungen der

\footnotetext{
${ }^{58}$ Siehe: Hämmerle, Kindheit im Ersten Weltkrieg (1993), S. 267-275.

${ }^{59}$ Siehe: Auer, Kriegskinder 7 (2008); Überegger, Heimatfronten (2006).

${ }^{60}$ So hieß es z. B. in Großbritannien, Kanada und den USA „Home Front“ (siehe: Beckett, Home front, 19141918 (2006); Ciment/Russell, The home front encyclopedia (2007); in Frankreich wurde der Begriff „,front de l'arrière" verwendet.

${ }^{61}$ Siehe Kapitel 9.

${ }^{62}$ In „Kriegsstunden“ wurde unabhängig von regulären Unterrichtsstunden über den Verlauf des Krieges und die aktuelle Situation an der Front gesprochen.
} 
Schüler zugunsten der Kriegsfürsorge besprochen und vorbereitet wurden. Auch die vormilitärische Ausbildung der Schuljugend und die Rolle der „Jugendkompanien“ werden ausgespart. Zwar setzte sich der Kultusminister zusammen mit dem Kriegsminister und dem Innenminister in einem Erlass vom 16. August 1914 für die Bildung von Jugendkompanien ein und außerdem bildeten sich diese meistens auf Initiative von Lehrern, sie standen jedoch in der Regel nicht unter dem Kommando von Lehrkräften. Insofern handelte es sich nicht primär um schulische Institutionen, zumal sich später auch Jugendklubs und Sportvereine den Kompanien anschlossen. Saul hat sich in seinem Aufsatz „Jugend im Schatten des Krieges“63 intensiv mit der vormilitärischen Ausbildung sowie besonders auch den Jugendkompanien allgemein auseinandergesetzt, während Grotjahn Belege für die „Aufstellung von Jugendkompanien“64 für den Zuständigkeitsbereich des X. Armeekorps Hannover zusammengestellt hat. Schubert-Weller geht im Zusammenhang mit der vormilititärischen Jugenderziehungwährend des Ersten Weltkriegs auch auf die Organisation und Praxis der Jugendkompanien ein. ${ }^{65}$

Auch die „Jugendbewegung“ bleibt in der Arbeit unberücksichtigt. ${ }^{66}$ Obwohl z. B. der „Wandervogel“, die „Freie Deutsche Jugend“, der „bayerische Wehrkraftverein“, der „Pfadfinderbund“ und der „Jungdeutschlandbund“ durchaus ,Zweckbedingte Kriegsarbeit“67 leisteten und viele Schüler weiterführender Schulen Mitglieder waren, fehlt der direkte Bezug zum Thema. Bei der Aktion „Kinder aufs Land“68 und den „Kriegsausstellungen“69 bzw. „Kriegsschulmuseen “70 waren die Schulen zwar ebenfalls beteiligt, initiiert und organisiert wurden sie jedoch meistens von Kommunen und Verbänden; deshalb werden sie in der Arbeit nicht thematisiert. Während die schulischen Spendenaktionen einen Schwerpunkt der Untersuchung bilden, bleiben die entsprechenden Aktivitäten der Lehrerverbände unberücksichtigt. Auch wenn von diesen den Wohlfahrtsverbänden ${ }^{71}$ immer größere Geldbeträge überwiesen oder für andere

\footnotetext{
${ }^{63}$ Saul, Jugend im Schatten des Krieges, in: Hackl (Hrsg.), Militärgeschichtliche Mitteilungen (1983) S. 91-185.

${ }^{64}$ Grotjahn, Stahl und Steckrüben Bd. 2 (1993), S. 220-230.

${ }^{65}$ Schubert-Weller, ,Kein schönrer Tod...“(1998), S.217-325.

${ }^{66}$ Zur Situation der „Jugendbewegung im Ersten Weltkrieg“ siehe: Fiedler, Jugend im Krieg (1989) und Karl, Willibald, Jugend, Gesellschaft und Politik im Zeitraum des Ersten Weltkriegs, Neue Schriftenreihe des Stadtarchivs München, Bd. 48 (o. J.).

${ }^{67}$ Karl, Willibald Jugend, Gesellschaft und Politik (o. J.), S. 134.

${ }^{68}$ Als die Ernährungsprobleme in den Städten und Industrieregionen größer wurden, brachte man Kinder für eine bestimmte Zeit in ländlichen Regionen unter, wo sie auch die Schulen besuchten.

${ }^{69}$ Es gab allerdings durchaus Schulen, die eigene ,Kriegsausstellungen' organisiert und ,Kriegsmuseen' eingerichtet haben. Darauf geht die Arbeit ebenso wenig ein wie auf das Verfassen von ,Kriegstagebüchern'.

${ }^{70}$ Siehe: einen Aufruf des Kantors Gustav Guericke (aus Velten bei Berlin) zur Gründung von Kriegsschulmuseen aus dem Jahre 1915: Schule und Krieg, Berlin 1915 (1915), S. 204.

${ }^{71}$ In den Verbandszeitschriften wurde permanent über die Höhe berichtet, z. B. über die „Kriegsspende des Berliner Philologen-Vereins für die Truppen“ (Deutsches Philologen-Blatt, 1915, Heft 6, S. 92-94) oder die „Kriegsspende Deutscher Frauendank“ 1915 (Die Lehrerin, Organ des Allgemeinen Deutschen Lehrerinnenvereins, S. 157f.).
} 
Zwecke gesammelt wurden, so spendeten die Lehrer und Lehrerinnen jedoch in ihrer Rolle als Verbandsmitglieder und nicht als Mitglieder der Schulkollegien.

Um zu repräsentativen Ergebnissen zu kommen, bezieht sich die Untersuchung auf die Situation der Schulen im gesamten Gebiet des Deutschen Kaiserreichs. Deshalb ist es, um der Materialfülle Herr zu werden, erforderlich und sinnvoll, aussagekräftige Beispiele aus unterschiedlichen Regionen (z. B. ländlichen sowie klein- und großstädtischen) und von allen Schulformen des allgemeinbildenden Schulwesens auszuwählen. Zwar stammt - vor allem aufgrund der insgesamt besseren Quellenlage ${ }^{72}$ - die Mehrzahl der Beispiele aus Preußen, und hier besonders von den Schulen des höheren Schulwesens, über die preußischen Volksschulen und die Schulen aus den süddeutschen Ländern jedoch liegen dennoch in ausreichendem Maße zeitgenössische Materialien vor, um gesicherte Aussagen über die Leistungen der deutschen Schule an der „Heimatfront“ machen zu können.

\subsection{Forschungsstand und Methode}

Während die Zahl der Veröffentlichungen über den Ersten Weltkrieg, die „Urkatastrophe des 20. Jahrhunderts“, wie der amerikanische Diplomat und Politikwissenschaftler George F. Kennan ihn 1978 genannt hat, unübersehbar ist ${ }^{73}$, thematisieren relativ wenige Autoren die Situation an der deutschen „Heimatfront“. Genannt seien die Arbeiten von Anne Roehrkohl, die schwerpunktmäßig die Situation in Westfalen untersucht ${ }^{74}$, Gerd Krumeich ${ }^{75}$, Elke Koch $^{76}$, Felix Höffler ${ }^{77}$ und Nikolaus Buschmann ${ }^{78}$. Sie gehen allerdings allenfalls sehr pauschal auf die Rolle der Schule im Ersten Weltkrieg ein. Dieses trifft auch auf die Publikationen zu, die sich in erster Linie mit der Situation der Frau im Krieg beschäftigen, wie z. B. Christiane Eifert $^{79}$, Hans Kramer ${ }^{80}$, Belinda J. Davis ${ }^{81}$ und Dorothee Sölle ${ }^{82}$.

\footnotetext{
${ }^{72}$ So sind beispielsweise das preußische Schulverwaltungsblatt und die Zeitschriften der Lehrkräfte an höheren Schule ergiebiger als die entsprechenden Quellen der süddeutschen Länder.

73 Siehe: z. B. Regulski, Bibliographie zum Ersten Weltkrieg (2005).

${ }^{74}$ Roerkohl, Der Erste Weltkrieg in Westfalen, Westfalen im Bild, Reihe: Westfälische Wirtschafts- und Sozialgeschichte, 1987; Biermann/Billstein/Büschenfeld/Roerkohl/Stenner/Trost, Der Erste Weltkrieg (2004); Roerkohl, Hungerblockade und Heimatfront (1991); Nr. 10, Roerkohl, Schlachtfeld Heimat (2004).

${ }^{75}$ Krumeich, Kriegsfront - Heimatfront, in: Hirschfeld (Hrsg.), Kriegserfahrungen (1997).

${ }^{76}$ Koch, ,Jeder tut, was er kann fürs Vaterland": Frauen und Männer an der Heilbronner „Heimatfront", in: Hirschfeld (Hrsg.), Kriegserfahrungen (1997).

${ }^{77}$ Höffler, Kriegserfahrungen in der Heimat: Kriegsverlauf, Kriegsschuld und Kriegsende in württembergischen Stimmungsbildern des Ersten Weltkriegs, in: Hirschfeld (Hrsg.), Kriegserfahrungen (1997).

${ }^{78}$ Buschmann, Der verschwiegene Krieg, http://www.erster-weltkrieg.clio-online.de/_Rainbow/documents/ Kriegserfahrungen/buschmann.pdf (11.12.2009).

${ }^{79}$ Eifert, Frauenarbeit im Krieg: Die Berliner Heimatfront 1914 bis 1918, IWK, 1985, 281; Kramer, Mobilisierung für die „Heimatfront" : Frauen im zivilen Luftschutz, Volksgenossinnen, 2007, 69; Sölle, Heimatfront: wir überlebten; Frauen berichten (1985).

${ }^{80}$ Kramer, Deutsche Kultur zwischen 1871 und 1918 (1971).

${ }^{81}$ Davis, Heimatfront (2002).

${ }^{82}$ Sölle, Heimatfront: wir überlebten (1985).
} 
So wie bei Christoph Nübel ${ }^{83}$, der sich auf Münster konzentriert, beziehen sich viele Veröffentlichungen lediglich auf einzelne Kommunen, wie z. B. Berlin ${ }^{84}$, Bremen $^{85}$, Emmendingen $^{86}$, Ellwangen ${ }^{87}$, Freiburg i. B. ${ }^{88}$, Heilbronn ${ }^{89}$, Hildesheim ${ }^{90}$, Jena ${ }^{91}$, Münchberg ${ }^{92}$, Neubrandenburg $^{93}$, Paderborn $^{94}$, Reutlingen ${ }^{95}$, Rostock ${ }^{96}$ und Titisee-Neustadt $^{97}$. Wie in den genannten Gemeinden, aus denen in der Untersuchung zitiert wird, wird die Situation der Schüler und der Lehrer auch in vielen anderen lediglich marginal behandelt.

Ähnlich ist es in den Gesamtdarstellungen und den Handbüchern, von denen beispielhaft Nipperdeys „Deutsche Geschichte“ ${ }^{98}$, das von Christa Berg herausgegebene „Handbuch der deutschen Bildungsgeschichte“999 und die von Gerhard Hirschfeld edierte „Enzyklopädie des Ersten Weltkriegs“"100 angeführt werden. Nipperdey beschreibt im Kapitel über das Bildungswesen in der Zeit von 1866 bis 1918 zwar die Situation der Schulen ausführlich, auf das Verhalten der Schüler und der Lehrer im Krieg geht er allerdings nicht ein. Auch die Autoren in Bergs Handbuch thematisieren die Kriegszeit nur sehr allgemein und knapp. So enthält z. B. Heinz Stübigs Beitrag über den „Einfluß des Militärs auf Schule und Lehrerschaft ${ }^{\text {101 }}$ keine Informationen über die „Heimatfront“. Berg hingegen gibt einen knappen Überblick über die Situation der „Jugend im Krieg““102 und nennt verschiedene Aktivitäten. In Hirschfelds Enzyklopädie ist als Beitrag zur „Heimatfront“ vor allem Stéphane Audoin-Rouzeaus Untersuchung „Kinder und Jugendliche“103 zu nennen, in dem er vor allem die Wirkung des Krieges auf die

\footnotetext{
${ }^{83}$ Nübel, Mobilisierung der Heimatfront und Selbstbehauptung im Feindesland, Rheinisch-westfälische Zeitschrift für Volkskunde, 2007, 131; Nübel, Die Mobilisierung der Kriegsgesellschaft Bd. 14 (2008).

${ }^{84}$ Kaeber, Berlin im Weltkriege (1921).

${ }^{85}$ Schwarzwälder, Geschichte der Freien Hansestadt Bremen (1987).

${ }^{86}$ Wiesmann, Die geistige Mobilisierung der ,Heimatfront' im Ersten Weltkrieg in der Stadt Emmendingen (1997).

${ }^{87}$ Gebhard, Ellwangen im 1. Weltkrieg (2000).

${ }^{88}$ Chickering/Renz/Nicolai, Freiburg im Ersten Weltkrieg (2009); Haußmann, Alltagsleben im Krieg, Nr. 15 (1994).

${ }^{89}$ Sommer, „Jeder tut, was er kann fürs Vaterland" (1997); ders. , Heilbronn im 1. Weltkrieg (1998).

${ }^{90}$ Heinemann, Für Kaiser und Vaterland (1989).

${ }^{91}$ Koch, Geschichte der Stadt Jena (1966).

${ }_{92}^{92}$ Hennig, Die Heimat im Ersten Weltkrieg. (2003).

${ }^{93}$ Maubach, Neubrandenburg im 1. Weltkrieg (1996).

${ }^{94}$ Fisch, Die Paderborner „Heimatfront" 1914-1918, in: Westfälische Zeitschrift, 1992, S. 361.

${ }^{95}$ Schneider, Der Krieg an der Heimatfront; Reutlingen 1914-1918 (1998).

${ }^{96}$ Strahl, Rostock im Ersten Weltkrieg (2007).

${ }^{97}$ Herbner, Titisee-Neustadt (1995).

${ }^{98}$ Nipperdey, Deutsche Geschichte (1994), Band 1.

${ }^{99}$ Berg, Handbuch der deutschen Bildungsgeschichte IV (1991).

${ }^{100}$ Hirschfeld, Enzyklopädie Erster Weltkrieg ${ }^{2}$ (2004).

${ }^{101}$ Berg, Militär und Militarisierung, in: Berg (Hrsg.), Handbuch der deutschen Bildungsgeschichte (1991), S. 515-523.

102 Berg (Hrsg.), Handbuch der deutschen Bildungsgeschichte IV (1991), S. 136f.

${ }_{103}$ Audoin-Rouzeau, Kinder und Jugendliche, in: Hirschfeld (Hrsg.), Enzyklopädie Erster Weltkrieg (2004); siehe dazu auch: Audoin-Rouzeau, Die mobilisierten Kinder: Die Erziehung zum Krieg an französischen Schule, http://www.erster-weltkrieg.clio-online.de/_Rainbow/documents/keiner\%20f\%C3\%BChlt\%20sich\%202/
} 
jüngeren Kinder untersucht. Michael Jeismann ${ }^{104}$ bezieht in seiner Untersuchung über die Propaganda die Schule ebenso wenig ein wie Hans-Peter Ullmann ${ }^{105}$ in seinem Beitrag zur Kriegswirtschaft. Roger Chickering geht in seinem Werk „Das Deutsche Reich und der Erste Weltkrieg“106 zwar differenziert auf das Alltagsleben ein, die Situation der Schulkinder wird jedoch recht knapp thematisiert.

Auch allgemeine oder regionale Schulgeschichten, wie beispielsweise die „Deutsche Schulgeschichte“107 von Hans-Georg Herrlitz oder „Die Schulgeschichte in Berlin“ “108 von Werner Lemm bzw. „Schule in Hamburg während des Ersten Kaiserreichs“109 von Reiner Lehberger setzen sich nicht ausführlich mit der Situation der Schulen an der „Heimatfront“ auseinander. Erwähnenswert sind vor allem Lemmermanns umfangreiche Analyse der „Kriegserziehung im Kaiserreich“"110, in der er sich mit der Funktion der Schulmusik beschäftigt, Klaus Sauls Aufsatz „Jugend im Schatten“, in dem er zwar die wichtigsten Erscheinungen der Kriegszeit darstellt, schwerpunktmäßig aber die vormilitärische Ausbildung untersucht, und Eberhard Demms Abhandlung über die Situation der deutschen Kinder im Krieg ${ }^{111}$. Demm thematisiert die Mobilisierung der Schule für die „Heimatfront“, insbesondere den Einsatz der Kinder für die Kriegswirtschaft, und geht auf die Rolle der Schüler und Lehrer als Agenten bzw. Adressaten der Propaganda ein. Der Aufsatz von Ingeborg Rürup („Kriegsbegeisterung, Schulalltag und Bürokratie in den höheren Schulen Preußens“(112) und der Sammelband „Lehrer helfen siegen“"113 ermöglichen lediglich einen vagen Einblick in die Zustände an den Schulen am Anfang des Krieges. Daneben gibt es einige umfangreichere Publikationen über die Situation der Schule in einzelnen Städten und Regionen. Zu nennen sind vor allem Harald Hohnsbehns Veröffentlichung über „Die Flensburger Schuljugend in der Zeit des Ersten Weltkriegs““114, Hans Christian Pusts Untersuchung „’Vaterländische Erziehung' für ,Höhere Mädchen'،115, in der er sich mit der Erziehung von Schülerinnen an höheren Mädchenschulen in SchleswigHolstein auseinandersetzt, und Karl Heinz Grotjahns Aufsatz über die „,hannoversche Jugend

audoin-rouzeau.pdf (18.01.2009), Audoin-Rouzeau, La guerre des enfants (1914-1918) (1993b) und AudoinRouzeau, Audoin-Rouzeau 1993.

104 Jeismann, Propaganda, in: Hirschfeld (Hrsg.), Enzyklopädie Erster Weltkrieg (2004); siehe auch: Jeismann, Das Vaterland der Feinde, Bd. 19 (1992).

${ }^{105}$ Ullmann, Kriegswirtschaft, in: Hirschfeld (Hrsg.), Enzyklopädie Erster Weltkrieg (2004).

${ }^{106}$ Chickering/Ameskamp, Das Deutsche Reich und der Erste Weltkrieg, (2002) S. 14-52.

${ }^{107}$ Zitiert nach: Herrlitz/Hopf/Titze/Cloer, Deutsche Schulgeschichte von 1800 bis zur Gegenwart (2005).

${ }^{108}$ Lemm, Schulgeschichte in Berlin (1987).

${ }^{109}$ Lehberger, Schule in Hamburg während des Kaiserreichs (1992)

${ }^{110}$ Lemmermann, Kriegserziehung im Kaiserreich (1984).

${ }^{111}$ Demm, Ostpolitik und Propaganda im Ersten Weltkrieg (2002).

${ }^{112}$ Rürup, „Es entspricht nicht dem Geist der Zeit, daß die Jugend müßig gehe“, in: Bönisch/Bussemer (Hrsg.), August 1914 (1989).

${ }^{113}$ Lehrer helfen siegen (1987).

${ }^{114}$ Hohnsbehn, Die Flensburger Schuljugend in der Zeit des ersten Weltkriegs (1996).

${ }^{115}$ Pust, ,Vaterländische Erziehung" für „höhere Mädchen" (2004). 
zwischen Kriegsdienst und Disziplinierung“"116. Hans-Ulrich Kammeiers Untersuchung des Landkreises Lübbecke (Ostwestfalen) im Ersten Weltkrieg ${ }^{117}$ gibt Aufschluss über die Situation der Schulen in einem ländlichen Raum.

Über die wichtigsten Bereiche der „Heimatfront“ - Sammlungen, Kaufs- und Verkaufsaktionen, Hilfsdienste, Feste und Feiern und Schulnagelungen, in denen Schüler und Lehrer aktiv waren, - fehlen spezielle Abhandlungen. August Ertheilers Publikation aus dem Jahre $1919^{118}$ gibt zwar einen Überblick über die einzelnen Sammlungen und ihre Bedeutung für die Kriegswirtschaft, auf die Beteiligung der Schulen geht er kaum ein. Auch über ihren Anteil an Einwerbungen von Zeichnungen der erfolgreichen neun Kriegsanleihen sind keine Veröffentlichungen vorhanden. Karl Hellfrich ${ }^{119}$, Gerhard Böke ${ }^{120}$, Werner Hinnen ${ }^{121}$ und Manfred Zeidler $^{122}$ thematisieren zwar im Zusammenhang mit der Kriegsfinanzierung die Kriegsanleihen, klammern jedoch die Schule aus. Arnulf Huegels Buch über „Kriegsernährungswirtschaft ${ }^{\star 123}$ hingegen enthält vor allem zum Einsatz der Schuljugend in der Landwirtschaft wichtige Hinweise.

In seinen Arbeiten über die politischen Feste in Hannover ${ }^{124}$ geht Gerhard Schneider auch auf die Beteiligung der Schule und die Wirkung der Feiern auf die Schulkinder ein. Dagegen wird in Dieter Düdings Sammelwerk über die öffentliche Festkultur ${ }^{125}$, Fritz Schellaks Arbeiten über die Nationalfeiertage in Deutschland ${ }^{126}$ sowie Jakob Vogels Untersuchung über die Militärfeiern in Deutschland und Frankreich ${ }^{127}$ die Schule allenfalls marginal erwähnt. Auch Ulrich Schroeder geht in seiner Dissertation zur „Funktion des patriotischen Festspiels in der

${ }^{116}$ Grotjahn, Vaterlandsverteidiger bis zum Jüngsten hinab, in: Mußmann (Hrsg.), Leben abseits der Front (1992).

${ }^{117}$ Kammeier, Der Landkreis Lübbecke und der 1. Weltkrieg (1998).

${ }^{118}$ Ertheiler/Plohn, Das Sammeln in der Kriegswirtschaft, Beiträge zur Kriegswirtschaft; Hrsg. von der Volkswirtschaftlichen Abteilung des Reichswirtschaftsministeriums (1919.

${ }^{119}$ Helfferich, Karl, Der Weltkrieg (1919).

${ }^{120}$ Böke, Die Kriegswirtschaft im deutschen Reich während des Ersten Weltkriegs und deren privatrechtliche Folgen (1997).

${ }^{121}$ Hinnen, Die Kriegsanleihen Deutschlands, Englands, Frankreichs und die Mobilisationsanleihen der Schweizerischen Eidgenossenschaft unter Berücksichtigung der Emissionssysteme (1923).

${ }^{122}$ Zeidler, Die deutsche Kriegsfinanzierung 1914 bis 1918 und ihre Folgen, in: Michalka (Hrsg.), Der Erste Weltkrieg (1994).

${ }^{123}$ Huegel, Kriegsernährungswirtschaft Deutschlands während des Ersten und Zweiten Weltkrieges im Vergleich (2003).

${ }^{124}$ Schneider, „Patriotische Schulfeste" und Schulunterricht im Kaiserreich, vorwiegend in Preußen (18711914), in: Pandel (Hrsg.), Verstehen und Verständigen (1991); Schneider, Über politische Feste der Bürger in Hannover [1866-1918], (2000); Schneider, Die Märzfeiern der hannoverschen Arbeiterbewegung, in: Schmid (Hrsg.), Feste und Feiern in Hannover (1995); Schneider, Politische Feste der Arbeiter (1995), Schneider, Herrschergeburtstagsfeiern in der preußischen Provinz 1867-1971, in: Sabellek (Hrsg.), Hannovers Übergang vom Königreich zur preußischen Provinz 1866 (1995).

${ }^{125}$ Düding, Öffentliche Festkultur (1988).

${ }^{126}$ Schellack, Nationalfeiertage in Deutschland von 1871 bis 1945415 (1990), Schellack, Sedan- und Kaisergeburtstagsfeste, in: Düding (Hrsg.), Öffentliche Festkultur (1988).

127 Vogel, Militärfeiern in Deutschland und Frankreich als Rituale der Nation (1871-1914), in: François/Siegrist/Vogel (Hrsg.), Nation und Emotion (1995). 
Wilhelminischen Kaiserzeit“ ${ }^{128}$ nur am Rande auf die Situation der Schule im Krieg ein. Über die Kriegsnagelungen deutscher Schulen gibt es ebenfalls kaum wissenschaftliche Arbeiten. Schneider, dessen grundlegende Veröffentlichungen zur Erinnerung an die weitgehend vergessenen Kriegswahrzeichen geführt haben, geht zwar in seinen Untersuchungen auch immer wieder auf Schulnagelungen ein, z. B. in seinem Aufsatz über die „Hannoverschen Nagelfiguren“"129 in einem entsprechenden Kapitel, macht jedoch das Thema Schulnagelungen nicht zum Gegenstand einer eigenständigen Untersuchung. $\mathrm{Zu}$ nennen sind ferner die Veröffentlichungen von Pust, der sich allerdings auf Nagelungen an den Mädchenschulen SchleswigHolsteins konzentriert. ${ }^{130}$

Auch in England und Frankreich als den Kriegsgegnern keine entsprechenden größeren Veröffentlichungen erschienen. Für Österreich liegt zwar Werner Auers umfangreiche Analyse der Schule im Ersten Weltkrieg vor ${ }^{131}$, sie beschränkt sich aber auf Tirol. Über die Situation der Kinder in Frankreich, und zwar vor allem die Erziehung zum Krieg, geben in erster Linie die Veröffentlichungen von Audoin-Rouzeau ${ }^{132}$ Aufschluss.

Hinweise zu den einzelnen Aktivitäten der Schüler, z. B. zum Einsammeln von Spendengeldern und Hilfsdiensten, an der „Heimatfront“ enthält der Ausstellungskatalog „In Papiergewittern“133.

In England hat das Thema „Schule und Heimatfront“ ebenfalls eine recht geringe Bedeutung. Beispielsweise wird in Ian Beckets „Home Front“ die Rolle der Frauen ausführlich dargestellt, nicht aber die der Schüler und der Lehrer. Auch „The Home Front Encyclopedia“"134, die die „Heimatfront“ in den USA, in Großbritannien und in Kanada thematisiert, klammert die Schule vollständig aus.

Das geringe Interesse der Geschichtswissenschaft an dem Thema „Schule im Ersten Weltkrieg“" verwundert insofern, als seit geraumer Zeit in der Kriegsforschung die Geschichte der Menschen im Mittelpunkt steht, vor allem die der Frauen und Kinder in der Heimat. Mit der Hinwendung zur Alltagsgeschichte, die sich als Geschichte der ,kleinen Leute', also als Ge-

\footnotetext{
${ }^{128}$ Schroeder, Funktion und Gestalt des patriotischen Schulfestspiels in der Wilhelminischen Kaiserzeit, 18711914 (1990).

${ }^{129}$ Schneider, Über hannoversche Nagelfiguren im Ersten Weltkrieg; in: Hannoversche Geschichtsblätter (1996) S. 247-253.

${ }^{130}$ Pust, „Vaterländische Erziehung" für „Höhere Mädchen" (2004), Pust, „Eisern war die Zeit“, Nagelfiguren im Ersten Weltkrieg, in: Grenzfriedenshefte (2002), S. 3-24); Pust, Schleswig-Holsteinische Nagelungsdenkmäler im Ersten Weltkrieg; in: Festschrift zum 65. Geburtstag von Jörn-Peter Leppien 55. Jahrgang (2003).

${ }^{131}$ Auer, Kriegskinder (2008).

${ }_{132}$ Audoin-Rouzeau, Audoin-Rouzeau 1993; Audoin-Rouzeau, Audoin-Rouzeau 2004; Audoin-Rouzeau, Die mobilisierten Kinder: Die Erziehung zum Krieg an französischen Schule; http://www. erster-weltkrieg.clioonline.de/_Rainbow/documents/keiner\%20f\%C3\%BChlt\%20sich\%202/audoin-rouzeau.pdf

(18.01.2009); Audoin-Rouzeau, Audoin-Rouzeau 1993.

${ }^{133}$ Didier/Hirschfeld, In Papiergewittern (2008), siehe: z. B. die Seiten 62ff.

${ }^{134}$ Ciment/Russell, The home front encyclopedia ( 2007).
} 
schichte , von unten' verstand, änderten sich die Forschungsparadigmen in den 80er Jahren ${ }^{135}$ und es ging nicht mehr ausschließlich um strukturgeschichtliche Interpretationen, sondern um die Kriegserlebnisse der Menschen auf allen Ebenen. Die Ereignisse an der Kriegsfront wurden langsam von Themen über die Situation an der „Heimatfront“ verdrängt. Neben Volker Ullrich, dessen Studie „Kriegsalltag“136 über Hamburg im Ersten Weltkrieg am Anfang der Neuorientierung stand, ist vor allem Peter Knoch mit seinem Buch „Kriegsalltag““137 aus dem Jahre 1989 zu nennen.

Um zu gesicherten und generalisierbaren Ergebnissen über die Erträge der Sammlungen und die Bedeutung der vielen Aktionen an der „Heimatfront“ zu gelangen, wie sie bisher nicht vorliegen, wird die Situation der Schule im Ersten Weltkrieg auf einer sehr breiten Basis von Quellen unterschiedlichster Gattungen analysiert. Dazu gehören in erster Linie zeitgenössische Äußerungen der Schüler und Lehrer und autobiografische Quellen sowie veröffentlichte Texte der Regierungen, der staatlichen Behörden, der Gemeinden, der Lehrerverbände und der Zeitungen, die hermeneutisch interpretiert werden. Zurückgegriffen wird aber auch auf quantifizierende Methoden wie das Auswerten von statistischen Übersichten, z. B. bei der Sammlung von Goldgeld, Hochrechnungen, z. B. beim Erfassen der im Reichsgebiet durch Schildnagelungen erzielten Spendeneinnahmen, oder durch Quellenmaterial begründete Schätzungen. Auf diese Weise beruhen die Ergebnisse der Untersuchung einerseits auf einer sehr breiten Grundlage mit hoher Belegdichte, andererseits führt die analytische Verknüpfung von Quellen antonymer und heterogener Überlieferungen zu vertieften Einsichten. Beispielsweise wird durch eine entsprechend zielgerichtete Auswertung von zeitgenössischen Schüleräußerungen und autobiografischen Quellen sowie Erlassen, Verfügungen und Aufrufen der Schulbehörden das Ineinandergreifen von Lebenswelten und Staat deutlich. Hämmerle spricht in diesem Zusammenhang von einer Wechselwirkung, die „quasi eine ,Aufhebung' von ,Kindheit" - im Sinne einer Lebensphase in einem familialen und kindzentrierten ,Schonraum ‘ - bewirkte und daß ,Kindheit‘ vom kriegsführenden Staat instrumentalisiert wurde ${ }^{\text {“138. }}$. Im Idealfall entsteht eine Gesamtdarstellung, in der sich die Sicht der einen Quellengattung in anderen widerspiegelt. Wenn also beispielsweise ein Tagebuchauszug einer preußischen Schülerin, eine Aussage in der offiziellen Schulchronik einer süddeutschen Schule, ein Bericht in einem sächsischen Schulverwaltungsblatt und ein autobiografischer Beitrag eines

\footnotetext{
${ }^{135}$ Auf Jürgen Kockas „Klassengesellschaft im Krieg“ zurückgehend standen vorher sozialgeschichtliche und soziologische Fragestellungen im Mittelpunkt der Forschung. Die Folge war, dass das Bewusstsein und die Erlebnisse der Menschen vernachlässigt wurden.

${ }^{136}$ Ullrich, Kriegsalltag (1982).

${ }^{137}$ Knoch/Dines, Kriegsalltag (1989).

${ }^{138}$ Hämmerle, Kindheit im Ersten Weltkrieg (1993), Seite 267.
} 
Hamburgers einander entsprechen und gleiche Ansichten und Einstellungen deutlich werden, so bedeutet das nicht nur eine Verifizierung der Ergebnisse, sondern lässt auch - positive Rückschlüsse auf deren Generalisierbarkeit zu. Allerdings kann auch die Tatsache, dass die in einigen Quellengruppen vorherrschenden Themen in anderen fehlen, zu wichtigen Erkenntnissen führen.

In der Untersuchung wird in der Untersuchung aber nicht nur besonderer Wert auf eine große Zahl von überlieferten Materialien und unterschiedlichen Quellenarten gelegt, also auf eine hohe Belegdichte. Der Zusammenstellung der Materialbasis liegen zudem, um sie so fundiert und differenziert wie möglich zu machen, weitere Kriterien zugrunde. Dieses soll am Beispiel der in der Arbeit berücksichtigten Schulen kurz erläutert werden. Da das Untersuchungsgebiet das gesamte Deutsche Reich ist, wird - entsprechend der Quellenlage - darauf geachtet, dass Schulen aus allen Regionen hinsichtlich ihres Engagements an der „Heimatfront“ untersucht werden, also sowohl aus den preußischen Provinzen als auch aus den süddeutschen Königreichen und den anderen deutschen Staaten. Außerdem spielen bei der Auswahl die Struktur der Gemeinde, in der die Schule liegt (ländliche Region, Kleinstadt, Großstadt), der Schulträger (weltlich oder geistlich), die Schulform (Volksschule, Mittelschule, Gymnasium) oder die geschlechtsspezifische Zusammensetzung der Schülerschaft (Jungen-, Mädchen- oder Koedukationsschule) eine wichtige Rolle.

Der Generalisierbarkeit dient auch die intensive Untersuchung von Publikationen, die sehr viele Adressaten erreichten, wie die Schulverwaltungsblätter der Staaten und der preußischen Provinzen, die meistens reichsweit verbreiteten Lehrerpublikationen, Tageszeitungen aus unterschiedlichen Regionen sowie Veröffentlichungen der überregional agierenden Wohlfahrtsverbände. Auch wenn solche offiziellen bzw. offiziösen Quellen oft ideologisch geprägt sind und ihr Aussagewert für diese Untersuchung deshalb grundsätzlich eingeschränkt ist, liefern sie bei quellenkritischer Betrachtung viele wichtige Informationen. Eine größere Beweiskraft hingegen haben die in der Untersuchung verwendeten ,persönlichen' Quellen, wie z. B. Tagebücher, Briefe, Aufzeichnungen, Erinnerungen, Berichte, Autobiografien und Erzählungen. Allerdings müssen auch diese Quellen sehr einfühlsam und mit Skepsis gegenüber „Ideologenen“ betrachtet werden. So sind gerade Erinnerungen an die Kindheit im Krieg oft überlagert durch spätere Erfahrungen und Erlebnisse sowie durch Verdrängungen. Hinzu kommt, dass aufgrund der großen zeitlichen Distanz zum Ersten Weltkrieg die Berichte teilweise aufgrund von Erinnerungslücken nur einen sehr fragmentarischen Einblick in das Leben im Krieg geben. 
Die Ergebnisse dieser Untersuchung, die um einer besseren Übersicht wegen jeweils am Ende eines Kapitels zusammengefasst und dann im Schulkapitel bilanzierend ausgewertet werden, sind also quellenmäßig sehr breit abgesichert; sie sind generalisierbar und lassen sich repräsentativ werten; denn sie beruhen auf einer, die relevanten unterschiedlichen Bereiche berücksichtigenden, zuverlässigen Materialbasis.

Meine Vorannahme zu Beginn der Bearbeitung war, dass es sinnvoll sein könnte, eine mentalitätsgeschichtliche Herangehensweise zu wählen. Nach intensiver Sichtung der Quellenlage zeigte sich jedoch, dass ein solcher methodischer Ansatz, also die Untersuchung kollektiver Denk- und Verhaltensweisen von Schülern und von Lehrern, nicht möglich ist, denn es sind vor allem von Schülern zu wenige schriftliche Zeugnisse überliefert, um sich dieser Gruppe mentalitätsgeschichtlich annähern zu können. Zwar liegt durchaus eine Reihe von lebensgeschichtlichen Aufzeichnungen und Biografien vor, in denen sich ehemalige Schüler zum Einsatz an der „Heimatfront“ äußern, ihre Erinnerungen sind jedoch häufig voller Lücken und die geschilderten Erfahrungen und Eindrücke werden überlagert von späteren Erlebnissen, vor allem solchen aus dem weniger lang zurückliegenden Zweiten Weltkrieg, und den Nachkriegsereignissen.

Auch die in großer Anzahl schriftlich überlieferten Äußerungen damaliger Lehrkräfte zur Situation der Schule an der „Heimatfront“ geben nur bedingt realistischen Aufschluss über ihre Gefühle und Erfahrungen sowie ihre Denk- und Verhaltensweisen und die der Schüler; sondern spiegeln die damalige Situation oft ideologisch verzerrt wider. Die Lehrkräfte waren in der Regel politisch angepasst und äußerten sich entsprechend der offiziellen Staatsdoktrin, denn sie waren von Gemeinde, Kirche und Staat als den Schulträgern abhängig und standen unter ständiger Kontrolle der Schulaufsicht.

Gegen den mentalitätsgeschichtlichen Ansatz spricht zudem die Tatsache, dass auch die überlieferten zeitgenössischen Schüleräußerungen oft nicht die tatsächlichen Gedanken und Gefühle der Schulkinder wiedergeben, da sie von den Lehrern und oft auch von ihrem familiären Umfeld massiv ideologisch beeinflusst und unter Druck gesetzt wurden.

\subsection{Quellenlage}

Für die Zeit vor dem Kriege und das erste Kriegsjahr bilden die gedruckten „Jahresberichte“ der Schulen, die zum Großteil in den Stadt- und Schularchiven vorhanden sind, die wichtigste Quelle. In ihnen stellten sich die Schulen gegenüber den vorgesetzten Behörden und den Eltern dar und dokumentierten ihre Aktivitäten, zum Beispiel im Bereich der Kriegshilfe.

Für Preußen und auch andere deutsche Staaten bricht die Quelle jedoch mit Ablauf des Schuljahrs 1915 ab, denn die Schulen sollten wegen des Papiermangels keine Berichte mehr verfas- 
sen. Da die Schulnagelungen z. B. jedoch erst mit Beginn des Schuljahrs 1915 einsetzten, fehlt für deren Erforschung die Hauptquelle. Auch in Archiven ist nur vereinzelt Material über die schulischen Kriegswahrzeichen vorhanden.

Detailliertes Material enthalten die teilweise handschriftlich verfassten Schulchroniken ${ }^{139}$ und Konferenzbücher, zu deren Führung die Schulen im Krieg verpflichtet waren, auch wenn sie hinsichtlich des Umfangs recht unterschiedlich ausfielen. Ortschroniken, die zum Teil von Lehrern verfasst wurden, sind ebenfalls von Bedeutung, da in ihnen meistens auch die Situation der Schulen und vor allem die Ergebnisse der Sammlungen dargestellt werden. Einbezogen werden vor allem die Kriegschroniken bzw. „Gedenkbücher“ der Städte. ${ }^{140}$, wie z. B. Material über die Leistungen der Schulen für die Kriegsfürsorge enthalten ferner die Rechenschaftsberichte und die Werbebroschüren des Roten Kreuzes und anderer gemeinnütziger Verbände und Vereine, wie z. B. der „Jugendspende für Kriegerwaisen“ (Essen), des „Jugenddanks für Kriegsbeschädigte“ (Berlin) und der „Freiwilligen Kriegshilfe“ in den Kommunen ${ }^{141}$.

Über die Situation der Schule geben zeitgenössische Veröffentlichungen teilweise recht detailliert Aufschluss, wie z. B. H. Bohnstedts „Die Kriegshilfe unserer Schuljugend“142 oder Heinrich Sohnreys „Kriegsarbeit auf dem Lande“ (1915) ${ }^{143}$.

Auch die Kataloge der zahlreichen Kriegsausstellungen und Kriegsmuseen ${ }^{144}$ enthalten neben dem umfangreichen Bildmaterial viele Informationen zum Thema. In dieser Arbeit werden vor allem die Ausstellungen in Berlin („Deutsche Kriegsausstellung 1916“145), Flensburg (,Deutsche Kriegsausstellung für die Nordmark $\left.{ }^{\star 146}\right)$, Hamburg ${ }^{147}$, Frankfurt a. M. („Ein Krieg

\footnotetext{
139 Schulchroniken waren z. B. seit 1872 für preußische Volksschulen verbindlich vorgeschrieben, seit 1907 sogar in normierter Form. Zur Geschichte und zur Bedeutung der Schulchronik als Quelle siehe: Ewert, Die Schulchronik als Quelle historischer Bildungsforschung (2009).

${ }^{140}$ Wichtige Informationen und Materialien enthielten vor allem die Chroniken von Augsburg, Bochum, Coburg, Essen, Frankfurt a. M., Göttingen, Gütersloh, Hildesheim und Münster.

${ }^{141}$ Siehe: beispielsweise: „Freiwillige Kriegshilfe Hannover und Linden e.V.“, StAH, C 8362.

${ }^{142}$ Bohnstedt, Die Kriegshilfe unserer Schuljugend, insbesondere im Hauswirtschaftsunterricht (1917).

${ }^{143}$ Sohnrey, Kriegsarbeit auf dem Lande (1915).

${ }^{144}$ Siehe: Schneider, Das Vaterländische Museum Hannover im Ersten Weltkrieg (2010).

${ }^{145}$ Die „Deutsche Kriegsausstellung" in Berlin fand vom 8. Januar bis 24. April 1916 statt. Während anfangs der erwartete baldige Sieg glorifiziert werden sollte, diente er dann mit zunehmender Dauer immer stärker der Stabilisierung der „Heimatfront“. Nach Beendigung der Ausstellung wurden Exponate als Wanderausstellung zusammen mit Ausstellungsstücken der regionalen Kriegsmuseen gezeigt. In Hannover z. B. war ab 22. Dezember 1916 eine große Kriegsausstellung zu sehen. Von dem Erlös, der 163.000 Mark betrug, kamen 110.000 Mark Kriegerfrauen, Hinterbliebenen und notleidenden Militärpersonen zugute. Siehe Schneider, Das Vaterländische Museum Hannover im Ersten Weltkrieg (2010), S. 139 ff. und auch Lange („Einen Krieg ausstellen“ [2003]), die sich vor allem mit der Berliner Kriegsausstellung beschäftigt.

${ }^{146}$ Deutsche Kriegsausstellung für die Nordmark (1916).

${ }^{147}$ Deutsche Kriegsausstellung 1916 in Hamburg (o. J. [1916]).
} 
wird ausgestellt ${ }^{\star 148}$ ) und Hannover ${ }^{149}$ einbezogen. ${ }^{150}$ Wichtige Quellen enthalten ferner die Ausstellungskataloge der Museen, die in den letzten Jahren ihre Weltkriegssammlungen ausstellten, wie zum Beispiel das Deutsche Historische Museum in Berlin („Der Weltkrieg, 1914-1918. Ereignis und Erinnerung“), oder der Bibliotheken (z. B. „In Papiergewittern“"151). Neben diesen Quellen sind die offiziellen Anweisungen der Kommunen und vor allem die der Schulbehörden für die Untersuchung von Bedeutung. Die Schulverwaltungsblätter enthalten neben den Lehrplänen zahlreiche Anweisungen und geben Aufschluss über die Situation der Schulen. Neben dem „Zentralblatt für die gesamte Unterrichtsverwaltung in Preußen“ (113 Erlasse $^{152}$ ) wird vor allem das „Amtliche Schulblatt für den Regierungsbezirk Hildesheim“, das besonders viele Verfügungen zum Verhalten der Schulen im Krieg enthält (181 Verfügungen ${ }^{153}$ ), zitiert. Daneben wurden die Schulverwaltungsblätter der anderen preußischen Provinzen, der größeren süddeutschen Länder (Königreich Bayern, Königreich Württemberg und Großherzogtum Baden), des Königreichs Sachsen, der Großherzogtümer MecklenburgSchwerin und Oldenburg sowie die Schulblätter für die Herzogtümer Braunschweig und Anhalt ausgewertet. ${ }^{154}$

Noch wichtiger für die Materialbeschaffung sind die pädagogischen Zeitschriften und die Publikationsorgane der Lehrerverbände, denn sie enthalten neben pädagogisch orientierten Aufsätzen oft authentische Berichte von Lehrern aus allen Regionen des Deutschen Reichs über Aktivitäten an der „Heimatfront“, die sie selbst initiiert und durchgeführt haben. Von den vielen Zeitschriften der verschiedenen Schulformen, die systematisch ausgewertet wurden, haben sich vor allem das „Deutsche[s] Philologen-Blatt““155, das Verbandsorgan der Gymnasiallehrer, „Die Lehrerin“, die Publikation des Allgemeinen Deutschen Lehrerinnenvereins und „Die Mittelschule“ als ergiebige Quellen erwiesen. Auch die „Deutsche Schulpraxis“ gibt guten Aufschluss über die unterrichtliche Situation der Schulen im Krieg. Recht wenige ver-

\footnotetext{
${ }^{148}$ Hoffmann (Hrsg.), Ein Krieg wird ausgestellt (1976); in der Ausstellung aus dem Jahre 1976 wurde die Weltkriegssammlung des Historischen Museums in Frankfurt a. M. präsentiert. Während viele Sammlungen im Zweiten Weltkrieg verloren gegangen ist, blieben die Frankfurter Exponate erhalten.

${ }^{149}$ Deutsche Kriegsausstellung, 1916-1917, Hannover, Ausstellungsverzeichnis der Kriegsausstellung, Hannover-Stadthalle 1916/1917 (1916).

${ }^{150}$ Siehe: Brandt, Kriegssammlungen im Ersten Weltkrieg, in: Hirschfeld/Krumeich/Renz (Hrsg.), Keiner fühlt sich hier mehr als Mensch (1993) und Zwach, Deutsche und englische Militärmuseen im 20. Jahrhundert (1999). Große Kriegsausstellungen gab es außerdem u.a. auch in Breslau, Darmstadt, Karlsruhe und Schwerin. Hinweise auf weitere Kriegsausstellungen in: Lange, Einen Krieg ausstellen (2003), S. 108-110.

${ }^{151}$ Didier/Hirschfeld, In Papiergewittern (2008).

${ }^{152}$ Siehe: Anhang Seiten 5-7.

${ }^{153}$ Siehe: Anhang Seiten 8-10.

${ }^{154}$ Angesichts der Fülle des Quellenmaterials und weil viele der nichtpreußischen Schulverwaltungsblätter die Erlasse des „Zentralblatt[s] für die gesamte Unterrichtsverwaltung in Preußen“ wörtlich übernommen haben, wurde auf eine Auswertung der Schulverwaltungsblätter der anderen - kleineren - Länder verzichtet.

155 Deutsches Deutsches Philologen-Blatt, Korrespondenz-Blatt für den akademisch gebildeten Lehrerstand, Hrsg. von Prof. Dr. A. Hufe, Verlag von Quelle \& Meyer in Leipzig.
} 
wertbare Materialien enthalten die Publikationsorgane der Volksschulen, wie beispielsweise „Der Volksschullehrer: Organ für die Interessen der deutschen Volksschule“, oder der süddeutschen Lehrerverbände, wie z. B. „Südwestdeutsche Schulblätter, Organ des badischen Philologenvereins, des hessischen Oberlehrervereins sowie des württembergischen Philologenverbandes“. Viele Materialien über den Kriegsalltag der Kinder und Jugendlichen in der Heimat sowie Literatur über den Ersten Weltkrieg bietet die Sammlung „Krieg 1914“ der Staatsbibliothek in Berlin. ${ }^{156}$

Auch wenn der Quellenwert durch die Pressezensur beeinträchtigt ist, stellen die regionalen Tageszeitungen eine weitere wichtige Quellengattung dar, denn sie enthalten viele genaue Schilderungen der kriegsbedingten Aktivitäten der Schulen und teilweise sogar Ansprachen von Schulleitern und Lehrkräften zu einzelnen Anlässen. Auch die unzähligen Flugblätter, Broschüren und Merkblätter, die durch ihren hohen Verbreitungsgrad eine wichtige Bedeutung im staatlichen Ernährungsprogramm hatten, sind für die Untersuchung wichtig, weil sie dokumentieren, wie sehr auch die Schuljugend und die Lehrer in den Kriegswirtschaftsapparat eingespannt waren.

Eine besondere Bedeutung für diese Untersuchung kommt den Archivalien zu. Zusätzlich zu den im Literaturverzeichnis genannten Archiven ist deshalb mit über 400 Stadt- und Staatsarchiven in allen Regionen Deutschlands schriftlich oder telefonisch Kontakt aufgenommen worden. $\mathrm{Zu}$ den vielen Archivalien, die von den Archiven freundlicherweise zur Verfügung gestellt wurden, gehören neben Abbildungen, dem Schriftwechsel der Schulen mit den lokalen Behörden, dem Schriftwechsel der Schulbehörden mit den Schulen und den Eltern, Statistiken, Verzeichnissen u. a. vor allem Ausschnitte aus den regionalen Tageszeitungen. Zwar wird der Quellenwert durch die damalige Pressezensur und dadurch beeinträchtigt, dass die Berichte oft geschönt und voller Übertreibungen sind, da sie aber häufig recht ausführlich berichten, geben sie dennoch einen guten Überblick über die kriegsbedingten Aktivitäten der Schulen. Teilweise enthalten sie Ansprachen der Schulleiter und der Lehrer. Ohne die Zeitungsquellen wäre beispielsweise die Untersuchung der Schulnagelungen nicht möglich gewesen.

156 Siehe: Online-Katalog: Prellwitz, Sachkatalog der Staatsbibliothek, http://ark.staatsbibliothekberlin.de/index.php?ebene=002.015.008\&ACT=\&IKT=\&TX=\&SET=\&NSI=SYS (15. 12. 2009) und Wojtecki, Kriegsalltag an der Front und in der Heimat, http://www.erster-weltkrieg.clio-online.de/ _Rainbow/Documents/einzelne/krieg-1914-wojtecki.pdf (11.12.2009). Zeugnisse über den Kriegsalltag der Kinder und Jugendlichen finden sich vor allem in der Gruppe XVII „Der Krieg und das geistige Leben“ (,Die deutsche Jugend und der Krieg“, „Ausländische Jugend“, „Schule und Krieg“) sowie in den Gruppen XII „Krieg und Wirtschaft“ („Volksernährung“), XIII „Der Krieg in finanzieller Hinsicht“ („Kriegsanleihen“) und XIV „Der Krieg und in sozialer Hinsicht“ (,Liebesgaben“,,Vaterländischer Hilfsdienst“, „Landbau, Erntehilfe“). 
Wichtige visuelle Quellen sind Bild- und Sachquellen, Fotos, Plakate, Urkunden und Medaillen, die in großem Umfang vorhanden sind. Vor allem Bildpostkarten waren im Ersten Weltkrieg außerordentlich beliebt. So wurden beispielsweise allein 28,7 Milliarden Feldpostsendungen zwischen Heimat und Front verschickt, sodass die Karten in der Masse ein schier unerschöpfliches Reservoir an Bildern darstellen. Die enorme Nachfrage nach Bildern ab $\mathrm{Au}-$ gust 1914 machte jedes Bild, das in irgendeiner Form mit dem Krieg zu tun hatte, zu einem potenziellen Motiv für die Bildpostkarte. Deshalb waren auch auf vielen Karten Szenen und Motive vom Kampf an der „Heimatfront“ abgebildet. Die Propagandabehörden hatten von Kriegsbeginn an die vielfältigen Möglichkeiten des neuen Massenmediums erkannt und nutzten sie für die staatliche Propaganda. ${ }^{157}$ Dieses trifft auch auf die politischen Plakate des Ersten Weltkriegs zu. Etwas später als die Alliierten nutzten auch die Deutschen das Medium für die politische Propaganda, und zwar in erster Linie, um gerade die Kinder und die Frauen immer wieder zum Kampf an der „Heimatfront“ aufzufordern, wie z. B. zum Zeichnen von Kriegsanleihen, zu Geld- und Goldspenden oder zur Teilnahme an Sammlungen. Der Anhang dieser Arbeit enthält viele Beispiele. ${ }^{158}$

Eine Reihe von autobiografischen Quellen, Erinnerungen, Biografien u. a. geben Aufschluss über die Lage der Schule in den Jahren 1914 bis 1918. Genannt seien vor allem die Sammelwerke „Kindheit im Kaiserreich“159 (Hrsg. Rudolf Pörtner), „Eine Kindheit im Ersten Weltkrieg“ (Hrsg. Christa Hämmerle) ${ }^{160}$ und „Wir Kinder hatten ein herrliches Leben“ (Hrsg. Ursula Blömer ${ }^{161}$ sowie beispielsweise die autobiografischen Werke von Karl Hampe ${ }^{162}$ und Sebastian Haffner ${ }^{163}$.

Von besonderer Bedeutung sind Kriegstagebücher, die von damaligen Schülern, Lehrern und Eltern verfasst worden sind, und zwar in erster Linie Jo Mihalys „,... da gibt's ein Wiedersehn!“(164, Erna Langes „1914 bis 1918 auf der Schulbank“165, Gerald Kiendls „Kriegstagebuch“166, Jakob Loewenbergs „Kriegstagebuch einer Mädchenschule“167 und Gertrud Schädlas „Tagebücher“168. Auch die „Aufzeichnungen der Antonia Helming“6169, von deren

\footnotetext{
${ }^{157}$ Siehe: Brocks, Die bunte Welt des Krieges 10 (2008).

158 Siehe: Schröder, Chronik des Weltkriegs; Vorsteher/Klotz/Müller/Sachs, Plakate des Ersten Weltkrieges (1996); Bohrmann/Malhotra/Hagen, Politische Plakate (1987).

${ }^{159}$ Pörtner, Kindheit im Kaiserreich (1990).

${ }^{160}$ Hämmerle, Kindheit im Ersten Weltkrieg (1993).

${ }^{161}$ Blömer/Garz (Hrsg.), „Wir Kinder hatten ein herrliches Leben“ (о. J.).

162 Reichert/Wolgast (Hrsg.), Karl Hampe (2004).

${ }^{163}$ Haffner, Geschichte eines Deutschen (2002).

${ }^{164}$ Mihaly, ... da gibt's ein Wiedersehn! (1986).

${ }^{165}$ Lange, 1914 bis 1918 auf der Schulbank (1933).

${ }^{166}$ Kiendl, Nessis Tagebuch aus dem Ersten Weltkrieg, http://www.zenker.se/History/nessi_tagebuch.shtml (01.12.2008).

${ }^{167}$ Loewenberg, Kriegstagebuch einer Mädchenschule (1916).

${ }^{168}$ Schädla, Die Tagebücher der Gertrud Schädla (2000).
} 
Kindern in der Zeit von 1914-1918 fünf zur Schule gingen, enthalten eine Reihe von Hinweisen zur „Schulfront“.

$\mathrm{Zu}$ den Quellen, die verwendet werden, gehören auch Sammlungen von Schüleraufsätzen, Anekdoten, Geschichten, Gedichten, Gebeten und Liedern, darunter vor allem Max Reinigers „150 Schüleraufsätze“170 (1915), Reinhold Brauns „Buch vom Weltkrieg für jung und alt““171 (1916) und Friedrich-Wilhelm Försters „,Die deutsche Jugend und der Weltkrieg““172 (1915) sowie Hermann Reichs „Buch Michael“173.

Die Abbildungen, die für die Arbeit von Bedeutung sind, stammen zum größten Teil aus regionalen Tageszeitungen, Franz Führens „Lehrer im Krieg“ und der umfangreichen Foto- und Ansichtskartensammlung des Verfassers.

Auch wenn die einzelnen Aktivitäten der Schulen während des Krieges nur selten zentral erfasst und ausgewertet worden sind, wie es z. B. bei den Kriegsanleihen und dem Goldumtausch geschehen ist, so können die einzelnen Ergebnisse der Arbeit durchaus generalisiert werden. Das ist zum einen darauf zurückzuführen, dass mit den Schulverwaltungsblättern wichtige Quellen für Preußen und alle anderen Länder des Deutschen Reiches vorliegen und auch die Zeitschriften der großen Lehrerverbände Einblick in die Arbeit der Schulen aller Schulformen im gesamten Reich ermöglichen. Zum anderen stehen, wie z. B. bei den Schulnagelungen, relativ viele konkrete Einzelbeispiele zur Verfügung, die gesicherten Aufschluss über die jeweilige Gesamtsituation geben.

Insgesamt reichen die vorhandenen Quellen zusammen mit der wissenschaftlichen Literatur aus, um die Leitfrage der Arbeitfrage, welche Bedeutung der Krieg für die Schule hatte und was die Schule im Rahmen ihrer Tätigkeit an der „Heimatfront“ für den Verlauf des Krieges bedeutete, fundiert und belegt zu beantworten.

\footnotetext{
${ }^{169}$ Helming/Fredeweß-Wenstrup, „Mutters Kriegstagebuch" (2005).

${ }^{170}$ Reiniger, Der Weltkrieg im persönlichen Ausdruck der Kinder (1915).

${ }^{171}$ Braun, Deutschlands Jugend in großer Zeit (1916).

${ }^{172}$ Förster, Die deutsche Jugend und der Weltkrieg (1915).

${ }^{173}$ Reich, Das Buch Michael (1917).
} 


\section{Sammlungen}

Nach Meinung des damaligen Staatssekretärs im Wirtschaftsministerium Karl Helfferich war zwar die „finanzielle Mobilmachung [...] in Friedenszeiten gründlich vorbedacht und vorbereitet worden“, man hatte jedoch ,,auf dem Gebiete der Gütererzeugung und des Warenhandels [...] ähnliche Vorkehrungen für den Kriegsfall nicht getroffen“174. Es gab also keinen umfassenden und einheitlichen Plan zur Umstellung auf die Kriegswirtschaft. So hatte man weder Vorsorge für die industrielle, gewerbliche und landwirtschaftliche Produktion noch Maßnahmen zur Sicherung des Lebensbedarfs der Zivilbevölkerung getroffen, obwohl man wusste, dass Deutschlands Ressourcen nicht zur Deckung des erforderlichen Lebens- und Futtermittelbedarfs ausreichten und auch nicht genügend Rohstoffe für Industrie und Gewerbe vorhanden waren. Zwar hatte der Generalstab seit Jahren gedrängt, eine entsprechende Kriegsvorsorge zu betreiben, aus politischen und finanziellen Bedenken jedoch war nichts geschehen.

Als sich die Hoffnung auf einen schnellen Sieg nicht erfüllte und mit der Handelsblockade sich die Versorgungsprobleme noch verschärften, versuchte die Regierung durch eine Reihe von Maßnahmen das Versäumte nachzuholen und den akuten Mangel zu beheben. So appellierten die Behörden an die Zivilbevölkerung, sparsam mit den knappen Rohstoffen umzugehen, und forderte sie darüber hinaus zum Sammel- und zum Hilfsdienst auf. Auch die Sozialfonds waren nicht so ausgestattet, um die ggfs. erforderlichen Mittel für die Kriegsverletzten und die Kriegshinterbliebenen aufzubringen. Eine besondere Bedeutung bei diesen Bemühungen kam den Lehrern und ihren Schülern zu, wie auch die vielen entsprechenden Vorschriften der Schulbehörden zeigen, die in den folgenden Abschnitten thematisiert werden. ${ }^{175}$

Außerdem bemühte sich die Regierung um den Aufbau einer zentralen Organisation, um die verschiedenen und wechselnden Bedürfnisse festzustellen, mit möglichst geringem Aufwand die Sammelgüter zu erfassen und sie zu verwerten. Gleichzeitig sollten die zentralen Wohlfahrtsverbände, die sich des Sammelns angenommen hatten, koordiniert werden. Trotz der Zentralisierung des Sammelwesens sollte die „Freiheit in der Art des Sammelns“ allerdings beibehalten werden.

Im Folgenden soll kurz auf die Organisation eingegangen werden. ${ }^{176}$ Die Initiative ging zunächst vom Kriegsministerium aus, das einen „Kriegsausschuß für Sammel- und

\footnotetext{
${ }^{174}$ Helfferich, Der Weltkrieg (1919), S. 153.

175 Siehe: Anhang, Seiten 5-10; dort sind die Erlasse des preußischen Unterrichtsministers und die Verfügungen des Regierungsbezirks Hildesheim aufgeführt.

${ }^{176}$ Siehe: Ertheiler/Plohn, Das Sammeln in der Kriegswirtschaft (1919).
} 
Helferdienst“, der die Führung auf diesem Gebiet übernahm, und eine besondere „Abteilung für Volksernährungsfragen“ (15. April 1916) beim „Armee-Verwaltungs-Departement“ begründete. Diese wurde dann von dem im November 1916 neu eingerichteten „Kriegsamt“ übernommen. Durch General Gröner, den Chef des Heeresamtes, der auch zum Vorstand des „Kriegsernährungsamtes“ gehörte, war die enge Zusammenarbeit zwischen den beiden wichtigen Ämtern gewährleistet. Die Leitung des „Kriegsausschusses für Sammel- und Helferdienst“ übernahm der „Kommissar des Kriegsamts beim Kriegsernährungsamt“. Er sorgte dafür, dass alle beteiligten Zentralstellen und deren nachgeordnete Behörden sowie die freiwilligen Kräfte reibungslos und effektiv zusammenarbeiteten. Erst im August 1917 war die Organisation des Sammelwesens im Deutschen Reich abgeschlossen. Die anderen Ressorts der Länder, vor allem die Kultusministerien, unterstützten das Kriegsamt bei seinen Bemühungen.

Seit dem Frühjahr 1917 hatte man auch begonnen, das regionale freiwillige Sammelwesen einheitlich zu organisieren. ${ }^{177}$ Überall dort, wo es möglich war, wurden Ortsausschüsse gebildet. Mehrere Ortsausschüsse wurden durch die Kriegsamtsstellen zusammengefasst. Oft wurden jene auch zu einem Kreisausschuss vereinigt und es wurden auch Kreissammelstellen eingerichtet. Deren Aufgabe war es, größere Ladungen des gleichartigen Sammelguts zu konzentrieren, um den einzelnen Ortssammelstellen die Verwertung zu erleichtern. Außerdem sollte der Transport rationeller gestaltet werden. Bei der Erfassung bestimmter Sammelgüter, z. B. von Laubheu und Bucheckern, wirkten neben den Kriegsamtsstellen auch die Kriegswirtschaftsämter mit, die dem Kriegsamt unterstellt waren.

Jeder Ortsausschuss, dem in der Regel Vertreter der örtlichen Lehrerschaft angehörten, richtete eine oder mehrere Ortssammelstellen ein, und zwar oft in Schulen. In den Kreisausschüssen, deren Vorsitz in allgemeinen die Landräte übernahmen, waren die Schulen durch die höheren Schulbehörden vertreten.

Der organisatorische Aufbau des Sammelwesens umfasste also:

Kriegsamt $>$ Kriegswirtschaftsamt $>$ Kriegsausschuss für Sammel- und Helferdienst $>$ Kriegsamtsstelle $>$ Kreisausschuss $>$ Kreissammelstelle $>$ Ortsausschuss $>$ Ortssammelstelle.

Mit der Zeitschrift „Das Kriegsamt“ und den „Wirtschaftliche(n) Mitteilungen für das Feldheer", die das Kriegsamt herausgab, standen dem Kriegsausschuss wichtige Werbe- und Nachrichtenmittel zur Verfügung. Den Kontakt zu der Lehrerpresse, der für den Erfolg der schulischen Sammeltätigkeit von außerordentlich großer Bedeutung war, stellte ein Ausschuss

\footnotetext{
${ }^{177}$ Ertheiler/Plohn, Das Sammeln in der Kriegswirtschaft (1919), S. 14-28.
} 
her, der dem Presserat angegliedert war; er sollte über die Entwicklung des Sammelwesens berichten.

Die Lehrerverbände unterstützten die Schulsammlungen von Anfang an und veröffentlichten immer wieder Aufrufe sowie Berichte von erfolgreichen Sammelaktionen. Im Juli 1917 gründeten Lehrer in Berlin die „Zentrale für Kriegshilfe der Schulen“, deren Vorsitz der Berliner Lehrer M. Ohmann übernahm. Ziel der Organisation war es, „durch eine planmäßig geregelte freiwillige Sammeltätigkeit [...] auch die kleinsten ${ }^{178}$, in ihrer Vereinzelung wertlosen, in ihrer Zusammenfassung aber bedeutsamen Mengen des verschiedensten Sammelgutes wirklich zu erfassen“"179.

Die Zentrale wurde dem - etwas später unter dem Vorsitz des Kriegsamtes gegründeten „Kriegsausschuss für Sammel- und Helferdienst“ angegliedert. Diese Organisationsstruktur zeigt, dass den Schulen bei den Sammlungen eine zentrale Bedeutung zukam. Weder der „Kriegsausschuß“ noch die „Zentrale“ machten allerdings den Ortsausschüssen oder den Schulen Vorschriften darüber, wie die Sammlungen durchgeführt werden sollten, denn es hatten sich bereits unterschiedliche Sammelsysteme herausgebildet. ${ }^{180}$ Diese sollen zunächst kurz beschrieben werden.

Das „Frankfurter System““181 war das am weitesten verbreitete und organisatorisch am besten durchgebildete. Alle am Sammelwesen beteiligten Gruppierungen bildeten den ,Ortsausschuss', der den Schulen die Leitung der Sammlung übertrug. Das Gebiet wurde in Bezirke unterteilt, denen jeweils eine Schule als Sammelstelle zugewiesen wurde. Die Schulen teilten die Häuser ihres Bezirks als Sammelbereiche unter den Schülern auf. Zunächst sollten die Schüler in der eigenen Familie sammeln, dann bei den kinderlosen Haushalten des Bezirks. Jedes Kind erhielt ein Sammelbuch mit seinem Namen, das als Ausweis diente und in das die Sammelmarken eingeklebt wurden, die es durch die Schule für die Ablieferung einer bestimmten Menge von Sammelgegenständen bekam. Beispielsweise wurde für vier Glühbirnen eine Marke ausgegeben. Enthielt das Sammelbuch 100 Marken, bekam der sammelnde Schüler einen Preis. ${ }^{182}$ Bei 1.000 Marken wurde ihm das ,Ehrenzeichen für den Sammeldienst in Eisen', bei 2.000 Marken das Zeichen in Silber und bei 5.000 Marken in Gold verliehen. Au-

\footnotetext{
${ }^{178}$ Solche kleine Mengen nannte man „Kriegsbrocken“.

${ }^{179}$ Trautwein Zentrale Kriegshilfe der Schulen, Deutsches Philologen-Blatt 1917, S. 421; siehe: auch den Gründungsaufruf, der zunächst an 2000 Schulen geschickt worden ist. Abgedruckt ist auch die Organisationsstruktur: Ohmann, Die Kriegshilfe der deutschen Schule, Deutsches Philologen-Blatt 1917, S. 99f.

180 Siehe: Ertheiler/Plohn, Das Sammeln in der Kriegswirtschaft (1919), S. 16-24.

${ }^{181}$ Siehe: auch Zenetti, Der Sammelhilfsdienst der Frankfurter Schuljugend und seine Ergebnisse am GoetheGymnasium, Deutsches Philologen-Blatt 1918, S. 7f.

${ }^{182}$ Bei der Zentrale war ein Zimmer eingerichtet, in dem für Kinder und Eltern die Preise ausgestellt waren, unter denen der erfolgreiche Sammler wählen konnte, z. B. Sparbuch, Lehrmittel, Experimentierkästen u.a. Wählte ein Kind ein Sparbuch, so war die Schule verpflichtet, den doppelten Betrag aus ihrem Guthaben auf das Sparbuch zu zahlen.
} 
Berdem gab es noch Sonderpreise. Bei deren Verleihung erhielt der Schüler ein vom stellvertretenden kommandierenden General unterschriebenes Besitzzeugnis und eine Anerkennungsurkunde. Das Sammelgut wurde in der Regel in der Schule abgeliefert und von Lehrern registriert. In jeder Klasse hing ein 'Ablieferungskalender', der Angaben über die Abholungstermine enthielt.

Alle Gegenstände wurden in drei Gruppen eingeteilt:

1. Die sog. Schwergruppe, die Papier und Flaschen umfasste;

2. Metalle;

3. Die sog. Leichtgruppe, zu der Frauenhaar, Glühbirnen, Gummi, Kork, Stanniol u. a. gehörten.

In der Schule konnten nur Gegenstände der Gruppen 1 und 3 abgegeben werden, während Metalle von den Schülern jeweils direkt zur zentralen Sammelstelle gebracht werden mussten. Dort lieferten auch die Schulen ihr Sammelgut ab (,Leichtgruppe'); die anderen Gegenstände mussten hingegen von der Sammelstelle abgeholt wurden.

Der für den Sammeldienst der Schule zuständige Vertrauensmann stellte bei der Abgabe eine Bescheinigung in dreifacher Ausfertigung aus, die von ihm und dem Bezirksabnehmer unterschrieben wurde. Einnahmen, die aufgrund der Verträge, die die Sammelzentrale mit den Abnehmern der gesammelten Gegenstände abgeschlossen hatte, erzielt wurden, kamen den Schulen zugute, deren Schüler die Sammelgüter abgeliefert hatten. Für jede Schule richtete die Zentrale ein Konto ein, dem $90 \%$ des Gewinns gut geschrieben wurden. Davon bezahlte die Schule die Preise für die Schüler, was etwa $30 \%$ der Einnahmen ausmachte. Über den Gewinn konnten die Schulen frei verfügen. Häufig wurde er für Schulzwecke verwendet oder für Kriegswohlfahrtszwecke gestiftet.

Berechnungen haben ergeben, dass eine Sammelmarke durchschnittlich 10 Pfennig wert war. Nachdem sich das Sammelsystem zunächst in Frankfurt a. M. bewährt hatte, wurde es auf den Bezirk des XVIII. Armeekorps übertragen ${ }^{183}$ und dann auch in vielen Regionen des Deutschen Reiches so oder ähnlich praktiziert. Änderungen wurden lediglich regional bedingt vorgenommen. Einige Sammelstellen zahlten z. B. nach Rücksprache mit den Eltern die angefallenen Summen in bar aus, um den Sammeleifer anzuspornen.

Auf das „Braunschweigische oder Hannoversche System“, das älter war, soll hier nicht näher eingegangen werden, da die Schuljugend zwar den Hauptanteil der Sammler stellte, aber „kein unmittelbarer Zusammenhang zwischen Schule und Sammlung“"184 bestand. Um Kinder

\footnotetext{
${ }^{183}$ Das Hauptquartier des XVIII. Armeekorps war in Frankfurt am Main; das Gebiet dieses Armeekorps umfasste den preußischen Regierungsbezirk Wiesbaden und das Großherzogtum Hessen.

${ }^{184}$ Siehe: Ertheiler/Plohn, Das Sammeln in der Kriegswirtschaft (1919), S. 20.
} 
für die Sammlungen zu gewinnen, wurden erfolgreichen Sammlern z. B. Besuche von eigens errichteten Kasperletheatern, Schieß- und Würfelbuden und anderen Vergnügungsstätten, für die Kinder empfänglich waren, ermöglicht. Außerdem bekamen sie für die Gutscheine, die ihnen bei der Abgabe des Sammelgutes ausgehändigt worden waren, Bücher, Spielsachen, Schuhe, Haushaltsgegenstände und auch Lebensmittel, die besonders gern genommen wurden. Wer in Hannover etwa 800 Pfund Küchenabfälle gesammelt hatte, bekam von der „Freiwilligen Kriegshilfe Hannover und Linden“" sogar ein Kaninchen. ${ }^{185}$

Das „Hamburger System“ stützte sich sowohl auf die Schulen als auch auf die öffentlichen Sammelstellen. Die Geldbeträge, die von den einzelnen Schülern durch die gesammelten und in der zuständigen Sammelstelle abgelieferten Gegenstände erzielten wurden, zahlte die eigene Schule aus. Bei jeder Ablieferung erhielt der Schüler eine Quittung, die er jeweils dem für seine Schule zum Sammelleiter bestellten Lehrer ablieferte. Dieser trug die Quittungen in Klassenlisten ein und leitete sie zur weiteren Verrechnung an den kaufmännischen Leiter der Sammelstelle weiter. An einem bestimmten Tag zahlte dann der Klassenlehrer das Geld an die Schüler aus, die eine entsprechende Mitteilung der Eltern unterschrieben vorlegen mussten.

Daneben gab es noch schulfreie „Hauptsammeltage“, an denen die von den Schülern gesammelten Altmaterialien direkt in der Schule abgeliefert wurden. Die Termine wurden von der Oberschulbehörde festgesetzt und in der Presse veröffentlicht. Allerdings nahm die Schule lediglich Papier, Flaschen, Konservendosen, Korken und Frauenhaar entgegen, während anderes Sammelgut bei den Sammelstellen abgegeben werden musste. Durch die schulfreien Tage wurde den Schülern und vor allem der Bevölkerung die Bedeutung der Sammlungen bewusst gemacht. Häufig wurden die Sammelaktionen im Rahmen von festlichen Veranstaltungen durchgeführt. $^{186}$

Im Königreich Württemberg organisierte hauptsächlich der „Schwabendienst“ die Sammlungen. Da in ihm die Schüler zwar als Sammler eine wichtige Rolle spielten, die Schule aber nicht intensiv in die Organisation eingebunden war, kann auf Einzelheiten verzichtet werden. Insgesamt kann festgestellt werden, dass die Einbindung der Schule für den Erfolg der Sammlungen und damit für die Beschaffung von Rohstoffen und für die Ernährung der Bevölkerung von zentraler Bedeutung war ${ }^{187}$, auch wenn angesichts der mitunter recht geringen Sammel-

\footnotetext{
185 Siehe: Schneider, Ein Photofund über die Arbeit der „Freiwilligen Kriegshilfe Hannover und Linden" im ersten Weltkrieg, Hannoversche Geschichtsblätter, 1999, S. 206.

${ }^{186}$ Siehe z. B. Kapitel Nr. 2.1.1.

${ }^{187}$ Um den Unterrichtsausfall zu verringern, die Schüler nicht zu überfordern und weil es oft nicht genügend Sammelgut vorhanden war, beteiligten sich nicht alle Schulen an sämlichen Sammlungen. Auf die Verwendung des Sammelguts wird in den entsprechenden Abschnitt der Untersuchung eingegangen.
} 
mengen der Verwaltungsaufwand teilweise unangemessen hoch war. Das geht auch aus einer im Jahre 1919 entstandenen Veröffentlichung hervor:

„Doch gelang es, die gestellten Aufgaben auf indirektem Wege zu lösen, indem die Schuljugend in den Dienst der Sache gestellt wurde. Im Gegensatz zu der Masse der Großen ist die Masse der Kleinen leicht zu beeinflussen. Unter dem Einfluß und der aufopfernden Mitwirkung der Lehrer wurde hier die Aufklärung über die Bedeutung des Sammelwesens leicht. Tatsächlich baute sich denn auch das Sammelwesen auf die Schule auf. Die Lehrerschaft bildete die Offiziere, die Schüler stellten die Mannschaften. Vielfach wurde die Schule selbst zum Sammellokal. Die Lehrerschaft hatte bald die Größe der Aufgabe erkannt und nahm sich ihrer mit Geschick und, ohne eine freiwillige Mehrarbeit zu scheuen, an. So vollzog sich die gesamte Sammeltätigkeit in ständigem Einvernehmen mit den Schulbehörden. “188

Das preußische Schulministerium und die anderen Schulbehörden unterstützten von Kriegsbeginn an in gesonderten Vorschriften und Merkblättern die Sammeltätigkeit der Schulen und nahmen fast zu jeder Sammelaktion und jedem Sammelgut Stellung. ${ }^{189}$

In der folgenden Untersuchung soll u. a. geklärt werden, inwieweit sich die Organisationsformen bewährten und ob die Schulen die ihr zugedachten Aufgaben tatsächlich erfüllen konnten. ${ }^{190}$

\subsection{Geld- und Edelmetallsammlungen ${ }^{191}$}

\subsubsection{Ankauf von Goldgeld}

Als infolge der Juli-Krise (1914) der Ausbruch des Kriegs immer wahrscheinlicher wurde, hob die Bevölkerung bis Ende des Monats Goldgeld im Wert von 100 Millionen von den Reichsbankkassen ab. ${ }^{192}$ Auch wenn diese Summe lediglich 6,6\% des vorhandenen Goldschatzes betrug, stellte die Reichsbank am 31. Juli 1914 die Auszahlung von Goldmünzen ein, um eine noch stärkere Verringerung der Goldvorräte zu verhindern.

Um an die von den Menschen, gehorteten' Goldmünzen zu kommen, wurde als eine der ersten Sammelaktionen von der Reichsbank der Ankauf von Goldmünzen, die als 10 oder 20 Goldmark im Umlauf waren, mit großem propagandistischen Aufwand durchgeführt. Ziel war

\footnotetext{
${ }^{188}$ Siehe: Ertheiler/Plohn, Das Sammeln in der Kriegswirtschaft (1919), S. 12.

${ }^{189}$ In einem recht frühen Erlass heißt es zur Sammeltätigkeit: „Die Schuljugend zur freiwilligen, freudigen Mitarbeit auf den wirtschaftlichen Gebieten, in denen ihre Kräfte mit Nutzen verwendbar sind, immer wieder anzuregen, ist in der bevorstehenden entscheidenden Zeit eine Hauptaufgabe der Schule." (Zitiert nach: Ertheiler/Plohn, Das Sammeln in der Kriegswirtschaft (1919), Fußnote auf S. 12).

${ }^{190}$ Bei den zusammengetragenen Mengenangaben handelt es sich fast ausschließlich um absolute Zahlen, die nur bedingt Aufschluss über die wirtschaftliche Bedeutung der gesammelten Güter und den Erfolg der Schule daran geben. Auch Untersuchungen von Führen, Hohnsbehn, Pust, Roerkohl und Saul, die teilweise recht detailliert auf die Sammlungen eingehen, fehlen durchgehend Bezugsparameter, wie z. B. Einwohner- bzw. Schülerzahl, Sozialstruktur oder erwirtschafteter Wert. Deshalb wird in den entsprechenden Abschnitten versucht, an einzelnen Beispielen, wie z. B. der Sammlung von Frauenhaar in Flensburg oder der Obstkernsammlung in verschiedenen Regionen, solche Parameter zu berücksichtigen, sofern die Quellenlage es zulässt.

${ }^{191}$ Siehe: Anhang Seiten 33-39.

192 Der Goldvorrat des Deutschen Reichs betrug bei Kriegsbeginn lediglich 1,5 Milliarden Mark; siehe: Zeidler, Die deutsche Kriegsfinanzierung 1914 bis 1918 (1994), S. 423.
} 
es, Goldmünzen, ein damals reguläres Zahlungsmittel, einzuziehen und gegen Papiergeld, das nominell den gleichen Wert hatte, einzutauschen. Es wurde propagiert, dass der Erfolg der Aktion neben der wirtschaftlichen Bedeutung auch einen wichtigen politischen Wert habe, denn den Kriegsgegnern sollten dadurch die „Einheit von Kriegs- und Heimatfront“ sowie die wirtschaftliche Stärke Deutschlands suggeriert werden. Geworben wurde in der massiven Kampagne vor allem mit dem Argument, dass für jede eingegangene Goldmark drei Reichsmark in Banknoten für die Kriegsführung ausgegeben werden könnten. ${ }^{193}$ So wurde z. B. den Schulkindern eingeredet, dass der Erfolg der Soldaten von ihren Sammelerfolgen an der „Heimatfront“ abhing.

Nachdem sich bereits am 30. September 1914 der Reichsbankpräsident an die Öffentlichkeit gewandt hatte, um über die ersten Erfolge der Aktion zu informieren und zu verstärkter Aktivität aufzurufen ${ }^{194}$, forderte der preußische Unterrichtsminister mit dem Erlass „Abführung von Reichsgoldmünzen an die Reichsbank“ vom 21. November 1915 Geistliche, Lehrer und Schulbehörden auf, die Aktion tatkräftig zu unterstützen. Seiner Meinung nach seien gerade die Lehrer (und Geistlichen) in der Lage, ,,auf diesem Gebiete durch Belehrung der Bevölkerung dem Vaterlande einen großen Dienst (zu) erweisen“195.

Der Deutsche Philologen-Verein gründete darauf die ,'Gold-in-die-Reichsbank!'Organisation“ und forderte die Philologen am 18. Februar 1915 zur Mitarbeit und damit zur „wirtschaftliche(n) Mobilmachung der deutschen Schule“196 auf. Ein propagandistischer Höhepunkt der Goldsammlungen 1915 war eine öffentliche Kundgebung der Schulen der Provinz Brandenburg-Preußen und der Lehrerverbände am 11. Mai 1915 im Berliner Ballhaus.

Oberlehrer Driesen referierte über das Thema „Die Gold in die Reichsbank-Organisation und die wirtschaftliche Mobilmachung der deutschen Schule“, und der Abgeordnete des Reichsta-

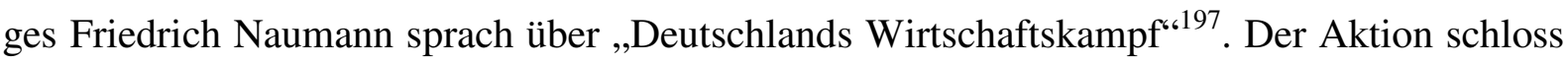
sich 1915 auch der Allgemeine Deutsche Lehrerinnenverein an. Driesen forderte seine Kollegen und Kolleginnen immer wieder nicht nur zu verstärkter Anstrengung auf, sondern bat sie auch, ihm die jeweiligen Sammelergebnisse der einzelnen Schule mitzuteilen. Diese wurden

\footnotetext{
${ }^{193}$ Zeidler, Die deutsche Kriegsfinanzierung 1914 bis 1918 (1994), S. 423.

${ }_{194}$ Abgedruckt in der Pädagogischen Zeitung; siehe: Führen, Lehrer im Krieg (1936), S. 78.

195 Ministerium der geistlichen und Unterrichts-Angelegenheiten, Abführen von Reichsgoldmünzen an die Reichsbank, Zentralblatt für die gesamte Unterrichtsverwaltung in Preußen, 1914, S. 732. Die Erlasse vom 9. Februar 1915 und 25. März 1915 sollten zur Verstärkung des Einsatzes führen.

${ }^{196}$ Driesen, Eine „Gold-in-die-Reichsbank!"-Organisation der deutschen Philologen, In: Deutsches PhilologenBlatt Korrespondenz-Blatt für den akademisch gebildeten Lehrerstand, 1915b, 122; der Aufruf erschien auch in den „Blättern des höheren Schulwesens“ (1915, Nr. 8), in der „Pädagogischen Zeitung“ (25.01.1915) und in „Die Lehrerin“ (27.02.1915).

${ }^{197}$ Siehe: Wegener, Das Joachimsthalsche Gymnasium - die Landesschule Templin (2007), S. 92f. und Versammlung von Vertretern der deutschen Schule, Deutsches Philologen-Blatt 1915, S. $282 \mathrm{f}$.
} 
dann in der Verbandszeitschrift veröffentlicht, was sicher auch ein Anreiz für Lehrer und Schüler zu weiteren Anstrengungen war. Außerdem berichteten Lehrer in der Verbandszeitschrift über erfolgreiche Aktionen und gaben Anregungen für erfolgreiches Sammeln, wie z. B. zwei Lehrer aus Görlitz ${ }^{198}$ (Provinz Schlesien) und Bochum (Provinz Westfalen) ${ }^{199}$.

Aufgrund der Initiative der Philologen liegen für der Bereich der höheren Schulen detaillierte Daten über die Ergebnisse der Sammlungen vor, auf die im Folgenden eingegangen werden soll. $^{200}$

\section{Sammelergebnisse}

Die Resultate der einzelnen höheren Schulen in alphabetischer Reihenfolge wurden bis zum Ende des Jahres 1915 in 23 Listen veröffentlicht. 1916 erschienen dann über die Goldgeldeingänge in den einzelnen Ländern noch acht Listen (Januar, März, April, Mai, Juli, September, Oktober/November und Dezember).

\section{$\underline{1915}$}

Für die erste Jahreshälfte liegt eine relativ detaillierte Übersicht der Sammelergebnisse aus Preußen vor. ${ }^{201}$ Insgesamt sammelten sämtliche Schulen des Königreichs bis zum 1. Juli 65 Millionen an Goldgeld, davon wurden ca. 33 Goldmark von den höheren Lehranstalten zusammengebracht. Im zweiten Halbjahr waren es dann 15 Millionen. ${ }^{202}$ Geht man jedoch davon aus, dass auch 1915 (wie 1916) die Schulen der anderen Reichsländer etwas $10 \%$ weniger als die in Preußen sammelten, so kämen noch 72 Millionen hinzu. Die Schulen in Deutschland haben also mit ziemlicher Sicherheit im Jahre 1915152 Millionen Goldmark aufgebracht. Vergleicht man diese Summe mit der Zunahme des Goldvorrats der Reichsbank für das Jahr 1915, die 353,1 Millionen ${ }^{203}$ betrug, so kommt man zu dem Ergebnis, dass etwa $43 \%$ davon von den Schulen aufgebracht worden sind.

Man kann davon ausgehen, dass sich die meisten Schulen an der Aktion beteiligt haben. ${ }^{204}$ Für den Bereich der höheren Schulen ist beispielsweise belegt, dass bis zum 1. Juli 1915 ca. 1.500 Schulen namhafte Beträge an die Reichsbank abgeliefert haben. Für die Volksschulen

\footnotetext{
${ }^{198}$ Koehler, Sammelt Gold!, Deutsches Philologen-Blatt 1915, 73f. U.a. schlägt er vor, den Stand des schulischen Sammelergebnisses regelmäßig auf einer im Schulflur hängenden Liste zu dokumentieren und sie mehrfach in der örtlichen Zeitung zu veröffentlichen.

${ }^{199}$ Schwarz, Sammelt Gold, Deutsches Philologen-Blatt 1915, 107. Schwarz stellte u.a. den Schülern die Veröffentlichung der Sammelergebnisse in den „Jahresberichten“ der Schule zu veröffentlichen.

${ }^{200}$ Die von Driesen in der Zeitschrift des Philologen-Vereins zusammengestellten Zahlen beruhten auch auf den Angaben der Schulbehörden, denen die Schulen die Sammelergebnisse mitteilen mussten.

201 Driesen, Gold in die Reichsbank!, Deutsches Philologen-Blatt: Korrespondenz-Blatt für den akademisch gebildeten Lehrerstand (Beilage), 1916, S. 33.

${ }^{202}$ Die Zahlen beruhen auf amtlichem Material; siehe: Führen, Lehrer im Krieg (1936), S. 78f.

${ }^{203}$ Driesen, Der Goldschatz unserer Feinde und die Aussichten unserer Goldpolitik, In: Deutsches PhilologenBlatt Korrespondenz-Blatt für den akademisch gebildeten Lehrerstand, 1915, S. 34.

${ }^{204}$ In Hannover haben sich z. B. alle höheren Schulen an der Goldgeld-Aktion beteiligt.
} 
fehlen zwar weitgehend genaue Daten, die vielen entsprechenden Hinweise in den Schul- und Ortschroniken bestätigen allerdings die Feststellung der großen Beteiligung der Schulen.

$\underline{1916}$

Die höheren Schulen des Deutschen Reiches (zusammen mit den Mittelschulen) sammelten 4.621.579 Goldmark, davon 2.500.878 in Preußen (ca. $55 \%$ ). ${ }^{205}$

\section{$\underline{1917 / 18}$}

Zwar wurde in den Schulen bis zum Kriegsende weiterhin Goldgeld gesammelt, da die Ergebnisse aber noch schlechter waren als 1916, wurden sie nicht mehr vollständig veröffentlicht. Belegt ist allerdings, dass im Jahre 1917 14.399.000 Goldmark gesammelt wurden, davon 1.209.000 von den Volksschulen. ${ }^{206}$

Von den 17 höheren Mädchenschulen Schleswig-Holsteins beispielsweise wurden 1917 noch 19.759,36 Goldmark und 1918 lediglich 2.390 Goldmark aufgebracht. ${ }^{207}$ Eine absolute Ausnahme bildete das Lyzeum I in Hannover, das 1917 Goldmünzen im Wert von 161.520 sammelte. $^{208}$ Selbst wenn die Zahlen nur teilweise gesichert sind, so steht fest, dass die Schulen damit einen großen Beitrag zur Finanzierung des Reiches geleistet haben. Mehrfach haben deshalb z. B. der Reichsbankpräsident und die Schulbehörden diese Leistung öffentlich gewürdigt. ${ }^{209}$

Dass die Goldsammlung die größten Gewinne im ersten Sammeljahr brachte, ist nachvollziehbar. Viele Menschen verfügten noch über genügend Goldgeld und waren angesichts der allgemeinen Siegeseuphorie auch bereit, es in Papiergeld umzutauschen und so ihren Beitrag zur Kriegsfinanzierung zu leisten. Als sich die Kriegslage 1916 zunehmend verschlechterte, änderte sich das allgemeine Bewusstsein. Man misstraute den offiziellen Versprechungen, dass das Papiergeld als Geldmittel genauso wertbeständig sei wie das Goldgeld, und hielt das Goldgeld zurück. Außerdem hatten viele Menschen im ersten Jahr ihre Goldreserven aufgebraucht. Deshalb wurde es für Lehrer und Schüler trotz großen Werbeaufwands immer schwerer, Menschen zum Eintausch ihrer Goldmünzen zu überreden.

\footnotetext{
${ }^{205}$ Masche, Der Goldmünzenumtausch an den höheren Schulen im Jahre 1916, Deutsches Philologen-Blatt 1917, S. 86. Provinzialschulkollegien und allen Beamten und Lehrern, die sich um die Durchführung der Maßnahme verdient gemacht haben, meinen Dank und meine Anerkennung ausspreche, ersuche ich, auch weiterhin mit allen Kräften und unermüdlich für die Fortsetzung der durch wichtige vaterländische Interessen gebotenen Sammeltätigkeit Sorge zu tragen und nach vier Monaten erneut über den Erfolg zu berichten." (Zitiert nach: Mitteilungen und Nachrichten, Deutsches Philologen-Blatt 1915, S. 642f.
} 
Abschließend soll am Beispiel einiger Schulen gezeigt werden, mit welchem Engagement die Schulen Goldgeld ankauften.

Eine der erfolgreichsten Schulen war das Berliner Reform-Realgymnasium Bismarckschule, das bis zum 20. Januar 1916 237.625 Mark Goldgeld ablieferte; die Höhere Mädchenschule in Kempten (Kgr. Bayern) brachte es bis zum 19. Februar 1916 auf 151.060 Mark (bei nur 160 Schülerinnen $)^{210}$ und das Königliche Kaiser-Wilhelms-Realgymnasium in Berlin sammelte bis zum 1. September 1915 152.000 Mark.

In Hannover (Provinz Hannover) waren bis zum 1. Juli 1915 die Humboldtschule (95.305 Mark), das Lyzeum I und Oberlyzeum (91.000 Mark), die Bismarckschule (58.810 Mark) und die Leibnizschule (54.399 Mark) besonders erfolgreich. ${ }^{211}$

In Relation zu der oft sehr geringen Schülerzahl waren aber die Volksschulen in Stadt und Land durchaus ebenfalls erfolgreich, wie die folgenden Beispiele zeigen.

Im Jahre 1915 wurden von der Schule in Hausbruch (Hamburg) 930 Mark $^{212}$, der Volksschule in Gütersloh (Provinz Westfalen) 420 Mark $^{213}$, der Volksschule in Fiestel (Provinz Westfalen) ${ }^{214}$ 2.080 Mark und der Ev. Volksschule in Lübbecke (Provinz Westfalen) 12.230 Mark ${ }^{215}$ gesammelt. In Flensburg betrug das Ergebnis der Volksschulen bis zum Dezember 1915 27.130 Mark. ${ }^{216}$

Trotzdem gab es insgesamt hinsichtlich der Sammelerfolge Unterschiede zwischen den Volksschulen und den höheren Schulen und auch zwischen Stadt- und Dorfschulen.

\footnotetext{
${ }^{210}$ Siehe: Driesen, Besonders erfolgreiche Schulen, Deutsches Philologen-Blatt 1916, S. 142.

${ }^{211}$ Die Ergebnisse wurden anhand der Listen 3, 5, 10, 11, 13, 14, 15, und 22, die Otto Driesen 1915 im Deutschen Deutsches Philologen-Blatt veröffentlicht hat, zusammengestellt.

212 1. Weltkrieg, http://www.schule-hausbruch.de/?Wir:Chronik:1._Weltkrieg (20.03.2008).

${ }^{213}$ Plümpe, Hauptschule Gütersloh, http://www.helmut-neuhaus.de/archiv-chronik3.html (26.11.2008), S. 81f.

${ }^{214}$ Stadtarchiv Fiesel Schulchronik von Fiestel (Amt Alswede).

${ }^{215}$ Kammeier, Der Landkreis Lübbecke und der 1. Weltkrieg (1998), S. 185.

${ }^{216}$ Hohnsbehn, Die Flensburger Schuljugend in der Zeit des ersten Weltkriegs (1996), S. 242.
} 


\section{Gründe für den Sammelerfolg}

Sehr wichtig für den Erfolg der Goldgeld-Sammlung, die das Motto „Konnt ich auch nicht Waffen tragen, half ich doch die Feinde schlagen" hatte, war zunächst die massive Propaganda der Presse, der Lehrerverbände und der Schulbehörden. Man vermittelte der Bevölkerung und natürlich auch den besonders leicht beeinflussbaren Schulkindern den Eindruck, sie könnten als „Soldaten an der Heimatfront“ durch gute Sammelergebnisse den Krieg verkürzen helfen und zum baldigen Sieg beitragen. So wurden in einem Aufruf der „'Gold-in-dieReichsbank!'-Organisation“ an die Lehrer der höheren Schulen die Sammelaktion als „Goldmobilmachung“ und die Sammler als „Gold-Freiwillige“ und „Gold-Landsturm“ genannt. Auch in vielen anderen Publikationen wurde die Sammelaktion als Kampf an der „Heimatfront" bezeichnet. Ob die Schüler sich tatsächlich auch als Heimat-Soldaten verstanden haben, soll u. a. in den nächsten Abschnitten untersucht werden.

Da Kinder zwar schnell für eine Aktion zu begeistern sind, ihr Engagement aber in der Regel bald nachlässt, dachten sich Lehrer und Behörden in zunehmendem Maße Anreize aus und stellten den Schülern Belohnungen in Aussicht. Besonders motivierend waren für die Schüler natürlich unterrichtsfreie Tage (,goldfrei“) sowie der Verzicht auf Hausaufgaben und von diesen Möglichkeiten machten die Schulleiter immer wieder Gebrauch. Ein Kieler Lehrer schrieb beispielsweise, dass an seiner Schule, die Sammlung ,erst in Fluß (kam), nachdem ein freier Tag versprochen wurde ${ }^{\text {2217. }}$.

Bei welcher Summe eine Klasse einen freien Tag bekam, war recht unterschiedlich; im Leibniz-Gymnasium in Berlin z. B. mussten jeweils 1.000 Mark gesammelt worden sein, während in einer Schule in Berlin-Schöneberg 20.000 Mark aufgebracht werden mussten. ${ }^{218}$ Sicher hängt die unterschiedliche Vorgehensweise der Schulen in erster Linie mit der sozialen Zusammensetzung der Schülerschaft zu sammen. In Kempten verlängerte der Stadtschulrat Dr. Reindl wegen guter Sammelergebnisse der Schulen die Osterferien 1915 um 2 1⁄2 Tage und versprach auch für die Osterferien 1916 eine Verlängerung, wenn 200.000 Mark erreicht wären. $^{219}$

Manchmal bekamen alle Schüler einer Schule „goldfrei“ und manchmal auch nur einige besonders erfolgreiche Klassen. In einigen Fällen, z. B. im Königlichen Gymnasium in Breslau (Provinz Schlesien), bestand die Belohnung von Klassen in einem Spaziergang mit dem Lehrer am Nachmittag oder in Ausflügen, z. B. an einer Berliner Schule in den Zoologischen Gar-

\footnotetext{
${ }^{217}$ Siehe: Philologen-Blatt 1915, S. 233-235, Liste 4.

${ }^{218}$ Die großen Unterschiede sind wahrscheinlich mit der unterschiedlichen sozialen Zusammensetzung der Elternschaft zu eklären.

${ }^{219}$ Driesen, Besonders erfolgreiche Schulen (1916), S. 142.
} 
ten oder in das Aquarium. Einige Klassen einer Schule in Berlin-Adlershof wurden in die Treptow-Sternwarte geführt, wo jeder Schüler für das Sammeln von 20 Goldmark durch das Fernrohr sehen durfte. Für besonders erfolgreiche Berliner Schüler bestand sogar die Möglichkeit eines Besuchs in der Reichsbank. ${ }^{220}$

Ein Berliner Gymnasium belohnte erfolgreiche Schüler durch die Erlaubnis, Zigarren und andere Liebesgaben in Berliner Lazaretten zu verteilen. Ein andere Möglichkeit des Ansporns bestand darin, die Namen der tüchtigsten Sammler in der örtlichen Presse oder sogar in den Zeitschriften der Lehrerverbände zu nennen zu lassen. Beispielsweise wurden im Flensburger Gymnasium 1915 Schüler im Rahmen einer Bismarckfeier öffentlich belobigt und in Königshütte (Provinz Schlesien) wurden die erfolgreichsten Schüler namentlich im Jahresbericht erwähnt. Auch Wettbewerbe der einzelnen Klassen innerhalb einer Schule in den "Goldsammelwochen“"stärkten das Engagement der Schüler. ${ }^{221}$

Im Philologen-Blatt gab es sogar eine Rubrik ,Ehrentafel“, in der besonders tüchtige Sammler lobend erwähnt wurden. So heißt es dort z. B. 1916:

„9. Der Schüler Walter Langmeier der Untertertia des Sophien-Gymnasiums zu Berlin wohnt in einer wenig bemittelten Gegend [...]. Trotzdem ist es ihm gelungen, allein im Monat Januar 1916 2.320 Mark in Gold aufzubringen. Seine gesamte Goldgeldleistung erreicht sogar die Höhe von 22.380 Mark.“222

Neben den genannten Anreizen war es üblich, Schüler und Klassen durch Geschenke zu belohnen, um sie zu weiteren Anstrengungen anzuspornen. Einige Beispiele seien genannt:

- Ansichtskarten

- Bilder des Kaisers, Hindenburgs und anderer Feldherrn

- Süßigkeiten

- Kunstblätter mit Kriegsmotiven

- Metallringe mit dem Eisernen Kreuz

- Hindenburgmesser

- Urkunden und Bescheinigungen ${ }^{223}$

- Silbernes Pferd als Krawattennadel (z. B. in Harzburg, Hzgt. Braunschweig)

- Versprechen, dass der im Felde stehende Angehörige für jedes Goldstück einen Tag Urlaub bekommt

- Bücher u. v. a.

Zusätzlich zu den genannten Anerkennungen, die in Berichten einzelner Schulen erwähnt werden, stellte die Reichsbank an 1. Juni 1917 den Schulen einige Präsente zur Verfügung. So

\footnotetext{
${ }^{220}$ Ein Besuch in der Reichsbank, Deutsches Philologen-Blatt: Korrespondenz-Blatt für den akademisch gebildeten Lehrerstand (Beilage), 1916, S. 281f.; abgedruckt ist ein ausführlicher Bericht über einen Besuch für 80 Jungen und Mädchen..

${ }^{221}$ Siehe: Spittler, Das höhere Schulwesen in der „polnischen Ecke" Westpreußens im Spannungsfeld der Nationalitätenpolitik (1986), S. 140f.

${ }^{222}$ Philologen-Blatt 1916, Heft 10, S. 14-22.

${ }^{223}$ Siehe: Anhang, Seite 35, Bilder 1-3.
} 
erhielten sie für 1.000 umgewechselte Mark fünf Geldtaschen mit dem Aufdruck der Reichsbank und für die seit dem 1. Juni 1917 eingelieferten Goldmünzen (mindestens 30 Mark) ein Buch mit Widmung. Ferner gab es Anstecknadeln in Emaille mit der Aufschrift „Goldsucher“ (ab 50 Mark), ein Gedenkblatt (ab 200 Mark) sowie eine vom Reichsbankpräsidenten unterzeichnete dekorative Urkunde (ab 500 Mark). Lehrer, deren Klassen besonders erfolgreich waren, und Schulleiter wurden für ihr Engagement durch das 'Verdienstkreuz für Kriegshilfe' ausgezeichnet und zu weiteren Anstrengungen für die Sammeltätigkeit angespornt. ${ }^{224}$

Je stärker die Sammelergebnisse ab 1916 zurückgingen, um so mehr bemühten sich Lehrer und Behörden ${ }^{225}$, die Schüler durch Belohnungen und Appelle zu verstärkter Aktivität anzuspornen. Lehrern wurden von der Reichsbank, von Behörden und Lehrerverbänden verschiedene Werbematerialien kostenlos zur Verfügung gestellt, wie z. B. die Broschüren „Goldsucher bei der Arbeit“" (vom Oberlehrer Dr. Borghorst) oder „Gold heraus“ (vom Kreisschulinspektor O. Kohlmeier). ${ }^{226}$ Immer wieder veröffentlichten Lehrer Vorschläge zur Verbesserung der Sammelergebnisse. Vor allem wurde überlegt, wie man an das Goldgeld der ärmeren Landbevölkerung kommen könnte, bei der man durchaus nennenswerte Mengen vermutete. ${ }^{227}$ Dass aber auch die Propaganda, die Belohnungen, das Engagement der Lehrerschaft, die Beeinflussung der Schulkinder durch Kinderbücher ${ }^{228}$ und die Aufforderung vieler Schulen an die Eltern, das Schuldgeld für die Kinder mit Goldgeld zu bezahlen ${ }^{229}$, den ständigen Rückgang der Goldgeldankäufe nicht verhindern konnten, zeigen die oben beschriebenen Ergebnisse.

\footnotetext{
${ }^{224}$ So erhielt z. B. Direktor Wirmer aus Warburg das Verdienstkreuz für ,seine Leistungen bei der Goldsammlung und den Kriegsanleihezeichnungen“, zusammen mit dem vom Kaiser eigenhändig unterschriebenen Reiterbildnis. (Deutsches Philogen-Blatt 1917, Jg. 25, Heft 32, S. 489).

${ }^{225}$ Zum Beispiel schrieb die Flensburger Schuldeputation am 23. Januar 1917 den Leitern der Volks- und Mittelschulen: „Die K[önig]liche Regi[erung] in Schleswig ersucht [...], die Goldsammlung von neuem aufzunehmen. Die Herren Schulleiter ersuchen wir ergebenst, die Kinder nochmals zum Einsammeln von Goldstücken zu veranlassen. Es ist vielleicht doch möglich, noch Goldmünzen der Reichsbank zuführen zu können." (Zitiert nach: Hohnsbehn, Die Flensburger Schuljugend in der Zeit des ersten Weltkriegs (1996), S. 242.

${ }^{226}$ Mellmann, Beschlüsse der Goldgeldkommission, Deutsches Philologen-Blatt: Korrespondenz-Blatt für den akademisch gebildeten Lehrerstand (Beilage), 1916, S. 33.

${ }^{227}$ Driesen, Das Gold auf dem Lande, Deutsches Philologen-Blatt: Korrespondenz-Blatt für den akademisch gebildeten Lehrerstand (Beilage), 1916, S. 8; Driesen, Wo steckt noch Gold?, Deutsches Philologen-Blatt: Korrespondenz-Blatt für den akademisch gebildeten Lehrerstand (Beilage), 1916, S. 68.

${ }^{228}$ Als Beispiel sei die Erzählung „Klassengold“ von Fritz Müller genannt (Braun, Deutschlands Jugend in großer Zeit, 1916, S. 101-106).

${ }_{229}$ Ministerium der geistlichen und Unterrichts-Angelegenheiten, Abführung von Reichsgoldmünzen an die Reichsbank, Zentralblatt für die gesamte Unterrichtsverwaltung in Preußen, 1915, S. 375.
} 


\section{Zeitgenössische Berichte}

In diesem Abschnitt soll die finanziell so erfolgreiche Goldgeld-Aktion aus zeitgenössischer

Sicht betrachtet werden, indem Äußerungen von Schülern und Lehrern zitiert und bewertet werden.

„Als Kostgänger Alfred hörte, daß bei einem Höker Gold sei, ist er hingegangen und hat dringlich darum gebeten. Aber der Höker rückte nicht damit heraus. Da hat Alfred allen Schülern, denen er begegnete, unwirsch gesagt, sie sollten nur hin zu jenem Höker gehen; denn er hätte Gold. Da ist der Laden ordentlich bestürmt worden. ${ }^{‘ 230}$

(Aus der Kriegschronik des Flensburger Lehrers Heinrich Schröder; 4. 3. 1915)

„Auf Goldsuche. Julius ist um 6 Uhr aufgestanden, um 7 Uhr nach Kollund zu fahren, wo er 80 Mark Papiergeld in Gold umwandeln will. Leider ist ihm sein patriotisches Werk völlig mißglückt; er brachte alles Papiergeld wieder heim. Ein Bauer hat 150 Mark in Gold gehabt; aber er hat vorgezogen, es zu behalten."

(Schröder 6. 3. 1915)

„Die Goldsammlung war wohl (im Vergleich mit den anderen Sammelaktionen) am interessantesten. [...] In den Läden unserer Stadt habe ich nicht viel Goldgeld bekommen. Einige Schüler bekamen ein paar Stunden oder einen ganzen Tag frei, um auf dem Lande, wo die Bauern von den anderen Sammlungen verschont blieben, ihr Glück zu versuchen. ${ }^{\text {‘231 }}$

(Oberrealschüler Otto Blumenberg, Anfang September 1917)

Die drei Aufzeichnungen zeigen, dass die Schüler voller Tatendrang und Abenteuerlust sich als ,Goldsucher' betätigt haben. Es wird aber auch deutlich, wie schwierig es war, die Menschen vom Umtausch zu überzeugen.

„'Aber wie kommen Sie noch zu Gold?' Mit staunenden Augen wiegt Dr. Hensberg die Stücke in der Hand. ,Mit dieser Ablieferung machen Sie sich einen Namen. He! Fräulein von Horn, wissen Sie noch, wie Gold aussah? Hier können Sie noch einmal was bewundern.' Und dann fragte auch noch Fräulein von Horn: 'Sie Glückspilz, wie sind Sie denn noch dazu gekommen?' Warum bin ich eigentlich verlegen - warum fange ich an zu stottern ...? , Durch Zufall - durch Bekannte - Ich habe so lange geredet, bis -'; Wenn ich nur wüßte, warum ich rot werde? Es ist doch die Wahrheit Oh, dieses winzig kleine Lächeln um Hensbergs Mundwinkel jetzt, das ich mehr fühle als sehe, es könnte mich rasend machen! Denn ich weiß, dahinter versteckt sich die Annahme, ich selber hätte das Gold so lange zurückgehalten. Vorbei ist die Freude. - Ich betrachte ziemlich gleichgültig den neuen Stempel auf meinem Goldeinlieferungsschein. Fast zwei Jahre sind seit dem letzten vergangen. Es gab ja kein Gold mehr. Umso stolzer ist nun dieser. Ich bekomme eine schwarzweißrote Papiergeldtasche und eine Anstecknadel mit der Aufschrift, Goldsucher'. Wenn nur dieses kleine Lächeln nicht gewesen wäre ... ‘232

(Aus Erna Langes „Erinnerungen“ an ihre Schulzeit 1914-18)

Die Szene, die eine Situation in einer Schulklasse aus dem Jahre 1917/18 wiedergibt, macht deutlich, mit welchem Eifer Schüler Goldgeld sammelten und wie groß der Druck auf die

\footnotetext{
${ }^{230}$ Zitiert nach: Hohnsbehn, Die Flensburger Schuljugend in der Zeit des ersten Weltkriegs (1996), S. 241.

${ }^{231}$ Die drei Texte wurden zitiert nach: Hohnsbehn, Die Flensburger Schuljugend in der Zeit des ersten Weltkriegs (1996), S. 241.

${ }^{232}$ Lange, 1914 bis 1918 auf der Schulbank (1933), S. 147f.
} 
Menschen sein konnte, ihre Goldmünzen nicht zurückzuhalten, sondern umzutauschen. ${ }^{233}$

Zudem zeigt sie, dass die Aktion bis zum Kriegsende fortgeführt wurde, obwohl die Schüler bei ihren Bemühungen in den letzten beiden Kriegsjahren kaum noch Erfolg hatten.

Ausschließlich positiv beurteilten in der Regel die Lehrer und natürlich die Schuldirektoren die Aktionen:

„Rührend war es in diesem Herbst, wie die kleinen Mädchen sich im Konferenzzimmer drängten, um an Herrn Intemann ihren Goldschmuck abzuliefern, meist ein goldenes Herz oder Kreuz, ein Kettle in oder Armband.“234

(Dr. Kyrieleis, Lehrer am Viktoria-Luise-Gymnasium Hameln, Provinz Hannover, 1916)

„Die Goldwoche ist die merkwürdigste. Sie zählt schon nach Monaten und währt noch immer. Noch immer kommt hier und da ein Goldfuchs aus einem geheimen Stall, noch immer bringt ihn uns ein kleines Händchen gebensfroh heran. Freilich, der Eifer der ersten ist verschwunden. ,Die Klasse, die am meisten zusammenbringt, wird zur Belohnung einen Ausflug machen.'

Wie das wirkte! Wie das zu Hause bitten, mahnen, prachern ${ }^{235}$ ließ! Keine Truhe war so verschlossen, sie sprang auf, kein Versteck so verstohlen, es offenbarte seine Schätze. Es war, als ob alle Sesams sich geöffnet hätten. Und wer war der Sieger? Natürlich unsere Kleinsten. “،236

(Schulleiter Jakob Loewenberg, Hamburg im Herbst 1915)

„Vor allem kam die Goldsammlung, unsere Schüler haben da wirklich Tüchtiges geleistet. Das konnten sie auch, denn hinter ihnen stand die Schule. Das haben wir älteren auch noch nicht einmal als Studenten gelernt, was unsere Schüler schon als Tertianer zu hören bekamen, und sie redeten sehr bald ganz geläufig von der Deckung der Noten durch das Gold der Reichsbank, von Valutaschwankungen, vom Warentausch usw. Der Erfolg blieb nicht aus: die auf wirkliche Kenntnisse sich stützende Sammeltätigkeit der Schulen hat ganz erstaunliche Ergebnisse gebracht: allein im Jahre 1916 betrugen die angemeldeten Sammelmengen über 4 1⁄2 Millionen. [...] An dieser Riesensumme kann man sehen, wie eifrig unsere Jungen bei der Arbeit waren und der Goldschatz der Reichsbank hat inzwischen zum großen Teil durch die Verbreitung des Sammelgedankens eine bis dahin nie erreichte Höhe von fast $2 \frac{1}{2}$ Milliarden erreichet. ${ }^{\text {“237 }}$

(Schulleiter Paul Hildebrand, Berlin, 1918)

„Um zu verhindern, daß meine Schüler bloß um des schnöden Gewinns wegen vaterländische Gesinnung betätigen, ließ ich dem genannten Versprechen eine gründliche Bearbeitung jeder einzelnen Klasse vorangehen. Erst nachdem mir auf meine schließliche Frage Wollt' ihr alle mitkämpfen und helfen, daß unser Vaterland siegt? Ein freudiges ,Ja!' entgegengeschollen war, kam ich mit meinem Versprechen heraus. “.238

(Schulleiter L. Koehler, Görlitz, 1915)

Recht kritisch beurteilte eine Zeitzeugin in ihren Lebenserinnerungen die Praxis der Goldsammlungen. Ihrer Meinung nach hat die Tatsache, dass nur die Soldaten den entsprechenden

\footnotetext{
${ }^{233}$ In der dargestellten Situation war es die Tante, die das Goldgeld (4 Zwanzigmarkstücke) zurückgehalten hatte.

${ }^{234}$ Schulchronik „Die Schule im Ersten Weltkrieg 1914-1918", http://www.vikilu.de/vikilu/index.php?id=61 (06.03.2009).

${ }^{235}$ Norddeutsche Bezeichnung für , betteln’.

${ }^{236}$ Loewenberg, Kriegstagebuch einer Mädchenschule (1916), S. 97f.

${ }^{237}$ Hildebrandt, Die Leistungen unserer Schüler im Kriege, in: Günther/Hildebrandt/Samuleit (Hrsg.), Jugenddank-Kalender (1919), S. 68.

${ }^{238}$ Deutsches Philologen-Blatt 1915, S. 282f.

${ }^{238}$ Koehler, Sammelt Gold!, Deutsches Philologen-Blatt; der Schulleiter versprach jedem Schüler, der 20 Goldmark ablieferte, ein Kunstdruckblatt mit dem Bild des Kaisers oder dem Hindenburgs.
} 
Sonderurlaub bekamen, die bemittelte Verwandte und Freunde hatten, sich negativ auf das Verhalten vieler Soldaten an der Front ausgewirkt.

„Als trotz der vielen Aufrufe das Gold nicht restlos zurückfloß, versuchte man es mit allen möglichen Mitteln, räumte den Säumigen Vorteile ein und stieß damit alle Getreuen vor den Kopf, so daß sie später auch zurückhaltender wurden. Wenn zum Beispiel einer ein Zwanzigmarkstück aus Gold ans Regiment schickte, bekam der Angehörige so und so viele Tage Urlaub dafür. Das war bitter für all die, die ihr Geld sofort abgeliefert hatten und für solche, die niemals etwas davon besessen hatten. Was an Gold gewonnen wurde, ging doppelt und dreifach an Treue verloren.“ 239

Die kritisierte Praxis war sicher auch ein Grund dafür, dass Schüler später nur noch relativ wenig Goldgeld zusammen bekamen. Nachdem die Bemühungen der Schüler kaum noch Erfolg hatten, wurde - wieder mit sehr großem Propagandaaufwand ${ }^{240}$ - eine neue Sammelaktion $^{241}$ gestartet und mit der alten verbunden.

\subsection{2 „Alles Gold dem Vaterlande“ (,Vaterlandsdank“242)}

Um die Sammlung von Gold zu intensivieren, wurde im Jahre 1916 die Sammlung von Goldgegenständen ${ }^{243}$, die es seit 1915 gab $^{244}$, unter dem Motto „Gold gab ich für Eisen“ noch stärker in das Bewusstsein der Bevölkerung gerufen. ${ }^{245}$ Ziel war es auch dieses Mal, die Goldvorräte der Reichsbank zu erhöhen. Die Bevölkerung wurde aufgerufen, ihre Wertgegenstände aus Gold, insbesondere Schmuck, in Gegenstände aus Eisen umzutauschen. Der Goldschmuck wurde eingeschmolzen und zur Bezahlung für die Importe benutzt. Mit dieser Aktion knüpfte man bewusst an eine ähnliche Spendenaktion aus den Jahren der Freiheitskriege gegen Napoleon an. ${ }^{246}$ Im Jahre 1813 hatte Prinzessin Marianne von Preußen demonstrativ ihren Schmuck gespendet und alle Frauen Preußens aufgefordert, ihren Goldschmuck in eiserne Schmuckstücke (vor allem Ringe) umzutauschen. Von dem Geld sollte die Armee gegen Napoleon finanziert werden. Wie 1813 so stieß auch die Aktion im Ersten Weltkrieg auf große Akzeptanz der Bevölkerung, wurde ihr doch durch den Bezug zu 1813 suggeriert, dass Deutschland sich in einem Freiheitskampf befinde, für den jeder Opfer bringen müsse. Eine

\footnotetext{
${ }^{239}$ Zitiert nach: Kammeier, Der Landkreis Lübbecke und der 1. Weltkrieg (1998), S. 185.

${ }^{240}$ Siehe: Anhang, Seiten 33-35.

${ }^{241}$ Siehe: 2.1 .2 .

${ }^{242}$ Die Sammlung „Vaterlandsdank" wurde zur Finanzierung der „Nationalstiftung für die Hinterbliebenen der im Krieg Gefallenen“, deren Hauptsitz in Berlin war, ins Leben gerufen.

${ }^{243}$ Gegenstände aus Silber wurden ebenfalls gesammelt.

${ }^{244}$ Bereits am 10. März 1915 hatte die Provinzialregierung in Schleswig verfügt: ,[...] zugunsten dieser Stiftung wird der unter der Leitung des Geheimen Regierungsrates im Handelsministerium Prof. Muthesius stehende ,Vaterlandsdank' vom 17. Mai bis 17. Juni d. Js. im ganzen Deutschen Reiche eine Sammlung von entbehrlichen Gold und Silbergegenständen veranstalten. Die uns unterstellten Schulbehörden ersuchen wir, die Angelegenheit nach Kräften zu fördern." (Amtliches Schulblatt für den Regierungsbezirk Schleswig, Schleswig 1915, S. 93; zitiert nach: Hohnsbehn, Die Flensburger Schuljugend in der Zeit des ersten Weltkriegs [1996], S. 243).

${ }^{245}$ Offiziell hieß die Aktion: „Gold gab ich zur Wehr, Eisen nahm ich zur Ehr“.

${ }^{246}$ Auf Ansichtskarten, die die Spender als Anerkennung bekamen, waren oft Bilder mit Motiven der Spendenaktion von 1813 abgedruckt; siehe: Anhang, Seite 34, Bilder 1 und 2.
} 
ähnliche Zielsetzung hatte die Waterloo-Gedenkausstellung in Hannover, die am 25. Mai 1915 in zwei Räumen des Küstlerhauses eröffnet wurde. ${ }^{247}$ Man wollte durch die Ausstellung ein ,,verständnisvolles Miterleben und Mitempfinden jener großen Zeit deutscher Erhebung“ ermöglichen, für deren Bedeutung den Menschen „die unser aller Herzen erfüllenden Ereignisse den Gegenwart (...) erst recht die Augen für die Leiden, Kämpfe und Siege geöffnet“" hätten. Den Besuchern sollte also deutlich werden, dass auch der aktuelle Krieg wie der Krieg gegen Napoleon nur dann siegreich beendet werden könnte, wenn die Deutschen wieder so heldenmüig kämpfen würden - und zwar auch an der „Heimatfront““.

Im Juli 1916 beschloss der Goldgeldausschuss des Deutschen Philologen-Vereins, auch diese neue Aktion zu unterstützen. In einem Schreiben an alle Leiter der höheren Schulen, der Lehrerbildungsanstalten und der Mittelschulen des Deutschen Reiches wurden die Schulen aufgefordert, neben Goldgeld nun auch Goldgegenstände zu sammeln:

\begin{abstract}
„Hochverehrter Amtsgenosse! Jetzt tritt eine neue Aufgabe an uns heran. Da naturgemäß das Zurückfließen der Goldmünzen allmählich schwächer und schwächer wird, es andererseits aber unbedingt notwendig ist, für den Krieg und gleicherweise für die erste Zeit nach Friedensschluß den Goldvorrat der Reichbank aufs Höchste zu steigern, so werden jetzt im ganzen deutschen Vaterlande Goldankaufstellen errichtet, die Goldsachen jeder Art nach Gewicht zum vollen Goldwert anzukaufen.

Auch in Ihrer Stadt wird in kürzester Zeit ein Ehrenausschuß sich bilden, dessen Aufgabe sein wird, die Errichtung einer Goldankaufstelle zu fördern, den Goldankauf zu leiten und zu überwachen. Wir bitten herzlich, daß Sie, Herr Kollege, bzw. falls mehrere höhere Schulen am Ort, der Dienstälteste von Ihnen, durch den Beitritt zu diesem Ehrenausschuß die Arbeit desselben fördern helfen.

Soll diese neue Bewegung, die geeignet und notwendig ist, das nicht hoch genug zu schätzende Werk der Goldgeldsammlung zu krönen, zu einem vollen Erfolge führen, dann gibt es kein besseres Mittel, als daß die Schule sich wiederum in den Dienst der Sache stellt. Sie, die über die begeisterungsfähigen Kinderherzen verfügt, sie hat es in der Hand, daß es bald wie eine Sturmflut über die deutschen Gaue kommt, daß die neue Losung: 'Alles Gold dem Vaterlande' in Stadt und Dorf, im Palast des Reichen und der Hütte des Armen erschallt.، ${ }^{248}$
\end{abstract}

Dem Appell, Mitglied im „Ehrenausschuß“ zu werden und sich für die Goldankaufstelle zu engagieren, sind sehr viele Schulleiter gefolgt. ${ }^{249}$ Das führte u. a. auch dazu, dass Schulen häufig als Sammelstellen dienten, zu denen auch die Schüler die Gegenstände brachten, die ihnen Eltern, Verwandte oder Bekannte anvertraut oder die sie bei Straßensammlungen zu-

\footnotetext{
${ }^{247}$ Die Ausstellung, durch die man ,,an die weiten Kreisen der Bevölkerung entschwundene Erinnerung war vor Kriegsausbruch geplant worden und an die Legion (M.K.: Gemeint ist die „, Könglich Deutsche Legion“") durch lebendige Anschauung ihrer heldenmütigen Kriegstaten“ erinnern wollte, ist bereits vor Kriegsbeginn geplant worden; siehe Schneider, Das Vaterländische Museum Hannover im Ersten Weltkrieg (2010), S. 130ff. Nach Ausbruch des Krieges bedurfte es einer zusätzlich Legitimation der Ausstellung.

${ }^{248}$ Masche, Goldsachenankauf, Deutsches Philologen-Blatt: Korrespondenz-Blatt für den akademisch gebildeten Lehrerstand (Beilage), 1916, S. 517.

249 In Schleswig gehörten z. B. vier Schulleiter zum Ehrenausschuss; siehe: Ritter, Goldspenden im Kreis Schleswig, Beiträge zur Schleswiger Stadtgeschichte, Heft 47, S. 71, Kapitel 2 und 3.
} 
sammengebracht hatten. ${ }^{250} \mathrm{Zu}$ den verschiedenen Werbemitteln, die den Schulen angeboten wurden, gehörten vor allem die beiden damals sehr bekannten Plakate von Bernhard („Das Gold dem Vaterlande“!) ${ }^{251}$ und Gipkens (,Bringt euren Goldschmuck den Goldankaufstellen!" $){ }^{252}$

Neben den Schulen nahmen in vielen Städten ${ }^{253}$ auch Museen Gold- und Silberschmuck entgegen. Man wollte dadurch, dass sie den Schmuck prüften, verhindern, dass gespendete Enzelstücke von historischem Wert eingeschmolzen wurden.

Für Goldgegenstände, die Schüler, Lehrer oder andere Personen bei den Goldankaufstellen ablieferten $^{254}$, erhielten die Schulen für die Spender eisernen Schmuck oder eiserne Uhrenketten. Z. B. hatten die Einlieferer goldener Ketten die Wahl unter „1. Kurze(n) Herren-Uhrkette, $29 \mathrm{~cm}$ lang, 2. Herren-Durchziehkette, $42 \mathrm{~cm}$ lang, 3. Damen-Uhr, 4. (Lorgnon)Kette, $158 \mathrm{~cm}$ lang“. ${ }^{255}$ Für die Ketten wurde zudem (von kommerziellen Ankaufsquellen) der volle Goldwert vergütet.

Auch bei dieser Aktion gab Anerkennungen für die eifrigen Sammler, wie freie Tage, Erinnerungskarten und Kaiserbilder. ${ }^{256}$ Ab 1918 stellte die Reichsbank den Schulen viele Belohnungen für Gold sammelnde Schüler zur Verfügung. Sie reichten von der Postkarte „Volksopfer 1813“ über eine „eiserne Gedenkmünze in silberner Fassung“ (ab 50 Mark) bis zu einer vom Präsidenten der Reichsbank unterzeichneten dekorativen Urkunde (ab 500 Mark). ${ }^{257}$

Im Unterschied zu der Sammlung von Goldgeld liegen über den Wert der gesammelten Goldgegenstände keine Übersichten vor. Um den Erfolg der Aktion einschätzen zu können, sollen deshalb die Ergebnisse aus einigen Schulen betrachtet werden.

\footnotetext{
${ }^{250}$ Beispielsweise wurden am 14. August 1916 beim Realgymnasium mit Realschule und der Mittleren Volksschule in Pirna Goldankaufstellen eröffnet Jensch, Pirna im Ersten Weltkrieg, http://www.geschichtepirna.de/Pirna\%20im\%201.\%20Weltkrieg.pdf (22.01.2010), S. 32.

${ }^{251}$ Lucian Bernhard, 1881-1972, Grafiker, Designer, Typograf und Architekt; erster Professor für Plakatkunst in Deutschland.

${ }^{252}$ Abgedruckt in: Masche, Das Gold dem Vaterland!, Deutsches Philologen-Blatt: Korrespondenz-Blatt für den akademisch gebildeten Lehrerstand (Beilage), 1916, S.571f.; siehe: Anhang, Seite 34, Bild 3. Julius Gipkens (1883-1968) war einer der bedeutendsten Vertreter der deutschen Plakatkunst zwischen 1906 und 1918.

${ }^{253}$ Als Beispiele seien die Museen in Hannover, Hildesheim, Göttingen Celle, Einbeck, Emden, Hameln, Nienburg, Goslar und Uelzen genannt. Die Bevölkerung konnte die zurückgehaltenen Stücke in einer Ausstellung besichtigen und ihrerseits Gegenstände erwerben - nach Schneider ,ein eigenartiges Verfahren, wenn man bedenkt, dass manches lang gehegte Familienerbstück auf diese Weise in die Hände betuchter Menschen gelangte, die das Objekt nur wegen des Sachwertes kauften!“ (Schneider, Das Vaterländische Museum Hannover im Ersten Weltkrieg (2010), S. 151.

${ }^{254}$ Siehe: Anhang, Seite 34, Bild 3.

${ }^{255}$ Siehe: Anhang, Seite 33, Bild 4.

${ }^{256}$ Siehe: Kapitel 2.1.1 („Gründe für den Sammelerfolg“).

${ }^{257}$ Masche, Belohnungen für Gold sammelnde Schüler, Deutsches Korrespondenz-Blatt für den akademisch gebildeten Lehrerstand (Beilage), 1918, S. 32f.
} 


\section{Flensburg (Provinz Schleswig-Holstein)}

Überliefert ist, dass sich mehrere Schulen an der Sammlung beteiligten und von der St. Marien-Mädchenschule II 216 eiserne Erinnerungsringe mit der Inschrift „Vaterlandsdank $1914^{\text {‘258 }}$ bestellt und den Sammlerinnen ausgehändigt wurden. In der Schulchronik heißt es außerdem: "Es zeigte sich eine große Opferwilligkeit - Manche eingelieferte wertvolle Gabe stammte aus wenig bemittelten Kreisen. Größere Mädchen zogen ihre Ringe vom Finger und legten diese zu den mitgebrachten Spenden.“' ${ }^{259}$ Die Kinder haben also nicht nur gesammelt, sondern auch selbst gespendet. Auch in Unterlagen des Königlichen Gymnasiums wird die Aktion erwähnt: „Die Ablieferung von Goldschmuck auf Vermittelung der Schule begann erst im Juli 1917 und ergab bis zum gleichen Monat in diesem Jahr [1918] ein Resultat im Werte von $1.806,15$. ، 260

\section{$\underline{\text { Berlin }}$}

Auch diese Aufzeichnung zeigt, dass viele Schülerinnen ihren Schmuck opferten. „Diesem jungen Oberlehrer mit den kalten dünnen Fingern übergeben sie auch ihren Schmuck als Vaterlandsopfer. Gewissenhaft notiert er alle Ablieferungen, die Kettchen und Anhänger und Nadeln. Eiserne Ringe soll es dafür geben. Zum Dank und zur Erinnerung.“261

\section{$\underline{\text { Weida (Großherzogtum Sachsen-Weimar-Eisenach) }}$}

Der Aufruf des Philologen-Vereins hatte auch in Weida Erfolg. Auf Initiative eines Lehrers wurde, unterstützt von zwei Untersekundanern der städtischen Realschule, die die Schreibarbeit übernahmen, eine Goldankaufshilfsstelle in der Wilhelmsschule eingerichtet.

Im Zeitraum vom 15. August 1916 bis zum 15. November 1917 konnten 475 Goldgegenstände im Wert von 5.184,50 Mark entgegengenommen. Für ihre eifrige Sammeltätigkeit wurden sieben Schüler und Schülerinnen mit Büchern, Nadeln mit der Aufschrift „Goldsucher“ und einer eisernen Gedenkmünze ausgezeichnet. ${ }^{262}$

\section{Dillingen (Provinz Hessen-Nassau)}

„Die Sammlung, Vaterlandsdank’ fand in den Schülern eifrige Werber, die für die Schule eine große Menge entbehrlicher Gold- und Silbergegenstände zugunsten der Nationalstiftung der Hinterbliebenen der im Kriege Gefallenen ablieferten. Dafür konnten 458 eiserne Erinnerungsringe an die Sammler verteilt werden. “263

\footnotetext{
${ }^{258}$ Siehe: Anhang, Seite 34, Bilder 5b.

${ }^{259}$ Hohnsbehn, Die Flensburger Schuljugend in der Zeit des ersten Weltkriegs (1996), S. 243.

${ }^{260}$ Hohnsbehn, Die Flensburger Schuljugend in der Zeit des ersten Weltkriegs (1996), S. 244.

${ }^{261}$ Lange, 1914 bis 1918 auf der Schulbank (1933), S. 38f.

${ }^{262}$ Hübschmann, Die Tätigkeit der Goldankaufshilfsstelle Weida, Deutsches Philologen-Blatt 1918, S. 32.

${ }^{263}$ Fischer, Kriegsarbeit in der Schule, 1916, S. 259.
} 
$\underline{\text { Hameln }}$ (Provinz Hannover)

Abgeliefert wurden Goldsachen im Wert von 7.504 Mark. ${ }^{264}$

$\underline{\text { Stein (Provinz Schleswig-Holstein) }}$

„Seitens der Schüler wurden (1916) 104 Gegenstände und 14,50 M abgeliefert.“265

$\underline{\text { Itzehoe (Schleswig-Holstein) }}$

In der Chronik der Auguste-Viktoria-Schule ist vermerkt: „Außerdem wurden der hiesigen Goldankaufstelle noch Schmucksachen im Wert von etwa 2.000 Mark zugeführt. Zudem war schon vorher eine große Sammlung alter Gold- und Silbersachen an das Altonaer Museum für den Vaterlandsdank abgeliefert worden. ‘266

Die genannten Beispiele zeigen, dass es gelang, die Schuljugend auch für die neue Sammelidee zu begeistern. Dass die Sammelerfolge trotzdem geringer als erhofft ausfielen, hatte seinen Grund vor allem in dem zunehmenden Misstrauen der Bevölkerung, die angesichts von Missbrauchsfällen $^{267}$ und der sich ständig verschlechternden Versorgungslage und der schwindenden Aussicht auf ein siegreiches Ende des Krieges gerade Gold- und andere Wertgegenstände zurückhielten. ${ }^{268}$ Daran konnten auch drastische Werbesprüche (,Das Gold, das ihr nicht aus dem Schranke geben wollt - bezahlen wir mit Menschenleben. ${ }^{\text {(269) }}$ ) und andere massive Propagandamaßnahmen nichts ändern.

\subsubsection{Geldsammlungen}

\section{Deutsches Geld}

An den vielen Spendenaktionen zugunsten der Kriegsfürsorge beteiligten sich auch die Schulen rege, wie aus Orts- und Schulchroniken, den Zeitschriften der Lehrerverbände und Archivalien hervorgeht. Ein Gymnasium (Berlin-Steglitz), ein Lyzeum (Altona bei Hamburg) und eine Dorfschule (Stein in Schleswig-Holstein) seien als Beispiele genannt:

\section{$\underline{\text { Gymnasium zu Berlin-Steglitz }}$}

„Ueberhaupt bildeten Geldsammlungen einen Hauptteil der Sammeltätigkeit der Schülerschaft. Immer wieder bot sich ein neuer Ansatz, den Werbeeifer der wackeren Jungen anzuregen: für die Steglitzer Kriegshilfe, für die Kriegsspende, für den Steglitzer Lazarettzug, für die deutsche Flotte, für die Schwesternspende, für die Ludendorffspende, für die Kolonialkriegerspende, für die Weih-

\footnotetext{
${ }^{264}$ Deutsches Deutsches Philologen-Blatt, 1917, Jg. 25, Heft 34, S. 538.

${ }^{265}$ Klindt/Bubert, 750 Jahre Stein (1990), S. 286.

${ }^{266}$ Chronik Itzehoe, 1918/19; zitiert nach: Pust, „Vaterländische Erziehung" für „Höhere Mädchen" (2004), S. 355

${ }^{267}$ So ist es vorgekommen, dass gespendeter Familienschmuckstücke nicht eingeschmolzen wurde, sondern in der Öffentlichkeit; z. B. sah eine Spenderin ihre Brosche an der Bluse einer anderen Dame.

${ }^{268}$ Sicher hat auch die Konkurrenz kommerzieller Ankaufsstellen zu dem Rückgang beigetragen.

${ }^{269}$ Zitiert nach: Pust, „Vaterländische Erziehung" für „Höhere Mädchen" (2004) S. 355.
} 
nachtsfeiern des Reservelazaretts Steglitz und der Groß-Berliner Lazarette, für die U-Boot-Spende, für die Volksspende zum Ankauf von Lesestoff für Heer und Flotte, für die Hindenburggabe zu Kriegsfürsorgezwecken zu des Feldmarschalls 70. Geburtstags (2. Oktober 1917), für die Jugendspende für Kriegerwaisen, für die Nationalstiftung der im Krieg Gefallenen, für die Kriegsbeschädigten-Fürsorge der Provinz Brandenburg u. dg. M.“‘270

\section{Lyzeum und Oberlyzeum zu Altona (Provinz Schleswig-Holstein)}

Die Schülerinnen haben 1918 für die folgenden Zwecke Geld gesammelt:

„...städtische Kriegshilfe, Jugenddank für Kriegsbeschädigte, Invalidendank, Ludendorffspende, Kaiser Wilhelmspende deutscher Frauen ${ }^{271}$, Nationalstiftung für die Hinterbliebenen, Reichsverband zur Unterstützung deutscher Veteranen ${ }^{272}$, deutscher Kriegshilfsbund, Kriegsspende deutscher Frauendank $^{273}$, Kolonialkriegerspende ${ }^{274}$, Armeeostergabe, U-Bootspende, Rotes Kreuz, Volksspende für Lesestoff.“ “275

\section{Dorfschule zu Stein (Provinz Schleswig-Holstein)}

In der Dorfchronik werden als Spendenaktionen, an denen die Schule beteiligt war, erwähnt:

Rotes Kreuz, Ostpreußenhilfe, Seemannserholungsheim in Berlin, Jugendspende für Kriegerwaisen, Hindenburggabe, Kaisergeburtstagsspende und Ludendorffspende. ${ }^{276}$

Diese drei Beipiele zeigen, welche Bedeutung die Geldsammlungen für die Schulen hatten. Da es nicht möglich und auch nicht erforderlich ist, auf alle Spendenaktionen einzugehen, an denen Schulen beteiligt waren, sollen im Folgenden lediglich diejenigen näher untersucht werden, für die besonders viele Schulen Geldspenden gesammelt haben, und zwar vor allem die Ludendorff-Spende, dann aber auch die U-Boot-Spende, die Hindenburg-Gabe sowie die Spenden für das Rote Kreuz. Andere Aktionen werden lediglich erwähnt, um die Ergebnisse zu ergänzen.

\footnotetext{
${ }^{270}$ Lehmann, Weltkriegs-Erinnerungen aus dem Kreise des Gymnasiums zu Berlin-Steglitz (1925), S. 14f.

${ }^{271}$ Es handelte sich um eine Spendenaktion, die der Bund deutscher Frauenvereine zugunsten der „Kaiser Wilhelms-Spende“ veranstaltete. Diese verdankte ihre Entstehung einer Sammlung, die nach den beiden Attentaten auf Kaiser Wilhelm I. (11. Mai und 2. Juni 1878) im Deutschen Reich veranstaltet worden war. Das Geld bildete insbesondere für die Arbeiter die Grundlage einer Altersrenten- und Kapitalversicherung.

272 Der „Reichsverband zur Unterstützung deutscher Veteranen E.V." war als Hilfsorganisation für in Not geratene Kriegsteilnehmer von 1864, 1866 und 1870/71 bald nach Gründung des Deutschen Reiches mit Sitz in Berlin gegründet worden. Im Ersten Weltkrieg unterstützte er auch bedürftige „Kriegsteilnehmer des Heeres und der Marine“"

${ }^{273}$ Die „Kriegsspende Deutscher Frauendank“, deren Hauptgeschäftsstelle in Berlin war, wurde organisiert durch den „Bund deutscher Frauenvereine“ in Verbindung mit dem „Katholischen Frauenbund“. Die Mittel wurden zur Hälfte der „Nationalstiftung für die Hinterbliebenen der im Kriege Gefallenen“ und zur Hälfte den Ausschüssen für die Kriegs-Invalidenfürsorge zugeführt.

${ }^{274}$ Der „Kolonialkriegerverein“ mit Sitz in Berlin. wurde im Jahre 1909 als eingetragener Verein zur Unterstützung ehemaliger Kolonialkrieger der Armee, Marine, der Schutz- und Polizeitruppen sowie deren Hinterbliebenen begründet. Ziel war es, diesen Kriegern durch Verschaffung geeigneter Stellungen zu einer gesicherten Lebensführung zu verhelfen, Bedürftige in Fällen unverschuldeter Not durch Geldspenden zu unterstützen und in Krankheitsfällen ärztliche Hilfe und Arzneien zu gewähren.

${ }^{275}$ LAS, Abt. 302, Nr. 3178; in dem Bericht wird außerdem erwähnt: „Für alle diese Zwecke wurden z. T. namhafte Summen bis zu 10000 M gesammelt.“

${ }^{276}$ Klindt/Bubert, 750 Jahre Stein (1990), S. 267-270.
} 


\section{Ludendorff-Spende für Kriegsbeschädigte}

Die 1918 ins Leben gerufene Spendenaktion, für die in einer „Opferwoche“ in der Zeit vom 1. bis 7. Juni reichsweit gesammelt wurde und die über das Ende des Krieges hinaus lief, diente der Unterstützung dauerhaft geschädigter Soldaten, die der Staat nicht ausreichend unterstützen konnte. Sie wurde mit großem Werbeaufwand durchgeführt, wie die vielen überlieferten Plakate $^{277}$ und öffentlichen Aufrufe zeigen. Auch wenn die folgende Aufstellung nach Schulart und Region so disparat ist, dass eine substanstantielle Analyse, z. B. hinsichlich der Einsatzbereitschaft der Schüler nicht möglich ist, so zeigt sich doch, dass sich Schüler unterschiedlichster Schulformen, aus Schulen Nord- Süd-, Ost- und Westdeutschlands sich beteiligten und die Spendensummen erheblich differierten.

Lyzeum Itzehoe (s. o.)

Lyzeum Altona (s. o.)

Realgymnasium Ohligs (Rheinprovinz)

Lyzeum in Pyritz (Provinz Pommern)

Höhere Mädchenschule Offenbach (Großherzogtum Hessen)

Gymnasium in Landshut (Kgr. Bayern)

Schule in Mittel-Podiebrad (Provinz Schlesien)

Schule in Stein (Provinz Schleswig-Holstein)

Schule in Gebersdorf (Provinz Brandenburg)

$$
\begin{aligned}
& \text { 32.000,00 } \text { Mark }^{278} \\
& \text { 5.808,24 } \text { Mark }^{279} \\
& \text { 2.922,28 } \text { Mark }^{280} \\
& \text { 2.527,27 } \text { Mark }^{281} \\
& \text { 200,00 Mark } \\
& \text { 184,15 } \text { Mark }^{283} \\
& \text { 34,00 Mark } \\
& \text { 7,40 } \text { Mark }^{285} \text { (1. Klasse) } \\
& \text { 6,50 } \text { Mark }^{286}
\end{aligned}
$$

Bei den Ergebnissen muss auch berücksichtigt werden, dass die größeren Schulen sich mitunter zeitnah an mehreren Spendenaktionen beteiligten. Auch wenn natürlich die genannten zehn Schulen nicht repräsentativ sind, so kann festgestellt werden, dass die von ihnen im Jahre 1918 im Durchschnitt gesammelten 4.376 Mark angesichts der damaligen wirtschaftich sehr schwierigen Zeit ein recht gutes Ergebnis darstellen. ${ }^{287}$ Z. B. sind die von einer 1. Klasse einer kleinen Dorfschule im Jahre 1918 aufgebrachten 7,40 Mark eine relativ hohe Summe

\footnotetext{
${ }^{277}$ Siehe: Anhang, Seite 39, Bilder 2-4.

${ }^{278}$ Pust, ,Vaterländische Erziehung" für „Höhere Mädchen" (2004), S. 356.

${ }^{279}$ Pust, „Vaterländische Erziehung" für „Höhere Mädchen" (2004), S. 356.

${ }^{280}$ Deutsches Philologen-Blatt 1918, Jg. 26, Heft 31f., S. 260.

${ }^{281}$ Deutsches Philologen-Blatt 1918, Jg. 26, Heft 27f., S. 238.

${ }^{282}$ Deutsches Philologen-Blatt 1918, Jg. 26, Heft 31f., S. 260.

${ }^{283}$ Ebermeier/Mayer-Mommertz/Pfaffenzeller, Die Geschichte des Hans-Carossa-Gymnasiums Landshut 16292004 (2004), S. 98.

${ }^{284}$ Johann/Tchech/Schicha/Zwikirsch/Matzel/Rosemann, Schulchronik der Schule zu Mittel-Podiebrad (2007).

${ }^{285}$ Klindt/Bubert, 750 Jahre Stein (1990), S. 270.

${ }^{286}$ Nerlich, Aus der Gebersdorfer Schulchronik 1911-1920, http://www.gebersdorf-mark.de/kalenderblatt.htm.

${ }^{287}$ Vergleicht man die durchschnittliche Spendensumme der zehn Schulen z. B. mit der 1918 in Hannover und Linden von der gesamten Bevölkerung aufgebrachten, die ca. 1,2 Millionen betrug (siehe Schneider, Ein Photofund über die Arbeit der „Freiwilligen Kriegshilfe Hannover und Linden" im ersten Weltkrieg, Hannoversche Geschichtsblätter, 1999, S. 204).so wird deutlich, dass die Schulen durchaus erfolgreich waren
} 
und auch die von Schülerinnen des Lyzeums in Pyritz selbst gespendeten 1.024 Mark stellten eine beachtliche Leistung dar. Dass eine Schule wie das Lyzeum in Itzehoe 32.000 Mark zusammenbrachte, ist in erster Linie darauf zurückzuführen, dass der Direktor der Schule die Sammelaktion selbst leitete. Berücksichtigt man, dass z. B. in Göttingen, einer Stadt mit etwa 40.000 Einwohner, ein Betrag von 73.000 Mark zusammenkam ${ }^{288}$, so wird die Bedeutung des Sammelergebnisses des Itzehoer Lyzeums und anderer Schulen deutlich.

Dass die Sammelergebnisse gerade bei der Ludendorff-Spende recht hoch waren, geht auch aus den Erinnerungen ehemaliger Schüler hervor. So schrieb z. B. Rudolf Steiner: „Wir mussten an Sonntagen Hindenburgpostkarten verkaufen und für die ,Ludendorffspende' sammeln. Und wir bekamen viel und reichlich.“289

\section{U-Boot-Spende}

Nachdem die deutsche Regierung zum 1.2. 1917 den uneingeschränkten U-Boot-Krieg erklärt hatte, wurde immer wieder zu eifriger Spendentätigkeit an „Opfertagen für die U-BootSpende des deutschen Volkes“ aufgerufen. ${ }^{290}$ Ziel der Aktion war es, eine starke U-BootFlotte aufzubauen. Durch Spendenaufrufplakate ${ }^{291}$ und Aufrufe in den Zeitungen appellierte man an die Spendenbereitschaft der Bevölkerung - und zwar auch bei den Schülern mit Erfolg. So betrug im Juni die Spendensumme des Lyzeums und Oberlyzeums in Thorn (Provinz Westpreußen) 414,30 Mark $^{292}$, die des Kaiser Wilhelm-Gymnasiums in Thorn (Westpreußen) sogar 1.046,65 Mark ${ }^{293}$ und die der kleinen Dorfschule in Fiestel (Provinz Westfalen) beachtliche 65,25 Mark $^{294}$.

Vom städtischen Lyzeum und Oberlyzeum in Insterburg (Provinz Ostpreußen) ist überliefert: „An der U-Boot-Spende beteiligten sich unsere Schülerinnen sammelnd und selbst reichlich gebend. Der Anstalt wurde vom Provinzial-Schulkollegium als Anerkennung für treu geleistete Kriegshilfe das Reiterbild des Kaisers verliehen. “295 In der Dorfschule in Copitz (Kgr. Sachsen) wurden die Schüler bei der U-Boot-Spende mehrfach ,zur Verteilung von Kriegsflugblättern“296 eingesetzt. Dass sich auch süddeutsche Schulen für die Sammlung engagier-

\footnotetext{
${ }^{288}$ Saathoff, Albrecht, Göttinger Kriegsgedenkbuch. 1914-1918 (1935), S. 74.

${ }^{289}$ Franke, 3. Die Kriegsgeneration in Blömer/Garz (Hrsg.), „Wir Kinder hatten ein herrliches Leben“, S. 263; es handelt sich nicht um den gleichnamigen Begründer der Waldorfpädagogik.

${ }^{290}$ Die Spendenanktion wurde über das Kriegsende hinaus weitergeführt.

${ }^{291}$ Z. B. das Plakat von Willy Stöwer mit dem Titel „Gebt für die U-Boot-Spende“ (Paß und Harleb GmbH in Berlin); siehe: Anhang, Seite 37, Bild 3.

${ }^{292}$ Deutsches Philologen-Blatt 1917, Jg. 25, Heft 24/25, S. 424.

${ }^{293}$ Deutsches Philologen-Blatt 1917, Jg. 25, Heft 33/34, S. 489.

${ }^{294}$ Schulchronik Fiestel S. 153f.; siehe: Kammeier, Der Landkreis Lübbecke und der 1. Weltkrieg (1998), S. 186.

${ }^{295}$ Deutsches Philologen-Blatt 1917, Jg. 25, Heft 24/25, S. 424.

296 Kuleßa, Mittelschule „Johann Heinrich Pestalozzi" in Pirna, http://www.mspesta.com/page63.html (15.07.2008).
} 
ten, zeigt als Beispiel das Hans-Carossa-Gymnasium in Landshut, das sich 1917 „rege“ beteiligte. $^{297}$ Von sehr vielen Schulen ist lediglich bekannt, dass sie sich an der Spendenaktion beteiligten, die Höhe der Spenden wird aber in den Chroniken nicht genannt. Insgesamt reichen allerdings die vorhandenen Quellen nicht aus, um differenziertere Angaben machen zu können, z. B. über die Einstellung der Schüler zu der Sammelaktion. Dass die Schüler jedoch teilweise recht erfolgreich waren, zeigt z. B. das Ergebnis des Kaiser Wilhelm-Gymnasiums in Thorn (s. o.), wenn man es in Relation zum Gesamtergebnis von Kommunen setzt. Im Vergleich zu der mit 31.176,93 Mark recht hohe Spendensumme in Hildesheim beispielsweise, für die die Stadt sogar ein Dankesschreiben des Reichstagspräsidenten erhielt; betrüge der Ertrag der Gummersbacher Schüler 3,6 \% ${ }^{298}$

\section{Hindenburggabe/Hindenburgspende ${ }^{299}$}

$\mathrm{Zu}$ den Geldsammelaktionen, bei denen sich die Schulen wegen Hindenburgs hohem Ansehen besonders engagierten, gehörte die Hindenburggabe, die anlässlich seines 70. Geburtstags am 2. Oktober 1917 ins Leben gerufen worden war und bis zum Ende des Krieges dauerte. Der gesammelte Erlös kam der Kriegswohlfahrt zugute. Einige Auszüge aus Chroniken sollen dieses dokumentieren.

In Stein (s. o.) spendeten die Kinder „freudigen Herzens“ 73,60 Mark. Als Zeichen des Dankes erhielt die Schule „,von der Hindenburgspende ein herrliches Bild“300. Sicher hatten die Schüler der Volksschule Neuenhaus (Grafschaft Bentheim, Provinz Hannover) zum Ergebnis der Kommune $(788,70$ M.) beigetragen, nachdem am 2. Oktober, dem 70. Geburtstage Hindenburgs, während der Schulfeier gesammelt worden war. ${ }^{301}$

Die Flensburger Volks- und Mittelschulen spendeten 531,96 Mark und die Oberrealschulen I und II 352,70 Mark. ${ }^{302}$ In der Volksschule von Gebersdorf (Provinz Brandenburg) kamen bei der Sammlung am 15. Oktober 1915 10,25 Mark zusammen, in Solingen spendeten zwei Klassen 50 Mark $^{303}$ und im Gymnasium Landshut (Niederbayern) waren es 136,75 Mark. ${ }^{304}$

\footnotetext{
${ }^{297}$ Ebermeier/Mayer-Mommertz/Pfaffenzeller, Die Geschichte des Hans-Carossa-Gymnasiums Landshut (2004), S. 98.

${ }^{298}$ Vogeler, Kriegschronik der Stadt Hildesheim (1929), S. 261.

${ }^{299}$ Die Hindenburg-Spende gab es seit 1915. Sie diente der besseren Ernährung der Rüstungsarbeiter (siehe: Hungerblockade und Heimatfront (1991), Nr. 10; S. 162-172) und ist nicht zu verwechseln mit der „Hindenburgspende für das Ostheer“, die es sich zum Ziel gesetzt hatte, die im Osten eingesetzten Truppen mit warmen Kleidungsstücken zu versorgen. Als das Spendenaufkommen der Hindenburg-Spende ständig zurückging, wurden vor allem Geistliche und Lehrer zu verstärkter Propagandaarbeit aufgefordert. Sie sollten die Kampagne durch Vorträge unterstützen.

${ }^{300}$ Klindt/Bubert, 750 Jahre Stein (1990), S. 269.

301 Wieferink, Schulchronik der Volksschule Neuenhaus, http://www.gbiu.de/Chroniken/02-nhs.htm (15.07.2008).

${ }^{302}$ Hohnsbehn, Die Flensburger Schuljugend in der Zeit des ersten Weltkriegs (1996), S. 248.

${ }^{303}$ Sinne/Motz, Solingen im 1. Weltkrieg (1984), S. 64.
} 
Die Schulchronik von Mittel-Podiebrad (Provinz Schlesien) erwähnt eine Spende von 25 Mark $^{305}$. Dass die Schulkinder „freudigen Herzens“ spendeten und auch Straßensammlungen gern durchführten, hing mit der großen Popularität Hindenburgs zusammen. Insgesamt war die Spendensumme niedriger als bei den beiden oben genannten Aktionen.

\section{Spendenaktionen des Roten Kreuzes}

Einige wenige Beispiele sollen zeigen, dass die Schulen bei den in der Regel regionalen Spendensammlungen eine beachtliche Rolle spielten. So wurden 1914 von der Dorfschule Stein (s. o.) 366,70 Mark überwiesen. ${ }^{306}$ In Münster (Provinz Westfalen) spendeten die Schülerinnen der Mittelschule 541 Mark; die „Abiturientia Paulina“307 und die Schülerinnen des Lyzeums und Oberlyzeums brachten 113,23 Mark bzw. 250 Mark zusammen. ${ }^{308}$ Auch in Coburg (Herzogtum Sachsen, Coburg und Gotha) sammelten die Schüler Geld für das Rote Kreuz. Über die Spende in der Volksschule Giesenhof (Provinz Pommern) ist vermerkt, dass die Kinder und Lehrer „gern und willig [...] Beiträge (gaben) für das Rote Kreuz“.

\section{$\underline{\text { 5. Andere Sammelaktionen }}$}

Ohne die Beteiligung von Schulen an den vielen anderen Spendensammlungen im Einzelnen zu untersuchen, sei abschließend als Ergänzung noch auf einige schulische Aktivitäten bei anderen Sammlungen hingewiesen. Generalisierende Aussagen sind aufgrund der schlechten Quellenlage allerdings nicht möglich.

\section{Ostpreußenhilfe $^{309}$}

In der Dorfchronik von Stein (s. o.) gibt folgende Passage Aufschluss: „Alle Kinder, ohne Ausnahme, brachten von ihren Spargroschen. Mit strahlenden Augen legten sie ihre Gabe auf den Altar der Liebe. 48,75 Mark ergab die Sammlung. Mit einem Brief an die Kinder Ostpreußens, geschrieben von einem Schüler, wurde das Geld an den Regierungspräsidenten a. D. Stockmann in Kiel gesandt. “310

\footnotetext{
${ }^{304}$ Ebermeier/Mayer-Mommertz/Pfaffenzeller, Die Geschichte des Hans-Carossa-Gymnasiums Landshut (2004), S. 98.

${ }^{305}$ Johann/Tchech/Schicha/Zwikirsch/Matzel/Rosemann, Schulchronik der Schule zu Mittel-Podiebrad (19.09.2007).

${ }^{306}$ Klindt/Bubert, 750 Jahre Stein (1990).

307 Schulte, Kriegschronik der Stadt Münster 1914-18, (1930), S. 38.

${ }^{308}$ Schulte, Kriegschronik der Stadt Münster 1914-18, (1930), S. 74.

${ }^{309}$ Die zweimalige Besetzung der östlichen und westlichen Grenzregionen Ostpreußens durch die russische Armee verursachte bei der Bevölkerung nachhaltige Not und Armut. Um schnelle und effektive Hilfe zu leisten, konstituierte sich eine Kriegshilfskommission unter Leitung des Oberpräsidenten von Ostpreußen in Königsberg, an die die Berliner Ministerien Befugnisse abtraten. Zwar stellte das Preußische Finanzministerium sofort 400 Millionen Mark zur Verfügung, da die Mittel aber nicht ausreichten, veranstaltete die Kommission Spendenaktionen. Die „Ostpreußenhilfe“ umfasste insgesamt 61 regionale „Hilfsvereine“ (siehe: Die Ostpreußenhilfe im Ersten Weltkrieg [2006]).

${ }^{310}$ Klindt/Bubert, 750 Jahre Stein (1990).
} 
$\underline{\text { Kolonialkriegerdank }}^{311}$

Im Altonaer Lyzeum wurden 933,50 Mark gesammelt. ${ }^{312}$

\section{Kaiser-Geburtstagsspende:}

Die Schulkinder in Stein (s. o.) spendeten 48,60 Mark $^{313}$, während in der Schule zu Grunewald (s. o.) 27,95 Mark zusammenkamen. ${ }^{314}$

\section{$\underline{\text { Kaiser-Wilhelm-Spende }}$}

Dass durch die Schule durchaus auch Druck auf die Schüler ausgeübt wurde, um ein gutes Spendenergebnis zu bekommen, und Schüler mitunter durchaus opponierten, geht aus den Erinnerungen der Zeitzeugin Margarete Buber-Neumann hervor. ${ }^{315}$ Sie beschreibt eine Episode im Lyzeum in Potsdam, die sie als zwölfjährige Schülerin erlebte:

„Wieder einmal betrat Thüm die Klasse und verkündete im Befehlston: 'Also morgen früh bringt jeder von euch für die Kaiser-Wilhelm-Spende mit! Weniger als eine Mark nehme ich gar nicht erst an!' Da überwand ich die Kinderschüchternheit, stand auf und erklärte, daß man so etwas nicht befehlen dürfe, daß ich gar nicht daran dächte, eine Mark mitzubringen, denn wir seien fünf Kinder, und so etwas könne man wohl nicht verlangen ...Darauf überschüttete mich der Pfarrer Thüm mit wüstem Geschimpfe und ließ keine Gelegenheit vorübergehen, mich zu demütigen.“316

\section{Kriegskinderspende:}

„Am 20. September 1918 als am Geburtstage unserer Kronprinzessin sammelte unsere Schule (im schlesischen Mittel-Podiebrad) 15 Mark zur Kriegskinderspende ,Zum Besten der im Kriege geborenen Kriegerkinder‘، ‘317

\section{Spende für arme Kriegsfrauen:}

Eine Schülerin aus Düren spendete am 30. Juli 1917 2,29 Mark; der Oberbürgermeister bedankte sich in einem handgeschriebenen Brief. ${ }^{318}$

Abschließend soll noch kurz auf das Aufstellen von Opferstöcken und Opferbüchsen eingegangen werden - eine damals von den Schulen recht häufig angewandte Methode, um zusätzlich zu den Nagelungen, Veranstaltungen, Verkäufen und Straßensammlungen an Bargeld zu kommen. Viele Initiatoren dieser Aktivitäten waren sicher durch die von Gemeinden,

\footnotetext{
${ }^{311}$ Siehe: Anhang, Seite 37, Bild 4.

312 Pust, ,Vaterländische Erziehung" für „Höhere Mädchen" (2004), S. 357.

${ }^{313}$ Klindt/Bubert, 750 Jahre Stein (1990), S. 270.

${ }^{314}$ Müller, Die Chronik der Schule zu Grunewald, http://www.mueller-nuembrecht.de/chronik/chronik1.htm (02.03.2009).

${ }^{315}$ Auch wenn es recht selten vorkam, dass gegen Sammelaktionen opponiert wurde, so ist handelt es bei der geschilderten Episode nicht um einen Einzelfall; siehe z. B. S. 59.

${ }^{316}$ Pörtner, Kindheit im Kaiserreich (1990), S. 18; Margarete Buber-Neumann, Schriftstellerin, 1901-1989.

${ }^{317}$ Johann/Tchech/Schicha/Zwikirsch/Matzel/Rosemann, Schulchronik der Schule zu Mittel-Podiebrad (19.09.2007).

${ }^{318}$ Geschichtswerkstatt, Spuren jüdischen Lebens in Düren (04.12.2008).
} 
Vereinigungen und Einzelpersonen aufgestellten öffentlichen Opferstöcke ${ }^{319}$ angeregt worden. Kommunale Opferstöcke und fest installierte Opferbüchsen gab es z. B. in Augsburg (Kgr. Bayern), Coburg (Hzgt. Sachsen-Coburg und Gotha), Hildesheim (Provinz Hannover), Schleswig (s. o.) ${ }^{320}$ und Stuttgart (Kgr. Württemberg).

Bereits im Dezember 1914 schlug ein Reichstagsabgeordneter in der Verbandszeitschrift der Gymnasiallehrer vor, in den Schulen Sparbüchsen aufzustellen:

„Man stelle doch nur in jeder Klasse eine Sparbüchse auf und ermahne die Jungen, daß sie sich für das ihnen mitgegebene Geld für das Frühstück Brot kaufen statt Süßigkeiten, daß sie aber das Ersparte in die Büchse stecken. Der Erfolg ist oft überraschend. Auf den erzieherischen Wert solcher Selbstbeschränkung in diesem Kriege, in dem es eben nicht gilt zu siegen, sondern vor allem zähe durchzuhalten, brauche ich kaum hinzuweisen. ${ }^{\text {‘321 }}$

Offensichtlich hatte der Aufruf eine große Resonanz, denn ein Gymnasiallehrer aus Münster ging davon aus, dass 1916 ,Zehntausende von Sammelbüchsen, deren Inhalt für irgendeinen der zahlreichen Zwecke der Kriegsliebestätigkeit bestimmt ist, [...] in diesem Kriege auch in den Schulen, den höheren wie den niederen, angebracht worden“‘322 sind. Dass das Aufstellen von Sammelbüchsen in den Schulen weit verbreitet war, geht auch aus dem Bericht über die „höheren realistischen Schulen Bayerns im Kriegsjahr 1914/15“3323 hervor.

Einen - von einem Oberlehrer entworfenen - besonders spektakulären Opferstock, den man auch benageln konnte, stellte man in Schwenningen auf. Er stand auf dem Marktplatz und erbrachte einen Erlös von 7.000 Mark, der einem Unterstützungsfonds für Kriegerwitwen und Kriegswaisen zugutekam. Ein Bild im Anhang zeigt Schulkinder beim Nageln am Opferstock. ${ }^{324}$ In Heidelberg hatte man die Form eines $42 \mathrm{~cm}$-Geschützes gewählt (,Dicke Berta'), in das die Schüler zahlreicher Schulen am 27. November 1915 im Rahmen eines Festaktes Geld einwarfen. ${ }^{325}$

Über die Höhe der Spendensummen gibt es keine Unterlagen. Sicher handelte es sich meistens um recht geringe Summen, denn in der Regel spendeten die Schüler nur kleine Nickelund Kupfermünzen. Das von dem Reichstagsabgeordneten Kuckhoff erhoffte Erziehungsziel, die Schulkinder zur Opferbereitschaft zu erziehen und den Durchhaltewillen zu stärken, dürfte in jedem Fall erreicht worden sein, denn die Opferbüchsen in den Klassenräumen, die stets im

\footnotetext{
${ }^{319}$ Opferstöcke stellte man seit den Kreuzzügen in den Kirchen auf.

${ }^{320}$ Siehe: Anhang, Seite 36, Bild 3.

${ }^{321}$ Kuckhoff, J., Wie können die höheren Schulen die wirtschaftliche Kriegsbereitschaft Deutschlands stützen helfen?, Deutsches Philologen-Blatt 1914, S. $745 f$.

${ }^{322}$ Beisenherz, Leeret die Sammelbüchsen häufiger!, Deutsches Philologen-Blatt 1916, S. $707 f$.

${ }^{323}$ Ebner, Die höheren realistischen Schulen Bayerns im Kriegsjahr 1914/15, Deutsches Philologen-Blatt 1915, S. $670 f$.

${ }^{324}$ Reinartz/Weber-Benzing, Schwenninger Bilddokumente 1 (1977), S. 30f.; siehe: Anhang, Seite 36, Bild 4.

${ }^{325}$ Reichert/Wolgast (Hrsg.), Karl Hampe (2004), S. 327, Fußnote 456.
} 
Blickfeld der Kinder waren, wirkten sicher wie eine permanente Aufforderung, sich am Kampf an der „Heimatfront“ zu beteiligen.

Die vielen regionalen Opfertage, Blumenwochen, Kornblumentage und andere kleinere Aktionen bleiben in dieser Arbeit unberücksichtigt, da die Quellenlage hinsichtlich der Beteiligung der Schulen keine gesicherten Aussagen zulässt. Es ist allerdings sehr wahrscheinlich, dass sich Schüler auch daran eifrig beteiligt haben.

Dass Kommunen oder Schulen sich weigerten, Sammlungen zu unterstützen oder sogar gegen die Durchführung protestierten, kam vereinzelt allerdings auch vor. Einen solchen Protest hat es beispielsweise 1915 in Flensburg gegeben, wo sich die Schuldeputation weigerte, eine Geldsammlung zugunsten der „Jugendspende für Kriegerwaisen“ durchzuführen. In der Begründung hieß es: „Die Sammlung in den Volksschulen wird abgelehnt, da die Eltern der Kinder durch die jetzigen Verhältnisse schon zu der äußersten Sparsamkeit genötigt sind.‘326 Außerdem durften nach einem Beschluss der Schuldeputation vom 24. Mai 1918 die Volksund die Mittelschüler nicht für die Ludendorff-Spende sammeln.

\section{Ausländisches Geld}

Im Juni 1915 startete ein Görlitzer Lehrer zusammen mit dem Zentralkomitee des Roten Kreuzes eine neue Sammelaktion für die höheren Schulen. Er forderte die Lehrkräfte auf, zusammen mit ihren Schülern ausländisches Geld und ungestempelte ausländische Briefmarken zu sammeln und dem Roten Kreuz zuzusenden. ${ }^{327}$ Am 7. Juli veröffentlichte er eine erste Spenderliste, die 18 Schulen mit einer Gesamtsumme von 1.212 Mark nennt. ${ }^{328}$ Die zweite Liste enthielt bereits 36 Schulen, die 1.471 Mark gesammelt hatten; es folgten fünf weitere Listen. Dann wurde die Aktion Ende August 1916 abgebrochen und die 7. Liste war die letzte. Nach Aussage des Initiators waren die Beiträge nur noch sehr spärlich eingegangen. Insgesamt beteiligten sich an der Sammelaktion etwa 400 höhere Schulen aus allen preußischen Provinzen. Bis zum 20. August 1916 kamen 20.211 Mark zusammen - nach Meinung des Görlitzer Lehrers „ein erfreuliches Ergebnis, mit dem manches Liebeswerk gefördert werden “6329 konnte. Die einzelnen Beträge waren sehr unterschiedlich und reichten von 2 Mark (Realschule Otterndorf, Provinz Hannover) bis zu 566 Mark (Kaiser WilhelmRealgymnasium in Berlin).

\footnotetext{
${ }^{326}$ Zitiert nach: Hohnsbehn, Die Flensburger Schuljugend in der Zeit des ersten Weltkriegs (1996), S. $244 \mathrm{f}$.

${ }^{327}$ Koehler, Ausländisches Geld, in: Deutsches Philologen-Blatt 1915, S. 412; man benötigte Devisen für Geschäfte mit dem Ausland.

${ }^{328}$ Koehler, Ausländisches Geld (1915).

${ }^{329}$ Koehler, Ausländisches Geld, in: Deutsches Philologen-Blatt 1916, S. 512.
} 
Dass die recht erfolgreiche Sammlung bereits im Sommer 1916 abgebrochen wurde, ist sicher darauf zurückzuführen, dass kaum noch ausländisches Geld in der Bevölkerung vorhanden war. Deshalb führten auch die Prämien für die erfolgreichen Schüler zu keinen besseren Ergebnissen mehr. ${ }^{330}$

\subsubsection{Zusammenfassung}

Der Stettiner Regierungs- und Schulrat Bohnstedt würdigte 1917 die großen Erfolge der „Kinderkriegshilfe im Kampf der Milliarden“. Seiner Meinung nach handelte es sich bei den Sparpfennigen der Jungen und Mädchen um „Millionenwerte“, und auch den Goldeintausch hob er als besonders wichtig für die Geldwirtschaft hervor. ${ }^{331}$ Selbst wenn die Aussagen des patriotischen Schulrats zeitgemäß pathetisch klingen, so haben doch die Untersuchungen in diesem Abschnitt ergeben, dass Bohnstedt insgesamt recht hatte. Die schulischen Sammeltätigkeiten waren tatsächlich für die Kriegswirtschaft und die Finanzierung der Wohlfahrtsverbände von großer Bedeutung, wie allein die folgenden von den Schulen gesammelten Geldspenden zeigen.

Königliches Gymnasium in Flensburg

Lyzeum Itzehoe (allein Ludendorff-Spende)

Regierungsbezirk Düsseldorf:

Potsdam (allein für die ,Nationalstiftung'):

Regierungsbezirk Magdeburg:

Berlin:

$$
\begin{aligned}
& \text { 23.819,66 } \text { Mark }^{332} \\
& \text { 32.000,00 Mark } 333 \\
& \text { 109.346,00 } \text { Mark }^{334} \\
& \text { 117.897,00 } \text { Mark }^{335} \\
& \text { 215.328,00 } \text { Mark }^{336} \\
& \text { 554.981,00 } \text { Mark }^{337}
\end{aligned}
$$

Auch wenn es insgesamt nicht möglich ist, gesicherte Angaben über die Gesamtsumme der durch die Schulen aufgebrachten Geld- und Edelmetallspenden zu machen, so zeigen die Quellen doch, dass es sich um Werte in Millionenhöhe handelte.

Obwohl die Geldsammlungen von ganz unterschiedlichen Organisationen und unter immer anderen Namen (wie es z. B. das Rote Kreuz tat) durchgeführt wurden, so ging es doch stets um die Deckung der Kriegskosten oder um die Finanzierung der Kriegsfolgekosten. Wie alle Sammlungen wurden auch diese von den Lehrern und den Behörden genutzt, um Schüler zum

\footnotetext{
${ }^{330}$ Für jeweils 25 Mark des eingelieferten Wertes erhielt die Schule für die Sammler eine „Denkmünze“.

${ }^{331}$ Siehe: Bohnstedt, Die Kriegshilfe unserer Schuljugend (1917), Seiten 29-31.

332 Das Gymnasium hatte an vielen Spendenaktionen teilgenommen, und zwar am ,Marineopfertag', ,Sammlung für Kriegs und Marineheime', ,U-Bootspende', ,Luther-Dank', ,Ludendorffspende' und dem ,Kolonialkriegerdank'; Hohnsbehn, Die Flensburger Schuljugend in der Zeit des ersten Weltkriegs (1996), S. 248.

${ }^{333}$ Pust, ,Vaterländische Erziehung" für „Höhere Mädchen" (2004), S. 356.

${ }^{334}$ Führen, Lehrer im Krieg (1936), S. 93.

${ }^{335}$ Führen, Lehrer im Krieg (1936), S. 93.

${ }^{336}$ Führen, Lehrer im Krieg (1936), S. 93.

${ }^{337}$ Führen, Lehrer im Krieg (1936), S. 93.
} 
Patriotismus und zur Opferbereitschaft zu erziehen. Dabei wurden die Schüler oft unter Druck gesetzt, was durchaus auch zu Widerständen und Bestrafungen führte. ${ }^{338}$

Leider reichen die vorliegenden Quellen nicht aus, um herauszufinden, ob die Schüler sich bei den Sammlungen für die Sozialfonds stärker engagierten und erfolgreicher waren als bei den Sammelaktionen zur Deckung der Kriegskosten. Dass sich allerdings vor allem die Schülerinnen besonders gern für Pflege- und Betreuungsdienste zur Verfügung stellten ${ }^{339}$ und gerade die Schildnagelungen zugunsten der gemeinnützigen Vereine „Jugendspende für Kriegerwaisen“340 und „Jugenddank für Kriegsbeschädigte“341 so außerordentlich erfolgreich waren, spricht durchaus dafür, dass die Schüler sich bei Aktionen für karikative Zwecke mit besonderem Engagement und deshalb sicher auch mit größerem Erfolg beteiligten.

\subsection{Sammlung von Altmaterialien ${ }^{342}$}

In Deutschland war man bei Kriegsausbruch wirtschaftlich nicht auf einen langen Krieg vorbereitet gewesen. Außerdem hatten die Verantwortlichen keine ausreichenden Vorstellungen von den Anforderungen eines modernen Krieges und dessen Auswirkungen auf die Bevölkerung gehabt. Zwar befanden sich, als der Krieg ausbrach, erhebliche Lagermengen aller für die Friedensindustrie erforderlich Rohstoffe in Lagerhäusern, in den industriellen Betrieben oder als Rohstoffe im Verarbeitungsprozess, auf vielen Gebieten aber waren die Vorräte in der ursprünglichen Rohstoffform recht gering, sodass mit Ausnahme von Gummi ${ }^{343}$ und Salpeter die Vorratshaltung bei Ausbruch des Krieges verhältnismäßig gering war. ${ }^{344}$ Um den sich durch die englische Wirtschaftsblockade verschärfenden Rohstoffmangel zu bekämpfen und die erforderlichen Rohstoffe der Industrie, die vor allem den Munitions- und Ausrüstungsbedarf der kämpfenden Truppe sicherstellen musste, zur Verfügung stellen zu können, wurden verschiedene Wege zu einem effizienteren Umgang mit Rohstoffen beschritten. Dazu gehörten die Senkung des Verbrauchs, Rohstoff sparende Produktionsverfahren, die Entwicklung von Ersatzstoffen und, was insbesondere die Schulen betraf, das Sammeln von unterschiedlichsten Abfallstoffen.

Ab Dezember 1914 riefen die Schulbehörden die Schulen immer wieder zur Sammeltätigkeit auf und unterstützten sie durch umfangreiche Informationsblätter. Am Beispiel der Verfügun-

\footnotetext{
${ }^{338}$ Siehe: z. B. 2.1 .3 („1. Kaiser-Wilhelm-Spende“).

${ }^{339}$ Siehe Kapitel 4.8.

${ }^{340}$ Siehe Kapitel 7.2.1.

${ }^{341}$ Siehe Kapitel 7.2.2.

${ }^{342}$ Unter diesem Oberbegriff werden auch verarbeitete Rohstoffe wie Zeitungen, Kleidung, Schuhe u.a. verstanden; siehe: Anhang, Seiten 5-10.

${ }^{343}$ Bei Ausbruch des Krieges betrugen Vorräte etwa 5000 t (siehe: Ertheiler/Plohn, Das Sammeln in der Kriegswirtschaft (1919), S. 16).

${ }^{344}$ Siehe: Goebel, Deutsche Rohstoffwirtschaft im Krieg (1930), S. 9-18.
} 
gen zur Sammlung von Altmaterialien des Regierungsbezirks Hildesheim soll dieses verdeutlicht werden. ${ }^{345}$

28. 12. 1914 Sammlung von Patronenhülsen

22. 03. 1915 Sammlung von altem Metall für Kriegszwecke (Berlin)

05. 07. 1915 Gummisammlung

18. 03. 1916 Sammlung von Zeitungspapier

27. 02. 1917 Sammlung kleinerer Gegenstände aus Sparmetallen

02. 07. 1917 Sammlung von nicht mehr gebrauchten Tauen

24. 10. 1918 Sammlung von Weißblech und Zinngegenständen

Neben den genannten Materialien gehörten vor allem die folgenden Materialien zu den Sammelgütern der Schüler ${ }^{346}$ :

- Schallplatten und Schallplattenbruch

- Kupfer

- Messing

- Bonze

- Reinnickel und Nickellegierungen

- Aluminium

- Zinn und Stanniolpapier

- Blei

- Zink

- Glühlampensockel

- Platinbrennstifte

- Flaschen

- Zelluloid

- Lumpen und Lederabfälle

- Korkabfälle

An Beispiel des Frankfurter Goethe-Gymnasiums ${ }^{347}$ und einiger anderer Schulen soll nun untersucht werden, in welchem Maße die Aufrufe der Behörden von den Schulen umgesetzt wurden und wie erfolgreich sie bei ihrer Sammeltätigkeit waren. Im Jahre 1917 sammelten die Frankfurter Schüler z. B. innerhalb von zehn Wochen ${ }^{348}$ :

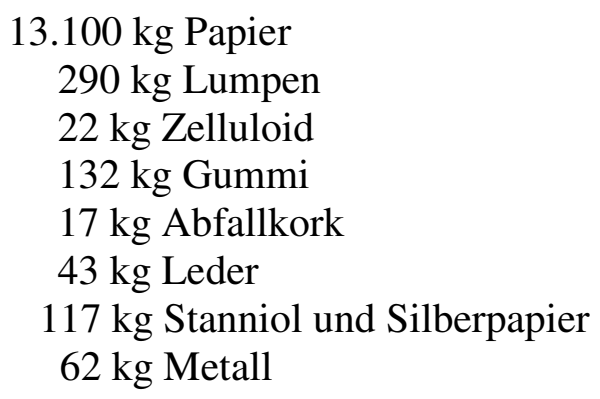

\footnotetext{
${ }^{345}$ Auf den Ankauf von Goldgeld und die Sammlung von Goldgegenständen soll hier nicht eingegangen werden; siehe: 3.1.1 und 3.1.2.

${ }^{346}$ Siehe: Ertheiler/Plohn, Das Sammeln in der Kriegswirtschaft (1919), S. 29-50. Das Kilo Kupfer wurde beispielsweise mit 1,70 M. vergütet, das Kilo Zink mit 0,40 Mark und $1.000 \mathrm{Kg}$. Konservendosen (Weißblech) mit 50 Mark.

${ }^{347}$ Zenetti, Der Sammelhilfsdienst der Frankfurter Schuljugend und seine Ergebnisse am Goethe-Gymnasium (1918).

${ }^{348}$ Frauenhaar, Lumpen, Kork und Filzhüte werden als „Naturerzeugnisse“ in 3.3 behandelt.
} 


\subsection{Flaschen \\ 4.900 Korken \\ 1.230 Glühbirnensockel 370 Filzhüte.}

An der Sammlung der genannten Altmaterialien nahmen 380 Schüler teil, die dafür 35.098 Sammelmarken bekamen. Der große Erfolg wurde nicht nur von der Presse gewürdigt, sondern auch die Schulbehörden und viele Kommunen waren auf das „Frankfurter System“ aufmerksam geworden. So ließ sich z. B. das Provinzial-Schulkollegium zu Kassel darüber berichten und in Berlin referierte der Direktor der Zentrale für den Sammeldienst ,an maßgebenden Stellen".

Da das Frankfurter Goethe-Gymnasium als ,Musterschule’ das „Frankfurter Sammelsystem ‘349 erprobt hat, sollen die Sammelergebnisse einiger anderer Schulen vergleichend hinzugezogen werden.

\section{$\underline{1917}$}

Lyzeum Flensburg: Platin: 20,1 kg, Weißblech: $2.160 \mathrm{~kg}$, Sparmetalle: $150 \mathrm{~kg}$, Summe: 2.310,02 Mark;

Lyzeum I Kiel: Platin: 7 kg, Weißblech: 823,8 kg, Sparmetalle: 13,66 kg, Gummi: 34 kg, Summe: 871,47 Mark;

Lyzeum Altona: Platin: 20,95 kg; Weißblech: 400 kg, Sparmetalle: $141 \mathrm{~kg}$; Summe 551,02 Mark.

Insgesamt sind 1917 von den 17 höheren Mädchenschulen Schleswig-Holsteins 5.292,48 kg Altmaterialien zusammengebracht worden und 1918 sogar $5.996,14 \mathrm{~kg} .{ }^{350}$

Auch wenn in den kleinen Dorfschulen hauptsächlich Naturprodukte gesammelt wurden, so nahmen sie aber auch an den Sammlungen für Metall, Gummi u. a. Teil, wie die folgenden Beispiele zeigen. ${ }^{351}$

\section{$\underline{\text { Schule in Kruspis (Provinz Hessen-Nassau) }}$}

„Eine Woche lang suchten meine Schüler auch alte Kupfer- und Messingsachen, die wir ans Artillerie-Depot nach Cassel sandten. [...] Da auch zu gleicher Zeit sich Gummimangel fühlbar machte, sammelten wir eine Woche hindurch altes Gummi. Meine Schüler entwickelten wie immer eine rege Tätigkeit und eine große Kiste voll alter Gummiwaren kam zusammen. “352

(Dorfschullehrer Schreiber aus Kruspis)

\footnotetext{
349 Zenetti, Der Sammelhilfsdienst der Frankfurter Schuljugend und seine Ergebnisse am Goethe-Gymnasium (1918).

${ }^{350}$ Angaben nach Pust, ,, Vaterländische Erziehung“ für „Höhere Mädchen“ (2004), S. 358f.

${ }^{351}$ Die Schulen auf dem Lande waren natürlich beim Sammeln von Naturerzeugnissen deutlich erfolgreicher

(s. Kapitel 2.3).

${ }^{352}$ Rasch, Der Weltkrieg 1914 - 1918: Berichte eines Zeitzeugen, http://hersfelder- zeitung.de /heimatland/40_1.htm (21.03.2008).
} 


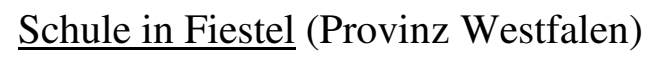

Ergebnis der ,Reichsgummiwoche' (14.-19.04.1915): 22, 5 kg ${ }^{353}$

Außerdem beteiligten sich die Schüler an einer Sammlung von Gegenständen aus Messing, Kupfer und Nickel und trugen ,'eine Unmenge von Gerätschaften aller Art' wie Mörser, Kessel und Kannen zusammen“‘354.

$\underline{\text { Schule in Drohne (Provinz Westfalen) }}$

Ergebnis der ,Reichsgummiwoche': 200 kg.

Aus der Stadt Hannover liegen für den Zeitraum vom 1. April 1916 bis 31. Dezember 1918 die Sammelergebnisse der Schüler der städtischen Mittel- und Volksschulen vor ${ }^{355}$ :

Weißblechdosen: $\quad 30.630 \mathrm{~kg}$

Metall:

$111.771 \mathrm{~kg}$

Papier, Lumpen, Gummi: $\quad 40.885 \mathrm{~kg}$

Für das Jahr 1917 gibt es statistisches Material über die Sammeltätigkeit der Schulen im Deutschen Reich, und zwar von 3.330 der insgesamt etwa 60.000 Schulen: ${ }^{356}$

Weißblech: $220.380 \mathrm{~kg}$ (Preußen $177.401 \mathrm{~kg}$ )

Altgummi: $\quad 37.629 \mathrm{~kg}$ (Preußen $30.420 \mathrm{~kg}$ )

Altpapier: $\quad 828.496 \mathrm{~kg}$ (Preußen $593.631 \mathrm{~kg}$ )

Von den Schulen aller Schulformen erzielten das höchste Ergebnis:

Altgummi: $\quad 1.300 \mathrm{~kg}$ durch das Kgl. Gymnasium in Flensburg

Altpapier: $50.000 \mathrm{~kg}$ durch die Schule Vosbergstraße in Hamburg

Platinstifte: 130 Stück durch die Unterstufe der kirchlichen St. Johann-Schule in Hamburg

Weißblech: $4.000 \mathrm{~kg}$ durch die Mädchenschule in Großottersleben bei Magdeburg.

Zwar ist es gelungen, die Schule in besonderem Maße für die Sammlung von Altmaterialien für die Rüstung zu aktivieren, die Sammelergebnisse jedoch sind bei vielen Materialien sicher hinter den Erwartungen des Kriegsamtes zurückblieben und konnten nur in geringfügigem Maße dazu beitragen, den Mangel an Rohstoffen zu beheben. ${ }^{357}$ Dieses soll am Beispiel der Sammlung von Weißblechdosen, die vorwiegend von Schülern durchgeführt wurden, kurz werden. Weißblechdosen dienten der Zinnrückgewinnung, wobei etwa aus $1000 \mathrm{~kg}$ Dosen,

\footnotetext{
${ }^{353}$ Kammeier, Der Landkreis Lübbecke und der 1. Weltkrieg (1998), S. 186.

354 Kammeier, Der Landkreis Lübbecke und der 1. Weltkrieg (1998), S. $186 f$.

355 StAH, HR 16 Schulamt Nr. 552, Schreiben Magistrat Hannover an Kriegsamtsstelle Hannover vom 4.1.1919; siehe: auch Grotjahn, Stahl und Steckrüben Bd. 2 (1993), S. 171.

356 Ohmann, Eine Statistik der Sammeltätigkeit der Schulen im Jahre 1917, Deutsches Philologen-Blatt 1918, S. 232.

${ }^{357}$ Neben Zinn fehlten u. a. Nickel, Aluminium und Kupfer.
} 
für die damals 50 Mark Vergütung gezahlt wurden, damals etwa $10 \mathrm{~kg}$ Zinn gewonnen wurden. Aus den von deutschen Schulen im Jahre 1917 gesammelten $220.380 \mathrm{~kg}$ konnten also ungefähr 22 Tonnen Zinn gewonnen und der Wiederverwendung zugeführt werden. Vor dem Krieg waren jährlich 14 - 15.000 t Rohzinn eingeführt worden. Die von den deutschen Schulen gesammelte Menge kompensierte also im Jahre 1917 lediglich etwas mehr als 0,6\% der vor 1914 eingeführten Menge. Ähnlich wird es bei den Sammlungen der Leichtmetalle (Kupfer, Messing, Aluminium, Blei, Zink u. a.) gewesen sein, denn da im Februar und April 1915 umfassende Metallbeschlagnahmungen erfolgt waren, war es für Schüler danach sehr schwer, Metallgegenstände aufzutreiben. Dass überhaupt mitunter noch relativ große Sammelmengen zusammenkamen, ist wohl darauf zurückzuführen, dass Metallgegenstände ,aus Furcht vor etwa eintretender Bestrafung wegen Nichtabgabe zurückgehalten worden waren“358. Sicher hat auch die recht geringe Vergütung Einfluss auf das Ergebnis gehabt. Mengenmäßig entsprach die „Metall-Mobilmachung“ vor allem beim Kupfer, das für die Waffenproduktion besonders wichtig war. ${ }^{359}$ Leider lassen die Quellen keine gesicherten Rückschlüsse auf den Anteil der Schulen daran zu. ${ }^{360}$

Wichtiger als das Sammelergebnis, dass trotz der teilweise doch recht geringen Sammelmengen in einem Ministerialerlass vom 24. April 1918 lobend erwähnt wurde ${ }^{361}$, war allerdings der pädagogische Nutzen, d. h. die emotionale Mobilisierung für den Kampf an der „Heimatfront".

Über die Einstellung damaliger Schüler und Lehrer zu der Sammeltätigkeit sollen im Folgenden einige Aussagen Aufschluss geben. Aus den Tagebüchern der Schülerinnen Elfriede Kuhr und Erna Lange geht hervor, mit welch großem Eifer die Schülerinnen sich an dem Sammlungen beteiligten. Vor allem der Wettbewerb zwischen den Klassen einer Schule und die Anerkennung durch die Lehrer waren für sie ein guter Ansporn. Dass sie die Sammelaktionen allerdings auch als ihre vaterländische Pflicht ansahen, zeigt besonders das Opfern der lieb gewordenen Spielzeugsoldaten, die „den Tod für das Vaterland“ sterben mussten. ${ }^{362}$

\footnotetext{
${ }^{358}$ Ertheiler/Plohn, Das Sammeln in der Kriegswirtschaft [1919], S. 47.

${ }^{359}$ Siehe: Goebel, Deutsche Rohstoffwirtschaft im Krieg (1930), S. 51.

${ }^{360}$ Bei den Ergebnissen der Schulen werden meistens die Mengen für die gesammelten „Leichtmetalle“ angegeben, zu denen auch Kupfer gehörte, Kupfer wird aber nur ganz selten einzeln aufgeführt.

${ }^{361}$ Siehe: Führen, Lehrer im Krieg (1936), S. 41.

362 Die Pflicht, Zinnsoldaten und anderes Spielzeug zu spenden, wurde auch in vielen Kinderbüchern und Zeitschriften für Kinder betont, wie z. B. in der Erzählung „Die Bleisoldaten“ von Maria Petzel („Das fromme und fröhliche Kind“, 1916, Nr. 7); abgedruckt in Oberschelp/Grotjahn, Stahl und Steckrüben Bd. 1 (1993), S. 136f.) oder in dem Gedicht „Alt-Metalltag in den Schulen“ (Braun, Deutschlands Jugend in großer Zeit, 1916, S. 100f. Das Gedicht ist im Anhang abgedruckt (siehe: Anhang, Seite 11). Auch Försters „Die deutsche Jugend und der Weltkrieg“ enthält zwei Episoden, in denen Kinder die Bleisoldaten als ihr liebstes Speilzeug spenden: „Das Kriegsopfer der ABC-Schützen“ (S. 119f.) und „Ein rührendes Beispiel kindlicher Opferwilligkeit“ (S. 120f.); Förster, Die deutsche Jugend und der Weltkrieg [1915]).
} 
„11. März 1915: In der Schule ist eine neue Sammlung angesagt. Diesmal geht's wieder um Kupfer, außerdem um Zinn, Blei, Zink, Messing und Alteisen. Daraus sollen Gewehrläufe, Kanonen, Patronenhülsen usw. gemacht werden. Unter den Klassen entsteht ein rasantes Wettsammeln. Unsere Klasse, die vierte, hat schon jetzt die größte Menge beisammen. Ich hab zu Haus das unterste zuoberst und das oberste zuunterst gekehrt. Mariechen schimpfte nicht schlecht: 'Das Fräulein Pietchen stiehlt uns alles weg!' Ich nahm alte Löffel, Messer, Gabeln, Töpfe, Kessel, ein Tablett, eine kupferne Schale, zwei Leuchter aus Messing, alte Gürtelschnallen, eine Pfanne, mehrere Haken und was weiß ich noch alles. Großmutter schlug die Hände zusammen und rief: 'Die Jöre macht mich bankrott! Verschenk doch lieber deine Bleisoldaten, anstatt mir die letzten Siebensachen zu nehmen!' So mußte meine kleine Armee, mit der Willi und ich so oft gespielt hatten, in den Tod. Um nicht alle Soldaten zu opfern, loste ich die Todeskandidaten aus. Auf wen das Los fiel, den nahm ich aus der Viererreihe und legte ihn abseits. Als alles durchgelost war, packte ich die Unglücklichen immer zu zweit in einen riesigen Blechlöffel und hielt ihn über die Glasflamme. Die Helden in ihren hübschen blauen Uniformen schmolzen den Tod fürs Vaterland [...]. Schrecklich! Ich schmolz auch die letzen ein. Am liebsten hätte ich geheult. Statt dessen lachte ich mit meinem Bruder. ${ }^{\text {(363 }}$ (Elfriede Kuhr)

„Die reine Produktenhandlung ist in den drei großen Kellerräumen eingerichtet worden. In Haufen und Bergen liegt dort alter Kram. Alles hat ja heute irgendwie einen Wert, kann weiterverwendet werden: Papier, Lumpen, Knochen, Stanniol, Korken, Gummi, Flaschenkapseln, Haare, zerbrochene Grammophonplatten, Konservenbüchsen. Im Souterrain unserer neuen Schule riecht es nach einer Trödler Wirtschaft. Aber wir reißen uns danach, dort arbeiten zu dürfen. In kleine Sammelheften kleben wir die für die Ablieferung der Sachen erhaltenen Marken.

,Das allermindeste müßt ihr entdecken,

Auf das geschwindeste in allen Ecken'.

stand auf der Deckelseite. Und wir entdeckten überall ablieferbare Gegenstände. Die Bodenkammern sämtlicher Bekannten werden gründlich abgesucht. Rosemarie hat neulich für ein vollgeklebtes Heftchen ein wunderschönes Buch bekommen. Dr. Hensberg hatte eine Widmung hineingeschrieben, die auch vom Direktor unterzeichnet worden war. Nun streben wir alle eifrigst nach der gleichen Zeit. Heute bringt Inge Leukner eine schwere Schachtel Bleisoldaten mit. ,Ich bin ganz lahm vom Schleppen', stöhnt sie und schwenkte den angestrengten Arm hin und her. Mit großer Begeisterung packen wir die Herrlichkeit aus. Große, selbstgegossene Musketiere sind es. Die Soldaten, die Soldaten! Wenn die herrlichen Freistunden doch nie zu Ende gehen möchten!

Ein Berliner Gymnasialschulleiter hob den Sammeleifer der Schüler hervor und betonte auf den pädagogischen Nutzen der Sammlungen. Seiner Meinung war es überflüssig und schadete der patriotischen Erziehung, Schüler zu Sammlungen und anderen Hilfsdiensten durch das Hilfsdienstgesetz“ (1916) zu verpflichten:

„Neben diesen Betätigungen hat nun gradezu eine Flut von Sammlungen eingesetzt, um die sich unsere Schüler ebenfalls große Verdienste erworben haben. Es ist alles gesammelt worden, was irgendwie der Allgemeinheit nützen konnte, alle Metalle, alle Ersatzmittel, die die Natur gab, alle ,alten Sachen'.[...] Ueberall gewannen die Schüler selber durch ihre Tätigkeiten neue Kenntnisse, wurden auf Dinge aufmerksam, die sonst kaum im Unterricht berührt wurden, z. B. auf Papiergewinnung usw.

Alle diese Sammlungen und Arbeiten geschahen zuerst freiwillig. Allmählich, namentlich seit der Annahme des Hilfsdienstgesetzes ${ }^{365}$, wurden die Schüler zu Dienstleistungen kommandiert. Damit entfiel dann der schöne Gedanke, daß sie aus freien Stücken ihre Zeit und Arbeit in den Dienst des Vaterlandes stellten. “366 (Paul Hildebrandt, Schulleiter in Berlin, 1918)

\footnotetext{
${ }^{363}$ Mihaly, ... da gibt's ein Wiedersehn! (1986), S. 156f.

${ }^{364}$ Lange, 1914 bis 1918 auf der Schulbank (1933), S. 79f.

365 5. Dezember 1916.

${ }^{366}$ Hildebrandt, Paul, Die Leistungen unserer Schüler im Kriege (1919), S. 69 und 79.
} 
Eine Lehrerin aus Berlin betonte, dass es hinsichtlich des Sammeleifers keine Unterschiede zwischen den Mädchen- und den Jungenschulen gab und dass der Wettbewerb zwischen den Schulen sowie die Aussicht auf freie Tage als Belohnung die Schüler zu verstärkter Aktivität anspornte:

„Die Mädchenschulen beteiligten sich eifrig an all den zahlreichen Sammlungen. [...] In den großen Städten wurde der Schwerpunkt auf andere Sammlungen gelegt, wie Kleidungsstücke, Papier, Metall, Stanniol, Kerne, Haare. [...] Groß war der Jubel, wenn es hieß: 'Morgen habt ihr frei, da ihr so fleißig gesammelt habt.' Der schulfreie Tag wurde dann zu neuer Werbearbeit genutzt. In alle den Sammlungen wetteiferten Knaben und Mädchenschulen. “367

(Anna Günther, Lehrerin in Berlin)

Abschließend sollen drei Zeitzeugen, die sich an ihre Schulzeit im Krieg erinnern, zitiert werden. Sie bestätigen die hohe Akzeptanz der Schüler und der Lehrer bei den Aktionen und ihren Sammeleifer, der durch den Wettbewerb zwischen den Klassen und den Schulen sowie durch Belohnungen immer wieder verstärkt wurde. Dass die Schüler gelegentlich bei ihrer Tätigkeit auch unangenehmen Situationen ausgesetzt waren, geht aus Johann Baptist Gradls Erinnerungen hervor.
„Die Lehrer hielten Sammlungen ab, zu denen wir brachten, was wir auftragsgemäß gesammelt hatten. Das gewünschte Material wechselte: Mal waren es Konservendosen aus Weißblech, mal Gummiteile, mal ausländisches Geld, mal was anders. Wir gingen beliebige Straßenzüge ab, klin- gelten im Bewußtsein vaterländischer Pflicht ungeniert an den Wohnungen und sagten unseren Wunsch. Zuweilen hatte man wirklichen Erfolg. [...] Die Regel war Bedauern, daß man nichts zu geben hatte, gelegentlich erntete man auch ein Schimpfwort. Für besondere Sammelerfolge gab es Prämien; in meinem Arbeitszimmer hängt ein Kunstdruck mit der Handschrift des Deutschlandlie- des und der Abbildung des Hauses, in dem Hoffmann von Fallersleben es auf Helgoland geschrie- ben hat. “368
(Johann Baptist Gradl, * 25. März 1904 in Berlin)

„Besonders die Ablieferung von Gold und Metallen wurde ein Sport für uns. Die Schulen machten untereinander Konkurrenz, welche am meisten abgeliefert hatte. Der Siegespreis war ein Tag ,Schulfrei'. Mit unserer Mutter hatten wir lange Diskussionen, bis wir durchsetzten, dass wir schoene, kupferne und zinnerne Tafelgeraete abliefern durften. Man bekam da fuer die Stunden, die man bei der Ablieferungsstelle warten musste, schulfrei. Die Ablieferungsstelle war zu unsrer groessten Freude in der Waitzstrasse, 30 Minuten von unsrer Wohnung. Und vor der Ablieferungsstelle standen hunderte von Schuljungen wie wir mit allem möglichen Hausrat aus Metall. Die Ablieferungsprozedur war typisch preussisch, sehr buerokratisch. ${ }^{\text {369 }}$

(W. M. Citron, * 10. November 1905 in Berlin)

„Ich hatte meinen Eltern die Kupferkessel und die letzten Goldstïcke weggeschleppt.“370 (Hilde Wenzel, * 1906 in Berlin)

Die Texte zeigen wie viele andere nicht nur, mit welch großem Engagement sich Schüler und Lehrer an den Sammlungen beteiligten, sondern lassen auch Rückschlüsse auf die

\footnotetext{
${ }^{367}$ Günther, Von der Kriegsarbeit der Mädchenschulen, Jugenddank-Kalender, 1919, Nr. 72, S.73.

${ }^{368}$ Pörtner, Kindheit im Kaiserreich (1990), S. 242f.

${ }^{369}$ Franke, 3. Die Kriegsgeneration, S. 199.

${ }^{370}$ Franke, 3. Die Kriegsgeneration, S. 212.
} 
gesellschaftliche Bedeutung der schulischen Aktionen zu. Durch die beharrliche Werbe- und Sammeltätigkeit der Kinder wurden Eltern, Verwandte und Bekannte sowie die gesamte Öffentlichkeit immer wieder mit dem Rohstoffmangel und der propagierten Pflicht, für die Soldaten an der Front und damit für das Vaterland persönliche Opfer zu bringen, konfrontiert. Dadurch wurde die Schule neben der Presse zum wichtigsten Multiplikator der staatlichen Propaganda.

\subsection{Sammlung von Naturerzeugnissen}

Der Kriegsausbruch traf besonders die großen Städte in Bezug auf die Nahrungsmittel unvorbereitet. Die Hoffnung der verantwortlichen Ministerien, der Krieg werde nicht lange dauern, hatte vorbeugende Maßnahmen verhindert. Zwar war durchaus mit einer Handelsblockade gerechnet worden, man hatte jedoch ihre Wirkung unterschätzt. Der Einfluss Englands auf Deutschlands und Österreichs wichtigste Handelspartner Holland, Dänemark und Schweden war bereits im zweiten Kriegsjahr so stark, dass die Einfuhr von Lebensmitteln und Rohstoffen aus diesen Ländern deutlich zurückging.

Als die deutsche Offensive im September 1914 an der Marne zum Erliegen kam, setzte hinsichtlich der Lebensmittelversorgung der Zivilbevölkerung ein Umdenken ein. Es folgten im Februar 1915 erste umfassendere Maßnahmen für eine Zwangsbewirtschaftung. ${ }^{371}$ Da ein Gesamtkonzept fehlte, vollzog sich der Aufbau einer Kriegswirtschaft sehr langsam. Erst im Frühjahr 1916 wurde mit der Gründung des ,Kriegsernährungsamtes’ eine Zentralstelle für alle Ernährungsfragen gegründet. Die Versorgungsprobleme verschärften sich jedoch trotzdem weiter. Besonders gravierend war der Fettmangel, den man mithilfe der Schule beheben wollte. Deshalb mussten Schulkinder zur Öl- und Fettgewinnung Obstkerne, Bucheckern und andere ölhaltige Waldfrüchte sammeln. Die Versorgungskrise erfasste aber darüber hinaus viele andere Produkte. Als im Winter 1916/17 die Kartoffelernte vor allem durch Krankheitserreger geringer ausfiel als üblich, kam es im ,Kohlrübenwinter' zur Hungersnot und das Versorgungsniveau in den Städten sank besorgniserregend. Immer wieder wurde deshalb die Schule zur Sammlung der unterschiedlichsten Naturprodukte aufgerufen. ${ }^{372}$ Ein Berichtsformular der Kriegsamtsstelle Münster aus dem Jahre 1918 gibt einen Überblick über die Sammelobjekte. Dort werden genannt: Küchenabfälle, Felle, Kienzapfen, Weißdornfrüchte, Pilze,

\footnotetext{
${ }^{371}$ Auf Anregung von Walter Rathenau war bereits im August 1914 eine Kriegsrohstoffabteilung beim Kriegsministerium gegründet worden, die Zentrale der Rohstoffbewirtschaftung, deren die er bis zum Frühjahr 1915 leitete.

${ }^{372}$ Eine Reihe von Büchern und Aufsätzen zur „Kriegsnaturkunde“ sollten den Lehrern die notwendigen Kenntnisse vermitteln, um die Schüler über die Bedeutung der einzelnen Sammelgüter informieren zu können, wie z. B. Wurthe, Beiträge zur Kriegsnaturkunde 15 (1917).
} 
Blätter, Blüten, Beeren, Früchte Sämereien, Bucheckern, Eicheln, Kastanien, Obstkerne, Rohrkolben, Brennnesseln, Ginster, Queckenwurzeln, Frauenhaar und Laubfutter. ${ }^{373}$

Wie umfangreich die Sammeltätigkeit der Schüler insgesamt gewesen ist, geht auch aus den vielen Erlassen der Schulbehörden hervor. ${ }^{374}$ Über die Ergebnisse der einzelnen Sammlungen durch die Schulen in den einzelnen Ländern oder im gesamten Deutschen Reich liegen allerdings keine umfassenden Übersichten vor, so dass vor allem aus den Ergebnissen einzelner Schulen, einzelner Gemeinden oder von Schulbezirken Rückschlüsse auf den Erfolg und die volkswirtschaftliche Bedeutung gezogen werden müssen. Die umfassendste Übersicht hat „Die Zentrale für Kriegshilfe der Schulen“ im Jahre 1917 vorgelegt. Von den 11.000 angeschriebenen Schulen (4.400 höhere und mittlere sowie 6.600 Volksschulen) haben 3.339 $(30,3 \%)$ Schulen den Fragebogen zur Sammeltätigkeit ausgefüllt und an die Zentrale zurückgeschickt. ${ }^{375}$ Die veröffentlichten Ergebnisse zeigen zwar, dass die zahlreichen Appelle der Behörden, sich an den Sammlungen zu beteiligen, von sehr vielen Schulen befolgt wurden, insgesamt jedoch sind sie wenig aussagekräftig, wie z. B. die Feststellung, dass statistisch jede Schule durchschnittlich $245 \mathrm{~kg}$ Eicheln und Kastanien, $245 \mathrm{~kg}$ Altpapier sowie $104 \mathrm{~kg}$ Obstkerne gesammelt hat. Dass das Engagement einzelner Schulen recht groß war, geht aus einer Aufstellung der erfolgreichsten Schulen hervor, auch wenn keine Angaben über die Anzahl der an den Sammlungen beteiligten Schüler gemacht werden. ${ }^{376}$

Vollständige Zahlenangaben liegen auch dann nicht vor, wenn die Schulbehörden, wie z. B. in der Provinz Schleswig-Holstein für die Volks- und Mittelschulen im Jahre 1917, offizielle Erhebungen durchführten. In einem Erlass aus dem Jahre heißt es dazu:

„Häufig sind die gesammelten Mengen nicht gewogen worden, oft sind sie erst durch Vermittlung der Schule abgeliefert, manches haben die Kinder auch für ihre Eltern gesammelt. Wenn darum die folgenden Zahlen über einige Hauptgegenstände der Sammlungen vielleicht nur die Hälfte der Erträge angeben, so dürften sie doch um so mehr allgemein gewürdigt werden als ein Ehrenzeugnis für die Kriegshilfe der Lehrer und Lehrerinnen wie der Kinder. ${ }^{\text {‘377 }}$

\footnotetext{
${ }^{373}$ Siehe: Führen, Lehrer im Krieg (1936), S. 71.

${ }^{374}$ Exemplarisch ist je eine Übersicht für den Regierungsbezirk Hildesheim und für das Reichsgebiet zusammengestellt worden; siehe: Anhang, Seiten 4-10.

${ }^{375}$ Gefragt wurde nach dem Ergebnis der Sammlungen für Altgummi, Altpapier, Eicheln und Kastanien, Knochen, Schulkriegssammlungsfonds, Nesselstängel, Obstkerne, Pilze, Platin-Brennstifte, Weißblech und Weißdornfrüchte. Siehe: Ohmann, Eine Statistik der Sammeltätigkeit der Schulen im Jahre 1917, S. 232.

376 Die erfolgreichsten Schulen waren: Obstkerne: $1.250 \mathrm{~kg}$ (Volksschule Beeskow, Mark Brandenburg), Knochen: $4.268 \mathrm{~kg}$ (Stadtschule Mittelwalde, Mark Brandenburg), Pilze: $5.000 \mathrm{~kg}$ (Bürgerschule Schleiz, Fürstentum Reuß), Weißdornfrüchte:, $1.110 \mathrm{~kg}$ (Realschule Otterndorf, Provinz Hannover), Nesselstängel: $4.505 \mathrm{~kg}$ (Ev. Stadtschule Bernstadt, Schlesien).

${ }^{377}$ Zitiert nach: Saul, Jugend im Schatten des Krieges (1983) S. 34.
} 
Verdoppelt man die angegebenen Zahlen, wie z. B. $77.854 \mathrm{~kg}$ der Ährenlese oder $46.586 \mathrm{~kg}$ an Weißdornfrüchten, so zeigen sie, dass die genannten Schulen sich für die Sammlungen sehr engagiert haben und recht erfolgreich waren.

Nach Untersuchungen von Pust trifft das auch auf die Sammlungen an den höheren Mädchenschulen in Schleswig-Holstein zu. ${ }^{378}$ Im Jahre 1917 kamen insgesamt 15.289,32 kg Sammelgut zusammen, 1918 sogar $63.255 \mathrm{~kg}$. Jede der 16 Schulen sammelte also durchschnittlich etwa $955 \mathrm{~kg}$ (1917) bzw. $3953 \mathrm{~kg}$ (1918).

In Schleswig war nach Meinung des Provinzialschulkollegiums die Beteiligung der höheren Schulen insgesamt sehr hoch, die Ergebnisse allerdings recht unterschiedlich. Die Behörde versuchte die Diskrepanzen zu erklären, z. B. für die Schulen an der Westküste:

„Für die Schulen an der Westküste unserer Provinz fehlen vielfach die Vorbedingungen für ertragreiche Sammlungen. Die Flora der Marsch ist verhältnismäßig arm, der Baumbewuchs nur spärlich. Dasselbe gilt z. T. für die Gegend um Tondern herum: Die Folge davon ist, daß die Erträge für Eicheln, Kaffee- und Teeersatzmittel aus Weißdornfrüchten dort nicht besonders bedeutend gewesen sein konnten. ${ }^{\text {3379 }}$

Die Sammlungen in den Großstädten unterschieden sich teilweise von denen der Landkommunen. ${ }^{380}$ So sammelten beispielsweise die Volks- und die Mittelschüler Hannovers in der Zeit vom 1. April 1916 bis zum 31. Dezember 1918 hauptsächlich Küchenanfälle (563.000 $\mathrm{kg}$ ) und Knochen (23.400). ${ }^{381}$ Insgesamt waren die Bedingungen bei der Sammlung von Naturerzeugnissen für die städtischen Schulen deutlich schlechter als für die Landschulen. Insgesamt kann festgestellt werden, dass die Schulen aller Schulformen auch bei der Sammlung von Naturerzeugnissen außerordentlich engagiert und erfolgreich waren. Dass in allen Regionen des Reiches eifrig gesammelt worden ist, bestätigen zudem die entsprechenden Hinweise in den in großer Zahl vorhandenen Orts- und Schulchroniken.

Aufgrund der Vielzahl von Naturerzeugnissen, die von den Schulkindern zusammengetragen worden sind, können nur einige wenige hinsichtlich der Verwertung, des Erfolgs der Sammlungen und der schulischen Akzeptanz untersucht werden. Ausgewählt wurden vor allem die, für die besonders geworben wurde und die für die Versorgung mit Nahrungs- und Futtermitteln von besonderer Bedeutung waren, und zwar Obstkerne und Bucheckern, Laubheu, Brennnesseln sowie Kaffee- und Tee-Ersatzmittel.

\footnotetext{
${ }^{378}$ Siehe: Pust, „Vaterländische Erziehung" für „Höhere Mädchen" (2004), S. 359-362. Für 1917 nennt Pust die folgenden Sammelergebnisse: Obstkerne $(4.939,35 \mathrm{~kg})$, Eicheln/Kastanien $(6.981,62 \mathrm{~kg})$, Kaffe/Tee-Ersatz $(1.118,31 \mathrm{~kg})$, Weißdornfrüchte $(994,54 \mathrm{~kg})$, Brennnesseln $(1.255,32 \mathrm{~kg})$.

379 Zitiert nach: Pust, „Vaterländische Erziehung" für „Höhere Mädchen" (2004), S. 361.

380 Siehe: dazu auch das Sammelergebnis im Sommer 1916 des Schulbezirks Roda im Herzogtum SachsenAltenburg: Führen, Lehrer im Krieg (1936), S. 16.

${ }^{381}$ Oberschelp/Grotjahn, Stahl und Steckrüben (1993), S. 171. Eine Ansichtskarte der Freiwilligen Kriegshilfe Hannover-Linden zeigt 4.000 Schulkinder, die Küchenabfälle gesammelt haben; siehe: Anhang, Seite 49, Bild 3.
} 


\subsubsection{Obstkerne, Bucheckern}

Beide Produkte wurden vom „Kriegsausschuß für pflanzliche und tierische Öle und Fette“ als „Obstkernöle“ bewirtschaftet. Die Obstkerne ${ }^{382}$ dienten der Ölgewinnung, die Rückstände wurden als Viehfutter verwendet. 1 Kilogramm Obstkerne ergab durchschnittlich 50 Gramm Öl. Nach Angaben des Kriegsausschusses wurden 1916 etwa 4.000 Tonnen Obstkerne gesammelt, aus denen 200 Tonnen Öl gewonnen wurden. Obwohl in den beiden folgenden Jahren das Sammelergebnis deutlich gesteigert werden konnte, blieb die Ölgewinnung aus Obstkernen doch unwirtschaftlich. Ähnlich war es mit der Verwertung von Bucheckern, auch wenn der Allgemeinheit immerhin $400.000 \mathrm{~kg}$ Speiseöl zugeführt werden konnten. ${ }^{383}$ Sogar vom Kriegsernährungsamt wurde der wirtschaftliche Wert einzelner Sammlungen nachträglich infrage gestellt, „da ihr Aufwand in keinem rechten Verhältnis zum erzielten Nährgewinn gestanden hätte “384 . Bei diesen und anderen Sammlungen sei der Kalorienverbrauch oft größer gewesen als der dadurch erzielte Kaloriengewinn. ${ }^{385}$

Im Folgenden sollen der Anteil der Schulen an den Sammelergebnissen und die Einstellung der Kinder zu den Sammlungen untersucht werden. Wegen ihrer großen Bedeutung für die Versorgung der Bevölkerung wurde für die Sammlungen viel Propaganda gemacht, wie die im Bilderanhang angedruckten Plakate dokumentieren ${ }^{386}$. Die folgenden Ergebnisse zeigen, dass die Werbeaktionen offensichtlich sehr erfolgreich waren. Dass gerade die Schule dabei wieder eine zentrale Rolle spielen sollte, geht aus der Tatsache hervor, dass in vielen Regionen von den Behörden angeordnet wurde: „(Es soll) an jeder Schule eine Sammelstelle für Obstkerne (Kirschen und Pflaumen!) eingerichtet werden. “387 Wie vor allem aus vielen Schulund Ortschroniken hervorgeht, ist die Anordnung offensichtlich weitgehend befolgt worden. So liegen z. B. entsprechende Hinweise über die Sammelergebnisse für die Volksschulen in Schwanheim (Provinz Hessen-Nassau) ${ }^{388}$, in Tiftlangerode (Provinz Hannover) ${ }^{389}$, in Hammoor (Provinz Schleswig-Holstein) ${ }^{390}$ und Gutzkow (Provinz Pommern) ${ }^{391}$, für

\footnotetext{
${ }^{382}$ Gesamt wurden Kerne von „Kirschen, Pflaumen, Zwetschen, Mirabellen, Reineclauden, Aprikosen, Zitronen, Apfelsinen und Kürbissen“ (Siehe: Ertheiler/Plohn, Das Sammeln in der Kriegswirtschaft [1919], S. 23).

${ }^{383}$ Siehe: Ertheiler/Plohn, Das Sammeln in der Kriegswirtschaft (1919), S. 33-35.

${ }^{384}$ Roehrkohl, Hungerblockade und Heimatfront (1991), S. 57.

385 Siehe: Ertheiler/Plohn, Das Sammeln in der Kriegswirtschaft (1919), S. 30.

${ }^{386}$ Siehe: Anhang, Seiten 45 (Bilder 2, 3), 46, 47.

${ }^{387}$ Zitiert nach: Hohnsbehn, Die Flensburger Schuljugend in der Zeit des ersten Weltkriegs (1996), S. 222.

388 Auszüge aus der Überherrner Schulchronik, http://www.erweiterte-realschule-ueberherrn.de/chronik.htm (25.04.2008).In der Chronik heißt es: „Die Sammlung von Kirschkernen, Mirabellen, Zwetschgen und anderen Obstkernen ergab große Mengen, die an die Sammelstelle in Höchst abgeliefert wurden.“

389 Oppermann, Krieg. Aus der Schulchronik von Tiftlangerode 1914-1925, Eichsfeld, Monatsschrift des Eichsfeldes, 1995, S. 163. Der Lehrer Oppermann schrieb 1917 in der Schulchronik von Tiftlangerode (Provinz Hannover): „Mit den Kindern habe ich 1,17 ctr Zwetschenkerne, 40 Pfd. Kirschkerne gesammelt“.
} 
die Brehnaer Schulen (Provinz Sachsen) ${ }^{392}$ und die Schulen des Schulbezirks Roda (Herzogtum Sachsen-Altenburg) ${ }^{393}$ sowie die St. Nikolai-Mädchenschule in Flensburg ${ }^{394}$ vor.

An den Sammlungen waren aber auch die höheren Schulen engagiert beteiligt, und zwar sowohl die Gymnasien als auch die Lyzeen. Als Beispiele seien das Scharnhorstgymnasium in Hildesheim (Provinz Hannover), das $1.350 \mathrm{~kg}$ Obstkerne sammelte, ${ }^{395}$ und die Kieler Lyzeen I (1918: $1.829,5 \mathrm{~kg})$ und II (1918: $1.253 \mathrm{~kg}(1918) .{ }^{396}$

Welche Bedeutung die Sammlungen für die Schulen hatten, zeigt das Beispiel der Obermehner Schule (Provinz Westfalen). Obwohl der Lehrer dort nur an drei Tagen anwesend war, da er noch an anderen Schulen unterrichten musste, beteiligten sich die Schulkinder an vielen Sammlungen. Z. B. sammelten sie im Herbst 1917100 kg Bucheckern. Ähnlich war es in den kleinen Nachbardörfern: Levern (20 kg Bucheckern), Twiehausen (25 kg Bucheckern) und Sundern (25 kg Bucheckern). ${ }^{397}$ Die Sammelerfolge sind auch insofern hoch einzuschätzen, als damals wegen des allgemeinen Ölmangels außer den Schülern noch sehr viele Menschen die Wälder durchstreiften, um Bucheckern zu sammeln. Dort „war der Andrang von Sammlern jedes Alters und Standes groß, denn sie erhielten gegen Ablieferung ihrer Funde das heißbegehrte Öl“398. Manche Wälder waren sogar für private Sammler gesperrt, da die Städte die Ausbeutung der Bucheckernsammlung mit eigenen Arbeitskräften selbst durchführten.

An einigen weiteren Beispielen sollen die Bedeutung und der Wert der Sammelergebnisse dargestellt werden. Im Jahre 1917 haben 3.330 Schulen im Deutschen Reich 345.554 kg Obstkerne gesammelt. ${ }^{399}$ Geht man davon aus, dass das Ergebnis dem des Jahres 1916 entsprach (Zahlen liegen nicht vor) und die gesamte Sammelmenge im Deutschen Reich 4.000 Tonnen betrug, so hätten die Schulen davon 11,6 \% aufgebracht und 23,2 Tonnen Ö1

\footnotetext{
${ }^{390}$ Hartwig, Chronik der Schule zu Hammoor, http://www.fincaverde.net/uns_doerp_2.htm (13.12.2008). In Hammoor sammeln die 92 Schüler und Schülerinnen der Volksschule 38 Pfund Sonnenblumenkerne und 24 Pfund Obstkerne.

${ }^{391}$ Langer, Schulfrei für den Krieg (2004), S. 59. Die Volksschule Gützkow brachte es 1917 auf 150 kg Kirschund Pflaumenkerne.

${ }^{392}$ Feldmann, Zur Geschichte der Brehnaer Schule von ihren Anfängen bis 1945 (2004), S. 12. Die Schulen (Provinz Sachsen) sammelten $600 \mathrm{~kg}$ Pflaumenkerne, während es die Schulen des Schulbezirks 1916 auf $142 \mathrm{~kg}$ Kirschkerne, $60 \mathrm{~kg}$ Sonnenblumenkerne und $177 \mathrm{~kg}$ Bucheckern brachten.

${ }^{393}$ Führen, Lehrer im Krieg (1936), S. 16. Die Schulen sammelten 1916177 kg Bucheckern, 142 kg Kirschkerne.

${ }^{394}$ Hohnsbehn, Die Flensburger Schuljugend in der Zeit des ersten Weltkriegs (1996), S. 229. Die Schülerinnen lieferten lediglich $8 \mathrm{~kg}$ Kirschenkerne, $3 \mathrm{~kg}$ Pflaumenkerne und 1 Pfund Kürbiskerne ab.

395 Scharnhorstgymnasium Hildesheim, Die Chronik des Scharnhorstgymnasiums, http://66023.nibis.de/website/index.php?id=35 (21.02.2008).

${ }^{396}$ Pust, „Vaterländische Erziehung" für „Höhere Mädchen" (2004), S. 361f.

${ }^{397}$ Kammeier, Der Landkreis Lübbecke und der 1. Weltkrieg (1998), S. 188.

${ }^{398}$ Vogeler, Kriegschronik der Stadt Hildesheim (1929), S. 339.

399 Ohmann, Eine Statistik der Sammeltätigkeit der Schulen im Jahre 1917 (1918).)
} 
erwirtschaftet. Berücksichtigt man, dass damit lediglich das Ergebnis von etwa 5,5\% der deutschen Schulen stammt und sich lediglich auf ein Jahr Sammeltätigkeit bezieht, so wird die kriegswirtschaftliche Bedeutung der Schule bei der Obstkernsammlung deutlich. Dass auch hier die Unterschiede zwischen einzelnen Schulen recht groß waren, soll an vier Beispielen dokumentiert werden: Die I. Bürgerschule und die Höhere Mädchenschule in Pirna (ca. 420 Schülerinnen und Schüler) sammelten in den Jahren 1914-1917 insgesamt $1.400 \mathrm{~kg}$ Obstkerne, die Schüler der Volksschule in Brehna (412 Schülerinnen und Schüler allein im Herbst $1916600 \mathrm{~kg}^{400}$, das Scharnhorstgymnasium in Hildesheim (ca. 400 Schüler) während der gesamten Kriegszeit $1.350 \mathrm{~kg}^{401}$, das Lyzeum in Schleswig (272 Schülerinnen) in den Jahren $1917(86,4 \mathrm{~kg}), 1918(460,5 \mathrm{~kg}) 547 \mathrm{~kg}^{402}$ und 2.350 Schulkinder von Vohwinkels Volksschulen im Sommer des Jahres 1917 lediglich 23 kg Obstkerne. Dass in einem vergleichbaren Zeitraum jeder Schüler in Brehna durchschnittlich etwa 1,5 kg, in Vohwinkel hingegen lediglich nur $9,8 \mathrm{~kg}$ sammelte ${ }_{2}^{403}$ in Brehna also die etwa 150fache Menge zusammengetragen wurde, ist nicht nur auf die besseren Sammelbedingungen im ländlichen Raum (Brehna im Kgr. Sachsen, ca. 2.000 Einwohner) gegenüber der Großstadtregion Wuppertal zu erklären. In der Großstadt Hannover z. B. sind bei einer Sammlung der Volks- und der Mittelschulen $563.000 \mathrm{~kg}$ Obstkerne (und Eicheln) zusammengekommen. ${ }^{404}$ Neben der geografischen Lage der Ortschaft und ihrer Versorgungslage war wie bei allen Sammlungen das Engagement der Behörden und vor allem der Lehrer von entscheidender Bedeutung für den Sammelerfolg.

Dass Unterrichtsstörungen von den Behörden bewusst in Kauf genommen wurden, geht aus verschiedenen Erlassen hervor. So schrieb z. B. der preußische Unterrichtsminister 1916: „Solche an sich unerwünschten Störungen des Unterrichts müssen ertragen werden angesichts der Notwendigkeit, die mancherlei Werte in Feld und Wald [...] rechtzeitig und restlos den Sammelstellen zuzuführen. “ ${ }^{405}$

Auch wenn die Sammelergebnisse lediglich für das Jahr 1917 in größerem Maße erfasst sind (3.339 Schulen sammelten in Deutschen Reich $354.892 \mathrm{~kg}$ Obstkerne), so kann anhand vieler Einzelangaben festgestellt werden, dass die Sammelmenge 1918 deutlich höher lag. Die 17

\footnotetext{
${ }^{400}$ Jensch, Pirna im Ersten Weltkrieg (2010), S. 66.

401 Scharnhorstgymnasium Hildesheim, Die Chronik des Scharnhorstgymnasiums, http://66023.nibis.de/ website/index.php?id=35 (21.02.2008).

${ }_{402}$ Pust, ,Vaterländische Erziehung" für „Höhere Mädchen" (2004), S. 361f.

${ }^{403}$ Geschichte Vohwinkels, http://www.agvv.org/160.htm (1.12.2010).

${ }^{404}$ Grotjahn, Stahl und Steckrüben Bd. 2 (1993), S. 171.

${ }^{405}$ Ministerium der geistlichen und Unterrichts-Angelegenheiten, Die Heranziehung der Schuljugend zum Sammeln der Waldfrüchte und zur Kartoffel-usw. Ernte, Zentralblatt für die gesamte Unterrichtsverwaltung in Preußen, 1916, S. 502f.
} 
höheren Schulen Schleswig-Holsteins sammelten 1917 beispielsweise 4.939,35 kg Obstkerne und 19187.909 , also etwa $62 \%$ mehr. $^{406}$

Insgesamt kann davon ausgegangen werden, dass sich an der Sammlung von Obstkernen die große Mehrheit der deutschen Schulen engagiert beteiligt hat, von der kleinen Dorfschule (z. B. Tiftlangerode) bis zu den höheren Schulen in den Großstädten (z. B. in Kiel). Zwar waren die Ergebnisse teilweise erstaunlich hoch, insgesamt jedoch sind die Bemühungen der Schulkinder angesichts des Aufwands ,als unwirtschaftlich anzusehen“407. Vielfach standen der zeitliche Aufwand und der Kalorienverbrauch zum Ertrag in einem „geradezu grotesken Verhältnis““408.

\subsubsection{Laubheu}

Vor allem 1918 (,Laubheu-Jahr') nahm die Sammlung von Laubheu in den Schulen viel Zeit in Anspruch, da eine Futternot drohte. Man benötigte es als Ersatz-Futtermittel, da Hafer fehlte. Zur Bewirtschaftung des Laubheus wurde die Laubfutterstelle der Heeresverwaltung gegründet, die die Sammlungen und die Verwertung koordinierte.

Mit Ausnahme des Goldregens, der Traubenkirsche und des Faulbaumes eigneten sich alle Laubbäume, wobei die jungen Blätter bevorzugt wurden. Vor allem für die Schulen war es schwierig, das Laub zu trocknen, denn es durfte nicht in den Säcken bleiben, damit es nicht schimmelte, sondern musste nach dem Pflücken sofort in Hallen, Räumen, Zimmern etc. etwa 10-15 cm hoch aufgeschüttet und immer wieder gewendet werden. Nachdem es dann abgeholt worden war, wurde es zu Laubheumehl gemahlen und unter Vermischung mit Melasse zu Laubfutterkuchen gepresst. Dieser galt als hochwertiges Futter, dessen Stärkewert den von gutem Heu sogar um $5 \%$ übertraf. ${ }^{409}$

Wegen der Bedeutung der Laubheugewinnung wurden die Schulen von den Schulbehörden wiederholt aufgefordert, entsprechende Sammlungen durchzuführen, so z. B. mit Erlass des preußischen Unterrichtsministers vom 28. März 1918, in dem die zuständigen Schulbehörden angewiesen wurden, ,dafür Sorge (zu) tragen, daß in den Schulen, insbesondere denen auf dem Lande, auf die Bedeutung dieses Gegenstandes hingewiesen und es den Schülern und Schülerinnen als eine vaterländische Pflicht empfohlen wird, sich an dem Sammeln von Reisig und Laubfutter, sofern sie dazu aufgefordert werden“, zu beteiligen.

\footnotetext{
${ }^{406}$ Pust, „Vaterländische Erziehung" für „Höhere Mädchen" (2004), S. 361f.; ähnlich war die Steigerung bei den anderen Naturerzeugnissen.

${ }^{407}$ Siehe: Ertheiler/Plohn, Das Sammeln in der Kriegswirtschaft (1919), S. 33. Von den im Jahre 1916 gesammelten 4.000 Tonnen Obstkernen sind lediglich 200 Tonnen Öl gewonnen worden.

${ }^{408}$ Hohnsbehn, Die Flensburger Schuljugend in der Zeit des ersten Weltkriegs (1996), S. 222.

${ }^{409}$ Siehe: Ertheiler/Plohn, Das Sammeln in der Kriegswirtschaft (1919), S. 37-39.
} 
Die Sammlungen sollten auch in den Ferien und an Sonntagen durchgeführt werden. Wie der folgende Auszug aus der Chronik der katholischen Schule Kattenstroth II (heute JanuszKorczak-Gesamtschule in Gütersloh, Provinz Westfalen) zeigt, wurde auch an den Sonntagen gesammelt.

„Durch Beschluß der Heeresverwaltung sollen alle Schulen bis zum 15. Sept. einschließlich Laub sammeln. An allen Sonnentagen wird gesammelt und das Laub auf dem Schulboden sowie auf Kornböden, die die Eltern der Kinder zur Verfügung gestellt haben, getrocknet. Der Preis für 1 Ltr. Laubheu beträgt $18 \mathrm{M}$, für $1 \mathrm{Ltr}$. grünes Laub $4 \mathrm{M}$. Das Laubheu soll zur Militär-Pferdefütterung dienen. Das Ergebnis des Laubheusammelns beträgt 26,8 Ltr.““110

Insgesamt haben sich die meisten deutschen Schulen an den Laubheu-Sammlungen beteiligt, und zwar meistens mit guten Ergebnissen, wie die folgenden Zahlen beispielhaft zeigen:

Dorfschule in Kröppelshagen (Provinz Schleswig-Holstein.): $150 \mathrm{~kg}(1918)^{411}$

Dorfschule in Elze (Provinz Hannover)

$480 \mathrm{~kg}(1918)^{412}$

Dorfschule Gesmold (Provinz Hannover)

$1.198 \mathrm{~kg}(1918)^{413}$

Dorfschule in Hausbruch (Hamburg)

$2.280 \mathrm{~kg}(1918)^{414}$

Schule in Lensahn (Provinz Schleswig-Holstein)

$2.550 \mathrm{~kg}(1918)^{415}$

Realgymnasium in Düren (Rheinprovinz)

$2.280 \mathrm{~kg}(1918)^{416}$

Lyzeum in Vohwinkel (Provinz Westfalen)

$3.115 \mathrm{~kg}(1918)^{417}$

5 Dorfschulen (Amt Levern, Provinz Westfalen)

$12.775 \mathrm{~kg}(1918)^{418}$

Volksschulen in Vohwinkel (ca. 2350 Kinder; s. o.)

$13.770 \mathrm{~kg}(1918)^{419}$

17 höhere Mädchenschulen Schleswig-Holsteins

$63.255 \mathrm{~kg}(1918)^{420}$

Um solche Ergebnisse zu erzielen, musste die große Mehrheit der Schüler mobilisiert werden, was auch offensichtlich gelungen ist. In Hannover beispielsweise waren an den Sammlungen allein im Jahre 1918 8.836 Volksschüler beteiligt. ${ }^{421}$ Hinzu kamen Tausende Mädchen und

410 Neuhaus, Janusz-Korczak-Gesamtschule, http://www.jkg-gt.de/schule/stadtteil/abschnitt-i-kriegschronik1914-1918.html (14.1.22008), S. 92f.; dort erhielten die Schüler sogar 900 Mark für 155 Zentner frisches Laub. Über die ungebräuchliche Maßeinheit konnte nichts weiter in Erfahrung gebracht werden.

${ }^{411}$ Hamester, Emil Duborg, http://www.fwk-f.de/emilduborg.htm (14.12.2008).

412 Hemme, Das Dorf Elze während des Krieges 1914-1918, http://www.dorf-elze.de/schulchronik1.htm (15.12.2008).

${ }^{413}$ Schule in Gesmold, http://www.schule-gesmold.de/modules/info/index.php?id=2:14 (15.12.2008).

414 1. Weltkrieg, http://www.schule-hausbruch.de/?Wir:Chronik:1. Weltkrieg (20.03.2008).

${ }^{415}$ Schule in Gesmold, http://www.schule-gesmold.de/modules/info/index.php?id=2:14 (15.12.2008).

${ }^{416}$ Stock, Schule und Erster Weltkrieg, http://www.sandermielke.de/ www/homepage3/mybb/showthread.php?tid=34 (07.07.2008).

${ }^{417}$ Wuppertal Vohwinkel, http://www.agvv.org/160.htm (27.12.2008).

${ }^{418}$ Kammeier, Der Landkreis Lübbecke und der 1. Weltkrieg (1998), S. 188; es handelt sich um die Dörfer Levern, Twiehausen, Sundern, Destel und Niedermehnen.

${ }^{419}$ Wuppertal Vohwinkel, http://www.agvv.org/160.htm (27.12.2008).

${ }^{420}$ Pust, ,„Vaterländische Erziehung" für „Höhere Mädchen" (2004), S. 363.

${ }^{421}$ StAH, HR 16, Nr. 553. 
Jungen der 30 Mittel- und höheren Schulen, von denen jeweils eine Gruppe von 500 vormittags und nachmittags zwei Stunden lang sammelte. ${ }^{422}$

Die Einnahmen wurden entweder gespendet oder an die beteiligten Schulkinder ausgezahlt, wie z. B. an der Volksschule in Elze (Provinz Hannover), wo im Juli 1918 49,50 Mark zur Verteilung kamen, oder in Wehrstedt (Provinz Hannover) ${ }^{423}$. Dass die Schüler ,zusätzlich Steine in den Säcken unterbrachten“424, um das Gewicht zu steigern und mehr zu verdienen, wie z. B. in Euskirchen (Rheinprovinz) behauptet wurde, wird, wenn es überhaupt stimmt, die Ausnahme gewesen sein.

Insgesamt waren die Sammelaktionen bei den Schülern und Schülerinnen recht beliebt, wie das damals in Euskirchen bekannte Gedicht „Eine Laub-Heu-Sammelfahrt““425, das im Volksblatt vom 16. 8. 1918 abgedruckt war, und eine Episode in Erna Langes „1914-1918 auf der Schulbank ${ }^{* 426}$ zeigen. In den Erinnerungen eines Schulleiters aus Hamburg (Rheinprovinz) heißt es: „Für Deutschlands Jugend beginnen fröhliche Tage“‘427.

In erster Linie freuten sich die Schulkinder naturgemäß über den Ausfall des Unterrichts. Um gute Ergebnisse zu erzielen, gingen die einzelnen Schulen unterschiedliche Wege. In der katholischen Schule in Bergneustadt (Rheinprovinz) sammelten beispielsweise ab Juli 1918 die Schüler der Mittel- und Oberstufe an zwei Vormittagen Laubheu ${ }^{428}$, während die Konferenz der Bingerbrücker Schule (Rheinprovinz) beschloss, dass ,alle Schulkinder vom 3. Schuljahr [...] mindestens an 3 Tagen in der Woche Laub sammeln““429.

Obwohl zusätzlich zu dem Lehrermangel der Unterricht durch die Sammelaktionen stark gestört wurde, ist in den Schulchroniken keine Kritik der Lehrer an den Sammlungen oder Proteste der Eltern vermerkt. Insgesamt teilten die meisten Lehrer und Eltern sicher die Meinung eines Schuldirektors aus Düren: „Daß hierbei der Unterricht nicht immer zu seinem Recht kam, war nicht zu vermeiden, dafür dürfte sich aber die Heranziehung des damaligen Schülergeschlechts zu all jenen Arbeiten erzieherisch ausgewirkt haben. “430

\footnotetext{
${ }^{422}$ STAH, HR 16, Nr. 200. An den von Direktoren der Gymnasien organisierten Laubheusammlungen der weiterführenden Schulen nahmen Schüler ab der 7. Klasse teil.

${ }^{423}$ Heimatverein Wehrstedt e.V., Die Dorfchronik, http://www.heimatverein-wehrstedt.de/drei.html\#titelanker15 (03.04.2008).

${ }^{424}$ Arntz, Chronik des Gymnasiums Marienschule Euskirchen, http://www.hans-dieter-arntz.de/ 100_jahre_marienschule.html (15.12.2008).

${ }^{425}$ Siehe: Anhang, Seite 12.

${ }^{426}$ Lange, 1914 bis 1918 auf der Schulbank (1933), S. 112-124.

427 1. Weltkrieg, http://www.schule-hausbruch.de/?Wir:Chronik:1. Weltkrieg (20.03.2008).

428 Stehle, Vorgeschichte der Berger Volksschule, http://www.berg-pfalz.de/historie/his5chronik.html (15.1.2008).

${ }^{429}$ Schleicher, Bingersbrücker und Rupertsberger Geschichte(n), http://www.bingerbrueck.de/pdf/schulchronik.pdf (15.07.2008).

${ }^{430}$ Weyrauch, Das Dürener Realgymnasium mit Realschule, http://www.wirteltor-gymnasium.de/828/index.html (15.12.2008).
} 
Es gab allerdings auch Schwierigkeiten bei den Aktionen, wie die Aufzeichnungen eines Lehrers aus Eickum (Provinz Westfalen) zeigen: „Die getrockneten Blätter mußten in Papiersäcke gestopft werden, eine mühsame und langwierige Arbeit. [...] Wir hatten schon viel Kummer damit.““31 Für die Schüler war das Sammeln von Laubheu offensichtlich recht anstrengend, sodass sie den Lehrkräften mitunter sogar leidtaten:

„Da mußten die Jungen von 10-14 Jahren über ihr Maß hinaus arbeiten und mancher Junge fuhr frisch allein mit dem kuhbespannten Wagen zum Felde, zur Wiese, vor allem ins Moor, und abends spät gegen 9 Uhr war sein Werk beendet. Dann mußten oftmals noch die Schularbeiten gemacht werden. Was dazu herauskam, kann man sich denken. Mitleid hat uns oft gepackt, und Erstaunen über solcher Kinder Größe, die den herben Ernst des Lebens schon in so frühen Jahren kennenlernen mußten. Kein Wunder, wenn man da am nächsten Morgen manch schwerfällige, müde Gestalt vor sich sitzen sah, über die man anfangs ärgerlich gewesen." ${ }^{\text {432 }}$

(Lehrerin Frieda Blanke aus Nettelstedt im Landkreis Lübbecke in ihren Lebenserinnerungen)

Aufgrund des Mangels an geeigneten Transportmitteln konnte offenbar das gesammelte Laubheu nicht immer vollständig und zeitnah abgeholt werden. In Erna Langes „1914 bis 1918 auf der Schulbank“ heißt es: „Und es kommt auch Nachricht, daß der Inhalt der übervollen Säcke total verfault angekommen sei. “433

Trotz einiger Schwierigkeiten allerdings war das Sammeln von Laubheu insgesamt ein großer Erfolg und entsprach den Erwartungen des Kriegsamtes. Deshalb sprachen sowohl der Generalintendant des Feldheeres ${ }^{434}$ als auch der Chef des Kriegsamtes allen daran Beteiligten öffentlich ihren Dank aus, und zwar ,insbesondere den Lehrern und Schülern““435.

\subsubsection{Brennnesseln}

Obwohl das Sammeln von Brennnesseln wegen der Schwierigkeiten - häufig fehlte es sogar an Handschuhen und Schuhwerk - nicht sehr beliebt war, waren die Ergebnisse insgesamt sehr beachtlich. Das hing damit zusammen, dass für die Sammlungen öffentlich stark geworben wurde ${ }^{436}$ und auch die Schulbehörden die Lehrer und die Schulvorstände ab 1915 mehrfach zur Teilnahme aufforderten und ihnen ausführliche Merkblätter zu Verfügung stellten, z. B. der preußische Unterrichtsminister mit den Erlassen vom 25. Oktober 1915 und vom 23. Juli 1917. Auch in den anderen Reichsländern wurde die Teilnahme propagiert. So wandte sich das Herzoglich Braunschweigisch-Lüneburgische Konsistorium am 20. Juni 1916 an die

\footnotetext{
${ }^{431}$ Kammeier, Der Landkreis Lübbecke und der 1. Weltkrieg (1998), S. 192.

${ }^{432}$ Kammeier, Der Landkreis Lübbecke und der 1. Weltkrieg (1998), S. 193.

${ }^{433}$ Lange, 1914 bis 1918 auf der Schulbank (1933), S. 146.

${ }^{434}$ Er schickte ein Telegramm mit folgendem Wortlaut: „Sammeleifer der Lehrer und Schulen hat sehr erfreuliches Ergebnis gezeigt und Kriegsheer in Zeiten größter Futternot unterstützt. Pferde fressen Laubkuchen gern. Allen an den Sammlungen Beteiligten, insbesondere Lehrern und Schulen, gebühret uneingeschränktester wärmster Dank.“ (Zitiert nach: Führen, Lehrer im Krieg [1936], S. 85).

${ }^{435}$ Siehe: Ertheiler/Plohn, Das Sammeln in der Kriegswirtschaft (1919), S. 39.

${ }^{436}$ Siehe: Anhang, Seite 48, Bilder 13.
} 
Leiter und die Lehrer der Gemeindeschulen und bat sie, „bei der Einsammlung von Brennesseln mitzuwirken und die Schulkinder zu einem solchen Einsammeln anzuhalten““437. Der preußische Unterrichtsminister stellte am 23. Juli 1917 sogar einen Zusammenhang zwischen dem Sammeln von Brennnesseln und der Verteidigung des Vaterlandes her: „Schulen, Schüler und Schülerinnen, die sich an der Brennesselsammlung mit Erfolg beteiligen, tragen nicht nur dazu bei, unser wirtschaftliches Durchhalten zu erleichtern, sondern erweisen auch der Landesverteidigung wertvolle Dienste.“438

Da die Behörden wussten, dass für den Sammeleifer der Schüler der Ausfall von Unterricht grundsätzlich sehr wichtig war, wurden die Schulen zur Beurlaubung ermächtigt:

„Wie bei der Sammlung der Weißdornfrüchte darf auch überall da, wo sich ganze Schulklassen oder Schulen unter Leitung ihrer Lehrer (Lehrerinnen) an der Brennesselsammlung beteiligen, nötigenfalls der Unterricht in erforderlichem Umfange ausgesetzt werden. Auch einzelnen Schülern und Schülerinnen, die sammeln wollen, ist in geeigneten Fällen der erforderliche Urlaub zu bewilligen.“ 439

Es gab natürlich auch noch andere Anreize. Für $100 \mathrm{~kg}$ getrocknete und entblätterte Nesselstängel wurden von der ,Nesselverwertungsgesellschaft' (ab 1917 ,Nesselanbaugesellschaft') 28 Mark gezahlt; in den letzten Kriegsmonaten erhielten die Sammler sogar Nähgarn aus Nesseln.

Der Mangel an Baumwolle, eine Folge der Handelsblockade, hatte Deutschland gezwungen, als Ersatz für die Baumwollimporte die Nesselfaser zu verwerten. Während aus den Stängeln die Fasern gewonnen wurden, dienten die Blätter als Futtermittel und die Samen wurden für den Anbau verwendet. Da man sehr große Mengen benötigte - z. B. zur Herstellung eines Soldatenhemdes etwa $4 \mathrm{~kg}$ getrocknete Nesselstängel (20 kg grüne Nesseln) -, war man in erster Linie auf die Mithilfe der Schulen angewiesen. Die aus Nesselgeweben hergestellten Kleidungs- und Ausrüstungsgegenstände fanden ausschließlich für Heereszwecke Verwendung. ${ }^{440}$

Auch wenn es keine zentrale staatliche statistische Erfassung der schulischen Sammelergebnisse gibt, so sind genügend überlieferte Informationen für eine gesicherte Einschätzung des Sammelerfolgs vorhanden. Das Sammelergebnis für 1917 von 1.242 deutschen Schulen wurde vom Philologen-Verein in seiner Verbandszeitschrift veröffentlicht. Danach sammelten die

\footnotetext{
${ }^{437}$ Abgedruckt in: Herzoglich Braunschweigisch-Lüneburgisches Konsistorium, Einsammeln von Brennesseln betreffend, Schulblatt für die Herzogtümer Braunschweig und Anhalt, 1916; der Erlass enthält auch detaillierte „Anweisungen für das Einsammeln von Brennesseln“.

${ }_{438}$ Ministerium der geistlichen und Unterrichts-Angelegenheiten, Brennesselsammlung; Merkblätter, Zentralblatt für die gesamte Unterrichtsverwaltung in Preußen, 1917, S. 539-553.

${ }^{439}$ Ministerium der geistlichen und Unterrichts-Angelegenheiten, Ministerium der geistlichen und UnterrichtsAngelegenheiten 1917, S. 94.

${ }^{440}$ Siehe: Ertheiler/Plohn, Das Sammeln in der Kriegswirtschaft (1919), S. 40f.
} 
Schüler und Schülerinnen $170.692 \mathrm{~kg}$ getrocknete Nesselstängel, im Schnitt also $137 \mathrm{~kg}$ pro Schule. Berücksichtigt man, dass die Menge ausreichte, um etwa 42.600 Hemden für die Soldaten herzustellen, so wird die Leistung der Schulen deutlich. Berücksichtigt man, dass in dem Ergebnis die überwiegende Mehrheit der 30.000 Landschulen nicht enthalten ist und die Schulen 1918 noch deutlich mehr Brennnesseln sammelten ${ }^{441}$, so war das Gesamtergebnis um ein Vielfaches höher.

Einige weitere Zahlen sollen weiteren Aufschluss über den Sammelerfolg geben:

In Teltow-Stadt (Provinz Brandenburg) konnten 2 Eisenbahnwagen gefüllt werden; in Magdeburg kamen 1917 bei den Schulsammlungen 808 Zentner zusammen, in Arnsberg (Provinz Westfalen) 745 Zentner, in Koblenz (Rheinprovinz) 700 Zentner und in Königsberg (Provinz Ostpreußen) 620 Zentner. ${ }^{442}$

In den Volks- und Mittelschulen Schleswig-Holsteins waren es $30.692 \mathrm{~kg}$ und 804.595 Stängel $(1917)^{443}$, während es die höheren Mädchenschulen auf $1.255 .5 \mathrm{~kg}$ (1917) und $5.265 \mathrm{~kg}$ $(1918)^{444}$ brachten.

Die Ergebnisse der einzelnen Schulen waren allerdings recht unterschiedlich, wie die folgenden Zahlen zeigen: Z. B. sammelten 2.350 Schulkinder im Sommer 1918 in Vohwinkel (Wuppertal, s. o.) lediglich $17 \mathrm{~kg}$ getrocknete Brennnesseln (Sommer 1918) ${ }^{445}$, während die ev. Stadtschule in Bernstadt (Provinz Schleswig-Holstein) $4.505 \mathrm{~kg}$ ablieferte. Die Elmshorner Bismarckschule (Provinz Schleswig Holstein) brachte es auf $1.925 \mathrm{~kg}$, die Dorfschule in Atzenhausen (Provinz Hannover) lediglich auf $27 \mathrm{~kg}$ Brennnesseln (1916). ${ }^{446}$ Viele Schulen sammelten sogar während der Ferien. In Flensburg z. B. zogen „Sammeltrupps“ unter Leitung der Lehrer in den Herbstferien 1918 los, um Brennnesseln (und Mehlbeeren) zu sammeln ${ }^{447}$, und in Gebersdorf (Provinz Brandenburg) wurde am 4. Juli 1918 ein „Brennesseloffensivtag“ durchgeführt, an dem der Unterricht ausfiel. ${ }^{448}$ Trotz der unangenehmen Begleiterscheinungen beim Sammeln waren die Ergebnisse insgesamt erstaunlich gut, wie die angeführten Beispiele zeigen.

Einige zeitgenössische Berichte sollen Aufschluss über die Einstellung der Schulkinder geben. Eine Lehrerin beschreibt ihre entsprechenden Erfahrungen mit sieben- und

\footnotetext{
${ }^{441}$ So sammelten die Schülerinnen der 17 höheren Schulen Schleswig-Holsteins $19171.255,54 \mathrm{~kg}$ und 1918 $5.256 \mathrm{~kg}$, also etwa das Vierfache (siehe: Pust, „Vaterländische Erziehung" für „Höhere Mädchen" (2004), S. $361 \mathrm{f}$.

${ }^{442}$ Angaben nach Führen, Lehrer im Krieg (1936), S. 93.

${ }^{443}$ Saul, Jugend im Schatten des Krieges (1983), S. 157.

${ }^{444}$ Pust, „Vaterländische Erziehung" für „Höhere Mädchen" (2004), S. 361f.

${ }^{445}$ Wuppertal Vohwinkel, http://www.agvv.org/160.htm (27.12.2008).

${ }^{446}$ Meinhard, Atzenhausen bis 1933, http://www.dr-ulonska.homepage.t-online.de/html/ body_atzenhausen_bis_1933.html (16.12.2008).

${ }^{447}$ Hohnsbehn, Die Flensburger Schuljugend in der Zeit des ersten Weltkriegs (1996), S. $234 \mathrm{f}$.

${ }^{448}$ Nerlich, Aus der Gebersdorfer Schulchronik 1911-1920, http://www.gebersdorf-mark.de/kalenderblatt.htm.
} 
achtjährigen Jungen und Mädchen. Nachdem sie indirekt an das Ehrgefühl der Kinder appelliert hatte (Vielleicht seid ihr diesmal wirklich zu klein, um mitzuhelfen. Es ist ziemlich schwer, es recht zu machen, und weh tut es auch.") und ihnen die Bedeutung der Brennnesseln für die Soldaten an der Front erklärt hatte, gingen die Kinder voller Begeisterung ans Werk. Am nächsten Tag hatten alle durch die Brennnesselstiche geschwollene Hände und rote Schwielen. Sie beklagten sich aber nicht, sondern präsentierten voller Stolz die gesammelten Nesseln. „Den Soldaten tut's auch weh“ und „den Soldaten tut's noch weher, wenn sie verwundet werden“, war „der ständige Kehrreim““449. Das Beispiel zeigt, welch großem moralischen Druck die Kinder in der Schule ausgesetzt waren. Sie sollten sich mit den Soldaten an der Front identifizieren, Schmerzen aushalten und Opfer bringen.

Auch ein Lehrer in Eickum (Provinz Westfalen) schilderte die Sammlung von Brennnesseln:

„Wir zogen mit den Schulklassen während des Unterrichts an vielen Tagen hinaus und rupften in Wäldern, Büschen und an Wegrändern große Mengen zusammen. Manche Kinder, besonders die kleinsten, (...) lockte das Geld, und sie sammelten in ihrer Freizeit. Aber nur wenige brachten es zu etwas; ihr Eifer erlahmte bald, wenn sie merkten, wie mühsam es war, eine lohnende Menge zusammenzubringen. “450

Die Erinnerungen einer ehemaligen Schülerin des Lyzeums I in Kiel zeigen, dass die Sammlungen von Nesseln mitunter auch als positiv empfunden wurden:

„Wir sollten zum Brennesselpflücken. Es ging nach Kitzeberg in einen verwilderten Professorengarten, wo wir, teils ohne Handschuhe, die langen Brennesselstauden pflückten, die wir nachher zum Trocknen auf den Schulboden am Blocksberg schleppten. Wahrlich kein Vergnügen! Doch wir taten alles freudig, galt es doch, die Rohstoffversorgung zu stärken und den Krieg gewinnen helfen. ${ }^{،} 451$

Über die Sammlungen in Flensburg liegen ebenfalls Erinnerungen von Zeitzeugen vor.

So erinnerte sich ein ehemaliger Schüler $(* 1909)$ :

„Wenn wir 30 Brennesseln brachten, brauchten wir keine Hausaufgaben machen, und wenn wir 20 brachten, brauchten wir nur [einen Teil] machen. Da bin ich dann los gewesen in den Gärten am der Apenradstraße und hab' diese Dinger gesammelt, mit wollenen Handschuhen, und da pieksten die Dinger durch. (...) Ich bin regelrecht krank gewesen am nächsten Tag davon.“ ${ }^{452}$

Dass die besten Sammelergebnisse veröffentlicht wurden und es weitere Anreize und Belohnungen für die erfolgreichen Schulkinder und Schulen gab, hat sicher ebenfalls zu dem groBen Erfolg der Nesselsammlungen beigetragen. Als beispielsweise das Gymnasium in

\footnotetext{
${ }^{449}$ In dem Bericht wird auch ein Junge zitiert, dessen Freund, der eine andere Klasse besuchte, nicht sammeln wollte, weil es ihm „z' domm“ sei: „Was meinst, wenn's unsere Soldaten em Schützengrabe an z' domm wäre, wie tät's dann uns gehen?" (Mahle, Naturkunde im Gegenwartsunterricht, Die Lehrerin: Organ des Allgemeinen Deutschen Lehrerinnenvereins 1916/17, $175 f$.

${ }^{450}$ Zitiert nach: Kammeier, Der Landkreis Lübbecke und der 1. Weltkrieg (1998), S. 192.

${ }^{451}$ Zitiert nach: Pust, „Vaterländische Erziehung" für „Höhere Mädchen" (2004), S. 360.

${ }^{452}$ Hohnsbehn, Die Flensburger Schuljugend in der Zeit des ersten Weltkriegs (1996), S. 235.
} 
Landsberg an der Warthe (Provinz Brandenburg) in 18 Wochen 12 1/2 Zentner Trockenstängel und 6 1/2 Zentner Blätter ablieferte, bekam es ein offizielles Schreiben der NesselfaserVerwertungsgesellschaft, in dem es u. a. hieß: „Wenn jede Schule Deutschlands ein solches Sammelergebnis zu verzeichnen hätte, könnten wir gut auf die Baumwolle Amerikas verzichten. “453

Wie es damals viele Schulen machten, wurde die Entschädigung nicht den Schülerkindern ausgezahlt, sondern der Kriegsfürsorge überweisen. Das Landsberger Gymnasium (Kgr. Bayern) spendete beispielsweise den Erlös von 370 Mark einer Fürsorgeeinrichtung (,Kriegsblindenfürsorge“). Natürlich machte der mit den Sammlungen verbundene recht große Unterrichtsausfall es für die Schüler leicht, die unangenehmen Folgen zu ertragen. ${ }^{454}$ Die Schüler des Landsberger Gymnasiums waren z. B. 1917 an 8 ganzen Tagen und 5 Nachmittagen mit dem Sammeln beschäftigt ${ }^{455}$ und Schülerinnen des Lyzeums zu Salzwedel (Provinz Sachsen) sogar „drei Wochen lang täglich““456.

Wegen der Bedeutung der Sammelaktion wurden die Schulen trotz der respektablen Ergebnisse von den Behörden und den Lehrerverbänden immer wieder zu verstärktem Engagement aufgefordert. Im Juli 1917 verfügte der preußische Unterrichtsminister, „die Brennesselsammlung in den Schulen immer wieder anzuregen und auf jede Weise zu fördern“, denn Schulen, Schüler und Schülerinnen trügen ,nicht nur dazu bei, unser wirtschaftliches Durchhalten zu erleichtern, sondern erweisen auch der Landesverteidigung wertvolle Dienste ${ }^{، 457}$.

Noch im Juli 1918 verschickte die „Zentrale für Kriegshilfe der Schulen“ einen „Sendbogen“ mit Informationen über die Sammlung an 11.000 Schulen im ganzen Reich. ${ }^{458}$

Dass die Appelle zusammen mit den zahllosen Plakataktionen Erfolg hatten und die Lehrer entsprechend auf ihre Schüler einwirkten, zeigen nicht nur die Ergebnisse, sondern auch viele Einträge in den zeitgenössischen Schulchroniken, wie zum Beispiel der folgende aus der Schule in Brehna (Provinz Sachsen). Dort hielt im Juni 1918 ein Lehrer „eine Lehrprobe über

\footnotetext{
${ }^{453}$ Böttger, Die Brennesselsammlung in Landsberg a. W., Deutsches Philologen-Blatt 1918, S. 39.

${ }^{454}$ Ein Schüler eines Breslauer Gymnasiums erinnerte sich z. B.: „Interessante Erinnerungen wie etwa das Trocknen von gesammelten Nesseln während des 1. Weltkrieges und damit Unterrichtsausfall (aus den Brennesseln wurden Textilien hergestellt) verdrängen eine unangenehme Erinnerung: In diesem Schulhaus habe ich 1917 die erste und letzte Ohrfeige meines Lebens bekommen." (Thomale, Die schlesische Festungsstadt Festenberg, http://www.gross-wartenberg.de/sukgw/s081.html (28.12.2008).

${ }^{455}$ Böttger, Die Brennesselsammlung in Landsberg a. W. (1918).

${ }^{456}$ Ohmann, Zur Statistik der Schulkriegshilfe, Deutsches Philologen-Blatt 1918, S. 109.

${ }^{457}$ Ministerium der geistlichen und Unterrichts-Angelegenheiten, Merkblatt für die Nesselernte, Zentralblatt für die gesamte Unterrichtsverwaltung in Preußen, 1917, S. 538.

${ }^{458}$ Ohmann, Ein besonderer Anreiz zur Nesselsammlung, Monatszeitschrift für höhere Schulen, 1918, S. 320.
} 
die Brennessel, welche durch die Vorgänge des Krieges zu einer wichtigen Kulturpflanze geworden (war) “459.

Über Probleme bei den Sammlungen ist kaum etwas bekannt. Aufgrund des Mangels an geeigneten Transportmitteln konnte allerdings das gesammelte Laubheu nicht immer vollständig abgeholt werden. Die ehemalige Schülerin Regi Relang aus Stuttgart (*1906) erinnerte sich: „Im Krieg, das muß Anfang 1915 gewesen sein, mußten wir mit der Schule zum Laubsammeln in den Kräherwald. Wir kletterten auf die Bäume, wiegten uns hin und her, rupften das Laub ab und streckten es in große Rupfensäcke. Es hieß später, man hätte das Laub nicht gebraucht, man hätte es vermodern lassen. “460

\subsubsection{Kaffee- und Tee-Ersatzmittel}

\section{Weißdorn}

Bereits im August 1916 rief der preußische Unterrichtsminister die Schulen zur „Sammlung der Früchte des Weißdorns“ auf, nachdem kurz zuvor eine eigene „Kriegsverwertungsgesellschaft für Kaffeeersatz“ gebildet worden war. Durch die Gewinnung und Verarbeitung der Früchte des Weißdorns (,Mehlbeere') als Kaffeeersatzmittel sollte der Verbrauch von Gerste und Brotgetreide zur Herstellung von Kaffee-Ersatz eingeschränkt werden. Wieder wurden Ortssammelstellen eingerichtet, die für ,,je 1 kg luftgetrockneter Früchte ein[en] Sammellohn von 20 Pfennig gewährten“461.

Weitere Erlasse folgten, z. B. der zur „Sammlung der Früchte des Weißdorns zur Gewinnung eines Kaffeeersatzmittels“ vom 11. Juli 1917. Auch diese Sammelaktion wurde wieder durch viele Werbeplakate unterstützt.

Einige Ergebnisse von Schulsammlungen sollen im Folgenden über den Erfolg der propagierten Sammlungen Aufschluss geben:

Von den sechs Dorfschulen des Kreises Lübbecke (Provinz Westfalen), deren Sammelergebnisse überliefert sind, beteiligten sich lediglich vier an der Sammlung, und zwar mit geringen Erträgen (Levern: 32 kg, 1917; Twiehausen 40 kg, 1917 und 20 kg, 1918, Arrenkamp, 42 kg, 1917). ${ }^{462}$ Auch das Sammelergebnis des Schulbezirks Roda (Sachsen-Altenburg) betrug 1916 lediglich $19 \mathrm{~kg}$. In Flensburg waren 9 Volksschulen aktiv und sammelten in der Zeit vom 30. September 1916 bis zum 5. Oktober $19611.512 \mathrm{~kg}$ Mehlbeeren. Der Erlös in Höhe von 272,40 Mark kam der „Kinderbespeisung“ zugute. ${ }^{463}$

\footnotetext{
${ }^{459}$ Feldmann, Zur Geschichte der Brehnaer Schule (2004), S. 12.

${ }^{460}$ Pörtner, Kindheit im Kaiserreich (1990), S. $261 f$.

${ }^{461}$ Pust, ,Vaterländische Erziehung" für „Höhere Mädchen" (2004), S 360.

${ }^{462}$ Kammeier, Der Landkreis Lübbecke und der 1. Weltkrieg (1998), S. 188

${ }^{463}$ Hohnsbehn, Die Flensburger Schuljugend in der Zeit des ersten Weltkriegs (1996), S. 225.
} 
Die 17 höheren Schulen Schleswig-Holsteins sammelten immerhin 1917995 kg und 1918 sogar $1.697 \mathrm{~kg}$ Weißdornfrüchte. ${ }^{464}$

Im Deutschen Reich lieferten 3.339 Schulen $44.072 \mathrm{~kg}$ ab, wobei die Realschule in Otterndorf (Provinz Hannover) mit $1.100 \mathrm{~kg}$ die erfolgreichste Schule war.

Auch wenn sich in der Zeit von 1916 bis zum Ende des Krieges viele Tausende Schulen aller Schulformen beteiligt haben, so waren die Erträge doch relativ geling. Zwar wurde die Sammelaktion nicht abgebrochen, wie man es mit der Sammlung von ,Kaffeegrund' getan hat$\mathrm{te}^{465}$, ab 1917 jedoch engagierten sich die Schulen verstärkt für andere Sammelgüter, wie z. B. das Laubheu und die Brennnesseln.

\section{$\underline{\text { Tee-Ersatzmittel }}$}

Auf Bitte des Präsidenten des Kriegsernährungsamtes forderte der preußische Unterrichtsminister am 8. Juni 1917 zur „Sammlung von Teeersatzmitteln“466 auf. Da die Einfuhr von Kaffee, Tee und Kakao durch die Handelsblockade unterbunden war und die Rohstoffe für die Herstellung von Kaffeeersatzmitteln nur in sehr geringem Umfange zur Verfügung standen ${ }^{467}$, gewann die Herstellung von Tee-Ersatzmitteln zur Versorgung der Bevölkerung mit warmen Getränken an Bedeutung. Gesammelt, getrocknet und dann zerkleinert werden sollten vor allem die jungen Blätter von Erdbeere, Himbeere und Brombeere, aber auch von Heidelbeere, Moosbeere, Kronsbeere, Schwarze Johannisbeere, Stechpalme, Kirsche, Birke, Ulme, Weide und Eberesche sowie des Schwarz- und Schlehdorns, des Waldmeisters, des Walnussbaums und des Weidenröschens.

Aufgabe der Lehrer war es, die Kinder von der „Notwendigkeit der ausreichenden Beschaffung dieser Kräutlein“ zu überzeugen, ihnen die notwendigen biologischen Grundkenntnisse beizubringen und sie bei den Sammelaktionen zu beaufsichtigen. Sie mussten dafür sorgen, dass ausschließlich die Blätter der genannten Pflanzen und Bäume gesammelt wurden, und keine „Heilpflanzen““468. Über den Erfolg der Sammelaktion geben nur wenige Quellen Auf-

\footnotetext{
${ }^{464}$ Pust, „Vaterländische Erziehung" für „Höhere Mädchen" (2004), S. 361 und 363.

${ }^{465} \mathrm{Zu}$ der Sammlung hatte die Trockenfuttermittel-Gesellschaft aufgerufen. Das Trocknen erwies sich jedoch als zu aufwendig und deshalb wurde die Aktion wegen Unwirtschaftlichkeit abgebrochen (Siehe: Ertheiler/Plohn, Das Sammeln in der Kriegswirtschaft (1919), S. 37.

${ }^{466}$ Ministerium der geistlichen und Unterrichts-Angelegenheiten, Sammlung von Teeersatzmitteln, Amtliches Schulblatt für den Regierungsbezirk Hildesheim, 1917, S. 127f.

${ }^{467}$ Die meisten Kaffeeersatzmittel waren zugleich wichtige Nahrungs- und Futtermittel und wurden als solche vorrangig verwendet.

${ }^{468}$ Lindenblütentee, Fliedertee, Pfefferminz, Sennesblätter, Fenchel, Kamille u.a. wurde wegen der Heilwirkung nicht „zur Herstellung von Familiengetränken“ verwendet (siehe: Ministerium der geistlichen und UnterrichtsAngelegenheiten, Ministerium der geistlichen und Unterrichts-Angelegenheiten 1917). Es gab deshalb eigenständige Sammlungen von „einheimischen Arzneipflanzen“. (Siehe: Königliche Regierung in Hildesheim, Sammlung von einheimischen Arzneipflanzen, Amtliches Schulblatt für den Regierungsbezirk Hildesheim, 1918, S. 53.
} 
schluss. Dieses lässt den Schluss zu, dass das Engagement der Schulen bei der Aktion relativ gering war. In einigen Schul- und Ortschroniken wird die Sammlung zwar erwähnt ${ }^{469}$, allerdings nur recht beiläufig und ohne Angaben von Mengen. In der umfassenden Zusammenstellung von Sammelergebnissen der Mittelschulen und der höheren Schulen des Deutschen Reiches im Jahr 1917 kommt das Sammeln von Tee-Ersatzmitteln nicht vor. ${ }^{470}$ Dass aber offensichtlich Tausende von Kindern bemüht haben, sollen zwei Beispiele zeigen.

Nach amtlichen Erhebungen der Schulbehörde sind 1917 von den Volk- und Mittelschulen der Provinz Schleswig-Holsteins immerhin $93.072 \mathrm{~kg}$ Blätter für Tee gesammelt worden. ${ }^{471}$ Bei einigen Sammelergebnissen wurde allerdings nicht zwischen Heilpflanzen und TeeErsatzkräutern unterschieden, wie z. B. bei denen in Marienwerder (Provinz Westpreußen; insgesamt $98.050 \mathrm{~kg}$ ), Schleswig (Provinz Schleswig-Holstein; $75.500 \mathrm{~kg}$ ), Stade (Provinz Hannover $29.000 \mathrm{~kg}$ ) und Arnsberg (Provinz Westfalen; $21.900 \mathrm{~kg}$ ). ${ }^{472} \mathrm{Da}$ in der Regel mehr Tee-Ersatzmittel abgeliefert wurden, machen die Zahlen durchaus deutlich, dass viele Schulen an den Aktionen beteiligt waren und gute Ergebnisse aufwiesen.

Die Flensburger Schulkinder sammelten beispielsweise $1917159 \mathrm{~kg}$ und bekamen dafür als Vergütung 216,25 Mark, die für eine soziale Einrichtung gespendet wurden. ${ }^{473}$

Dass die Sammlung dennoch insgesamt weniger erfolgreich war als beispielsweise die von Laubheu und Brennnesseln, ist vor allem auf zwei Ursachen zurückzuführen. Zum einen hatte der preußische Unterrichtsminister in dem genannten Erlass darauf hingewiesen, dass der Einsatz von Schülern bei landwirtschaftlichen Arbeiten Vorrang gegenüber dem Sammeln von Tee-Ersatzmitteln haben sollte, und zum anderen hatten die ohnehin außerordentlich belasteten Lehrer nicht genügend Zeit, die Kinder beim Sammeln zu beaufsichtigen. Im Unterschied zu anderen Sammlungen war ihre ständige Anwesenheit bei dieser unbedingt erforderlich.

\subsubsection{Weitere Sammelaktionen}

Neben den genannten Produkten gab es viele weitere, die von den Schulkindern gesammelt werden sollten und auch wurden. Da sie allerdings hinsichtlich der Beteiligung der Schulen und in Bezug auf die Sammelerträge insgesamt deutlich weniger bedeutsam waren, sollen einige der Sammlungen nur kurz erwähnt werden.

\footnotetext{
${ }^{469}$ In der Schulchronik von Klingelbach ist z. B. vermerkt: „Mai 1916. Um einer Mahnung der Kgl. Regierung zwecks Beschaffung von Tee-Ersatzkräutern nachzukommen, übernahm der inzwischen als zeitig garnisonsdienstfähige College Schneider an mehreren Nachmittagen Sammlungen von Waldmeister, Brombeeren an vielen Schulen usw. Schulchronik, http://www.vg-katzenelnbogen.de/buch2/15.htm (10.10.2007).

${ }^{470}$ Siehe: Ohmann, Eine Statistik der Sammeltätigkeit der Schulen im Jahre 1917 (1918).

${ }^{471}$ Saul, Jugend im Schatten des Krieges (1983), S. 157, Anhang Nr. 32.

472 Siehe: Führen, Lehrer im Krieg (1936), S. 93.

${ }^{473}$ Hohnsbehn, Die Flensburger Schuljugend in der Zeit des ersten Weltkriegs (1996), S. 226.
} 
Angesichts der schlechten Versorgung mit Lebensmitteln wurden vor allem von den ländlichen Schulen ,Naturalien' gesammelt, und zwar teilweise mit erstaunlich guten Ergebnissen, die allerdings gravierend differieren. Zum Beispiel kamen im Jahre 1917 im Regierungsbezirk Schleswig 13.335 Eier, 25 Zentner Speck, 777 Flaschen Saft und 90 Zentner Obst zusammen. In Allenstein (Provinz Ostpreußen) waren es 118.149 Eier, 862 Zentner Speck, 163,5 kg Butter und Schmalz und in Stettin (Provinz Pommern) kamen 523.762 Eier sowie 260 Zentner Fett und Wurst zusammen. ${ }^{474}$ Ferner wurde von den Behörden angestrebt, „die wertvollen Erzeugnisse des Waldes, namentlich die Pilze, für die Volksernährung in möglichst weitem Umfang nutzbar zu machen“, wie es z. B. in dem Erlass des preußischen Unterrichtsministers vom 15. Mai 1915 heißt. ${ }^{475}$ Um den Lehrern zu helfen, den Schülern im naturkundlichen Unterricht die erforderlichen Kenntnisse zu vermitteln, hatte das Kaiserliche Gesundheitsamt ein Pilzmerkblatt zusammen mit einer Pilztafel erarbeitet und den Schulen zur Verfügung gestellt. Außerdem bot der gemeinnützige Verein „Jugendspende für Kriegerwaisen e. V.“476, den Essener Lehrer gegründet hatten, den Schulen vier große farbige Pilztafeln als Wandbilder für je 5 Mark und zwei Merkblätter für die Hand der Schüler zu jeweils 0,20 Mark an. Der Reinerlös sollte den Kriegerwaisen zugutekommen. ${ }^{477}$

Auch die amtlichen Schulblätter wiesen mehrfach auf die Bedeutung der Pilze für die Volksernährung hin und riefen zur Sammlung auf; die Regierungen in Düsseldorf („,Pilze für die Volksernährung“) und Hildesheim z. B. richteten „Pilzbestimmungsstellen“ ein. Aufschluss darüber, in welchem Umfange die Bemühungen Erfolg hatten, geben nur wenige Quellen. Im Jahr 1917 wurden nach Angaben des Philologenvereins im Deutschen Reich von dem 3.339 Schulen 99.280 kg Pilze gesammelt. Das beste Ergebnis hatte die städtische Bürgerschule in Schleiz (Fürstentum Reuß), die es auf $5.000 \mathrm{~kg}$ brachte. ${ }^{478}$ Wie wichtig die Sammlungen der Schule waren, zeigt z. B. ein Sammelergebnis aus Münster. Dort waren innerhalb von 3 Monaten für einen besonderen Verkaufsstand insgesamt $1.365 \mathrm{~kg}$ Pilze gesammelt worden, davon $986 \mathrm{~kg}$ von Schülern ( = ca. $72 \%$ ). ${ }^{479}$ Auch wenn die Orts- und Schulchroniken kaum Aufschluss über die Sammelerträge geben, so kann festgestellt werden, dass zwischen dem nicht unerheblichen Werbeaufwand und dem Sammelerfolg eine deutliche Diskrepanz bestand. Vielen Lehrern fehlte es einfach an Zeit, um mit den Schulkindern im Wald Pilze zu

\footnotetext{
${ }^{474}$ Siehe: Führen, Lehrer im Krieg (1936), S. 83.

${ }^{475}$ Ministerium der geistlichen und Unterrichts-Angelegenheiten, Nutzbarmachung der Erzeugnisse des Waldes, Zentralblatt für die gesamte Unterrichtsverwaltung in Preußen, 1915, S. 521.

${ }^{476}$ Siehe: Kapitel 7.2.1.

${ }^{477}$ Siehe: Königliche Regierung in Hildesheim, Pilztafeln und Merkblätter, Amtliches Schulblatt für den Regierungsbezirk Hildesheim, 1917, $168 \mathrm{f}$.

${ }^{478}$ Siehe: Ohmann, Eine Statistik der Sammeltätigkeit der Schulen im Jahre 1917 (1918).

${ }^{479}$ Siehe: Schulte, Kriegschronik der Stadt Münster 1914-18 (1930), S. 360.
} 
sammeln, und viele scheuten sich sicher auch, die Verantwortung bei der Auswahl genießbarer Pilze zu übernehmen. Hinzu kam, dass Pilze schon immer von Privatpersonen für den persönlichen Bedarf gesammelt worden sind und es keiner Weiterverarbeitung der Pilze bedurfte. Ein Beispiel aus Hildesheim zeigt, wie begehrt damals Pilze waren und wie schwer es deshalb Schulkinder bei den entsprechenden Sammlungen hatten: „In den Wäldern nahm die Pilzjagd einen immer größeren Umfang an, ed fanden gemeinschaftliche Pilzwanderungen statt, an denen sich die Leute aller Stände beteiligten; die Eisenbahn gewährte Fahrpreisermäßigungen, deren Andrang war bisweilen so groß, dass die Bahn die Teilnehmer kaum befördern konnte. ${ }^{، 480}$

Besonders in den größeren Städten gab es ab 1916 Bestrebungen, Küchenabfälle zu sammeln und an bestimmte Sammelstellen abzuführen, von wo sie dann Tierhalter als Kraftfutter abholen sollten. Man hatte errechnet, dass von den 17 Millionen Menschen, die in Städten mit mehr als 40.000 Einwohnern wohnten, im Jahr 3.060.000 Doppelzentner frische Küchenabfälle ,produziert' würden (60 g pro Kopf), die 750.000 Doppelzentner Kraftfutter ergäben. Allerdings gab es bei der Realisierung der Pläne einige Schwierigkeiten, insbesondere wegen der geringen Haltbarkeit der Abfälle und des Transportes, denn es waren im Krieg nicht genügend Transportmittel vorhanden, sodass die Sammlung insgesamt keinen Erfolg hatte. ${ }^{481}$ Dass in einigen größeren Kommunen Schulen aber trotzdem ziemlich erfolgreich Küchenabfälle sammelten, zeigt das Beispiel Hannovers. Aus einem Bericht des Polizeipräsidenten vom 5. Dezember 1916 geht hervor, dass sich bei den Sammlungen der der „Freiwilligen Kriegshilfe“" zu diesem Zeitpunkt etwas 6-8000 Schüler, und zwar fast ausschließlich der Volksschule, organische Abfälle sammelten. „Vordem soll etwa die doppelte Zahl tätig gewesen sein “482. Da die Schüleraktivitäten als patriotische Tat galten, erhoffte man sich bei ihnen „günstige Auswirkungen auf die Gesinnung der Volksschüler (...). Denn gerade diese entstammten jenem sozialen und politischen Milieu, von dem man nicht unbedingt erwarten durfte, daß es die Kriegsziele der Reichsregierung auf Dauer mittragen würde“ ${ }^{483}$ Im Jahre 1918 sammelten Schüler und Schülerinnen der städtischen hannoverschen Mittel- und Volksschulen im Jahre 1918562.296 kg Küchenabfälle. ${ }^{484}$ Sie zogen in Scharen durch die Stadt und

\footnotetext{
${ }^{480}$ Vogeler, Kriegschronik der Stadt Hildesheim (1929), S. 338.

${ }^{481}$ Siehe: Ertheiler/Plohn, Das Sammeln in der Kriegswirtschaft (1919), S. 36f.; siehe auch: Anhang, Seiten 44/45, Bild 1.

${ }^{482}$ Zitiert nach: Schneider, Ein Photofund über die Arbeit der „Freiwilligen Kriegshilfe Hannover und Linden" im ersten Weltkrieg, Hannoversche Geschichtsblätter, 1999, S. 207.

${ }^{483}$ Schneider, Ein Photofund über die Arbeit der „Freiwilligen Kriegshilfe Hannover und Linden" im ersten Weltkrieg, Hannoversche Geschichtsblätter, 1999, S. 207.

${ }^{484}$ StAH, HR 16 Schulamt Nr. 553; Karl-Heinz Grotjahn (Grotjahn, Stahl und Steckrüben Bd. 2 (1993), S. 171) nennt für den Zeitraum vom 1. April 1916 bis 31. Dezember 1918 als Menge $563.000 \mathrm{~kg}$ Küchenabfälle und beruft sich auf die gleiche Quelle. Berücksichtigt man, dass die Reichsverwertungsgesellschaft durchschnittlich
} 
holten in den Haushaltungen die angefallenen Abfälle ab. „Wer etwa vier Pfund ablieferte, bekam einen Gutschein, und eine Anzahl dieser Gutscheine berechtigte den fleißigen Sammler zum Anspruch auf eine Prämie. Für 75 Gutscheine gab es eine Mütze oder ein gutes Buch, für 200 Gutscheine ein Kaninchen, sofern die Eltern gegen diesen neuen Hausbewohner nicht einzuwenden hatten. “485 Mit diesen Küchenabfällen wurde die von der „Kriegshilfe“ wegen des Fleischmangels aufgebaute Kaninchenzucht unterhalten und zeitweise auch einige Schweine außerhalb Hannovers gefüttert. Die Aussicht auf die Prämien, einen schulfreien Tag, Ausflüge und einen Besuch des Kleintierzoos oder eines Kasperletheaters führten dazu, dass sich so viele Kinder bei den Sammlungen engagierten. ${ }^{486}$ Anlässlich von Hindenburgs 68. Geburtstag durften sogar „4000 Schulkinder aus Hannover und Linden, fleißige Sammler von Küchenabfällen, (...) dem Generalfeldmarschall von Hindenburg ihre Glückwünsche zum 68. Geburtstag“ darbringen und sein Haus „mit selbstgebunden Kränzen aus Feldblumen “487 schmücken. Auch in anderen Großstädten verliefen die Sammlungen von Küchenabfällen ähnlich. Die Kommune legte Sammeltage fest, die Schüler holten an diesen die Essensreste in den Haushalten ab und brachten sie mit Handwagen oder von der Stadt zur Verfügung gestellten Transportfahrzeugen ${ }^{488}$ zu der entsprechenden Sammelstelle.

Auf die Sammlung von Knochen, Eicheln und Kastanien ${ }^{489}$, Pflanzen und Kräutern für Arzneien sowie Kaninchenfellen, an den viele Schulen ebenfalls mit guten Ergebnissen beteiligt waren $^{490}$, soll nicht weiter eingegangen werden. In der Regel war die volkswirtschaftliche Bedeutung jeweils recht gering.

Dieses trifft zwar auch auf die Sammlung von Frauenhaar zu, sie soll aber trotzdem besonders erwähnt werden, um die Bandbreite der gesammelten Produkte und Materialien zu zeigen. ${ }^{491}$

1,50 Mark für den Zentner bezahlte, so wurden durch die von den Schülern gesammelten Küchenabfälle. 843.444 Mark eingenommen bzw. hätten aus den Abfällen mehr als 4.000 Doppelzentner Kraftfutter für Tiere hergestellt werden können. Den Erlös der Sammelaktion erhielt die „Freiwillige Kriegshilfe Hannover-Linden“. Siehe: Anhang, Seite 44, Bild 2.

${ }^{485}$ Tätigkeitsbericht der Freiwilligen Kriegshilfe Hannover und Linden, in: Akte NHStAH Hann 180 Hannover Nr. 552, zitiert nach: Schneider, Ein Photofund über die Arbeit der „Freiwilligen Kriegshilfe Hannover und Linden" im ersten Weltkrieg, Hannoversche Geschichtsblätter, 1999, S. 206.

${ }^{486}$ Siehe: Schneider, Ein Photofund über die Arbeit der „Freiwilligen Kriegshilfe Hannover und Linden" im ersten Weltkrieg, Hannoversche Geschichtsblätter, 1999, S. $206 \mathrm{f}$.

${ }^{487}$ Siehe: Anhang, Seite 4 (Bild 2).

${ }^{488}$ Siehe: Anhang, Seiten 45 (Bild 1).

${ }^{489}$ Siehe: Anhang, Seiten 49 (Bild 1), 50 und 51.

${ }^{490}$ Z. B. sammelten 2.350 Schulkinder der Volksschulen in Wuppertal-Vohwinkel im Sommer des Jahres 1918 $5.2187 \mathrm{~kg}$ Eicheln, $104 \mathrm{~kg}$ Kastanien und $448 \mathrm{~kg}$ Knochen (Wuppertal Vohwinkel, http://www.agvv.org/160.htm (27.12.2008) ). In Hannover brachten die Jungen und Mädchen der Mittel und Volksschulen in der Zeit vom 1.4.1916 bis $31.12 .191823 .000 \mathrm{~kg}$ Knochen, $5.960 \mathrm{~kg}$ Pflanzen und Kräuter für Arzneien und $16.375 \mathrm{~kg}$ Obstkerne und Eicheln zusammen.

${ }^{491}$ Insgesamt sind nach Ertheiler/Plohn (Das Sammeln in der Kriegswirtschaft [1919]), S. 39f.) erhebliche Mengen von Frauenhaar zusammengebracht worden, was sicher vor allem auf den „Höchstpreis“ (2 Mark für $1 \mathrm{~kg}$ ), der von den Verwertungsstellen bezahlt wurde, zurückzuführen ist. Welchen Anteil die Schulen daran hatten, kann anhand der überlieferten Quellen nicht mehr genau festgestellt werden. Allerdings haben einige Schulen 
Man benötigte schon bald nach Kriegsbeginn in sehr großen Mengen Frauenhaar als Ersatz für Kamelhaar, das nicht mehr eingeführt werden konnte, um daraus Treibriemen und Filzdichtungen (insbesondere für U-Boote) herzustellen. Das gesammelte Haar musste in bestimmten Säckchen an die ,Deutsche Frauenhaarsammlung' des Deutschen Roten Kreuzes Magdeburg oder Augsburg geschickt werden, von wo aus es dann an die entsprechenden Firmen weitergeleitet wurde. Von zwei Firmen ist bekannt, dass sie 340.000 kg bzw. $165.000 \mathrm{~kg}$ Frauenhaar zu Treibriemen mit einem Wert von 6.8000.000 Mark bzw. 3.500.000 Mark verarbeitet haben. ${ }^{492}$ Angesichts der kriegswirtschaftlichen Bedeutung der Sammlung hatte man eigens hergestellte Werbeplakate herausgegeben, auf denen die Schulkinder teilweise direkt angesprochen wurden. ${ }^{493}$

Welchen Anteil die Schulen daran hatten, ist nicht zu klären, er dürfte allerdings nicht gering gewesen sein, obwohl die Schulen sich nur unter bestimmten Bedingungen daran beteiligen konnten. So durfte das Einsammeln der mit Frauenhaar gefüllten Beutel nicht durch Schulkinder erfolgen und außerdem bedurfte die Teilnahme der besonderen Genehmigung durch den Schulleiter. Um Mädchen in ihrem Patriotismus vor sich selbst zu schützen und zu verhindern, dass sie ihre Haare wegen des Sammelerfolgs abschnitten, sollten lediglich ausgekämmte Haare gesammelt werden. Außerdem war festgelegt, dass ,,weder mittelbar noch unmittelbar [...] ein Zwang auf die Schülerinnen bei der Sammlung ausgeübt werden (dürfe) ${ }^{6494}$.

Allerdings zeigen Quellen, dass trotzdem Hunderte von Schulen an der Sammlung von Frauenhaar beteiligt waren. Von den 17 höheren Mädchenschulen in Schleswig-Holstein beteiligten sich sowohl 1917 als auch 1918 fünf Schulen am den Sammlungen. Die Sammelergebnisse sind nicht bekannt, wohl aber die der Flensburger Mädchenschulen, die 151,60 kg zusammengetragen haben, welche mit 3.336,30 Mark vergütet wurden. ${ }^{495}$

durchaus beachtliche Mengen gesammelt, wobei die Sammlungsergebnisse der einzelnen Schulen doch stark differierten. So benötigten 226 Schüler des Frankfurter Goethe-Gymnasiums sechs Wochen, um 26 kg Frauenhaar zu sammeln, während das Lyzeum in Wuppertal-Vohwinkel mit 278 Schülerinnen im Sommer des Jahres 191811 1/2 kg sammelten (http://www.agvv.org/160.htm ). Besonders gut war das Ergebnis der Flensburger Schülerinnen ( ca. 4.000), die 1917 151,65 kg zusammenbrachten und einen Erlös 3.360,30 Mark erzielten Siehe: Hohnsbehn, Die Flensburger Schuljugend in der Zeit des ersten Weltkriegs [1996], S. 220). Jede Schülerin hat also durchschnittlich fast $400 \mathrm{~g}$ zusammengebracht (im Jahr), während es die Jungen des GoetheGymnasiums ,lediglich' auf 115 g (in sechs Wochen; Zenetti, Der Sammelhilfsdienst der Frankfurter Schuljugend und seine Ergebnisse am Goethe-Gymnasium, S. 7) und die Mädchen des Lyzeums in Vohwinkel sogar nur auf 41 g. (im Jahr) im Schnitt brachten. Die großen Unterschiede sind sicher in erster Linie auf das jeweilige Engagement der Lehrer zurückzuführen und nicht darauf, ob es sich um eine Schule mit Jungen oder mit Mädchen handelte. Aus den Unterlagen geht allerdings hervor, dass Mädchen sich bei diesen Sammlungen insgesamt stärker beteiligt haben, da es sich bei dem Sammelgut um weibliche Haare handelte.

${ }^{492}$ Siehe: Ertheiler/Plohn, Das Sammeln in der Kriegswirtschaft (1919), S. $36 f$.

${ }^{493}$ Siehe: Anhang, Seite 50.

${ }^{494}$ Siehe: Pust, „Vaterländische Erziehung" für „Höhere Mädchen" (2004), S. 366f.

${ }^{495}$ Siehe: Hohnsbehn, Die Flensburger Schuljugend in der Zeit des ersten Weltkriegs (1996), S. 220. 
Die ca. 2.350 Kinder der Volksschulen Vohwinkels (heute Stadtteil von Wuppertal, Rheinprovinz) hingegen brachten es im Sommer 1918 lediglich auf 11,5 kg ${ }^{496}$, während die 380 Schüler des Frankfurter Goethe-Gymnasiums innerhalb von 6 Wochen $26 \mathrm{~kg}$ sammelten. ${ }^{497}$ Sogar die kleine Dorfschule in Tonnenheide (Provinz Westfalen) beteiligte sich an der Sammlung und lieferte $1,5 \mathrm{~kg}$ Haare ab. ${ }^{498}$ Meistens wird in den Chroniken lediglich erwähnt, dass die Schulen sich an der Sammlung von Frauenhaar beteiligt haben, die gesammelten Mengen werden aber nicht genannt. ${ }^{499}$

Angesichts der militärischen Bedeutung und der guten Bezahlung (20 Mark für $1 \mathrm{~kg}$ ) waren die Kommunen insgesamt sehr an guten Ergebnissen interessiert und bemühten sich in besonderem Maße um die Schulen. Die Stadt Mainz beispielsweise richtete für den „SchülerSammeldienst" zur Annahme des Sammelgutes und zur Ausgabe der Sammelbeutel eine Sammelstelle ein und wies in mehreren Spendenaufrufplakaten darauf hin. ${ }^{500}$ Offensichtlich wurde in jeder Schule eine Sammelstelle eingerichtet, wie aus einem Plakat hervorgeht, das die Hauptsammelstelle in Magdeburg veröffentlichte (,Abnahmestelle jede Schule“) und das sich an „alle Frauen und Mädchen“ wandte. ${ }^{501}$ Auch die Sammelstelle der Bayerischen Frauenhaarsammlung in Augsburg wies in einem Aufruf, der sich auch an ,,alle Schulen, Klöster und Anstalten“ wandte, darauf hin, dass das Ministerium für Kirchen- und Schulangelegenheiten zugesagt habe, die Einrichtung von Sammelstellen ,in jeder Schule, ja in jeder Schulklasse“ zu unterstützen. ${ }^{502}$ Angesichts der massiven Förderung der Sammlung durch die Behörden und Kommunen sowie der aufwendigen Plakataktionen fühlten sich viele Schulen verpflichtet, durch eigene Sammelaktionen dem „Vaterland (zu) zu dienen“503, zumal sie als Sammelstellen nahezu täglich damit konfrontiert wurden. Über die Einstellung der Schulkinder zum Sammeln von Frauenhaar sollen die Erinnerung einer ehemaligen Schülerin des Flensburger Lyzeums und Tagebucheinträge einer Schülerin beispielhaft Aufschluss geben. Helene J. erinnerte sich: „Nicht so großen Anklang fand bei uns die Sammlung in Häusern von ausgekämmten Haaren; wir gingen ohne Protest los, es war ja für die Marine, also für die

\footnotetext{
${ }^{496}$ Wuppertal Vohwinkel, http://www.agvv.org/160.htm (27.12.2008).

${ }^{497}$ Zenetti, Der Sammelhilfsdienst der Frankfurter Schuljugend und seine Ergebnisse am Goethe-Gymnasium, S. 7.

${ }^{498}$ Kammeier, Der Landkreis Lübbecke und der 1. Weltkrieg (1998), S. 187.

${ }^{499}$ Zum Beispiel in der Burgschule Nordhorn, der Oberrealschule in Heide, der Sophienschule in Hannover und der Volksschule zu Röhrenfurth.

${ }^{500}$ Siehe: http://www.dhm.de/datenbank, Inventarnr.1988/19177 und 1988/2083; siehe auch: Anhang, Seite 50, Bilder 1 und 5.

${ }^{501}$ Siehe: http://www.dhm.de/datenbank, Inventarnr. PL DHM/1; siehe auch: Anhang, Seite 50, Bild 2.

502 Stadtarchiv Augsburg - Archiv und Schule, http://www.stadtarchiv.augsburg.de/index.php?id=17256 (01.01.2009).

503 Stadtarchiv Augsburg - Archiv und Schule, http://www.stadtarchiv.augsburg.de/index.php?id=17256 (01.01.2009).
} 
Front, dass wir losgeschickt worden. “504 Die Schülerinnen der Klasse waren also offensichtlich über die Verwendung der Haare für Kriegszwecke informiert worden und empfanden ihren Einsatz als Unterstützung der militärischen Front. Am 14. Januar 1918 notierte die Flensburger Schülerin Anneliese C. in ihrem Tagebuch: „Um 12 heute frei, sollten ja Haare sammeln. H. und ich hatten den Südergraben, der Bezirk geht ja, wurden doch ziemlich viele Tüten los. Bei einer alten Frau kriegten wir auch schon graue Haare.“ Zwölf Tage später heißt es: „H. und ich trafen uns um 1/2 10 am Burgplatz, wir sollten ja Haare sammeln. [...] Zogen dann los. Kriegten ne ganze Masse Haare, H. hatte d. Tüte schon fast voll. Ist doch ein ekliges Geschäft, dieses ewige Treppauf, Treppab.“

Am 15. und 17. Mai zogen die beiden Mädchen noch einmal los: „In der letzten Stunde H. und ich z. Haarsammeln, war schönes Wetter, wir brauchen ja nur dahin, wo Tüten genommen worden waren. [...] In der letzten Stunde H. und ich wieder Haare gesammelt, ist wirklich kein schönes Geschäft. “605

Die Tagebuchaufzeichnungen verdeutlichen den Ablauf der von dem Lehrer gut organisierten Sammlung. Jeweils zwei Schülerinnen bekamen zunächst einen Sammelbezirk zugeteilt. Sie warben dann in den Häusern ihres Bezirks für die Haarspenden und händigten spendewilligen Bewohnern „Sammeltüten“ (meistens Beutel) aus, die sie dann später gefüllt wieder abholten. Insgesamt fanden die Sammlungen am Vormittag statt und ersetzten den regulären Unterricht. Bemerkenswert ist, dass die Schülerinnen die Beutel wieder einsammelten, obwohl das vom preußischen Unterrichtsminister untersagt worden war.

Insgesamt entspricht die zeitgenössische Einschätzung weitgehend den später aufgeschriebenen Erinnerungen. Beide Quellen zeigen, dass die Frauenhaarsammlungen von den Schülerinnen nur ungern durchgeführt und als Opfer empfunden wurden, das sie allerdings widerspruchslos für das Vaterland erbrachten.

\subsection{Fazit}

Kurz nach Beendigung des Krieges zog August Ertheiler, ehemaliger Referent im Kriegsministerium, Bilanz über die Sammeltätigkeit der Schuljugend:

„Unberührt von politischen und wirtschaftlichen Klassengegensätzen, trugen Millionen von Schulkindern aus allen Kreisen in die Elternhäuser den ihnen von den Lehrern gelehrten Ruf: ,Heraus mit entbehrlichen Dingen und Abfallstoffen!', ,Hinaus in Wald und Flur!', um den immer stärker drückenden Mangel an Rohstoffen und Nahrungsmitteln entgegen zu arbeiten. Wenn irgendwelche heimatlichen Vorgänge während des Kriegs Berechtigung zu Befriedigung geben konnten, so waren sie in der Entfaltung der freiwilligen Sammel- und Hilfstätigkeit der Jugend gelegen. Es war ei-

\footnotetext{
${ }^{504}$ Erinnerungen der Schülerin Helene J, zwei Seiten handschriftlich; zitiert nach: Pust, „Vaterländische Erziehung" für „Höhere Mädchen" (2004), S. 366.

505 Zitiert nach: Pust, „Vaterländische Erziehung" für „Höhere Mädchen" (2004), S. 367.
} 
ne Freude zu sehen, wie die Begeisterung der opferwillig tätigen Lehrerschaft sich auf die Kinder und mittelbar auf das Elternhaus übertrug, wie auch aus den Häusern der minderbemittelten Volksschichten nicht des Gelderlöses wegen, sondern aus Gemeinsinn die auf andere Weise vorteilhafter zu verwertenden Sachen von den Kindern in die Ablieferungsstellen gebracht wurden. “506

Ähnlich positiv hatte sich der preußische Unterrichtsminister im Februar 1918 ausgedrückt: „Diese begeisterungsfähige Mitarbeit unserer Schuljugend auf den verschiedenen kriegswirtschaftlichen Gebieten ist ein Ruhmesblatt in der Geschichte des gegenwärtigen Weltkriegs. “507 Auch die preußischen Provinzialregierungen äußerten sich nahezu euphorisch, wie z. B. die Regierung Schleswig-Holsteins 1918: „Wenn darum die folgenden Zahlen über einige Hauptgegenstände der Sammlung vielleicht nur die Hälfte der Erträge angeben, so dürften sie doch um so mehr allgemein gewürdigt werden als ein Ehrenzeugnis für die Kriegshilfe für die Lehrer und Lehrerinnen wie der Kinder.““508 ${ }^{60}$ Ferner geht die Wertschätzung der schulischen Sammelleistung aus vielen anderen offiziellen Äußerungen hervor, z. B. dem Gedenkblatt „Heil der Jugend! ‘509.

Dass beide Aussagen hinsichtlich der schulischen Sammelerfolge richtig waren, haben die Untersuchungen gezeigt. Auch die Ergebnisse der vielen Sammlungen, auf die nicht näher eingegangen worden ist, wie z. B. die von Kastanien, Knochen, Eicheln und Altpapier, bestätigen den Erfolg der Schulen. Da das gesamte Sammelwesen in erster Linie auf den Schulen aufbaute, war deren Engagement für den Erfolg der verschiedenen Aktionen von besonderer Bedeutung. Entsprechend groß war der Druck auf die Schulen und die Anzahl der Appelle an die Jugend, ihren patriotischen Pflichten nachzukommen. Dieses zeigen die vielen Erlasse, Aufrufe und Plakate, die - wie nachgewiesen - insgesamt durchaus den erwünschten Erfolg hatten. Der volkswirtschaftliche Nutzen der vielen Sammelaktionen ist allerdings kaum exakt zu beurteilen, da vor allem hinsichtlich der Lebensmittelsammlungen ,genauere statistische Angaben über Umfang und Verwertung fehlen“6510.

Einzelne Sammlungen, z. B. die von Kaffeegrund als Trockenfuttermittel oder Lederabfälle und Lumpen, waren offensichtlich wenig erfolgreich und wurden als unwirtschaftlich eingestellt. Auch das Ziel, durch die Sammlung von ölhaltigen Früchten die Versorgungslage der Bevölkerung entscheidend zu verbessern, wurde trotz respektabler schulischer Sammelergebnisse nicht erreicht. Sogar der „Kriegsausschuss für pflanzliche und tierische Fette“ hielt die Verwertung der Obstkerne für unwirtschaftlich. ${ }^{511}$

\footnotetext{
${ }^{506}$ Siehe: Ertheiler/Plohn, Das Sammeln in der Kriegswirtschaft (1919), S. 1f.

${ }^{507}$ Zitiert nach: Pust, „Vaterländische Erziehung" für „Höhere Mädchen" (2004), S. 367.

${ }^{508}$ Saul, Jugend im Schatten des Krieges (1983), Seite 157, Quelle 32.

${ }^{509}$ Siehe: Anhang, Seite 52.

${ }^{510}$ Roerkohl, Der Erste Weltkrieg in Westfalen, (1987), S. 54.

${ }^{511}$ Siehe: Ertheiler/Plohn, Das Sammeln in der Kriegswirtschaft (1919), S. 33.
} 
Nach Meinung des Agrarwissenschaftlers Friedrich Aereboe haben die großen Nahrungssorgen „dem Menschen das klare wirtschaftliche Denken erschwert“ und zu einer „Kriegspsychose“512 geführt. Es wäre sinnvoller gewesen, ,,die Kinder zum Kartoffelroden und Rübenroden und die Schweine zum Sammeln von Bucheckern zu verwenden“. August Ertheiler stellte einige Sammlungen ebenfalls nachträglich infrage. So sei der „Kalorienverbrauch beim Einsammeln von Wildgemüsen leicht größer (als der) dadurch erzielte Kaloriengewinn““513 gewesen. Auch die Sammlung von Arzneipflanzen und Arzneikräutern dürfte in den meisten Fällen den an sie gestellten Ansprüchen nicht entsprochen haben. ${ }^{514}$ Allerdings hatten diese Sammlungen einen propagandistischen Wert, denn sie trugen dazu bei, den Durchhaltewillen der Kinder zu stärken, indem ihnen das Gefühl vermittelt wurde, etwas zum militärischen Sieg der Soldaten beizutragen.

Dem Sammeleifer der Schüler haben einige „Verdrießlichkeiten“515 kaum Abbruch getan. So kam es wiederholt vor, dass die Kommunen nicht genügend Transportmittel zur Verfügung stellen konnten, um das Sammelgut zeitnah abzuholen. Beispielsweise blieben manchmal die gesammelten Eier in der Schule so lange liegen, bis sie faul wurden. Auch über Kriegsverwertungsgesellschaften wurde oft geschimpft, da sie angeblich zu hohe Gewinne aus der Verarbeitung des Sammelgutes erzielten und sie nicht an den Staat abführten.

Insgesamt jedoch überwogen die im Sinne der Regierungen und Behörden erfolgreichen Sammelaktionen. Auch wenn nach Meinung des preußischen Schulministers „die Sammeltätigkeit hier und da durch die große Inanspruchnahme der Schulkinder in den landwirtschaftlichen Betrieben beeinträchtigt ${ }^{* 516}$ wurde, trugen die Schulen nicht nur zur Finanzierung des Krieges und zur Verbesserung der Versorgung mit Rohstoffen, Lebensmitteln und Kleidungsstücken bei, sondern „mit zunehmender Kriegsdauer wurde die Multiplikatorenwirkung der Schule immer gezielter ausgenutzt. “517

Da die meisten Sammlungen während der Unterrichtzeit stattfanden, war vor allem im letzten Jahr angesichts der zahlreichen Aktionen ${ }^{518}$ regulärer Unterricht kaum noch möglich, was die Schulbehörden billigend in Kauf nahmen. Schließlich würden sie den Gemeinsinn stärken, zur Sparsamkeit erziehen, die körperliche Fitness und die Freude an der Natur stärken sowie den

\footnotetext{
${ }^{512}$ Aereboe, Der Einfluß des Krieges auf die landwirtwirtschaftliche Produktion in Deutschland (1927), S. 58. Zitiert nach: Roerkohl, Der Erste Weltkrieg in Westfalen (1987), S. 54.

${ }^{513}$ Siehe: Ertheiler/Plohn, Das Sammeln in der Kriegswirtschaft (1919), S. 30.

${ }^{514}$ Siehe: Ertheiler/Plohn, Das Sammeln in der Kriegswirtschaft (1919), S. 31.

${ }^{515}$ Führen, Lehrer im Krieg (1936), S. 70.

${ }^{516}$ LAS, Abtlg. 302, Nr. 3178; Denkschrift für das preußische Abgeordnetenhaus 1918, S. 4.

517 Saul, Jugend im Schatten des Krieges (1983), S. 119.

${ }^{518}$ In der Meisenburger Chronik sind z. B. aufgeführt: „Alte Wollsachen bei der Reichswollwoche, alte und neue Kleider bei der Ostpreußensammlung, Brombeeren (527 kg), Ähren, Brennesseln, Bücher, Kupfer, Aluminium, Blechbüchsen, Gummi, Stanniol, Korkstopfen, Frauenhaar, Wildgemüse, Eicheln, Bucheckern, Laubheu, Sonnenblumensamen, Pilze und was nicht alles“ (Führen, Lehrer im Krieg [1936], S. 86).
} 
Schulunterricht ergänzen, indem den Schülern Kenntnisse über die Wiederverwendung von Abfall und Altstoffen vermittelt würden, hieß es.

Erschwert wurde der Unterricht auch dadurch, dass das meiste Sammelgut bis zur Abholung in den Schulen gestapelt wurde und die „Schulen bald riesigen Altwarenlagern glichen“ ${ }^{* 519}$. Auch wenn die Schule sicher insgesamt für den Abwehrkampf gegen die Wirtschaftsblockade erfolgreich mobilisiert und durchaus wirksam für die Kriegswirtschaft an der „Heimatfront“ eingesetzt worden ist, so ist die Beurteilung der schulischen Sammelhilfe des Stettiner Regierungs- und Schulrat im Jahre 1917 auch propagandistisch übertrieben: „Als Abwehrmittel gegen den Erschöpfungs- und Hungerkrieg [...] haben wir wieder die Lehrer und Kinder gerufen, und sie haben es ${ }^{520}$ erhalten, gemehret, gerettet in wirksamer Kriegshilfe.“521

Allerdings trifft es zu, dass es dem Staat gelungen war, sich erfolgreich sowohl der Schulkinder als Sammler und Werber als auch der kostenlosen Organisationsstruktur der Schule zu bedienen.

Die wenn auch oft recht geringe Vergütung sollte den Sammlern einen kleinen finanziellen Anreiz geben. Dass die Aktionen wegen ihres Umfangs und ihrer Art teilweise sogar gesundheitsgefährdend waren, wurde in der Regel von den Behörden ignoriert. Lediglich die Schulen griffen mitunter regulierend ein.

\footnotetext{
${ }^{519}$ Führen, Lehrer im Krieg (1936), S. 86.

${ }^{520}$ Gemeint ist das Sammelgut.

${ }^{521}$ Siehe: Bohnstedt, Die Kriegshilfe unserer Schuljugend (1917), S. 35.
} 


\section{Kaufs- und Verkaufsaktionen}

Neben Sammlungen und Spenden gab es an den Schulen verschiedene Kaufs- und Verkaufsaktionen, deren Erlöse sowohl der Kriegsfinanzierung (Kriegsanleihen) als auch Wohlfahrtszwecken zugutekamen.

Sieht man von den Kriegsanleihen ab, so waren die entsprechenden Aktivitäten der Schulen zunächst weitgehend unkoordiniert, wurden mit zunehmender Dauer des Kriegs jedoch in beträchtlichem Umfang institutionalisiert. Neben den Kultusbehörden engagierten sich in diesem Bereich besonders die von Lehrern gegründeten gemeinnützigen Vereine „Jugendspende für Kriegerwaisen“ (Essen) ${ }^{522}$ und „Jugenddank für Kriegsbeschädigte“ (Berlin) ${ }^{523}$.

\subsection{Staatlich unterstützte Aktionen}

Seit Kriegsbeginn forderten Schulbehörden die Schulen immer wieder durch Erlasse auf, bestimmte Gedenkblätter, Karten und andere Produkte zu verkaufen bzw. zu kaufen. Einige solcher Objekte seien kurz angeführt:

September 1914 Kriegsschriften des Kaiser-Wilhelm-Danks ${ }^{524}$ (Broschüre)

Dezember 1914 Glückwunschkarten des Kaisers ${ }^{525}$

August 1916

Mai 1916

Dezember 1916

Kriegsbilderbogen-Woche (Sammlung) ${ }^{526}$

Dezember 1916

Vertrieb eines Bildes zum Besten der Nationalstiftung ${ }^{527}$

Januar 1917

Weihnachtsglückwunsch Seiner Majestät des Kaisers (Karte) ${ }^{528}$

Januar 1917

Januar 1917

Weihnachtsgruß der Heimat (Feldpostkarte) ${ }^{529}$

Januar 1917

Bilderbuch zum Besten kriegsverletzter Landsturmmänner ${ }^{530}$

Der Kaiser im Felde (Buch) ${ }^{531}$

Kriegsfingerhut (Skulptur) ${ }^{532}$

\footnotetext{
${ }^{522}$ Siehe: 7.2.1. „Jugendspende für Kriegerwaisen“.

${ }^{523}$ Siehe: 7.2.2 „Jugenddank für Kriegsbeschädigte“.

${ }^{524}$ Kriegsschriften des Kaiser-Wilhelm-Danks, Amtliches Schulblatt für den Regierungsbezirk Königsberg, 9. September 1914.

${ }^{525}$ Erwähnt in: Weihnachtsgruß der Heimat, Amtliches Schulblatt für den Regierungsbezirk Königsberg, 1916, S. 148.

${ }^{526}$ Kriegsbilderbogen-Woche, Amtliches Schulblatt für den Regierungsbezirk Hildesheim, 1916, S. 106f.

${ }^{527}$ Den Vertrieb eines Bildes in den Schulen zum Besten der Nationalstiftung für die Hinterbliebenen der im Kriege Gefallenen betreffend, Schulblatt für die Herzogtümer Braunschweig und Anhalt, 1916, S. 298.

${ }^{528}$ Weihnachtsglückwunsch Seiner Majestät des Kaisers, Amtliches Schulblatt für den Regierungsbezirk Königsberg, 1916, S. 148.

${ }^{529}$ Weihnachtsgruß der Heimat, Amtliches Schulblatt für den Regierungsbezirk Königsberg, 1916, S. 148.

${ }^{530}$ Bilderbuch zum Besten kriegsverletzter Landsturmmänner, Amtliches Schulblatt für den Regierungsbezirk Hildesheim, 1917, Nr. 5.

${ }^{531}$ Krieger, Der Kaiser im Feld, Amtliches Schulblatt für den Regierungsbezirk Hildesheim, 1917, Nr. 6.

${ }^{532}$ Kriegsfingerhut, Amtliches Schulblatt für den Regierungsbezirk Hildesheim, 19171, Nr. 7.
} 
Januar 1917

Mai 1917

Mai 1918

August 1918
Mappe mit Bildern des Kaisers und der Heerführer ${ }^{533}$

Wohlfahrtskarte Seiner Majestät des Kaisers ${ }^{534}$

Postkarten für eine U-Bootspende ${ }^{535}$

Verkauf einer Fotografie der Kronprinzessen (Kunstblatt) ${ }^{536}$

In den entsprechenden Erlassen ist die Werbung für die Produkte insgesamt recht zurückhaltend formuliert. So heiß es z. B. in der Verlautbarung zum „Kriegsbilderbogen-Woche“:

„Aushänge, die auf die Kriegsbilderbogen-Woche hinweisen, dürfen in den Schulgebäuden und Klassen vom 1. September d. Js. ab angebracht werden, auch dürfen die Schüler und Schülerinnen zum Kauf von Kriegsbilderbogen angeregt und darauf hingewiesen werden, wie jedes der eigenen Sparbüchse entnommene Zehnpfennigstück dazu helfen soll, die Not der Kriegsmütter zu lindern. Den Schülern und Schülerinnen, die nach ihrem Alter und nach ihrer Haltung dafür in Betracht kommen, ist der Verkauf der Kriegsbilderbogen zu gestatten." ${ }^{\text {‘53 }}$

Für den Verkauf der Kriegsbilderbögen sei ein Beispiel aus Hameln genannt. In der Schulchronik ist vermerkt: „Vom 6. bis 26. September 1916 Verkauf von Kriegsbilderbögen auf der Straße durch junge Mädchen. ${ }^{\text {‘538 }}$

Hinsichtlich der Glückwunschkarten des Kaisers wurden die Schulen allerdings angewiesen, bei den Schülern für die Mitwirkung beim Vertrieb zu werben. ${ }^{539}$ Dass die Behörden einige der Verkaufsaktionen nur mit Bedenken genehmigten, geht beispielsweise aus dem folgenden Erlass des preußischen Unterrichtsministers über den „Vertrieb von Postkarten für eine UBootspende“ hervor: „Ich will in dem vorliegenden Falle ausnahmsweise einen Vertrieb der Karten in den Schulen genehmigen, wobei ich jedoch voraussetze, daß jeder Zwang zum Kauf der Karten gegenüber den Schülern und Schülerinnen vermieden wird. “540

Die Schulbehörden dürften befürchtet haben, dass die Schüler neben den vielen außerunterrichtlichen Einsätzen, wie z. B. der Erntehilfe, den Sammlungen oder der Herstellung von Liebesgaben, durch entsprechende Verkaufsaktionen noch weiter belastet würden. Ein anderer Grund für die Zurückhaltung war der Missbrauch, der mit einigen Verkaufsaktivitäten

\footnotetext{
${ }^{533}$ Mappe mit Bildern des Kaisers und der Heerführer, Amtliches Schulblatt für den Regierungsbezirk Hildesheim, 1917, Nr. 6.

${ }^{534}$ Wohlfahrtskarte Seiner Majestät des Kaisers, Amtliches Schulblatt für den Regierungsbezirk Hildesheim, S. $114 \mathrm{f}$.

${ }^{535}$ Vertrieb von Postkarten für eine U-Bootspende, Amtliches Schulblatt für den Regierungsbezirk Hildesheim, 1918, S. 91f.

${ }^{536}$ Siehe: Pust, „Vaterländische Erziehung" für „Höhere Mädchen” (2004), S. 392.

${ }^{537}$ Kriegsbilderbogen-Woche, Amtliches Schulblatt für den Regierungsbezirk Hildesheim, 1916k, $106 / 107$

${ }^{538}$ Schulchronik „Die Schule im Ersten Weltkrieg 1914-1918", http://www.vikilu.de/vikilu/index.php?id=61 (06. 03.2009).

${ }^{539}$ Siehe z. B.: Weihnachtsglückwunsch Seiner Majestät des Kaisers, Amtliches Schulblatt für den Regierungsbezirk Königsberg, 1916, S. 148.

${ }^{540}$ Vertrieb von Postkarten für eine U-Bootspende, Amtliches Schulblatt für den Regierungsbezirk Hildesheim, 1918, S. $91 f$.
} 
betrieben worden war. Dieses geht aus einem Erlass vom 6. Mai 1916 hervor, in dem der preußische Unterrichtsminister die Schulbehörden auffordert, der „Beteiligung von Schulkindern an derartigen Geschäften in geeignet erscheinender Weise entgegenzuwirken “541. Eine Firma hatte beispielsweise den Schülern für den Verkauf von 100 patriotischen Ansichtskarten Uhren, Ketten und Ringe als Prämie versprochen. „Die Karten waren meist recht minderwertig, teilweise ausländischen Ursprungs und oft auch nach dem Gegenstande der Abbildungen zum Vertriebe durch Kinder wenig geeignet.“

Auch wenn es aufgrund der Quellenlage nicht möglich ist, den Erfolg des Verkaufs der Ansichtskarten und der anderen Produkte zu quantifizieren, so geht doch aus entsprechenden Hinweisen in Schulchroniken hervor, dass an vielen Schulen Schüler vor allem die angebotenen Ansichtskarten sowohl gekauft als auch in besonderem Maße verkauft haben. Als Beispiele seien ein Gymnasium bei Berlin und eine sächsische Volksschule genannt:

Jaochimthalsche Gymnasium in Templin (Provinz Brandenburg):

„Genannt wurden u. a. [...] (als Belastungen des Unterrichts der) Vertrieb von Kaiserpostkarten. “542

\section{Volksschule Copitz (Kgr. Sachsen):}

1915 „Haus und Straßensammlung verbunden mit dem Verkauf von Postkarten und Abzeichen“6543

1917 „Haus und Straßensammlung verbunden mit dem Verkauf von Postkarten und Abzeichen“654

\subsection{Aktionen von „Jugendspende“ und „Jugenddank“}

\section{„Jugendspende für Kriegerwaisen e. V.“645}

Bereits vor der offiziellen Gründung des Vereins bat der Initiator und spätere Vorsitzende, der Essener Lehrer Reinirkens, die Behörden um Genehmigung für eine „Sammlung einer Jugendspende für Kriegerwaisen“. Der preußische Unterrichtsminister entsprach der Bitte mit Erlass vom 27. Januar 1915. ${ }^{546} \mathrm{Im}$ gleichen Jahr wurde in Essen dann von Reinirkens und anderen Lehrern der Verein „Jugendspende für Kriegerwaisen e. V.“ gründet, der es sich zum Ziel setzte, Waisenkinder zu unterstützen und ihnen eine gute Berufsausbildung zu vermitteln.

\footnotetext{
${ }^{541}$ Verbot des Verkaufs von Ansichtskarten durch Schulkinder, Amtliches Schulblatt für den Regierungsbezirk Hildesheim, 1916, S. 57.

${ }^{542}$ Wegener, Das Joachimsthalsche Gymnasium - die Landesschule Templin (2007), S. 97.

543 Kuleßa, Mittelschule „Johann Heinrich Pestalozzi" in Pirna, http://www.mspesta.com/page63.html (15.07.2008).

544 Kuleßa, Mittelschule „Johann Heinrich Pestalozzi" in Pirna, http://www.mspesta.com/page63.html (15.07.2008).

545 Siehe auch: 7.2.1.

${ }^{546}$ Der Erlass ist u.a. abgedruckt in: Sammlung einer Jugendspende für Kriegerwaisen, Amtliches Schulblatt für den Regierungsbezirk Hildesheim, 1915, S. 83f.
} 
Noch bevor sie mit dem Vertrieb der durch die Firma Glasmachers ${ }^{547}$ hergestellten Nagelschilde $^{548}$ so außerordentlich erfolgreich waren, hatten sie durch den Verkauf des „FeldherrnBlattes“ (entworfen von Prof. Münzer, Düsseldorf; Vierfarbdruck; 53 : $42 \mathrm{~cm}$ ) erhebliche Mittel in den Schulen zusammengebracht - insgesamt 1 Million Mark. Das Bild zeigte „die bedeutendsten Heerführer des jetzigen Krieges““549 und wurde im Handel für 3 Mark verkauft. Schüler erhielten das Gedenkblatt, wenn sie mindestens 1 Mark gespendet hatten. Sie klebten 10 Marken zu 10 Pfennig in ein Sparheftchen ${ }^{550}$ und bekamen das Bild dann als äußere Anerkennung für die gespendeten Ersparnisse. Obwohl es durchaus Kritik von Lehrern an der Gestaltung des Bildes gab ${ }^{551}$, wurde es von vielen Schulen bestellt und Schülern zu besonderen Anlässen überreicht. ${ }^{552}$ Später kam dann das Kunstblatt „Kaiser und Hindenburg“ hinzu (entworfen von Tillak, Berlin; Vierfarbdruck; 50: $68 \mathrm{~cm}) .{ }^{553}$ Staatliche Stellen hatten den Verein von Anfang an unterstützt. ${ }^{554}$ Das preußische Kultusministerium genehmigte bereits am 27. Februar 1915 die Spendenaktion für das Königreich Preußen „unter Betonung völliger Freiwilligkeit ${ }^{\star 555}$.

\footnotetext{
${ }^{547}$ Die Essener Wandtafelfabrik Glasmachers wurde 1890 von Gottfried Glasmachers gegründet. Als im Ersten Weltkrieg der Verkauf von Wandtafeln zurückging, produzierte sie zusätzlich für die „Jugendspende“ und den „Jugenddank“ in größerem Umfang Nagelschilde. Wie aus einer Rechnung aus dem Jahre 1925 hervorgeht (Sammlung Kronenberg), stellte man nach dem Krieg wieder verstärkt Wandtafeln und anderen Schulbedarf her.

${ }^{548}$ In den zeitgenössischen Quellen wird für die Nagelbretter sowohl der Begriff „der Schild“ als auch „das Schild“ verwendet. Da die Firma Glasmachers, die die meisten Nagelbretter für die Schulen hergestellt hat, jenen Begriff (Schild mit der Bedeutung ,Schutzwaffe') benutzt, verwendet ihn der Verfasser um der Einheitlichkeit wegen ebenso.

549 Jugendspende für Kriegerwaisen, Die Lehrerin: Organ des Allgemeinen Deutschen Lehrerinnenvereins 1917, S. 13; abgebildet waren die Kaiser von Deutschland und Österreich sowie einige Heerführer.

${ }_{550}$ Siehe: Anhang, Seite 64, Bilder 1 u.2; Anmerkung: In der Sammlung des Deutschen Historischen Museum in Berlin sind die Marken auf das Jahr 1943 datiert (Inventarnummer Do2 2000/1978; http://www.dhm.de/datenbank/). Nach Auskunft eines Briefmarkenhändlers vom 3.9.2008 (Guido Krolik ,Alter Postweg 154, D 26133 Oldenburg) stammen die Marken jedoch aus den Jahren 1916/17. Für diese Datierung spricht vor allem auch die Tatsache, dass auf der Marke ein Eisernes Kreuz, und kein Hakenkreuz abgebildet ist. Außerdem gibt das Museum als Bezeichnung der Marke „Jugendspende der Kriegswaisen“ an, obwohl es auf der Marke „Jugendspende für Kriegerwaisen“" heißt.

${ }^{551}$ Sz., Kriegswahrzeichen für jede Schule, Die Mittelschule: Zeitschrift der Reichsfachschaft Mittelschule im Nationalsozialistischen Lehrerbund., 1916, S. 526: „Ein Bedenken sei hier noch ausgesprochen. Hoffentlich fallen die Schilder etwas , künstlerischer' aus als die Bilder! Das Feldherrngedenkblatt erregte bei kunstverständigen Leuten allgemeines Schütteln des Kopfes.“

${ }_{552}$ StAH, HR 16, Nr.553: Z. B. wurden an der Stadttöchterschule II Am Clevertor in Hannover 191816 Bilder verkauft und Spenden in Höhe von 24 Mark an den Verein überwiesen.

${ }^{553}$ Aufruf zur Nagelung des Kriegswahrzeichens der Stadt Witten, Wittener Tageblatt, S. 496f.; siehe: Anhang, Seite 64, Bild 3.

${ }^{554}$ In der Provinz Hannover war die Aktion der „Jugendspende“ zunächst nicht genehmigt worden, da der Oberpräsident eine „Belastung der Verwaltung befürchtete“. Dieser Beschluss (vom 10.Juni 1915) wurde jedoch von der Provinzialschulbehörde mit Erlass vom 10. Juni 1915 aufgehoben und eine bis zum 30. November 1915 befristete Erlaubnis erteilt. Siehe: Jugendspende für Kriegerwaisen, Amtliches Schulblatt für den Regierungsbezirk Hildesheim, 1915, S. 138.

${ }^{555}$ Kammeier, Der Landkreis Lübbecke und der 1. Weltkrieg (1998), S. 324.
} 
Fast alle anderen deutschen Bundesstaaten folgten; sie erteilten ebenfalls die Genehmigung und informierten die Schulen ihres Zuständigkeitsbereichs. ${ }^{556}$

Neben den Schildnagelungen und dem Verkauf der beiden genannten Gedenkblätter gab es eine Reihe weiterer Initiativen zur Geldbeschaffung. Beispielsweise wurde die „Jugendspende“ 1917 am Vertrieb der „Wohlfahrtsmarke Seiner Majestät des Kaisers“ in den Schulen beteiligt, die als Tiefdruckpostkarte für 10 Pfennig und als Bromsilberpostkarte für 20 Pfennig verkauft wurde. ${ }^{557}$ Außerdem wurden die Schulen aufgefordert, Sammlungen durchzuführen und den Erlös der ,Jugendspende“ zur Verfügung zu stellen. Insgesamt sind nur relativ wenige Schulen dem Appell gefolgt. Sie haben stattdessen in der Regel die Erlöse aus Sammlungen für Kriegsnagelungen verwendet oder Projekte in der eigenen Gemeinde mitfinanziert. Als Beispiel sei das Dorf Gadegast (Provinz Sachsen) genannt, wo offensichtlich mit der „Jugendspende 1917“ eine Gedächtnistafel zum Reformationsjubiläum finanziert worden ist. ${ }^{558}$

\section{,Jugenddank für Kriegsbeschädigte e. V.“659}

Auch die ebenfalls von Lehrern in Berlin 1916 gegründete Hilfsorganisation „Jugenddank“, der gegen Ende des Krieges über 4.000 Schulen und Jugendvereine angehörten ${ }^{560}$, finanzierte sich zum großen Teil durch die Erlöse aus den Schildnagelungen sowie durch Veranstaltungen und Verkaufsaktionen, wie aus dem in allen Verbandszeitschriften der Lehrerverbände veröffentlichten Gründungsaufruf hervorgeht:

„Bis jetzt wurden $u$. a. die folgenden Veranstaltungen vorgeschlagen und zum Teil auch bereits mit Erfolg durchgeführt.

Begründung von Schülervereinigungen mit mäßigen laufenden Beiträgen.

Heranziehung bereits bestehender Schülervereinigungen.

Musikalische, turnerische und ähnliche Vorführungen.

Vorträge.

Verkauf von vervielfältigten Zeichnungen der Schüler (Ansichtspostkarten, Briefverschlussmarken).

Verkauf von Handfertigkeitsarbeiten oder Nadelarbeiten, die in der Schule angefertigt sind.

Verkauf der Ernten bei Schulen, die Gemüsebau usw. betreiben. “561

\footnotetext{
${ }^{556}$ Voos, Kriegswahrzeichen für jede Schule (1916), S. 496-499; die Provinzialregierung in Düsseldorf hatte es übernommen, die Sammlung allen anderen preußischen Regierungen zu empfehlen (Kammeier, Der Landkreis Lübbecke und der 1. Weltkrieg (1998), S. 324).

${ }^{557}$ Siehe: Erlass des Preußischen Schulministers vom 25. Mai 1917; abgedruckt in: Vertrieb einer Wohlfahrtskarte, Zentralblatt für die gesamte Unterrichtsverwaltung in Preußen, 1917, S. 67.

${ }^{558}$ Es heißt in der Geschichte der Gadegaster Kirche „Jugendspende 1917“; insofern könnte es sich auch um eine allgemeine „Jugendspende“ gehandelt haben, und nicht um eine Spende für den Essener Verein; siehe:

Grützbach/Meinhof, Die Geschichte der Kirche in Gadegast,http://www.seyda.de/Nachbarn\&Partner/ Gadegast/Geschichte.htm (03.09.2008).

${ }_{559}$ Siehe: Kapitel 7.2.2.

${ }^{560}$ Günther/Hildebrandt/Samuleit, Jugenddank-Kalender (1919), S. 3.

${ }^{561}$ Aufruf an alle deutschen Schulen, Hannoversche Schulzeitung. Organ des Provinzial-Lehrervereins, der Bezirks- und Pestalozzivereine der Provinz Hannover, des Lehrer-Brandversicherungsvereins für Hannover, Bremen und das Fürstentum Lippe., 1915, S. 326f.
} 
Im Folgenden sollen einige der größeren Aktionen beschrieben und hinsichtlich ihres Erfolgs beurteilt werden.

„Preisausschreiben zur Gewinnung von Jugenddankpostkarten“‘562

Im Jahre 1917 erging ein Aufruf an alle Schulleiter in Deutschland, in dem für die Beteiligung von Schülern und Schülerinnen an einem Preisausschreiben geworben wurde. Ziel der Aktion war es, gerade auch die kleinen Schulen für die Jugenddank-Idee zu gewinnen. „Von der schlichtesten Dorfschule bis zur großstädtischen höheren Lehranstalt im ganzen Reich“ sollten die Schüler und Schülerinnen ,wetteifernd gemeinsam ans Werk“ gehen und Postkartenentwürfe bis zum 15. Juni einreichen. In der Gestaltung waren die Schüler weitgehend frei; die Entwürfe sollten allerdings „mit der Kriegszeit und der Jugenddank-Idee im Zusammenhang stehen“. Die 60 besten der eingesandten Postkartenentwürfe sollten prämiert und vervielfältigt werden. ${ }^{563}$ Alle Schulen sollten später einen Bogen mit Bildern der ausgewählten Karten sowie 2 bis 3 Probekarten erhalten, um dann möglichst viele zu bestellen. Außerdem sollte jeder Sendung eine Anmeldepostkarte beiliegen. Der Wettbewerb wurde durch die preußischen Schulbehörden unterstützt, da durch die Aktion der Jugend Gelegenheit gegeben werde, ,ihre Dankesschuld gegen unsere tapferen Kämpfer auf dem Gebiet der Kriegsbeschädigtenfürsorge abzutragen ${ }^{6564}$.

In welchem Umfang sich Schulen an dem Wettbewerb beteiligt haben, ist nicht mehr genau feststellbar. Einerseits sind einige der preisgekrönten Ansichtskarten überliefert, so dass angenommen werden kann, dass die Beteiligung durchaus rege war, andererseits wird der Wettbewerb im Jahresbericht des Vereins vom 31. Januar 1918, mehr als 6 Monate nach Einsendeschluss, überhaupt nicht erwähnt. Recht detailliert werden dort vor allem die Einnahmen aus den Nagelungen (207.640 M.) ${ }^{565}$ und anderen Großveranstaltungen aufgeführt. ${ }^{566}$ Das ,Verschweigen' lässt den Schluss zu, dass der Wettbewerb ein finanzieller Misserfolg war.

Wie in Preußen wurden auch in den anderen deutschen Staaten Jugenddank-Organisationen gegründet, z. B. der „Sächsische Jugenddank“ am 11. Juni 1917, der unter dem Vorsitz des sächsischen Kultusministers stand. Die erforderlichen Gelder sollten durch „,Veranstaltungen

\footnotetext{
${ }^{562}$ LHASA Hannover, MD, Rep. C 20 I, Ib, Nr. 3448 Bd. 10; die, Vereinigung zur Bekämpfung des Schmutzes und Schundes in Wort und Bild' veranstaltete 1915 in Schulen einen ähnlichen Wettbewerb, dessen Erlös für Kriegshilfszwecke verwendet werden sollte. Die besten der 550 eingereichten Entwürfe wurden prämiert und gedruckt, in der Ausstellung ,Schule und Krieg' in Berlin gezeigt und verkauft (Kriegs-Ansichtspostkarten, Deutsches Philologen-Blatt 1915, S. 407).

563 „Zur Verteilung gelangen wenigstens 20 erste Preise von je 30 Mk., 20 zweite Preise von je 20 Mk., 20 dritte Preise von je $10 \mathrm{Mk}$. Die betreffenden Summen werden den Schulleitern nach den Sommerferien mit der Bitte zugestellt, dafür dem preisgekrönten Schüler einen seiner künstlerischen Weiterbildung dienenden Wunsch zu erfüllen.“ (LHASA Hannover, MD, Rep. C 20 I, Ib, Nr. 3448 Bd. 10).

${ }^{564}$ Preisausschreiben des Jugenddanks für Kriegsbeschädigte zur Gewinnung von Jugenddank-Postkarten, Amtliches Schulblatt für den Regierungsbezirk Hildesheim, 1918/19, S. 124.

${ }^{565}$ Siehe: Kapitel 7.2.2.

${ }^{566}$ Verein Jugenddank für Kriegsbeschädigte e.V., Kriegswahrzeichen (1918).
} 
der Jugend, wie musikalische, schauspielerische, turnerische Vorträge, Verkauf von selbstgefertigten Zeichnungen und Arbeiten, gezogenen Pflanzen, Ernteerzeugnissen, gesammelten Früchten u. dergl.“" ${ }^{567}$ aufgebracht werden.

Innerhalb des Vereins schlossen sich der „Sächsische Heimatschutz“, die sächsischen Zeichenlehrervereine sowie der „Landesverband zur Förderung der Knabenhandarbeit“ zu einem „Landesausschuß für werktätige Jugenddankarbeit“ zusammen. Dieser erarbeitete eine Reihe von Anregungen und recht konkrete Vorschläge, um den Schulen bei der Herstellung und dem Verkauf von selbstgefertigten Objekten zu helfen. ${ }^{568}$ Zudem stellten sie den einzelnen Schulen Musterarbeiten zur Verfügung und größere Verbände konnten „Muster oder Wanderausstellungen“ anfordern. Vorgeschlagen wurden Papier- und Papparbeiten (Weihnachtssterne, Stundenpläne, Notiztafeln, Abrisskalender, Spiele, Glückwunschkarten, Buchhüllen, verschiedene Sammelmappen, Lesezeichen), Schattentheater, Schmucklaternen, diverse Kästen, Kaleidoskope, Laternen, Stempel, Papier- und Silhouettenschmuck, Linoldrucke, Briefverschlussmarken, Messer und Scherenschnitte, Schmuckfriese, Schreibwerkzeuge, Wandsprüche, Monogramme, Freundschaftsblätter, Brotschneidebrettchen, Schlüsselhalter, Bürstenbretter, Nadelkissen, Rahmen, Brieföffner, Federhalterschalen, Postkartenständer, Brettspielzeug“, Puppenmöbel, Flechtarbeiten u. v. a.

Als Beispiel dafür, dass die Anregungen auch aufgegriffen wurden, sei auf einen Bericht eines Obertertianers der Dreikönigsschule in Dresden hingewiesen:

„Unser Zeichenlehrer brachte mich nun auf den Gedanken, Elefanten zum Verkauf für den ,Jugenddank' zu bauen. Glücklicherweise erlaubten dies meine Eltern, und ich tat mich mit einigen Schulkameraden zusammen, um nach meinen Modellen Elefanten zu bauen. In der kurzen Zeit von einer Woche verfertigten wir 27 Elefanten, die schon einige Abnehmer gefunden haben. Wir freuten uns, daß wir dem Vaterlande auch ein wenig helfen dürfen, zwar mit bescheidenen Mitteln, aber - viel Wenig machen ein Viel.“ ${ }^{569}$

Dem Bericht waren eine von dem Schüler angefertigte Zeichnung und eine Bastelanleitung des Lehrers beigefügt.

Auf einer „Tagung für Jugenddank-Arbeit“ am 27./28. September 1917 in Dresden wurde Bilanz gezogen und man kam zu einem insgesamt ernüchternden Ergebnis. In einem Tagungsbericht heißt es:

„Die Hochforderungen aber ließen sich nicht immer restlos in eine schlackenfreie Tat umsetzen. Person, Ort, äußere Mittel und störender Zufall werden immer gewisse Hemmungen bringen. [...] Die scharfe Kritik mag bei Darbietungen und Werkarbeiten Erwachsener, die sich an die Öffent-

\footnotetext{
${ }^{567}$ Günther/Hildebrandt/Samuleit (Hrsg.), Jugenddank-Kalender (1919), S. 33f.

${ }^{568}$ Hildebrand, Jugenddank-Arbeit, Die Arbeitsschule, 1918, S. 33.

${ }^{569}$ Hildebrand, Jugenddank-Arbeit, Die Arbeitsschule, 1918; siehe: Anhang, Seite 53.
} 
lichkeit wagen, einsetzen, nicht aber bei Schülerleistungen, die selbstverständlich nur Entwicklungsleistungen sein können. ${ }^{\text {‘570 }}$

Konkreter wird der Leipziger Schulleiter F. Hildebrand. Er ist zwar vom „,erzieherischen Wert der Jugenddankveranstaltungen“ überzeugt, kritisiert aber, dass die Verkaufsaktionen zu kommerziell seien. „Wenn das kaufmännische Motiv vielfach zu stark betont wird, so sind die Ursachen dafür naheliegend. Entsteht in großen Städten mit vielen Schulen ganz von selbst ein Wettbewerb, so wird dieser durch die Veröffentlichung der rechnerischen Ergebnisse noch verschärft und auf falsche Bahnen gelenkt. “571 Seiner Meinung wurde auf den entsprechenden Messen zu viel „Plunder und Kitsch“ vertrieben, was die „mühsam errungenen Erziehungserfolge vernichten“"würde.

Sieht man von der Kritik an der Qualität der verkauften Werkstücke ab, so wird aber deutlich, dass die Verkaufsaktionen in wirtschaftlicher Hinsicht insgesamt ein großer Erfolg waren. ${ }^{572}$ Im folgenden Abschnitt soll näher auf eine solche Verkaufsmesse eingegangen werden.

„Handfertigkeits-Ausstellung der Lübecker Stadt- und Landschulen im Dezember 1917“573

Im Frühjahr 1917 bildete sich in Lübeck ein Arbeitsausschuss aus Handarbeitslehrern und Handarbeitslehrerinnen sowie zwei Mitgliedern des allgemeinen Jugenddankausschusses, der die Schulen aufforderte, sich an einer Messe zu beteiligen, auf der von Schülern hergestellte Produkte verkauft werden sollten. Die Aktion, die fünf Tage dauerte und in den Räumen der Oberrealschule am Dom stattfand, wurde durch die Schulbehörde unterstützt und von der Öffentlichkeit gut angenommen. So wurden 14.000 Eintrittskarten, die gleichzeitig zur Teilnahme an einer Verlosung berechtigten, verkauft. Die 5.400 angebotenen Gegenstände verkauften sich so gut, dass am Mittag des dritten Tages der Verkauf vorzeitig beendet werden musste, da man die 600 Produkte, die noch übrig waren, als Preise für die Verlosung benötigte. Der Gewinn der Aktion betrug nach Abzug der Kosten 9.700 Mark.

Auch wenn über andere ähnliche Aktionen, die es in vielen Städten gegeben hat, nicht so detailliert berichtet worden ist, ist davon auszugehen, dass Verkaufsmessen für den ,Jugenddank“ neben den Nagelungen eine besonders wichtige Einnahmequelle waren.

\section{Jugenddank-Kalender}

\footnotetext{
${ }^{570}$ Stiehler, Tagung für Jugenddankarbeit Dresden 1918, 27. und 28. September, in: Die Arbeitsschule, 1918, S. $201 \mathrm{f}$.

${ }^{571}$ Hildebrand, Jugenddank und Erziehung, Die Arbeitsschule, 1918, S. 177.

572 „So stellte z. B. in der bei der Dresdner Jugenddanktagung bekanntgegebenen Statistik eine sächsische Großstadt durch eine bei einer Weihnachtsmesse erzielte Summe alle ihre Schwestern in den Schatten." (Hildebrand, Jugenddank und Erziehung, Die Arbeitsschule 1918, S.177).

${ }^{573}$ Beilage I zum Jahresbericht des Jugenddanks für Kriegsbeschädigte 1918 (Jugenddank für Kriegsbeschädigte e.V., Jahresberichte 1917 und 1918 (1917 und 1918)). Offensichtlich wegen des großen Erfolgs der Aktion wurde der recht ausführliche Bericht des Vereins auch in Lehrerzeitschriften abgedruckt, um zur Nachahmung aufzurufen, z. B. in Jugenddank für Kriegsbeschädigte e.V. 1917.
} 
Der von zwei Schulleitern und einer Lehrerin im Auftrag des „Jugenddanks“ herausgegebene Taschenkalender (gebunden, 124 Seiten) diente weniger der Geldbeschaffung für den Verein als vielmehr der patriotischen Erziehung der Schüler. Das Vorwort ${ }^{574}$ sowie Artikel wie „Die Technik im Dienste des Krieges“, „Die Leistungen unserer Schüler im Kriege“, „Von der Kriegsarbeit der Mädchenschulen“, „Zum Tode eines Fliegers“, „Russenschlacht“, „Im Schützengraben“ und „Der Krieg und die Kinder“ zeigen die Zielsetzung eindeutig. ${ }^{575}$ Mit dem Kauf des Kalenders erhielt der Schüler ein „Jugenddank-Notizbuch“, in das er u. a. die „Ersparnisse zu Gunsten des Jugenddanks“ eintragen sollte.

Inwieweit mit dem Kalender ein Gewinn erwirtschaftet werden konnte und ob es auch nach 1919 noch weitere Ausgaben gab, konnte nicht ermittelt werden. Da jedoch die Publikation in keiner einzigen Schulchronik erwähnt wird und auch in den Lehrerzeitschriften nicht für sie geworben worden ist, war der Jugenddank-Kalender offensichtlich nicht sehr weit verbreitet.

\subsection{Aktionen von allgemeinen Wohlfahrtsverbänden und einzelnen Schulen}

\section{Rotes Kreuz u. a.}

Da Verkaufsaktionen der Wohlfahrtsverbände, an denen Schulkinder beteiligt waren, häufig mit Sammlungen, die bereits im 2. Kapitel ausführlich untersucht worden sind, verbunden waren, ${ }^{576}$ soll hier nur sehr knapp darauf eingegangen werden. ${ }^{577}$

Recht groß angelegt war z. B. eine Aktion des Zentralen Roten Kreuzes, die bereits im Herbst 1914 ins Leben gerufen wurde. Schüler sollten sog. „Kreuz-Pfennig-Marken“ zum Preis von 5 oder 10 Pfennig verkaufen. Der preußische Unterrichtsminister genehmigte den Verkauf zwar, allerdings mit Bedenken und unter bestimmten Auflagen. So sollten in jeder Klasse lediglich einem einzigen Schüler, und zwar ausschließlich unter Aufsicht des Schulleiters oder des Klassenlehrers, der Verkauf der Marken gestatten werden. Außerdem sei „unter allen Umständen bei dem Verkauf der Marken alles fern zu halten, wodurch etwa die vollständige

\footnotetext{
${ }^{574}$ Dort heißt es u.a.: „Denkt daran, Ihr deutschen Jungen und Mädchen, dass sie (Anm.: die Soldaten) ihre Gesundheit für Euch zum Opfer gebracht haben und vergeßt niemals, dass Ihr ihnen unauslöschlichen Dank schuldet.[...] Was auch kommen mag - für die Opfer dieses Krieges zu sorgen, wird vornehmste Aufgabe sein und bleiben“. (Günther/Hildebrandt/Samuleit (Hrsg.), Jugenddank-Kalender [1919], S. 3).

575 Die genannten Artikel sind im Jugenddank-Kalender 1919 abgedruckt. Das Manuskript war vor dem Ende des Krieges fertig gestellt, der Kalender wurde hingegen erst im Januar 1919 ausgeliefert; siehe: Günther/Hildebrandt/Samuleit (Hrsg.), Jugenddank-Kalender (1919).

576 Siehe: Kapitel 2.

577 So erinnerte sich Hans Wendt (*1903)): „Ich machte mit Begeisterung bei Rote-Kreuz-Sammlungen für die Verwundeten mit. Wir verkauften Papiermargueriten.“ (Pörtner, Kindheit im Kaiserreich [1990], S. 197).
} 
Freiwilligkeit der Beteiligung von Schülern und Schülerinnen in Frage gestellt werden könn-

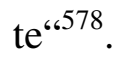

Da der Verkauf der Marken eine der ersten Verkaufsaktionen war, dürften sich angesichts der allgemeinen Kriegsbegeisterung viele Schulen beteiligt haben. $\mathrm{Zu}$ ihnen gehörte z. B. die Oberrealschule in Bad Oldesloe (Provinz Schleswig-Holstein), an der bis zum Ende des Schuljahrs 1914/15 durch den „Verkauf von Kriegspfennigmarken für das Rote Kreuz eine Einnahme von 50 Mark $^{\text {“579 }}$ erzielt wurde. Neben den „Kreuzpfennigmarken“ verkauften Schüler auch „Kriegsmarken“, die der Verein ,Deutschtum im Ausland' ausgegeben hatte; der Erlös kam ebenfalls dem Roten Kreuz zugute. ${ }^{580}$

Als zweites Beispiel für eine große Verkaufsaktion sei eine Aktivität des „Hilfsvereins deutscher Frauen“ genannt, die reichsweit einen Reinerlös von 60.000 Mark erbrachte. Beteiligt waren eine Reihe von Schulen, wie z. B. die kleine Dorfschule in Fiestel (Provinz Westfalen). Unter Leitung ihres Lehrers verkauften die Schüler 1915 fünfzig sogenannte „Kriegs- und Ruhmesblätter, und zwar sogar in den Ferien. Die besonders erfolgreichen Kinder erhielten als Auszeichnung eine Ehrennadel “581.

Die 1915 gegründete „Ostpreußenhilfe“ zum Wiederaufbau Ostpreußens finanzierte sich durch Spenden und den Verkauf von Ansichtskarten. Schüler wurden sowohl als Käufer als auch für den Verkauf eingesetzt. Offensichtlich wurden an einigen Schulen die Schüler zum Kauf der Karten genötigt, wie aus den Erinnerungen eines Zeitzeugen hervorgeht: „Nach dem Festakt (Siegesfeier) musste jeder Schüler eine sogenannte Tannenbergkarte kaufen, deren Erlös vaterländischen Zwecken zufloß. “582

Es gab zwar noch viele andere Organisationen, die in den Schulen ihre Produkte verkauften bzw. sie durch Schüler verkaufen ließen ${ }^{583}$, da ihre Bemühungen im Vergleich mit anderen Aktionen, z. B. denen der „Jugendspende für Kriegerwaisen“, den Schulbetrieb nur wenig beeinflussten, sollen die Aktionen nicht weiter thematisiert werden.

\footnotetext{
578 „Kreuz-Pfennig"-Marken, Amtliches Schulblatt für den Regierungsbezirk Hildesheim, 1914, S. 189; wie andere Regierungen auch so hatte die Regierung des Herzogtums Braunschweig den Verkauf genehmigt und die Schulleiter angewiesen, ,für die Anbringung eines Plakates über die Verbreitung der ,Kreuz-Pfennig-Marken’ zur Beschaffung von Mitteln für die Krankenhauspflege an geeigneter Stelle Sorge zu tragen.“ Es wurde auch auf die Freiwilligkeit für die Schulkinder beim Vertrieb hingewiesen, die „völlig und strengstens gewahrt“ sein müsse. (Rundschau, Schulblatt für die Herzogtümer Braunschweig und Anhalt, Jg.29, 1916, S. 144-148.)

${ }^{579}$ Vergleicht man den Betrag mit der Kaiserspende der Schüler (1915), die 300 Mark betrug, so war der aus dem Verkauf der Marken erzielte Gewinn doch recht gering.

${ }^{580}$ Bockmann, Unsere Liebestätigkeit seit Kriegsbeginn (Wiesbaden), in: Die Lehrerin: Organ des Allgemeinen Deutschen Lehrerinnenvereins 1915, S. 319f..

${ }^{581}$ Siehe: Kammeier, Der Landkreis Lübbecke und der 1. Weltkrieg (1998), S. 195.

${ }^{582}$ Franke, 3. Die Kriegsgeneration, S. 252.

583 „Vaterslandsdank“, „Heimatdank“, „Kaiser-Wilhelms-Dank“, „König Wilhelm-Stiftung“ „KolonialKriegerdank“ und „Deutscher Frauendank“ u.a.
} 


\section{Initiativen der einzelnen Schulen}

Die meisten Schulen verkauften Produkte, die sie selbst hergestellt (Postkarten, Spielzeug und andere Werkstücke), gesammelt (z. B. Altpapier) oder angebaut (Gemüse, Obst u. a.) hatten. Da auf die ,Kriegsgärten ${ }^{, 584}$ und die ,Sammlungen, ${ }^{585}$ an anderer Stelle eingegangen worden ist bzw. werden wird und auch im Werk- und Handarbeitsunterricht hergestellte Verkaufsprodukte bereits oben thematisiert wurden ${ }^{586}$, wird in diesem Abschnitt ausschließlich der Verkauf von selbst gestalteten Ansichtskarten analysiert. ${ }^{587}$

Beispielhaft sei auf das Städtische Lyzeum in Berlin-Schöneberg (Fontaneschule) hingewiesen, dessen Jahresbericht 1914/15 als Anhang auf sieben Seiten farbige Postkartenmotive enthält. Sie zeigen Karten, die die Schülerinnen der Oberstufe im Zeichenunterricht hergestellt und verkauft haben. ${ }^{588}$

Mit dem Erlös wollte man vor allem Wolle für Strümpfe kaufen und die fertigen Strickwaren den Soldaten an der Front schicken. Der Direktor der Schule unterstützte das Projekt und ließ die Kriegspostkarten durch eine Kunstanstalt vervielfältigen. Jeweils drei Karten wurden für 25 Pfennig verkauft. Zunächst wurden 8.000 Karten hergestellt, die einen Reingewinn von 560 Mark ergaben. „Am ersten Tag, als die Karten erschienen, wurden sofort die ersten 1.000 abgesetzt. “589 $\mathrm{Ob}$ es eine weitere Auflage gegeben hat, ist nicht bekannt. Der Verkaufserfolg hing sicher damit zusammen, dass es Ende 1914 noch nicht so viele Sammel- und Verkaufsaktionen gab und die Bereitschaft, den Soldaten zu helfen, im ersten Kriegswinter besonders groß war. Hinzu kam, dass die Karten künstlerisch recht gut gelungen waren, wie beispielsweise die drei in den Anhang aufgenommenen Bilder zeigen. ${ }^{590}$ Kriegspostkarten sind auch aus vielen anderen Schulen überliefert. Zwar gibt es in der Regel keine Informationen über die Auflagenhöhe und den erzielten Gewinn, sie dürften sich aber ebenfalls gut verkauft haben, denn sonst wären nicht so viele Schulen dem durch eine große Lehrerzeitschrift („Die Lehrerin“) bekannt gemachten Beispiel der Fontaneschule gefolgt.

Im Anhang sind neben den oben genannten Karten Beispiele aus weiteren Schulen zu sehen, und zwar aus der Luisenschule in Düsseldorf, dem Lyzeum in Berlin-Pankow, dem

\footnotetext{
${ }^{584}$ Siehe: Kapitel 4.2.

585 Siehe: Kapitel 2.

${ }^{586}$ Siehe: 3.2. Konkret sei außerdem auf die Marie-Curie-Oberschule in Berlin-Wilmersdorf hingewiesen, wo neben Kriegspostkarten auch „Kriegsgedichte, Liederbücher, Kriegskochbücher“ u.a. vertrieben wurden. (Wildhagen, „Laß dich gelüsten nach der Männer Bildung ..." [1994], S. 122).

${ }^{587} \mathrm{Zu}$ selbst gestaltete Ansichtskarten, die anlässlich von Nagelungen verkauft wurden, siehe: Anhang, Seiten 54-56.

${ }^{588}$ Siehe: Wildhagen, „Laß dich gelüsten nach der Männer Bildung (1994), S. 120f.

${ }^{589}$ Kriegshilfe einer deutschen Mädchenschule, Die Lehrerin: Organ des Allgemeinen Deutschen Lehrerinnenvereins 1914, S. 262.

${ }^{590}$ Siehe: Anhang, Seite 55.
} 
Privatgymnasium zu Eberswalde (Provinz Brandenburg) ${ }^{591}$, dem Heinrich Hertz Realgymnasium in Hamburg ${ }^{592}$, der Königin-Luisen-Schule ${ }^{593}$ in Charlottenburg und Berliner Gemeindeschulen. ${ }^{594}$

Häufig kam es auch vor, dass junge Mädchen Blumen pflückten und sie verkauften, wie z. B. 1916 Schülerinnen vom Viktoria-Luise-Gymnasium in Hameln (Provinz Hannover): „Am 1. Oktober Opfertag für die Marine, die Mädchen liefen in blauen Schifferblusen auf den Straßen umher und verkauften Blumensträuße und anderes. “595

\subsection{Kriegsanleihen}

\subsubsection{Ablauf und Ergebnisse}

Bei Kriegsbeginn war das Deutsche Reich auch in finanzieller Hinsicht nicht auf einen langen Krieg vorbereitet, sondern stand vor der äußerst schwierigen Aufgabe, einen modernen Krieg fast ganz ohne wirtschaftliche Hilfe von Außen durchzustehen. Hinzu kam, dass die Reichsschuld, vor allem wegen der Flottenausrüstung um die Jahrhundertwende, 4,8 Milliarden Mark betrug und 26\% des ordentlichen Staatshaushaltes zur Schuldentilgung benötigt wurden. Der im Spandauer Juliusturm aufbewahrte Reichskriegsschatz, der einst auf Anregung Bismarcks gebildet worden war, betrug lediglich 205 Millionen Reichsmark; diese Summe reichte gerade, um zwei durchschnittliche Kriegstage zu finanzieren. ${ }^{596}$ Die politische Führung stand vor der Frage, ob sie die Steuern erhöhen oder Kredite aufnehmen sollte ${ }^{597}$, und entschied sich, Kriegsanleihen aufzulegen. Dass man sich für die Anleihefinanzierung und gegen Steuererhöhung entschied, entsprach dem liberalen Wirtschaftsgeist der Epoche vor Kriegsbeginn. ${ }^{598}$ Man befürchtete, dass neue Steuern nur schwer durchsetzbar waren und nur langsam griffen. Zudem befürchtete man, den innenpolitischen „Burgfrieden“ mit den Sozialdemokraten und ihrer großen Wählerschaft dadurch zu gefährden, dass neue Steuern auch die

\footnotetext{
${ }^{591}$ Siehe: Anhang, Seite 56, Bilder 1-3.

${ }^{592}$ Siehe: Anhang, Seite 89, Bild 6. Überliefert ist auch eine Karte (zum Besten des Roten Kreuzes und der Kriegsfürsorge), für die der Schüler Bertolt Brecht unter dem Pseudonym ,Bertold Eugen' im Herbst 1914 das folgende Gedicht geschrieben hat: „Kriegsfürsorge/Gar viele Tausend zogen hinaus/ Für’s Vaterland sie starben/ Und ließen Weib und Kind zu Haus,/ Die müssten jetzt darben/ Die müssten hungern, wenn Dir nicht/ Mein Volk, die Dankbarkeit nun Ehrenpflicht./ Zu teilen heißt es jetzt sein Hab und Gut/ Mit denen deren Nährer mit dem Schwert/ In Fäusten ließen stolz für Dich ihr Blut./ Jetzt zeige Dich, mein Volk,der Opfer wert.“ (Frisch/Obermeier, Brecht in Ausgburg (1986)).

${ }^{593}$ Siehe: Anhang, 56, Bild 1.

${ }^{594}$ Lemm, Schulgeschichte in Berlin (1987).

595 Schulchronik „Die Schule im Ersten Weltkrieg 1914 - 1918", http://www.vikilu.de/vikilu/index.php?id=61 (06.03.2009).

${ }^{596}$ Zur Kriegsfinanzierung siehe: Zeidler, Die deutsche Kriegsfinanzierung 1914 bis 1918 (1994), S. 423.

597 Auf andere Maßnahmen, wie z. B. die Einrichtung von Darlehenskassen, denen man das Recht übertrug, Darlehenskassenscheine zu verausgaben, wird nicht eingegangen.

${ }^{598}$ Beispielsweise hatte der Bonner Nationalökonom Gottlob Heinrich Dietzel in eines 1912 erschienen Studie „Kriegssteuer oder Kriegsanleihe“ vor Erhöhung der Steuern gewarnt („Hände weg von der Steuerschraube!); zitiert nach: Zeidler, Die deutsche Kriegsfinanzierung 1914 bis 1918 (1994), S. 423.
} 
gering verdienenden Bevölkerungsschichten belasteten. Durch Anleihen hingegen schöpft man nur die verfügbare Kaufkraft ab, und zwar in erster Linie des insgesamt patriotisch gesinnten Bürgertums. Man ging davon aus, dass es gelingen würde, dieses für die nationalen Ziele mobilisieren zu können, zumal man das finanzielle Engagement mit einer recht hohen Rendite belohnen wollte ${ }^{599}$. Für die Anleihefinanzierung sprach auch, dass man durch eine langfristige Tilgung die Abzahlung der Kriegskosten in die Zeit nach dem Krieg verlegen und die Finanzlast der nächsten Generation übertragen konnte. ${ }^{600}$

Da bereits die erste Mobilmachungswoche mit etwa 750 Millionen und für den ersten Monat 2,25 Milliarden Mark veranschlagt waren, die der Staat vorfinanzieren musste, war er darauf angewiesen, dass die erste Kriegsanleihe (10. bis 19. September 1914) möglichst erfolgreich war. Um das zu erreichen, war die Zinsofferte von $5 \%$ für die damalige Zeit recht hoch; außerdem wurde mit großem organisatorischen und propagandistischen Aufwand für die Anleihe geworben.

Entgegen der Meinung vieler Skeptiker wurde die 1. Anleihe trotz der kurzen Zeichnungsfrist mit einem Erlös von ca. 4,5 Milliarden bei 1.177.235 Einzelzeichnungen ein großer Erfolg. ${ }^{601}$ Die Mindesteinlage betrug 100 Mark $^{602}$ und sicher war auch das ein Grund dafür, dass man die Schulen in die Aktion nicht mit einbezogen hatte. Im März 1915 folgte dann die 2. Kriegsanleihe. Offensichtlich auf Anregung der Vossischen Zeitung vom 10. März 1915 „wurde auch die Schule für die Kriegsanleihe mobil gemacht“, wie es ein Berliner Schulleiter formulierte, allerdings erst acht Tage vor Ablauf der Zeichnungsfrist. ${ }^{603}$ Trotzdem waren die Schulanleihen durchaus erfolgreich. So ist von 60 Berliner Schulen bekannt, dass sie Anleihen in einer Höhe von 1.184.475 Mark zeichneten, wie aus einer Übersicht (Liste 1) des Lehrers Masche aus Berlin-Pankow hervorgeht. ${ }^{604}$ Obwohl das Ergebnis der gemeinsamen Zeich-

\footnotetext{
${ }^{599}$ Kriegs- und Schatzanleihen wurden mit $5 \%$ verzinst, Schatzanweisungen mit $4,5 \%$.

${ }^{600}$ Es wurde damit geworben, dass die Rückzahlung nach dem - gewonnenen - Krieg durch von den Kriegsgegnern zu zahlende Reparationen gesichert sei. Ein Beispiel aus einer Essener Schule zeigt, dass auch die Schüler damit zur Zeichnung bewegt werden bzw. mit dem Argument werben sollten: „Man soll dem Aberglauben entgegentreten, dass unsere Gegner zur Zahlung einer Entschädigung kein Geld haben. Es wird gut sein, wenn solche Gedankengänge in der Schule, vor allem in den oberen Klassen, hier und da hervortreten. Sie sind für unsere zukünftigen Bürger zumindest so wichtig wie die Erklärung der Kriegslage." (Kuckhoff, Die dritte Kriegsanleihe und die Schule, Deutsches Philologen-Blatt 1915, S.520f.

${ }^{601}$ Siehe: Anhang, Seite 17.

${ }^{602} \mathrm{Ab}$ der 2. Anleihe konnte jeder Betrag zwischen 20 und 100 Mark gezeichnet werden und ab der 6. Anleihe war es möglich, in den Sparkassen, Schulen und durch Vertrauensleute „Kriegssparkarten“ zu 2, 3 oder 10 Mark oder „Anteilscheine“ zu 5, 10, 20 oder 50 Mark zu erwerben.

${ }^{603}$ Lier, III. Kriegsanleihe, Deutsches Philologen-Blatt 1915, S. 328.

604 Masche, Die Schul Kriegs-Anleihe, Deutsches Philologen-Blatt 1915, S. 211f. Masche aus Berlin-Pankow führte die Statistik der höheren Lehranstalten, der Mittelschulen und der Lehrer- und Lehrerinnenbildunganstalten im Auftrage der Reichsbank.
} 
nung $^{605}$ weitgehend auf große Akzeptanz stieß, wurde es vom ,Berliner Tageblatt', dem ,Vorwärts' und dem ,Reichsboten’ als „pädagogischer Missgriff“ heftig kritisiert. ${ }^{606}$ Eine zweite Liste enthielt noch einmal 23 Schulen aus allen Teilen Preußens mit insgesamt 773.050 Mark. ${ }^{607}$ Berücksichtigt man, dass sich an dieser Anleihe ausschließlich höhere Schulen beteiligten und Prof. Masche sicher bei Weitem nicht alle beteiligten Schulen erfasst hatte, so war das Ergebnis der Schulzeichnungen überraschend gut und führte dazu, dass für die 3. Anleihe (September 1915) gerade auch in den Schulen massiv geworben wurde. Welchen Anteil die Schulen an dem erstaunlich guten Gesamterlös dieser Anleihe (11.980 Millionen) hatte, lässt sich allerdings nicht errechnen.

Die 3. Anleihe wurde von allen großen Lehrerverbänden unterstützt. Vor allem in den Verbandspublikationen wurde massiv für die Teilnahme geworben, indem man Aufrufe abdruckte, über positive Erfahrungen berichtete und praktische Vorschläge zur Organisation machte. So erschienen zum Beispiel 1915 im ,Deutschen Philologen-Blatt' etwa zwanzig entsprechende Berichte. Für die zunehmend hohe Beteiligung der Schulen war sicher auch eine Initiative des Lehrers Masche aus Berlin-Pankow entscheidend. Er schickte vor jeder Anleihe an alle höheren deutschen Schulen und Mittelschulen Listen und bat die für die Anleihe verantwortlichen Lehrer, die Zeichnungsergebnisse einzutragen und an ihn zurückzuschicken. ${ }^{608}$ Die Ergebnisse veröffentlichte er in sehr detaillierter Form fortlaufend in den Verbandszeitschriften. ${ }^{609}$ So liegen für die 3. bis 8 . Anleihe sehr genaue Informationen über die Ergebnisse der Schulanleihen von fast allen höheren Schulen und Mittelschulen vor. Im Folgenden soll beispielhaft auf die 3. Anleihe näher eingegangen werden. ${ }^{610}$ Insgesamt haben von 1928 Schulen

\footnotetext{
${ }^{605}$ Es gab für Schüler zwei Zeichnungsmöglichkeiten. Zum Einen konnten sie selbst für kleinere oder größere Geldbeträge bei den Sparkassen zeichnen. Von dieser Möglichkeit konnten allerdings lediglich die wohlhabenderen Schüler Gebrauch machen. Zum Anderen zogen die älteren Schüler durch die Dörfer, warben für die Kriegsanleihe und ließen Interessenten Zeichnungsscheine unterschreiben, die ihnen die Postverwaltung zur Verfügung stellte. Z-udem richtete man im Hinblick auf die 3. Anleihe ,Kriegssparkassen' ein, um den Ertrag noch zu steigern. Die Schüler verpflichteten sich zum Sparen eines bestimmten wöchentlichen Betrags (1 oder 2 Mark), welche der für die Schulanleihe zuständige Lehrer auf einer Bank bis zur Einbringung in die Kriegsanleihe zinsbringend deponierte; (siehe: Anhang, Seite 58, Bilder 2 und 3).

${ }^{606}$ Zitiert nach: Wegener, Das Joachimsthalsche Gymnasium - die Landesschule Templin (2007), S. 92. Es wurden hauptsächlich kritisiert, dass der Druck auf die Schüler und Schülerinnen, sich an der Aktion zu beteiligen, zu groß gewesen sein.

607 Masche, Die Schul-Kriegsanleihe, Deutsches Philologen-Blatt 1915, S. 265f.; in der Liste 3 (15 Schulen, 276.300 Mark) und 438 Schulen 769.483 Mark) wurden weitere aufgeführt, so dass Masche insgesamt 137 Schulen aufführte, die für 300.308 Mark Kriegsanleihen erworben haben. (Masche, Die Schul-Kriegsanleihe, Deutsches Philologen-Blatt 1915, S. 378; Masche, Die zweite Schulkriegsanleihe, Deutsches Philologen-Blatt 1915, S. 528).

${ }^{608}$ Nach eigenen Angaben verschickte Masche etwa 40.000 Listen.

${ }^{609}$ Siehe: Anhang, Seite $15 \mathrm{f}$.

${ }^{610}$ Die Angaben wurden entnommen: Masche, Statistik der Sammelzeichnungen der höheren und mittleren Schulen des Deutschen Reiches auf die dritte Kriegsanleihe, Hannoversche Schulzeitung. Organ der ProvinzialLehrervereins, der Bezirks- und Pestalozzivereine der Provinz Hannover, des Lehrer-Brandversicherungsvereins für Hannover, Bremen und das Fürstentum Lippe., 1916, S. 20.
} 
750.000 Schüler und Schülerinnen Anleihen in Höhe von 31,5 Millionen Mark gezeichnet, d. h. jeder Schüler im Schnitt für 128 Mark. ${ }^{611}$ In Masches Statistik wurden ausschließlich schulische ,Sammelzeichnungen' erfasst, d. h. Sammlungen, bei denen sich die Gesamtsumme von mehreren Zeichnern einer Schule aufgebracht wurde. Sie ermöglichten es, Anleihen mit einem Betrag von weniger als 100 Mark zu erwerben, was auf fast die Hälfte der Schüler zutraf. Reichsweit beteiligten sich 40 Prozent aller Schüler. An den Gymnasien und den Lyzeen hatten $44 \%$ der Schülerschaft gezeichnet ${ }^{612}$, an den Mittelschulen hingegen lediglich $28 \%$. Unterschiede gab es auch zwischen Knabenschulen (154 Mark pro Schüler im Schnitt) und Mädchenschulen (122 Mark). Insgesamt hatte sich etwa die Hälfte aller höheren Schulen beteiligt. Zu dem großen Erfolg hatte auch beigetragen, dass an vielen Schulen Schüler, die eifrig für die Zeichnung von Anleihen geworben hatten, ein oder zwei Tage schulfrei bekamen. Teilnehmende Schulen erhielten eine Urkunde, in der der Kaiser den Schülern seinen Dank aussprach ${ }^{613}$ :

„Des Kaisers Dank an die Schuljugend

Wie ich höre hat zu dem glänzenden Ergebnis der Zeichnungen auf die dritte Kriegsanleihe die Tätigkeit der Lehrer und Schüler in erfreulicher Weise beigetragen. In Würdigung des überraschend großen Erfolges wünsche ich der Schuljugend meinen Dank zum Ausdruck zu bringen und bestimme, dass in den Schulen der Monarchie am morgigen Tage der Unterricht ausfällt.

Berlin 24. Sept. Wilhelm I. R.“614

Sicher hat neben dem freien Tag auch die Verleihung der repräsentativ gestalteten Urkunde für die folgenden Kriegsanleihen weitere Schulen zur Zeichnung bewegt.

Setzt man den Anteil der Schuljugend (nur Sammelzeichnungen) zu dem Gesamtergebnis der 3. Kriegsanleihe in Relation, so ergibt sich folgendes Bild:

Gesamtbevölkerung: $\quad$ 12.030 Millionen Mark bei 3.996.418 Zeichnern

Schulzeichnungen: $\quad 31$ Millionen Mark bei 750.000 beteiligten Schülern.

Auch wenn die Schüler der höheren Schulen und der Mittelschulen damit lediglich 0,25\% der

Gesamtsumme aufbrachten, so war ein solches Ergebnis allgemein nicht erwartet worden.

\footnotetext{
${ }^{611}$ Deutlich höher lagen die Erlöse einzelner Schüler aus der Werbetätigkeit. Am erfolgreichsten war die Realschule in Neustadt (4. Anleihe), deren Schüler durchschnittlich 2.160 Mark einwarben; der höchste Einzelerlös betrug 25.200 Mark.(Ohmann, Zur Statistik der Werbetätigkeit der Schulen für die vierte Kriegsanleihe, Deutsches Philologen-Blatt 1916, S. 381f.

${ }^{612}$ Bei der 4. Anleihe waren es $67 \%$ und bei der 5. sogar 73\% (Siehe: Saul, Jugend im Schatten des Krieges [1983], S. 173, Anmerkung 168).

${ }^{613}$ Siehe: Anhang, Seite 6, Bild 1.

${ }^{614}$ Mit gleichem Wortlaut schickte er ein Telegramm an die Kultusminister und wies sie an, den unterrichtsfreien Tag zu verfügen. (Mitteilungen und Nachrichten, Deutsche Tageszeitung, 1915, S. 575f.); in Flensburg ist zusätzlich eine Schulfeier durchgeführt worden: „Der Kaiser hat beschlossen, daß die Schulkinder wegen ihrer großen Bemühungen um die 3. Kriegsanleihe eine Schulfeier und dann einen freien Tag haben sollten. [...] Wir haben bei der Schulfeier in meiner Klasse das Kaiserbild mit Rosen geschmückt, weil er den Kindern diese Freundlichkeit erwiesen hat." Diese Erinnerung eines Zeitzeugen ist abgedruckt in: Hohnsbehn, Die Flensburger Schuljugend in der Zeit des ersten Weltkriegs (1996), S. 251.
} 
Schließlich hatte jeder Schüler durchschnittlich etwa 48 Mark gezeichnet. In einigen Städten lag der Anteil der Schulen allerdings deutlich höher. In Münster z. B. zeichneten allein die schüler von zwei Schulen (städtisches Gymnasium mit Realgymnasium und katholisches Lyzeum mit Studienanstalt) für 198,500 Mark, während die Gesamthöhe in der Stadt bei 14.000.000 Mark lag $(=1,4 \%) .{ }^{615}$ Berücksichtigt man, dass Münster damals etwa 20 Schulen hatte, die sich alle an der Aktion beteiligen, so war der Anteil der Schulen an dem Gesamtergebnis doch recht bedeutsam. Setzt man ferner das Ergebnis der bei der (4.) Kriegsanleihe , mit 1.800.000 Mark erfolgreichsten Schule, der Oberrealschule in Gummersbach, zum Ergebnis von Münster in Beziehung, so hätten die Schüler einer einzigen Schule ca. $14 \%$ der in einer Stadt mit etwa 55.000 Einwohnern aufgebrachten Anleihesumme.

Hinzu kam, dass viele Schüler und Lehrer - besonders auf dem Lande - Erwachsene für die Zeichnung der Anleihen geworben hatten. Betrachtet man beispielhaft die bei der 4. Anleihe eingeworbenen Summen der erfolgreichsten Schulen, so wird deutlich, dass der Anteil der Schulen an Erlösen der Anleihen wesentlich größer war.

1. Oberrealschule Gummersbach (Rheinprovinz)

2. Bismarckschule Magdeburg (Provinz Sachsen)

3. Oberrealschule Heide (Provinz Schleswig-Holstein)

4. Gymnasium Rheinbach (Rheinprovinz)

5. Marien-Lyzeum München-Gladbach (Rheinprovinz)

\subsubsection{0 (407 Werber)}

$1.243 .000(421)$

$931.000(106)$

$745.000(97)$

$710.000(400)$

Die Gesamtwerbesumme betrug 45.012.400 Mark und war höher als die 3. Sammelanleihe der Schulen (31 Millionen) und damit nur etwas geringer als die 5. (54 Millionen). Ähnlich hoch waren die Erlöse bei den anderen Anleihen.

Für die 4. Anleihe war der Propagandaaufwand auch an den Schulen noch wesentlicher gröBer. So wurde z. B. in den Lehrerzeitschriften in ganzseitigen Anzeigen eindringlich dafür geworben $^{616}$, was sicher entscheidend zu dem noch größeren Erfolg beigetragen hat. Auch die Schulbehörden forderten die Schulen zur Teilnahme nachdrücklich auf, wie u. a. aus einer Verfügung der Oberschulbehörde an alle Hamburger Schulen hervorgeht:

ist mit allen Mitteln dahin zu streben, dass der für die Reichsfinanzen unbedingt notwendige Erfolg der neuen Anleihe erreicht wird. Dies ist nicht nur aus finanziellen Gründen, sondern auch aus politischen Erwägungen unbedingt geboten, weil unsere Gegner ein geringeres Ergebnis der Anleihe als ein Zeichen der Schwäche betrachten und dadurch von neuem in der Hoffnung sich gestärkt fühlen würden, durch Hinhalten des Krieges unsere Kräfte weiter aufzureiben und uns dadurch zu jedem Frieden gefügig zu machen. Dagegen wird ein gutes Ergebnis der Ausleihe nicht verfehlen, eine entsprechende Wirkung auf unsere Feinde auszuüben und so zu einer

\footnotetext{
${ }^{615}$ Schulte, Kriegschronik der Stadt Münster 1914-18 (1930), S. 130.

${ }^{616}$ Siehe: Anhang, Seite 57.
} 
früheren siegreichen Beendigung des Krieges beizutragen. Die Werbearbeit muß dieses Mal in die weitesten Volkskreise hineingetragen werden. “617

916.000 Schüler (53\% der Schüler) ${ }^{618}$ zeichneten Anleihen in Höhe von 53 Millionen und bekamen als Anerkennung für den Erfolg, wie bei den späteren Anleihen auch, jeweils einen Tag schulfrei.

Die Anleihen 5 bis 8 erbrachten jeweils weitere Steigerungen:

5. Anleihe: 54 Millionen (54\% der Schüler waren beteiligt)

6. Anleihe: 72 Millionen (54\%)

7. Anleihe: 82 Millionen $(56 \%)^{620}$

8. Anleihe: 116 Millionen (52\%) $)^{621}$

Mit jeder neuen Kriegsanleihe intensivierten die Schulbehörden die Propagandamaßnahmen. Aus einer Übersicht des Provinzialschulkollegiums in Schleswig-Holstein, das über alle Aktivitäten genau Buch führte, geht z. B. hervor, dass für die 5. Anleihe insgesamt 671 Merkblätter, 252 Flugblätter und 48 der vorgefertigten Werbevorträge an die Schulen verschickt worden sind. ${ }^{622}$

Die 9. und letzte Schulkriegsanleihe (September 1918) ist von Masche statistisch nicht mehr erfasst worden. Es kann aber davon ausgegangen werden, dass die Schulen auch dieses Mal wieder recht erfolgreich waren ${ }^{623}$, denn es war erneut sehr massiv geworben worden. ${ }^{624}$ Insgesamt kamen über die schulischen Sammelzeichnungen (3. - 8.) Einnahmen in Höhe von 408 Millionen Mark zusammen. ${ }^{625}$ Sie erzielten damit ein Ergebnis, das niemand für möglich

\footnotetext{
${ }^{617}$ Kriegsanleihe und Schule, Deutsches Philologen-Blatt 1916, S. 175.

${ }^{618}$ Die Zahlen beziehen sich auf die Schulen, deren Sammelergebnisse Masche erfasst hat.

${ }^{619}$ Auch für die 6.Anleihe war in den Schulen wieder massiv geworben worden, was zu den gegenüber der 5. Anleihe deutlich gestiegenen Einnahmen führte. So waren z. B. in der Provinz Ostpreußen die Schulen durch einen Erlass vom 16. März 1917 zu verstärkten Anstrengungen aufgerufen worden: „Die Tätigkeit der Schulaufsichtsbeamten, Lehrer und Schulkinder brachte bei der dritten Kriegsanleihe nur etwa 600.000 Mark, bei der vierten mehr als das sechsfache, rund 4.100.000 Mark, bei der fünften rund 5.000.000 Mark! Wir vertrauen, daß Lehrer und Aufsichtsbeamte helfen werden, dieses Ergebnis der Schulwerbung des Bezirks weit zu übertreffen.“ (Sechste Kriegsanleihe, Amtliches Schulblatt für den Regierungsbezirk Königsberg, 1917, S. 32).

${ }^{620}$ Für die 7. Kriegsanleihe war nicht nur in den 4.400 höheren und mittleren Schulen geworben worden, sondern auch in 6.500 Volksschulen. Ohmann, Siebente Kriegsanleihe und Schule, Deutsches Philologen-Blatt 1918, S. 515.

${ }^{621}$ Saul beziffert die Höhe der von den Schulen gesammelten Kriegsanleihen auf 365 Millionen, wovon die Volksschulen 169 Millionen aufbracht haben

${ }^{622}$ LAS, Abt. 302, Nr.3034, 15. XII. 1916; siehe auch: Pust, „Vaterländische Erziehung" für „Höhere Mädchen" (2004), S. 381.

${ }^{623}$ Saul nennt für die beiden letzten Anleihen eine Höhe von 365 Millionen (Saul, Jugend im Schatten des Krieges (1983), S. 173, Fußnote 168).

${ }^{624}$ Die ,Zentrale für Kriegshilfe für Schule' verschickte ein Schreiben an die Schulen, das die Titel von 13 Formularen und Werbemitteln enthielt, die bestellt werden konnten. Darunter waren ,ein Merkblatt zur Schülerwerbearbeit“", Hinweise und Materialien zur Durchführung eines „Volksunterhaltungsabend(s) zur 9. Kriegsanleihe“, eine „Hindenburg-Denkmünze für Schulkriegshilfe“, eine „Ehrenurkunde zur Hindenburg-Denkmünze“ und ein „Postkartenheftchen ,Dem deutschen Volke', bestehend aus zehn Postkarten.“ (Ohmann, Zur Förderung der neunten Kriegsanleihe durch die Schulen, Deutsches Philologen-Blatt 1918, S. 292).
} 
gehalten hatte. Tatsächlich aber war der Erfolg der Schule noch wesentlich größer, denn aufgrund der intensiven Werbetätigkeit der Schüler und der Lehrer hatten viele Erwachsene Anleihen gezeichnet. ${ }^{626}$ Obwohl die wirtschaftliche Lage zunehmend schwieriger geworden war und auch die militärische Situation sich ständig verschlechtert hatte, war es der allgemeinen Propaganda und den Lehrern immer wieder gelungen, noch mehr Schüler für die Anleihen zu gewinnen. Die Schüler und Schülerinnen der höheren Schulen kamen damit in besonderem Maße im Rahmen der „Heimatfront“ ihrer „finanziellen Wehrpflicht“ nach, wie es Reichsstaatssekretär Karl Helfferich gefordert hatte. Das Beispiel eines Magdeburger Gymnasiums zeigt z. B., wie motiviert und entschlossen die Schüler ihre Aufgabe wahrnahmen: „Schüler der Bismarckschule zogen zu Fuß, mit dem Rade, mit der Bahn bis ins Mansfeldische, in das Braunschweigerland, bis weit in die Altmark. “627

\subsubsection{Ursachen des Erfolgs}

Auf den großen propagandistischen und organisatorischen Aufwand als eine Ursache für den zunächst nicht erwarteten Erfolg der ersten Kriegsanleihen ist oben bereits hingewiesen worden. Als die Einnahmen in der 4. Anleihe insgesamt einbrachen ${ }^{628}$, verstärkten Regierung und Reichsschatzamt die Werbemaßnahmen und man beauftragte den bekannten Grafiker Lucian Bernard, wirkungsvolle Werbeplakate zu entwerfen. Er und dann auch andere Künstler schufen in der Folgezeit sehr viele Plakate mit einprägsamen kurzen Aussagen, bei denen weniger der finanztechnische Hintergrund als vielmehr die Zeichnung der Kriegsanleihen als Pflicht der „Heimatfront“ betont wurde. Die Werbeoffensive war sicher auch ein Grund für die hohen Ergebnisse der Kriegsanleihen 5 bis 9. ${ }^{629}$ Hinzu kam, dass es ab der 4. Kriegsanleihe möglich war, Sammelanleihen auch für weniger als 100 Mark zu zeichnen, und den Zeichnern versprochen wurde, dass ihnen der eingezahlte Betrag spätestens zwei Jahre nach Beendigung des Kriegs mit den Zinsen ausgezahlt werde.

\footnotetext{
${ }^{625}$ Die Zahl bezieht sich ausschließlich auf die Sammelzeichnungen, nicht auf die Werbetätigkeit der Schüler. Berücksichtigt man die Zahlen von Saul für die beiden letzten Sammlungen (365 Millionen), so errechnet sich eine Gesamtsumme von 573 Millionen.

${ }^{626}$ Auch die Zeichnungen der Lehrer der höheren Schulen, die sich im Rahmen des „Heimatdanks“ an den Anleihen beteiligt haben, sind nicht berücksichtigt worden. Die Organe der Stiftung „Heimatdank“, der

„Heimatdank in Sachsen“ und der „Badische Heimatdank“, die die Aufgaben der „Nationalstiftung für die Hinterbliebenen der Kriege Gefallenen“ nach deren Regeln übernahmen, gewährten den Kriegsinvaliden und den hilfsbedürftigen Hinterbliebenen der gefallenen Soldaten Rat und Hilfe.

${ }^{627}$ Ohmann, Zur Statistik der Werbetätigkeit der Schulen für die vierte Kriegsanleihe 1916, S. 384.

${ }^{628}$ Das trifft allerdings nicht auf die Schulanleihen zu.

${ }^{629}$ Siehe: Martens, Heimatbild und Feindbild, Geschichte Lernen, 2006, S. 22; dort sind Bilder der 6. und der 8. Anleihe abgegedruckt.
} 
Auch der Schule kam bei der Werbung eine besondere Bedeutung zu. Da die Lehrer überwiegend monarchisch gesonnen waren, konnten sie leicht als Werber gewonnen werden. Ihre Aufgabe war es vor allem, das Misstrauen der ländlichen Bevölkerung gegenüber den Anlagen zu überwinden und sie zum Zeichnen der Anleihen zu bewegen. Immer wieder wurden sie von den Schulbehörden und den eigenen Standesorganisationen dazu aufgefordert, wie z. B. im September 1917 durch den ,Deutschen Lehrerverein' und den ,Katholischen Lehrerverband':

„Und diesmal kommt viel darauf an, daß der unvergleichliche, weitreichende Einfluß der Schulen [...] zur vollen Wirkung kommt. [...] Um den Milliardensieg so glänzend wie möglich zu gestalten, darf sich die Schule nicht auf die bisherige Aufklärungs- und Sammelarbeit beschränken, sondern muß darüber hinaus bemüht sein, in der Jugend und durch die Jugend in die breitesten Schichten unseres Volkes für die neue Kriegsanleihe Stimmung zu machen. “630

Am Beispiel eines Dorfschullehrers aus Getmold im Landkreis Lübbecke (Provinz Westfalen) soll aufgezeigt werden, mit welch großem Engagement die Lehrer die Aufgabe wahrnahmen. Seine Aktivitäten hat er in der Schulchronik festgehalten. ${ }^{631}$ So gab er z. B. im Zusammenhang mit der 6. Kriegsanleihe 1917 jedem Kind einer 2. Klasse den folgenden Text mit:

„Lieber Vater (Mutter) ...

Gehe heute noch zu Lehrer Wieldt und bringe ihm Kriegsgelder. Er nimmt $1 \mathrm{M}$ bis 15 Milliarden. Wenn du nichts bringst, tust du Sünde. Du hast Geld genug für Eier, Butter, Vieh und Korn gekriegt.

Es grüßt Dein (Deine) ... “632

Einen ähnlichen, ihrem sprachlichen Niveau angepassten Brief erhielten die älteren Schüler. Zusätzlichen diktierte er ihnen einen geschickt formulierten Brief für die in der Landwirtschaft tätigen Knechte und Mägde in Getmold, die unverheiratet und kinderlos waren. Die Getmolder Soldaten ließ er durch Schülerpostkarten über das Ergebnis der Auszeichnungen informieren, damit sie sich angesichts der guten Einnahmen, die zum Kauf von Waffen verwendet werden konnten, an der Front sicher fühlten.

Für die 7. Anleihe ließ sich der Lehrer wieder etwas Originelles einfallen. Er diktierte den Kindern die Parabel „Und der Teufel lacht dazu ...“ in die Hefte, die mit der Ansprache an die Bevölkerung endete: „Liebe Getmolder, der Teufel lacht dazu, wenn wir nicht zeichnen!“633

\footnotetext{
${ }^{630}$ Führen, Lehrer im Krieg (1936).

${ }^{631}$ Siehe: Kammeier, Der Landkreis Lübbecke und der 1. Weltkrieg (1998), S. 348.

${ }^{632}$ Schulchronik Getmold, S. 163; zitiert nach: Kammeier, Der Landkreis Lübbecke und der 1. Weltkrieg (1998), S. 194.

${ }^{633}$ Siehe: Kammeier, Der Landkreis Lübbecke und der 1. Weltkrieg (1998), S. 196.
} 
Wenige Tage später schickte er erneut einen ,Schülerbrief' an die Getmolder, in dem er mit Beispielen aus der Landwirtschaft argumentierte. Auch der Brief an „alle guten Getmolder“ zur 8. Kriegsanleihe ist überliefert, den er nicht als ,Schülerbrief', sondern als Lehrer und Vertrauensmann schrieb. Er endete mit dem Appell: „Wenn nun Lehrer Wieldt zu Euch kommt, so beweist Euer Gottvertrauen auf unseren Sieg und Eure Vaterlandsliebe, also Eure heiligsten Güter, mit der Tat, indem Ihr Kriegsanleihe bei ihm zeichnet. “634 Wegen der erfolgreichen Werbemethoden, die er auch seinen Kollegen mitgeteilt hatte, bekam er ein Dankesschreiben des Lübbecker Rektors, der für die Kriegsanleihen im Landkreis zuständig war.

Das Engagement eines Lehrers der Schule in Mittel-Podiebrad (Provinz Schlesien) sei als weiteres Beispiel genannt. Die Schulchronik gibt detailliert über seine Aktivitäten und die Zeichnungserfolge für die Anleihen 3-8 Auskunft:

„....Für die 5. und 6. Kriegsanleihe wurde eine ungemein rege Werbearbeit entfaltet. Hauptlehrer Zwiekirsch bereitete den Boden vor durch Vorträge über Deutschlands Wirtschaftskräfte, Deutschlands Finanzkraft, das Unterseeboot und seine Erfolge, die gegenwärtige Lage, die Kriegsanleihe. Darauf ging er von Haus zu Haus in allen vier Ortschaften, um auf jedes Gemeindemitglied persönlich einzuwirken und etwaige Einwände zu entkräften. Der Erfolg blieb nicht aus. Für die 5. Kriegsanleihe wurden durch die Schule 7.500 Mark und für die 6. Kriegsanleihe $10.800 \mathrm{M}$ gezeichnet. [...] Infolge der regen Werbearbeit des Hauptlehrers Zwiekirsch sind durch ihn zusammen 61.400 Mark an Kriegsanleihe gezeichnet worden.“635

Selbst Schulleiter agierten als Werber, wie ein Beispiel aus Kyllburg (Rheinprovinz) zeigt:

„Im März veranstaltete die Schule im Hotel Stern [...] eine Versammlung, in welcher der Schulleiter die Bedeutung und die drei verschiedenen Zeichnungsarten der vierten Kriegsanleihe erläuterte. Der folgende Tag war Zeichnungstag. Es war schulfrei und von morgens 9 drängten sich die Kleinen und Kleinsten um den Zeichnungstisch. Manche brachten ihre Sparbüchsen mit, Mütter brachten auf den Armen die Allerkleinsten, um auch für die kleinen Beträge zu zeichnen [...] so ging es bis abends 21.30 Uhr. Auch am folgenden Tag kamen noch Einzeichner, und als die Liste geschlossen wurde, hatten 185 Einzeichner 6.477,75 Mark gezeichnet. ${ }^{\text {‘636 }}$

Auf weitere Beispiele für Lehrer als Multiplikatoren kann verzichtet werden, da die in anderen Quelle erwähnten Werbemaßnahmen den oben dargestellten ähnelten. Dass in vielen Schulchroniken gerade auch über diese Sonderaufgaben der Lehrer berichtet wird, zeigt, in welch großer Zahl vor allem die Volksschullehrer als Werber für die Anleihen tätig waren.

Aber nicht nur die Lehrer fungierten als Multiplikatoren, sondern auch die Schulkinder waren Träger und Vermittler der Propaganda bei ihren Eltern und Verwandten. „Wir forderten unsere Kinder auf, über das Gehörte und Gelernte zu sprechen“, schrieben Lehrer in Baden an das

\footnotetext{
${ }^{634}$ Kammeier, Der Landkreis Lübbecke und der 1. Weltkrieg (1998), S. 199.

${ }^{635}$ Johann/Tchech/Schicha/Zwikirsch/Matzel/Rosemann, Schulchronik der Schule zu Mittel-Podiebrad (19.09.2007).

${ }^{636}$ Chronik der Stadt Kyllburg 800-2000, http://www.mueller-kyllburg.de/weltkrieg_eins/kriegsanleihen.html (10.09.2008).
} 
Kreisschulamt und ein Kriegsbuchautor betonte die „wichtige Möglichkeit der Einwirkung auf die Einsicht der Stimmung des Hauses durch die Kinder“637.

Wie die in 3.5.1 aufgeführten Ergebnisse zeigen, waren Tausende von Schulkindern als Werber aktiv und sehr erfolgreich. Bei ihren Bemühungen wurden sie von den Lehrern in vielfältiger Weise unterstützt, und zwar durch Schulung, Beratung und Informations- und Werbematerial, wie z. B. Zinsberechnungslisten sowie Formulare. Für die 4. Anleihe (und für die folgenden) wurde von Berliner Lehrern eine große Propagandaaktion gestartet, um Schüler als Werber zu gewinnen und zu schulen. An 4.300 höhere Schulen wurden die Informationsblätter „Der Unterricht an die Schüler über Wesen und Bedeutung der Kriegsanleihe“ und „Auf Werbung zur Kriegsanleihe“ geschickt. ${ }^{638}$ Viele Schulen hatten zudem ein Werbebüro eingerichtet, das täglich geöffnet war. Ab der 6. Anleihe bekamen die Schüler die Kosten für die Werbefahrten mit der Bahn sogar erstattet. Neben Hausbesuchen und Informationsständen gab es auch spektakuläre Aktionen der Schüler. Ein damals recht bekanntes Bild, das in der Berliner Ausstellung ,Schule und Krieg“ zu sehen und auch in vielen Publikationen abgebildet war, zeigt Berliner Schüler und Schülerinnen, die in langer Reihe auf einer Straße gehen und ein Schild mit der Aufschrift „Wer Kriegsanleihe zeichnet verkürzt den Krieg“ vor sich her tragen. ${ }^{639}$ Über eine ähnliche Situation in München existiert ebenfalls ein Foto. Es zeigt Schüler, die in einer belebten Straße Fahnen und Postkarten verkaufen. ${ }^{640}$

Auch das Realgymnasium zu Ahlen (Provinz Westfalen) veranstaltete zur Förderung der (7.) Kriegsanleihe einen „öffentlichen Werbeumzug“, an dem alle Schüler und Lehrer teilnahmen. Der verantwortliche Lehrer berichtete darüber, um andere Schulen zu ähnlichen Aktionen zu bewegen:

„Von Trommlern geführt, begab sich der Zug mit fliegenden Fahnen und unter Vorantragung von Werbeplakaten zum Markt und Rathausplatz und weiter durch die wichtigsten Straßen der Stadt. An sieben Plätzen wurde unter Leitung des Gesanglehrers der Anstalt von einem Chor von etwa 250 Stimmen das ,Lied vom grauen Geld' vorgetragen. Kräftig schallte es in den klaren Herbstmorgen und drang in die Häuser und Herzen der Bürger. Der gute Wille, aus dem das Unternehmen hervorging, und der würdige Ernst, mit dem es durchgeführt wurde, traf nirgends auf Spott oder Ablehnung. Das zeigte das Ergebnis der Hauswerbung, die im Anschluß an den Umzug sofort von den Schülern durchgeführt wurde. Brachte sie doch, nachdem der Nationaltag vorbei war und die Zeichnungsfrist nur mehr 2 Tage betrug, noch Zeichnungen in Höhe von 64.800 Mark, großenteils Nachzeichnungen, aber auch erste Zeichnungen von teilweise beträchtlicher Höhe, die nur durch die Werbung veranlasst wurden.

So lohnte der Erfolg den Optimismus, der das Unternehmen gewagt hatte; und den Teilnehmern bleibt der Tag eine Lebenserinnerung aus großer Zeit.“641

\footnotetext{
${ }^{637}$ Zitiert nach: Demm, Ostpolitik und Propaganda im Ersten Weltkrieg (2002), S. 88.

${ }^{638}$ Ohmann, Schüler als Werber für die vierte Kriegsanleihe, Deutsches Philologen-Blatt 1916, S. 153.

${ }^{639}$ Siehe: Anhang, Seite 59, Bild 1.

${ }^{640}$ Brudmann, Grosser Bilderatlas des Weltkrieges (1915ff.)

${ }^{641}$ Wagler, Ein neues Werbemittel für die Kriegsanleihe, Deutsches Philologen-Blatt 1918, S. 116.
} 
Über die schulischen Werbeaktivitäten wurde gerne und fast immer positiv von den Zeitungen berichtet ${ }^{642}$, was dann auch ein Grund für verstärkte Aktivitäten bei der nächsten Anleihe war. Außerdem strahlte das bekannt gemachte Vorbild der Schulen auf die allgemeine Öffentlichkeit aus.

Besonders wichtig für das Engagement der Schüler waren neben der Aussicht auf schulfreie Tage und andere Belohnungen das Vorbild und die Überzeugungskraft der Lehrer. Viele zeitgenössische Berichte geben darüber Aufschluss, wie intensiv die Lehrer ihre Schüler im Unterricht beeinflusst haben. Auf den Lehrer Wieldt aus Getmold ist bereits oben hingewiesen worden. Er ließ z. B. das im Unterricht Gelernte in Aufsätzen, die dann auch die Eltern lasen, verarbeiten. Ein Thema lautete: „Warum wir alle die 6. Kriegsanleihe zeichnen wollen“. Die Ergebnisse zeigen, dass der Unterricht ganz im Zeichen des Krieges gestanden hatte und die Meinung des Lehrers unreflektiert übernommen worden war. ${ }^{643}$

Einem zeitgenössischen Bericht aus einem Dorf bei Salzdetfurth (Provinz Hannover) ist über die Beeinflussung durch die Schule zu entnehmen: „Eindringlich belehrte (in Wehrstedt) der Lehrer die Kinder über die aufgelegte Kriegsanleihe.“644 Das dritte. Beispiel stammt von einem Zeitzeugen, der sich an seine Schulzeit in Solingen und die Werbung für die Kriegsanleihen erinnerte: „Das Wort ,Kriegsanleihe’ glich einer Beschwörungsformel. Mindestens zweimal jährlich wurde zur Zeichnung von Reichsschatzanweisungen aufgerufen. Sogar in der Schule appellierte der Lehrer an die Erfüllung dieser vaterländischen Pflicht.“645

Wie groß oft auch der moralische Druck gewesen sein muss, den die Lehrer ausgeübt haben, um ihre Schüler zur Zeichnung oder zur Werbetätigkeit zu bewegen, lässt sich der Meinung eines Lehrers entnehmen, die offensichtlich damals von vielen Kollegen und Kolleginnen geteilt worden ist ${ }^{646}:$ „Unsere Anleihen sind eigentlich nichts als öffentlicher Dank. In den Kriegen hielt man früher nicht nur Bußtage, sondern auch Dankgebetstunden. Ein solch Dankgebet ist - richtig verstanden - die Kriegsanleihe. “647

\footnotetext{
${ }^{642}$ Zum Beispiel von den Flensburger Nachrichten: „(Es gibt) kein trefflicheres Mittel zur Charakterbildung als die Erziehung zum Gemeinsinn, zur freiwilligen Arbeit im Dienste anderer, im Dienste des Volksganzen." (Zitiert nach: Pust, „Vaterländische Erziehung" für „Höhere Mädchen" [2004], S. 378).

${ }^{643}$ Kammeier, Der Landkreis Lübbecke und der 1. Weltkrieg (1998), S. 194/195.

${ }^{644}$ Heimatverein Wehrstedt e.V., Die Dorfchronik, http://www.heimatverein-wehrstedt.de/drei.html\#titelanker15 (03.04.2008).

${ }^{645}$ Sinne/Motz, Solingen im 1. Weltkrieg (1984), S. 64, S. 92.

${ }^{646}$ Das trifft z. B. auch auf den Lehrer Wieldt aus Getmold zu, der „Gottvertrauen auf unseren Sieg und Eure Vaterlandsliebe“ als die ,heiligsten Güter" bezeichnete, die es auch durch die Zeichnung von Anleihen zu verteidigen gelte“. (Schulchronik Getmold, S. 163; zitiert nach: Kammeier, Der Landkreis Lübbecke und der 1. Weltkrieg [1998], S. 194.)

${ }^{647}$ „Diesmal wird es nichts!", Hannoversche Schulzeitung. Organ der Provinzial-Lehrervereins, der Bezirks- und Pestalozzivereine der Provinz Hannover, des Lehrer-Brandversicherungsvereins für Hannover, Bremen und das Fürstentum Lippe., 1917, S. 318f.
} 
Eine weitere Ursache für die Zeichnungserfolge lag sicher auch darin, dass einzelne Schüler innerhalb einer Klasse, einzelne Klassen innerhalb einer Schule und einzelne Schulen innerhalb einer Stadt oder einer Region miteinander konkurrierten und jeder möglichst gut abschneiden wollte. Schließlich wurden die Ergebnisse der Erfolgreichsten durch die örtliche Presse bekannt gemacht oder sogar in den Lehrerzeitschriften reichsweit veröffentlicht. ${ }^{648}$ Auf ein Beispiel aus Mittel-Podiebrad (Provinz Schlesien) sei stellvertretend für viele andere hingewiesen, wo in der Chronik der Volksschule voller Stolz das eigene gute Ergebnis hervorgehoben und zu dem anderer Schulen in Beziehung gesetzt wurde: Bei der 3. Anleihe im September 1915 wurde für 5.800 Mark gezeichnet, „so daß unsere Schule in hervorragendem Maße unter allen Schulen des Kreises an erster Stelle stand“.

Ähnlich war es im März 1916 bei der 4. Anleihe: „Die Beteiligung an der Zeichnung der 4. Kriegsanleihe war sehr erfreulich. Es wurden 6.700 M gezeichnet. Diesmal stand unsere Schule an der Spitze aller Landschulen des Kreises; nur das Gymnasium und die Stadtschule haben einen höheren Betrag gezeichnet. “649

Innerhalb der einzelnen Klassen und einer Schule spornten sicher auch das damals weitverbreitete ,Kriegsanleihe-Thermometer ${ }^{650}$ und der ,Kriegsanleihe-Kalender, ${ }^{651}$ die Schüler an. Im Philologenblatt wurde 1917 für jene Methode in einer ganzseitigen Anzeige geworben, die Aufschluss über die außergewöhnliche Werbemethode gibt. ${ }^{652}$ Am Beispiel des KaiserWilhelms-Realgymnasiums in Berlin, wo die Maßnahme ausprobiert worden war, wurde das ,Kriegsthermometer' erklärt. Auf dem Schulhof war regengeschützt ein großes Plakat, auf das ein Thermometer gezeichnet war, aufgehängt worden, auf dem täglich die Summe der Anleihezeichnungen zu sehen war. Anfangs war nur die Kugel geschwärzt, dann zunehmend auch die ,Quecksilber'-Röhre. Jeweils in den Pausen stieg dann die ,Anleihe-Temperatur'. In kleinen Schulen bestand die Einteilung der Messskala aus Einheiten von jeweils tausend Mark, in großen von zehntausend. Das Berliner, Anleihe-Thermometer' ist von vielen Schulen mit Erfolg nachgeahmt worden. Der ,Kriegsanleihe-Kalender' hing in Klassenräumen und enthielt die im Zusammenhang mit der Kriegsanleihe wichtigen Termine und Informationen, z. B. die Zeichnungsfristen, geplante Werbeaktionen u. a.

\footnotetext{
${ }^{648}$ Siehe dazu: Kapitel 3.4.1 Ablauf und Ergebnisse.

${ }^{649}$ Johann/Tchech/Schicha/Zwikirsch/Matzel/Rosemann, Schulchronik der Schule zu Mittel-Podiebrad (19.09.2009).

${ }^{650}$ Siehe: Anhang, Seite 59, Bild 2.

${ }^{651}$ Siehe: Anhang, Seite 60, Bild 1; der Kalender stammt vom September/Oktober 1917 und wurde zur 7. Kriegsanleihe in einer Hildesheimer Schule aufgehängt.

${ }^{652}$ Kennen Sie schon das Kriegsanleihe-Thermometer?, Deutsches Philologen-Blatt: Korrespondenz-Blatt für den akademisch gebildeten Lehrerstand (Beilage), 1917, S. 556.
} 
Zuletzt sei noch auf eine gemeinsame Werbeaktion der vier höheren Schulen in Flensburg hingewiesen. ${ }^{653}$ Für die 3. Kriegsanleihe riefen die Schulen mit einer Zeitungsanzeige gemeinsam zur Zeichnung auf. Am Donnerstag, 9. September 1915, sollten sich alle Schüler und Schülerinnen in der Aula ihrer eigenen Schulen versammeln, wo sie über Einzelheiten informiert werden sollten. Man wollte durch diese konzertierte Aktion auch die Aufmerksamkeit der gesamten städtischen Bevölkerung auf die neue Anleihe lenken, um den „hohen Zweck (d. h. ein gutes Zeichnungsergebnis) auch in unserer Stadt zu erreichen“6554.

Abgesehen von den freien Tagen, die ab der 3. Anleihe alle deutschen Schüler jeweils als Belohnung für ihren entsprechenden Einsatz bei den Kriegsanleihen bekamen, wurde den Schülern einer Stadt oder einer Schule mehrfach freigegeben, wenn eine bestimmte Summe erreicht worden war. Dazu ist beispielsweise in der Chronik der Auguste-Viktoria-Schule in Flensburg im April 1918 vermerkt: „Am II. April war schulfrei, weil die Kriegsanleihe über 100.000 betrug. “655 Auch einzelne Schüler bekamen freie Tage, wenn sie aufs Land fuhren, um dort für die Anleihen zu werben, und für besondere Zeichnungserfolge.

Einen großen Anreiz für Schüler und Lehrer, sich bei jeder neuen Anleihe immer wieder neu anzustrengen und den Erfolg der letzten Anleihe noch zu übertreffen, stellten auch die offiziellen Anerkennungen und Prämien in Form von Ehrenurkunden, Gedenkmünzen, Bildern, die den Kaiser oder Hindenburg zeigten, Postkartenheftchen u. a. dar. Auf einige Beispiele, die teilweise auch im Bilderanhang zu sehen sind, soll hingewiesen werden:

- Hindenburg-Plakette mit einer Ehrenurkunde für „Schulkriegshilfe im Weltkriege"656 (Porträt Hindenburgs, Feinzink $50 \mathrm{~mm}$ ).

- Großes Bild Hindenburgs: „Im Juli 1918 stellte das Reichsbankdirektorium dann den Schulen, die sich an den Kriegsanleihen beteiligt hatten, ,ein großes Bild Hindenburgs' zur Verfügung. “657

- Dekorative Schülerurkunden „zur Erinnerung an freudige Mithilfe“, die den Spruch „Große Zeit fand dich bereit! Halfst schmieden das Schwert zu hartem Streich!“" enthielten. ${ }^{658}$ Sie

\footnotetext{
${ }^{653}$ Der Aufruf ist teilweise abgedruckt in: Hohnsbehn, Die Flensburger Schuljugend in der Zeit des ersten Weltkriegs (1996), S. 250f.

${ }^{654}$ Siehe: Anhang, Seite 60, Bild 2.

${ }^{655}$ Zitiert nach: Pust, „Vaterländische Erziehung" für „Höhere Mädchen" (2004), S. 390. Über den freien Tag berichteten auch die ,Flensburger Nachrichten'. Nachdem 75.000 Mark zu Beginn der Herbstferien zusammengekommen waren, hatte man den Schülerinnen einen freien Tag in Aussicht gestellt, wenn 100.000 Mark erreicht würden.

${ }^{656}$ Ohmann, Eine Gedenkmünze zur Kriegshilfe der Schulen für besonders verdiente Helfer, in: Deutsches Philologen-Blatt 1918, S. 127. Die Schulen konnten die von Prof. L. Manzel gestaltete Plakette zum Preis von 4,30 Mark erwerben und den in der Kriegshilfe besonders erfolgreichen Schülern in feierlichem Rahmen überreichen. Auf der Rückseite stehen die Worte Hindenburgs „Vergeßt den Geist von 1914 nie“ und „Für Schulkriegshilfe im Weltkriege"; siehe: Anhang, Seite 63, Bild 1a/1b.

${ }^{657}$ Siehe: Pust , „Vaterländische Erziehung" für „Höhere Mädchen" (2004), S. 390.

${ }^{658}$ Siehe: Anhang, Seite 63, Bild 2; die gezeigte Urkunde $(15 \times 21 \mathrm{~cm})$ wurde bei der 4. Kriegsanleihe im Frühjahr 1916 der Schülerin Helene Knorr, die die Höhere Bürgerschule besuchte, überreicht. Dem Verfasser liegt außerdem eine Urkunde vor, die der Schüler Rudolf Lehmann derselben Schule zum gleichen Zeitpunkt bekommen hat.
} 
wurden in der Regel den Schülern, die bei der Zeichnung oder der Werbung besonders erfolgreich gewesen waren, in größerem schulischen Rahmen vom Schulleiter feierlich überreicht.

- Dekorative Ehrenurkunde, „Als Anerkennung für erfolgreiche Werbearbeit zur [...] Kriegsanleihe“"

- Dekorative Gedenkblätter. Das in den Anhang aufgenommene Exemplar wurde anlässlich der 8. Kriegsanleihe im April 1918 dem Gymnasium in Bautzen (Kgr. Sachsen) für das Sammelergebnis in Höhe von 18.367 Mark verliehen und an den erfolgreichsten Schüler stellvertretend ausgehändigt. ${ }^{659}$

- Blätter zur Erinnerung an die „Kinder-Kriegsanleihe“, die dem Kaiser gewidmet waren und jeweils ein Gedicht enthielten. ${ }^{660}$

- Reiterbildnis des Kaisers mit eigenhändiger Unterschrift (für die Schule) ${ }^{661}$

Für die Lehrer war die Aussicht, ein ,Verdienstkreuz für Kriegshilfe' verliehen zu bekommen, sicher ein ganz besonderer Anreiz, sich für die Kriegsanleihen (und andere Aktionen der Kriegshilfe) erfolgreich zu engagieren, denn die Auszeichnungen lagen in der preußischen ,Ordenshierarchie" recht weit oben und die Geehrten wurden im Reichsanzeiger genannt. Überliefert sind Abbildungen von Verdienstkreuzen, die in den Königreichen Preußen und Sachsen sowie im Großherzogtum Baden häufig an Lehrer verliehen worden sind. ${ }^{662}$ Es gab aber auch in anderen Ländern solche Ehrungen. ${ }^{663}$

Abschließend soll noch auf die Werbung für die Kriegsanleihen durch Ansichtskarten hingewiesen werden, von denen einige Beispiele im Bilderanhang zu sehen sind. So wendet sich eine Karte direkt an die „Deutsche Schuljugend“ und fordert die Kinder zur Zeichnung auf: „Alle bis zur letzten Reihe/ zeichnen freudig Kriegsanleihe./Klüger als manch’ grosse Leute/Zeigen sich die Kleinen heute.“664 Auf der Ansichtskarte „,'Zeichen'-Stunde“ ist eine Lehrerin mit ihren Schülerinnen zu sehen, die sich an der schulischen Sammelzeichnung begeistert beteiligen: „Lehrerin: ,Wie viele Kriegsanleihen hast du denn schon gezeichnet, Else? / Else (Gastwirtstöchterlein): ,Ich Fräulein? Alle Neune'!،665.

Auf ein drittes Beispiel sei hingewiesen: Ein Junge und ein Mädchen überlegen zu Hause, in welcher Höhe sie zeichnen wollen: „Die große Frage ,Wieviel Kriegsanleihe wollen wir denn zeichnen, Hannchen?' ,200 Mark! - Da wird sich aber Hindenburg freuen! ‘،666

\footnotetext{
${ }^{659}$ Siehe: Anhang, Seite 63, Bild 3.

${ }^{660}$ Siehe: Anhang, Seite 21, Bild 2.

${ }^{661}$ Gymnasium Warburg z. B.:,,Dem G. ist für seine Leistungen bei der Goldsammlung und den Kriegsanleihezeichnungen das Reiterbildnis des Kaisers mit eigenhändiger Unterschrift verliehen (worden).“ (Mitteilungen aus den Kollegien, Deutsches Philologen-Blatt 1917, S. 489).

${ }^{662}$ Dass die Kreuze in der Regel aus ,Kriegsmetall', d .h. einer Zinklegierung, bestanden, war für die Empfänger von sekundärer Bedeutung.

${ }^{663}$ Im Philologen-Blatt sind viele Schuldirektoren und Lehrer namentlich genannt, die das ,Verdienstkreuz für Kriegshilfe' erhalten haben; z. B. 1916 in Heft 5/6 auf Seite 46 für vier Lehrkräfte aus der Provinz SchleswigHolstein.

${ }^{664}$ Siehe: Anhang, Seite 62, Bild 1

${ }^{665}$ Siehe: Anhang, Seite 62, Bild 2.
} 
Neben den Kriegskarten für Schüler gab es auch Plakate, die gezielt Schüler und deren Familien ansprachen. ${ }^{667}$ Dass in der zeitgenössischen Kinder- und Jugendliteratur für das Zeichnen von Kriegsanleihen geworben wurde, wie z. B. Gustav Schröers Erzählung „Die Kriegsanleihe der Jungen von Erbesbach“668 zeigt, hat sicher ebenfalls viele Schüler beeinflusst.

Insgesamt ist deutlich geworden, mit welch großem Aufwand und kaum erwarteten Erfolg die Behörden und die Lehrerschaft für die Kriegsanleihen geworben und sich eingesetzt haben. Ein Regierungs- und Schulrat aus Stettin nannte die Anleihen 1917 einen „Kampf der Milliarden“, bei dem der „Kampf“ der Schüler und Lehrer „schöne Erfolge“ gehabt habe. Neben den Zeichnungen der Schüler selbst hob er die Bedeutung der Schule für die Zeichnungsmoral weiter Kreise der Bevölkerung hervor:

„Millionenwerte haben die Sparpfennige der Knaben und Mädchen, Millionenwerte hat die Aufklärung, Anregung, das fleißig zähe Werben und Drängen, das sie frohen Mutes auf sich nahmen und übten, aus den Mitteln auch der Erwachsenen ihrer Kreise jenen zugeführt. Keine Mühe und kein Versuchen immer neuer Formen hat die Lehrerschaft gescheut, um hier Verständnis und guten Willen zu schaffen, auch nicht die naheliegende Gefahr, bei allerlei Ängstlichen Engherzigen und Missgünstigen sich in ihrem Werben verkannt und vielleicht verlästert zu sehen. “669

Hier werden Vorbehalte und Widerstände gegen die Kriegsanleihen angedeutet, die es durchaus nicht selten gab und auf die im nächsten Abschnitt eingegangen werden soll.

\subsubsection{Vorbehalte, Kritik und Widerstände}

Das „fleißig zähe Werben und Drängen“ der Schulkinder, das der Schulrat Bohnstedt so positiv beurteilte, wurde von vielen Erwachsenen als sehr lästig empfunden und sogar von einem Abgeordneten der USPD in einer Reichstagsdebatte (13. Mai 1918) heftig kritisiert: „Einen geradezu hässlichen Eindruck hat es bei der letzten Kriegsanleihe gemacht, daß man sogar eine systematische Bettelei durch Schulkinder in die Wege geleitet hat. Ganz abgesehen, ob und inwieweit das von Erfolg begleitet war, ist die erzieherisch schlechte Wirkung auf die Jugend selbst direkt zu verwerfen. “670

Auch die Probleme, die Lehrer bei ihrer Werbearbeit hatten, und die Widerstände, die es zu überwinden galt, hat Bohnstedt erwähnt. Einige Beispiele sollen die Schwierigkeit verdeutlichen.

\footnotetext{
${ }^{666}$ Siehe: Anhang, Seite 62, Bild 3.

${ }^{667}$ Siehe: Anhang, Seite 62, Bilder 5/6.

${ }^{668}$ Schröer, Die Kriegsanleihe der Jungen von Erbesbach und andere Erzählungen aus dem Weltkrieg (o. J.).

${ }^{669}$ Siehe: Bohnstedt, Die Kriegshilfe unserer Schuljugend (1917), S. 29.

${ }^{670}$ Reichstags-Protokolle 1914-1918, Bd. 312, 164. Sitzg. S. 5110C; zitiert nach: Pust, „Vaterländische Erziehung" für „Höhere Mädchen" (2004), S. 384.
} 
Lehrer Kiel aus Twiehausen:

„Das Sammelgeschäft war wahrlich nicht leicht. Meistens waren die Leute nicht zu Haus. Eine unangenehme Geschichte bei den entfernt liegenden Höfen. [...] Trifft man die Leute endlich an, so ermahnt man sie an ihre Pflichten. Wieviele Bedenken hatte man da zurückzuweisen, wieviele Zaghafte gab es da: der eine erzählte von seinen Schulden, der andere von seinem Unglück und der dritte verwies ernst auf seinen Toten ... er habe genug geopfert. “671

Lehrer Herold aus Klingelbach:

„Der neuen Kriegsanleihe-Versicherung stehen unsere schwer zu überzeugenden Leute leider noch misstrauisch gegenüber. Allerwärts sind Miesmacher am Werk und erschweren unseren Propagandadienst außerordentlich. [...] Nichtsdestoweniger kommen Zweifler doch noch in den letzten Zeichnungstagen zur Einsicht. [...] (1918) Die Überschlauen preisen sich glücklich, ihr Geld nicht auf ein von vornherein verlorenes Spiel gesetzt zu haben. “672

Lehrer Oppermann aus Tiftlangerode:

1918 „IX. Kriegsanleihe vom 18. Sept. - 5. Nov. Brachten hierorts 2400 Mark. Die Leute wollen nicht mehr.“673

Je länger der Krieg dauerte und je unsicherer der siegreiche Kriegsausgang wurde , um so häufiger wurden kritische Stimmen und Ablehnung der Zeichnung. Auch in dieser Hinsicht dürften die großen Materialschlachten des Jahres 1916 (um Verdun, an der Somme), die Hunderttausende von Kriegsopfern brachten, eine Zäsur darstellen. Bezeichnend für den Wandel der Einstellung der Bevölkerung zu den Kriegsanleihen, ist die folgende Episode, die zeigt, dass Vorbehalte gegenüber den Kriegsanleihen sogar bei Bankfachleuten bestanden:

„Ein Verwandter von mir war einer der größten Bankiers Deutschlands und hat sich natürlich amüsiert, wie ich als 10jaehriger ihm vorschlug, doch bei mir 20 Mark zu zeichnen. Er hat mich als Jungen damals schwer beleidigt und sein Ansehen bei mir spaeter sehr erhoeht durch die Form der Ablehnung dieses Geschaeft zu machen, worin er gezeigt hat, dass er klueger war als $75 \%$ der Deutschen. Er hat mir gesagt: 'Hier schenke ich Dir fuenf Mark. Das ist mir lieber als 20 zu verlieren.' Weitere Erklaerungen hat er nicht gegeben. “6774

Kritische Schüleräußerungen liegen kaum vor. Allerdings kann man davon ausgehen, dass Schüler angesichts des Drucks, den manche Lehrer auf sie ausübten ${ }^{675}$, durchaus nicht selten sich unwillig an den entsprechenden Aktionen beteiligten. Als Beispiel sei der Zeitzeuge Walther von Loewenich $(* 1903)$ angeführt, der sich u. a. auch an die Werbung in der Schule für die Kriegsanleihen erinnerte: „In Schülerversammlungen wurde für das Zeichnen von Kriegs-

\footnotetext{
${ }^{671}$ Kammeier, Der Landkreis Lübbecke und der 1. Weltkrieg (1998), S. 203.

${ }^{672}$ Schulchronik, http://www.vg-katzenelnbogen.de/buch2/15.htm (10.10.2007).

${ }^{673}$ Oppermann, Krieg. Aus der Schulchronik von Tiftlangerode 1914-1925 (1995), S.159.

${ }^{674}$ W. W. Citron, (*1905), zitiert nach: Franke, Die Kriegsgeneration, S. 202.

${ }^{675}$ Z. B. wurde von den Flensburger Volksschulkindern verlangt, ,,ihre Sparguthaben für die Kriegsanleihe zu opfern.“(Hohnsbehn, Die Flensburger Schuljugend in der Zeit des ersten Weltkriegs [1996], S. 251.)
} 
anleihen geworben. Ich hörte allerdings, wie einer meiner Mitschüler das bereits boshaft glossierte. “676

Wenig begeistert war offensichtlich auch die Flensburger Schülerin Anneliese C., wie aus ihrem Tagebuch 1918 hervorgeht: „Ich sollte [...] i[n] d[er] Kappelner Str. Kriegsanleihe werben, was ja gar keinen Zweck hat. [...] Selbstverständ[lich] kriegten wir i[n] d[er] Kappelner Str. auch nichts, alles solche kl[einen] Spelunken, die hatten nichts.“677 Die Schülerin Hedwig Regnart (*1908) weigerte sich sogar, etwas zur Kriegsanleihe beizusteuern. Als die empörte Lehrerin sie vor der Klasse zur Rede stellte, rechtfertigte sie sich mit der Begründung ihrer Mutter: „Wenn wir für den Krieg spenden, dauert er nur noch länger.“678

\subsection{Fazit}

Trotz der durchaus geäußerten Kritik ${ }^{679}$ zeigen die beschriebenen Aktionen, dass es dem Staat gelungen war, die Schule für kriegswirtschaftliche Interessen $\mathrm{zu}$ instrumentalisieren und zu einem wichtigen Teil der umfassenden staatlichen Werbeorganisation zu machen. Zwar waren die vielen Initiativen einzelner Schulen im Dienste der Kriegsfürsorge in volkswirtschaftlicher Hinsicht insgesamt von geringer Bedeutung, sie wurden jedoch von den Behörden in erster Linie unterstützt und teilweise auch forciert, um die Schüler patriotisch zu indoktrinieren. Wesentlich wichtiger war die Mobilisierung der Schüler und vor allem der Lehrer bei den Kriegsanleihen. Hier haben tatsächlich „Kinderhände Millionenwerte gesammelt““680 und Lehrer als „Volkserzieher“ über die Kinder und durch Aufklärungsarbeit einen großen Teil der Bevölkerung zur Zeichnung von Kriegsanleihen bewegen können. ${ }^{681}$ Dass die Volksanleihen (ab der 3. Anleihe), die für die Finanzierung des Krieges von großer Bedeutung waren, von ca. $75 \%$ der Bevölkerung gezeichnet wurden und finanziell so erfolgreich waren, ist in besonderem Maße auch das Verdienst der Lehrerschaft gewesen. Sie waren für den Staat gerade bei der Kriegsfinanzierung eine unentbehrliche Stütze. Über sie ist es gelungen, die Menschen auch im kleinsten abgelegenen Dorf zu erreichen und dank ihrer Autorität zum Zeichnen zu bewegen, indem sie an deren patriotisches Pflichtgefühl appellierten. Sie erfüllten damit vor-

\footnotetext{
${ }^{676}$ Pörtner, Kindheit im Kaiserreich (1990), S. 233.

${ }^{677}$ Zitiert nach: Pust, „Vaterländische Erziehung" für „Höhere Mädchen" (2004) S. 385.

${ }^{678}$ Asmuth, Frauen im Wiederstand, http://www.gedenkstaette-moringen.de/geschichte/ frauen/pol_wid/pol_wid.html (17.08.2008).

${ }^{679}$ Verbreitet war vor allem die Meinung, dass die Zeichnung von Kriegsanleihen den Krieg verlängere.

${ }^{680}$ Siehe: Bohnstedt, Die Kriegshilfe unserer Schuljugend (1917), S. 10.

${ }^{681}$ Die Behörden waren sich der „Werbekraft [...] der Schüler durch die Lehrer“ bewusst und wollten sie nutzen, wie aus einem amtlichen Flugblatt hervorgeht. Deswegen sollten die Lehrer die Kinder als „Werber daheim und bei Verwandten und Bekannten“ einsetzen („Bittende Kinder sind eine Großmacht.“); Siehe: LAS , Abtl. 309, 13114.
} 
bildlich die Forderung des Reichsstaatssekretärs Karl Helfferich: „Der Gedanke der finanziellen Wehrpflicht muß [...] hunderttausendfältig den Köpfen eingehämmert werden.“682 Auch wenn die staatlichen Stellen den Erfolg in erster Linie auf die umfassenden Propagandamaßnahmen, z. B. die Plakataktionen, zurückführten, so hatte die Schule doch ebenfalls großen Anteil daran. Neben den Volksschullehrern in den Landgemeinden waren es vor allem die Lehrer der Gymnasien, die sich im Philologen-Blatt durch eine Vielzahl von Aufrufen, Informationen, Materialien und Berichten, die auch in den Zeitschriften anderer Lehrerverbände abgedruckt wurden, in besonderem Maße für die Kriegsanleihen engagierten.

${ }^{682}$ Michalka, Der Erste Weltkrieg (1994), S. 424. 


\section{Hilfsdienste}

Im Frühjahr 1915 wandten sich die Schulbehörden der preußischen Reinprovinz mit einem Flugblatt an die Schulkinder, in dem es hieß: „Ihr seid dann auch Soldaten, die für das Vaterland kämpfen. Seht die Ackerfurche als euren Schützengraben, die Kartoffeln, die ihr legt, sind eure Kanonenkugeln, die Steine, die ihr von der Wiese wegholt, sind eure Granaten, und das Unkraut ist ein Feind, den ihr ausrotten müßt mit Stumpf und Stiel.“683

Diese grotesk anmutende Aufforderung, die den Arbeitseinsatz in der Landwirtschaft mit dem militärischen Kampf an der Front gleichsetzt, lässt vermuten, dass auch für die landwirtschaftlichen (und anderen) Hilfsdienste in den deutschen Schulen wieder mit ähnlich großem propagandistischem Aufwand geworben wurde wie beim ,Goldgeld' oder den ,Kriegsanleihen'. In diesem Kapitel soll untersucht werden, inwieweit es gelungen ist, die Schule umfassend für die verschiedenen Hilfsdienste zu ,mobilisieren' und ob die Schüler sich bei den landwirtschaftlichen Arbeiten und den anderen Hilfsarbeiten tatsächlich als „Soldaten, die für ihr Vaterland kämpfen“, gefühlt haben.

\subsection{Arbeitseinsätze in der Landwirtschaft ${ }^{684}$}

Bei Kriegsbeginn am 1. August 1914 war die Sommerernte weitgehend beendet. Das Problem, für die eingezogenen Bauern, Knechte und Landarbeiter Ersatz zu bekommen, stellte sich zwar auch schon bei den Herbstarbeiten ${ }^{685}$, vor allem jedoch erst für das nächste Jahr, zumal auf die seit Jahren bewährten polnischen ${ }^{686}$, russischen ${ }^{687}$ und galizischen Wanderarbeiter zunächst weiter zurückgegriffen werden konnte. ${ }^{688}$ Trotzdem gab es von allen Seiten einsetzende Forderungen, der Landwirtschaft beim Einbringen der Ernte zu helfen. Die Folge war, dass viele freiwillige Helfer aus der Stadt, wie z. B. Schüler und Mitglieder der Jugendverbände, sich für die Arbeit auf dem Lande zur Verfügung stellten. Auch in der Lehrerschaft gab es die Sorge um das Einbringen der Ernte, wie u. a. aus einem Aufruf des damaligen Vorsitzenden des Bayerischen Volksschullehrervereins, J. W. Schubert, vom 1. August 1914 hervorgeht:

\footnotetext{
${ }^{683}$ Saul, Jugend im Schatten des Krieges (1983), S. 52.

684 Siehe auch: Anhang, Seiten 65-69.

${ }^{685} \mathrm{Zu}$ den Herbstarbeiten gehörte vor allem die Hilfeleistung bei der Grummet-, Kartoffel-, Obst- und Rübenernte.

${ }^{686}$ Gemeint sind vor allem russische Polen.

${ }^{687}$ Viele russische Wanderarbeiter wurden nach Kriegsbeginn gezwungen, weiter in Deutschland zu arbeiten.

${ }^{688}$ Bei Kriegsbeginn arbeiteten im Regierungsbezirk Hannover ca. 3.000 Saisonarbeiter (Grotjahn, Stahl und Steckrüben Bd. 2 [1993], S. 33).
} 
„Unser deutsches Vaterland ist in Gefahr. [...] Viele Lehrer sind mit hinausgezogen und sind bereit, Blut und Leben für das Vaterland zu opfern. Wir, die wir zurückgeblieben sind - werden wir Helfer und Tröster ihrer Frauen und Kinder! Wir wollen aber noch mehr tun! Draußen auf dem Felde steht der reife Gottessegen und will geborgen werden. Die Jugend der Städte will hinaus, um den Landleuten der Städte beim Einbringen der Ernte zu helfen. Kollegen auf dem Lande, werdet mit euren Frauen diesen Knaben und Mädchen Führer und Pfleger! Kollegen in Stadt und Land, stellt euch in den Dienst der Kriegsfürsorge! Tut, was ihr könnt!“689

Auch die Generalkommandos und die Kultusbehörden wurden hinsichtlich des Ernteeinsatzes aktiv. So ordnete der Kommandierende General v. Schenk am 1. August 1914 in Frankfurt a. M. an, dass ,im Interesse der schnellen Einbringung der Ernte die Schüler, vor allem die Schüler der höheren Schulen, von ihren Leitern aufgefordert werden sollten, bei der Erntearbeit auf dem Lande zu helfen“690.

Durch Erlasse und Verfügungen vom 1., 2. und 3. August 1914 wurden die älteren Jahrgänge der Volksschulen und die Schüler der höheren Schulen zu Erntearbeiten beurlaubt. ${ }^{691}$ Sogar Kaiser Wilhelm II. forderte am 3. August 1914 ,durch seinen Generaladjutanten, Generaloberst von Plesse, den Kultusminister telefonisch auf, für den Ernteeinsatz der Schuljugend die oberen Klassen freizugeben“692. Noch am gleichen Tag meldete der preußische Unterrichtsminister, dass er bereits angeordnet habe, die ,älteren Schüler zur Mithilfe bei den Erntearbeiten zu beurlauben“693. Diese überstürzten Aktivitäten führten nach einer Mitteilung des Leiters der im Reichsamt des Inneren neu errichteten „Reichszentrale der Arbeitsnachweise“, Ministerialdirektor Lewald, zu einem „Überangebot an Arbeitskräften für die Erntewirtschaft ${ }^{\star 6994}$.

In Flensburg z. B. informierte Stadtschulrat Lorenz die Königliche Regierung in seinem Bericht vom 13. 08. 1914:

\footnotetext{
${ }^{689}$ Führen, Lehrer im Krieg (1936), S. 38. Auch der Berliner Lehrerverein beispielsweise „Da auf dem Lande Hilfskräfte nötig seien, möchten die Landlehrer den Bedarf feststellen. Lehrer und Lehrerinnen möchten sich bereithalten zur Führung von Arbeitskolonnen (und sollten sich in den neu eingerichteten Büros melden)." (Führen, Lehrer im Krieg [1936], S. 39).

${ }^{690}$ Führen, Lehrer im Krieg (1936).

${ }^{691}$ Ministerium der geistlichen und Unterrichts-Angelegenheiten, Teilnahme von Schülern höherer Lehranstalten an den Erntearbeiten infolge der Mobilmachung, Zentralblatt für die gesamte Unterrichtsverwaltung in Preußen, 1914, S. 489 ; Ministerium der geistlichen und Unterrichts-Angelegenheiten, Beurlaubung der größeren Schulkinder zur Teilnahme an den Erntearbeiten, Zentralblatt für die gesamte Unterrichtsverwaltung in Preußen, 1914, S. 512 ;Verwendung der Schulkinder zu Erntearbeiten Jg. 13. (6. August 1914), S. 94.

${ }^{692}$ Ministerium der geistlichen und Unterrichts-Angelegenheiten, Einsatz von Schülern in der Landwirtschaft, 1914, S.94. .

${ }^{693}$ Ministerium der geistlichen und Unterrichts-Angelegenheiten, Einsatz von Schülern in der Landwirtschaft, 1914, S. 94.

${ }^{694}$ In Flensburg hatten sich beispielsweise im Sommer 1914270 Schüler und 38 Schülerinnen der höheren Lehranstalten zum Erntedienst gemeldet; von ihnen konnten lediglich 24 Schüler und keine Schülerin vermittelt werden. Noch niedriger war die Vermittlungsquote bei den Flensburger Volksschulen. Hier wurden von 606 arbeitswilligen Schülern lediglich 7 und von 399 Schülerinnen keine eingesetzt (Hohnsbehn, Die Flensburger Schuljugend in der Zeit des ersten Weltkriegs [1996], S. 254).
} 
„Gegen die Vermittlung von Jugendlichen macht sich hier eine starke Bewegung geltend, weil die arbeitslosen Erwachsenen, wohl auch mit Recht, befürchten, dass ihnen dadurch der Broterwerb sehr erschwert wird. Ich habe im Einverständnis mit der Kommission für Vaterländische Arbeitsvermittlung die Schulleiter angewiesen, nur solche Kinder für Erntearbeiten zu beurlauben, die zu Verwandten gehen. ${ }^{6695}$

Da solche Probleme auch aus anderen Regionen gemeldet wurden, untersagte der Unterrichtsminister mit Erlass vom 10. August „,bis auf weiteres [...] die Urlaubserteilung an Schüler zu ihrer Beteiligung an den Erntearbeiten“696. Ausnahmen seien lediglich für die Schüler höherer Lehranstalten möglich, wenn Eltern in denjenigen Provinzen Anträge zur Teilnahme ihrer Söhne an den Erntearbeiten stellten, in „denen die Ernte gefährdet“ sei.

Wenige Tage später schon, am 26. August 1914, trat der Erlass „Beurlaubung von Schulkindern zur Teilnahme an den Erntearbeiten“ in Kraft“697. In ihm wurde zwar erneut festgestellt, dass „,ür die Getreideernte (...) im allgemeinen überall genügend Arbeitskräfte zur Verfügung (stehen), so dass es besonderer Maßnahmen zur Beschäftigung der Schuljugend bei diesen Arbeiten nicht mehr bedarf “698, gleichzeitig wurde jedoch auf den Arbeitskräftemangel hingewiesen, der im Herbst bei der „Hackfrucht und besonders für die Kartoffelernte“ entstehen werde: „Bei ihr können die Schulkinder, wie es regelmäßig alljährlich geschieht, mit bestem Erfolge verwandt werden; und unter den gegenwärtigen Verhältnissen kann sie ohne die Schuljugend kaum durchgeführt werden." Um den Unterricht nicht allzu sehr zu belasten, sollten die Herbstferien so gelegt werden, dass die „Bergung der Hackfrüchte“ in den Ferienzeiten erfolgen könne. Andernfalls sei „den zu Erntearbeiten geeigneten Schulkindern der erforderliche Urlaub zu gewähren“. Dieser Erlass wurde an alle Regierungen des Königreichs Preußen geschickt und von diesen umgesetzt. So wurde er z. B. in verkürzter Form im Amtsblatt für den Regierungsbezirk Königsberg veröffentlicht („Betrifft Verwendung von Schülern zu Erntearbeiten“): „Der Herr Minister der geistlichen und Unterrichts-Angelegenheiten hat entschieden, dass trotz eines Erlasses vom 10. d. Mts. [...], wonach bis auf weiteres Schüler zu Ernteurlauben nicht mehr beurlaubt werden sollten, dieser Urlaub weiter erteilt werden

\footnotetext{
${ }^{695}$ Hohnsbehn, Die Flensburger Schuljugend in der Zeit des ersten Weltkriegs (1996), S. 253.

${ }^{696}$ Erlass des preußischen Kultusministers vom 10. August 1914; zitiert nach: Wegener, Das Joachimsthalsche Gymnasium - die Landesschule Templin (2007), S.89f. Ministerium der geistlichen und UnterrichtsAngelegenheiten, Einsatz von Schülern in der Landwirtschaft.

${ }^{697}$ Beurlaubung von Schulkindern zur Teilnahme an den Erntearbeiten, in: Zühlke (Hrsg.), Bildpropaganda im Ersten Weltkrieg (26. August 1914), S. 609f.

${ }^{698}$ Außerdem genehmigte der preußische Schulminister in einem Erlass vom 19. August 1914 („Beurlaubung von Schulkindern zum Viehhüten“), dass „für die Dauer des jetzigen Ausnahmezustandes Schulkinder im Bedürfnisfall auch zum Viehhüten beurlaubt werden können. Hierbei ist jedoch darauf Bedacht zu nehmen, dass die zu beurlaubenden Kinder, soweit es irgend angeht, täglich 2 bis 3 Stunden am Unterricht teilnehmen." (Ministerium der geistlichen und Unterrichts-Angelegenheiten, Einsatz von Schülern in der Landwirtschaft, 1914, S. 94.
} 
kann, wo ein Bedürfnis vorliegt. “699 Die vielen, teilweise sich widersprechenden Regelungen zeigen, dass es auch hinsichtlich der Aufrechterhaltung der landwirtschaftlichen Produktion und der Sicherung des Lebensbedarfs der Zivilbevölkerung keine umfassende Planung und Vorsorge gab. ${ }^{700}$ Durch die englische Blockade des gesamten Nordseeraumes, die am 2. November 1914 verhängt wurde, verschärfte sich die Situation. Die Folgen der Blockade für die Nahrungsmittelversorgung der deutschen Zivilbevölkerung waren verheerend. Allein 1916 sank der Import von Lebensmitteln innerhalb weniger Monate um die Hälfte, nachdem die Blockadepolitik der Lebensmittelexporte aus den skandinavischen Ländern verschärft worden war. ${ }^{701}$ Da sich im Laufe des Krieges auch die Arbeitskräftesituation in der Landwirtschaft weiter drastisch verschlechterte ${ }^{702}$, griff man in zunehmendem Maße zunächst auf die Schüler und dann auch auf die Schülerinnen als Arbeitskräfte zurück, wie aus den Erlassen der Kultusbehörden hervorgeht. So wies der preußische Unterrichtsminister mit Erlass vom 5. März 1915 auf die schwierige Situation in der Landwirtschaft hin und regelte die Beurlaubung der Schulkinder: "Die ordnungsgemäße und rechtzeitige Durchführung der landwirtschaftlichen Arbeiten wird in diesem Jahre wegen des Mangels an Arbeitskräften und Gespannen voraussichtlich besonderen Schwierigkeiten begegnen und in vielen Fällen nur mit Zuhilfenahme der größeren Schulkinder sich ermöglichen lassen.“ Er ermächtigte die Regierungen und die Provinzialschulkollegien ,für die Dauer des Krieges, älteren Schulkindern im Bedarfsfall für landwirtschaftliche Arbeiten, Gartenbestellung usw. [...] den erforderlichen Urlaub zu gewähren““703. In der Folgezeit wurden die Schulen durch die Kultusbürokratie immer wieder zu allgemeiner Erntehilfe oder zu ganz bestimmten landwirtschaftlichen Hilfseinsätzen aufgefordert, ${ }^{704}$ wobei diese Tätigkeiten häufig als „Kampf“ bezeichnet wurden, als Kampf an der „Heimatfront“. Im Erlass zur „Bekämpfung der Obst- und Gemüseschädlinge durch Schuljugend. - Nutzbarmachung der Erzeugnisse des Waldes“ vom 15. Mai 1915 heißt es:

„Die umsichtige Bekämpfung der Obst- und Gemüseschädlinge unter den Insekten ist aus naheliegenden Gründen gerade im laufenden Jahre dringend erwünscht. Bei zweckentsprechender Belehrung und Anleitung kann die Schuljugend sich bei diesem Kampfe erfolgreich betätigen und gege-

\footnotetext{
${ }^{699}$ Ministerium der geistlichen und Unterrichts-Angelegenheiten, Einsatz von Schülern in der Landwirtschaft, 18. August 1914.

${ }^{700}$ Siehe: Sicken, Die Festungs- und Garnisonstadt Wesel im Ersten Weltkrieg, in: Kirchgässer/Scholz (Hrsg.), Stadt und Krieg (1989), S. 127.

${ }^{701}$ Siehe: Roerkohl, Hungerblockade und Heimatfront (1991) Nr. 10, S. 16.

702 „In der zweiten Hälfte des Jahres 1917 waren von den insgesamt in der Landwirtschaft beschäftigten 7,8 Millionen Männern 3,5 Millionen eingezogen“(Huegel, Kriegsernährungswirtschaft Deutschlands während des Ersten und Zweiten Weltkrieges im Vergleich 2003, S. 190).

${ }^{703}$ Ministerium der geistlichen und Unterrichts-Angelegenheiten Beurlaubung von Schulkindern für landwirtschaftliche Arbeiten usw. 5. März 1915.

${ }^{704}$ Auf Sammelaktionen wird hier nicht eingegangen; siehe: 2.3 Sammlung von Naturerzeugnissen.
} 
benenfalls die Obst- und Gemüseernte vor empfindlicher Schädigung bewahren helfen. Daher würde nichts dagegen sprechen, wenn in Notfällen Schulklassen zur Abhilfe, z. B. zur Beseitigung einer starken Raupenplage, aufgeboten werden.“705

Außerdem wurden die Schulen zur ,Bekämpfung des Kartoffelkäfers', zur ,Unkrautvertilgung', zur ,Vertilgung der Raupennester' sowie zur ,Vertilgung von Mäusen und Hamstern' u. a. aufgerufen. Dass diesen Aufforderungen offensichtlich in großem Maße Folge geleistet worden ist, zeigt ein Rundschreiben des Kriegswirtschaftsamtes für die Provinz Sachsen an die Kreisschulamtsinspektoren des Bezirks vom 4. Dezember 1917:

„Die Gefährdung des Ertrags unserer Felder durch Hamster und Mäuse hat die Aufmerksamkeit auf die Heranziehung unserer Schuljugend zur Vertilgung der schädlichen Nager gelenkt. Es liegt uns ein Bericht über die vorbildliche Betätigung der Knaben der Ober und Mittelschulen hiesiger Schulen vor, die teils aus eigenem Antriebe, teils auf Anordnung der Schulen hier an bis zu zwei oder drei Tagen beinahe 10.000 Hamster und etwa 50.000 Mäuse getötet haben. Dabei ist zu erwägen, daß die Erfurter Feldmark recht klein ist und daß die Inhaber der Klein- und Schrebergärten für die Tötung der Mäuse selbst gesorgt haben. An Beute wurden eingebracht: rund 9 Zentner Roggen, 44 Zentner Weizen, 15 Zentner Hafer, 15 Zentner Gerste, 7 Zentner Hülsenfrüchte, 1 Zentner gemischte Früchte. “706

Wegen des großen Nahrungsmittelmangels wurden ab 1915 die Schüler immer wieder auch zur ,Nachlese' auf den Feldern eingesetzt, wie z. B. aus dem preußischen Erlass vom 3. Juli 1915 hervorgeht:

„Nach der Getreideernte des vorigen Jahres haben in einem Schulaufsichtsbezirk Schulen unter Aufsicht ihrer Lehrer mit Erlaubnis der Besitzer auf den Feldern zum Besten des Roten Kreuzes Ähren gelesen und, wo noch alte Frauen oder arme Leute sich die Mühe des Ährenlesens machten, erst nach diesen. Von nur 29 Schulen des betreffenden Kreises, die Gelegenheit zum Ährenlesen gefunden hatten, sind Getreidemengen im Gesamtwert von $900 \mathrm{M}$ dem Verkommen entzogen und zum Besten des Roten Kreuzes dem Verbraucher zugeführt worden. Neben der dadurch geförderten Erziehung der beteiligten Schulkinder zur Sparsamkeit und zum Gemeinsinn erscheint der wirtschaftliche Erfolg von nicht zu unterschätzender Bedeutung. ${ }^{\text {" } 707}$

Auch die „Nachlese der Kartoffeln vor allem“ wurde von den Behörden propagiert. Wie groß der Arbeitskräftemangel in der Landwirtschaft im Herbst 1917 geworden war, dokumentiert ein preußischer Erlass vom 25. September. In ihm wurden die Schulleiter aufgefordert, auch die jüngeren Schüler vom Unterricht zu befreien, damit sie die noch nicht schulpflichtigen Geschwister zu Hause beaufsichtigen konnten, während die Mütter ihrer Arbeit auf dem Felde nachgingen.

\footnotetext{
705 Eckert, Gemeinde- und Schulchronik, von Lowkowitz, http://www.schloss-ellguth.de/lowkowitz2.htm (05.04.2008).

${ }^{706}$ Sauer, Plakate, Geschichte Lernen, Heft 114 (2005).

${ }^{707}$ Ilgen, „Vergessene" Krieger, in: Deutsches Philologen-Blatt 1916, S. 315.
} 
Das am 5. Dezember 1916 in Kraft getretene „Gesetz über den vaterländischen Hilfsdienst““708 war auch für die höheren Schulen von großer Bedeutung, denn es betraf alle männlichen Schüler, die das 17. Lebensjahr vollendet hatten. Als vaterländischer Dienst galten u. a. die Arbeiten in der Landwirtschaft und in der Krankenpflege, für die die Schüler bereits seit Kriegsbeginn in großem Umfange herangezogen worden waren. Da die Leitung des vaterländischen Hilfsdienstes bei dem vom ,Preußischen Kriegsministerium' errichteten Kriegsamt lag, entschied der preußische Unterrichtsminister nicht mehr allein über die landwirtschaftlichen Einsätze der Schulkinder. Es kam deshalb in der Folgezeit immer wieder zu Auseinandersetzungen zwischen der Militär- und der Kultusverwaltung.

„So beschwerte sich am 28. Dezember 1916 das Kgl. Provinzial-Schulkollegium für Hessen/Nassau über den Antrag des Stellv. Kommandierenden Generals des 18. Armeekorps, zur Behebung des Mangels an Arbeitskräften in den landwirtschaftlichen und gärtnerischen Betrieben die städtische Schuljugend vom 12. Lebensjahr ab aufwärts zur Mitarbeit heranzuziehen und zur Vorbereitung für diese geplante Tätigkeit an jeder Anstalt eine Organisation zur theoretischen und praktischen Heranbildung für den Hilfsdienst zu schaffen." ${ }^{* 709}$

Am 7. Januar 1917 forderte das Kriegsamt dringend die stärkere Heranziehung der städtischen Schuljugend beiderlei Geschlechts „,vom 12. Lebensjahr“ an bei der Bestellung der Ernte in landwirtschaftlichen und gärtnerischen Betrieben, obwohl dieses eindeutig dem o. g. Gesetz widersprach. Weiter verlangte es eine umfassende Organisation der Kinderhilfsarbeit, die im Einvernehmen mit den Verwaltungsbehörden, den Schulverbänden, den Schulleitern und den Leitern der militärischen Jugendbehörden geschaffen werden sollte. Weil jede gesetzliche Handhabe zur zwangsweisen Heranziehung fehlte, sollte die Mitarbeit der städtischen Jugend, für die jede Schule bei den Eltern und den Kindern werben sollte, freiwillig sein. Unter Berufung auf die landesübliche Praxis, in den ländlichen Bezirken die Schuljugend bereits vom 12. Lebensjahr aufwärts zur Mitarbeit in der Landwirtschaft heranzuziehen, kritisierte das Kriegsamt in einem weiteren Schreiben vom 19. Februar 1917, dass bisher zu wenig Knaben und Mädchen der städtischen Schulen für diese Zwecke herangezogen worden seien. Um dem für die Zukunft abzuhelfen, verlangte es die systematische Vorbereitung der Schuljugend bis herab zur zwölften Altersklasse, die konsequente Anwendung und die Befolgung eines Arbeitsplans für den Helfer- und Sammeldienst der Jugend. Dieser sah jährlich von März bis November jahreszeitlich bedingte Hilfsleistungen sowohl bei der Bestellung der Felder und Gärten als auch bei den Getreide-, Heu-, Kartoffel-, Obst- und Rübenernten vor. Zusätzlich verlangte der Arbeitsplan von den Schulkindern das Ährenlesen und das Sammeln von Arznei-

\footnotetext{
${ }^{708}$ Gesetz über den vaterländischen Hilfsdienst in Reichs-Gesetzblatt 1916 (5. Dezember 1916); abgedruckt in: Cartarius, Deutschland im Ersten Weltkrieg. Texte u. Dokumente 1914-1918 Nr. 2931 (1982), S. 92-94.

${ }^{709}$ Wegener, Das Joachimsthalsche Gymnasium - die Landesschule Templin (2007), S. 98.
} 
pflanzen, Beeren, Brennnesseln, Bucheckern, Eicheln, Hagebutten, Haselnüssen, Kamille und Weißdornfrüchten. ${ }^{710}$ Zwar konkretisierte das Unterrichtsministerium mit Runderlass vom 21. Februar 1917 die „Heranziehung der städtischen Jugend zu landwirtschaftlichen Hilfsmaßnahmen bei der Frühjahrsbestellung“, die Regelungen gingen dem Kriegsamt aber nicht weit genug. Es legte deshalb am 15. Mai 1917 Vorschläge für eine radikale Neuordnung des Schülerhilfsdienstes vor. Danach sollten generell in allen Provinzen des Königreiches Preußen und in den Bundesstaaten des Deutschen Kaiserreiches ,Kriegswirtschaftsämter' gebildet werden, die für den Einsatz der Schüler in der Landwirtschaft und in der Industrie verantwortlich sein sollten. Diese ,Kriegswirtschaftsämter' sollten die Befugnisse der bereits bestehenden Organisationen für Schüler übernehmen. Schüler, die für den landwirtschaftlichen Hilfsdienst bestimmt waren, sollten als Jungmannen“ eigene Jungmannen-Kompanien bilden und unter der Leitung eines Lehrers oder anderen Führers bei landwirtschaftlichen Einsätzen, als ,Trupps' zuammengefasst, arbeiten.

\begin{abstract}
„Zur umgehenden Durchführung dieser Notstandsarbeiten sollte das Unterrichtsministerium die Provinzial-Schulkollegien anweisen, alle zur Land und sonstigen Kriegsarbeit beurlaubten Jungmannen, also auch die unter 17 Jahre alten Jungmannen, als im vaterländischen Dienst beschäftigt anzusehen. [...] Parallel dazu wurde beim Stab des Kriegsamtes ein Referat für Jungmannen eingerichtet, das in enger Zusammenarbeit mit den einzelnen Kriegswirtschaftsämtern für die Sache die Propaganda in der Landwirtschaft und in den höheren Bildungsanstalten über die einzelnen Vertrauensmänner aus dem Kreise der Lehrerschaft zu machen hatte.“711
\end{abstract}

Das Provinzial-Schulkollegium in Brandenburg riet dem Kultusminister dringend ab, die Organisation für die Sommer- und Herbstarbeiten militärischen Stellen zu übertragen und die zahlreichen in der Landwirtschaft engagierten Schüler den Jugendkompanien ${ }^{712}$ einzugliedern, hatte jedoch selbst keine Bedenken, auch Schüler, die das 17. Lebensjahr noch nicht vollendet hatten, für Hilfsdienste zu beurlauben. Während der Unterrichtsminister den Forderungen des Kriegsamtes und der Generalkommandos der Armeekorps schließlich nachgab, widersetzte sich der Oberpräsident der Provinz Brandenburg einer Eingliederung jener Schüler in die Jugendkompanien und forderte die Beibehaltung des Grundsatzes der Freiwilligkeit des Arbeitseinsatzes. Das Kriegsamt setzte sich schließlich durch und ließ am 15. November 1917 im ,Zentralblatt für die gesamte Unterrichtsverwaltung in Preußen’ den Erlass „Die Re-

\footnotetext{
${ }^{710}$ Wegener, Das Joachimsthalsche Gymnasium - die Landesschule Templin (2007), S. 99.

${ }^{711}$ Wegener, Das Joachimsthalsche Gymnasium - die Landesschule Templin (2007), S. 102.

712 Durch die Bildung der Jugendkompanien (in Preußen mit Erlass vom 16. August 1914), denen sich bis Ende 1914 etwa 600.000 Jugendliche angeschlossen hatten, wurden der Landwirtschaft zunächst viele jugendliche Arbeitskräfte entzogen, da sie für ihre vormilitärische Ausbildung für sechs bis zehn Wochen vom Unterricht befreit wurden. Für die Ernte 1915 und die der folgenden Jahre wurden die Jugendkompanien dann oft geschlossen zum Ernteeinsatz abkommandiert. Siehe: Anhang, Seite 69.
} 
gelung der Vermittlungsfrage für die Jungmanneshilfe “"713 veröffentlichen. Insgesamt ist deutlich geworden, welch große Bedeutung von amtlichen Stellen dem Einsatz von Schülern in der Landwirtschaft und damit für die Versorgung der Bevölkerung zugemessen wurde. Je länger der Krieg dauerte und je größer der Mangel an Arbeitskräften wurde, umso stärker wurde der Einfluss der Militärverwaltung auch in diesem Bereich. Dass schließlich sogar die freiwillig in der Landwirtschaft arbeitenden Schüler der höheren Schulen wie die Mitglieder der Jugendkompanien „Jungmannen“ genannt und zentral von Kriegsamt eingesetzt wurden, zeigt, in welch großem Umfang inzwischen auch die Schulen militarisiert worden waren. ${ }^{714}$ Wie die Soldaten an der Front so sollten auch die „Jungmannen“ für ihren landwirtschaftlichen Arbeitseinsatz an der „Heimatfront“ nach dem Willen des Kriegsamtes einen ,Orden’ (,Jungmannenabzeichen“) verliehen bekommen, das Vorhaben scheiterte jedoch an fehlenden finanziellen Mitteln. ${ }^{715}$

Im Folgenden soll konkret am Beispiel einiger Schulen auf die Durchführung der Arbeitseinsätze und auf aufgetretene Probleme eingegangen werden. Dabei soll u. a. der Frage nachgegangen werden, ob die Arbeitseinsätze der Kinder und der Jugendlichen auch eine Form der politischen Gesinnungsbildung waren und inwieweit sie der Vorbereitung auf den Militärdienst dienten. Entsprach es der damaligen Praxis der Schulen, dass die Einsätze fast militärisch organisiert und durchgeführt wurden, wie es auf einem Bild aus dem Jahre 1916 zu sehen ist? Dort ist ein Hauptlehrer mit den Kindern seiner Schule - „,seiner Schüppgarde bei Sonnenblumenpflanzungen“ - abgebildet, die die Pflanzgeräte wie Waffen halten und teilweise fast uniformiert wirken. ${ }^{716}$

Vor dem Beginn eines landwirtschaftlichen Einsatzes auf einem Landgut hielt ein Klassenlehrer einer Berliner Schule zur Einstimmung und Vorbereitung seiner gymnasialen Oberstufenklasse eine längere Rede ${ }^{717}$, die eine Reihe von Rückschlüssen auf den Arbeitseinsatz ermöglicht. Vor allem fällt am Vokabular des Lehrers auf, dass der landwirtschaftliche

\footnotetext{
${ }^{713}$ Kriegsamt, Regelung der Vermittlungsfrage für die Jungmannenhilfe 1917 (15. November 1917).

${ }^{714}$ Da die „Jungmannen im landwirtschaftlichen Hilfsdienst“ und die Jungmannen in den ,Jugendabteilungen für die militärische Vorbildung der Jugend“ häufig verwechselt wurden, stellte das Kriegsamt in einem Erlass die Unterschiede dar. „Um Verwechslungen vorzubeugen, wird nach dem Vorgehen des Kriegswirtschaftsamtes für Sachsen angeordnet, die einheitliche Bezeichnung ,JMO' für die Jungmannen-Organisation im landwirtschaftlichen Hilfsdienst zu gebrauchen." (Kriegsamt, Jungmannen im landwirtschaftlichen Hilfsdienst und Jugendabteilungen für die militärische Vorbildung der Jugend 1917 [31. Oktober 1917]).

715 Jungmannenauszeichnung für Schülen höherer Lehranstalten für die männlichen Schüler 1917 (8. Oktober 1917). Da die Auszeichnung nicht finanzierbar war, schlug das Kriegsamt vor, Schüler, die sich im landwirtschaftlichen Hilfsdienst besonders bewährt hatten, ,durch einen Vermerk im Schluß- und Abschlusszeugnis auszuzeichnen."

${ }^{716}$ Löher, Mit Gott für König und Vaterland, in: Löher/Wulf (Hrsg.), Furchtbar dräute der Erbfeind! Band 3, S. 105.

${ }^{717}$ Wettley, Zum landwirtschaftlichen Hilfsdienst unserer Schüler, Deutsches Philologen-Blatt 1917, S. 236. Bei der Klasse handelte es sich um eine Prima eines Berliner Realgymnasiums.
} 
Einsatz offensichtlich als Militärdienst gedacht war und als solcher organisiert werden sollte. So rückten die Schüler ,ins Feld“ und hatten dem Lehrer „,bedingungslosen, militärischen Gehorsam entgegenzubringen“. Den „Befehlen“ des Lehrers als dem „Kompanieführer“ hatten sich die Schüler ,während des Hilfsdienstes zu unterwerfen“. In den Stuben, in denen sie „einquartiert“ wurden, hatte „militärische Zucht, Ordnung und Sauberkeit (zu) herrschen“. Auch von „Kameraden“ und „Stubenältesten“ war die Rede.

Große Sorge machte sich der Lehrer offensichtlich um die Moral seiner Schüler. Er fordert sie gegenüber „weiblichen Arbeitskräften [...] Frauen und Mägden“ zu „Vorsicht und vornehmer Zurückhaltung“ auf. Er betonte, dass es ihm eine große Enttäuschung wäre, wenn sie ,in einer Zeit, wo ihre Brüder und Väter im schwersten Todeskampf vorm Feind stehen, nach unsauberen Dingen trachteten und sich durch Unreinheiten entweihten“. Zum Schluss spricht der Lehrer noch zwei Motive an, die viele Schüler bewogen haben dürften, sich für den Arbeitseinsatz auf dem Lande freiwillig zu melden: „Ihr habt recht, wenn Ihr Euch auf die bevorstehende Unterbrechung der Schularbeit freut [...]. Ihr sagt der Großstadt mit ihrem Hasten und Lärmen, ihren schweren Nahrungssorgen auf lange Zeit Lebewohl.“

Im Unterschied zu den in euphorischer Stimmung erlebten ersten Kriegsmonaten wollten viele Schüler offensichtlich jetzt vor allem dem Schulalltag entfliehen und sich endlich wieder einmal satt essen. Patriotisches Pflichtbewusstsein gegenüber dem bedrohten Vaterland kam bei den meisten sicher erst an zweiter Stelle.

Sehr detailliert informiert der Bericht eines Gymnasialprofessors des Hans-CarossaGymnasiums in Landshut (Königreich Bayern) über den Einsatz seiner „Jungmannen in Weihenstephan bei Hohenthann im vierten Kriegsjahr (1918)“6718. An ihm soll der Ablauf eines Arbeitstages exemplarisch dargestellt worden.

6:15 Uhr

7:00 Uhr

Anschließend

Ca. 10:00 Uhr

Ca. 10:30 Uhr
Wecken der 12 Landshuter Schüler; Aufschütteln der Strohsäcke, Zusammenlegen der Decken, Reinigen des Zimmers

Frühstück

Der Pächter des Hofes verteilt die Arbeit:

- zwei Schüler begießen die Blumen und die Gemüsepflanzen mit Wasser

- einer begleitet das Doppelochsenfuhrwerk an die acht Kilometer entfernte Bahn

- die anderen arbeiten unter Leitung der Frau des Oberknechtes auf dem Kartoffelacker; sie müssen den Acker vom Unkraut befreien.

Brotzeit auf dem Bauernhof

Arbeit auf dem Feld, zusammen mit Kriegsgefangenen aus Russland und Frankreich; Wagen werden mit Heu beladen.

\footnotetext{
${ }^{718}$ Ebermeier/Mayer-Mommertz/Pfaffenzeller, Die Geschichte des Hans-Carossa-Gymnasiums Landshut (2004),
} S. 207-209. 
Ca. 13: $00 \mathrm{Uhr}$

Ca. 14: $00 \mathrm{Uhr}$

Ca.18:00 Uhr

Anschließend

20:30 Uhr
Gemeinsames Mittagessen auf dem Feld

Fortsetzen der Arbeit; Abbruch wegen eines Regenschauers;

Brotzeit;

Rüben und Krautpflanzen werden gesetzt;

Rückmarsch zum Hof „unter Absingen eines Marschliedes“.

Abendessen

„Führer“ gibt einen „kurzen Überblick über die jüngsten Kriegsereignisse“"

Freizeit; Ansichtskarten werden geschrieben; Bücher gelesen; gemeinsames Singen von Liedern

Es ,ertönt das Gebetläuten“; Nachtruhe.

Wie bei den Berliner „Jungmannen“ so war auch im bayerischen Weihenstephan der Ernteeinsatz militärisch organisiert. Jede Stube hatte einen „Wochendiensthabenden“, der die Stube reinigte, und wenn die Schüler gruppenweise zum „Einsatz“ gingen, so traten sie ,in geschlossenem Zuge“ an und rückten „unter Absingen eines Marschliedes“ ab.

Aus Sicht des Lehrers nahmen die Schüler die harte und für sie ungewohnte Arbeit in dem Bewusstsein auf sich, ,dem Vaterland nützliche Dienste erwiesen zu haben, sich selbst zur Kräftigung des Körpers, dem allgemeinen Besten zu Nutz und Frommen“. Ob die Schüler ihre Arbeit auch so empfunden haben, lässt sich dem Text nicht entnehmen.

Ähnlich wie in Weihenstephan verliefen auch die Arbeitstage für die Schüler des Gymnasiums zu Berlin-Steglitz, wie aus den Weltkriegs-Erinnerungen der Schule hervorgeht ${ }^{719}$. Sie waren auf einem Rittergut bei Potsdam (Provinz Brandenburg) eingesetzt. Der Leiter der Gruppe, ein Lehrer, beklagt, dass drei „Jungmannen“ sich deshalb erkältet hätten und zu Hause hätten bleiben müssen, weil das Kriegswirtschaftsamt nicht genügend Decken geliefert habe. Mit ihnen sei die Gruppe von „30 auf 21 zusammengeschmolzen“. Seiner Meinung nach waren manche ,in Anbetracht des jugendlichen Alters doch der Arbeit nicht gewachsen“. Die Zurückgebliebenen seien ,,allerdings mit die fleißigsten Arbeiter“ gewesen. Etwas später, am 9. Oktober 1918, geht der Lehrer genauer auf die ungewohnte Rolle seiner Schüler ein, und zwar recht kritisch:

„Sie hatten wohl auf Betten gerechnet, erhielten aber nur ein Strohlager mit Decken, noch dazu in unzureichender Zahl; es war ein Glück, dass nach den ersten acht Tagen eine Anzahl von ihrem Sonntagsurlaub nicht zurückkehrte, so dass die treu gebliebenen mehr Decken zur Verfügung hatten, was für die kälter werdenden Oktobernächte sehr notwendig war. Das Essen war, auch unter Berücksichtigung der überall schlechten Versorgung mit Nahrungsmitteln, sehr einfach. Wahrscheinlich hatten die Jungen mit mehr gerechnet. Das war sicher auch ein Grund dafür, weshalb Eltern ihre Jungen nicht mehr zurückfahren ließen. Die Stimmung war nicht schlecht, der Humor verließ die Jungen auch bei der Arbeit nicht. Natürlich hatten sie sich am ersten Tage sogleich so überanstrengt, dass sie in den nächsten Tagen nicht viel leisten konnten. [...] Seitens der

\footnotetext{
${ }^{719}$ Lehmann, Weltkriegs-Erinnerungen aus dem Kreise des Gymnasiums zu Berlin-Steglitz (1925).
} 
Gutsherrschaft hatte man wohl mehr von den Jungen erwartet, wobei jedoch die landwirtschaftliche Leistungsfähigkeit der Stadtjungen zweifellos überschätzt wurde.“

Der Lehrer beklagt auch, dass es an der nötigen Nachtruhe gefehlt habe, ,,wodurch zweifellos die Arbeitsfähigkeit beeinträchtigt wurde“. Ab 21 Uhr sollte geschlafen werden, ,aber das war nicht zu erreichen, da Störenfriede darunter waren“. Im Unterschied zu den meisten Berichten über die Arbeit der Schüler in der Landwirtschaft wird hier in überraschend deutlicher Weise auch Kritik geäußert.

Dass auch Schüler anderer Schulen Probleme hatten, wird in dem Beitrag „Die Leistungen unserer Schüler im Kriege“ im Jugenddank-Kalender 1919 angedeutet:

„1916 fing's schüchtern an, dass unsere Jungen hinauszogen auf's Land, um draußen zu helfen, wo die Männer eingezogen waren und wo es an geschulten Kräften fehlte. Da lachten die Bauern wohl zuerst ordentlich über die ungeschickten Städter, die keine Harke anfassen konnten; sie wollten ihnen zeigen, , was eine Harke ist' - aber bald zeigten ihnen die Großstädter mit zusammengebissenen Zähnen, daß ,Kien' in ihnen war. Mancher hat natürlich da draußen , schlapp gemacht' und ist dann mit Recht und Höflichkeit ,in die Heimat abgeschoben' worden; mancher auch, der glaubte, die Schule habe ihn vorsorglich nur hinausgesandt, damit er ordentlich Fett ansetze, und daneben faulenzte, fand sich schmählich enttäuscht und gab, wenn er klug war, klein bei, indem er ordentlich ,schuftete’. Aber die Mehrheit hat doch tüchtig ihren Mann gestanden.“" ${ }^{720}$

Von solchen Problemen ist in einem Bericht über die Erntehilfe des Oranienburger Realprogymnasiums in Liebenberg (Provinz Brandenburg) nicht die Rede, sondern es wird vom Lehrer M. Lindenau aus Oranienburg bei Berlin ein idyllisches Bild gezeichnet. ${ }^{721}$ Die Schüler wurden unter Leitung einiger Lehrer für vier Tage auf dem Gut des Fürsten Eulenburg in Liebenberg bei der Kartoffelernte eingesetzt. Ihre Arbeit bestand „hauptsächlich in dem Aufsammeln der von den Wildschweinen herausgewühlten, angefrorenen und faulen Kartoffeln“. Es wird hervorgehoben, „mit welchem Eifer ein jeder Schüler die ihm auferlegte Aufgabe erfüllte. Jeder suchte seine Sache möglichst gut zu machen, und wenn auch manchem das andauernde, ungewohnte Bücken sauer wurde, man ließ sich keine Ermüdung anmerken“. Vielleicht waren die Schüler dieser Schule tatsächlich besonders motiviert, denn ihnen wurde „gebührender Lohn“ erteilt. ,Jeden Abend durften sie sich ihre Rucksäcke mit selbst gebuddelten Kartoffeln füllen, und wer die heimkehrenden, schwer beladenen Schüler in ihrem heiteren Aufzuge auf dem Bahnhof gesehen hat, dem wird dieses Bild der Gymnasiasten in Liebenberg eine freundliche Erinnerung an die ernste Kriegszeit bleiben.“

Anders als andere schulische Hilfstrupps waren die Schüler des Oranienburger Gymnasiums nicht kaserniert, sondern fuhren jeden Tag zum Arbeitsort mit dem ,Kartoffelzug' morgens um 6 Uhr, den offensichtlich auch die Schüler anderer Gymnasien benutzten.

\footnotetext{
${ }^{720}$ Hildebrandt, Die Leistungen unserer Schüler im Kriege, (1919), S. $65 f$.

${ }^{721}$ Lindenau, Die Erntehilfe des Oranienburger Realprogymnasiums in Liebenberg, Deutsches Philologen-Blatt 1916, S. 781.
} 
Ein sehr ausführlicher Bericht eines Lehrers liegt auch über den Einsatz Gelsenkirchener Schüler auf der Königlichen Domäne in Calbe an der Saale (Provinz Sachsen) im Jahre 1917 vor. ${ }^{722}$ Als das Kriegswirtschaftsamt der Provinz Westfalen sich am 1. Mai 1917 mit einem Aufruf zur freiwilligen Landarbeit an die höheren Schulen in Gelsenkirchen wandte, meldeten sich 150 Schüler. Diese wurden unter Führung eines Oberlehrers in sechs Gruppen eingeteilt und in der Stadtgärtnerei und bei einigen heimischen Landwirten drei Wochen lang auf den Ernteeinsatz vorbereitet. „Nun wartete man auf Aufforderung seitens der Landwirte, die jedoch im Sommer, wie fast überall in Westfalen, nicht erfolgte.“ Die 50 Kräftigsten wurden schließlich für den Einsatz auf der Domäne, die die Stadt Gelsenkirchen (Provinz Westfalen) gepachtet hatte, ausgewählt. „Nach militärärztlicher Untersuchung konnten die „Jungmannen“ am 20. Juli ihre Reise antreten. Von Anfang an schien es den Führern notwendig, eine gewisse militärische Einteilung zu treffen, was sich vorzüglich bewährte.“

Der Lehrer beschrieb ausführlich den Tagesablauf, die Unterbringung sowie die Art der Arbeit und ging dann auch auf einige Probleme ein:

"Was die Arbeitsfreudigkeit der Schüler betrifft, so erwies sich das im Aufrufe vom August 1917 Gesagte als richtig. In der ersten Woche ein großer Eifer, dann Nachlassen infolge von Ermüdung oft bis zum Verdruß, dann infolge der Gewöhnung wieder reger Eifer. Es verlohnt sich vielleicht die Frage der Rentabilität der Schülerarbeit kurz zu betrachten, mit der unsere Landwirte leider immer noch allzu sehr rechnen und die ich für einen Hauptgrund halte, warum so wenig Schüler in Westfalen angefordert worden sind. In den meisten Fällen wird nur bei richtiger Arbeitsteilung das Ergebnis der Arbeit als befriedigend gelten können. Treten besonders günstige Umstände hinzu, wie es in Calbe der Fall war ${ }^{723}$, so kann das Ergebnis sogar als gut bezeichnet werden. “724

Insgesamt dauerte der Ernteeinsatz von Ende Juli bis zum 7. August 1917; er musste „wegen Mangels an Arbeit nach dem Einbringen der Körnerfruchternte“ vorzeitig abgebrochen werden.

$\mathrm{Zu}$ einer ähnlich positiven Einschätzung der Landarbeit seiner „Jungmannen“ kam ein Lehrer vom Gymnasium zu Cöln in der Eifel (Rheinprovinz), der über verschiedene Arbeitseinsätze seiner Schule im Kreis Daun (Eifel) berichtet, an denen jeweils ca. 50 Schüler teilgenommen hatten:

„In dem Zeugnis, das der Führer sich von den Arbeitgebern erbat, hatte er angeben lassen, inwieweit die Arbeit eines Jungmannen der einer gleichaltrigen ländlichen Arbeitskraft entspreche. Da-

\footnotetext{
${ }^{722}$ Gutzmann, Die Schüler der höheren Lehranstalten in der Landarbeit, Deutsches Philologen-Blatt 1917, S. $607 f$.

${ }^{723}$ Der Lehrer schreibt dazu: „Für die Unterhaltung der Schüler wurde in der Art gesorgt, daß geschichtliche und geologische Vorträge über die Umgebung von den Führern gehalten, Ausflüge in die nähere und weitere Umgebung, z.B. nach Halle, Magdeburg, Wittenberg, zur Rudelsburg und in den Harz, unternommen wurden." Außerdem standen den Jungmannen eine Leihbibliothek und zwei Zeitungen zu ihrer Zerstreuung zur Verfügung.

${ }^{724}$ Der Lehrer schreibt dazu: „Für die Unterhaltung der Schüler wurde in der Art gesorgt, daß geschichtliche und geologische Vorträge über die Umgebung von den Führern gehalten, Ausflüge in die nähere und weitere Umgebung, z.B. nach Halle, Magdeburg, Wittenberg, zur Rudelsburg und in den Harz, unternommen wurden. Außerdem standen den Jungmannen eine Leihbibliothek und zwei Zeitungen zu ihrer Zerstreuung zur Verfügung.
} 
nach war festzustellen, dass von 50 Fällen in 27 eine ganze, in 14 eine dreiviertel und in 9 eine halbe ersetzt wurde. [...] Auch das Urteil, das der Führer von den Behörden, dem Landrat des Kreises Daun und den Herren Bürgermeistern erhielt, gipfelte in der, vollen Anerkennung für die wertvolle Hilfe'، ،725

Seltener als die Gymnasiasten wurden die älteren Schüler der Volksschulen auf dem Lande eingesetzt. Ein Lehrer aus Solingen schrieb ebenfalls sehr positiv über die gemachten Erfahrungen:

„Als im vorigen Jahre in der Übergangszeit so manche Stadt des Industriebezirks ohne Kartoffeln war, konnte Solingen auf den Ertrag eigener Felder zurückgreifen. Die Schwierigkeit, für die Bevölkerung sofort die nötigen Mengen zur Verfügung bereitzustellen, veranlasste den verantwortlichen, verdienstvollen Leiter der betr. Stelle, den Rektor einer hiesigen Volksschule, seine oberste Klasse heranzuziehen. [...] (Die) Arbeitsfreude unserer Jungen ist gut geblieben, ihre Leistungen sind prachtvoll. Die Arbeiten der höheren Schüler, Volksschüler und Volksschülerinnen gehen ruhig ohne jede Disharmonie nebeneinander her.“726

In Flensburg hatten sich zwar im Jahre 1914606 Schüler zum Arbeitsdienst gemeldet, es konnten jedoch lediglich sieben vermittelt werden, da ein Überangebot an Arbeitskräften bestand. Der Aufforderung des für Schleswig-Holstein zuständigen Stellvertretenden Generalkommandos des IX. Armeekorps an die Schulen, sich für die Frühjahrsernte 1917 zur Verfügung zu stellen, folgten 320 Jungen und 81 Mädchen sämtlicher Flensburger Volksschulen. ${ }^{727}$ Über den Ernteeinsatz der Flensburger Volksschuljugend im Jahre 1918 machte die Schuldeputation folgende Angaben: „Von der Hilfsdienstmeldestelle wurden 309 Schüler zur Landwirtschaft vermittelt, die 927 Tage arbeiteten. Außerdem wurde eine Anzahl von Kindern, deren Zahl nicht festgestellt ist, zu landwirtschaftlichen Arbeiten beurlaubt. “728

Angesichts der Bedeutung schulischer Hilfseinsätze für die Landwirtschaft und die Versorgungslage berichteten natürlich auch die Zeitungen häufig über erfolgreiche Aktionen einzelner Schulen. Am 16. Mai 1917 erschien in der Rheinisch-Westfälischen Zeitung ein Artikel über "Gymnasiasten als Landarbeiter“"729 . In ihm heißt es:

„Man schreibt uns aus Trier: Wacker arbeiten jetzt allenthalben unsere Gymnasiasten draußen auf den Feldern der Landleute. Der ungewohnten Tätigkeit haben sie alle bereits die froheste Seite abgewonnen und mit Stolz und Genugtuung schildern sie in launigen Kartengrüßen, die nach Feierabend zwischen Müdigkeit und Lagerstatt geschrieben worden sind, den Ihrigen ihr neues Leben. ,Wir fühlen uns wie Spartaner, essen wie Scheunendrescher und lagern uns nach getaner Arbeit auf

\footnotetext{
${ }^{725}$ Lamath, Die Jungmannen des Kgl. Friedrich Wilhelm-Gymnasiums zu Cöln in der Eifel., Deutsches Philologen-Blatt 1917, S. $642 \mathrm{f}$.

${ }^{726}$ Erbach, Die Schüler höherer Lehranstalten in der Landarbeit, Deutsches Philologen-Blatt 1917, S. 485f.

${ }^{727}$ Hohnsbehn, Die Flensburger Schuljugend in der Zeit des ersten Weltkriegs (1996), S. 256; von den beiden Oberrealschulen und dem Lyzeum meldeten sich 186 Jungen und 100 Mädchen.

${ }^{728}$ Hohnsbehn, Die Flensburger Schuljugend in der Zeit des ersten Weltkriegs (1996), S. 259; Hohnsbehn weist darauf hin, dass in einem anderen Bericht lediglich 128 Schüler genannt werden, die 1.390 Tage gearbeitet hätten.

${ }^{729}$ Gymnasiasten als Landarbeiter, In: Deutsches Philologen-Blatt Korrespondenz-Blatt für den akademisch gebildeten Lehrerstand, 1917, S. 191f.
} 
der Diele wie die Germanen ...' lautete eine solcher Mitteilungen. Aus großen und kleinen Städten sind die Schüler aufs Land gewandelt und dort ist man durchweg mit ihren Leistungen zufrieden. In unserer Moselstadt gab ein Gymnasium 60 Gymnasiasten auf ein Stadtgut, und diese 60 Jungen, zwischen 14 und 17 Jahren, haben ganze Ackerbreiten sauber und korrekt unter der Leitung eines Verwalters bestellt. [...] Ein förmlicher militärischer Schneid beseelt die ackernde Schar. [...] Die Gruppen der Landdienst tuenden Gymnasiasten werden nach einiger Zeit abgelöst, damit die ersteren ihre wissenschaftlichen Studien wieder aufnehmen und die anderen dafür im Ackerdienst sich nützlich machen können. Bei diesem Hilfsdienst auf dem Lande gewinnen beide Teile, der Landmann, der flotte, helfende Hände braucht, und der Gymnasiast, der seinen Gesichtskreis erweitert und den Körper stählt. “730

Der erzieherische Gedanke, die Kluft zwischen Stadt und Land zu verringern, taucht in vielen Berichten und Erlassen auf. Ob der Autor, der auf den gesundheitlichen Aspekt der Landarbeit hinweist (,den Körper stählt“) die Landarbeit als Vorbereitung der Gymnasiasten auf den späteren Einsatz als Soldaten an der Front versteht, geht aus dem Text nicht hervor und kann deshalb allenfalls vermutet werden. Parallelen zwischen der Landarbeit der Schüler und dem militärischen Einsatz der Soldaten klingen hingegen auch in diesem Text an („Ein förmlich militärischer Schneid beseelt die ackernde Schar").

Auch die Deutsche Tageszeitung berichtete am 19. 10. 1917 über „Deutschlands Jugend bei der vaterländischen Hilfsarbeit“"731:

\begin{abstract}
„Die Jungmannen haben sich fast ohne Ausnahmen freiwillig und mit Begeisterung für die von ihnen verlangte vaterländische Hilfspflicht gemeldet. Weit über 20000 konnten je nach Anforderung sowohl dem Großgrundbesitz als auch für die bäuerlichen Anwesen zur Verfügung gestellt werden. Die Anforderungen mussten bei den Kriegswirtschaftsämtern geschehen. [...] Gewöhnlich wurden Gruppen von 15 Schülern gebildet, deren Führung und Aufsicht möglichst eine Lehrkraft übernahm. [...] Die Erfahrungen, die von den Landwirten mit den Jungmannen gemacht wurden, waren zufriedenstellend. Selbstverständlich konnten die städtischen Schüler nicht das gleiche leisten wie ein Landarbeiter. Aber der gute Wille und die Erkenntnis ihrer wichtigen Aufgabe hat sie zu Arbeitskräften gemacht, die manchen Landstrich für die allgemeine Volksernährung sichern konnten, er sonst hätte brachliegen müssen. Ihre wertvollste Leistung war jedoch ihre Erntehilfe. Sie füllten beim Dreschen des Brotgetreides manche empfindliche Lücke aus und halfen vor allem die Kartoffelernte dieses Jahres einzubringen. [...]. Die Jungmannen selbst sind mit der Aufnahme, die sie auf dem Lande fanden, zufrieden. [...] Wohl sind vereinzelte Fälle vorgekommen, in denen nicht alles klappte, wo vor allem das Essen nicht die wünschenswerte Beschaffenheit aufwies. Aber solche einzelnen Fälle werden sich bei jedem Unternehmen ergeben. Sie sind jedenfalls ohne Einfluß auf die große Zahl von Jungmannen, die sich durchaus als Heimatsoldaten gefühlt und erwiesen haben, die im Dienste des Vaterlandes kleine Unannehmlichkeiten ertragen müssen. Daß sie sich draußen wohl fühlten, beweisen die vielen Bande freundschaftlicher Beziehungen, die sich ergeben haben, und die geeignet sind, für heute und spätere Zeiten manchen Gegensatz zwischen Stadt und Land zu mildern und Bauer und Städter einander näher zu bringen.“
\end{abstract}

Dieser Bericht ist ebenfalls durchgehend positiv und deutet Probleme (z. B. schlechtes Essen, mangelnde Effizienz) lediglich an. Auch er versteht den landwirtschaftlichen Hilfsdienst als Kampf an der „Heimatfront“, den die Schüler als „Heimsoldaten“ führen. Am 12. 12. 1917

\footnotetext{
730 Ähnlich wie bei anderen Zeitungsberichten sind sicher auch bei diesem hinsichtlich des Wahrheitsgehaltes Abstriche zu machen, denn solche Berichte waren um der öffentliche Wirksamkeit wegen recht häufig geschönt. ${ }^{731}$ Deutschlands Jugend bei der vaterländischen Hilfsarbeit, Deutsches Philologen-Blatt 1917, S. 609.
} 
erschien erneut in der Deutschen Tageszeitung ein Bericht über „Die Jungmannen bei der nächsten Frühjahrsbestellung“. Aus ihm geht hervor, dass

„im vergangenen Jahr allein durch die Organisation des Kriegswirtschaftsamtes mehr als 30000 Schüler in die Landwirtschaft geschickt worden (sind). In Wirklichkeit haben vielmehr draußen gearbeitet, z. B. bei Verwandten, Bekannten usw. Die Rheinprovinz hatte allein 10000 ausgesandt! Im allgemeinen kann man sagen, dass die Erfahrungen mit den Jungmannen in der Landwirtschaft gut waren und dass man von den Landwirten überwiegend gute Urteile gehört hat. Die nächste Frühjahrsbestellung wird für uns von großer Bedeutung sein und es werden alle mithelfen müssen, dass hierbei das möglichste geleistet wird. Die Hilfe von Jungmannen wird dabei sehr erwünscht sein. Die Landwirte, die solcher Hilfe bedürfen, müssen sich rechtzeitig an das Kriegswirtschaftsamt wenden. Schon hat die Provinz Ostpreußen 30000 Jungmannen erbeten. “732

In dem gleichen Artikel wird noch auf Änderungen in der Jungmannen-Hilfe hingewiesen: Zum einen soll sich jeder Schüler vor dem Ernteeinsatz einer ,militärärztlichen Untersuchung auf seine Eignung“ hin unterziehen und zum anderen soll von dem Grundsatz, ,jeder Kolonne einen Lehrer mitzugeben“, abgegangen werden. „Unter Umständen würde sogar ein Schüler selbst die Aufsicht übernehmen können.“ Offensichtlich waren für den Einsatz in der Landwirtschaft nicht mehr genügend Lehrkräfte bereit oder verfügbar, sodass man auf Schüler als ,Führer' zurückgreifen musste.

Um weitere geeignete Schüler für den Hilfsdienst zu gewinnen, fanden in Deutschland in den Jahren 1917 und 1918 Informationsveranstaltungen statt, z. B. am 24. Januar 1918 im großen Saal der Philharmonie in Berlin für Tausende von höheren Schülern. Wie aus einem Bericht des Provinzialschulkollegiums in Schleswig hervorgeht, ist das offensichtlich nicht gelungen, da die „Schulen über wenige geeignete Führer (verfügten), weil alle kräftigen und älteren Schüler im Felde standen““733.

Das Kriegswirtschaftsamt hatte im Einverständnis mit dem Provinzial-Schulkollegium zu einem Vortrag des Landrats v. Meyer eingeladen, um über die Aufgaben, welche auf die „Jungmannen“ bei der Beschäftigung in der Landwirtschaft zukamen, besser aufzuklären. ${ }^{734}$ Der Redner ging auch auf organisatorische Fragen ein:

„Sämtliche Jungmannen, die bis zum 1. März d.J. das 15. Lebensjahr erreichen, werden auf ihre Verwendbarkeit in der Landwirtschaft erst in einer oberflächlichen (Ausscheidung der von vorneherein Untauglichen), dann in einer genauen, der Heeresmusterung vergleichbaren Untersuchung geprüft. Die Gesamtsumme der Tauglichen wird dem Kriegswirtschaftsamt gemeldet, ihre Verwendung ist jedoch von der Zustimmung der Eltern abhängig. Als Kolonnenführer werden ältere Schüler verwandt, die Lehrer wirken in größeren Schulen als Vertrauensmänner. Sie vermitteln bei Streitfällen zwischen Jungmannen und Arbeitgeber.“

\footnotetext{
732 Jungmannen bei der nächsten Frühjahrsbestellung, Deutsches Philologen-Blatt 1918, S. 12.

${ }^{733}$ LAS, Abtlg. 302, Nr. 3178.

${ }^{734}$ Trantow, Die Jungmannen bei der Landarbeit im Jahre 1918, Deutsches Philologen-Blatt 1918, S. 38.
} 
Dass sich die Schüler einer „der Heeresmusterung vergleichbaren Untersuchung“ unterziehen mussten, zeigt wieder die zunehmende Militarisierung der schulischen Hilfsdienste. Diese Tendenz findet sich ebenfalls in den sehr detaillierten „Leitsätze(n) über die zukünftigen Aufgaben des schulischen Hilfsdienstes “ ${ }^{\text {735 }}$ wieder, die von dem Referenten beim Kriegsamt, Professor Broßmer, zusammengestellt und veröffentlicht wurden.

Welch große Bedeutung dem landwirtschaftlichen Schülerhilfsdienst von amtlicher Seite zugemessen wurde, geht aus einer Denkschrift hervor, die der preußische ,Minister für geistliche und Unterrichtsangelegenheiten’ über die „Beteiligung der Schuljugend bei kriegswirtschaftlichen Arbeiten 1917“ den Abgeordneten des Reichstages vorgelegt und die im Reichsanzeiger vom 20. Februar 1918 veröffentlicht wurde. ${ }^{736}$ In ihr heißt es:

„Nach dem Umfange der geleisteten Arbeit sowie ihrer wirtschaftlichen Bedeutung ist an erster Stelle die Mithilfe der Schülerinnen und Schüler bei den landwirtschaftlichen Arbeiten zu nennen. Auf dem Lande sind fast alle irgend verwendbaren Schulkinder in der Landwirtschaft tätig gewesen. Meist halfen sie in der elterlichen Wirtschaft. Da, wo sich größere Güter befinden, waren sie auch auf diesen tätig. Sie wurden zu landwirtschaftlichen Arbeiten aller Art, sowohl zu den Bestellungsarbeiten im Garten und auf dem Felde, wie besonders zum Graben, zum Säen oder Pflanzen der Kartoffeln, Rüben und der verschiedenen Gemüsearten, zum Jäten und Hacken, als auch zu den verschiedenen Arbeiten bei der Heu-, Getreide- und Obsternte herangezogen. Besonders bedeutungsvoll war ihre Hilfe bei der Kartoffel- und Rübenernte, die zu einem guten Teil durch Schulkinder eingebracht ist. Die größeren Knaben haben vielfach Knechte und Arbeiter ersetzen müssen. In nicht wenigen Betrieben waren sie die alleinigen Mithelfer der Mütter, die während des Heeresdienstes ihrer Männer den ganzen Betrieb führen mussten. So verrichteten 12 bis 14jährige Knaben die schwersten Arbeiten wie Düngen und Pflügen, Säen und Mähen. Selbst die Führung der Selbstbindermähmaschine ist ihnen stellenweise anvertraut worden. Die Mädchen leisteten auch in der Hauswirtschaft und Beaufsichtigung der jüngeren Geschwister gute Dienste. Auf dem ganzen landwirtschaftlichen Gebiet hat sich die Mitarbeit der Schuljugend als unersetzlich und wertvoll erwiesen, dass, wie in den meisten Berichten der Regierungen hervorgehoben wird, ohne die Beteiligung der Schulkinder zahlreiche landwirtschaftliche Betriebe nicht in vollem Umfange hätten aufrecht erhalten werden können und die restlose Einbringung der Ernte, besonders der Kartoffelernte, nicht möglich gewesen wäre. Neben diesen eigentlichen landwirtschaftlichen Arbeiten haben die Schulkinder auch das Vieh gehütet und sich durch Beseitigung des Unkrauts, die Vertilgung der Raupen, Kohlweißlingen und sonstigen Schädlinge verdient haben.“

Der Bericht geht dann auf den Einsatz der Schüler und Schülerinnen der höheren Schulen ein, wobei die Mädchen hauptsächlich beim Anlegen von Gärten und im Gemüseanbau beschäftigt worden sind.

„Beispielsweise haben mitgeholfen: in der Rheinprovinz bei der Frühjahrsbestellung 7500, im Spätsommer 8700 Schüler, in der Provinz Brandenburg rund 8900, in Hessen-Nassau 10150 Schüler und Schülerinnen an 271200 Arbeitstagen und in der Provinz Hannover 15560 Schüler und Schülerinnen an 365950 Tagen. Ein Teil der Schüler ist aufgrund des Hilfsgesetzes tätig, die weitaus größere Zahl frei organisiert. [...] Bei der Betätigung auf landwirtschaftlichem Gebiet ist zu

\footnotetext{
${ }^{735}$ Leitsätze über die zukünftigen Aufgaben des freiwilligen Schülerhilfsdienstes, Deutsches Philologen-Blatt 1918, S. 59f.

${ }^{736}$ Veröffentlicht im Reichsanzeiger vom 20.2.1918; zitiert nach:Beteiligung der Schuljugend bei kriegswirtschaftlichen Arbeiten im Jahre 1917, Deutsches Philologen-Blatt 1918, S. $162 \mathrm{f}$.
} 
scheiden zwischen der Hilfe der Schülerinnen und Schüler bei den Eltern und Verwandten sowie einzelner Schüler in fremden Betrieben einerseits und der Hilfe durch fremde Hilfe von Helferkolonnen oder Arbeitskommandos andererseits. Die erste Art der Verwendung war sehr begehrt, die zweite ist nur vereinzelt in Anspruch genommen worden und zwar deshalb, weil viele Landwirte der Hilfe durch fremde Schüler aus der Stadt anfangs misstrauisch und ablehnend gegenüberstanden. Dagegen berichten verschiedene Provinzial-Schulkollegien, dass sich die Schülerkolonnen da, wo sie tätig waren, im allgemeinen gut bewährt haben."

Abschließend geht der Kultusminister noch auf Maßnahmen ein, die die schulischen Nachteile der für den Einsatz in der Landwirtschaft beurlaubten Schüler und Schülerinnen kompensieren sollten. So seien „durch den Erlaß vom 18. Juni v. J. für das Winterhalbjahr besondere Veranstaltungen angeregt worden, um die entstandenen Lücken nach Möglichkeit zu füllen“. Außerdem sei dort festgelegt, „dass bei der Versetzung bzw. Prüfung zu Ostern 1918 auf die Hemmnisse Rücksicht zu nehmen sei, die den Schülern (Schülerinnen) aus ihrer Mithilfe bei notwendigen vaterländischen Arbeiten erwachsen sind. Nötigenfalls sei auf die volle Innehaltung der lehrplanmäßigen Anforderungen zu verzichten und ein Teil der Lehraufgaben auf das nächste Schuljahr zu übertragen““737.

Wie aus Hohnsbehns Untersuchungen hervorgeht, stellten sich durchaus auch Mädchen für die landwirtschaftlichen Arbeiten zur Verfügung, sie waren aber nur selten vermittelbar. ${ }^{738}$ Von den 437 Flensburger Mädchen, die sich im Sommer 1914 gemeldet hatten, kam kein einziges zum Einsatz. 1917 meldeten sich 181 Schülerinnen aller Schulen; wie viele tatsächlich tätig waren, ist nicht bekannt. Einige konkrete Zahlen liegen auch aus den höheren Mädchenschulen Schleswig-Holsteins vor. ${ }^{739}$ Insgesamt waren im Jahre 1915368 Schülerinnen der 16 Schulen tätig, und zwar 344 bei den Eltern und 342 bei Fremden. Das sind lediglich $12 \%$ der Gesamtschülerzahl (5.867). Pust vermutet, dass der Anteil der aktiven Schülerinnen deshalb so niedrig war, weil es sich bei den Schulen um städtische Einrichtungen handelte und der Kontakt zur Landwirtschaft aus diesem Grund relativ gering war. Der ehemalige Direktor der höheren Mädchenschule in Kiel erklärte rückblickend die geringe Beteiligung der Mädchen auch damit, dass nur ,sehr wenige Schülerinnen etwas von der landwirtschaftlichen Arbeit verstanden hätten und die Landleute keine ungelernten Arbeiter annehmen wollten““740. Sicher führten auch Widerstände in den Lehrerkollegien der Mädchenschulen zu der niedrigen Beteiligung. Z. B. lehnte das Kollegium des Altonaer Lyzeums den Einsatz von Mädchen zunächst

\footnotetext{
${ }^{737}$ Mit Erlass vom 8. Januar (,Verhütung von Schädigungen infolge der Beteiligung der Schüler und Schülerinnen der höheren Schulen und der Lehrerbildungsanstalten an kriegswirtschaftlichen Arbeiten“) hat der preußische Schulminister seine Vorstellungen präzisiert (Verhütung von Schädigungen infolge der Beteiligung der Schüler und Schülerinnen der höheren Schulen und der Lehrerbildungsanstalten an kriegswirtschaftlichen Arbeiten 1918 (8. Januar 1918).

${ }^{738}$ Hohnsbehn, Die Flensburger Schuljugend in der Zeit des ersten Weltkriegs (1996), S. 253-262.

${ }^{739}$ Pust, ,Vaterländische Erziehung" für „Höhere Mädchen" (2004), S. 372.

${ }^{740}$ Theile, Zur Geschichte des Lyzeums I mit Oberlyzeum zu Kiel (1911-1936) in Festschrift zur 75-Jahrfeier des Oberlyzeums I mit Reform-Gymnasialer Studienanstalt zu Kiel, Kiel 1936; zitiert nach: Pust, Pust 2004, S. 373.
} 
ab: Begründet wurde die Entscheidung mit dem Argument, der sittliche Schutz der Schülerinnen erscheine nicht genügend gesichert. ${ }^{741}$ Der Direktor der Flensburger Auguste-ViktoriaSchule sah die Ursache im Verhalten der Eltern. Da die Organisation des landwirtschaftlichen Hilfsdienstes hauptsächlich auf die männliche Jugend zugeschnitten sei, hätten die Eltern zum überwiegenden Teil die Erlaubnis für ihre Töchter verweigert. ${ }^{742}$

Ein weiterer Grund könnte in den unterschiedlichen Bestimmungen für die Leistungsbeurteilung von Jungen und Mädchen in den ersten Kriegsjahren gelegen haben. So wurden zunächst nur Schülern und keinen Schülerinnen für die Teilnahme am vaterländischen Hilfsdienst „gewisse Vergünstigungen gewährt“, wie z. B. die Versetzung in eine höhere Klasse. Die Bestimmungen dazu lauteten:

"Sie erhalten die Versetzung in die nächsthöhere Klasse zu demselben Zeitpunkt wie bei weiterem Besuch der Anstalt, wenn bei ihrem Austritt mit Wahrscheinlichkeit zu erwarten war, dass sie die Versetzung erreichen würden, jedoch nur unter der Voraussetzung, dass sie nachweislich bis zu diesem Zeitpunkte im vaterländischen Dienst verblieben sind. Scheiden sie vorher aus, so ist bei ihrer Versetzung auf die besonderen Verhältnisse gebührend Rücksicht zu nehmen.“773

In der Verbandszeitschrift „Die Lehrerin“ fragt eine Lehrerin provokativ: „Was soll dadurch herabgesetzt werden, die Schulleistung der in der Zwischenzeit zu Hause gebliebenen Jungen oder die Arbeit der an der Heimatfront stehenden Mädchen? Soll den letzteren durch - nur auf sie angewandte - Androhung des Sitzenbleibens die Lust am Mittun genommen werden?“744 Die Angst vor schulischen Nachteilen hat sicher eine Reihe von Schülerinnen abgehalten, sich freiwillig für die Landarbeit zu melden. ${ }^{745}$ Dass sehr viele Mädchen andere Hilfsdienste leisteten, wie z. B. die Herstellung von Liebesgaben, das Knüpfen von Kontakten zu ,vergessenen Soldaten', Tätigkeiten in Kriegsschreibstuben, Beaufsichtigung von Kindern, Dienst in Kindergärten, Anlegen und Pflege von Schulgärten und Aktivitäten in der Pflege von Verwundeten, und sich auch bei den zahlreichen Sammelaktionen engagierten, hat sicher auch zu dem relativ geringen Engagement in der Landwirtschaft geführt. Dieses zeigt beispielhaft die

\footnotetext{
${ }^{741}$ Pust, ,„Vaterländische Erziehung" für „Höhere Mädchen" (2004), S. 372.

${ }^{742}$ LAS, Abt. 302, Nr. 616, 20.I.1916; siehe auch: Pust, „Vaterländische Erziehung" für „Höhere Mädchen" (2004), S. 373.

${ }^{743}$ Zitiert nach: Treuge Vaterländischer Hilfsdienst für Schüler und Schülerinnen höherer Lehranstalten, Die Lehrerin: Organ des Allgemeinen Deutschen Lehrerinnenvereins 1917, S. 398.

${ }^{744}$ Treuge, Vaterländischer Hilfsdienst 1917, S. 398.

${ }^{745}$ Siehe: Anmerkung 51: Mit dem Erlass „Heranziehung der Schuljugend zu landwirtschaftlichen Arbeiten“ vom 18.Juni 1917 wurde die Benachteiligung der Mädchen, die in der Landwirtschaft eingesetzt waren, beseitigt: „Im Winterhalbjahr sind für die Schüler (Schülerinnen), auch der Herbstklassen, besondere Veranstaltungen in Aussicht zu nehmen, um die entstandenen Lücken nach Möglichkeit wieder auszufüllen. Bei der Versetzung bzw. Prüfung zu Ostern 1918 ist auf Hemmnisse Rücksicht zu nehmen, die den Schülern (Schülerinnen) infolge ihrer Beteiligung an landwirtschaftlichen Arbeiten erwachsen sind. Nötigenfalls ist auf die volle Innehaltung der lehrplanmäßigen Anforderungen zu verzichten und gegebenenfalls ein Teil der Lehraufgaben auf das nächste Schuljahr zu übertragen." (Heranziehung der Schuljugend zu landwirtschaftlichen Arbeiten 1917 (18. Juni 1917).
} 
„Kriegsmäßige Schulordnung“, die sich die Auguste-Victoria-Schule in Trier gegeben hatte. Dort heißt es im III. Abschnitt:

„Es sollten folgende Abteilungen gebildet werden:

1. Näh- und Strickabteilung

2. Kinderpflegeabteilung

a) Kindergarten

b) Kinderhort

3. Küchenabteilung

4. Abteilung für Schreibarbeiten jeglicher Art

5. Abteilung für kleinere Dienstleistungen. “746

Bezeichnenderweise war keine, Abteilung für Landwirtschaftshilfe’ gebildet worden.

Im Unterschied zu den Arbeiten der „Jungmannen“ gibt es nur wenige konkrete Berichte über die Ernteeinsätze der Mädchen. Einer erschien 1917 in der „Rheinisch-Westfälischen Zeitung“: „Überall an Rhein, an der Mosel und Lahn sieht man Schülerinnen zwischen 10 und 16 Jahren fleißig bei der Landarbeit. Der erste Heuschlag hat begonnen. Die Frühkartoffelernte steht vor der Tür, und die Erdbeeren reifen auf den Feldern. ${ }^{، 747}$ Es folgt eine fast romantisch verklärende Schilderung eines Tagesablaufs.

Sachlicher ist eine Notiz über den Einsatz von Mädchen in der Provinz Schlesien: „Lyzeumschülerinnen der ersten Klasse beteiligen sich, wie aus Grünberg in Schlesien berichtet wird, seit Wochen auf mehreren Gütern des Grünberger Kreises bei landwirtschaftlichen Arbeiten. Die beidseits gemachten Erfahrungen sind durchweg zufriedenstellend.“748

In ihrem Kriegstagebuch hat eine Lehrerin aus Flensburg unter dem 4. Juli 1917 vermerkt: „Gestern und vorgestern waren einige Mädchen meiner Klasse beim Rübenziehen bei einem Hofbesitzer der Umgebung. Die Mädchen haben die Arbeiten gut und gern ausgeführt.“" ${ }^{749}$ Wegen der relativ wenigen vorliegenden Berichte können keine gesicherten Schlüsse über den Verlauf der Einsätze und die Erfahrungen mit den Mädchen gezogen werden. Es kann jedoch angenommen werden, dass der Ablauf eines Arbeitstages ähnlich wie bei den „Jungmannen“ war und dass die Erfahrungen durchaus befriedigend waren. Sonst hätten offizielle Stellen ab 1917 die Lyzeen nicht immer wieder aufgefordert, die Namen geeigneter und williger Mädchen den Meldestellen mitzuteilen, wie z. B. das für die höheren Lehranstalten der Provinz

\footnotetext{
${ }^{746}$ Kriegshelferdienst der Schülerinnen als Vorbereitung auf das weibliche Dienstjahr, Die Lehrerin: Organ des Allgemeinen Deutschen Lehrerinnenvereins 19161, S. 180.

747 Die höhere Tochter als Landarbeiterin Die Lehrerin: Organ des Allgemeinen Deutschen Lehrerinnenvereins 1917, S. 26

${ }^{748}$ Höhere Mädchen- und Frauenbildung, Die Lehrerin: Organ des Allgemeinen Deutschen Lehrerinnenvereins 1917, S. 131.

${ }^{749}$ Marquardsen, Festschrift des staatlichen Oberlyzeums zu Flensburg, 1966-1936 (1936); zitiert nach: Pust, „Vaterländische Erziehung" für „Höhere Mädchen” (2004), S. 373.
} 
Schleswig-Holstein zuständige Garnisonskommando am 10. März $1917 .^{750}$ Insgesamt jedoch sind also weit weniger Mädchen als Jungen in der Landwirtschaft beschäftigt worden, und zwar besonders selten im Bereich der organisierten Erntehilfe, wie die relativ wenigen Hinweise in Zeitungen und Schulchroniken vermuten lassen.

Im Folgenden soll untersucht werden, inwieweit Orts- und Schulchroniken sowie Tagebücher und Erinnerungen weiteren Aufschluss über die landwirtschaftlichen Arbeiten der Jungen und Mädchen geben.

Hans Wendt (*1903), der das Reformgymnasium in Magdeburg besuchte, erinnert sich:

„Im dritten Jahr meldeten sich die meisten von uns Untersekundanern zum freiwilligen Hilfsdienst in der Landwirtschaft. Im eisigen Herbst rodeten wir Rüben. Im Sommer 1918 wurden wir durch die Jungmannen-Organisation aus der Schule geholt. Die Unterbrechung war uns recht, obwohl wir zu unseren ,Paukern', den einberufenen, an die wir ins Feld schrieben, wie zu den als Ersatz geholten alten ein gutes Verhältnis hatten. ${ }^{\text {" }}{ }^{751}$

Auch Franz Thedieck (*1900), Schüler des Aufbaugymnasiums in Köln-Lindenthal, war in der Landwirtschaft eingesetzt:

„Lange Wochen war ich mit meinen Mitschülern in verschiedenen landwirtschaftlichen Hilfsdiensten im Rheinland eingesetzt. Im Jahre 1917 gingen wir mit zweitausend ,Jungmannen' in das französische Etappengebiet der Heeresgruppe des Kronprinzen zum Ernteeinsatz, für junge Menschen natürlich ein großartiges Erlebnis. Die im Innern des Landes immer schlechter werdende Lebensmittelversorgung schwächte zwar unsere Gesundheit, aber nicht unsere Einsatzfreude.“752

Ein anderer Zeitzeuge, Herr R. (*1905) aus Flensburg, hat weniger gute Erinnerungen an den Arbeitseinsatz: „Wir wollten nur arbeiten für Kartoffeln, nicht für Geld; Geld war ja nichts. Da waren wir 14 Tage [...] Zuerst mussten wir Kartoffeln rausnehmen, aber nachher mussten wir auch Rüben zupfen; die waren schon mit Eis [bedeckt], morgens, wenn wir da reingingen. Das wollte ich dann nicht mehr.“753

Die drei Berichte zeigen, dass es unterschiedliche Motive für den landwirtschaftlichen Hilfsdienst der Schüler gab und dass auch die Erfahrungen recht verschieden waren.

Auch einige ausgewählte Auszüge aus Schulchroniken und Berichten sollen zur Ergänzung zitiert werden ${ }^{754}$.

\footnotetext{
${ }^{750}$ Treuge, Vaterländischer Hilfsdienst für Schüler und Schülerinnen höherer Lehranstalten, Die Lehrerin: Organ des Allgemeinen Deutschen Lehrerinnenvereins 1917, S. 398.

${ }^{751}$ Pörtner, Kindheit im Kaiserreich (1990), S. 197.

${ }^{752}$ Pörtner, Kindheit im Kaiserreich (1990), S.143.

${ }^{753}$ Hohnsbehn, Die Flensburger Schuljugend in der Zeit des ersten Weltkriegs (1996), S. 249.

754 Ähnliche Berichte liegen vor aus: Volksschule in Schwanheim in Hessen 1914 (Reyher, Die Schwanheimer Schulchronik , S. 2), www.schulserver.hessen.de/...Die\%20Schwanheimer\% 20Volksschule\%20im\% 201. Weltkrieg.doc

(29.02.2008), S. 2); der Volksschule Oberweis im Kreis Bitburg (Evertz, Oberweis im Wandel der Geschichte, http://www.oberweis.de/historie.html (06.04.2008)); der westfälischen Martinschule 1917 (Friedel, Chronik der Martinschule www.cappelpower.de/martinschule/geschichte/geschichte/_ool.htm (03.10.2006)); Volksschule Elze bei Hannover (Das Dorf Elze während des Kriegs 1914-18, http://www.wedemark.de/dorfelze/ schulchro-
} 
Volksschule Drohne (Provinz Westfalen), 1914:

„Besonderes Verdienst erwarben sich die Schulkinder der ersten Klasse dadurch, dass sie unermüdlich arbeiteten, um alles Getreide und Heu unter Dach zu bringen. Im Herbst eilten jeden Nachmittag 10-20 Kinder auf die Kartoffeläcker der Einberufenen und halfen unter Aufsicht des Lehrers, die Knollen aufzunehmen, so dass am Schlusse der Ferien kaum noch jemand Kartoffeln in der Erde hatte [...] Die Freude und der aufrichtige Dank der Geholfenen war hinreichender, schöner Lohn dafür.“"755

\section{Volksschule Lobkowitz (Provinz Schlesien),}

1915

„Durch weitere Einberufung kriegstauglicher Mannschaften und dem damit verbundenen zunehmenden Arbeitermangel waren ausreichende Beurlaubungen der Kinder der I. und II. Klasse zur Aushilfe in der Landwirtschaft unbedingt notwendig.“

1917

„Nach Mitteilung der Königlichen Kreisschulinspektion konnten die Kinder der Ober und Mittelklasse vom 8. bis 15. Mai d. Js. zur Aushilfe in der Frühjahrsbestellung beurlaubt werden. Dies ist unter Hinweis auf die dringende schnelle Beendigung der Ackerbestellung auch geschehen.

Die Kinder sind angewiesen worden, nicht nur den Angehörigen sondern auch den Nachbarn, überhaupt denjenigen, die z. B. mit dem Stecken der Kartoffeln im Rückstande sind, unentgeltlich zu helfen. Infolge der Beurlaubung der Kinder der Mittel und Oberstufe hatte Klasse III während dieser Zeit wiederum 24 Stunden, in die sich die beiden Lehrer, wie vorher, teilten.“

(Gemeinde- und Schulchronik ${ }^{756}$ )

\section{$\underline{\text { Schule St. Willibrord Wardt (Xanten, Rheinprovinz) }}$}

„Die Landwirtschaft ist in der Kriegszeit wegen Mangel an Arbeitern in eine mißliche Lage geraten. Die Kinder des 4. bis 8. Schuljahres werden teils für ganze teils für halbe Tage auf längere Zeit zwecks Aushilfe im landwirtschaftlichen Betriebe beurlaubt."

(Schul-, Dorf- und Kirchenchronik ${ }^{757}$ )

\section{Evangelische Volksschule zu Daufenbach (Westerwald, Rheinprovinz)}

„Vom 3. August 1914 an sind die Schulen geschlossen, damit die Kinder in dieser ernsten und gefahrvollen Zeit bei Einbringung der Ernte ihren Eltern und den Familien, deren Arbeitskräfte fürs Vaterland ins Feld gezogen sind, helfen sollen. Die Kinder der Unterklasse, die nicht helfen können, haben morgens von 8-10 Uhr Schule." (Lehrer H. Geißler ${ }^{758}$ )

\section{Gebersdorf (Provinz Brandenburg), 1916/1917}

„Die Herbstferien dauerten vom 21. September bis 16. Oktober. Sie mussten der Kartoffelernte wegen für die Unterstufe bis zum 22. und für die Mittel und Oberstufe bis zum 29. verlängert werden. Der Unterricht begann somit am 30. Oktober. Am Erntedankfest sang der Schulchor in der Kirche beim Gottesdienst. ,Großer Gott, wir loben dich'. [...] Die Sommerferien dauerten vom

nik1.htm (06.04.2008); Gymnasium Emmanuel-Kant-Schule Rüsselsheim, 1914 (Immanuel-Kant-Schule Rüsselsheim, http://www.iks-ruesselsheim.de/44.html (02.10.2007); Königliches Kaiser Wilhelms Gymnasium Hannover, 1914/15 (Jahresbericht des Königlichen Kaiserin Auguste Victoria-Gymnasiums zu Linden (1915c), S. 14); Leibnizschule Hannover, 1914/15 (Meyer, Siebenunddreissigster Jahresbericht der städtischen Leibnizschule zu Hannover (1915), S. 14).

${ }^{755}$ Kammeier, Der Landkreis Lübbecke und der 1. Weltkrieg (1998), S. 189.

756 Eckert, Gemeinde- und Schulchronik von Lowkowitz,, http://www.schloss-ellguth.de/lowkowitz2.htm (05.04.2008).

757 Aus der „Schul-, Dorf- und Kirchenchronik" St. Willibrord Wardt, http://www.xantenweb.de/Domstadt/WardtChro5.html (03.04.2008).

758 Auszüge aus Schulchronik und Schultagebüchern der Evang. Volksschule zu Daufenbach, http://www.duerrholz.com/arbeitsgruppen/Chronik/Chronikseite43bis56.pdf (04.04.2008), S. 13. 
14. Juli. - 7. August. $50 \%$ der Ober- und Mittelstufe fehlen wegen weitergehendster Gewährung von Urlaub zur Einbringung der Ernte." (Schulchronik ${ }^{759}$ )

\section{Wilhelm-Gymnasium Braunschweig (Herzogtum Braunschweig), 1916/1918}

„1916 wurde ein Hilfsdienst eingerichtet, vor allem für die Landwirtschaft, der die älteren Schüler heranzog, vorwiegend Primaner und Sekundaner. Das waren im Jahre 1918104 Schüler. Insgesamt haben die durch diesen Hilfsdienst erfassten Schüler 3258 Arbeitstage abgeleistet. An eine geregelte Arbeit war unter diesen Bedingungen nicht zu denken." (Nach den Schulakten ${ }^{760}$ )

Die Texte bestätigen, dass sich Schulen aus nahezu allen Städten und Gemeinden an den landwirtschaftlichen Hilfseinsätzen beteiligt haben' und zwar sowohl die kleine Volksschule aus einem Dorf, wie z. B. Elze (ca. 550 Einwohner, Provinz Hannover), als auch Gymnasien aus Braunschweig (ca. 143.550), Hannover (ca. 302.000) oder der Millionenstadt Berlin ${ }^{761}$. Natürlich engagierten sich auch die Mittelschulen, die Lyzeen und die Fortbildungsschulen. Die Schüler und Schülerinnen kamen aus allen Klassenstufen, von der ersten Klasse bis zur Oberprima. $\mathrm{Ob}$ es sich um Schulen in privater Trägerschaft, um städtische oder staatliche Schulen handelte, ist hinsichtlich der Beteiligung nicht von Bedeutung. Auffällig an allen untersuchten Schulchroniken ist, dass nicht in einer einzigen Probleme erwähnt werden. Dass es sie durchaus gab, ist bereits dargestellt worden und soll im Folgenden durch einige zeitgenössische Quellen ergänzt werden: durch Äußerungen eines Lehrers, einer Schülerin und eines Gutspächters.

\section{Lehrer Rosbund aus Mewe (Provinz Westpreußen):}

„Auch üble Erfahrungen sollen nicht verschwiegen werden. Eine Mannschaft war, zufällig ohne ihren Führer, bei einem Pächter. Die Behandlung und Aufnahme ließ zu wünschen, die Gläser für das Getränk waren unsauber, der Hund hatte von der Milch geleckt, so beklagten die Jungen. Der Bauer war mit der Arbeitsleistung und Haltung mehrerer Jungen unzufrieden. Er ließ sie trotz Hitze und Mattigkeit den 2 Kilometer weiten Rückweg zu Fuß machen. Natürlich wurde am nächsten Tage das Arbeitsverhältnis gelöst.“" ${ }^{\text {(762 }}$

Schülerin Elfriede Kuhr (12 Jahre) aus Schneidemühl (Provinz Posen):

10. Oktober 1914 „Die Schulen haben viele Schüler aufs Land geschickt, damit sie den Frauen bei den Herbstarbeiten helfen, aber die Schüler sind bald wieder nach Haus gekommen. [...] Sie erzählen alle, dass sie die Arbeit nicht ausgehalten hätten. Die meisten schimpfen ganz schrecklich. Sie behaupten, sie seien niemals satt geworden. Bei den Kleinbauern kann ich das verstehen, denn sie haben selber nichts. Aber gerade bei den Kleinbauern haben die Jungen gar nicht gearbeitet, sondern bei den Großbauern oder auf Gütern. Dann ist das stinkender Geiz, finde ich, dass sie den Jungen nicht satt zu essen gegeben haben. Denn unsere Großbauern und Gutsbesitzer sind wohlha-

\footnotetext{
${ }^{759}$ Nerlich, Aus der Gebersdorfer Schulchronik 1911-1920, http://www.gebersdorf-mark.de/kalenderblatt.htm.

${ }^{760}$ Bracke, 100 Jahre Wilhelm-Gymnasium Braunschweig 1885-1985 (1995), S. 84f.

${ }^{761}$ Die Berliner Schuljugend arbeitete nicht nur auf landwirtschaftlichen Betrieben im Umfeld, sondern auch direkt innerhalb der Stadt: „Eine Riesenscheune in Berlin. Wagen auf Wagen fährt in die Tenne. In den Bansen, auf Bergen geschnittenen Korns glühende Kindergesichter, heiße Wangen und strahlende Augen. Auf dem Wagen steht ein alter Knecht und wirft die Garben, ernst in kurzen Hosen, die Brust geöffnet, eine schlanke biegsame Gestalt. Wenn das so weitergeht, wird er in sechs Wochen diensttauglich sein! Hoch oben ein paar Mädchen, die einstopfen..." (Kranzler, Für Vaterland und Ehre (o.J.), S. 62).

${ }^{762}$ Rosbund, Schülerhilfe in der Landwirtschaft, Deutsches Philologen-Blatt 1917, S. 449.
} 
bend, sie haben genug Speck und Fleisch und Eier und Milch im Eiskeller und in den Rückerkammern. Ich hab mich oft bei ihnen umgeschaut und weiß das. Einer von Willis Klassenkameraden, Andreas Zorn, hat erzählt, dass auf dem Großbauernhof, auf dem er gearbeitet hat, die Gymnasiasten um 4 Uhr morgens geweckt wurden. Dann bekamen sie schlechtes Frühstück und mussten in tiefer Dunkelheit zum Feld marschieren. Sie haben stundenlang gebückt Kartoffeln oder Rüben ausgelesen. Manchmal war es so dunkel, dass sie kaum etwas sehen konnten. Den Jungen sind vor Kälte die Finger abgestorben, und sie gingen ganz krumm vor Rückenschmerzen, aber man hat sie weiter zur Arbeit angetrieben. Viele haben sich erbrechen müssen oder sind einfach vor Übermüdung umgefallen. Aber Schonung gab's nicht. Immer hieß es: 'Wollen den Muttersöhnchen mal das Arbeiten beibringen!' Die Jungen hatten sich alle auf die Landarbeit gefreut. Jetzt ist es so, wie Andreas Zorn sagt: 'Uns kriegen keine zehn Pferde mehr aufs Land!'، ‘63

Ludwig Sträter (*13.04. 1861), Pächter und Verwalter auf Gut Rondeshagen im einstigen Herzogtum Lauenburg (Provinz Schleswig-Holstein)

„In der Wirtschaft hatte ich (1918) 15 Jungmannen, mit einem Professor zur Hilfe, sie haben nicht viel geleistet, es waren 15-17jährige Gymnasiasten, denen in der Hauptsache darum zu tun war, sich satt zu essen, in den Städten gab's nicht mehr viel.“" ${ }^{\text {764 }}$

Trotz durchaus auch negativer Erfahrungen vieler Schüler und Lehrer stellten sich bis in das letzte Kriegsjahr hinein in allen Teilen des Landes viele Tausende von Schülern freiwillig für den Dienst in der Landwirtschaft zur Verfügung. Beispielsweise meldeten sich im Februar 1917 2.500 Bremer Schüler über 12 Jahre mit Genehmigung der Eltern zum Arbeitseinsatz in der Landwirtschaft. ${ }^{765}$ In der Rheinprovinz halfen bei der bei der Frühjahrsbestellung 7.500 und im Spätsommer 8.700 Schüler und in der Provinz Brandenburg rund 8.900. 10.150 Schüler und Schülerinnen halfen in Hessen-Nassau (an 271.200 Arbeitstagen) und in der Provinz Hannover etwa 15.560 Schüler und Schülerinnen (an 355.950 Tagen). ${ }^{766}$

Wie die Berichte aus den zitierten Schulchroniken und den Lehrerzeitschriften zeigen, wurde fast ausschließlich auf die positiven Ergebnisse und die Erfolge hingewiesen, sodass die Probleme der Öffentlichkeit weitgehend nicht bekannt waren. Immer wieder wurde von offiziellen Stellen der Ernteeinsatz als patriotischer Dienst am Vaterland und als militärischer Einsatz an der „Heimatfront“ propagiert, so wie es z. B. der Kronprinz, Kommandeur der Heeresgruppe, in einem Schreiben vom 30. 10. 1917 an den Leiter des Kriegswirtschaftsamtes der Rheinprovinz in Bonn tat:

"Mit Genugtuung und Interesse habe ich im Verlaufe des Sommers die Tätigkeit und Arbeit der Jungmannen in der Rheinprovinz im Bereiche der Heeresgruppe verfolgt und an ihrer vortrefflichen Haltung und dem frischen militärischen Antreten meine besondere Freude gehabt. Ich bitte

\footnotetext{
${ }^{763}$ Mihaly, ... da gibt's ein Wiedersehn! (1986), S. 84.

764 Gemeinde Rondeshagen, Pächter und Verwalter auf Gut Rondeshagen \& Bauernvögte des Dorfes Rondeshagen, http://www.rondeshagen.com/Verwalter_Paechter.html (08.04.2008).

${ }^{765}$ Bremens Geschichte, http://www2.bremen.de/info/history/WK1.html (07. 04. 2008). Von diesen waren 1.000 Schüler unter Federführung der Lebensmittelkommission in längeren Einsatz; sie erhielten einen Stundenlohn zwischen 20 und 50 Pfennigen.

${ }^{766}$ LAS, Abtlg. 302, Nr. 3178, „Denkschrift über die Beteiligung der Schuljugend bei kriegswirtschaftlichen Arbeiten“, S. 1.
} 
Sie, dem Kriegswirtschaftsamt, den Führern der Jungmannen und den beteiligten Dienststellen, in Sonderheit dem Provinzial-Schulkollegium meinen Dank und meine Anerkennung auszusprechen. Der Versuch, die frische Jugend des Rheinlandes zu Arbeitsleistungen in besetzten Gebieten heranzuziehen, hat beste Erfolge gezeitigt. Die hingebende Arbeit zum Wohle des Ganzen, die Disziplin und straffe Ordnung der Organisation und nicht zuletzt die Nähe des Krieges mit seinen unauslöschlichen Eindrücken, werden die Jungmannen körperlich und erzieherisch aufs beste beeinflusst haben. Die hier auf französischem Boden durchlebte Zeit wird ihnen eine wertvolle Grundlage für ihre spätere Leistungsfähigkeit sein, der unser Volk alles verdankt.“767

Was in anderen Quellen anklang, wird hier deutlich angesprochen: Die Arbeit in der Landwirtschaft wurde nicht nur als Kampf an der „Heimatfront“ verstanden, sondern durch sie sollten die „Jungmannen“ auch für den bevorstehenden Einsatz als Soldaten an der militärischen Front vorbereitet werden. ${ }^{768}$ Vor allem deshalb wurden die Tauglichkeitsuntersuchungen der Gymnasialschüler, die an Musterungen von Wehrpflichtigen erinnerten, von den Militärärzten durchgeführt. Es erklärt auch, warum offizielle Stellen am Engagement von Mädchen weit weniger Interesse hatten als an dem der gleichaltrigen Jungen. Insofern dienten die landwirtschaftlichen Arbeitseinsätze durchaus auch der sozialen Militarisierung.

Hauptsächlich jedoch benötigte man angesichts des immer größer werdenden Mangels an Arbeitskräften Kinder und Jugendliche in sehr großer Zahl, um die Ernten einbringen und die Ernährung der Bevölkerung sicher stellen zu können. „Für das Jahr 1917 dürften für das Reichsgebiet nach einer Schätzung etwa 75.000 "Jungmannen" in der Landwirtschaft tätig gewesen sein.“769 Mit 14.880 lag die Beschäftigung im Königreich Württemberg weit über dem Reichsdurchschnitt, während beispielsweise im Bereich des stellvertretenden Generalkommandos des X. Armeekorps in Hannover nur etwas mehr als 1.700 ältere Schüler in der Landwirtschaft eingesetzt wurden. 1918 stieg hier die Gesamtzahl von 7.495 im April auf 22.310 im Juni und 36.014 im August, um im September wieder auf 30.065 und im Oktober auf 25.474 abzufallen. ${ }^{770}$

Die insgesamt recht hohe Beteiligung der Schulen war, wie eingangs vermutet, vor allem auch auf die massive Propaganda zurückzuführen. Von Kriegsanfang an wurde immer wieder durch Vorschriften der Kultusbehörden und Aufrufe der Kommunen in Zeitungen, Zeitschriften der Lehrerverbände und in Jugendbücher sowie durch Ansichtskarten ${ }^{771}$ und Plakate für die landwirtschaftlichen Hilfsdienste geworben. So war z. B. in dem damals weitverbreiteten Buch „Deutschlands Jugend in großer Zeit“ das folgende Gedicht abgedruckt:

\footnotetext{
${ }^{767}$ Der Kronprinz an die Jungmannen, Deutsches Philologen-Blatt 1917, S. 646.

${ }^{768}$ Siehe: Anhang, Seite 69, Bilder 1 und 2.

${ }^{769}$ Huegel, Kriegsernährungswirtschaft Deutschlands während des Ersten und Zweiten Weltkrieges im Vergleich (2003), S.193.

${ }^{770}$ Saul, Jugend im Schatten des Krieges (1983), S.117

${ }^{771}$ Siehe: Anhang, Seiten 67/68.
} 
„Die Jugend bringt die Ernte ein

Zur Seite tat der Bauersmann den Pflug, er gab die Sense aus den schwieligen Händen.

Der Ernte heiliges Werk nun zu vollenden,

blieb, da ein Sturm sich hob, nicht Zeit genug.

Denn aus der Wolke, die den Donner trug, begann der Herr, seine Wetter zu entsenden; nun galt es, dort die zähen Schollen wenden, wo Gottes Zorn den fremden Acker schlug.

Und da die Brüder für die Deutschen Farben

Im Feld, im Graben kämpften, siegten, starben,

scholl hier ein Ruf: ,A u c h i c h will S tre i ter s e in!'

Mein deutsches Volk, sieh' her - du sollst nicht darben:

Rings schwillt die Flur in Früchten und in Garben,

und Jugend bringt die Ernte ein!",772

(Franz Lüdtke)

In den ersten Kriegsjahren bestand bei vielen Bauern aufgrund von Vorurteilen und schlechten Erfahrungen eine ablehnende Haltung gegenüber der Beschäftigung der für die Landwirtschaft kaum qualifizierten Schüler. Dieses änderte sich auch nur wenig, als man die ausgewählten „Jungmannen“ durch Schulungskurse auf den landwirtschaftlichen Dienst vorbereitete und ihnen Grundkenntnisse vermittelte, z. B. im Umgang mit landwirtschaftlichen Maschinen. Im letzten Jahr allerdings waren Landwirte froh, ,,wenn ihnen bei dem immer empfindlicher werdenden Mangel an Arbeitskräften wenigstens jugendliche Hilfen zur Verfügung gestellt wurden. Doch weder sie noch die „Jungmannen“ konnten entscheidend einen Beitrag zur Reduzierung des Arbeitsmangels beitragen.“773

Trotzdem war unter den vielen Hilfsdiensten der Schüler und Schülerinnen im Krieg, deren kriegswirtschaftlicher Nutzen nach Saul insgesamt „hoch“774 war, der Dienst in der Landwirtschaft der weitaus wichtigste. Dieses betonte auch der preußische Unterrichtsminister in seinem Erlass „Kriegshilfe der Schulen“ vom 24. April 1918.

"Nach dem Umfange der geleisteten Arbeit sowie ihrer gesamtwirtschaftlichen Bedeutung stand an erster Stelle die Mithilfe der Schuljugend an den landwirtschaftlichen Arbeiten. Wie die meisten Berichte der Königlichen Regierungen hervorheben, hätten auch im verflossenen Jahre ohne die Beteiligung der Schuljugend zahlreiche landwirtschaftlichen Betriebe nicht in vollem Umfange aufrechterhalten und die restlose Einbringung der Heu, Obst, Körner und besonders der Kartoffelernte nicht bewirkt werden können." ${ }^{\text {(775 }}$

\footnotetext{
${ }_{772}$ Braun, Deutschlands Jugend in großer Zeit, 1916, S. 106.

${ }^{773}$ Huegel, Kriegsernährungswirtschaft Deutschlands während des Ersten und Zweiten Weltkrieges im Vergleich (2003), S.194.

${ }^{774}$ Saul, Jugend im Schatten des Krieges (1983), S. 119.

${ }^{775}$ Ministerium der geistlichen und Unterrichts-Angelegenheiten, Kriegshilfe der Schulen, Zentralblatt für die gesamte Unterrichtsverwaltung in Preußen, 1918, S. 410.
} 


\subsection{Schul- und Schülergärten}

Ende des Jahres 1916 verschlechterte sich die Ernährungslage bedrohlich. Deshalb bemühte man sich nicht nur, noch mehr Jugendliche für die Erntehilfe zu gewinnen und den Jugendeinsatz effektiver, d. h. militärischer zu organisieren, sondern auch brachliegende Anbauflächen und Gärten, deren Besitzer als Soldaten eingezogen worden waren, durch Schulen bewirtschaften und pflegen zu lassen. „Wo das Wasserschleppen, das Steinesammeln, das Einebenen die ganze mühselige Einzelarbeit der Kleingartenkunst keinen Erwachsenen locken konnte, dafür Zeit und Kräfte und Geld zu opfern, da ließ sich von der unentgeltlichen Arbeit der zäh fleißigen, - richtig geleitet - auch immer geschickten Schulkinder immerhin noch etwas erwarten."“776

Mit Erlass vom 14. Februar 1915 wandte sich der preußische Unterrichtsminister an die Lyzeen, um sie hinsichtlich einer größeren Effizienz der „Gartenbauversuche“ zu beraten, da trotz des vaterländischen Interesses der Schülerinnen die Ergebnisse dieser Versuche nicht erfolgreich genug waren. ${ }^{777}$ Als Hauptgrund wurde angeführt, dass geeignetes Land nur selten in der Nähe der Schulen zu haben und dass besonders seit Ausbruch des Krieges fast jedes Stück anbaufähigen Bodens bereits vergeben sei und bewirtschaftet werde. Das Ministerium schlug vor, die Arbeiten nur dann fortzusetzen, wenn ein größeres nutzbar zu machendes Stück Garten oder Ackerland zur Verfügung gestellt werden könnte und die schwereren, die Kräfte der Mädchen übersteigenden Arbeiten des Aufbrechens und Bereitens des Bodens von anderen Personen geleistet werden könnten. Ferner sollten die betreuenden Lehrkräfte über entsprechende fachliche Kenntnisse verfügen, also z. B. Gartenbaulehrerinnen sein. Die Frage, inwieweit Gartenbauarbeit in den Lehrplan aufgenommen werden könne, sei noch nicht entschieden. Da man die älteren Schüler dringend bei der Erntehilfe benötigte, wurden Schulgärten bzw. Schülergärten überwiegend von Mädchenschulen angelegt, und deshalb wurden mit dem Erlass ausschließlich die Lyzeen angesprochen.

In einem späteren Erlass (18. März 1918) forderte der Unterrichtsminister die Lehrerbildungsanstalten auf, Kurse über den Gartenbau anzubieten, um den Lehrkräften das nötige Interesse und die erforderlichen Fähigkeiten auf diesem Gebiet beizubringen. Denn allein durch geeignete Belehrungen und Anleitungen sowie durch sein eigenes Beispiel könne der Lehrer nicht nur bei den Schulkindern das nötige Verständnis für den Obst- und Gemüsebau

\footnotetext{
${ }^{776}$ Siehe: Bohnstedt, Die Kriegshilfe unserer Schuljugend (1917), S. 33.

777 Ministerium der geistlichen und Unterrichts-Angelegenheiten, Gartenbauversuche an Lyzeen, Zentralblatt für die gesamte Unterrichtsverwaltung in Preußen, 1917, S. 322.
} 
hervorrufen, sondern auch außerhalb der Schule auf die Erwachsenen anregend und aufklärend einwirken und so zur Hebung ,dieser wichtigen Kulturzweige“6778.beitragen.

Im Folgenden sollen beispielhaft einige solcher Gartenbauprojekte vorgestellt und bewertet werden.

\section{Der Kriegsgarten des Kaiser-Karl-Gymnasiums zu Aachen (Rheinprovinz) ${ }^{779}$}

Bereits kurz nach Kriegsbeginn hatte der Direktor der Schule angeregt, auf dem Schulgrundstück einen Garten für den botanischen Unterricht anzulegen „Als dann der Krieg ausbrach und im Frühjahr 1915 die Behörden zur Sicherung unserer Volksernährung auf die Wichtigkeit des Gemüseanbaus hinwiesen, lag der Gedanke nahe, mithilfe der Schüler diese Plätze dem Gemüsebau nutzbar zu machen.“ Die Stadt als Eigentümer überließ der Schule das Gelände und stellte finanzielle Mittel zur Beschaffung von Werkzeug und Sämereien zur Verfügung, sodass bereits im März 1915 mit der Gartenarbeit begonnen werden konnte. Die Leitung des Projekts wurde einem Lehrer übertragen. Das Gelände hatte früher einmal als Garten gedient und war voller Gerümpel, Steine, Bauschutt, verdorrter Bäume und verwilderter Sträucher.

„Der Arbeit im Kriegsgarten lag das erziehliche Arbeitsprinzip zugrunde, welches die Aufgabe der Schule, zu erziehen und zu belehren, unterstützt und fördert. Da dieses Prinzip sich an die Selbständigkeit wendet, bestand die erzieherische Bedeutung dieser Einrichtung darin, daß die Schüler im Garten zweckmäßig beschäftigt wurden. Auch mußte die Mitwirkung der Schüler bei der Anlage und Unterhaltung des Gartens auf vollständiger Freiwilligkeit beruhen““780,

schrieb der verantwortliche Lehrer in einem sehr detaillierten Bericht. Ausführlich geht er auch auf den pädagogischen Nutzen des Kriegsgartens ein, der als „,treffliches Lernmittel“ die Schüler zur Gartenarbeit und damit zur „denkenden Naturbetrachtung“ befähige, sodass er seinem Wesen nach ein Schulgarten sei. Ein Verzeichnis gibt Aufschluss über die angebauten und die wild wachsenden Pflanzen, insgesamt „9 ausdauernde Gewächse, 47 Kulturpflanzen und 40 Unkräuter und Ödlandspflanzen““781. Da der Garten nach Aussage des Lehrers guten Boden enthielt, war die Ernte offensichtlich sehr erfreulich. Im ersten Jahr hatte der „Fleiß der jungen Gärtner der Erde einen Schatz von insgesamt 1400 Pfund Gemüse entlockt“ und in der „Zeit vom 2. Juni bis 27. November wurden von den Schülern 30 Sendungen im Gewichte von 1.102 Pfund zur städtischen Kriegsküche gebracht"“782. Hinweise auf Probleme enthält der Bericht, den der betreuende Lehrer selbst geschrieben hat, nicht.

\footnotetext{
${ }^{778}$ Ministerium der geistlichen und Unterrichts-Angelegenheiten, Förderung des Gemüse- und Obstbaues, Zentralblatt für die gesamte Unterrichtsverwaltung in Preußen, 1918, S. 327.

${ }^{779}$ Holl, Der Kriegsgarten des Kaiser-Karl-Gymnasiums zu Aachen, Die Arbeitsschule, 1917, S. 156.

${ }^{780}$ Holl, Der Kriegsgarten des Kaiser-Karl-Gymnasiums zu Aachen, Die Arbeitsschule, 1917, S. 158.

${ }^{781}$ Siehe: Anhang, Seite 18.

${ }^{782}$ Holl, Der Kriegsgarten des Kaiser-Karl-Gymnasiums zu Aachen, Die Arbeitsschule, 1917, S. 159.
} 


\title{
2. Schulgarten einer Schule in Dresden ${ }^{783}$
}

Über die Erfahrungen mit einem „Jahr Gartenarbeit im Kriege“ liegt aus Dresden ebenfalls ein sehr genauer Bericht vor. Der verantwortliche Lehrer schrieb:

\begin{abstract}
„Um auch den Kindern schon Lust zum Gärtnern zu machen und ihnen einige Anleitung zu geben, gestalteten wir in der Kriegszeit den Schulgartenbetrieb anders, als es bis jetzt geschehen war. Bisher hatten wir in althergebrachter Weise unter Mithilfe größerer Schüler außerhalb der Schulzeit den Schulgarten bearbeitet und gepflegt. Wir zogen uns die Anschauungsobjekte heran, möglichst unter den ihnen eigenen Lebensbedingungen und betrachteten und besprachen sie dann mit den Kindern. Das wurde nun anders. Auf unseren Antrag hin pachtete uns die Schulbehörde einen 150 qm großen Schrebergarten in der Nähe der Schule und kaufte uns so viel Arbeitsgeräte, daß 20 Kinder gleichzeitig Beschäftigung finden konnten. Der Grundsatz wurde maßgebend: Die Kinder bearbeiten den Garten selbst, der Lehrer leitet sie an.“"784
\end{abstract}

Er geht dann detailliert auf die Arbeiten, die 1916 anfielen, und den Inhalt der auswertenden unterrichtlichen Besprechungen ein. Angebaut wurden „Radieschen, Rettiche, Möhren, Kohlrabi, weiße Feldrüben, Tomaten (Rohkost als Ersatz für Brotschnitten ${ }^{785}$ ); Erbsen und Bohnen (mehlhaltig, Mangel an Hülsenfrüchten); Lein, Mohn, Sonnenrosen (ölhaltig, Mangel an Fetten) ${ }^{\text {“786 }}$. Über die Ernteerträge oder aufgetretene Probleme steht nichts in dem Bericht.

\section{Schulgarten einer Mädchenschule ${ }^{787}$}

Die verantwortliche Lehrerin hatte bereits im Frühjahr 1914 einen 300 qm großen Garten gepachtet, in dem jede Schülerin ein eigenes Beet anlegen und bewirtschaften konnte. Aber sie war weder mit dem Aussehen des Gartens noch mit den Erträgen zufrieden. Sie fragte sich immer wieder,

"ob dieser im Grunde doch etwa spielerische Betrieb des Gartenbaus der Rechte sei, und die im Winter 1914/15 einsetzende Sorge um die Volksernährung gab mir die Antwort darauf. Im zweiten Sommer wollte ich es anders anfangen, und als es nun Zeit wurde zur Frühjahrsbestellung, stellte ich es den Kindern als vaterländische Pflicht vor, im Garten mitzuhelfen zur Gewinnung von Nahrung, und fragte sie, wer zur Mitarbeit bereit wäre, auch wenn es diesmal keine Eigenbeete gäbe, sondern alles gemeinsam erbaut und dann an die fleißigen Helferinnen verteilt würde. ${ }^{\text {“788 }}$

Zwar meldeten sich zunächst recht viele, im Laufe der nächsten Wochen wurden es jedoch immer weniger, bis schließlich lediglich fünf übrig blieben. Ein Jahr später versuchte es die Lehrerin mit anderen Klassen erneut und hatte nach eigener Einschätzung mehr Erfolg.

\footnotetext{
${ }^{783}$ Göhl, Ein Jahr Gartenarbeit im Kriege, Die Arbeitsschule, 1917, S. 268.

${ }^{784}$ Göhl, Ein Jahr Gartenarbeit im Kriege, Die Arbeitsschule, 1917, S. 269.

${ }^{785}$ Gemeint sind offensichtlich mit Wurst oder Käse belegte Schnitten.

${ }^{786}$ Göhl, Ein Jahr Gartenarbeit im Kriege, Die Arbeitsschule, 1917, S. 269.

${ }^{787}$ Gärtner, Gartenarbeit mit Schulkindern, Die Lehrerin: Organ des Allgemeinen Deutschen Lehrerinnenvereins 1917, S. 87.

${ }^{788}$ Gärtner, Gartenarbeit mit Schulkindern, Die Lehrerin: Organ des Allgemeinen Deutschen Lehrerinnenvereins 1917, S. 89.
} 
Ausführliche Darstellungen von Schulgartenversuchen liegen auch aus Berlin ${ }^{789}$, Dortmund $^{790}$, Jena $^{791}$ und Pirna ${ }^{792}$ vor. In diesen wird fast ausschließlich von positiven Erfahrungen berichtet. Ein Lehrer (Pirna a. d. Elbe, Königreich Sachsen) schrieb z. B., dass in einem Jahr „458 Pfund Kürbisse, 117 Pfund Bohnen, 60 Pfund Porree, 54 Pfund Grünkohl, 50 Pfund Rüben, 120 Pfund Kohlrabi (mittlere und kleine nicht mitgezählt), 60 Köpfe Weißkraut, 3 1⁄2 Pfund ausgesuchte Sonnenrosenkerne ${ }^{793}$, ferner Tomaten, Rettiche, Radieschen und Schoten (geerntet und) zum weitaus größten Teile an bedürftige, kinderreiche Familien verschenkt (worden sind)“.

Die Erträge waren offensichtlich befriedigend; sie wurden entweder verkauft oder an Wohltätigkeitsanstalten verschenkt. In Jena erzielte man bei den Verkäufen einen Reingewinn von 800 bis 900 Mark, der der örtlichen Kriegshilfeorganisation überwiesen wurde.

Auch an den Mittelschulen gab es entsprechende Initiativen. So forderte ein Mittelschulrektor aus Burg a. Fehmarn 1915 in einem Aufsatz seine Kollegen und Kolleginnen auf, „,in diesem Jahre auch das geringste Fleckchen Erde mit Kartoffeln (zu) bestellen, so daß im nächsten Winter für jede Familie mehr als 10 Zentner vorhanden sind““794. Er errechnete, dass die ca. 30.000 Landschulen bei einer Anbaufläche von nur je 1 Hektar Brachland Millionen Zentner Kartoffeln ernten könnten. Wie aus dem Artikel hervorgeht, hatte der Rektor bereits Kontakt mit Hamburger Schulen aufgenommen und war auf große Akzeptanz gestoßen. Sein Ziel war es, den Artikel in sämtlichen großen Zeitungen Deutschlands erscheinen lassen. Außerdem plante er, das Projekt Schulgärten reichsweit zu koordinieren.

Einen ähnlichen Aufruf veröffentlichte eine Mittelschullehrerin aus Halle (Saale). Sie appellierte an die Schule als „die Führerin der jungen Generation“, dafür zu sorgen, dass die Zurückgebliebenen ihren Vaterlandspflichten nachkämen und durch landwirtschaftliche Kriegshilfsaktionen zu „Deutschlands nationaler Weiterexistenz“ beitrügen. „Alle Brachländer, Moore, Parkstücke, Blumengärten, Wegstreifen usw. sollten demnach dieses Jahr mit Fleiß angebaut werden. Jeder sollte in seinen Mußestunden Landarbeit tun.“795

\footnotetext{
${ }^{789}$ Wolde, Schulgärten und Schülergärten, Deutsches Philologen-Blatt 1916, S. 763.

${ }^{790}$ Höfler, Zum Kriegsgartenbau der höheren Schule., Deutsches Philologen-Blatt 1917, $286 f$.

791 Schön, Schule und Krieg, Deutsches Philologen-Blatt 1915, S. 312f.; Schön, Bebauung von Brachland als Kriegsarbeit der Schüler., Deutsches Philologen-Blatt 1916, S. 509f.; Schön, Landwirtschaftliche Arbeit der Schüler, Deutsches Philologen-Blatt 1915, S. 280.

${ }^{792}$ Nottnagel, Kriegsgartenbau der Schule, Deutsches Philologen-Blatt 1917, S. $236 \mathrm{f}$.

${ }^{793}$ Begriff in Schwaben für Sonnenblumenkerne.

${ }^{794}$ Drenckhahn, Mobilmachung unserer Schulkinder, Die Mittelschule: Zeitschrift der Reichsfachschaft Mittelschule im Nationalsozialistischen Lehrerbund., 1915, 98, S. 102. Der Aufruf ist offensichtlich tatsächlich in den meisten Tageszeitungen veröffentlicht worden; siehe: Führen, Lehrer im Krieg (1936), S.91.

${ }^{795}$ Kuntz, Die Volksernährung im Kriege und in der Schule, Die Mittelschule: Zeitschrift der Reichsfachschaft Mittelschule im Nationalsozialistischen Lehrerbund., 1915, S. $98 f$.
} 
Auch in ländlichen Volksschulen beschäftigte man sich mit Gartenbaubauprojekten. In Becklingen (Provinz Hannover) z. B. bekam ein Lehrer 1914 für die zweite Lehrerprüfung das Thema „Wie ich meinen Schulgarten den Kindern im Unterricht nutzbar machte“"796. Aus der Provinz Ostpreußen liegen konkrete Angaben über die Anzahl der Schulen und der Schulkinder, die angebaute Fläche sowie die Erträge der Schülergemüsegärten für die Jahre 1916 und 1917 vor. $^{797}$ Insgesamt gab es dort 1916 (1917) 451 (536) Gärten, die von 10.764 (16.131) Schülern und Schülerinnen bewirtschaftet wurden und einen Reingewinn von 32.753,61 Mark (76.478,87 Mark) erbrachten. Die Steigerung von 1916 zu 1917 ist vor allem damit zu erklären, dass das Unterrichtsministerium mit Erlass vom 23. Februar 1917 die Kreisschulinspektoren ersucht hatte darauf hinzuwirken, dass auch die Schulen, die 1916 noch keinen Gemüsegarten angelegt hatten, solches tun sollten. Bis zum 16. April sollten sie berichten, „,bei welchen Schulen neue Gärten angelegt worden sind und bei welchen es nicht gelungen ist und welche Gründe die Anlage verhindert haben““798.

Die Presse nahm trotz solcher Aufrufe nur wenig Notiz von der Einrichtung der „Kriegsgärten“. Allenfalls erschienen kurze Meldungen über solche schulischen Aktivitäten, wie z. B. über die Kriegskartoffeläcker des Kaiser-Friedrich-Realgymnasiums in Königsberg ${ }^{799}$ und einer Schule in Neukölln („,Deutsche Tageszeitung“c). ${ }^{800}$

In Flensburg hatte nach Hohnsbehn eine größere Zahl von Volksschülern Gartenland, das mehrere Knabenschulen angemietet hatten, bewirtschaftet. Als erster gelang es der St. Nikolai-Knabenschule, von der Stadt 4.000 qm Land zur landwirtschaftlichen Nutzung zugewiesen und Geld für die erforderlichen Gartengeräte und Pflanzkartoffeln zur Verfügung gestellt zu bekommen. Beteiligt waren aus jeder der sechs oberen Klassen 20-30 Kinder, die abwechselnd arbeiteten. Der Ertrag, der an die Volksküche abgeliefert wurde, „war sehr befriedigend“601.

Die Zeitung berichtete über das Projekt und offensichtlich trug das dazu bei, dass im nächsten Frühjahr (1916) vier weitere Schulen Schulgärten anlegten, und zwar die Petri-Knabenschulen I und II (1.000 qm und 1.200 qm Gartenland), die St. Johannis-Knabenschule (1.000 qm) und die St. Marienschule II (1.500 qm). Über die beachtlichen Erträge der St. Petri-Knabenschule

\footnotetext{
${ }^{796}$ Ebel, Dorfchronik Becklingen 1916-1937 I (1988), S. 147-150; Lehrer Gronau legte eine ausführliche Projektbeschreibung vor.

${ }^{797}$ Königliche Regierung für Ostpreußen, Schülergemüsegärten, Amtliches Schulblatt für den Regierungsbezirk Königsberg, 1918, S. 44f.

${ }^{798}$ Königliche Regierung, Abteilung für Kirchen- und Schulwesen, Schülergemüsegärten, Amtliches Schulblatt für den Regierungsbezirk Königsberg, 1917, S. 26. In dem gleichen Erlass wird den Schulen empfohlen, das Buch „Der Gemüsegarten“ des Kreisschulinspektors Toennis, das 50 Pfennig kostete, anzuschaffen.

${ }^{799}$ Führen, Lehrer im Krieg (1936), S.91.

${ }^{800}$ Kriegskartoffelacker des Kaiser-Friedrich-Realgymnasiums zu Neukölln., Deutsche Tageszeitung .

${ }^{801}$ Siehe: Hohnsbehn, Die Flensburger Schuljugend in der Zeit des ersten Weltkriegs (1996), S. 260.
} 
I, die den Schülern selbst zugutekamen, schreibt Hohnsbehn: "Im Jahre 1917 wurden 36,7 Zentner Kartoffeln, 700 Pfund Kohl und 2030 Pfund Bohnen geerntet'. Davon erhielt jeder Schüler [...] 47 Pfund Kartoffeln [und] 10 Pfund Kohl gegen eine Vergütung von 1 M zur Deckung der Ausgaben'. An der St. Johannis-Knabenschule wurden dagegen sämtliche Erzeugnisse verkauft und der ,Gewinn der Schulkasse zugeführt'،"802 1918 gab es Probleme zwischen den Schulen und der Schuldeputation; diese hatte die Schulen aufgefordert, den Ertrag an gemeinnützige Anstalten (Kriegsküchen, Lazarette u. a.) abzuliefern. Darauf gab die St. Johannis-Knabenschule den Schulgarten mit der Begründung auf: "Der Boden war schlecht und das Land ungedüngt. Der Ertrag entsprach nicht der aufgewandten Mühe und der Unruhe, die die Bearbeitung in die Schule hineinbrachte.“

Bis auf eine Schule (St. Nikolai-Knabenschule) widersetzten sich die Schulen ebenfalls jener Forderung, die auf eine Anordnung der Königlichen Regierung in Schleswig zurückging, und überließen die Ernteerträge den Eltern der betreffenden Kinder zu günstigen Preisen. Hohnsbehn kommt zu dem Ergebnis, dass die Schulen insgesamt „durch ihre Gartenbautätigkeit zwar keinen bedeutsamen, wohl aber einen nennenswerten Beitrag zur Ernährungssicherung geleistet (haben), und so manche Mutter wird sich über die zusätzlichen Kartoffeln, Rüben oder Kohlköpfe sehr gefreut haben““803.

Im November 1916 veröffentlichte das Provinzialschulkollegium einen sehr detaillierten Bericht über die geleisteten Arbeiten an den einzelnen Lyzeen in Schleswig-Holstein und wies auf die vielen Probleme hin, die mit Gartenbauprojekten verbunden waren, u. a. auf die Beschaffung von Land, Geräten und Düngemitteln sowie auf die von den jüngeren Schülerinnen nicht zu bewältigenden Arbeiten. Sicher waren die vielen negativen Erfahrungen ein wichtiger Grund dafür, dass von den 17 Lyzeen nur fünf Schulen Kriegsgärten eingerichtet hatten, und zwar die Lyzeen in Flensburg, Schleswig, Elmshorn und Kiel (Lyzeum II und PrivatLyzeum von Fräulein Kraus). In Elmshorn (93 Schülerinnen) und Flensburg (65 Schülerinnen) war die Beteiligung am höchsten, während am Privat-Lyzeum 32 und an anderen Schulen nur ganz wenige Schülerinnen beteiligt waren. Die Erzeugnisse wurden an die Eltern der Schülerinnen oder die Küchen der Frauenschulen „meist unter dem Marktpreis“ verkauft.

Obwohl offensichtlich das Engagement der höheren Mädchenschulen in Schleswig-Holstein und sicher auch in den anderen preußischen Provinzen nicht sehr groß gewesen ist, dankte im

\footnotetext{
${ }^{802}$ Hohnsbehn, Die Flensburger Schuljugend in der Zeit des ersten Weltkriegs (1996), S. 261.

${ }^{803}$ Hohnsbehn, Die Flensburger Schuljugend in der Zeit des ersten Weltkriegs (1996), S. 262.
} 
Februar 1917 der preußische Unterrichtsminister den Schülerinnen und ihren Lehrern, dass sie sich im vaterländischen Interesse willig auch dieser Arbeit unterzogen“804 hätten.

Zusammenfassend kann festgestellt werden, dass die Erträge aus den Schul- und Schülergärten zwar vielen Familien der betroffenen Schüler und Schülerinnen und auch einigen Volksküchen ein kleines Zubrot verschafften, volkswirtschaftlich jedoch fast ohne jede Bedeutung waren. In erzieherischer Hinsicht waren die Aktionen allerdings insgesamt erfolgreicher, denn die beteiligte Schuljugend hat dadurch manches gelernt, z. B. im Gemüseanbau, in der Botanik und durch den Verkauf der Produkte auch in der Wirtschaft. Dass auch die Schulaufsicht den Erfolg der Schulkriegsgärten als „,nicht erheblich“ einstufte, geht u. a. aus dem Erlass des preußischen Unterrichtsministers vom 14. Februar 1917 hervor, der sich ausschließlich an die Lyzeen wandte. ${ }^{805}$ Deshalb gab es - im Gegensatz zu den allgemeinen landwirtschaftlichen Einsätzen - auch nur ganz wenige Erlasse der deutschen Kultusbürokratie zu den Schulgärten. Hinweise in den Schulchroniken sind kaum vorhanden, was ebenfalls auf eine relativ geringe Zahl solcher Gartenbauversuche schließen lässt. Die untersuchten Berichte über derartige Projekte zeigen zwar, dass Lehrer und Schüler bei der Arbeit in den Schulgärten durchaus das Gefühl hatten, sie täten für das Vaterland etwas Gutes, im Unterschied zu vielen „Jungmannen“, die im Ernteeinsatz waren, kamen sie sich allerdings nicht wie „Heimsoldaten“ ${ }^{606}$ vor, die halfen, ihr Vaterland an der „Heimatfront“ zu verteidigen. Dieses ist sicher darauf zurückzuführen, dass es überwiegend Mädchen waren, die sich um die Schul- und Schülergärten kümmerten.

Auf die Pflege der Gärten und des Dienstlandes der eingezogenen Lehrer durch die Schulen, die von den Behörden angeordnet wurde ${ }^{807}$, wird angesichts der geringen Bedeutung nicht näher eingegangen.

\subsection{Arbeitseinsätze in Industrie und Handel}

Nach $\S 2$ des „Gesetz(es) über den vaterländischen Hilfsdienst“ vom 5. Dezember 1916 konnte u. a. jeder Schüler, der das 17. Lebensjahr vollendet hatte, also in der Regel ausschließlich Gymnasiasten, auch zum Dienst in der Kriegsindustrie und ,,in Betrieben, die für Zwecke der Kriegführung oder der Volksversorgung unmittelbar oder mittelbar Bedeutung haben“, ver-

\footnotetext{
${ }^{804}$ Ministerium der geistlichen und Unterrichts-Angelegenheiten, Ministerium der geistlichen und UnterrichtsAngelegenheiten 1917 .

${ }^{805}$ Ministerium der geistlichen und Unterrichts-Angelegenheiten, Ministerium der geistlichen und UnterrichtsAngelegenheiten 1917.

${ }^{806}$ Deutsche Tageszeitung, 19.10.1917.

${ }^{807}$ Ministerium der geistlichen und Unterrichts-Angelegenheiten, Bestellung der Schulgärten und des Dienstlandes der zum Kriegsdienste eingezogenen Volksschullehrer mit Kartoffel usw., Zentralblatt für die gesamte Unterrichtsverwaltung in Preußen, 1915, S. $386 f$.
} 
pflichtet werden. Inwieweit Schüler tatsächlich in industriellen Betrieben als Hilfskräfte eingesetzt worden sind, soll im Folgenden untersucht werden.

Nach Ausbruch des Krieges waren viele Arbeitskräfte aus den ländlichen Regionen und Kleinstädten in die Großstädte gewandert, um dort wegen der höheren Löhne in der Munitionsfertigung zu arbeiten. Allerdings fehlten zunächst Arbeitskräfte im gewerblichen Bereich und kaufmännisches Personal, was zu Einschränkungen der Produktion, zu BetriebsschlieBungen und zu Entlassungen und damit zu einer steigenden Arbeitslosigkeit führte. ${ }^{808}$ Durch die Umstellung von der Friedens- auf die Kriegswirtschaft erholte die Wirtschaft sich jedoch schnell und ab 1915 gab es eine große Nachfrage nach Arbeitskräften. „Die Millionen Eingezogenen im Arbeitsprozeß zu ersetzen, ließ sich nur im Rückgriff auf die bisher unvollkommen in Anspruch genommene industrielle ,Reservearmee' halbwegs verwirklichen. “809 $\mathrm{Zu}$ dieser gehörten neben älteren Menschen, Frauen, Kriegsgefangenen, Strafgefangenen, Kriegsbeschädigten und deportierten Arbeitskräften aus den besetzten Gebieten auch Jugendliche. Da Schüler aber ebenfalls in der Landwirtschaft dringend benötigt wurden, wo sie wegen des saisonalen und jeweils nur wenige Wochen umfassenden Einsatzes sinnvoller beschäftigt werden konnten, haben deutlich weniger von ihnen in industriellen Betrieben gearbeitet. Dass es aber seitens des Industrie eine verstärkte Nachfrage nach „Jungmannen“ gegeben hat, geht aus einem Erlass des preußischen Unterrichtsministers vom 15. November 1917 hervor. $^{810}$

Das Kriegsamt des Kriegsministeriums, das für den Schülerhilfsdienst zuständig war, veröffentlichte im Dezember 1917 die Erfahrungen des verflossenen Sommerhalbjahres hinsichtlich der Verwendung in der Industrie und bei Behörden und nannte die zukünftigen Aufgaben. ${ }^{811}$ Prof. Boßmer, Referent beim Stabe des Kriegsamtes, wies auf eine Reihe von Problemen hin, die es abzustellen gelte:

„Es ist einmal darauf zu achten, daß die Schüler nicht zum Lohndruck verwendet werden und ihre Abberufung überhaupt erst erfolgt, wenn keinerlei Arbeitskräfte mehr zu Gebote stehen. An manchen Orten haben Schüler ihre Notprüfung vor der Abberufung machen können und haben sich dann beim Kriegswirtschaftsamt gemeldet. Die oberste Schulbehörde sieht solche Fälle für völlig unerwünscht an und auch das Kriegsamt steht auf dem Standpunkt, daß das Leben der Schule in den Wintermonaten nur in dringendsten Fällen durch Abberufung von Schülern in die Industrie und

\footnotetext{
${ }^{808}$ Siehe: Grotjahn, Stahl und Steckrüben Bd. 2 (1993), S. 13.

${ }^{809}$ Grotjahn, Stahl und Steckrüben Bd. 2 (1993), S. 19.

${ }^{810}$ Ministerium der geistlichen und Unterrichts-Angelegenheiten, Die Regelung der Vermittlungsfrage für die Jungmannenhilfe, Zentralblatt für die gesamte Unterrichtsverwaltung in Preußen, 1917, S. 782. In dem Erlass wird auch festgelegt, dass ,, die Jungmannen in Industrie und Landwirtschaft [...] in der Bezahlung [...] gleichzustellen“ seien. Damit wollte man verhindern, dass die Schüler und ihre Eltern sich aus finanziellen Gründen gegen den Dienst in der Landwirtschaft entschieden.

${ }^{811}$ Broßmer, Leitsätze über die zukünftigen Aufgaben des freiwilligen Schülerhilfsdienstes, Zentralblatt für die gesamte Unterrichtsverwaltung in Preußen, 1917, S. 253.
} 
zu Behörden gestört werden soll. Schon aus einem rein volkswirtschaftlichen und volksgesundheitlichen Grunde darf mit der Gesundheit unserer Jugendlichen kein Raubbau getrieben werden. In all den Fällen, in denen eine Verwendung von Schülern in der Industrie oder bei Behörden durch die Notlage dringend erscheint, muß darauf geachtet werden, daß ihre Entlohnung keinesfalls unter der ortsüblichen Bezahlung erfolgt. “812

Aufgrund der Erfahrungen bestanden also Sorgen über Lohndruck und Gesundheitsprobleme der „Jungmannen“. Zudem haben einige offensichtlich den Arbeitsdienst genutzt, um trotz schlechter Leistungen das ,Notabitur' zu bekommen. Da den Schulbehörden die Probleme bekannt waren, haben sie nicht für den Hilfsdienst in der Industrie geworben, sondern immer wieder den Einsatz in der Landwirtschaft propagiert. Dieses trifft auch auf die untersuchten Lehrerzeitungen aller Schulformen zu. Dort gibt es offensichtlich keinen einzigen ausführlichen Bericht über die Erfahrungen mit Schülern in der Industriearbeit. In Schul- und Ortschroniken, Lebenserinnerungen, Schulaufsätzen u. a. sind nur vereinzelt vage Hinweise zu finden. ${ }^{813}$ Aus Schwerin (Großherzogtum Mecklenburg-Schwerin) ist z. B. überliefert, dass die Mädchen des Oberlyzeums und vom Lyzeum mit Studienanstalt in einer Munitionsfabrik eingesetzt worden sind ${ }^{814}$ und auch aus Kassel (Provinz Hessen-Nassau) liegen ähnliche Informationen vor. Hier haben „Schülerinnen der oberen Klassen der Studienanstalt und des Oberlyzeums ihre Ferienzeit damit ausgefüllt, daß sie in die Munitionsfabrik gegangen sind“615. In Hannover entfielen im Jahre 1918 auf 556 Schulkinder 6.569 Arbeitsstunden in Industriebetrieben, d. h., jedes der dort eingesetzten Kinder arbeitete durchschnittlich lediglich etwa 12 Stunden. ${ }^{816}$

Ein Lehrer aus Berlin-Steglitz nennt in einem Aufruf ${ }^{817}$, in dem er die Kollegen zur weiteren „wirtschaftlichen Mobilmachung“ aufruft und den er an 2.000 höhere Schulen geschickt hat, 15 mögliche Gebiete der Schulkriegshilfe; die Arbeit in Industrie und Handel wird allerdings nicht erwähnt. Auch die „Kriegsjahresberichte 1941/15 der bayerischen gymnasialen Anstalten“ ${ }^{\star 818}$ und der Bericht „Der Weltkrieg und die höheren Schulen Badens im Schuljahre 1914-

\footnotetext{
${ }^{812}$ Broßmer, Broßmer 1917, S. 256.

${ }^{813}$ Z. B. heißt es in einem „Jugenddank-Kalender“: „,...sie halfen in der Industrie und im Handel“. (Günther/Hildebrandt/Samuleit [Hrsg.], Jugenddank-Kalender [1919], S.67).

${ }^{814}$ Langer, Schulfrei für den Tod 85 (1988), S.33.

${ }^{815}$ Vaterländischer Hilfsdienst der Mädchen, Die Lehrerin: Organ des Allgemeinen Deutschen Lehrerinnenvereins 1917/18, S. 94

${ }^{816}$ StAH, HR 16, Nr, 553; im gleichen Zeitraum leisteten in der Landwirtschaft 3898 Kinder 60.946 Arbeitsstunden ab (durchschnittlich 15,6 Stunden pro Schüler); in Handel und Gewerbe entfielen auf 333 Kinder 9.095 Arbeitsstunden (durchschnittlich 27,3). Hier waren also recht wenig Schüler eingesetzt, die allerdings relativ lange arbeiteten.

817 Ohmann, Die Kriegshilfe der deutschen Schule 1917, Deutsches Philologen-Blatt 1917, S. 99f.

${ }^{818}$ Stemplinger, Kriegsjahresberichte1914/15 der bayrischen gymnasialen Anstalten, Deutsches Philologen-Blatt 1915, S. 747. Auch ein anderer Bericht für das Kriegsjahr 1914/15 enthält entsprechenden Angaben Ebner, Das zweite Kriegsjahr der höheren realistischen Schulen in Bayern, Deutsches Philologen-Blatt 1916, S. 670f.
} 


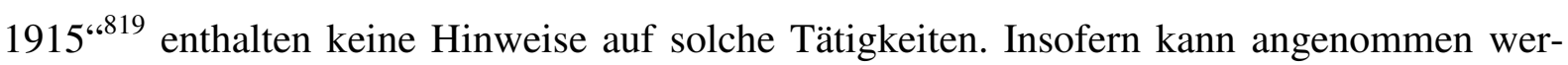
den, dass in vielen Städten eine Reihe von Schülern durchaus in der Industrie Hilfsdienste geleistet haben, es jedoch nahezu keine von der Schule organisierten Arbeitseinsätze in der Industrie gegeben hat.

\subsection{Sonderdienste}

Von Kriegsbeginn an wurden die Schulen außer zu den Sammlungen und Ernteeinsätzen auch zu vielen weiteren Sonderaufgaben herangezogen, die den normalen Unterrichtsbetrieb störten und die Lehrerschaft zusätzlich sehr stark belasteten. Diese sollen im Folgenden dargestellt und hinsichtlich ihrer gesellschaftlichen und militärischen Bedeutung bewertet werden. Da Hilfsdienste von Lehrern und Schülern vor allem in vielen Orts- und Schulchroniken sowie in Lehrerpublikationen und Lebenserinnerungen erwähnt werden, ist die Quellenlage insgesamt recht gut. Allerdings sollen für die vielen einzelnen Aktivitäten jeweils nur ganz wenige typische konkrete Bespiele angeführt werden. Die Bereiche ,Liebesgaben' und ,Sanitätsdienst' werden wegen ihres Umfangs und ihrer Bedeutung in gesonderten Abschnitten thematisiert.

\subsubsection{Schüler und Schülerinnen}

Im Jahresbericht 1915 geht der Direktor eines Gymnasiums in Göttingen auch auf die Hilfsdienste ein: „Eine völlige Umwälzung im Schulleben führte der Ausbruch des Kriegs herbei. [...] Alle Schüler, die waffenfähig waren, suchten sich während der Ferien im nationalen Hilfsdienst oder durch Dienstleistungen bei den Militär- und Zivilbehörden nützlich zu machen. Nicht alle fanden die ersehnte Beschäftigung; aber 135 Schüler aller Klassen konnten Verwendung finden. Als Hilfsarbeiter bei der Einbringung der Ernte waren 65 Schüler tätig und zu diesem Zweck für einen Teil des zweiten Viertelhalbjahrs im Sommerhalbjahr beurlaubt. ${ }^{820}$ Im Folgenden soll der Frage nachgegangen werden, inwieweit die Aussage generalisierbar ist und in welchem Umfang das Leben der Kinder von Beginn an vom Krieg bestimmt war. Im ersten Text geht ein Lehrer vor allem auf die ersten Kriegstage ein:

„Da war dann der Kriegsdienst wichtiger als der Schuldienst. 'Herr Hauptmann, wir melden uns zur Stelle!' Und es dauerte nicht lange, da waren die Kinder alle auf dem Wege, den Soldaten die Quartiere und die Ställe für ihre Pferde auf den zerstreut und zum Teil sehr weit entfernt liegenden Bauernhöfen zu zeigen. [...] Der neue Tag bringt neue Aufgaben: Die Transportzüge der Eisenbahn liegen oft lange an der Station, der letzten vor der größeren Stadt, die in Friedenszeiten Garnison war. Und die Soldaten sind von langer Fahrt durstig. Mit Esswaren sind sie reichlich versorgt, aber der Durst quält in diesen heißen Zeiten. Da gibt es für die Mädchen zu tun. Am Morgen wer-

\footnotetext{
${ }^{819}$ Berger, Der Weltkrieg und die höheren Schulen Badens., Deutsches Philologen-Blatt 1915, S. 564f.

${ }^{820}$ Saathoff, Göttinger Kriegsgedenkbuch (1935), S. $139 f$.
} 
den einige durch das Dorf und zu den näheren Höfen geschickt, um Geld zu sammeln, Geld für Limonade, die den Soldaten während des kurzen Aufenthalts am Bahnhof köstlich munden soll.“ ‘821

Auch der folgende Auszug aus dem Bericht „Die Leistungen der Schüler im Kriege“ stammt von einem Lehrer:

„... die Hilfeleistung fing doch bei der Mobilmachung an [...]: ich erinnere mich noch ganz genau, wie es auf dem Stettiner Bahnhof in Berlin aussah, als ich am 1. September 1914 aus Schweden nach Hause zurückkehrte, wie plötzlich die Gepäckträger verschwunden und statt ihrer unsere Jungs eingetreten waren. Auch da stellten sie sich zunächst nicht sehr geschickt an. [...] Aber auch da machte Uebung den Meister, und nach drei, vier Tagen klappte es schon famos! Schließlich waren die Berliner ganz erstaunt, daß sie ihre Koffer doch noch heil in ihre Hände bekamen, die sie schon verloren geglaubt hatten. Und dann sahen die Bewohner aller größeren Städte des Reiches ihre braven Schüler wieder als Post- und Telegraphenboten und als freiwillige Radfahrer, als Briefsortierer und Paketverteilen. “ 822

Ein ähnlicher Bericht liegt von einer Berliner Lehrerin vor:

„Viele Schüler und Schülerinnen der Oberklassen machten von Anfang an mit. Sie machten nachmittags Botengänge, radelten, fuhren, liefen, trugen Depeschen, Briefe, Pakete aus. Andere halfen in Krippen und Kinderhorten, in den Büros der Unterstützungskommissionen und des Roten Kreuzes, des Nationalen Frauendienstes, überall da, wo die Dienste der jugendlichen Helfer und Helferinnen gewünscht und gebraucht wurden. ${ }^{\text {“823 }}$

Dass es offensichtlich nicht an jugendlichen Helfern fehlte, bestätigen auch die „WeltkriegsErinnerungen“ des Gymnasiums in Berlin-Steglitz:

„Es fehlte niemals an Freiwilligen, wenn die Gemeinde Steglitz Boten brauchte für die Verteilung der Brotkarten, für die Feststellung der Kartoffelvorräte, der Schweinebestände u. s. w. [...]. Als es nach der Einbeziehung der allerletzten Landsturm-Jahrgänge auch im GemeindeVerwaltungsdienst an Arbeitskräften mangelte, sprang die Schülerschaft willig ein, um sich unter Leitung von Lehrern bei Wind und Wetter, zum Teil bei grimmiger Kälte, an der Befreiung der Bürgersteige von Schnee, Eis und Schmutz zu beteiligen ${ }^{824}$, ebenso beim Abtragen der Kohlen für die Schule. [...] Mehr und mehr wurde die Jungmannschaft zum Hilfsdienst herangezogen, z. B. zur Aushilfe bei der Bank und dem Magistrat, zur Gepäckabfertigung bei der Post und Eisenbahn, zur Lebensmittelkartenabfertigung und Bezugsscheinverteilung, zur Munitionsherstellung, zum Wachdienst auf den Güterbahnhöfen, zum Botendienst im Großen Hauptquartier usw. “825

Die Chronik „Coburg im Weltkrieg 1914-18“ enthält ebenfalls viele Hinweise auf entsprechende Tätigkeiten der Schulkinder; dort heißt es:

„Die älteren Schüler der Stadt wurden in Anspruch genommen von der Feuerwehr, die durch die Einbeziehung viele Mitglieder verloren hatte; sie halfen bei der Überführung der Verwundeten in die Lazarette. Um den Stockungen in der Verteilung der notwendigen Massengüter, wie Kohlen und Brennholz, bei dem empfindlichen Mangel an leistungsfähigen Pferden zu begegnen, wurde

\footnotetext{
${ }^{821}$ Führen, Lehrer im Krieg (1936), S. 36f.

${ }^{822}$ Günther/Hildebrandt/Samuleit (Hrsg.), Jugenddank-Kalender (1919), S. 67.

${ }^{823}$ Günther/Hildebrandt/Samuleit (Hrsg.), Jugenddank-Kalender (1919), S. 72f.

${ }^{824}$ Siehe: Anhang, Seite 71, Bild 1.

${ }^{825}$ Alexander, Der Kölner Bauer (1987), S. 14f.
} 
auch hier ein Schülerhilfsdienst eingerichtet, um mit Handwagen, die vom Magistrat angeschafft wurden, Aufträge der Stadtbevölkerung auszuführen.“ ${ }^{\text {(826 }}$

Auch in Flensburg wurden die Schüler vielfach als Hilfskräfte eingesetzt, und zwar vor allem im Winter, da sie im Frühjahr und Herbst in der Landwirtschaft benötigt wurden. So wurden z. B. Anfang 1918 die Jungenschulen zu Räumdiensten herangezogen, da keine Arbeitskräfte zur Beseitigung des Schnees im Januar vorhanden waren. ${ }^{827}$ Bereits im Herbst 1916 hatte die königliche Regierung in Schleswig die Schulen zur „Gestellung von Schülern zu Entladearbeiten“ aufgefordert und dieses ausführlich begründet:

„Die Generalkommandos haben zur Herabsetzung der Entladepflichten den Empfängern von Gütern und den Eisenbahnverwaltungen, falls diese zur Zwangsentladung und Zwangszuführung genötigt sind, auf ihr Ansuchen jede nur verfügbare Zahl von Leuten und Gespannen zur Verfügung zu stellen. Da es sich um kurzfristige Mitwirkung handeln wird, ist es nach einer uns zugegangenen Anregung zweckmäßig, auch die älteren Klassen der Schulen zu diesen Arbeiten in weitestem Maße heranzuziehen. Wir weisen daher die nachgeordneten Schulbehörden an, alle geeigneten Schüler sofort den Kommandanturen oder Garnisonskommandos namhaft zu machen.“ ${ }^{28}$

Nach Hohnsbehn hat es solche Regelung, durch die die Schüler einer militärischen Behörde unterstellt waren, bei keiner anderen Maßnahme gegeben. Deshalb wurde die Anordnung etwas später verändert: Dem Einsatz mussten die Eltern zustimmen und außerdem erfolgte die Anforderung nicht mehr durch die militärischen Stellen. ${ }^{829}$

Eine gute Übersicht über die Aktivitäten der Schüler geben auch die „Jahresberichte“ der bayerischen Schulen: „Volle Anerkennung verdient auch der Eifer in allen Zweigen der Kriegshilfe. Da finden wir in den Jahresberichten: [...] Verpflegung durchreisender Truppen, Einrichtung von Lazaretten, Botendienste für die Behörden (was mehreren Schulen amtliche Anerkennungsschreiben eintrug), Austragen von Brot und Mehlkarten, Bestandaufnahme der Kartoffelvorräte. “ 830

Über den Umfang der Hilfstätigkeiten und die Einstellung der Schüler liegen viele weitere zeitgenössische Reaktionen aus den meisten Regionen des Reiches vor. So weist z. B. ein Schweriner Gymnasialdirektor 1918 darauf hin, dass mit zunehmender Dauer des Krieges die Schüler ständig neue Aufgaben übernehmen mussten und ihnen der Krieg dadurch immer „näher komme“ ${ }^{\text {831. }}$. Auch im Jahresbericht des Hans-Carossa-Gymnasiums in Landshut (Königreich Bayern) wird eine Vielzahl von Hilfstätigkeiten aufgeführt. ${ }^{832}$ Häufig wird

\footnotetext{
${ }^{826}$ Ungelenk, Coburg im Weltkrieg 1914-18; Ein Denk- u. Dankstein (1922), S. 145.

${ }^{827}$ Siehe: Hohnsbehn, Die Flensburger Schuljugend in der Zeit des ersten Weltkriegs (1996), S. 262.

${ }^{828}$ Hohnsbehn, Die Flensburger Schuljugend in der Zeit des ersten Weltkriegs (1996), S. 263.

${ }^{829}$ Siehe: Hohnsbehn, Die Flensburger Schuljugend in der Zeit des ersten Weltkriegs (1996), S. 264.

${ }^{830}$ Ebner, Die höheren realistischen Schulen Bayerns im Kriegsjahr 1914/15 (1915), S. 671.

${ }^{831}$ Langer, Schulfrei für den Krieg, in: Mecklenburg-Magazin 1994, Nr. 12, S. 66f.

${ }^{832}$ Ebermeier/Mayer-Mommertz/Pfaffenzeller, Die Geschichte des Hans-Carossa-Gymnasiums Landshut (2004), S. $97 f$.
} 
betont, dass angesichts der Hilfsdienste der Unterricht für die Schüler nur noch eine untergeordnete Rolle gespielt habe. ${ }^{833}$ Recht kritisch äußerte sich eine Lehrerin 1915 u. a. über Schülerinnen, die als Hilfskräfte in Kindergärten arbeiten wollten:

„Während die Nachfrage nach Plätzen in Kindergärten und Tagesheimen noch mäßig ist, kann man von einem Überangebot an ungeduldigen, tatendurstigen Helferinnen sprechen. Damit diese etwas zu tun haben, sollen Kinder herbeigerufen, gespeist und beaufsichtigt werden, so sieht die Sache aus. Eine doppelte Gefahr liegt in diesem Zustrom derjenigen, die sich in der Beschäftigung mit Kindern einen Lebensinhalt schaffen wollen: zum Teil sind die Frauen und jungen Mädchen ganz ungeübt und ungeschult; es ist viel guter Wille da, aber Vollbringung des Guten fehlet. Welche schwerwiegenden Folgen kann z. B. die mangelnde Kenntnis hygienischer Maßnahmen haben; wie will ein junges Mädchen aus guter Familie beurteilen, wie weit man bei Kindern des Volkes in ihren Ansprüchen an Sauberkeit gehen darf und was sie unbedingt fordern muß! Vor allen Dingen ist vor mangelhaften Einrichtungen bei Krippen zu warnen, die gesundheitsschädlich im weitesten Sinne sein können. Auch die Kinderheime für die Schuljugend werden unbedingt unter ärztliche Aufsicht gestellt werden müssen, da sie sonst Brutstätten für Krankheiten und Epidemien werden können. All diese Gefahren steigern sich, wenn unerfahrene ganz an die Stelle der ausgebildeten treten. Und hier setzt die zweite bedenkliche Folge des freiwilligen Helferdienstes ein: stellenlose Kindergärtnerinnen und Erzieherinnen werden verdrängt. “834

Immer wieder kam es auch vor, dass die Presse über die Hilfsdienste der Schüler berichtete, wie ein Beispiel aus dem Jahre 1917 aus Berlin-Schöneberg zeigt):

„Gymnasiasten als Schneeschipper. Beim Schneeschippen betätigten sich seit heute Vormittag in flotter Arbeit Schüler der Höheren Schulen in Schöneberg, die sich freiwillig in den Dienst der Allgemeinheit gestellt hatten und denen es augensichtlich Freude macht, in dieser Weise als freiwillige Schipperkompagnie tätig zu sein. Diese Hilfsleistung erfolgte durch Eingreifen des Schönebergers Oberbürgermeisters, an den sich die Verwaltung der Städtischen Straßenreinigung in ihrer Not gewandt hatte. Er war es, der auf die Idee kam, die älteren Schüler der Höheren Schulen heranzuziehen und nach eingeholter Zustimmung des Oberpräsidenten den Schuldirektoren den Aufruf von Freiwilligen über 16 Jahren empfahl. Die jungen Leute taten ihre Arbeit gern und gut.“ ${ }^{\text {835 }}$

Insgesamt zeigen die ausgewählten Beispiele, dass es vor allem die Schüler in den Städten waren, die in großer Zahl Hilfsdienste übernahmen und sie offensichtlich auch recht gut ausführten. Mädchen engagierten sich hauptsächlich im Sanitätsdienst sowie bei der Beaufsichtigung von kleinen Kindern und stellten Liebesgaben her. Wie groß der Wunsch von Mädchen, sich bei der Kriegsfürsorge zu engagieren, gewesen ist, geht aus einem Bericht des Schulministers an das preußische Abgeordnetenhaus 1918 hervor:

„Bei den Mädchenschulen nahm die Hilfstätigkeit hier und da eigenartige Formen an. An einem Lyzeum nähten die Schülerinnen der Oberklassen an den Nachmittagen freiwillig Pulverbeutel, Artelleriearsenal, in einem anderen wurden Tupfen für die Wundbehandlung angefertigt, wieder in

\footnotetext{
${ }^{833}$ Pörtner, Kindheit im Kaiserreich (1990), S.143; Schott, Das zweite Jahr Kriegsstunden am Gymnasium, Deutsches Philologen-Blatt 1915, Nr. 25, S. 23.

${ }^{834}$ Kinder- und Jugendfürsorge im Krieg, Die Lehrerin: Organ des Allgemeinen Deutschen Lehrerinnenvereins 1914, S. 171.

${ }^{835}$ Gymnasiasten als Schneeschipper, Tageblatt für den amtshauptmannschaftlichen Bezirks Borna, 16. 09.1917.
} 
einem anderen wurden in den Handarbeitsstunden Ausbesserungsarbeiten für das städtische Säuglingsheim vorgenommen. “ 836

Die Schulkinder der kleinen Landschulen wurden noch dringender als die städtischen Altersgenossen in der Landwirtschaft benötigt und standen deshalb für andere Hilfsdienste nur ganz selten zur Verfügung. ${ }^{837}$ Über die Aktivitäten der Schulkinder wird zusammenfassend in einem Bericht des Schulministers an das Preußische Abgeordnetenhaus ausgeführt: „Die Schülerinnen haben sich besonders bei der Beaufsichtigung von Kindern, deren Eltern in der Rüstungsindustrie beschäftigt sind, in den Kinderhorten, in den Kriegsküchen.“ ${ }^{\star 838}$ erfolgreich engagiert Ferner heißt es dort: Außerdem haben sie sich in ,den Rotkreuzvereinen, beim Einkochen von Obst, Gemüse und Marmelade, bei der Herstellung von Bekleidungsgegenständen, Wäschestücken, Wolldecken für das Heer, für Lazarette und Kriegskinder sowie bei ähnlichen für Frauen geeigneten Wohltätigkeitsarbeiten nützlich gemacht".

Vor allem auf dem Lande waren neben den Lehrern ${ }^{839}$ auch die Schüler bei den „Vaterländischen Volksabenden“ häufig beteiligt. Während die Lehrer die Bevölkerung über größere Siege und die aktuelle Kriegslage durch Vorträge informierten, waren die Schüler meistens an der Gestaltung des Rahmenprogramms beteiligt, indem sie mit dem Schülerchor auftraten und vaterländische Lieder sangen oder Gedichte rezitierten. Auf die Möglichkeit, Schüler mit einzubeziehen, haben die Schulbehörden mehrfach hingewiesen. ${ }^{840}$ Als Beispiel für den Ablauf solcher Veranstaltungen sei auf einen „Kriegsabend“ hingewiesen, der am 24. Januar 1915 in der Volksschule Dranske (Provinz Preußen) stattfand. ${ }^{841}$ Im Mittelpunkt stand ein Kriegsvortrag des Lehrers über „Die Gründe, die unsere Gegner in den Weltkrieg trieben“ (1.Teil) und „Die Kriegsereignisse von A bis Z.“ (2. Teil). Daneben deklamierten Schüler Gedichte, bildeten „Pyramiden mit Flaggen“, führten ein Theaterstück auf und zeigten Turnübungen. Da die meisten Kriegsabende ähnlich abliefen, kann auf weitere konkrete Beispiele verzichtet werden. Auch bei Sieges- und Trauerfeiern sowie patriotischen Feiern, bei denen es sich nicht um Schulveranstaltungen handelte ${ }^{842}$, gestalteten Schüler durch ähnliche Beiträge das Programm mit.

\footnotetext{
${ }^{836}$ LAS, Abtlg. 302, Nr. 3178.

${ }^{837}$ Zum Beispiel sind für die Schulen des Landkreises Lübbecke keine entsprechenden Sonderaufgaben überliefert; siehe: Kammeier, Der Landkreis Lübbecke und der 1. Weltkrieg (1998).

${ }^{838}$ LAS, Abtlg. 302, Nr. 3178, Seite 5 des Berichts.

${ }^{839}$ Siehe Kapitel 4.4.2.

${ }^{840}$ Z. B. die „Aufforderung an die Lehrerschaft des Regierungsbezirks Hildesheim“ vom 29. August 1914: königliche Regierung in Hildesheim, Aufruf an die Lehrerschaft, Amtliches Schulblatt für den Regierungsbezirk Hildesheim, 1915, S. 134.

${ }^{841}$ Langer, Schulfrei für den Krieg (2004), S. 47.

${ }^{842}$ Siehe dazu Kapitel 5 („Patriotische Feste und Feiern“).
} 
Inwiefern die Schüler ihren Dienst als Kampf an der „Heimatfront“ empfanden, geht aus den zitierten und den zahlreichen anderen untersuchten Quellen nicht direkt hervor. Wenn allerdings ein Zeitzeuge den Unfalltod eines Mitschülers damals als „eine Art von Heldentod“643 empfand und in einer Zeitung die als Schneeschipper eingesetzten Schüler ,als freiwillige Schipperkompagnie“ bezeichnet wurden, so ist es durchaus möglich, dass viele Schüler ebenso dachten und auch den freiwilligen Hilfsdienst als Kampf für das Vaterland empfanden.

\subsubsection{Lehrkräfte}

Noch stärker als die Schüler waren die Lehrkräfte durch Hilfsdienste belastet, denn sie mussten häufig ihre Schüler bei solchen Einsätzen begleiten und wurden darüber hinaus für viele andere Aufgaben herangezogen. In der Provinz Posen z. B. übte ein Landschullehrer Ende 191715 nahezu durchweg ehrenamtliche Hilfsdienste aus. ${ }^{844}$ Für wie wichtig diese Kriegshilfe von Kommunen und Staat gehalten worden ist, zeigen die vielen diesbezüglichen Verfügungen der Schulaufsichtsbehörden. Zunächst sollen am Beispiel der Regierungsbezirke Hildesheim und Königsberg die entsprechenden Verwaltungsvorschriften aufgeführt werden. Die Liste der Tätigkeiten soll dann ergänzt werden, u. a. durch Hinweise in Lehrerzeitungen; schließlich sollen die Tätigkeiten anhand von Schul- und Ortschroniken sowie anderen Quellen unter dem Aspekt untersucht werden, inwieweit die Vorschriften umgesetzt worden sind und wie die Lehrerschaft sie insgesamt empfunden hat.

Amtliches Schulblatt für den Regierungsbezirk Hildesheim:

28.01. 1915 Beteiligung der Lehrer bei der Aufnahme der Getreide- und Mehlvorräte;

Mithilfe der Lehrerschaft bei den Maßnahmen zur Regelung des Verbrauchs der Lebensmittelvorräte

12.03.1915 Teilnahme von Lehrern an Viehzählungen

20.11.1917 Beteiligung der Lehrer an der Volkszählung

Amtliches Schulblatt für den Regierungsbezirk Königsberg:

26.02.1917 Viehzählung

14.05.1917 Kriegswirtschaftliche Bestandsaufnahmen

Im Schulblatt für die Herzogtümer Braunschweig und Anhalt wurden entsprechende Kriegsverfügungen der Oberschulbehörden veröffentlicht. ${ }^{845}$ Am 17. September 1916 erschien eine Verfügung zu der am 1. Oktober 1915 vorzunehmenden Vieh-Zwischenzählung, die sich an die Lehrerschaft wandte: "Bei der außerordentlichen Wichtigkeit, welche dieser Zählung bei-

\footnotetext{
${ }^{843}$ Pörtner, Kindheit im Kaiserreich (1990), S. 206.

${ }^{844}$ Saul, Jugend im Schatten des Krieges (1983), S. 113.

${ }^{845}$ Rundschau, Schulblatt für die Herzogtümer Braunschweig und Anhalt, 1917, S. 144.
} 
zumessen ist, kann im Interesse einer zuverlässigen Durchführung die Lehrerschaft nicht entbehrt werden.“ Außerdem verlangte die Regierung Anhalt mit Erlass vom 12. Februar 1916 von den Lehrern, an der Aufklärung der Bevölkerung über die Ernährung „regsten Anteil““ zu nehmen: „Bei den Vorträgen in den Lehrerkreisen sei besonders zu betonen, daß die Aufklärung der Bevölkerung, namentlich auf dem Lande, auch von Haus zu Haus und in der Schule erfolge.“ Ferner bezeichnete die Herzogliche Regierung die Mitwirkung der Lehrerschaft bei der „für die vom 1. bis 5. Februar vorgenommene Feststellung der Vorräte an Brotgetreide und Mehl [...] als dringend erwünscht“. Auch zur „Beteiligung am Werk der Kriegsbeschädigtenfürsorge“" waren die Lehrkräfte aufgerufen worden (21. September 1915).

In besonderem Maße wurden die Landlehrer aufgrund ihrer beruflichen Autorität für bestimmte Hilfsdienste eingesetzt. So wurden sie

„,in den Dienst der quartiersuchenden Soldaten, des quartiermachenden, pferdemusternden, listenschreibenden Gemeindevorstehers (gestellt), in den Dienst gemeinnütziger Organisationen der landwirtschaftlichen Kasinos, der Molkereien, deren Geschäftsführer fast unvorbereitet die Posten verlassen mussten, in den Dienst seelsorgerischer Tätigkeit der Tröstung und Aufrichtung der Leichtverzagten. [...] Der Lehrer führte die Liste der Adressen, die er natürlich auch zu schreiben hatte. Ach, wie viel Listen er zu führen hatte in den Jahren bis zum schweren Ende: Sammellisten aller Art und die Listen der Verwundeten, Vermißten und Gefallenen! Und dann kam die Zeit der Bestandserhebungen der landwirtschaftlichen Produkte - und es war selbstverständlich, daß der Lehrer mit in die Keller und auf die Böden musste, um Kartoffeln, Möhren und Weizen abzuschätzen. “846

Auch zur Bewachung von wichtigen Objekten sowie zur Sperrung von Straßen und zur Sicherung von Feldfrüchten wurden Lehrer eingesetzt. ${ }^{847}$

Einen weitaus größeren Raum nahm jedoch die Instruktion der Erwachsenen durch die Lehrer und Lehrerinnen ein. Als Beispiel sei ein Dorfschullehrer angeführt, der 14tägig vor Männern Vorträge zu folgenden Themen hielt:
„Unsere Feinde
Die Kriegsbereitschaft Deutschlands
Die Kavallerie im heutigen Kriege
Moderne Festungen
Minen, Torpedos und Unterseeboote
Der Feldzug im Westen
Der Islam und der Weltkrieg
Kartoffelverwertung (Kriegsbrot)
Die Schweinezucht
Unsere Auslandskreuzer
Der Krieg gegen Russland und die Kämpfe der Österreicher
Früher Gemüseanbau. “\$48

\footnotetext{
${ }^{846}$ Führen, Lehrer im Krieg (1936), S. 344/347.

${ }^{847}$ Ungelenk, Coburg im Weltkrieg 191418; Ein Denk- u. Dankstein (1922), S. 400.

${ }^{848}$ Kammeier, Der Landkreis Lübbecke und der 1. Weltkrieg (1998), S. 211.
} 
Aufgrund ihrer Stellung, ihrer Sprachfertigkeit und ihres Wissens waren die einzelnen Lehrer nach Kammeier als Bindeglieder zwischen der Bevölkerung sowie der politischen und militärischen Führung für die Aufklärung, z. B. über Fragen der Ernährung, Information über den Kriegsverlauf, und die Stärkung der Siegeszuversicht sowie des Durchhaltewillens vor allem der ländlichen Bevölkerung, von großer Bedeutung. ${ }^{849}$

Die genannten Beispiele, die noch durch sehr viele überlieferte Eintragungen in den Orts- und Schulchroniken ergänzt werden könnten ${ }^{850}$, zeigen, dass sich sehr viele der nicht an der Front eingesetzten Lehrkräfte in einer Vielzahl von außerschulischen Tätigkeitsgebieten engagiert haben und den Appellen an ihre ,große Opferwilligkeit“ gefolgt sind. Beispielsweise hatte die Regierung Arnsberg im November 1916 der Lehrerschaft ihres Bezirks mitgeteilt, es sei „Pflicht der Volkserzieher [...] durch opferfreudige Hingabe ihre Gesamtkräfte dem Vaterland zu widmen, zum leuchtenden Vorbild für die Jugend, zum Ansporn für die Volksgenossen (zu werden) $)^{\text {‘851. }}$.

Zu den 50 Aufgabenfeldern, die die Schulabteilung der Regierung in Trier nannte, gehörten neben den in diesem Kapitel thematisierten Hilfsdiensten vor allem auch die vielen Sammelund Werbeaktionen. ${ }^{852}$ Von den für die Kommunen so wichtigen administrativen Aufgaben (Verteilung der Lebensmittelkarten, Mitwirkung an Zählungen u. v. a.) waren vor allem die Lehrkräfte der Schulen in den kleineren Gemeinden betroffen.

Eine große politische Bedeutung wurde den schulischen Informationsveranstaltungen, den Vorträgen, der ,Hausagitation' und der indirekten Beeinflussung der Eltern durch die Lehrer beigemessen. Nach Saul wurde ,schließlich der Volksschullehrer insbesondere in den Dörfern und kleineren Städten zum Agenten der Kriegspropaganda“ und „,die ,Schulfront' (entwickelte) sich zu einer der wichtigsten Bastionen der Heimatfront ${ }^{\text {“853. }}$.

\footnotetext{
${ }^{849}$ Den Lehrern und den anderen Multiplikatoren wurden oft von den Regierungen oder Kommunen detaillierte „Leitsätze“ zur Verfügung gestellt, wie z. B. im Regierungsbezirk Arnstadt (Provinz Nordrhein-Westfalen): Leitsätze zur Aufklärung über Volksernährungsfragen im Ersten Weltkrieg für den Regierungsbezirk Arnsberg, 1915.

850 Siehe: z. B. Rasch, Der Weltkrieg 1914-1918: Berichte eines Zeitzeugen, http://hersfelderzeitung.de/heimatland/40_1.htm (21.03.2008), S.3; Aus der „Schul-, Dorf- und Kirchenchronik" St. Willibrord Wardt, http://www.xanten-web.de/Domstadt/WardtChro5.html (03.04.2008); Eckert, Gemeinde- und Schulchronik von Lowkowitz, http://www.schloss-ellguth.de/lowkowitz2.htm (05.04.2008); Schulchronik, http://www.badliebenwerda.de/prieschka/schule.htm (21.10.2009); Reyher, Die Schwanheimer Schulchronik, www.schulserver.hessen.de/.../Die\%20Schwanheimer\%20Volksschule\%20im\%201.Weltkrieg.doc

(29.02.2008); Johann/Tchech/Schicha/Zwikirsch/Matzel/Rosemann, Schulchronik der Schule zu MittelPodiebrad, http://petertscherny.pe.funpic.de/strehlen/podiebrad/chronp.pdf. (19.09.2009).

${ }^{851}$ Saul, Jugend im Schatten des Krieges (1983), S. 113.

${ }^{852}$ Siehe: Kapitel 2.

${ }^{853}$ Demm, Ostpolitik und Propaganda im Ersten Weltkrieg (2002), S. 75.
} 


\title{
4.5 Liebesgaben ${ }^{854}$
}

Die Herstellung, Zusammenstellung, das Verpacken und der Versand von ,Liebesgaben' nahmen von Beginn des Krieges an einen breiten Raum im schulischen Alltag ein, und zwar vor allem in den Volks- und Mädchenschulen. Wenige Tage nach Kriegsausbruch hatte sich der Vorstand des Vaterländischen Frauenvereins an den preußischen Minister für Handel und Gewerbe mit der Bitte gewandt, den Handarbeitsunterricht ausschließlich dafür nutzen zu können, für die Soldaten an der Front Liebesgaben herzustellen.

In der Antwort des Handelsministers Dr. Sydow hieß es u. a.:

\begin{abstract}
„Dem Vorstand beehre ich mich zu erwidern, daß für die Mädchenschulen, wie für sämtliche Schulen meiner Verwaltung, von jeher der Grundsatz gegolten hat, alles zu vermeiden, was dazu beitragen könnte, durch die Schulen den Gewerbetreibenden und den von ihnen beschäftigten Arbeitskräften eine unerwünschte Konkurrenz zu bereiten. Eine Heranziehung der Schulen zur Herstellung von Liebesgaben für die im Felde stehenden Truppen kann ich daher nur unter der Einschränkung befürworten, daß es sich um solche Arbeiten handelt, durch die den Lohnarbeiterinnen Arbeitsgelegenheit nicht entzogen wird. Als unbedenklich zuzulassende Arbeiten können z. B. in Frage kommen, das Stricken von Strümpfen, Pulswärmern u. dgl., in der Regel aber nicht das Nähen von Bettüchern, Hemden und sonstiger Wäsche. Innerhalb der sich hiernach ergebenden Grenzen bin ich den Wünschen des Vaterländischen Frauenvereins gern entgegengekommen, indem ich die Schulaufsichtsbehörden meines Geschäftsbereichs mit entsprechender Anweisung versehen habe. ${ }^{6855}$
\end{abstract}

Darauf schlug der Frauenverein dem Schulminister vor,

„an sämtliche Unterrichtsanstalten für den Dienstbereich die Aufforderung ergehen zu lassen, in den Handarbeitsstunden von jetzt ab ausschließlich Liebesgaben für die im Felde stehenden Truppen anfertigen zu lassen und sie den Vaterländischen Frauenvereinen der betreffenden Orte zur Verfügung zu stellen. Als Liebesgaben kommen wesentlich in Betracht:

wollene Strümpfe (mittleres und größeres Maß)

wollene gestrickte Leibbinden

wollene gestrickte Unterziehjacken.

Soweit die einzelnen Anstalten bzw. Schülerinnen nicht in der Lage sein sollten, das für die Herstellung erforderliche Material selbst zu beschaffen, bitten wir die Schulleiter anzuregen, dasselbe von den an den einzelnen Orten bestehenden Geschäften zu erbitten. ${ }^{4856}$

Der Minister griff den Vorschlag auf, ließ das Schreiben des Frauenvereins im „Zentralblatt für die gesamte Unterrichtsverwaltung in Preußen“" abdrucken und erließ am 18. August 1914 einen entsprechenden Erlass für die weibliche Jugend der höheren Lehranstalten sowie die mittleren und die Volksschulen ${ }^{857}$.

\footnotetext{
${ }^{854}$ Siehe: Anhang, Seiten 75/76.

${ }^{855}$ Der preußische Handelsminister Dr. Sydow über die Liebestätigkeit in den Schulen, Die Lehrerin: Organ des Allgemeinen Deutschen Lehrerinnenvereins 1914, S. 183.

${ }^{856}$ Vorstand des Vaterländischen Frauenvereins, Liebesgaben, Zentralblatt für die gesamte Unterrichtsverwaltung in Preußen, 1914, S. 569.

${ }^{857}$ Ministerium der geistlichen und Unterrichts-Angelegenheiten, Anfertigung von Liebesgaben für das Heer in dem Handarbeitsunterricht für die weibliche Jugend., Zentralblatt für die gesamte Unterrichtsverwaltung in Preußen, 1914, S. 568f.
} 
Einer ähnlichen Bitte des Evangelisch-Kirchlichen-Hilfsvereins „Frauenhilfe“ wurde vom preußischen Unterrichtsminister mit Erlass vom 28. September 1914 ebenfalls entsprochen. ${ }^{858}$ Auch die Regierungen der preußischen Provinzen förderten das Projekt ,Liebesgaben für die Front'. So verfügte z. B. die Regierung in Düsseldorf, „dass die Hauswirtschafts-, Handarbeits- und die Turnlehrerinnen, auch nachdem der Unterricht wieder begonnen hat, zu freiwilliger Liebestätigkeit beurlaubt werden“"859.

Die Initiativen der Frauenvereine und anderer Organisationen stießen von Anfang an in den Schulen aller Schulformen auf außerordentlich große Resonanz. Während die hergestellten Stricksachen zunächst in den Sammelstellen des Roten Kreuzes und anderer Hilfsorganisationen abgeliefert wurden, gingen die meisten Schulen bald dazu über, selbst Pakete zu packen und zu verschicken. ${ }^{860}$

Ein Beispiel aus Breslau (Provinz Schlesien) soll das Ausmaß der Aktionen verdeutlichen. ${ }^{861}$ Auf weitere Beispiele für Liebesgaben aus dem ersten Kriegsjahr, die vor allem in Schulchroniken und Jahresberichten sehr zahlreich und ausführlich dokumentiert sind, kann hier verzichtet werden, da sie sich insgesamt nicht vom genannten unterschieden.

Innerhalb sehr kurzer Zeit wurden durch Volksschulkinder hergestellt und bei den Sammelstellen abgeliefert: „2451 Paar Strümpfe, 1433 Paar Fußlappen, 616 Paar Pulswärmer, mehrere Dutzend Handschuhe, Kniewärmer und wärmende Sachen [...], nicht zu zählen die verschiedenen Paare von Strümpfen, wollenen Unterkleidern und Decken, die den in den Schulhäusern liegenden Soldaten, der Arbeiterkompagnie in Hünern und Landsturmleuten unmittelbar überwiesen worden sind“"862.

Insgesamt sind bis zum 19. Dezember 1914 von 2.800 Schülerinnen der Volksschulen angefertigt worden: „6333 Paar Strümpfe, 2055 Paar Pulswärmer, 261 Paar Handschuhe, 368 Kopf und Ohrenschützer, 187 Leibbinden, 91 Brust- und Lungenschützer, also etwa 9700 Wollsa-

\footnotetext{
${ }^{858}$ Führen, Lehrer im Krieg (1936), S. 61.

${ }^{859}$ Vom eifrigen Kampf unserer Jugend, Die Lehrerin: Organ des Allgemeinen Deutschen Lehrerinnenvereins 1914, S. 190.

${ }^{860}$ Die Herstellung von Strickwaren durch Schülerinnen wurde von Anfang an von vielen als Konkurrenz zur bezahlten Berufsarbeit empfunden. Ein Beispiel aus Schwerin zeigt, dass solche Befürchtungen von den Schulen teilweise durchaus ernst genommen wurden. Dort hatte die Handarbeitslehrerin folgende Anzeige 1914 in den Mecklenburgischen Nachrichten aufgegeben: „Um beim Herannahen des Winters arbeitssuchenden Frauen und Mädchen Gelegenheit zu geben, durch Näharbeit Verdienst zu finden, stellt der freiwillige Nähverein im Lyzeum mit dieser Woche seine gemeinsamen Nähstunden einstweilen ein. Es wird jedoch an jedem Mittwoch, nachm. über zweckmäßige Anfertigung der zurzeit besonders erwünschten Liebesgaben informiert; auch werden Zuwendungen von altem Leinen, neuen Stoffen und Geldmitteln dort jederzeit entgegengenommen.“

${ }^{861}$ Ähnliche Texte in: Jahresberichte des Königlichen Kreisschulinspektors an die Königliche Regierung, allgemeiner Schulbericht vom 28.6.1915; zitiert nach: Hohnsbehn, Die Flensburger Schuljugend in der Zeit des ersten Weltkriegs (1996), S.191; Auszüge aus der Überherrner Schulchronik, http://www.erweiterte-realschuleueberherrn.de/chronik.htm (25.04.2008); Arbeit der Volkschullehrerinnen in Breslau, Die Lehrerin: Organ des Allgemeinen Deutschen Lehrerinnenvereins 1914/15, S. $222 \mathrm{f}$.

${ }^{862}$ Arbeit der Volkschullehrerinnen in Breslau, Die Lehrerin: Organ des Allgemeinen Deutschen Lehrerinnenvereins $1914 / 15$, S. $222 \mathrm{f}$
} 
chen (ohne die, die in der ersten Zeit unmittelbar verschickt wurden und ohne die Sachen, die gesammelt wurden) ${ }^{\text {‘863. }}$.

Außer durch Spenden und Geldsammlungen finanzierten viele Schulen die Liebesgaben auch durch den Verkauf von selbst gestalteten Ansichtskarten ${ }^{864}$ oder Einnahmen aus anderen Aktionen, wie z. B. Vortragsabende oder musikalische Veranstaltungen.

Die Mobilisierung für diese Fürsorgemaßnahmen war deshalb erfolgreich, weil sie stärker als das Sammeln von Altmaterial die Gefühle der Kinder ansprach ${ }^{865}$.

Da von nahezu allen Schulmädchen im Deutschen Reich für die Soldaten gestrickt wurde, ergaben sich in zunehmendem Maße Schwierigkeiten bei der Materialbeschaffung; außerdem war der Bedarf an Wollsachen teilweise bald gedeckt. ${ }^{866}$

Um dem Mangel an Wolle abzuhelfen, wurde in der Zeit vom 18. bis 24.1. 1915 eine „Reichswollwoche“ durchgeführt, die die erste reichsweite Sammelaktion des Krieges war. ${ }^{867}$ Was an Woll- oder Baumwollsachen entbehrlich war, wurde von freiwilligen Helferinnen eingesammelt. Auch viele Schulen waren an der Aktion, für die Lehrer und Schüler vom Unterricht freigestellt wurden, beteiligt ${ }^{868}$, und zwar nicht nur bei der Materialbeschaffung, sondern auch bei der Verarbeitung und Ausbesserung der Kleidungsstücke, wie auch aus einem Schreiben der Flensburger Schuldeputation vom 11. 12. 1916 hervorgeht:

„Aus den Ergebnissen der Reichswollwoche wurde gefertigt: 176 Paar Strümpfe, 53 Kinderunterröcke, 43 Kinderunterhemden, 27 Kinderhosen, 13 Erstlingsjacken, 12 Kinderkappen, weitere Lätzchen, Pulswärmer, Leibchen, Mützen usw. Daneben wurden Röcke, Strümpfe usw. ausgebessert, gestopft und geflickt. Auch während der Ferien haben die Kinder an den genannten Gegenständen gearbeitet. “869

\footnotetext{
${ }^{863}$ Führen, Lehrer im Krieg (1936), S. 62.

${ }^{864}$ Als Beispiel sei die Fontaneschule in Berlin-Schöneberg genannt; siehe: Seite 105 und Anhang, Seite 76.

${ }^{865}$ Siehe: Demm, Ostpolitik und Propaganda im Ersten Weltkrieg (2002), S.86.

${ }^{866}$ Beteiligung der Volksschulen an den kriegswirtschaftlichen Maßnahmen 1918-1922, Bericht der Handarbeitslehrerin Anna Braasch vom 5.8.1915; zitiert nach: Hohnsbehn, Die Flensburger Schuljugend in der Zeit des ersten Weltkriegs (1996), S. 191.

${ }^{867}$ Der Aufruf des „Kriegsausschusses für warme Unterkleidung“ vom 1. Januar 1915 ist abgedruckt in: Grotjahn, Stahl und Steckrüben Bd. 2 (1993), S. 331, T 3/39. Siehe auch: Anhang, Seite 78. Etwa zeitgleich wurde die „Ostpreußenhilfe“ ins Leben gerufen. Sie diente dazu, um die durch den russischen Einfall in den Kommunen angerichteten Schäden zu beseitigen.

${ }^{868}$ Dieses geht z. B. aus einem zeitgenössischen Bericht (1915) hervor: „Was Kinderhände nützen können unter Führung der Lehrer, das hat, um nur ein Beispiel anzuführen, im Kreise Schrimm die Reichswollwoche dargetan. Die Ausführung der mit der Woche verbundenen Arbeiten hatten die Kreisschulinspektoren übernommen. Sie setzten sich mit sämtlichen Lehrern des Kreises in Verbindung. Diese gewannen dafür die Gemeinde und Gutsvorsteher, und die Kinder holten aus jedem Hause die zur Verfügung gestellten Wollsachen heraus, die sogleich auf Wagen geladen und zur Desinfektion in die Kreisstadt gefahren wurden. Diese Organisation hatte ein vorzügliches Resultat. Ohne die vielen tausend Kinderhände, die zum Gelingen des Werkes mitgeholfen haben, wäre ein so glänzender Erfolg nicht möglich gewesen.“ (Sohnrey, Kriegsarbeit auf dem Lande [1915], S. 113f.).

${ }^{869}$ Zitiert nach: Hohnsbehn, Die Flensburger Schuljugend in der Zeit des ersten Weltkriegs (1996), S.191; Schreiben der Schuldeputation vom 11.12.1916.
} 
Wie auch andere ähnliche Zusammenstellungen zeigen, wurden die Kleidungsstücke bald weniger für die Soldaten an der Front als vielmehr für die Not leidenden Menschen in Deutschland hergestellt bzw. ausgebessert.

Nach wie vor wurden zwar täglich Tausende von Päckchen an die Front geschickt, bei den Liebesgaben handelte es sich jedoch nicht mehr überwiegend um wollene Kleidungsstücke, die Schülerinnen angefertigt hatten. Dieser Wandel soll an einem Beispiel aus Duisburg dokumentiert werden. In dem Bericht der Stadt heißt es:

„Bis Ende Januar 1915 gingen an den Sammelstellen der Duisburger Schulen ein: 29806 Zeitschriften, 2928 Bücher, 7096 Stöcke für Verwundete, 30454 Zigaretten, 40854 Zigarren, 5864 Pakete Rauchtabak, 1201 Rollen Kautabak, 9118 Pfeifen, 200 Unterhosen, 444 Hemden, 745 Taschentücher, 1009 Nähzeuge, 3718 Suppenwürfel, 3387 Platten Schokolade, 9176 Schreibzeuge, 2309 Feuerzeuge, 999 Stück Seife, 338 Verbandsstoffe, 2447 Kleidungsstücke. Die im Felde stehenden Väter und Brüder der Schüler erhielten 146199 Zeitungszusendungen. “870

Hauptsächlich bestand also ab 1915 ein großer Bedarf an Rauchwaren und Lesestoff. ${ }^{871}$

Den Päckchen mit den gespendeten oder hergestellten Liebesgaben wurden häufig von den Schulkindern Begleitschreiben und Briefe mit kleinen Gedichten beigefügt ${ }^{872}$. Drei Beispiele seien angeführt:

„Ich bin noch klein,

Kann noch nicht viel machen;

Doch dankbar, das kann ich sein;

Drum stricke ich dir wollene Sachen,

$\mathrm{Da}$ du hüllest deine frostigen Glieder ein. “873

„Das Mädchen, das diese Sachen gestrickt,

Das ist im Stricken nicht allzu geschickt,

Möchte lieber kämpfend im Felde stehn,

Als Tag für Tag zur Schule gehn. ${ }^{6874}$

Ein Begleitschreiben einer Klasse aus Gundershofen (Königreich Württemberg) hatte der

Lehrer in folgendes Gedicht umgeformt:
„Die Mädchen können Socken stricken
Und andere warme Sachen
Und sie dann an Soldaten schicken
Und ihnen Freude machen,
Was sie auch brav getan schon haben.
Was aber tun wir Knaben?
Da haben wir denn so gedacht:

\footnotetext{
${ }^{870}$ Führen, Lehrer im Krieg (1936), S. 63.

${ }^{871} \mathrm{Zu}$ den „Reichsbuchwochen“ siehe: Kapitel 6.6.

${ }^{872}$ Häufig wurden auch Ansichtskarten verschickt, die im Unterricht hergestellt worden waren. Der Aufsatz „Besondere Schularbeit in der Kriegszeit“ von Georg Stiehler enthält viele Abbildungen Stiehler, Besondere Schularbeit in der Kriegszeit, Die Arbeitsschule, 1915, S. 2.

${ }^{873}$ Führen, Lehrer im Krieg (1936), S. 64.

${ }^{874}$ Loewenberg, Kriegstagebuch einer Mädchenschule (1916), S. 34.
} 
Eine Sparbüchse ist ja schnell gemacht.

Dann wollen wir jeden Pfennig sparen,

Den wir, wenn wir fleißig waren,

Von Eltern und Nachbarn bekommen haben.

So können helfen Mädchen und Knaben.

Schnell machten wir ein Kistchen leer

Und stellten eine Sparbüchse her.

In der Schule wurde sie aufgestellt,

Wir warfen hinein das verdiente Geld,

Sooft wir in die Schule kamen.

Bald schon war eine hübsche Summe beisammen.

Wir schauten, ob wir genug bald hätten.

Es reichte. Wir kauften Zigaretten.

Zwei Radler taten's. Sie kamen zurück.

Und hatten ein Kistchen mit tausend Stück.

Das senden wir nun den Soldaten ins Feld

Und hoffen, daß es dort allen gefällt.

Und denken, es hat das rechte getroffen

Die Oberstufe von Gundershofen.

Grüß Gott, ihr Soldaten, raucht fröhlich und heiter,

Es kommt bald ein zweites, wir sammeln weiter." ${ }^{\text {(875 }}$

Nachdem nicht mehr nur wärmende Strickwaren verschickt wurden, beteiligten sich in zunehmendem Maße neben den Schülerinnen auch die Schüler aller Schulformen an den Paketaktionen, wie der Jahresbericht 1914/15 der städtischen Leibnizschule in Hannover, eines Gymnasiums für Jungen, eindrucksvoll bestätigt:

\begin{abstract}
„Auch die Anregung zur Beteiligung an Liebesgaben für unsere kämpfenden Truppen fiel auf fruchtbaren Boden. Zu Weihnachten erhielt jeder im Felde stehende Schüler des letzten Jahres ein Paket und mancher Gruß aus Feindesland zeigte, wie dankbar sie waren für unser Gedenken. Die Ordnung und Verteilung hatte Prof. Schrader übernommen. Im Oktober richteten wir eine wöchentliche Zigarren-, Zigaretten- und Tabakssammlung ein, und dieselbe ergab zum 1. März ungefähr 16000 Zigarren, 3000 Zigaretten, 450 Pakete Tabak. Außerdem wurden einmal 300 versandfertige 1 Pfund-Pakete mit Liebesgaben von den Schülern abgegeben und zwei große Liebesgabensammlungen vor Weihnachten veranstaltet, welche hiesigen Ersatzbataillonen und Sammelstellen zugeführt worden. Im ganzen konnten 22 Regimenter und 6 Lazarette bedacht werden. Lebensmittel, Wollsachen, Briefpapier, Pfeifen und Tabaksbeutel, Seife, Kerzen und Laternen; sowie andere Sachen, die ein Soldatenherz erfreuen, wurden gesammelt. Dank der Opferfreudigkeit unserer Jungen und der Eltern konnten wir z. B. 50 Pfeifen, je 25 Tabaksbeutel und Feuerzeuge, 100 Würste, 25 Stück Speck, 75 Konservendosen, 120 St. Seife, 50 Kerzen, 100 Taschentücher, Waschlappen und Handtücher, 150 St. Wollsachsen, 50 Pakete Briefpapier, 75 Bleistifte, 20 Flaschen Wein und Kognak, 9 Flaschen Himbeersaft und Marmeladen, 50 Tafeln Schokolade, 200 Pakete Keks und Süßigkeit verschicken.“‘776
\end{abstract}

Dass sich die Liebesgabensendungen der einzelnen Schulen weitgehend entsprachen, zeigt ein Vergleich der verschickten Gegenstände des großstädtischen Gymnasiums für Jungen (Leibnizschule Hannover) mit denen der katholischen Volksschule in Freisenbruch bei Essen

\footnotetext{
${ }^{875}$ Führen, Lehrer im Krieg (1936), S. 64.

${ }^{876}$ Meyer, Siebendreissigster Jahresbericht der städtischen Leibnizschule zu Hannover (1915), S.14f.
} 
(Antoniusschule) und kleinen Dorfschulen im Landkreis Lübbecke. So ist in der Schulchronik der Antoniusschule zu lesen:

„Von der ersten Sendung am 8. 10. 1914 bis zur letzten notierten Sendung, der Siebten vom 24. 01. 1916, wurden insgesamt von unserer Schule 1538 Pakete verpackt und verschickt. Enthalten waren außer wärmender Kleidung, wie Strümpfen, Pulswärmern, Kopfschützern und Kniewärmern, Genussmittel wie Tabak, Zigarren, Zigaretten, Schokolade, Kriegskuchen, aber auch Fleisch und Gebetbücher. Spenden dazu wurden in der Gemeinde aufgebracht und auch von Lehrern gesammelt. So fand auch eine Sammlung von Wollsachen durch die Schule statt. 3 Wagen voll, schwer bepackt, mit einem Pferd bespannt, wurden zum Amt gebracht. Nachdem die Sachen dort ausgeräuchert waren, wurden sie von den Lehrerinnen, den Schülerinnen und einer großen Anzahl Frauen und Jungfrauen, zu Decken, Westen und dgl. verarbeitet." 877

Ganz ähnlich liefen die Aktionen in Börninghausen und Tonnenheide (Provinz Westfalen) Ende $1914 \mathrm{ab}^{878}$.

Neben all den vielen genannten Gegenständen, die in der Regel in den Paketen waren, gab es immer wieder neue Ideen in den Schulen, von denen einige wenige genannt werden sollen. In der Bürgerschule in Krefeld (Rheinprovinz) z. B. wurden im Oktober 1914,100 dauerhafte Kästchen“ beschafft und in den Zeichenstunden bemalt. Gefüllt wurden sie mit „Tannenzweige(n), Winterlandschaften, Schattenbildern und Flaggenzeichnungen" sowie den üblichen Beilagen. Diese und etwas später weitere 464 solcher Pakete wurden zu Weihnachten an Angehörige der Schülerinnen an die Front geschickt. ${ }^{879}$

In Saarbrücken schrieb der Kommandierende General des 21. Armeekorps an den Vorsitzenden des Roten Kreuzes, dass sich bei den Truppen in ihren Quartieren, in den Schützengräben und Unterständen ein Verlangen nach Unterhaltungsspielen bemerkbar machte und die von Spezialgeschäften gelieferten Spiele nicht geeignet seien. Der Landrat wandte sich darauf an die Handarbeitslehrer der Stadt und des Landkreis Saarbrücken und bat sie, ,sie möchten etwa 1500 Mühl- und Damspiele für die Truppen anfertigen. Der zeitgemäße Auftrag wurde be-

\footnotetext{
877 Aus der Geschichte der Antoniusschule, http://www.antoniusschule.homepage.t-online.de/chronik.htm (25.04.2008).

878 „In Börninghausen beispielsweise sammelten die Schüler der 1. Klasse Geld von denjenigen Familien ein, die niemanden an der Front hatten; es kamen 162,50 M sowie Zigaretten, Nüsse und Bouillonwürfel zusammen. Von dem Geld wurden weitere Waren gekauft. Jeder Börninghauser Soldat (im November 1914 34) erhielt (am 27. 11. 1914 abgeschickt) zu Weihnachten ein Paket mit einer Pfeife, 250 gr Tabak, einer Taschenlampe, Keksen, Zucker, Bleistift, Zigarren, Kautabak und Nüssen. Jedes Paket enthielt ferner einen von einem Schüler bzw. einer Schülerin verfassten Brief. Die 152 Ende 1915 aus Tonnenheide verschickten Pakete enthielten je 2 Tafel Schokolade, 1 Taschentuch, 10 Postkarten, 1 Tintenstift, 1 Stück Seife, 1 Schachtel Salmiakpastillen, 12 Zigarren, 1Kerze und 1 Tannenzwei mit Lametta." (Kammeier Der Landkreis Lübbecke und der 1. Weltkrieg [1998], S.183.

${ }^{879}$ Strater, Wie in der Bürgerschule für Mädchen zu Crefeld während der verflossenen Kriegsmonate gearbeitet worden ist; Die Mittelschule: Zeitschrift der Reichsfachschaft Mittelschule im Nationalsozialistischen Lehrerbund, 1915, 154, S. 156-158.
} 
reitwilligst ausgeführt. [...] Die Freude der Knaben und Mädchen über die Verwendung ihrer Handarbeiten bei den Soldaten war fast unbeschreiblich. “ ${ }^{880}$

Gleichzeitig stellten die Schülerwerkstätten verschiedene Gebrauchsgegenstände für die Reservelazarette her, wie z. B. „Tische, Feldstühle, Bank, Apothekenschränke, Regale, Schlüsselschaft, Garderobe und Handtuchhalter, Fußschemel und -bänkchen, Leserpult usw.“

Zuletzt sei auf zwei etwas kuriosen Ideen hingewiesen, die Herstellung von „Schützengrabenspiegeln“ und „Schießhandschuhen“881. Mit den Schießhandschuhen sollte den „Soldaten ein Mittel in die Hand gegeben werden, wodurch ihnen mehr Ruhe und Sicherheit geschafft" werden sollte. Durch den Schützengrabenspiegel sollte bewirkt werden, dass es nicht mehr so „viele Opfer, welche an Kopfschüssen im Schützengraben ihr Ende gefunden hatten“, gebe. Der Lehrer allein schickte etwa 60 Geräte an die Front und seine Schüler ließen viele ihren Verwandten zukommen. Nach Meinung eines Offiziers waren die Schützengrabenspiegel an der Front sehr willkommen: „Dieser Spiegel ist ganz famos, er ist das praktischste Exemplar, welches ich je gesehen und benutzt habe.“

Im Folgenden sollen die Liebesgaben-Aktionen exemplarisch aus der Sicht einiger damaliger Schüler und Lehrer betrachtet werden.

„Zu Anfang des Krieges, als noch Wolle in Mengen vorhanden war, regten sich Tausende von fleiBigen Mädchenhänden. Schon die kleinsten ABC-Schützen, die kaum die Stricknadeln halten konnten, strickten und brachten - wenn auch nicht Strümpfe - so doch Wasch- und Putzlappen zustande. Die Größeren strickten Strümpfe, Schals, Leibbinden, Knie und Pulswärmer, Kopfschützer in ungezählten Dutzenden und fertigten Kissen und Schlafdecken. Ein Festtag für die Schule war der Tag der Ablieferung. Auf langen Tafeln lagen die fertigen Gegenstände da. Alle Schülerinnen durften die aufgehäuften Schätze betrachten. Freudig führten sie ihre Lehrer und Lehrerinnen. Dann kamen Feldgraue mit großen Säcken und Körben zur Abholung. Ihnen beim Einpacken zu helfen, war eine Ehre für die fleißigsten Arbeiterinnen. Als dann die Wollvorräte sich erschöpften, fand sich andere Arbeit. Es begann ein eifriges Zuschneiden und Nähen; Hemden und Hosen, Röcke und Kleidchen, Windeln wurden angefertigt für die Kinder unserer Krieger. Da galt es, aus alten Sachen neue zu machen, Reste zu verwenden. Vor allem wurden die kleinen Erdenbürger mit notwendigen Kleidungsstücken bedacht. “882

(Anna Günther, Lyzeallehrerin an der Auguste-Viktoria-Schule, Berlin-Charlottenburg)

„Wir beginnen gleich am ersten Schultag, die Schülerinnen zur werktätigen Hilfe heranzuziehen. Zwei Sammelbüchsen werden aufgestellt, eine für das Rote Kreuz, eine für die Kriegshilfe. Jedes Kind bringt seine Gabe mit. Selbstverständlich ganz nach Belieben, ganz freiwillig, wie überhaupt aller Zwang ausgeschlossen ist. Er ist aber nicht nötig. Alle geben so gern! Für das sonst noch eingegangene Geld werden Stoffe gekauft. Manche Kinder bringen ganze Ballen Wolle und Leinenzeug aus den Geschäften der Eltern mit. Die Schülerinnen der ersten Klassen helfen einige Nachmittagsstunden in der Volksküche und beim Einmachen des Obstes, in anderen Stunden nähen sie Hemden für Verwundete, die der mittleren Klassen stricken Strümpfe, Schals, Leibbinden, Pulswärmer für die Krieger. [...] Aus dem Nebenfach (Handarbeit) ist ein Hauptfach geworden und

\footnotetext{
${ }^{880}$ Scherer, Liebesgaben aus der Schülerwerkstatt, Die Arbeitsschule, 1915, 85/86, S. 85.

${ }^{881}$ Messing, Der Schützengrabenspiegel, Die Arbeitsschule, 1915, S. 319-321.

${ }^{882}$ Günther, Von der Kriegsarbeit der Mädchenschulen, S. 73f.
} 
keinem Fach widmen die Mädchen jetzt so viel Eifer als dem Nähen und Stricken. Am liebsten möchten sie alle Stunden damit ausfüllen. Wer gut und schnell stricken kann, steigt im Ansehen. In den Pausen sind die alten Reigen und Spiele verschwunden und statt des Balles haben die Mädchen ihr Strickzeug in der Hand. Da wird für alle möglichen Kriegs und Friedenszwecke mit einer Freude, mit einer inneren Anteilnahme gearbeitet, die geradezu etwas Rührendes hat. Die Kleineren blicken mit Neid auf die größeren Mitschülerinnen. ${ }^{\text {“883 }}$

(Jakob Loewenberg, Direktor eines Lyzeums in Hamburg)

„Die Schülerinnen der Schneidemühler Schulen kommen nachmittags in den einzelnen Klassen zusammen, um Strümpfe, Schals, Kopfwärmer, Knieschützer, Pulswärmer, Handschuhe und Ohrenschützer für die Soldaten zu stricken. Aus den gesammelten Geldbeträgen wird pfundweise feldgraue Wolle gekauft. Einen Schal zu stricken ist nicht schwer, immer rechte Maschen und auf der Rückseite linke. Aber um den Füßling eines Strumpfs zu stricken, muß man ein Zauberkünstler sein. Wenn ich mit Ach und Weh die beiden Waden fertig habe, nimmt Großmutter die Strümpfe zum Bahnhof mit und strickt zwischen Suppekochen und Kaffee-Eingießen die Füßlinge dran. “884

(Elfriede Kuhr, 12jährige Schülerin in Schneidemühl, 30. August 1914)

„In der Schule wird gestrickt und genäht, daß es nur so eine Art hat. Und alles für die Feldgrauen. Viele große Pakete sollen zum Weihnachtsfeste die tapferen Krieger erreichen. Oh, die Mädel sind mächtig stolz! Sie können wirklich für die Soldaten arbeiten! Die Jungen nicht. Die können bloß im Wege stehen und Krach machen. Aber die Frauen und Mädchen, die schaffen und helfen richtig! Sie stricken sich fast die Finger wund. Die Geschäfte kriegen gar nicht soviel Wolle heran, wie jetzt verlangt wird. Im Nadelarbeitsunterricht, in allen Freistunden, heimlich unter dem Tisch bei der Durchnahme langweiliger Regeln - sogar in den Pausen wird gestrickt, gestrickt. ${ }^{\text {“8 } 85}$

(Erna Lange, Schülerin in Berlin)

„Der Erste Weltkrieg war ausgebrochen. Ich erinnere mich noch zu Beginn an das tobende Glockenläuten. Wir kleinen Mädchen strickten Strümpfe, beherrschten das Fersenmachen aus dem Effeff. Jedes Kind hatte seinen 'Feldgrauen', der die Strümpfe und Päckchen zugeschickt bekam. Ich hatte den Neffen unseres Kindermädchens. “886

(Regina Relang, *1906, Schülerin in Stuttgart)

Die Aussagen der fünf genannten Zeitzeugen und vieler anderer, die hier nicht zitiert werden, bestätigen, dass die Schulkinder und ihre Lehrer insgesamt mit Begeisterung und voller Patriotismus Liebesgaben in außerordentlich großer Zahl herstellten bzw. beschafften und verschickten. Ein Lehrer verglich die Arbeit der Schulkinder mit dem Kampf an der militärischen Front:

„... und indem ich allenthalben wie in unserem stillen Heimatdorf in Stadt und Land die fleißigen Kinderhände und lachenden Kinderaugen sehe, so sehe ich die große Arbeit der Kinder und jugendlichen Menschen neben der Armee im Felde - die so ganz andere Armee der Heimat, die nicht dadurch, daß sie schafft und wirkt, sondern auch dadurch, daß sie den Soldaten draußen das Los

\footnotetext{
${ }^{883}$ Loewenberg, Kriegstagebuch einer Mädchenschule (1916). S. 13-17.

${ }^{884}$ Mihaly, ... da gibt's ein Wiedersehn! (1986), S. 51f.

${ }^{885}$ Lange, 1914 bis 1918 auf der Schulbank (1933), S. 28f.

${ }^{886}$ Pörtner, Kindheit im Kaiserreich (1990), S. 261.
} 
erleichtern will und ihnen die Treue und den Mut und ihr Wollen stärkt, hilft, den Feind zu schlagen. “887

Vereinzelt gab es aber durchaus auch recht kritische Stimmen zu der Tätigkeit der Schüler. Als Beispiel sei aus den Erinnerungen der Zeitzeugin Cläre Preisner aus Bremen zitiert:

„Und denn, wie der Krieg kam, was die uns ausgenutzt haben. Da mußten wir also stricken, stricken und noch mal stricken. Ohrenwärmer und Socken. Mein Vater, der sagte immer, sag mal, die sind ja wohl wahnsinnig, solche Socken, das ist ja was für Elefanten, aber nicht für Soldaten! So groß waren die. Und dann fing das an mit dem Wettstricken. Also die letzte Stunde in der Schule mußten wir nur stricken, und beim Stricken mußten wir dann vaterländische Lieder singen. ${ }^{* 888}$

Ende 1917 appellierte die Heeresverwaltung an die Kommunen und die Schulen, auf den Versand von Weihnachtspaketen zu verzichten, da nicht genügend Transportkapazitäten zur Verfügung stünden. Stattdessen sollten Geld und Sachspenden direkt der Heeresverwaltung zur Verfügung gestellt werden, da sie preiswerter einkaufen und die Sachspenden pünktlich den Soldaten zukommen lassen könne.

Die Folge war ein weiterer Rückgang der Liebesgabensendungen. Das Engagement der Schüler bei den Liebesgaben hatte mit zunehmender Kriegsdauer bereits vorher nachgelassen. Viele von ihnen waren unterernährt und durch die vielen kriegswirtschaftlichen Hilfstätigkeiten erschöpft. Außerdem war es in zunehmendem Maße schwieriger geworden, genügend Liebesgaben für die Pakete aufzutreiben.

\section{6 ,Vergessene Soldaten“}

Mit zunehmender Kriegsdauer wurden die Liebesgaben von vielen Schulen zum größten Teil nicht mehr an Sammelstellen abgegeben, sondern direkt an Soldaten geschickt, und zwar entweder, wie z. B. in der Leibnizschule Hannover, an ehemalige Schüler, Lehrer und Angehörige der Schulkinder oder an sog. ,,vergessene Soldaten“, d. h. Soldaten, die keine Angehörigen hatten und deshalb keine Post bekamen.

Nach einer Umfrage sämtlicher militärischer Kommandostellen gab es im Jahre 191575.000 Soldaten, die „,niemals die geringste Liebesgabe“ ${ }^{689}$ erhielten. Der „Bund für freiwilligen vaterländischen Heimatdienst, Abteilung: Spende für Vergessene“ nahm sich des Problems an und vermittelte auch Adressen alleinstehender Soldaten. 1915 wurden die Schulen auch in diesem Bereich aktiv. Die Initiative ging von dem Berliner Schulleiter Paul Ilgen aus, der mit

\footnotetext{
${ }^{887}$ Führen, Lehrer im Krieg (1936), S. 59.

888 den Lindemann/Jung, Erinnerungen einer Freischülerin in: Beck/Boehncke (Hrsg.), Jahrbuch für Lehrer (1981), S. 338-340; zitiert nach: Lemmermann, Kriegserziehung im Kaiserreich (1984), S. 866.

${ }^{889}$ Ilgen, Eine dankbare Aufgabe für die höheren Lehranstalten, Deutsches Philologen-Blatt 1915, S. 624.
} 
einem Artikel in der Verbandszeitschrift „Deutsches Philologenblatt“ ${ }^{\star 890}$ die höheren Lehranstalten aufrief, sich „,dieser Vergessenen anzunehmen“. Er schrieb:

„... es bedarf dazu keiner großen Organisation. Eine Umfrage in den Klassen, wer es allein oder in Gemeinschaft mit einigen Mitschülern übernehmen will, etwa zweimal monatlich einem bestimmten Soldaten ein Päckchen ins Feld zu schicken, ergibt schnell die erforderliche Zahl von Adressen. [...] Wünschenswert ist, daß an jeder Anstalt ein Kollege sich der Sache besonders annimmt. Mit welcher Begeisterung die Jungen auf die Sache eingehen, mit welchem Stolz sie den Dank ihrer Schützlinge aus dem Feld erhalten, wie sie es verstehen, auch ihre Angehörigen zu dieser persönlicheren Liebestätigkeit anzuregen, das wird jeder Kollege mit derselben Freude erfahren, wie ich selbst es täglich erfahre.“

Er betonte, dass es bald keine, vergessenen Krieger' mehr gäbe, wenn jede der 1.000 höheren Schulen die Versorgung von etwa 75 Soldaten übernähme.

Die Anregung wurde offensichtlich von sehr vielen Schulen aufgegriffen. Wenige Wochen später wies Ilgen darauf hin, ,daß der Bund für freiwilligen Heimatdienst die Hochflut der Bestellungen trotz angestrengtester Arbeit in Tag- und Nachtschicht nicht mit der wünschenswerten Schnelligkeit erledigen kann“891.

Einige Schulen besorgten sich deshalb direkt bei den militärischen Kommandostellen oder anderen Behörden Anschriften. 1916 wandte sich Ilgen erneut an die Lehrerschaft und berichtete über den Erfolg der Aktion, der ,weit über die kühnste Erwartung hinaus ging. [...] Zehntausende von ihnen werden jetzt von Schülern und Schülerinnen damit versorgt und danken es mit z. T. prächtigen Briefen, aber weitere Zehntausende sind inzwischen eingerückt und sehnen sich auch danach, von der Liebestätigkeit der Heimat bedacht zu werden““892.

Außerdem rief er die Schulen zu verstärkter Aktivität auf: "Wohl ist diese von Monat zu Monat schwieriger geworden, denn knapper sind sowohl die Mittel des einzelnen, als auch die zur Versendung geeigneten Sachen. Aber Liebe und guter Wille weiß auch Schwierigkeiten zu besiegen, wo es ein schönes Ziel gibt، “893

Trotz des erneuten Appells ließ sich die Zahl der an der Aktion teilnehmenden Schulen wegen der genannten Schwierigkeiten nicht mehr steigern, sondern das entsprechende Engagement nahm wegen geringer werdende Ressourcen zunehmend ab. Dass die Hilfsaktion der Schulen für die , vergessenen Krieger' dennoch insgesamt ein großer Erfolg war, geht aus den genannten Zahlen hervor ${ }^{894}$ und soll im Folgenden durch einige Bespiele weiter belegt werden:

\footnotetext{
${ }^{890}$ Ilgen, Eine dankbare Aufgabe für die höheren Lehranstalten (1915).

${ }^{891}$ Ilgen, Spende für "vergessene Krieger', Deutsches Philologen-Blatt 1915, S. 719.

${ }^{892}$ Ilgen, Spende für "vergessene Krieger (1916).

${ }^{893}$ Ilgen, Spende für "vergessene Krieger' (1916).

${ }^{894}$ Beispielsweise konnten vom „Bund für freiwilligen Vaterlandsdienst“ bis 1915,95000 Adressen bedürftiger Krieger“ vermittelt werden (Schmidt, Fürsorge für die „vergessenen Krieger", Deutsche Tageszeitung, 1915, S.739).
} 
Hameln: „An 70 , vergessene Krieger’ des 2. Bataillons des Infanterie-Regiments 146 (Hameln) werden von den Schülern der Prima bis Obertertia des Gymnasiums und der Oberrealschule von jetzt ab in Zwischenräumen von 14 Tagen Liebesgabenpakete gesandt. Die Adressen werden direkt vom Bataillon erbeten. “695

Flensburg: Teilnahme von 100 Schülern ${ }^{896}$

Gelsenkirchen, Oberrealschule: 190 Soldaten ${ }^{897}$

Herford: Teilnahme von 160 Schülern ${ }^{898}$

Hannover-Linden, Friederikenschule: Teilnahme von 290 Schülerinnen, 123 Soldaten $^{899}$

Hannover, Sophienschule: 220 Schülerinnen ${ }^{900}$

Jever, Städtische höhere Mädchenschule: 95 Soldaten $^{901}$

Neumünster, 430 Soldaten ${ }^{902}$

Magdeburg, König-Wilhelms-Gymnasium: 280 Soldaten $^{903}$

Solingen, Gymnasium und Realschule: 224 Soldaten $^{904}$

Ulm, Gymnasium: 40 Soldaten $^{905}$

Die Beispiele, denen noch sehr viele hinzugefügt werden könnten, zeigen die große Resonanz, die die Aktion ,Vergessene Krieger' sowohl in den höheren Jungen als auch in den Mädchenschulen hatte - und zwar im gesamten Reichsgebiet.

Ein Grund für den großen Erfolg war sicher auch die Tatsache, dass die Schülerinnen und die Schüler die Liebesgaben direkt an einen namentlich bekannten Soldaten schickten und meistens auch von diesen persönliche Dankesschreiben erhielten. Im Jahresbericht der Realschule Butzbach (Ghzgt. Hessen-Darmstadt) heißt es dazu: „Zahlreiche Dankesschreiben bewiesen, daß die kleinen Geschenke bei den Empfängern immer große Freude hervorriefen. Zwischen manchem Feldgrauen, der ein solches Paketchen erhielt, und dem Absender wurde auf diese Weise eine dauernde Verbindung hergestellt.“906 Häufig nannte man jene auch „Klassensoldaten “607.

\footnotetext{
${ }^{895}$ Bünning, „Vergessene Krieger", Deutsches Philologen-Blatt 1916, S. 739.

${ }^{896}$ Schmidt, Fürsorge für die „,vergessenen Krieger" (1915).

${ }^{897}$ Feldpausch, Gelsenkirchen, Deutsches Philologen-Blatt 1916, S. 26.

${ }^{898}$ Denecke, Herford, 1915, 740.

${ }^{899}$ Baumert, Fürsorge für die „vergessenen Krieger“, Deutsches Philologen-Blatt 1916, S. 9.

${ }^{900}$ Beyte, Sophienschule Hannover, 1916, S. 153.

${ }^{901}$ Brill, Jever, Deutsches Philologen-Blatt 1916, S. 26.

${ }^{902}$ Schnoor, Neumünster, Deutsche Tageszeitung, 1915, S. 740.

${ }^{903}$ Knoche, Magdeburg, Deutsches Philologen-Blatt 1916.

${ }^{904}$ Thambahn, Solingen, Deutsches Philologen-Blatt 1916.

905 Schott, Fürsorge der höheren Schulen für die „vergessenen Krieger", Deutsches Philologen-Blatt 1916, S. 135.

${ }^{906}$ Fürsorge der höheren Lehranstalten für die „,vergessenen" Krieger, Deutsches Philologen-Blatt 1916, S.152.

${ }^{907}$ Der Begriff wurde allerdings nicht nur für die ,vergessenen Krieger' verwendet, sondern darüber hinaus für alle Soldarten, die von einer Klasse regelmäßig Pakete mit Liebesgaben erhielten. In Husum hatte z. B. ,jede
} 
Sowohl einige solcher Dankesschreiben, von denen sehr viele überliefert sind ${ }^{908}$, als auch Briefe der Schulkinder an die Soldaten sollen auszugsweise angeführt werden. Stets wurde die Post der Soldaten von der Klasse mit großer Spannung erwartet und dann voller Freude im Unterricht vorgelesen. Das Verlesen der Antwortschreiben wurde sogar „meist zu einer feierlichen Stunde gestaltet“`909:

,Schlettstadt, 17. Oktober, 1915

Lieber Soldat! Da wir von Ihnen die Adresse erfahren haben, wollen wir Ihnen auch einmal schreiben. Ich hörte, daß Sie keine Eltern und Geschwister mehr haben. Wir errichteten eine Kriegskasse. Manche Kinder brachten Geld, viele Zigaretten und Äpfel. Wenn wir einige Mark beisammen haben, schicken wir Ihnen ein Paket. Ich möchte gern wissen, ob Sie Kinder haben. Schreiben Sie uns auch, was Sie im Frieden für ein Handwerk haben und woher Sie sind. Bitte, schreiben Sie uns einen langen, langen Brief. Die ganze Klasse wird ihn dann lesen. Also bitte baldige Antwort! Es grüßt Sie herzlich die ganze Klasse und besonders die Schwester und Margarethe Jehl.“910

Etwa zwei Wochen später kam die Antwort.

„Belgien, den 5. November 1915

Meine liebe kleine Margaretha!

Dein liebes Briefchen habe ich soeben erhalten. Meinen herzlichsten Dank dafür! Am meisten freut es mich, daß Du an mich denkst, auch die ganze Klasse an die Soldaten denkt, die keine Eltern mehr haben. Ich habe schon manchmal beim Austeilen der Post die Kameraden beneidet, weil sie alle Tage etwas von zu Hause bekommen. Um so mehr Freude macht es mir, daß Du und Deine Mitschülerinnen auch an mich denken. Grüße auch die liebe Schulschwester und bete auch für uns Krieger, daß dieser schreckliche Krieg bald zu Ende ist.

Und nun, mein liebes Gretchen, frägst Du mich, was ich im Frieden für ein Handwerk habe. Frage doch den Vater, ob er den Arbeiter von Ludwig Eberle nicht kennt, und er wird Dir das Weitere erzählen. Auch lässt er Dich und alle von der Familie Jehl grüßen; wir sind beisammen in einem Dorf.

Es grüßt Dich und Deine lieben Mitschülerinnen und die liebe Schulschwester

Sanitäts-Unteroffizier Karl Moser, Fuhrpark-Kolonne V.A.K. Westen. “`911

Die beiden folgenden Briefe stammen aus der Kriegschronik eines Hamburger Lyzeums. Eine Sieben- oder Achtjährige schrieb an ,ihren’ Klassensoldaten: „Lieber Krieger, ich schicke Dir ein schönes Weihnachtsgeschenk, ein Paar Pulswärmer und ein Paar Strümpfe und dann auch braune Kuchen, das wird Dich sicherlich freuen! Wie geht es Dir denn im Schlachtfeld, ist es dort kalt? Und wie muß es schrecklich sein, wenn die Granaten über Deinen Kopf hinwegspringen. Viele Grüße an den lieben Soldaten.“ ${ }^{912}$

Der Name der Schülerin, an die der folgende Brief gerichtet ist, ist nicht bekannt.

Klasse ihre eigenen ,Klassensoldaten', die sie versorgte.“ (Hohnsbehn, Die Flensburger Schuljugend in der Zeit des ersten Weltkriegs [1996], S. 368).

${ }^{908}$ Ein Lyzeum berichtet von mehr als 4.000 Dankschreiben (LAS, Abtl. 302, Nr. 3178, IV.1919; siehe: auch Hohnsbehn, Die Flensburger Schuljugend in der Zeit des ersten Weltkriegs (1996), S. 368.

${ }^{909}$ Führen, Lehrer im Krieg (1936), S. 66.

${ }^{910}$ Führen, Lehrer im Krieg (1936), S. 66.

${ }^{911}$ Führen, Lehrer im Krieg (1936), S. 66.

${ }^{912}$ Loewenberg, Kriegstagebuch einer Mädchenschule (1916), S. 29. 
„Mein lieber Kamerad, hoffentlich bist Du nicht böse, daß ich diese Anrede und das Du gebrauche. Es ist mir nicht anders möglich. Denn Du hast Dich, durch Dein herrliches Paket, zu einem meiner besten Kameraden gemacht. Kann Dir gar nicht sagen, wie sehr ich mich mit Deinem Paketchen gefreut habe. Hast aber auch an alles gedacht. War nämlich schon mal verwundet und befinde mich zum zweiten Male an der Front. Wir liegen schon ziemlich lange hier fest. Aus der Zeitung wirst Du wohl schon von den Kämpfen bei Ypern gelesen haben. Da war ich auch schon oft dabei. Schon manche Granate und Schrapnell ist dicht neben mir krepiert. Aber bis jetzt hat's noch immer gut gegangen. Ich bin Telefonist. Ein ziemlich schwerer, aber auch äußerst interessanter Posten. $\mathrm{Na}$, hoffentlich sind wir bald in London. - So, muß jetzt schließen. Meine Apparate summen alle und wollen bedient sein. Meine Kameraden, welche von Deinen schönen Sachen was abbekommen haben, lassen bestens danken. Leb' wohl für heute, sei vielmals gegrüßt von Deinem Kameraden. ${ }^{913}$

Wie aus den beiden zitierten Briefen der Soldaten, so geht aus vielen anderen Antwortschreiben hervor, in welchem Maße sie sich über die Gaben aus der Heimat gefreut haben und wie dankbar sie waren. Einige Auszüge seien zitiert:

„Hier im Feindesland von deutschen Mädchen beschenkt zu werden, ist eine übergroße Freude“,

„Ich habe mich sehr gefreut, aus Deinen Kinderhändchen eine Liebesgabe zu bekommen. Es ist mir, als ob ich Heimatsluft atme",

„Wir fühlen uns stark, wenn wir erfahren, mit welcher Hingabe die deutschen Mädchen und Frauen für unser Wohl arbeiten. ${ }^{، 914}$

Die Schüler und Schülerinnen haben also durch die Liebesgabensendungen durchaus mit dazu beigetragen, den Kampfgeist der Soldaten zu stärken. Ein Soldat hat es in einem Brief folgendermaßen ausgedrückt: "Wir werden die Strapazen des Feldzuges umso leichter tragen, nachdem wir wissen, was das deutsche Volk für uns übrig hat. “915

Neben den Liebesgaben selbst war also für die Soldaten die Tatsache, von der Heimat nicht vergessen zu sein, von besonderer Bedeutung. Die Schülerin Elfriede Kuhr aus Schneidemühl, die regelmäßig vier Frontsoldaten geschrieben hat, vermerkte in ihrem Kriegstagebuch dazu: “Aber was soll man schon schicken? [...] Ich denke aber, daß die ,Muschkoten“ sich einfach über das Gedenken aus der Heimat freuen. Sie sind so tapfer, sie opfern, ohne zu murren, ihr Leben fürs Vaterland.“916

\section{7 „,Kriegsarbeitsstuben“}

Aus dem Jahresbericht der Königlichen Auguste-Victoria-Schule in Trier geht hervor, dass die Schule sich eine „Kriegsmäßige Schulordnung“ gegeben hat. ${ }^{917}$ So hat sie eine „Kriegsarbeitsstelle“ eingerichtet und diese der Leitung des Trierer Roten Kreuzes unterstellt. Sie bezeichnete „sich demnach als Rote-Kreuz-Hilfsarbeitsstelle Auguste-Victoria-Schule“.

\footnotetext{
${ }^{913}$ Loewenberg, Kriegstagebuch einer Mädchenschule (1916), S. 50f.

${ }^{914}$ Loewenberg, Kriegstagebuch einer Mädchenschule (1916), S. 72.

915 Loewenberg, Kriegstagebuch einer Mädchenschule (1916), S. 72.

${ }^{916}$ Loewenberg, Kriegstagebuch einer Mädchenschule (1916), S. 261.

${ }^{917}$ Kriegshelferdienst der Schülerinnen als Vorbereitung auf das weibliche Dienstjahr, Die Lehrerin: Organ des Allgemeinen Deutschen Lehrerinnenvereins 1916, S. 179f.
} 
Im Folgenden soll auf die in den Abteilungen 1 („Näh- und Strickabteilung“), 2 („Kinderpflegeabteilung“) und 4 (,Abteilung für Schreibarbeiten aller Art“) genannten Hilfsdienste näher eingegangen werden.

\subsubsection{Kriegsküchen}

Neben den vielen Appellen ${ }^{918}$, mit den zur Verfügung stehenden knappen Lebensmitteln äußerst sparsam umzugehen, gab es eine Reihe von weiteren Maßnahmen. Besonders wichtig für die Volksernäherung war - in der Mehrzahl ab 1915 - die Einrichtung von „Kriegsküchen“ und teilweise sogar besonderen „Kinderküchen“ in den Kommunen. In der Regel wurden sie von gemeinnützigen Einrichtungen, wie z. B. den Landesverbänden des Roten Kreuzes, oder örtlichen privaten Organisationen betrieben. Dort bekamen in der Regel vor allem die Kinder bis zum Ende des Krieges ${ }^{919}$ ein kostenloses warmes Mittagessen und für besonders bedürftige gab es sogar eine „Kinderabendsuppe“. Über die Bedürftigkeit entschied in der Regel der „Hilfsausschuss“ des Einrichtungsträgers.

Bereits am 5. Dezember 1914 hatte der preußische Unterrichtsminister verfügt,

„daß die Schulküchen der Mädchenschulen aller Art in den Stunden, in denen sie für die Schülerinnen nicht gebraucht werden, Vereinen oder Einzelpersonen zur Verfügung gestellt werden, die sich der Fürsorge der Familien der zum Heeresdienste einberufenen Krieger oder sonst Bedürftiger widmen. In den Küchen können unter Beteiligung der Hauswirtschaftslehrerinnen Vorträge, Belehrungen und Besprechungen über empfehlenswerte Nahrungsmittel, ihren Wert und ihre beste und sparsamste Verwendung für die Volksernährung, besonders während der Kriegszeit, veranstaltet werden. Auch wird es möglich sein, dort Speisen für die Pflegebefohlenen der Vereine usw. herzustellen und Speisungen einzurichten.“920

Auch die Kommunen appellierten an die Hauswirtschaftslehrerinnen, unter „Beihilfe von praktischen Hausfrauen“ mehrere Male täglich in den „Kochschulen“ Kurse abzuhalten. ${ }^{921}$ Viele Schulen gingen über den Erlass noch hinaus und wandelten ihre „Schulküchen in Volksküchen“ um, z. B. in Dresden, wo die Hauswirtschaftslehrerinnen die Leitung der Küchen übernahmen. Dort stellten die Mädchen der obersten Schulklassen unter Leitung ihrer Lehrerinnen das Essen her, das während der Dauer des Krieges an bedürftige Familien abgegeben wurde. ${ }^{922}$ Auch in Solingen wurde eine Reihe von Volksküchen eingerichtet, von denen vier unter der Leitung von technischen Lehrerinnen standen. Täglich wurden etwa 1.300 Portionen Mittagessen verabreicht. ${ }^{923}$

\footnotetext{
918 Siehe z. B. das Flugblatt des Nationalen Frauendienstes „An die deutschen Mädchen“ Nationaler Frauendank, An die deutschen Mädchen, Die Lehrerin: Organ des Allgemeinen Deutschen Lehrerinnenvereins 1914/15, S. $284 \mathrm{f}$.

${ }^{919}$ Nach dem Krieg löste das amerikanische Kinderhilfswerk in vielen Bereichen die Einrichtungen ab.

${ }^{920}$ Ministerium der geistlichen und Unterrichts-Angelegenheiten, Verwendung der Schulküchen für vaterländische Zwecke, Zentralblatt für die gesamte Unterrichtsverwaltung in Preußen, 1914, S. 746f.

921 Zur Unterweisung und Herstellung nahrhafter und billiger Gerichte, Die Lehrerin: Organ des Allgemeinen Deutschen Lehrerinnenvereins 1914, S. 211.
} 
In Ohligs (Rheinprovinz) wurden für bedürftige Kinder Suppen ausgegeben, die von einer Handarbeitslehrerin mit zwei Schülerinnen gekocht wurden. 2.000 Volksschulkinder erhielten in Düsseldorf täglich die Schulspeisung, die von den Schulen organisiert wurde. Auch die Coburger Kriegschronik enthält entsprechende Hinweise: „Sehr wertvoll war auch die Mithilfe der 1. Mädchenklasse, aus der täglich 34 Mädchen sich einstellten zum Wegbesorgen, Gemüseputzen, Kartoffelschälen usw. [...] Die Speisung erfolgte in dem neben der Kriegsküche gelegenen Klassenzimmer.“" ${ }^{924}$ In Pirna war auf Anregung des Schuldirektors in der 2. Bürgerschule eine Kriegsküche gegründet worden, die ab dem 1. November 1916 vorübergehend 200 bedürftige Schulkinder in der Frühstückspause mit je einem halben Liter warmer Suppe versorgte. ${ }^{925}$ Als letztes Beispiel sei Brandenburg angeführt, wo die Kinder von den Lehrern und Lehrerinnen klassenweise zu den Speisungen geführt wurden. ${ }^{926}$

Obwohl die Einrichtung von Schülerspeisungen erst 1916 vom kaiserlichen Gesundheitsamt dringend empfohlen wurde, gab es sie bereits im Jahre 1915 in nahezu allen deutschen Städten. ${ }^{927}$ Aus verschiedenen Berichten geht hervor, dass die technischen Lehrerinnen auch nach Schulschluss und in den Ferien kochen mussten: „Wir mussten tapfer weiter kochen“ heißt es z. B. aus Dresden. Insgesamt waren die Schulen neben dem „Verein für Kindervolksküchen und Volkskinderhorte“ die wichtigste Institution im Kampf gegen den Hunger der Kinder.

\subsubsection{Kriegsschreibstuben}

Als am Anfang des Krieges viele Briefe und Päckchen die Adressaten an der Front nicht erreichten, da das Adressenformular falsch ausgefüllt war oder die Pakete nicht ordnungsgemäß gepackt worden waren, wurden in Stadt und Land „Feldpost und Kriegsschreibstuben“ eingerichtet, und zwar vor allem in Schulen, und von Lehrern verwaltet, wie aus einer Statistik vom 2. September 1915 hervorgeht. ${ }^{928}$

In den Lehrerzeitungen wurden Lösungsmöglichkeiten des Problems immer wieder diskutiert und Vorschläge gemacht, wie beispielsweise auch der folgende:

„Unser Kollegium hat eine recht freudige Einrichtung getroffen. Täglich, auch Sonntags, ist abends von 6-7 Uhr jemand im Lehrerzimmer, der Schreibarbeiten für die Angehörigen der im Felde stehenden Krieger besorgt. Wenn es auch keine Analphabeten bei uns gibt, so finden sich doch genug

\footnotetext{
${ }^{922}$ Ohnesorge, Volkschularbeit im Kriege, Die Lehrerin: Organ des Allgemeinen Deutschen Lehrerinnenvereins 1914, S. 181-183.

${ }^{923}$ Führen, Lehrer im Krieg (1936) 1936, S. 42.

${ }_{924}$ Ungelenk, Coburg im Weltkrieg 191418; Ein Denk- u. Dankstein (1922), S. 392.

925 Jensch, Pirna im Ersten Weltkrieg, http://www.geschichte-pirna.de/Pirna\%20im\%201.\%20Weltkrieg.pdf (22.01.2010), S. 36.

${ }^{926}$ Führen, Lehrer im Krieg (1936), S. 42.

${ }^{927}$ Führen, Lehrer im Krieg (1936), S. 42.

${ }^{928}$ Führen, Lehrer im Krieg (1936), S. 352.
} 
Leute, deren arbeitsharte Hände die Feder nicht mehr gerne führen, stellt sich manches Mütterchen ein, dessen Augen trübe geworden sind - auch von Tränen. Und viele finden sich nicht gut zurecht mit den Postvorschriften für die Sendungen im Feld. All diese kommen und lassen sich beraten oder diktieren uns in die Feder, was sie denen da draußen zu sagen haben. Die Stunde, in der wir den Angehörigen unseren Tapferen dienen, verwandelt sich oft zur Weihestunde. Viele Herzenszartheit wird bei den Briefdiktierern offenbar. Etwas wie die Verantwortlichkeit des beichtehörenden Priesters kommt über den schreibenden und beratenden Lehrer, der sich in den Dienst zagender, liebender Seelen stellt. In kleinen Städten und auf den Dörfern kann darum die Einrichtung solcher Schreibstuben nicht herzlich genug empfohlen werden. “929

Die Schreibstuben, in denen oft auch Schüler und Schülerinnen halfen ${ }^{930}$, wurden von der Postverwaltung sehr unterstützt. Insgesamt waren nach einer Zählung 1915 ,im Reichspostgebiet 1853 (Kriegsschreibstuben für Feldpostsendungen) vorhanden, außerdem 83 Verpackungsstellen und 515 vereinigte Kriegsschreibstuben und Verpackungsstellen (vorhanden) ${ }^{\text {‘931 }}$. Vor allem die Lehrer und Lehrerinnen hatten also die große Bedeutung der Feldpost für die Soldaten an der Front erkannt und in vielen Regionen sofort gehandelt. ${ }^{932}$ Sie wussten, wie wichtig für jene das Gefühl war, von der „Heimatfront“ moralisch und materiell unterstützt zu werden.

\subsubsection{Kriegsnähstuben}

Da der Bedarf an warmen Kleidungstücken ständig größer wurde und zudem viele Kommunen eigene „Notstandsnähschulen“ einrichteten ${ }^{933}$, wurde in den „Kriegsnähstuben“ von den Schülerinnen Kleidungsstücke weiter in großer Stückzahl produziert.

Dieses geht vor allem sowohl aus vielen Schulchroniken als auch aus entsprechenden Fotos hervor. Manche der Nähstuben waren sehr provisorisch, andere hingegen hatten viele Arbeitsplätze und waren gut ausgestattet. Z. B. konnte man in einem Hamburger Lyzeum in einer Turnhalle ledig vier Nähmaschinen, die ein Geschäft leihweise zur Verfügung gestellt

\footnotetext{
${ }^{929}$ Führen, Lehrer im Krieg (1936), S. 351.

${ }^{930}$ Siehe: Liebig-Oberrealschule in Frankfurt am Main: Keyl, Unsere Feldpost. Aus der Liebig-Oberealschule in Frankfurt a. M., Deutsches Philologen-Blatt 1916, S. 121f.

${ }^{931}$ Kriegsschreibstuben für Feldpostsendungen, Die Lehrerin: Organ des Allgemeinen Deutschen Lehrerinnenvereins 1915/16, S. 63.

932 Allerdings gab es offensichtlich Regionen, in denen zu wenig Kriegsschreibstuben und Verpackungsstellen eingerichtet worden waren, wie z. B. in Ostpreußen. Dort hatte sich die Oberpostdirektion an die Schulbehörden gewandt, da die Anregung zur Errichtung von Kriegsschreibstuben und Verpackungsstellen ,an einer größeren Anzahl von Orten [...] noch unbeachtet geblieben“" sei. In einem Erlass der königlichen Regierung vom 16. April 1915 wurden darauf die „Herren Schulinspektoren und Lehrer“ gebeten, ,auf die Einrichtung weiterer Kriegsschreibstuben hinzuwirken." (Königliche Regierung für Ostpreußen, Kriegsschreibstuben in den Schulen und Schreibunterricht, Amtliches Schulblatt für den Regierungsbezirk Königsberg, 1915, S. 50).

${ }^{933}$ Zum Beispiel war bereits am 10. September 1914 im Norden Berlins eine Notstandsnähschule für 100 Arbeiterinnen eingerichtet worden (Notstandsarbeiten für Frauen, Die Lehrerin: Organ des Allgemeinen Deutschen Lehrerinnenvereins 1914/15).
} 
hatte, benutzen ${ }^{934}$; auf einem Foto aus einer Volksschule sind nur drei Nähmaschinen zu sehen. ${ }^{935}$

Da bereits im Kapitel 4.5 Mengenangaben zu den von Schülerinnen hergestellten Liebesgaben gemacht worden sind, sollen hier lediglich drei Beispiele angeführt werden. In der Kriegschronik der Stadt Münster ist folgender Auszug aus dem Jahresbericht des Lyzeums und der Realgymnasialen Studienanstalt abgedruckt: „In den ersten Wochen (des Jahres 1915) wurden 4 Dutzend Kissenbezüge, 3 Dutzend Bettücher, 5 Dutzend Handtücher, 500 Armbinden für das Rote Kreuz genäht. In den Ferien fand eine größere Anzahl von Schülerinnen Beschäftigung beim Instandhalten von Uniformen. “936 In München wurde auf Anregung eines Lehrers in den Kellerräumen der Gisela-Kreisrealschule eine Nähstube eingerichtet und „,zahlreichen arbeitslosen Frauen [...] dadurch Beschäftigung gegeben. [...] Der Gesamtumsatz betrug bis Ende Juni 1914 415.356 M. Die Schüler waren beim Verpacken und Abliefern der fertigen Näharbeiten beschäftigt.“ (In der kurzen Zeit wurden z. B.) „5000 Bettbezüge, 10000 Strohsäcke, 3000 Wickelgamaschen, 20000 Drillichjacken, 17000 Unterhosen usw. hergestellt‘937. Konkrete Zahlen liegen ferner aus den Berliner Fortbildungsschulen vor: Dort wurden „gesammelt, gereinigt, wiederhergestellt und verschenkt: 600 Kleider, 400 Mäntel, 500 Jacken, 300 Röcke, 950 Blusen, 600 Unterröcke, 550 Schürzen, 400 Hemden, 1200 Stück Kinderwäsche; 50 Männeranzüge, 70 Jacketts, 50 Röcke, 120 Hosen, 120 Hosen, 200 Mäntel usw.“938 Neben den Hauswirtschaftslehrerinnen waren es häufig auch Lehrerfrauen, die als Leiterinnen von Näh- und Strickschulen tätig waren. ${ }^{939}$ Dass ihre Tätigkeit auch von den Empfängern an der Front gewürdigt wurde, zeigt folgender Briefauszug:

„... meines entfernt von den übrigen Truppen stehenden Regiments mit Spenden gedacht wurde. Ich bitte Sie, meinen wärmsten Dank entgegenzunehmen und der in segensreicher Weise wirkenden ,Nähstube' zum Ausdruck bringen zu wollen. Man muß erstaunt sein, was von Ihrem Verein für die Kriegsfürsorge aufgewendet wird und was für Liebesgaben zur Verfügung steht. Es kommt auch darin wieder zum Ausdruck, welch herrlicher vaterländischer Geist unsere Lehrerschaft, insbesondere unsrer Stadt Nürnberg, erfüllt, zu welcher Opferfreudigkeit sie stets bereit ist, wenn es dem Wohl des Vaterlandes gilt. N ..., Oberst. ${ }^{\text {‘940 }}$

\footnotetext{
${ }^{934}$ Siehe: Loewenberg, Kriegstagebuch einer Mädchenschule (1916), S. 14.

935 Siehe: Anhang, Seite 73, Bild 1.

936 Schulte, Kriegschronik der Stadt Münster 1914-18 (1930), S. 106.

937 Ebner, Die höheren realistischen Schulen Bayerns im Kriegsjahr 1914/15 (1915), S. 670.

938 Führen, Lehrer im Krieg (1936), S. 479.

${ }^{939}$ Führen, Lehrer im Krieg (1936), S. 352.

${ }^{940}$ Führen, Lehrer im Krieg (1936), S. 354.
} 


\title{
4.8 Sanitätsdienste, Verwundeten- und Truppenbetreuung
}

Anfang August 1914 riefen Lehrerverbände auf, sich für die ,freiwillige Krankenpflege' zu melden. Es würden „Kurse eingerichtet und Urlaub bewilligt““941. In welchem Umfange solchen Aufrufen, die an die Lehrer gerichtet waren, gefolgt worden ist, lässt sich den Quellen nicht entnehmen. Allerdings haben sich offensichtlich recht viele Lehrerinnen und Schülerinnen für Pflege- und Betreuungsdienste zur Verfügung gestellt, wie aus einem Erlass der Regierung in Düsseldorf hervorgeht:

„An Frauen und Mädchen, die sich in der gegenwärtigen Kriegszeit ihre Kräfte der Allgemeinheit, besonders im Sanitätsdienste, zur Verfügung stellten, scheint erfreulicherweise kein Mangel zu sein; wir sind gern damit einverstanden, daß die Hauswirtschafts-, Handarbeits- und Turnlehrerinnen, auch nachdem der Unterricht wieder begonnen haben wird, zu freiwilliger Liebesarbeit beurlaubt werden. Dagegen halten wir es für notwendig, daß im allgemeinen die wissenschaftlichen Lehrerinnen sich nach den Ferien für den Schulunterricht zur Verfügung halten, um die zahlreichen Lücken auszufüllen, die durch die Einberufung von Lehrern zum Heeresdienst entstanden sind.“942

Während anfangs Lehrerinnen durchaus für die Verwundetenpflege beurlaubt wurden, konnten sie sich ab 1915, als der Lehrermangel immer größer wurde, in diesem Bereich lediglich nach Schulschluss engagieren. Der folgende Erinnerungsbericht einer Berliner Lehrerin spiegelt beispielhaft die Belastungen wider, die viele Lehrerinnen auf sich nahmen:

\begin{abstract}
„Mitte August 1914 wurden zwei Lehrerinnenkurse eingerichtet zur Ausbildung in der freiwilligen Krankenpflege. Wir hatten abends Unterricht, soweit ich mich entsinnen kann, jeden Abend und machten im September die Helferinnenprüfung.

Im November wurden sieben von uns in das Barackenlazarett auf dem Tempelhofer Felde einberufen. Zum Entsetzen der Oberin hatten wir vormittags Dienst in der Schule und konnten nur nachmittags erscheinen. Ich hatte damals zwei Ordinariate, eine 1. Mädchenklasse und eine 7. Knabenklasse in der Nachbarschule. Nachmittags von 3-8 Uhr war ich im Lazarett tätig. Anfangs wurden wir Lehrerinnen von Nachtwachen verschont, später mussten wir jeden Monat eine übernehmen, und zwar immer in der Nacht von Sonnabend zu Sonntag. Ich war auf einer chirurgischen Station, habe übrigens noch die Hilfsschwesternprüfung gemacht und wurde im Februar 1916 entlassen. Die Arbeit hat mir so viel Freude gemacht, daß ich ganz unglücklich war, als man uns Lehrerinnen klar machte, man brauchte uns nicht mehr. Zum Trost bekamen wir die Rote-Kreuz-Medaille.“943
\end{abstract}

Eine andere Lehrerin aus Berlin geht noch genauer auf ihre Motive ein: „Urlaub zur Krankenpflege hatten wir nicht, sondern taten Dienst neben dem Schuldienst; vormittags 8-12 oder 1 Uhr Lazarettdienst, nachmittags 3-6 Uhr Schuldienst. Wir waren jung, wollten unserem Vaterlande dienen und unsere Kräfte opfern. Leicht war es manchmal nicht. Ich nahm in der Zeit 60 Pfund ab und wurde ziemlich elend. Aber schön war's doch. “944

\footnotetext{
${ }^{941}$ Führen, Lehrer im Krieg (1936), S. 38.

${ }^{942}$ Lehrerinnen als Vertreter von zum Heere einberufenen Lehrern, Die Lehrerin: Organ des Allgemeinen Deutschen Lehrerinnenvereins 1914/15, S. 190.

${ }^{943}$ Führen, Lehrer im Krieg (1936), S. 399.

${ }^{944}$ Führen, Lehrer im Krieg (1936), S. 399.
} 
Anfang 1916 gab es nach Aussage einer Lehrerin aus Ostpreußen genug Schwesternnachwuchs ${ }^{945}$ und deshalb wurde weitgehend auf die Ausbildung und Einberufung von Lehrerinnen in den Sanitätsdienst verzichtet, zumal der Lehrermangel in den Schulen immer größer wurde. Allerdings kümmerten sich sehr viele Lehrerinnen zusammen mit Schülerinnen neben der Schule weiter um Verwundete in den Lazaretten und um Kriegsbeschädigte und betreuten durchreisende Soldaten. Oft taten sie das in den Nachtstunden, da diese Zeiten nur schwer zu besetzen waren.

„Wer stenographieren konnte, nahm im Operationssaal Kranken- und Operationsberichte auf. [...] Auch im Sanitätsdepot für Herausgabe von Medikamenten und in der Auskunftsstelle für Verwundetenfürsorge wurden Lehrerinnen verwendet, und in der Gefangenenfürsorge waren sie tätig. Oft schrieben sie für die Verwundeten Briefe. An einem Ort bildeten die Lehrerinnen einen Gesangschor, der in Lazaretten vorsang. Andere gingen mit ihren Klassen dahin zu demselben Zweck. " "946

Da die meisten Jungen in der Landwirtschaft eingesetzt waren oder andere Hilfsdienste übernahmen, war ihr Engagement in jenen Bereichen deutlich seltener. Hohnsbehn sieht eine weitere Ursache dafür in der Tatsache, dass die Mädchen sich in besonderem Maße zu den verletzten Soldaten hingezogen fühlten. Seiner Meinung nach scheinen sie sich vor den Verbänden und den dahinter verborgenen Verletzungen nicht besonders gefürchtet zu haben. ${ }^{947}$

\section{Bahnhofdienst $\mathbf{t}^{948}$}

Viele Schülerinnen und Schüler eilten spontan zu den Bahnhöfen, wenn Züge mit an die Front reisenden Soldaten oder Lazarettzüge ankamen, wie z. B. die zwölfjährige Elfriede Kuhr in Schneidemühl (Provinz Posen):

„Ich habe geholfen, mindestens 100 Kaffeetassen in Körbe zu packen, die vom Roten Kreuz für 8 Pfennig das Stück gekauft worden sind. [...] Wir laufen herum, verteilen Brot, Kaffee, Suppe. Im Durchschnitt werden auf dem Bahnhof täglich 400 Kilobrote, 1/2 Zentner Kaffee, 100 Liter Milch und 1 Zentner Schmalz verbraucht. In einer einzigen Stunde kommen manchmal drei bis vier Militärzüge mit je 1500 Mann. Dazwischen laufen Züge mit Flüchtlingen ein und Personenzüge, die in Lazarettzüge umgewandelt sind. “949

Franz Thedick war 14 Jahre alt, als der Krieg ausbrach. In seinen Erinnerungen schrieb er: „Ich selbst ging sofort zum Bahnhofshilfsdienst, der die Soldatenzüge und später die Verwundetenzüge betreute. Alle waren in bester Stimmung.“ “950

\footnotetext{
${ }^{945}$ Führen, Lehrer im Krieg (1936), S. 398.

${ }^{946}$ Führen, Lehrer im Krieg (1936), S. 399f.

${ }^{947}$ Hohnsbehn, Die Flensburger Schuljugend in der Zeit des ersten Weltkriegs (1996), S. 303f.

${ }_{948}^{94}$ Hier war in erster Linie der Nationale Frauendienst aktiv. Bei Personalnot griff er gern auf Schüler zurück.

${ }^{949}$ Mihaly, ... da gibt's ein Wiedersehn! (1986), S. 2 und 55.

${ }^{950}$ Pörtner, Kindheit im Kaiserreich (1990), S. 143.
} 
Auch Erna Lange beschreibt in ihren Erinnerungen eine Szene auf dem Bahnhof: „Zwei Stunden warteten sie bereits. Der Lazarettzug kommt und kommt nicht. [...] In diesem Augenblick schallt es durch die angesammelte Menschenmenge: 'Sie kommen! Sie kommen! Der Zug ist da!' Sie haben sich geirrt, die damals ins Feld zogen. Es ist doch zum Schießen gekommen. Der Trieb zum Helfen und Heilen ist groß und stark in ihr.“951

Hilfsdienste der Schüler und Schülerinnen für die Verwundeten wurden in der Regel durch die Schulleiter unterstützt und teilweise von den Lehrkräften auch organisiert. Als Beispiel sei ein Bericht aus der 1916 erschienenen Landshuter Stadtchronik zitiert:

„Auch der so aufopfernden Hingabe unserer im Dienste der Verwundetenfürsorge so sehr unterstützenden Sanitätskolonne muß hier besonders gedacht werden. Bei allen Verwundetenzügen - der erste kam bereits am 25. August (1914) - war sie mit ihren Fahr- und Tragfahrzeugen hilfreich anwesend und nicht nur die Transporte von und zu den Lazaretten besorgte sie, sondern auch die gelähmten und ambulanten Verwundeten wurden von ihr in die Anlagen und Konzertveranstaltungen etc. gefahren und getragen. Unterstützt wurde die Sanitätskolonne mit Genehmigung des Gymnasialdirektors Dr. Reisermeyer durch die Gymnasiasten der oberen Klassen, die sich freiwillig zum Sanitätsdienst meldeten und von ihrem hochsinnigen Rektor auch jeweils während der Schulstunden abgelassen wurden und die besonders an Sonn- und Feiertagen, sowie an schulfreien Nachmittagen Verwundete spazieren fuhren oder - ein erhebendes Bild - auf dem Rücken trugen. “952

Einen Eindruck von der ,Bahnhofshilfe' vermitteln auch zeitgenössische Propagandakarten und Fotos, wie z. B. eine Aufnahme aus Dortmund. Diese zeigt „Schülerinnen am Versorgungsstand während der Mobilmachung“953.

Insgesamt lassen schon diese wenigen Berichte den Schluss zu, dass die Schule beim Bahnhofsdienst aktiv und in großem Umfang geholfen hat und die Schulkinder sich dabei gern engagiert haben, denn der „Trieb zum Helfen und Heilen ist groß und stark“ gewesen (Erna Lange).

\section{Lazarettbesuche}

Auch über die Besuche von Lehrerinnen und Schülerinnen in Lazaretten liegen viele Informationen, Berichte und Schilderungen vor. ${ }^{954}$ Allein diese Tatsache zeigt, dass derartige Hilfsdienste für Schulen von großer Bedeutung waren. So erinnerte sich z. B. eine ganze Reihe von Zeitzeugen aus Flensburg daran; drei von ihnen sollen zitiert werden:

\footnotetext{
${ }^{951}$ Lange, 1914 bis 1918 auf der Schulbank (1933), S. 35f.

${ }_{952}$ Marschall, Landshuter Stadtchronik; Bd 2 (1989), S. 95.

${ }^{953}$ Löher/Wulf, Furchtbar dräute der Erbfeind! 3; siehe: Anhang, Seite 74, Bild 1.

${ }^{954}$ Einige Schulen verzichteten sogar auf Abschlussfeiern und besuchten stattdessen an ihrem letzten Schultag die Verwundeten in Lazaretten und brachten ihnen Geschenke, wie z. B. die Schülerinnen des städtischen Lyzeums in Buer (Schule und Krieg, Die Lehrerin: Organ des Allgemeinen Deutschen Lehrerinnenvereins A, 1915/16, S. 6).
} 
„Hilde nahm heute ein Dutzend Äpfel mit zur Schule. Sie will sie nach dem Lazarett haben; die ganze Klasse geht hin. Um 4 Uhr sind sie nach dem Lazarett am Pferdewasser gewesen, haben den Verwundeten die Weihnachtsgeschichte erzählt, gesungen und deklamiert. “955

„Der größere Teil der Mädchen, die dem Sonderchor angehörten, (haben) in 6 Lazaretten den Verwundeten und Kranken, die der Einladung ins Kolosseum nicht folgen konnten, eine Reihe der schönsten Lieder vorgetragen [...] und dadurch viel Freude bereitet. “956

„Im 2. Schuljahr hatten wir Fräulein Hild als Klassenlehrerin, mit der sind wir dann in die Lazarette gezogen. Das Lazarett war in der Nikolai-Volksschule damals untergebracht, und da haben wir dann Aufführungen gemacht, aber die waren nicht national betont, sondern: Schneeflöckchen, Weißröckchen, komm zu uns geschneit, mit den weiteren Wintergedichten, die wir so lernten in der Zeit.“957

Dass sich die Zeitzeugen nach etwa 75 Jahren noch an jene Besuche erinnert haben, zeigt, welch großen Eindruck sie damals auf sie gemacht haben.

Im Folgenden soll kurz auf Berichte von zwei damaligen Schülerinnen und einem Schulleiter eingegangen werden. Sie verdeutlichen $u$. a. die große Freude, die die Besuche bei den Verwundeten und Kranken auslösten. Erna Lange beschreibt zunächst, dass der Ankündigung der Lehrerin, mit ihrer Klasse das Lazarett zu besuchen, „,der stürmische Jubel“ nach „,einer Minute sprachlosen Staunens“ folgte. Sie geht dann detailliert und recht gefühlvoll auf den Ablauf des Besuchs ein. Es wurden auf allen Stationen Volkslieder und Vaterlandslieder gesungen und Gespräche mit den verwundeten Soldaten geführt. „Fräulein Rönnlein kennen sie alle. Sie kommt oft, besorgt ihnen Kleinigkeiten, liest vor - ist frisch und lebhaft.“ Die Soldaten „freuen sich wirklich über den jungen Besuch. Man sieht es ihren strahlenden Gesichtern an“. Zum Schluss des Besuchs singen sie auch noch den Schwerverwundeten leise einige Lieder. ${ }^{958}$

Am 28. Januar 1915 vermerkte Elfriede Kuhr in ihrem Tagebuch:

„Manchmal wird von der Schule klassenweise ein Lazarettbesuch befohlen. Dann gehen wir unter Leitung einer Lehrerin mit vielen Liebesgaben in irgendein Lazarett. Auf diese Weise lernte ich neulich ein Lazarett weit draußen vor der Stadt in einer Baracke kennen. War das ein schreckliches Lazarett! Die Holzwände braun vor Alter und ganz rissig, die Betten alte, Bettstelle in allen Größen und Arten, mit schlechten Kissen. In dem einzigen düstern Raum standen die Betten so eng neben einander, dass wir Schülerinnen kaum Platz zum Umdrehen hatten. “959

\footnotetext{
${ }^{955}$ Schröder, Chronik des Weltkriegs, 18.12.1914, S. 174; zitiert nach: Hohnsbehn, Die Flensburger Schuljugend in der Zeit des ersten Weltkriegs (1996), S. 303.

${ }^{956}$ Madsen, Nachrichten über das Flensburger Volksschulwesen im Auftrag der städtischen Schuldeputation Heft XV, S. 25; zitiert nach: Hohnsbehn, Die Flensburger Schuljugend in der Zeit des ersten Weltkriegs (1996), S. 303.

${ }^{957}$ Zitiert nach: Hohnsbehn, Die Flensburger Schuljugend in der Zeit des ersten Weltkriegs (1996), S. 303.

${ }^{958}$ Lange, 1914 bis 1918 auf der Schulbank (1933), S. 53-58.

${ }^{959}$ Mihaly, ... da gibt's ein Wiedersehn! (1986), S.132f.
} 
Die Schülerin hat mehrfach Lazarette besucht und war stets schockiert über die schlechte Unterbringung der Kranken und über deren schwere Verletzungen. ${ }^{960}$ Entgegen den offiziellen Berichten haben solche Besuche die jungen Mädchen durchaus auch belastet.

Ganz anders wirkt ein Tagebucheintrag Jakob Loewenbergs („Im Lazarett, Winter 1914/15“961). Die Schülerinnen waren unaufgefordert in Festtagskleidern gekommen. Auch den Schulleiter „selber ergriff eine Feiertagsstimmung, eine Andacht“, wie er sie noch nie gefühlt hatte. Die Schule hatte ein leichtes Programm mit viel Abwechslung zusammengestellt, da „man den Leuten, die sich noch alle in der Genesung befanden, deren Seele vielleicht noch von den Wirren und Schrecknissen des Kriegs bedrückt war, nicht mit schweren und langwährenden Darbietungen kommen dürfte“. Volkslieder und Volkstanz, ,,Vortragsfolge' mit passenden Sinnbildern“, Klaviermusik und die Verteilung von Liebesgaben wechselten sich ab.

„Als wir uns verabschiedeten, rief es von allen Seiten: Wiederkommen! Wiederkommen! So glückliche, strahlende Kindergesichter wie an diesem Abend hab ich selten gesehen. Wir sind noch oft wiedergekommen. Und einmal sind auch Verwundete durch Vermittlung eines Arztes, der sie behandelte, zu uns in die Schule gekommen. Die Oberklasse hatte sie eingeladen, ihrer fünfundzwanzig. Da gab es wieder Klavierspiel, Lieder, Gedichte und dazu Zigarren und einen Kaffee mit ganzen Bergen von Kuchen, es hätte für hundert gereicht. Das Klassenzimmer war mit Blumen und Fähnchen geschmückt, und das Bild dieser fröhlichen, feiertäglichen Stunden wird den Schülerinnen in dankbarer Erinnerung bleiben."

Wie der Direktor des Hamburger Lyzeums sahen viele Lehrer und Lehrerinnen in dem „schöne(n) Brauch [...], daß die Schüler und Schülerinnen der oberen Klassen in die Lazarette gehen, um dort unseren weilenden lieben Feldgrauen gut eingeübte Lieder vorzusingen““962, großen pädagogischen Nutzen. Sicher auch deshalb wurde in einer Verbandszeitung gefordert: "Laßt auch die Kleinen in die Lazarette gehen!“963 Daneben erhoffte man sich vom Einsatz der Kleinen eine größere Wirkung auf die Soldaten. „Erfahrungsgemäß ist ja bei jeder öffentlichen Veranstaltung der Beifall und die Freude der Zuhörer umso größer, je kleiner der vortragende Künstler ist. [...] Manch Ohr, das sich den Größeren verschloss, öffnet sich willig den Kleinen.“ Um sicherzustellen, dass nicht nur die von den Schulen - oft zufällig - ausgesuchten Lazarette besucht und mit Liebesgaben bedacht würden, versuchten Organisationen wie das Rote Kreuz oder der Berliner Fröbelverein die Hilfe zu koordinieren. Dieser richtete sich z. B. 1915 mit einem Aufruf an die Jugend, der die planmäßige Versorgung der Lazarette

\footnotetext{
${ }^{960}$ Siehe z. B.: Mihaly, ... da gibt's ein Wiedersehn! (1986), S. 108-110.

${ }^{961}$ Loewenberg, Kriegstagebuch einer Mädchenschule (1916), S. 37-46.

${ }^{962}$ Kaufnicht, Laßt auch die Kleinen in die Lazarette gehen!, Die Lehrerin: Organ des Allgemeinen Deutschen Lehrerinnenvereins 1916/17, S. 225.

${ }^{963}$ Kaufnicht, Laßt auch die Kleinen in die Lazarette gehen! Die Lehrerin: Organ des Allgemeinen Deutschen Lehrerinnenvereins 1916/17 (1916), S. 225.
} 
mit Erfrischungs- und Liebesgaben vorbereiten sollte. Es wurde an die Schüler und Schülerinnen aller Altersstufen appelliert, sich an der Aktion zu beteiligen, und ihnen versprochen: "Ihr werdet über die Größe Eurer gemeinsamen Gabe staunen! Und nun bedenkt, wenn sämtliche Schulen Groß-Berlins planmäßig diese Fürsorgearbeit durchführen, welch großes Verdienst Ihr durch Euren Zusammenschluß dem Vaterlande leistet. “964

Inwieweit die Schulen dem Aufruf gefolgt sind, lässt sich nicht konkret belegen. Allerdings steht fest, dass sich sehr viele Schulen im gesamten Reichsgebiet auf vielfältige Weise um die verwundeten und kranken Soldaten in den Lazaretten gekümmert haben. ${ }^{965}$ Dieses haben die Schüler und vor allem die Schülerinnen zusammen mit ihren Lehrern und Lehrerinnen in der Regel bereitwillig getan, wie die angeführten Berichte zeigen, und zwar in der Regel, um den Verwundeten einfach nur „eine Freude (zu) machen“, wie es eine Zeitzeugin in Schleswig ausgedrückt hat.

\section{Beschaffung von Lesestoff, Aufbau und Betreuung von Lazarettbüchereien}

Eine besondere Hilfe der Schulen für die verwundeten Soldaten in den Lazaretten bestand darin, ihnen Lesestoff zur Verfügung zu stellen und Lazarettbüchereien durch Lehrer betreuen zu lassen. Deshalb wurde in Tageszeitungen mehrfach darauf hingewiesen, dass es unbedingt notwendig sei, die Soldaten an der Front, besonders aber die Verwundeten in den Lazaretten hinter der Front, mit Unterhaltungs- und religiösen Schriften zu versehen. Im April 1915 forderte deshalb ein Lehrer in Dillingen an der Saar (Rheinprovinz) in der Zeitschrift „Die Höhere Schule“ die Schulen auf, sich „diesem neuen Liebesdienst zu widmen. [...] Damit vermieden wird, daß die einzelnen Lazarette ungleichmäßig bedacht werden, empfiehlt sich die Einrichtung einer Zentrale für den Westen und den Osten“9666.

Der Appell stieß bei den Lehrern auf große Resonanz. So bezog sich z. B. ein Schulleiter aus Gelsenkirchen auf ihn und berichtete von den Bemühungen an seiner eigenen Schule: „Wir erließen hier eine Aufforderung in den Zeitungen und der Erfolg war der allerbeste. ${ }^{967}$ Beispiele aus vielen anderen Schulen ließen sich anführen. Die erfolgreichen Bemühungen der höheren Schulen führten dazu, dass sich ein „Gesamtausschuß zur Verteilung von Lesestoff im Felde und in den Lazaretten“ bildete und eine „Kriegsbuchwoche“ plante. ${ }^{968}$ Ein Schulleiter aus Essen beklagte, dass die Schulen in die Organisation der Aktion nicht genügend

\footnotetext{
${ }^{964}$ Aufruf an die Jugend, Die Lehrerin: Organ des Allgemeinen Deutschen Lehrerinnenvereins 1914/15, S. 254.

965 Allein vom städtischen Gymnasium in Dirschau (Provinz Westpreußen) sind die Programme von fünf Lazarettveranstaltungen überliefert; siehe: Schule und Krieg, 1915, S. 31.

${ }^{966}$ Fischer, Mehr Lesestoffe für unsere Krieger in den Lazaretten!, Deutsches Philologen-Blatt 1915, S. 268.

${ }^{967}$ Terner, Unterhaltung in den Lazaretten, Deutsches Philologen-Blatt 1915, S. 294.

${ }^{968}$ Kuckhoff, Die Reichskriegswoche und Ähnliches, Deutsches Philologen-Blatt 1915, S. 323f.
} 
eingebunden seien und dass man deshalb den beabsichtigten Zweck nicht voll erreichen werde. ${ }^{969}$ Sie würde „Erfolg haben, wenn die Lehrer sich mit ganzer Seele der Sache annehmen und den deutschen Jungen das Bewusstsein einimpfen, daß es sich um eine hervorragende patriotische Tat handelt“ ${ }^{\circ 70}$.

In der Zeit vom 13. bis zum 19. Juni 1915 wurde mit Genehmigung der deutschen Schulbehörden an den mittleren und den höheren Schulen die Buchwoche durchgeführt. Schüler und Schülerinnen aller Klassen hatten mindestens ein Buch für die Krieger zu spenden und in der Reichskriegswoche im Schulgebäude abzuliefern. ${ }^{971}$ Die Sammlung war sehr erfolgreich. Insgesamt konnten bis Februar 1916 ungefähr 5.750.000 Bücher (ohne Broschüren, Hefte u. a.) den Soldaten im Felde und vor allem in den Lazaretten übergeben werden (Lazarette: etwa 1.850.000, Lazarettzüge: etwa 25.000, Feldlazarette: 128.000, Kriegs- und Etappenlazarette: 150.000 u. a.). ${ }^{972}$ In der Bücherwoche sind allein von den Schulkindern etwa 1 Million Bände zusammengetragen worden. Aufgrund des Erfolgs wurde die Aktion vom 28. Mai bis 3. Juni 1916 als „Reichsbuchwoche“ wiederholt. ${ }^{973}$ Auch wenn sie sich nicht auf die Schulen beschränkte, so wurden die Schüler und Schülerinnen in dem Aufruf „An die deutsche Jugend“ besonders angesprochen. U. a. heißt es darin: „Wir hoffen, daß kein Schüler und keine Schülerin sich von diesem vaterländischen Werke ausschließen und daß jeder mindestens ein Buch für den großen Zweck opfern wird. “974

Da inzwischen in dem Arbeitsausschuss des „Gesamtausschusses zur Verteilung von Lesestoff im Felde und in den Lazaretten“ die Lehrerschaft mehrfach vertreten war ${ }^{975}$, wurde der Aufruf in den Verbandszeitschriften der Lehrerverbände veröffentlicht. ${ }^{976}$

Zusätzlich appellierten Lehrer an die Schulen als Teil der „Heimatarmee“, sich wieder aktiv zu beteiligen, wie z. B. der Schulleiter F. Johannesson aus Berlin: "Und gerade an diesem

\footnotetext{
${ }^{969}$ Die Reichskriegswoche und Ähnliches (1915), S. 323.

${ }^{970}$ Die Reichskriegswoche und Ähnliches (1915), S. 324.

${ }^{971}$ Die „Kriegsbuchwoche", Deutsches Philologen-Blatt 1915, S. 364.

972 Reichsbuchwoche, 28. Mai bis 3. Juni 1916, Deutsches Philologen-Blatt 1916, S. 276 f.

${ }^{973}$ Auch diese Sammlung wurde mit sehr großem Aufwand angekündigt und propagiert. Beispielsweise wurde mit Plakataktionen für die Teilnahme geworden. Siehe: Objektdatenbank des Deutschen Historischen Museums Berlin, Datensätze GOS-Nr. PL002826, GOS-Nr. D2A05860, GOS-Nr. D2A04921 und GOS-Nr. PL003143, (http://www.dhm.de/cgibin/suche).

974 Reichsbuchwoche, 28. Mai bis 3. Juni 1916, Deutsches Philologen-Blatt 1916, S.276f.

975 „Geh. Studienrat Prof. Buchdrucker, Vorsitzender des Vereinsverbandes akademisch gebildeter Lehrer Deutschlands; Prof. Dr. Trautwein, Vorsitzender der Delegierten-Konferenz der Preuß. Philologenvereine, Prof. Dihle, Vorsitzender des Berliner Philologen-Vereins; Mittelschulrektor Breidenstein, Erster Vorsitzender des Preußischen Vereins für das mittlere Schulwesen; Mittelschullehrer Leo Dreyer, Zweiter Vorsitzender“ (1916, S. 277).

${ }^{976}$ Z. B. im Deutschen Deutsches Philologen-Blatt (1916, S. 276f.) und in „Die Lehrerin“, Reichsbuchwoche der deutschen Schuljugend: 28. Mai bis 3. Juni 1916, Die Lehrerin: Organ des Allgemeinen Deutschen Lehrerinnenvereins 1916, S.60f.
} 
Liebeswerk sich zu beteiligen, ist die Schule an erster Stelle berufen, denn eine starke volkserziehliche Kraft wohnt ihm inne, eine Kulturaufgabe wird mit ihm erfüllt.“،977

Man empfand die Kriegsbuchwoche sogar als Gelegenheit, „Lebenskunde“ in der höheren Schule zu praktizieren, um z. B. durch die Auswahl der Bücher Anknüpfungspunkte zur Auseinandersetzung mit den Formen neuerer Literatur zu bekommen und eine „menschliche Beziehung zwischen denen draußen und uns Daheimgebliebenen“ ${ }^{‘ 978}$ herzustellen. Deshalb sollte auch ein Aufsatz „Mein Buch für die Kriegsbuchwoche“ für jede Klasse obligatorisch sei. Obwohl wieder sehr viele Schulen dem Aufruf gefolgt waren und viel Lesestoff gesammelt hatten $^{979}$, wurde die Aktion 1917 nicht wiederholt. Der große Mangel an Nahrungs- und Futtermitteln sowie Rohstoffen führte dazu, dass verstärkt in diesen Bereichen Sammlungen durchgeführt wurden.

\subsection{Fazit}

$\mathrm{Zu}$ den zahlreichen genannten Hilfsdiensten hätten noch viele weitere hinzugefügt werden können. ${ }^{980}$ So waren z. B. die Lehrerinnen zusammen mit ihren Schülerinnen außerdem in der Kinder- und Familienpflege tätig, indem sie u. a. Kinderhorte einrichteten und betreuten, Kinderspeisungen organisierten sowie Kinderlesehallen verwalteten und sich um die Bekleidung bedürftiger Kinder kümmerten. Ferner haben sie Weihnachtsgeschenke für arme Kinder besorgt und diesen überreicht.

Wie einige männliche Kollegen und Mitschüler engagierten sie sich in „mannigfaltigen Institutionen der caritativen und sozialen, der staatlichen, kommunalen und kirchlichen Fürsorge $^{\text {“981 }}$, von denen lediglich die für die Schulen nach Umfang und Bedeutung wichtigsten untersucht worden sind. Das Engagement war sowohl bei Lehrerinnen und Lehrern als auch bei

\footnotetext{
977 Johannessen, Die zweite Kriegsbuchwoche, Deutsches Philologen-Blatt 1916, S. 305f. In der von Johannessen geleiteten Schule in Berlin waren z. B. in der 1. Kriegsbuchwoche Bücher im Wert von 800 Mark zusammengetragen worden.

978 Treuge, „Lebenskunde" im Lyzeum, Die Lehrerin: Organ des Allgemeinen Deutschen Lehrerinnenvereins 1915, S. 123.

979 In Neubrandenburg z. B. hatte die Aktion einen „,befriedigenden Erfolg. An brauchbaren Büchern wurden insgesamt 2.339 Bände eingeliefert. Hinzu kamen die Zeitschriften mit ca. 2.000 Einzelnummern und 46 vollständige Jahrgänge“(Maubach, Neubrandenburg im 1. Weltkrieg (1996), S.160).

${ }^{980}$ Beispielsweise ist auf „Kriegspatenschaften“ durch Schulkinder nicht eingegangen worden, da sie relativ selten vorkamen. 1916 war der „Reichsverband für Kriegspatenschaften“ gegründet worden, der es sich zum Ziel gesetzt hatte, ,durch Heranziehung geeigneter Paten den Kriegswaisen persönliche Pflege und Berater zur Seite zu stellen“ (Stranz, Reichsverband für Kriegspatenschaften, Die Lehrerin: Organ des Allgemeinen Deutschen Lehrerinnenvereins 1917/18, S. 268f.); auch Schulklassen konnten gemeinsam Patenschaften ausüben. Insgesamt allerdings sind sehr viele Patenschaften vermittelt worden, auch an Lehrerinnen und Lehrer. In Breslau beispielsweise waren es bis zum 31.12.1917 5.759. (Nachrichten, Die Lehrerin: Organ des Allgemeinen Deutschen Lehrerinnenvereins 1918, S. 62). Welchen Anteil die Lehrkräfte daran hatten, ist nicht bekannt. In Österreich gab es eine ähnliche Initiative, die „Kriegspatenschaft für Säuglinge“ (Soziale Rundschau, Die Lehrerin: Organ des Allgemeinen Deutschen Lehrerinnenvereins 1916, S. 360).

981 Führen, Lehrer im Krieg (1936), S. 40.
} 
Schülerinnen und Schülern aller Schulformen ziemlich groß, und zwar in sämtlichen Regionen des Deutschen Reiches. Für die Lehrerkräfte in den ländlichen Volksschulen waren zum Beispiel Aufklärungsvorträge und Schreibdienste wichtiger als für die Kollegen und Kolleginnen der städtischen Gymnasien und Lyzeen, die sich besonders bei den Arbeitseinsätzen in der Landwirtschaft oder in den Lazaretten engagierten. Wie außerdem deutlich geworden ist, waren Gemeinden und Städte gleichermaßen auf die ,private Kriegsarbeit' der Lehrkräfte angewiesen. Ohne die Schulen hätten die Kommunen schon aufgrund des Arbeitskräftemangels viele Aufgaben nicht wahrnehmen können.

Eine große Bedeutung für die Versorgung der Bevölkerung mit Lebensmitteln kam mit zunehmender Kriegsdauer den Arbeitseinsätzen der älteren Schüler in der Landwirtschaft zu, auch wenn es gerade in diesem Bereich sowohl aus Sicht der Schulen als auch der Landwirte einige Probleme gab.

Besonders wichtig war auch die Unterstützung der militärischen Front durch die „, schulische Heimatfront“, die sich um die „Vergessenen Soldaten“ und die Verwundeten in den Lazaretten kümmerte und Hunderttausende von Liebesgabenpaketen verschickte, wie in vielen Dankesschreiben betont worden war: „Wir fühlen uns stark, wenn wir erfahren, mit welcher Hingabe die deutschen Mädchen und Frauen für unser Wohl arbeiten. “982

Auffälligerweise gab es nur wenige Aktionen zugunsten von Kriegswaisen ${ }^{983}$ und -witwen. Zwar kümmerten sich die Kommunen und die Organisationen um diese Personengruppen ${ }^{984}$, an Sammlungen zu ihren Gunsten jedoch wurden die Schulen in der Regel nicht beteiligt. Offensichtlich wollten die offiziellen Stellen die Schulkinder nicht mit dem Kriegstod konfrontieren.

Der Vorsitzende der Bayerischen Landesgetreidestelle fasste die Leistungen der Schule gegen Kriegsende wie folgt zusammen:

„In dem Maße, in dem Schule und Lehrer durch die lange Dauer des Krieges ihrer ureigensten Aufgabe, der Jugendbildung entzogen wurden, in dem gleichen Maße wurden sie freiwillig oder gezwungen durch die Verhältnisse in das Kriegsdienstheer der Heimat eingereiht. Lebensmittelverteilung, Landwirtschaft und Kriegsfürsorge, das sind die Hauptgebiete der Kriegsarbeit der Schule. Ohne die Schule hätte wir keine Kriegsgärten, ohne Schule oft mangelhafte Bestellung unserer Äcker, Felder und Wiesen, ohne Schule Stockung in der Erntearbeit, ohne Schule ein Fehlen

\footnotetext{
${ }^{982}$ Siehe z. B.: Loewenberg, Kriegstagebuch einer Mädchenschule (1916), S. 72: „Wir fühlen uns stark, wenn wir erfahren, mit welcher Hingabe die deutschen Mädchen und Frauen für unser Wohl arbeiten.“

983 Allerdings beteiligten sich Zehntausende von Schulkinder an den Aktionen des Vereins „Jugenddank für Kriegsbeschädigte e.V."; siehe: Kapitel 3.2 und 7.2.2.

${ }^{984}$ Z. B. „Nationalstiftung für wurde zur Finanzierung einer Nationalspende für die Hinterbliebenen der im Kriege Gefallenen“, die Sammlung „Vaterlandsdank", die „Stiftung Heimatdank in Sachsen“, „Badischer Heimatdank“ und „Marinestiftung“; siehe: Friedeberg/Wronsky, Handbuch der Kriegsfürsorge im Deutschen Reich (1917)
} 
gründlicher Aufklärung, ohne Schule endlich große Lücken in der charitativen Kriegsarbeit und Kriegsfürsorge. “985

Die Einschätzung entsprach insgesamt der Realität und beschreibt die Leistungen der Lehrer in Stadt und Land richtig. Dass es auch Lehrkräfte gab, die weniger aufgrund ihrer patriotischen Einstellung als vielmehr ,gezwungen durch die Verhältnisse in das Kriegsdienstheer der Heimat eingereiht“" wurden, d. h. die Hilfsdienste durchaus unfreiwillig leisteten, trifft sicher zu. Die Lehrer waren allerdings zu stark von den Kommunen, den Kirchen und der staatlichen Schulaufsicht abhängig, um die Übernahme von Hilfsdiensten verweigern oder gar öffentlich Widerstand dagegen leisten zu können. Dass bis zum Kriegsende kein spürbares Nachlassen des entsprechenden Einsatzes der Lehrer festzustellen ist, kann auch mit der gegen Ende des 19. und zu Beginn des 20. Jahrhunderts hinsichtlich des Sozialprestiges und des Gehalts deutlich aufgewerteten Situation der Volksschullehrerschaft zusammenhängen. Hätten sie sich nicht ohne Zögern und Widerspruch in die „Heimatarmee“ eingereiht und hätten sie nicht die vielen zusätzlichen Dienste übernommen, wäre sicher der Verdacht der Opposition entstanden. Um das zu vermeiden und, so mögen sie befürchtet haben, möglicherweise negative Folgen für die gerade erst errungene soziale Stellung hinnehmen zu müssen, haben sie alles vermieden, was ihnen als oppositionelles Verhalten hätte angerechnet werden können.

Die große Mehrheit der Schüler hingegen legte bis zum Schluss anscheinend eine ungebrochene Einsatzbereitschaft an den Tag und glaubte noch zuversichtlich an den Sieg ${ }^{986}$, als die meisten Erwachsenen den Krieg längst verloren gegeben hatten und zu weiteren Opfern nicht mehr bereit waren. Dass jedoch auch die Bereitschaft der Kinder und der Jugendlichen in den letzten Kriegsjahren nachließ, hing in erster Linie mit der zunehmend sich verschlechternden Versorgungslage zusammen. Viele Schüler, und zwar vor allem in den Städten, waren unterernährt ${ }^{987}$ und viel zu erschöpft, um zusätzlich anstrengende Arbeitsleistungen erbringen zu können. Häufig fehlte es den Kindern auch einfach an Zeit. Sie „mußten (oft) stundenlang nach den rationierten Lebensmitteln anstehen, wegen der Berufstätigkeit der Mütter jüngere Geschwister beaufsichtigen, Hamster- und Bettelfahrten in die Umgebung machen oder sie blieben zuhause, weil sie zu erschöpft waren oder keine brauchbaren Schuhe und ausreichen-

\footnotetext{
${ }^{985}$ Führen, Lehrer im Krieg (1936) 1936, S. 548.

${ }^{986}$ Es gab natürlich auch Schüler, die völlig desillusioniert waren, wie der Tagebucheintrag am 1. März1918 von Elfriede Kuhr zeigt: „Wir dürfen auf den Schwindel nicht mehr reinfallen, den uns die Alten vorgezaubert haben. Wir waren ja noch Kinder, Schüler, und alle in der Schule, der Direktor und die Lehrer voran, haben hurra geschrieen.“ (Mihaly, ... da gibt's ein Wiedersehn! [1986], S. 314).

987 Seit Mitte des Jahres 1916 nahmen die Warnungen wegen des Gesundheitszustandes der Schulkinder ständig zu. Die Behörden befürchteten deshalb, dass bei den Vätern an der Front durch die Sorge um die Gesundheit ihrer Kinder „Widerstandskraft, Leistungsfähigkeit und Kampfkraft“ nachlassen könnten (Erlass verschiedener preußischer Ministerien; zitiert nach: Saul, Jugend im Schatten des Krieges [1983], S. 115).
} 
de Kleidung mehr hatten“" ${ }^{988}$. Deshalb wurde in zunehmendem Maße von der offiziellen Propaganda in den Aufrufen auch nicht die patriotische Ehrenpflicht gegenüber dem Vaterlande betont,

sondern ,immer stärker an das wohlverstandene Eigeninteresse appelliert“`989 . Viele Tätigkeiten wurden deshalb oft durch kleinere Geldbeträge oder Naturalien vergütet. Dass die Schüler dadurch zur Versorgung der Familie mit beitragen konnten, war sicher für viele ein weiterer Anreiz, zusätzliche Tätigkeiten zu übernehmen.

${ }^{988}$ Demm, Ostpolitik und Propaganda im Ersten Weltkrieg (2002), S. 89.

989 Saul, Jugend im Schatten des Krieges (1983), S. 100. 


\section{Patriotische Feste und Feiern}

Da Feiern und Feste das Denken und die Vorstellungen einer Epoche widerspiegeln und Rückschlüsse auf die herrschenden Mentalitäten zulassen, sollen in diesem Kapitel Inhalte und der Verlauf verschiedener Schulfeiern sowie Reaktionen der Betroffenen analysiert werden.

Im Deutschen Kaiserreich gab es eine Vielzahl von Festen und Gedenkfeiern, sodass zeitgenössische Kritiker von einer „Festmanie und von einer [...] Häufung festlicher Veranstaltun-

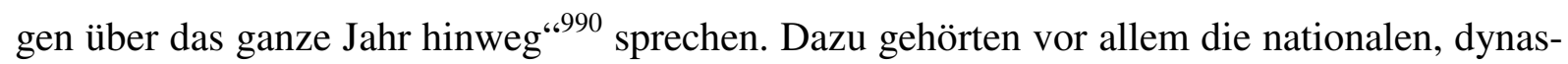
tischen, militärischen und kirchlichen Feste. ${ }^{991}$ Neben der freien Zeit, die viele Menschen im industriellen Zeitalter durch eine schrittweise Verkürzung der Arbeitszeit hatten, ist nach Schneider die Zunahme auch darauf zurückzuführen, dass es angesichts der großen innenpolitischen Probleme einen besonderen Integrationsbedarf des neu gegründeten Deutschen Reiches gab. Auch wenn die Euphorie über die Reichsgründung insgesamt sehr groß war, stand doch ein erheblicher Teil der Bevölkerung dem neuen Bundesstaat reserviert gegenüber. Eine gute Möglichkeit, auf die Gesellschaft einzuwirken, sahen die Eliten in der wirkungsvollen Inszenierung politischer Feste; sie glaubten, dadurch das Selbstbewusstsein der Bürger stärken und sie für die Monarchie gewinnen zu können. Dieses ist allerdings nur bedingt gelungen. Denn obwohl beispielsweise die 'Sedanfeier' in bürgerlichen Kreisen populär war, standen die Sozialdemokratie und Teile der katholischen Kirche dem Fest sehr kritisch gegenüber. Eine weitere wichtige Aufgabe der Feste war es, die Loyalitätsbindung des Bürgertums immer wieder dadurch zu stärken, dass die loyalen Bürger während des entsprechenden Festakts im Kaiserhoch und im Hoch auf den jeweiligen Landesherrn alljährlich ihrem Oberhaupt huldigten und damit ihre Gefolgschaftstreue ständig erneuerten.

Die Feste waren während der Regierungszeit Wilhelms II. stärker als in den Jahren nach der Reichsgründung geprägt durch einen Patriotismus, der bestimmt war durch die Loyalität zum Herrscherhaus und die besondere Betonung des Militärs. Als Beispiel sei die Inszenierung der nationalen Erinnerungsfeiern an die Freiheitskriege ein Jahr vor dem Ausbruch des Ersten Weltkriegs genannt. ${ }^{992}$

\footnotetext{
${ }^{990}$ Schneider, Über politische Feste der Bürger (2000), S. 92.

${ }^{991}$ Gerhard Schneider hat in einer typologischen Übersicht die wichtigsten Feste zusammengestellt; siehe: Schneider, Politische Feste der Arbeiter (1995), S. 26.

${ }_{992}$ Siehe: Siemann, „Krieg und Frieden in historischen Gedenkfeiern des Jahres 1913“; in: Düding, Öffentliche Festkultur (1988), S. 298-320.
} 
Von Anfang an waren auch die Feste an Schulen ein wichtiger Bestandteil der nationalen Festkultur. Zwar wurden bereits vor 1871 vielfältige patriotische Schulfeiern in Preußen und den anderen deutschen Ländern ${ }^{993}$ begangen, eine herausragende Bedeutung allerdings erlangten nach der Reichsgründung erst der „Sedantag“ und der Geburtstag des Kaisers ${ }^{994}$. Die Schulen waren zunächst nicht verpflichtet, sich an den offiziellen Feierlichkeiten zu beteiligen, viele taten es aber oder führten an den Feiertagen patriotische Schulfeiern durch. Wenige Jahre nach dem Regierungsantritt Wilhelms II. war es zur Regel geworden, dass die Schulen die nationalen Feiertage durch eigene Feiern festlich begingen. In Preußen wurden die Schulen zur Durchführung der Schulfeiern sogar verpflichtet, wie z. B. aus einer Verfügung der Königlichen Regierungen zu Posen und Bromberg vom 10. Januar 1893 hervorgeht: „Die Kinder sind zur Teilnahme an der Feier des Geburtstages Sr. Majestät und des Sedanfestes ebenso wie sonst zum Besuche der Schule verpflichtet, und unentschuldigtes Fernbleiben ist wie jedes andere Schulversäumnis zu bestrafen. “995 Die Schulfeiern wurden als ein gutes Instrument gesehen wurden, bei der Jugend die Reichs- und Herrschertreue zu stärken, sie gegen die Sozialdemokratie zu immunisieren und sie emotional an das Herrscherhaus zu binden. Wie vor allem der Geschichtsunterricht sollten auch besonders die nationalen Schulfeiern die Vaterlandsliebe der Schüler dadurch vertiefen und pflegen, dass sie „durch Vorführung geeigneter Beispiele jene Hingebung und Opferwilligkeit erzeugt, welche die Grundlage wahrer Vaterlandsliebe ist ${ }^{\star 996}$. Um die entsprechende Wirkung zu erzielen, wurden von den Schulbehörden „Amtliche Anweisungen zur Gestaltung von nationalen Schulfeiern“997 veröffentlicht. $\mathrm{Ob}$ die nationalen Schulfeste und die Beteiligung der Schulen an den nationalen Festen diesem Anspruch genügen konnten und inwieweit es gelang ${ }^{998}$, die Schüler auf den Kampf an der militärischen Front oder der „Heimatfront“ einzustimmen und vorzubereiten, soll im Folgenden untersucht werden. Da Feiern und Feste das Denken und die Vorstellungen einer Epoche widerspiegeln und Rückschlüsse auf die herrschenden Mentalitäten zulassen, sollen neben Inhalten und Abläufen einer Reihe von Schulfeiern auch die Reaktionen der Betroffenen analysiert werden. In erster Linie sollen anhand konkreter Beispiele die Schulfeiern zu den nationalen Feiertagen ,Sedantag' (2. September) und ,Kaisergeburtstag' (27. Januar) betrachtet

\footnotetext{
${ }^{993}$ So wurde in den meisten Ländern der Geburtstag des Landesherrn gefeiert.

${ }^{994}$ Der Geburtstag wurde, außer in Bayern, in allen Ländern des Deutschen Reiches gefeiert.

995 Zitiert nach: Schroeder, Funktion und Gestalt des patriotischen Schulfestspiels in der Wilhelminischen Kaiserzeit (1990), S. 31.

${ }^{996}$ Auszug aus Max Hübners „Methodik des Geschichtsunterrichts in preußischen Volksschulen“; zitiert nach: Schroeder, Funktion und Gestalt des patriotischen Schulfestspiels in der Wilhelminischen Kaiserzeit (1990), S. 6.

997 Beispielhaft sei auf ein Rundschreiben des Regierungsbezirks Lüneburg vom 22. Januar 1888 verwiesen; zitiert nach: Lemmermann, Kriegserziehung im Kaiserreich (1984), S. 745-747.

998 Schroeder, Funktion und Gestalt des patriotischen Schulfestspiels in der Wilhelminischen Kaiserzeit (1990).
} 
werden. Außerdem werden die Hohenzollernfeier (21. Oktober 1915), die Reformationsfeier (30. Oktober 1917) sowie der 70. Geburtstag Hindenburgs (2. Oktober 1917) einbezogen, nicht aber Bismarcks 100. Geburtstag am 1. April 1915, da er in den Schulen eine eher untergeordnete Rolle spielte. ${ }^{999}$ Dynastische Feiern in den einzelnen Ländern allerdings werden weitgehend ausgeklammert. Thematisiert werden hingegen die patriotischen Veranstaltungen aus Anlass militärischer Siege und die Trauerfeiern für gefallene Lehrer und Schüler.

\subsection{Sedantag}

Nachdem sich die Sedanfeiern seit 1871 als örtliche Festlichkeit in Städten und Orten allmählich durchsetzten ${ }^{1000}$, gestattete bereits im August des Jahres 1873 die königlich-preußische Regierung den Schulen die Teilnahme an den Feiern und forderte sie auf, die Feierlichkeiten zu unterstützen. In einer Anordnung vom 13. August bestimmte sie ferner, „daß überall, wo von anderer Seite am 2. September als dem Jahrestage der Schlacht von Sedan eine patriotische Erinnerungsfeier veranstaltet werde, die Schulen in angemessener Weise daran zu beteiligen seien“ “ ${ }^{1001}$. Es wurde angeordnet, dass für diesen Tag der Unterricht ausfallen solle.

In der Regierungszeit Kaiser Wilhelms II. wandelte sich der Sedantag von einem nationalen Volksfest zu einer Militärfeier mit großen Manövern und farbenprächtigen Paraden. Wie aus Verfügungen der Kgl. Regierungen zu Posen und Blomberg aus dem Jahr $1893^{1002}$ hervorgeht, waren die Schulen in dieser Zeit zur Durchführung einer Sedanfeier ebenso verpflichtet wie die Schüler und Schülerinnen zur Teilnahme an den entsprechenden Schulveranstaltun-

\footnotetext{
999 „Trotz der mitunter beeindruckenden Mobilisierung des städtischen Bürgertums blieben die Feiern letztlich doch auf einen überschaubaren Kreis ,bismarcktreuer’ Anhänger beschränkt.“ (von Seggern, „Bismarck Heil!" Kanzlerkult in der Festkultur des Kaiserreiches, http://www.ruhr-uni-bochum.de/iga/isb/isbhauptframe/forschung/Tagung\%20Kaiserreich/von\%20seggern.pdf (11.07.2008), S. 21). Allerdings gab es eine Reihe von Schulen, die Bismarckfeiern durchführten, wie z. B. die Chronik des Schillergymnasiums in Köln ausweist: „Zu Jubiläen wurden außerordentliche Feiern abgehalten, etwa zu [...] Bismarcks 100.Geburtstag.“ (Schmitz, Die Geschichte des Schiller-Gymnasiums Köln 1899 - 2006, http://www.schillergymnasiumkoeln.de/schule/geschichte/grafik/geschichte-1.pdf (11.03.2009), S. 14). Dass der Ablauf der Bismarckfeiern denen der anderen nationalen Feiern entsprach, zeigt eine Reihe von überlieferten Festprogrammen, wie z. B. das einer Mittelschule in Coburg (siehe Deutsche Schulpraxis, 1915, S. 91f.). Außerdem waren die Schulen auch an den Feiern der Kommunen beteiligt, wie z. B. in Göttingen, wo ein Lehrer der Realschule die Festrede hielt (Saathoff, Albrecht, Göttinger Kriegsgedenkbuch. 1914-1918 (1935), S. 186). Auch in den Zeitschriften der Lehrerverbände wurde in Aufsätzen zum Jubiläum die Schulen dazu aufgerufen, des ehemaligen Reichskanzlers zu gedenken: „Richten wir vor der Jugend, dem Volke, gerade in dieser harten Zeit, die Heldengestalt des Mannes auf: er ist ein Talisman, eine Bürgschaft des Erfolgs." (Grünwald, Bismarck, Deutsches Philologen-Blatt 1915, 185, S.189). Auch in der Zeitung des Deutschen Lehrerinnenvereins erschien ein Beitrag zum Bismarckjubiläum (Treuge, Aus Bismarcks Kindheit und Schülerjahren, Die Lehrerin: Organ des Allgemeinen Deutschen Lehrerinnenverein 1914/15, 395f.).

${ }^{1000}$ Düding, Öffentliche Festkultur (1988), S. 281.

${ }^{1001}$ Amtsblatt der Königl. Reg. Koblenz 1871, S. 200; zitiert nach: Düding, Öffentliche Festkultur (1988), S. 282.

${ }^{1002}$ Auch für die anderen preußischen Regierungsbezirke liegen entsprechende Verfügungen vor.
} 
gen. ${ }^{1003}$ Mit dem Beginn des Ersten Weltkriegs wurde dann weitgehend auf die offiziellen Feiern mit militärischem Gepräge verzichtet. ${ }^{1004}$ Allerdings nutzte eine Reihe von Kommunen den Feiertag, um ihre Kriegswahrzeichen einzuweihen. ${ }^{1005}$ Wie aus einem Erlass des preußischen Schulministers vom 26. August $1915^{1006}$ hervorgeht, sollte in den preußischen Schulen auch nach Kriegsbeginn eine Schulfeier durchgeführt werden und danach unterrichtsfrei sein. Inwiefern die „Feier den gegenwärtigen Zeitumständen“ angepasst werden sollte, blieb den Schulleitern überlassen. In den anderen Ländern des Deutschen Reiches wurde ähnlich verfahren. Im Folgenden soll der Frage nachgegangen werden, in welchem Umfang der Sedantag an den Schulen festlich begangen wurde und inwieweit der Krieg tatsächlich den Ablauf des nationalen Erinnerungsfestes in den Schulen veränderte. Zahlreiche Quellen bezeugen, dass die Schulen in den Jahren 1914 und 1915 in feierlichem Rahmen des Sieges bei Sedan gedachten. ${ }^{1007}$ Während einige Schulen patriotische Schulfeiern wie in den Vorkriegsjahren veranstalteten - mit Gesang, Vorträgen und der Aufführung eines vaterländischen Festspiels oder im Rahmen von Festgottesdiensten ${ }^{1008}$-, passten andere ihre Feiern den gegenwärtigen Umständen dadurch an, dass sie an aktuelle Ereignisse des Ersten Weltkriegs anknüpften. So wurde der Gedenktag 1914 im Gymnasium zu Berlin-Steglitz genutzt, „um der in der Aula versammelten Schülerschaft durch kurze Vorträge Kenntnis zu geben erstens von Hindenburgs glänzendem Cannä-Sieg bei Tannenberg und zweitens dem Aufmarsch der deutschen Heere an der Westfront und ihrem siegreichen Vorstürmen in Feindesland.“"1009 Vor allem im ersten Kriegsjahr setzten die Festredner vielerorts den aktuellen Krieg mit dem

${ }^{1003}$ Siehe: Schroeder, Funktion und Gestalt des patriotischen Schulfestspiels in der Wilhelminischen Kaiserzeit (1990), S. 33. Allerdings sollte ,,die Feier den gegenwärtigen Zeitumständen“ des Krieges angepasst werden, wie z. B. in zwei Verfügungen der Provinzialregierung in Schleswig angeordnet worden war (Jg. 7, 1915, S. 125; Jg. 8, 1916, S. 124); siehe: Pust, ,Vaterländische Erziehung" für „Höhere Mädchen" (2004), S. 343.

${ }^{1004}$ Siehe: Düding, Öffentliche Festkultur (1988), S. 286.

1005 ,Isdern Kerl' in Emden (1915), ,Wappenschild' in Hameln (1915), ,Eiserner Schützenvogel' in Harburg (1915), ,Eiserner Greif’ in Rostock (1915), u. a. Dass die Schulen an den Einweihungsfeiern beteiligt waren, kann angenommen werden (siehe: Kapitel 9.3). In Hameln z. B. nahmen ,die Schülerinnen und Schüler sämtlicher hiesigen Schule“ an der „Vaterländischen Kundgebung am Sedantag“ teil (Vaterländische Kundgebung am Sedantag 1915, Hamelner Tageblatt). Zwar fand die Einweihung des, Eisernen Kreuzes’ in Neustadt erst am 5. 9. 1915 statt, der „Feier ging jedoch voran ein Sedangottesdienst in der Stadtkirche“, an dem auch die Schuljugend teilnahm. (Ungelenk, Coburg im Weltkrieg 1914-18 (1922), S. 394.

${ }^{1006}$ StAH, HR 16, Nr.496. Ein Jahr später, am 24. August 1916, wurde ein Erlass mit gleichem Wortlaut veröffentlicht.

1007 Als Beispiele seien genannt: Schneidemühl (Mihaly, ... da gibt's ein Wiedersehn! [1986], S. 53f. und S. 188f.), Oberrealschule in Bad Oldesloe (Prof. Dr. Brenner, Die Oberrealschule zu Bad Oldesloe während des Weltkrieges, [1914 bis 1918], http://de.tms-od.de/ (14.02.2008), Realschule Nortorf (Die Geschichte der Städtischen Realschule Nortorf, http://www.realschule-nortorf.lernnetz.de/ geschi_3.php?group=4 (17.06.2008).

Halver (Dresbach, Kriegs-Chronik der Gemeinde Halver von 1914 bis 1919 [1932], S. 8),

Gymnasium in Berlin-Steglitz (Lehmann, Weltkriegs-Erinnerungen aus dem Kreise des Gymnasiums zu BerlinSteglitz [1925], S. 12, Kaiser-Wilhelms-Gymnasium in Hannover (Mücke, Königliches Kaiser Wilhelms Gymnasium in Hannover (1915), S. 12-16).

${ }^{1008}$ Z. B. in der Oberrealschule in Bad Oldesloe (Prof. Dr. Brenner, Die Oberrealschule zu Bad Oldesloe während des Weltkrieges, [1914 bis 1918], http://de.tms-od.de/ (14.02.2008),

${ }^{1009}$ Lehmann, Weltkriegs-Erinnerungen aus dem Kreise des Gymnasiums zu Berlin-Steglitz (1925), S. 12. 
Krieg von 1870/71 gleich und betonten die Hoffnung auf einen erneuten schnellen Sieg. Teilweise wurde sogar hervorgehoben, dass es ab nächstem Jahr keine Sedanfeier mehr geben würde, da es dann einen größeren Sieg zu feiern gäbe.

Immer wieder wurden auch die für die Erziehung der Schuljugend positiven Folgen des Krieges von den Lehrern und Schulleitern in ihren Reden hervorgehoben. So waren z. B. nach Meinung des Direktors des Gymnasiums in Plauen (Kgr. Sachsen) „besonders die Gottesfurcht und die Menschenliebe in ihren verschiedenartigen Betätigungen wieder erweckt oder gesteigert (worden) “1010. Kriegsspiele im Gelände, wie sie in der Vorkriegszeit am Sedantag häufig von den Schulen durchgeführt wurden ${ }^{1011}$, gab es ab 1914 nicht mehr.

Mit den verlustreichen Schlachten bei Verdun und an der Somme in der ersten Hälfte des Jahres 1916 änderte sich auch der Charakter der Sedanfeier in den Schulen. Man verzichtete in der Regel auf ein Programm „,mit leerem, lauten Festgepränge“1012, wie es ein Lehrer damals formulierte, und beschränkte sich weitgehend auf eine schlichte gemeinsame Gedenkstunde mit einer Ansprache des Schulleiters. Da es kaum noch Siege zu bejubeln gab, die Hoffnung auf einen schnellen Sieg geschwunden war und es Hunderttausende von Opfern zu beklagen gab, waren die Reden von Durchhalteparolen und Aufrufen zu verstärktem Einsatz an der „Heimatfront“ bestimmt. Die „Sedanrede im Kriegsjahr 1916“ eines Lehrers aus Ölsnitz (Kgr. Sachsen), die damals sicher ähnlich in vielen anderen deutschen Schulen gehalten worden ist, zeigt die veränderte Bedeutung der Feiern. So konfrontierte der Lehrer am Anfang seiner Ansprache die Schüler mit den Schrecken des Krieges (,Und diese, deine Liebe, dein Vaterland, ist bedroht von Not und Tod“), um sie dann zu fragen: „Was können schwache Kinder helfen im schrecklichen Männerkriege?“"Es folgten viele Appelle an die Schüler „als das Geschlecht der Helden, das hinter der Front mit Arbeit und Entsagung für das deutsche Vaterland kämpft“. Am Ende schwor er sie auf den Kampf an der „Heimatfront“ ein: „Arbeiten, Entsagen, Ertragen! Das sei unsere Sedanlösung 1916“.

Neben den oben erwähnten Quellen wurden etwa 250 weitere Orts- und Schulchroniken untersucht. Dass diese für die Zeit des Ersten Weltkriegs relativ wenige Hinweise auf die Durchführung von schulischen Sedanfeiern enthalten, lässt durchaus den Schluss zu, dass die patriotischen Feiern für die Schulen im Krieg weniger bedeutsam waren als in der Vorkriegszeit. Sie zeigen allerdings auch, dass der Sedantag an vielen Schulen bis zum Kriegsende begangen worden ist. Zu diesem Ergebnis kommt beispielsweise auch Pust in seiner Untersuchung über

\footnotetext{
1010 Schmidt, Der Sedantag am Plauener Gymnasium, http://www.schulgeschichte.de/der-sedantag-am-plauenergymnasium.html (6.12.2010),

${ }^{1011}$ Siehe z. B. Schmidt, Der Sedantag am Plauener Gymnasium, http://www.schulgeschichte.de/der-sedantagam-plauener-gymnasium.html (6.12.2010).

${ }^{1012}$ Zanther, Eine Sedanrede im Kriegsjahr 1916, Deutsche Schulpraxis 1916, S. 265.
} 
die höheren Mädchenschulen in Schleswig-Holstein. ${ }^{1013}$ Er weist für alle Kriegsjahre schulische Sedanfeiern nach und kommt im Vergleich mit den Feiern der Vorkriegszeit zu dem Ergebnis, dass zu den traditionellen Inhalten im Krieg aktuelle Kriegsbezüge hinzugekommen seien. ${ }^{1014}$

Im Vergleich zur Vorkriegszeit waren die Sedanfeiern im Krieg allerdings weniger bedeutsam. ${ }^{1015}$ Wie viele Beispiele zeigen, wurde des Sieges vom 2. September 1870 zwar bis zur Kapitulation in der Regel gedacht ${ }^{1016}$, angesichts der vielen aktuellen Siegesfeiern zu Beginn des Krieges und der sich ab 1916 ständig verschlechternden militärischen und wirtschaftlichen Situation war das offizielle Gedenken an die historische Schlacht, zu dem man verpflichtet war, für viele Schulen aber nur noch von untergeordneter Bedeutung. Hinzu kam, dass der Sedantag nach dem Regierungsantritt Wilhelms II. aufgrund des überzogenen Personenkults, der in den öffentlichen und schulischen Feiern mit der Person des Kaisers betrieben wurde, in den Schatten des Kaisergeburtstages geraten war. ${ }^{1017}$ Insofern unterschied sich der Umgang der Schulen mit dem nationalen Gedenktag kaum von dem der Verbände und der Kommunen. $^{1018}$

\subsection{Kaisergeburtstag}

Der 27. Januar, der Geburtstag Kaiser Wilhelms II., war neben dem Sedantag der zweite deutsche Nationalfeiertag. Da „Herrschergeburtstage als dynastische Huldigungsfeiern“ in den verschiedenen Bundesstaaten bereits vor der Gründung des Deutschen Kaiserreichs üblich waren, fand auch der Feiertag zum Geburtstag des Kaisers nach 1871 fast zwangsläufig in das Festzeremoniell des neuen Reiches Eingang. ${ }^{1019}$ Nach dem Regierungsantritt Wilhelms II. im Jahre 1888 „entwickelten sich die Feiern (schnell) zu einem alljährlichen Großereignis“1020. Sie waren das zentrale gesellschaftliche Ereignis und der „Gradmesser für die patriotische Einstellung eines jeden Ortes und seiner Vereine und Schulen“'1021. Besonderen Wert legte

\footnotetext{
1013 Pust, „Vaterländische Erziehung" für „Höhere Mädchen" (2004), S. 345.

1014 Pust, „Vaterländische Erziehung" für „Höhere Mädchen" (2004), S. 345.

1015 Allerdings hatte die Bedeutung des Sedantag bereits nach der 25. Jahrfeier abgenommen, und zwar auch deshalb, weil die Zahl der Teilnehmer am Krieg 1870/71 stark zurückgegangen war.

${ }^{1016}$ Es gab aber auch Schulen, die ab 1915 auf Sedanfeiern verzichteten, wie z. B. die Leibnizschule in Hannover. In der Begründung hieß es: „Eine Feier sei in Zeiten des Krieges nicht angemessen.“ (Günnewig, Schulische Festkultur am Beispiel der Wilhelm-Raabe-Schule, die Höhere Töchterschule I in Hannover in Landeshauptstadt Hannover (Hrsg.), Hannoversche Geschichtsblätter (2003/2004), S. 98.

${ }^{1017}$ Schroeder, Funktion und Gestalt des patriotischen Schulfestspiels in der Wilhelminischen Kaiserzeit (1990), S.33.

${ }^{1018}$ Am 27. 08. 1919 schaffte das Innenministerium der Weimarer Republik die Sedanfeiern ab, da diese nicht mehr zeitgemäß waren.

${ }^{1019}$ Düding, Öffentliche Festkultur (1988), S. 278.

${ }^{1020}$ Schellack, Sedan- und Kaisergeburtstagsfeste (1988), S. 289.

${ }^{1021}$ Schroeder, Funktion und Gestalt des patriotischen Schulfestspiels in der Wilhelminischen Kaiserzeit (1990), S. 31 .
} 
man auf die aktive Teilnahme der Schulen. So war bereits bald nach der Regierungsübernahme durch Wilhelm II. die Durchführung einer patriotischen Schulfeier anlässlich des kaiserlichen Geburtstages die Regel. ${ }^{1022}$

Um sicherzustellen, dass die Schulfeiern die gewünschte dauerhafte Wirkung erzielten, nämlich „mit der Verehrung für den ,Heldenkaiser’ zugleich die erwünschte patriotische Gesinnung in den Köpfen und Herzen der heranwachsenden Generation“‘1023, veröffentlichten die einzelnen Regierungen entsprechende Vorschriften und Anleitungen zur Gestaltung von Schulfeiern. So wurde z. B. in einer Verfügung der Königlichen Regierungen zu Posen und Bromberg vom 10. Januar 1893 als pädagogisches Ziel der Feiern genannt: „Liebe für den Herrscher und das Vaterland in den Herzen der Jugendlichen zu erwecken und zu pflegen“"1024

Konsequenterweise war die Teilnahme an den Schulfeiern deshalb für die gesamte Schülerschaft verpflichtend: „Dieser erziehlichen Einwirkung darf ohne triftigen Grund kein Schulkind entzogen werden; die Kinder sind zur Teilnahme an der Feier des Geburtstages Sr. Majestät und des Sedanfestes ebenso wie zum Besuche der Schule verpflichtet und unentschuldigtes Fernbleiben ist wie jedes andere Schulversäumnis zu bestrafen. “1025

Entsprechend der pädagogischen Intention enthielten bereits die Fibeln der Schulanfänger und die Schulbücher für die älteren Schüler entsprechende Texte und Bilder zum Geburtstag des Kaisers. ${ }^{1026}$

Als Beispiel dafür, dass die Feiern in Friedenszeiten wie politisch gewünscht abliefen, sei aus einer Untersuchung Schneiders über ,politische Feste in Hannover' zitiert:

„An allen Schulen der Stadt wurde der Geburtstag (1872) des Kaisers am Vormittag mit einem , solemnen Schulactus' begangen. Patriotische Gesänge und Deklamationen der Schüler, dazu die obligatorische Festrede bildeten das Programm der Schulfeiern. Besonders fleißige Schüler wurden an diesem Tage mit Preisen - das waren meist erbauliche oder patriotische Bücher - ausgezeichnet.“1027

Da in den Schulen vieler anderer Kommunen die Feiern ähnlich abliefen, wird auf die Auswertung entsprechender Berichte, die in einer Vielzahl vorliegen, verzichtet.

\footnotetext{
${ }^{1022}$ Schroeder, Funktion und Gestalt des patriotischen Schulfestspiels in der Wilhelminischen Kaiserzeit (1990), S. 31 .

${ }^{1023}$ Schneider, Über politische Feste der Bürger in Hannover (1866-1918), (2000), S. 100.

${ }^{1024}$ Zitiert nach: Schroeder, Funktion und Gestalt des patriotischen Schulfestspiels in der Wilhelminischen Kaiserzeit (1990), S. 31.

${ }^{1025}$ Verfügung der Königlichen Regierung zu Posen und Bromberg vom 10. Januar 1893; zitiert nach: Schroeder, Funktion und Gestalt des patriotischen Schulfestspiels in der Wilhelminischen Kaiserzeit (1990), S.31.

${ }^{1026}$ Siehe: Wulf, Hurra, heut ist ein froher Tag, des Kaisers Wiegenfest, in: Löher/Wulf (Hrsg.), Furchtbar dräute der Erbfeind!

${ }^{1027}$ Schneider, Über politische Feste der Bürger, Bd. 72 (200), S. 98.
} 
Wie aber entwickelten sich die Schulfeiern zum Kaisergeburtstag in den Jahren 1915-18? Für die Feier am 27. Januar 1915 hatte der Kaiser persönlich angeordnet, die Feiern dem Ernste der Zeit anzupassen. In den Schulen allerdings sollten die Festakte in der gewohnten Form stattfinden. ${ }^{1028}$ Auch wenn eine Reihe von Kommunen den Feiertag nutzten, um ihre Kriegswahrzeichen mit aufwendigen patriotischen Zeremonien einzuweihen ${ }^{1029}$, so wurde der ,Wunsch' des Kaisers nach schlichten Feierlichkeiten weitgehend respektiert. ${ }^{1030}$ In einigen Stadtchroniken, z. B. im „Göttinger Kriegsgedenkbuch“ ist dazu vermerkt, dass des Kaisers Geburtstag ,die letzten vier Male im Krieg besonders festlich begangen (wurden) durch Militärgottesdienst, Schulfeiern und Abendgottesdienst der Gemeinden“. ${ }^{1031}$

Zunächst soll am Beispiel des städtischen Schiller-Gymnasiums zu Cöln-Ehrenfeld ${ }^{1032}$ hinsichtlich der für solche Feiern typischen Phänomene wie Inszenierungen, Reden, patriotische Gesänge, populäre Musikstücke ${ }^{1033}$, Symbole und Fahnen untersucht und dann mit einer entsprechenden Veranstaltung des Königlichen Realgymnasiums in Wiesbaden verglichen werden. Die beiden Schulen wurde als Beispiele ausgewählt, da die Quellen über den Ablauf ihrer Feiern detaillerte Informationen enthalten, während die Feiern des Kaisergeburtstages in den meisten deutschen Schulen lediglich recht allgemeine Hinweise vorliegen. Sie reichen allerdings aus, um gesicherte Aussagen zum Ablauf der Gedenkfeiern nicht nur in den höheren Schulen Preußens machen zu können, sondern auch über zu dem in Volks- und höheren Mädchenschulen als auch den Schulen in Süddeutschland.

${ }^{1028}$ Siehe: Allgemeines Schulblatt für die Provinz Schleswig-Holstein, Jg. 7, 1915, S. 13.

1029 ,Stadtwappen' in Stadthagen (1916), ,Eiserner Brunnen' in Wetzlar (1916), ,Eiserner Mann' in Cleve (1916) ,Eisernes Kreuz' in Stolzenau (1917) u.v.a. Die Einweihung des ,Junggermanen' in Münster hatte zwar bereits am 21. Oktober 1915 (Hohenzollernjubiläum) stattgefunden, am 27. Januar 1916 jedoch benagelten im Rahmen der ,Kinderwoche beim Junggermanen' 12.000 Kinder die Statue (Nübel, Mobilisierung der Heimatfront und Selbstbehauptung im Feindesland (2007), S. 141).

${ }^{1030}$ So ist in der Kriegschronik der Gemeide Halver 1915 dazu vermerkt: „Der Geburtstag Sr. Majestät des Kaisers ist auf Allerhöchsten Wunsch auf eine kirchliche Feier zu beschränken und im übrigen ernst und geräuschlos zu begehen." (Dresbach, Kriegs-Chronik der Gemeinde Halver von 1914 bis 1919 [1932], S. 19)

${ }^{1031}$ Saathoff, Albrecht, Göttinger Kriegsgedenkbuch. 1914-1918 (1935), S. 186.

1032 Siehe: Anhang, Seiten 19/20.

${ }^{1033}$ Wichtige Elemente der patriotischen Feiern waren neben vaterländischen Gedichten Volks- und Marschlieder, Choräle, Hymnen, Balladen, Instrumentalmärsche und andere populäre Musikstücke. Durch sie sollten die in der Heimat Zurückgebliebenen gestärkt und ideologisch beeinflusst werden, indem Vorurteile gefestigt und Feindbilder verschärft wurden. So fehlte beispielsweise das antifranzösische Lied „Die Wacht am Rhein“ damals in kaum einer nationalen Feier. Der Musikschriftsteller Arthur Seidl (1863-1928) verstand die funktionalisierte Musik sogar als „Musikalische Kriegsrüstung“. Er wollte den Organisatoren patriotischer Feiern zur ,geistigstofflichen" Aufrüstung verhelfen und veröffentlichte eine Aufstellung von ca. 670 Komponisten mit Werken, die die Menschen im Rahmen patriotischer Feiern im staatserhaltenden Interesse beeinflussen könnten (zitiert nach: Giesbrecht, Musikalische Kriegsrüstung, Populäre Musik im kulturwissenschaftlichen Diskurs, Beiträge zur Popularmusikforschung, S. 165). Auch wenn heute die meisten Stücke weitgehend unbekannt sind, so soll wegen ihrer damaligen ideologischen Wirkung doch eine Reihe von ihnen in dieser Arbeit genannt und analysiert werden. Entsprechende Hinweise zu Informationsquellen oder das Aufführen einiger Strophen sollen helfen, die damalige Wirkung nachvollziehen zu können. 
Auch wenn keine entsprechenden Hinweise vorliegen, kann davon ausgegangen werden, dass die Räumlichkeiten, in denen die Feiern stattfanden, entsprechend dem Anlass mit einem Kaiserbild und schwarz-weiß-roten Fähnchen ausgeschmückt waren und der Raum damit die Schüler auf die nationale Feierstunde einstimmte. Dass sicher auch einige Lehrer in der Uniform eines Reserveoffiziers anwesend waren, wie es bei solchen Anlässen häufig vorkam, wird der Feier ein militärisches Gepräge gegeben haben.

Nach dem einleitenden Orgelpräludium von Mendelsohn, vorgetragen von einem Schüler, sang die Schulgemeinde das damals weitverbreitete „Niederländische Dankgebet“ (1. Strophe: Wir treten zum Beten/ Vor Gott den Gerechten./ Er waltet und haltet/ Ein strenges Gericht./ Er läßt von den Schlechten/ Die Guten nicht knechten;/ Sein Name sei gelobt/ Er vergißt unser nicht./ Herr, laß uns nicht!“1034), ein sehr gefühlvolles Lied aus dem Jahre 1626, das an den Sieg der Niederländer 1597 im Freiheitskampf gegen die Spanier erinnerte. Dadurch sollten den Schülern Siegesgewissheit und das Gefühl vermittelt werden, dass Deutschland in dem Krieg, der ihm aufgezwungen worden sei, um seine Freiheit und damit für eine gerechte Sache kämpfe.

Nach der Deklamation von zwei pathetischen Kriegsgedichten („Gebet ans Volk“ von Richard Dehmel, 1. Strophe: "Dank dem Schicksal, Volk in Waffen/ Deutschland gegen alle Welt!/ Nicht um Beute zu erraffen,/ hat uns Gott zum Kampf geschaffen,/ rein zum Kampf im Ehrenfeld/, Heldenvolk.““(1035) und „Große Zeit““) folgte der gemeinsame Gesang des Kampfliedes der Soldaten „Drohn Feinde rings umher, und geht's um Deutschlands Ehr ““1036, das inhaltlich an das Niederländische Dankgebet anknüpfte und die Verteidigungsbereitschaft stärken sollte.

Es schloss sich der Vortrag von zwei patriotischen Gedichten („Hohenzollern“, „Germania“) und einem gemeinsamen Lied („Ich bin ein Preuße, kennt ihr meine Farben“‘1037, 1832) an.

${ }^{1034}$ Das Lied enthält umfasst insgesamt vier Strophe (vollständiger Text: siehe: Niederländisches Dankgebet, http://ingeb.org/spiritua/wirtretz.html).

${ }^{1035}$ Richard Dehmels (1863-1920) Kriegsgedicht (1914) ist voller Enthusiasmus für den Krieg; Es folgt eine zweite Strophe. Die Vorstellung von Deutschland als dem von Gott auserwählten „Heldenvolk“, das die Feinde angegriffen haben, sollen die Emotionen gegen die Kriegsgegner geweckt und die Siegeszuversicht gestärkt werden.

${ }^{1036}$ In einer Feier der katholischen Schule in Bergneustadt bildete „,das kernige, zeitgemäße Lied“ zusammen mit dem „stürmischen“ Kaiserhoch. sogar den Höhepunkt der Feier (Kamp, Chronik der katholischen Schule Bergneustadt, http://www.gm.nw.schule.de, S. 20); /kgsb/links/Chronik\%20der\%20katholischen\% 20Schule\%20 Bergneustadt.pdf) Text: „Drohn Feinde ringsumher/ und geht's um Deutschlands Ehr/ und geht's um Kopf und Kragen/ wir wollen nicht verzagen/zum Kampf für's deutsche Vaterland/für's Vaterland“.

${ }^{1037}$ Das bekannte preußische Kampflied, dessen Text aus dem Jahre 1830 stammte (Strophe 7 aus dem Jahr 1851), wurde in den preußischen Schulen während des Ersten Weltkriegs sehr oft gesungen.1. „Ich bin ein Preuße, kennt ihr meine Farben?/ Die Fahne schwebt mir schwarz und weiß voran;/daß für die Freiheit unsre Väter starben,das deuten, merkt es, meine Farben an./Wie werd ich bang verzagen,wie jene will ich's wagen/l: sei's trüber Tag, sei's heitrer Sonnenschein, ich bin ein Preuße, will ein Preuße sein." Es folgen sechs weitere Strophen (siehe: http://ingeb.org/Lieder/preussen.html). 
Vom Heldentum der Soldaten im Ersten Weltkrieg und der Notwendigkeit, für das Vaterland Opfer zu bringen, handelten die Gedichte „U59“ und „S. M. Kreuzer Cöln“, die zwei Schüler dann deklamierten. Auch das nächste von allen gesungene Lied (,Stolz weht die Flagge Schwarz-Weiß-Rot“(1038) war ein Appell an die Vaterlandsliebe. Jetzt erst wurde des eigentlichen Anlasses der Feier, des Kaisergeburtstages, gedacht, und zwar durch den Vortrag von zwei Huldigungsgedichten. Die Festrede des Oberlehrers Dr. Wrede ist zwar nicht überliefert, sie dürfte sich aber nicht von anderen obligatorischen patriotischen Ansprachen unterschieden haben. Wie viele solcher Feiern endete die Veranstaltung mit der pathetischen Kaiserhymne „Heil dir im Siegerkranz“1039 (1790). Der Ablauf der Feier entsprach in jeder Hinsicht den offiziellen administrativen Gestaltungsanweisungen: Dem gemeinsamen Singen von geistlichen und nationalen Liedern schlossen sich vaterländische Deklamationen und eine dem Anlass angemessene patriotische Ansprache an. ${ }^{1040}$ Die Frage, ob und inwieweit es durch die Feier gelungen ist, den Schülern die Vorstellung eines vom Feind aufgezwungenen Krieges, das Bild eines friedensliebenden Kaisers und den Glauben an einen siegreichen Friedensschluss zu vermitteln, kann anhand der vorliegenden Quellen nicht definitiv beantwortet werden, allerdings dürfte das nationale Pathos der Gemeinschaftsveranstaltung nicht ohne die erzieherisch beabsichtigte - Wirkung geblieben sein.

Der Ablauf der Feier des Königlichen Gymnasiums in Wiesbaden ${ }^{1041}$ entsprach weitgehend der beschriebenen Veranstaltung. Chorgesänge („Hoch tut euch auf ${ }^{\star 1042}$, „Fridericus Rex“1043,

\footnotetext{
${ }^{1038}$ Auch das „Deutsche Flaggenlied“ (Text: 1886, Musik: 1883) war sehr populär und gehörte zum Programm vieler Feiern; Text der 1. Strophe: „Stolz weht die Flagge Schwarz-Weiß-Rot/ von uns'rer Schiffe Mast/ Dem Feinde Tod, der sie bedroht/ Der diese Farben haßt/ Sie flattert an der Heimat Strand/ im Winde hin und her/ und weit vom deutschen Vaterland/auf sturmbewegten Meer/ Ihr woll'n wir treu ergeben sein/getreu bis in den Tod/Ihr woll’n wir unser Leben weih’n/ der Flagge Schwarz-Weiß-Rot/ Hurra!“ Zu dem Lied gehören zehn weitere Strophen (Siehe: http://www.volksliederarchiv.de/text2796.html). Durch die eingängige Melodie sollte der kriegerische Text sich besonders effektiv in den Köpfen der Schüler verankern.

${ }^{1039}$ Die Kaiserhymne „Heil dir im Siegerkranz“, die auf Ernst Moritz Arndts (1797-1884) Gedicht „Was ist des Deutschen Vaterland" (1813) zurückgeht und deren Melodie der der englischen Nationalhymne entsprach, war von 1871 bis 1918 ein populäres Repräsentationslied des Deutschen Kaiserreiches - quasi die Nationalhymne -, welches zu zahlreichen patriotischen Gelegenheiten gespielt und gesungen wurde. Insbesondere die süddeutschen Staaten standen dem Lied allerdings skeptisch gegenüber. Text der 1. Strophe: „Heil dir im Siegerkranz,/ Herrscher des Vaterlands!/ Heil, Kaiser, dir!/ I: Fühl in des Thrones Glanz / Die hohe Wonne ganz, Liebling des Volks zu sein!/Heil Kaiser, dir!“ Es folgen vier weitere Strophen.I

${ }^{1040}$ Siehe: Düding, Öffentliche Festkultur (1988), S. 286ff.

${ }^{1041}$ Siehe: Anhang, Seite 21.

1042 Der Choral „Hoch tut euch auf“ (24. Psalm), den Willibald Gluck komponiert hat, enthielt keine direkten Bezüge auf den Krieg. Vielleicht wurde er, wie in anderen klassischen Stücken von Bach, Beethoven u.a., in das Programm von Schulfeiern aufgenommen, um den Zuhörern Mut zu machen und sie von der Bedrohung durch den Krieg abzulenken. Auf Angehörige gefallener Soldaten sollten kirchliche Musikstücke tröstend wirken. Text und Partitur: Siehe: http://www.tonger.de/pdf/S3209-1.pdf.

1043 Der Text des damals sehr populären Marschliedes „Fridericus Rex“ (1832 zuerst in seinem Roman „Cabarus" erschienen), das von Carl Loewe vertont wurde, stammt von Willibald Alexis (1798-1871). In Anlehnung an diese Vertonung komponierte in den sechziger Jahren des 19. Jahrhunderts ein preußischer Militärmusiker den „Fridericus-Rex-Grenadiermarsch“. Durch die Parallelen zum Siebenjährigen Krieg (1756-63) wurde die Siegeszuversicht der Menschen im Ersten Weltkrieg gestärkt; Text der ersten drei Strophen:
} 
„Sehnsucht nach dem Rhein“) wechselten mit Gedichtvorträgen und einem Musikstück sowie der Festrede eines Lehrers. Sieht man davon ab, dass die Redner in der Regel auch auf die Kriegsereignisse eingingen, so unterschieden sich Abläufe und Inhalte der beiden beschriebenen nationalen Schulfeiern aus dem Jahre 1916 nicht von denen der Vorkriegszeit. Ob sie sich allerdings mit fortschreitender Kriegsdauer und der Verschlechterung der militärischen und wirtschaftlichen Situation veränderten und welche Bedeutung die Feiern für die Volks- und der Realschulen hatten, soll anhand einer Reihe von Schulen aus verschiedenen Schulformen und Regionen sowie bestimmter Kategorien im nächsten Abschnitt untersucht werden.

\title{
5.2.1 Vorbereitung und Ablauf
}

Insgesamt wurden die Schulfeiern in den Volks- und den Mittelschulen weit weniger aufwendig begangen, denn es fehlte in der Regel an größeren Versammlungsräumen und außerdem konnte man meist nicht auf ein Schulorchester oder eigene Chöre zurückgreifen.

Das im Folgenden genannte Festprogramm der Volksschule in Stommelerbusch (Rheinprovinz) aus dem Jahre 1915 allerdings unterschied sich nicht wesentlich von den pompösen Feiern der Gymnasien ${ }^{1044}$ :
„1. Gebet
2. Einleitende Ansprache des Lehrers
3. Lied. Wer will unter die Soldaten ${ }^{1045}$
4. Gedicht: Der Kaiser ist ein lieber Mann ${ }^{1046}$

\begin{abstract}
„Fridericus Rex Grenadiermarsch“ („,Fridericus Rex, unser König und Herr/ Der rief seine Soldaten allesamt ins Gewehr/ Zweihundert Bataillons und an die tausend Schwadronen/ Und jeder Grenadier kriegt sechzig Patronen// ,Ihr verfluchten Kerls', sprach seine Majestät/ Daß jeder in der Bataille seinen Mann mir steht!/ Sie gönnen mir nicht Schlesien und die Grafschaft Glatz/ Und die hundert Millionen in meinem Schatz.

Die Kais'rin hat sich mit den Franzosen alliiert/ Und das römische Reich gegen mich revoltiert./ Die Russen seind gefallen in Preußen ein/Auf, laßt uns sie zeigen, daß wir brave Landeskinder sein!" Es folgen sechs weitere Strophen (siehe: http://www.volksliederarchiv.de/text2884.html).

${ }^{1044}$ Siehe: zum Vergleich von gymnasialen Schulfeiern anlässlich der Geburtstage Wilhelms II in den Jahren 19913, 1914 und 1915: Schroeder, Funktion und Gestalt des patriotischen Schulfestspiels in der Wilhelminischen Kaiserzeit (1990), S. 71-75.

${ }^{1045}$ Das Volkslied (Text: Friedrich Güll (1812-1879), 5. Strophe von L. Schücking, Musik: Friedrich Kücken (1810-1882) war damals populär. Das Lied, das der Kriegserziehung diente, wurde in Preußen vor dem Ersten Weltkrieg vom Unterrichtsminister für den Unterricht in der fünften und der sechsten Klasse empfohlen, aber offensichtlich auch in jüngeren Klassen eingesetzt. Das Lied diente der Kriegserziehung im Kaiserreich und findet sich auch in Soldatenliederbüchern. Der Text der 1. Strophe lautet: „Wer will unter die Soldaten/ der muß haben ein Gewehr,/ das muß er mit Pulver laden/und mit einer Kugel schwer./ Büblein, wirst du ein Rekrut/ merk dir dieses Liedlein gut/ Pferdchen munter, immer munter/ lauf Galopp, hopp, hop, hopp“. Das Lied umfasst sechs Strophen.

${ }^{1046}$ Dieses Kinderlied, das nach der Melodie von „Üb immer Treu und Redlichkeit" (Wolfgang Amadeus Mozart) gesungen wurde, ist vermutlich in der ersten Hälfte des 19. Jahrhunderts entstanden. Der Text lautete zunächst „Der König ist ein lieber Mann" und ist in Schulliederbüchern seit 1856 belegt. Im Kaiserreich war das Lied fester Bestandteil von Schulfibeln und -liederbüchern und integraler Bestandteil der Inszenierung von „Kaisers Geburtstag" als Höhepunkt des Schuljahres. Indem der Kaiser als „lieber Mann" verniedlicht wird, soll bereits bei jüngeren Schülern die Liebe zum Monarchen geweckt und verstärkt werden; Text des Gedichts: „Der Kaiser ist ein lieber Mann/ er wohnet in Berlin/ und wär das nicht so weit von hier/ so ging ich heut noch hin.//Wisst ihr, was ich beim Kaiser wollt// Ich gäb ihm eine Hand/ und brächt das schönste Blümchen ihm/ das
\end{abstract}


5. Gedicht: Der Kaiser lebe hoch!

6. Lied: Deutschland, Deutschland über alles ${ }^{1047}$

7. Gedicht: Mein Vaterland

8. Gedicht: Ein Rat

9. Lied: Es braust ein Ruf

10. Gedicht: Hohenzollern

11. Vortrag des Lehrers über die Zustände der Mark Brandenburg im 15. Jahrhundert und Hinweise auf die Waffentaten unseres Herrn.

12. Heil dir im Siegerkranz

13. Gebet.

Das Klassenzimmer war geschmückt, trotzdem sehr wenig vorhanden war.“1048

Der Ablauf entsprach dem von den Gymnasien bekannten offiziellen Feierstil; sowohl die Loyalitätsbekundungen gegenüber dem Herrscherhaus als auch die Liebe zum Vaterland und die religiöse Prägung unterschieden sich von jenen überhaupt nicht. Häufig kam es vor, dass man hier im Rahmen der Festveranstaltung verdiente Schüler auszeichnete und ihnen Preise überreichte. ${ }^{1049}$ Seltener war es, dass Reden von Schülern zum Programm gehörten, wie es z. B. am Oberlyzeum Kaiserin-Auguste-Viktoria-Schule in Halberstadt der Fall war. Dort erörterte eine Schülerin in einem Vortrag die Frage „Was ist Kriegspoesie und wie kann der furchtbare Krieg mit all seinem Schrecken und all seinem Weh überhaupt Poesie enthalten?“1050 Dass man teilweise trotz des allgemeinen Mangels großen Wert auf die Ausschmückung der Schulen legte, zeigen Beispiele von Feiern aus Löbau (Westpreußen) ${ }^{1051}$ und Schneidemühl (Provinz Posen):

„Heut ist Kaisers Geburtstag. In jeder Schulklasse hängt ein Bild von Kaiser Wilhelm II. ${ }^{1052}$, um das Kränze aus grünen Tannenzweigen geschlungen sind. Die große Kaiserbüste aus Gips, die in

ich im Garten fand// Und sagte dann: In treuer Lieb/ bring ich das Blümchen dir/ Und dann lief ich geschwinde fort/ so wär ich wieder hier."

${ }^{1047}$ Das „Lied der Deutschen“ wurde von August Heinrich Hoffmann von Fallersleben am 26. August 1841 auf der Insel Helgoland gedichtet. Die Melodie stammt aus dem Kaiserquartett von Joseph Haydn. Seine ersten Verse (,Deutschland, Deutschland über alles, über alles in der Welt, wenn es stets zu Schutz und Trutze brüderlich zusammenhält“) drücken die Sehnsucht der Zeit nach einem geeinten Deutschland aus, das sich im Gegensatz zum Heiligen Römischen Reich gegen Frankreich erfolgreich verteidigen könne. Anders als in den „Rheinliedern“ (Z. B. Max Schneckenburgers „Es braust ein Ruf wie Donnerhall“) werden in dem Lied jedoch weder Frankreich noch der Rhein genannt. Das Lied war fester Bestandteil der Feiern im Ersten Weltkrieg und diente der „musikalischen Aufrüstung“ (Arthur Seidl).

${ }^{1048}$ Wißkirchen, Schulchronik Stommelerbusch (2002), S. 39.

1049 Zum Beispiel im Realgymnasium in Halberstadt: „Die Kaiserprämie ,Deutschland zur See', ein Buch von der deutschen Kriegsflotte'von Graf Reventlow, empfing der Tertianer Walter Koch.“ (Aus der Stadt, Halberstädter Zeitung und Intelligenzblatt mit Berlin).

${ }^{1050}$ Aus der Stadt, Halberstädter Zeitung, 28. Januar1915.

1051 Das höhere Schulwesen in der "polnischen Ecke" Westpreußens im Spannungsfeld der Nationalitätenpolitik (1986), S. 140: „In der folgenden Woche findet das erste ,Kriegskaisergeburtstagsfest' statt. Aus diesem Anlaß erhält der Treppenaufgang zur Aula einen wahrhaft erhebenden Schmuck, eine ,Heldengalerie, bestehend aus den 6 charaktervollen Steinzeichnungen von Bersch: Moltke, Kluck, Hindenburg, Kronprinz Rupprecht, Kronprinz Friedrich Wilhelm, Unser Kaiser'.“

${ }^{1052}$ Schulwandbilder für die Klassenzimmer galten als ,Lehrmittel' und wurden von den entsprechenden Verlagen den Schulen offeriert. So inserierte z. B. die Trierische Lehrmittel-Anstalt 1914/15: „In keiner Schule dürfte das Bild unseres Heldenkaisers Wilhelm II. fehlen, der demnächst am 27. Januar1915 seinen 57. Geburtstag 
der Aula steht, ist quer mit einem goldenen Lorbeerkranz geschmückt. Auf dem Kopf trägt Kaiser Wilhelm noch einen grünen Lorbeerkranz. Die Lehrer hatten angeordnet, daß wir zur Feier des Tages schwarz-weiß-rote Schleifen tragen sollten. [...] Wir hatten heute nur zwei Schulstunden, dann gab es ,frei'. Vorher hielt der Direktor in der Aula eine lange Rede, und wir sangen stehend ,Heil dir im Siegerkranz'. Früher hatten die Leute an Kaisers Geburtstag lange Reihen von Kerzen zwischen die Doppelfenster geklebt, die abends angezündet wurden. Das sah sehr feierlich aus. Auch gab es immer einen Fackelzug, an dessen Spitze die Militärkapelle marschierte. Und natürlich überall Fahnen ... Die gab es heute auch. Die Zeitungen hatten geschrieben:' Flaggen heraus! Verräter, wer das Gebot der Stunde missachtet!' [...] Der Kaiser hatte durch die Presse bitten lassen, seinen Geburtstag nicht zu sehr zu feiern. Aber nun doch!“‘1053

Während in den Gymnasien die Lehrer, die Reserveoffiziere waren, durchaus in Uniform an der Festveranstaltung teilnahmen und damit das Militär verkörperten, waren es in den Volksschulen nicht selten die Schulkinder, die wie Soldaten gekleidet waren und z. B. Matrosenanzüge trugen.

Auch in Mädchenschulen verliefen die Feiern nach dem beschriebenen Muster. ${ }^{1054}$ Als Beispiel soll die Feier zum Geburtstag des Kaisers in der Krefelder Bürgerschule für Mädchen im Jahre 1915 angeführt werden. Wie aus dem Bericht einer Lehrerin hervorgeht ${ }^{1055}$, „war das Beiwerk der Aufführungen und Reigen, das die früheren Feiern im Frieden so reizvoll ausgestaltete" wegen des Krieges gestrichen worden. Sonst entsprach der Ablauf der Veranstaltung mit „Geigenchor, Lieder(n), Gedichten“ und der Festrede eines Lehrers dem gängigen Zeremoniell. Vorwiegend in katholischen Gegenden und katholischen Schulen schloss sich an die Schulfeier meistens für die gesamte Schulgemeinschaft ein Festgottesdienst an. Wenn sich den Schulen die Gelegenheit bot, verknüpften sie auch ,Kaisergeburtstag' gern mit Nagelungsaktionen, deren Programm allerdings die Gestaltungselemente der typischen patriotischen Schulfeier enthielt und oft sogar mit militärischem Gepränge ablief. ${ }^{1056}$ In Münster marschierten beispielsweise am 27. Januar 1916 12.000 Schulkinder „mit Fahnen und Gesang, Trommeln und Pfeifen“ zum Prinzipalmarkt, um dort den „Eisernen Germanen“ zu benageln. ${ }^{1057}$ Daneben hielten ,auch sämtliche (...) höhere Lehranstalten und die Volkschulen (...) mit Reden und Vorträgen, Musikdarbietungen und Liedern engere Feiern ab.“1058

feiert." (Schiffler, Der 1. Weltkrieg und die Schule, http://www.schulmuseum-ottweiler.net/ mason/site/view.html?section=kaiser-6\&language $=(20.03 .2008))$.

${ }^{1053}$ Mihaly, ... da gibt's ein Wiedersehn! (1986), S. 131.

${ }^{1054}$ Siehe auch die „Schulansprache zum 27. Januar 1918“ (Treuge, Der Kaiser und sein Reich, in: Die Lehrerin: Organ des Allgemeinen Deutschen Lehrerinnenverein 1918, S. 257-259).

${ }^{1055}$ Meyer, Wie in der Bürgerschule für Mädchen zu Crefeld während der verflossenen Kriegsmonate gearbeitet worden ist, Die Mittelschule: Zeitschrift der Reichsfachschaft Mittelschule im Nationalsozialistischen Lehrerbund., 1915, S. 154.

${ }^{1056}$ Siehe: 7.2.8. Z. B. wurde das Kriegswahrzeichen in Gütersloh („Adler“) am 27. Januar 1916 eingeweiht Helming/Fredeweß-Wenstrup, ,Mutters Kriegstagebuch" (2005), S. 119.

${ }^{1057}$ Schulte, Kriegschronik der Stadt Münster 1914-18 (1930), S. 181; siehe Kapitel 7.3.4.

${ }^{1058}$ Schulte, Kriegschronik der Stadt Münster 1914-18 (1930), S. 261. 
Die Beispiele zeigen, dass den patriotischen Schulfeiern aller Schulformen der schon in der Zeit vor dem Ersten Weltkrieg entwickelte übliche Festritus zugrunde lag, und zwar sowohl hinsichtlich der Programmfolge als auch des Symbolgehaltes. Sogar die jüngsten Schüler die begingen den Geburtstag des Kaisers mit dem Singen patriotischer Lieder, dem Vortrag vaterländischer Gedichte und Kriegsgebeten. So schrieb beispielsweise eine Berliner Lehrerin in einem Bericht über „Kaisers Geburtstag in der Kinderlesestube“ am 27. Januar 1915, dass die „Vaterlandslieder, die ja so bekannt sind, daß alle Kinder ohne Ausnahme sie mitsingen konnten und sogar alle Strophen mit richtigem Text gesunden wurden““1059. Über den Ablauf der Feiern in Süddeutschland, die dort wie überall im Deutschen Reich stattfanden, können aufgrund der schlechten Quellenlage keine gesicherten Aussagen gemacht werden. Dass z. B. die bayrischen Schulchroniken kaum Hinweise auf die Durchführung von Kaisergeburtstagsfeiern im Ersten Weltkrieg feiern, lässt durchaus den Schluss zu, dass die Feiern für die bayerischen Schulen weit weniger bedeutsam waren als für die Schulen in Preußen.

\subsubsection{Elemente der Schulfeier}

Die bisher untersuchten Programmabläufe haben gezeigt, dass sie sich durchgehend aus den gleichen Elementen zusammensetzten, und zwar patriotischen Liedern und Gedichten, Orchester und Chorwerken, Gebeten und Kirchenliedern sowie der Festrede einer Lehrkraft oder des Schulleiters. Damit entsprachen sie den offiziellen Vorgaben. ${ }^{1060}$

\section{Patriotische Lieder $^{1061}$, Gedichte ${ }^{1062}$ und Gebete}

Die meisten Deklamationstexte und Lieder knüpften an die Tradition der panegyrischen Dichtung an, d. h., es handelte sich Lobeshymnen, die bei den Hörern bestimmte Assoziationen und Gefühle auslösen sollten. Einige wenige Beispiele seien genannt: „Der Kaiser ist ein lie-

\footnotetext{
${ }^{1059}$ Hecker, Kaisers Geburtstag in der Kinderlesestunde des Pestalozzi-Fröbel-hauses I, in: Die Lehrerin: Organ des Allgemeinen Deutschen Lehrerinnenvereins 1918, S. 351.

${ }^{1060}$ Zum Beispiel hatte die Kgl. Regierung in Lüneburg 1888 angeordnet: „Dieser Charakter der Feier ist in Gesängen, Vorträgen und Gebet zum Ausdruck zu bringen.“ (Zitiert nach: Schröder, Chronik des Weltkriegs, S. 54).

${ }^{1061}$ Siehe: Zoozmann, Das ist der Krieg der Kriege!; Ernstes u. Heiteres f. Gesang u. Vortrag aus d. Weltkriege 1914 (1915); die Sammlung enthält die meisten der damals gesungenen Lieder.

${ }^{1062}$ Die Zahl der Kriegsgedichte und auch der in den Feiern vorgetragenen Gedichte ist unüberschaubar. Allein im August 1914 entstanden anderthalb Millionen Kriegsgedichte (siehe: Giesbrecht, „Lieb' Vaterland, magst ruhig sein", in: Lück, Hartmut/ Senghaas Dieter (Hrsg.), Vom hörbaren Frieden (2005), Frankfurt am Main, S. 432) Deshalb und weil es sich bei den meisten Gedichten um literarisch wertlose patriotische Gebrauchskunst handelt, wird in dieser Arbeit darauf verzichtet, einzelne Gedichte zu analysieren. Zu den von Schülern vorgetragenen Gedichten gehörten Hassgedichte auf die Kriegsgegner, Huldigungsgedichte, Fürbittengedichte, Heldengedichte, Schützengrabengedichte, Gedichte mit Durchhalteparolen u.v.a. Einen kleinen Einblick bietet die 1914 erschienene Sammlung „Das Volk in Eisen“( Das Volk in Eisen. Kriegsgedichte der Täglichen Rundschau (1914), Verlag der Täglichen Rundschau, Berlin). Für den Überblick eignet sich Bab, Die deutsche Kriegslyrik 1914-1918. Eine kritische Bibliographie (1920).
} 
ber Mann““1063, „Der Kaiser lebe hoch!““ ${ }^{1064}$ (Volksschule Stommelerbusch, Rheinprovinz) und „Mit Gott für Kaiser und Vaterland““1065 (Bismarckschule Hannover). ${ }^{1066}$

Auch Marsch- und Soldatenlieder sowie Weltkriegsgedichte gehörten in der Regel zum Festprogramm, wie z. B. die Lieder „Fridericus Rex“, „O Deutschland hoch in Ehren“, „Ich hatt’ einen Kameraden““1067 und „Feinde ringsumher“ sowie die Gedichte „U59“ und „S. M. Kreuzer Cöln“ und „Mein Vaterland“. Fast immer gehörte das ,Niederländische Dankgebet“ („Wir treten zum Beten“) zum Programm. In kaum einer Feier fehlten außerdem die alte Königshymne Preußens („Heil dir im Siegerkranz“), die zusammen mit der „Wacht am Rhein“1068 die Nationalhymne des Deutschen Kaiserreichs bildete und häufig auf Feiern gesungen wurde, sowie die Hymne „Lied der Deutschen“ von August Heinrich Hoffmann von Fallersleben. $\mathrm{Zu}$ den besonders oft gesungenen Kirchenliedern gehörten Joachim Neanders „Lobe den Herren“1069 und vor allem Martin Luthers „Ein feste Burg ist unser Gott“, das auch schon vor dem

${ }^{1063}$ Das folgende Lied war seit 1864 in den Schulbüchern der dritten und vierten Klasse: „Der Kaiser ist ein lieber Mann / er wohnet in Berlin / und wär das nicht so weit von hier / so ging ich heut noch hin // Wisst ihr, was ich beim Kaiser wollt' / Ich gäb ihm eine Hand / und brächt das schönste Blümlein ihm / das ich im Garten fand // Und sagte dann: In treuer Lieb / bring ich das Blümlein dir / und dann lief ich geschwinde fort / so wär ich wieder hier" (http://www.volksliederarchiv.de/text4240.html [20.09.2010]).

${ }^{1064}$ „Dem Kaiser sei mein erstes Lied / ihm kling der erste Klang / des Vaterlandes Schirm und Hort / preis ich mit lautem Sang / Sein Name füllt mit reger Lust / jedwedes Deutschen treue Brust / Der Kaiser lebe hoch“ (Volksliederarchiv, http://www.volksliederarchiv.de/modules.php?op=modload\&name=Search\&file=index [6.12.2010]).

1065 „Kredenze den Becher uns Vater Rhein / stimm ein in das fröhliche Klingen / heut wollen beim deutschen Kaiserwein / den deutschen Trinkspruch wir bringen / Trag ihn von den Alpen zum Nordseestrand /mit Gott für Kaiser und Vaterland“" (Volksliederarchiv, http://www.volksliederarchiv.de/modules.php?op=modload \&name $=$ Search\&file=index [6.12.2010]).

${ }^{1066}$ Siehe: Wolbe, Kriegsgedichte 1914 (1915); die damals bekannte Gedichtsammlung wurde oft zur Planung der Schulfeiern herangezogen.

${ }^{1067}$ Seit dem verlustreichen Krieg von 1871 wurde das Lied, dessen Text aus dem Jahre 1809 von Ludwig Uhland (1787-1862) stammt, bei offiziellen Trauerfeiern gespielt und auch bei Feiern im 1. Weltkrieg gehörte es oft zum Programm. Es diente der Beschönigung und Verklärung des Kriegsopfers und des Heldentods.

„Ich hatt einen Kameraden,/Einen bessern findst du nit/ Die Trommel schlug zum Streite, Er ging an meiner Seite// Im gleichen Schritt und Tritt./ Eine Kugel kam geflogen:/ Gilt sie mir oder gilt sie dir?/Ihn hat es weggerissen,/Er liegt mir vor den Füßen/Als wär's ein Stück von mir./ Will mir die Hand noch reichen,/ Derweil ich eben lad'./ Kann dir die Hand nicht geben,/ Bleib du im ew'gen Leben/ Mein guter Kamerad!"

${ }^{1068}$ Max Schneckensburgers „Die Wacht am Rhein“ gehörte zu den populärsten antifranzösischen Liedern. Es war im Jahre 1841 verfasst worden, als ein Krieg mit Frankreich um die Rheingrenze drohte. Bekannt aber wurde es erst in einer vertonten Fassung von Carl Wilhelm während des Deutsch-Französischen Kriegs 1870/71.Das Lied appelliert sehr stark an religiöse Vorstellungen und nationale Gefühle. Vor allem die Jugend wird beschworen, ,den deutschen Rhein“, das Symbol deutscher Macht und nationaler Einheit, gegen den 'Erbfeind' Frankreich zu verteidigen. Auch dieses Lied war integraler Bestandteil der meisten Schulfeiern; Text der 1. Strophe: „Es braust ein Ruf wie Donnerhall, wie Schwertgeklirr und Wogenprall:/Zum Rhein, zum Rhein, zum deutschen Rhein!/Wer will des Stromes Hüter sein?

Refrain: Lieb Vaterland magst ruhig sein,/ lieb Vaterland magst ruhig sein:/ Fest steht und treu die Wacht,/ die Wacht am Rhein!/ Fest steht und treu die Wacht,/die Wacht am Rhein!“ Das Lied umfasst fünf Strophen.

${ }^{1069}$ Joachim Neanders (gest. 1680) bekanntestes Kirchenlied ist das 1679 erschienene Lied „Lobe den Herren, den mächtigen König der Ehren “. Es war in Seidls Liste kriegswichtiger Musik aufgenommen worden wie der Choral „Nun danket alle Gott“, den der Eilenburger Geistliche Martin Rinckart (1586-1649) 1630 verfasst hat. Berühmt wurde er im 18. Jahrhundert in Anlehnung an die Schlacht von Leuthen als „Choral von Leuthen“. Am Abend nach der Schlacht von Leuthen (5. Dezember 1757) sollen 25.000 Soldaten spontan „Nun danket alle Gott" angestimmt haben. Der Choral wurde zunächst in Preußen und später im ganzen Reich eine der populärsten Hymnen und gehörte neben Martin Luthers militantem Trutzlied „Ein feste Burg“ und einigen anderen Kir- 
Ersten Weltkrieg immer wieder mit nationalen und militärischen Zusammenhängen verbunden worden war. Aufgrund seiner Burg- und Festungsmetaphorik machte sich die offizielle Propaganda das populäre Lied der Protestanten zunutze, um die Bevölkerung und insbesondere die Jugend immer wieder aufzurufen, die durch äußere Feinde bedrohte Freiheit des Vaterlandes zu verteidigen. Es wurde neben der „Wacht am Rhein“ und „Feinde ringsumher“ zum ,Kampflied der Deutschen'.

Durch die Sprache ${ }^{1070}$ und die religiösen Lieder sowie durch die Gedichte und die Gebete sollten eine sakrale Atmosphäre erzeugt und die kriegerischen Handlungen der Deutschen religiös überhöht werden.

\section{Festreden}

Die Reden des Schulleiters oder eines Lehrers thematisierten die Tugenden und die Wohltaten des Kaisers und verpflichteten die Schüler zur Liebe, zum Dank und zur Treue gegenüber den Hohenzollern. Dass in den meisten Reden der Kaiser fast zum ,Heilsbringer' stilisiert wurde, sollte bei den Schülern zu einem blinden Vertrauen gegenüber dem Monarchen führen.

Am Beispiel einer Rede aus dem Jahre $1918^{1071}$ und einiger Auszüge soll diese Einschätzung belegt werden. In einem Lyzeum betonte die Rednerin, dass der Anlass für die Feierstunde in der Aula der „Wunsch, das Gelöbnis der Treue zu wiederholen““1072 und die „Verbundenheit [...] mit dem weithin sichtbaren Träger der deutschen Krone“" gewesen sei. Sie wies angesichts der schwierigen militärischen Lage besonders auf die große Bedeutung des Zusammenhalts der „Schicksalsgemeinschaft“" von Herrscher und Volk hin. Nach einem historischen Abriss über die Verdienste der Hohenzollern seit 1871 gelobte sie am Schluss für die Schulgemeinschaft, ,dem Kaisertum zu seiner höchsten Ausprägung mit (zu) verhelfen“.

Im Lyzeum in Schleswig nahm der Schuldirektor 1917 ebenfalls Bezug auf die politischmilitärische Situation:

„Bei dieser Feier wird sich Gelegenheit bieten, darauf hinzuweisen, daß gerade in diesem Jahre der Geburtstag seiner Seiner Majestät des Kaisers und Königs eine besondere Bedeutung hat nach dem hochherzigen und aus tiefstem menschlichen Empfinden entsprungenen Friedensangebot und des-

chenliedern zum festen patriotischen Repertoire. Viele hielten solche Kirchenlieder für kriegswichtig, in denen „Ergebung in das Schicksal, Dank, Gotteslob und Trost im Leid thematisiert sind“ (Giesbrecht, Musikalische Kriegsrüstung, S. 176).

1070 Zum Beispiel kam in den von Schülern vorgetragenen Liedern und Gedichten das Epitheton ,heilig' besonders häufig vor, durch das eine sakrale Atmosphäre erzeugt werden sollte.

${ }^{1071}$ Treuge, Der Kaiser und sein Reich, in: Die Lehrerin: Organ des Allgemeinen Deutschen Lehrerinnenvereins 1918, S. 257. Auch aus Itzehoe liegt eine Rede (1915) in - fast - vollem Wortlaut vor (Jahresbericht der städtischen höheren Mädchenschule in Itzehoe 1914/15, S. 20f.).

1072 Die Formulierung „,der Wunsch, das Gelöbnis der Treue zu wiederholen“ wurde in vielen Reden benutzt. Wahrscheinlich haben die Redner sie aus der „Schulansprache zum 27. Januar (1916)“ von Margarete Treuge übernommen (Treuge, Der Kaiser und sein Reich [1918], in: Die Lehrerin: Organ des Allgemeinen Deutschen Lehrerinnenvereins 1918, S. 257. 
sen Ablehnung durch unsere Feinde, die uns nunmehr zwingt, den Frieden mit dem Schwert zu erkämpfen. Der Tag wird daher ein besonderer Anlaß sein, unverbrüchliche Treue zu Kaiser und Reich neu zu geloben und als Ausdruck unseres felsenfesten Vertrauens zu der sicheren Führung seiner Majestät Liebe und Verehrung unserem Kaiser darzubringen. “1073

Auch am Gymnasium in Hannoversch-Münden (1915) wurde die besondere Bedeutung des

Kaisers für den Ausgang des Kriegs hervorgehoben:

„Der diesjährige Geburtstag Sr. Majestät des Kaisers, unseres allerhöchsten Kriegsherrn, hatte ein besonders weihevolles Gepränge, das sich durch ungewöhnlichen starken Besuch unserer Schulfeier auch äußerlich zeigte. Nach Gesängen und Vorträgen der Schüler hielt der Direktor die Festrede, in der er ausführte, wie die großen Taten unseres vielgeliebten Herrschers infolge des Krieges ihre rechte Bedeutung erlangt haben.“1074

Der folgende Auszug stammt aus Wetzlar:

„Auch die Gymnasialfeier trug in ihrer Gestaltung und Durchführung dem Ernst der Kriegszeit Rechnung. Sowohl die musikalischen Darbietungen wie die rezitatorischen Vorträge waren auf ihn abgestimmt. Die Festrede hielt Herr Professor Dr.Gloel. Sein Vortrag galt der vaterländischen Dichtung vor 100 Jahren, insbesondere dem Dichter der ,Hermannsschlacht'. [...] Die vielgepriesenen deutschen Tugenden, wie sie Kleist in seinen heldenhaften Gestalten versinnbildlichte, bestanden in diesen schweren, kampfdurchbrausten Tagen aufs neue die Feuerprobe. Wir freuen uns, in unserem Kaiser diese Tugenden vereinigt zu sehen. Das Band zwischen Kaiser und Volk ist durch den Krieg nur noch enger geknüpft geworden. Voller Liebe und Vertrauen und aus innigstem Herzen heraus bringt Alldeutschland daher an diesem Tag dem Kaiser Glückwünsche dar, die einen siegreichen Frieden dem Kaiser als obersten deutschen Heerführer wünschen und das Gelöbnis unwandelbarer Liebe und Treue erneuern. Zur Bekräftigung dieses Versprechens und als Huldigung stimmten daher alle Anwesenden in ein 3maliges Kaiserhoch und Gesang der Nationalhymne ein." ${ }^{1075}$

Da die genannten Beispiele für die Kriegszeit typisch sind, kann festgestellt werden, dass die Festredner auf die Kriegssituation eingingen, dem Kaiser huldigten und besonders den Glauben an den Sieg und die Größe des deutschen Vaterlandes betonten. Höhepunkt jeder Feier war das gemeinschaftliche Gelöbnis der Schulgemeinschaft, die Huldigung des Monarchen, durch die die ,erwünschte patriotische Gesinnung in den Köpfen und Herzen der nachwachsenden Generation dauerhaft verankert wurde“1076. Lehrer und Schüler verpflichteten sich durch einen feierlichen ,Eid' zur „Liebe zum Vaterland, Ehrfurcht gegenüber dem angestammten Fürstenhause, vaterländischen Sinn und Unterthanentreue “1077 und dankten dem Monarchen.

In der Verbandszeitschrift der Gymnasiallehrer ist ein solches Gelöbnis 1917 folgendermaßen formuliert worden: „Jetzt ist die Stunde da, wo wir ihm danken können, wo wir uns sammeln wollen, um unseren Kaiser in froher Zuversicht, wo wir ihm geloben wollen, seiner Führung

\footnotetext{
1073 Zitiert nach: Pust, „Vaterländische Erziehung" für „Höhere Mädchen” (2004), S. 324.

1074 Buchholz, Jahresbericht des Gymnasiums zu Hann. Münden, (1915), S. 8.

1075 Die Feier der Brunnennagelung in Wetzlar, Kreisblatt für den Kreis Wetzlar.

1076 Schneider, Über politische Feste der Bürger in Hannover (1866-1918), (2000), S. 100.

1077 Aus einem Erlass der Kgl. Regierung in Danzig; zitiert nach: Schroeder, Funktion und Gestalt des patriotischen Schulfestspiels in der Wilhelminischen Kaiserzeit (1990), S. 41.
} 
zu folgen in unverwandelbarem Vertrauen bis an das Ende. Dann wird das Ende der Sieg, ein Sieg, in dem unsrer Kaiser der Welt den ersehnten Frieden schenken wird. Das walte Gott. “1078

Aus der Tatsache, dass die Reden sich bis zu wortwörtlichen Übereinstimmungen glichen, schließt Pust ${ }^{1079}$, dass es hinsichtlich der zu vermittelnden Inhalte offensichtlich offizielle Vorgaben vonseiten der Regierung für die Feiern gegeben haben muss. Das ist zwar durchaus wahrscheinlich, viele Redner werden aber mit Sicherheit die in den zahlreichen Materialiensammlungen enthaltenen ,Musterreden ${ }^{1080}$ Vorlage übernommen oder als Vorlage benutzt haben.

\subsubsection{Reaktionen der Teilnehmer und Berichterstattung in der Presse}

Nicht nur über die offiziellen kommunalen Feiern, sondern auch über die Schulfeiern wurde in der örtlichen Presse ausführlich berichtet. Von den vielen überlieferten Berichten soll auf zwei aus den Jahren 1915 und 1916 zurückgegriffen werden. Sie zeigen, welch hohen öffentlichen Stellenwert die Schulfeiern hatten und wie positiv die Zeitungen darüber berichteten. Bezeichnend für die Berichte ist, dass sie das Engagement sowie die Festfreude der Kinder besonders hervorheben, wie z. B. die Epitheta „fröhlich“, "lustig“ und „herzlich“ zeigen. Indem man den Eindruck erweckte, es habe sich um unbeschwerte schulische Feste gehandelt, wurde von den Schrecken des Krieges abgelenkt. Man wollte durch die Berichterstattung durchaus auch „der zunehmenden Kriegsmüdigkeit weiter Teile der Bevölkerung ideologisch“"1081 entgegenwirken.

1915 wurde in der Halberstädter Zeitung über die Feiern am Realgymnasium und am Oberlyzeum berichtet, wie der folgende Ausschnitt zeigt:

„Kaisergeburtstagsfeier am Oberlyzeum. Die Kaiserin-Auguste-Viktoria-Schule hatte am Geburtstage des Kaisers eine stimmungsvolle Feier. Die 1. Klasse des Lyzeums hatte es sich zur Aufgabe gestellt, aus der unübersehbaren Flut der Kriegsgedichte nur wirklich poetisch wertvolle Kriegslieder zu Gehör zu bringen, und so an Proben zu zeigen, daß die große Zeit auch große Dichter gefunden und erweckt hat. In die ernste Stimmung versetzte alle das Lutherlied ,Ein feste Burg ist unser Gott' und das vom Chor gesungene Niederländische Volkslied mit seinem frommen Kampfesmut für Freiheit und Recht. Dann erörterte eine Schülerin in einem Vortrag die Frage: Was ist Kriegspoesie? Und wie kann der furchtbare Krieg mit all seinem Schrecken und all seinem Weh überhaupt Poesie enthalten? Es folgten im Wechsel mit musikalischen Einlagen Kriegsgedichte, deren Verfasser meist selbst gekämpft haben oder gar den Heldentod gestorben sind. Das

${ }^{1078}$ Zum 27. Januar 1917, Deutsches Philologen-Blatt 1917, S. 2.

${ }^{1079}$ Pust, „Vaterländische Erziehung" für „Höhere Mädchen" (2004), S. 343.

${ }^{1080}$ Siehe z. B.: Leschhorn, Handbuch für Schulfeiern (1913/14), Splett, Kaisers Geburtstag in der Volksschule (Breslau); Jahnke, Kaiser-Geburtstagfeier in der Schule (1893); Hübner, Vaterländische Gedenktage in der Schule (1889); Bongaertz, Zur Feier des Geburtstages Sr. Majestät Kaiser Wilhelm II. (1909); Bürgel, Die Feier vaterländischer Gedenk- und Erinnerungstage in der Volksschule (1894); Rohde, Die Schulfeste in der Volksschule (1894); Schwellnus, Vaterländische Festtage in der Schule (1911).

${ }^{1081}$ Goldberg, Schulgeschichte als Gesellschaftsgeschichte (1994), S. 66. 
,Österreichische Reiterlied', das so echt den schlichten Ton des Volksliedes getroffen hat, wurde mit Lautenbegleitung in der Vertonung von Kothe gesungen. Im Sologesang brachte die schöne volle Altstimme die tiefe poetische Kraft des Liedes so recht zur Geltung. - Zum Schluß wies der Direktor der Anstalt darauf hin, daß die gemeinsame Kriegsnot unsern ritterlichen Kaiser den Herzen des Volks näher gebracht hat.“1082

Noch wesentlich ausführlicher und stimmungsvoller beschäftigte sich das Wetzlarer Kreisblatt mit den Feierlichkeiten der Schulen 1916, die am gleichen Tage wie die Einweihung des Kriegswahrzeichens (Nagelung des ,Eisernern Brunnens') ${ }^{1083}$ stattfanden:

„Kaisers Geburtstag ist in ganz Deutschland zwar in geräuschloser, dafür aber umso herzlicherer Weise von allen Kreisen des deutschen Volkes begangen worden. Drang auch die Sonne nicht recht durch die Wolken hindurch, so war es doch meistens trocken und hell, so daß die an den Häusern aufgesteckten Fahnen lustig im Winder flatterten. Den ersten Gruß zum Kaisertage brachte die Schuljugend, die in ihrem Sonntagsstaate fröhlich den Schulfeiern zustrebt. Nach Schluß der Schulfeiern fanden in den Kirchen stark besuchte Festgottesdienste statt, in denen mit Dank und Fürbitte des Kaisers gedacht wurde.“

An anderer Stelle des Berichtes heißt es:

„Wie überall im Vaterlande, so stand auch bei uns in Wetzlar die Kaisersgeburtstagsfeier wiederum unter dem Zeichen des Krieges. Daß der Gedenktag trotzdem in mancher Hinsicht nach außen hin stärker wie voriges Jahr in die Erscheinung trat, liegt unzweifelhaft daran, daß mit ihm eine vaterländische Feier verbunden war, über die an anderer Stelle berichtet wird. ${ }^{1084}$

In gewohnter Weise erklangen früh die Glocken, bald bedeckten sich die Häuser mit Fahnen und munteren Schrittes eilten Scharen der kleinen und großen Schüler, um an den diesmal fast durchweg in schlichter Form erfolgenden Schulfeiern teilzunehmen. “1085

Die detaillierte und durchgehend positive Berichterstattung in den Zeitungen hat offenkundig die Schulen zusätzlich bewogen, die Feiern auch im Krieg mit recht großem Aufwand durchzuführen. Dass es mit fortschreitender Dauer des Krieges immer schwerer wurde, durch die Feierlichkeiten glaubhaft an dem Patriotismus der Schüler zu appellieren und ihnen die Zuversicht auf den Sieg zu vermitteln, soll eine von damals sicher nicht seltenen Stimmen verdeutlichen, die eines Mitschülers von Bertolt Brecht in Augsburg, der als Erwachsener die damalige Zeit reflektiert:

„(Die Feiern,) die im Treppenhaus abgehalten wurden, ärgerten uns durch ihre zunehmende Geschmacklosigkeit. Die großen Worte der Lehrer klangen hohl, ihre Resonanz bei uns Schülern war mäßig. Auch stellte sich beim Singen vaterländisch-anfeuernder Lieder nicht mehr die erhoffte Begeisterung ein, einfach weil der Kriegsalltag den Idealismus zersetzt, was bei uns jedoch nicht zu irgendwelchen Schlußfolgerungen führte. “1086

\footnotetext{
${ }^{1082}$ Aus der Stadt, Halberstädter Zeitung und Intelligenzblatt mit Berlin, 28. Januar 1915.

${ }^{1083}$ Die Schulen waren auch bei der Einweihungsfeier beteiligt. Zur Einleitung der Feier sangen ,die Knaben der Ev. Volksschule unter Lehrer Schneiders Leitung“ aus dem altniederländischem Dankgebiet ,Wir treten zum Beten' (1916).

${ }^{1084}$ Gemeint ist die Einweihung des Wetzlarer Kriegswahrzeichens.

${ }^{1085}$ Die Feier der Brunnennagelung, Kreisblatt für den Kreis Wetzlar 28. Januar 1916; es werden dann einzeln die Veranstaltungen der Lehrerbildungsanstalten, der evangelischen Volksschulen, der Katholischen Schule, der Unteroffiziersschule, des Gymnasiums und des städtischen Lyzeums teilweise sehr detailliert beschrieben.

${ }^{1086}$ Frisch/Obermeir, Brecht in Augsburg (1986), S. 69.
} 
Sogar ein patriotischer Schulleiter, der vom erzieherischen Wert der Schulfeiern überzeugt war, bedauerte 1917, dass ,diese Feiern des frischen Lebens und neuer Formen entbehren“61087.

\subsubsection{Entwicklung der nationalen Schulfeiern im Krieg}

Angesichts der sich ständig verschlechternden militärischen und wirtschaftlichen Lage nahm die Bedeutung des Kaisergeburtstages deutlich ab, auch wenn die Berichte in manchen Schulchroniken noch voller Verehrung dem Kaiser huldigen, wie z. B. in Lobkowitz (Provinz Schlesien):

„Schon zum vierten Male muß Kaiser Wilhelm sein Wiegenfest im brandenden Weltkriege begehen. Sonst war dieser Tag ein jubelndes Volksfest. Jetzt aber wünscht der Kaiser selbst, von rauschenden Veranstaltungen abzusehen und nur in ernster Weise seiner zu gedenken. Die kirchliche Feier war am Geburtstage selbst mit Hochamt und Te Deum. Gott wolle unserm geliebten Kaiser und seinem Volk recht bald den langersehnten Frieden schenken. “1088

In Münster (Provinz Westfalen) wurden am 2. Januar 1918 von zahlreichen Schulen vor vielen externen Ehrengästen sogar „,besondere Feiern veranstaltet, „mit Musikdarbietungen, Gesangsvorträge und Festreden“ ${ }^{1089}$. Dass solche aufwendigen Feiern nur selten veranstaltet wurden, hing auch mit dem Ansehen Hindenburgs zusammen, das angesichts seiner anfänglichen großen Siege an der Ostfront ständig zunahm, sodass er den Kaiser in seiner Rolle als „Verkörperung der deutschen Siegeshoffnungen“"1090 schließlich ablöste. Offensichtlich auch deshalb wird der 27. Januar in den Orts- und Schulchroniken für die letzten beiden Kriegsjahre oft nur noch ganz beiläufig erwähnt. Zum Beispiel wurde in der Chronik der preußischen Stadt Schweidnitz (Provinz Schlesien) für 1917 Hindenburgs 70. Geburtstag erwähnt ${ }^{1091}$, nicht aber der Geburtstag des Kaisers. ${ }^{1092}$ Ähnlich war es in Augsburg, wo der Kaisertag zwar noch genannt wird („Am 26.1. den Geburtstag des Kaisers [gefeiert]“ ${ }^{1093}$ ), Hindenburgs Jubiläumsgeburtstag jedoch offensichtlich eine größere Rolle gespielt hat. In Kleve (Rheinpro-

\footnotetext{
${ }^{1087}$ Meinardus, Schulfeiern, Monatszeitschrift für höhere Schulen, 1917, S. 546f.

1088 Fuckner, Gemeinde- und Schulchronik von Lobkowitz, http://www.schloss-ellguth.de/lowkowitz2.htm (19.06.2008).

${ }^{1089}$ Schulte, Kriegschronik der Stadt Münster 1914-18 (1930), S. 319.

1090 Siehe: Hoegen, Der Held von Tannenberg (2007), Kapitel II.2.b. Eine ähnliche Meinung vertritt Christoph; siehe: Nübel, Die Mobilisierung der Kriegsgesellschaft (2008), Kapitel 1.3.2.

${ }^{1091}$ Dabei ist allerdings zu berücksichtigen, dass Hindenburg 1917 einen ,runden' Geburtstag feierte.

1092 „1917, 2.10. Hindenburgs 70. Geburtstag. In den Schulen Feiern schon am Samstag, 29.9. Am Geburtstag selbst um 15.30 Festakt in der Hindenburghalle. Allgemeine Beflaggung." (Schweidnitz/Geschichte 1914 -1918 http://wiki-de.genealogy.net/Schweidnitz/Geschichte_1914-1918 (19.06.2008)).

1093 Stadtarchiv Augsburg - Archiv und Schule, http://www.stadtarchiv.augsburg.de/index.php?id=17256 (01.01.2009).
} 
vinz) musste sogar der für den 27. Januar 1918 geplante Nageltag am ,Eisernen Mann’ „wegen der zunehmenden Kriegsmüdigkeit“" abgesagt werden. ${ }^{1094}$

Allerdings waren die Schulen bis zum Ende des Krieges zur Durchführung von Feiern verpflichtet und die Veranstaltungen haben auch, wie nachgewiesen, in der traditionellen Form stattgefunden.

Vergleicht man abschließend die schulische Durchführung des Kaisergeburtstages der Vorkriegszeit mit den Feiern in den Kriegsjahren, so lässt sich feststellen, dass sie sich nicht wesentlich voneinander unterschieden. Dass sie nach 1914 ,wesentlich chauvinistischer“1095 begangen wurden, wie Wildhagen behauptet, kann anhand der untersuchten Quellen nicht bestätigt werden. Wie die zitierten Reden zeigen, war Kaisertreue vor dem Krieg und bis zum Kriegsende eines der wichtigsten Erziehungsziele, auch wenn in den letzten Kriegsjahren die Person des Kaisers zunehmend zurücktrat. Die Festredner nutzten die Möglichkeit, um den Schulkindern propagandistisch Durchhaltewillen und Siegeszuversicht zu vermitteln.

Goldberg ist zuzustimmen, dass man darüber hinaus durch die Schulfeiern, und zwar vor allem zum Kaisergeburtstag und zum Sedantag, auch „der zunehmenden Kriegsmüdigkeit weiter Teile der Bevölkerung ideologisch““1096 entgegenwirken wollte. ${ }^{1097}$ Sicher war

Zwar entsprachen bei beiden Veranstaltungen die Gestaltungselemente denen der typischen patriotischen Schulfeier vor dem Krieg ${ }^{1098}$, es fehlte aber jegliches militärische Zeremoniell und auch das nationale Pathos sowie die Loyalitätsbezeugungen gegenüber dem Kaiser waren wenig ausgeprägt. Der Krieg wurde nicht mehr so stark verherrlicht, sondern mitunter sogar als Ereignis „mit all seinen Schrecken“ empfunden.

\subsection{Hindenburgfeiern}

Der Aufstieg des bei Kriegsbeginn im Volk weitgehend unbekannten Generals Paul von Hindenburg (*geb. 2. Oktober 1847) zum Volkshelden und Mythos begann mit der Vernichtung der russischen Narew-Armee bei Tannenberg (26.-30.08.1915). Dieser Sieg, der sowohl mit der Schlacht bei Cannae (2. August 216 v. Chr.) als auch mit dem Sieg bei Sedan (2.9.1870) in Verbindung gebracht wurde, wurde nicht nur als Garant der Erfolge gegen Russland

\footnotetext{
1094 „Bei der Kaiser-Geburtstagsfeier von 1918 machte er (Anmerkung: ,Der Eiserne Mann’) nicht mehr mit. Das Volk war nicht mehr zu mobilisieren.“(12000 Jahre Niederrhein - 800 Jahre Kleve, http://www.heimatkleve.de/geschichte/chronik/15.htm (17.09.2009)). Es gab aber Städte, in denen der Kaisergeburtstag 1918 in großem Rahmen inszeniert wurde, wie z. B. in Münster, siehe: Nübel, Die Mobilisierung der Kriegsgesellschaft Bd. 14 (2008), S. 134f.

1095 Wildhagen, „Laß dich gelüsten nach der Männer Bildung“ (1994), S.125.

1096 Goldberg, Schulgeschichte als Gesellschaftsgeschichte (1994), S. 66.

${ }^{1097}$ Auch wenn an den Feiern in der Regel nur Schüler und Lehrer teilnahmen, so sorgte doch die örtliche Presse meistens für die entsprechende Publizität. Siehe: 5.2.2.

${ }^{1098}$ Siehe: Kapitel 5.2.2.
} 
verstanden, sondern sollte auch ,zum Sinnbild der Hoffnung auf einen Gesamtsieg im Krieg“ werden. ${ }^{1099}$

Auch wenn im Gegensatz zur Schlacht von Sedan der Sieg von Tannenberg keine kriegsentscheidende Bedeutung hatte, denn er brachte lediglich die Wende an der Ostfront, so entwickelte sich daraus nach Jesko von Hoegen in der Folgezeit ein regelrechter „HindenburgMythos“. „Da der anonymisierte Massenkrieg kaum Raum für individuelles Heldentum bot, konzentrierte sich die deutsche Gesellschaft auf den ,Helden von Tannenberg' als ,Quelle der Begeisterung, “ " ${ }^{1100}$ Hindenburgs Ansehen nahm im Laufe Krieges immer weiter zu, da er ,auf kommunikative Entfaltungsmöglichkeiten (traf), die es ihm gestatteten, sich selbst innerhalb der kriegsbedingten Restriktionen medial so zu vermarkten, daß der Hindenburg-Mythos trotz

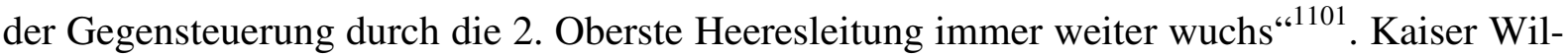
helm II., der in medialer Hinsicht hingegen völlig abgetaucht war, war der „Hauptleittragende der visuellen Omnipräsenz seines Heerführers (...). Hindenburg drohte in seiner Eigenschaft als Medienereignis den Kaiser förmlich zu erdrücken: Während die Porträts Wilhelms II. auf Anordnungen von oben in den Amtsstuben und staatlichen Einrichtungen hingen, stand hinter der Zuschaustellung Hindenburg das Bekenntnis zu einer Symbolfigur“ ${ }^{\text {1102. }}$.

$\mathrm{Zu}$ der großen Popularität Hindenburgs trugen auch allerlei Anekdoten bei, in denen ihm besondere Attribute angedichtet wurden. ${ }^{1103}$ So wurden z. B. immer wieder Frömmigkeit und Bescheidenheit als Charaktermerkmale betont, wie auch das folgende Beispiel zeigt:

„(Im Anschluss) an die Huldigung der Posener Schuljugend im Dezember 1914 nach dem Sieg bei Lodz soll der Feldmarschall, laut ,Kreuzzeitung', folgendermaßen geantwortet haben:

,Ich danke Ihnen für die freundlichen Worte des Dankes [...] Mir gebührt nicht der Dank für die Erfolge, die wir gegenüber den russischen Feinden errungen haben. Ich habe nur den Namen dazu hergegeben. Der Dank gebührt Gott dem Herrn, der uns immer gnädig behütet hat und der uns auch fernerhin behüten wird, denn er kann uns nicht plötzlich von seiner Vaterhand loslassen [...]. Ich sehe getrost in die Zukunft, Gott der Herr wird uns einen ehrenvollen Frieden schenken.' ${ }^{\prime 1104}$

Dass man neben den Geburtstagen des Monarchen auch die des zum Volkshelden stilisierten Hindenburg offiziell feierte und der siebzigste, der ,in ganz Deutschland ungeachtet der Milieu-Zugehörigkeit als nationaler Festtag, als ,Nationalfeiertag' begangen wurde“1105, ist angesichts der großen Popularität Hindenburgs verständlich. Wie die beiden anderen nationalen Feste (Sedantag, Kaisergeburtstag), so wurden selbstverständlich auch die ,Hindenburgtage' -

\footnotetext{
${ }^{1099}$ Hoegen, Der Held von Tannenberg (2007), S. 47.

${ }^{1100}$ Hoegen, Der Held von Tannenberg (2007). S. 75.

${ }^{1101}$ Pyta, Hindenburg (2007), S. 116.

${ }^{1102}$ Pyta, Hindenburg (2007), S. 129.

${ }^{1103}$ Hoegen, Der Held von Tannenberg (2007), S. 81.

${ }^{1104}$ Hoegen, Der Held von Tannenberg (2007), S. 122.

${ }^{1105}$ Hoegen, Der Held von Tannenberg (2007), S. 132.
} 
vor allem in Preußen - in vielen Schulen gefeiert. Dieses soll an einigen wenigen Beispielen im Folgenden genauer untersucht werden.

Über Hindenburgs 68. Geburtstag am 2. Oktober 1915, den man in Berlin mit einer feierlichen Nagelung des ,Eisernen Hindenburg' verknüpfte, wurde in der Presse im ganzen Reich ausführlich berichtet. ${ }^{1106}$ So erschienen z. B. am 2.10. in der, Vossischen Zeitung' zwei Berichte über die Aktivitäten der Schulkinder, die auszugsweise zitiert werden sollen:

„Heute findet am Königsplatz die Geburtstagsfeier für den großen Heerführer statt. Um 19 1/4 Uhr singen tausend Schulkinder unter Führung des Stadtschulrats Fischer und unter Leitung des Rektors Hofmann, der darauf eine Ansprache hält. Sämtliche Kinder nageln dann ...“

„Tausend Kinder kommen zum Hindenburg und abertausend geben ihnen das Geleit. Sie alle wolle ihn feiern, der heute vor 68 Jahren Deutschland geschenkt ward. Da stehen die Kinder und schauen zu ihm auf, der mit gebietendem Feldherrnauge über das Heer seiner Gratulanten blickt; wenn sie seine Größe nicht erfassen können, die Kleinen und Kleinsten, sie kennen ihn von den schulfreien Tagen und den fahnenflatternden Straßen; Zahlen, fünf, sechsstellig schwirren uns durch den Kopf, wenn wir an Hindenburg denken. Sein Name heißt Sieg. “"1107

Die Feiern liefen nach dem gewohnten Ritual ab: Ein Schulleiter hält eine patriotische Ansprache, die Kinder singen religiöse ${ }^{1108}$ und vaterländische Lieder ${ }^{109}$, eine Militärkapelle spielt und am Ende stimmen die Anwesenden „,begeistert“ in ein ,Hoch’ auf den Feldherrn ein. Welches Ausmaß die Hindenburg-Verehrung bereits am Anfang des zweiten Kriegsjahres angenommen hatte, geht aus derselben Quelle hervor: „Das ganze deutsche Volk, das Kind in der Schule, der Gelehrte am Schreibtisch, alle wissen, was uns Hindenburg ist, mehr als ein Feldherr, mehr als ein Held: ein Schutzpatron, ein Nationalheiliger, zum dem wir mit blindem Vertrauen aufblicken. “1110

Dass in jeder Klasse neben dem Bild des Kaisers ein Hindenburgbild hing, verwundert angesichts einer derartigen Verehrung nicht. Sieht man von der religiösen Überhöhung Hindenburgs ab (,Schutzpatron“, „Nationalheiliger“), so wird auch hier die Bedeutung der Schule als Teil der „Heimatfront“ deutlich: Hindenburg blickt „,mit gebietendem Feldherrnblick über das Heer seiner (jugendlichen) Gratulanten“1111.

In Dresden wurde der 68. Geburtstag zum Anlass genommen, die „Hindenburg-Säule“ feierlich einzuweihen und zu benageln. Zwar werden in dem entsprechenden Zeitungsbericht vom 3. Oktober Schüler und Lehrer nicht besonders erwähnt ${ }^{1112}$, es kann jedoch angenommen

\footnotetext{
${ }^{1106}$ Siehe auch: Kapitel 7.3.4.

1107 Schütze, Der eiserne Hindenburg (2007), S. 72f.

${ }^{1108}$ Zum Beispiel „Harre meine Seele“.

${ }^{1109}$ Zum Beispiel „Die Wacht am Rhein“.

1110 Schütze, Der eiserne Hindenburg (2007), S. 72.

${ }^{1111}$ Schütze, Der eiserne Hindenburg (2007), S. 72.

1112 Hindenburg-Feiern, Dresdner Anzeiger, 1915, Nr. 55
} 
werden, dass die Schule wie bei ähnlichen Veranstaltungen in anderen Städten in Dresden ebenfalls daran beteiligt war.

Auch in vielen anderen Städten wurden zu Ehren Hindenburgs am 2. Oktober unter Beteiligung der Schulen Nagelungen durchgeführt. Man folgte der Anregung der Hauptstadt Berlin, ,an diesem Tag überall in den Gemeinden, in denen bereits ein Kriegswahrzeichen aufgestellt worden war, ein ,Geburtstagsnageln’ zu veranstalten“"1113.

Die Wertschätzung Hindenburgs gipfelte in den Feiern zu seinem siebzigsten Geburtstag am 2. Oktober 1917. „Die Öffentlichkeit überschlug sich förmlich in ihrer Verehrung, die bei weitem nicht allein dem Feldherrn, sondern mindestens ebensosehr der Verkörperung der nationalen Einheit galt. (...) Ganz Deutschland wurde in Hindenburgfeiern getaucht, in denen - ob in den preußischen Kernlanden oder im fernen Süden ${ }^{1114}$ - Hindenburg eine nicht gekünstelte, sondern eine echte Hommage gebracht. “1115 Natürlich wurde der Geburtstag auch in den Schulen wie ein Nationalfeiertag gefeiert, bei dem die Schulkinder schulfrei bekamen. Dem Erlass des preußischen Unterrichtsministers, in dem die Schulen zum feierlichen Gedenken aufgefordert wurden, ,um die Dankbarkeit und Verehrung für den siegreichen Heerführer zum Ausdruck zu bringen “1116, wurde allgemein Folge geleistet.

In den Verbandszeitschriften der Lehrer wurde ebenfalls zu Aktionen für den 2. Oktober 1917 aufgerufen. So regte z. B. der Vorsitzende des bayerischen Lehrerverbandes an, ,an diesem Tag [...] eine Kriegs-Geburtstagsgabe im Sinne der oft bewährten vaterländischen Betätigung dar (zu)bringen“"1117. In Gotha beispielsweise entschlossen sich die Lehrer, „eine Bücherwoche (Bücher und Zeitschriften) zu veranstalten, deren Ergebnis am 2. Oktober den hiesigen Lazaretten übermittelt werden soll ${ }^{\text {1118. }}$.

Auch in Bad Kreuznach, wo sich Hindenburgs Stabsquartier befand, feierte man seinen 70. Geburtstag mit sehr viel Aufwand. In der Presse wurde darüber ausführlich berichtet:

„Während sich der ,Vorwärts' erkennbar in der Berichterstattung über den ,Nationalfeiertag’ zurückhielt, war in der übrigen Presse zu lesen, daß die Straßen von Hindenburgs Wohnung bis zum Generalstabsgebäude am Morgen des 2. Oktober 1917 von Schulkindern eingesäumt waren, die dem Volkshelden Herbstblumen auf den Weg streuten, während Flieger Blumen und Lorbeer abwarfen. Des weiteren hatte sich eine große Menschenmenge versammelt, die dem Generalfeldmarschall auf seinem Weg zum Dienst ,jubelnde Huldigungen’ bereitet haben soll.“1119

\footnotetext{
${ }^{1113}$ Hindenburg-Feiern, Dresdner Anzeiger, 1915, Nr. 55.

${ }^{1114}$ In München versammelten sich am 2. Oktober 1917 beispielsweise annähernd hunderttausend Personen auf dem Königsplatz, um an einer Feier zu Ehren des Jubilars teilzunehmen (siehe: Pyta, Hindenburg [2007], S. 296. 1115 Pyta, Hindenburg (2007), S. 296.

1116 Allgemeines Schulblatt für die Provinz Schleswig-Holstein; zitiert nach: Pust, „Vaterländische Erziehung" für „Höhere Mädchen" (2004), S. 349.

${ }^{1117}$ Bayer, Eine Hindenburg-Ehrung, Deutsches Philologen-Blatt 1917, S. 546.

${ }^{1118}$ Bayer, Eine Hindenburg-Ehrung ( 1917).

${ }^{1119}$ Hoegen, Der Held von Tannenberg (2007), S. 190.
} 
Im Mittelpunkt der schulischen Hindenburgfeiern stand in der Regel eine zentrale Schulveranstaltung, an der die Schülerinnen und die Schüler teilnehmen mussten. Sie unterschied sich kaum von der, die am ,Kaisergeburtstag' durchgeführt wurde. Da dem Feldherrn auch von der Jugend eine nahezu religiöse Verehrung entgegengebracht wurde, wurden neben den patriotischen Liedern in der Regel auch Kirchenlieder gesungen. Im Itzehoer Lyzeum, über dessen Feier ein überliefertes Programm Aufschluss gibt ${ }^{1120}$, war deshalb der gemeinsame Gesang von „Ein feste Burg ist unser Gott“ und „Zu dir heb ich die Hände“ Teil des Programms. Nach Pust wurde in dieser Veranstaltung und vielen ähnlichen Feiern „der Mischcharakter von weltlicher und kirchlicher Feier deutlich“"1121.

Vielfach wurde Hindenburgs Geburtstag auch zum Anlass genommen, eine sog. ,Hindenburgspende' durchzuführen. Das Lyzeum in Altona sammelte beispielsweise 314,04 M. ${ }^{1122}$ In Landshut (Königreich Bayern) wurden zugunsten einer Hindenburgspende „Postkarten und Erinnerungszeichen“"1123 verkauft und eine Haussammlung durchgeführt. Die Schüler des Gothaer Gymnasiums beteiligten sich an einer Büchersammlung, deren Erlös den kommunalen Lazaretten zugutekam. ${ }^{124}$ Trotz des bayerischen ,Preußenhasses, ${ }^{1125}$ wurde Hindenburg auch in Bayern sehr verehrt und deshalb wurden die Hindenburgfeiern unter Einbeziehung der Schulen aufwendig begangen. Die Feierlichkeiten in Landshut entsprachen sicher denen anderer bayerischer Städte. Sie wurden „,durch hehre Schulfeier im Rathaussaale und Ansprache des Oberbürgermeisters, Standparade vor dem Rathause, feierliche Nagelung am Kriegswahrzeichen unter allgemeiner Beteiligung [...] der Schulen festlich begangen“"1126. Teilweise allerdings wurde die Durchführung der Veranstaltungen durch die akuten Versorgungsprobleme beeinträchtigt. Im Augsburger St. Anna Gymnasium z. B. feierte man „den 70. Geburtstag Feldmarschall Hindenburgs - im kleinen Kreis - wie auch bei allen anderen Feiern, denn Heizmaterial war knapp, und so konnte dafür nur der Musiksaal genützt werden“1127.

\footnotetext{
${ }^{1120}$ Siehe: Pust, „Vaterländische Erziehung" für „Höhere Mädchen" (2004), S. 349.

${ }^{1121}$ Pust, „Vaterländische Erziehung" für „Höhere Mädchen" (2004), S. 349.

${ }^{1122}$ Chronik Altona, 1917/18; siehe: Pust, „, Vaterländische Erziehung“ für „Höhere Mädchen“ (2004), S. 349.

${ }^{1123}$ Tausche, Landshuter Stadtchronik Band II (1989), S.95f.

${ }^{1124}$ Bayer, Eine Hindenburg-Ehrung (1917).

${ }^{1125}$ Spindler, Handbuch der bayerischen Geschichte 4, 1. Teilband (1979), S. $378 f$.

${ }^{1126}$ Tausche, Landshuter Stadtchronik, Bd. 2(1989), S. 95f.

${ }^{1127}$ Stadtarchiv Augsburg - Archiv und Schule, http://www.stadtarchiv.augsburg.de/index.php?id=17256 (01.01.2009), S. 6. Im Abschnitt 1 b) „Der Krieg und die Schule: Das Gymnasium bei St. Anna“ heißt es: „Man feierte den 70. Geburtstag Feldmarschall Hindenburgs - im kleinen Kreis, wie auch bei allen anderen Feiern, denn Heizmaterial war knapp, und so konnte dafür nur der Musiksaal genützt werden." Offensichtlich hatte es bereits am 2. Oktober 1917 einen Kälteeinbruch gegeben.
} 
In der Ortschronik von Schweidnitz (Provinz Schlesien) wurde über die Feierlichkeiten 1917 berichtet: „Hindenburgs 70. Geburtstag. In den Schulen Feiern schon am Samstag, 29.9. Am Geburtstag selbst um 15.30 Festakt in der Hindenburghalle. Allgemeine Beflaggung. “1128

In Göttingen hingegen wurde dieser Tag

„ganz besonders festlich begangen. Er wird vor allem unserer Jugend, die ihre eigene HindenburgFeier hatte, unvergesslich sein. Am Sonntag, 30. September, war eine Eröffnungsfeier in dem Kolosseum, das 2600 Menschen Platz bot. [...] Um 6 Uhr ward die Feier begonnen mit einem Musikstück der Militärkapelle und einem Chorliede, von 200 Kindern gesungen [...].

An dem Geburtstage selbst war am Nachmittag die Jugendfeier, die Gymnasialdirektor Schreiber und Rektor Tecklenburg vorbereitet hatten. Es war strahlender Sonnenschein und eine sommerlich warme Witterung war dieser Feier im Freien beschieden. Ein großer Festumzug, an dem mehr als 3500 Kinder teilnahmen, ging unter Musik der Militärkapelle, der Städtischen Kapelle und der Spielleute der Jugendwehr vom Weendertor durch die reich geschmückten und beflaggten Straßen zum Kasernenplatz am Geismartor. Hier war eine Festkanzel errichtet, grün geschmückt, an beiden Seiten waren Gewehrpyramiden aufgebaut. “" ${ }^{\text {1129 }}$

Der Festakt lief dann nach dem gleichen Schema wie ähnliche Feiern ab.

Neben offiziellen Schulfeiern und Aktionen zugunsten der ,Hindenburgspende' gab es noch eine ganze Reihe weiterer schulischer Aktivitäten zu Ehren Hindenburgs. Vielfach wurde eine „Hindenburg-Eiche“ gepflanzt, wie z. B. in der thüringischen Kleinstadt Lucka ${ }^{1130}$. Seltener kam es vor, dass Schulen - wie in Göttingen ${ }^{1131}$ - einen „Hindenburgstein“ errichteten. Einige höhere Schulen nahmen den 70. Geburtstag zudem zum Anlass, sich nach dem Feldherrn zu benennen. $^{1132}$

Auch im letzten Kriegsjahr wurde der Geburtstag Hindenburgs von vielen Schulen begangen, nach Pust ,jedoch wohl nicht so aufwendig wie zum runden siebzigsten Geburtstag des Vorjahres“1133. Das stellvertretende Generalkommando in Altona hatte die Schulen durch das Provinzial-Schulkollegium Schleswig-Holsteins auffordern lassen, den Anlass mit „entsprechenden Ansprachen“ zu begehen. Der preußische Unterrichtsminister hatte kurz zuvor auBerdem die Schulen dazu aufgerufen, eine Erklärung Hindenburgs mit Durchhalteparolen an die Schüler und Schülerinnen zu verteilen.

\footnotetext{
${ }^{1128}$ Adler, Chronologischer Abriß der Stadt Schweidnitz von 1243 bis 1918, http://www.horst-adler.de/ Schweidnitz_1243-1918.pdf (08.07.2008).

${ }_{1129}$ Saathoff, Albrecht, Göttinger Kriegsgedenkbuch. 1914-1918 (1935), S. 186f.

1130, ,2.10.17. Am 70. Geburtstag des Generalfeldmarschall von Hindenburg wurde auf dem Schulplatz die ,Hindenburgeiche' gepflanzt.“ Die „Luckauer Heimatblätter“ befinden sich nach Auskunft des Archivs der Stadt Meuselwitz am 8.10.2004 im Thüringischen Staatsarchiv in Altenburg.

${ }^{1131}$ „Im September 1915 haben Knaben an der Ecke der Lotze und Riemannstraße einen Hindenburgstein errichtet und eine richtige Weihefeier gehalten." (Saathoff, Göttinger Kriegsgedenkbuch. 1914-1918 [1935], S. 136).

${ }^{1132}$ Als Beispiel sei das Kaiser-Wilhelm-Gymnasium in Trier genannt: „1917 Anläßlich seines 70. Geburtstages erlaubt der Generalfeldmarschall von Hindenburg der Schule, seinen Namen zu tragen." Das Schreiben vom 26. Oktober, das die eigenhändige Unterschrift Hindenburgs trug, hing bis zur Zerstörung des Schulgebäudes 1944 unter Glas und Rahmen im Konferenzzimmer der Anstalt. (Müller, Schulgeschichte von 1821 bis 1959, http://hgt.bildung-rp.de/seiten/chronik1.htm).

${ }^{1133}$ Pust, „Vaterländische Erziehung" für „Höhere Mädchen" (2004), S. 350.
} 
Wie die angeführten Beispiele zeigen, hatte sich der „Hindenburg-Tag“ auch für die Schulen, die für diesen Tag generell schulfrei gewährten und flaggten, mit zunehmender Kriegsdauer zu einem dritten Nationalfeiertag entwickelt und an Beliebtheit in den letzten Kriegsjahren sogar den ,Kaisergeburtstag' insgesamt übertroffen.

Abschließend sei aus dem Gratulationsbrief eines Schülers aus der Schule Pr. Battau bei Neukuhren (Provinz Ostpreußen) zitiert, den dieser anlässlich des 68. Geburtstages an den Generaloberst von Hindenburg geschrieben hatte:

„Sehr geehrter Herr General von Hindenburg! In der Zeitung habe ich gelesen, daß Sie am 2. Oktober Geburtstag haben. Die Schule Pr. Battau im Kreise Fischhausen gratuliert aufs herzlichste und wünscht, daß Sie dem Russen wie bisher, so auch weiter das Leder vollhauen möchten. [...] Hier schicke ich Ihnen auch ein Bild, auf welchem wir als Soldaten angetreten sind. Ich bin der Anführer und habe ein Eisernes Kreuz auf der Brust. Auf einem Bilde stricken die Mädchen für die Soldaten Strümpfe. Ich möchte gern ein Bild von Ihnen haben, aber ein recht großes. Wir wollen es in unserer Schule neben unseren Kaiser hängen. “"1134

Der Brief verdeutlicht die Popularität Hindenburgs und spiegelt sicher nicht nur die Einstellung der Schüler in Pr. Battau (Provinz Ostpreußen) zu dem Feldherrn wider ${ }^{1135}$, sondern lässt Rückschlüsse auf die Einstellung der Allgemeinheit zu. ${ }^{1136}$ Der Schreiber versteht sich durchaus als Soldat an der „Heimatfront“, der unter dem Kommando Hindenburgs steht und in der Schule sich für den Kampf an der militärischen Front vorbereitet.

\subsection{Hohenzollernfeier}

Am 21. Oktober 1915 begingen viele Schulen die ,Hohenzollernfeier' (500 Jahr Hohenzollern). ${ }^{1137} \mathrm{Da}$ sie sich nicht wesentlich von den Schulfeiern an den Nationalfeiertagen unterschieden, soll anhand von wenigen Beispielen nur kurz darauf eingegangen werden.

Besonders ausführlich wurde über die entsprechende Veranstaltung der höheren Schule in Neuß (Rheinprovinz), die wie in einigen anderen Schulen auch mit einer Nagelung verbunden wurde, in der Neuß-Grevenbroicher Zeitung berichtet:

„Gestern abend schon hatte die Schule Marienberg ihre Zöglinge zu einer schönen und erhebenden Feier versammelt, der auch viele Angehörige der Kinder beiwohnten. Hübsche Gedichte und Vorträge wechselten mit recht gut zum Vortrag gebrachten echt patriotischen Chören. Besondere Erwähnung dürfte vor allem der 2. Akt aus dem Schauspiel ,Kolberg' von Paul Heyse verdienen, der von den Schülerinnen mit wahrem Empfinden und echtem vaterländischem Feuer vorgetragen wurde. Am Schlusse hielt der hochwürdige Herr Rektor Emonds die Festrede, bezugnehmend auf den Sinn des Festes und alle ermahnend treu zu Kaiser und Reich zu stehen jetzt und immerdar. Er

\footnotetext{
${ }^{1134}$ Förster, Die deutsche Jugend und der Weltkrieg (1915), S. 127.

${ }^{1135}$ Bei dieser und ähnlichen Quellen stellt sich die Frage nach der Autentizität, denn der Brief kann z. B. durchaus auch von einem Lehrer diktiert worden sein.

${ }^{1136}$ Siehe: Anhang, Seite 79.

${ }^{1137}$ Am 21. Oktober 1415 huldigten die brandenburgischen Stände auf einem Landtag zu Berlin dem Hohenzoller Friedrich IV. von Nürnberg. Die förmliche Belehnung mit der Kurmark und die Verleihung der Würde des Erzkämmerers wurden am 18. April 1417 vom Kaiser vollzogen.
} 
ließ seine Rede ausklingen in ein kräftiges Hoch auf die Zollern und auf unseren jetzigen Kaiser, worauf stehend die National-Hymne gesungen wurde. “1138

Einen Tag später, am Morgen des 21. Oktober ${ }^{1139}$, fand nach einem feierlichen Hochamt die Einweihung und Nagelung eines eisernen Kreuzes durch die Schulgemeinde statt. ${ }^{1140}$ Auch in der Oberrealschule zu Bad Oldesloe wurde der Gedenktag mit einer feierlichen Nagelung begangen. ${ }^{1141}$

Viele Berichte über die schulischen Aktivitäten anlässlich des Hohenzollernjubiläums beschränken sich auf Hinweise, dass eine Feier stattgefunden habe und anschließend schulfrei gewesen sei, wie z. B. in Brehna ${ }^{1142}$, Mittel-Podiebrad, ${ }^{1143}$ Schweidnitz $^{1144}$ oder in BerlinCharlottenburger Volksschulen.

Der Wortlaut der Festreden durch die Schulleiter oder andere Lehrer ist nur in Ausnahmefällen überliefert, die vorhandenen Quellen zeigen jedoch, dass die Ansprachen sich insgesamt nicht wesentlich von der Festrede der Oberstudienrätin Hedwig Jahnow an der Elisabethschule in Marburg unterschieden haben dürften, die über das Thema „Die Entwicklung der Staatsgesinnung unter den Hohenzollern" sprach. ${ }^{1145}$

Viele Festredner werden sich inhaltlich sicher auch an dem „Gedenkblatt zum 21. Oktober 1915“ orientiert haben, das kurz vor dem Jubiläum im ,Deutschen Philologen-Blatt’ veröffentlicht worden ist. In ihm setzte sich der Lehrer Paul Meinold sehr ausführlich mit dem Thema „Hohenstaufen und Hohenzollern - Das alte und das neue Reich“ auseinander. ${ }^{1146}$

1138 Chronik der Schule Marienberg nach den vorhandenen Unterlagen, http://www.erzbistumkoeln.de/export/sites/erzbistum/schule/marienberg/_galerien/download/Chronik_der_Schule_Marienberg_nach den_vorhandenen_Unterlagen.pdf (13.11.2007).

${ }^{1139}$ Der 21. Oktober 1915 ist recht häufig für feierliche Nagelungen genutzt worden.

1140 Siehe: Kapitel 7.

1141 „Am 21. Oktober 1915 wurde der Gedenktag der 500jährigen Herrschaft des Hohenzollernhauses in Brandenburg durch einen Festaktus gefeiert. Prof. Dr. Hansen hielt die Festrede. Nach der Feier begaben sich die Schüler unter Führung der Lehrer nach dem Kurhause zur Nagelung eines dort zum Besten des Roten Kreuzes aufgestellten Eisernen Kreuzes. Der erste goldene Nagel wurde eingeschlagen mit dem Spruch: ,In den Staub mit allen Feinden Brandenburgs! " Prof. Dr. Brenner, Die Oberrealschule zu Bad Oldesloe während des Weltkrieges (1914 bis 1918) http://de.tms-od.de/ (14.02.2008).

${ }_{1142}$ „Am 21. Oktober 1915 wurde in einer Schulfeier der 500 Jahre zuvor (gedacht).“ (Feldmann, Zur Geschichte der Brehnaer Schule von ihren Anfängen bis 1945, S. 44).

1143 „Am 21. Oktober fand anlässlich der 500jährigen Herrschertätigkeit des Hohenzollernhauses eine Schulfeier statt. Der Unterricht fiel aus." (Johann/Tchech/Schicha/Zwikirsch/Matzel/Rosemann, Schulchronik der Schule zu Mittel-Podiebrad, S. 24 (19.09.2007).

1144 „1915, 22.10.: 500 jähriges Hohenzollernjubiläum. Feiern in den Schulen, danach schulfrei, Fahnen [...].“ (\{Adler, Chronologischer Abriß der Stadt Schweidnitz von 1243 bis 1918, http://www.horstadler.de/Schweidnitz_1243-1918.pdf [08.07.2008]).

1145 Jahnow, Die Entwicklung der Staatsgesinnung unter den Hohenzollern. Festrede, gehalten am 21. Oktober 1915, Neue Jahrbücher für das klassische Altertum, Geschichte und deutsche Literatur, 512; Weyer, EXPERIMENT-Sonderheft, http://www.elisabethschule.de/schueler/schuelerzeitung/experiment_sonder.html (98.7.2008); Hedwig Jahnow (21. März 1879 - 23.3.1944) war Lehrerin an der Elisabethschule in Marburg (ab 1925 stellv. Direktorin); sie wurde als Jüdin nach Theresienstadt deportiert.

${ }^{1146}$ Meinhold, Hohenstaufen und Hohenzollern, Deutsches Philologen-Blatt 1915, S. 601-603. 
Neben den genannten schulischen Feierlichkeiten kam es häufiger vor, dass Lehrer Informationsveranstaltungen und Unterhaltungsabende zum Hohenzollernjubiläum organisierten bzw. als Redner auftraten, wie z. B. in Mittel-Podiebrad. ${ }^{1147}$

Eine Reihe von Kommunen nutzte die Jubiläumsfeier nicht nur, um Ortschroniken und ,Gedenkbücher' zu veröffentlichen ${ }^{1148}$, an denen häufiger auch Lehrer mitgeschrieben haben dürften, sondern auch, um neue Schulen einzuweihen. Beispielhaft sei die „Chronik der Stadt Friesack“1149 (Provinz Brandenburg) des Rektors Gustav Zimmermann genannt. Auch wenn selbstverständlich die Schulen bei weiteren dynastischen Feiern in Preußen oder in den anderen deutschen Staaten beteiligt waren ${ }^{1150}$, so soll hier nicht darauf eingegangen werden, da sie sich insgesamt nicht von denen zum Hohenzollernjubiläum 1915 unterschieden.

Die Ergebnisse zeigen, dass sich die Schulfeiern und andere schulische Aktivitäten zum Jubiläum der Hohenzollern (und ähnlichen dynastischen Feiern in den anderen deutschen Staaten) hinsichtlich der Rituale und Inszenierungen nicht von denen der Nationalfeiertage unterschieden. Wie an ,Kaisergeburtstag' standen die Loyalitätsbezeugungen gegenüber dem Kaiser und der Herrscherfamilie und Durchhalteparolen im Vordergrund.

1147 Johann/Tchech/Schicha/Zwikirsch/Matzel/Rosemann, Schulchronik der Schule zu Mittel-Podiebrad (19.09.2007).

${ }^{1148}$ Zum Beispiel erschien zum 21.Oktober 1915 die „Chronik der Stadt Friesack“, (Die Chronik der Stadt Friesack, http://www.awo-friesack.de/ge/ge3.html).

${ }^{1149}$ Im Juni 1913 freut sich der Friesacker Rektor Gustav Zimmermann über das 500jährigen HohenzollernJubiläum und ,tief beseelt von diesem freudigem Ereignis schreibt er dem Kaiser zu Ehren und dem Bürger zur Erbauung ,Die Chronik der Stadt Friesack'. Auf 137 Seiten rückt Zimmermann unser Städtchen in das rechte Licht der europäischen Weltgeschichte“ (Die Chronik der Stadt Friesack, http://www.awofriesack.de/ge/ge3.html).

${ }^{1150}$ Als Beispiel sei die 100jährige Zugehörigkeit der Rheinlande zu Preußen genannt, wegen der in St. Willibrord Wardt eine „Schulfeier veranstaltet“ wurde. Über sie wurde berichtet: „Durch Vortrag wies der Lehrer darauf hin, daß das Rheinland besonders unter der Herrschaft der Hohenzollern, ganz besonders unter der Herrschaft des Friedenskaisers Wilhelm II., zu der jetzt blühenden Provinz geworden sein. Deshalb sei mit dem Dichter zu sprechen: 'Sie sollen ihn nicht haben den freien deutschen Rhein!' und ,Wir wollen alle Hüter sei!'. Deshalb sangen die Kinder das Lied mit Begeisterung ,Es braust ein Ruf wie Donnerhall'! Nachdem aus dem Lesebuch ein Stück über die Rheinlande gelesen war, wurde unserm geliebten Kaiser Wilhelm ein ,Hoch' gebracht und das Lied ,Heil dir im Siegerkranz' gesungen.“ (Aus der „Schul-, Dorf- und Kirchenchronik" St. Willibrord Wardt, http://www.xanten-web.de/Domstadt/WardtChro5.html (03.04.2008)).

Auch in Dessau wurde beispielsweise am Geburtstag des Herzogs am 20. August 1915 eine „Schulfeier vor dem ,Kreuz in Eisen”“ durchgeführt; siehe: Kapitel 9.3.4 (Die Schulfeier vor dem „Kreuz in Eisen” im Landesmuseum der Stadt Dessau, Anhaltinisches Tageblatt); am 28. Juni 1916 begann die Nagelung des Kriegswahrzeichens in Speyer mit Beteiligung von Schulklassen , genau an dem Tage, an dem 100 Jahre vorher König Maximilian I. von Bayer zum ersten Male nach der Besitzergreifung der Pfalz durch Bayern seinen Einzug gehalten hatte". (Kriegswahrzeichen der Stadt Speyer); http://www.museum.speyer.de/sammlungen/neuzeit/ sammlungen _neuzeit_kriegszeichen). 


\subsection{0jähriger Gedenktag der Reformation (31. Oktober 1917)}

Der 400jährige Gedenktag an die Reformation am 31. Oktober 1917 wurde zwar hauptsächlich in den deutschen Staaten mit überwiegender protestantischer Bevölkerung gefeiert ${ }^{1151}$, aber auch in den katholischen Gebieten, die sich unter der Herrschaft des protestantischen Preußens befanden, begingen die evangelischen Gemeinden und häufig auch die Schulen das Jubiläum festlich. ${ }^{1152}$ Der preußische Unterrichtsminister ließ für die evangelischen Schüler und Lehrer den Unterricht ausfallen und ordnete an, „,würdige Schulfeiern abzuhalten“. Diese sollten aber nicht in die Zeit der kirchlichen Feiern gelegt werden, damit Schüler und Lehrer an den Festgottesdiensten teilnehmen könnten. ${ }^{1153}$ Die Kultusbehörden in einigen preußischen Provinzen empfahlen den Schulen sogar, ,zur bleibenden Erinnerung an die Feier des 400jährigen Gedächtnisses der Reformation“"1154 ein Lutherbild (Cranach) zu erwerben und die Schulräume der evangelischen Schule damit auszuschmücken. Zur Vorbereitung der Schüler auf das Jubiläum und zur Durchführung der Schulfeiern erschienen zahlreiche Publikationen. ${ }^{1155}$ Wie aus einem Beitrag in der ,Monatsschrift für Höhere Schulen’ zum Jahreswechsel 1917/18 hervorgeht, ist das Jubiläum an vielen deutschen Schulen feierlich begangen worden. ${ }^{1156}$

Hauptsächlich am Beispiel der preußischen Rheinprovinz soll untersucht werden, inwieweit die Schulen an den Feierlichkeiten beteiligt waren und sich die Inszenierungen des kirchlichen Jubiläumsfests von denen der patriotischen, weltlichen' Feiern unterschieden haben. Während für den Hunsrück lediglich eine einzige Schulfeier nachgewiesen ist, gab es im Landkreis Meisenheim und in der Stadt Koblenz umfangreiche Feierlichkeiten, in die auch die Schulen eingebunden waren. ${ }^{1157}$

Die ,Hunsrücker Zeitung' erwähnte in ihrer Ausgabe vom 1. November, dass die Reformationsfeier der höheren Schulen in Meisenheim ,am gestrigen Tag in würdiger, stiller, der Zeit

\footnotetext{
${ }^{1151}$ Im Gegensatz zu Jubiläum 1883 verzichtete man in vielen Städten wegen des Kriegs auf öffentliche Volksfeiern, sondern beschränkte sich auf Festgottesdienste und Schulfeiern; siehe z. B. die Feier in Bremen (Veeck, Die Reformation in Bremen [1917]).

1152 Auch in Bayern bekamen Schüler und Lehrer am 31. Oktober 1917 schulfrei, (Oskar-von-MillerGymnasium, Chronik, http://www.ovmg.de/index.php?page=chronik (20.01.2010).

${ }^{1153}$ Feier des Gedenktages der Reformation, Zentralblatt für die gesamte Unterrichtsverwaltung in Preußen, 1917, S. 103f.

${ }^{1154}$ Zur Gedächtnisfeier der Reformation, Amtliches Schulblatt für den Regierungsbezirk Königsberg, 1917, S. 104.

${ }^{1155}$ Siehe: „Zur Jubel-Feier der Reformation: (1517-1917); Ausgeführte Schulfeier mit Ansprachen Liedern und Vortragsstoffen, nebst Reden und Gedichten“" Schreck, Zur Jubelfeier der Reformation: 1517-1917 (1917)) und „Lutherlieder: ein Fest- und Schulbüchlein zur Feier des Jubeljahres der Reformation 1917“ (von der Heydt, Lutherlieder: ein Fest- und Schulbüchlein zur Feier des Jubeljahres der Reformation 1917 (1917).

${ }^{1156}$ Zum Jahreswechsel, Monatszeitschrift für höhere Schulen, 1918, S. 2.

${ }^{1157}$ Landesarchivverwaltung Rheinland-Pfalz, Vor 85 Jahren, http://www.landeshauptarchiv.de /blick/archiv.html?31.10.2 (08.07.2008) .
} 
angemessener Weise verlaufen“"1158 sei. Einige Tage später, am 4. November, fanden öffentliche Schulfeiern der Lateinschule und der evangelischen Volksschule im Gemeindehaus statt. ${ }^{1159}$ Wie bei den großen nationalen Festen war gebeten worden, ,am 31. Oktober, dem Tage des Reformationsjubiläums, die Häuser mit Flaggenschmuck zu versehen“.

Auch an einer „Jubelfeier der evangelischen Gemeinde“ war die Schule beteiligt, denn im Mittelpunkt des umfangreichen Programms stand die Rede des Rektors der Lateinschule, der u. a. ,in fesselnden Worten darlegte, wie Luther christlichen Geist und germanisches Wesen vereint und seinem Volke Gewissensfreiheit gebracht habe“.

Für den 31. Oktober 1917 war wegen des guten Erfolges bei der 7. Kriegsanleihe von der Regierung der Rheinprovinz ein schulfreier Tag angeordnet worden. Deshalb fanden in den meisten Schulen morgens zunächst Reformationsfeiern statt, nach deren Ende die Schulkinder entlassen wurden. ${ }^{1160}$ Über den genauen Ablauf der Feiern ist wenig bekannt, allerdings kann davon ausgegangen werden, dass generell zwar die Person Martin Luthers im Mittelpunkt stand, die Veranstaltungen aber nach ähnlichem Ritual abliefen wie die nationalen Gedenktage. Wenn der ,Allgemeine Anzeiger für den Kreis Meisenheim' am 31.10.1017 Luther als den „deutscheste(n) Mann, den es je gegeben hat“, bezeichnet, so zeigt das sowohl die Bedeutung, die dem Reformationsjubiläum zugemessen wurde - sogar in der Rheinprovinz mit einer überwiegend katholischen Bevölkerung ${ }^{1161}$-, als auch die enge Verbindung von Kirche und Staat, wobei die religiösen Elemente stärker als bei weltlichen Feiertagen betont wurden. ${ }^{1162}$ Für Nipperdey war die „Nationalisierung Luthers im Jubiläumsjahr 1917“،1163 ein Höhepunkt des nationalen Enthusiasmus der evangelischen Kirche.

Als Beispiel dafür, dass auch das Reformationsjubiläum im Rahmen von wirkungsvoll inszenierten Nagelungsfeiern begangen wurde ${ }^{164}$, sei auf die Schulchronik aus Ladegast (Provinz Brandenburg) hingewiesen. ${ }^{1165}$

\footnotetext{
${ }^{1158}$ Landesarchivverwaltung Rheinland-Pfalz, Vor 85 Jahren, http://www.landeshauptarchiv.de /blick/archiv.html?31.10.2 (08.07.2008) .

${ }^{1159}$ Zum Programm gehörte z. B. das „Lutherspiel ,Jung Luthers silbernes Ringlein”“ (Landesarchivverwaltung Rheinland-Pfalz, Vor 85 Jahren, http://www.landeshauptarchiv.de/blick/archiv.html?31.10.2 (08. 07. 2008) ).

${ }^{1160}$ Siehe z. B. die Schule in Wardt bei Xanten (Aus der „Schul-, Dorf- und Kirchenchronik" St. Willibrord Wardt, http://www.xanten-web.de/Domstadt/WardtChro5.html (03.04.2008)).

${ }^{1161}$ Landesarchivverwaltung Rheinland-Pfalz, Vor 85 Jahren, http://www.landeshauptarchiv.de /blick/archiv.html?31.10.2 (08.07.2008).

${ }^{1162}$ Siehe: Vondung, Kriegserlebnis (1980), S. 62-84.

${ }^{1163}$ Nipperdey, Deutsche Geschichte (1994), Band 1, S. 491.

${ }^{1164}$ Dieses geht auch aus dem Jahresbericht des „Jugenddanks für Kriegsbeschädigte“ (Januar 1918) hervor, in dem hervorgehoben wird, dass Nagelungen , anläßlich des Reformationsjubiläums an vielen Orten veranstaltet wurden“. (Jugenddank für Kriegsbeschädigte e.V., Jugenddank für Kriegsbeschädigte e.V. 1917 und 1918, S. 5). 1165 „Der Gottesdienst verlief nach dem von der Kirchenbehörde aufgestellten Programm. Ein Schild mit aufgezeichneter Bibel und Schwert zum Benageln wurde als Erinnerungszeichen an diese Feier gestiftet (Reformationsgedächtnisschild) und mit der Nagelung begonnen.“(,Lieber Herr Pastor!“, http://www.beepworld.de/members3/seydaaktuell/heimatstube.htm [11.03.2010]).
} 
Die reichsweit durchgeführten Feiern, die einen breiten Raum in der öffentlichen Berichterstattung einnahmen ${ }^{1166}$, dienten vorrangig nicht der Stärkung des Durchhaltewillens, sondern boten vielmehr angesichts der bedrohlichen militärischen und schlechten wirtschaftlichen Lage eine vorübergehende Ablenkung von den Auswirkungen des Krieges.

\subsection{Siegesfeiern}

Im Gegensatz zu den jährlich sich wiederholenden Festen (Kaisergeburtstag und Sedantag) wurden, gab es bei den kriegsbedingten Feiern, also den Sieges- und Gedankfeiern, hinsichtlich der terminlichen Festsetzung und der Durchführung in den Kommunen deutliche Unterschiede $^{1167}$. Die Entscheidung, ob Siegesfeiern angesetzt wurden, überließ man weitgehend den Landräten und den Oberbürgermeistern. ${ }^{1168}$ Sie strebten zwar an, in den Schulen desselben Ortes gemeinsame Schulfeiern zu begehen, wie es die staatlichen Behörden angeordnet hatten, allerdings gelang dieses nicht immer. ${ }^{1169}$ Wenn allerdings das am Ort garnisonierende Regiment an einem Sieg beteiligt war, so feierten die Schulen in der Regel gemeinsam den Sieg. Auch die staatlichen Behörden bemühten sich mehrfach, die Durchführung der Siegesfeiern durch Erlasse und Verfügungen zu vereinheitlichen. ${ }^{1170}$ So regelte z. B. der preußische Unterrichtsminister mit Erlass vom 18. 02. 1915 das Verhalten der Schulbehörden bei militärischen Erfolgen der deutschen Truppen und ordnete an, dass am Tage nach dem Sieg in der Schule eine gemeinsame Feier stattfinden und danach schulfrei sein sollte. ${ }^{1171}$ Die Provinzialregierungen und Provinzial-Schulkollegien ${ }^{1172}$ erließen ebenfalls entsprechende

\footnotetext{
${ }^{1166}$ In der wissenschaftlichen Literatur ist dem Thema allerdings nur wenig Aufmerksamkeit gewidmet worden. So gibt es eine umfangreiche Literatur zu dem Jubiläum von 1883 (siehe z. B.: Schmid, Reformations- und Lutherfeiern in Hannover 1617-1883 in Schmid (Hrsg.), Feste und Feiern in Hannover (1995), Burkhardt, Reformations- und Lutherfeiern in Düding (Hrsg.), Öffentliche Festkultur (1988), nicht aber über den Gedenktag am 31. Oktober 1917.

${ }^{1167}$ Zwar waren die Schulen häufig auch an den kommunalen Siegesfeiern beteiligt, die Quellen geben über die Art der Beteiligung allerdings nur selten und vage Aufschluss. Deshalb beschäftigt sich das Kapitel ausschließlich mit den schulischen Feiern.

${ }^{1168}$ Siehe: Meinardus, Schulfeiern, Monatszeitschrift für höhere Schulen, 1917, S, 546f.

${ }^{1169}$ Siehe: Flensburg (Pust, ,Vaterländische Erziehung" für „Höhere Mädchen" (2004), S. 338.

1170 Führen zitiert eine Reihe von Verfügungen und Erlassen, z. B. der Königlichen Kreis und StadtSchulinspektion IIV Köln, der Königlichen Regierung in Düsseldorf, der Schuldeputation in Frankfurt a. M., des bayerischen Kultusministeriums und der Regierung in Hildesheim (Führen, Lehrer im Krieg [1936], S. 107117).

${ }^{1171}$ Siehe: 75 Jahre Knaben-Mittelschule Augustplatz/ Realschule, John.F.-Kennedy-Platz in Braunschweig, http://www.nibis.de/ rskennedyplatz/schulgeschichte/schulgeschichte.html (19.07.2008).

${ }_{1172}$ Zum Beispiel in einem Erlass des Provinzial-Schulkollegiums in Schleswig-Holsteins vom 10. September1914: „Durch Gottes Hilfe sind uns in den schweren, von den Feinden uns aufgezwungenen Kriege schon jetzt mehrere bedeutsame Erfolge zuteil geworden. Das deutsche Volk hofft, daß ihm auch fernerhin ähnliche Erfolge beschieden sein werden. Damit die große Zeit sich recht kräftig dem Gedächtnis der Jugend einpräge, ermächtigen wir Sie, den Unterricht bei solchen Gelegenheiten ausfallen zu lassen. Doch sind vorher in einer kurzen, würdigen Schulfeier die Schüler auf die Bedeutung der Ereignisse hinzuweisen." (Zitiert nach: Pust, „Vaterländische Erziehung" für „Höhere Mädchen" [2004], S. 331).
} 
Vorschriften, in denen sie auch den Ablauf der Feiern regelten, wie u. a. die Provinzialregierung in Königsberg:

„Es sind Zweifel darüber entstanden, ob in den Volksschulen unseres Bezirks aus Anlaß größerer Siege Schulfeiern unter Aussetzung des Unterrichts selbständig durch die Lehrer abgehalten werden oder erst durch Anordnung der vorgesetzten Behörde stattfinden dürfe. Wir ordnen daher an, daß bei Bekanntwerden von größeren Siegen unserer Truppen in den Schulen vor Beginn oder am Ende des planmäßigen Unterrichts eine schlichte patriotische Feier stattzufinden hat. Wenn die Siege nach dem Urteil des Lehrers bedeutungsvoller insbesondere für unsere Heimatprovinz und für die Gestaltung des ganzen Feldzugs erscheinen, kann der Unterricht an dem Tage der Schulfeier ausfallen. In jedem Falle ist ein Vermerk in das Tagebuch und die Schulchronik aufzunehmen. Die Lehrpersonen des Bezirks sind entsprechend anzuweisen." ${ }^{1173}$

Offensichtlich ist es trotz der offiziellen Regelungen insgesamt nicht gelungen, den Unterrichtsausfall an Schulen bei militärischen Siegen zu vereinheitlichen, wobei insbesondere an höheren Schulen häufiger Siegesfeiern durchgeführt wurden als an Volks- und Bürgerschulen. ${ }^{1174}$ Unterschiede zwischen den Schulen gab es auch hinsichtlich der Siege, die gefeiert wurden $^{1175}$, da die Schulen in der Auswahl der Anlässe zunächst verhältnismäßig frei waren und auch die Kommunen später beim Versuch einer Vereinheitlichung der Feiern ihrer Schulen nur bedingt Erfolg hatten. Hauptsächlich lag das daran, dass die Schulen nicht schnell genug informiert wurden. ${ }^{1176}$ Mit zunehmender Kriegsdauer kam es aber durchaus auch vor, dass Schulleiter trotz wichtiger militärischer Siege den Unterricht nicht ausfallen ließen, um den ohnehin schon starken Unterrichtsausfall etwas einzuschränken. ${ }^{1177}$

Im Folgenden soll vor allem den Fragen nachgegangen werden, in welchem Umfang Feiern in den Schulen durchgeführt wurden, wie die Feiern abliefen und ob die Schüler sich mehr über die militärischen Siege oder über die schulfreien Tage freuten. Wie von den Behörden angeordnet, waren die Schulen verpflichtet, Siegesfeiern im Tagebuch und in der Schulchronik zu vermerken. Da viele solcher Unterlagen erhalten sind, ist die Quellenlage insgesamt recht gut und ermöglicht einen gesicherten Überblick über die Durchführung der Feiern.

In der Regel fiel in den ersten beiden Kriegsjahren wegen der militärischen Erfolge jährlich an etwa 10 bis 20 Tagen der Unterricht aus. Beispielsweise waren es in der Schule IV in

\footnotetext{
${ }^{1173}$ Königliche Regierung für Ostpreußen, Betrifft Schulfeiern aus Anlaß größerer Siege, Amtliches Schulblatt für den Regierungsbezirk Königsberg, 1915, S. 40.

${ }^{1174}$ Dieses wird beispielsweise am 8.6.1916 in den ,Schleswiger Nachrichten kritisiert: „Es erregt jedes Mal Verdruß, wenn Schulen da sind, die nicht frei bekommen, insonderheit wird es von den Bürgerschulen übel vermerkt, wenn wohl die höheren Schulen, aber nicht sie frei bekommen.“(Zitiert nach: Pust, „Vaterländische Erziehung" für „Höhere Mädchen" (2004), S. 332).

${ }^{1175}$ Hohnsbehn, Die Flensburger Schuljugend in der Zeit des ersten Weltkriegs (1996), S. 177.

${ }^{1176}$ Die ,Kieler Neuesten Nachrichten' kritisierten am 13.05.1916 solche Verzögerungen: „Gerade im jugendlichen Gemüt ist doch die Begeisterung des ersten Augenblicks die höchste.“ (Zitiert nach: Pust, „Vaterländische Erziehung" für „Höhere Mädchen" [2004], S. 332).

${ }^{1177}$ So erinnert sich eine ehemalige Schülerin der Sophienschule in Hannover: „Wißt ihr noch die Verkündung der Siegesnachrichten auf dem Schulhof? Siegesfrei gab es nur am Anfang, später hieß es: 'Unsere Soldaten haben auch nicht frei'.“(Beyte, Sophienschule Hannover [1916]).
} 
Marxloh (Hamborn) 11 Tage $^{1178}$ und in der Eugen-Langen-Schule (Hilfsschule) in WuppertalBarmen 19. ${ }^{1179}$ Zwar gab es Siege, die an nahezu allen deutschen Schulen gefeiert wurden, wie z. B. die Einnahme von Antwerpen (9. Oktober 1914) und die Schlacht im Skagerrak (3. Juni 1916), vielfach jedoch unterschieden sich die Anlässe, die an den Schulen zu den Siegesfeiern führten. So wurden in den Husumer Schulen im Zeitraum zwischen Juni 1915 und Februar 1916 sechs Schulfeiern durchgeführt, während für Flensburg und Itzehoe keine Siegesfeiern bekannt sind. ${ }^{1180} \mathrm{Ab} 1917$ gab es wegen der ausbleibenden militärischen Erfolge nur noch vereinzelt Siegesfeiern. ${ }^{1181}$ Die für den 25. März 1918 von offiziellen Stellen angeordneten Feiern ${ }^{1182}$, die u. a. in der Eugen-Langen-Schule (Sieg bei Cambrai-La-Fère) sowie in Flensburg und in der Lensahner Schule (Provinz Schleswig-Holstein) ${ }^{1183}$ am 26. März 1918 stattfanden, gehörten mit zu den letzten, die an deutschen Schulen begangen wurden. Für die höheren Mädchenschulen Schleswig-Holsteins sind sogar von März 1918 an keine entsprechenden Veranstaltungen mehr bezeugt.

\section{Ablauf der Siegesfeiern}

Als nach Kriegsbeginn die ersten Meldungen über die militärischen Siege deutscher Truppen eintrafen, war auch in den Schulen die Begeisterung groß und es kam an vielen Orten zu spontanen Aktionen. Über die erste Siegesfeier des Krieges am 21. August 1914 berichtete z. B. die Göttinger Zeitung:

„Als die Siegeskunde von Metz mit Blitzesschnelle unsere Stadt durcheilte, ging eine jubelnde Freude durch alle Herzen! Mit einem Male war das Straßenbild verändert, überall ernstfrohe Gesichter und gläubige Zuversicht. Auf dem Marktplatz, im Herzen der Stadt, staute sich die Volksmenge. Hier kam die Begeisterung zu hellem Ausbruch. Schülerinnen des Lyzeums, durch einen Zufall vereint, waren es, die zuerst durch Singen vaterländischer Lieder ihrer Freude Ausdruck gaben. Schnell wuchs die Menge an, und immer lauter erscholl in dankbarer Freude ein Lied nach dem anderen."“1184

\footnotetext{
1178 1914-1918 Der erste Weltkrieg und was unsere Schulchronik dazu sagt, http://www.du.nw.schule.de/ grimm/grimmold3.htm (21.07.2008).

${ }^{1179}$ Eugen-Lange-Schule, http://www.eugen-langen-schule.de/1_weltkrieg.htm (01.09.2007).

1180 Siehe: Pust, ,, Erziehung" für „Höhere Mädchen" (2004), S. 336.

1181 Beispielsweise fanden in Copitz/Pirna (Kuleßa, Mittelschule „Johann Heinrich Pestalozzi" in Pirna, http://www.mspesta.com/page63.html (15.07.2008)) und Obermarxloh 1917 keine Feiern statt, in der EugenLange-Schule in Wuppertal-Barmen lediglich eine (2.11.; Sieg am Tagliamento).

1182 In der Lensahner Schulchronik heißt es dazu: „25. März (1918) S. M. der Kaiser befahl infolge des glänzenden Erfolges der Offensive im Westen den Unterricht ausfallen zu lassen. Die Siegesfeier fand am 26. März statt.“ (Stock, Schule und Erster Weltkrieg, http://www.sandermielke.de/www/homepage3/mybb/ showthread.php?tid=34 (07.07.2008).

${ }^{1183}$ Hohnsbehn, Die Flensburger Schuljugend in der Zeit des ersten Weltkriegs (1996), S. 178.

${ }^{1184}$ Saathoff, Albrecht, Göttinger Kriegsgedenkbuch. 1914-1918 (1935), S. 62f.
} 
In Münster ergriff die Bevölkerung nach einem Bericht der „Kreuzzeitung“ ebenfalls ein „Sturm der Begeisterung und alt und jung, Gymnasiasten, Arbeiter, Kaufleute und Studenten“1185 marschierten in ,geschlossenen Zügen“ durch die Stadt.

Auch in Hannover ,gab es für unsere Jugend kein Halten mehr, alles stürmte so schnell wie möglich auf die Straßen, mit freudestrahlenden Gesichtern zogen Schüler truppweise durch die Straßen, patriotische Lieder singend und daheim erzählend von dem Grunde des frühzeitigen Nachhausekommens“"1186. Über ihre Zeit an einer Bremer Volksschule erinnerte sich eine Zeitzeugin: „Die Kinder in den Klassen sangen: 'Deutschland, Deutschland über alles', die größeren auch: 'O Deutschland hoch in Ehren'. Aus der obersten Mädchenklasse klang es mit frischen Mädchenstimmen rein und klar: ,Kein schönrer Tod ist auf der Welt ${ }^{1187}$. Weit weg ist der Krieg, weit weg. Die Kinder ... bemerkten und teilten nur die Freude, wenn die Siegesnachrichten eintrafen, die Flaggen aufgezogen wurden und der Unterricht ausfiel. " ${ }^{1188}$ In der Kriegschronik der Gemeinde Halver (Provinz Westfalen) ist zu dem Sieg bei Metz vermerkt: „20. August: Die Glocken läutern, laute Böllerschüsse von der Karlshöhe, die Kinder ziehen mit Fähnchen singend durch die Straßen, am Abend große Versammlung am Denkmal vor der Kirche, der Posaunenchor bläst ,Nun danket alle Gott', die Menge stimmt ein, Hauptlehrer Schulte hält eine Ansprache, die Versammelten singen ,Heil dir im Siegerkranz', die Häuser sind geflaggt. “1189

Ähnliche Aktionen gab es in vielen Dörfern und Städten des Reiches. Als sich jedoch die Siegesnachrichten häuften, ließ die spontane Begeisterung der Schulkinder und Lehrer über die Siege oft nach und für die Schuljugend stand vor allem die Freude über den unterrichtsfreien Tag im Vordergrund. ${ }^{1190}$ Dieses geht aus Äußerungen von damaligen Schülern und Schülerinnen hervor. So bedauerte es z. B. Elfriede Kuhr aus Schneidemühl am 28. August 1914, dass die Nachricht von einem Sieg erst so spät in der Schule eintraf, dass der Unterricht erst nach „Mathematik und Geographie“"1191 ausfiel, und am 9. September 1914 trug sie in ihr Tagebuch ein: „Wir haben natürlich wieder schulfrei. In der Klasse tanzten die Mädels vor Ver-

\footnotetext{
1185 Zitiert nach: Nübel, Die Mobilisierung der Kriegsgesellschaft Bd. 14 (2008), S. 77.

1186 Hannoverscher Kurier, 24. August 1914; zitiert nach: Oberschelp/Grotjahn, Stahl und Steckrüben Bd. 1 (1993), S. 91.

${ }^{1187}$ Bei dem viel gesungenen Lied. „Kein schön'rer Tod ist in der Welt“ (1836) von Friedrich Silcher (17891860) handelt es sich um eine Umbildung eines Meistergesanges des 16. Jahrhunderts; Text der 1. Strophe:, „Als wer vorm Feind erschlagen/ Auf grüner Heid, im freien Feld/ Darf nicht hör'n groß Wehklagen//. Im engen Bett nur Ein'r allein/ Muß an den Todesreihen, Hier aber find't er Gesellschaft fein,/ Falln mit wie Kräuter im Maien." Es folgen zwei weitere Strophen (siehe: http://ingeb.org/Lieder/keinscht.html).

${ }^{1188}$ Frank, Erinnerungen aus dem 1. Jahrzehnt unserer Schule in 50 Jahre Schule an der Rechenflether Straße 1905-1955 (1955), S. 34.

${ }^{1189}$ Dresbach, Kriegs-Chronik der Gemeinde Halver von 1914 bis 1919 (1932), S. 6.

${ }^{1190}$ Siehe: Anhang, Seite 49.

${ }^{1191}$ Mihaly, ... da gibt's ein Wiedersehn! (1986), S. 49.
} 
gnügen. Mathematik, Deutsch-Grammatik, Französisch, Physik und Religion fielen aus. Trude Jakobi schrieb: ,Jeden Tag eine Schlacht, und wir brauchen nicht mehr in die Penne!'،1192 Eine Zeitzeugin aus Flensburg (*1909) erinnerte sich an ein Lied, das die Freude über die ,siegfreien' Tage ausdrückt:

„Heißa hopsa, heißa hopsa,

heut ist siegesfrei,

und die Schule und die Schule

ist mit einerlei!‘6193

Natürlich konnte diese wenig patriotische Einstellung der Kinder und der Jugendlichen nicht akzeptiert werden. Deshalb versuchten die Behörden durch Empfehlungen und Vorschriften zum Ablauf der schulischen Feiern auf die Einstellung der Schuljugend Einfluss zu nehmen, um die erwünschte patriotische Gesinnung in den Herzen und Köpfen der Kinder und der Jugendlichen dauerhaft zu verankern. Z. B. heißt es in einem Erlass des preußischen ProvinzialSchul-Kollegiums in Schleswig-Holstein vom 10. September 1914: „Durch Gottes Hilfe sind uns in den schweren, von den Feinden uns aufgezwungenen Kriege schon jetzt mehrere bedeutsame Erfolge zuteil geworden. [ ... ] Damit die große Zeit sich recht kräftig dem Gedächtnis der Jugend einpräge, ermächtigen wir Sie, den Unterricht bei solchen Gelegenheiten ausfallen zu lassen. Doch sind vorher in einer kurzen, würdigen Schulfeier die Schüler auf die Bedeutung der Ereignisse hinzuweisen.“1194 Der Stadt- und Kreisschulinspektor von Berlin, Dr. Schepp, schlug vor, die Zahl der Feiern einzuschränken. Außerdem sollten die ,Siegestage' ganz frei sein und die gemeinsamen Feiern erst am nächsten Tage durchgeführt werden. Das habe den Vorteil, dass die Schulen nicht mehr improvisieren müssten, sondern sich besser darauf vorbereiten könnten. Die Lehrer könnten im Anschluss an einen kurzen Festakt der

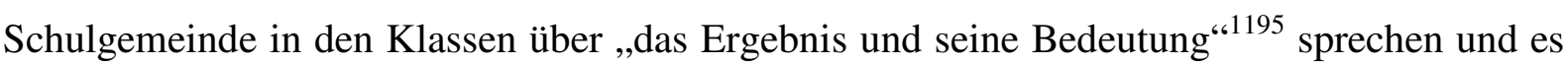
würdigen. Der vaterländische Gewinn wäre entschieden größer.

Ein Schulleiter aus Saarbrücken ging ebenfalls in einem ausführlichen Artikel in der Zeitschrift „Höhere Schule“ auf die Bedeutung von Siegesfeiern ein und machte eine Reihe von Vorschlägen zu ihrer Gestaltung. Auch für ihn waren sowohl der unterrichtsfreie Tag als auch die Durchführung einer gemeinsamen festlichen Schulfeier besonders wichtig:

„Nicht das soll für unsere Schüler die Hauptsache sein, daß sie einen freien Tag haben, sondern daß dieser Tag durch eine so frohe Feier eingeleitet wird, daß dann dazu der gewöhnliche Unterricht nicht mehr stimmen will. Beides gehört zusammen: die gemeinsame Feier und der freie Tag, daß

\footnotetext{
${ }^{1192}$ Mihaly, ... da gibt's ein Wiedersehn! (1986), S. 59.

${ }^{1193}$ Hohnsbehn, Die Flensburger Schuljugend in der Zeit des ersten Weltkriegs (1996), S. 175.

${ }^{1194}$ Zitiert nach: Pust, ,Vaterländische Erziehung" für „Höhere Mädchen" (2004), S. 331.

${ }^{1195}$ Schepp, Schule und Krieg, Die Woche, S. 407f.
} 
sich so das geschichtliche Ereignis fest der jungen Seele einprägt. [...]. (Es) wäre schlimm, wenn unsere Jugend an den einen oder anderen großen Sieg mit dem bittern Gedanken zurückdenken müsste, daß das Ereignis nicht einmal auf die richtige Weise gefeiert worden sein.“ ${ }^{1196}$

Seiner Meinung nach hatte sich an den Schulen inzwischen folgender Ablauf der Feier herausgebildet und bewährt ${ }^{1197}$ : Nach dem Gesang des Chores weist der Direktor auf die Bedeutung des Ereignisses hin; mit einem Hoch auf den Kaiser und einem allgemeinen Vaterlandslied endet die Feier; anschließend ist schulfrei. Die Quellen bestätigen, dass der Ablauf generell durch die Rede des Schulleiters, der gemeinsame Gesang patriotischer Lieder sowie ein Hoch auf Vaterland, Kaiser und Heer bestimmt wurde.

Im Folgenden soll am Beispiel von drei Quellen gezeigt werden, dass die Schüler sich offensichtlich nicht nur über den Unterrichtsausfall freuten, sondern auch die Feiern und deren Anlässe auf hohe Akzeptanz stießen. Außerdem zeigen sie die patriotische Einstellung der Lehrer. Auch wenn es sich bei der Schilderung des Volksschullehrers um einen offiziösen Eintrag in die Schulchronik handelt und der Tagebuchauszug von einem Schuldirektors stammt, lassen sie durchaus Rückschlüsse auf die begeisterte Aufnahme der Siegesmeldungen in den Schulen und die hohe Akzeptanz der Schulfeiern durch die Schüler zu. Viele ähnliche Äußerungen von Zeitgenossen und Tagebucheintragungen bestätigen, dass die Schüler über die Erfolge der Soldaten voller „Begeisterung, jubelnder Vaterlandsliebe und Dankbarkeit““198 waren, wie es Erna Lange in ihrem Kriegstagebuch formuliert hat. Direktor Loewenberg verglich die Siegesmeldungen des „WTB““1199 sogar mit Verheißungen der biblischen Heilsgeschichte (s. u.).

\section{Volksschule Tonnenheide, Lehrer Sturhan (Schulchronik 1915)}

„Am 5. Mai kam die Nachricht vom glücklichen Ausgang der Durchbruchsschlacht am Dujanec in Galizien. Hell läutete die Glocke, lustig flatterten die Fahnen. Mit wenigen Worten wurde auf die große Bedeutung dieses Sieges hingewiesen. Ein Hoch auf unseren Kaiser, auf das Heer und seine Führer folgte. Vaterlands und Dankeslieder erklangen von begeisterten Lippen. Und da es gerade sonniger Maientag war, wurde ein Spaziergang nach Frontheim zu den gefangenen Franzosen angeschlossen. - In ähnlicher Weise feierten wir in der Schule am 4.6. die Einnahme von Przemysl, am 24.6. die Besetzung Lembergs, am 21.8. die Eroberung von Kowno und Nowo Georgiewsk, am 26.8. die Besetzung von Brest-Litowsk und am 4.9. die Einnahme Grodnos.“" ${ }^{\prime 200}$

\footnotetext{
${ }^{1196}$ Meinardus, Schulfeiern, Monatszeitschrift für höhere Schulen, 1917, S. 546f.

${ }^{1197}$ Dieses trifft auf Schulen aller Schulformen vor, also sowohl für die höheren Schulen und die Mittelschulen als auch für die Volksschulen und die Hilfsschulen. Als Beispiel für den Ablauf einer Siegesfeier an einer Hilfsschule sei auf eine Schule in Dresden hingewiesen (siehe: Lehm, Zwei Siegesfeiern [1915], in: Deutsche Schulpraxis 1915, S. 403-407).

${ }_{1198}$ Siehe z. B. auch: Franke, 3. Die Kriegsgeneration, S. 208; Kramer, Die Schulgemeinde Marten Band 1 (1992), S. 57.

1199 „WTB“ ist die Abkürzung für „Wolffs Telegraphisches Bureau“, die wichtigste deutsche Nachrichtenagentur.

${ }^{1200}$ Kammeier, Der Landkreis Lübbecke und der 1. Weltkrieg (1998), S. 209. Tonnenheide lag im Regierungsbezirk Minden, Provinz Westfalen.
} 
Privates Lyzeum in Hamburg, Direktor Jakob Loewenberg (Kriegstagebuch 25. August 1914)

„Es ist zwischen halb eins und eins. In allen Klassen wird unterrichtet. Hier und da klingt die Stimme einer Lehrerin oder das Chorsprechen einer Klasse auf den Korridor. Sonst tiefe Stelle im ganzen Hause. Da kommt eine Mutter in die Sprechstunde und mitten in die Unterhaltung sagt sie: ,Sie wissen doch, daß Namur besetzt und fünf Forts gefallen sind?' ,Namur?' Ich springe auf und sende schnell einen Boten hinaus, um mir Gewißheit zu holen. Es könnte wieder wie bei Belfort sein, wo man den Wunsch so überzeugungsvoll als Wirklichkeit nahm. Nach wenigen Minuten kommt der Bote zurück, ein Extrablatt in der Hand. ,Namur gefallen!' in Riesenlettern und davor die drei Buchstaben WTB, die uns in dieser Zeit heilig wie ein Bibelwort galten. Ich lasse die Mutter sitzen, ohne mich zu entschuldigen, und laufe mit dem Blatt von Klasse zu Klasse. Ich sage kein Wort, ich halte es nur hoch, daß sie es alle sehen können, und wie auf Befehl, nein, aus innerstem Drange heraus, ertönt es sofort in allen Klassen, aus jedem Mund, bei den Kleinsten wie bei den Größten: ,Deutschland, Deutschland über alles.' Die Lehrerinnen stürzen auf den Korridor und umarmen sich, und die Kinder schließen den Unterricht. Die Kinder! Es ist einfach unmöglich, sie in dieser Stimmung weiter zu unterrichten. Jubelnd, mit blitzenden Augen ziehen sie an mir vorbei, und ich muß die Tränen zurückdrängen. Es ist eine der ergreifendsten Stunden, die ich in der Schule erlebt habe.“"1201

\section{Höhere Schule, Erna Lange (Kriegstagebuch)}

"Die Hoffnung auf das Geschlossenwerden der Schulen erfüllt sich nicht. Aber trotzdem, sie können sich nicht beklagen. Gibt es keine Ferien, so gibt es doch viele stolze, große Siege. Und die werden gebührend gefeiert. Nie vergißt die Regierung, für den Tag das Ausfallen des Unterrichts anzuordnen. Hei! So mitten aus der Schule heraus in die Aula! - ,Sieg! Sieg!' ,Ein ganz großer soll es sein!' Riesige Zahlen von gefangenen Feinden und erbeuteten Maschinengewehren werden laut. Im Lehrerzimmer ist die Depesche. Es stimmt alles. Noch größer gar sind die Zahlen auf dem Papier angegeben. Die Orgel braust auf, mehrere hundert junge Kehlen fallen gewaltig ein: ,Nun danket alle Gott mit Herzen, Mund und Händen ...' Direktor Mengel steht hinter dem Pult. Er hält eine kurze, markige Ansprache. Zum Schluß: ... ,Das deutsche Vaterland, unser geliebter Kaiser, unser stolzes Heer alle die tapferen Kämpfer zu Lande, zu Wasser und in der Luft hurra! hurra! hurra!' Die Aula, die doch auch so neu und frisch ist und des Morgens immer noch nach Farbe riecht, hallt wider von Begeisterung, jubelnder Vaterlandsliebe und Dankbarkeit. Nun noch schnell die paar Bücher in die Mappe geworfen und dann ein ganzer, langer freier Tag!“‘1202

Grundsätzlich ging dem vorzeitigen Schulschluss also eine gemeinsame Schulfeier voraus, auf der die Schulleiter über die Bedeutung des jeweiligen Sieges sprachen, die Schüler gemeinsam patriotische Lieder sangen und am Schluss in ein Hoch auf Vaterland, Kaiser und Heer einstimmten. ${ }^{1203}$ Dieses Vorgehen hat in der Regel bei den Kindern Siegeszuversicht hervorgerufen.

Insgesamt stießen die Siegesfeiern bei den Lehrern und Schulleitern auf hohe Akzeptanz, wie auch die angeführten Beispiele bezeugen. Es gab jedoch vereinzelt durchaus auch Kritik, die

\footnotetext{
${ }^{1201}$ Loewenberg, Kriegstagebuch einer Mädchenschule (1916), S. 19f.

1202 Lange, 1914 bis 1918 auf der Schulbank (1933), S. 27.

${ }^{1203}$ Auf drei weitere Beispiele sei hingewiesen: (Ebermeier/Mayer-Mommertz/Pfaffenzeller, Die Geschichte des Hans-Carossa-Gymnasiums Landshut (2004), S. 97); Hohnsbehn, Die Flensburger Schuljugend in der Zeit des ersten Weltkriegs (1996), S. 174); Mihaly, ... da gibt's ein Wiedersehn! (1986), S. 49). Die Beispiele aus dem Norden (Flensburg), dem Süden (Landshut) und dem Osten (Schneidemühl) zeigen, dass die Siegesfeiern in allen Regionen des Deutschen Reiches ähnlich abliefen.
} 
sich nicht nur auf den großen Unterrichtsausfall bezog. ${ }^{1204}$ So äußerte sich z. B. ein Lehrer in der Preußischen Lehrerzeitung sehr ausführlich:

„Schon wieder ein großer Sieg! Hurra! - Die Schule fällt aus, und jubelnd ziehen die Schüler die Straße entlang. - Wir wollen nicht diesen lauten, oberflächlichen Jubel, er passt nicht zu dem Ernst der Zeit. Gewiß wollen wir uns unsrer Siege wahrhaft freuen; aber wenn Tausende in ihrem Blut liegen, muß sich die Freude mäßigen und wir der Opfer gedenken, die sie kostete, und wenn Tausende und aber Tausende übermenschliche Strapazen erdulden, wollen wir nicht müßig gehen. Denn was tun sonst die Kinder, wenn die Schule ausfällt? [...]. Und darum glaube ich, wird es die ganze Lehrerschaft für richtig befinden, daß mit der 70er Mode gebrochen wird, und nur erst, wenn der letzte Sieg verkündet wird, wenn ,das Ganze halt' geblasen wird, sagen: Jetzt jubelt laut, daß die Bücher ruhen!“‘1205

Diese und ähnliche Veröffentlichungen lösten heftige Reaktionen in großen Teilen der Lehrerschaft aus. ${ }^{1206}$ Allerdings gab es durchaus Schulleiter, die ähnlich wie jener Lehrer dachten und handelten. Als Beispiel sei der Direktor des Kaiser Wilhelms Gymnasiums in Hannover genannt, der in seinem Jahresbericht 1914/15 schrieb:

„Durch Verfügung des Königlichen Provinzial-Schulkollegiums war es dem Ermessen der Schulleiter anheimgestellt, größere Siege unseres herrlichen Heeres auch durch Ausfall des Schulunterrichts zu feiern. Ich habe nur ganz wenige Male von dieser Erlaubnis Gebrauch gemacht. Es widerstrebte meinem Empfinden, wie ich in der Schulgemeinde wiederholt auseinandergesetzt habe, bloßes Nichtstun zu begünstigen zu einer Zeit, wo unsere Väter, Söhne und Brüder unermüdlich bei Tag und Nacht unter Daransetzung des Lebens vor dem Feinde standen, und wo der Unterricht wegen Mangels an Lehrern sowieso eingeschränkt werden musste.“ ${ }^{1207}$

Häufig war auch der hohe Unterrichtsausfall der Grund für die Kritik an den schulischen Siegesfeiern. In Bayern z. B. verfügte deshalb das Kultusministerium, dass die Siege zwar an den Mittelschulen durch einen freien Tag gefeiert werden sollten, in den Volksschulen der Unterricht aber stattzufinden habe. Man begründete diese Maßnahme vor allem mit dem Argument, dass an den Volksschulen wegen der vielen eingezogenen Lehrer ohnehin schon sehr viel

\footnotetext{
${ }^{1204}$ Der Direktor des Königlichen Kaiserin Auguste Viktoria-Lyzeums in Hannover schrieb im Jahresbericht 1914/15: „Eintreffen der Nachrichten über die herrlichen Erfolge unserer Truppen, an denen gerade Regimenter aus Hannover so stark beteiligt waren, [...] nahm die Aufmerksamkeit aller so in Anspruch, daß für einen regelrechten Schulbetrieb wenig überblieb. Erst allmählich war es möglich, die Schüler in das gewohnte Gleis der Pflichterfüllung zurückzubringen, besonders durch den immer wiederholten Hinweis darauf, daß unsere Brüder da draußen unablässig den größten Anstrengungen und Beschwerden sich unterziehen, ihre Gesundheit und ihr Leben dahingeben müssten, um das heimische Gebiet vor den Horden der Feinde zu bewahren, um uns Daheimgebliebenen ein von den Leiden des Krieges freies Leben sichern.“ (Baumert, Hannover-Linden (1916), S. 14f. ${ }_{1205}$ Führen, Lehrer im Krieg (1936), S. $113 f$.

${ }^{1206}$ Z. B. Leipziger Lehrerzeitung Nr. 33 vom 14. Oktober 1914; siehe: Führen, Lehrer im Krieg (1936), S. 114.

${ }^{1207}$ Mücke, Königliches Kaiser Wilhelmsgynasium in Hannover (1915), S. 12) Der Direktor der Sophienschule in Hannover hatte offensichtlich eine ähnliche Einstellung zu des Siegesfeiern. Eine ehemalige Schülerin erinnerte sich: „Wißt ihr noch die Verkündung der Siegesnachrichten auf dem Schulhof? Siegesfrei gab es nur am Anfang, später hieß es: 'Unsere Soldaten haben auch nicht frei'. ' (Beyte, Sophienschule Hannover [1916]).
} 
Unterricht ausfalle: „Wenn überhaupt noch etwas Ersprießliches im Volksschulunterricht erzielt werden soll, (sei) die verfügbare Zeit nach Möglichkeit auszunützen.“

Heftiger Widerstand der Lehrerverbände und anderer Gruppierungen führte Anfang des Jahres 1915 dazu, dass das bayerische Kultusministerium den Erlass zurückzog und wie alle anderen deutschen Länder allgemeine Siegesfeiern einführte. ${ }^{1208}$

Wie es bereits die Königliche Regierung in Hildesheim in einer Verfügung vom 29. August 1914 formuliert hatte, sollte nicht der „Gedanke an die Opfer die [...] Siegesfreude und Siegeshoffnung trüben“, sondern der Jugend sollte die „Erinnerung an die große Zeit, welche sie jetzt miterlebt, unauslöschlich in das Gedächtnis geprägt werden“1209. Diese Ziele wurden von allen deutschen Regierungen propagiert und von dem größten Teil der Lehrerschaft bejaht und unterstützt, offensichtlich aber nicht immer erreicht. Beispielhaft sei ein Mitschüler von Bertolt Brecht zitiert, der damals zusammen mit dem späteren Schriftsteller das Königliche Realgymnasium in Augsburg besuchte: „Natürlich war die Kriegsbegeisterung in dieser Zeit (1916) nicht mehr so stark wie während der ersten Kriegsmonate. Aber die nationale Stimmung kurbelte man von Fall zu Fall durch Siegesfeiern und andere Veranstaltungen immer wieder neu an. “1210

Sehr selten war eine so scharfe Kritik wie die einer ehemaligen Schülerin der Schule an der Schmidtstraße in Bremen, die in ihren Erinnerungen schrieb:

\begin{abstract}
„Dann kamen die Siegesmeldungen, das war furchtbar für uns. Aber die Leute standen Schlange, da kamen die Postkarten heraus. Ich hatte einen Bekannten, der mußte die mit zeichnen, der war Kunstmaler, der war arbeitslos. Da wurden diese Postkarten gemacht, ,jeder Stoß ein Franzos, jeder Schuss ein Russ, jeder Tritt ein Britt'. Und diese Karten kamen in die Schule, die wurden dann an die Wandtafel geheftet, damit wir das richtig sahen. Und dann kamen die Siegesmeldungen aus dem Osten. Von wegen diese vielen Gefangenen. Und dann kam er ja mit seinem Lied, der Herr Christian. Und da ich Vorsängerin war, sollte ich das denn singen. Er spielte das vor, er sprach das denn so, singen konnte er ja nicht. Nachher mußte die Klasse dann im Chor singen.'Wie ist's dem Russen hier ergangen, er tilgt es aus mit Stumpf und Stil. Hat 90000 Mann gefangen, den Rest gejagt in See und Sumpf. Sich an die Grenz zu winden durch und einen Dank dem Hindenburg, dem Hiha-Hindenburg, den Hindenburg.' Die Schülerin weigert sich, das Lied zu singen und ihr Vater billigt anschließend schriftlich das Verhalten seiner Tochter.“" ${ }^{\text {(1211 }}$
\end{abstract}

Über Störungen der gemeinsamen Feiern oder Elternproteste liegen keine Quellen vor. ${ }^{1212}$

\footnotetext{
1208 Siehe: Führen, Lehrer im Krieg (1936), S. 110-113.

${ }^{1209}$ Königliche Regierung in Hildesheim, Aufruf an die Lehrerschaft, Amtliches Schulblatt für den Regierungsbezirk Hildesheim, 1915, S. 93f.

${ }^{1210}$ Frisch/Obermeier, Brecht in Augsburg (1986), S. 69.

1211 den Lindemann/Jung, Erinnerungen einer Freischülerin (1981), S. 338-340; zitiert nach: Lemmermann, Kriegserziehung im Kaiserreich (1984), S. 866.

${ }^{1212}$ Der Schüler Franz Moritz Blumenfeld, geb. 1899, wurde „,in Kassel wg. Störung der Siegesfeier der Schule verwiesen“. (Weyer, EXPERIMENT-Sonderheft, http://www.elisabethschule.de/schueler/ schuelerzeitung/ experiment_sonder.html (28.7.2008)). Außerdem berichtet Rudolf Steiner über einen Vorfall: „Bei der Feier waren auch Mütter der Absolventen anwesend. Nach dem Vortrag löste sich aus der Stille ein Schrei und eine Frau auf der Galerie brach in Weinen aus'.“(Franke, 3. Die Kriegsgeneration, S. 263).
} 
$\mathrm{Ob}$ die gemeinsamen Feierstunden nicht nur für den einzelnen Schüler und die Schulgemeinschaft, sondern auch eine positive Wirkung auf die Stimmung der Soldaten an der militärischen Front hatten, lässt sich anhand der untersuchten Quellen nicht beurteilen. Die Soldaten waren aus eigener Erfahrung als Schüler und durch vielfältige Kontakte durchaus darüber informiert, wie die Siege in den Schulen, also an der „Heimatfront“, gewürdigt und gefeiert wurden. Einige dürften durch die Siegesfeiern in ihrem Siegesbewusstsein und Durchhaltewillen bestärkt worden sein, während andere durch die lautenVeranstaltungen angesichts schrecklicher Kriegserlebnisse sicher unangenehm berührt waren.

\subsection{Gedenkfeiern für gefallene Schüler und Lehrer}

Angesichts der vielen Trauerfeiern konnte den Schülern die Illusion von ständig siegenden Truppen kaum noch glaubhaft vermittelt werden. Außerdem war es nicht mehr glaubwürdig, die kriegerischen Kampfhandlungen weiter so stark zu verharmlosen. Insofern stellt sich vor allem die Frage nach der Zielsetzung derartiger Feiern. Sollte tatsächlich gemeinsam der gefallenen Mitschüler und Lehrer gedacht oder sollte deren Tod zum heldenhaften Opfer für das Vaterland stilisiert werden?

Dass die Behörden kein großes Interesse an der Durchführung solcher Gedenkfeiern in den Schulen hatten, zeigt schon die Tatsache, dass es im Gegensatz zu allen anderen Feiern keine entsprechenden amtlichen Vorschriften und Veröffentlichungen gab. Offensichtlich traute man es den Schulen zu, der Gefallenen im angemessenen Rahmen zu gedenken, ohne die $\mathrm{Zu}$ versicht auf den militärischen Sieg und die Wehrbereitschaft der Schüler zu schwächen.

An einigen ausgewählten Beispielen soll vor allem der Frage nach der Zielsetzung der Gedenkveranstaltungen nachgegangen werden. Ein Schuldirektor aus Saarbrücken ließ jedes Mal, wenn „einer unserer jungen Helden, der die Schule verlassen hatte, um dem Vaterlande zu dienen, den Heldentod gestorben war", die ganze Schulgemeinschaft in der Aula zu einer Trauerandacht zusammenkommen. Es wurden Volkslieder gesungen ('Es ist ein Schnitter, der heißt Tod', ,Es geht bei gedämpftem Trommelschlag' u. a.), die der Veranstaltung „etwas besonders Weihevolles“"geben sollten. Im Mittelpunkt der Feier stand jeweils eine kurze Ansprache des Direktors mit dem Tenor: "Niemand hat größere Liebe denn die, daß er sein Leben lässt für seine Freunde.“"1213 Der den meisten Schülern durch den Religionsunterricht oder aus dem Gottesdienst bekannte Vers aus dem Johannesevangelium $(15,13)$ diente weniger der Erinnerung an die Gefallenen und dem Trost über die getöteten ehemaligen Mitschüler,

\footnotetext{
${ }^{1213}$ Meinardus, Schulfeiern, Monatszeitschrift für höhere Schulen, 1917 S. 546f. und S. 554.
} 
sondern sollte in erster Linie die zukünftigen Soldaten auf ihren gefährlichen Einsatz an der Front vorbereiten.

Im Gymnasium zu Berlin-Steglitz wurde der gefallenen Schüler während der Schulandachten und in den Kriegsstunden der entsprechenden Klassen gedacht, während „den Lehrern, denen das Los beschieden war, ihr Leben dem Vaterlande zu opfern, eine besondere Trauerfeier gewidmet“ wurde. In der Schulchronik heißt es dazu weiter: „Tiefer Ernst und aufrichtige Trauer ergriff die Daheimgebliebenen, wenn die Kunde von dem Heldentod eines der an der Front kämpfenden Mitglieder unsres Kreises eintraf, zumal als sich seit dem November 1914 die Trauernachrichten in erschütternder Weise häuften. “1214

In Landsberg (Provinz Schlesien) veranstaltete man 1916 einen Tage vor Totensonntag für gefallene Schüler und Lehrer eine gemeinsame Feier. ${ }^{1215}$ In einer verhältnismäßig langen Rede, die sogar in der Verbandszeitschrift des Philologenverbandes veröffentlicht wurde, gibt der Schulleiter Aufschluss über die von ihm propagierte Zielsetzung der Gedenkfeiern: Die von ihm gewählte Erzählperspektive ist die der im Krieg gefallenen ehemaligen Mitschülen und Lehrkräfte, die zu den Schülern sprechen: „So sprechen wir zu Euch, eure Toten. Wir haben unseren Schwur gehalten, und nun hebt ihr die Hand und sprechet Kindern und Kindeskindern vor: „Deutschland muß leben, und wenn wir sterben müssen. Amen.“1216 Wie die religiöse Bekräftigungsformel „Amen“, die am Ende jedes christlichen Gebets steht, zeigt, werden die Schüler verpflichtet, eine Art Glaubensbekenntnis auf das ,heilige‘ Vaterland abzulegen und zu schwören, sogar das eigene Leben für seinen Schutz zu geben und auch ihre Nachkommen auf die Ziele hin zu erziehen. Die Rede macht besonders deutlich, dass die Trauer um den Mitschüler oder den Lehrer zurücktrat hinter die Liebe zum Vaterland und die Verherrlichung des Heldentods. Vor allem in den Gymnasien wollte man durch solche Feiern an die älteren Schüler ${ }^{1217}$ appellieren, weiter an den Sieg zu glauben und sich freiwillig zum Militär zu melden. Damit wollte man an die ersten beiden Kriegsjahre anknüpfen, in denen voller Begeisterung überall im Reich die Jahrgänge der Oberprimaner oft geschlossen Soldaten geworden waren. ${ }^{1218}$ Beispielsweise waren noch vor dem Ende der Sommerferien 191430

\footnotetext{
${ }^{1214}$ Lehmann, Weltkriegs-Erinnerungen aus dem Kreise des Gymnasiums zu Berlin-Steglitz (1925), S. 12.; am Ende jedes Kriegsjahres wurde jeweils am Totensonntag eine Gedächtnisfeier zu Ehren der gefallenen Lehrer und Schüler durchgeführt.

1215 Grünwald, Eine Totenfeier, Deutsches Philologen-Blatt: Korrespondenz-Blatt für den akademisch gebildeten Lehrerstand , 1917, S. 25.

${ }^{1216}$ Grünwald, Eine Totenfeier, Deutsches Philologen-Blatt 1917, S. 27.

${ }^{1217} \mathrm{Zu}$ den Oberprimanern kamen noch zahlreiche Schüler aus der Unterprima sowie aus der Unter- und Obersekunda.

${ }^{1218}$ Für sie bestand oft auch die Möglichkeit einer nachträglichen Notreifeprüfung, die später sogar am Kriegsschauplatz abgelegt werden konnt.
} 
Schüler des Landshuter Gymnasiums zu den Fahnen geeilt ${ }^{1219}$ und unter den stichprobenweise untersuchten Berliner Schulen ,fand sich nicht eine einzige, deren Oberprimaner sich nicht vollzählig““1220 gemeldet hatten. Zu ähnlichen Ergebnis kommt eine Untersuchung über die im Schuljahr 1914/15 in Baden ins Heer eingerückten Schüler. ${ }^{1221}$ Nachdem die erste Kriegsbegeisterung verflogen war und die Schüler - vor allem nach den verlustreichen Schlachten bei Verdun und an der Somme - immer stärker mit den Schrecken des Krieges konfrontiert wurden, meldeten sich nur noch vereinzelt Schüler freiwillig zum Militär. Insofern dienten die Trauerfeiern neben der intendierten Vaterlandsliebe auch der Stärkung der Wehr- und Opferbereitschaft der Schüler.

Wie viele Jahresberichte 1914/15 geht auch der der Leibnizschule in Hannover ausführlich auf die Mitglieder der Schulgemeinschaft ein, die den „Heldentod fürs Vaterland starben“. Während lediglich die Zahl der gefallenen Schüler genannt wird (38), würdigt der Direktor ausführlich die Persönlichkeit des getöteten Lehrers Dr. Grethen und geht auch auf die Umstände seines Todes ein. Ferner weist er auf die Trauerfeier in der Schule hin und beschreibt detailliert die Beerdigungsfeier, an der ebenfalls das Kollegium und viele Schüler teilnahmen. ${ }^{1222}$ Zwar wird der Lehrer als „leuchtendes Beispiel für seine Schüler“ beschrieben, der sich im Alter von 54 Jahren für den Kriegsdienst gemeldet hatte, aus dem Bericht des Schulleiters geht aber eindeutig auch die tiefe Betroffenheit hervor, die der Tod des Lehrers in der Schule hervorgerufen hat. Ähnlich empfand man wohl im Kaiserin-Auguste-VictoriaGymnasium zu Linden (heute Hannover). Im Jahresbericht 1914/15 finden sich entsprechende Hinweise. $^{1223}$

12191219 Ebermeier/Mayer-Mommertz/Pfaffenzeller, Die Geschichte des Hans-Carossa-Gymnasiums Landshut 1629-2004 (2004), S. 95.

${ }^{1220}$ Wildhagen, „Laß dich gelüsten nach der Männer Bildung (1994), S. 116.

${ }^{1221}$ Häußner, J., DerWeltkrieg und die höheren Schulen Badens im Schuljahr 1914-1915 (o. J.), S. 57; abgedruckt in: Bergmann / Schneider, Gegen den Krieg, Band 1 (1982), S. 85.

${ }^{1222}$ „Seine Amtsgenossen und Schüler gaben am 21. November (1914) bei einer Trauerfeier in der Schule ihrem Schmerz und ihrer Verehrung für den Entschlafenen Ausdruck. Am gleichen Tag wurde sein Leib unter militärischen Ehrenerweisungen auf dem Strangrieder Kirchhofe zur letzten Ruhe gebettet. Nicht nur seine Amtsgenossen und Schüler umstanden sein Grab, sondern auch viele ehemalige Schüler, zum großen Teil im Waffenrock, waren herbeigeeilt, um dem geliebten, hochverehrten früheren Lehrer die letzte Ehre zu erweisen. Als die Ehrensalven verklungen und die Musik das Lied 'Ich hatt einen Kameraden' als letzten Gruß ertönen ließ, da blieb wohl kein Auge trocken; wußten wir doch alle, daß sich hier das Grab schloß über einem Manne, der uns in der langen Zeit seines Wirkens an unserer Schule ein lieber Freund war, ein Mitarbeiter von vornehmer Denkweise und vorbildlicher Pflichttreue, der sein umfassendes Wissen mit der Begeisterung für seinen Beruf und mit herzlicher Anteilnahme für die ihm anvertraute Jugend verband. Zahlreiche Beileidsbeweise aus der Heimat, aus dem fernen Auslande und vom Kriegsschauplatze bewiesen, wie fest die Liebe zu ihm in den Herzen seiner Schüler wurzelt." (Meyer, Siebendreissigster Jahresbericht der städtischen Leibnizschule zu Hannover ([1915], S. 8).

1223 „Am 17. November (1915) traf die Todesnachricht ein; am 19. nach der dritten Unterrichtsstunde wurde seiner in einer kurzen Gedächtnisfeier auf der Aula gedacht. [...] Als Leutnant der Reserve trat am 1. August ein der Oberlehrer Beermann, dem es auch bestimmt war, sein junges Leben dahingeben zu müssen; bei Beginn des Winterhalbjahrs wurde nach der Andacht sein Andenken vor den versammelten Schülern geehrt.“ [1915], S. 12). 
Weitverbreitet in Deutschland ${ }^{1224}$ war ein Gedicht des 18jährigen Schülers Richard Fricke vom Gymnasium in Berlin-Charlottenburg, das er für seinen gefallenen Lehrer verfasst hatte und das auf der Trauerfeier vorgetragen wurde:

„Für uns!

Ferne, ferne im Osten, da gähnt ein Grab,

Da senkt man zu tausend die Toten hinab.

Für uns!

Im Westen, da ragt manch Kreuz schlicht und klein,

Da liegen sie stumm in langen Reih'n -

Für uns!

Und wo im Winde rauscht das Meer,

Da gaben sie freudig ihr Leben her -

Für uns!

Sie opferten Zukunft und Jugendglück,

Sie kehren nie wieder zur Heimat zurück -

Für uns!

Sie gaben ihr Alles, ihr Leben, ihr Blut,

Sie gaben es hin mit heiligem Mut -

Für uns!

Und wir? Wir können nur weinen und beten

Für sie, die da liegen bleich, blutig, zertreten -

Für uns!

Denn es gibt kein Wort, für das Opfer zu danken,

Und es gibt keinen Dank für sie, die da sanken -

Für uns!‘ ${ }^{1225}$

Das Gedicht wurde in ein 1917 vom Pestalozzi-Verein herausgegebenes Schulbuch aufgenommen und „als Requiem für die Gefallenen“"1226 sogar vertont.

Der entsprechende Jahresbericht des Königlichen Kaiser-Wilhelms-Gymnasium in Hannover enthält zwar keine Hinweise auf Trauerfeiern, wohl aber auf die „früheren Glieder unserer Gemeinschaft [...], die die Liebe zum Vaterlande mit dem Tod besiegelt haben“"1227. Der Direktor äußerte die Hoffnung, eine „,vollständige Ehrentafel“ mit den Namen aller gefallenen

\footnotetext{
${ }^{1224}$ So wird das Gedicht z. B. auch in der Kriegschronik der Stadt Hildesheim erwähnt (siehe: Vogeler, Kriegschronik der Stadt Hildesheim (1929), S. 114f. und die vertonte Version war u.a. im Greifswalder Gymnasium bekannt (siehe: Langer, Lernziel Krieg! [2000], S. 27).

${ }^{1225}$ Zitiert nach: Vogeler, Kriegschronik der Stadt Hildesheim (1929), S. 114f.

${ }^{1226}$ Siehe: Langer, Lernziel Krieg! (2000), S. 26f. und Anhang, Seite 25; ferner wurde es auf einer Postkarte des „Deutschen Jugenddanks“ 1915 abgedruckt.

${ }_{1227}$ Mücke, Königliches Kaiser Wilhelmsgynasium in Hannover (1915), S. 18.
} 
Schüler und Lehrer zusammenstellen zu können. Namentlich werden alle genannt, die im Schuljahr 1914/15 den „Heldentod“ gestorben sind. ${ }^{1228}$

Zwangsläufig besonders häufig fanden Gedenkfeiern in den Gymnasien statt, die aufgrund der vielen Kriegsfreiwilligen die meisten Opfer zu beklagen hatten. Aber auch die anderen Schulformen gedachten nicht selten der Opfer. ${ }^{1229}$ Neben den gefallenen Lehrern ehrte man oft auch die Angehörigen der Schüler. In Volksschulen gab es in der Regel keine gemeinsamen Schulfeiern, sondern der Lehrer sprach innerhalb der Klasse mit den Kindern über den Toten und betete mit ihnen, wie z. B. aus der Schulchronik des Lehrers Wieldt in Getmold (Provinz Westfalen) hervorgeht. ${ }^{1230}$

Im Juli 1916 wurde der Wiederbeginn des Unterrichts nach dem Sommerferien am Lyzeum in Altona mit einer Trauerfeier für einen im Juli gefallenen Lehrer verbunden. Der Schulchronik ist zu entnehmen, dass der Direktor in seiner Rede besonders die „Pflichttreue“ des Lehrers hervorhob. ${ }^{1231}$ Einen Tag später beschloss die Lehrerkonferenz, ein Bild von ihm im Lehrerzimmer aufzuhängen und eine Gedenktafel für den Kollegen zu errichten. ${ }^{1232}$

Auch aus Flensburger Volksschulen liegen Berichte über solche Trauerfeiern vor. ${ }^{1233}$ Eine Zeitzeugin erinnerte sich z. B. 1991 in einem Gespräch: „Dann wurde aufgestanden, wenn [...] die Nachricht gekommen war. Dann hatten wir alle eine Schweigeminute, das war damals schon. Jedenfalls unser Lehrer hat es so gemacht. Ob die anderen Lehrer das auch so gemacht haben, das weiß ich nicht, aber bei uns war es so. Lehrer Magnus; ich hab' ihn nie vergessen, das war ein guter Lehrer.“'1234

\footnotetext{
${ }^{1228}$ Er nennt 42 Namen, darunter den eines Referendars.

${ }^{1229}$ In Flensburg z. B. kehrten von 76 eingezogenen Volksschullehrern 13 nicht zurück (Hohnsbehn, Die Flensburger Schuljugend in der Zeit des ersten Weltkriegs (1996), S. 175).

${ }^{1230}$ „Barmherziger Gott und Vater, es ist geschehen, unser lieber Karl Oberschmidt ist auf dem Felde der Ehre gefallen. Wir wissen aber ja, daß viele Opfer für unser liebes, teures Vaterland gebracht werden müssen, aber wir empfinden doch über den Verlust dieses Tapferen und edlen tiefen Schmerz. Er war die Freude und Hoffnung seiner Eltern. Nun bitten wir Dich, lieber himmlischer Vater [...] Laß' unsern lieben, guten Karl Obernagel (sic!!), der den Heldentod fürs Vaterland gestorben ist, in Frieden ruhen und laß' ihm leuchten das ewige Licht. Amen." (Kammeier, Der Landkreis Lübbecke und der 1. Weltkrieg (1998) 1998, S. $204 f$.

${ }^{1231}$ Zitiert nach: Pust, „Vaterländische Erziehung" für „Höhere Mädchen” (2004), S. 338f.

1232 Neben den genannten Ehrungen wurde in der Zeitschrift des Philologenverbandes eine weitere propagiert: „Die Frankfurter ,Musterschule' (Reformrealgymnasium), die wie manche Anstalt eine regelmäßige ,Kriegszeitung' erscheinen lässt, hat das neueste (29.) Heft im vollen Umfange (32 S. in Bogengröße) als ErinnerungsWeihegabe ihrem ersten Oberlehrer, Prof. Dr. Wilhelm Reinhardt, dargebracht. [...] In einer langen Reihe kleiner Artikel und Skizzen, die mit guten Bildern ernsten und heiteren Inhalts durchsetzt sind, wird ein volles Lebensbild des trefflichen Mannes vorgeführt.[...] Das Heftchen, das abgesehen von seinem menschlich ergreifenden Inhalt den für spätere Jahresberichte geplanten Nachrufen für unsere gefallenen Amtsgenossen ein Vorbild sein kann, ist noch [...] zu beziehen, wobei bemerkt sei, daß der Ertrag einer ,Reinhardtstiftung' zugute kommt, die der körperlichen Ertüchtigung und Kräftigung bedürftiger Schüler dienen soll.“ (Koch, Schöne Ehrung für einen gefallenen Philologen, Deutsches Philologen-Blatt 1917, S. 511).

${ }^{1233}$ Hohnsbehn, Die Flensburger Schuljugend in der Zeit des ersten Weltkriegs (1996), S.175f.

1234 Zitiert nach: Hohnsbehn, Die Flensburger Schuljugend in der Zeit des ersten Weltkriegs (1996), S.176; Flensburger Zeitzeugen erinnern sich: Kindheit und Jugend im Ersten Weltkrieg.
} 
Besonders aufwendig wurden entsprechend ihrer herausgehobenen Position Gedächtnisfeiern für gefallene Schuldirektoren begangen. ${ }^{1235}$

Über die mit der Nagelung von Gedenkschilden ${ }^{1236}$ verbundenen Trauerfeiern sind zwar keine detaillierten Berichte bekannt, es kann jedoch davon ausgegangen werden, dass sie sich nicht wesentlich von den oben beschriebenen unterschieden haben.

Insgesamt kann festgestellt werden, dass die Gedenkfeiern für gefallene ehemalige Schüler und Lehrer von Kriegsbeginn an ein durchaus wichtiger Teil des Schullebens waren und - vor allem in den Höheren Schulen - sorgfältig inszeniert wurden. Auch wenn natürlich die Schulgemeinschaft aufrichtig um Kollegen, Mitschüler oder Schüler trauerte, so ging es doch in den offiziellen Reden und Reaktionen immer wieder offensichtlich weniger um die Persönlichkeit der Gefallenen als vielmehr darum, sie zu Helden und Vorbildern zu stilisieren. Angesichts der im Laufe des Krieges mehr und mehr ausbleibenden militärischen Erfolge und durch die zahlreichen Todesfälle, von denen die Schulgemeinschaft betroffen war, konnte man das zunächst vermittelte Bild, das das Kriegsgeschehen verharmloste, nicht weiter propagieren. Um dennoch die angestrebte begeisterte Vaterlandsliebe zu erreichen, wurden die Gefallenen pauschal zu vorbildhaften Helden erhoben, die ihr Leben gern und uneigennützig für Kaiser und Vaterland gegeben haben, und die Gedenkfeiern zu ,Weihestunden'. So zitierten Direktoren häufig die beiden letzten Verse aus dem bekannten Gedicht von Horaz: „Dulce et decorum est pro patria mori““1237, um die von Kriegsbeginn an vorhandene Kriegsbegeisterung der Jugend aufrechtzuerhalten und somit auch den allgemeinen Durchhaltewillen zu stärken.

\subsection{Fazit}

Schulfeiern waren, unabhängig vom Anlass, ein wichtiges Element der Erziehung zum Patriotismus und gipfelten fast immer in einem feierlichen Bekenntnis zu Kaiser, Vaterland und Militär. Erinnerungskräftige, eindrucksvolle Bilder, Symbole und Aktionen, wie es z. B. die Nagelungsobjekte waren, sollten das patriotische Empfinden der Schuljugend stärken und sie für eine opferfreudige Hingabe des Lebens begeistern. Vor allem in den ersten Kriegsjahren sind die propagierten Ziele in der Regel auch erreicht worden. ${ }^{1238}$

\footnotetext{
${ }^{1235}$ Beispielhaft sei angeführt: Kramer, Die Schulgemeinde Martin, (1992), S. 134f.

${ }^{1236}$ Siehe: Kapitel 7.2.2 und drei Abbildungen im Anhang, Seite 84.

${ }^{1237}$ Wilfred Owen nennt die Verse „,best known poem of the First World War” (Owen, best known poem of the First World War, http://www.warpoetry.co.uk/owen1.html [13.08.2007]).

${ }^{1238}$ So spiegelt die folgende Tagebucheintragung einer Schülerin über eine Bismarckfeier am 1. April 1915 in Dresden die Empfindung vieler damaliger Schüler durchaus wider: „Am 1. April habe ich etwas Herrliches erlebt, nämlich die hundertjährige Geburtstagsfeier Bismarks. [...] Es war einfach herrlich feierlich! Das werd' ich nie vergessen!“" (Kiendl, Nessis Tagebuch aus dem Ersten Weltkrieg, http://www.zenker.se/History/ nessi_tagebuch.shtml (01.12.2008).
} 
Die Landesverteidigung in einem Krieg, dessen weltgeschichtliche Dimension immer wieder von den Schulleitern in ihren Reden betont wurde, wurde als heilige Pflicht dargestellt. Durchgehend wurden die Soldaten vorbildhaft zu Helden stilisiert, die das Vaterland todesmutig schützten. Aber auch jüngere Schüler und die Schülerinnen, deren militärischer Einsatz noch nicht bzw. überhaupt nicht in Betracht kam, sollten durch die Feiern angesprochen und instrumentalisiert werden, da auch von ihnen Kriegsdienstleistungen erwartet wurden - und zwar an der „Heimatfront“. Welch hohen Stellenwert in der Erziehung die feierlichen Veranstaltungen im Krieg hatten, verdeutlicht exemplarisch die Forderung eines Saarbrücker Schulleiters: „Die ganze Schulfeier sollte doch ein Kunstwerk sein“, damit sich das geschichtliche Ereignis, dessen man gemeinsam gedenkt, „fest der jungen Seele einprägt“"1239. Und deshalb solle man über die verordneten Feiern hinaus nach weiteren Gelegenheiten zu solchen Feiern suchen.

${ }^{1239}$ Meinardus, Schulfeiern, Monatszeitschrift für höhere Schulen (1917), S. 546f. 


\section{Veranstaltungen zu wohltätigen Zwecken}

Neben den vielen Nagelfeiern, Lazarettbesuchen, Verkaufsaktionen und anderen entsprechenden Aktivitäten, auf die in dieser Arbeit in anderem Zusammenhang eingegangen wird, sollen hier Aktionen thematisiert werden, die vor allem das Ziel hatten, Geld für die Kriegshilfe einzunehmen. U. a. soll untersucht werden, in welchem Umfang Schulen in diesem Bereich aktiv wurden und ob über den Gelderwerb hinaus noch weitere Ziele verfolgt worden sind. Aufgrund der insgesamt schlechten Quellenlage werden die - relativ wenigen - Großaktionen, über die Details bekannt sind, zum großen Teil einzeln aufgeführt, während kleinere Veranstaltungen, wie z. B. Unterhaltungsabende oder Theateraufführungen, die es zu Tausenden gegeben hat, lediglich anhand einiger ausgewählter Beispiele dargestellt werden. So ergibt sich ein einigermaßen gesichertes Ergebnis, zumal wenn man es im Zusammenhang mit den anderen schulischen Aktivitäten an der „Heimatfront“ beurteilt.

Sieht man von einem Erlass des preußischen Unterrichtsministers vom 6. Oktober 1916 ab, in dem empfohlen wurde, die schulentlassene Jugend an den Veranstaltungen, die im Zusammenhang mit Elternabenden durchgeführt würden, zu beteiligen, und zwar ,aktiv und passiv, durch Musik und Gesang, Vorträge und Darbietung von Lichtbildern“"1240, so gab es keine Anweisungen und Ratschläge der Schulbehörden an die Schulen für die Durchführung von öffentlichen Veranstaltungen zugunsten der Kriegshilfe. Dass trotzdem sehr viele Schulen in unterschiedlicher Form Unterhaltungsabende durchführten, ist auf die Initiativen einzelner Lehrer, die öffentlichen Aufrufe der Lehrerverbände oder die Aktivitäten der durch Lehrer gegründeten gemeinnützigen Vereine „Jugenddank für Kriegsbeschädigte“ und „Jugendspende für Kriegerwaisen“ zurückzuführen.

So forderte z. B. ein Lehrer 1915 in verschiedenen Verbandspublikationen seine Kollegen zu folgenden Aktionen auf:

„Unsere Schulkinder sollten mehr öffentlich singen; an stillen, schönen Abenden auf Plätzen, in den Anlagen, wo die Arbeitenden den Feierabend verbringen, in Berlin am Kriegerdenkmal, im kleinen Tiergarten, im Humboldt und Friedrichshain, im Schillerpark und so überall in Stadt und Land. Es brauchen und sollen keine neuen Lieder sein, die sie singen, sondern die alten, schönen Volks-, Kriegs- und Vaterlandslieder, die wir sangen, als unsere kämpfende Jugend noch bei uns war, die Lieder, mit denen sie hinauszog ins Feld, mit denen sie dem Siege und dem Tode entgegengeht... Manche schöne Feierstunde könnte unseren Müttern, Frauen, Bräuten, sorgenden Alten und sonst Hiergebliebenen bereitet werden durch Kindergesang am rechten Ort und zur rechten Stunde. Es bedarf nicht vieler Worte darüber. Wenn unsere jungen Sänger unter Führung ihrer Gesanglehrer da, wo man sich nach schweren Arbeitsstunden zusammenfindet,

\footnotetext{
${ }^{1240}$ Pflege der schulentlassenen Jugend in Verbindung mit Elternabenden usw., Zentralblatt für die gesamte Unterrichtsverwaltung in Preußen, 1916, S. 532.
} 
vielleicht jede Woche ein paar Lieder singen würden, jeder würde es ihnen danken. Insbesondere würden die Lieder einen Widerhall wecken, wenn Verwundete, Genesende, Beurlaubte aus den Schützengräben dabei sind. Die Kindergesänge könnten ein Ersatz für die Feierstunden sein, die an den Winterabenden daheim ernste Reden mit Bildern und Liedern geboten haben. Möchte dafür das Lied erklingen, das Lied von jungen Lippen, ein Frühlings- und Hoffnungsklang allen, die in schweren Tagen etwas brauchen, was sie emporhebt und zu Kampf und Arbeit stark macht." ${ }^{1241}$

Bezeichnenderweise ist hier ausschließlich die Rede von der Stärkung des Durchhaltewillens durch Gesangsdarbietungen der Schulkinder und nicht von der Möglichkeit, durch Eintrittsgelder die Kriegshilfe zu unterstützen. Einen ähnlichen Tenor hatte beispielsweise auch ein Artikel in der Sächsischen Lehrerzeitung, der zu Beginn des Jahres 1916 erschien („Laßt die Kinder öfters in Lazaretten singen!“"1242). Der Verein „Jugenddank“ hingegen wies in einem im Mai 1916 veröffentlichten Aufruf, der in nahezu allen Lehrerzeitungen erschien ${ }^{1243}$, besonders auf die Durchführung von Veranstaltungen als empfehlenswerte Form der Spendenbeschaffung hin. Für besonders geeignet wurden ,musikalische, turnerische und ähnliche Veranstaltungen“ gehalten sowie „Vorträge“, die den rechtlichen Bestimmungen in Preußen entsprächen und auch bereits mit Erfolg durchgeführt worden seien. Dass immer wieder Lehrer und Lehrerinnen aller Schulformen in den Verbandszeitschriften über ihre eigenen - ausschließlich positiven - Erfahrungen mit solchen Veranstaltungen berichteten, hat sicher viele Lehrkräfte ermutigt, selbst solche Aktionen zu initiieren und durchzuführen. ${ }^{1244}$

Im Folgenden soll an einigen konkreten Beispielen auf die unterschiedlichen Veranstaltungsarten sowie deren Wirkung näher eingegangen werden.

\subsection{Unterhaltungsveranstaltungen}

Von den vielen Veranstaltungen, die es gegeben hat, können hier wegen der Quellenlage lediglich einige wenige genauer untersucht werden. Eine der größten fand am 28. Februar 1915 auf Initiative des Berliner Stadtschulrates Dr. Fischer in Berlin im Zirkus Busch statt; an ihr nahmen 2.000 Berliner Gemeindeschulkinder teil. Der Aktivität war so erfolgreich, dass sie noch dreimal wiederholt wurde (7., 14. und 21. März). Die Einnahmen in Höhe von 12.000 Mark wurden dem Berliner Magistrat für bedürftige Kinder, deren Väter an der Front kämpften, verwendet und den Kriegskindergärten überwiesen. ${ }^{1245}$ Über das Programm ist bekannt, dass ein Lehrer einen Prolog hielt und dass sich dann Lied- und Gedichtvorträge abwechsel-

\footnotetext{
${ }^{1241}$ Zitiert nach: Führen, Lehrer im Krieg (1936), S. 53f.

1242 Abgedruckt in: Führen, Lehrer im Krieg (1936), S. 53.

${ }^{1243}$ Z. B. in: Jugenddank für Kriegsbeschädigte, Deutsches Philologen-Blatt 1916, S. 331.

${ }^{1244}$ Siehe z. B. den Beitrag von Margarete Treuge, die über „Unterhaltungsabende“ und „Theatervorstellungen“ berichtet: Treuge, Weihnachten, der Krieg und die Jugend, Die Lehrerin: Organ des Allgemeinen Deutschen Lehrerinnenvereins 1914, S. 273.

${ }^{1245}$ Siehe: Führen, Lehrer im Krieg (1936), S. 54.
} 
ten. ${ }^{1246}$ Gesungen wurden u. a. das „Schwertlied““1247, das bei vielen solcher Veranstaltungen zum Programm gehörte, und das „Gebet während der Schlacht“ ${ }^{\star 1248}$, das religiöse Ergriffenheit intendierte. $^{1249}$

Im Dezember des Jahres 1916 wurde von den gleichen Schulen erneut ein Unterhaltungsabend veranstaltet, dieses Mal zugunsten des „Jugenddanks für Kriegsbeschädigte““1250. Das Konzert musste wie im Jahr zuvor dreimal wiederholt werden und erbrachte fast 20.000 Mark Reingewinn.

Unterstützt vom königlichen Provinzial-Schulkollegium und zahlreichen Gemeindevertretungen Groß-Berlins gaben im Mai 1918 Chöre von 95 höheren Schulen aus Berlin und Umgebung im Zirkus Busch ein ähnliches Konzert, das von Lehrern vorbereitet und organisiert worden war. $^{1251}$

Die allgemeine Presse und die Lehrerzeitungen berichteten ausführlich über die Großveranstaltungen. Meistens wurde die Meinung vertreten, dass andere den guten Beispielen folgen möchten, wie z. B. durch einen Berliner Lehrer im Deutschen Philologen-Blatt: „Recht erfreulich wäre es, wenn auch in anderen Städten, wo die Verhältnisse wesentlich einfacher liegen dürften, ähnliche Versuche unternommen würden, die höheren Schulen zu gemeinsamer Betätigung zum Besten der Kriegswohlfahrtspflege zu vereinigen. “1252 Dass solche Aufrufe Wirkung hatten, geht z. B. aus einem Artikel eines Lehrers hervor, der sich direkt den Appell eines Berliner Kollegen bezieht. ${ }^{1253}$

Allerdings wurde durchaus auch öffentlich Kritik an den Massenveranstaltungen geübt und vor der Gefahr gewarnt, die Konzerte könnten in Effekthascherei und Massensuggestion ausarten. Als immer mehr solcher Veranstaltungen durchgeführt wurden, gingen die Berliner Gesanglehrer der höheren Schulen mit einigen ,Leitsätzen’ sogar an die Öffentlichkeit:

\footnotetext{
${ }^{1246}$ In einem Lesebuch über den Krieg ist die Schilderung „Zweitausend Berliner Schulkinder singen vor Verwundeten im Zirkus Busch" abgedruckt (Braun, Deutschlands Jugend in großer Zeit, 1916, S. 114-116.

1247 Theodor Körner (1791-1813) hat das „Schwertlied“, das insgesamt 16 Strophen umfasst, wenige Stunden vor seinem Tod geschrieben. Text der ersten beiden Strophen: „Was soll dein heitres Blinken?/ Schaust mich so freundlich an./ Hab' meine Freude dran/Hurra!// Mich trägt ein wackrer Reiter; Drum blink' ich auch so heiter; Bin freien Mannes Wehr; Das freut dem Schwerte sehr. Hurra!“.

${ }^{1248}$ Auch dieses Gedicht stammt von Theodor Körner aus dem Jahre 1813

(Text: http://www.goethezeitportal.de/index.php?id=3908).

${ }^{1249}$ Lemmermann, Kriegserziehung im Kaiserreich (1984), S. 311.

${ }^{1250}$ Siehe: Sitzungsbericht 1918, S. 43 (Jugenddank für Kriegsbeschädigte e.V., Jugenddank für Kriegsbeschädigte e.V. 1917).

${ }^{1251}$ Siehe: Dihle, Ein beachtenswerter Versuch, Deutsches Philologen-Blatt 1917, 630f. Professor Dihle war der Vorsitzende des Berliner Philologen-Vereins.

${ }^{1252}$ Dihle, Ein beachtenswerter Versuch (1917), S. 631.

${ }^{1253}$ „Zunächst bildete sich ein aus Realgymnasiasten und Oberrealschülern bestehender freiwilliger gemischter Chor, dem sich nunmehr die besten Sängerinnen vom Oberlyzeum und Lyzeum angeschlossen haben. Dieser Chor wirkt bei den verschiedensten Gelegenheiten [...] mit. An den Totensonntagen hat der Chor für die ärmsten Witwen rund 1.300 M. ersingen helfen.“ (Herrmann, Noch ein beachtenswerter Versuch, Deutsches PhilologenBlatt 1918, S. 6).
} 
„Außergewöhnliche Massenaufführungen, aus Begeisterung für eine große Sache geboren, werden Begeisterung wecken, und deshalb ist ihnen zuzustimmen.“1254 Sie warnten aber davon, solche Aufführungen regelmäßig durchzuführen, da sie dem Musikunterricht nur eingeschränkt förderlich seien. Die rhythmischen und melodischen Feinheiten würden verloren gehen. Vielmehr sollten die Aufführungen in der Regel Sache der einzelnen Schulen bleiben. $^{1255}$

Viel Erfolg hatte die Initiative der Berliner Musiklehrer allerdings nicht, denn die Massenkonzerte fanden weiter statt. Sehr öffentlichkeitswirksam war auch eine Gesangsaufführung in der ausverkauften Berliner Oper und dann ein zweites Mal in der Königlichen Hochschule für Musik, bei der 1.000 Schulkinder des 9. Berliner Schulbezirks „vaterländische Gesänge“ vortrugen. Sie fanden in Anwesenheit der Prinzessin Eitel Friedrich statt und erbrachten einen Erlös von 4.118,50 Mark, der dem „Jugenddank“ zur Verfügung gestellt wurde. ${ }^{1256}$

Auch aus anderen Städten liegen Berichte über musikalische Großveranstaltungen der Schulen vor. Beispielsweise trugen in Altona am Jahrestage des Kriegsbeginns 350 Jungen und 400 Mädchen der Oberrealschule, des Lyzeums, des Lehrerseminars sowie der Mittel- und der Volksschulen zugunsten des Roten Kreuzes und der Altonaer Kriegshilfe „Volks- und Vaterlandslieder" vor; in Görlitz sangen 800 Gemeindeschulkinder und in Stettin gaben 1.000

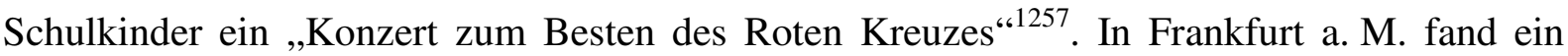
Schülerkonzert statt, an dem mehr als 800 Kinder der Volks- und der Mittelschulen teilnahmen; sie sangen in fünf Zyklen alte und neue Kriegslieder’ („Friede - Gefahr - Aufmarsch Entschlossenheit - Kampf - Sieg“). Auch in Bremen ${ }^{1258}$ und in Stettin gab es Konzerte (1915), bei denen jeweils 1.000 Kinder sangen. Noch mehr waren es 1918 in Dresden, wo 1.500 Volksschüler Seemannslieder vortrugen. ${ }^{1259}$ Wie groß das Interesse der Öffentlichkeit und ihrer Repräsentanten gewesen ist, zeigt besonders ein Beispiel aus Straßburg. Dort gaben Lehrer und Lehrerinnen der Volksschulen am 13. Februar 1916 vor ,einer auserlesenen Besucherschar, die durch ihr Erscheinen den Veranstaltern gewiß große Ehre (erwies) ${ }^{\star 1260}$, ein

\footnotetext{
${ }^{1254}$ Lemmermann, Kriegserziehung im Kaiserreich (1984), S. 312.

${ }^{1255}$ Lemmermann, Kriegserziehung im Kaiserreich (1984), S. 312.

${ }^{1256}$ Jugenddank für Kriegsbeschädigte e.V., Jugenddank für Kriegsbeschädigte e.V. 1917; Januar 1917, S. 6.

${ }^{1257}$ Führen, Lehrer im Krieg (1936), S. 54.

1258 In Bremen wurde Waldemar von Baussnerns „Schlachtenhymne“ aufgeführt (Lemmermann, Kriegserziehung im Kaiserreich [19849, S. 311).

1259 Lemmermann, Kriegserziehung im Kaiserreich (1984), S. 311.

${ }^{1260}$ Führen, Lehrer im Krieg (1936), S.65. Es werden genannt: „Der Oberkommandierende der Truppen im Elsaß Generaloberst von Falkenhausen in Begleitung zweier Generale, darunter der stellvertretende Kommandeur des XV. Armeekorps Ritter Hentschel von Hilgenheim, der Statthalter, der Staatssekretär, Bischof Dr. Fritzen, die Schulbehörde, an der Spitze der Direktor des Oberschulrats, Dr. Kaiser, der Rektor der Universität, Prof. Dr. Schwartz, der Bezirkspräsident vom Unter-Elsaß Bürgermeister Dr. Schwander und andere hochgestellte Persönlichkeiten mehr.“
} 
Wohltätigkeitskonzert zum Besten der Kriegsbeschädigten im Elsass. Neben den Großveranstaltungen, die von mehreren Schulen gemeinsam veranstaltet wurden, gab es in allen Teilen Deutschlands Konzerte und andere Unterhaltungsangebote, die einzelne Schulen ebenfalls mit gutem Erfolg durchführten. Als Beispiele seien ein Liebesgabenkonzert der 126. Berliner Gemeindeschule (Einnahmen 200 Mark) ${ }^{1261}$, Konzerte des Gymnasiums zu BerlinSteglitz ${ }^{1262}$, ein Konzert des Friedrich-Wilhelm-Gymnasiums in Berlin (Spendensumme 256 Mark) ${ }^{1263}$ und musikalische Veranstaltungen der Leibnizschule ${ }^{1264}$ sowie des KaiserWilhelms-Gymnasiums ${ }^{1265}$ in Hannover genannt.

Da viele der bisher genannten Beispiele vor allem aus Berlin und anderen Großstädten stammen, soll im Folgenden noch auf eine ländliche Region eingegangen werden, und zwar auf Flensburg in der preußischen Provinz Schleswig-Holstein. Dort fanden in der Zeit vom 18. Februar 1915 bis 1918 jährlich mehrere Kinderkonzerte und Gesangsabende der Volksschulen statt, bei denen insgesamt 13.000 Mark eingenommen wurden. Hinzu kamen noch Konzerte der Oberrealschule I und des Lyzeums. ${ }^{1266}$ Die Konzerte, an denen bis zu 400 Kinder teilnahmen, waren durchgehend sehr erfolgreich und mussten teilweise mehrfach wiederholt werden.

Viele Orts- und Schulchroniken enthalten zwar Hinweise zur Durchführung solcher Unterhaltungsveranstaltungen und häufig auch Angaben über die Einnahmen und deren Verwendung, selten jedoch erfährt man etwas über den genauen Ablauf und die dargebotenen Lieder und Gedichte. Mitunter ist lediglich die Rede von ,patriotischen Liedern oder Volksliedern“.

Da Programmabläufe Rückschlüsse auf die politische Intention und auch die Wirkungen ermöglichen, sollen im Folgenden einige genauer untersucht werden. In Flensburg begann die Gesangsaufführung der Volksschulen am 21. Februar 1915, die von Rektor Henningsen geleitet wurde, mit einem längeren Gedicht. Die anschließend vorgetragenen beliebten Lieder waren thematisch gegliedert und stellten ein in sich geschlossenes Programm dar. Auf vier

\footnotetext{
${ }^{1261}$ Führen, Lehrer im Krieg (1936), S. 54.

${ }^{1262}$ Lehmann, Weltkriegs-Erinnerungen aus dem Kreise des Gymnasiums zu Berlin-Steglitz (1925), S. 12.

1263 Jahres-Bericht über das Königliche Friedrich-Wilhelm-Gymnasium zu Berlin (Ostern 1915), S. 7; zitiert nach: Lemmermann, Kriegserziehung im Kaiserreich (1984), S. 308. Für den 20. März 1915 war ein zweites Konzert vorgesehen.

${ }^{1264}$ Im Jahresbericht 1915 heißt dazu: „Sogar Frau Musika war mehrfach bei den Leibnizern zu Gaste. Mit Klavier und Geige wurden den Zuhörern alte treffliche Heeresmärsche vorgeführt, wieder ein anderer sang seinen Mitschülern schöne alte Soldatenlieder vom Kaiser Max bis auf des Generals Emmich Heldentat vor, und auch Gedichte wurden hin und wieder vorgetragen“ (Meyer, Siebendreissigster Jahresbericht der städtischen Leibnizschule zu Hannover [1915], S. 14).

1265 Über die Veranstaltung ist im Jahresbericht 1914/15 vermerkt: „Am Sonnabend, dem 27. Februar, veranstaltete Herr Musiklehrer Schwarze in der Aula ein Konzert. Der Reinertrag in Höhe von 300 Mark wurde dem Roten Kreuz überwiesen.“ Mücke, Königliches Wilhelms Gymnasium in Hannover (1915), S. 18.

1266 Siehe: Hohnsbehn, Die Flensburger Schuljugend in der Zeit des ersten Weltkriegs (1996), S. 248-250. Ein Konzert des Lyzeums in der Marienkirche, bei dem ein Eintrittsgeld von 30 Pfennig erhoben wurde, erbrachte 260 Mark, wie aus der Chronik des Lyzeums hervorgeht (Band II, 1907-1930, S. 130).
} 
Lieder zur „Friedenszeit“ folgte ein von einem Schulrektor verlesener Aufruf des Kaisers und dann der mit „Krieg“ überschriebene Hauptteil, der acht Lieder umfasste. Der letzte Teil (,Ausblick“) endete mit der Nationalhymne, in die alle Anwesenden einstimmten. ${ }^{1267}$ Sieht man davon ab, dass es keine Rede durch einen Schulleiter oder Lehrer gab, so entsprach das Konzert durchaus allgemeinen vaterländischen Feiern und offiziellen Schulfeiern.

Fast immer bezogen sich die musikalischen Darbietungen und die Deklamationen auf das Kriegsgeschehen. ${ }^{1268}$ Die Schulkinder waren durch die Deklamationen direkt in die Veranstaltungen eingebunden und wurden mit den Kriegsthemen, die in den Programmfolgen dominierten, direkt konfrontiert. Meistens ging es um die - angebliche - Überlegenheit deutscher Soldaten und Waffen sowie um eine allgemeine Verharmlosung und gleichzeitige Verherrlichung des Krieges.

Dieses zeigte sich auch bei der Auswahl der musikalischen Beiträge. Wurden von den Schülern reine instrumentale Stücke dargeboten, so handelte es sich überwiegend um Märsche. Lieder, teilweise erst im Weltkrieg geschaffen, bezogen sich ebenfalls sehr häufig auf das Kriegsgeschehen und passten zu den aktuellen militärischen Ereignissen. So gehörten z. B. „Die Musik kommt“, „Hinter Metz“ und das Soldatenlied „Durch Belgien 1914“ im Dezember 1914 zum Programm eines Schulkonzerts. Thematisiert wurde durch die Lieder wiederholt auch das damals propagierte Ideal der Treue bis zum Tod, wie z. B. in „Treue Liebe bis zum Grabe“. Die Konzerte endeten in der Regel mit dem gemeinsamen Gesang von „Es braust ein Ruf wie Donnerhall“, „Heil Dir im Siegerkranz“, „O Deutschland hoch in Ehren“ und natürlich „Deutschland, Deutschland über alles“. 1269

Auch aus Schwelm, München, Essen und Berlin liegen genaue Informationen über den Ablauf der vaterländischen Schüleraufführungen vor ${ }^{1270}$, von denen das Programm der Kgl. Rupprecht-Kreisrealschule in München hier beispielhaft dargestellt wird.

Die Feier fand am 12. Mai 1915 unter Leitung des Kgl. Gesang- und Musiklehrers W. Kohlbecker statt und hatte folgenden Ablauf:

\footnotetext{
${ }^{1267}$ Siehe: Hohnsbehn, Die Flensburger Schuljugend in der Zeit des ersten Weltkriegs (1996), S. 249.

${ }^{1268}$ Presseberichten nach gab es u.a. folgende Deklamationen: ,'Furor teutonicus' von J. Lauff“, „Wie es anfing“, „Drei Söhne“, „Wohlauf, Kameraden, aufs Pferd, aufs Pferd“, „Bekenntnis eines Arbeiters“, „Die Pferde“, „Die Posten“, „Deutscher Schwur“, „Hindenburg“, “V. 187 und Ariadne“, „Der Untergang der Emden“, „Die Schlacht“, „Vorm Ziel“, ,'Reiterlied' von G. Hauptmann“, ,'Was kraucht dort im Busch herum' von HoffmannKuschke“ und ,'Am Ysergebiet' von G. Fauth' (Pust, „Vaterländische Erziehung" für „Höhere Mädchen" (2004), S. 394). Fünf Beispiele für Lieder und Deklamationen in Schulfeiern sind auf den Seiten 483f.abgedruckt.

1269 Siehe: Pust, „Vaterländische Erziehung" für „Höhere Mädchen” (2004), S. 394f. und Meyer, Siebendreissigster Jahresbericht der städtischen Leibnizschule zu Hannover (1915), S. 14.

${ }^{1270}$ Lemmermann, Kriegserziehung im Kaiserreich (1984), S. 861-862. In Schwelm wurden in den Jahren 1914 1916 insgesamt 16 Veranstaltungen durchgeführt, davon 10 „Vaterländische Abende“.
} 
1. Heldenmarsch für Orchester von Fr. Schubert ${ }^{1271}$

2. Ansprache

3. Vorträge: Der Krieg bricht los!

a) Am 1. August 1914 (Ludwig Thoma)

b) Ihr habt's gewollt (Hermann Strodthoff)

c) Lied des Knaben (Otto Crusius)

4. Chöre

a) „Hinaus ins Feld“ (B. Müller)

b) „Ein Kaiserwort“ (R. Wintzer)

c) „Der Deutschen Kriegsgesang 1914“ (Fr. Könnecke)

5. Vorträge: Im Kriege!

a) Zwischen Metz und den Vogesen (Rudolf Herzog)

b) Unsere Toten (Ferdinand Goetz)

c) Das Soldaten Kind (Richard Zorzmann)

6. Chöre

a) „Reiterlied“ (S. Breu)

b) "Stolz zieh'n wir in die Schlacht“ (altpreußischer Armeemarsch)

c) „Waffentanz“ (K. Kreutzer)

7. Vorträge: Ausblick

a) Der Knabe (Adolf Holst)

b) Michel, sei stolz! (Otto Reuter)

8. Chöre

a) „Sieg!“” (M. Ludwig)

b) „Echt deutsch sein und bayerisch!“ (R. Effert)

c) „Altniederländisches Dankgebet“ (Eduard Kremser)

9. Zwei preußische Armeemärsche

a) Marsch der Garde

b) Pariser Einzugsmarsch

10. Huldigung. ${ }^{1272}$

Bereits die einzelnen Titel zeigen, dass in allen Programmteilen der vaterländischen Feier der Krieg thematisiert und verherrlicht wurde. Neben den Vorträgen, die sich hauptsächlich auf den Kriegsbeginn und einzelne Episoden an der Front bezogen, nahmen damals beliebte Marschlieder und Armeemärsche einen breiten Raum ein. Durch die Reden, die Liedtexte und auch vor allem durch die damals bekannten und beliebten militärischen Weisen sollte die emotionale positive Einstellung zum Krieg verstärkt werden. Auch hier werden wieder die nationalistischen und militärischen Intentionen deutlich, die durch die Verbindung von Musik und Dichtung mit dem Militarismus erreicht werden sollten, indem auf die meist jugendlichen Akteure und Zuhörer emotional eingewirkt wurde.

\footnotetext{
${ }^{1271}$ Franz Schuberts „Heldenmarsch“ (opus 27, Nr. 3) ist ein Beispiel für die Instrumentaliserung klassischer Werke. Es ging nicht um das Musikstück als ästhetisches Ganzes, sondern wichtig waren vor allem der Titel und der Marschrythmus. Siehe dazu: Giesbrecht, "Lieb' Vaterland, magst ruhig sein" in Lück/Senghaas Dieter (Hrsg.), Vom hörbaren Frieden (2005), S. 436-439.

1272 Monatsschrift für Schulgesang, 10.Jg., 1915/16, S. 144; zitiert nach: Lemmermann, Kriegserziehung im Kaiserreich (1984), S. 862.
} 
Auf weitere Beispiele kann verzichtet werden, da in der Regel die entsprechenden Veranstaltungen der Schulen aller Schulformen im gesamten Deutschen Reich den oben untersuchten Volksschulen ${ }^{1273}$ und höheren Mädchenschulen in Schleswig-Holstein und der bayerischen Kreisrealschule entsprechen. Es ist deshalb davon auszugehen, dass die Schulkonzerte weitgehend den allgemeinen vaterländischen Feiern entsprachen und neben der materiellen Unterstützung der Kriegswohlfahrt patriotische Ziele wie die Verherrlichung des Krieges und die Stärkung des Durchhaltewillens verfolgten. Detaillierte Zeitzeugenberichte über die Wirkung auf die Schüler und Schülerinnen sowie auf erwachsene Besucher liegen nicht vor.

\subsection{Schüleraufführungen}

Neben den genannten Unterhaltungsveranstaltungen führten viele Schulen Theateraufführungen durch, oft auch in Verbindung mit musikalischen Beiträgen oder Rezitationen. Damit knüpfte man an die Tradition des „patriotischen Schulfestspiels“1274 aus der Zeit der Friedensphase des Deutschen Reichs an. Nach Auffassung Schroeders war die Veröffentlichung von mehr als 450 patriotischen Theaterstücken ein Beleg dafür, dass ,,sowohl die Autoren als auch die für die Aufführung verantwortlichen Lehrer die vom Staat propagierten Indoktrinationsziele, die der Herrschaftssicherung dienten, akzeptiert haben und in der Aufführung von Schulfestspielen eine besonders geeignete Möglichkeit erkannten, die politische Bewußtseinsbildung der Jugend diesen Zielen gemäß zu prägen“"1275.

Sie dienten der Herrschaftsstabilisierung und bereiteten die Schulkinder auf den Krieg vor. Entweder wurde der Tod auf dem Schlachtfeld in den Theaterstïcken verschwiegen oder er wurde derartig verharmlost, dass sich der junge Mensch für den Heldentod für Kaiser und Reich regelrecht begeisterte.

Neben ideologischen Zielen dienten die Aufführungen im Ersten Weltkrieg aber auch der finanziellen Unterstützung der Kriegshilfe. Der Verein „Jugenddank“ stellte den Schulen ,zur Aufführung in jetziger Zeit geeignete Theaterstücke“1276 zur Verfügung und auch Verlage boten den Schulen gebrauchsfertiges Material an. ${ }^{1277}$

\footnotetext{
${ }^{1273}$ Dass die Mehrzahl der geschilderten Beispiele aus Volksschulen stammt, ist durchaus intendiert, denn in den anderen Kapiteln sind aufgrund der Quellenlage die höheren Schulen teilweise überpräsentiert.

${ }^{1274}$ Siehe: Schroeder, Funktion und Gestalt des patriotischen Schulfestspiels in der Wilhelminischen Kaiserzeit (1990).

1275 Schroeder, Funktion und Gestalt des patriotischen Schulfestspiels in der Wilhelminischen Kaiserzeit (1990), S. 289.

${ }^{1276}$ Jugenddank für Kriegsbeschädigte e.V., Jugenddank für Kriegsbeschädigte e.V. 1917, 1918, S. 5.

${ }^{1277}$ Fitzke/Matzdorf, Eiserne Kreuz-Nagelungen zum Besten der Kriegshilfe und zur Schaffung von Kriegswahrzeichen ; Gebrauchsfertiges Material f. vaterländ. Volksunterhaltung durch Feiern in Schulen ... Von Benno Fitzke u. Paul Matzdorf (1916); die Titel lauteten beispielsweise „Das schwarze und das rote Kreuz“ (P. Matzdorf) oder „Die Liebe siegt“.
} 
Insbesondere ein „Nagelungsfestspiel“, der vaterländische Einakter „Der Sohn“, sowie „Colberg“1278 wurden von vielen Schulen aufgeführt. ${ }^{1279}$ Neben den patriotischen Schulfestspielen wurden aber durchaus auch Stücke gespielt, die zwar patriotische Züge, aber keinen direkten Bezug zum Krieg hatten. Beispielsweise wurde in einem Flensburger Lyzeum Carl Reinickes Märchenspiel „Schneewittchen“, im Rendsburger Lyzeum E. J. Groths „Frau Ursula. Ein Theaterstück aus der Reformationszeit ${ }^{\star 1280}$ und von einem Frankfurter Realgymnasium der Schwank „Der Roßdieb“"1281 von Hans Sachs aufgeführt.

Auf ein Theaterstück der Auguste-Viktoria-Schule in Flensburg, das am 22. Oktober 1917 „zum Besten der Schwesternspende“ im Stadttheater aufgeführt und am 29. Oktober noch einmal wiederholt wurde, soll etwas näher eingegangen werden. ${ }^{1282}$ Trotz der Papierknappheit war ein Programmheft gedruckt worden, dessen Titelblatt entsprechend den Reichsfarben Schwarz-Weiß-Rot gestaltet war. Natürlich berichtete die Lokalpresse mehrfach über die Aufführung.

Am Anfang der Veranstaltung stand ein patriotisches Festlied, dem ein Vorspruch durch eine Lehrerin folgte. In ihm wurde die Opferbereitschaft junger Schwestern gefeiert, die im Krieg verwundeten und sterbenden Soldaten halfen. Er endete mit einer Verherrlichung der Kaiserin als Protektorin des Roten Kreuzes. Im Anschluss daran präsentierten die Schülerinnen ein „Lebendes Bild: Schleswig-Holstein. Nach dem Kaiser-Wilhelm-Denkmal“. Lebende Bilder waren damals eine gängige Darstellungsform. ${ }^{1283}$ Der erste Hauptteil der Feier bestand unter dem Motto „schleswig-holsteinisches Volksleben in Wort und Bild“ aus Kinderspielen, Reigen und Tänzen, während im zweiten Teil das Märchenspiel „Schneewittchen“ von Carl Reinicke aufgeführt wurde. In der Pause verkauften die Schülerinnen selbst hergestellte Ansichtskarten ${ }^{1284}$ und kleinere Handarbeiten. Der Erlös, über dessen Höhe keine Informationen vorliegen, wurde an das Rote Kreuz überwiesen.

Während die beschriebene Veranstaltung zwar durchaus patriotische Züge trug, aber keine kriegsverherrlichende und indoktrinierende Zielsetzung, gab es viele Schüleraufführungen, die den Krieg verherrlichten, zur Opferbereitschaft aufriefen und ideologisch einseitig beeinflussten. Ein solches im Krieg viel gespieltes Stück war Paul Matzdorfs „Das schwarze und

\footnotetext{
${ }^{1278}$ Hoffmann (Hrsg.), Ein Krieg wird ausgestellt (1976), S. 236.

1279 Jugenddank für Kriegsbeschädigte e.V., Jugenddank für Kriegsbeschädigte e.V. 1917, 1918, S. 4.

${ }^{1280}$ Siehe: Pust, ,Vaterländische Erziehung" für „Höhere Mädchen" (2004), S. 398-400.

${ }^{1281}$ Hoffmann (Hrsg.), Ein Krieg wird ausgestellt( 1976), S. 236.

1282 Siehe: Pust, „Vaterländische Erziehung" für „Höhere Mädchen" (2004), S. 398-400.

1283 Zur Funktion und Wirkungsweise von Kriegsritualen siehe: Hüppauf, Transformationen von Gewalt in Kriegsritualen der Moderne, in: Korff (Hrsg.), Alliierte im Himmel (2006), S. 56ff.

${ }^{1284}$ Siehe: Anhang, Seite 80.
} 
das rote Kreuz“1285. Ein kleiner Ausschnitt zeigt eindeutig den pseudoreligiös-patriotischen Charakter und den konkreten Bezug zum Krieg:

„Ich streifte durch des Ostens Weiten

Bis hin zum weißen Russenzaren.

Was ich da sah an unerhörten Heldentaten,

Will ich gern künden.

In Hindenburg ist unserm Volk

Ein Held erstanden wie der Alte Fritz.

Er ist's, der die Millionen Russenheere

$\mathrm{Zu}$ Paaren trieb und ihre Festungen

Wie Nüsse knackte.

Heil ihm, dem edlen Mann,

Der nun die Ostmark frei vom Feind gefegt

Und Polens Sklavenketten brach.

Ihm fliegt des Volkes Liebe zu.“

Im Vergleich zu den musikalisch ausgerichteten Veranstaltungen, die tausendfach stattfanden, waren schulische Theaterabende relativ selten. Häufiger wurden Schüleraufführungen allerdings im Rahmen von Weihnachtsfeiern veranstaltet. Ob diese in erster Linie christlich ausgerichtet waren und inwieweit Bezüge zum Krieg vorhanden waren, soll im nächsten Abschnitt untersucht werden.

\subsection{Weihnachtsfeiern}

Am 20. Dezember 1916 fand abends um 18 Uhr in der Aula des Katharineums eine Weihnachtsfeier der Oberrealschule im Lübecker Dom zum Besten des „Jugenddanks“ statt, deren Programm überliefert ist. ${ }^{1286}$

Sieht man von Heinrich Lerschs Schützengrabengedicht („Mutter Gottes im Schützengraben“) ab, so war die Feier wenig zeitgebunden und hätte auch heute so ähnlich ablaufen können: mit Musik von Bach, der Weihnachtsgeschichte, christlichen Gedichten, einem Krippenspiel und bekannten Liedern („Stille Nacht“, „O du fröhliche“). Eindeutig stand die christliche Botschaft im Mittelpunkt. ${ }^{1287}$

Häufig fanden Weihnachtsfeiern in Gegenwart von Verwundeten statt, die dann während der Feier Geschenke erhielten. 1914 beispielsweise führten die Schülerinnen eines Privatgymnasiums in Kiel in der Aula der Schule „Kriegers Weihnachten“ auf, begleitet von Gesängen und Deklamationen. ${ }^{1288}$ Ähnliche Veranstaltungen gab es 1915 und 1916 im Lyzeum in Blankenese und im Flensburger Lyzeum. Nach Auffassung von Pust wurde oftmals das aktuelle

\footnotetext{
${ }^{1285}$ Fitzke/Matzdorf, Eiserne Kreuz-Nagelungen zum Besten der Kriegshilfe und zur Schaffung von Kriegswahrzeichen (1916), S. 23-28.

${ }^{1286}$ Beispiel einer Vortragsfolge, in: Die Arbeitsschule, 1918, S. 112.

${ }^{1287}$ Siehe: Lersch, Weihnachten im Schützengraben, http://www.uibk.ac.at/brenner-archiv/editionen/ ged_wk1/links/lersch_gr6.html (14.11.2008).

${ }^{1288}$ Pust, „Vaterländische Erziehung" für „Höhere Mädchen" (2004), S. 401.
} 
Kriegsgeschehen thematisiert, wie z. B. der Titel der Ansprache im Lyzeum in Itzehoe 1914 (,Kriegsweihnachten“) und 1916 das Thema der Ansprache (,Welchen Trost gewährt uns das Weihnachtsfest im 3. Kriegswinter?“(1289) zeigen. In Flensburg führten die Schülerinnen des Lyzeums in einem Lazarett „ein Weihnachtsspiel auf, das die Christnachtstimmung in der Natur, an der Krippe und im Weltkrieg widerspiegelte“"1290.

Auch ein von zwei Schülerinnen aus Blankenese vorgetragener Dialog bezog sich eindeutig auf den Krieg:

„1. Kind: Der Kaiser ist der beste Mann, wie gern möchte' ich ihn sehen!

2. Kind: Doch Hindenburg der zweite Mann, Könnt ich doch zu ihm gehen!

1. Kind: Viel tausend Russen fing er schon, das musst du wohl bedenken.

2. Kind: Was wird der Kaiser ihm zum Lohn zu Weihnachten wohl schenken?“1291

In der Regel wurde für Weihnachtsfeiern kein Eintrittsgeld erhoben, sondern am Ende der Veranstaltungen um eine Spende gebeten, die der Kriegshilfe zugutekam. Konkrete Angaben über deren Höhe können aufgrund der schlechten Quellenlage allerdings nicht gemacht werden. Gerade in kleinen Dörfern wurden Weihnachtsfeiern gemeinsam von Kirche und Schule durchgeführt. Als Beispiel sei aus der Schulchronik des Dorfes Zaasch (Provinz Sachsen) zitiert, in der zum Weihnachtsfest 1917 vermerkt ist:

„Um 1/2 8 Uhr hatten sich die Gemeindemitglieder und Schulkinder im Saale des Gasthauses versammelt. Nach einer kurzen Begrüßungsrede des Herrn Kantor Gebhardt wurde mit dem alten Weihnachtslied ,O Tannenbaum' begonnen. Im 1. Teil des Unterhaltungsabends wechselten dann Gedichtvorträge und Chorgesänge miteinander ab. Den 2. Teil füllte eine Lichtbildervorführung aus. Herrn Pastor Ehrhardt, Zschernitz, führte 40 Lichtbilder vom Beginn des Weltkrieges bis zum Jahr 1915 vor, die Herr Kantor Gebhardt in interessanter und humorvoller Weise zu erklären wusste. Den Höhepunkt aber erreichte der Unterhaltungsabend mit dem Erscheinen Knecht Ruprechts, der mit voll gepacktem, von zwei Ziegenböcken gezogenem Wagen im Saale Einzug hielt. Für jeden brachte der Weihnachtsmann eine Gabe. In liebenswürdiger Weise hatten die hiesigen Einwohner das Unternehmen mit Geld, Äpfeln und sonstigen Gaben unterstützt. Ein frohes Kinderlachen erfüllte den Saal, wie man es wohl kaum seit Ausbruch des Kriegs gehört hatte. Mit dem gemeinsamen Schlußlied ,Wir treten zum Beten ${ }^{1292}$ schloß diese wohlgelungene Feier. Die Herzen voll wahrer Weihnachtsfreude schieden die Gäste voneinander.

Am Heiligen Abend fand in der hiesigen Kirche zum ersten Male eine Christmette unter Leitung des Lehrers statt.

\footnotetext{
1289 Siehe: Pust, „Vaterländische Erziehung" für „Höhere Mädchen" (2004), S. $401 \mathrm{f}$.

${ }^{1290}$ Pust, „Vaterländische Erziehung" für „Höhere Mädchen" (2004), S. 402.

1291 Zitiert nach: Pust, „Vaterländische Erziehung" für „Höhere Mädchen” (2004), S. 401. Der Text hat sich in einem Schreibheft einer Schülerin erhalten.

1292 Dieses Lied aus dem Jahr 1577, auch als „Niederländisches Dankgebet“ bekannt, wurde sehr häufig bei nationalen Feierlichkeiten gesungen.
} 
Als Ersatz für die beschlagnahmten Orgelpfeifen fertigten die Schulkinder Papp-Orgelpfeifen an, die mit Aluminiumbronze gestrichen wurden."“1293

Ähnlich wie in Zaasch liefen viele Weihnachtsfeiern ab - mit traditionellen Elementen (hier Weihnachtslieder und Auftritt des Knecht Ruprecht mit Geschenken) und aktuellem Kriegsbezug (hier Bildervortrag und Schlusslied). Es gab aber durchaus auch Schulen, die zu öffentlichen „Kriegsweihnachtsfeiern“ einluden, wie z. B. die Schule in Mittel-Podiebrad (Provinz Schlesien). ${ }^{1294}$ In der Chronik ist für das Jahr 1915 vermerkt, dass die Rede des Hauptlehrers sowie die Gesänge und Vorträge der Kinder ,,in Beziehung zu der ernsten Zeit“" standen. Wie in jedem Jahr wurden während der Feier arme Kinder beschenkt.

Häufig gingen Schulkinder in der Weihnachtszeit in die Lazarette. Darüber schrieb die Lehrerin Anna Günther:

\begin{abstract}
„Mit Vorliebe wurden solche kleinen Feiern in der Weihnachtszeit veranstaltet. Wenn die Liebesgaben an die Front geschickt waren, rüstete man in der Heimat zur Weihnachtsfeier für die Kriegsbeschädigten. Auch unter dem lichterlosen Christbaum klingen die alten lieben Weihnachtslieder und Gedichte erhebend; auch ohne reiche Gaben fühlen die Verwundeten den heißen Dank der deutschen Jugend. Auch in den Lazaretten fanden kleine Vorführungen statt, um den Kranken und Verwundeten, die noch nicht ausgehen durften, eine kleine Zerstreuung und Ablenkung zu geben. Solche kleinen Feiern sind die Höhepunkte im Schulleben. “1295
\end{abstract}

Wie die wenigen Beispiele zeigen, wurde fast immer in den Weihnachtsfeiern - wenn auch in unterschiedlicher Intensität - auf das Kriegsgeschehen Bezug genommen. Sie lassen allerdings kein fundiertes Urteil darüber zu, ob die schulischen Weihnachtsfeiern mit zunehmender Kriegsdauer der Bezug zur Kriegszeit stärker wurde oder - was wahrscheinlicher ist - der Ablauf der Feiern christlich- traditioneller wurde.

\title{
6.4 Kriegsvorträge
}

Im Gegensatz zu den in 6.1 bis 6.3 genannten Aktionen propagierten die Behörden von Kriegsbeginn an Veranstaltungen, in deren Mittelpunkt Vorträge über aktuelle Kriegsthemen standen. So wandte sich z. B. das Hildesheimer Regierungspräsidium bereits am 29. August 1914 in einer sehr ausführlichen Verfügung an die Lehrerschaft des Regierungsbezirks und forderte sie auf, ,schlichte Vorträge über die Kriegslage zu halten, um die Gemeinde, die sicherlich bereitwillig teilnehmen wird, anhand von Karten“"1296 über die Situation an der Front zu informieren. Es wurde angeregt, ,zur Erhöhung der begeisterten Stimmung“, gemeinsam

\footnotetext{
${ }^{1293}$ Hube, Chronik, Zaasch http://www.zaasch.de/pdf/Chronik_Zaasch.pdf (14.11.2008), S. 20f.

1294 Johann/Tchech/Schicha/Zwikirsch/Matzel/Rosemann, Schulchronik der Schule zu Mittel-Podiebrad, http://petertscherny.pe.funpic.de/strehlen/podiebrad/chronp.pdf (05.09.2010), S. 24.

${ }^{1295}$ Günther, Von der Kriegsarbeit der Mädchenschulen (1919), S. 74.

${ }^{1296}$ Ministerium der geistlichen und Unterrichts-Angelegenheiten, Vorträge der Lehrerschaft des Regierungsbezirks Hildesheim, Zentralblatt für die gesamte Unterrichtsverwaltung in Preußen, 1914, S. 644.
} 
patriotische Lieder singen zu lassen. Ziel sollte es sein, die Siegeszuversicht zu stärken sowie „Verluste teurer Angehöriger“ als notwendige Opfer für den Sieg zu verstehen und stolz auf die Gefallenen zu sein. Die Anwesenheit von älteren Schulkindern wurde gestattet. Auf die Möglichkeit, Eintrittsgeld zu erheben und den Erlös der Wohlfahrtspflege zukommen zu lassen, was später zur Regel wurde, wurde nicht hingewiesen.

Dieser und ähnlichen offiziellen Aufforderungen in anderen Gebieten des Deutschen Reichs wurde eifrig Folge geleistet. Während die Volksschullehrer in großer Zahl im Allgemeinen zu der Landbevölkerung in Dorfgaststätten und Gemeindesälen sprachen, luden die städtischen Gymnasien und Lyzeen in erster Linie die Öffentlichkeit zu Unterhaltungsabenden in die Schulen ein, in deren Mittelpunkt Vorträge über die aktuelle Kriegslage oder allgemeine auf den Krieg bezogene Themen standen. Unterschiede hinsichtlich der Vortragsthemen gab es zwischen den ländlichen Volksschulen und den städtischen höheren Schulen insgesamt nicht. Zunächst soll ein Beispiel aus Dranske, einem Dorf in Vorpommern, näheren Aufschluss über entsprechende Veranstaltungen für die Dorfbevölkerung geben. ${ }^{1297}$ In der Chronik der Volksschule ist über den „Kriegsabend“ am 12.1. 1915 vermerkt, dass er gut besucht war und durch die Eintrittsgelder 16,40 Mark eingenommen wurden, die das Rote Kreuz bekam. Nach einigen Deklamationen und einer kurzen Ansprache referierte der Lehrer über „Die Gründe, die unsere Gegner in den Weltkrieg trieben“ (I. Teil) und „Die Kriegsereignisse von A bis Z“ (II. Teil). Nach dem Vortrag folgte ein Unterhaltungsblock mit sportlichen Darbietungen und der Aufführung des Stückes „Herr mache uns frei“, das der Lehrer selbst geschrieben hatte. $^{1298}$

Ähnliche Veranstaltungen hat es durchaus auch in anderen Landgemeinden gegeben, aber sie waren doch relativ selten, denn häufig fehlten in den Schulen für so aufwendig inszenierte Veranstaltungen wie in Dranske geeignete Räumlichkeiten. Für die höheren Schulen in den Städten war die Durchführung von Kriegsabenden hingegen fast die Regel.

Zielsetzung, Programmgestaltung und Erfolg sollen im Folgenden am Beispiel des Lyzeums in Schleswig näher untersucht werden. ${ }^{1299}$

In der Zeit vom 3. November 1914 bis 21. März 1915 führte die Schule in ihrer Aula insgesamt 11 öffentliche Veranstaltungen durch. Ab Oktober 1915 gab es dann eine zweite Staffel. Sie waren ähnlich konzipiert wie Schulfeiern ${ }^{1300}$ und enthielten Gesangs- und andere Musikdarbietungen sowie Deklamationen. Im Mittelpunkt stand jeweils ein Vortrag, den der Direk-

\footnotetext{
${ }^{1297}$ Langer, Schulfrei für den Krieg (2004).

${ }^{1298}$ Langer, Schulfrei für den Krieg (2004), S. 47.

${ }^{1299}$ Pust, ,Vaterländische Erziehung" für „Höhere Mädchen" (2004), S. 392-397.

${ }^{1300}$ Siehe: Kapitel 5.
} 
tor der Schule oder eine Lehrkraft hielt. Die Themen waren in den ersten Kriegsjahren fast immer auf das aktuelle Kriegsgeschehen bezogen. So sprach Direktor Dr. Walsemann zum Beispiel am 30. November 1914 über den „Siegeszug“ in Belgien und äußerte sich am 28. Februar 1915 zu den ,,neuesten Vorgängen auf den türkischen Kriegsschauplätzen“. Anfangs war nach Meinung Pusts die Kaiserverehrung noch fester Bestandteil der Reden und nahm fast die „Züge von Heiligenverehrung“ an, im Laufe des Krieges rückten dann jedoch mehr und mehr Ludendorff und Hindenburg in den Vordergrund.

Die meisten Deklamationen, die die Schülerinnen zum Programm beisteuerten, bezogen sich auf das Kriegsgeschehen und hatten die Überlegenheit deutscher Soldaten und Waffen zum Thema. Wie alle öffentlichen Feiern und Kundgebungen endeten die Abende mit dem gemeinsamen Gesang patriotischer Lieder, wie z. B. „Es braust ein Ruf wie Donnerhall“, „Heil dir im Siegerkranz“ und „Deutschland, Deutschland über alles“.

Die Veranstaltungen, über die mehrfach in der Presse berichtet wurde, waren offensichtlich gut besucht. So schrieben die Schleswiger Nachrichten am 15. 03. 1915: „Eine erstaunliche Kraft wohnt den Unterhaltungsabenden im Lyzeum inne [...] noch immer ist der Besuch ein außerordentlich starker; auch gestern mussten sich wieder etliche mit einem Stehplatz begnügen. “" ${ }^{1301}$ Besonders beliebt waren die Veranstaltungen, die von vielen Soldaten besucht wurden, beim Militär, das bei der Ausgestaltung durch ein Musikkorps des Landwehr ErsatzBataillons mitwirkte. Militärs zahlten ermäßigten Eintritt und Verwundete hatten sogar freien Zutritt, während andere 20-30 Pfennig bezahlen mussten. Der Reinertrag des ersten Veranstaltungszyklus (11 Abende) betrug 411,70 Mark und wurde insgesamt zehn Organisationen der Kriegshilfe überwiesen.

Wegen des Erfolgs wurde am 8. Oktober 1915 die Durchführung eines zweiten Vortragszyklus beschlossen. Zwar sollten die Veranstaltungen wieder alle zwei Wochen stattfinden, da aber inzwischen die Kriegsbegeisterung deutlich nachgelassen hatte und die Siege seltener geworden waren, sollten die Vorträge nicht mehr auf das aktuelle Kriegsgeschehen bezogen sein, sondern die Geschichte der Hohenzollern behandeln. So sprach z. B. Dr. Walsemann, Direktor des Schleswiger Lyzeums, am 24. Oktober 1915 über „Die Hohenzollern als Kurfürsten von Brandenburg“. Das Rahmenprogramm der Fortsetzungsveranstaltungen, das wieder aus Liedern, Deklamationen und anderen Aufführungen bestand, war natürlich ,auf den Grundton ,deutsch’ gestimmt““1302, wie es die Schleswiger Nachrichten am 16. 11. 1915 formulierten. Als der Besuch der Unterhaltungsabende nachließ, beschloss die Lehrerkonferenz

\footnotetext{
${ }^{1301}$ Pust, „Vaterländische Erziehung" für „Höhere Mädchen” (2004), S. 395.

1302 Zitiert nach: Pust, „Vaterländische Erziehung" für „Höhere Mädchen" (2004), S. 396.
} 
am 7. März 1916, die Veranstaltungen zunächst einzustellen und weitere ab Oktober 1916 ,in zwangloser Form“ durchzuführen und kein Eintrittsgeld mehr zu erheben.

Auch wenn es sicher im Deutschen Reich nur wenige Schulen wie das Schleswiger Lyzeum gegeben hat, die entsprechende Veranstaltungen mit einer solchen Regelmäßigkeit durchgeführt haben, so ermöglichen die oben beschriebenen doch generell einen guten Einblick in Schulveranstaltungen dieser Art. Denn die Unterhaltungsabende anderer Schulen waren ganz ähnlich konzipiert, wie sich trotz der relativ wenigen vorhandenen Quellen feststellen lässt. $\mathrm{Zu}$ den Vortragsveranstaltungen in den Schulen wurden oft gern auch Militärs als Referenten eingeladen, wie beispielsweise am 12. September 1914 im Kaiser-Wilhelms-Gymnasium in Hannover. Dort hielt Kapitän z. S. a. D. Wilde vor Schülern der höheren Klassen in der Aula einen Vortrag über „Die Marine und ihre Aufgaben unter Berücksichtigung ihres Materials“. Eine Sammlung, die dem Roten Kreuz zugutekam, ergab 73,54 Mark. ${ }^{1303}$ Neben diesen ,Wanderrednern', die zu den Schülern und Schülerinnen mehrerer Schulen in besonderen Schulveranstaltungen über Kriegsthemen sprachen, gab es auch jene, zu deren Vorträgen, die außerhalb der Schulen stattfanden, Schüler und Lehrer eingeladen wurden. Bei den Rednern handelte es sich oft um hochdekorierte Offiziere, die von offizieller Seite auf Vortragsreise geschickt wurden. Ein Beispiel aus Ulm sei zusätzlich angeführt:

„Sondervorträge, wie die eines höheren Offiziers über die französischen Festungen oder über die Riesenunterschiede zwischen 1870/71 und heute wandten sich in erster Linie an das Verständnis der älteren; aber reichen Gewinn hatten sie von ihnen, wie auch von poetischen Darbietungen aus dem Munde eines Kriegsdeklamators oder von Schilderungen des Seelenlebens durch einen sehr geschickten Wanderredner doch wohl alle Anwesenden. An solchen Tagen fanden sich dann auch die Oberklassen anderer Schulen der Stadt ein, wobei die Teilnahme der ,höheren Töchter' diesen Stunden in den Augen der Primaner einen besonderen Glanz verlieh.“" ${ }^{31304}$

Offensichtlich stießen die Redner, wie im Text angedeutet wird, bei den Schülern nicht immer auf hohe Akzeptanz.

Abschließend kann festgestellt werden, dass die durchgehend national eingestellten Lehrer, unterstützt von Militärs, durch die ,Kriegsvorträge' für die offizielle Kriegspropaganda wichtige Multiplikatoren waren. ${ }^{1305}$ Sie unterstützten den Durchhaltewillen der Bevölkerung und stabilisierten die „Heimatfront“. Aufgrund der zeitgemäßen Inhalte und des in der Regel ansprechenden abwechslungsreichen Rahmenprogramms erreichte man große Teile der Gesell-

\footnotetext{
${ }^{1303}$ Mücke, Königliches Wilhelms Gymnasium in Hannover (1915), S. 16. Der Referent hielt den gleichen Vortrag in der Zeit vom 8.-12. September 1914 mehrfach im Königlichen Goethe-Gymnasium in Hannover (Nack, Jahresbericht des Königlichen Goethe-Gymnasiums Hannover [1915], S. 12).

${ }^{1304}$ Schott, Ein Jahr Kriegstunden am Gymnasium, Deutsches Philologen-Blatt 1915, S. 617f.

${ }^{1305}$ In ländlichen Gebieten wurden oft lokale Autoritäten, neben Pastoren vor allem Lehrer, als ,Wanderredner' eingesetzt.
} 
schaft, denn die meistens öffentlichen Vortragsabende waren in den ersten Kriegsjahren sehr gut besucht.

\subsection{Veranstaltungen der Lehrerinnen und Lehrer}

Unabhängig von den offiziellen Schulveranstaltungen engagierten sich Lehrer und Lehrerinnen in vielfältiger Weise für die Kriegshilfe. ${ }^{1306}$ So veranstaltete der Berliner Lehrerinnenverein zusammen mit dem Berliner Frauenverein im Frühjahr 1915 eine Vortragsreihe mit folgendem Programm:

13. Januar: „Die Zusammengehörigkeit des militärischen und geistigen Deutschlands“ (Referentin: Margarete Treuge ${ }^{1307}$ );

3. Februar: „Das Problem der wirtschaftlichen Befreiung vom Ausland“ (Referentin: Dr. Gertrud Bäumer ${ }^{1308}$ );

24. Februar: „Deutsche Kultur in Mode und Hausrat“ (Referentin: Dr. Gertrud Bäumer);

17. März: „Der deutsche Geist in der Lebensanschauung“ (Referentin: Dr. Gertrud Bäumer).

Auch wenn die Vorträge nicht wie die meisten der schulischen Unterhaltungsabende direkt auf den aktuellen militärischen Verlauf des Krieges bezogen waren, so entsprachen sie dennoch dem allgemeinen nationalen Zeitgeist. Helene Lange, die Vorsitzende des Berliner Lehrerinnenvereins und des Allgemeinen deutschen Lehrerinnenvereins, schrieb dazu: „Unsere Teilnahme und unsere Tatkraft gehört den neuen Pflichten, die die gewaltigen geschichtlichen Ereignisse, deren Zeugen wir sind, uns auferlegt haben.“1309 $\mathrm{Zu}$ den genannten „Pflichten“ gehörte für die Lehrerinnen des genannten Verbandes und anderer

Verbände im besonderen Maße die Unterstützung der Kriegsfürsorge, wie der Appell Helene Langes in der Ankündigung der Vortragsreihe an ihre Kolleginnen zeigt:

„Da die Zeit mehr als je alle Wohlfahrtsbestrebungen in den Vordergrund stellt, so wollen wir die Beteiligung an den Vorträgen auch Nichtmitgliedern zugänglich machen gegen Zahlung eines Eintrittsgeldes von $1 \mathrm{M}$ für den Abend. Der Ertrag soll der Krankenkasse des Berliner Frauenvereins zufließen, die dringend neuer Einnahmen bedarf. Wir dürfen daher die Mitglieder unserer beiden

\footnotetext{
${ }^{1306}$ Da die Aktivitäten der Lehrerverbände in dieser Untersuchung zwar weitgehend unberücksichtigt bleiben, mitunter aber an den Veranstaltungen der Verbände auch Schüler aktiv beteiligt waren, werden hier einige wenige Beispiele genannt.

${ }^{1307}$ Margarethe Treuge (1876-1962), Direktorin der Sozialen Frauenschule in Hamburg; bis 1933 Mitglied der DDP, dann von den Nationalsozialisten ihres Amtes enthoben; nach dem Krieg gehörte sie zu den Mitbegründerinnen des Hamburger Frauenrings und initiierte 1949 zusammen mit anderen die Bildung der Arbeitsgemeinschaft Hamburger Frauenorganisationen.

${ }^{1308}$ Gertrud Bäumer (1893-1954), Oberlehrerin in Berlin und Mitglied im Vorstand des Allgemeinen Deutschen Lehrerinnenverbandes; für die DDP Mitglied des Reichstages bis 1932; 1920-1933 als Ministerialrätin für Jugendwohlfahrt und Schulwesen zuständig; im Nationalsozialismus aller öffentlichen Ämter enthoben; Schriftstellerin.

${ }^{1309}$ Lange, Vorträge, Die Lehrerin: Organ des Allgemeinen Deutschen Lehrerinnenvereins 1914/15, S. 299.
} 
Vereine, für die der Eintritt unentgeltlich ist - wohl herzlich bitten, möglichst viel zahlende Besucher heranziehen zu helfen. ${ }^{* 1310}$

Über den finanziellen Erfolg der Vortagsreihe liegen keine Informationen vor.

Neben solchen Vortragsveranstaltungen führten viele Lehrerverbände in allen Teilen des Reichs „Kriegs-Volksabende“ durch, die der „Hebung der Stimmung“, also der Stärkung der Siegeszuversicht und des Durchhaltewillens sowie der materiellen Unterstützung der Wohlfahrtsverbände dienten. Eine ausführliche Berichterstattung liegt für eine entsprechende Veranstaltung des Magdeburger Lehrervereins vor. ${ }^{1311}$ Der „Volksabend“, der bereits der fünfte des Winterhalbjahrs 1914/15 war, fand in der voll besetzten Aula der Augustaschule in Magdeburg statt. Das Programm entsprach dem der allgemeinen schulischen Feiern. Nach einem Orgelvorspiel und Darbietungen des Lehrergesangsvereins („Deutsches Gebet“ von Richard Wagner, „Sturmbeschwörung“ von Dürner u. a.) hielt ein Lehrer einen Vortrag über das Thema „Unser heiliger Krieg in der Dichtung“. Es folgten Gesangsstücke eines Kammersängers („Mahnung“ von Hans Hermann, „Morgenhymne“ von Henschel, „Fridericus Rex“ von Carl Löwe u. a.). Orchestermusik und einige Lieder des Lehrergesangvereins („Kamerad, komm“ von Klughardt, „Heut scheid’ ich“ von Ilsemann und „Lützows wilde Jagd“ von Karl Maria v. Weber ${ }^{1312}$ ) schlossen sich an. Der ,,von echtem vaterländischen Geist getragene Volksabend“ endete mit dem gemeinsamen Gesang „Deutschland über alles“"1313.

Neben solchen ,Volksabenden' veranstalteten die Lehrerverbände in großer Zahl auch Kriegskonzerte zugunsten der Kriegsfürsorge, wie z. B. in Berlin, Hamburg und Mühlhausen. ${ }^{1314}$ Diese fanden teilweise auch außerhalb der Schulen statt (z. B. am 5. November 1914 in der Berliner Philharmonie) und waren stets sehr gut besucht. In den meisten Fällen ist die Höhe der Einnahmen zwar nicht bekannt, die wenigen überlieferten Zahlen lassen aber Rückschlüsse auf den - insgesamt sehr beachtlichen - finanziellen Erfolg der Konzerte zu. Beispielsweise konnten die Breslauer Lehrer nach ihrem Konzert 600 Mark an den Nationalen Frauendienst überweisen und in Görlitz kamen für den Kriegsunterstützungsausschuss 805 Mark zusammen. ${ }^{1315}$ Ähnlich hoch werden auch die Einnahmen bei anderen Konzerten gewesen sein, da in der Regel der Eintritt zwischen 1 und 5 Mark kostete und die Konzerte meistens ausgebucht waren und häufig sogar wiederholt werden mussten. Die Kriegskonzerte trugen also zur Finanzierung der Kriegsfürsorge bei.

\footnotetext{
${ }^{1310}$ Lange, Vorträge, Die Lehrerin: Organ des Allgemeinen Deutschen Lehrerinnenvereins 1914/15, S. 299.

1311 Führen, Lehrer im Krieg (1936), S. 308f.

1312 Das berühmte Lied, das Carl Maria v. Weber (1786-1826) 1814 vertonte, schrieb Theodor Körner am 24. April 1813.

${ }^{1313}$ Führen, Lehrer im Krieg (1936), S. 309.

${ }^{1314}$ Beschreibung des Programms, in: Führen, Lehrer im Krieg (1936), S. 309-311.

1315 Siehe: Führen, Lehrer im Krieg (1936), S. 311.
} 


\subsection{Andere Veranstaltungen}

Über die genannten vielen Veranstaltungen hinaus gab es in einzelnen Schulen immer wieder Aktionen zugunsten der Kriegshilfe. Auch wenn die folgenden Beispiele wenig aussagekräftig sind und z. B. nichts über die Höhe der gesammelten Spendengelder und die Akzeptanz des Publikums aussagen, so zeigen sie doch die Vielfältigkeit der Aktivitäten und das Engagement der Schulen.

1. Die Schülerblaskapelle des „Städtischen Realprogymnasiums mit Realschule“ (seit 1983 Geschwister-Scholl-Gymnasium) in Velbert (Rheinprovinz) spielte für eine Spende oft bei militärischen Anlassen, Siegesfeiern sowie Beerdigungen und gab eigene Wohltätigkeitskonzerte. $^{1316}$

2. Für Berliner und andere preußische Lyzeen sind „Spielabende“ bezeugt, an denen einzelne Klassen im Unterricht einstudierte vaterländische Spielszenen aufführten sowie Lieder und Gedichte vortrugen. ${ }^{1317}$

3. In einigen Städten wurden Filmnachmittage mit den ,neuesten amtlichen Kriegsfilmen veranstaltet", an denen die älteren Jahrgänge der Schulen oft geschlossen teilnahmen, z. B. in Oberhausen. ${ }^{1318}$ Die - geringen - Eintrittsgelder gingen an die örtliche Kriegsvorsorge. ${ }^{1319}$

4. Eine Reihe von Schulen führte auch gelegentlich Sportveranstaltungen durch. In Oberhausen z. B. gehörten turnerische Vorführungen zum Programm der Opfertage ${ }^{1320}$ und in Bautzen lud die höhere Mädchenschule „zu einer turnerischen Vorführung“ ein, deren Ertrag für „vaterländische Zwecke“ verwandt wurde. ${ }^{1321}$

\subsection{Fazit}

Die untersuchten Veranstaltungen, die zugunsten der Kriegsfürsorge von den Schulen veranstaltet wurden, unterschieden sich in Zielsetzung und Gestaltung generell nicht von den allgemeinen Feiern. Sie waren durchgehend patriotisch ausgerichtet und somit Teil der nationalen Gesinnungsvermittlung. Herrscherverehrung, Vaterlandsliebe, Siegesgewissheit, Förderung des Durchhaltewillens und Opferbereitschaft waren die angestrebten Erziehungsziele, die auch dadurch erreicht werden sollten, dass die Kinder und Jugendlichen in die Veranstaltungen sehr oft als Akteure eingebunden wurden. Von Ausnahmen abgesehen ging die Initiative vor allem von Schulleitern, aber auch von Lehrerkonferenzen und einzelnen Lehrkräften aus. Wie Dr. Walsemann, Direktor des Lyzeums in Schleswig, waren die Schulleiter aller

\footnotetext{
${ }^{1316}$ Siehe: Fischer-Feldsee, 100 Jahre Geschwister-Scholl-Gymnasium Velbert, www.gsgvelbert.de/joomla/media/flyer_festschrift.pdf (18.07.2008) .

${ }^{1317}$ Goldberg, Schulgeschichte als Gesellschaftsgeschichte (1994), S. 66f.

${ }^{1318}$ Herrmann, Noch ein beachtenswerter Versuch (1918) , S. 9.

${ }^{1319}$ Auf den propagandistischen Stellenwert des deutschen Films im Ersten Weltkrieg soll hier nicht eingegangen werden, auch wen Propagandafilme in den Schulen oft eingesetzt wurden; es fehlt der direkte Bezug zum Thema; siehe: Oppelt, Film und Propaganda im Ersten Weltkrieg (2002).

${ }^{1320}$ Herrmann, Noch ein beachtenswerter Versuch (1918), S. 9.

${ }^{1321}$ Kriegshilfe der Schülerinnen, Die Lehrerin: Organ des Allgemeinen Deutschen Lehrerinnenvereins 1914/15, S. 271
} 
Schulformen ganz überwiegend monarchisch und national eingestellt; sie hielten den Krieg für erforderlich und gerecht.

Da die Erlöse meistens den örtlichen sozialen Einrichtungen zugutekamen, wurden die Veranstaltungen von den Kommunen begrüßt und unterstützt. So stellten sie ihnen geeignete Räumlichkeiten zur Verfügung, wenn die Schulen keine geeigneten besaßen, wie z. B. in Berlin die Philharmonie, in Hamburg den großen Saal der Musikhalle und in Bonn die Beethovenhal$1 \mathrm{e}^{1322}$. Die örtliche Presse berichtete in der Regel ausführlich und durchweg positiv und trug sicher zu der insgesamt großen Akzeptanz in der Öffentlichkeit und damit zum finanziellen Erfolg bei. Viele Veranstaltungen mussten wegen der großen Nachfrage sogar mehrfach wiederholt werden.

Auch wenn wegen der schlechten Quellenlage nur relativ wenige gesicherte Zahlen vorliegen, so lässt sich trotzdem feststellen, dass die eingenommenen Gelder teilweise erheblich waren und für die meist lokalen Wohlfahrtsverbände eine wichtige Einnahmequelle bedeuteten. Allerdings differierten die Erlöse außerordentlich stark, denn sie reichten bei den untersuchten Beispielen von 16,40 Mark (Kriegsabend in Dranske) bis 20.000 Mark (Konzert der Schulkinder in Berlin). Insgesamt dienten die in diesem Kapitel thematisierten schulischen Veranstaltungen sowohl in ideologischer als auch in finanzieller Hinsicht der Stabilisierung der „Heimatfront“.

\footnotetext{
${ }^{1322}$ Pörtner, Kindheit im Kaiserreich (1990), S. 206; Heinrich Lützeler (*1902) erinnert sich an einen „Unterhal-
} tungsabend" in der Beethovenhalle, bei dem er selbstverfasste Gedichte vortrug. 


\section{Schulnagelungen}

\subsection{Allgemeine Nagelungen - Ursprünge und Entwicklung bis 1918}

Die eigentliche Geschichte der Kriegsnagelungen beginnt am 6. März 1915 mit der feierlichen Einweihung des „Wehrmanns in Eisen“ in Wien. Die Ritterfigur, die der Bildhauer Josef Müllner ein Jahr zuvor aus Lindenholz hergestellt hatte, wurde auf dem Schwarzenbergplatz im vierten Bezirk aufgestellt und von der Bevölkerung benagelt. Zwar gab es zu diesem Zeitpunkt bereits eine Jahrhunderte alte Tradition des Nagelns ${ }^{1323}$, von der Nagelung des Wehrmanns in Wien jedoch ging eine Wiederbelegung des alten Brauchs aus, der sich „epidemieartig über das ganze Deutsche Reich und Österreich-Ungarn ausbreitete“"1324 und von dem nahezu jede größere Gemeinde erfasst wurde. ${ }^{1325}$

Im Gegensatz zu den Nagelungen in der Antike und im Mittelalter verfolgte man im Ersten Weltkrieg vorrangig keine magischen Ziele, z. B. im Sinne des heidnischen „Schad- und Bannzaubers“ oder des „Opfers und der Weihe“ ${ }^{\text {1326 }}$, sondern verstand das Kriegsnageln vor allem als Symbol einer gegenseitigen Verpflichtung, bei der „die Gemeinschaft der Nagelnden sich die gemeinsame Unterstützung der Kriegshinterbliebenen zum Ziel setzte und zugleich ihre symbolische Einheit mit der kämpfenden Truppe zum Ausdruck “1327 brachte. Die Nagelungen waren also nicht nur eine spektakuläre neue Form der Beschaffung von Geldmitteln, sondern hatten weitere Funktionen, z. B. die der „patriotischen Gesinnungsbildung“, „der Kraftübertragung“, „als Gelübde“, ,als gemeinschaftsstiftende Aktion“ und ,als Kriegerdenkmal ${ }^{\star 1328}$.

Die erste offizielle Nagelung ${ }^{1329}$ im Deutschen Reich begann am 23. April 1915 mit der feierlichen Einweihung des Eisernen Kreuzes in Darmstadt ${ }^{1330}$ und lief bis Ende November des

\footnotetext{
${ }^{1323}$ Schneider, Zur Mobilisierung der Heimatfront, Zeitschrift für Volkskunde, Bd. 32 (1999), S. 32-66.

${ }^{1324}$ Schneider, Zur Mobilisierung der Heimatfront, Zeitschrift für Volkskunde, Bd. 32 (1999), S. 34.

1325 Allerdings gab es durchaus größere Kommunen, in denen keine Nagelfiguren aufgestellt worden sind. So beschloss z. B. der „Kriegskreisausschuß“ der Stadt Dorsten am 16.09.1915, kein Nagelungszeichen aufzustellen, da „,der aus der Nagelung zu erwartende Ertrag in keinem Verhältnis zu dem nicht unerheblichen Kostenaufwand aus Gemeindemitteln zur Ausführung des Wahrzeichens..." stehe (Schreiben der Stadtverwaltung Dorsten vom 05.10.2004; Archivale B 2452). Beil, Der ausgestellte Krieg (2004) S.275/76: In Niedersachsen wurde in Bückeburg, Celle, Göttingen, Helmstedt und Hildesheim auf offizielle Nagelungen verzichtet; Schulnagelungen hat es in diesen Orten allerdings gegeben. Goebel nennt außerdem „Gladbeck, Herten, Lünen und Marl“ (Vermischtes, Die Mittelschule: Zeitschrift der Reichsfachschaft Mittelschule im Nationalsozialistischen Lehrerbund, 1915, S. 358f.).

${ }^{1326}$ Schneider, Zur Mobilisierung der Heimatfront, Zeitschrift für Volkskunde, Bd. 32 (1999), S. 34.

1327 Schneider, Zur Mobilisierung der Heimatfront, Zeitschrift für Volkskunde, Bd. 32 (1999), S. 34.

${ }^{1328}$ Schneider, Zur Mobilisierung der Heimatfront, Zeitschrift für Volkskunde, Bd. 32 (1999), S. $43 \mathrm{ff}$.

${ }^{1329}$ Schneider, Zur Mobilisierung der Heimatfront, Zeitschrift für Volkskunde, Bd. 32 (1999), S. 37: Bereits im Dezember 1915 ist im Gasthaus „Kaiserhof“ in Ruhla ein Eisernes Kreuz und wenige Monate später im Gasthof „Zum Schwanen“ in Villingen ein Stammtisch benagelt worden.
} 
Jahres. Den Erlös aus der vollständigen Benagelung des Kriegswahrzeichens in Höhe von 57.644,44 Mark erhielten zu gleichen Teilen die „Nationalstiftung für die Hinterbliebenen der im Krieg Gefallenen“, der Hessische Landesverein des Roten Kreuzes und die Stadt Darmstadt für den „Unterstützungsfonds für Kriegsbeschädigte und Kriegshinterbliebene“. Zwei Wochen später, am 7. Mai 1915, schlug Königin Charlotte von Württemberg im Rahmen der Einweihungsfeier den ersten Nagel in den 2,50 m großen „Ritter Eisenhart“, die erste vollplastische Nagelfigur in Deutschland. ${ }^{1331}$ Auch diese Nagelung wurde ein großer Erfolg ${ }^{1332}$, denn bereits Ende des Jahres waren die vorgesehenen 20.000 Nägel eingeschlagen und die Aktion wurde beendet. ${ }^{1333}$

Dass über beide Veranstaltungen in der Presse sehr ausführlich und überaus positiv berichtet wurde, trug sicher entscheidend dazu bei, dass in den nächsten Wochen viele Kommunen sich entschlossen, ebenfalls Nagelaktionen durchzuführen. Die Folge war, dass „,der sich schnell abzeichnende Erfolg dieses wiederbelebten Brauchs ... staatliche und nichtstaatliche Institutionen [veranlasste], sich an die Spitze dieser Bewegung zu stellen“1334. So wurde zum 1. Jahrestag des Kriegsausbruchs die Aktion „Nationalgabe Nagelung von Kriegswahrzeichen in allen Gauen Deutschlands zugunsten der Nationalstiftung für die Hinterbliebenen der im Krieg Gefallenen“ ins Leben gerufen. Den Ehrenvorsitz übernahm Generalfeldmarschall von Hindenburg, um durch sein hohes Ansehen die Akzeptanz für die Aktion zu erhöhen. Ihr Ziel war es, ,eherne Wahrzeichen in allen Gauen Deutschlands zu errichten“ “1335, um für die Nationalstiftung neue Geldquellen zu erschließen.

Zur Durchführung der angeregten Spendennagelungen wurde neben dem genannten „Aufruf“ eine „Anleitung“ an die Regierungspräsidenten, Landräte und Bürgermeister der Städte über 100.00 Einwohner in Preußen versandt. Sie enthielt recht detaillierte Anregungen und

In dem Tagebucheintrag der zwölfjährigen Elfriede Kuhr vom 2. November 1914 wird eine Schulnagelung in Schneidemühl erwähnt: „Wir haben jetzt in der Schule ein großes ,Eisernes Kreuz’ aus Holz an der Wand hängen, in das man 1000 eiserne Nägel einschlagen muß ... “(Mihaly, ... da gibt's ein Wiedersehn! (1986), S. 94f.). Dieses ist meines Erachtens der früheste Hinweis auf eine Kriegsnagelung. „Dass der so frühe Vorgang des Schulnagelns später eingefügt oder irgendwie gefälscht sein könnte, ist wohl nicht anzunehmen“, meint Schneider in einem persönlichen Schreiben.

${ }^{1330}$ Hessische Kriegshefte, 8/9, S.53f.; Darmstädter Tageblatt vom 23., 24., 26. und 28.4.1915.

${ }^{1331}$ Schneider, Über hannoversche Nagelfiguren im Ersten Weltkrieg; in: Hannoversche Geschichtsblätter (1996) S. 216f., Fußnote 32.

${ }^{1332}$ Der Schulleiter, Chronik der Wirgeser Schule (o.J.): Allerdings waren in der Folgezeit nicht alle Nagelungen finanziell erfolgreich. So wurde z. B. in Oldenburg ,nach nur fünf Wochen ...d er gar nicht so eiserne Heinrich abgebaut“, da man dort offensichtlich ,die Kaufkraft der Oldenburger Bevölkerung völlig überschätzt“ hatte. Die Erstnagelung hatte am 5. September 1915 stattgefunden.

${ }^{1333}$ Kriegschronik des Württembergischen Landesvereins vom Roten Kreuz (1921), S. 11f.

${ }^{1334}$ Schneider, Zur Mobilisierung der Heimatfront, Zeitschrift für Volkskunde, Bd. 32 (1999), S. 38.

${ }^{1335}$ Der „Aufruf“ ist wie die „Anleitung zur Errichtung von Wahrzeichen in allen Gauen Deutschlands zum Besten der Nationalstiftung für die Hinterbliebenen der im Kriege Gefallenen“ und ein Erlass des preußischen Innenministers vom 17.August 1915 (III. 1452) an die „Regierungspräsidenten, Landräte und Bürgermeister der Städte über 10000 Einwohner" in vielen Stadtarchiven enthalten, wie z. B. im Stadtarchiv Peine; StAP, AF 34, Nr.8). 
Vorschläge zur Durchführung der Nagelaktionen, z. B. zur Höhe der Spenden (,,50 Pfennig oder $1 \mathrm{Mk}$ “), zu der Bildung von Ausschüssen, die für die Aufstellung und Durchführung der Nagelung verantwortlich sind, dem Ablauf der Einweihungsfeierlichkeiten und die „für den Erfolg ausschlaggebende“ Bedeutung der Presse. Ferner enthielt sie den Vorschlag, dass der Erlös der Nagelungen zu drei Vierteln der Stiftung ${ }^{1336}$ und auf Wunsch ein Viertel den dortigen Kriegswohltätigkeitseinrichtungen zufließe. ${ }^{1337}$

Dass sich die „Nationalgabe“ nicht ausschließlich auf das Königreich Preußen beschränken sollte, geht nicht nur aus den im „Aufruf“ genannten Zielen hervor, sondern auch aus der Zusammensetzung des „Zentralausschusses“, dessen 138 Mitglieder dort namentlich und mit Titeln genannt werden. Unter ihnen befanden sich offizielle Vertreter aus nahezu allen Ländern des Deutschen Reiches - in der Mehrzahl Minister oder Gesandte. ${ }^{1338}$ Entsprechend der Bedeutung, die in der „Anleitung“ der Presse zugesprochen wurde, gehörten auch 18 Chefredakteure und andere Vertreter wichtiger deutscher Zeitungen zum „Zentralausschuss“. AuBerdem waren in ihm weitere wichtige Repräsentanten aus den Bereichen Politik, Militär, Verwaltung und Wirtschaft vertreten. Dass die Einbeziehung der Schuljugend aus Sicht der Initiatoren für den Erfolg der „Nationalgabe“ durchaus von großer Bedeutung war, geht vor allem aus der „Anleitung“ (,... Schule und Jugend-Kapellen sind während der Nagelung, wenn irgend möglich, heranzuziehen“"), aber ebenso aus der Tatsache hervor, dass sowohl der preußische Kultusminister von Trott zu Solz als auch einer seiner Abteilungsdirektoren, Dr. Schmidt, im „Zentralausschuss“ vertreten waren. An eigenständige Schulnagelungen ist zu jener Zeit jedoch offensichtlich noch nicht gedacht worden.

Die Umsetzung der durch die „Nationalgabe“ propagierten Nagelungen übernahmen die Regierungen der einzelnen Länder. So schickte z. B. das preußische Innenministerium „Aufruf“ und „Anleitung“ an alle Oberpräsidenten des Königreichs und forderte sie in dem Erlass vom 17. August 1915 auf, den ihm unterstellten Amtsstellen die Durchführung von Nagelungsaktionen zu empfehlen. Der Oberpräsident der Provinz Hannover beispielsweise leitete dann bereits am 23. August 1915 die Aufrufe weiter an die ihm unterstellten Regierungspräsidenten, u. a. auch den Regierungspräsidenten von Hildesheim, der seinerseits schon am 25. August

\footnotetext{
${ }^{1336}$ Gemeint ist die „Nationalstiftung für die Hinterbliebenen der im Krieg Gefallenen“.

${ }^{1337}$ Nach Gerhard Schneider (Schneider, Zur Mobilisierung der Heimatfront, Zeitschrift für Volkskunde, Bd. 32 [1999], S. 38) ist der Appell, der „Stiftung“ drei Viertel des Erlöses zu überweisen, jedoch kaum befolgt worden: „Die offensichtliche Zurückhaltung der Gemeinden gegenüber den Vorschlägen der ,Nationalgabe' mag darin ihren Grund gehabt haben, dass man mit der gängigen Spendenverteilungspraxis nicht zufrieden gewesen war. Bis zum Zeitpunkt, da das Nageln reichsweit einsetzte, waren...schon zahlreiche Spendenappelle an die Bevölkerung gerichtet worden, und nie erfuhr der einzelne Spender, was mit seiner Spende geschah oder wer in den Genuss der Spenden kam. Dieser anonymen Art und Weise der Spendenverteilung sollte durch das Nageln entgegengewirkt werden ..."

${ }^{1338}$ In dem „Zentralausschuss“ waren lediglich die Stadtstaaten Hamburg und Lübeck nicht offiziell vertreten.
} 
1915 die Landräte seines Bezirks über die Aktion informierte und um ihre Unterstützung bat. Auf diesem Weg erhielt auch der Landrat des Landkreises Münden die Aufrufe, die sich heute im Stadtarchiv von Hannoversch Münden (Provinz Hannover) befinden. ${ }^{1339}$ Den gleichen Weg beschritten nicht nur die preußischen Behörden, sondern auch die anderen Länder des Deutschen Reiches unterstützten die Aktion zügig und auf ähnliche Weise, wie z. B. in Bayern die „Entschließung des K. Staatsministeriums des Inneren“ vom 1. September 1915 (Nr.2748a 62) ${ }^{1340}$ und in Baden ein Erlass des Großherzoglichen Innenministeriums an die Bezirksämter von Anfang 1916 zeigen. In Baden wurde den Kommunen nicht nur wie in den meisten anderen Ländern empfohlen, Nagelungen durchzuführen, sondern es war ihnen „die Anbringung von genagelten Kriegswahrzeichen vorgeschrieben“"1341.

Auch wenn die Kommunen die Entscheidung über Motiv und Ausführung der Nagelfiguren weitgehend selbstständig trafen, so versuchten die Länderregierungen durch Zusammenstellung von Musterentwürfen und den Verkauf vorgefertigter Kriegswahrzeichen Einfluss zu nehmen. Wie im Großherzogtum Baden wollte man auch in den anderen Ländern sicherstellen, „dass bei der Auswahl der zur Nagelung bestimmten Wahrzeichen die nötige Rücksicht auf deren künstlerisch einwandfreie Ausgestaltung genommen und Geschmacksverirrungen, die sich hierbei vielfach geltend machen, vermieden werden““1342.

So stellten u. a. die „Nationalgabe“ den Kommunen und Institutionen das Musterbuch „Entwürfe von Kriegs-Wahrzeichen zum Benageln“1343, der Bayerische Landesausschuss der „Nationalstiftung für die Hinterbliebenen der im Kriege Gefallenen“ eine 64seitige Broschüre mit Beispielen ${ }^{1344}$ und der Württembergische Landesausschuss für Natur- und Heimatschutz

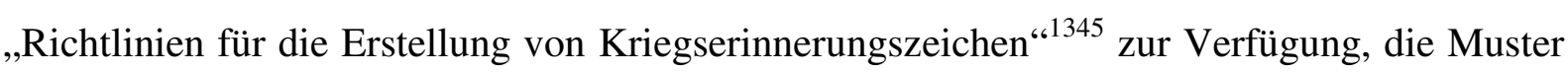
wurden aber kaum befolgt. Speziell an kleinere Kommunen richtete sich die Broschüre „Der Stock in Eisen". Praktische Ratschläge zur Errichtung einfacher Nagelholzmale mit IdeenSkizzen und Kostenberechnung “1346. Auch der Deutsche Werkbund veröffentlichte

\footnotetext{
${ }^{1339}$ Archiv der Stadt Münden, AStM IX, 4, 53; B1. 1 u. 2 (,Errichtung eines Kriegswahrzeichens [Eisernes Kreuz] in hiesiger Stadt“, Band 1; abgedruckt in: Meyer, Die Nagelungen des Eisernen Kreuzes 1915/16 in Hann Münden [1996/97], S. 28f.

${ }^{1340}$ Die „Entschließung“ ist in vielen Archiven vorhanden; hier wurde eine Kopie des Bayerischen Hauptstaatsarchivs verwendet (Signatur: MK 19269).

${ }^{1341}$ Nationalgabe, Entwürfe von Kriegs-Wahrzeichen zum Benageln (1915).

1342 Großherzogliches Badisches Landesgewerbeamt, A. Stürzenacker, Über genagelte Kriegswahrzeichen (1916), S. 6-8.

${ }^{1343}$ In vielen Stadtarchiven vorhanden; z. B. im Stadtarchiv Eisfeld, Inv.-Verzeichnis-Nr. 823.

${ }^{1344}$ Rattinger, Bayrischer Heimatschutz 1915 Heft 5/6/7/8/9/10 (1915).

${ }^{1345}$ Hantke, Die Schule und der Krieg Heft 603 (1915).

1346 Öffentliche Einladung, Meißner Tageblatt 14.11.1915.
} 
„69 Entwürfe aus einem Preiswettbewerb“1347 und übte im Vorwort gleichzeitig heftige Kritik an der „Nationalgabe“, da sie nur wenige dieser Entwürfe übernommen habe. Stattdessen habe diese sich noch andere Entwürfe beschafft, die „selbst in diesen verwilderten Zeiten“ von „ungewöhnlicher Geschmacklosigkeit“ seien. Auch Hermann Muthesius, bis 1916 zweiter. Vorsitzender des Deutschen Werkbundes ${ }^{1348}$, wies die Gemeinden und Städte im Zusammenhang mit den Nagelungen auf die „Gefährlichkeit des Vorgehens““1349 hin. Mit der massiven Kritik stand der Deutsche Werkbund allerdings nicht allein. Auch die Königliche Akademie der Künste und die Königliche Akademie für das Bauwesen veröffentlichten eine „Mahnung zur Selbstbeschränkung in der Errichtung von Kriegsdenkmälern““1350. Hans Sachs ${ }^{1351}$ z. B. sprach von „Nagelungsdenkmal-Scheußlichkeiten“ und befürchtete, dass durch sie der „Geschmack des Publikums noch mehr verirrt und verbildet werden würde“1352, und Gertrud Bäumer ${ }^{1353}$ sah „,mit Scham und Grauen den Berliner Hindenburg vor der Siegessäule aufragen ${ }^{* 1354}$.

Da solche Kritik den Spendenerfolg der Nagelungen negativ beeinflussen konnte, reagierten übergeordnete Instanzen umgehend und veröffentlichten ,Musterbücher mit Kriegswahrzeichen', an denen teilweise sogar namhafte Künstler mitgearbeitet hatten, um die Kommunen vor allem bei der Auswahl der Motive der Nagelobjekte und deren Aufstellung sowie der Durchführung und der Vermarktung ${ }^{1355}$ der Nagelungen zu unterstützen. Dieses war auch deshalb wichtig, weil die benagelten Wahrzeichen als Denkmäler für spätere Generationen

\footnotetext{
${ }^{1347}$ Kriegs-Wahrzeichen zum Benageln (1915).

1348 Der „Deutsche Werkbund“ wurde am 5. und 6. Oktober 1907 auf Anregung von Hermann Muthesius von zwölf Künstlern zur Förderung des Kunstgewerbes in München gegründet.

${ }^{1349}$ Muthesius, Zur „Nagelung vom Kriegswahrzeichen", Tremona Nr. 267(26.9.1915).

1350 Bracke (Hrsg.), 100 Jahre Wilhelm-Gymnasium Braunschweig. 1885-1985. Festschr. zum 100jährigen. Jubiläums des. WG (1985), S. 47.

${ }^{1351}$ Begründer des „Vereins der Plakatfreunde“ in Berlin; er lebte von 1881-1974.

1352 Schöllkopf, Vom „Helfensteiner Ritter” im Heimatmuseum, Geschichtliche Mitteilungen von Geislingen und Umgebung, 1933, Nr. 52/53, S. 9.

1353 1873-1954; Lehrerin, Frauenrechtlerin, Schriftstellerin, Politikerin.

1354 Bracke (Hrsg.), Wilhelm-Gymnasium Braunschweig 1985, S. 48.

1355 Am Beispiel der Nagelung des Kölner „Isern Buer“ (Die Kaiserproklamation 1871 in Versailles im Vergleich zur Frankfurter Nationalversammlung 1848 (1985); S. 186-190) soll gezeigt werden, wie die eigentlichen Nagelspenden durch zusätzliche Werbe- und Verkaufsauktionen gesteigert worden sind: Verkauf von Ansichtskarten (für Köln sind dem Verfasser 21 unterschiedliche Motive bekannt; Sammlung Kronenberg); Miniaturen der Nagelfigur aus Eisenguss (Höhe 21 cm); Pillen- oder Schnupftabakdosen (Höhe $2 \mathrm{~cm}$; Durchmesser 3,5 cm); gravierte Spendennägel; Spendenurkunden $(20$ x $16 \mathrm{~cm})$; eiserne Halskette; Abzeichen zum Anstecken; Plakate. In Krefeld wurden darüber hinaus Zierlöffeln mit dem Bild des „Eisernen Georg“ verkauft, in Kaufbeuren langstielige Pfeifen mit der Abbildung des Kriegswahrzeichens auf dem Nagelkopf (Sammlung Kronenberg); auch die Vermarktung des Eisernen Schmieds in Hagen war nach Stefan Goebel ,vorbildlich“. Das Angebot reichte von Schmuckanhänger, Brosche, Vorstecknadel, Uhrkette, Andenkenbuch und Erinnerungsmedaille bis hin zur eisernen Ministatue des ,Schmiedes'.
} 
„zum Gedächtnis der Eisernen Zeit“ dienen sollten, wie es vor allem in vielen Reden bei Erstnagelungen betont wurde und auf vielen Nagelkarten zu lesen ist. ${ }^{1356}$

Nach Schneider gewann das „Musterbuch der Nationalgabe“ durchaus Einfluss auf die in den Gemeinden späterhin realisierten Nagelobjekte, auch wenn sich offensichtlich nur wenige Gemeinden entschlossen, die Entwürfe unverändert zu übernehmen. ${ }^{1357}$ Man beauftragte meistens ortsansässige Künstler und Handwerker, auf der Basis der Mustervorlagen eigene Entwürfe herzustellen. Eine ähnliche Wirkung werden die anderen „Musterbücher“ gehabt haben.

Mit dem Nachlassen der anfänglichen Siegeseuphorie und der schwindenden Hoffnung auf ein baldiges Kriegsende verringerte sich die Nagelungsbereitschaft der Bevölkerung trotz des großen propagandistischen Aufwands deutlich, sodass in einigen Orten die Nagelungen sogar ganz eingestellt wurden. Deshalb beendete im Dezember 1916 ein Erlass des preußischen Innenministeriums die Nagelungen für das Königreich Preußen formal. ${ }^{1358}$ Allerdings wurden trotzdem ,sowohl in Preußen als auch in den anderen Staaten des Deutschen Reiches gelegentlich auch noch später Nagelobjekte aufgestellt “"1359.

Nach dem Krieg wurden viele der nicht vollständig vernagelten Kriegswahrzeichen entfernt und teilweise vernichtet. „Die ursprünglich für die Ewigkeit konzipierten Kriegserinnerungszeichen erwiesen sich dann doch als ganz ephemere Zeichen ihrer Zeit. Sie verschwanden fast vollständig aus dem öffentlichen Bewusstsein, sodass auch in Gemeinden, in denen einst genagelt wurde, heute kaum noch eine Erinnerung daran besteht. “1360

\footnotetext{
${ }^{1356}$ So steht sowohl auf der Nagelungskarte der Weidaer Schuljugend vom 27. Januar 1916 als auch auf der Ansichtskarte über die Nagelung des Eisernen Kreuzes zu Jena am 1. August 1915: „Wir haben die Nägel geschlagen/ in das Eiserne Kreuz zu Weida/ zum Gedächtnis der Eisernen Zeit/und in Dankbarkeit/ gegen unsere verwundeten Krieger.“ (Siehe: Anhang) Strophe 3 eines Gedichts „Zur Nagelung des Eisernen Wappens der Stadt Castrop am 26. September 1915“ lautet: „So erstehe in Eisen! Im schlichten Kleid/ Gib dem spätern Geschlechte Kunde, Wie voll Liebe und Opfer unsere Zeit/ Und wie eisern und heilig die Stunde." Die anlässlich der Nagelung des Zaitenstocks in Kassel ausgestellte Urkunde enthält folgende Formulierung: „Inhaber dieser Urkunde, Ellen Könitzer, hat im Kriegsjahr 1916 in den zum Andenken an die Eiserne Zeit errichteten Zaitenstock einen Erinnerungsnagel eingeschlagen.“ (zitiert nach den Ansichtskarten aus der Sammlung Kronenberg). Viele Ansichtskarten enthalten ähnliche Formulierungen, z. B. über die Nagelungen in Fürth (,Der Zukunft zeug ich stumm von heldenhaftem Ringen.") und Gaimersheim (,Aus großer Zeit").

Als Beispiele für solche Aussagen in Festreden seien einige genannt: Z. B. aus der Ingolstädter Zeitung Nr. 13 vom 18.Januar 1916 der Bürgermeister, Hofrat Kroher (,Fest eingefügt in den Erdball wird dieses deutsche Wahrzeichen aus Eiche und Granit hoch aufgerichtet stehen für alle Zeiten.") und der stellvertretende Festungskommandant, Generalmajor Ott, (,,ist ein dauerndes Denkmal an Deutschlands schwerste und zugleich ruhmreichste Zeit, ein allzeit sichtbarer Beweis ... und eine stete Mahnung kommenden Geschlechtern, es gleichzutun dem heutigen in vaterländischer Gesinnung, Opferwilligkeit, treuen Zusammenstehen und kräftiger Mannestat.").

${ }^{1357}$ Siehe: Schneider, Zur Mobilisierung der Heimatfront, (1999), S. 38.

1358 Schneider, Zur Mobilisierung der Heimatfront, (1999), S. 42.

1359 Schneider, Zur Mobilisierung der Heimatfront, (1999), S. 42

${ }^{1360}$ Schneider, Zur Mobilisierung der Heimatfront, (1999), S. 56.
} 
Acht Jahre nach dieser - zutreffenden - Feststellung hat man sich allerdings in einigen Gemeinden wieder der eigenen Nagelfiguren erinnert und u. a. in Mainz ${ }^{1361}$, Oldenburg ${ }^{1362}$ und Wiesbaden ${ }^{1363}$ mit deren Restaurierung begonnen.

\subsection{Nagelungen in Schulen}

Die erste nachweisbare Nagelung in einer Schule fand bereits am 2. November 1914 in Schneidemühl (Provinz Posen) in der Kaiserin-Auguste-Viktoria-Schule statt. In ihrem Kriegstagebuch berichtet die 12jährige Elfriede Kuhr darüber:

„Wir haben jetzt in der Schule ein großes „Eisernes Kreuz“ aus Holz an der Wand hängen, in das man 1000 eiserne Nägel einschlagen muß. Es sind schwarze Nägel und solche, die wie Silber aussehen. Wenn alle Nägel eingeschlagen sind, ist es wirklich ein eisernes Kreuz. Jede Schülerin kann so viele Nägel einhämmern, wie sie will. Die schwarzen Nägel kosten pro Stück 5 Pfennig, die silbernen 10 Pfennig. Ich habe zwei schwarze und einen silbernen Nagel eingeschlagen. Es macht Spaß. Der Erlös wird zu Kriegszwecken verwendet. “'1364

Von einer sehr frühen schulischen Nagelaktion (2. September 1915) erzählte auch O. Ostrowski am 15. September 1915 unter der Überschrift „Eine neue Anregung“ sehr ausführlich im „Deutschen Philologen-Blatt“:

„Wir haben nun für unsere Anstalt am letzten Sedantag einen neuen Weg gefunden, der sich, stets gleich erfolgreich, für viele Schulen, für alle möchte ich sagen, höhere und niedere, für Knaben und Mädchen, in Stadt und Land, ausgestalten lässt: Wir haben unsere Feier mit einer jetzt so viel geübten Nagelung verbunden. Wir haben aber kein Eisernes Kreuz ... sondern einen großen Bilderrahmen genagelt, der das ausdrucksvolle Bild unseres Hindenburg umschließt. ... Der Rahmen wird bald voll sein. Wir wollen dann einen zweiten und dritten im Schulsaal nageln. Hindenburg gehört zwischen Kaiser und Kronprinz. Der Ertrag des ersten Rahmens wird sein: 940 Nägel zu 10 Pfg. 104 Nägel zu 1Mk.= Mk. 198.“"1365

\subsection{1 „Verein Jugendspende für Kriegerwaisen“}

Sicher hat es noch viele Nagelungen in deutschen Schulen gegeben, bevor im Mai 1916 mit einem Aufruf des Essener Vereins „Jugendspende für Kriegerwaisen e. V.“ an die deutsche Lehrerschaft schulische Nagelaktionen zu einer Massenbewegung wurden - propagiert und unterstützt von Schulbehörden ${ }^{1366}$ und Lehrerverbänden ${ }^{1367}$. Offensichtlich hielt man die

\footnotetext{
${ }^{1361}$ Stadt Mainz, Kur für die Nagelsäule (05.09.2007).

${ }^{1362}$ Nolte, Isern Hinnerk warb um Spenden, Nordwest-Zeitung 21. Juni 2007.

1363 Cuntz, 60000 Nägel für Krieg und Frieden, Wiesbadener Kurier 9. Mai 2007.

${ }^{1364}$ Mihaly, ... da gibt's ein Wiedersehn! (1986), S. 94.

1365 Ostrowski, Eine neue Anregung, Deutsches Philologen-Blatt 1915, S. 538f.

1366 Z. B. informierte Mitte August 1916 die Königliche Regierung der preußischen Provinz Schleswig-Holstein in Schleswig die Schulen des Regierungsbezirks über die Aktion (Amtliches Schulblatt für den Regierungsbezirk Schleswig 16. [1916]); siehe: Pust, „Vaterländische Erziehung" für „Höhere Mädchen" (2004), S. 410.
} 
Aktivierung der Schulen zu diesem Zeitpunkt für besonders wichtig, denn obwohl man damals wegen der verlustreichen Schlachten auf die Einnahmen aus den Nagelungen in besonderem Maße angewiesen war, war das allgemeine Interesse an den Nagelungen stark zurückgegangen. ${ }^{1368}$

Der Verein war 1915 von Lehrern gegründet worden ${ }^{1369}$, um Waisenkindern ,eine möglichst gute grundlegende Erziehung und Schulbildung sowie nach Maßgabe ihrer besonderen Begabung eine gute Berufsausbildung zu vermitteln“. Die Mittel waren zunächst vor allem durch den Verkauf des „Feldherrn-Blattes“ (entworfen von Prof. Münzer, Düsseldorf; Vierfarbdruck; $53 \mathrm{~cm} \mathrm{x} 42 \mathrm{~cm}$ ) in Schulen zusammengebracht worden - insgesamt 1 Million Mark. Das Bild zeigte die bedeutendsten Heerführer des Krieges ${ }^{1370}$ und wurde im Handel für 3 Mark verkauft. Schüler erhielten das Gedenkblatt, wenn sie mindestens 1 Mark gespendet hatten. Obwohl es durchaus Kritik von Lehrern an dem Bild gab, wurde es von vielen Schulen bestellt und Schülern zu besonderen Anlässen überreicht. ${ }^{1371}$ Später kam dann das Kunstblatt „Kaiser und Hindenburg“ hinzu (entworfen von Tillak, Berlin; Vierfarbdruck; $50 \mathrm{~cm}$ x 68 $\mathrm{cm}) .{ }^{1372}$ Staatliche Stellen hatten den Verein von Anfang an unterstützt. Das preußische Kultusministerium genehmigte bereits am 27. Februar 1915 die Spendenaktion für das Königreich Preußen „unter Betonung völliger Freiwilligkeit ${ }^{\star 1373}$ für die Schüler. Fast alle anderen deutschen Bundesstaaten folgten und erteilten ebenfalls die Genehmigung und informierten die Schulen ihres Zuständigkeitsbereichs. ${ }^{1374}$

Der Verein „Jugendspende“ hatte zunächst beabsichtigt, seine Tätigkeit zum 1. April 1916 einzustellen und sein Vermögen der „Nationalstiftung für die Hinterbliebenen der im Kriege Gefallenen“ zu überweisen. Der länger andauernde Krieg sowie die täglich wachsende Zahl

\footnotetext{
${ }^{1367}$ Am 19. Juni 1915 erschien in der Zeitschrift „Die Lehrerin“ ein sehr ausführlicher „Aufruf an die Lehrerschaft“ Rößler, „Als der Krieg über uns gekommen war ..." (1993); auch in der Ausgabe vom 14. April 1917 stand ein ,Aufruf an die Lehrer' (Bergmann, Geschichtsdidaktik [1998]).

${ }^{1368}$ Goebel, Kohle und Schwert, Zur Konstruktion der Heimatfront, S. 264.

${ }^{1369}$ Die Anregung hatte der Lehrer Josef Reinirkens gegeben. Zu den Mitgliedern des Vorstands und des Kuratoriums gehörte auch Helene Lange, die Vorsitzende des „Allgemeinen Deutschen Lehrerinnenvereins“, Frauenrechtlerin und Politikerin; 1843-1930; ebenfalls die Vorsitzenden des „Verbandes akademisch gebildeter Lehrer“ (Prof. Buchdrucker), des „Verbandes deutscher Volkschullehrerinnen“ (Th. Gilbert), des „Katholischen Lehrerverbandes des Deutschen Reiches“ (Rektor Kamp) und des „Landesvereins preußischer Volksschullehrerinnen (Kammeier, Der Landkreis Lübbecke und der 1. Weltkrieg [1998], S. 325).

${ }^{1370}$ Bergmann, Geschichtsdidaktik (1998), S.13; abgebildet waren die Kaiser von Deutschland und Österreich sowie einige Heerführer.

${ }^{1371} S z$. Kriegswahrzeichen für jede Schule, in: Die Mittelschule: Zeitschrift der Reichsfachschaft Mittelschule im Nationalsozialistischen Lehrerbund, 1916, S. 526: „Ein Bedenken sei hier noch ausgesprochen. Hoffentlich fallen die Schilder etwas ,künstlerischer' aus als die Bilder! Das Feldherrngedenkblatt erregte bei kunstverständigen Leuten allgemeines Schütteln des Kopfes.“

${ }_{1372}$ Voos, Kriegswahrzeichen für jede deutsche Schule, in: Die Mittelschule: Zeitschrift der Reichsfachschaft Mittelschule im Nationalsozialistischen Lehrerbund, 1916, S. 496.

${ }^{1373}$ Führen, Lehrer im Krieg (1936). S. 324.

1374 Voos, Kriegswahrzeichen (1916), S. 496; die königliche Regierung in Düsseldorf hatte es übernommen, die Sammlung allen anderen preußischen Regierungen zu empfehlen. (Führen, Lehrer im Krieg [1936] S. 324).
} 
der Kriegerwaisen veranlasste ihn jedoch, beim Staatskommissar um die Erlaubnis zur Fortsetzung der Sammeltätigkeit nachzusuchen, die ihm bereitwillig erteilt wurde. Der Verein hatte dann eine zukunftsträchtige Idee, um weitere Gelder flüssigzumachen. Er ließ von der Schulwandtafelfabrik G. Glasmachers in Essen nach Entwürfen der Akademieprofessoren Körner, Ederer und Huber (später kamen weitere hinzu) Kriegswahrzeichen in Form von Nagelschilden herstellen. ${ }^{1375}$ Sie wurden den Schulen in Deutschland zusammen mit einer Anleitung, einem Hammer, einem Vorlocher und einem Nagelkasten mit den benötigten Nägeln kosten- und portofrei unter der Bedingung zur Verfügung gestellt, „dass der dadurch erzielte Erlös überwiesen wird, der nach Abzug der Selbstkosten unverkürzt den Kriegswaisen

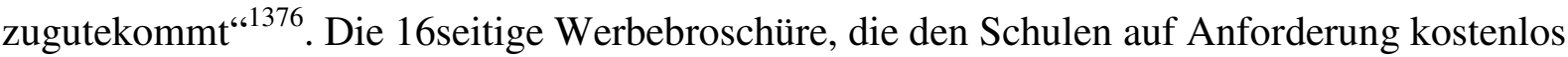
zugeschickt wurde, enthielt Bilder von 11 Nagelschilden ${ }^{1377}$ mit unterschiedlichen kriegsnahen Motiven und detaillierten Vorschlägen für die Nagelungen; später wurde das Angebot noch erheblich erweitert.

Neben den standardisierten allgemeinen Kriegswahrzeichen konnten die Schulen auch von Prof. Körner entworfene Erinnerungsschilde bestellen, die Namen, Ort und Zeitpunkt der im Krieg gefallenen Lehrer enthielten. ${ }^{1378}$ Die meisten zeigten entweder als Motiv einen Stahlhelm mit zwei Kerzen und ein kreuzähnliches Schwert sowie die Inschrift „Alles Große muss im Tod bestehn“ oder einen Leuchter mit vier Kerzen und einem kreuzähnlichen Schwert und der Inschrift „Dem Gedächtnis unserer gefallenen Helden“. Seltener wurde das Motiv des Eisernen Kreuzes gewählt. ${ }^{1379}$ Andere verwendete Zitate stammten von Kaiser Wilhelm II., wie z. B. „Noch nie wurde Deutschland überwunden, wenn es einig war“ (1914) und „Unsere Zukunft liegt auf dem Wasser“ (1898), oder dem preußischen König Friedrich Wilhelm I. („Einigkeit macht stark“(1380). Auch der Schlachtruf „Mit Gott für Kaiser und Vaterland“, der auf den Koppelschlössern der deutschen Soldaten stand, wurde als Text für eine Karte gewählt. Diese und andere Sinnsprüche ${ }^{1381}$ auf den Kriegswahrzeichen zeigen, dass die Nagel-

\footnotetext{
${ }^{1375}$ Die Schilde (viele hatten die Größe 73 x $73 \mathrm{~cm}$ ) waren aus Weidenholz hergestellt und hatten eine Aufhängevorrichtung; die Einschlagstellen für die Nägel waren vorgebohrt.

${ }^{1376}$ Kriegswahrzeichen (1916), S. 3; die Broschüre ist u.a. in der wissenschaftlichen Abteilung der Stadtbücherei Essen (Yc 456) vorhanden.

1377 Motive und Beschriftung: Schild I „Adler“(„1914/16 Deutsche Wacht“ ); Schild II „Löwe“ („Weltkrieg 1914-16“); Schild III „Adlerkopf (“1914/16“); Schild IV „Schwert“ („1916 Das höchste Heil liegt im Schwerte“); Schild V „Helm“ („1914/16 Noch nie wurde Deutschland überwunden, wenn es einig war“); Schild VI „Flugzeug“ („Kriegsjahr 1916“); Schild VII „Möve“ („1916“); Schild VIII „Schiff“ („1916 Vom Fels zum Meer“); Schild IX „Kreuz“ („Deutschland unser Vaterland 1916“); Schild X „Vier Adler“ („Einer für alle/ alle für einen“); Schild XI „Füllhorn“(,1914-1916“) - siehe: Abbildungen im Anhang, Seite 81.

${ }^{1378}$ Kriegswahrzeichen, Oberfränkischer Anzeiger und Bayreuther Anzeigen 28. Mai 1916, S. 16.

${ }^{1379}$ Siehe: Abbildungen im Anhang, Seite 89.

${ }^{1380}$ Der Ausspruch geht auf das lateinische ,unitate vires" zurück.

${ }^{1381}$ Sammlung Kronenberg.
} 
aktionen nicht nur dazu dienten, in Not geratenen Mitschülern zu helfen, sondern „ein Akt bewusster ideologischer Beeinflussung der Schüler“1382 waren.

Zwei Jahre nach seiner Gründung schloss sich der Verein „Jugendspende für Kriegerwaisen e. V.“ der „Nationalstiftung für die Hinterbliebenen der im Kriege Gefallenen“ an. ${ }^{1383}$ Um den Kindern eine wirkungsvollere „Anregung zum Nageln zu geben ... und weitere Kreise für den guten Zweck zu gewinnen“, wie es in der Werbebroschüre heißt ${ }^{1384}$, lieferte der Essener Verein den Schulen zum Preis von 4 Pfennig farbige Postkarten mit dem Motiv des Schildes, der von der entsprechenden Schule benagelt wurde. Wurden mindestens 300 Karten bestellt, so übernahm der Verein auch die Kosten für den Aufdruck des Namens der Schule. Die Karten sollten den Schülern als Quittung für eine Spende von 10 Pfennig dienen, wobei 6 Pfennige für die Nagelung verwandt wurden. Von dieser Möglichkeit haben die meisten Schulen Gebrauch gemacht, wie die hohe Zahl der heute noch vorhandenen Ansichtskarten belegt. ${ }^{1385}$

Ab 1917 bot der Verein den Schulen in Deutschland zum Preis von 30 Pfennig als neues Werbemittel Urkunden an, die ,den opferfreudigen Naglern und Naglerinnen als dauerndes Andenken an die Betätigung ihres vaterländischen Sinnes in die Hand gegeben werden“" sollten, wie es in einem Schreiben an die Schulen heißt. Jedes der künstlerisch gestalteten „Diplome“ (22,5 x 32,5 cm, hartes Kartonpapier) zeigt das von der Schule genagelte Kriegswahrzeichen ${ }^{1386}$ und enthält den folgenden patriotischen Spruch:

„Der Väter Blut die Erde trank: Den Kindern dank

Die Liebe mit der Gebehand: Baut ihnen treu

Die Zukunft neu: Und neu das Vaterland.“

Ein Siegel der „Jugendspende für Kriegerwaisen Essen“ und die Unterschrift des entsprechenden Schulleiters sollten die Bedeutung des Zertifikats betonen, das die Schüler - mit Eintrag ihres Namens - als Anerkennung erhielten, wenn sie zwei oder drei Mark gestiftet hatten. Offensichtlich hatte zu jenem Zeitpunkt die Spendenbereitschaft auch in den Schulen nachgelassen, sodass der Verein den Schulen 1917 und 1918 neue Werbemittel zur Verfügung stellte. ${ }^{1387}$

\footnotetext{
${ }^{1382}$ Schneider, Über hannoversche Nagelfiguren im Ersten Weltkrieg (1996), S. 248.

${ }^{1383}$ Jugendspende für Kriegerwaisen, Die Lehrerin: Organ des Allgemeinen Deutschen Lehrerinnenvereins 1917, S. 13.

${ }_{1384}$ Kriegswahrzeichen, Oberfränkischer Zeitung und Beireuther Anzeiger, 28. Mai 1916, S.16.

${ }^{1385}$ In der Sammlung Kronenberg befinden sich etwa 400 solcher Karten (,Jugendspende“ und „Jugenddank“); sie stellen eine wichtige Quelle dar, da es außer ihnen oft keine Hinweise auf die Nagelung von Kriegswahrzeichen in bestimmten Schulen gibt. Sie enthalten u.a. den Namen des Schule und der Kommune, in der die Schule lag, und teilweise auch das Jahr der Nagelung.

${ }^{1386}$ Dem Verfasser sind Urkunden mit den folgenden Motiven bekannt: „Schiff“, „Eisernes Kreuz“, „Flugzeug“, „Adlerkopf“, „Füllhorn“, „Adler“, „U-Boot“, „Helm“, „Eisernes Kreuz mit Lorbeerkranz“, „, Adler“, „Schwert mit Schlange“, „Löwe“; „Möve“ (Sammlung Kronenberg); siehe: Anhang, Seiten 81f.

${ }^{1387}$ Das Anschreiben hatte die Firma Glasmachers an die Schulen geschickt (Sammlung Kronenberg).
} 
Außerdem konnten sich die Schulen kostenlos Sammellisten schicken lassen, die der Verein hatte anfertigen lassen. Neben den Schülern sollten sich spendenfreudige „Gönner“ in die Listen eintragen, „die in den Schulakten ein dauerndes Andenken an die Gebefreudigkeit in schwerer und grosser Zeit bilden“ sollten. Auch wenn keine Belege für Schildnagelungen des Vereins „Jugendspende“ nach dem Krieg gefunden werden konnten, so ist davon auszugehen, dass sie noch in Einzelfällen weitergeführt worden sind. ${ }^{1388}$ Dafür spricht, dass es den Verein selbst noch bis 1945 gegeben hat ${ }^{1389}$ und dass entsprechende Nagelungen des Vereins „Jugenddank“ nach 1918 bezeugt sind. ${ }^{1390}$

\subsection{2 „Jugenddank für Kriegsbeschädigte“}

Auch die zweite große Hilfsaktion der Lehrerschaft, der am 24. Juni 1916 in Berlin gegründete „Jugenddank für Kriegsbeschädigte e. V.“, warb für die Nagelung von Kriegswahrzeichen in Schulen und stellte ihnen Nagelschilde zur Verfügung. ${ }^{1391}$ Wie die in den Zeitschriften der Lehrerverbände veröffentlichten Aufrufe zur Gründung des Vereins an die Lehrerschaft zeigen, hatte man zunächst allerdings offensichtlich nicht an den Erfolg der Schulnagelungen geglaubt, denn in keinem der sieben Vorschläge für mögliche Spendenaktionen werden sie erwähnt. ${ }^{1392}$ Aber der große Erfolg der durch die konkurrierende „Jugendspende“ initiierten Nagelschilde der Firma Glasmachers führte offensichtlich dazu, dass in den folgenden Aufrufen an die Lehrerschaft unter den vorgeschlagenen sieben Aktionen auch die „Nagelungen von Wappen, Kreuzen usw.“ genannt werden. Der Gedanke wurde aber erst dann von der Mehrzahl der Mitglieder des „Jugenddanks“ aufgegriffen, als man sich entschloss, den Schulen die Nagelschilde der Firma Glasmachers zur Verfügung zu stellen, die sich von denen, welche die „Jugendspende“ lieferte, überhaupt nicht unterschieden. Auch die Ansichtskarten sind bis auf den eingedruckten Namen „Jugenddank“ bzw. „Jugendspende“ völlig gleich.

\footnotetext{
${ }^{1388}$ Vereinzelt hat es auch nach Beendigung des 1. Weltkriegs Nagelungen gegeben, z. B. am 25.März 1923 in der Schule in Mittel-Podiebrand, wo für die „Ehrung“ der im Krieg Gefallenen ein „Ehrenschild, das Eiserne Kreuz darstellend“, von den Schulkindern genagelt wurde. (http://petertscherny.pe.funpic.de/strehlen/ podiebrad/chronp.pdf [3.10.2009]).

${ }^{1389}$ Das zeigt u. a. ein Block mit 100 Spendenmarken des Vereins ,Jugendspende für Kriegerwaisen“ aus dem Jahre 1943; siehe: Datensatz GOS-Nr. 20005298 des Deutschen Historischen Museums in Berlin, Unter den Linden 2, 10117 Berlin.

${ }^{1390}$ Siehe: Kapitel 7.2.2.

1391 „Der Verein bietet seinen Mitgliedern kostenlos und portofrei zur Nagelung vorbereitete Schilde, Eiserne Kreuze und Sinnspruchtafeln mit den dazugehörigen Nägeln in einem Nagelkästchen, sowie Hammer, Vorlocher und Nagelanweisung, unter der einzigen Bedingung, dass der Ertrag der Nagelung dem Jugenddank zufließt. Außerdem liefert der Verein kostenlos Postkarten ..." Siehe: Gotthardt, Die Nagelung von eisernen Wahrzeichen im Kreise Beeskow-Storkow 1915/16 (o. J.), S. 2f. siehe: Kapitel 3.2.

1392 Der Aufruf war in den Zeitschriften der Lehrerverbände abgedruckt worden: z. B. in: Günther, Von der Kriegsarbeit der Mädchenschulen (1919); Vereinsnachrichten aus dem deutschen Lehrerverein Hannoversche Schulzeitung. Organ der Provinzial-Lehrervereins, der Bezirks- und Pestalozzivereine der Provinz Hannover, des Lehrer-Brandversicherungsvereins für Hannover, Bremen und das Fürstentum Lippe., 1915, S. 326.
} 
In der 1. Hauptsammlung des Vereins am 25. 02.1917 wurde auf die „kostenlose Hergabe von Nagelungsschilden und -Tafeln" hingewiesen und in einem Bericht einer Lehrerzeitung hieß es: „Für kleinere Veranstaltungen einzelner Schulen zu Gunsten des Jugenddanks sei erneut darauf aufmerksam gemacht, dass der Verein kostenlos (...) Nagelungsschilde in Gestalt von eisernen Kreuzen und Nagelungstafeln für kurze Sinnsprüche zur Verfügung stellt. “'1393

Zwar wurde die Firma Glasmachers in Essen nicht genannt, die mitgelieferten Ansichtskarten weisen sie jedoch eindeutig als Hersteller aus. Als Beispiel seien die neun von den Schülerinnen des Lyzeums in Allenstein (Provinz Ostpreußen) genagelten Kriegswahrzeichen genannt: Drei zeigen das - variierte - Motiv des Eisernen Kreuzes, zwei einen Sinnspruch („Gott mit uns“ und „Mit Gott für Kaiser und Reich“) und die anderen die allgemein beliebten Motive „U-Boot“, „Flugzeug“, „Adlerkopf“ und „Schwert““. ${ }^{1394}$ Es wurden aber für den ,Jugenddank“ auch Schilde mit den Motiven „Adler“, „Kaiserkrone“, „Möve“, „Soldat“, „Schiff“, „,Kriegerkopf“, „Helm“ und „Löwe“ (rot), „Handgranatenwerfer“ und „Drei Adler“ benagelt, wie entsprechende Ansichtskarten zeigen. ${ }^{1395}$

Im Jahre 1918 stellte der „Jugenddank“ zusammen mit der Firma Glasmachers den Schulen wie ein Jahr zuvor bereits die „Jugendspende“ - eine umfangreiche Werbebroschüre zur Verfügung. Sie war ganz ähnlich gestaltet, aber mit 34 Seiten deutlich umfangreicher. Angeboten wurden 28 verschiedene Kriegswahrzeichen: 15 allgemeine Nagelschilde, 6 Schilde, die auch mit Gedenkinschriften für gefallene Lehrer angeboten wurden, und 7 Spruchschilde. Einige der hier aufgeführten Schilde, die im Katalog der „Jugendspende“ fehlen, sind 1918 auch von ihr vertrieben worden. Insgesamt enthält die Broschüre offensichtlich eine vollständige $\mathrm{Zu}$ sammenstellung aller von der Firma Glasmachers hergestellten und von den beiden Hilfsorganisationen vertriebenen Kriegswahrzeichen.

Vereinzelt sind auch nach Kriegsende noch Nagelschilde benagelt worden, denn z. B. in der Schulchronik von Gebersdorf (Provinz Hessen-Nassau) findet sich für das Jahr 1919 der folgende Eintrag: „Durch Vermittlung des Lehrers wurde der Schule vom „Jugenddank für Kriegsbeschädigte" ein Nagelschild „,Krieger im Stahlhelm“ darstellend, zu [r] Verfügung [gestellt], das nach vollendeter Nagelung in unseren Besitz übergeht ${ }^{\text {“1396. }}$.

\footnotetext{
${ }^{1393}$ Der Aufruf ist in den Zeitschriften der Lehrerverbände veröffentlicht worden, z. B. Jugenddank für Kriegsbeschädigte, Deutsches Philologen-Blatt 1916, S. 331; Kriegschronik des Württembergischen Landesvereins vom Roten Kreuz (1921).

1394 Sammlung Kronenberg.

1395 Sammlung Kronenberg.

${ }^{1396}$ H.-G. Nerlich, Historisches Kalenderblatt 2 (20.09.2009).
} 


\subsubsection{Kriegshilfe anderer Organisationen}

Neben den beiden durch Lehrer initiierten Organisationen, die überwiegend in Nord-, Westund Ostdeutschland erfolgreich agierten, war es vor allem das Rote Kreuz, das ähnliche Nagelaktionen durchführte und den Schulen sog. „Gedächtnisschilde“1397 zur Verfügung stellte. ${ }^{1398}$

Die farbigen Schilde $(30,5 \mathrm{~cm}$ x 23,5 cm), die mit den erforderlichen Nägeln (100 Nägel zu je 10 Pfennig, 3 Ehrennägel zu je 1 Mark) zum Preis von 13 Mark abgegeben wurden, zeigen auf der Vorderseite als Motiv einen Adler mit dem Zeichen des Roten Kreuzes in der Mitte und umlaufend den patriotischen Spruch „DEUTSCHLAND HOCH IN EHREN - DU HEIL'GES LAND DER TREU!“'1399. Auf der Rückseite trugen sich die Spender namentlich ein. Diese Kriegswahrzeichen, die ,zu öffentlichen Nagelungen auf der Straße nicht verwendet werden“ ${ }^{1400}$ durften, waren vor allem im Königreich Württemberg verbreitet. War der Schild vollständig benagelt, wurde er „mit der Unterschrift des Bezirksvertreters versehen dem Abnehmer urkundlich zur dauernden Verfügung überlassen“.

Postuliertes Ziel des Roten Kreuzes war es u. a., dass ,jede Schule [...] künftig das schlichte Erinnerungszeichen an unsere eiserne Zeit zieren"sollte, wie aus einem Aufruf des Roten Kreuzes im Bezirk Esslingen hervorgeht. Es ging dem Württembergischen Landesverein also nicht in erster Linie um das Einsammeln von Spendengeldern, sondern um patriotische Erziehungsziele.

Wie die Nagelung der Klasse IVa in der damaligen Höheren Töchterschule in Reutlingen (Kgr. Württemberg) zeigt, wurden jeweils 13 Mark eingenommen, wenn der Schild vollständig benagelt war, und dem Roten Kreuz überwiesen. ${ }^{1401}$ Da diese Summe genau dem Anschaffungspreis entsprach, kann davon ausgegangen werden, dass Unkosten und Spendeneinnahmen miteinander verrechnet wurden - wenn nicht, was häufig der Fall war, Sponsoren die Beschaffungskosten übernommen hatten. ${ }^{1402}$

\footnotetext{
1397 Offensichtlich wurden diese Schilde auch „Hindenburg-Tafeln“ genannt, z. B. in Sondernach (HindenburgTafel aus Sondernach, Eninger Tagblatt 3. Januar 1916) und Schelklingen.

1398 Z. B. wurden in Backnang ,kleine Gedächtnisschilde“ benagelt (Rauscher, Das Volksschulwesen in Backnang 1880-1952 (2. Teil), Backnanger Jahrbuch (2003), S. 107.

1399 Siehe: Beispiele aus Backnang und Sondernach (Kgr. Württemberg) sowie Bad König (Ghzgt. HessenDarmstadt) im Anhang, Seite 85. Nach Auskunft der entsprechenden Stadtarchive sind auch für Isny, Oberndorf am Neckar und Villingen-Schwenningen (Ghzg. Baden) solche Schilde überliefert.

${ }^{1400}$ Lange, 1914 bis 1918 auf der Schulbank (1933); Kriegschronik des Württembergischen Landesvereins vom Roten Kreuz (1921), S. 11f.

${ }^{1401}$ Von der ehemaligen Höheren Töchterschule der Stadt Reutlingen (Kgr. Württemberg) sind aus dem Schuljahr 1915/16 Abbildungen von zwei Nagelschilden im Stadtarchiv Reutlingen vorhanden StAR , AZ 361-51-5 (Schreiben vom 25.10.2004).

${ }^{1402}$ Siehe: Kapitel 7.3.3 („Finanzielle Unterstützung von Schülern“).
} 
Dass das Interesse der Schulen an solchen Nagelungen insgesamt groß gewesen sein muss, geht auch aus einem Eintrag in der „Ehrenchronik Weltkrieg 1914-18“ hervor: „Am Anfang des Jahres 1916 wurden vom Roten Kreuz Gedächtnisschilder aus Holz vertrieben ... Es wurden namentlich von den Schulen und Vereinen solche Ehrenschilder verlangt und in den Schulzimmern und Gesellschaftsräumen aufgehängt. In den katholischen Schulen hängen heute noch solche Schilder. Insgesamt wurden 637,70 Mark vernagelt, wovon dem Bezirk 189,20 verblieben. “ ${ }^{1403}$

Im Unterschied zum Roten Kreuz kaufte die „Kriegskinderspende deutscher Frauen“ wie die „Jugendspende“ und der „Jugenddank“ die Nagelschilde bei der Firma Glasmachers in Essen und stellte sie den Schulen zur Verfügung. Aus der St. Nikolai-Mädchenschule in Flensburg ist überliefert, dass die Lehrerschaft am 29. September 1916 beschloss, „eine Bildbestellung bei der Kriegerspende deutscher Frauen“ aufzugeben und ,in jeder Klasse eine Nagelung vorzunehmen“1404. Das Rote Kreuz förderte zwar in Schleswig-Holstein tatkräftig Nagelaktionen ${ }^{1405}$, aber offensichtlich kümmerte man sich in dieser Hinsicht wenig um die Schulen, da dort neben anderen Organisationen vor allem der Verein „Jugendspende“ mit großem Erfolg aktiv war.

In Großherzogtum Hessen-Darmstadt wurde die Nagelaktion zentral von der Regierung organisiert. Diese hatte ,an den Schulen angeordnet, dass die Schüler gegen Bezahlung auf einem gewissen Brett, auf dem sich ein Muster befand, die Nägel einschlagen durften. Meistens war das Wappen des Großherzogs das Muster ${ }^{1406}$. Nach Beendigung der Nagelaktion wurde der Schild dem Großherzog zugesandt, der ihn mit einer Widmung versah und zurückschickte. Er wurde dann als Wandschmuck in den Schulräumen aufgehängt. Sicher hat das ,persönliche' Engagement des Monarchen viele Schulen zusätzlich motiviert, sich an den Nagelaktionen zu beteiligen.

In welchem Umfang Kommunen als Schulträger ihren Schulen Nagelschilde zur Verfügung gestellt haben, kann aufgrund der spärlichen Quellen lediglich vermutet werden. Da Recherchen in Stadtarchiven, in vielen Bibliotheken und im Internet zu keinen konkreten Ergebnissen geführt haben, kann davon ausgegangen werden, dass es solche Aktionen nicht allzu häufig gegeben hat. Das wäre insofern auch erklärbar, als die Gemeinden die Schulen

\footnotetext{
${ }^{1403}$ Siegloch/Stadtarchiv Isny, Nagelfiguren (Isny), Schreiben vom 28.09.2004.

${ }^{1404}$ Hohnsbehn, Die Flensburger Schuljugend in der Zeit des ersten Weltkriegs (1996), S. 193.

${ }^{1405}$ So war das Rote Kreuz z. B. Mitveranstalter der meisten Kriegsausstellungen; außerdem war es der Initiator der Flensburger Nagelsäule; Pust, "Vaterländische Erziehung“ für „Höhere Mädchen" (2004), S. 412 ff.

1406 Großherzogliches Badisches Landesgewerbeamt, Großherzogliches Badisches Landesgewerbeamt 1916 (1916); nach Auskunft des Archivs lief ,die Bretternagelung im 3. Reich (...) ähnlich ab. Als Muster war meist die Raute der Hitlerjugend vorgegeben."
} 
sehr stark in die kommunalen Nagelungsaktionen einbezogen ${ }^{1407}$ und deshalb wenig Interesse an konkurrierenden schuleigenen Nagelungen gehabt haben dürften. Dieses war den Firmen, die Kriegswahrzeichen herstellten, sicher bekannt und wurde offensichtlich von ihnen in ihren Angeboten berücksichtigt. So wendete sich das Gothura-Werk in Gotha (Hrzgt. SachsenCoburg-Gotha) in seinem ausführlichen Katalog zwar vorrangig an die Kommunen und die Wohlfahrtsverbände ${ }^{1408}$, machte aber ein spezielles Angebot für Schulen. ${ }^{1409}$ Inwieweit Schulen sich für einen der drei angebotenen Schilde entschieden haben, ist nicht bekannt. Die Kaufbereitschaft muss jedoch recht gering gewesen sein, denn konkrete Hinweise enthielten die Antworten der angeschriebenen Stadtarchive nicht. $\mathrm{Zu}$ vermuten ist allerdings, dass vor allem das Rote Kreuz und der „Vaterländische Frauen-Verein“ eine Reihe der gekauften Schilde auch den Schulen zur Nagelung überlassen haben, denn dass z. B. von den 100 Schilden, die das Rote Kreuz in Gotha, und den 48, die der Vaterländischer Frauen-Verein in Adelnau (Provinz Posen) erworben haben, keine den Schulen überlassen worden sein sollen, ist kaum vorstellbar. ${ }^{1410}$ Die Produkte der Firma Gothura waren sicher im Deutschen Reich durchaus bekannt, denn auch die Nationalgabe hat einen ihrer Nagelschilde in die Broschüre „Entwürfe von Kriegs-Wahrzeichen zum Benageln“"1411 aufgenommen. Aus einer anderen Beschreibung geht ebenfalls hervor, dass man bei der Vermarktung der Wandschilde durchaus auch an die Schulen gedacht hatte. Dort heißt es: „Schulklassen (...) werden gern einen oder mehrere solcher von dem betr. Wohltätigkeitsinstitut kostenlos überlassenen Wandschilde besitzen wollen.“ Ferner wurde vorgeschlagen, dass „Schulkinder diese Schilde umhertragen“" und Verwandte und Bekannte um das Einschlagen von Nägeln bitten. ${ }^{1412}$ Über organisierte Schildnagelungen in bayerischen Schulen ist nichts bekannt. ${ }^{1413}$

\subsubsection{Akzeptanz der Schildnagelungen}

Insgesamt geben nur relativ wenige zeitgenössische Quellen Aufschluss darüber, wie Schüler

\footnotetext{
${ }^{1407}$ Siehe: Kapitel 7.3.

${ }^{1408}$ Genannt werden „Rotes Kreuz“ und „Vaterländischer Frauenverein“.

${ }^{1409}$ Der ausführliche Prospekt der Firma Gothura ist in vielen Stadtarchiven vorhanden. Hier wurde zitiert aus einem Exemplar des Archivs der Stadt Greiz: Bestand B, Nr. 481, Seite 87.

${ }^{1410}$ Die Fabrik weist auf mehr als 100 Kommunen als Kunden hin und nennt namentlich 22 Käufer von insgesamt 377 Schilden; darunter sind keine Schulen.

${ }^{1411}$ Nationalgabe, Entwürfe von Kriegs-Wahrzeichen zum Benageln (1915), S.26; der Katalog ist in vielen Stadtarchiven vorhanden. Hier wurde zitiert aus einer Kopie des Archivs der Stadt Eisfeld (StAEF), Inventarverzeichnis Nr. 823; siehe: Abbildungen Anhang, Seite 81, Bild 1.

${ }^{1412}$ Die „Beschreibung“, die keinen ,Absender’ ausweist, wirbt für die Schilde der Firma Gothura. Sie ist u.a. im Stadtarchiv Bamberg (StABA) vorhanden (Bestand: C 56 KA; Nummer: 10/20m) und enthält ein Bild eines Nagelschildes, den das Rote Kreuz in Berlin bestellt hat. Es hat 15 Mark gekostet und sollte einen Nettoüberschuss von 66 Mark erbringen. Mit dem Schild wurden „Buch der Spender, Hammer und 150 Nägel“ geliefert.

${ }^{1413}$ Dass allerdings auch bayrische Schüler bei Nagelungen beteiligt waren, geht u. a. aus dem Jahresbericht der „höheren realistischen Schulen“ hervor; siehe: Ebner, Das zweite Kriegsjahr der höheren realistischen Schulen in Bayern, in: Deutsches Philologen-Blatt, 1916, S. 612.
} 
und Lehrer die Schildnagelungen empfunden haben. Am ausführlichsten berichtete ein Schüler der königlichen Realschule in Saarbrücken über die Nagelungsaktionen in den einzelnen Klasse seiner Schule:

„Natürlich war der Andrang sehr groß. Jeder wollte den ersten Nagel bei diesem feierlichen Akt einschlagen. Jeder Schüler wollte sich so verewigen, daß er in späterer Zeit seinen Nagel immer wieder sehen könnte. In jeder Pause vernimmt man in den Räumen unserer Schule ein emsiges Hämmern, so daß man meint, die Handwerker hätten ihren Einzug gehalten. Kaum hat sich der Lehrer entfernt, so schlägt sich alles um einen der Hämmer, deren Zahl sehr bald auf 6 angewachsen ist. Zwischen allen Klassen herrscht ein reger Wettstreit, denn diejenige Klasse, die zuerst ihren Schild benagelt hat, erhält einen schulfreien Tag. Nach Schluß des Unterrichts wird eine Wanderung durch die Klassen angetreten, um deren Arbeit zu sehen. Dann heißt es wohl mal: Diese Klasse kommt zum Wettbewerb nicht in Betracht. (...) Hatte ich angefangen zu nageln, so ruhte ich auch nicht, bis ich keinen Pfennig mehr in der Tasche hatte. Unsere Freude war groß, als uns unser Klassenleiter verkündete, daß wir alle Klassen übertroffen hätten. Die stattliche Summe von 167,50 Mk. konnten wir für die Kriegerwaisen abliefern. “1414

Anna Günther, Lehrerin am Lyzeum Viktoria-Auguste-Schule in Charlottenburg, äußerte sich ebenfalls uneingeschränkt positiv:

„Solche kleinen Feiern sind die Höhepunkte im Schulleben. Aber auch im Alltagsleben der Schulen gedenken die Kinder der Tapferen und ihrer Angehörigen. Mit Eifer wird genagelt. Es gibt wohl kaum eine deutsche Schule, in der sich nicht wenigstens ein Schild befindet. Ein jeder eingeschlagene Nagel hilft mit, aus Pfennigen werden größere und große Summen, die den Kriegsbeschädigten oder den Kindern der Gefallenen zugute kommen. Welche Freude, wenn ein Schild fertig gestellt ist und an einem Ehrenplatz aufgehängt werden kann. ${ }^{\text {"1415 }}$

Auch der Lehrer M. Exner aus Neukölln (bei Berlin) betont die ,außerordentliche Beliebtheit der Nagelungen bei Kindern“"1416 und in den Aufzeichnungen des damaligen Lehrers der evangelischen Volksschule Hahnkamp (Provinz Westfalen) heißt es: „Wie leuchteten die Augen der Schüler, als am ersten Arbeitstage die Nagelung des künstlerischen Wahrzeichens begonnen wurde.“1417 Dass sich das Kollegium der Städtischen Höheren Mädchenschule in Bad Oeynhausen (Provinz Westfalen), der Luisenschule, 1918 in der Aula vor zwei Nagelschilden (,Löwe“ und „Adlerkopf“) fotografieren ließ, zeigt ebenfalls die positive Einstellung

\footnotetext{
${ }^{1414}$ Jung, Der „Eiserne Ritter“ der Ursulinenschulen (1993), S. $76 f$.

${ }^{1415}$ Gemeint sind die Schilde der Firma Glasmachers; Günther/Hildebrandt/Samuleit (Hrsg.), JugenddankKalender (1919), S. 74.

${ }^{1416}$ In dem Jahresbericht des ,Jugenddanks“ veröffentlicht wurde, heißt es: „Von meinen zahlreichen Sammlungen für die Kriegswohlfahrtspflege, veranstaltet in Kl. I und II der 2. Gem.- Schule, (hat) mir keine nur annähernd so viel Freude eingetragen wie die Nagelung der künstlerischen Kriegswahrzeichen. Am 25. April begann ich mit Schild III: Reichsadler und Schlange. Die Begeisterung war so groß, daß ich die Goldnägel zum doppelten Preise verkaufen, das Fest der Schlußnagelung schon am 30. August feiern und 122 M. Ertrag abliefern konnte." Er geht dann auf die Nagelung von zwei weiteren Schilden ein. Insgesamt kamen bei den drei Nagelaktionen der Mädchen 383 Mark zusammen; Jugenddank für Kriegsbeschädigte e.V., Jahresberichte 1917 und 1918 (1917 und 1918).

${ }^{1417}$ Zitiert nach: Kammeier, Der Landkreis Lübbecke und der 1. Weltkrieg (1998), S. 203; Chronik der Schule in Hahnkamp.
} 
der Lehrkräfte zu den Nagelungsaktionen. ${ }^{1418}$ Anlässlich der Nagelung ließ sich in Hamburg am 27. November 1915 sogar die gesamte Schulgemeinschaft des Heinrich Hertz-RealGymnasiums mit einem Schild der Firma Glasmachers fotografieren. ${ }^{1419}$

Die Befragung von Zeitzeugen in Flensburg im Jahre 1991 ergab, dass sich zwar die ehemaligen Schüler an die Nagelung erinnerten, nicht aber an Einzelheiten oder wie die Aktion auf sie wirkte. ${ }^{1420}$

Kritik von Schülern oder Lehrern an den Schulnagelungen ist nicht überliefert worden. Zwar lehnte in Schleswig die Lehrerkonferenz am 23. September 1916 „das Anerbieten, Kriegswahrzeichen zu nageln zum Besten des ,Vereins Jugendspende für Kriegerwaisen'“ ab, die Entscheidung kann jedoch nicht als grundsätzliche Kritik an der Aktion gewertet werden. ${ }^{1421}$ Da man in der Konferenz am 18. August 1916 beschlossen hatte, für die Nagelung des „Isern Hinnerk" in Schleswig in der Schule zu sammeln, wollte man offensichtlich keine eigenen Nagelprojekte beginnen. ${ }^{1422}$

Wegen der schlechten Quellenlage kann nicht fundiert beurteilt werden, inwieweit die Nagelungen der von der Firma Glasmachers vertriebenen Kriegswahrzeichen bei den Schülern beliebt waren, auch wenn der Bericht des zitierten Schülers aus Saarbrücken und entsprechende Reaktionen von Kindern im Zusammenhang mit den allgemeinen Nagelungen für eine große Akzeptanz der Schüler sprechen. Bei den Feststellungen der Lehrer, die die Aktionen insgesamt unterstützten, muss berücksichtigt werden, dass sie sich natürlich davor scheuten, auf mangelndes Interesse ihrer Schüler hinzuweisen. Über die Akzeptanz der anderen zentral organisierten Nagelaktionen liegen keine konkreten Erkenntnisse vor. Es ist jedoch zu vermuten, dass z. B. auch die Kinder im Königreich Württemberg und im Großherzogtum Baden gerne Nägel in die Nagelbrettchen geschlagen haben und stolz waren, wenn das benagelte Wahrzeichen im Klassenzimmer aufgehängt wurde.

\footnotetext{
${ }^{1418}$ Kammeier, Der Landkreis Lübbecke und der 1. Weltkrieg (1998), S.204; siehe: Anhang, Seite 88, Bild 2.

${ }^{1419}$ Das Bild ist zwar unscharf, es zeigt jedoch zwei Lehrer inmitten der Schulgemeinschaft, die das runde Nagelschild mit dem Motiv des Kreuzes präsentieren. Siehe: Anhang, Seite 88, Bild 1.

${ }^{1420}$ Hohnsbehn, Die Flensburger Schuljugend in der Zeit des ersten Weltkriegs (1996), S. $193 \mathrm{f}$.

${ }^{1421}$ Chronik Husum, S.7; zitiert nach: Pust, „Vaterländische Erziehung" für „Höhere Mädchen" (2004), S. 410.

1422 Bei der Sammlung waren insgesamt 160,50 Mark zusammengekommen (Pust, „Vaterländische Erziehung" für „Höhere Mädchen"[2004], S. 404).
} 


\subsubsection{Auswertung der Schildnagelungen}

Nach eigenen Angaben hat der Verein „Jugendspende“ bis zum 14. April 1917 „weit mehr als 20.000 Schilde“1423 und der „Jugenddank“ bis zum 31. Dezember 19172.590 Schilde abgesetzt. ${ }^{1424}$ Über die vom Roten Kreuz vertriebenen Nagelbrettchen (s. Kapitel 7.2.4) liegen keine konkreten Zahlen vor. Da auch im Jahre 1918 noch nachweislich genagelt worden ist, liegt die Gesamtzahl deutlich höher. Hinzuzurechnen wären noch die Schilde, die andere Organisationen von der Firma Glasmachers bezogen haben, wie z. B. die „Kriegskinderspende deutscher Frauen“, bei der u. a. die St. Nikolai-Mädchenschule in Schleswig für jede Klasse ein Schild bestellt hatte. ${ }^{1425}$ Deshalb kann davon ausgegangen werden, dass die Zahl der genagelten Schilde über 30.000 lag.

Im Rechenschaftsbericht des „Jugenddanks“ 1918 geht der Verein von einem Reingewinn von „207.640 Mark“ aus. Überträgt man dieses Ergebnis auf die vertriebenen Schilde der „Jugendspende“, so betrug der Gewinn dieses Vereins etwa 1.603.398 Mark. Wahrscheinlich lag er sogar noch höher, denn vollbenagelte Schilde erbrachten im Schnitt 131,45 Mark Einnahmen (Schild „Schiff“ 55,13 M bis „Löwe“ 176,64 M). Bei 20.000 Schilden erzielte man also ungefähr 2.620.000 Mark Einnahmen, von denen dann noch die Unkosten abzuziehen wären. Die Gesamteinnahmen der überregionalen schulischen Schildnagelungen betrugen also etwa 2,5 Millionen Mark. ${ }^{1426}$

Interessanter als die Frage nach dem finanziellen Gewinn ist sicher die nach der Anzahl der bei den Nagelungen beteiligten Schulen und Schüler, die allerdings nur recht vage beantwortet werden kann. Geht man von der Zahl 30.000 Schilde aus und berücksichtigt man, dass ein Schild der Firma Glasmachers im Durchschnitt Platz für 4.493 Nägel hatte (Schild „Schwert“ 2.942 bis „Löwe“ 6.368), so sind 134.790.000 Nägel eingeschlagen worden. Vorausgesetzt, jeder Schüler bzw. Lehrer hat 10 Nägel eingeschlagen, so waren 13.479.000 Personen an den Schulnagelungen beteiligt. Berücksichtigt man, dass es außerdem in vielen Schulen eigene Nagelobjekte gab und die Schulen zudem sich an fast allen kommunalen Nagelungen beteiligten (siehe Kapitel 7.3), so kann davon ausgegangen werden, dass die ganz große Mehrheit der Schüler und Lehrer des Deutschen Reiches als Nagelnde an der „Heimatfront“ ,gekämpft” haben. Die Zeitzeugin Frau J. Schröder bestätigt das. Ihrer Erinnerung nach waren die

\footnotetext{
${ }^{1423}$ Die Angaben stammen aus einer Werbeschrift der Firma Glasmachers über die Lieferung von Nagelurkunden an die Schulen. Sammlung Kronenberg. Sie werden auch in der Ausgabe der Zeitschrift „Die Lehrerin“ vom 14.04.1917 genannt (Schule im Kaiserreich - Erziehung zum Patriotismus).

${ }^{1424}$ Jugenddank für Kriegsbeschädigte e.V., Jahresberichte 1917 und 1918 (1917 und 1918). Der Jahresbericht ist in vielen Stadtarchiven vorhanden. Hier wird zitiert aus: $L A S$, Abt. Nr. 1944, 2. Bericht 1918, S. 5.

${ }^{1425}$ Hohnsbehn, Die Flensburger Schuljugend in der Zeit des ersten Weltkriegs 49 (1996), S. 193.

${ }^{1426}$ Mit einer solchen Summe hätte man im Jahre 1918 etwa ein Jahr lang 1.000 Kriegerfamilien finanziell unterstützen können; siehe dazu: Vogeler, Kriegschronik der Stadt Hildesheim (1929), S. 327.
} 
„Wehrmale in allen Schulen zu finden“1427. Entsprechend äußerte sich auch die Berliner Lyzeallehrerin Anna Günther im Jahre 1918: „Es gibt wohl kaum eine deutsche Schule, in der sich nicht mindestens ein Schild befindet.“1428 Auch wenn diese Feststellung sicher etwas übertrieben ist, denn es gab durchaus Gegenden, in den nicht genagelt worden ist, so ist gegenüber der Tatsache, dass die große Mehrheit der deutschen Schulen sich an den Nagelungen beteiligt hat, die Spendensumme in Höhe von ca. 2,5 Millionen Mark ${ }^{1429}$ von ungeordneter Bedeutung, auch wenn z. B. mithilfe der Spenden vielen Kriegswaisen („Jugendspende“) und Kriegsbeschädigten (,Jugenddank“) geholfen werden konnte. Über die Verteilung der Spendengelder gibt es relativ wenige konkrete Unterlagen. Aus einem - unten zitierten - Briefwechsel zwischen der „Jugendspende“ und der Stadt Hannover geht hervor, dass die städtischen Fürsorgeeinrichtungen an den Verein Anträge auf finanzielle Unterstützung stellen konnten, über die ein Ausschuss des Vereins entschied. Noch weniger ist über die Verwendung der Einnahmen des „Jugenddanks“ bekannt. Zwar enthalten die Jahresberichte 1917 und 1918 einen genauen Kassenbericht, jedoch keine Angaben zur Verwendung der Spendengelder.

Dass die Nagelungen eine so große Bedeutung erlangten, war vor allem den von Berliner bzw. Essener Lehrern gegründeten Vereinen „Jugenddank“ und vor allem „Jugendspende“ zu verdanken. Von 438 dem Verfasser bekannten Schilden konnten 327 den beiden Vereinen ${ }^{1430}$ eindeutig zugeordnet werden; und zwar sind 216 von der „Jugendspende“ geliefert worden (ca. $66 \%$ ) und 111 vom „Jugenddank“ (ca. $34 \%$ ). Sieht man vom Königreich Bayern ab ${ }^{1431}$, so haben Schulen in allen Ländern des Deutschen Reiches Glasmachers Kriegswahrzeichen genagelt. Besonders verbreitet waren die Nagelungen in den Herzogtümern Braunschweig und Anhalt und vor allem in Preußen. 366 der 438 bekannten Schilde sind in Preußen benagelt worden (ca. $83 \%$ ). Obwohl der „Jugenddank“ reichsweit agierte, bemühte er sich, sich mit der Konkurrenz aus Essen zu arrangieren und Preußen in zwei Nagelungsbereiche aufzuteilen. Die ,gewünschte Verständigung [...] konnte zwar 1917 nicht herbeigeführt werden, trotzdem mehrfach Verhandlungen angeknüpft wurden“1432, ein Jahr später jedoch verfügte der Staatskommissar der Kriegswohlfahrtspflege in Preußen, dass „,das Gebiet östlich der Elbe

\footnotetext{
${ }^{1427}$ Hohnsbehn, Die Flensburger Schuljugend in der Zeit des ersten Weltkriegs (1996), S. 194.

1428 Günther, Von der Kriegsarbeit der Mädchenschulen (1919), S. 74.

${ }^{1429}$ Entsprechend der Kaufkraft umgerechnet also etwa 7,75 Millionen Euro (1915: Faktor 6,2).

${ }^{1430}$ Viele Ansichtskarten enthalten nicht den Aufdruck „Kriegswahrzeichen genagelt zum Besten der Jugendspende für Kriegswaisen von ..." bzw. „... des Jugenddanks für Kriegsbeschädigte ...“, so dass sie nicht zuzuordnen sind; Sammlung Kronenberg.

${ }^{1431}$ Auch in Bayern gab es Schildnagelungen; die „Wehrschilde“ wurden aber nicht von bestimmten Firmen vertrieben, sondern die Kommunen ließen sie jeweils von einem ortsansässigen Künstler oder Handwerker anfertigen. Zum Beispiel wurde in Rosenheim ein Wehrschild („Eiserne Rose“) benagelt, wie auf einer Ansichtskarte zu sehen ist; Sammlung Kronenberg.

${ }^{1432}$ Jugenddank für Kriegsbeschädigte e.V., Jahresberichte 1917 und 1918 (1917 und 1918), S. 3.
} 
ausschließlich dem Jugenddank für Kriegsbeschädigte zugesprochen worden ist. In dem westlich der Elbe gelegenen Teil der Monarchie steht das Nagelungsrecht der ,Jugendspende für Kriegerwaisen' in Essen zu.“ Ferner steht in dem Bericht, dass man „hinsichtlich der gegenseitigen Nutzung der Schildentwürfe zu einem durchaus befriedigenden Abkommen gelangt“ $(\text { sei })^{1433}$.

Offensichtlich hatte man sich 1916 auch bemüht - allerdings vergeblich - bei den süddeutschen Bundesstaaten eine Genehmigung des „Jugenddanks“ zu erreichen.

Die Firma Glasmachers lieferte von 1915-1918 Schilde mit insgesamt 29 unterschiedlichen Motiven ${ }^{1434}$, darunter drei Varianten des Eisernen Kreuzes. ${ }^{1435}$ Am beliebtesten unter den 438 untersuchten Schilden waren „Schwert“ (13,6\%), „Eisernes Kreuz“ (13,6\%) „Helm“ $(11,8 \%)$, ,Kriegsschiff“ (8,6 \%), „Loewe“ (7,9\%), ,Adler“ $(7 \%)$ und „U-Boot“ $(6 \%) .{ }^{1436}$

Die Schildnagelungen waren offensichtlich in Jungen- und Mädchenschulen gleichermaßen beliebt. Berücksichtigt man nur die Nagelungen in Gymnasien und Lyzeen, so entfallen von den 124 Schildnagelungen der höheren Schulen 63 auf die Jungen- und 61 auf die Mädchenschulen. Berücksichtigt man ferner, dass es erheblich mehr Gymnasien als Lyzeen gab, so wird deutlich, wie beliebt die Nagelungen vor allem bei den Mädchen waren. Dass die vier Schulen mit den meisten genagelten Schilden Lyzeen waren, bestätigt die große Akzeptanz der Nagelungen bei den Mädchen. ${ }^{1437}$ Dieses ist sicher zum einen damit zu erklären, dass in den Gymnasien oft die Abschlussklassen fehlten, da sehr viele Schüler sich freiwillig zum Militärdienst gemeldet hatten. Zum anderen könnte die Tatsache, dass viele Mädchen sich wie die Jungen an der „Heimatfront“ engagieren wollten, sie aber weniger Möglichkeiten hatten, da beispielsweise nur wenige von ihnen in der Landwirtschaftshilfe eingesetzt werden konnten, ein Grund dafür sein, dass sie sich verstärkt für die schulischen Nagelungen einsetzten.

Aber auch in allen anderen Schulformen und in Lehrerseminaren wurde häufig genagelt, am meisten in den Volksschulen (24\%) und in den Mittelschulen. Dabei war es nicht von Bedeutung, ob die Schulen in staatlicher oder privater Trägerschaft waren. Dass aus evangelischen Schulen (8\%) etwas mehr Schildnagelungen bekannt sind als aus katholischen (5\%), erklärt sich aus der Tatsache, dass die Vereine „Jugendspende“ und „Jugenddank“ im ,katholischen” Süden wenig erfolgreich waren und es z. B. in Preußen viel mehr evangelische als katholische Schulen gab.

\footnotetext{
1433 Jugenddank für Kriegsbeschädigte e.V., Jahresberichte 1917 und 1918 (1917 und 1918), S. 4f.

${ }^{1434}$ Dazu zählen nicht die Gedenkschilde für gefallene Lehrer.

1435 Siehe: Anhang, Seite 82.

${ }^{1436}$ Forschungsstand am 4. April 2010.

${ }^{1437}$ Kaiserin Auguste-Viktoria-Schule in Bielefeld: 11 Schilde; Stadttöchterschule II Am Clevertor in Hannover: 9; Städtisches Lyzeum in Allenstein (Ostpreußen): 8; Ev. Lyzeum in Lippstadt: 6.
} 
Vergleicht man abschließend die Anzahl der quellenmäßig belegten Schildnagelungen in der Metropole Berlin, der Großstadt Hannover, in Flensburg als einer Stadt mittlerer Größe und in den Kommunen des Landkreises Lübbecke als ländlichem Bereich, so ergibt sich folgendes Ergebnis ${ }^{1438}$ :

Berlin:

Hannover:

Flensburg:

Landkreis Lübbecke: mindestens 68 Nagelschilde in 54 Schulen

“ $\quad 15$ Nagelschilde in 7 Schulen

“ mehr als 10 Nagelschilde in 3 Mädchenschulen, Mittelschulen und Volksschulen

Bei dem Ergebnis fällt die relativ geringe Beteiligung der Hannoverschen Schulen auf. ${ }^{1439}$ Dass dieses nicht ausschließlich auf die schlechte Quellenlage zurückzuführen ist, zeigt ein Briefwechsel zwischen dem Verein „Jugendspende“ und städtischen Fürsorgeeinrichtungen. ${ }^{1440}$ Aufgefordert, ,eine bestimmte Anzahl befähigter, bedürftiger und würdiger Kinder dem Verein Jugendspende für Kriegswaisen namhaft zu machen“, reichte das städtische Fürsorgeamt am 13. Januar 1917 eine Liste mit insgesamt acht Kindern ein. Am 31. Mai 1917 teilte der Verein mit, dass lediglich zwei Kriegerwaisen unterstützt werden könnten. Man hätte gern mehr Kinder unterstützt, sehe sich ,,aber dazu nicht in der Lage, da in den Schulen der Stadt Hannover durch freiwillige Sammlung für unsere Zwecke nur ein verschwindend kleiner Betrag (M. 684) eingenommen sei. Es liegt das wohl hauptsächlich an der schroff ablehnenden Haltung des dortigen Schuldezernenten, Herrn Dr. Wehrhahn, gegenüber unserer Sammeltätigkeit durch Bilderverkauf und Benagelung von Kriegswahrzeichen.“

Nach Schneider geben die vorliegenden Unterlagen keinen Aufschluss darüber, ob der Vorwurf zutrifft. Die Tatsache, dass der Schuldezernent die Nagelung eines von der Lutherschule selbst angefertigten Schildes genehmigt hatte, die Spenden in Höhe von mehr als 1.100 Mark ergab, spricht jedoch gegen die Kritik des Vereins „Jugendspende“. Noch geringer waren die Spenden für den ,Jugenddank“ in der Stadt Hannover, denn bis Januar 1917 war als einzige Schule Hannovers die Schillerschule dem Verein beigetreten, wie in dem Rechenschaftsbericht des Vereins für 1916 steht. Da insgesamt 41 Schulen der Provinz Hannover lediglich

\footnotetext{
${ }^{1438}$ Die Ergebnisse für Hannover beruhen auf den Forschungen von Gerhard Schneider und eigenen Recherchen (Schneider, Über hannoversche Nagelfiguren im Ersten Weltkrieg [1996]), für Flensburg auf den von Harald Hohnsbehn (Hohnsbehn, Die Flensburger Schuljugend in der Zeit des ersten Weltkriegs [1996], S.192-194), für den Landkreis Lübbecke auf den von Heinz-Ulrich Kammeier (Der Landkreis Lübbecke) und für Berlin auf eigenen Untersuchungen.

${ }^{1439}$ Wie aus einem Schreiben des Schulamtes vom 5. Februar 1919 an die königliche Regierung hervorgeht, sind allerdings an der Stadttöchterschule II Am Clevertor neun „Holzschilder zum Besten der Jugendspende für Kriegerwaisen (Essen)" benagelt und ein Erlös in Höhe von 976 Mark an den Verein überwiesen worden; siehe: StAH, HR 16, Nr. 553.

${ }^{1440}$ Zitiert nach: Schneider, Über hannoversche Nagelfiguren im Ersten Weltkrieg (1996), S. 251-253.
} 
979,22 Mark an den Verein „Jugendspende“ überwiesen haben, wird der Betrag aus der Stadt Hannover für den „Jugenddank“ ebenfalls ziemlich niedrig gewesen sein. Zwar sammelten ein Jahr später insgesamt 109 Schulen der Provinz Hannover 2.605,82 Mark an Spendengeldern für die „Jugendspende“ ein, die Schulen der Stadt Hannover werden aber wieder nur relativ wenig zu der Summe beigesteuert haben. Dass das Interesse an den hannoverschen Schulen an der Arbeit des „Jugenddank“ wohl ziemlich gering war, geht auch aus der Tatsache hervor, dass, anders als in der Regel in den anderen Provinzen, keiner der beiden Obmänner der „Vertreter-Ausschüsse“ aus Hannover als der Provinzhauptstadt stammte, sondern aus Aurich und Osnabrück. ${ }^{1441}$ Vielleicht waren die Lehrer durch andere Aktionen bereits stark belastet und engagierten sich deshalb weniger bei den Schildnagelungen. ${ }^{142}$ Dieses könnte auch die „schroff ablehnende Haltung“ des Schuldezernenten (s. o.) erklären, die der Verein „Jugendspende“ ihm vorwarf.

Insgesamt kann festgestellt werden, dass in Hannover - wie sicher auch in einer Reihe anderer Kommunen - relativ wenige Schilde der Firma Glasmachers genagelt worden sind.

Nagelaktionen sind jedoch auch bei den Schülern dieser Dörfer und Städte recht beliebt gewesen, wie z. B. in Hannover die große Spendensumme der Lutherschule zeigt. ${ }^{1443}$

\subsubsection{Individuelle schuleigene Nagelobjekte}

\section{Motive kleinerer Objekte}

\section{Eisernes Kreuz}

Anfang 1917 stellte Hans Sachs, der Gründer des „Vereins der Plakatfreunde“ in Berlin, in einem sehr kritischen Aufsatz („Vom Hurrakitsch“) fest, dass beinahe jede Schulklasse ihr eigenes Wahrzeichen habe. ${ }^{1444}$ Damit meinte er nicht nur die Nagelschilde, die die Vereine „Jugendspende“und „Jugenddank“ oder die Wohlfahrtsverbände vertrieben, sondern auch die vielfältigen Nagelobjekte, die die Schulen selbst entwarfen, herstellten, teilweise feierlich einweihten und benageln ließen.

Um Schulen zu eigenen Nagelungen anzuregen oder denen, die sie bereits planten, bei der Realisierung zu helfen, erschien 1916 die 72seitige Veröffentlichung „Eiserne KreuzNagelungen zum Besten der Kriegshilfe und zur Schaffung von Kriegswahrzeichen;

\footnotetext{
1441 Jugenddank für Kriegsbeschädigte e.V., Jahresberichte 1917 und 1918 (1917 und 1918), S. 10.

1442 Auch in Husum waren aus Sorge vor einer Überforderung der Schüler Schildnagelungen nicht genehmigt worden; siehe: Chronik Husum, S.7; zitiert nach: Pust, „Vaterländische Erziehung" für „Höhere Mädchen" (2004), S. 410.

${ }^{1443}$ Siehe: Abschnitt 7.2.6; die Nagelung eines Schildes in der Oberrealschule ,An der Lutherkirche' in Hannover (heute Gymnasium Lutherschule) zugunsten der schwer verwundeten Soldaten hatte 1.100 Mark erbracht.

${ }^{1444}$ Sachs, Vom Hurrakitsch, Das Plakat, 1917, S. 3.
} 
Gebrauchsfertiges Material f. vaterländ. Volksunterhaltung durch Feiern in Schulen““ ${ }^{1445}$ Sie enthält neben Vorschlägen zur Gestaltung der Einweihungsfeier, Weihereden, Nagelsprüchen, Weihekarten u. a. auch eine „Anweisung zur Herstellung des Nagelungs-Kreuzes“. Beigefügt war ein Bauplan für ein Kreuz mit einer Größe von 34 x 34 cm, das 160 Nägeln Platz bieten sollte. Als Alternative wurde ein Kreuz mit 40 x $40 \mathrm{~cm}$ für 200 Nägel angegeben. Auch die Vermittlung ,sachgemäße[r] Anfertigung von Holzkreuzen und die rechtzeitige Übersendung geeigneten Nagelmaterials“"1446 wurde angeboten. Die beiden Autoren wiesen anhand eines Zitats aus einer Festrede, die 1916 anlässlich einer Nagelung gehalten worden war, auf die Bedeutung des Eisernen Kreuzes hin: „In einzigartiger Weise verknüpfen sich (...) soldatische Frömmigkeit und christliche Vaterlandsliebe. “1447

Ob tatsächlich der christlich-religiöse Bedeutungsinhalt für die Auswahl des Nagelmotivs von Bedeutung war und inwieweit die Schulen die Anregungen nutzten, ist zwar nicht bekannt, offensichtlich spielte aber die Gründungsgeschichte der Kriegsauszeichnung für die Auswahl des Motivs eine wichtige Rolle. Durch den Bezug zu den Freiheitskriegen sollte propagiert werden, dass Deutschland sich in einem Freiheitskampf befinde, für den jeder Opfer bringen müsse. Wahrscheinlich gab es deshalb recht viele schulische Kreuz-Nagelungen. Dass das Motiv des Eisernen Kreuzes offensichtlich recht beliebt war, geht schon aus der Tatsache hervor, dass O. Ostrowski sich in einem Artikel im Deutschen Philologenblatt vom 15. September 1915 („Wir haben aber kein Eisernes Kreuz genagelt ${ }^{\star 1448}$ ) von den offensichtlich weitverbreiteten Kreuz-Nagelungen abgrenzte. Als Direktor des Lyzeums in BerlinLankwitz wird er durchaus über die Nagelungen an anderen Schulen informiert gewesen sein. Diese Annahme wird durch einen Hinweis eines Heimatmuseums bestätigt: „Das häufigste Symbol war das Eiserne Kreuz [...], das auch von den Korntaler Schulen ausgesucht wurde. “1449 Da der an der genannten Schule durch die Nagelung eingenommene Betrag in Höhe von 300 Mark an das Rote Kreuz Bulgarien als Weihnachtsgabe geschickt wurde, kann ausgeschlossen werden, dass es sich um einen Schild von „Jugendspende“ oder „Jugenddank“

\footnotetext{
${ }^{1445}$ Fitzke/Matzdorf, Eiserne Kreuz-Nagelungen zum Besten der Kriegshilfe und zur Schaffung von Kriegswahrzeichen (1916). Das Eiserne Kreuz (EK) war eine ursprünglich preußische Kriegsauszeichnung, die vom preußischen König Friedrich Wilhelm III. im Jahre 1813 gestiftet und dann von dem Deutschen Reich übernommen wurde. Das Motiv geht auf den Deutsche Orden zurück, der einerseits durch das Kreuzesmotiv seine christliche Prägung betonen und sich andererseits durch das gewählte schwarze „Tatzenkreuz“ von anderen Ritterorden abgrenzen und unterscheiden wollte. Das EK symbolisiert die Verknüpfung von Kirche, Militär und Patriotismus.

${ }^{1446}$ Fitzke/Matzdorf, Fitzke, Eiserne Kreuz-Nagelungen zum Besten der Kriegshilfe und zur Schaffung von Kriegswahrzeichen (1916), S.10.

${ }^{1447}$ Fitzke/Matzdorf, Eiserne Kreuz-Nagelungen zum Besten der Kriegshilfe und zur Schaffung von Kriegswahrzeichen (1916), S. 15.

${ }^{1448}$ Ostrowski, Eine neue Anregung (1915), S. 539.

${ }^{1449}$ Heimatmuseum Münchingen, „Sonst geht es mir gut" - Korntal und Münchingen im Ersten Weltkrieg, http://www.korntal-muenchingen.de/kultur_veranst/heimatmuseum.htm (07.10.2007).
} 
handelte. Auf die früheste Kreuznagelung, die bereits am 2. November 1914 in der KaiserinAuguste-Viktoria-Schule in Schneidemühl (Provinz Posen) stattfand, ist bereits oben hingewiesen worden ${ }^{1450}$. Die Höhe der Einnahmen wird nicht erwähnt. ${ }^{1451}$

Häufig wurde der Geburtstag des Kaisers zum Anlass für Nagelungen genommen ${ }^{1452}$, wie z. B. in Boostedt (Provinz Schleswig-Holstein): „Am 27. Januar 1916, dem Geburtstag des letzten deutschen Kaisers, wurde in der Schule die Benagelung eines Eisernen Kreuzes vorgenommen. Die Nagelung ergab 157,30 Mark. Davon wurden für 133,45 Mark Pakete an die Front geschickt.“" ${ }^{1453}$ Den gleichen Termin für die Nagelung wählten die „Weidaer Schuljugend “1454 und der Rosengartner Gesamtschulverband (Provinz Schlesien), der zwei Nageltafeln mit dem Motiv des Eisernen Kreuzes herstellen ließ und die Spendenaktion einem Lehrer übertrug. Die Aktion, die über das Kriegsende hinausging, endete am 22. März 1919 und ergab eine Summe von 57,01 Mark. ${ }^{1455}$ Über einige Nagelungen von Kreuzen bzw. Schilden mit dem Kreuzmotiv liegen als Quelle lediglich von der Schule selbst gestaltete und vertriebene Ansichtskarten vor. ${ }^{1456}$ So zeigt eine Karte von „De Schooljungs von Steenhauserdamm“ in Hamburg ein großes Eisernes Kreuz und enthält ein Gedicht in niederdeutscher Sprache. ${ }^{1457}$ Der Ertrag der Nagelung des Kreuzes in Höhe von 418,11 Mark und der Reinerlös aus dem Verkauf der Karten wurden der Hamburgischen Kriegshilfe zur Verfügung gestellt. In einer anderen Hamburger Schule, dem Heinrich Hertz-Realgymnasium, nagelte eine Klasse (O IIIa) eine Tafel mit einem Eisernen Kreuz sowie mit einem Adler darüber und vertrieb eine farbige Ansichtskarte. ${ }^{1458}$ Die Nageltafel hatte ein Schüler angefertigt und das Gedicht auf der rechten Seite stammte ebenfalls von einem Schüler.

Auch in Neukölln gab es eine „Eisern Kreuz-Nagelung“, wie eine Ansichtskarte, die „Neuköllns Kriegsdank an seine Heldensöhne“ vertrieb, zeigt. Dargestellt sind eine Schülerin, die eine Spende in eine Opferbüchse des Roten Kreuzes wirft, und ein Schüler, der einen Nagel in ein Eisernes Kreuz schlägt. Aus dem patriotischen vierstrophigen Gedicht von Joh.

Bergknecht geht hervor, dass „Dies Kreuz, [das] Kinderhände einst aufgerichtet / Für die Helden, die wir ehren und lieben. “" ${ }^{459}$ Anscheinend hatte eine Schule das Nagelkreuz errichtet.

\footnotetext{
${ }^{1450}$ Siehe: Anfang des Kapitels 7.

${ }^{1451}$ Mihaly, ... da gibt's ein Wiedersehn! (1986), S. 94f.

${ }^{1452}$ Siehe: Kapitel 5.2.

${ }^{1453}$ Jaensch, Boostedt und der Erste Weltkrieg, http://www.forgottenplaces.de/boostedt03g.htm (16.11.2004).

${ }^{1454}$ Siehe: Kapitel 5.2.1.

${ }^{1455}$ Stadtarchiv Frankfurt (Oder), Vom „Eisernen Kreuz" von Rosengarten, http://www.frankfurtoder.de/data/stadtarchiv/aktuell/ablage/nagelbld/nbld1.htm (25.03.2009).

${ }^{1456}$ Siehe: Anhang, Seite 89.

${ }^{1457}$ Siehe: Anhang, Seite 89, Bild 7.

1458 Siehe: Anhang, Seite 89, Bild 6.

${ }^{1459}$ Siehe: Anhang, Seite 89, Bild 3.
} 
Dass auch in katholischen Privatschulen eiserne Kreuze benagelt wurden, zeigt die Nagelung an der Mädchenschule in Marienberg (Bistum Köln). Dort wurde am 21. Oktober 1915 das „erste Kriegswahrzeichen der Schule ... ein schlichtes eisernes Kreuz“ von der Oberin des Hauses eingeweiht ${ }^{1460}$.

\section{Bilder, Granaten, Schwerter und andere Motive}

Am meisten verbreitet waren Nagelschilde und -bilder, da die Herstellung relativ einfach und preiswert war. Sehr ausführlich beschrieb O. Ostrowski, Direktor eines Lyzeums in BerlinLankwitz, die Nagelung in seiner Schule. Benagelt wurde ein „Hindenburgbild“: „Drei Stunden dauerte [am ersten Tage] die lustige Hämmerei, eiferten die begeisterten Kinder um die Wette an der Verzierung des Rahmens“ ${ }^{1461}$. Bei der Sammlung kamen 102 Mark zusammen. Auch an einem Lyzeum in Hamburg unterstützte der Schulleiter, Jakob Loewenberg, die schuleigene Nagelung. In seinem Kriegstagebuch (28. Oktober 1915) berichtete er detailliert über die Aktion. Dabei ist bemerkenswert, dass die Zeichenlehrerin, die das Nagelobjekt herstellte, kein patriotisches Symbol wählte, sondern ,ein viereckiges Holzschild, darauf ein Spaten vor einer aufgehenden Sonne ${ }^{\text {1462 }}$. Eine Ansichtskarte gibt über die Nagelung eines Kriegswahrzeichens der 26. Volksschule im Rhiemsweg in Hamburg Aufschluss. ${ }^{1463}$ Die Erstnagelung des Schildes mit dem Hamburger Wappen am 27. März 1916 war sehr erfolgreich, denn die 2.300 eingeschlagenen Nägel erbrachten 600 Mark.

Auch die Nagelung eines Schildes in der Oberrealschule ,An der Lutherkirche' in Hannover (heute Gymnasium Lutherschule) war finanziell ein großer Erfolg, denn die Spende zugunsten der schwer verwundeten Soldaten betrug 1.100 Mark. In seinem Bericht über die Kriegsjahre 1915-1917 an die Stadtverwaltung schrieb der Direktor:

„Um auch für die kommenden Geschlechter unserer Anstalt die Erinnerung an die große Zeit festzuhalten, machte ich den Vorschlag, einen Schild zu nageln und fand damit bei Lehrern und Schülern großen Anklang. Zeichenlehrer Becker fertigte den Entwurf an und leitete in dankenswerter Weise die Nagelung, die in kurzer Zeit den Betrag von 1100M. brachte, der für schwerverwundete Krieger bestimmt ist. Jetzt ist der Schild Hauptschmuck unsers [!] schönen Treppenhauses. “1464

Über die Schildnagelung im Husumer Lyzeum ist nur bekannt, dass die Schülerinnen ein „Gedenkzeichen zum Besten armer Kriegerwaisen“ nagelten, das selbst entworfen worden

\footnotetext{
1460 Chronik der Schule Marienberg nach den vorhandenen Unterlagen, http://www.erzbistumkoeln.de/export/sites/erzbistum/schule/marienberg/_galerien/download/Chronik_der_Schule_Marienberg_nach den_vorhandenen_Unterlagen.pdf (13.11.2007).

${ }_{1461}$ Ostrowski, Eine neue Anregung (1915), S. 538f.

${ }^{1462}$ Loewenberg, Kriegstagebuch einer Mädchenschule (1916), S. 93f.

${ }^{1463}$ Entworfen von Prof. C.O. Czeschka, fotographiert am 23. Oktober 1915; siehe: Anhang, Seite 89, Bild 1.

1464 Zitiert nach: Schneider, Über hannoversche Nagelfiguren im Ersten Weltkrieg (1996), S. 250f.; siehe: Anhang, Seite 90, Bild 2.
} 
war, und dass der Reinerlös 100 Mark betrug. ${ }^{1465}$. Auch die Höhere Mädchenschule in Alzey (Ghzgt. Hessen) und die Emil-Nolde-Schule in Bargteheide (Provinz Schleswig-Holstein) nagelten Schilde: jene ein „Ehrenschild“ (Erstnagelung am 26. Januar 1917) ${ }^{1466}$ und diese ein „Kaiserinnenschild“1467, das Platz bot für 568 Nägel. Das Ergebnis der Erstnagelung in Bargteheide am 12. Februar 1916 war ein Reingewinn von 100 Mark für die 286 eingeschlagenen Nägel. ${ }^{1468}$

Gerne wurden von den Schülern Schilde mit kriegerischen Motiven benagelt, und zwar vor allem „Granaten“"1469, „Stahlhelme“ und „Schwerter“.

Dass Schüler Nagelungen nicht nur anregten, sondern auch selbst die Nagelobjekte herstellten bzw. stifteten, kam nur selten vor. Im Bericht der Großherzoglichen Realschule in Langen (Ghzgt. Hessen-Darmstadt) über das Schuljahr 1915/16 wird allerdings von einer solchen Spende berichtet: „Der Quartaner Max Herchenröder stiftete aus den Mitteln seiner Sparbüchse ein Holzschwert zur Nagelung. Das Einschlagen der Nägel in das Kriegswahrzeichen erbrachte das Ergebnis von 160 Mark, einhundert davon erhielt die Kriegsfürsorge, die Restsumme wurde der sogenannten Jubiläumsspende - sie diente ebenfalls einem ,vaterländischen’ Zweck - zugeführt. “'1470

Insgesamt kann festgestellt, dass neben dem Eisernen Kreuz fast ausschließlich Kriegsmotive für die schuleigenen Nagelfiguren verwendet wurden. Damit wollte man in erster Linie die Verbundenheit der schulischen „Heimatfront“ mit den Soldaten an der militärischen Front zum Ausdruck bringen.

Dass im Unterschied zu den weitverbreiteten Nagelschilden der Firma Glasmachers individuelle Nagelobjekte teilweise von Schülern mit angeregt und sogar hergestellt worden sind, hat sicher zu den insgesamt höheren Spendeneinnahmen beigetragen. Aus den vorliegenden Unterlagen geht ferner hervor, dass die Schüler sich durchgehend gern an den Nagelungen beteiligt und größtenteils sogar begeistert mitgemacht haben.

\footnotetext{
1465 Chronik Husum, S.7; zitiert nach: Pust, „Vaterländische Erziehung" für „Höhere Mädchen” (2004), S. 410.

${ }^{1466}$ Auskunft durch Gerhard Schneider.

1467 Über das außergewöhnliche Motiv konnte nichts Näheres in Erfahrung gebracht werden. Dem Verfasser ist kein Kriegswahrzeichen bekannt, das der Kaiserin gewidmet ist oder auf sie Bezug nimmt.

1468 Burmester/Rühle, Die Kaiserzeit (1887-1918), http://www.emil-nolde-schule.de/altschul/inhalt.htm (09.10.2007)

1469 Als Beispiele sein genannt: „Granate als Kriegswahrzeichen“ in Wirges [Rheinprovinz] (Der Schulleiter, Chronik der Wirgeser Schule [o. J])., „Erinnerungs-Granate“ in Klingelbach [heute Katzenelnbogen, Rheinprovinz] ( http://www.vg-katzenelnbogen.de/buch2/15.htm [10.10.2007]), „Stahlhelm“ in Schweidtnitz [Provinz Schlesien] (Adler, Chronologischer Abriß der Stadt Schweidnitz von 1243 bis 1918, http://www.horstadler.de/Schweidnitz_1243-1918.pdf [08.07.2008], S. 24), ein „Hindenburg-Schwert“ in Bonn (Jugendspende für Kriegerwaisen, Die Lehrerin: Organ des Allgemeinen Deutschen Lehrerinnenvereins 1917, S. 13), eine „Kriegskarte“ in Aschendorf [Provinz Hannover] (Osnabrück, Ems-Zeitung, 7. September 1915).

${ }^{1470}$ Der Schulleiter, Bericht der Großherzoglichen Realschule über das Schuljahr 1915/16 (1916).
} 


\section{Standbilder}

Da man kleinere Wahrzeichen leichter und preiswerter herstellen bzw. erwerben konnte, gab es nur ziemlich wenige Schulen, die große Nagelungs-Standbilder aufstellten. Zwei Beispiele sollen hier angeführt werden:

Über den Eisernen Hindenburg-Roland in Jüterbog (Provinz Brandenburg), der selbst nicht erhalten geblieben ist, wissen wir durch eine ,Nagelungsurkunde', eine ,'Einladung zur Nagelung' und das ,Eiserne Nagelbuch', das sich heute im Stadtmuseum Jüterbog befindet, Bescheid. ${ }^{1471}$ Ein Jüterboger Bürger hatte der Königlichen Schillerschule ein 2,60 m hohes Denkmal, geformt aus Jüterboger Linde, geschenkt. Dieses wurde auf dem Schulhof „den gefallenen Helden zum Gedächtnis, den Hinterbliebenen zum Trost und zur Unterstützung der Jugend, unserer Zukunft und unserem Stolz, zur Nacheiferung" aufgestellt und am 21. Oktober 1916 eingeweiht.

Die Figur war dem alten Schutzpatron der Stadt, dem Heiligen Mauritius, der oft auch als Roland bezeichnet wird und dessen Steinfigur sich am Rathaus befindet, nachgebildet; sie trug allerdings die Gesichtszüge Hindenburgs. Der Einheitspreis für den Nagel betrug 50 Pfennig; die auf den Namen des Spenders ausgestellte Urkunde kostete 10 Pfennig. Der Ertrag der Sammlung war für die Angehörigen der im Krieg gefallenen Jüterboger Bürger bestimmt. Am 24. Oktober fand eine zweite Nagelung statt. Die genaue Spendensumme und der Verbleib der Nagelfigur nach dem Ersten Weltkrieg sind nicht bekannt.

Über die Nagelung des „Eisernen Ritters“ in der Ursulinenschule in Saarbrücken gibt es detailliertere Informationen. ${ }^{1472}$ Dort wurde im Sommer 1915 in der Turnhalle der Schule eine lebensgroße Holzskulptur aufgestellt, eine „Rittergestalt mit Helm und Schild und Schwert “1473. Später fand sie ihren Platz im Portal der Schule. Die Einnahmen aus der Nagelungsaktion kamen den „Kriegerwitwen und Kriegswaisen, deutschen Kriegsgefangenen und Frontsoldaten, Kriegsversehrten und dem Roten Kreuz zugute“1474. Der Ritter diente aber nicht nur dem Einsammeln von Spendengeldern, sondern war auch ein ,,universeller , Nothelfer“ und Wohltäter in Alltagsangelegenheiten. Er hatte die Aufgabe, Zuversicht und Stärke zu

\footnotetext{
${ }^{1471}$ Morling, "Eiserner Hindenburg-Roland" (Schreiben vom 05.02.2003); siehe: Anhang, Seite 91, Bilder 1-3. ${ }^{1472}$ Briel, Aus der Chronik der Ursulinenschule, Saarbrücken, 1895-1938 (1938). Es gibt keine Hinweise darauf, dass es sich bei der Figur um ein allgemeines Nagelobjekt gehandelt hat, für das man die Schule als geeigneten Aufstellungsort gewählt hat.

${ }^{1473}$ Jung, Der „Eiserne Ritter“ der Ursulinenschule, in „Als der Krieg über uns gekommen war..." Die Saarregion und der Erste Weltkrieg; Katalog des Regionalgeschichtlichen Museums im Saarbrückener Schloss (1993); siehe: Anhang, Seite 91, Bilder 4 und 5.

${ }^{1474}$ Briel, Aus der Chronik der Ursulinenschule (1938), S. 21.
} 
vermitteln, an ,deutsche Tugenden' zu erinnern und die Opferbereitschaft der Kinder und Jugendlichen zu fördern.“"1475

Auch wenn keine konkreten Angaben über die Gesamtsumme der Nagelspenden vorliegen, so kann davon ausgegangen werden, dass die Einnahmen erheblich waren, denn der in der Ausstellung „Als der Krieg über uns gekommen war“ (1993) gezeigte Ritter war vollbenagelt. ${ }^{1476}$

\subsubsection{Einweihungsfeiern und Ablauf der Nagelungen}

Über den Ablauf der Nagelungen in den Schulen liegen nur wenige detaillierte Berichte vor, doch lassen diese den Schluss zu, dass die Feiern sich nur unerheblich voneinander unterschieden. Dafür spricht u. a., dass den Schulen ,gebrauchsfertiges Material für vaterländische Volksunterhaltung durch Feiern“1477 zur Verfügung gestellt und sicher auch von diesen benutzt wurde. Die ersten neun Kapitel beschäftigen sich auf 74 Seiten mit der Planung von „Nagelungs-Feiern“; z. B. enthält das dritte. Kapitel einen Mustervorschlag für eine „Festfolge“ und das vierte. für eine „Weiherede“.

Zwar werden, wie die vorliegenden Quellen zeigen, die meisten Schulfeiern bei Weitem nicht so aufwendig durchgeführt worden sein, wie es die Vorschläge von Fitzke und Matzdorf in den Materialien vorsahen, sie entsprachen ihnen allerdings in wichtigen Punkten. In der Regel gehörten zum Programm von Einweihungsfeiern, an denen die ganze Schulgemeinschaft teilnahm, musikalische Beiträge (meistens Chorgesang), Gedichtvorträge, eine Weiherede durch den Schulleiter oder einen Lehrer, Nagelung mit Nagelsprüchen und der Eintrag in die Spenderliste. In welchem Umfang auch die vorgeschlagene Aufführung eines Festspiels (z. B. „Das schwarze und das rote Kreuz") tatsächlich realisiert worden ist, ist nicht bekannt; sie dürfte jedoch wegen des großen unterrichtlichen und organisatorischen Aufwands in der auch für die Schulen schwierigen Kriegszeit die absolute Ausnahme gewesen sein. Dass es solche Aktionen gegeben hat, zeigt die unten beschriebene „Hohenzollernfeier“ in Neuß (Rheinprovinz).

Im Folgenden soll eine Nagelfeier der Höheren Mädchenschule zu Neuß näher untersucht werden, die in ähnlicher Weise in vielen Schulen ablief, und zwar vor allem in Mädchenschulen. Gerade die älteren Mädchen engagierten sich oft in besonderem Maße im Rahmen der „Heimatfront“, während viele gleichaltrige ältere Schüler die Gymnasien verlassen hatten und Soldaten geworden waren. In Neuß nahm die Höhere Mädchenschule die „Hohenzollernfeier

\footnotetext{
1475 Jung, Der „Eiserne Ritter“ der Ursulinenschule (1993), S. 76; Heute steht die Figur im Regionalgeschichtlichen Museum im Saarbrücker Schloss.

${ }^{1476}$ Siehe: Anhang, Seite 91, Bilder 4 und 5.

${ }^{1477}$ Fitzke/Matzdorf, Eiserne Kreuz-Nagelungen zum Besten der Kriegshilfe und zur Schaffung von Kriegswahrzeichen (1916).
} 
(500 Jahre Hohenzollern)“ am 20./21. Oktober 1915 zum Anlass, ihr Kriegswahrzeichen feierlich einzuweihen. Die Neuß-Grevenbroicher Zeitung berichtete über die Feier:

"Gestern abend schon hatte die Schule Marienberg ihre Zöglinge zu einer schönen und erhebenden Feier versammelt, der auch viele Angehörige der Kinder beiwohnten. Hübsche Gedichte und Vorträge wechselten mit recht gut zum Vortrag gebrachten echt patriotischen Chören. Besondere Erwähnung dürfte vor allem der 2. Akt aus dem Schauspiel ,Kolberg' von Paul Heyse verdienen, der von den Schülerinnen mit wahrem Empfinden und echtem vaterländischen Feuer vorgetragen wurde. Am Schlusse hielt der hochwürdige Rektor Emonds die Festrede ..." ${ }^{\text {‘478 }}$

Noch feierlicher ging es am nächsten Tag zu, wie der Schulchronik zu entnehmen ist:

„Am Morgen des 21. Oktober findet ein feierliches Hochamt statt, danach Versammlung im großen Saal: das erste Kriegswahrzeichen der Schule soll benagelt werden, ein schlichtes eisernes Kreuz. Eingeleitet wird die Feier durch patriotische Gesänge und kleinere Gedichte. Herr Religionslehrer Louis weist auf die Bedeutung des Eisernen Kreuzes und den Zweck der Zusammenkunft hin. Er zeigt das vorläufig noch hölzerne Kreuz, das durch die Opferfreudigkeit der Marienberger Schülerinnen zu einem eisernen werden soll. Alsdann folgt die Nagelung. Unter dem Jubelruf der Schülerinnen treibt die Schwester Oberin des Hauses, Mutter Alexa, den ersten Nagel ein. Es folgen die Direktorin und die Lehrer und Lehrerinnen des Kollegiums. Ihnen reihen sich die Schülerinnen an. Gegen elf ein halb fällt der letzte Hammerschlag. Die ungefähr zwei Stunden dauernde Nagelung hatte $124 \mathrm{M}$ erbracht.“”

Obwohl nichts über den Inhalt der Weiherede bekannt ist, kann gleichwohl angenommen werden, dass sie wie viele andere solcher Reden einer Predigt ähnelte. Vielleicht ist der Religionslehrer der Anregung von Paul Fitzke und Benno Mardorf gefolgt und hat das Eiserne Kreuz als Verknüpfung „,von soldatischer Frömmigkeit und christlicher Vaterlandsliebe“ gedeutet. ${ }^{1479}$ Dass der Nagelung ein feierliches Hochamt vorausging, ein Religionslehrer die Weiherede hielt und die Oberin selbst den ersten Nagel einschlug, zeigt den pseudoreligiösen Charakter der Veranstaltung.

Feierlich ging es auch in der Emil-Nolde-Schule bei der Nagelung des „Kaiserinnenschildes“ am 12. Februar 1916 in Bargteheide zu:

„Mit dem Lied ,Ich habe mich ergeben“ wurde die Feier eingeleitet. Darauf hielt der Rektor eine längere Ansprache, die mit einem Hurra auf Volk, und Vaterland, auf Heer und Heeresführer und auf den obersten Kriegsherrn, unseren geliebten Kaiser und König endete. Hierauf wurde von allen Anwesenden das Lied ,O Deutschland hoch in Ehren' gesungen, und nun begann die Nagelung. Das Lehrerkollegium und die größeren Schulkinder schlugen die Nägel ein, wobei die Hammerschlägen von patriotischen Worten begleitet waren." ${ }^{\text {"1480 }}$

\footnotetext{
1478 Chronik der Schule Marienberg nach den vorhandenen Unterlagen, http://www.erzbistumkoeln.de/export/sites/erzbistum/schule/marienberg/_galerien/download/Chronik_der_Schule_Marienberg_nach_ den_vorhandenen_Unterlagen.pdf (13.01.2007).

${ }^{1479}$ Fitzke/Matzdorf, Eiserne Kreuz-Nagelungen zum Besten der Kriegshilfe und zur Schaffung von Kriegswahrzeichen (1916), S. 15.

${ }^{1480}$ Burmester/Rühle, Die Kaiserzeit, (1887-1918), http://www.emil-nolde-schule.de/altschul/inhalt.htm (09.10.2009).
} 
Insgesamt lässt sich trotz der schlechten Quellenlage feststellen, dass die Schulen die patriotischen Einweihungsfeiern teilweise in Verbindung mit Gedenkfeiern sehr sorgfältig planten und unter Einbeziehung der gesamten Schulgemeinschaft durchführten. Sie waren ein Höhepunkt im Schuljahr. In ihrem Ablauf unterschieden sie sich insgesamt kaum von den öffentlichen Nagelfeiern. Patriotische oder kirchliche musikalische Beiträge, Gedichtvorträge, eine Weiherede, Nagelung mit Nagelsprüchen, der Eintrag in die Spenderliste und das Kaiserhoch am Ende waren die wichtigsten Elemente sowohl der schulischen als auch der öffentlichen Nagelfeiern. Während das militärische Zeremoniell mit Aufmarsch, Fahnen und Militärkapellen bei den schulischen Feiern fehlte, handelte es sich bei ihnen genau wie bei den allgemeinen Feiern um quasi-religiöse Weiheakte.

Über die Verwendung der von den Schülern aufgebrachten Spendengelder wird selten etwas gesagt. Wie die erwähnten Beispiele dokumentieren, wurden die Spendengelder in vielen Fällen der kommunalen Kriegsfürsorge oder dem Roten Kreuz zur Verfügung gestellt, z. B. in Wirges (Rheinprovinz) ${ }^{1481}$ und Saarbrücken (Rheinprovinz) ${ }^{1482}$. Daneben wurden die Erlöse auch „zu Kriegszwecken“ verwendet, z. B. in Schneidemühl ${ }^{1483}$ oder in Langen (Ghzgt. Hessen-Darmstadt) ${ }^{1484}$. Wie in Langen teilte man manchmal auch die Einnahmen auf und ließ sie sowohl der Kriegsfürsorge als auch militärischen Stellen zukommen. Dass mit den Spenden allerdings Waffen und anderes Kriegsgerät finanziert wurden, wie die Quellen vermuten lassen, ist wenig wahrscheinlich, denn anscheinend waren sie ebenfalls „den Kriegsarmen zur Hilfe $^{1485 ، ~}$ bestimmt, wie z. B. der Bürgermeister bei einer Nagelfeier in Schneidemühl betonte.

Da die meisten Quellen zum Ablauf der Feiern von Schulleitern, Lehrern oder der Presse stammen und nur ganz wenige authentische Schüleräußerungen vorliegen, ist die Frage nach der Akzeptanz bei den Schülern nur schwer zu beantworten. Während die Saarbrücker Schülerin offensichtlich begeistert ist, wie aus den Tagebuchaufzeichnungen hervorgeht, beschreibt Elfriede Kuhr die Nagelung sehr sachlich. Aus der Tatsache, dass die Schüler in Goslar außerordentlich hartnäckig Spenden für die Nagelung sammelten, kann man schließen, dass sie vom Sinn ihrer Aufgabe überzeugt waren. ${ }^{1486}$ Da keine zeitgenössische Schüleräußerung und keine Erinnerung eines Zeitzeugen kritische Bemerkungen zu den Nagelungen enthalten, kann davon ausgegangen werden, dass sie allgemein auf große Akzeptanz der Schüle-

\footnotetext{
${ }^{1481}$ Der Schulleiter, Chronik der Wirgeser Schule (o.J.) S. 311.

${ }^{1482}$ Briel, Aus der Chronikder Ursulinenschule (1938), S. 21.

${ }^{1483}$ Mihaly, ... da gibt's ein Wiedersehn! (1986), S. 94. Aus der Textstelle geht nicht hervor, für welche „Kriegszwecke" die Spenden verwendet wurden.

${ }^{1484}$ Der Schulleiter, Bericht der Großherzoglichen Realschule über das Schuljahr 1915/16 (1916), S. 194.

${ }^{1485}$ Mihaly, ... da gibt's ein Wiedersehn! (1986), S. 189.

${ }^{1486}$ Siehe: 7.3.1, erster Absatz.
} 
rinnen und der Schüler stießen. Dass von Lehrern und Schulleitern sowie der Presse keine kritischen Äußerungen erfolgten, ist verständlich, aber wäre die Beschreibung der großen Begeisterung der Kinder bei den Nagelungen so euphorisch ausgefallen, wenn viele Schülerinnen und Schüler nur widerwillig und lustlos genagelt hätten? Der Erfolg der Schildnagelungen zugunsten der „Jugendspende“ und des ,Jugenddanks“ beispielsweise dürfte nur deshalb so groß gewesen sein, weil das gemeinschaftliche Benageln der bunten Schilde ganz offensichtlich dem Bedürfnis der Schülerinnen und der Schüler entsprach. Allein der Akt des Nägeleinschlagens und das feierliche Gemeinschaftserlebnis haben bei den Kindern sicher großen Eindruck hinterlassen und sie in ihrem Bemühen bestärkt, ihren Beitrag an der „Heimatfront" ${ }^{\text { }} \mathrm{zu}$ leisten und die Folgen des Krieges zu mindern. ${ }^{1487}$

Über die feierlichen Einweihungen von Nagelschilden, wie sie die Firma Glasmachers herstellte, geben die vorhandenen Quellen keinen Aufschluss. Hohnsbehn vermutet für die Flensburger Schulen, dass an Schulen, die nicht für jede Klasse ein Nagelbild anschafften, die vorhandenen Exemplare im Eingangsbereich oder vor dem Lehrerzimmer aufgestellt wurden und die Schüler dort in den Pausen Nägel kaufen und einschlagen konnten. Es sei aber auch denkbar, dass die Schilde von einer Klasse zur anderen weitergereicht wurden. ${ }^{1488}$

\subsection{Beteiligungen der Schulen an allgemeinen Nagelaktionen}

Bei nahezu allen Nagelaktionen der Gemeinden waren die Schulen durch die Direktoren, die Lehrerschaft sowie die Schüler in vielfacher Weise beteiligt. In diesem Abschnitt soll ihre Rolle näher untersucht werden. Im Unterschied zu den schuleigenen Nagelungen ist die Quellenlage deutlich besser, da die Presse über die Nagelaktionen der Kommunen häufig und meistens sehr detailliert berichtet hat.

\subsubsection{Schulleiter und Lehrer in Arbeits- und Festausschüssen}

Am Anfang jeder Nagelaktion stand die Gründung eines „Festausschusses“"1489, dessen Vorsitzender in der Regel der Ortsbürgermeister war. Es kam allerdings auch vor, dass Schulleiter den Ausschüssen vorstanden, wie z. B. der Zwickauer „Schuldirektor i. R. Becker“ (Nagelung des „Eisernen Roland“). ${ }^{1490}$ Die Ausschüsse, die dann häufig noch Unterausschüsse bildeten, kümmerten sich vor allem um Herstellung und Finanzierung des Kriegswahrzeichens, den

\footnotetext{
${ }^{1487}$ Sicher gab es durchaus aus Schüler, die sich nicht freiwillig an den Nagelungen beteiligt haben, denn. da es sich dabei um Schulveranstaltungen handelte, dürften Verweigerungen und Abstinenz kaum vorgekommen sein.

1488 Hohnsbehn, Die Flensburger Schuljugend in der Zeit des ersten Weltkriegs (1996), (13.01.2005 und 14.01.2008), S. 194.

1489 Andere Bezeichnungen sind „Arbeitsausschuß“, „Ausschuss für die Nagelung“, „Komitee“ u. a.

${ }^{1490}$ Teichert/Stadtarchiv Zwickau, „Eiserner Roland" und andere Nagelfiguren, Schreiben vom 13.02.2003.
} 
Standort für die Aufstellung, den Ablauf der Einweihungsfeier, die ,Vermarktung' der Nagelungen und die Verteilung der Spendengelder. Zu den Honoratioren der Stadt, die von den Bürgermeistern zur Mitarbeit in den Ausschüssen eingeladen und die dann auch gewählt wurden, gehörten oft auch Schulleiter und Lehrer. Aus Unterlagen des Stadtarchivs Mühlhau$\operatorname{sen}^{1491}$ (Provinz Sachsen) geht beispielsweise hervor, dass der Oberbürgermeister die Leiter der dortigen Schulen gebeten hatte, dem „Ausschuss für die Nagelung“ beizutreten. Von den Schulleitern der „Georgii-Schule“, der „Petri-Volksschule“ und der „Mittelschule für Knaben“ liegen schriftliche Zusagen an den Oberbürgermeister vor.

Generell waren Lehrer und Schulleiter in den Ausschüssen stark vertreten; teilweise wurden sie sogar zu Vorsitzenden gewählt. ${ }^{1492}$ Das ist einerseits angesichts der vielen Belastungen, denen die Schulleiter während der Kriegszeit ausgesetzt waren, erstaunlich, andererseits jedoch aufgrund der patriotischen Gesinnung gerade dieser Berufsgruppe und des besonderen Interesses der Magistrate an ihrer Mitwirkung nicht verwunderlich. Da man in erster Linie die Schüler zur Teilnahme an den Nagelungen gewinnen wollte, war man in besonderem Maße auf die Unterstützung durch die Direktoren angewiesen. Das Engagement beschränkte sich allerdings keineswegs auf die Tätigkeit in Ausschüssen, sondern umfasste vielfältige andere Tätigkeiten, wie in den nächsten Abschnitten nachgewiesen wird. Bekannt sind auch außerschulische Nagelprojekte, die auf Anregung von Lehrern und Schulleitern zustande kamen. Als Beispiele seien eine Kreuznagelung aus Bad Berka (Frst. SchwarzburgSondershausen) ${ }^{1493}$, ein Patriotenkreuz aus Unterboihingen (Kgr. Württemberg) ${ }^{1494}$ und eine Eiserne Uhr aus Titisee-Neustadt (Ghzgt. Baden) ${ }^{1495}$ genannt.

Besonders kleinere Gemeinden, die die Kosten für die Herstellung der Nagelfiguren durch einen Künstler sparen wollten, griffen gern auf die Schulen zurück und ließen sie durch Zeichenlehrer gestalten. Beispielsweise entwarfen Kunsterzieher in Göppingen (Kgr. Württem-

\footnotetext{
${ }^{1491}$ StA Mühlhausen, Aktenzeichen sig. 11/425/18 fol. 81, 82, 83, 86.

1492 Als Beispiele seien Witten, wo eine Reihe von Schulleitern und Lehrern sowohl zum „Ehrenausschuss“ als auch ,zum Festausschuss“ gehörten (1916), Hagen (Der Eiserne Schmied von Hagen [1916], S. 81) und Witten (Aufruf zur Nagelung des Kriegswahrzeichens der Stadt Witten, Wittener Tageblatt, 18. Januar 1917) genannt.

${ }^{1493}$ Bad Berka gehörte zum Fürstentum Schwarzburg-Sondershausen.

${ }^{1494}$ Hergenröder, Wendlingen am Neckar (1992), S. 324; das Buch enthält auf der gleichen Seite auch ein Bild, das den Schulleiter beim Nageln des geschmückten Eisernen Kreuzes zeigt.

${ }^{1495}$ Herbner, Titisee-Neustadt( 1995), S. 212.
} 
berg) den Eisernen Barbarossa ${ }^{1496}$, in Wetter (Rheinprovinz) das Eiserne Schwert ${ }^{1497}$ und in Mühlhausen (Provinz Sachsen) das Eiserne Ehrenmal ${ }^{1498}$.

Auf die Mitarbeit von Lehrkräften beim Roten Kreuz und anderen Wohlfahrtsverbänden, die häufig vorkam, soll lediglich an einem Beispiel hingewiesen werden, und zwar das des Roten Kreuzes in Jena (Provinz Sachsen). Im Mitarbeiterverzeichnis des Ortsvereins sind für die Jahre 1914-18 19 Lehrer und Schulleiter aller Schulformen genannt. ${ }^{1499}$

\subsubsection{Einweihungsfeiern}

\section{$\underline{\text { Ablauf }}$}

Da die Einweihungsfeiern in den meisten Städten und Gemeinden ähnlich verliefen, und zwar stets aufwendig und ritualisiert ${ }^{1500}$, soll zunächst der Ablauf am Beispiel von Wismar ${ }^{1501}$ dargestellt und dann durch einige Besonderheiten ergänzt werden.

Der „Volksfestausschuss zu Wismar“ lud in einem in der Zeitung veröffentlichen Aufruf die gesamte Bürgerschaft der Stadt für den 17. Oktober 1915 nachmittags um 3 1⁄2 Uhr zur Nagelung des „Koggenwappens Wismars“ vor dem Rathause ein:

\section{„Die Festordnung ist folgende:}

Gemeinsamer Gesang: ,Wir treten zum Beten.'

Festansprache des Herrn Superintendenten Rische vom Balkon des Rathauses aus.

Gesang der Schuljugend: ,O, Deutschland hoch in Ehren.'

Feierliche Übergabe des Wahrzeichens in den Schutz des Rates der Stadt.

Die Vollziehung der ersten Nagelung.

Konzert der städtischen Musikkapelle bis zum Dunkelwerden. “1502

Vor dem Beginn der eigentlichen Veranstaltung erfolgten der in der Regel fast militärisch organisierte Aufmarsch und die Aufstellung der Schulen, Vereine und Verbände; in Wismar

\footnotetext{
${ }^{1496}$ Die Nagelung des Stadtwappens, Wertheimer Zeitung 31.01., 01.02. und 02.02.1916; Nageln für einen sozialen Zweck (1915), http://www.goeppingen.de/servlet/PB/menu/1101628_pcontent_11 /navigate1195566625218.html(18.01.2008); siehe: Anhang, Seite 94, Bild 1.

${ }^{1497}$ Thier, Das Kriegswahrzeichen von Wetter (Ruhr): die Nagelspende, das Eiserne Schwert, Schriftenreihe der Friedrich-Harkort-Gesellschaft Wetter (Ruhr) und des Stadtarchivs Wetter (Ruhr), S. 214; siehe: Anhang, Seite 94, Bilder 2 und 3.

${ }^{1498}$ Gailus, Nagelfiguren des Ersten Weltkriegs (Oktober 2002); Ulrich hat ebenfalls ein „Gedenkblatt in Foliogröße mit dem Namen des Stifters“ entworfen (Braun, Großherzog Ernst Ludwig nagelt, Offenbacher-Post 5./6. August 1989).

${ }^{1499}$ Rotes Kreuz (Hrsg.), Das Rote Kreuz in Jena im Weltkriege 1914-1918 (1919), S. 70-79.

${ }^{1500}$ Siehe: Diers, Schlagbilder. Zur politischen Ikonographie der Gegenwart (1997), S. 84.

1501 Auch über die Einweihungsfeier des Rostockers Kriegswahrzeichens liegt das Programm vor (Unter den Schutze ..., Rostocker Anzeiger, 2./3. September 1915). Es entspricht weitgehend der Wismarer Nagelung.

1502 Nagelung eines Wahrzeichens, Mecklenburger Tageblatt. Vorbereitung und Durchführung sind in der Ratsakte des Stadtarchivs nachvollziehbar (StAW, XIY,1,26 ${ }^{\text {III) }}$. Weitere Informationen zu der Nagelung bei Schütt, Vom „Stierkopfwappen" zum „Koggenwappen" - Die Wappen der Hansestadt Wismar (1999).
} 
nahmen rund 3.000 Personen teil. Auch hier vollzog sich der „Aufmarsch der Schulen und Vereine [...] pünktlich wohlgeordnet und ohne jede Störung ${ }^{\text {‘1503. }}$.

Nicht selten nahmen an den Feierlichkeiten auch Mitglieder der regierenden Fürstenhäuser und Monarchen teil und schlugen die ersten Nägel ein. In Wismar waren es der Großherzog von Mecklenburg-Schwerin und seine Frau:

“[...] geruhte Se. Königl. Hoheit dann mitten in die Krone des Wappenschildes den e r s t e $n$ g o 1 d e $n$ N a g e 1 einzuschlagen, der mit erhabener Aufschrift das verschlungene FF. trägt. Den zweiten Nagel schlug Ihre Königliche Hoheit die Großherzogin ein, die auch für den Großherzog den dritten Nagel in die Krone einschlug, während der Großherzog wiederum den vierten Nagel und zwar für den zweiten Sohn, den Prinzen Ludwig Christian, durch kurzen Hammerschlag in das Wismarer Kriegswahrzeichen eintrieb.“

Ganz ähnlich wie in Wismar verliefen die Erstnagelungen in den anderen deutschen Gemeinden. Aufmarsch mit Fahnen, Chorgesang, Weiherede, Platzkonzert während der Nagelungen, Eintragung in das Eiserne Buch und Ausgabe von Nagelkarten gehörten fast immer dazu. Häufiger wurden zudem Gedichte rezitiert und beim Einschlagen der Nägel Weihesprüche vorgetragen.

Das „Kaiserhoch“1504 mit dem Lied „Heil Dir im Siegerkranz“ war neben dem „Deutschlandlied“ (1. Strophe), dem „Niederländischen Dankgebet“, „O Deutschland hoch in Ehren“ und „Nun danket alle Gott“ ebenfalls ein immer wiederkehrender Programmpunkt. Häufig wurden die Feiern mit dem gemeinsamen Gesang von Martin Luthers „Ein feste Burg ist unser Gott““ beendet. Immer wieder kam es vor, dass den Nagelfeiern ein Gottesdienst in einer Kirche voranging oder dass sie mit einem Feldgottesdienst begannen. ${ }^{1505}$ Die besondere Betonung des religiösen Weihecharakters der Veranstaltungen prägte viele Erstnagelungen ähnlich wie das militärische Zeremoniell des Aufmarsches mit Fahnen und Militärkapellen sowie der Aufstellung und häufig auch die Marschmusik. Dieser zeigte sich ebenfalls in der Wahl der Hauptredner, denn neben den Bürgermeistern und Schuldirektoren wurden bevorzugt auch Geistliche für diese Aufgabe ausgewählt. ${ }^{1506}$

\footnotetext{
${ }^{1503}$ Nagelung eines Wahrzeichens, Mecklenburger Tageblatt., 10.10. und 19.10 1915.

${ }^{1504}$ Bei manchen Feiern wurde zusätzlich ein Hoch auf den eigenen Landesherrn ausgebracht, zum Beispiel am 2. April 1916 in Landsberg: "Ich bitte Sie, mit mir diese Gefühle zum Ausdruck zu bringen, indem Sie rufen: Seine Majestät König Ludwig III. von Bayern, Seine Majestät der Deutsche Kaiser Wilhelm II., unsere Armee und Marine sie leben hoch, hoch, hoch.“" (Die Nagelung des Landsberger Kriegswahrzeichens, Oberbayerischer Generalanzeiger; 1. April 1916, Rede des Bürgermeisters Dr. Strasser).

1505 Beispiele: Bayreuth (Programm, Oberfränkische Zeitung und Bayreuther Anzeiger), Cham, (Erstnagelung des Chamer Kriegswahrzeichens, Amts-Blatt für den Bezirk Cham); Wertheim (1916), Grevesmühlen (Redersborg, Nagelung von sogenannten Kriegswahrzeichen im Ersten Weltkrieg, Informationen des Heimatvereins Grevesmühlen e.V., 1996a, S. 14-16, S. 26); Mölln (1915); Rudolstadt (Zur Nagelung des "Eisernen Kreuzes", Schwarzburg-Rudolstädtische Landeszeitung; St. Georgsberg (1915) und Wetter (Thier, Das Kriegswahrzeichen von Wetter [1994], S. 215).

${ }^{1506}$ Beispiele: „Pfarrer Menzel“ bei der Einweihung des „Michael Mort in Eisen“ in Bad Kreuznach (Fink, Der Michael Mort in Eisen [2000], S. 2); Hauptpastor Bestmann (Ständer, Der "Eiserne Michael" an der Südwest-
} 
Die Ausgabe von Erinnerungsurkunden und Spendenkarten sowie der Verkauf von Ansichtskarten zur Erinnerung an die Nagelung und als zusätzliche Einnahmequelle gehörten ebenfalls in der Regel zur Durchführung der Einweihungen.

\section{Teilnehmer und Veranstaltungsorte}

Die Veranstalter von Nagelungsfeiern legten großen Wert auf eine möglichst hohe Präsenz der Einwohnerschaft, wie aus vielen öffentlichen Aufrufen hervorgeht. Besonders große Bedeutung maß man der Teilnahme der Honoratioren bei. So heißt es z. B. in dem Aufruf zur Nagelung der „Meißener Kriegssäule“ (Kgr. Sachsen): ,[...] richtet sich die ergebene Bitte, die heimatliche und vaterländische Feier durch ihre Anwesenheit auszuzeichnen, an die Vertreter der Königlichen und der Reichsbehörden, sowohl vom Militär wie vom Zivil, an den Stadtrat und die Stadtverordneten, an Kirche und Schule, an die Industrie und das Gewerbe, sowie an die Vorstände der benachbarten Gemeinden. “1507

Besonders gern gesehen war natürlich die Teilnahme von Fürsten, die den Einladungen der größeren Kommunen oftmals folgten. Welche Rolle die Schule bei den Feierlichkeiten spielte, soll im übernächsten Abschnitt untersucht werden.

Die Weihefeiern fanden überwiegend im Freien vor dem Rathaus oder auf anderen großen Plätzen der Gemeinden statt, wie z. B. in Wismar (,vor dem Rathause“), Rostock („Neuer Markt"), Bad Kreuznach („Kurpark“), Bayreuth (,alter Schlossplatz“), Cham („Rathaus“), Hannover (am „Tivoli“), Leipzig („Naschmarkt“), Rudolstadt („Oberanger“) oder Zwickau (,Hauptmarkt“). Auch auf Schulhöfen (z. B. in Bad Biberach ${ }^{1508}$ ) und vor Schulen (z. B. in Meißen ${ }^{1509}$ ) wurden Nagelungsfeiern durchgeführt.

Konnten wegen der Jahreszeit die Feiern nicht im Freien stattfinden, wählte man in vielen Fällen die Turnhallen der Schulen als Orte der Veranstaltungen. ${ }^{1510}$ Zum einen waren das sicher Notlösungen, weil man keine anderen geeigneten großen Räume zur Verfügung hatte, wie z. B. der Bericht über die Nagelung in Wertheim betont: “Als Ort zur Nagelung ist vorerst die Turnhalle in Aussicht genommen.“ Zum anderen jedoch wählte man sicher auch deshalb

ecke des Ohrdrufer Rathauses, http://82.165.28.118/akgeschichtendetails . php4? codered=\&lang=us\&nr=30 [08.02.2008]); „Oberpfarrer Köhler“ in Pößneck (Ziermann/Leiterin Stadtmuseum/Stadtarchiv,

Pößnecker „Nagelfigur" (25.10.2004) und „Kirchenrat Köhn“ in Ständer, Der „Eiserne Michael” an der Südwestecke des Ohrdrufer Rathauses, http://82.165.28.118/akgeschichtendetails. php4? codered=\&lang=us\&nr=30 (08.02.2008).

1507 Öffentliche Einladung, Meißner Tageblatt, 14.11. 1915.

${ }^{1508}$ Kuhn, Kriegs-Chronik der Gemeinde Biberach (1922), S. 253ff.; die weiteren Nagelungen fanden dann im Rathaus statt.

${ }^{1509}$ Öffentliche Einladung, Meißner Tageblatt 14.11.1915.

${ }^{1510}$ So fand am 21. November 1915 in Geislingen ,die feierliche Eröffnung der Nagelung vormittags 11 Uhr in der Turnhalle statt". 
gern Turnhallen und Schulhöfe, da man auf diese Weise die Schulen stärker in die Aktionen einbinden konnte.

Um auch die Bürger, die nicht an den Feierlichkeiten teilnahmen, auf die Nagelaktionen aufmerksam zu machen und einzubeziehen, bemühten sich die Organisatoren häufig um ein festlich geschmücktes Stadtbild. In einem Aufruf in Meißen heißt es: "Es wird [...] die geehrte Einwohnerschaft wiederholt gebeten, ihre Anteilnahme an dem vaterländischen Werke durch reiches Beflaggen der Häuser [...] zu bestätigen. “1511

\section{Beteiligung von Schulleitern, Lehrern und Schülern}

\section{Festreden}

Neben Bürgermeistern und Geistlichen hielten auch recht häufig Schulleiter und auch Lehrer die Weihereden. Einige von ihnen seien beispielhaft genannt.

In dem ausführlichen Bericht des „Gütersloher Tageblatts“ vom 21. Oktober 1915 über die Einweihung des Kriegswahrzeichens wird besonders hingewiesen auf die „Festrede, welche von einem echt deutsch-patriotischen Geiste durchweht war und von Herrn GymnasialOberlehrer Dr. Richter [...] gehalten wurde [...]. Mit patriotischen Aufrufen [,Noch muß der deutsche Aar sein Heiligtum verteidigen'] und einem dreimaligen Hochleben des Herrscherpaares, des Heeres und des Vaterlandes endete die emphatische Rede, die von der begeisterten Menge mit dem Deutschlandlied beschlossen wurde.“"1512 In Quakenbrück (Provinz Hannover) wurde zur „Burgmanns-Nagelung“ ein Oberlehrer des Realgymnasiums

Quakenbrück als Redner berufen. Die Nagelung wurde unter der Leitung des Zeichenlehrers Karl Geismar durchgeführt. ${ }^{1513}$

Sehr stark engagierte sich auch der „königl. Studienrat Dr. Knitl“ bei der Weihefeier des „Eisernen Torschmieds“ in Neumarkt (Oberpfalz). Er hielt nicht nur die Festrede vor einer ,unzählbaren Volksmenge“, sondern hatte auch den Text für das „Torschmiedslied“ und einige „Prologe“ („Preis des Heldentums“, „Preis der Liebe“, „Witwentrost“, „Elternliebe“, „Fürs Vaterland“, „Todestrennung“ u. a.) gedichtet, die während der Feier vorgetragen wurden. ${ }^{1514}$ Auch in Zwickau (Kgr. Sachsen) war es ein - ehemaliger - Schuldirektor, der die Festrede zur Einweihung des „Eisernen Hindenburg-Rolands“ am 14. November 1915 hielt: “[...]

\footnotetext{
1511 Öffentliche Einladung, Meißner Tageblatt 14.11.1915.

1512 Grimm, Das Kriegswahrzeichen auf dem Rathausplatz 1915 bis 1917, in: Gütersloher Beiträge zur Heimatund Landeskunde (1993), S. 817.

1513 Bockstiegel, Der „Eiserne Burgmann" im Rathaussaal” zu Quakenbrück (1980), S. 57f.

${ }^{1514}$ Maier, Der „eiserne Torschmied", das Kriegswahrzeichen von Neumarkt i. Opf.(1916).
} 
erwartungsvoll lauscht die Menge den markigen Worten des Festredners. Vaterländische, warm empfundene Worte waren es auch, die der Vorsitzende des Arbeitsausschusses des Rolands von Zwickau, Schuldirektor i. R. R. Becker, zu der großen Festgemeinde sprach.“1515

Die Festrede bei der Einweihung des „Eisernen Stadtlöwen“ in Wasserburg (Kgr. Bayern) am 12. Dezember 1915, die ein Realschullehrer hielt, wurde in der örtlichen Presse im Wortlaut wiedergegeben. ${ }^{1516}$ Wie viele andere Redner wies er besonders auf die Pflicht der nicht an der Front eingesetzten Menschen hin, die Soldaten an der Front zu unterstützen und ,in der Heimat Mitkämpfer“ zu sein.

Als Ergebnis lässt sich festhalten, dass in vielen Gemeinden Schulleiter als Festredner ausgewählt wurden und dass ihre Reden in der Regel von starkem vaterländischen Pathos und Aufrufen zum Durchhalten bestimmt waren. ${ }^{1517}$

\section{Musik und Rezitationen}

Auch am musikalischen Rahmenprogramm, das zu jeder Einweihungsfeier der Kriegswahrzeichen gehörte, waren in der Regel die Schulen beteiligt. Eine Reihe von Beispielen soll dieses belegen und einen Überblick über die Formen der musikalischen Beiträge geben. ${ }^{1518}$ In erster Linie waren es Schulchöre, die bei den Veranstaltungen auftraten. „Helle Kinderstimmen eröffneten, vor dem Kriegswahrzeichen angekommen, den Festakt mit dem von Herrn Lehrer Schmaus dirigierten und von der Musik begleiteten herrlichen Liede: ,Mein Vaterland'“1519, heißt es in dem Bericht der Chamer Zeitung (Kgr. Bayern) über die Einweihung des Kriegswahrzeichens.

Auch bei der Nagelung des „Eisernen Ritters“ in Karken (Rheinprovinz) am 26. November 1915 „leiteten (die Oberklassen der Volksschule) die Feier durch prächtig vorgetragene Lieder ... ein““1520. In Altona hingegen endete die Enthüllungsfeier, ,indem, der Schülerchor die ,Wacht am Rhein' anstimmte, das die Mitstehenden mitsangen“, wie es in einem Bericht der ,Hamburger Nachrichten' hieß ${ }^{\text {“1521. }}$.

\footnotetext{
1515 Teichert/Stadtarchiv Zwickau, „Eiserner Roland" und andere Nagelfiguren, Schreiben vom 13.02.2003; Chemnitzer Zeitung vom 14. November 1915; die Rede ist im Wortlaut abgedruckt.

${ }^{1516}$ Benagelung des Stadtlöwen, Wasserburger Anzeiger, 18. Dezember 1915.

${ }^{1517}$ Informationen über die Reden der Schulleiter und der Lehrer an ,Nageltagen' und anderen Nagelfeiern stehen im Abschnitt 7.3.2.

${ }^{1518}$ Musiklehrer waren häufig auch als Leiter von nichtschulischen Chören beteiligt (z. B. in Weingarten: Dort „,sangen die vereinigten Männerchöre Liederkranz und Sängerriege Harmonie unter Direktion des Herrn Hauptlehrers Trips einen passenden Männerchor"; in: Anzeiger von Weingarte, 22. November 915). Diese Aktivitäten werden in dieser Arbeit nicht näher untersucht, da der direkte Bezug zur Schule fehlt.

${ }^{1519}$ Erstnagelung des Chamer Kriegswahrzeichens, Amts-Blatt für den Bezirk Cham, 15. Mai 1915.

${ }^{1520}$ Nagelung des Kriegswahrzeichens, Heinsberger Volkszeitung.

${ }^{1521}$ Anmerkung: Nagelung des „Isern Hinnerk“ am 6. Juli 1915; Pust, „Vaterländische Erziehung” für „Höhere Mädchen" (2004), S. 402f.; zur Einweihungsfeier in Altona siehe: auch: Diers , Schlagbilder (1997), S. 84-87.
} 
Patriotisch war auch der „Kinder-Festgesang“ („Ich hab’ mich ergeben“) unter Leitung des Lehrers Metelmann bei der Einweihung des Rostocker Kriegswahrzeichens am 10. September $1915 . .^{1522}$

Hingewiesen werden soll noch auf die Nagelfeiern in Sondershausen (Fstm. SchwarzburgSondershausen), wo ein Kinderchor am 19. September 1915 dreistimmig sang ${ }^{1523}$, in Pößneck (Hzgt. Sachsen-Meiningen), wo die Schüler am 1. August 1915 ,gemeinschaftliche vaterländische Gesänge“ vorgetragen haben, “um die Feier erhebender zu gestalten““1524, in Rudolstadt (Fstm. Schwarzburg-Rudolstadt), wo ein Schülerchor zusammen mit anderen Chören das „Niederländische Dankgebet“ und allein ,einige schöne Volkslieder in guter Weise zu Gehör gebracht“1525, sowie in Wismar (Ghztm. Mecklenburg-Schwerin) ${ }^{1526}$.

Neben den von Musiklehrern geleiteten Schulchören gestalteten auch Lehrerchöre mitunter das Programm der Feiern mit. So waren angehende Lehrer der „k. Präparandenschule“ in Landsberg (Kgr. Bayern) wichtige Akteure für die vaterländische Feier und die Schildnagelung am Sonntag, dem 2. April 1916. Sie spielten den „Krönungsmarsch aus der Oper: „,Der Prophet' für Streichorchester“ und „Für Kaiser und Reich, vierstimmiger Chor mit Klavierbegleitung “'1527 zu Beginn der Zeremonie.

Im Bremen wurde beispielsweise die Feier zur Einweihung des „Eisernen Roland“ eröffnet „mit dem machtvollen Beethoveschen Chor ,Die Himmel rühmen des Ewigen Ehre', den der Lehrergesangverein, der sich auf der Domtreppe vor dem Nordportal aufgestellt hatte, unter Leitung seines Dirigenten, Herrn Musikdirektor Thienel, weihevoll zum Vortrag brachte“. Zu Beginn der Nagelung „, [...] sang dann der Lehrergesangsverein das markige Lied ,Was ist des Deutschen Vaterland?،“1528, dem später noch ein weiteres Lied folgte.

Aber nicht nur als Mitglieder von Chören und Orchestern waren Schüler (und Lehrer) an den Feierlichkeiten beteiligt, sondern, wenn auch nicht so häufig, ebenfalls durch Gedichtvorträge. Einige wenige Beispiele sollen dieses belegen. Nach einem Bericht in der Andernacher Volkszeitung (Rheinprovinz) vom 16. 10. 1916 trug ein Primaner bei der Einweihung des „Eisernen Stadtwappens“ ein Gedicht vor, in dem die Bürger Andernachs zum Nageln des „Eisernen Wappens“ aufgefordert werden.“1529

\footnotetext{
${ }^{1522}$ Unter dem Schutze ..., Rostocker Anzeiger, 2. und 3. September 1915.

${ }^{1523}$ Döring, Die Zeitereignisse der Jahre 1914-1920 (o. J.), S. 17

${ }^{1524}$ Nagelung des Eisernen Kreuzes in Pößneck, Pößnecker Zeitung 2. August 1915.

1525 Die feierliche Einweihung des „Eisernen Kreuzes" von Schwarzburg-Rudolstadt, SchwarzburgRudolstädtische Landeszeitung.17. August 1917.

1526 Siehe: Bestände des Stadtarchivs Wismar: Vorbereitung und Durchführung der Nagelung; Signatur XIV $1,26^{\mathrm{III}} ; 1915$.

${ }^{1527}$ Die Nagelung des Landsberger Kriegswahrzeichens, Oberbayerischer Generalanzeiger 1916.

${ }^{1528}$ Der Eiserne Roland in Bremen, Bremer Nachrichten, 16. Juli 1915.

${ }^{1529}$ Schäfer, Eisernes Wappen, Schreiben vom 20.10.2004.
} 
In Kaufbeuren (Kgr. Bayern) war es ein „weißgekleidetes Mädchen“, das am 1. Mai 1917 zur Einweihung des Kriegswahrzeichens am Fünfknotenturm ein „Festgedicht“ vortrug. Eine besonders ehrenvolle Aufgabe wurde einer Schülerin des Lyzeums in Sondershausen übertragen, denn sie überreichte anlässlich der Nagelung der Fürstin von Schwarzburg-Rudolstadt einen „Strauß gelber Blumen““. 1530

Auch Lehrer gehörten manchmal zu den Rezitatoren. So trug z. B. ein Lehrer den in Hexametern verfassten Text der von ihm entworfenen Stiftungsurkunde des „Eisernen Schwertes“ in der Einweihungsfeier in Wetter a. d. Ruhr (Provinz Westfalen) vor. ${ }^{1531}$

Auf weitere Aktivitäten von Schülern soll lediglich kurz hingewiesen werden, da die zeitgenössischen Zeitungsberichte nur am Rande darüber berichten und sie auch nicht zum offiziellen Programm der Feierlichkeiten gehörten. Mehrfach werden nämlich ,,junge Mädchen“ erwähnt, die erfolgreich Nägel, Ansichtskarten, Programme und Werbemittel, wie z. B. Broschen, Medaillen und gravierte Ziernägel, verkauften und damit die Einnahmen aus den Nagelungen erhöhten. Sicher waren es häufig Schülerinnen, die die Nagelaktionen auf diese Weise unterstützten. $^{1532}$

\section{Teilnahme der Schulkinder}

Es kann davon ausgegangen werden, dass bei den stets feierlich und publikumswirksam inszenierten Nagelungen neben anderen Gesellschaftsgruppen auch nahezu immer Schülerinnen und Schüler beteiligt waren, denn den Schulkindern galt ein besonderes Augenmerk. Für fast alle Städte lassen sich Nagelungen von Schulen nachweisen, die entweder das Nageln klassenweise oder die Schule als Ganzes vollzogen.

In welchem Umfang die Schulen auch an den Einweihungsfeiern beteiligt waren und inwieweit die Schülerinnen und die Schüler bei diesen Veranstaltungen selbst einen Nagel eingeschlagen haben, soll im Folgenden beispielhaft untersucht und dann ausgewertet werden.

\footnotetext{
${ }^{1530}$ Döring, Die Zeitereignisse der Jahre 1914-1920 (o. J).

${ }^{1531}$ Thier, Das Kriegswahrzeichen der Stadt Wetter hier (1994), S. 216 f.

1532 Als Beispiel sei zunächst die Nagelung des „Hindenburg-Roland“ in Zwickau angeführt: „Die Einnahmen aus den Sammelbüchsen (Postkartenverkauf) am Tage der Roland-Weihe brachte 377,87 Mark. Die 7 jungen Damen, die sich der Mühe des Postkartenverkaufs unterzogen, haben damit ein sehr schönes Ergebnis erzielt, das ihrem Eifer und ihrem ,einnehmendem Wesen' alle Ehre macht.“ (Teichert/Stadtarchiv Zwickau, „Eiserner Roland" und andere Nagelfiguren, Schreiben vom 13.02.2003); Zeitungsartikel vom 20. November 1915). Auch in Schwarzburg waren es „Junge Mädchen, die sich in den Dienst der guten Sache stellten“. Sie ,verkauften Programme und fanden reichlich Absatz..“ (1917). Ähnlich war es in Sondershausen, wo „Junge Damen [...] die Nägel gegen Bescheinigung“" verkauften (Döring, Die Zeitereignisse der Jahre 1914 bis 1920, o. J.). In Wupperal-Vohwinkel ,übernahmen (die Schüler) die Kartenverteilung jeder Art“. (Wuppertal, Vohwinkel, http://www.agvv.org/160.htm (27.12.2008)). Bei der Nagelung des „Eisernen Grafen“ in Hamm i. Westf. „schwebten die Verkäuferinnen und Gymnasiasten durch die Menge und betätigten sich für eine gute Sache“ (Der Eiserne Graf in Hamm [1916], S. 30).
} 
Es gibt viele Bilder, die über den Verlauf der Einweihungen Aufschluss geben, selten sind jedoch Schülerinnen und Schüler darauf zu erkennen. Auf drei Bildern aus Weilheim (Kgr. Bayern) jedoch sind sie detailliert zu sehen und dies lässt einige Rückschlüsse auf ihre Rolle und die Bedeutung ihrer Anwesenheit bei der vaterländischen Feier zu. Da sehr viele Jungen und Mädchen zu sehen sind, dürfte die zeitgenössische Zeitungsnotiz zutreffend sein, dass die „Spendenaktion ... auf dem Hauptplatz der Stadt unter Beteiligung aller [...] Schulen“"1533 durchgeführt wurde. Dieses war für kleinere Orte die Regel, in größeren Städten allerdings war die Schülerschaft in der Regel durch Abordnungen vertreten, wie die folgenden Beispiele zeigen. Dass die Kinder in Weilheim sehr weit vorn und nahe am Kriegswahrzeichen standen ${ }^{1534}$, lässt vermuten, dass sie gesungen haben. Ferner fallen zwei Dinge auf: Zum einen ist es die militärisch anmutende Aufstellung der Schülerinnen und der Schüler in ,Reih und Glied' und zum anderen ihre festliche Kleidung. Während die Jungen Jacken und Mützen bzw. Hüte tragen, wirken die Mädchen in den weißen Kleidern mit weißen Schleifen im Haar so, als ob sie zur Kommunion gingen. Es entsteht beim Betrachter der Eindruck einer pseudoreligiösen Zeremonie, der sich auch darin zeigt, dass die Jungen später - wie beim Betreten einer Kirche - ihre Kopfbedeckungen abnehmen. Ähnliches lässt sich auch vielen Berichten über andere, Weihefeiern' entnehmen. Dass die Veranstaltungen tatsächlich in der Regel eine Mischung aus militärischem Zeremoniell, religiöser Überhöhung, vaterländischem Pathos und Volksfest waren, wird nachstehend belegt werden. In Ohrdruf (Hzgt. Sachsen-Coburg und Gotha) ${ }^{1535}$ marschierte eine Militärkapelle an der Spitze des Zuges und in Meißen (Kgr. Sachsen) formierte sich ein „Festzug“, der dann „,nach dem Schulplatz“ marschierte, wo die „feierliche Einweihung der Kriegssäule“ stattfand. Wie wichtig dem Festausschuss die Teilname der Schulen war, geht auch aus der öffentlichen Einladung hervor: "Er bittet ferner die Rektoren und Direktoren der Schulen von Meißen und Umgebung [...] zur Weihefeier Abordnungen, womöglich mit Fahnen zu entsenden.“1536 Entsprechend dem Wunsch der Veranstalter war die Stadt wie bei anderen Volksfesten mit vielen Fahnen ,zu Ehren des Ereignisses geschmückt““. In dem Pressebericht über die Einweihung am 14. November 1915 hieß es:

„Kurz nach 11 Uhr, also auf die Minute pünktlich, nahte mit schmetternder Marschmusik - ein jetzt seltener Genuß - der auf der Neugasse zusammengestellte Festzug. An ihm nahmen teil die Feuerwehr, die Schüler der höheren Schulen (Fürstenschule St. Afra, Realgymnasium mit

\footnotetext{
${ }^{1533}$ Wöl, Kriegsnagelungen, Schreiben vom 18.10.2004; siehe: Anhang, Seite 95.

${ }^{1534}$ Siehe: Anhang, Seite 95, Bilder 2 und 3.

${ }^{1535}$ Ständer, Der „Eiserne Michael" an der Südwestecke des Ohrdrufer Rathauses., http://82.165.28.118/akgeschichtendetails.php4?codered=\&lang=us\&nr=30 (08.02.2008).

${ }^{1536}$ Steinecke/Ortschronist der Stadt Meißen, Nagelfigur in Meißen, Schreiben vom 03.11.2004.
} 
Realschule, Städtische Handels- und Gewerbeschule, Landwirtschaftliche Schule) mit ihren Direktoren und Lehrern, die Lehrerkollegien der Bürgerschulen.“

Es erfolgte dann die Aufstellung in einem ,weiten Halbkreise, den die Vereine und Schulen mit einem Viertelhundert Fahnen um das Denkmal bildeten“. Dass dann die Feier mit dem Choral „Ein feste Burg ist unser Gott“ (dirigiert vom Oberlehrer Dr. Kind) eingeleitet wurde und ein Geistlicher die „Weiherede hielt, die in allen vaterländischen Herzen“ patriotische Gefühle erweckte, zeigt, dass die Veranstaltung in Meißen der in Weilheim weitgehend ähnelte, auch wenn sich der pseudoreligiöse Charakter hier nicht erster Linie in der Kleidung der Teilnehmer äußerte, sondern im Gesang, in dem Redner und in seiner Ansprache, die fast einer Predigt entsprach. Der Pastor führte nämlich u. a. aus:

"Der Gott der Eisen wachsen ließ, der wollte keine Knechte! Der Schöpfergott, der uns zum starken, wehrhaften Volke werden ließ, der uns ein Vaterland gab mit Bergen und Eisen darin, der gab uns auch das Selbstbestimmungsrecht eines freien Volkes; ehrlos wären wir und feige Knechte (wie Arndt sagt), wollten wir dies Recht uns rauben lassen! Krank wären wir, fehlte uns das Eisen in unserem Blute!“

Dass eine solche Inszenierung der Massenveranstaltungen mit Festumzug, der oft an eine Prozession erinnerte, Marschmusik, Fahnenschmuck, patriotischen Reden und pseudo-religiösem Pathos besonders auf die Kinder und Jugendlichen eine intensive Wirkung ausübte und sie gezielt ideologisch beeinflusste, kann angenommen werden. Weitere Beispiele belegen das. Ganz ähnlich verlief die „schöne vaterländische Feier“" in Cham (Kgr. Bayern) am 15. Mai 1915, die laut Zeitungsbericht „wohl noch lange im Gedächtnis der Beteiligten, namentlich der Jugend, fortleben wird“1537. Anders als in den beiden oben genannten Städten wurde beispielsweise auch in Cham vor der eigentlichen Einweihung ein Gottesdienst abgehalten. Auch die Chamer Feier war wieder ein Konglomerat aus militärischen, religiösen und patriotischen Elementen mit Volksfestcharakter. Andrea Fink spricht in Bezug auf den Festzug und die Aufstellung des „Michael Mort in Eisen“ in Bad Kreuznach (Rheinprovinz) sogar von einer "Wallfahrt zum Aufstellungsort“. Ihrer Meinung nach „entpuppt sich der Ablauf des Weiheaktes als pseudoreligiöses Zeremoniell“ und das Kirchenlied am Anfang sei in „militärische Dienste gestellt“. Ferner sei das Vokabular des einzigen Festredners, eines Pfarrers, „religiös gefärbt gewesen“ und voller „,christlicher Versatzstücke“. Insgesamt kommt sie zu dem Ergebnis, dass der „Michel Mort in Eisen“ als Instrument zur Ideologisierung der Bevölkerung gedient habe. ${ }^{1538}$ Aber auch wenn kein Geistlicher die Festrede hielt, sondern beispielsweise ein hoher Funktionsträger oder ein Lehrer, glich sie in Form und Duktus einer Predigt. Nach Schneider konnte auch die von einem Nagelspruch begleitete Nagelung „wie im Gottesdienst

\footnotetext{
${ }^{1537}$ Erstnagelung des Chamer Kriegswahrzeichens, Amts-Blatt für den Bezirk Cham, 15. Mai 1915.

${ }^{1538}$ Fink, Der Michael Mort in Eisen (2000), S. 3.
} 
den Charakter der Anrufung Gottes annehmen oder eine Art Gebet, Gelöbnis oder Glaubensbekenntnis sein und in einem selbstverpflichtenden Schwur enden “1539. Diese Einschätzung trifft, wie die Beispiele zeigen, besonders auch auf die Kinder und Jugendlichen zu.

Ein markantes Beispiel für den militärischen Charakter der Nagelfeiern liegt aus Freiburg im Breisgau (Grhzgt. Baden) vor, wo die Quinta der dortigen Oberrealschule von ihrer Schule aus „stramm marschierend und schöne Soldatenlieder singend“1540 zum Nagelbaum am Schwabentor zog. Die Einweihung des Eisernen Kreuzes in Andernach (Rheinpfalz) am 15. Oktober 1916 war ebenfalls militärisch inszeniert, wie aus dem Aufruf des Bürgermeisters zur Teilnahme hervorgeht. Nach der „Aufstellung sämtlicher Vereine und Schulen auf dem Marktplatz“ erfolgte der „Abmarsch unter Vorantritt der gesamten Musikkapelle des Fuß-Art. Regts. Nr. 9 in Koblenz [...] nach dem Rheintore“. Es ist davon auszugehen, dass der Weg des Zuges geschmückt war, da der Bürgermeister an die Bürgerschaft „,die ergebene Bitte gerichtet, durch Beflaggen der Häuser der Stadt ein festliches Gepräge zu geben““1541.

Über einen paramilitärischen Umzug und Aufmarsch in Borna (Kgr. Sachsen) bei der Weihe der „Kriegs-Kirchentüre“ am 25. Juni 1916 wurde in der Ortszeitung zwar nicht berichtet, wohl aber über die rege Beteiligung der Schulen, die mit Fahnen zur Nagelung erschienen waren:

„Links und rechts standen das Stadtbanner, sowie die Fahnen der Vereine und Schulen, die sich an der Feier beteiligten: [...] Kgl. Seminar, 3 Fahnen der Mädchenklassen unserer Bürgerschulen, das Kgl. Realgymnasium [...] 2 Fahnen der Knabenklassen unserer Bürgerschulen. In großem Halbkreis umstanden nun die dazugehörigen Vereine und Schulen [...] und die Musikkapelle des Ersatzbataillons der Landsturmkompanie [...] den Platz der Weihe.“

Natürlich waren auch die „Leiter und Lehrer der Bornaer Schulen“ gekommen. „Den Höhepunkt der Feier aber bildete die wuchtige, herzerfassende Weiherede des Herrn Superintendent Oberkirchenrat Richter.“ Wie viele solcher Veranstaltungen klang auch diese aus „,in einem stürmisch aufgenommenen Hoch auf unseren Kaiser, unsern König, unsere Wehrmacht und in dem Liede ,Deutschland, Deutschland über alles ““1542.

\section{Beteiligung des Militärs}

Dass viele Nagelfeiern auch militärische Spektakel waren, lag nicht nur an dem paramilitärischen Aufmarsch der Schulen und der Verbände sowie der Marschmusik der Militärkapellen, sondern auch an der teilweise starken Präsenz des örtlichen Militärs, der Krieger- und

\footnotetext{
1539 Schneider, Über hannoversche Nagelfiguren im Ersten Weltkrieg (1996), S. 331.

${ }^{1540}$ Schneider, Über hannoversche Nagelfiguren im Ersten Weltkrieg (1996), S. 330.

1541 Schäfer/ Stadtarchiv, Andernachs Eisernes Wappen (Schreiben vom 20.10.2004); Aufruf vom 11. Oktober 1916.

${ }^{1542}$ Die Weihe der Kriegs-Kirchtüre zu Borna, Tageblatt für den amtshauptsmannschaftlichen Bezirk Borna 26. Juni 1916, S. 3.
} 
Regimentsvereine und der Jugendkompanien. In Berlin z. B. marschierten zur Einweihung des „Eisernen Hindenburg“ am 4. September 1915 in Anwesenheit hoher Generäle ${ }^{1543}$ große Abordnungen des 3. Garderegiments und des 2. Masurischen Infanterieregiments Nr. $147^{1544}$ und in Offenbach (Grzhgt Hessen-Darmstadt) zu der Enthüllung des „Eisernen Mannes“ am 3. Oktober $1915^{1545}$ viele Soldaten des Infanterieregiments 168 auf. Auch in Hamm, wo der Bataillonskommandeur die erste Rede hielt, waren große Teile des Offizierkorps, des Unteroffizierskorps und der Mannschaften des ortsansässigen Bataillons bei der Feier am „Eisernen Grafen“ anwesend. ${ }^{1546}$ An der Einweihung der „Hindenburgsäule“ in Dresden nahmen neben einigen Truppenverbänden sogar ein kommandierender General und ein Generalleutnant teil. ${ }^{1547}$ In Münster war es der Kommandierende General selbst, der am 21. 10. 1915 den ersten Nagel in den „Eisernen Junggermanen“ schlug. Auf einem Bild, auf dem in der 1. Reihe noch weitere Offiziere zu sehen sind, steht er unmittelbar vor der Nagelung neben dem Bürgermeister. ${ }^{1548}$ Auch über die Nagelung des „Eisernen Landsturmmannes“ am 24. 11. 1915 in Erfurt gibt es ein Foto; es zeigt ebenfalls die starke Präsenz des Militärs. ${ }^{1549}$ Bei der Einweihung des Chemnitzer Kriegsmales am 1. Oktober 1915 war neben deutschen Soldaten auch eine größere Gruppe von österreichischen Soldaten anwesend und hat Nägel eingeschlagen. Gab es ein Lazarett in der Stadt, so nahmen häufig auch verwundete Soldaten an der Weihezeremonie teil. $^{1550}$

In der Regel waren auch die ortsansässigen Jugendkompanien bei den Nagelfeiern anwesend, wie z. B. in Hagen, wo alle Jugendkompanien des Jugendbataillons mit Fahnen und Musik zum „Eisernen Schmied“ aufmarschiert waren. ${ }^{1551}$ Die militärischen Vereine jeder Stadt fehlten bei keiner Weihefeier. Auch wenn deren Mitglieder meistens nicht uniformiert waren ${ }^{1552}$, so trugen sie doch vor allem durch den geschlossenen Aufmarsch mit Marschmusik und Fahnen und die Aufstellung in Reih und Glied zum militärischen Charakter der Nagelfeiern bei.

\footnotetext{
${ }^{1543}$ Z. B. war der Oberkommandierende in den Marken v. Kessel anwesend.

${ }^{1544}$ Zum Zeitpunkt der Einweihung trug das Regiment den Namen Hindenburgs. Hoegen, Der Held von Tannenberg (2007), S. 58.

${ }^{1545}$ Braun, Großherzog Ernst Ludwig nagelt, (1989). In einem Zeitungsartikel aus dem Jahre 1940 wird der 5. Oktober 1915 als Datum genannt (StAO, Mappe 41/9).

1546 1916, S. 14 ff; auf einem Bild sieht man sowohl die Militärs in großer Zahl als auch die militärischen Verbände mit Fahnen (S. 21).

${ }^{1547}$ Hindenburg-Feiern, Dresdner Anzeiger, 3. Oktober 1915.

1548 Nübel, Mobilisierung der Heimatfront und Selbstbehauptung im Feindesland (2007), S. 140. 1549 StAE.

${ }^{1550}$ Siehe z. B. die Feiern in Wetter (Ruhr, Provinz Westfalen); siehe: Thier, Das Kriegswahrzeichen von Wetter [1994], S.215) und in Neumarkt (Oberpfalz, Kgr. Bayern; Maier, Der "eiserne Torschmied", das Kriegswahrzeichen von Neumarkt i. Opf. (1916).

${ }^{1551}$ Siehe: Der Eiserne Schmied von Hagen (1916), S. 44f. Auf einem der Bilder sind dort die militärisch aufgestellten Einheiten zu sehen.

${ }^{1552}$ Allerdings trugen sie in der Regel breite Schärpen.
} 
Zur Wirkung der pseudoreligiös-militärischen Nagelzeremonien trug auch bei, dass sich zum gemeinschaftlichen Handeln oft Tausende von Menschen zusammenfanden. So waren es bei der Weihe des Kriegswahrzeichens von Eisenberg (Fstm. Waldeck) am 9. April 1916 rund 2.500 Personen, darunter auch das fürstliche Gymnasium und die städtischen Schulen ${ }^{1553}$, und in Wismar waren es 3.000 Personen, die an der Feier teilnahmen. ${ }^{1554}$ Auch zu der Enthüllung des „Eisernen Mannes“ in Offenbach am 3. Oktober 1915, an der die großherzogliche Familie teilnahm ${ }^{1555}$, waren Tausende gekommen, darunter Abordnungen der Schulen. ${ }^{1556}$ In Erfurt waren es ebenfalls Tausende, die zur Nagelung des „Eisernen Landsturmmannes“ geströmt waren. ${ }^{1557}$

Wie aus den bisher beschriebenen Nagelfeiern deutlich geworden ist, war das Zeremoniell stets ganz ähnlich. Um Redundanzen zu vermeiden, soll abschließend lediglich auf einige weitere quellenmäßig dokumentierte Einweihungsfeiern aus verschiedenen Regionen des Deutschen Reiches, an denen Schulen sich beteiligten, hingewiesen werden ${ }^{1558}$ : Bamberg ${ }^{1559}$, Geislingen $^{1560}$, Grevesmühlen ${ }^{1561}$, Heinsberg ${ }^{1562}$, Itzehoe ${ }^{1563}$, Königsberg ${ }^{1564}$, Neumarkt (Oberpfalz) $^{1565}$, Kassel ${ }^{1566}$, Kronach ${ }^{1567}$, Sondershausen ${ }^{1568}$, Strehlen ${ }^{1569}$, Wetter/Ruhr ${ }^{1570}$, Weiden ${ }^{1571}$ und Weingarten ${ }^{1572}$.

\footnotetext{
${ }^{1553}$ Aus der Heimat, Eisenberger Nachrichtenblatt.

1554 Nagelung eines Wahrzeichens Mecklenburger Tageblatt 1915, 10. und 17.10.1915.

1555 Online-Redaktion, Vor 90 Jahren wurde der „Eiserne Mann" auf dem Aliceplatz enthüllt, http://www02.offenbach.de/Themen/Rathaus/Aktuelles_\&_Medien/Pressearchiv/2005/news/p1eisernermann031 0.html (11.02.2008).

${ }^{1556}$ Braun, Großherzog Ernst Ludwig nagelt (1989). In einem Zeitungsartikel aus dem Jahre 1940 wird der 5. Oktober 1915 als Datum genannt ( StAO, Mappe 41/9); siehe: Anhang, Seite 96, Bild 1.

1557 Weihe und Nagelung des Eisernen Landsturmmannes, Erfurter Allgemeiner Anzeiger; siehe: auch Anhang, Seite 96, Bild 2: die Schüler sind auf dem Bild vorn links an den Schülermützen erkennbar.

${ }^{1558}$ Auf eine regionale Zuordnung der Städte wurde hier verzichtet, da alle Kommunen an anderer Stelle lokalisiert worden sind.

${ }^{1559}$ Gailus, Nagelfiguren des Ersten Weltkriegs (2002), S. 27.

${ }^{1560}$ Schöllkopf, Vom „Helfensteiner Ritter" im Heimatmuseum Schöllkopf (1933).

1561 Redersborg, Nagelung von sogenannten Kriegswahrzeichen im Ersten Weltkrieg (Teil 2), Heimatverein 1996, S. $26 f$.

${ }_{1562}$ Nagelung des Kriegswahrzeichens, Heinsberger Volkszeitung 2. Dezember 1918.

1563 Pust, ,Vaterländische Erziehung" für „Höhere Mädchen" (2004), S. 407f.

${ }^{1564}$ Keine bibliografischen Angaben möglich; die Webseiten, denen die Angaben entnommen wurden, existieren nicht mehr.

${ }^{1564}$ Maier, Der „eiserne Torschmied", das Kriegswahrzeichen von Neumarkt i. Opf. (1916).

${ }^{1565}$ Maier, Der „eiserne Torschmied", das Kriegswahrzeichen von Neumarkt i. Opf. (1916).

${ }^{1566}$ Klaube, Nagelung des ,Zaitenstocks" (07.10.2004); „Blick zurück“ (1966) vom 28.8.1965.

${ }^{1567}$ Aus Nah und Fern, Kronacher Tagblatt. 8.1.1916.

${ }^{1568}$ Döring, Die Zeitereignisse der Jahre 1914-1920, o. J.

1569 Johann/Tchech/Schicha/Zwikirsch/Matzel/Rosemann, Schulchronik der Schule zu Mittel-Podiebrad (2007).

${ }^{1570}$ Thier, Das Kriegswahrzeichen von Wetter (1994), S. 217.

${ }^{1571}$ Nägel für Kriegsopfer, http://www.zeitung.org/onetz/760742-118,1,0.html (09.02.2008).

1572 Aus Stadt und Land, Anzeiger von Weingarten 22. November 1915.
} 
Beteiligt waren aber nicht nur die städtischen Schulen, sondern auch sehr viele kleine Dorfschulen. Eine Reihe von ihnen machte Ausflüge in die nächstgelegene Stadt, um an Einweihungsfeiern teilnehmen zu können. ${ }^{1573}$

Zusammenfassend kann festgestellt werden, dass die Schulen - und zwar aller Schulformen bei den meisten Einweihungsfeiern der Gemeinden und der Städte präsent waren. Wenn die Kommune, in der die Veranstaltungen stattfanden, nicht groß war, nahmen Schüler und Lehrer geschlossen teil, andernfalls wurden Abordnungen geschickt. Dass Schüler im Rahmen der Einweihungszeremonie nagelten, kam relativ selten vor. Meist nagelten sie zu einem späteren Zeitpunkt. In größeren Städten, wie z. B. in Halberstadt, Osnabrück, Münster, Hagen, Hannover oder Berlin wurden allenfalls Schulleiter und Lehrer zu den Einweihungen eingeladen und für die Schülerinnen und Schüler eigene ,Nageltage' durchgeführt. In keinem Fall kann daraus geschlossen werden, dass diese Kommunen keinen besonderen Wert auf die Teilnahme der Schuljugend legten, sondern ihre Feiern waren auch ohne die Kinder und Jugendlichen schon überfüllt und deshalb wurden für sie eigene Veranstaltungen (,Nagelungstage') angeboten. Inwieweit diese im Ablauf und hinsichtlich des öffentlichen Interesses den offiziellen Einweihungen entsprachen, soll später untersucht werden. ${ }^{1574}$

Eine Antwort auf die Frage, warum die Kommunen unbedingt auch die Schulen in die Nagelaktionen einbeziehen wollten, gibt ein Bericht der Heinsberger Volkszeitung: „Auch die Schulkinder sollen ihren Nagel einschlagen, auf dass sie heranwachsen und ein Bewußtsein haben an dem Werk zu Gunsten der Hinterbliebenen der Krieger aus dem Landkreis Heinsberg mitgewirkt zu haben. “1575 Diese Einschätzung kann sicher verallgemeinert werden, auch wenn es den Kommunen nicht nur um die ideologische Erziehung der Schulkinder ging, sondern auch um eine Erhöhung des Spendenaufkommens. Der nächste Abschnitt, der sich mit der finanziellen Unterstützung von Schülernagelungen befasst, wird weiteren Aufschluss über die Hintergründe für die offiziell gewünschte und geforderte Beteiligung der Schulen an den Nagelaktionen geben.

\subsubsection{Finanzielle Unterstützung von Schülern}

Angesichts der wirtschaftlich schwierigen Situation im Schuljahr 1915/16 und der Verarmung vieler Menschen war es Eltern oft nicht möglich, ihren Kindern Geld für den Erwerb von Nä-

\footnotetext{
1573 Als Beispiel sei die Stadt Beeskow (Provinz Brandenburg) angeführt, in der am 21.Oktober 1915 eine Tür mit einem Eisernen Kreuz eingeweiht wurde: „An der Nagelung beteiligten sich außer Bürgern der Stadt viele Gäste von außerhalb, sowie folgende Schulen: Beeskow Mittelschule und Volkschule, Buckow, Dienstorf, Glienicke, Görzig, Lindenberg, Neubrück, Radinkendorf, Ragow, Gr. Rietz, Tauche und Trebatsch.“" (Gotthardt, Die Nagelung von eisernen Wahrzeichen im Kreise Beeskow-Storkow 1915/16 [o. J.]).

${ }^{1574}$ Siehe: Kapitel 7.3.4.

${ }^{1575}$ Die Fahrt des Heinsberger Kriegswahrzeichens, Heinsberger Volkszeitung 1. August 1917.
} 
geln zu geben, wie auch aus einer - außerordentlich gefühlvollen und pathetischen - Darstellung eines Rektors in einer Festschrift aus Hamm hervorgeht.“"1576 Den größten Teil des Geldes für diese Nagelaktion hatte der entsprechende Arbeitsausschuss, nämlich 260 Mark, durch ein Konzert am Abend der Einweihung des „Eisernen Grafen“ eingenommen. Dieser Erlös ermöglichte 700 unbemittelten Kindern die Teilnahme an den Nagelungen. Weitere solcher Unterstützungsmaßnahmen werden im Folgenden dargestellt und ausgewertet.

Wie in Hamm ging es den Verantwortlichen der anderen Kommunen natürlich nicht vorrangig darum, den Kindern eine Freude zu machen, wie es der Schulleiter Terbrüggen beschreibt, und es ging auch nicht primär um die Erhöhung des Spendenaufkommens, denn dann hätte man beispielsweise die 260 Mark den Hinterbliebenen der im Kriege Gefallenen direkt zukommen lassen können und sie nicht auf dem ,Umweg' der Nagelung durch die Kinder bekommen. Vielmehr wollte man gerade den Kindern die Teilnahme an den gemeinschaftsstiftenden Aktionen ermöglichen ${ }^{1577}$ und ihnen dadurch das Gefühl vermitteln, zusammen mit vielen anderen an der „Heimatfront“ zu kämpfen und die Soldaten zu unterstützen. Dieses erklärt, warum viele Gemeinden und Städte immer wieder Spender und wie Hamm besondere Wege suchten und fanden, um möglichst viele oder sogar alle Schulkinder nageln zu lassen, denn Nagelungen eigneten sich im besonderen Maße zur Mobilisierung der „Heimatfront“ . 1578 In Dresden kümmerte sich sogar als Vorsitzende des „Vereins Kriegskreuz 1914“ die Prinzessin Johann Georg, Herzogin von Sachsen, persönlich um die Organisation und schrieb am 4. Oktober 1915 einem Schuldirektor einen Brief, in dem sie ihm mitteilte, dass ,zur Nagelung des Kriegskreuzes auf dem Altstadtmarkt durch Kinder der Dresdner Bezirksschulen [...] seitens einiger Gönner unseres Vereins größere Geldspenden überwiesen worden sind, die uns in den Stand setzen 500 Kinder ihrer Schule nageln zu lassen“1579. Auch in Hagen fanden sich Bürger, welche Beträge stifteten, damit alle Waisenkinder der Stadt nageln konnten; andere ließen Hunderte von Schulkindern nageln. ${ }^{1580}$ Es kam sogar vor, wie beispielsweise in Borna, dass ein Schuldirektor selbst 50 Mark spendete, damit Schüler seiner Schule sich an der Nagelung beteiligen konnten. ${ }^{1581}$

Immer wieder wurden in den Zeitungen Bürger aufgerufen, für ärmere Kinder zu spenden, wie z. B. in Bayreuth ("Empfehlenswert wäre auch die Ueberweisung an Schulklassen [für

\footnotetext{
${ }^{1576}$ Terbrüggen, Der Eiserne Graf und die Jugend, in: Der Eiserne Graf in Hamm (1916), S. 39-48.

${ }^{1577}$ Siehe: Schneider, Zur Mobilisierung der Heimatfront, Zeitschrift für Volkskunde (1999), S. 47f.

1578 Siehe: Schneider, Zur Mobilisierung der Heimatfront, Zeitschrift für Volkskunde, Bd. 32 (1999).

${ }^{1579}$ Kaden/Stadtarchiv Dresden, Kriegskreuz 1914, Schreiben vom 31.12.2004.

${ }^{1580}$ Siehe: Der Eiserne Schmied von Hagen (1916), S. 25.

${ }^{1581}$ Die Weihe der Kriegs-Kirchtüre zu Borna 1916, Tageblatt für den amtshauptsmannschaftlichen Bezirks Borna. 25. Juni 1916.
} 
ärmere Kinder], an die Waisenhäuser und dergl.“1582) und in Erfurt. Hier heißt es im Erfurter Allgemeinen Anzeiger am 20. Oktober 1915:

"Endlich sei noch darauf hingewiesen, dass in den Vorverkaufsstellen und am Sonntag auf dem Friedrich-Wilhelms-Platz Sammelbüchsen aufgestellt sind für die Nägel, die die Stifter aus irgendeinem Grunde nicht selbst einschlagen wollten. Diese Nägel sollen später von Schulkindern unter Leitung ihrer Lehrer eingeschlagen werden. Es wird den Schulkindern gewiß eine große Freude bereiten, auch ihrerseits in dieser Weise zu dem Gelingen des schönen Werks beizutragen. Es ergeht deshalb die Bitte, die gekauften Nägel nicht achtlos wegzuwerfen."“1583

Die Stadtverwaltung Mannheim hatte es sich sogar zum Ziel gesetzt, der gesamten Schuljugend die Möglichkeit zu bieten, sich an der Nagelung zu beteiligen. ${ }^{1584}$ Darauf war man sehr stolz („Unseres Wissens ist Mannheim die einzige Stadt, in der dies der Fall ist“). Aber obwohl es zahlreiche und sehr großzügige Stiftungen gegeben hatte, auch seitens der Stadtverwaltung Mannheims ${ }^{1585}$, und man den Preis für den billigsten Nagel (1Mark) reduziert hatte, konnten nicht alle der 45.000 Schüler, sondern lediglich ,etwa 41.600 Schulkinder [...] für einen billigen Preis von 20 Pfennig auch ihrerseits an diesem symbolischen Opfergang teilnehmen“1586. Die Herabsetzung des Preises führte dazu, dass einerseits die Schüler mehr als die Hälfte der insgesamt 80.000 Nägel einschlugen, andererseits jedoch zu der Gesamtspendensumme in Höhe von 64.500,93 Mark ,nur' 8.320 Mark beitrugen. Die formulierte Intention eines „symbolischen Opferganges“ war nach Schneider ein Akt „der Solidarität, die ,freudige Opferbereitschaft' der Daheimgebliebenen, demnach vom selben Geist beseelt wie die oft beschworene ,freudige Kampf- und Opferbereitschaft` der Soldaten an der Front““1587.

Durch solche Spendenaufrufe angeregt und verstärkt durch die Tatsache, dass Spender immer wieder in der Öffentlichkeit auch namentlich genannt wurden, fanden sich in vielen Kommunen Bürger, die Schülerinnen und den Schülern die Teilnahme an den Nagelungen ermöglichten, darunter häufiger Unternehmer, die durch größere Spenden Schülern die Teilnahme an den Nagelungen ermöglichten. So spendeten z. B. ein Fabrikbesitzer in Chemnitz ${ }^{1588}$, ein Kommerzienrat in Peine (1.000 Mark für 1.800 Schulmädchen) ${ }^{1589}$, ein Fabrikbesitzer in Barmen ${ }^{1590}$ und zwei Firmen in Münster (für insgesamt 3.500 Schüler). ${ }^{1591}$

\footnotetext{
1582 Kriegswahrzeichen, Oberfränkische Zeitung und Bayreuther Anzeiger 28. Mai 1916.

${ }^{1583}$ Vom Eisernen Landsturmmann, Erfurter Allgemeiner Anzeiger.20. Oktober 1915

${ }^{1584}$ Genagelt wurde der „Eiserne Roland“ am Wasserturm in Mannheim.

${ }^{1585}$ Mannheim, General-Anzeiger (Badische Neueste Nachrichten 24.11.1916).

${ }^{1586}$ Rotes Kreuz (Hrsg.), Das Rote Kreuz in Mannheim 1914-1918 und in der Nachkriegszeit (1934).

1587 Schneider, Zur Mobilisierung der Heimatfront, Zeitschrift für Volkskunde, Bd. 32 (1999), S. 46.

${ }^{1588}$ Uhle, Chemnitz in großer und schwerer Zeit (1919), S. 117.

1589 Stadt Peine (Hrsg.), Nagelung der Peiner Eule, Peiner Zeitung 8. Mai 1916.

${ }^{1590}$ Siehe: Barmer Nagelung, http://www.eugen-langen-schule.de/1__weltkrieg.htm (14.11.2008).

${ }^{1591}$ Siehe: Schulte, Kriegschronik der Stadt Münster 1914-18 (1930), S. 146.
} 
Wie gerade auch im nächsten Kapitel nachgewiesen wird, war die Beteiligung der Schülerinnen und der Schüler an den Nagelungen außerordentlich groß. Das ist sicher nicht zuletzt auch darauf zurückzuführen, dass sich so viele Spender aus verschiedenen Schichten des Volkes fanden, die die Kosten für die ärmeren Kinder und Jugendlichen übernahmen, also in der Regel nicht für die Schülerinnen und die Schüler der Gymnasien und Lyzeen. Die Spenden reichten von 20 Mark für zehn Volksschüler bis zu 6.500 Mark für 13.000 Kinder und stammten u. a. von Privatleuten, Akademikern und der kommunalen Verwaltung oder wurden aus der Wirtschaft zur Verfügung gestellt. Sie kamen Schülerinnen und Schülern aller Altersstufen und bevorzugt den Kindern der Volks- und Mittelschulen zugute. Darauf, dass es nicht vorrangig darum ging, Kindern eine Freude zu machen, sondern man durch die wirksam inszenierten Nagelaktionen helfen wollte, sie zu patriotischen Kämpfern an der „Heimatfront“ zu erziehen, ist schon hingewiesen worden.

Über andere Motive kann aufgrund der Quellenlage allenfalls gemutmaßt werden. Allerdings kann mit Moritz Föllmer angenommen werden, dass besonders Männer, die nicht selbst an der Front standen, erheblichen Rechtfertigungszwängen unterworfen waren. Sicher waren die teilweise sehr hohen Spenden als ,patriotischer Beitrag zur Kriegsführung“ zu verstehen, der ihnen auf diese Weise „eine äußere wie innere Legitimation““1592 verlieh, zumal gegen Kriegsende Spendenunwillige sogar als Vaterlandsverräter diffamiert wurden.

Insofern ist auch erklärlich, warum sie den jeweiligen Betrag in der Regel öffentlichkeitswirksam für Schulkinder spendeten und nicht direkt den für die Nagelungen Verantwortlichen zukommen ließen oder selbst die sehr teuren goldenen Nägel einschlugen und die Schilder annagelten. Denn wie die angeführten Beispiele zeigen, berichtete die Presse ausführlich über fast jede Spende - ob sie nun zwei Mark für zehn oder 6.500 Mark für 13.000 Kinder betrug.

\subsubsection{Nagelungstage und andere Aktionen der Schulen}

Auch die Schulen waren dem großen propagandistischen Aufwand, der die meisten Nagelaktionen im Deutschen Reich vor und nach dem Einweihungstag begleitete, sowie dem sozialen und moralischen Druck ausgesetzt. Der Oberbürgermeister von Osnabrück, Rissmüller, verfasste z. B. einen Spendenaufruf, in dem er auch die 34 Schulen der Stadt aufforderte, sich mit Spenden zu beteiligen. Dieser war erfolgreich, denn ,ganze Schulklassen und Vereine marschierten auf, um ihren Beitrag zu den Kriegsanstrengungen zu leisten. Angesichts derartiger Anstrengungen wurde die Sammelaktion ein voller Erfolg. “1593

\footnotetext{
1592 Föllmer, Die Verteidigung der bürgerlichen Nation (2002), S. 97.

${ }^{1593}$ Der Tod als Maschinist (1998), S. 304. In Osnabrück wurde der „Eiserne Karl der Große“ benagelt.
} 
Das gleiche Ziel verfolgte man in Wertheim (Ghztm. Baden) bei der Nagelung des Stadtwappens (,Adler in Eisen“), wo „die ganze S c h u 1 j u g e n d zum späteren eigenen Andenken sich daran beteiligen“ " 1594 sollte.

In einer Rede, die der Ausschussvorsitzende bei der Schlussnagelung des „Eisernen Zaitenstockes“ in Kassel hielt, wurde gerade das Interesse an der Beteiligung der Jugend besonders hervorgehoben: „Namentlich aber baten wir darum, uns die Jugend zu schicken, die Jugend, die in ihr empfängliches Herz mit der Handlung der Pietät die Erinnerung an diese Stunden legen sollte, um sie mit sich zu nehmen durchs Leben. “1595 Viele weitere Beispiele ließen sich anfügen.

In diesem Kapitel soll an einigen Beispielen vor allem der Programmablauf der schulischen Nagelfeiern (,Nageltage') untersucht und dann mit dem Zeremoniell der offiziellen Einweihungsfeiern verglichen werden. Da die Zeitungen in der Regel auch über die schulischen Nagelungen ausführlich berichtet haben, ist die Quellenlage relativ gut. Ferner geben die überlieferten ,Nagelbücher' sowie in Einzelfällen Lebenserinnerungen von Beteiligten Aufschluss über diese Nagelungen. Auch die überlieferten Fotos und Postkarten können als Quellen herangezogen werden. ${ }^{1596}$

Zudem soll die Frage, wie die vielen Schulkinder, die aus armen Familien stammten und für die kein ,Sponsor' die Kosten übernahm, die entsprechenden Spendensummen aufbrachten, beantwortet werden.

Am Anfang der Untersuchung wird die Nagelung der 21 Schulen in Dessau (Hztm. Anhalt) stehen. Diese war sehr erfolgreich und bietet detailliertes Material für eine nähere Betrachtung. Es folgen dann schwerpunktmäßig die Aktionen aus Hagen, Hamm, Halberstadt und Münster; Nagelungen aus anderen Kommunen werden mit einbezogen, wie z. B. die aus dem Landkreis Lübbecke, aus Flensburg, Hannover und Berlin.

In den etwas größeren Städten wurden für die Schulen (oder andere gesellschaftliche Gruppen, wie z. B. Vereine) ,Nageltage' eingerichtet, d. h. Tage, an denen nur Schulkinder einer oder mehrerer Schulen die Möglichkeit zur Nagelung bekamen. So hatte man in Dessau für den 19. August 1915 alle Schulen zu einer Schulfeier vor dem „Kreuz in Eisen“ in das Landesmuseum eingeladen, über die das Anhaltinische Tageblatt einen Tag später sehr ausführlich berichtete ${ }^{1597}$ :

\footnotetext{
${ }^{1594}$ Die Nagelung des Stadtwappens, Wertheimer Zeitung, 31.01, 01.02. und 02.02.1916.

1595 Klaube/Stadtarchiv Kassel, Nagelung des „Zaitenstocks" (Schreiben vom 07.10.2004).

${ }^{1596}$ Siehe: Anhang, Seiten 85-108.

1597 Die Schulfeier vor dem „Kreuz in Eisen" im Landesmuseum der Stadt Dessau, Anhaltinisches Tageblatt vom 20. August 1915.
} 
„Am Geburtstage S. H. des Herzogs hatten sich um 11 Uhr Vertretungen der sämtlichen Schulen von Dessau eingefunden, um namens der Schulen eine Nagelung am Kreuz in Eisen vorzunehmen. Anwesend waren die sämtlichen Herren Leiter der staatlichen und städtischen Schulanstalten, der Mädchen-Realgymnasial-Kurse, der kaufmännischen Fachschule, der katholischen Schule und des Luisen-Institutes, sowie die beiden ältesten Schüler und Schülerinnen der sämtlichen Klassen unter Führung ihrer Herren Lehrer und Lehrerinnen. [...] Es war ein liebliches Bild, welches die Halle darbot. An den Pfeilern standen die Schulfahnen, die Schulklassen nahmen wohl geordnet alle verfügbaren Plätze ein, von denen man das Kreuz in Eisen sehen konnte, bis zur Treppe hinauf. Die Feier begann mit dem Chorgesang: ,Salvum fac ducem ' der vereinigten Chöre des Gymnasiums und der Ober-Realschule unter Leitung des Hrn. Musikdirektor Theile.“

Zu den Ehrengästen gehörten u. a. der Regierungspräsident, der Stadtverordnetenvorsteher, Stadträte und der Schulrat. In seiner sehr patriotischen Ansprache forderte der Oberbürgermeister u. a. die Jugend von Dessau auf: „Die Zukunft gehört Euch; darum müsst Ihr aus der Vergangenheit lernen und von vaterländischem Hochgefühl Euch erfüllen lassen, wie wunderbar Gott der Herr unser Volk geführt und nach jahrhundertelangem Ringen auf eine hohe Warte gestellt hat.“ Am Ende ging er auch auf den Zweck der Nagelung ein (,„.. wir wollen auch sorgen für die Verletzten.“).

Dem Herzoglichen Marien-Oberlyzeum, das begann, folgten noch 19 weitere namentlich genannte Schulen. Zuletzt nagelten das Herzogliche Friedrichs-Gymnasium sowie Realschulklassen und Vorschule. Die zwei Vertreter trugen jeweils einen ,Weihespruch' vor, so z. B. für das Friedrichs-Gymnasium: „Herzvolk Europas, zittre nicht! / Der große Gott im Himmel spricht: / Durch Kampf zum Sieg, durch Haß zur Ehr / Ich bin dein Schild und starke Wehr“. Wie in vielen solcher Berichte wurde auch in Dessau die gesamte Spendensumme nicht explizit genannt, da es offensichtlich in erster Linie nicht auf das eingenommene Geld ankam $^{1598}$, sondern die ideologische Beeinflussung der Schulkinder im Vordergrund stand. Schließlich war es das postulierte Ziel, dass „,die Schulfront sich zu einer der wichtigsten Bastionen der Heimatfront entwickelte“1599. Die Anwesenheit der hochrangigen Ehrengäste, der fahnengeschmückte Ort, Choräle, die Weiherede des Oberbürgermeisters, Kaiser- und Herzogs-Hoch, gemeinsamer Gesang, Nagelsprüche, Eintrag in das Eiserne Buch und die Nagelzeremonie selbst werden bei den Schulkindern die gewünschten patriotischen Gefühle mit der Opferbereitschaft an erster Stelle ausgelöst haben. Anders als in Dessau wurden bei vielen ähnlichen Aktionen in anderen Kommunen den Spendern zur Erinnerung an die Nagelung auch noch Urkunden (Nagelkarten) ausgehändigt, wie z. B. in Mühlhausen. ${ }^{1600}$

Nach der Schulfeier aus dem Herzogtum Anhalt soll mit der Nagelung in Hagen soll ein weiteres Beispiel untersucht werden, über das ebenfalls detaillierte Informationen

\footnotetext{
${ }^{1598}$ Insgesamt sind 63 Mark eingenommen worden; 21 Silbernägel wurden eingeschlagen, von denen jeder drei Mark kostete.

${ }^{1599}$ Demm, Ostpolitik und Propaganda im Ersten Weltkrieg (2002), S. 75.

${ }^{1600}$ Siehe: Anhang, Seiten 88f.
} 
vorliegen. ${ }^{1601}$ Aus der Veröffentlichung „Der Eiserne Schmied von Hagen - Das erste Jahr seiner Geschichte 1915/1916“1602 geht hervor, dass diese Nagelung im Vergleich zu denen in Berlin („Eiserner Hindenburg“), Köln („Kölscher Boor“) und Düsseldorf („Eiserner Löwe“) finanziell am erfolgreichsten war, und zwar mit 3,26 Mark pro Einwohner. Inwieweit die Schulen daran Anteil hatten, wird allerdings nicht erwähnt.Im Unterschied zur Nagelung in Dessau nahmen an dem schulischen Nageltag in Hagen alle Schulkinder teil, und nicht nur ausgewählte Vertreter. Das hing sicher mit der jeweiligen Örtlichkeit zusammen, denn während in Dessau sich die Zeremonie in einer Halle im Landesmuseum abspielte, bot in Hagen „,der große freie Platz vor dem Rathause [...] zum geschlossenen Anmarsch und zur zweckmäßigen Aufstellung vor dem Denkmal prächtige Gelegenheit“1603. Etwa sechs Wochen nach der Einweihung (29.11.1915), am Sonntag, dem 16. Januar 1916,

,erschien als erste unserer Schulen die Evangelische Volksschule 10 (Lange Straße) mit 1200 Kindern, Trommler und Pfeifer, Fahnen und Bänder voran am Eisernen Schmied. Es war eine rechte Herzensfreude, die Kleinen und Kleinsten erwartungsvoll und stolz auf ,ihren' Tag am Eisernen Schmied zu sehen. Jubeln erklang das Lied vom Vaterland über den Platz; dann richtete ein Knabe mit kräftiger Stimme einen von seiner Lehrerin gedichteten Vorspruch an den Eisernen Schmied. Der Rektor der Schule erläuterte den Kindern den Vaterlandsgedanken, der unsere Zeit erfüllt und zur Errichtung dieses Denkmals geführt hat. Dann ward das erste Schild einer

Volksschule angebracht. Viele, viele andere sind ihm später gefolgt, fast alle mit einer schönen Feier. Besonders hübsch machte sich dabei immer die Nagelung, welche Kinder als Vertreter der einzelnen Klassen vornahmen, wobei jedes Kind einen markigen Nagelspruch sagte, der von der vielhundertköpfigen Schar der umstehenden Kleinen mit Andacht verfolgt und zumal, wenn er einen heiteren Einschlag hatte, mit lautem Beifall aufgenommen wurde. Diese Nagelfeiern der Schulen haben allemal Kindern wie der Bürgerschaft Freude gemacht und werden dem heranwachsenden Geschlecht eine lange nachwirkende Kriegserinnerung haben. Insgesamt haben 27 Hagener Schulen jeweils einen Schild am Sockel des „"isernen Schmieds“ angeschlagen.“

Es gab aber noch weitere Veranstaltungen, an denen Schulen beteiligt waren. So „erschien ein ganzer Stadtteil am Eisernen Schmied. Es waren die Delsteiner. In festlichem Zuge kamen ihre Schulen und Vereine mit Fahnen und Musik zum Denkmal gezogen“ (12. März 1916). Der Ablauf entsprach dem der oben beschriebenen Nagelfeier: Nach dem Aufmarsch erfolgte der Vortrag eines von einer Lehrerin verfassten ,Vorspruchs' durch einen Schüler, dann Festrede mit einem Hoch auf Kaiser und Heer, Gesang von Schulchören, Anbringen der Nagelschilde und der Rückmarsch. Sogar die „Buben und Mädels der Kleinkinderschulen des ev. Frauenvereins“, etwa 400 Kinder, mussten zur Nagelung antreten. „Unter Führung der

\footnotetext{
1601 Über die schulischen Nagelaktionen in Hamm ( siehe: Der Eiserne Graf in Hamm [1916], S. 38-48) und Halberstadt (siehe: „Aus der Stadt", Halberstädter Zeitung und Intelligenzblatt 1916) liegen ebenfalls detaillierte Informationen vor.

${ }^{1602}$ Der Schmied von Hagen (1916), S.3; Berlin liegen detaillierte Informationen vor: 22 Pfennig, Düsseldorf: 1,20 Mark, Köln: 1,37 Mark.

${ }^{1603}$ Der Schmied von Hagen (1916), S. 35; Kapitel „Nagelfeiern am Schmied“, S. 35-41.
} 
Schwestern und des Vorstands zogen sie jubelnd und singend hinter dem Trommlerkorps einer Kompagnie unseres Jugendbataillons daher, die Knaben mit Schärpen und Fähnchen, die Mädchen mit Blumenkränzen im Haar.“ Natürlich fehlten die Festrede (durch einen Pastor) und das ,dreimalige Hoch' nicht. Die schulischen Nagelaktionen sind im Bild festgehalten worden. ${ }^{1604}$

Im Unterschied zur Veranstaltung in Dessau spielte in Hagen der paramilitärische Aufmarsch mit Marschmusik und Fahnen offensichtlich eine besondere Rolle, während sonst die Abläufe sich im Wesentlichen entsprachen. Wieder aber gibt es keine konkreten Angaben zu den Spendensummen; nicht einmal der Preis für einen Spendenschild wird genannt.

Als weiteres Beispiel seien die Nagelungen im benachbarten Münster angeführt, über die vor allem in der umfangreichen Kriegschronik der Stadt berichtet wird. Dort hatte man eine „Kinderwoche am Junggermanen“, die nach einem Bericht der Lokalpresse Münster in einen „Belagerungszustand“" versetzte, eingerichtet. ${ }^{1605}$

„12000 Schulkinder kamen nacheinander mit Fahnen und Gesang, Trommeln und Pfeifen zum Nageln des Kriegswahrzeichens des ,Eisernen Junggermanen', um ,zahlreiche Namenschilder mit Sinnsprüchen, Reimen und Namen' anzuschlagen. ,Am Kaisergeburtstage nagelten um 11 Uhr die letzten 500 Kinder'. Dann wurde ein Schild ,Die Volksschulen der Stadt Münster' angebracht, denen die Lehrer und Lehrer dieser Schulen ein Schild folgen ließen.““606

Genannt werden u. a. weitere Schulen und Lehrerverbände, die sich beteiligt und mehr als 100 Mark für die Anbringung eines Eisenschildes gespendet hatten. Die Aufzählung reichte von der Evangelischen Gymnasialvorschule über die Katholische Mittelschule bis zum Katholischen Lyzeum sowie dem Verein katholischer deutscher Lehrerinnen und dem Gymnasialgesangverein.

Nahezu geschlossen nahm in Barmen die Schülerschaft an der Nagelung des Denkmals (Wappen der Stadt und des Feldmarschalls von Hindenburg) teil. Wie in vielen anderen Städten zogen die Kinder in geschlossenem Zuge, mit wehender Fahne und unter Gesang von Vaterlandsliedern zur Ruhmeshalle, wo die Nagelung stattfand. ${ }^{1607}$

In Bergisch Gladbach (,Eiserne Tafel“) kümmerte sich der Bürgermeister persönlich um die Vermarktung und richtete ,extra ,Vernagelungsstunden’ für die Schulkinder ein, um auch ihnen die Möglichkeit zur Nagelung zu geben“‘1608.

\footnotetext{
${ }^{1604}$ Siehe: Anhang, Seite 88f.

1605 Nagelung des Junggermanen, Münsterischer Anzeiger 23.1.1916.

1606 Schulte, Kriegschronik der Stadt Münster 1914-18 (1930), S. 181f.

${ }^{1607}$ Schulchronik, (1913/14), http://www.eugen-langen-schule.de/1_weltkrieg.htm (22.07.2007; am 18.02.2008 war die Seite nicht mehr aufrufbar.

${ }^{1608}$ Ehrenmal und Ärgernis (1997), S. 53.
} 
In der Regel konnten an den Nageltagen der Schulen die einzelnen Schüler aus Zeitgründen nicht selbst einen Nagel einschlagen oder sich in das Spendenbuch eintragen. Deshalb wurden einzelne Schülerinnen und Schüler ausgewählt, die dann stellvertretend für die Klassen die Nagelungen und die Einträge vornahmen. ${ }^{1609}$

Über viele Nagelfeiern geben Fotos Aufschluss. Im Anhang sind Beispiele aus Erfurt ${ }^{1610}$, Bad Oeynhausen, Kleve, Köln, Schwerin, Rudolstadt und Zweibrücken zu sehen. ${ }^{1611}$ Sie zeigen sowohl ganze Schulgemeinschaften (Kleve ${ }^{1612}$ als auch einzelnen Klassen (Erfurt u. a.) vor den Kriegswahrzeichen. Auffällig ist vor allem die festliche Kleidung der Jungen und Mädchen, die der, weihevollen' Nagelaktion offensichtlich für angemessen gehalten worden ist.

Nachdem bisher im Wesentlichen auf Schulnagelungen in Nord-, West- und Ostdeutschland eingegangen worden ist, sollen nun auch schulische Nagelfeiern in Süddeutschland berücksichtigt werden, und zwar in Titisee-Neustadt im Königreich Württemberg sowie in Traunstein im Königreich Bayern und in Wertheim im Großherzogtum Baden. In Titisee-Neustadt wurde 1916 auf Betreiben eines Gymnasialdirektors eine „Eiserne Uhr“ aufgestellt, an deren Benagelung sich auch die Schulen eifrig beteiligten.

Über die Zeremonie in Neustadt wurde berichtet:

„... bald erschienen ganze Schulklassen. Im November fand eine geschlossene Nagelung der Realschule Neustadt statt, denn die zweite, dritte, vierte, fünfte und sechste Klasse haben sich mit in Schönschrift eingetragenen Versen im Buch verewigt.

,Wir Sextaner vom Badner Land

nageln mit starker Hand

erstens für den Kaiser

zweitens für das Reich

drittens für unsere Gauen

und Blauen zugleich'."

(Die Lehrer der Realschule spendeten einen gravierten Nagel zu 25 Mark.)

„Weil die Schüler auf eine Vergütung verzichteten, kam der Erlös der Eisernen Uhr zugute, wobei in dem Eintrag der Betrag offengelassen wurde. Anschließend folgten klassenweise die Unterschriften aller Schüler, die an der Kräutersammlung teilnahmen und zur Belohnung einen Nagel einschlagen durften." ${ }^{1613}$

In Traunstein, wo den Schulen von der Stadt ebenfalls eigene Nageltage zur Verfügung gestellt wurden, zeigte bereits der für die Nagelung gewählte und geschmückte Ort (“der zur Opferstätte umgewandelte Pavillon war auf das wirkungsvollste mit Blumen und Tannenreis

\footnotetext{
${ }^{1609}$ Pust, „Vaterländische Erziehung" für „Höhere Mädchen" (2004), S. 404.

1610 Siehe: Anhang, Seite 103.

${ }^{1611}$ Siehe: Anhang, Seiten 104/105

1612 Siehe: Anhang, Seite 103.

${ }^{1613}$ Herbner, Titisee-Neustadt (1995), S. $212 \mathrm{f}$.
} 
geschmückt"“) die pseudoreligiöse Inszenierung. Hinzu kommt, dass dort Choräle gesungen wurden. ${ }^{1614}$

Wie an vielen Orten wurden auch hier zur Erinnerung an die Nagelung entsprechende Ansichtskarten verkauft, allein bis Ende 1915 2.600 Stück. In dem Gedenkblatt wurden zwar Angaben über die Höhe der eingenommenen Spenden gemacht (9.346,54 Mark), nicht jedoch darüber, welchen Anteil die Schulkinder daran hatten. Der Leser erfährt lediglich, dass das „Direktorat des städtischen Knabenpensionats Traunstein“ sowie die Lehrerkollegien der königlichen Realschule, des königlichen Progymnasiums und der städtischen Knabenschule in der Einweihungsfeier am 10. Oktober 1915 jeweils ein Metallschild zum Preis von 20 Mark angenagelt haben.

Insgesamt unterscheiden sich Ablauf und Berichterstattung in der bayerischen Stadt nicht von denen in den Königreichen Preußen oder Württemberg und anderen Ländern des Deutschen Reiches, wie auch die Nagelfeiern in Wertheim zeigen. Die Nagelung des „Eisernen Stadtwappens“ in Wertheim ging auf eine Initiative der Jugendwehr des Ortes zurück. Von vornherein war geplant, „die ganze Schuljugend“ sich daran beteiligen zu lassen. Über den Nageltag der Volks- und der Mädchenbürgerschule am 2. Februar 1916, der sich „,zu einem kleinen Feste gestaltete“, wurde in der Zeitung ausführlich berichtet.“1615

Insgesamt haben Kinder und Jugendliche aller Altersgruppen genagelt - vom dreijährigen Kind der „Kinderschule“ bis den Jugendlichen der Abschlussklassen der Gymnasien und der Lyzeen sowie den Berufsschülern.

Neben den ,Nageltagen' für die einzelnen Schulen wurden auch ,Vernagelungstunden' für einzelne Klassen eingerichtet, über die allerdings in der örtlichen Presse weniger ausführlich berichtet worden ist. Dass auch diese eifrig genutzt wurden, sollen einige Beispiele zeigen. In Ludwigsburg (Kgr. Württemberg) kam auf diese Weise z. B. am 12. 10. 1915 bei der Nagelung der „Zwei Feldgrauen“ eine Spendensumme in Höhe von 105,90 Mark (264 Nägel) zusammen. Es waren „erschienen die Klassen III (67 Nägel) und VII (67 N.) der Knabenvolksschule, ferner Klasse IIa der Elementarschule und die Gewerbeschule (24 N.)“. Einen Tag zuvor hatte die „Klasse IIb der Oberrealschule (Oberlehrer Seibold) für 49 Mark Nägel eingeschlagen. Die 5. Klasse der Knabenvolksschule schlug am 20.12. „1 gold gravierten Klassennagel und weitere 24 Nägel ein. Es wurden bei diesem Anlaß verschiedene Lieder gesungen und von Lehrer Gauß eine Ansprache gehalten; auch Gedichte kamen zum Vortrag. “1616

\footnotetext{
${ }^{1614}$ Naue, Gedenkblatt zur Benagelung des „Ehernen Wehrschildes" der Stadt Traunstein im Jahre 1915 (1915).

${ }^{1615}$ Die Nagelung des Stadtwappens, Wertheimer Zeitung, 31.01., 01.02. und 02.02.1916.

${ }^{1616}$ Die zwei Feldgrauen, Ludwigsburger Zeitung , 13./14./15.10.1916.
} 
Ähnlich feierlich gestaltete sich auch die Nagelung der Arndt-Eiche in Bonn: „Und an diesen sogenannten Nagelungen beteiligten sich ganze Schulklassen im Rahmen einer ,kleinen patriotischen Feier mit Gesang, Deklamationen und Kaiserhoch“" ${ }^{\prime 1617}$, heißt es in einer Chronik. Dass sich auch an der Nagelung der „Türe des Rauthausturmes“ in Kornwestheim (Kgr. Württemberg) Knaben- und Mädchenklassen beteiligten, geht aus den Eintragungen in das Gedenkbuch hervor ${ }^{1618}$. Wie überall trugen auch in Offenbach („Eisenhart“) Schulkinder dazu bei, dass die Nagelung ,zum großen Erfolg““ wurde. ${ }^{1619}$

In Wiesbaden fanden sich ebenfalls ,viele Schulklassen mit den Klassenlehrern“ beim „Eisernen Siegfried“ zur Nagelung und zum Eintrag in das Nagelbuch ein. ${ }^{1620}$ Nagelungen in Zweibrücken und Schwerin sind bildlich dokumentiert. ${ }^{1621}$

Diese Beispiele zeigen, dass überall im Reich Schulkinder klassenweise zu den Kriegswahrzeichen ihrer Gemeinde zogen, sie benagelten und sich in ,Nagelbücher' eintrugen. Es kann davon ausgegangen werden, dass die meisten Nagelungen im Rahmen einer kleinen Feier vorgenommen wurden, wie z. B. in Bonn und Ludwigsburg.

Angesichts der großen öffentlichen Resonanz der Nagelaktionen, für die in besonderem Maße die Presse sorgte, wäre es für die Schulen schwer möglich gewesen, sich zurückzuhalten bzw. sogar auszuschließen, wie ein Beispiel aus Bad Kreuznach zeigt. Dort war im „Kreuznacher Anzeiger" vom 9. 11. 1915 moniert worden, dass die Schulen sich an der Nagelung kaum beteiligt hätten. ${ }^{1622}$ Weitere Berichte über ,säumige' Schulen liegen nicht vor.

Auch Schulkindern vom Lande, in deren Dörfern keine Kriegswahrzeichen aufgestellt wurden, ermöglichte man häufig die Teilnahme an Nagelaktionen, indem einzelne Klassen Ausflüge in nahe gelegene Kommunen, die Nagelobjekte aufgestellt hatten, machten. Am 16. September 1915 beispielsweise ,fanden sich die ABC-Schützen der Schule BruchNiederbecksen am Hindenburgkreuz in Bad Oeynhausen (Provinz Westfalen) ein““1623. Klassen der Lorcher Schule (Rheinprovinz) mit insgesamt 652 Schulkindern suchten den „Eisernen Siegfried“ in Wiesbaden auf, wo sie sich nach der Nagelung in das Eiserne Buch eintrugen. $^{1624}$

\footnotetext{
${ }^{1617}$ Harling, Schulen in der Bonner Nordstadt: Nordschule - Marienschule - Karlschule, http://www.bonnergeschichtswerkstatt.de/schule.html (18.11.2008).

${ }_{1618}$ Die Türe des Rathausturmes, Ludwigsburger Kreiszeitung (Beilage); StAK, VA 2; siehe: auch Feges /Weber/Weirauch, Belagerungswappen Speyer.

${ }^{1619}$ Jacobi, „Ritter Eisenhart", Heilbronner Stimme, Heft 4, 21.1.1915; „Schulklassen kommen mit gravierten Nägeln."

${ }_{1620}$ Büttner, Siegfried oder Gerechtigkeit für ein vaterländisches Denkmal, Wiesbadener Leben, 1982, S. 9.

1621 Siehe: Anhang, Seite 104.

${ }^{1622}$ Fink, Der Michael Mort in Eisen (2000).

${ }^{1623}$ Kuderer/Schneider, Nageln für das Vaterland, Beiträge zur Heimatkunde der Städte Löhne und Bad Oeynhausen, 2006, S. 197.

${ }^{1624}$ Büttner, Siegfried oder Gerechtigkeit, in: Wiesbadener Leben, Heft 4 (1982).
} 
In einigen Orten, die keine großen Standbilder aufgestellt, sondern sich für transportable Nagelschilde entschieden hatten, beschritt man einen ganz anderen Weg, um Schulen in die Nagelaktionen einzubeziehen. Über eine solche Aktion in Rosenheim (Kgr. Bayern), wo ein Schild mit dem Stadtwappen („Eiserne Rose“) benagelt wurde, berichtete das Oberbayerische Volksblatt: „Zu bestimmten Anlässen wurde der Schild auch zu Nagelungen größerer Gruppen transportiert. [...] Am 11. April fand eine solche Veranstaltung im Gymnasium statt, zwei Tage später in der Realschule.“"1625

\section{Landkreis Lübbecke, Flensburg, Hannover, Berlin}

Nachdem bereits die Nagelfeiern in verschiedenen geografischen Regionen verglichen worden sind, soll die schulische Beteiligung an allgemeinen Nagelaktionen beispielhaft an den Schulen aus unterschiedlichen Kommunen untersucht werden, und zwar aus einem ländlichen Bereich (Landkreis Lübbecke, Provinz Westfalen), einer Kleinstadt (Flensburg, Provinz Schleswig-Holstein), einer Provinzhauptstadt (Hannover, Provinz Hannover) und der Reichshauptstadt Berlin.

\section{Landkreis Lübbecke}

Obwohl Kammeier die Orts- und Schulchroniken, Zeitungen und Zeitschriften, die regionalgeschichtliche Literatur und die ungedruckten Quellen der infrage kommenden Archive untersucht hat, ist er lediglich auf eine einzige Nagelaktion gestoßen, und zwar die in Fiestel, wo insgesamt 4.295 Nägel eingeschlagen wurden. ${ }^{1626}$

\section{Flensburg}

Die Situation in Flensburg unterschied sich im Vergleich zu Nagelaktionen anderer Kommunen insofern deutlich, als die „Nagelsäule“ - als „große Attraktion“ - im Rahmen der „Kriegsausstellung für die Nordmark“ (22. Oktober bis 19. November 1916) in den Räumen des Lyzeums Auguste-Viktoria-Schule zum Benageln aufgestellt wurde. Dadurch ergab sich natürlich eine besondere Nähe der Schülerinnen des Lyzeums zur Nagelung.

Da die Schulen „ein bevorzugter Adressat der Ausstellung waren“, wurde sie im Amtlichen Schulblatt des Regierungsbezirks Schleswig angekündigt. ${ }^{1627}$

Insgesamt 27 Schulen mit über 4.000 Schülern und Schülerinnen aus dem gesamten Umland besuchten allein in der ersten Woche die Ausstellung und viele von ihnen dürften auch einen Nagel in die Säule eingeschlagen und sich in das „Eiserne Buch“ eingetragen haben. Explizit

\footnotetext{
${ }^{1625}$ Leicht/Herzog, Unbekanntes Denkmal der Stadtgeschichte, Oberbayerisches Volksblatt, Nr. 253, 3.11.1987.

${ }^{1626}$ Kammeier, Der Landkreis Lübbecke und der 1. Weltkrieg (1998), S. 181-186.

${ }^{1627}$ Pust, ,Vaterländische Erziehung" für „Höhere Mädchen" (2004), S. 414 ff.
} 
genannt werden allerdings nur die Klasse VIIa des Flensburger Lyzeums und die Oberrealschule Flensburg. Nach Pust dürften aber auch viele Eintragungen von einzelnen Schülerinnen ohne Angabe ihrer Klasse stammen. ${ }^{1628}$

\section{Hannover}

In Hannover gab es eine Reihe von Nagelobjekten, z. B. die Großplastiken „Das Eiserne Sachsenroß“, die „Feldkanonen Oskar und Roland“ und den „Eisernen Roland in der Südstadt“ sowie weitere Kriegswahrzeichen. ${ }^{1629}$ Obwohl der „Hannoversche Kurier“ und der „Hannoversche Anzeiger“ häufig über die Nagelungsaktionen berichteten, gibt es relativ wenige konkrete Hinweise auf die Beteiligung der Schulen. ${ }^{1630}$ Es steht jedoch fest, dass wie in allen größeren deutschen Städten auch in Hannover die Schulen sich aktiv und umfassend an den Nagelungen beteiligten. In der Zeit nach der Einweihung des „Eisernen Sachsenrosses“ am 15. August 1915 ,versammelten sich dort Vereine aller Art, dort treffen auswärtige Besucher zum Nageln ein und dorthin führen Lehrer die ihnen anvertrauten Schulklassen, um durch gemeinsames Nageln zu zeigen, dass sie ihre Lektion gelernt haben“ und

„durch eifriges Nageln den Nachweis ihrer patriotischen Gesinnung erbringen. So soll es, wie es im ,Kurier' heißt, den Schülern der 3. Vorklasse des Ratsgymnasiums, also den allerkleinsten, eine große Freude bereitet haben, mit ihrem Lehrer zum Tivoli zu ziehen, um dort unter dem Gesang ,Deutschland, Deutschland über alles' und ,Es braust ein Sturm wie Donnerhall' [...] , für jedes gesammelte Goldstück einen Nagel ins Sachsenroß klopfen zu können.' Und zum Nachweis ihrer Gesinnung ließen sie am Sachsenroß, bevor sie ,in gleichem Schritt und Tritt lustig singend' abzogen, ein Schildchen zurück, auf dem die Verse zu lesen waren:

,Auch wir, die kleinsten der Gymnasiasten, wollten im Weltkrieg nicht ruhen und rasten,

Drum sammelten wir fleißig und wechseln ein,

Manches blanke Goldstück gegen den Schein'. ‘1631

Noch häufiger haben Schulkinder offensichtlich die ,Eisernen Feldkanonen' benagelt ${ }^{1632}$, die als weitere Publikumsattraktionen nacheinander auf dem Gelände der Ausstellung „MusterKriegsschauplatz“ (Vahrenwalder Heide) und später (Ende 1915 bis Mitte 1917) in der Stadthalle aufgestellt worden waren. ${ }^{1633}$ Sogar in den Schulen wurde schon wenige Tage nach der Eröffnung der Feldstellung für das Publikum für diese außerordentliche Attraktion geworben. Presseberichten zufolge war der Besucherandrang ,,andauernd gewaltig“. In den ersten drei

\footnotetext{
${ }^{1628}$ Pust, „Vaterländische Erziehung" für „Höhere Mädchen" (2004) 2004, S. 218

1629 Schneider, Über hannoversche Nagelfiguren im Ersten Weltkrieg (1996).

${ }^{1630}$ Im sozialdemokratischen „Volkswillen“ hingegen erschien kein einziger Bericht über die Nagelungen in Hannover und Umgebung. Schneider, Über hannoversche Nagelfiguren im Ersten Weltkrieg (1996), S. 218; lediglich in der Ausgabe vom 10.Oktober 1915 gab es einen - sehr kritischen - allgemeinen Artikel über die „Eisernen“ (Oberschelp/Grotjahn, Stahl und Steckrüben Bd. 1 (1993), S. 134f.

${ }^{1631}$ Schneider, Über hannoversche Nagelfiguren im Ersten Weltkrieg (1996), S. $228 \mathrm{f}$.

${ }^{1632}$ Bis zum Frühjahr 1916 hatte das Nageln bereits 50.000 Mark eingebracht.

${ }^{1633}$ Siehe Schneider, Das Vaterländische Museum in Hannover (2010), S. 147-149.
} 
Monaten kamen mehr als 300.000 Personen, darunter auch viele Schulkinder. ${ }^{1634}$ Da gleichzeitig das Interesse an der Benagelung der ,Feldkanone' so groß war, dass eine zweite aufgestellt werden musste, ist davon auszugehen, dass viele Hannoversche Schüler den Besuch der ,Feldstellung ${ }^{1635}$ nutzten, um Nägel in diese Nagelobjekte zu schlagen, zumal man vor allem auch den Schulen hatte Gelegenheit geben wollen, ,sich auf der Kanone zu verewigen“1636.

Wie in einigen anderen Städten so gab es auch in Hannover Fälle von Vandalismus. So wurden in der Nacht zum 9. November 1916 „,vom Sockel des Eisernen Sachsenrosses sechs zum Teil wertvollere Schilder von Bubenhand losgerissen und gestohlen“"1637. Die Tatsache, dass die Polizei die Täter ausfindig gemacht hatte, hielt Anfang Januar 1917 andere Jugendliche nicht davon ab, erneut Schilder vom „Sachsenroß“ zu stehlen. Ob es sich bei den Tätern um Schüler handelte, geht aus den Berichten das Hannoverschen Kuriers (12. 2. 1917 und 9. 1. 1917) nicht hervor.

\section{$\underline{\text { Berlin }}$}

Auch in der Reichshauptstadt gab es sehr viele verschiedene Nagelobjekte, allen voran die Kolossalstatue des „Eisernen Hindenburg“, die trotz der allgemeinen Akzeptanz der Kriegsnagelungen teilweise sehr heftig kritisiert worden ist. Aufgrund ihrer Größe (12 Meter hoch $^{1638}$ ) und besonderen Lage (auf dem Königsplatz vor der Siegessäule und dem Reichstag) sowie der Publizität - schließlich war der Sieger von Tannenberg dargestellt - stand sie im Mittelpunkt der schulischen Aufmerksamkeit, und nicht die anderen, teilweise auch recht spektakulären Standbilder, wie z. B. der ca. fünf Meter große „Neuköllner Roland“ (eingeweiht am 5. September 1915), der „Roland-Hindenburg“ in Berlin-Friedrichshagen oder das Modell eines U-Bootes. ${ }^{1639}$ So ist in Lebenserinnerungen damaliger Schüler stets die Rede von ,Besuchen’ beim „Eisernen Hindenburg“ und nicht von Nagelungen der vielen anderen Kriegswahrzeichen. Drei Beispiele seien genannt:

„Ab und zu gingen wir klassenweise zu dem Platz, auf dem vor dem Reichstag der ,Eiserne Hindenburg' stand, eine riesige, von einem Gerüst umgebene Holzstatue, die mit silbernen Nägeln beschlagen werden sollte. Es gab Nägel mit eisernen, versilberten und vergoldeten Köpfen zu entsprechend gestaffelten Preisen, ich glaube, zehn Pfennig, fünfzig Pfennig und eine Mark. Man sagte uns, dies sei ein Opfer für die Kriegskosten. Die Stelle, an der man nagelte, konnte man sich

\footnotetext{
${ }^{1634}$ Schneider, Über hannoversche Nagelfiguren im Ersten Weltkrieg (1996), S. 241.

${ }^{1635}$ Es handelte sich um ein Musterschützengrabensystem.

1636 Schneider, Über hannoversche Nagelfiguren im Ersten Weltkrieg (1996), S. $240 f$.

${ }^{1637}$ Schneider, Über hannoversche Nagelfiguren im Ersten Weltkrieg (1996), S. 231.

${ }^{1638}$ Die Angaben über die Höhe sind nicht eindeutig; es gibt auch Dokumente, die die Höhe mit 13 Meter angeben.

${ }^{1639}$ Für Schulkassen wurden Führungen durch die Ausstellung („Einen Krieg ausstellen“, 1916) organisiert; sicher trugen Schulkinder zu dem guten Ergebnis der Benagelung des U-Bootes in Höhe von 5.881 Mark entscheidend bei. (Lange, 1914 bis 1918 auf der Schulbank [1933], S. 91f.)
} 
aussuchen. Ich hatte meine Lieblingsstelle, die ich später wieder erkennen wollte - aber sollte sie nicht mehr finden. “1640

(Johann Baptist Gradl, geb. 1904 in Berlin, Redakteur, Bundestagsabgeordneter, Minister)

„Neben dem Reichstagsgebäude in Berlin war aus Holz eine große Hindenburgstatue errichtet worden zum Benageln für patriotische Zwecke. Auch ich schlug während eines Besuchs bei den Tanten einen Nagel ein. Immer mehr wurde für uns alle, groß und klein - je mehr der Kaiser aus dem Blickfeld entschwand - Hindenburg, der Generalfeldmarschall, zum Mittelpunkt ... Wir hungerten nicht für Wilhelm II., sondern für Hindenburg. “" ${ }^{641}$

(Hans Wendt, geb. 1903 in Magdeburg, Korrespondent und Studioleiter)

„... wir benagelten im Tiergarten das Monstrum einer Hindenburgstatue mit eisernen und kupfernen Nägeln ..."“642

(Wolfgang Yourgrau, geb. 1908 in Berlin; Physiker, Schriftsteller)

Dass man offensichtlich auch die ,Nagelfeste der Schulen' mit sehr großem Aufwand inszenierte, geht aus auch aus Zeitungsbericht hervor vom 3. Oktober 1915 hervor. ${ }^{1643}$ Ein Jahr später wiederholte sich die gleiche Zeremonie: „... An Hindenburgs 69. Geburtstag marschierte die Berliner Jugend vor seinem eisernen Ebenbild auf und „huldigte“ ihm durch „Darbringung eines Riesenstraußes“. Die Jugendlichen steckten jeweils eine einzelne Blume auf die dafür vorgesehene Unterlage. “1644 Natürlich übte die Kolossalstatue auch auf die Gemeinden aus dem Umland eine besondere Wirkung aus. ${ }^{1645}$

Auch wenn in manchen Schulchroniken Hinweise auf die Nagelung des „Eisernen Hindenburg" fehlen, so lassen die vorhandenen Hinweise darauf schließen, dass die Mehrzahl der Berliner Schulkinder sich am Königsplatz zum Nageln eingefunden hat. ${ }^{1646}$ Einige Bilder über die Nagelung am Königsplatz und in Berlin-Steglitz sind im Bilderanhang zu sehen. ${ }^{1647}$

\subsubsection{Nagelungs- und Weihesprüche}

Dass bei Nagelaktionen die Spender, also auch die Schulkinder, häufig Sinnsprüche vortrugen und solche Deklamationen fester Bestandteil des Zeremoniells waren, ist bereits mehrfach angeführt worden. Inwieweit es dabei tatsächlich um die Anerziehung einer vaterländischen Grundhaltung bei den Kindern ging und ob vielleicht noch andere Erziehungsziele damit verfolgt wurden, soll nun an Beispielen aus Städten untersucht werden, für die Nagelungs- und

\footnotetext{
${ }^{1640}$ Pörtner, Kindheit im Kaiserreich (1990), S. 243.

${ }^{1641}$ Pörtner, Kindheit im Kaiserreich (1990), S. 196.

${ }^{1642}$ Franke, 3. Die Kriegsgeneration, S. 243.

${ }^{1643}$ Feier in Berlin, in: Dresdner Anzeiger 3. Oktober 1915.

${ }^{1644}$ Lange, Einen Krieg ausstellen (2003), S. 68.

1645 Biermann/Billstein/Büschenfeld/Roerkohl/Stenner/Trost, Der Erste Weltkrieg (2004), S.179: „Ganze Schulklassen machten sich auf den Weg nach Berlin, um ihren Teil für den ,Sieg' beizutragen.“

${ }^{1646}$ So enthält die Schulchronik Steglitz zwar genaue Hinweise auf die Nagelungen der Nagelschilde der Firma Glasmachers, der ,Eiserne Hindenburg“ wird jedoch nicht erwähnt.

${ }^{1647}$ Siehe: Anhang, Seiten $106 f$.
} 
Weihesprüche im Wortlaut überliefert sind, und zwar an den Nagelungen in Dessau ${ }^{1648}$, Hagen $^{1649}$, Hamm ${ }^{1650}$, Münden ${ }^{1651}$, Wetter ${ }^{1652}$ und Zweibrücken ${ }^{1653}$.

Bemerkungswert ist, dass schon die Kleinsten, z. B. die Zöglinge der „Kleinkinderschule“ in Wetter (Ruhr), zum Hämmern solche Begleitsprüche aufsagen mussten, wie z. B. „Zum Wohl des Vaterlands/ gibt auch gern Kinderhand“, „Gott schütze mit einer Hand/ unser teures Vaterland“, „Wir wollen Kinder sein, / drum schlagen wir auch Nägel ein“. Die Ausrichtung auf eine ausschließlich positive Sicht eines starken deutschen Vaterlandes ist eindeutig. Das bekannte Lutherlied „Ein feste Burg“, durch das natürlich Erziehungsziele in christlichlutherischem Sinn angestrebt worden sein könnten, wirkt im Zusammenhang mit den anderen, eindeutig national ausgerichteten Sprüchen ebenfalls patriotisch.

Zwei Beispiele von Schulkindern der 1. Klassen aus Zweibrücken folgen: „Dem Vaterland aus Kinderhand“ (Kath. und prot. Volksschule 1b, 1a Knaben) und „Ich hab nur wenig, ich bin noch klein, Doch will ich meine Gabe dem Vaterland weih'n“ (Klasse 1a kath. Volksschule). Trotz der kindlichen Sprache im ersten Vers dominiert wieder die patriotische Aussage. Häufig ist das Alter der Volksschüler, die die Sprüche, wie hier z. B. Schillerzitate, vortragen, nicht genau erkennbar:

\title{
Münden (Werra):
}

\begin{abstract}
„Wir wollen sein ein einig Volk von Brüdern, In keiner Not uns trennen und Gefahr."

(Schüler der Knabenvolksschule)

„Wir wollen frei sein, wie die Väter waren.

Eher den Tod, als in Knechtschaft leben.“

(Schüler der Knabenvolksschule)
\end{abstract}

Hagen:

„Gott schütze unser Vaterland“

(Kath. Volkschule I; Bergstraße)

„Durchhalten, auch daheim!“

(Städt. Israelitische Volksschule)

„Durch Kampf zum Sieg!“

(Die ev. Volkschulen 4,5,18)

„Der Väter Erbe sei uns heilig!“

(Katholische Volksschule III; Eilpe)

„Allezeit treubereit für des Reiches Herrlichkeit“

(Kath. Volkschule Delstern)

\footnotetext{
1648 Die Schulfeier vor dem „Kreuz in Eisen", Anhaltinisches Tageblatt 20. August 1915.

${ }^{1649}$ Der Eiserne Schmied (1916).

${ }^{1650}$ Der Eiserne Graf in Hamm (1916).

${ }^{1651}$ Deutsch/Drebning/Korf, Die Nagelung des Eisernen Kreuzes 1915/16 in Hann.-Münden (Wettbewerbeitrag 1996/97).

1652 Thier, Das Kriegswahrzeichen von Wetter (1994).

${ }^{1653}$ Loth, Das Kriegswahrzeichen der Stadt Zweibrücken (1916).
} 
„Heil und Sieg dem Vaterlande!“

(Kath. Volksschule XI.)

Wieder zeigen sich die nationalen Tendenzen sehr deutlich. Lediglich durch die Verwendung des Schiller-Zitats aus „Wilhelm Tell“ im ersten Spruch der Mündener Knabenvolksschule und durch die Aussage im ersten Teil des nächsten Spruchs wird ein anderer Aspekt betont der Freiheitsgedanke, der auch bei anderen Nagelungen häufiger auftaucht. So verwendet z. B. die Quinta der höheren Schule in Wetter ebenfalls ein Zitat aus „Wilhelm Tell“: „Ans Vaterland, ans teure, schließ' dich an, das halte fest mit ganzem Herzen.“ Bedenkt man, dass diese literarischen Aussprüche vor dem Hintergrund, dass ein Land okkupiert und seiner Freiheit beraubt worden war, erfolgten, so wurden bei den deutschen Kindern Ängste vor dem Verlust der Freiheit hervorgerufen und Gefühle wie Ablehnung und Hass gegen Deutschlands Feinde geschürt. Dieses Ziel machen auch die beiden folgenden Sprüche besonders deutlich:

„Es dräut der Feind in West, Süd, Ost dem Vaterland.

Des Kriegs Wetter brüllt und tost.

Die Banner fliegen. Herr hilf uns siegen!“

(Katholische Schule, Dessau)

„Die Faust noch klein

Treibt doch ganz fein

Den Nagel ein.

$\mathrm{O}$ wär ich groß

Ich schlüg drauf los.“

(1b Klasse Realschule Zweibrücken)

Noch aggressiver waren die Verse einer höheren Mädchenschule aus Zweibrücken:

„Ins Holz den Nagel

Ans Holz Herrn Grey,

Links Sassanow, rechts Poincaré,

leicht ist dann noch ein Plätzchen frei

Für Pasitsch, Costa, Salandra!“”

(8. prot. Mädchenklasse)

Imperialistische Töne enthielt vor allem dieser Spruch aus Münden:

„Deutschland, Deutschland!

Umsonst nicht bist Du Europas Herz:

Streb' immer höher, streb' himmelwärts!“

Klasse der städt. Höheren Mädchenschule Münden (Werra)

Es folgen drei weitere Beispiele der Höheren Schulen, die zeigen, dass sie sich nicht wesent-

lich von denen der anderen Schulformen unterscheiden.

„Edel sei der Mensch, hilfreich und gut,

und das Beispiel der Gefallenen mache uns noch edler, hilfreicher und besser!“

(Höhere Mädchenschule, Wetter)

„Ein Kreuz in Eisen ist daher das augenfällige Sinnbild unserer Zeit. Fest wie Eisen sei aber auch unser Entschluß, kämpfend und duldend auszuharren, bis der Sieg errungen ist.“ 
(Herzogliches Antoinetten-Lyzeum, Dessau)

„An das größte Opfer, das die Welt gesehen, erinnert das Kreuz. So möge auch dieses Kreuz uns an die zahllosen Opfer erinnern, welche der blutige Krieg von unserem Volke gefordert hat, und uns mahnen, in rechter Dankbarkeit allezeit der Helden zu gedenken, welche willig ihr Blut für ihre Brüder hingegeben."

(Herzogliches Marien-Oberlyzeum, Dessau.)

Da die Sprüche entweder von den Lehrern verfasst oder ihre Auswahl von diesen beeinflusst worden waren, unterschieden sich ihre eigenen konsequenterweise kaum von denen ihrer Schulkinder:

„Mag auch die Welt in Flammen stehn, Deutschland kann nicht untergehn.“

(Lehrer Adams, Wetter)

„Der Gott, der Eisen wachsen ließ, der wollte keine Knechte.“

(Direktor des Gymnasiums in Münden/Werra)

„Freue dich, daß du ein Deutscher bist.

Wachse hinein in des Vaterlands Ehre!“

(Lehrer Rümenapf, Münden/Werra)

„Den deutschen Helden zum Gedächtnis, der deutschen Jugend zur Nacheiferung. “

(Rektor Boese, Münden/Werra)

Erziehung zur Vaterlandsliebe, Stärkung des Durchhaltewillens, Schüren von Hass auf die Kriegsgegner und Vorbereitung auf den Krieg an der Front oder der „Heimatfron“ - das sind die Erziehungsziele, die die Nagelsprüche widerspiegeln. Ob die Kinder und Jugendlichen eine Schule in konfessioneller oder kommunaler Trägerschaft oder eine Vorschule, Volksschule oder Höhere Schule, eine Mädchen- oder Jungenschule besuchten, ist dabei nicht von Belang. Auch wenn die Verwendung von literarischen Sinnsprüchen, von denen hier nur wenige zitiert worden sind, insgesamt weniger aggressiv oder patriotisch klingen, so ändert das nichts an der Gesamttendenz, denn auch sie lassen keine Distanz zum Vaterland erkennen. Hinzu kommt, wie gezeigt, dass ein Teil der Nagelsprüche aus dem Zusammenhang gerissen ist und ihre eigentlichen Aussagen durch den Kontext, in den sie gestellt worden sind, umgedeutet und verfälscht werden.

\subsubsection{Schlussnagelungen; Probleme}

Waren die Nagelobjekte vollständig, vernagelt', so kam es meistens zu sog. Schlussnagelungen. Diese waren dann ähnlich stimmungsvoll und aufwendig inszeniert wie die Einweihungen. Da ihr Programm in der Regel jenen stark ähnelte und die Schulen wieder oft beteiligt waren, soll hier nur an zwei Beispielen kurz darauf eingegangen werden. Gut zehn Monate nach der Einweihung des „Eisernen Hindenburg-Roland“ in Zwickau (Kgr. Sachsen) fand am 
2. September 1916 abends um 9 Uhr die Schlussnagelung statt. ${ }^{1654}$ Sicher nahmen wegen der späten Uhrzeit an einem Sonnabend keine Schulklassen teil, besonders zahlreich war aber „die Jungmannschaft des Gymnasiums“ erschienen. Außerdem waren die Schulen mit dem Hauptredner, „Schuldirektor Gustav Becker“ und dem Zwickauer Lehrergesangverein vertreten. Die Feier endete mit dem Großen Zapfenstreich und einem Festkonzert von Stadt- und Militärkapelle. ${ }^{1655}$

Auch in Kassel hob der Vorsitzende des Arbeitsausschusses in seiner Rede die besondere Bedeutung der Jugend hervor: „Namentlich aber baten wir darum uns die Jugend zu schicken, die ihr stets empfängliches Herz mit der Handlung der Pietät an diese Stunden legen sollte, um sie mit sich zu nehmen durchs Leben. Und über alles Denken, Hoffen und Erwarten hat sich unser Wunsch herrlich erfüllt.“" ${ }^{6556}$ In Kassel hatte sich nach den Worten des Redners, wie in nahezu allen deutschen Gemeinden und Städten, die Schuljugend in großer Zahl an der Nagelung (des „Eisernen Zaitenstocks“) beteiligt.

Sieht man einmal von ,nervenden' kindlichen Werbern ab, wie sie z. B. in Goslar vorkamen ${ }^{1657}$, so gibt es im Zusammenhang mit dem Verhalten von Schulkindern bei den Nagelaktionen keine Hinweise auf ernsthafte Probleme. Zwar wurde in einigen Kommunen durchaus „Ungutes“ durch „rohe Lausbuben“ beklagt ${ }^{1658}$, da aber kein direkter Zusammenhang zu den Schulen bestand, soll hier nicht genauer darauf eingegangen werden, auch wenn die Tatsache, dass die Störungen sich in der unterrichtsfreien Zeit an Nachmittagen oder am Wochenende ereigneten, durchaus dafür spricht, dass es sich bei jenen um Schulkinder gehandelt haben dürfte.

Dass die Lehrer sicher oft großen Druck auf ihre Schüler ausgeübt haben und Nagelspenden in bestimmter Höhe von ihnen gefordert haben, zeigt ein Beispiel aus Augsburg. ${ }^{1659}$ Dort hatten sich die Gemeindebevollmächtigten beim Stadtschulkommissär darüber beschwert, dass angesichts der bevorstehenden Nagelung ,von Lehrpersonen ein Zwang ausgeübt oder dass bestimmte Beträge“ von den Schülern verlangt wurden. Auch wenn der Stadtschulkommissär

\footnotetext{
${ }^{1654}$ Im Anhang ist das Programm der Schlussfeier in Erfurt abgedruckt; siehe: Anhang, Seite 29.

${ }^{1655}$ Teichert/Stadtarchiv Zwickau, ,Eiserner Roland" und andere Nagelfiguren, Schreiben vom 13.02.2003.

${ }^{1656}$ Klaube/Stadtarchiv Kassel, Schreiben vom (07.10.2004).

${ }^{1657}$ Siehe: Kapitel 7.3.8.

${ }^{1658}$ Z. B. gab es in Aschaffenburg ,,auch Ungutes vom Nagelungsort“ zu berichten. „So forderte man, die Benagelungsbude, manche nannten sie Pavillon, an den Nachmittagen und an Sonnabenden durch einen Schutzmann bewachen zu lassen, da ,rohe Lausbuben' die Rot-Kreuz-Damen immer wieder belästigten und die Bude mit Steinen bewarfen“. Krämer, Die Nagelung des Eisernen Mannes in Aschaffenburg (1995), S. 486. Ähnliche Vorfälle hat es ebenfalls in anderen Gemeinden gegeben. Auch in Hannover wurden angenagelte Schilder gestohlen.

1659 Schmitz/Popp, „Ein Markstein des Dankes aus Eiserner Zeit", http://www.europe14-18.eu /preview_site/telechargements02/zeit_aallll.doc (14.09.2009), S. 7; die beiden Aussagen wurden nach dieser Publikation zitiert.
} 
sich dagegen verwahrte, solange „,bis mir die Beteiligten mit Namen genannt sind“, so ist davon auszugehen, dass die Vorwürfe stimmten, denn ähnliche Klagen hat es, wenn auch vereinzelt, auch bei Sammelaktionen gegeben.

\subsubsection{Finanzierung, Werbung, Spendensummen}

Auf die Frage, wie angesichts der wirtschaftlich schlechten Zeiten gerade die Schulkinder aus ärmeren Familien ,ihren' Nagel bezahlen konnten, ist bereits ansatzweise eingegangen worden. Im Wesentlichen gab es zwei Möglichkeiten: Entweder die Kosten wurden von privaten Spendern übernommen, wie z. B. in Chemnitz, Dresden, Mannheim, Peine und Unna, oder die Schüler - meistens im Klassenrahmen - verdienten ${ }^{1660}$ sich das Geld durch Sammlungen selbst, wie die folgenden Beispiele aus Husum, Königsberg (Ostpreußen) Krefeld, Neumünster Traunstein und Schleswig zeigen.

In der „Niederrheinischen Volkszeitung“ wurde am 10. März 1916 darauf hingewiesen, dass die Klassen 1b und 5 der Volksschule 25 am „Eisernen Georg“ in Krefeld erschienen seien, um „ihr in vielen Wochen gesammeltes Scherflein beizutragen“1661. Vergleichbar war es in Traunstein: "Ganz besonders rührend war es, wie manche Kinder ihre Spargroschen brachten, um ihrerseits ihr Scherflein beizutragen. “1662

Verhältnismäßig erfolgreich waren die Sammlungen am Lyzeum und Oberlyzeum in Schleswig, die in einer Lehrerkonferenz am 18. August 1916 beschlossen worden waren: „Am Sedantage soll der ,Isern Hinnerk' benagelt werden. In den Klassen soll gesammelt werden und von dem Erlös ein Schild oder Nägel erworben werden. “1663 Insgesamt sind 160,50 Mark zusammen gekommen, die dem Roten Kreuz überwiesen wurden. In Augsburg, wo Schüler des Realgymnasiums, darunter Bertolt Brecht, ,zur Bekundung ihres patriotischen Sinnes“ zusammen mit ihren Lehrern eine Holzsäule benagelten, betrug die Nagelspende im Juli 1916 361 Mark. $^{1664}$

Die Mitwirkung der Schülerinnen und der Schüler in Husum, wo ein Modell des Stadtwappens benagelt wurde, ist in den Husumer Nachrichten mehrfach lobend erwähnt worden: „Selbst die Schulkinder wollen nicht zurückstehen und ihr Scherflein beitragen, sie veranstalteten deshalb Sammlungen in den verschiedenen Klassen. “1665

\footnotetext{
${ }^{1660}$ Lehmann, Weltkriegs-Erinnerungen aus dem Kreise des Gymnasiums zu Berlin-Steglitz (1925), S. 14-18.

${ }^{1661}$ Vom Eisernen Georg, Niederreinische Volkszeitung 11. März 1916.

1662 Naue, Gedenkblatt zur Benagelung des „Ehernen Wehrschildes" der Stadt Traunstein im Jahre 1915.

1663 Pust, ,Vaterländische Erziehung" für „Höhere Mädchen” (2004), S. 404.

${ }^{1664}$ Frisch/Obermeier, Brecht in Augsburg (1986), S. 77f.

1665 Pust, „Vaterländische Erziehung" für „Höhere Mädchen" (2004), S. 405.
} 
Auch in Königsberg (Provinz Ostpreußen) ,sammelten (Schüler) kleine Beträge zur Nagelung des ,Eisernen Wehrmanns“, der am Paradeplatz aufgestellt war““1666. Die Aktionen am Lyzeum in Neumünster waren insofern besonders interessant, als die Mädchen in ihrer Schule Nagelschilde der Firma Glasmachers benagelten, ,,deren Ertrag der Kreuznagelung am Sonntag zugeführt werden soll“1667. Hier wurde also die Nagelung des kommunalen Kriegswahrzeichens durch schuleigene Nagelungen finanziert.

Eine andere Möglichkeit der Geldbeschaffung nutzten die Schülerinnen und die Schüler der Realschule in Neustadt. Sie waren der Aufforderung zur „Sammlung von Heilpflanzen im Sommer 1918“ gefolgt und hatten unter Leitung ihrer Lehrer „Ehrenpreis, Schafgarbe, Spitzwegerich, Breitwegerich, Arnika-Blüten, Mutterkorn gesammelt. Das Saatgut übernahm und vergütete die Badische Landwirtschaftskammer in Karlsruhe. Weil die Schüler auf eine Vergütung verzichteten, kam der Erlös der Eisernen Uhr zugute.“1668

Schon diese wenigen Beispiele zeigen, dass Schulkinder aller Altersstufen in allen Regionen Deutschlands, von Husum (Provinz Schleswig-Holstein) bis Traunstein (Kgr. Bayern) und von Königsberg (Provinz Ostpreußen) bis Krefeld (Provinz Westfalen), durch verschiedene Sammelaktionen selbst für die Finanzierung der Spendennägel gesorgt haben. Es ist daneben auch vorgekommen, dass Schüler nicht für die eigenen Spendennägel sammelten, sondern als eifrige Werber für die Beteiligung der Bevölkerung an den Nagelungen auftraten und durch ihre Aufdringlichkeit die Bevölkerung verärgerten. In der Goslarschen Zeitung vom 20. August 1915 wurde über einen Fall ausführlich berichtet. ${ }^{1669}$ Nachdem die Spendenbereitschaft auch in Goslar (Provinz Hannover) offensichtlich nachgelassen hatte und weder die ,jungen Damen“ noch die „Jugendwehr“ als Verkäufer der Karten und der Nägel erfolgreich waren, griff man auf Kinder der Grundschulen zurück, die zwar Erfolg hatten, aber durch ihren Eifer und offensichtlich auch durch ihre Penetranz die Bevölkerung verärgerten.

Die Frage, welchen materiellen Nutzen die schulische Beteiligung an den kommunalen Nagelaktionen hatte, lässt sich aufgrund der schlechten Quellenlage nur ansatzweise beantworten. Es ist bei der Beschreibung einzelner Aktionen bereits mehrfach darauf hingewiesen worden, dass zwar in der Regel jeweils die Höhe der Spendensumme genannt worden ist, der Anteil der Schulkinder daran jedoch nur sehr selten. Offensichtlich kam es den Verantwortlichen hauptsächlich auf die Anwesenheit der Jungen und Mädchen und die Wirkung der,Weihestunden' auf sie an - und nicht auf das materielle Ergebnis.

\footnotetext{
${ }^{1666}$ Keine genaue Quellenangabe möglich. Der Text im Internet kann seit dem 7.2.2009 nicht mehr aufgerufen werden.

${ }^{1667}$ Pust, ,Vaterländische Erziehung" für „Höhere Mädchen” (2004), S. 409.

${ }^{1668}$ Herbner, Titisee-Neustadt (1995), S. 213.

${ }^{1669}$ Stadt und Kreis Goslar, Goslarsche Zeitung 20. August 1915.
} 
Die wenigen vorliegenden exakten Zahlen lassen trotzdem einige Schlüsse zu. Aus Münden (Provinz Hannover) liegen für die Monate Oktober bis Dezember 1916 detaillierte Zahlen vor. ${ }^{1670}$ Insgesamt wurden in diesem Zeitraum etwa 16.000 Mark an Nagelspenden eingenommen; darin enthalten sind 309 Mark der Schulkinder (= 1,93 \% der Gesamtsumme). Berücksichtigt man, dass neben den Schulen Mündens sich noch 10 Schulen des Landkreises an der Nagelung des „Eisernen Kreuzes“ beteiligten, so stehen Aufwand und Ertrag der schulischen Nagelaktionen in einem krassen Missverhältnis. Ferner fällt auf, dass die Schulkinder der Stadtschulen (275,29 Mark) erheblich mehr gestiftet haben als die der 10 Dorfschulen (34,50 Mark). Diesen Unterschied bestätigen die Ergebnisse aus anderen Kommunen.

Außerdem waren die Spenden der Gymnasiasten und der Schülerinnen der Lyzeen erheblich höher als die der Volksschulen. So spendeten die Schülerinnen der Privaten Vorschule und Höheren Töchterschule in Ahrensburg (Provinz Schleswig-Holstein) 314 Mark $^{1671}$, während die Jungen und Mädchen der Volksschule Augustenburg (Provinz Schleswig-Holstein) für 17 Mark $^{1672}$ und der Schule in Borsfleth (Provinz Schleswig-Holstein) für 20 Mark nagelten. In Neustadt kauften die Schulkinder der Realschule für 25 Mark Nägel, während im Lyzeum in Husum 148 M. und im Lyzeum Schleswig 160,25 M. zusammenkamen. In Ludwigsburg betrugen die Spenden der Schulen sogar 485,90 M. ${ }^{1673}$

Auch wenn sich teilweise Schüler (z. B. die Obersekunda des Gymnasiums in Zwickau im Kgr. Sachsen, die 50 Mark spendete) und Lehrer (in Krefeld spendeten sie 1.500 Mark) relativ beachtliche Summe sammelten und spendeten ${ }^{1674}$, so war der Anteil der Schulen an den Gesamteinnahmen der Nagelungen doch ziemlich gering und auch hinsichtlich des materiellen Nutzens nicht bedeutsam. Dieses zeigt auch das Spendenergebnis in Wetter (Ruhr): Drei Monate nach Einweihung des Kriegswahrzeichens waren an Spenden 73.865,07 Mark eingenommen worden; davon entfielen auf die Vereine 3.750,70 Mark und auf die Schulen 898,76 Mark. ${ }^{1675}$ Die Nagelungen der Schüler machten also lediglich 0,82 \% aus!

Vergleicht man sie mit den Summen, die von einzelnen Spendern den Schulkindern zur Verfügung gestellt wurden (z. B. 900 Mark für 1.800 Schülerinnen in Peine, in Münster finanziel-

\footnotetext{
${ }^{1670}$ Deutsch/Drebning/Korf, Die Nagelung des Eisernen Kreuzes 1915/16 in Hann.-Münden (1996), S. 55-58 und 67.

${ }^{1671}$ Mehlis, Festschrift zur 50-Jahr-Feier der Stormarnschule Ahrensburg im Mai 1977, http://stormarnschule.lernnetz.de/archiv/buch1977/mehlis.htm (14.02.2008).

${ }^{1672}$ Für die gesammelten 17 Mark durfte der Klassenerste Albert Schröder 3 goldene und 2 silberne Nägel einschlagen (Brandt, Die Weltkriege und die Zeit dazwischen, http://www.kkbz.de/augusten/weltkriege.htm [25.03.2009]).

${ }^{1673}$ Die zwei Feldgrauen, Ludwigsburger Zeitung 13./14./15. Oktober 1916.

${ }^{1674}$ Nagelung des Hindenburg-Roland (1915-1916).

1675 Thier, Kriegswahrzeichen von Wetter (1994), S. 223.
} 
le Mittel für 3.000 Kinder oder in Offenbach 6.500 Mark für 13.000 Kinder), so bestätigt sich die Annahme, dass die Schulen selbst lediglich relativ geringe Spenden aufbrachten.

Wenn sich Organisatoren, Kommunen und auch Lehrer so intensiv bemühten, möglichst viele Schulkinder an den Nagelzeremonien teilnehmen zu lassen, so ist das nur damit zu erklären, dass man sie ideologisch beeinflussen und ihnen das Gefühl vermitteln wollte, zusammen mit vielen anderen Kämpfern an der „Heimatfront“ zu sein. Außerdem erhofften sich die Verantwortlichen durch die Teilnahme Tausender von Schulkindern offensichtlich auch einen Werbeeffekt für die erwachsenen Bürger, die den Kindern ihrer Gemeinde oder Stadt nicht nachstehen wollten.

\subsection{Fazit}

Die schulischen Nagelungen waren aufwendig inszenierte Veranstaltungen mit pseudoreligiösen und militärischen Elementen sowie patriotischen Reden und Liedern, die gerade bei Schulkindern bleibende Eindrücke hinterlassen haben dürften. Überwiegend standen nationale Erziehungsziele im Vordergrund, und nicht die materielle schulische Hilfe für die Kriegsfürsorge, denn die war ebenfalls - wie gezeigt - verhältnismäßig gering.

In der Arbeit ist mehrfach darauf hingewiesen worden, dass die Kultusbehörden sich immer wieder intensiv bemühten, die Schulen zum Sammeln, zur Liebestätigkeit und zu Hilfsdiensten aller Art anzuhalten. Auffällig ist, dass die vielen staatlichen Aufrufe in den Schulverwaltungsblättern sich fast nie auf Nagelaktionen bezogen. Lediglich die Tätigkeiten von „Jugendspende“ und „Jugenddank“ wurden einige Male am Rande erwähnt. ${ }^{1676}$

Sicher hängt das zum einen mit den relativ geringen Spendensummen, die die Schüler aufbrachten, und zum anderen damit zusammen, dass diese Gelder in erster Linie der kommunalen Kriegsfürsorge zugutekamen und nicht staatlichen Einrichtungen, wie es z. B. beim gesammelten Goldgeld und den gezeichneten Kriegsanleihen der Fall war. Es waren deshalb in erster Linie die Gemeinden und die Städte, die sich in dieser Hinsicht bemühten, die Schülerinnen und die Schüler aller Altersstufen und jeder Schulform en zusammen mit ihren Lehrern an den aufwendig inszenierten Weiheveranstaltungen zu beteiligen - und zwar mit sehr groBem Erfolg, wie die vielen aufgeführten Beispiele zeigen. Dabei kam es den Veranstaltern weniger auf die von den Schülern erbrachten Spenden an als vielmehr auf die pädagogisch-

\footnotetext{
${ }^{1676}$ In einem Bericht des preußischen Schulministers an das preußische Abgeordnetenhaus aus dem Jahre 1918 werden die Schulnagelungen ebenfalls - lobend - erwähnt: „Auf dem Gebiete der Wohltätigkeit hat sich die Schuljugend an all den zahlreichen Sammlungen und Veranstaltungen, die die Wohlfahrtspflege für Kriegs- und gemeine Zwecke ins Leben gerufen hat, mit erfreulichem Eifer beteiligt, insbesondere [...] an der Nagelung von Kriegswahrzeichen“(LAS, Abtlg. 302, Nr. 3178, S. 5 des Berichts).
} 
propagandistische Wirkung und die Multiplikatorenfunktion der Schulkinder. Über die Kinder wollte man die Eltern und die übrigen Verwandten zum Spenden motivieren.

„Wir fordern unsere Kinder auf, über das Gehörte und Gelernte mit ihren Angehörigen zu sprechen“, schrieben Lehrer in Baden an das Kreisschulamt und von einem Schriftsteller wurde auf ,die wichtige Möglichkeit der Einwirkung auf die Einsicht und Stimmung des Hauses durch die Kinder“1677 hingewiesen.

Hinzu kommt noch, dass für viele Erwachsene der Anblick von festlich gekleideten Mädchen und Jungen, jene mit Kränzen im Haar und weißen Kleidern und diese Fähnchen schwenkend, die unter den Klängen einer Militärkapelle zu Tausenden durch die geschmückte Stadt zum Festplatz zogen, um dort Nägel einzuschlagen, mit Sicherheit auch ein Beweggrund war, um ihrerseits an den Nagelungen und anderen Sammelaktionen teilzunehmen. Dass die Schulen sich fast ausnahmslos an den Nagelaktionen beteiligten haben und sowohl ganze Schulgemeinschaften als auch einzelne Klassen , aufmarschiert' sind und eigene ,Weiheveranstaltungen' inszeniert haben, ist auch auf die Berichterstattung der örtlichen Presse zurückzuführen. Von ihr ging ein Druck ist, dem sich auch die Schulen insgesamt nicht entziehen konnten. Denn es wurde detailliert über den Ablauf der Veranstaltungen und die Anwesenheit einzelner Klassen mit ihren Lehrern berichtet und sogar Spendenlisten veröffentlicht. Schulen und sogar einzelne Klassen, die noch nicht zum Nageln erschienen waren, wurden monierend genannt. Auch die Konkurrenz der Schulen an selben Schulort und mit Schulen der Nachbarschaft dürfte zum Nageln angespornt haben.

Nachdem das allgemeine Interesse an den Nagelaktionen im Laufe des Jahres 1916 nachgelassen hatte, wurden sie in den Schulen verstärkt propagiert - und zwar ebenfalls mit sehr großem Erfolg. Es kann davon ausgegangen werden, dass die große Mehrheit der knapp sechs Millionen deutschen Schulkinder einen oder mehrere Nägel in ein Nagelschild bzw. ein anderes Objekt in ihrer Schule geschlagen oder sich zumindest an einer kommunalen Nagelaktion beteiligt hat. Dass sie das durchgehend gern getan hat, zeigen Äußerungen aus jener Zeit und Erinnerungen von Zeitzeugen. Den meisten ging es so wie Franz Thomale bei der Nagelung der „Eisernen Kreuzes“ in Festenberg (Provinz Schlesien), der „ungeheuer stolz war“1678, als er einen Nagel einschlagen durfte.

Obwohl allein die Einnahmen der Vereine „Jugendspende“ und „Jugenddank“ mit ca. 2,5 Millionen Mark aus den Schildnagelungen beachtlich hoch waren ${ }^{1679}$ und die einzelnen Na-

\footnotetext{
1677 Demm, Ostpolitik und Propaganda im Ersten Weltkrieg (2002), S. 88.

1678 Thomale, Die schlesische Festungsstadt Festenberg, http://www.gross-wartenberg.de/sukgw/s081.html (28.12.2008).

${ }^{1679}$ Berücksichtigt man dabei, dass die Gesamteinahmen aus den allgemeinen Nagelungen, zu denen auch die Schulen ein wenig beigetragen haben, nach Schneider ,mehr als 10 Millionen Mark“ betrugen
} 
gelspenden der Schulen unter den damaligen Bedingungen oft erheblich waren, so spielten sie im Vergleich mit den anderen aufgezeigten Zielen eine untergeordnete Rolle. Entscheidend war es, den Schulkindern das Gefühl zu vermitteln, Mitglied der großen deutschen Volksgemeinschaft zu sein, zusammen mit anderen an der „Heimatfront“ für den Sieg Deutschlands zu kämpfen und die Jungen auf den späteren Einsatz an der militärischen Front vorzubereiten. Dieses ist an der „Schulfront“ mit den Nagelaktionen gelungen. 


\section{Sparen und Einschränkungen}

Zum Kampf der Schulen an der „Heimatfront“ gehörte neben Sammlungen, Verkäufen, Spenden und Veranstaltungen eine Reihe weiterer Maßnahmen. „Die heimatliche Kriegswaffe war zunächst der innere und äußere Zwang äußerster Sparsamkeit (sowie) die weise Verteilung des zur Verfügung stehenden Ernährungsmaterials (...).“1680 Immer wieder wurde durch Verordnungen und Erlasse an den vaterländischen Opfersinn der Schuljugend appelliert und dazu aufgerufen, sich einzuschränken und asketisch zu leben. In dieser Hinsicht wurde auch die Multiplikatorenwirkung der Schule in zunehmendem Maße genutzt, um die Bevölkerung entsprechend zu beeinflussen. So bat z. B. der Präsident des Kriegsernährungsamtes 1917 die Landlehrer, „schon die Kinder immer wieder an die vaterländische Pflicht des Einschränkens und Sparens und Abgebens von Vorräten für die Verpflegung des Heeres und der für das Heer arbeitenden, in Großstädten und Industriebezirken zusammengedrängten Volksgenossen ernst und dringend zu mahnen und damit durch die Kinder auf die Eltern einzuwirken“"1681.

Die Schulen sollten daneben noch in anderen Bereichen helfen, durch den sparsamen Umgang mit den Ressourcen und durch Propaganda die allgemeine Versorgungslage zu verbessern. Inwieweit das gelungen ist und wie vor allem die Schüler auf die Appelle an ihren Opfersinn reagierten und die damalige Situation empfanden, soll in den folgenden Abschnitten untersucht werden.

\subsection{Ernährung}

Bald nach Kriegsbeginn setzten ,Hamsterkäufe' bei der Bevölkerung bei Lebensmitteln ein, die aufgrund der Verknappung einiger Produkte nach den Gesetzen des Marktes zu Preissteigerungen führten. Zusätzlich wurde die Versorgung der Bevölkerung durch die Blockade der Einfuhren aus dem Ausland in zunehmendem Maße gefährdet. Die Festsetzung von Höchstpreisen erwies sich als ungeeignetes Mittel bei der Bekämpfung des ,Kriegswuchers', denn es führte in der Regel dazu, dass die Waren vom Markt verschwanden und die Knappheit sich noch verschärfte. Deshalb versuchte man den Mangel durch Einsparungen beim Verbrauch und durch Umstellung der Essgewohnheiten zu beheben. Zum Beispiel sollte auf Fleisch weitgehend verzichtet und stattdessen vegetarisch gegessen werden.

Da aber die Ernährungsprobleme trotzdem ständig größer wurden, entschloss sich die Reichsregierung nach langem Zögern zur Zwangsbewirtschaftung der Lebensmittel. So wurden 1915

\footnotetext{
${ }^{1680}$ Führen, Lehrer im Krieg (1936), S. 81.

${ }^{1681}$ Zitiert nach: Saul, Jugend im Schatten des Krieges (1983), S. 119.
} 
u. a. die Reichsgetreidestelle (Februar), die Reichsfleischstelle (1915), die Reichskartoffelstelle (Mai) und die Reichsfettstelle (Juli 1916) eingerichtet. Sehr spät, und zwar erst am 22. Mai 1916, wurden die Ämter einer Zentrale, dem neu errichteten Kriegsernäherungsamt unterstellt. Dieses führte u. a. Bestandsaufnahmen durch, ermittelte den Bedarf, legte Rationsgrenzen fest und übertrug die Verantwortung für die Versorgung der Bevölkerung weitgehend den kommunalen Behörden. Außerdem ließ es die Schulen durch die Schulbehörden häufig zur Mithilfe im Kampf gegen die Lebensmittelknappheit auffordern und „die Kinder immer wieder an die vaterländische Pflicht des Einschränkens und Sparens und Abgebens von Vorräten ${ }^{\star 1682}$ erinnern.

Insgesamt konnten aber alle Maßnahmen der Verwaltung nichts an den Versorgungsdefiziten ändern, was sich besonders im ,Steckrübenwinter’ (1916/17) zeigte, denn ,ernährungswirtschaftlich war der Krieg bereits zu Beginn des dritten Kriegsjahrs verloren“"1683.

Von den vielen Ernährungsmerkblättern, Appellen und Erlassen, die die Behörden an die Schulen schickten, soll beispielhaft auf vier eingegangen werden.

Im Jahr 1915 waren im ,Zentralblatt für die gesamte Unterrichtsverwaltung in Preußen’ „Ratschläge für die Kriegszeit“" der Zentralstelle für Volkswohlfahrt abgedruckt. Dort wird auch an die Schüler und die Lehrer als „Mitkämpfer und Opferwillige“ appelliert, „mitzuringen um den Lorbeer des Siegs“, indem sie vor der „Vergeudung der Nahrungsmittel gewarnt“ werden. Ferner werden sie zu „vernünftiger Lebenshaltung, die dem Ernst der Lage entspricht“, aufgerufen. Der sparsame Umgang mit Lebensmitteln schädige nicht die Gesundheit, sondern sei „vielmehr eine Quelle körperlicher und sittlicher Kraft“1684. Außerdem werden ausführliche Hinweise zur sinnvollen Nutzung der einzelnen Produkte gegeben und Vorschläge zur Zusammenstellung der Mahlzeiten gemacht.

Dass es teilweise schwer war, die Menschen von der Verschwendung des Brotes und der Verfütterung von Getreide an das Vieh abzuhalten, bezeugt die folgende Anordnung einer Kreisschulinspektion vom 14. 01. 1916:

„Sofort! Infolge der großen Futtermittelknappheit und der allgemeinen Vorstellung von einer reichlichen Ernte hat in weiten Volkskreisen trotz der ergangenen Verfütterungsvorschriften das Verfüttern von Brotgetreide sehr überhand genommen. [...] Lehrerinnen und Lehrer wollen daher sofort ihren ganzen Einfluß auf die Bevölkerung geltend machen und durch Hinweise und

Belehrungen im Unterrichte und im Verkehr außerhalb der Schule so schnell als möglich dieser Verfütterungsgefahr entgegenwirken. Die Herren Schulleiter ersuche ich, alsbald nach Empfang

\footnotetext{
${ }^{1682}$ Zitiert nach: Saul, Jugend im Schatten des Krieges (1983), S. 119.

1683 Skalweit, Die deutsche Kriegsernährungswirtschaft (1927), S. 3.

${ }^{1684}$ Zentralstelle für Kriegswohlfahrt (Hrsg.), Ernährungsmerkblatt, Zentralblatt für die gesamte Unterrichtsverwaltung in Preußen (1915), S. 426.
} 
von dieser Verfügung Abschrift zu nehmen, dieselbe dem Lehrkörper zur weiteren Veranlassung bekanntzugeben und das Original sofort weiterzugeben." ${ }^{1685}$

Während in den ,Ratschlägen' aus dem Jahre 1915 an die Pflicht der Lehrer (auf dem Lande) und ihrer Schüler als Kämpfer an der „Heimatfront“ appelliert wird („Mitkämpfer und Opferwillige“), wirkt der Aufruf „Sofort“ wie ein verzweifelter Versuch, die Menschen doch noch mithilfe der Lehrer von der Notwendigkeit zu überzeugen, das für die Versorgung der Bevölkerung lebensnotwendige Getreide nicht an Tiere zu verfüttern. Es wird deutlich, welch große Bedeutung man der Schule im Kampf gegen den „englischen Aushungerungsplan“ beimaß.

Im Unterschied zu den genannten Beispielen, wo die Lehrkräfte die direkten Adressaten waren, wurden in einem „Aufruf an Deutschlands Jugend“1686 die Schulkinder selbst angesprochen. Der Aufruf war von der beim Berliner Provinzialschulkollegium eingerichteten „Zentralstelle für Fragen der Volksernährung" verfasst und zur Verteilung an die Schülerinnen und Schüler der höheren Schulen bestimmt. In Anlehnung an die christlichen Zehn Gebote wurden die Schulkinder am Anfang darauf hingewiesen, dass es „Pflicht eines jeden“ sei, die zehn „Kriegsgebote“ zu beachten. Sie enthielten Appelle zur Enthaltsamkeit und Sparsamkeit (z. B. „6. Seid sparsam mit der Butter") sowie Vorschläge zur Veränderung der Essgewohnheiten (z. B. „3. Laßt euch Zeit zum Essen“). Das letzte Gebot war ein allgemeiner Appell an die Schüler in ihrer Rolle als Soldaten an der „Heimatfront“: „10. Bei allem, was ihr tut, bedenkt, daß ihr an eurem bescheidenen Teil mithelfen könnt, das neue Vaterland zu schaffen, auf das wir hoffen. Fühlt euch als Kämpfer der Heimarmee. Opfert und arbeitet.“1687

Noch bezeichnender für die Indoktrinierung der Schüler im Krieg war ein „Schülermerkblatt über kriegsmäßige Ernährung“ (1915), das damals wie ähnliche Veröffentlichungen auch die bisherigen Lesestücke im Unterricht ersetzte.

„B. Deine eigenen Schülertaten als Mitkämpfer in der Heimarmee gegen den englischen Aushungerungsplan.

(...)

3. Ich ziehe täglich als Apostel der neuen kriegsgemäßen Ernährungsweise in meine Familie ein.

4. Ich bitte mit Freundlichkeit um 2-3 fleischlose Tage in jeder Woche.

(...)

8. Ich werde um Weichkäse an Stelle von Fleisch bitten, weiß ich doch, dass $1 \frac{1}{2}$ Pfd. Weichkäse fast genau so viel Prozent Eiweiß enthält wie 1/2 Pfd. Rindfleisch.

9f. (...) ich bitte, nie die rohen Kartoffeln zu schälen, sondern sie stets mit Schale zu kochen;

${ }^{1685}$ Führen, Lehrer im Krieg (1936), S.82.

1686 Zentralstelle für Fragen der Volksernährung, Wir alle wollen Streiter sein!, Deutsches Philologen-Blatt 1915, S. 197f.

${ }^{1687}$ Ein ähnliches Kriegsmerkblatt für Schulkinder gab der Schöneberger Magistrat heraus; siehe: Merkblatt für Schulkinder, Die Lehrerin: Organ des Allgemeinen Deutschen Lehrerinnenvereins 1914/15, S. 346. 
g. (...) bitte, keine Torten und Kuchen zu unserer Einsegnungsfeier zu bestellen und auch sonst jede Hausbäckerei zu vermeiden;

h. (...) ich (bitte) abends oft statt um Brot lieber um Grütze-Suppe und mittags um Mehlspeisen mit Obst.

10. Ich mache einen Versuch, eine Kochkiste herzustellen, durch welche die Nährstoffe besser ausgenutzt werden. (...)

13. Ich verbreite als Mitkämpfer der Heimarmee den Trostgedanken: Laßt die Engländer getrost über unsere Brot- und hoffentlich bald auch über die Fleisch- und Buttermarken lachen! (...)

14. Ich mache darauf aufmerksam, daß viele Leute beim Hinaufsteigen von drei Treppen schon atemlos sind; ich werde oft erwähnen, daß solche Leute durch die neue Ernährungsweise und Einschränkung gesünder werden. “1688

In diesem Merkblatt werden die Schüler nicht nur als „Mitkämpfer in der Heimarmee“ bezeichnet, sondern darüber hinaus auch als „Apostel“. Durch die hyperbolische, ja blasphemische Ausdrucksweise bekommt der Auftrag für die - christlichen - Schüler eine nahezu missionarische Bedeutung, denn im Verständnis der christlichen Tradition sind Apostel Gesandte, die Christus beauftragt hat, das Evangelium zu verkünden. Dieses Beispiel zeigt besonders eindrucksvoll, welch außerordentlich großer moralischer Druck auf die Schulkinder ausgeübt wurde, um die „Wirtschaftsfront“" zu mobilisieren.

Solche pseudoreligiösen Vorstellungen waren durchaus nicht selten, sondern tauchten in vielen Aufrufen und Beiträgen in den Lehrerzeitschriften auf. So sollten z. B. nach Meinung eines Posener Lehrers die Kinder durch die Schule davon überzeugt werden, dass sie keine Pausenbrote, die mit Wurst oder Fleisch belegt sind, zur Schule mitbringen, denn ,ein solcher Fleischgenuß während des Krieges (sei) eine Sünde gegen das Vaterland und gegen unser ganzes Volk“.

Die genannten und viele weitere Erlasse, Verfügungen und andere Veröffentlichungen führten zu einer regen Diskussion innerhalb der Lehrerschaft. Treuge z. B. wies 1915 in einem Aufsatz auf die besondere Verantwortung der Schulen hin: „Seit Monaten wird in allen Schulen Deutschlands die Unterweisung der Jugend, durch diese wieder die Einwirkung auf die Elternkreise in Fragen der Lebenshaltung, der Ernährung durchgeführt. Diese Arbeit (ist) eine der $\mathrm{H}$ a u p $\mathrm{t}$ l e i s t u n g e n der Schule in der Gegenwart.“1689

Von den vielen Vorschlägen der Lehrerinnen und Lehrer, die helfen sollten, in dem, wie es damals hieß, ,englischen Feldzug gegen Frauen und Kinder“ siegreich zu bleiben, sollen einige hier angeführt werden.

Zum Beispiel verboten einige Berliner Schulleiter das 2. Frühstück in ihren Schulen. Die Maßnahme war jedoch sehr umstritten und wurde u. a. von dem Berliner Stadt- und Kreisschulinspektor kritisiert, der befürchtete, sie könne die Kinder- und Jugendlichen in ihrer

\footnotetext{
${ }^{1688}$ Lemm, Schulgeschichte in Berlin (1987), S. 109f.

${ }^{1689}$ Treuge, Die Aufgaben der Schule bei der Aufklärungsarbeit über die deutsche Volksernährung, Die Lehrerin: Organ des Allgemeinen Deutschen Lehrerinnenvereins 1915, S. 341.
} 
Entwicklung hemmen. ${ }^{1690}$ Er selbst schlug vor, in den Schulen an mehreren Stellen gut sichtbar das Schild „Ein deutscher Junge nascht nicht mehr, er spart und sorgt fürs deutsche Heer“ anzubringen, um die Schulkinder dadurch zur Sparsamkeit anzuhalten und von der Vergeudung abzuhalten.

Die Lehrer und die Schüler der Leibniz-Oberrealschule in Charlottenburg gründeten bereits im Herbst 1914 einen Verein, dessen Ziel es war, über den sparsamen Umgang mit Lebensmitteln aufzuklären und zur Enthaltsamkeit beim Trinken und Essen aufzurufen. Besonderen Wert legte man auf eine Anleitung zum gründlichen Kauen, „um den Nährwert der Speisen besser auszunutzen“. Die Mitglieder des Vereins verpflichteten sich zudem schriftlich, „sich in Art und Größe des Frühstücks zu beschränken und die Einhaltung des Versprechens wechselseitig zu überwachen“. Alle Mitglieder trugen als Vereinsabzeichen eine Nadel mit einer entsprechenden Aufschrift zur Schau. ${ }^{1691}$

Einen ähnlichen Zusammenschluss gab es in München. Auch dort verpflichteten sich die Mitglieder,

„,alle Nahrungsmittel nur in einem zur Erhaltung der Gesundheit erforderlichen Maße zu verzehren, in ihren Kreisen auf größte Sparsamkeit mit allen Lebensmitteln hinzuwirken und Fleischgenuß (Fische ausgenommen) bei sämtlichen Nebenmahlzeichen, außerdem an zwei vollen Tagen der Woche oder an Stelle der zwei vollen Tage wenigstens bei vier Hauptmahlzeiten der Woche (mittags und abends), zu unterlassen. “1692

Mit detaillierten Vorschlägen wandte sich der „Verband der akademisch gebildeten Lehrerinnen“ in einem Flugblatt speziell „An die deutschen Mädchen“. Da die einzelnen Vorschläge denen in den bereits genannten Veröffentlichungen entsprechen, kann auf Einzelheiten verzichtet werden. Bezeichnend allerdings ist, dass die angesprochenen Schülerinnen als „Haustöchter“ stolz darauf sein sollten, „daß sie als eine Armee im Lande durch Sparsamkeit und Pflichtreue unseren Soldaten helfen können, den Sieg zu erringen“.

Eine Lehrerin aus Eisenach verfasste einen Sparappell in Liedform und stellte ihn den Schulen zum Singen im Unterricht kostenlos zur Verfügung:

\footnotetext{
${ }^{1690}$ Siehe: Schepp, Schule und Krieg (1915).

1691 August 1914, Ein Volk zieht in den Krieg (1989), S. 187.

1692 Zitiert nach: Huckert, Förderung der Sparsamkeit in betreff der Lebensmittel durch die Lehrer der höheren Schulen, Deutsches Philologen-Blatt 1916, S. 147.
} 
„Aufruf.

(Melodie: Wohlauf, Kameraden.)

Laut klingt ein Kriegsruf vom Feinde her:

,Nicht retten euch Streiter, die braven,

Nicht schützt euch die blanke Torpedowehr:

Wir lassen kein Schiff in den Hafen!

In Deutschland schleicht der Hunger ein,

Und Deutschland, es wird bezwungen sein!'

Die Väter schau'n kühn der Not ins Gesicht,

Erwägen bedacht die Gefahren:

,Einen Hungerfrieden schließen wir nicht,

Da mög' uns der Herrgott bewahren.'

In Treu' hält Grenz und Seewehr stand,

Auch wir, wir kämpfen fürs Vaterland.'

Es schwören in bitterer Kriegsnot

Fürsorgende Mütter und Frauen:

,Wir waren, wir sparen das heilige Brot,

Alldeutschland kann uns vertrauen.

Wie wär'n wir sonst am heim'schen Herd

Der draußen blutenden Kämpfer wert?'

,Jungfröhliche Schar, die helfen begehrt,

Ihr deutschen Mädchen und Knaben,

Frisch auf jetzt zum Kampf! - Nicht stahlhartes Schwert,

Doch stahlharten Sinn müßt ihr haben!

Spart mit das Brot, die edle Wehr,

Eßt dankbar, was not, doch niemals mehr.'

,Wir sparen!' - Sie rufen's von Haus zu Haus,

,Wir sparen!' geloben Millionen.

Viel Wenige machen ein Vieles aus!

Und Gott wird das Ringen belohnen.

In Huld schau Er vom Himmel drein:

Er woll' uns Sieg und Frieden verleih'n!'،“1693

Auch in diesem Lied, in dem wieder die religiösen Gefühle der Schulkinder angesprochen werden, geht es um patriotische Pflichterfüllung, Stärkung des Verteidigungswillens und Opfermut.

Besonders wurde von Lehrern und den Behörden für den Verzehr von Kartoffeln und Kriegsbrot (K-Brot) ${ }^{1694}$ sowie den weitgehenden Verzicht auf Wurst und Fleisch geworben. ${ }^{1695}$ Bäumer schrieb beispielsweise 1915 in einem Aufsatz, dass es zu den „Kriegspflichten“ der Schule gehöre, den Kindern ,mit aller patriotischen Eindringlichkeit die Mahnung zur Sparsamkeit einzuprägen [...] Auch die Kleinsten sind dem Gedanken zugänglich, daß wir hier

\footnotetext{
${ }^{1693}$ Aufruf, Die Lehrerin: Organ des Allgemeinen Deutschen Lehrerinnenvereins 1915/16, S. 13f.

1694 Über die Herstellung von Kriegsbrot wird in der Schul-, Dorf- und Kirchenchronik von St. Willibrord Wardt berichtet: „Roggenbrot durfte nicht ohne Zusatz von wenigstens 5\% Kartoffelmehl hergestellt werden. Die Bäcker durften bis 20\% Kartoffelmehl zusetzen.“ Siehe: http://www.xanten-web.de/Domstadt/WardtChro5.html (03.04.2008). Neben Kartoffeln gab es auch noch andere Zusätze, wie z. B. Gerstenmehl.

${ }^{1695}$ Siehe: Anhang, Seite 109 , Bilder 1 und 2.
} 
mit jedem Stück Brot sparsam sein müssen.“ Ihrer Meinung nach war die Bevölkerung moralisch verpflichtet, Kriegsbrot zu essen.

Von den Lehrern wurde für den Ausnahmefall auch die sog. „Schiebewurst“ propagiert. ${ }^{1696}$ Damit bei der großen Fleischknappheit wenigstens die Soldaten und die Arbeiter in der Schwerindustrie damit versorgt werden konnten, gab es viele Appelle und Veröffentlichungen zum Verzicht auf Fleischmahlzeiten. Als Beispiel sei der damals sehr bekannte ,Kriegsstruwwelpeter', der auch Lektüre im Unterricht war, genannt. ${ }^{1697}$ Er enthielt eine entsprechende Bildergeschichte, in der eine gut genährte Familie zu sehen ist, die an einem „fleischlosen Tag“ ausschließlich Kartoffeln isst. Der - fast ironisch wirkende - Text lautet:

„Dem Deutschen wird fürs Vaterland

Kein Opfer je zu schwer.

Drum fort mit Schinken und Kotelett, Und Pellkartoffeln her!“”

Auch über die Vorteile der Verwendung von „Kochkisten““1698 wurden die Schulkinder, die die Informationen an die Mütter weitergeben sollten, aufgeklärt. Die erforderlichen Informationen und Argumente für ein sparsames Umgehen mit Lebensmitteln fanden die Lehrer in einer umfangreichen „Literatur zur Volksernährung", die ihnen angeboten wurde. Bücher wie „Die deutsche Volksernährung und der englische Aushungerungsplan“ (P. Eltzbacher), der Ratgeber „Ernährung im Kriege“ sowie die „Staatsbürgerliche Belehrungen in der Kriegszeit“ (Kgl. Preuß. Landesgewerbeamt) waren damals in der Lehrerschaft bekannt.

Außerdem wurden die Lehrer geschult, damit sie die Bevölkerung durch ihre Vorträge wirkungsvoll beeinflussen konnten. Beispielsweise nahmen an einem vom Ministerium des Inneren in der Zeit vom 3. bis zum 6. Februar 1915 veranstalteten „Kurses für Redner über die Volksernährung im Kriege“1699 150 Lehrer (und Geistliche) teil. Einige Tage später (16. Februar) wurde für sämtliche Leiterinnen und Leiter der höheren Schulen von GroßBerlin eine Konferenz durchgeführt, in der es unter anderem um die Frage ging, was die höheren Schulen tun könnten, „um an ihrem Teil energisch mitzuwirken, das Defizit (an Getreide) zu decken“.

Auch wenn es nur relativ wenige zeitgenössische Quellen gibt, die über die Wirkung der schulischen Appelle Aufschluss geben, so kann aufgrund des Verhaltens der patriotisch erzo-

\footnotetext{
1696 Auf eine mit Margarine bestrichene Scheibe Brot legte man eine hauchdünne Scheibe Wurst, die mit den Zähnen beim Essen bis zum letzten Bissen weitergeschoben wurde. Man hatte sie also schon eine Weile gesehen, gerochen und geschmeckt, bevor man sie am Ende voller Genuss verspeiste. Siehe: dazu: Aus neuen Büchern, Deutsches Philologen-Blatt 1916, Beilage Nr. 1.

${ }^{1697}$ Olszewski, Der Kriegs-Struwwelpeter (1915); siehe: Anhang, Seite 10, Bild 3.

${ }^{1698}$ Es handelte sich um eine Holzkiste, die so gut isoliert war, dass in einem Kochtopf auf dem Herd erhitzte Speisen nur sehr langsam abkühlten und ohne weitere Energiezufuhr weitergarten.

${ }^{1699}$ Buchenau, Literatur zur Frage der Volksernährung, Deutsches Philologen-Blatt 1916, S. $196 f$.
} 
genen Kinder bei den Sammlungen und in Folge der massiven Beeinflussung durch die Lehrer davon ausgegangen werden, dass die meisten Kinder sich um einen sparsamen Umgang mit Lebensmitteln bemühten. Insofern spiegelt der folgende Brief eines Schülers durchaus die Einstellung der Schülerschaft wider: „Lieber Onkel! ... Wir essen nur Kriegsbrot und Kriegsbrötchen. Es ist so gut wie jedes andere Brot. Es ist auch viel nahrhafter.“1700

In den letzten beiden Kriegsjahren war die Versorgungslage so schlecht, dass es bei den meisten Menschen weniger um Einsparung und Verzicht ging als vielmehr um den täglichen Kampf gegen den Hunger. Ein anschauliches Beispiel für einen solchen Tagesablauf (20. April 1917) findet sich z. B. in „Nessis Kriegstagebuch“"1701. Auch der Zeitzeuge Rudolf Dunkmann berichtete ähnlich über die damalige Not. ${ }^{1702}$

\subsection{Kleidung}

Große Probleme gab es auch bei der Versorgung der Bevölkerung mit Schuhen und Textilien. Bereits Ende August 1914 trafen sich deshalb in Flensburg die Vertrauensmänner des örtlichen Lehrervereins, um auch über die Frage zu sprechen, wie man die „Not unter den Schulkindern in Bezug auf die Kleidung “1703 lindern könne. Aus den Akten der Schulverwaltung geht hervor, dass ein Mädchen im Dezember nicht zur Schule gehen konnte, da es an warmer Kleidung mangelte. Auch wenn eine solche Not zu diesem frühen Zeitpunkt des Krieges noch die Ausnahme war, so machte sich der Kleidermangel doch bereits im ersten Kriegsjahr in vielen ärmeren Familien bemerkbar. Während zu Beginn des Krieges der Hauptgrund für fehlende Kleidung der hohe Preis war, den einige nicht mehr bezahlen konnten, so zeigte sich in zunehmendem Maße die Wirkung der Handelsblockade auch in diesem Bereich, denn Deutschland verfügte über zu wenige Rohstoffe zur Herstellung von Wäsche, Kleidung und Schuhen. Im Herbst 1915 wurde deshalb die Reichsbekleidungsstelle eingerichtet und eine Bezugsscheinpflicht für Kleidung und Schuhe eingeführt.

Um dem Mangel an Rohstoffen abzuhelfen, wurden Textilien aus Brennnesselstängeln hergestellt ${ }^{1704}$ sowie bisher übliche Unter- und Bettwäsche durch Papierwäsche ersetzt. Schuhe stellte man „aus Linoleum, Pappe, Holz, Hartgummi (und) Lederabfällen aller Art ${ }^{\star 1705}$ her. Die Ergebnisse waren jedoch insgesamt unbefriedigend und reichten nicht zur Lösung der Versorgungsprobleme.

\footnotetext{
${ }^{1700}$ Lemm, Schulgeschichte in Berlin (1987), S. 110.

1701 Kiendl, Nessis Tagebuch aus dem Ersten Weltkrieg, http://www.zenker.se/History/nessi_tagebuch.shtml (01.12.2008).

${ }^{1702}$ Dunkmann/Sauermann, Aus dem Leben eines Heuerlings und Arbeiters 23 (1980), S. $31 \mathrm{ff}$.

${ }^{1703}$ Hohnsbehn, Die Flensburger Schuljugend in der Zeit des ersten Weltkriegs (1996), S. 57.

${ }^{1704}$ Siehe: Kapitel 2.3.3.

${ }^{1705}$ Meerwarth/Günther/Zimmermann, Die Einwirkung des Krieges auf Bevoelkerungsbewegung, Einkommen und Lebenshaltung in Deutschland (1932), S. 42.
} 
In diesem Abschnitt soll untersucht werden, was die Schule unternahm, um den Mangel, unter dem in zunehmendem Maße auch die wohlhabenderen Familien litten, zu lindern. Relativ spät, erst im Mai 1916, wandte sich der preußische Unterrichtsminister mit einem Erlass („Bekämpfung der Modeauswüchse“) an die Leiter sämtlicher Schulen, die von Mädchen besucht wurden, um die Schülerinnen „zum sparsamen Verbrauch mit den Vorräten“ (gemeint waren Stoffe) auffordern zu lassen. Er kritisierte die herrschende Mode mit ihren „oft übertrieben faltenreiche(n) Formen, da die Röcke und Mäntel doppelt so große Stoffmengen benötigten als bei einfacherer Ausführung" und forderte die Lehrerinnen und Lehrer auf, an den Patriotismus der Mädchen zu appellieren: „Die Aufklärungen haben darin zu gipfeln, daß es vaterländische Pflicht unserer Frauen und Mädchen ist, sich in der Bekleidungsfrage den Verhältnissen anzupassen und durch eine vernünftige und schlichte Kleidung das Durchhalten auch in dieser Beziehung zu ermöglichen. “1706

Bereits vor dieser Initiative des Ministeriums hatten viele Schulleiter ihre Schülerinnen zu entsprechender Sparsamkeit aufgerufen. So hatten sich im April 1916 die Direktorinnen und Direktoren der höheren Bildungsanstalten in Düsseldorf mit dem folgenden Aufruf an die weibliche Jugend gewandt:

„Deutsche Mädchen, zeigt eure vaterländische Gesinnung auch in der Art, wie ihr euch kleidet! Die Kriegszeit verlangt Sparsamkeit mit Stoffen und Leder. Die im Augenblick aufkommende Mode aber zeigt sinnlose Verschwendung in den übermäßig weiten Röcken und hohen Stiefeln. Werdet nicht zu Sklaven dieser Mode, denkt daran, daß mehr als je in dieser Zeit E i $\mathrm{n} \mathrm{f} \mathrm{a} \mathrm{h} \mathrm{h}$ e it und $S$ p a r s a m k e i t eure Ehre und euer kleidsamster Schmuck sind! Es wäre eine tiefe Beschämung für alle deutschen Frauen, wenn erst die Behörde dem Unfug der Mode durch Verbote steuern müßte. “1707

Auch wenn aufgrund der Quellenlage keine gesicherten Aussagen über die Wirksamkeit solcher Appelle und Aufrufe gemacht werden können, so kann doch davon ausgegangen werden, dass die meisten Mädchen wahrscheinlich auf eine zu aufwendige Kleidung verzichtet haben. Neben ihrer patriotischen Einstellung werden der soziale Druck durch die Mitschülerinnen aus den ärmeren Familien und der durch die Lehrkräfte ausgeübte moralische Druck viele Mädchen von einer zu modischen Kleidung abgehalten haben. Allerdings stellte sich bald das Problem mit der stoffaufwendigen modischen Kleidung nicht mehr, da die Versorgungsprobleme so groß wurden, dass auch die wohlhabenderen Schichten von dem Mangel betroffen waren. Gegen Ende des Krieges war jedes erträgliche Maß überschritten. „So machte sich denn im letzten Kriegsjahre eine Abgerissenheit breit, die jedem Ausländer, der Deutschland

\footnotetext{
${ }^{1706}$ Ministerium der geistlichen und Unterrichts-Angelegenheiten, Bekämpfung der Modeauswüchse, Zentralblatt für die gesamte Unterrichtsverwaltung in Preußen, 1916, S. 426f.

${ }^{1707}$ Aufruf an die Schülerinnen, Die Lehrerin: Organ des Allgemeinen Deutschen Lehrerinnenvereins 1915/16, S. 35 .
} 
1918 besuchte, [...] ins Auge gefallen ist. “" ${ }^{1708}$ Es ist sogar vorgekommen, dass Kinder nichts mehr anzuziehen hatten und deshalb die Schule nicht besuchen konnten. ${ }^{1709}$

Noch wesentlich größer als bei den Textilien machte sich der Mangel bei der Versorgung der Bevölkerung mit Schuhwerk bemerkbar. „Die zunehmende Knappheit an Leder und damit an Schuhwaren und Ausbesserungsmaterial für Schuhe zwingt zu größter Sparsamkeit im Gebrauch von Schuhlederzeug“, schrieb der preußische Unterrichtsminister im Juli 1917 und beauftragte die Provinzialregierungen, die Schüler

„zum sparsamen Verbrauch des Schuhwerks anzuhalten. [...]. Insbesondere sind sie anzuregen, Holzschuhe oder Sandalen mit Holzsohlen zu tragen oder, soweit es die Gesundheit zuläßt, während der Sommerzeit barfuß zu gehen, um das Schuhzeug für den Winter aufzusparen. Selbstverständlich ist den Schülern (Schülerinnen) zu gestatten, auch barfuß oder in Holzschuhen oder in Sandalen mit Holzsohlen zur Schule zu kommen." ${ }^{1710}$

Da das Klappern den Unterricht störte, war das Tragen von Holzsandalen in der Schule vor dem Krieg verboten. Aufgrund des großen Ledermangels wurde es jedoch bald nach Kriegsbeginn von den meisten Schulleitern erlaubt und von den Lehrern sogar empfohlen. Darüber hinaus beschäftigten sich die Lehrer in Konferenzen mit dem Problem, um vor allem den Kindern in den ärmeren Familien zu helfen. Am 18. Dezember 1916 „wies der Direktor (der Viktoria-Luise-Schule in Hameln) auf der Konferenz auf die immer verzweifeltere Stimmung im Volke hin u. auf die Aufgabe der Schule, dem entgegenzuwirken. Dann wurde [...] die Zweckmäßigkeit des Tragens von Holzschuhen besprochen“"1711.

In Flensburg bildete sich eine „Schuhfürsorge“, in der auch Lehrkräfte mitarbeiteten. Sie hatte es sich zum Ziel gesetzt, die größte Not bei den Kindern zu lindern: „Aus einer Hilfskasse, die aus freiwilligen Spenden gespeist wurde, konnten 620 Schulkinder unentgeltlich mit brauchbarem Schuhwerk versehen werden. Außerdem wurden in den letzten beiden Jahren durch besondere Mittel 484 Kinder zu Weihnachten mit Holzstiefeln, Holzschuhen und Hausschuhen beschenkt. “ ${ }^{1712}$

Wie groß die allgemeine Versorgungsnot in der Bevölkerung und besonders bei den Kindern im Krieg war, geht aus vielen Chroniken, Tagebüchern und Erinnerungen von Zeitzeugen hervor. Einige Äußerungen sollen hier zitiert werden.

\footnotetext{
${ }^{1708}$ Meerwarth/Günther/Zimmermann, Die Einwirkung des Krieges auf Bevoelkerungsbewegung, Einkommen und Lebenshaltung in Deutschland (1932), S. 421.

${ }_{1709}$ Siehe: Hohnsbehn, Die Flensburger Schuljugend in der Zeit des ersten Weltkriegs (1996), S. 57.

${ }^{1710}$ Ministerium der geistlichen und Unterrichts-Angelegenheiten, Sparsamkeit im Gebrauch von Lederschuhzeug., Zentralblatt für die gesamte Unterrichtsverwaltung in Preußen, 1917/18, S. 38f. Bereits am 3.11.1916 hatte preußische Unterrichtsminister in einem Erlass auf das Problem hingewiesen und zu größter Sparsamkeit aufgefordert.

1711 Schulchronik „Die Schule im Ersten Weltkrieg 1914-1918", http://www.vikilu.de/vikilu/index.php?id=61 (06.03.2009).

${ }^{1712}$ Zitiert nach: Hohnsbehn, Die Flensburger Schuljugend in der Zeit des ersten Weltkriegs (1996), S. 63.
} 
„In der warmen Jahreszeit gingen unsere Schulkinder meistens barfuß - im Winter erdröhnte das endlose Geklapper der vielen Holzpantinen." ${ }^{\star 1713}$ (Bericht über Barmbeker Gemeindeschulen)

„Der ,Verfügung’, mit bloßen Füßen zu laufen, kommen die Kinder reichlich nach.“1714

(Aus der Chronik der Martinsschule zu Cappel, Sommer 1917)

„Wegen der Lederknappheit hat man unter die Stiefelsohlen Holzklötzchen genagelt. Aus alten Servietten nähte Mutter für mich Unterhosen. “'1715

(Walter von Loewenich, *1903)

„In einem Sommer wurde uns nahegelegt, barfuß in die Schule zu gehen, um Leder zu sparen. So wanderte ich barfuß über das Hallesche Tor durch die Friedrichstraße zur Kochstraße. Erfreulicherweise hat sich die Empfehlung nicht wiederholt. “"1716

(Johann Baptist Gradl, *1904)

„Ich hatte ein Paar Stiefel, das waren Damenstiefel. Die wurden früher noch mit einem Haken zugeknöpft. Das waren solche langen, und da war Holz unter. Solche Stiefel hatte ich; Gott sei Dank hatte ich die auch noch." ${ }^{1717}$

(Zeitzeuge aus Flensburg, *1905)

„Man benutzt jetzt vielfach kleine zugeschnittene Lederstücke ,Laufe patent' als Sohlenschoner. Ich will ein Schustereisen fürs Besohlen kaufen und ,Laufe patent' unter die Sohle nageln. “1718

(Heinrich Schröder, Lehrer in Flensburg)

„Auch ich hatte ein paar Stiefel, da waren solche Stücken Holz drunter, dann war die zweite Schicht, [...] so "ne Art Kunstleder und das obere Stück, das war Papier. [...], das ging dauernd kaputt." "1719

(Zeitzeugin aus Flensburg, *1908)

Insgesamt dokumentieren die zitierten Äußerungen nicht nur den großen Mangel an Schuhwerk, sondern zeigen auch, dass die Schule wenig helfen und allenfalls die größte Not der Kinder etwas lindern konnte.

Wie groß der Mangel an Kleidung gegen Ende des Krieges war und wie die Bevölkerung darunter litt, zeigt die Einschätzung des Flensburger Lehrers Heinrich Schröder, der Anfang 1918 schrieb: „Die Kleidungsnot ist jetzt wohl die schlimmste. Viele Arme, die von der Hand in den Mund leben müssen, werden kein Hemd mehr haben. “1720

Auch wenn man berücksichtigen muss, dass Schröder als Flensburger vor allem die ländliche Bevölkerung Schleswig-Holsteins im Blick hatte, die nicht so sehr unter Nahrungsmittelknappheit litt wie die der großen Städte, so beschreibt sie insgesamt zutreffend die damalige Situation.

\footnotetext{
${ }^{1713}$ Dörnte, Katholische Schulen in Hamburg 1832 bis 1933 (1984), S. 186.

1714 Friedel, Chronik der Martinschule, www.cappelpower.de/martinschule/geschichte/geschichte/_oo1.htm (03.10.2006).

${ }^{1715}$ Pörtner, Kindheit im Kaiserreich (1990), S. 233.

${ }^{1716}$ Pörtner, Kindheit im Kaiserreich (1990), S. 243.

${ }^{1717}$ Herr R. am 6.6.1991; zitiert nach: Hohnsbehn, Die Flensburger Schuljugend in der Zeit des ersten Weltkriegs (1996), S. 61f.

${ }^{1718}$ Hohnsbehn, Die Flensburger Schuljugend in der Zeit des ersten Weltkriegs (1996), S. 62; siehe: Anhang, Seite 110 .

${ }^{1719}$ Zitiert nach: Hohnsbehn, Die Flensburger Schuljugend in der Zeit des ersten Weltkriegs (1996), S. 61.

${ }^{1720}$ Schröder, Chronik des Weltkriegs, S. 245.
} 


\section{3 ,Kriegsgerechtes' Verhalten}

In diesem Anschnitt geht es im Unterschied zu den anderen nicht um Versorgungsprobleme, sondern um chauvinistische Erziehungsziele und deren Umsetzung. Bei den Schülerinnen und Schüler sollte die „Lust am Kampfe geweckt (werden) gegen jegliche Fremdtümelei, besonders gegen die wirklich entbehrlichen Fremdworten“1721.

Auch durch diese sprachpuristische Maßnahme sollten die Kinder zu Kämpfern an der „Heimatfront" erzogen werden, indem sie Ausdrücke aus der Sprache der Kriegsgegner vermieden. Dass die entsprechende Beeinflussung durch die Lehrer sehr erfolgreich war, zeigen viele zeitgenössische Berichte. So gründeten die Schülerinnen der Fontaneschule in BerlinSchöneberg in mehreren Klassen eine „Kriegskasse“, in die für jedes unnötige Fremdwort eingezahlt werden musste. ${ }^{1722}$

Auch die Schülerinnen der katholischen höheren Mädchenschule in Münster (heute Annettevon-Droste-Hülshoff-Gymnasium) beteiligten sich am „Kampf" gegen den „Fremdwörterunfug", wie es der damals bekannte Autor populärwissenschaftlicher, pädagogischer und fachdidaktischer Schriften, der Oberregierungsrat Dr. Adolf Matthias, nannte. Für jeden Gebrauch von Fremdwörtern im Unterricht mussten die Schülerinnen 5 Pfennig bezahlen. ${ }^{1723}$

Auch die zwölfjährige Schülerin Elfriede Kuhr aus Schneidemühl (Provinz Posen) äußerte sich ausführlich über den Kampf gegen den Gebrauch von Fremdwörtern, und zwar bereits am 3. August 1914:

„In der Schule sagen uns die Lehrer, wir hätten die vaterländische Pflicht, nicht mehr fremde Worte zu gebrauchen. Ich habe zuerst nicht gewußt, was sie damit meinten. Jetzt ist mir klar: Man darf nicht mehr ,Adieu' sagen, weil das französisch ist. Es ist eine Ehre ,Lebwohl' oder ,Auf Wiedersehen' zu sagen, meinetwegen auch ,Grüß Gott'. Mama muss ich jetzt ,Mutter' nennen, aber ,Mutter' ist nicht zärtlich genug. Ich werde ,Muttchen' sagen. Wir haben eine kleine Blechkasse gekauft, in die wir jedesmal fünf Pfennige legen sollen, wenn wir uns versprochen haben. Der Inhalt der Kriegssparkasse wird zum Einkauf von Strickwolle verwendet. [...] Ich sagte heute zu unserem Naturkundelehrer: ,Soll ich die Geschichte vom Mäusebussard ins Diarium schreiben?' Herr Schiffmann antwortete: ,Wir haben uns doch vorgenommen, in unserer schönen deutschen Sprache zu reden. Diarium heißt Kladde.'

Ich dachte, Herr Schiffmann mache einen Witz und fing an zu lachen. Da wurde er böse.“1724

\footnotetext{
${ }^{1721}$ Ministerium der geistlichen und Unterrichts-Angelegenheiten, Beseitigung und Vermeidung fremdsprachlicher Ausdrücke und Redeweisen, Zentralblatt für die gesamte Unterrichtsverwaltung in Preußen, 1914, S. $277 \mathrm{f}$. In der Folgezeit gab es noch viele entsprechende Erlasse des preußischen Unterrichtsministers (z. B. am 19. Juni 1917 , Verdeutschung von Fremdwörtern', S. 516, A 159, 9. Heft) und der preußischen Provinzialregierungen (z. B. Schreiben der Regierung in Düsseldorf ,Beseitigung und Vermeidung fremdsprachlicher Ausdrücke und Redeweisen', abgedruckt in „Die Lehrerin“, Organ des Allgemeinen Deutschen Lehrerinnenvereins 1914/15, S. 12f. sowie Verfügungen der Schulbehörden.

1722 Jahresbericht der Fontaneschule 1914/15, siehe: Wildhagen, „Laß dich gelüsten nach der Männer Bildung (1994), S. 123.

${ }^{1723}$ Weber, Zur Geschichte des Annette-von-Droste-Hülshoff-Gymnasiums Münster 1690-1945, http://www.muenster.org/annette/ (28.01.2009).

${ }^{1724}$ Mihaly, ... da gibt's ein Wiedersehn! (1986), S. 16f.
} 
Dieser Text zeigt eindrucksvoll, in welchem Maße die Kinder teilweise unter Druck gesetzt wurden, um ausschließlich deutsche Begriffe zu verwenden. Allerdings gab es durchaus Lehrkräfte, denen der Sprachpurismus zu weit ging. Beispielsweise schrieb die Oberlehrerin Marie Sturm 1915 in der Zeitschrift „Die Lehrerin“: „Der löbliche Eifer, Fremdwörter durch deutsche zu ersetzen, hat neben manchen hübschen auch unpraktische, ja sogar häßliche ins Leben gerufen, die nie ein Glied der lebendigen Sprache werden können. Ich denke dabei an das Wort ,Inruhestandsversetzung (statt Pensionierung).“" ${ }^{1725}$ Aber auch sie stellte die ideologisch bedingte Sprachlenkung nicht prinzipiell infrage, sondern kritisierte lediglich deren Auswüchse.

Grundsätzlich wurde von der Lehrerschaft die Bekämpfung der Fremdwörter als eine Möglichkeit verstanden, sich mit den Soldaten an der Front solidarisch zu zeigen, indem sie die Sprache der Kriegsgegner boykottierten. ${ }^{1726}$ Bei dem Kampf wurden sie von der Presse, den Behörden und auch den Verlagen unterstützt. So wurden ihnen ,Eindeutschungslisten' und ,Verdeutschungswörterbücher' zur Verfügung gestellt. ${ }^{1727}$

Einen anderen Beitrag zum Kampf an der „Heimatfront“ sollten die Lehrer und die älteren Schüler dadurch leisten, dass sie auf den Genuss von Alkohol verzichteten. Nach Meinung der Bielefelder Lehrerin Wilhelmine Lohmann sei eine solche Abstinenz eine ,patriotische Liebestat“". Sie begründete in ihrem Aufsatz, in dem sie besonders die Lehrerinnen ansprach, ihre Forderung mit den „Schäden des Alkoholgenusses“, die die Widerstandskraft des eigenen Volkes schwächen und damit den Gegnern nutzen würden. Deshalb müsse man den Alkohol als den ,inneren Feind“ bekämpfen. Wilhelmine Lohmann gründete sogar eine „Zentralstelle“, bei der sich alle melden sollten, die sich zur Enthaltsamkeit entschlössen. ${ }^{1728}$ Ihre Forderungen, die von dem ,Verein abstinenter Philologen' und dem ,Bund abstinenter Frauen' unterstützt wurden, stießen durchaus auf eine positive Resonanz in der Lehrerpresse. Während sie zunächst besonders bei ihren Kolleginnen geworben hatte, wandte sie sich 1915 in einem

\footnotetext{
1725 Sturm, Zur Fremdwörterfrage, Die Lehrerin: Organ des Allgemeinen Deutschen Lehrerinnenvereins 1916/17, S. 333.

${ }^{1726}$ Neben der Vermeidung von Fremdwörtern wurde auch der Boykott von ausländischen Produkten von der schulischen Heimatfront betrieben. So heißt es beispielsweise in einem amtlichen Schreiben: „Ich bitte ergebenst darauf hinzuwirken, dass die Schulkinder keine englischen Stahlfedern mehr führen. [...] Die deutschen Stahlfedern z. B. aus den Fabriken Sönnken - Bonn und Brause - Iserlohn sind englischen Stahlfedern mindestens ebenbürtig." Zitiert nach: Löher, Furchbar dräute der Erbfeind, Band 3, S.108). Auch das in den Schulen verwendete Papier sollte ,deutschen Ursprungs“ sein, wie in einem Erlass des preußischen Unterrichtsministers vom 30.3.1915 verlangt wurde (Zentralblatt für die gesamte Unterrichtsverwaltung in Preußen, 1915, S. 456). ${ }^{1727}$ Siehe z. B.: Engel, Entwelschung (1918) und Anhang, Seite 111, Bilder 2 und 3.

${ }^{1728}$ Lohmann, Die Abstinenz als patriotische Liebestat, Die Lehrerin: Organ des Allgemeinen Deutschen Lehrerinnenvereins 1914/15, S. 260f. der Aufsatz wurde Interessenten kostenlos zur Verfügung gestellt.
} 
großen „Aufruf an die deutsche Jugend“1729 und rief sie zur Teilnahme am „Deutschen Jugenddank 1915“ auf. In ihm wurde besonders an den Patriotismus und die Verpflichtung zur Dankbarkeit gegenüber dem Kaiser, den Soldaten und dem Vaterland appelliert:

„Ihr Jünglinge und Mädchen, die ihr den Ernst und die Größe unserer Zeit erkannt habt, gedenket, daß Ihr es seid, für die das Vaterland jetzt verteidigt wird, auf daß ihr deutsch bleiben dürft auf deutscher Heimaterde. Laßt Eure Herzen erglühen in heißer Dankbarkeit für die unermeßlichen Opfer, die Eurer Sicherheit, Eurer Freiheit dargebracht werden - macht Euch ihrer würdig! [...] Drum fort mit allem, was Eure Wehrkraft, was Eure körperlichen und geistigen Fähigkeiten schwächt! Keine Zugeständnisse mehr an verweichlichende, gefährliche Zugeständnisse, an törichte Moden und an falsche Moral [...].

Gedenkt Eurer Dankesschuld gegen Kaiser und Vaterland! Gedenkt seiner warnenden Worte!

Sagt dem Alkohol ab, auf daß Ihr rechte Männer und Frauen werdet, die Stammeltern kraftvoller Geschlechter!

Unserem Kaiser zur Freude!

Unseren Helden zum Danke!

Unserem Volke zum Heil!

Unseren Feinden zum Trotze.

Das sei der , deutsche Jugenddank 1915!

Vorwärts deutsche Jugend!“(1730

Der „Deutsche Jugenddank“ ließ sogar Karten mit dem Aufdruck „Freiwilliger Verzicht deutscher Jünglinge u. Mädchen auf Alkoholgenuß für eine bestimmte Frist“" drucken und verkaufte sie. ${ }^{1731}$

Inwieweit die Schuljugend (und die Lehrerschaft) jener nationalistisch und chauvinistisch formulierten Aufforderung zur Abstinenz nachgekommen ist, lässt sich anhand der vorhandenen Quellen nicht nachweisen, doch ist anzunehmen, dass die Wirkung lediglich begrenzt gewesen ist, zumal die Schulbehörden die Initiative offensichtlich nicht unterstützt haben, denn sonst gäbe es entsprechende Hinweise in den Berichten damaliger Schüler und Lehrer oder Dokumentationen.

Wenngleich der Versuch, die Vaterlandsliebe der älteren Schülerinnen und Schüler auszunutzen, um sie zu Antialkoholikern zu machen, im Gegensatz zu dem Kampf gegen die Benutzung von Fremdwörtern offensichtlich gescheitert ist, so zeigt er doch, dass jedes Mittel genutzt wurde, um die Opferbereitschaft der Schüler und damit die „Heimatfront“ zu stärken.

\footnotetext{
${ }^{1729}$ Lohmann, Deutscher Jugenddank 1915, Die Lehrerin: Organ des Allgemeinen Deutschen Lehrerinnenvereins 1915/16, S. 278f. zusammen mit dem Aufruf wurden Erläuterungen zur Durchführung der Aktionen für Lehrer und Erzieher abgedruckt.

${ }^{1730}$ Lohmann, Deutscher Jugenddank, Die Lehrerin Organ des Allgemeinen Deutschen Lehrerinnenvereins 1915/16, $278 f$.

${ }^{1731}$ Sammlung Kronenberg.
} 


\title{
8.4 Schulalltag
}

Von Kriegsbeginn an wurde die Arbeit in den Schulen durch eine Reihe von Faktoren stark beeinträchtigt. So machte sich zunächst besonders der starke Lehrermangel bemerkbar, denn allein in Preußen waren von den 94.303 Lehrkräften 56.559 eingezogen worden, also 59,9\%. Für den Bereich der Volksschullehrer liegen Zahlen für das gesamte Reichsgebiet vor: Hier waren es von 149.172 männlichen Lehrkräften insgesamt 68.118, d. h. 45,4\%. Auch wenn viele Lehrkräfte die Vertretung ihrer Kollegen übernahmen, Vertretungslehrkräfte eingestellt und Klassenfrequenzen erhöht wurden ${ }^{1732}$, musste der Unterricht in der Regel gekürzt werden oder fiel teilweise aus. Aufschluss über die schwierige Personalsituation und die Einstellung der fast durchweg patriotisch eingestellten Lehrer gibt ein Beitrag eines Lehrers in einer Leipziger Lehrerzeitung:

\begin{abstract}
„Da immer mehr Lehrer zur Fahne einberufen werden, ist man hier und dort besorgt, ob sich der Unterrichtsbetrieb in zureichendem Maße aufrechterhalten läßt, und versucht deshalb dem Lehrermangel entgegenzuarbeiten, indem man Klassen zusammenlegt, Stunden streicht, Stoffe kürzt, Stundenermäßigungen rückgängig macht, Ruheständler beschäftigt, 18jährige Seminaristen, ,kulturverbreitend in entlegene Gaue' schickt u.s.w. [...].

Mögen sich unsere Reihen auch immer lichten, so wollen wir Zurückgebliebenen uns trotzdem den verschiedenen Mehrarbeiten gern unterziehen. Wir wollen, wenn es sein muß, neue Klassen übernehmen; Überstunden erteilen; mit scharfem Blicke zwischen wesentlichen und zur Not entbehrlichen Stoffen schieden; für die Freiheit in Bezug auf Lehrplan und Stundenplan kämpfen, damit wir den Schulbetrieb ohne Hilfe von Nichtlehrern aufrechterhalten können. ${ }^{\text {"1733 }}$
\end{abstract}

Allerdings gab es durchaus auch Klagen von Lehrern über die manchmal unerträglichen Rahmenbedingungen des Unterrichts, wie ein Bericht in der ,Pädagogischen Rundschau' vom 20. Mai 1915 belegt: „Es ist unmöglich, in einer Klasse mit 50 Sitzplätzen 80 bis 100 und mehr Kinder so unterzubringen, daß auch nur 10 Minuten ungeteilte Aufmerksamkeit herrscht. Die Kinder berühren sich dauernd und es fliegt die Unterrichtssaat über ihre Köpfe hinweg. Die Kombinationen haben ferner den Nachteil, daß sie die Kraft der Lehrenden besonders intensiv verbrauchen. “1734

Zum Lehrermangel kam noch in zunehmendem Maße der Mangel an Schulraum hinzu, denn immer mehr Schulen wurden entweder in Lazarette und oder in Kasernen umgewandelt. So hatten beispielweise in Preußen am 1. Dezember 19182.981 Klassen keinen Unterricht, da Räume fehlten. ${ }^{1735}$ In Berlin wurde bereits 1916 jede elfte Gemeindeschule als Kaserne genutzt, sodass in den verbliebenen Schulen Schichtunterricht eingeführt werden musste. In Turnhallen und Aulen wurden zudem häufig Sammelstellen für Laubheu, Lebensmittelspen-

\footnotetext{
${ }^{1732}$ Nach einer Verordnung des preußischen Kultusministers vom 6. Mai 1907 konnten einem Volksschullehrer bis zu 120 Kinder zugewiesen werden.

${ }^{1733}$ Führen, Lehrer im Krieg (1936), S. 104f.

${ }^{1734}$ Führen, Lehrer im Krieg (1936), S. 107.

${ }^{1735}$ Siehe: Führen, Lehrer im Krieg (1936), S. 97.
} 
den, Heilkräuter, Metalle u. a. eingerichtet. Außerdem waren 1916 in zehn Turnhallen von Berliner Gemeindeschulen Volksküchen eingerichtet worden. ${ }^{1736}$ Zusätzlich litten die Schulen vor allem unter dem Mangel an Arbeitsmaterialien, einer schlechten Ausstattung sowie unzureichender Heizung, Beleuchtung und Reinigung. Dieses soll an einigen konkreten Beispielen erläutert werden. Wie die zahlreichen Aufrufe zum Sammeln von Altpapier zeigen, herrschte in Deutschland ein starker Papiermangel. Wegen des Krieges war die Erzeugung von Papier und Zellstoff verringert worden und außerdem benötigte man Papier und Zellstoff in großem Maße für Spinnzwecke. Zudem wurde aus Holzzellulose Schießbaumwolle hergestellt. Zwar waren die Sammlungen von Altpapier als Rohstoff für die Erzeugung von neuem Papier und Pappe durchaus erfolgreich, die Produktion konnte jedoch den Bedarf bei Weitem nicht decken und deshalb musste gespart werden - und zwar besonders in der Verwaltung sowie an den Hochschulen und Schulen. Mehrfach wandte sich deshalb der preußische Unterrichtsminister mit Erlassen an die Schulen, um sie zum sparsamen und sorgsamen Umgang mit Schulheften, Schulbüchern, Zeichenmaterial, Papier für den Verwaltungsbedarf u. a. aufzufordern. Die Behörde ging insofern mit gutem Beispiel voran, als sie mit dem Schuljahr 1914/15 auf die bis dahin obligatorischen ,Jahresberichte' verzichtete. Im Erlass vom 19. Mai 1916 hieß es dazu: „Insbesondere wird auf die Drucklegung von Jahresberichten, Chroniken, Verwaltungsberichten usw. überhaupt verzichtet werden oder wenigstens ihre Erstattung für einen längeren Zeitraum als ein Jahr vorgesehen werden. “1737

In einem anderen Erlass (4. September 1915) wurde verlangt, dass „,neue Schulbücher und Lehrmittel, deren Gebrauch nicht unbedingt notwendig ist, nicht eingeführt und angeschafft werden“. Etwas später (17. Mai 1916) wurden die Lehrer aufgefordert, „durch Einwirkung auf die Schüler“ (dafür zu sorgen), „daß die Zurückweisung von Heften wegen schwachen Auslaufens und Durchschlagens der Tinte während des Krieges, soweit es angeht, unterbleibt.“ Offensichtlich hatte es Unmut und Proteste wegen der schlechten Qualität der Schreibhefte gegeben. (Der Minister erwartete von Schülern und Lehrern, dass) „ein jeder im vaterländischen Interesse seine Ansprüche an die Leimung des Papiers herabsetzen muss “1738. In einigen Regionen sollte sogar auf Zuckertüten, die die Kinder vor dem Krieg und teilweise auch noch bis 1915 kostenlos und feierlich von der Schule überreicht bekommen hatten, verzichtet werden, um Pappe (und Lebensmittel) zu sparen.

Viele Schulen ließen sogar wieder Schiefertafeln benutzen, wie die folgenden Texte zeigen:

\footnotetext{
${ }^{1736}$ Lemm, Schulgeschichte in Berlin (1987), S. 108.

1737 Ministerium der geistlichen und Unterrichts-Angelegenheiten, Verringerung der Druckaufträge auf dem Gebiete des Schulwesens, Zentralblatt für die gesamte Unterrichtsverwaltung in Preußen, 1916, S. $420 f$.

${ }^{1738}$ Zitiert nach: Deutsches Philologen-Blatt, 1916, Jg., 24, Heft 32, S. 511.
} 
„Der Papierverbrauch ist in den Schulen soweit wie möglich einzuschränken. Schüler und Schülerinnen haben nur so viele Hefte zu führen, als unumgänglich nötig ist. Jedes Heft ist voll auszunutzen, jede Raumverschwendung zu vermeiden und das Heft regelmäßig aufzubrauchen. Umschläge um die Hefte sind unberechtigt. In geeigneten Klassen und Fächern ist in möglichst weitem Umfange die Schiefertafel zu benutzen." ${ }^{1739}$ (Erlass des preußischen Unterrichtsministers vom 18. März 1916)

„Qualitätsminderungen des Papiers und schließlich Papierknappheit ließen die Schiefertafel wieder dominieren“"1740 (Realschule in Moabit).

kommt in der Schule die Schiefertafel wieder zu Ehren. Die Ober- und Mittelstufe macht Rechen-Hausaufgaben jetzt an der Tafel“" ${ }^{1741}$ (Volksschule in Haste, Kreis Schaumburg).

Auf weitere Einschränkungen im Schulalltag sei kurz hingewiesen. So wurde die Verwendung von „Stauböl“ für die Pflege der Fußböden in Klassenräumen verboten und als Seife durfte nur noch „Kriegsseife“ (K-Seife) sparsam verwendet werden. ${ }^{1742}$

Dass Kohle, Gas, Strom und Petroleum ebenfalls nicht ausreichend zur Verfügung standen, geht aus vielen zeitgenössischen Berichten hervor, z. B. aus einem über die Volksschule in Köln-Brück: „Auf Anordnung beginnt der Unterricht erst um 9 Uhr, um Licht und Brennstoff zu sparen. Vom 17. Februar bis 19. März 1916 bleiben in Cöln Schulen, Museen und Theater geschlossen. Die Kinder müssen allerdings morgens zur Schule kommen, um sich Hausaufgaben abzuholen, die nicht zu umfangreich sein sollen. “1743

Insgesamt ist deutlich geworden, dass der Schulalltag im Krieg durch viele Versorgungsprobleme und Sparzwänge geprägt war. Insofern ist die folgende Einschätzung eines hohen preuBischen Beamten aus dem Jahre 1918 falsch und entspricht nicht der damaligen

Wirklichkeit: „So ist das Bild, das die Schule unter der Einwirkung des Weltkrieges darbietet, im wesentlichen ein recht erfreuliches. “1744

Da die Probleme teilweise offensichtlich waren, schränkte er seine positive Beurteilung etwas ein, um einigermaßen glaubwürdig zu erscheinen. Wie es damals bei den Schulbehörden und anderen offiziellen Stellen üblich war, wurden Probleme so lange wie möglich verschwiegen, bestritten oder beschönigt, denn man war beim Kampf an der „Heimatfront“ auf die Opferwilligkeit und den Siegeswillen der Schüler angewiesen.

\footnotetext{
1739 Zitiert nach: Langer, Schulfrei für den Krieg (2004), S. 54.

${ }^{1740}$ Ebert, 75 Jahre Menzel-Oberschule (1902977), http://www.schule.de/schulen/menzel/allg/hist_ebert/ebert_3.html (29.01.2009).

${ }^{1741}$ Oelkers, Chronologie der Schule http://www.haste.de/chronik.html (15.07.2008).

1742 Seife war ebenfalls sehr knapp, sodass immer wieder zum sparsamen Umgang damit aufgerufen wurde; siehe: Anhang, Seite 110, Bild 1.

${ }^{1743}$ Dohm, Aus der Chronik der alten Brücker Volksschule, http://www.koeln-brueck.de/geschich/alteschu.htm (22.04.2008).

${ }^{1744}$ Schwarte, Der Weltkrieg in seiner Einwirkung auf das Deutsche Volk (1918), S. 425.
} 


\subsection{Fazit}

In diesem Kapitel ging es um die Einschränkungen des Schulbetriebes und die Folgen für Schüler und Lehrer. Wie das Beispiel der Berliner Schulen zeigt, waren die größeren Städte durch die Folgen der Fremdnutzung von Schulgebäuden, durch Schichtunterricht und Zusammenlegung von Klassen wesentlich stärker betroffen als die kleineren Landgemeinden mit nur einer Volksschule. Andererseits litten die Volksschulen auf dem Lande mehr unter dem Lehrermangel als die städtischen Schulen.

Trotz der teilweise unzumutbaren Rahmenbedingungen und der daraus resultierenden Belastungen für die Lehrer gab es keine nennenswerten Proteste der Lehrerschaft, auch wenn einzelne Lehrkräfte durchaus auf die Mängel und ihre Folgen hingewiesen haben. Insgesamt wurde akzeptiert, dass die militärischen Interessen grundsätzlich Vorrang vor den schulischen hatten. Diese Prioritätensetzung traf nicht nur auf die Nutzung der Schulgebäude zu, sondern bezog sich ebenfalls auf die Ausstattung, die Instandhaltung und vor allem auf die Lehrerversorgung. So zeigt die Tatsache, dass beispielsweise in Preußen fast $60 \%$ aller Lehrer zum Militär eingezogen worden sind, dass man die massive Störung des Unterrichtsbetriebes und die daraus resultierenden pädagogischen, staatsbürgerlichen und auch gesundheitlichen Folgen bewusst in Kauf nahm. Die Lehrerschaft versuchte insgesamt zwar der schwierigen Situation durch verstärkte Anstrengungen Rechnung zu tragen, war jedoch trotz allen patriotischen Eifers überfordert. Auf die Schulen in den Gebieten, die unmittelbar an der Front lagen, wie z. B. das Elsass oder Ostpreußen, und deshalb noch stärker von den Einschränkungen betroffen waren, soll hier nicht näher eingegangen werden. Insgesamt waren die personellen und materiellen Einschränkungen für die Schulen im gesamten Reichsgebiet dramatisch. Daran konnten auch die Sparappelle der Behörden und die Bemühungen der einzelnen Kommunen und Schulen kaum etwas ändern. 


\section{Kriegsunterricht}

Nachdem bisher die vielen Aktionen der Schulen an der „Heimatfront“ untersucht worden sind, soll in diesem Kapitel der Frage nachgegangen werden, welchen Anteil der Unterricht an den doch größtenteils beachtlichen Ergebnissen der Schüler hatte und welches die Folgen des starken außerunterrichtlichen Engagements für Erziehung und Bildung der Kinder waren. Grundlage dieser Untersuchung sind vor allem Erlasse und Verfügungen der Schulbehörden, Veröffentlichungen von Pädagogen zur „Kriegspädagogik“, Erfahrungsberichte und Unterrichtsmodelle aus der Kriegspraxis der Schule in den Lehrerverbandszeitungen und der fachdidaktischen Presse, Aufsatz- und Gedichtsammlungen, Unterrichtsmaterialien, Chroniken, Tagebücher und Erinnerungen. Aufgrund der Quellenbasis handelt es sich größtenteils um die intendierten Unterrichtsabläufe und nur teilweise um eine Beschreibung der Unterrichtswirklichkeit.

Eine der ersten amtlichen Verfügungen zur Situation der Schulen im Krieg war die „Aufforderung an die Lehrerschaft des Regierungsbezirks Hildesheims“" vom 29. August 1914:

„Der Gedanke an die Opfer, die wir bringen müssen, darf nicht die Siegesfreude und die Siegeshoffnung trüben. Und wenn die Kunde von dem Verluste teurer Angehöriger zu uns dringt, dann soll sie uns ein Trost und ein Stolz sein, daß sie für die höchsten Güter, für die Errettung des Vaterlandes aus schwerer Gefahr, freudig ihr Leben eingesetzt haben. Solche Gedanken müssen in die Herzen der Jugend gepflanzt werden. Wir erachten es für eine Aufgabe der Lehrerschaft, die Schuljugend zu einem bewußten Miterleben der großen Gegenwart anzuleiten.“

Die Verfügung enthält dann Hinweise zur Bedeutung der einzelnen Fächer im Rahmen der „Kriegspädagogik“; neben Geschichte, deren Aufgabe es sein soll, „,das Verständnis für die kriegerischen und die politischen Ereignisse des Tages zu wecken und zu fördern“, werden Deutsch, Erdkunde und Gesangunterricht genannt. Von Anfang an war man sich durchaus der negativen Folgen für die fachliche Unterrichtsqualität bewusst:

„Auf die Einhaltung des vorgesehenen Stoffverteilungsplans kommt es nicht an. In dieser Zeit müssen die unterrichtlichen Aufgaben der Schule gegenüber den erziehlichen zurücktreten. Gottvertrauen, Dankbarkeit und Geduld, feurige Liebe zum Vaterland, Kameradschaftlichkeit und Opfersinn und Opferfreudigkeit, das gilt es in den Kindern zu pflanzen und zu pflegen und auf solche Weise auch auf weitere Kreise zu wirken. “'1745

Einen ähnlichen Aufruf an die Lehrerschaft veröffentlichte wenige Tage später der Essener Kreisschuldirektor. ${ }^{1746}$ Viele der von ihm genannten Erziehungsziele entsprechen den in der Hildesheimer Verfügung genannten; er weist außerdem noch auf die Bedeutung des Handar-

\footnotetext{
${ }^{1745}$ Ministerium der geistlichen und Unterrichts-Angelegenheiten, Aufforderung an die Lehrerschaft des Regierungsbezirks Hildesheim, Amtliches Schulblatt für den Regierungsbezirk Hildesheim, 1914, S. 133-135.

${ }^{1746}$ Saul, Jugend im Schatten des Krieges (1983), S. 117. Der Aufruf wurde am 1. 10. 1914 im Amtlichen Schulblatt für den Regierungsbezirk Düsseldorf abgedruckt und damit der gesamten Lehrerschaft des Regierungsbezirks zur Umsetzung empfohlen.
} 
beitsunterrichts und vor allem der religiösen Erziehung im Unterricht hin: „Der hohe nationale Aufschwung muß durch den Geist herzlicher Frömmigkeit geweiht werden. Die Kinder sind daher zu besonders eifriger und andächtiger Beiwohnung der Gottesdienste anzuleiten und anzuhalten, eingedenk des kaiserlichen Mahnwortes: ,Gehet in die Kirchen und betet! “ In den späteren preußischen Erlassen und Verfügungen und auch in den Rechts- und Verwaltungsvorschriften der anderen deutschen Staaten werden außerdem noch „Kriegsrechnen“, Zeichenunterricht, Turnen sowie die naturkundlichen Fächer als kriegsrelevant genannt. In einem Runderlaß des Großherzoglichen Staatsministeriums in Mecklenburg-Strelitz an die Direktoren der höheren Lehranstalten vom 29. Juni 1915 („Einstellung des Unterrichts auf die Gegenwartsfragen“) wird zwar nur Geschichte - als wichtigstes Fach - genannt, es wird aber darauf hingewiesen, dass ,alle Fächer“ bei der Umstellung des Unterrichts auf die „Gegenwartsfragen“" von Bedeutung seien. ${ }^{1747}$ Vergleichbare Vorschriften liegen auch aus allen anderen Staaten des Deutschen Reichs vor. Beispielsweise hat das zuständige bayerische Ministerium ähnliche „,von patriotischem Geist getragene Leitsätze aufgestellt, die zur Klärung der wilden Kriegsereignisse und zu ihrer Vermittlung an die Schule anregten““1748.

\subsection{Pädagogische Schriften}

Wie aber reagierten die Lehrer der verschiedenen Schulformen auf die propagierten Ziele der „Kriegspädagogik“? Stimmt es, wie Ulrich Bendele behauptet, dass die „,pädagogische Mobilmachung (...) willig, eifrig und rasch“ erfolgte? ${ }^{1749}$ Diesen Fragen soll im Folgenden anhand von Veröffentlichungen zur „Kriegspädagogik“, die in nahezu unüberschaubarem Umfang vorhanden sind, nachgegangen werden. Allein das Deutsche Bücherverzeichnis registrierte unter dem Stichwort „Weltkrieg: Jugend, Schule und Krieg“ rund 700 aktuelle Titel. ${ }^{1750}$ In jeder pädagogischen Zeitschrift und in allen Periodika der Lehrerverbände setzte sich die Lehrerschaft mit den Herausforderungen, die die Kriegsereignisse für die unterrichtliche Arbeit in der Schule bedeuteten, auseinander. Die Autoren nahmen zwar teilweise auch zu unterrichtspraktischen Fragen Stellung (Wie kann der Unterrichtsbetrieb trotz des Lehrer- und des Raummangels aufrecht erhalten werden?), vorrangig jedoch ging es ihnen um die Erziehungsund Lernziele (Wie kann dem neuen Geist Rechnung getragen werden?). Diese sollen zunächst am Beispiel der Publikation eines Rektors aus Pasewalk (Provinz Pommern) ${ }^{1751}$ näher betrachtet werden. Der Autor ging davon aus, dass ,die unvergleichlich große Gegenwart (...)

\footnotetext{
${ }^{1747}$ Langer, Lernziel Krieg! (2000), S. 54.

${ }^{1748}$ Hensold, Ein Jahr Kriegspädagogik (1915), in: Deutsches Deutsches Philologen-Blatt 1915, S. 633.

1749 Bendele, Krieg, Kopf und Körper (1984), S. 143.

${ }^{1750}$ Siehe: Bendele, Krieg, Kopf und Körper (1984), S. 143.

${ }^{1751}$ Hantke, Die Schule und der Krieg (1915).
} 
all unser Denken und Handeln auf das Vaterland, auf Kaiser und Reich, Heer und Wehr, Krieg und Sieg“ ein Umdenken in der Schule erforderte, damit die Jugend ,,ihren gebührenden Anteil haben (könne) an Freude und Sorge, an Liebe und Haß, an Glaube und Hoffnung ${ }^{61752}$.

Er leitete daraus die folgenden pädagogischen Leitziele ab:

- Die Schule hat die Pflicht, ,die Kinder zum aufmerksamen Miterleben der großen Gegenwart zu führen“.

- Die Schule hat die Pflicht, „die Begeisterung der Kinder wachzuhalten (...) und das Interesse auch so zu vertiefen und für Unterricht und Erziehung dienstbar zu machen“.

- Die Schule klärt „über die wahren Ursachen des Krieges“ auf.

- Die Schule vermittelt zum Verständnis der Ereignisse die „kriegerischen und technischen Einzelheiten“.

- Die Schule vermittelt die ,hohe(n) vaterländische(n) Werte“ und pflegt sie sorgsam.

- Die Schule vermittelt „,die sittlichen und religiösen Werte“.

- Die Schule mobilisiert die Jugend ,zu gemeinsinniger, freiwilliger, vaterländischer Betätigung“.

Das letzte Lernziel, das das Engagement an der „Heimatfront“ fordert, war für den Autor der Höhepunkt der „Mobilmachung der Jugend“, gegenüber dem die anderen Ziele weniger bedeutsam seien. Ähnlich ist der Tenor fast aller anderen Publikationen, die das Thema „Schule und Krieg“" variierten, und zwar unabhängig von der Schulform, in der der Autor arbeitete. Einige Beispiele sollen dieses verdeutlichen.

\section{Volksschule}

Die Autorin der Abhandlung „Was sollen wir mit den Kindern vom Kriege sprechen?“1753 kam zu ähnlichen Ergebnissen wie der Pasewalker Rektor. Man solle die Gunst der Stunde nutzen, denn „nie wieder wird eine Zeit kommen, die eine so tiefe ethische Wirkung“ habe wie der Krieg, der belehrend auf die Schulkinder wirke. Es sei wichtig, den Kindern täglich zu zeigen, wie ,sorgfältig überlegt und vorbedacht auch die Maßnahmen der Regierung“ seien, und ihnen verstärkt „die Liebe zum Herrscherhaus“ nahe bringen, damit sie „tiefer und herzlicher“ werde. Außerdem sollten sie lernen, ,etwas zu opfern (...), um das stolze Gefühl zu haben: Auch ich kann etwas lernen in der schweren Zeit, und es ist eine Ehre, etwas tun zu dürfen“. Wie in den meisten Veröffentlichungen zur „Kriegspädagogik“ wird auch hier der Krieg als „ein großer Erzieher der Jugend“ gesehen. Ausgehend von der Frage „Hat das neue

\footnotetext{
${ }^{1752}$ Hantke, Die Schule und der Krieg (1915), S. 3.

${ }^{1753}$ Schulte $\beta$, Was sollen wir mit den Kindern vom Kriege sprechen? (1914).
} 
Schuljahr neue Gebote?“ beschreibt eine Lehrerin 1916 eine „, Kriegsstunde mit Kindern“1754, in der sechs neue „Gebote“ erarbeitet werden, von denen drei hier angeführt werden sollen:

„Du sollst mehr denn je alle Maßnahmen, Wünsche, Verordnungen, Regeln, unserer Staatsdiener beachten und deinen Kreis, auch als Kind, beeinflussen (...).

Lache der neuen Bosheit der Feinde, laß das Herze lachen mit den im 3. Jahre Genesenden. Singe den Leuten nach, die ins Feld marschieren. Juble dem kommenden Sieg entgegen (...).

Du sollst soviel dem Lande opfern, wie das Land dir im dritten Jahre Schutz, Ruhe und Ehre beschied.“1755

Die Gebote verpflichteten - wie die anderen drei auch - die Kinder, weiter an den Sieg zu glauben, für das Vaterland Opfer zu bringen und ihm dankbar zu sein. Ob tatsächlich mit zunehmender Kriegsdauer die patriotischen Lernziele wie die Liebe zum Vaterland und zum Herrscherhaus gegenüber Zielen wie dem Glauben an den Sieg und dem Engagement für die Heimatfront an Bedeutung verlieren, wie der Text vermuten lässt, soll anhand weiterer Texte überprüft werden.

\section{Mittelschule}

Da die Veröffentlichungen zur „Kriegspädagogik“von Mittelschullehrern insgesamt die oben genannten Lernziele lediglich geringfügig variieren, soll hier auf konkrete Beispiele bis auf eine Ausnahme verzichtet werden. Bei den nach 1916 erschienenen Texten fällt allerdings auf, dass - wie bei der „Kriegsstunde mit Kindern“ - die von den Schülern erwartete praktische Hilfe im Mittelpunkt steht, d. h. die Aktivitäten an der „Heimatfront“. So wird in „Die Mobilisierung der deutschen Schule für die Kriegshilfe“ auf den „empfindlichen Mangel an Rohstoffen jeglicher Art“" hingewiesenund an die Begeisterungsfähigkeit der Jugend appelliert (,,von dem einmütigen Geiste der Gemeinschaftsidee “1756). Außerdem werden praktische Vorschläge gemacht, um die Sammeltätigkeit noch effektiver zu machen.

\section{Lyzeum}

Auch von den meisten Lehrerinnen wurde der Krieg als ein positives Ereignis verstanden, wie das folgende Beispiel aus Chemnitz (Kgr. Sachsen) zeigt:

„Nun ist das Volk gerade noch zur rechten Zeit hart angepackt und aufgerüttelt worden, daß es sich besann auf das, was Großes und Edles in ihm schlummerte. Wollte Gotte, daß dieses plötzlich auflodernde Feuer eine Reinigung für das ganze Volk bedeute, eine Reinigung von allem, was eigentlich nicht deutsch ist und was doch der Seele anhaftet, - daß es reiner, besser, vertiefter nach diesem Krieg dastünde. “" ${ }^{\prime 157}$

\footnotetext{
${ }^{1754}$ Forstreuter, Hat das neue Kriegsjahr neue Gebote? (1916), S. 43 f. Eine weitere „Kriegsstunde“ mit einer Anfangsklasse ist abgedruckt in: Niemann, Der Krieg und die Schule (1915), S. 1.

${ }^{1755}$ Forstreuter, Hat das neue Kriegsjahr neue Gebote? (1916), S. 43f.

1756 Ohmann, Die Mobilisierung der deutschen Schule für die Kriegshilfe (1917), S. 400.

${ }^{1757}$ Petzold, Eine notwendige Arbeit im Dienst der Kriegshilfe, in: Die Lehrerin, Organ des Allgemeinen deutschen Lehrerinnenvereins 1914, S. 34.
} 
Die Autorin versteht wie viele andere auch den Krieg durchaus als ,Erzieher', im Unterschied zu den meisten Veröffentlichungen in den Publikationsorganen der Volksschullehrer und der Gymnasiallehrer setzen sich die Lyzeallehrerinnen allerdings stärker mit der Frage auseinander, wie die Schule der notleidenden Bevölkerung helfen kann. So wird im Text die Forderung an die Schule erhoben, sich nicht nur der „,materiellen Not der unteren Volksschichten“ anzunehmen, sondern auch der, ,innere(n) Not““1758, und z. B. Hausbesuche zu machen, um die Mütter in Erziehungsfragen zu beraten, oder „Mütterabende“ für die Mütter der Schülerinnen zu veranstalten. Gertrud Bäumer hielt es für eine Kriegspflicht der Schule“1759, die Öffentlichkeit über die Schwierigkeiten der Ernährung aufzuklären. Andere Aufsätze beschäftigten sich mit Hilfen für die Kinder, deren Väter an der Front waren („Gedenkt der Kinder!“(1760), und der „Kinder-und Jugendfürsorge im Krieg““1761 . Während die Lyzeallehrerinnen ihre Aufgabe darin sahen, die Mädchen auf ihre Rolle an der „Heimatfront“ vorzubereiten ${ }^{1762}$, fühlten sich die Lehrkräfte der Jungenschulen überdies dazu verpflichtet, die Schüler für ihren späteren Einsatz an der militärischen Front zu begeistern, wie der folgende Abschnitt zeigt.

\section{Gymnasium}

Bereits kurz nach Kriegsausbruch und in den darauf folgenden Monaten erschien eine Fülle von pädagogischen Aufsätzen, die sich, wie bereits deren Titel zeigen, mit den neuen Anforderungen an den Unterricht beschäftigten: „Der Krieg und der Schulunterricht“"1763 (1914), „Kriegspädagogische Betrachtungen“(1764 (1914), „Der Unterricht und der Krieg““1765 (1914), „Unterricht in der Kriegszeit““1766 /1915), „Zehn Gebote einer Kriegspädagogik““1767 (1915)

\footnotetext{
${ }^{1758}$ Petzold, Eine notwendige Arbeit im Dienst der Kriegshilfe, in: Die Lehrerin, Organ des Allgemeinen deutschen Lehrerinnenvereins 1914, S. 33.

${ }^{1759}$ Bäumer, Eine Kriegspflicht der Schule, in: Die Lehrerin, Organ des Allgemeinen Deutschen Lehrerinnenvereins 1914, S. $241 \mathrm{f}$.

${ }^{1760}$ Tews, Gedenkt der Kinder, in: Die Lehrerin, Organ des Allgemeinen Deutschen Lehrerinnenvereins 1914, S. $164 \mathrm{f}$.

${ }^{1761}$ Kinder- und Jugendfürsorge im Krieg, in: Die Lehrerin, Organ des Allgemeinen Deutschen Lehrerinnenvereins 1914, S. 170f.

${ }^{1762}$ Dieses geht auch aus einem Aufsatz von Margarete Treuge hervor: Man müsse die Kinder so erziehen, dass „dem nationalen Gedanken sich der volkswirtschaftliche verbinde“ (Treuge, Was können wir Lehrerinnen tun? In: Die Lehrerin, Organ des Allgemeinen Deutschen Lehrerinnenvereins 1914, S. 175f.)

${ }^{1763}$ Biese, Der Krieg und der Schulunterricht, in: Deutsches Philologen-Blatt Korrespondenz-Blatt für den akademisch gebildeten Lehrerstand, 1914. 562f.

${ }^{1764}$ Hartmann, Kriegspädagogische Betrachtungen, in: Deutsches Philologen-Blatt, Korrespondenz-Blatt für den akademisch gebildeten Lehrerstand, 1915, S. 42-45.

${ }^{1765}$ Wehrmann, Der Unterricht und der Krieg, in: Deutsches Philologen-Blatt, Korrespondenz-Blatt für den akademisch gebildeten Lehrerstand, 1914, S. 665.

${ }^{1766}$ Knebel, Unterricht in Kriegszeit, in: Deutsches Philologen-Blatt, Korrespondenz-Blatt für den akademisch gebildeten Lehrerstand, 1914, S. 638f.

1767 Ziegler, Zehn Gebote der Kriegspädagogik, in: Deutsches Philologen-Blatt, Korrespondenz-Blatt für den akademisch gebildeten Lehrerstand, 1914, S. 594.
} 
und „Wir alle wollen Streiter sein““1768 (1915). Alle Autoren betonten die große Chance, die der Krieg trotz vieler zusätzlicher Belastungen den Lehrern biete: „Eine so erschütternd große Zeit fordert vom Lehrer ihr Dolmetsch zu sein und in das tief durchfurchte Seelenleben der Jugend den Samen zu streuen, der volle Frucht auch für die Jugend verspricht.“ An ihrem Volk zu erleben, wie die „sittliche Macht der Not ungeahnte Kräfte“1769 entwickele, sei für die Kinder und Jugendlichen von größter Bedeutung. Immer wieder wurde in den Texten hervorgehoben, dass der Krieg ein „staatsbürgerlicher Erzieher allerersten Ranges““1770 sei und man deshalb die Kriegszeit verantwortungsvoll nutzen müsse.

Offensichtlich waren sehr viele Lehrer den Appellen, den an den Lehrplänen orientierten Unterricht zugunsten des von aktuellen Ereignissen ausgehenden „Kriegsunterrichts“ zu vernachlässigen, so konsequent gefolgt, dass eine Reihe von Lehrern Kritik übten und vor den Folgen warnten. Dieses soll an den Aufsätzen von Lehrern aus Dresden, München und Leipzig aus den Jahren 1915 und 1916 erläutert werden.

W. Becher (Dresden) war zwar auch der Meinung, dass der Krieg „viel Gutes“ bringe und der aktuelle Unterrichtsstoff „freudiger aufgenommen (werde) als im Friedensalltag“, er hielt den Kriegsunterricht aber auch für ein „Stück geistiger Verarmung“, da er zulasten des „,inhaltsreichen“ Unterrichts gehe. Er warnte eindringlich vor der Gefahr einer „Überfütterung“ der Schüler mit zu viel Kriegsstoff, da der „Mangel an Abwechslung (...) Überdruß, Sehnsucht nach dem Gegensatz“ erzeugen werde. Außerdem lasse die „öffentliche Wertschätzung der kriegerischen Taten (...) Schülern und auch Lehrern die Arbeit der Schule minder wertvoll erscheinen“1771. Dieses werde vor allem zu einer Ablehnung der Fremdsprachen und auch der Vergangenheit führen.

Aloys Fischer (München) ging in seiner Kritik noch weiter und kritisierte, „daß man die Schule nun ausdrücklich auf die Bewährung im Krieg anlegt, ihre Lehrpläne auf das auf im Krieg erforderliche zuschneidet, sie in eine Schule für den Krieg umwandelt“"1772. Es sei zwar erforderlich, sich über die Schule Gedanken zu machen, jedoch „,nicht um die Schule auf den Krieg hin zu orientieren noch um den Krieg unmittelbar der Schule dienstbar zu machen, sondern um die Einseitigkeit und Befangenheit des Denkens im (zukünftigen) Frieden durch die Ein-

\footnotetext{
1768 „Wir alle wollen Streiter sein!“隹 ein Aufruf an Deutschlands Jugend, in: Deutsches Philologen-Blatt, Korrespondenz-Blatt für den akademisch gebildeten Lehrerstand, 1915, S. 197f.

${ }_{1769}$ Biese, Der Krieg und der Schulunterricht, in Deutsches Philologen-Blatt, Korrespondenz-Blatt für den akademisch gebildeten Lehrerstand, 1914, S. 562.

${ }^{1770}$ Ziegler, Zehn Gebote einer Kriegspädagogik, in: Deutsches Philologen-Blatt, Korrespondenz-Blatt für den akademisch gebildeten Lehrerstand, 1914, S. 594.

${ }^{1771}$ Becher, Der Krieg und die Schule, in: Deutsches Philologen-Blatt, Korrespondenz-Blatt für den akademisch gebildeten Lehrerstand, 1915, S. 668f.

${ }^{1772}$ Fischer, Die höhere Schule im Lichte der Kriegserfahrung, in: Deutsches Philologen-Blatt, KorrespondenzBlatt für den akademisch gebildeten Lehrerstand, 1915, S. 713.
} 
wirkung der veränderten Stimmung, Bewußtseinslage und Betrachtungsweise im Krieg zu korrigieren““ ${ }^{1773} \mathrm{Er}$ wollte also aus der Kriegszeit Lehren für die zukünftige Gestaltung der Schule nach dem Ende des Krieges ziehen.

Johannes Richter (Leipzig) wollte vor allem die ,pädagogische Tiefe“ erhalten. Er war der Meinung, dass die Schule sich nicht „,auf Wehrhaftmachung und Kriegsstimmungspflege im edelsten Sinne“ beschränken solle und der Krieg nicht das „erzieherische Tagewerk“ hemmen dürfe, „wenn er nicht unwiederbringlich zerstören“ wolle. Ihm kam es in erster Linie auf den „deutschen Erziehungsgedanken“ an, dessen Wesen „im Genie des Kleinen, in Tüchtigkeit, Ordnung, Gründlichkeit, Arbeitsfreude und in der Spannkraft des Gemüts, in Selbstbeherrschung, Verantwortungsbewußtsein, Pflichtreue, Opferfähigkeit und Glauben“ liege. Daneben werde noch genügend Zeit für ein „,besonderes Kriegsgedenken““1774 blieben.

Auch wenn es weitere ähnlich kritische Aufsätze gab, so war doch die Mehrheit der Lehrerschaft an Gymnasien und an anderen Schulformen der Meinung, dass man entsprechend dem 8. Gebot der Kriegspädagogik (,Du sollst [...] allen Unterricht in Beziehung zu den Ereignissen des Tages [setzen]“(1775) aktuellen „Kriegsunterricht“ grundsätzlich dem durch die Lehrpläne vorgeschriebenen Unterrichtsstoff vorzuziehen habe.

Angesichts der dargestellten breiten Zustimmung zur „Kriegspädagogik“ war zu erwarten, dass die propagierten neuen Lernziele von den meisten Lehrern im Unterricht umgesetzt wurden, was auch, wie der nächste Abschnitt zeigen wird, zutraf. Es gab allerdings, zumindest in den ersten beiden Kriegsjahren, durchaus auch in anderer Hinsicht Kritik am „Kriegsunterricht“. Ein Lehrer aus Ansbach (Kgr. Bayern) kritisierte z. B. im November 1915, dass es vielen Kollegen nicht gelinge, die eigene Begeisterung für den Krieg den Schülern zu vermitteln: „Viele können das heilige Feuer, das in ihnen so tief brennt wie in irgendeinem Deutschen, einfach nicht weitergeben. Sie sind zu objektiv.“"1776

Auch Schulaufsichtsbehörden waren anfangs nicht immer mit dem „Kriegsunterricht“ einverstanden, wie eine Verfügung der Schulabteilung des Regierungsbezirks Stettin vom 23.2. 1915 verdeutlicht. Kommissaren war dort bei Unterrichtsbesuchen aufgefallen, dass die Kinder ,durchweg noch mehr zu dem Bewußtsein geführt werden (müssten), welch eines gewaltigen Stückes Geschichte Zeugen sie sind“. In dem Text wird dann noch eine Reihe von konkreten Vorschlägen gemacht, damit die Schüler vor allem auch „dem persönlich Großen in

\footnotetext{
${ }^{1773}$ Fischer, Die höhere Schule im Lichte der Kriegserfahrung, in: Deutsches Philologen-Blatt, KorrespondenzBlatt für den akademisch gebildeten Lehrerstand, 1915, S. 715.

${ }^{1774}$ Richter, Vom Kriegsthema in der deutschen Schule, in: Die Arbeitsschule, 1916, S. 354f.

1775 Ziegler, Zehn Gebote der Kriegspädagogik, in: Deutsches Philologen-Blatt, Korrespondenz-Blatt für den akademisch gebildeten Lehrerstand, 1914, S. 594.

${ }^{1776}$ Hensold, Ein Jahr Kriegspädagogik (1915), in: Deutsches Deutsches Philologen-Blatt 1915, S. 634.
} 
diesem Heldenkampf unseres Volkes, zumal bei den leitenden Männern, anschauend und mitempfindend innerlich nahekommen. “" ${ }^{1777}$ In erster Linie wurde also, wie es der Ansbacher Lehrer auch tat, kritisiert, dass der „Kriegsunterricht“ nicht anschaulich und begeisternd genug sei.

Dass in den Schulen insgesamt jedoch die „Kriegspädagogik“ den traditionellen Lehrstoff fast erdrückte, geht auch aus veröffentlichten Protesten hervor. Auf zwei soll kurz eingegangen werden, und zwar auf einen aus der Arbeiterschaft und einen von Intellektuellen. In der „Zeitschrift für die Interessen der Arbeiterinnen“" wurde kritisiert, dass die Regierung in der Schule „einen wertvollen Bundesgenossen zur Entfachung und Erhaltung einer kriegsstarken Gesinnung" bei der Jugend und in hohem Grade auch der Elternschaft habe, denn der Unterricht stehe seit Kriegsbeginn „ganz im Banne der Zeitereignisse“. Es wurde die Befürchtung geäuBert, dass das auf die Dauer „zu unersetzlichen Lücken im Wissen und Können der Schüler“ führen werde. Den „bürgerlichen Lehrern“ wurde vorgeworfen, dass ihrem „kriegsgefärbten Unterricht (...) das für ersprießliche Erziehungsarbeit notwendige Maß an Abgeklärtheit des Urteils und der Stimmung “1778 fehle.

Der „Aufruf an Eltern, Lehrer und Erzieher“ vom Dezember 1915 stellte zwar die Berechtigung der „Kriegspädagogik“ nicht grundsätzlich in Frage, die 13 Unterzeichner, Professoren, Schriftsteller und ein Lehrer, machten sich aber große Sorgen im Blick auf das geistige und sittliche Wohl der künftigen Generationen: „Haß, Rachedurst, Verachtung und Schadensfreude gegenüber den feindlichen Nationen und eigener nationaler Hochmut haben eine so erschreckende Ausdehnung gewonnen, daß es an der Zeit ist, das Schweigen hierüber zu brechen und sich ernstlich an alle zu wenden, welche die schwere Verantwortung der Erziehung tragen. “1779

Im folgenden Abschnitt soll der Frage nachgegangen werden, welchen Anteil die einzelnen Unterrichtsfächer bei der Umsetzung kriegspädagogischer Lernziele hatten und in welchem Umfang der Unterricht der ,Mobilmachung“ der Schüler für die „Heimatfront“ diente.

\subsection{Fächer}

\subsubsection{Geschichte}

Unter den Pädagogen und den Schulaufsichtsbeamten bestand Einigkeit darüber, dass von allen Fächern vor allem der Geschichtsunterricht es den Schülern ermögliche, ,die ruhmvolle (Kriegs-)Zeit verständnisvoll mitzuerleben“, da es seine Aufgabe sei, „,die Ereignisse der Ge-

\footnotetext{
1777 Saul, Jugend im Schatten des Krieges (1983), S. 127.

${ }^{1778}$ Elsner, Der Krieg und die Schule (1915), zitiert nach: Saul, Jugend im Schatten des Krieges (1983), S. 134f.

1779 Abgedruckt in: Saul, Jugend im Schatten des Krieges (1983), Material Nr. 17, S. 137f.
} 
genwart unmittelbar darzustellen und sie (...) als Ausgleichspunkte und Vergleichsmittel für die Vergangenheit zu nutzen“"1780. Sicher war das der Grund dafür, dass der preußische Unterrichtsminister im Krieg ausschließlich die Lehrpläne für Geschichte änderte und sie den Erfordernissen der „großen Zeit“ anpasste. Der Erlass „Die Neuordnung des Geschichtslehrplans für die höheren Schulen in Preußen vom 2. September 1915“ schrieb „Stoffverschiebungen (...) zugunsten der neuesten Geschichte“ vor. Ziel der Reform war es, die älteren Perioden erheblich zu kürzen und zusammenfassend zu behandeln, „,damit die Geschichte der letzten 50 Jahre ausführlich durchgenommen werden kann““1781. Ähnliche Erlasse traten etwas später für die Reformgymnasien (12. Oktober 1915) ${ }^{1782}$ und die höheren Mädchenschulen (26. Februar 1916) ${ }^{1783}$ in Kraft.

Wie stark die deutsche und die europäische Geschichte in erster Linie als Vorgeschichte des Weltkriegs gedeutet wurden, soll am Beispiel des Stoffverteilungsplans des Doberaner Gymnasiums (Ghzgt. Mecklenburg-Schwerin), den die Fachkonferenz Geschichte auf Anordnung der Regierung am 3. September 1915 beschlossen hatte, veranschaulicht werden. Leitziel des Unterrichts für die Klassen aller Jahrgangsstufen war es, den Schülern Kenntnisse über den Verlauf des Krieges zu vermitteln. Während beabsichtigt war, den Schülern in der Unterstufe durch Schilderungen der ,großen Führer und Helden des Krieges - der Kaiser, Kronprinz, Kronprinz von Bayern, Herzog von Württemberg, Hindenburg, Weddingen ${ }^{1784}$, Graf Spee u. a. -“ ein Bild vom Kriegsverlauf zu vermitteln, sollten die Schüler in der Mittelstufe Kenntnisse über „das deutsche Wehrwesen“ (Aufbau von Heer und Marine, Sanitätswesen u. a.) erwerben und sich die Kriegsereignisse in chronologischer Ordnung einprägen. Jeweils in Verbindung mit besonderen Aktionen an der „Heimatfront“, wie z. B. der Goldgeldsammlung und der Kriegsanleihe, sollte die wirtschaftliche Rüstung des Reiches erörtert werden. Ziele des Oberstufenunterrichts waren neben der Beherrschung des Kriegsverlaufs vor allem Kenntnisse über die ,inneren Ursachen des Krieges sowie die unmittelbaren Vorgänge, die zum Krieg geführt haben“. Auf Beispiele von Schulen aus anderen Staaten des Deutschen Reichs kann verzichtet werden, da sie weitgehend dem erläuterten entsprechen. Teilweise waren die Stoffverteilungspläne sehr detailliert und enthielten konkrete Vorschläge für Unterrichtseinheiten, wie z. B. „Das Zeitalter Wilhelms II.“, „Die Vorbereitung des Weltkrieges

\footnotetext{
${ }^{1780}$ Runderlaß des großherzoglichen Staatsministeriums, Abteilung für Unterrichtsangelegenheiten an die Direktoren der höheren Lehranstalten vom 29. Juni 1915, zitiert nach: Langer, Schulfrei für den Krieg, (1994), S. 54.

${ }^{1781}$ Der Minister der geistlichen usw. Angelegenheiten, Erlass zur „Neuordnung des Geschichtslehrplans für die höheren Schulen in Preußen“ vom 2. September 1915, abgedruckt in: Deutsches Philologen-Blatt, Korrespondenz-Blatt für den akademisch gebildeten Lehrerstand, 1915, S. 533-535.

1782 Zentralblatt für die gesamte Unterrichtsverwaltung in Preußen, 1915, S. 729.

${ }^{1783}$ Zentralblatt für die gesamte Unterrichtsverwaltung in Preußen, 1916, S. $314 f$.

${ }^{1784}$ Otto Weddingen, 1882-1915, bekannter Kommandant eines U-Bootes (U 9).
} 
durch Deutschlands Feinde, des Kaisers Fürsorge für Heer und Flotte“, „Ein Gang durch die Geschichte mit Berücksichtigung des gegenwärtigen Krieges“, „Deutschlands Machtstellung. Die Kriegführung einst und jetzt“, „Die guten Wirkungen des Krieges: Einigung des Volkes, Weckung des Vaterlandsgefühls, Opfermut und Opferwilligkeit“, „Die punischen Kriege an der Gegenwart veranschaulicht“, „Die Kolonisation der Deutschen im Osten mit der von heu-

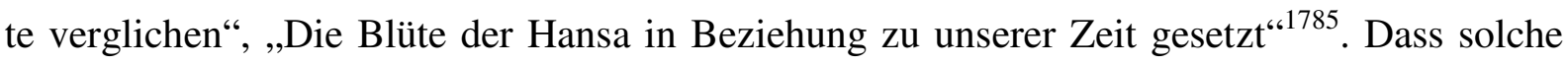
Themen entsprechend der „Kriegspädagogik“ umgesetzt worden sind, zeigen veröffentlichte Unterrichtsskizzen, wie z. B. „Zum Untergang des ,U 14““1786 (7. Schuljahr) oder „Englische Industriestädte von deutschen Luftschiffen heimgesucht"“1787 (7. Schuljahr).

Im Geschichtsunterricht wurde also in erster Linie über die aktuellen Kriegsereignisse informiert, Ereignisse aus der deutschen Geschichte mit der aktuellen Kriegsentwicklung verknüpft und die Bedeutung der „Heimatfront“ für das siegreiche Ende hervorgehoben.

\subsubsection{Deutsch}

Der Deutschunterricht war ebenfalls in besonderem Maße von der „Kriegspädagogik“ beeinflusst, da man glaubte, in diesem ,Gesinnungsfach“ die Kinder vielfältig beeinflussen zu können. Noch stärker als im Fach Geschichte, bei dem die aktuellen kriegerischen Ereignisse im Mittelpunkt standen, war Deutsch auf das „nationale Element“ ausgerichtet. Ein Oberlehrer formulierte es im Jahr 1915 folgendermaßen: „Nicht die Behandlung kriegerischer Ereignisse, sondern die Erziehung zu Persönlichkeiten, die Deutsch sind bis ins Mark ihrer Knochen, stellt uns die neue Zeit als Aufgabe.“1788 An Beispielen aus den Bereichen „Sprachlehre“, „Aufsatzlehre“, „Rechtschreibung“ und „Lesen bzw. Literatur“ soll diesem Aspekt weiter nachgegangen werden.

Sprachlehre

Kurz nach Kriegsausbruch wurden die Schulen von den Regierungen angewiesen ${ }^{1789}$, im Unterricht alle fremdsprachlichen Ausdrücke und Redeweisen zu vermeiden, sofern deutsche Begriffe zur Verfügung stünden. ${ }^{1790}$ Durch den Kampf gegen überflüssige Fremdwörter wollte man das Nationalbewusstsein stärken. Gegenstand des Unterrichts wurde ferner die Sprache der deutschen Soldaten (,Soldatendeutsch“) und das Einüben der sprachlich oft schwierigen Standortbezeichnungen der deutschen Truppen im Ausland. Auch der Entwurf von Tex-

\footnotetext{
${ }^{1785}$ Die Themen stammen aus der Untersuchung Pust über die Höheren Mädchenschulen in Schleswig-Holstein: Pust, ,,Vaterländische Erziehung" für „Höhere Mädchen" (2004), S. 317-322.

${ }^{1786}$ Deutsche Schulpraxis, 1915, S. 239. In der Zeitschrift sind zu allen Fächern Unterrichtsskizzen abgedruckt.

${ }^{1787}$ Deutsche Schulpraxis 1916, S. 237f.

${ }^{1788}$ Kießner, Gedanken zum Deutschen Unterricht in den Tagen des großen Krieges (1915); zitiert nach: Pust, „Vaterländische Erziehung" für „Höhere Mädchen" (2004), S. 315.

${ }^{1789}$ Z. B. am 27. August durch Verfügung der preußischen Provinzialregierung zu Düsseldorf.

${ }^{1790}$ Siehe Kapitel 8.3
} 
ten für Postkarten und Briefe für die Soldaten im Feld und das Üben von Anschriften waren fester Bestandteil des Unterrichts. Für den sprachkundlichen Unterricht wurde ebenfalls das Führen von „Kriegstagbüchern“ und einer „Schulkriegschronik“"1791 , an der auch die einzelnen Schüler mitarbeiten sollten, empfohlen. Dass selbst die jüngsten Schüler in den Elementarklassen im Unterricht massiv mit dem Krieg konfrontiert wurden, zeigt die Schilderung eines „Fahnenstündlein(s) zur Einübung der deutschen Sprache“. Die Unterrichtsstunde, in der sich die Schüler Sprachübungen am Beispiel der deutschen, österreichischen, sächsischen, preußischen und bayerischen Fahne machten, endete mit der Feststellung des Lehrers:

„So, jetzt seid ihr Soldaten. Jetzt müßt ihr marschieren. Ihr anderen seid die Musik. Was wird gespielt? Achtung! Stillgestanden! Vorwärts-marsch!! Ich hatt einen Kameraden, einen bessern findst du nit...die Vöglein im Walde...in der Heimat da gibt's ein Wiedersehn. Halt! Die Fahnen könnt ihr daheim malen. Wer es ganz fein machen will, nimmt buntes Papier, schneidet feine Streifen, klebt die an ein Holzstäbchen - und fertig ist die Fahne.“1792

\section{Aufsatzlehre}

Vor allem aus den Jahresberichten der Schulen und den veröffentlichen Aufsatzsammlungen geht hervor, dass sich die meisten Aufsätze mit dem Krieg beschäftigten, und zwar unabhängig von der Jahrgangsstufe. Während ältere Schüler der höheren Schulen häufig Zitate deutscher Klassiker zur aktuellen Kriegslage in Beziehung setzten ${ }^{1793}$, beschrieben jüngere Schüler in erster Linie, wie sie den Krieg direkt erlebt und was sie über ihn gehört hatten. Ihre Aufsätze handelten von Meldungen über große Siege (z. B. „Antwerpen ist gefallen“), von Heldentaten, von der Pflege verwundeter und vom Tod tapferer Soldaten („Ein Held“, „Wie für unsere verwundeten Krieger gesorgt wird“ und „Der Heldentod meines Onkels“), vom Kaiser („Der Kaiser auf dem Schlachtfelde“) und vor allem vom Kampf an der „Heimatfront “ ${ }^{* 1794}$, von dem hier mehrere Themen genannt werden, da sie Aufschluss über die schulischen Aktivitäten an der „Heimatfront“ geben:

\footnotetext{
${ }^{1791}$ Die Kreisschulinspektion aus Herford veröffentlichte eine ,Musterchronik‘, siehe: Amreihn, Der Weltkrieg im Unterricht (1916), S. 48f.

${ }^{1792}$ Zeibig, Ein Fahnenstündlein zur Übung der deutschen Sprache in meiner Elementarklasse, in: Deutsche Schulpraxis 1915, S. 326f.

${ }^{1793}$ In Lyzeum in Rendsburg (Provinz Schleswig-Holstein) erhielten die Schülerinnen im Zusammenhang mit der Lektüre von Schillers „Die Braut von Messina“ folgendes Thema: „Wie erleben wir gegenwärtig die Wahrheit des Chorworts ,Schön ist der Fried! Ein lieblicher Knabe liegt er gelagert am ruhigen Bach [...]. Aber der Krieg hat auch seine Ehre, der Beweger des Menschengeschicks?"“. Auch das Zitat aus Schillers, Wallensteins Tod“ „Der Krieg ist schrecklich wie des Himmels Plagen; doch ist er gut, ist ein Geschick wie sie“ musste von Schülerinnen im Kontext des Weltkriegs bearbeitet werden; zitiert nach: Pust, „Vaterländische Erziehung" für „Höhere Mädchen" (2004), S. 315. Dort werden weitere Beispiele genannt.

${ }_{1794}$ Die genannten Aufsatzthemen stammen aus: Reiniger, Der Weltkrieg im persönlichen Ausdruck der Kinder, 150 Schülerkriegsaufsätze (1915)
} 
„Die Siegesfeier auf dem Neumarkt.“

„Wie der Fall Antwerpens bei uns gefeiert wurde.“

„Was habe ich für mein Vaterland getan?“

„Kriegsbrot.“

„Ersatz fehlender Nahrungsmittel.“

„Der Gemüsegarten in der Kriegszeit.“

„Was wir an Nahrungsmitteln haben, und was uns fehlt.

„Die Reichswollwoche.“

„Woran wir merken, daß Krieg ist.“

Im Laufe des Krieges änderten sich die Schwerpunkte der Aufsatzthemen. Standen anfangs die Erlebnisse während der ersten Augusttage 1914 und die großen Siege im Mittelpunkt, so mussten sich die Schüler später hauptsächlich mit den vielen Tätigkeiten aus dem Bereich der Kriegswohlfahrt auseinandersetzen. Durch die Beschäftigung mit Themen wie „Unser Liebesgabenpaket“, „Mein Soldatenpaket“, „Unsere patriotische Weihnachtsfeier“, „Ein Weihnachtsbrief ins Feld“ „Was können wir Mädchen während des Krieges tun?“ und „Wie trage ich an meinem Teil dazu bei, daß das Vorhaben unserer Feinde, Deutschland auszuhungern, mißlingt?“ wollte man die Schüler für den Kampf an der „Heimatfront“ aktivieren. ${ }^{1795}$

\section{$\underline{\text { Rechtschreibung }}$}

Der vielfach vorgetragenen Forderung, dass Rechtschreibestoffe „feldgrau“ werden müssten, sind die Lehrer weitgehend gefolgt, wie viele Beispiele belegen. Es wurden Kriegsgeschichten aller Art diktiert, wobei häufig Hindenburg in vielen Diktatstoffen vorkam. ${ }^{1796}$ Auch bei einzelnen Übungen wurden militärische Inhalte verwendet, wie z. B. bei den folgenden Übungssätzen: „Im Marschieren haben unsere Soldaten Unglaubliches geleistet“ (Großschreibung) oder „Der Russe ist unser Feind“ (Doppel ,s‘) ${ }^{1797}$. Sogar der Lese- und Schreiblehrgang der Erstklässler war „feldgrau““1798, wie die Kriegsfibeln zeigen.

\section{Lesen bzw. Literatur}

Bei den Lehr-und Lektüreplänen der höheren Schulen sind mit Kriegsbeginn kaum Veränderungen vorgenommen worden. Nach wie vor standen im Unterricht für die älteren Jahrgänge die Werke der deutschen Klassiker im Mittelpunkt der Literaturbetrachtung, die immer wieder an die aktuellen Kriegsereignisse anknüpfte. Beispielsweise wurde Jeanne d'Arc aus Schillers „Jungfrau von Orleans“ in erster Linie als leuchtendes Beispiel der „Vaterlandsliebe“, der

\footnotetext{
${ }^{1795}$ Die Beispiele stammen aus: Pust, „Vaterländische Erziehung" für „Höhere Mädchen" (2004), S. 316.

${ }^{1796}$ Siehe z. B. „Hindenburg als Diktatstoff” (1915), abgedruckt in: Langer, Lernziel Krieg! (2000), S. 59f.

1797 Ausstellung Schule und Krieg 1915; zitiert nach: Bendele, Krieg, Kopf und Körper (1984), S. 161.

1798 Z. B. die "Fibel von Johannes Gosseck und Gustav Metelmann" aus dem Jahre 1918; siehe: Langer, Krieg! (2000), S. 56.
} 
„Selbstüberwindung“ und der „uneingeschränkten Opferbereitschaft“ interpretiert, dem es im gegenwärtigen Krieg nachzueifern gelte. ${ }^{1799}$ Auch Schillers „Maria Stuart“ und „Die Braut von Messina“ sowie Goethes „Faust“ wurden besonders häufig gelesen und ,kriegsnah“ interpretiert.

Soweit keine Ganzschriften gelesen wurden, wurden im Unterricht der jüngeren Schüler häufig Kriegsgeschichten besprochen, wie sie die „Kriegslesebücher“ und „Kriegslesehefte“ in großer Zahl enthielten. ${ }^{1800}$ Mit zunehmender Kriegsdauer wurde dort auch immer häufiger die Situation an der „Heimatfront“ thematisiert, wie z. B. die Erzählungen „Die Kriegsanleihe der Jungen von Erbesbach““1801 und „Der Held daheim““1802 zeigen. In letzterer wird der „Kriegsabend" eines Lehrers geschildert.

Dass auch Hilfsaktionen selbst als Themen für den Unterricht genutzt wurden, zeigt das Beispiel der 1915 durchgeführten „Buchwoche“. Für viele Lehrer bot sie

„Anknüpfung für die verschiedensten Erörterungen. Die Möglichkeit der Auswahl - historischer oder Gesellschaftsroman, die Novelle und die Reisebeschreibung, die Humoristen usw. - führte von selbst in die neuere Literatur ein und ersetzte mindestens drei dafür vorgesehene Stunden, befestigte durch die stärkere Anteilnahme der Schülerinnen das Gedächtnis für Namen und Dichtwerke, ermöglichte es, Geschmacksrichtungen etwas zu biegen und zu verfeinern, sanfte Einflüsse auch auf die Lektüre im Elternhaus zu gewinnen“1803.

Einen sehr breiten Raum im Deutschunterricht aller Schulformen nahm die „Kriegslyrik“ ein. Das gilt besonders für die Gedichte der Befreiungskriege (z. B. von E. M. Arndt, Th. Körner, M. v. Schenkendorf, Fr. Rückert) und noch stärker für die zeitgenössischen lyrischen Werke. Neben Autoren, die schon vor dem Krieg als Lyriker bekannt waren, wie Richard Dehmel, Max Dauthendey und Hermann Hesse, waren es auch „Männer aus dem Volke, die, von der hohen Woge der nationalen Begeisterung getragen, an der Front, mitten im Donner der Geschütze, den dichterischen Beruf in sich verspürten und Herrliches schufen“"1804. An zwei Beispielen soll aufgezeigt werden, welcher Art die Gedichte waren, die im Unterricht besprochen wurden.

\footnotetext{
${ }^{1799}$ Siehe dazu: Pust, „Vaterländische Erziehung" für „Höhere Mädchen" (2004), S. 313f.

${ }^{1800}$ Eine kleine Auswahl enthält: Bendele, Krieg, Kopf und Körper (1984), S. 158.

${ }^{1801}$ Schröer, Die Kriegsanleihe der Jungen von Erbesbach und andere Erzählungen aus dem Weltkrieg (o. J.), S. $5-11$.

${ }^{1802}$ Schröer, Die Kriegsanleihe der Jungen von Erbesbach und andere Erzählungen aus dem Weltkrieg (o. J.), S. $12-16$.

${ }^{1803}$ Treuge, ,Lebenskunde“ im Lyzeum, in: Die Lehrerin, Organ des Allgemeinen Deutschen Lehrerinnenvereins 1915, S. 12-123.

${ }^{1804}$ Hecker, Kriegspoesie 1914/16, IX. Poetische Stimmungsbilder aus großer stolzer Zeit, in: Deutsche Schulpraxis 1916, S. 229-231.
} 
Das Gedicht „Schwert aus der Scheide“ der damals recht bekannten Schriftstellerin Isolde Kurz (1853-1944) schildert die Situation im August 1914. Da „Verwüstung, unserm Wohlstand Zertrümmerung, unserer Ehre Beschimpfung ${ }^{\text {1805 }}$ drohte, unterzeichnet der Kaiser im Augenblick „der letzten Not“1806 den Mobilmachungsbefehl und zieht damit „,das Schwert aus der Scheide“. Der Lehrer beendete die Beschreibung der unterrichtlichen Gedichtbesprechung mit dem Satz: „Mit vollem Herzen aber beteiligen sich die Kinder an der Aussprache darüber, wie es sein wird, wenn es einmal heißt: Schwert in die Scheide.“ Dass sich Schüler zusammen mit dem Lehrer im dritten Kriegsjahr Gedanken über die Zeit nach dem Krieg machten, war durchaus keine Ausnahme.

Das andere Beispiel - „Thielemann“ - stammt von Rudolf Herzog (1869-1943), der sehr viele Kriegsgedichte verfasst hat, und wurde 1916 mit 13-14jährigen Volksschülern besprochen. In dem Gedicht wird, so hat es der Lehrer den Kindern am Anfang der Stunde mitgeteilt, von einem Landwehrmann erzählt, „,der Weib und Kinder zu Haus lassen mußte, draußen vor dem Feinde Wache stand, in treuem Ausharren den Heldentod fand und von lieber Kameradenhand bestattet ward“ ${ }^{\text {1807}}$. Nach der inhaltlichen und sprachlichen Analyse des Gedichts wurde über Anforderungen an den Vortrag des Gedichts gesprochen, die der Lehrer dann zusammenfasste: „Eine weihevolle Stimmung liegt über dem Gedichte, die auch im Vortrag zum Ausdruck kommen muß. Dann erst vermag es seine rechte Wirkung auf den Hörer auszuüben (...), immer wieder in unser Herz hineinklingen lassen.“1808 Dass der Dichter den Tod auf dem Schlachtfelde behandelte, war im Jahre 1916 nach den verlustreichen großen Schlachten keine Seltenheit. Nach der Besprechung des Gedichts sollten die Schüler es in ihr „Kriegstagebuch“ schreiben. Wie in vielen Gedichten und Geschichten, in denen man den Tod eines Soldaten thematisierte, wurde auch in Herzogs Gedicht der Tod eines Menschen religiös verklärt ${ }^{1809}$ und zum heldenhaften Opfer für das Vaterland stilisiert. Dass die Kinder außerdem zum Hass auf den Kriegsgegner, hier Frankreich, erzogen wurden, geht deutlich aus der Beschreibung des Lehrers hervor: "Was wäre geworden, wenn die Franzosen in unser deutsches Vaterland gekommen wären! Sie hätten ähnlich den Russen arg gehaust. Deutschland sollte ja vernichtet werden. “1810

\footnotetext{
${ }^{1805}$ Müller, Schwert aus der Scheide, in: Deutsche Schulpraxis 1916, S. 384. Auf Seite 383 ist das dreistrophige Gedicht abgedruckt.

${ }^{1806}$ Müller, Schwert aus der Scheide, in: Deutsche Schulpraxis 1916, S. 383, Strophe 1, Vers 7.

${ }^{1807}$ Tauscher, Behandlung eines Kriegsgedichts, in: Deutsche Schulpraxis 1916, S. 100. Auf den Seiten 100f. ist das fünfstrophige Gedicht abgedruckt.

${ }^{1808}$ Tauscher, Behandlung eines Kriegsgedichts, in: Deutsche Schulpraxis 1916, S. 100.

${ }^{1809}$ Im Gedicht (Strophe 7) spricht „Gottvater“: „Ich liebe die Thielemänner.“

${ }^{1810}$ Tauscher, Behandlung eines Kriegsgedichts, in: Deutsche Schulpraxis 1916, S. 102.
} 
Zum damaligen Unterricht gehörte neben der Besprechung von lyrischen Texten aber auch das Verfassen von eigenen Gedichten. Auf ein damals recht bekanntes Produkt („Für uns“) ist bereits hingewiesen worden. ${ }^{1811}$ Aus der großen Anzahl überlieferter Schülergedichte soll ein weiteres angeführt werden. Es stammt von einem Schüler der Volksschule in Dranske (Provinz Pommern) und wurde zu Beginn des Jahres 1915 verfasst:

\section{„Unser Krieg}

Fast vierzig Jahre hatten wir Frieden.

Doch länger war es uns nicht beschieden.

Der Russe, der Franzmann und auch der Brite

Erklärten den Krieg zur Jahresmitte.

Sie hofften, Deutschland bald zu erdrücken,

Mit siegreichen Fahnen in Berlin einzurücken.

Ein halbes Jahr haben sie schon gefochten,

Doch sind uns die Hände noch nicht geflochten.

Bis jetzt hab'n die Deutschen die Oberhand.

Wir kämpften siegreich in Feindesland.

So möge es enden, und zwar recht bald,

Du Deutschland siege! Behalte Gewalt.““1812

Die Kriegsgedichte von Lehrern unterschieden sich inhaltlich in der Regel nicht wesentlich von denen ihrer Schüler. Allerdings gibt es einige, in denen sich die Verfasser direkt an ihre eigenen Kollegen wandten, wie z. B. das in der „Mecklenburgischen Schulzeitung“ vom 11. 6. 1915 veröffentlichte „Kriegserziehung“, von dem die erste Strophe lautete: „Willst du deine Pflicht erfüllen / An der Jugend in der Not, stärke ihren schwachen Willen, stärke ihn mit Seelenbrot.“ ${ }^{1813}$ Auch wenn sich die meisten Deutschlehrer der minderwertigen Qualität solcher kriegsbedingten ,Gelegenheitsgedichte' bewusst waren, so wurden sie in den damals in großer Zahl erscheinenden und von den Regierungen empfohlenen Gedichtsammlungen für den Unterricht immer wieder abgedruckt und auch im Unterricht besprochen. Häufig wiederkehrende Motive waren die ,heldenhafte Stimmung des deutschen Heeres (und) sein heldenhaftes Ringen“, „die echte Soldatentreue (und) die opferwillige Hingabe des eigenen Lebens“" ${ }^{\text {1814, }}$, Siegeszuversicht sowie die opferbereite Entschlossenheit der Menschen an der „Heimatfront“.

Aufgrund seiner Bedeutung für die Umsetzung der „Kriegspädagogik“ wurde der Deutschunterricht an einer Reihe von Schulen auf Kosten anderer Fächer erweitert, wie z. B. am Lyzeum in Neumünster (Provinz Schleswig-Holstein). Was immer wieder in vielen pädagogischen

\footnotetext{
${ }^{1811}$ Siehe Kapitel 7.3, Seite 239.

1812 Langer, Der Krieg als Erzieher (2004), S. 50.

1813 Zitiert nach: Langer, Lernziel Krieg! (2000), S. 53.

${ }^{1814}$ Hecker, Kriegspoesie 1914/16, IX. Poetische Stimmungsbilder aus großer stolzer Zeit, in: Deutsche Schulpraxis 1916, S. $230 f$.
} 
Aufsätzen gefordert wurde ${ }^{1815}$, ist - und zwar nicht nur nach Meinung einer Lyzeallehrerin aus Neumünster - eingetroffen: „Erst der Krieg hat also (...) d e m Fach zu seinem Recht verholfen, das von vornherein (... im) Mittelpunkte stehen sollte““. ${ }^{1816}$

\subsubsection{Religion}

Auch der Religionsunterricht stand deutlich unter dem Einfluss des Krieges. Welche große Bedeutung dem Fach neben Geschichte und Deutsch von offizieller Seite beigemessen wurde, geht schon aus der Tatsache hervor, dass in einigen Ländern während des Krieges seine Stunden noch erhöht wurden, wie z. B. in Preußen, wo 1917 an den Mittelschulen wegen der „Bedeutung, die dem Religionsunterricht gerade auch für die mittleren Schulen“ zugesprochen wurde, die Stundenzahl von zwei auf drei auf Antrag erhöht werden konnte. ${ }^{1817}$ Für die Unterstufe blieb es bei der - im Vergleich zu anderen Fächern recht hohen - Zahl von drei Stunden. Wie in den anderen Fächern auch wurden im Religionsunterricht religiöse Inhalte zu den Kriegsereignissen in Beziehung gesetzt, wobei die Themen in erster Linie aus dem Alten Testament und der Kirchengeschichte gewählt wurden, da sich deren Texte für die intendierte „Kriegsethik“ besser eigneten als die des Neuen Testaments. Einige unterrichtspraktische Beispiele sollen zeigen, wie die Lehrer versuchten, christliche Ideale wie Nächstenliebe, Barmherzigkeit, Treue und Glauben mit den Kriegsereignissen zu verknüpfen.

Beispielsweise schreibt eine Lehrerin über eine Unterrichtsstunde in ihrer Unterstufenklasse, in der vor allem über Matthäus 5,7 (,Selig sind die Barmherzigen“) aus der Bergpredigt gesprochen wurde:

„Das sind z. B. die, die in diesem Krieg nichts wollen als allein dem Vaterland dienen und damit Gott, die tapfer sind und treu bis zum Sterben, weil sie fühlen, dass Gott sie zu einer heiligen Aufgabe gerufen hat. Dabei wird einem klar, daß die Besten nicht, Gott strafe England!' fühlen oder denken, wenn der Feind fällt, daß der Wille zur Sache des Vaterlandes das ganze Herz füllen kann, daß nicht Raum bleibt für etwas, was man für den Feind als Menschen auch fühlen könnte.“"1818

Die Botschaft an die Kinder lautete also, dass die Liebe zum Vaterland so groß sein muss, dass kein Platz für den Hass auf die Kriegsgegner mehr bleibt.

Zum Vergleich sei auf die „Gedanken zu einer Besprechung in der Oberklasse“ in Radebeul bei Dresden hingewiesen, in denen das Gebot der Feindesliebe („Liebet eure Feinde; segnet, die euch fluchen; tut wohl denen, die euch hassen; bittet für die, so euch beleidigen und ver-

\footnotetext{
${ }^{1815}$ Siehe z. B.: Wilke: „Der Kern des deutschen Geistes der Zukunft“ und der Deutschunterricht, in: Die deutsche Schule, 1916, S. 77-86.

${ }^{1816}$ Zitiert nach: Pust, „Vaterländische Erziehung" für „Höhere Mädchen” (2004), S. 313.

${ }^{1817}$ Ministerium der geistlichen und Unterrichts-Angelegenheiten, Erhöhung der Zahl der Unterrichtsstunden für Religion in der Mittelschule, Amtliches Schulblatt für den Regierungsbezirk Hildesheim, 1917, S. 15.

${ }^{1818}$ Fahland, Vom Krieg und vom Religionsunterricht, in: Die Lehrerin, Organ des Allgemeinen Deutschen Lehrerinnenvereins 1917, S. 73.
} 
folgen!“ Matthäus 5,44) besprochen wurde. ${ }^{1819}$ Das Ergebnis der Stunde gibt die folgende Feststellung des Lehrers wieder:

„Der deutsche Landwehrmann, der beim Durchsuchen eines belgischen Hauses nach Freischützen ein verlassenes Kindlein tränkte, das dem Verschmachten nahe war; der Krankenträger, der einen schwer verwundeten Franzosen auf sein herzzerreißendes Flehen hin zwei Stunden bis zum nächsten deutschen Lazarett schleppte, unsere Feldgrauen, die ihren Teller Suppe und ihr letztes Brot mit hungernden und bettelnden Kinder teilten (...), - waren sie nicht alle c h r i s t 1 i c h e Krieger, Männer,die im Geiste Jesu handelten, getreu seiner Meinung: Tut Euern Feinden Gutes!?“1820

Die beiden Beispiele zeigen deutlich, wie das Evangelium missbraucht wurde, um die Taten der Soldaten zu glorifizieren und die Kinder zum Patriotismus zu erziehen. Häufig war es auch Ziel der Lehrer, das Engagement an der „Heimatfront“ als gottgefällig darzustellen und die Schüler so zu stärkerem Engagement aufzurufen. Über die Besprechung des dritten Hauptstücks von Martin Luthers kleinem Katechismus (4. Bitte: „Unser tägliches Brot gib uns heute. Was ist das ...") schrieb der Lehrer: „Denkt daran, was die Bitte heute zu bedeuten hat (...). Und dann geht's vom Kriegsbrot und der Brotkarte und anderen Karten und vom Einteilen und Haushalten, und wie wir Selbstzucht üben gelernt haben - Segen des Krieges! (...) Wo hilfst du? Daheim, bei gute Freunden und getreuen Nachbarn, bei Soldatenfrauen und witwen und -waisen (...).“ Nachdem der Lehrer ausführlich auf ,kriegsgerechte "Ernährung, Kleidung und Sparsamkeit hingewiesen hat, heißt es: „Denk aber nicht nur dich! Reichswollwochen. Spinnfaserordnung; Brennesselsammlung, Hand ans Werk im Sommer“'1821.

\subsubsection{Erdkunde}

Sehr stark war auch der Erdkundeunterricht von den Kriegsereignissen geprägt, und zwar unabhängig von der Schulform und der Jahrgangsstufe. Für den Unterricht in der Volksschule wurde z. B. in der Mecklenburgischen Schulzeitung am 12.11. 1914 gefordert: „Im erdkundlichen Unterricht ist es unerläßlich, für einige Wochen die Arbeit ganz auf Krieg einzustellen und die an demselben beteiligten Staaten [Deutschland und Oesterreich-Ungarn selbstverständlich!] zu behandeln (...). Vor allen Dingen sollen die Lebensbedingungen dieser Staaten klar erfaßt, auch soll ihr Kolonialbesitz beachtet werden. “ ${ }^{1822}$ Neben den hier vorgeschlagenen Themen wurden viele weitere kriegsrelevante im Unterricht behandelt, von denen einige genannt werden sollen: Vorgeschichte des Krieges, „Die Kriegsschauplätze; wirtschaftlicher und militärischer Vergleich der kriegführenden Staaten“, Der Einfluss „,der Bodengestaltung auf die Kriegführung“, „Die Religions-, Rassen- und Spracheigentümlichkeiten unserer Ver-

\footnotetext{
${ }^{1819}$ Freudenberg, Matthäus 5,44 im Lichte des Krieges, in: Deutsche Schulpraxis 1916, S. 202-205.

${ }^{1820}$ Freudenberg, Matthäus 5,44 im Lichte des Krieges, in: Deutsche Schulpraxis 1916, S. 205.

${ }^{1821}$ Wohlrab, Ein Tag. Ein Ausschnitt aus dem Schuljahre 1915/16, in: Deutsche Schulpraxis 1916, S. 169.

1822 Zitiert nach: Langer, Lernziel Krieg! (2000), S. 27, S. 52.
} 
bündeten und unserer Feinde mit ihren Hilfshorden“, „Strategische Geographie der Grenzlande“1823 u. a. Zusätzlich sei auf eine „Methodische Einheit zeitgemäßer Erdkunde“ („Berlin Konstantinopel - Bagdad“) hingewiesen, die ein Lehrer aus Bautzen (Kgr. Sachsen) konzipierte und in einer Lehrerzeitung veröffentlichte. Im Mittelpunkt der Besprechung stand die politische und wirtschaftliche Bedeutung des „Orientexpress“.

Für viele Schulen ist bezeugt, dass Karten mit den Kriegsschauplätzen in der Schule aufgehängt wurden, um den Verlauf des Krieges im Unterricht und in den Pausen verfolgen zu können. Dass der Erdkundeunterricht durchaus auch direkt der vormilitärischen Erziehung diente, geht aus einer Verfügung des preußischen Schulministers vom 10. November 1915 hervor: Die Schüler der höheren Schulen sollten Kenntnisse und Fertigkeiten im „Geländeaufnehmen“ und im „Anfertigen von Krokis ${ }^{1824}$ und Geländeskizzen“ erwerben. ${ }^{1825}$ Der Erdkundeunterricht trug aber auch dazu bei, die Schüler zum Hass auf die Kriegsgegner zu erziehen, wie ein Beispiel aus einer Schneidemühler Schule zeigt (Provinz Posen). Im Kriegstagebuch einer Schülerin ist für den 5. August 1914 vermerkt: „In der Geographiestunde beschäftigen wir uns wieder mit Serbien ( ... ). Jetzt haben wir einen großen Haß auf dies kleine Land und schreien:‘ Nieder mit Serbien!،“،1826

\subsubsection{Moderne Fremdsprachen (Englisch, Französisch)}

Gegenüber den ,Gesinnungsfächern“ hatten es vor allem Englisch und Französisch, die Sprachen der Kriegsgegner, schwer und es gab mehrfach Forderungen, jene auf Kosten der Sprachen auszuweiten. So wurde z. B. in der deutschen Tageszeitung 1916 ein Artikel mit der Überschrift „Mehr Deutschgesinnung in den Schulen!“ abgedruckt, in dem der Fremdsprachenunterricht grundsätzlich infrage gestellt wurde. ${ }^{1827}$ Ähnlich äußerte sich der Direktor des Lyzeums in Neumünster: „Aber ich halte die Einschätzung von Geschichte, Erdkunde und Naturkunde als Nebenfächer gegen Englisch und Französisch als Hauptfächer für unverträglich mit wahrhaft deutscher Art und Bildung; sie wird der Krieg wie so manches hinwegfegen.“" ${ }^{1828}$ Auch bei vielen Schülern stieß das Fremdsprachenlernen zu Kriegsbeginn immer wieder auf Ablehnung, wie z. B. bei einer Schülerin in Neumünster: „Im Englischen machte der Unterricht nach Ausbruch des Krieges anfänglich wenig Freude, da ältere und jüngere Schülerinnen am liebsten garnichts von der Sprache der verräterischen ,Vettern' wissen woll-

\footnotetext{
${ }^{1823}$ Die Themen wurden zitiert nach: Pust, „Vaterländische Erziehung" für „Höhere Mädchen” (2004), S. 322f.

${ }^{1824}$ Krokis sind einfache Geländeskizzen bei Armee und Pfadfindern.

1825 Zentralblatt für die gesamte Unterrichtsverwaltung in Preußen, 1915, S. 776.

${ }^{1826}$ Mihaly, ... da gibt's ein Wiedersehn! (1986), S. 26.

${ }^{1827}$ Siehe Pust, „Vaterländische Erziehung" für „Höhere Mädchen" (2004), S. 324.

1828 Zitiert nach: Pust, „Vaterländische Erziehung" für „Höhere Mädchen" (2004), S. 324.
} 
ten. “1829 Selbst die Lehrer hatten teilweise Verständnis für die Haltung der Schüler oder verstärkten sie sogar. So schrieb ein Oberlehrer aus Berlin-Steglitz 1915: „Ich kann mir denken, daß ein deutscher Schüler erklärt, er könne sie (M. K.: Gemeint ist die Lektüre von Zolas „Attaque du moulin“) nicht ertragen! Und ich würde ihn darum nur umso höher achten.“1830 Allerdings hielt die Mehrheit der Lehrer die Sprachen keinesfalls für entbehrlich und auf die Dauer ist es ihnen auch gelungen, die Schüler von der Notwendigkeit des Sprachenlernens zu überzeugen. Ein Lehrer aus Gelsenkirchen hat im Jahre 1916 die Begründung folgendermaßen formuliert:

„Wir treiben es (gemeint sind das „Fremdländische“, d. h. Sprache und Völkerkunde) nicht aus Liebe zu anderen Völkern, sondern aus Liebe zu unserem eigenen: weil wir es brauchen als ein wertvolles Mittel, um uns selbst zu bilden und zu gestalten. Nur in unbefangener Teilnahme an den Erscheinungsformen fremder Kulturen neben dem tiefen Verständnis und liebevollen Eindringen in deutsche Sprache und Geschichte, deutsche Literatur und Kunst werden wir unseren Zöglingen die Mittel in die Hand geben, das zu werden, was sie werden sollen: echte Vertreter deutschen Volkstums.“" 1831

Insgesamt haben die Fremdsprachenlehrer ebenso wie die Kollegen der anderen Fächer ihre verordnete - Pflicht getan, um ihrerseits „dazu beizutragen, die Schüler in vaterländischem Sinn zum Verständnisse der gegenwärtigen großen Ereignisse heranzuziehen“. ${ }^{1832}$

\subsubsection{Latein}

Die Lateinlehrer waren im Krieg mit besonderen Legitimitäts- und Motivationsproblemen konfrontiert. Ihnen wurde oft, wie es ein Lehrer aus Köln formuliert hat, „mit überlegenem Naserümpfen das weltfremde Wesen und Treiben“1833 speziell der Gymnasien vorgeworfen. Auch die „Schar der ungeduldigen, kampfbegeisterten Knaben“ war offensichtlich schwer für das Lernen zu motivieren und die Lehrer hatten Mühe, die ,immer gleich trockenen Verbalformen von toten und lebenden Sprachen (zu) traktieren und die langatmigen Kapitel weltferner Schriftsteller in ein einigermaßen verständliches Deutsch zu übertragen."Wie eine Reihe von Texten bezeugen, versuchten auch die Lateinlehrer sich auf die Erfordernisse der „Kriegspädagogik“ einzustellen, indem sie verstärkt Texte behandelten, die sich mit der aktuellen Kriegssituation in Verbindung bringen ließen. Sie lasen z. B. in dem „Kriegstagebuch“ Caesars, dessen Name allein genügte, sich „mitten in den Gang der jetzigen Kriegsereignisse

\footnotetext{
${ }^{1829}$ Zitiert nach: Pust, „Vaterländische Erziehung" für „Höhere Mädchen” (2004), S. 324.

${ }^{1830}$ Klatt, Willibald, Nationale Rücksichten bei der Auswahl der fremdsprachlichen Lektüre, in: Deutsches Deutsches Philologen-Blatt 1915, S. 230-232.

${ }^{1831}$ Töwe, Deutsches und fremdes Volkstum in der höheren Schule, in: Deutsches Deutsches Philologen-Blatt, 1916, Jg. 24, S. 143f.

1832 LAS, Abtlg. 302, Nr. 641. Verfügung vom 18. Mai 1915.

${ }^{1833}$ Knebel, Unterricht in Kriegszeit, in: Deutsches Philologen-Blatt 1914, S. 639f.
} 
$\mathrm{zu}$ versetzen und im $\mathrm{Nu}$ hat(te) sich die friedliche Klasse in einen Stab von Kriegsstrategen verwandelt, die ohne Schwierigkeiten ganze Heere“ verschoben. Der o. g. Lehrer ging dann weiter auf die Berechtigung des Lateinunterrichts in Zeiten des Krieges ein: „Das Wertvollste für unseren Zweck ergibt sich dabei von selbst: gemeinsam besprechen wir in zusammenfassender Art und Weise die zahlreichen Zusammenstöße zwischen der romanisch-französischen und der germanisch-deutschen Nation im Laufe der Geschichte, indem wir sie möglichst als Ergebnis historisch gewordener Gegensätze zu ergründen suchen.“1834 Dass „,selbst der Unterricht in lateinischer Sprache die Schüler verführen sollte zu: dulce et decorum est pro patria mori, und zu: si vis pacem, para bellum“, geht aus einer Biografie des den Schriftstellers Wolfgang Weyrauch (1904-1980) hervor. ${ }^{1835}$ Selbst der Lateinunterricht wurde also - zumindest teilweise - kriegsbezogen unterrichtet, um dem akademischen Nachwuchs ,,in dieser eisernen Wirklichkeit wertvolles Rüstzeug“'1836 zur Verfügung zu stellen. Da die Lateinlehrer recht häufig in den gleichen Klassen auch den Geschichtsunterricht erteilten, waren sie für die Umsetzung der kriegsbezogenen Lernziele sehr wichtig.

\subsubsection{Turnen}

In diesem Fach spielte vor allem an Oberschulen für Jungen das Militärische eine besonders wichtige Rolle. Ein Gymnasialdirektor schrieb in einer Veröffentlichung dazu: „Am wirksamsten wird die Schule der militärischen Ausbildung immer noch durch einen guten Turnunterricht und Unterstützung von Turn-, Ruder- und Wandervereinigungen arbeiten. “1837 Er hält neben Turnen in der Halle Sprungübungen im Freien über „Hecken, Gräben, Bäche und Baumstämme“, Rudern und vor allem das „Marschieren“ für besonders geeignet. Auch ein Studiendirektor aus Strehla (Kgr. Sachsen) propagiert „Ertüchtigungsmärsche“ für die Schüler: „Dazu erscheinen außer den planmäßigen Übungen in den Turnstunden regelmäßig wiederkehrende Wanderungen, ,Ertüchtigungsmärsche“ in jetziger Zeit besonders geeignet. Und weil man ihre Vorteile in Erzieherkreisen einmütig anerkennt, sieht man jetzt gar oft durch unsere heimatlichen Gefilde Schüler höherer Lehranstalten, Jungmannschaften, Wandervögel u. a. m. in Reih und Glied und Schritt und Tritt stramm marschieren. “1838

Um das Turnen in Schule, Verein und Heer aufeinander abzustimmen, erließ der preußische Unterrichtsminister 1916 eine entsprechende Vorschrift („Die Angliederung des Turnens in

\footnotetext{
${ }^{1834}$ Knebel, Unterricht in Kriegszeit, in: Deutsches Philologen-Blatt 1914, S. 639.

1835 Landzettel, Der Schriftsteller Wolfgang Weyrauch, in: http://deposit.ddb.de/cgi-in/dokserv?idn= 973877707 \&dok_var=d1\&dok_ext=pdf\&filename=973877707.pdf (12.8.2010), S: 65 .

${ }^{1836}$ Knebel, Unterricht in Kriegszeit, in: Deutsches Philologen-Blatt 1914, S. 639.

${ }^{1837}$ Grünwald, Schule und militärische Jugendvorbereitung, in: Deutsches Philologen-Blatt 1917, S. 560.

${ }^{1838}$ Weis, Ertüchtigungsmärsche unserer Schuljugend in der Kriegszeit, in: Deutsche Schulpraxis 1916, S. 188.
} 
Schule, Verein und Heer“ ${ }^{(1839}$ ) und verhandelte gleichzeitig mit den anderen Staaten des Deutschen Reichs über ein gemeinsames Vorgehen. Im 5. Abschnitt heißt es dort: „Schule und Verein haben schon bisher in der Übungsauswahl die Bedürfnisse des Heeresdienstes in weitem Maße berücksichtigt. Sie sind bereit, weitere Wünsche der Heeresverwaltung namentlich nach den Erfahrungen des gegenwärtigen Krieges zu prüfen und tunlichst zu berücksichtigen." Abgesehen von der Intensivierung der vormilitärischen Ausbildung wollte man durch die Kooperation mit Vereinen und dem Heer angesichts des großen Mangels an Sportlehrern die ordnungsgemäße Durchführung des Sportunterrichts vor allem an den Oberschulen für Jungen sicherstellen.

Neben den Unterrichtsinhalten wurden natürlich auch die bei den Kindern und Jugendlichen so beliebten Spiele der Kriegslage angepasst. So wurde aus Völkerball „Kriegsball“, bei dem Wettkampfgruppen „Deutsche“ und „Österreicher“ gegen „Franzosen“, „Engländer“ und „Russen“ kämpften. Allerdings gab es durchaus auch Stimmen, die vor der „Soldatenspielerei“ warnten. ${ }^{1840}$ Ein Rektor aus Hagen (Provinz Westfalen) lehnte Pläne, „das Turnen der Knaben mehr als bisher in den Dienst der unmittelbaren (militärischen) Vorbereitung zu stellen, also ein Stück Kasernendrill in dieses Fach aufzunehmen“, ab. Knaben könnten „nicht ernstlich zu Soldaten ausgebildet werden, sie können nur Soldaten spielen ${ }^{1841 ، .}$.

Hinsichtlich des Turnunterrichts an den Mädchenschulen sind keine größeren kriegsbedingten Veränderungen festzustellen. Offensichtlich aber haben sich einige Schulen durchaus bemüht, das Turnen teilweise, zeitgemäß` durchzuführen. Beispielsweise ist im Jahresbericht des Lyzeums in Neumünster vermerkt: „Das Schlagballspiel stand, den kriegerischen Empfindungen der Kinder entsprechend, so lange es ging im Vordergrund.“" ${ }^{1842}$ In erster Linie jedoch verfolgte man im Sport das Ziel, die Gesundheit der Mädchen zu stärken, da diese ,nicht ein persönliches, sondern ein nationales Kapitel (sei) ${ }^{\text {‘1843 }}$, wie eine Lehrerin damals formulierte. Es gab im Krieg also über die schulhygienischen Ziele der körperlichen Ertuichtigung hinaus durchaus Gedanken, warum gewisse „militärische Übungen unter Leitung ausgebildeter Turnlehrerinnen nicht auch für das weibliche Geschlecht interessant und nützlich sein (sollten) ${ }^{\text {“1844, }}$, den Mädchensport haben sie aber nicht entscheidend verändert.

\footnotetext{
${ }^{1839}$ Die Angliederung des Turnens in Schule, Verein und Heer, in: Deutsche Schulpraxis, Wochenblatt für deutsche Lehrkunst, für Geschichte und Schrifttum der Erziehung und des Unterrichts, 1916, S. 199.

${ }^{1840}$ Grünweller, Der Krieg als Volkserzieher und die Volksschule (1915), S. 21.

${ }^{1841}$ Störmer, Der Weltkrieg und die deutsche Schule, in: Die deutsche Schule, 1915, S. 562

1842 Zitiert nach: Pust, „Vaterländische Erziehung" für „Höhere Mädchen" (2004), S. 331.

1843 nach: Pust, „Vaterländische Erziehung" für „Höhere Mädchen" (2004), S. 331.

${ }^{1844}$ Grünweller, Der Krieg als Volkserzieher und die Volksschule (1915), S. 21.
} 


\subsubsection{Singen}

Mit Kriegsbeginn gewann das Fach in erheblichem Maße an Bedeutung. ${ }^{1845}$ Durch das Singen älterer vaterländischer Lieder (z. B. „Die Wacht am Rhein“ oder „Deutschland, Deutschland über alles“) und neuerer Kriegslieder, die in großer Zahl produziert wurden, sollte die Kriegsbegeisterung der Schüler entfacht, aufrecht erhalten und verstärkt werden. Viele Schulen schafften deshalb neue patriotische Liederbücher an, die von zahlreichen Verlagen angeboten wurden. Welche Bedeutung dem Singen patriotischer Lieder beigemessen wurde, geht schon aus der Tatsache hervor, dass der preußische Schulminister den ,korrekten“ Text mehrerer Lieder im „Zentralblatt für das gesamte Unterrichtswesen“ veröffentlichte. ${ }^{1846}$

Zum Unterricht gehörte neben dem Singen und der Interpretation solcher Lieder für die älteren Schüler auch das Abspielen von Armeemärschen. Angesichts der dem Gesangsunterricht zugesprochenen Wichtigkeit für die vaterländische Erziehung der Kinder wurde immer wieder über den Mangel an qualifizierten Musiklehrern, und zwar vor allem an den Volksschulen, und die geringe Zahl der Musikstunden geklagt und eine Erhöhung gefordert:

„Wir wissen alle, daß unser Gesangsunterricht in der Volksschule nicht das ist, was er sein sollte und sein könnte. Und sicherlich liegt in der mangelhaften Pflege des Volksschulgesanges eine Schuld, eine Schuld, die ein Volksschullehrer gerade in diesen Tagen deutscher Erhebung schwer empfindet. Die geringe Stundenzahl für Gesangunterricht, die mangelhafte Ausnützung des Deutschunterrichts für Wiederholung und Befestigung unserer herrlichen Volkslieder, eine falsche Pädagogik in der Singstunde “61847

sind für den Autor die Hauptursachen des Problems. Die Klagen waren sicher berechtigt, denn es fiel sehr viel Unterricht aus. Der Unterricht wurde häufig fachfremd oder durch Externe erteilt, wie z. B. durch den Pastor oder den Kantor am Ort. Die Untersuchung hat allerdings ergeben, dass trotz der genannten ungünstigen Faktoren in großem Umfange patriotische Lieder gesungen worden sind und zwar von der 1. Klasse der Volksschule an bis zur Abschlussklasse der Oberschule. Für die Lyzeen in Schleswig-Holstein hat Pust entsprechende Quellen zusammengetragen und ausgewertet. ${ }^{1848}$ Dass auch an den Volksschulen dem Singen vaterländischer Lieder eine große Bedeutung beigemessen wurde, geht aus der Veröffentlichung eines Lehrers aus Oschatz (Kgr. Sachsen) hervor. Sie enthält eine umfangreiche Übersicht über die Lieder, die die „Schulrekruten“ (also die Erstklässler) von vielen Schulen aus ver-

\footnotetext{
1845 Über die Bedeutung der Musik im Krieg siehe: Lemmermann, Kriegserziehung im Kaiserreich (1984). Die umfangreiche Untersuchung ,zur politischen Funktion von Schule und Schulmusik 1890 - 1918“ enthält zahlreiche Materialien.

1846 Dazu gehörten „Die Wacht am Rhein” (Zentralblatt, 1915, S. 518f.) und „O Deutschland hoch in Ehren“ (Zentralblatt 1916, S. 518 f.).

${ }^{1847}$ Leupold, Mehr Gesangsstunden, in: Deutsche Schulpraxis“, 1916, S. 29.

1848 Pust, ,Vaterländische Erziehung" für „Höhere Mädchen" (2004), S. 328f.
} 
schiedenen Regionen Deutschlands gekannt und im Unterricht gesungen haben. ${ }^{1849}$ Den Schülern waren insgesamt so viele Lieder bekannt, dass der Autor „seine helle Freude“ hatte. Er forderte deshalb, auch in den Anfangsklassen die Lieder zu singen, die die Schüler bereits kannten. Dazu gehörten u. a. fast immer „Deutschland, Deutschland über alles“, „Es braust ein Ruf wie Donnerhall“, „Ich hatt einen Kameraden“ und „Wer will unter die Soldaten“. Dass der Lehrer in seiner Untersuchung die Erstklässler „Schulrekruten“ nennt, zeigt, dann er seinen Unterricht durchaus als Teil einer vormilitärischen Erziehung verstand.

Im Folgenden soll die Bedeutung des Faches Singen an einem konkreten Unterrichtsbeispiel veranschaulicht werden, und zwar der 6. Klasse einer Grundschule in Brambach (Kgr. Sachsen). Nach Religion, Deutsch und Rechnen erteilte der Lehrer in der 4. Stunde Singen. Darüber schrieb er: „Es kann nicht alles und jedes jetzt im Zeichen des Krieges stehen, das ist meines Erachtens übertrieben. Aber wir dürfen an nichts vorübergehen, was unbedingt hineingehört.“ Er thematisierte zuerst das „Loblied“, das zwar weitgehend unbekannt war, aber seiner Meinung nach „in unsere Schule, in unsere Kirche, in unser deutsches Haus“ hineingehöre. Nachdem über das Lied gesprochen worden war und ein Kind es vorgesungen hatte, stellte der Lehrer fest: „Da durchfliegen wir noch einmal in Gedanken, was die Lenker der Schlachten 1914-16 an unseren Männern draußen zu Lande, zu Wasser und in der Luft getan.“"1850 Anschließend sangen alle Kinder, begleitet vom Lehrer auf dem Harmonium, das Lied. Auf ihn wirkte der Gesang wie eine „Andacht“. Im zweiten Teil der Stunde wurde ein „Hindenburglied“, nach Meinung des Lehrers ein „echtes Volkslied“, gesungen und darüber gesprochen. Obwohl der Lehrer also durchaus Vorbehalte gegen die ständigen Kriegsbezüge im Unterricht hatte, wurde die Singstunde eng mit dem Kriegsgeschehen verknüpft.

Abschließend soll darauf hingewiesen werden, dass der Musikunterricht die Kinder nicht nur indirekt auf ihren Einsatz an der „Heimatfront“ vorbereitete, indem z. B. ihre Vaterlandsliebe und ihre Wehrbereitschaft gestärkt wurden, sondern die musikalischen Beiträge, mit denen sich Schüler häufig an Festen und anderen Veranstaltungen beteiligten ${ }^{1851}$, waren stets im Unterricht einstudiert und geprobt worden.

\subsubsection{Zeichnen}

Auch der Zeichenunterricht diente der ,ideologischen Mobilmachung‘. Beispielsweise zeichneten und malten Schüler Postkarten, deren Verkaufserlös häufig der Kriegshilfe zugute-

\footnotetext{
1849 Zeißig, Etwas von heurigen Schulrekruten, in: Deutsche Schulpraxis1915, S. 342 f.; ders.,Noch etwas von heurigen Schulrekruten, in: Deutsche Schulpraxis, 1916, S. 93-96.

${ }^{1850}$ Wohlrab, Ein Tag. Ein Ausschnitt aus dem Schuljahre 1915/16, in: Deutsche Schulpraxis 1916, S. 172.

${ }^{1851}$ Siehe dazu die Kapitel 5.2.2 und 7.3.2.
} 
$\mathrm{kam}^{1852}$ und mit denen man sich an entsprechenden Wettbewerben beteiligte. Die Karten, häufig waren es sogar Serien, zeigten meistens typische - verklärt und romantisiert wiedergegebene - Szenen aus dem Soldatenleben. Darüber hinaus wurden Bilder mit Kriegsmotiven gemalt, die entweder ebenfalls verkauft wurden oder in den Schulen als zeitgemäßer Wandschmuck, der die Kriegsmoral stärken sollte, dienten. In Berlin gab es sogar eine groß angelegte Aktion aller Gemeindeschulen, die sog. „Kriegszeichenwochen“, in denen die Schulkinder Bilder zum Thema Krieg malten. Auch das Bild des Kaisers oder die Köpfe Hindenburgs und anderer bedeutender Heerführer wurden von älteren Schülern anhand von Vorlagen gezeichnet. $\mathrm{Zu}$ den Motiven für die Zeichnungen gehörten in allen Klassen vor allem auch Gegenstände, die in Verbindung mit dem Krieg standen, wie z. B. Flaggen, Waffen und Eiserne Kreuze, wie die folgenden unterrichtspraktischen Beispiele zeigen.

Ein Lehrer aus Chemnitz (Kgr. Sachsen) veröffentlichte 1916 Vorschläge für „Zeichenlektio-

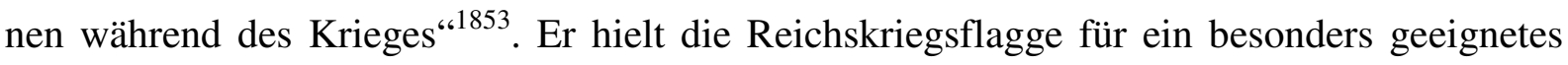
Motiv - und zwar für das 2., 3. und 4. Zeichenjahr in einer Volksschule für Jungen. Vor und nach den Zeichenübungen sollte seiner Meinung jeweils das bekannte patriotische Lied „Stolz weht die Flagge Schwarz-Weiß-Rot" gesungen werden. Außerdem schlug er vor, in der Abschlussklasse ein „Brummergeschoss“, d. h. ein besonders großes Kanonengeschoss (1 Meter Länge, $10 \mathrm{~cm}$ Durchmesser), möglichst naturgetreu zu zeichnen.

Der pädagogische Aufsatz eines anderen Lehrers („Kriegszeichnen“) ging vom Interesse der Schulkinder aus: „Gottlob drängt es keinen deutschen Jungen, stundenlang an der genauen Symmetrie eines Teekessels herumzudoktern. Vor seinem Geiste stehen Bilder von Krieg und Kriegsgerät (...). Säbel und Gewehre, Geschosse der fleißigen Berta und U-Boote will der Schüler zeichnen; dazu drängt ihn sein Interesse, davon malt er sich ein lebhaftes Bild.“1854 Der Lehrer nennt dann - nach Schulstufen geordnet - sehr viele Kriegsgegenstände, die sich als Motive eignen würden: Für die Unterstufe „Soldatenknöpfe, Kugeln, Bomben, Granaten, Patronen, Patronenhülsen, Feldflaschen“ u. v. a., für die Mittelstufe „Gewehre, Tornister, Koppel, Schiffsmasten, Trommeln“ u. v. a. und für die Oberstufe „Im Schützengraben, kleines Gefecht, Truppen auf dem Marsche, Feldküchen, Lazarettzüge“ u. v. a. Seiner Meinung nach würden sich den Schülern die militärischen Gegenstände und Situationen viel besser einprägen, wenn er sie graphisch oder bildlich selbst abbildete. Die Bilder sollten dann in ei-

\footnotetext{
${ }^{1852}$ Siehe dazu Kapitel 3.3. („Initiativen einzelner Schulen”).

1853 Zill, Stolz weht die Fahne: Schwarz-Weiß-Rot. Anschließend das Brummergeschoss, in: Deutsche Schulpraxis 1915 , S. 398f.

${ }^{1854}$ Göhrs, Kriegszeichnen, in: Deutsche Schulpraxis 1915, S. 246-248.
} 
nem „Kriegszeichenheft“ bzw. einer „Kriegsmappe“1855 gesammelt werden, damit sie ,,jedem Schüler Freude und Belehrung schaffen und ihm noch in späteren Jahren eine schöne Erinnerung an diese große Zeit (seien)“1856.

Im Zeichenunterricht wurden also Schüler vom ersten Schuljahr an (z. B. durch das Gestalten von Eisernen Kreuzen und Fahnen mit Knetgummi) bis zu den Abschlussjahrgängen (z. B. durch das perspektivische Zeichnen von Kriegssituationen und das Entwerfen von Wappen für Kriegsberichte) in starkem Maße politisch beeinflusst. Eine Reihe der im Unterricht entstandenen Produkte, wie z. B. die Kriegspostkarten, die zugunsten der Kriegshilfe verkauft oder zusammen mit den Liebesgabenpaketen an die Soldaten an der Front geschickt wurden, sind den Aktivitäten für die „Heimatfront“ zuzuordnen.

\subsubsection{Handarbeiten}

Wie kaum ein anderes Fach wurde Handarbeit in den Dienst der „Heimatfront“ gestellt. Während die Jungen in erster Linie Kriegsspielzeuge bastelten, wie z. B. Flugzeuge, Kriegsfahrzeuge aller Art und Kanonenrohre, mussten die Mädchen nützliche Gegenstände stricken, häkeln und nähen, beispielsweise Pulswärmer, Handschuhe und Ohrenschützer für die Soldaten an der Front. Immer wieder wiesen die Behörden auf die Bedeutung solcher Arbeiten an der „Heimatfront“ hin. So informierte der preußischen Schulminister angesichts der „Not des Krieges“ in einem Erlass vom 7. Dezember 1916 über die Bedeutung der „Pflege des Strickens und anderer Nutzarbeiten im Nadelarbeitsunterricht der Mädchenschulen“. Um auch das außerschulische Umfeld entsprechend zu beeinflussen, wurde in dem Erlass empfohlen: „Ein einheitliches Vorgehen aller Schulen in diesem Sinne dürfte vorbildliche und erziehliche Wirkung auf weiteste Volkskreise haben.“ Da vor allem in den Abschnitten 4.5-4.7 dieser Untersuchung detailliert auf die entsprechenden Tätigkeiten der Schülerinnen und Lehrerinnen eingegangen worden ist, kann hier auf konkrete Beispiele verzichtet werden. Welche Bedeutung das Fach im Krieg hatte, verdeutlicht die folgende Äußerung eines Hamburger Schulleiters: „Aus einem Nebenfach ist ein Hauptfach geworden.“1857

\subsubsection{Rechnen bzw. Mathematik}

Selbst dieses Fach sollte zu den aktuellen Kriegsereignissen in Beziehung gesetzt werden, wie beispielsweise aus einem Aufsatz eines Lehrers aus dem Jahre 1915 hervorgeht: „Der Rechenunterricht hat dafür zu sorgen, daß die Menge der Wörter, die die Schüler jetzt hören,

\footnotetext{
1855 Dieser Begriff wurde am Lyzeum in Schleswig verwendet, siehe: Pust, „Vaterländische Erziehung” für „Höhere Mädchen" (2004), S. 330.

${ }^{1856}$ Göhrs, Kriegszeichnen, in: Deutsche Schulpraxis 1915, S. 247.

${ }^{1857}$ Loewenberg, Kriegstagebuch einer Mädchenschule (1916), S. 17.
} 
lesen und selbst unklar gebrauchen, mit genauen Vorstellungen verbunden werden. Durch Rechnen sollen die Schüler lernen, die Verhältnisse des Krieges denkend zu betrachten. Durch Kriegsrechnen soll ihr nationaler Wille angeregt werden.“1858 Nach Bendele kannte man im Unterricht nur noch die „Kriegszahl”: „Ob Millionen oder Milliarden, die Kriegsanleihen waren das Anschauungsmaterial; ob Hunderter oder Tausender, gefangene Russen, Franzosen oder Engländer steckten dahinter; ob Meter oder Kilometer, um die Flugweite verschiedener Geschoßarten ging es; ob Gramm oder Kilogramm, die Brotkarte lag auf der Schulbank ${ }^{* 1859}$ und bot zeitgemäßes Anschauungsmaterial. Drei Beispiele sollen dieses veranschaulichen und zeigen, dass der „Kriegsrechenunterricht“ bereits in der ersten Klasse begann und die Kinder in jeder Jahrgangsstufe begleitete. Die Elementarschüler sollten einfache Additionsaufgaben lösen, von denen eine ,5 Soldaten + 5 Soldaten“ lautete. Auf einer Zeichnung waren dazu fünf heranstürmende (deutsche) Soldaten dargestellt, die ihre fünf Kameraden in vorderster Linie beim Sturmangriff unterstützen sollten. ${ }^{1860}$ Ein Volksschullehrer ließ nach eigener Aussage seine Schüler „fast nur mit Soldaten arbeiten“ und auch brachte gern „,aus dem Krieg (...) ,Rechengeschichten““, wie die folgenden Aufgaben zeigen: „Ein Deutscher bringt 3 Engländer und 6 Franzosen $=9$ Gefangene“ oder „Da droben marschieren 10 Russen; wir schießen erst 3 weg und dann noch 5 weg und dann noch einen weg." Der Lehrer merkte zwar an, dass Totschießen nicht "grade nach jeder Manns Geschmack ist", er lehnte jedoch ein Verbot ab (,Soll ich in falscher Gefühlsduselei ihnen die ,Schießerei ‘ verbieten?“), da er keine „Gefühlsverrohung“ bei den Kindern befürchtete. Seiner Meinung nach war Rechnen für die Mobilisierung der Schüler von besonderer Bedeutung, denn „keine Stunde (... stand) so sehr im Zeichen des Krieges wie die Rechenstunde“. ${ }^{1861}$ Ein drittes Beispiel zeigt vor allem, wie man in allen Jahrgangsstufen in diesem Fach die Kinder auf den Kampf an der „Heimatfront“ aktivieren wollte:

„Jeder Deutsche bekommt täglich $200 \mathrm{~g}$ Mehl.

1. Stufe: Rechnen mit Broten.

2. Stufe: Rechnen mit Schnitten, je $40 \mathrm{~g}$.

3. Stufe: Täglicher, wöchentlicher ... Mehlbedarf für den Schüler, für Familien.

4. Stufe: Täglicher, wöchentlicher ... Mehlbedarf für das Dorf ( Die Straße.).

5. Stufe: Rechnen mit der Brotkarte. Umrechnen von Brot, Mehl und Getreide.

6. Stufe: Zutaten zum K- oder KK-Brot. Preiswürdigkeit des einen zum andern. - Wie groß ist die Ersparnis, wenn jeder Deutsche bei dreimal täglichem Brotessen je $5 \mathrm{~g}$, die er sonst verkrümelt, spart, täglich, im Jahr?

7. Stufe: Täglicher, wöchentlicher ... Brotbedarf einer Großstadt (Berlin) des Deutschen Reiches. (In Eisenbahnzügen von 50 Wagen je 15000 kg.) Länge eines Zuges mit dem jährlichen Bedarf, verglichen mit geographischen Entfernungen.

\footnotetext{
${ }^{1858}$ Göhrs, Kriegszeichnen, in: Deutsche Schulpraxis 1915, S. 101.

${ }^{1859}$ Bendele, Krieg, Kopf und Körper (1984), S. 164.

${ }^{1860}$ Siehe Langer, Lernziel Krieg! (2000), S. 62.,

${ }^{1861}$ Wohlrab, Ein Tag. Ein Ausschnitt aus dem Schuljahre 1915/16, in: Deutsche Schulpraxis 1916, S. 173.
} 
8. Stufe: Leistung einer Kriegsgetreidegesellschaft: Hätte sie auch nur 3000000 t Brotgetreide zu bewegen, wieviel Eisenbahnzüge muß sie dann in jeder Stunde kaufmännisch bearbeiten, wenn sie die Arbeit vom 15. März bis 15. Mai leisten will, bei täglich 10stündiger Arbeit?“1862

Die aktualisierten Schulbücher bzw. die Ergänzungshefte enthielten in großem Umfang Aufgaben aus dem Bereich der „Heimatfront“, die den Lehrern halfen, die Schüler für die entsprechenden Sammlungen, Aktionen und Hilfsdienste zu aktivieren. Als Beispiel sei Löwenhaupts Schrift „Der große Krieg in Zahlen“1863 genannt, das eine Sammlung von Aufgaben für die Kriegsanleihen, die Volksernährung und die verschiedenen Zweige der Kriegsfürsorge enthält

Auch der „Formenlehreunterricht“" wurde militarisiert. Sollten beispielsweise, wie im Königreich Sachsen für Volksschulen vorgeschrieben, Zeichnungen und Berechnungen, die sich auf Kreis und Walze bezogen, vorgenommen werden, so wurden die Operationen häufig „an Geschossen aller Art “1864 durchgeführt, wobei die entsprechenden Anschauungsmittel hergestellt oder beschafft wurden. Berechnet wurden vor allem das Kaliber, der Umfang und der Rauminhalt der verschiedenen im Krieg verwendeten Granaten.

Welche Bedeutung das Rechnen für den Kampf der Schule an der „Heimatfront“ haben sollte, ist von einem Mittelschullehrer aus Düsseldorf im Jahre 1915 sehr deutlich formuliert worden:

„Eine besondere Bedeutung erhält der Rechenunterricht dadurch, daß er die Daheimgebliebenen in überzeugender Weise an der Hand von Ziffern an ihre Pflichten erinnert. (...) Viele haben in der Ernährungsfrage noch nicht den Ernst der Lage begriffen; viele halten ihr Gold aus Angst oder Dummheit zurück. Da ist es höchste Zeit aufzuklären; jeder Deutsche zu Hause, ob Mann, ob Frau, ob Kind muß Soldat sein auf wirtschaftlichem Gebiete. Auf jeden einzelnen kommt es an. Nach dieser Richtung hin kann der Rechenunterricht dem Vaterlande einen großen Dienst erweisen. An der Hand von Zahlen kann er Verständnis für Regierungsmaßnahmen z. B. in der Volksernährung, in der Goldfrage, anbahnen, jeden zur Mitarbeit anregen, die Sorglosigkeit in kluge Vorsorge umwandeln. Neben zahlreichen statistischen Tabellen könnten selbst Anekdoten aus Zeitungen zu Aufgaben verwandt werden; z. B. um den Zinsverlust ausrechnen zu lassen, den die Leute durch Zurückhalten des Geldes haben.(...) Lassen wir also auch im Rechnen den Krieg von der militärischen wie der volkswirtschaftlichen Seite eintreten in die Schulstube.“ ${ }^{\text {(1865 }}$

\subsubsection{Naturkunde (Biologie, Physik, Chemie)}

Der Naturkundeunterricht sollte die Schüler planmäßig auf ihre Rolle an der „Heimatfront“ und die Jungen zudem auf den späteren Militärdienst vorbereiten. Bereits 1914 war speziell für das Fach in Berlin die „Preußische Zentralstelle für den naturwissenschaftlichen Unterricht gegründet worden, die sich mit der kriegspropädeutischen Umgestaltung des Biologie-,

\footnotetext{
1862 Göhrs, Kriegszeichnen, in: Deutsche Schulpraxis 1915, S. 161f. Weitere Aufgaben aus dem Bereich der „Heimatfront“ in: Bendele, Krieg, Kopf und Körper (1984), S. 165.

${ }^{1863}$ Löwenhaupt, $V$., Der große Krieg in Zahlen. Eine Ergänzung zu den Rechenbüchern.

${ }^{1864}$ Müller, Geschosse im Formenlehreunterricht, in: Deutsche Schulpraxis 1916, S. 126.

${ }^{1865}$ Tussing, Der Krieg und der Unterricht im Rechnen, in: Die Mittelschule: Zeitschrift der Reichsfachschaft Mittelschule im Nationalsozialistischen Lehrerbund., 1916, S. 135.
} 
Physik- und Chemieunterrichts an den höheren Schulen befasste und z. B. Lehrerfortbildungskurse durchführte.

Auch wenn in der „Kriegsnaturkunde“ stärker als in den ,Gesinnungsfächern“das „Intellektuelle und Technische“1866 betont wurden, spielten in diesem Fach patriotische Erziehungsziele eine wichtige Rolle. Zum Beispiel wurde im naturkundlichen Unterricht auf die Vermeidung von Fremdwörtern geachtet, wie aus einem Kriegstagebucheintrag einer Schülerin aus Schneidemühl hervorgeht. ${ }^{1867}$ Der ,zeitgemäße Naturkundeunterricht“ sollte das ,technische Verständnis in weitesten Kreisen“ ausbreiten und zum Verständnis der Kriegsführung beitragen. Daneben sollte er „unterrichtlich und erziehlich als Volkswirtschaftskunde“ wirken, da die „Lehre von den Naturstoffen und Naturkräften, Physik, Chemie nebst Mineralogie“،1868 dazu vor allem berufen sei.

In Biologie wurden Parallelen zwischen dem Kampf der Soldaten und dem der Tiere gesucht und besprochen, z. B. dem Errichten der Soldaten von Schützengräben und dem Einbuddeln der Scholle im Meeresboden oder Kampfmitteln wie Gas- und Rauchwolken bei Menschen und Tieren (z. B. beim Tintenfisch). ${ }^{1869}$ Themen der Pflanzen- und Nahrungsmittelkunde wurden sehr häufig genutzt, um Schüler für die „Heimatfront“ zu mobilisieren, indem über die Bedeutung der Pflanzen, die für die Produktion von Ersatzstoffen, für die Ernährung und für die Heilkunde wichtig waren, gesprochen wurde. Die Gespräche über den Nährwert der einzelnen Nährstoffe wurden fast immer mit Appellen zur persönlichen Einschränkung verbunden, z. B. bei Fleischgenuss. ${ }^{1870}$ Häufig nahmen die Naturkundelehrer mit ihren Schülern an entsprechenden Sammlungen teil oder bewirtschafteten Schulkriegsgärten. ${ }^{1871}$ Über

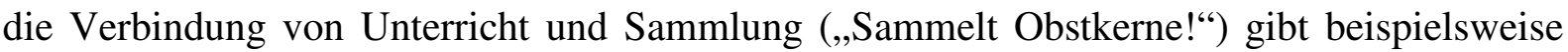
die Unterrichtsskizze eines Volksschullehrers Aufschluss. ${ }^{1872}$

Ein wichtiges Gebiet der „Kriegsnaturkunde“ war auch die Gesundheitslehre:

„Bei der so bedeutsamen Lehre vom menschlichen Körper stehen Belehrungen über Wund- und Blutungsbehandlung, erste Hilfe bei Unglücksfällen, über Marschhygiene, Ernährung, Schulung der Sinne, über ansteckende Krankheiten und Desinfektion im Vordergrunde des Interesses. Der Unterricht über Fäulniserreger von Pocken, Typhus, Cholera, Ruhr, Wundstarrkrampf ist sehr zeit-

\footnotetext{
${ }^{1866}$ Amrhein, Der Weltkrieg im Unterricht (1916), S. 107.

${ }^{1867}$ Mihaly, Jo, ... da gibt's ein Wiedersehn! Kriegstagebuch eines Mädchens, München 1986, S. 17.

${ }^{1868}$ Brinkmann, Der Naturkundeunterricht zur Kriegszeit, in: Deutsche Schulpraxis 1916, S. 162.

${ }^{1869}$ Weitere Beispiele bei: Brinkmann, Der Naturkundeunterricht zur Kriegszeit, in: Deutsche Schulpraxis 1916 , S. $162 f$.

${ }^{1870}$ Siehe dazu:Ernst, Wie steht es um unsere Ernährung? Betrachtung mit einer Oberklasse, in: Deutsche Schulpraxis 1916, S. 186-189. Die Unterrichtsskizze enthält neben Sachinformationen eine Reihe von Appellen zur zum sparsamen Umgang mit Lebensmitteln.

${ }^{1871}$ Siehe Kapitel 4.2.

${ }^{1872}$ Ernst, Sammelt Obstkerne!, in: Deutsche Schulpraxis 1916, S. 311.
} 
gemäß. Als eine methodische Einheit drängt sich auch die Behandlung der Kleiderlaus auf und ist, entsprechend der Bedeutung, von den Behörden vorgeschrieben. “ 1873

Der Text, der von einem Lehrer stammt, zeigt, dass der Biologieunterricht der vormilitärischen Erziehung der Jungen („Marschhygiene“ u.a.) und der Vorbereitung der Mädchen auf den Sanitätsdienst diente. Wie militarisiert der Unterricht mitunter war, zeigen die folgenden beiden Beispiele. In einer Klasse einer Schneidemühler Schule (Provinz Posen) zeichneten die Schülerinnen die ganze Naturkundestunde lang „Kriegsschiffe, Panzerkreuzer, Torpedoboote, Minensucher usw. “1874 und in einem Berliner Lyzeum mussten sich die Schülerinnen auf Befehl der Lehrerin wie bei einem Angriff im Trommelfeuer verhalten:

„'Krieg ist, Kinder, Krieg! Und so ist er!! - Im Schützengraben kauern sie eng nebeneinander. Deckung suchend vor diesem furchtbaren Feuer. - Sie können nichts tun als Deckung suchen - Nichts weiter, nichts weiter! - - ,Deckung! Deckung!' Ihre Stimme schrillt, ihre Augen irren über die Klasse (...) ,Ihr seid jetzt im Schützengraben - - Rechts und links sausen die Kugel. Jede bringt zerfetzte Glieder - - Tod ... Deckung! Deckung suchen!! ““ Die Schülerinnen warfen sich darauf auf den Boden und suchten unter Stühlen und Tisch Schutz.“ ${ }^{1875}$

Physik und Chemie boten noch mehr Kriegsstoffe und die Lehrer hatten keine Schwierigkeiten, die Schüler für den Unterricht zu begeistern. Nach Meinung zeitgenössischer Pädagogen verlangten die Schüler „,brennend nach Belehrung über Torpedos, Minen, Umschaurohre, Scherenfernrohre und Entfernungsmesser“"1876. Neben Stoffen aus der Ballistik (z. B. Flugbahn der Geschosse von Haubitze und Mörser), dem Kriegsschiffsbau (z. B. dem U-Boot) und der Luftschifffahrt (z. B. Berechnung der Bombengeschwindigkeit) wurden in der „Kriegsphysik“" Themen aus der Optik ( z. B. Bedeutung der Scheinwerfer für den Festungs- und Wasserkrieg), der Elektrizitätslehre ( z. B. elektrische Schlag- und Zündwirkungen bei Minen), der Lehre vom Schall ( z. B. für die Artillerie), der Wetterkunde u.a. behandelt. Beispielsweise sollten die Schüler ,die hohe Bedeutung der Wetterkunde sowohl für die in der Luft, auf dem Meere und zu Lande kämpfenden Truppen als auch für die ernährende Landwirtschaft ${ }^{\text {1877 }}$ erkennen.

Ähnlich zahlreich waren die Themen der „Kriegschemie“. Genannt seien vor allem Sprengstoffe, Leuchtbomben, chemisch hergestellte Ersatzstoffe (z. B. als Benzinersatz) und Kunstdünger für die Landwirtschaft. Wegen des Massenverbrauchs von Metallen an der Front und

\footnotetext{
${ }^{1873}$ Brinkmann, Der Naturkundeunterricht zur Kriegszeit, in: Deutsche Schulpraxis 1916, S. 162.

${ }^{1873}$ Weitere Beispiele bei: Brinkmann, Der Naturkundeunterricht zur Kriegszeit, in: Deutsche Schulpraxis 1916, S. $163 \mathrm{f}$

${ }^{1874}$ Mihaly, ... da gibt's ein Wiedersehn! (1986), S. 72.

1875 Lange, 1914 bis 1918 auf der Schulbank (1933), S. 45f.

1876 Hahn, Der Physikunterricht an den bayrischen Oberrealschulen, zitiert nach: Kreme/ Rieß, Mobilmachung im Unterricht. Die Instrumentalisierung der Physikpädagogik für Nation und Krieg im Kaiserreich, http://wanderforschung.de/files/ kaiserreich1267643749.pdf (5.01.2011).

${ }^{1877}$ Brinkmann, Der Naturkundeunterricht zur Kriegszeit, in: Deutsche Schulpraxis, 1916, S. 164
} 
weil die Schüler bei den Metallsammlungen immer wieder Hülsen und Geschosse mit in die Schule brachten, kam es häufig ,zur eingehenderen Behandlung von Eisen, Blei, Kupfer, Messing und Nickel. Die Begriffe Härte, Schmelzbarkeit, Elastizität, Farbe, Gewicht und Festigkeit (... waren) geläufiger denn je.“1878

Bei der kurzen Betrachtung der naturkundlichen Fächer ist deutlich geworden, dass sie zu einer „Naturkriegskunde“ geworden waren. Es gab allerdings damals einige Lehrer, die davor warnten, angesichts der Propagierung der staatsbürgerlichen Unterrichtsziele die naturwissenschaftlichen Lernziele aus den Augen zu verlieren: „Wir wollen uns aber bei aller Berücksichtigung der Kriegsstoffe vor Einseitigkeit hüten und die Erreichung der großen Ziele des Naturkundeunterrichts nach wie vor unsere erste Sorge sein lassen. “1879

\subsubsection{3 „Kriegsstunden“}

Neben dem regulären Unterricht in den genannten Fächern wurden vor allem an Gymnasien von Kriegsbeginn an „Kriegsstunden“ erteilt, die „ebenso der nationalen Unterweisung wie der staatsbürgerlichen Erziehung“ dienten. In den „Ausnahmestunden“, die sich vom Schulalltag abheben sollten, sollte den Schülern „das Unermeßliche dieser Ausnahmesituation““1880 nahegebracht werden. Ein Ulmer Gymnasialdirektor, der gleich nach Kriegsbeginn an seiner Schule „Kriegsstunden“ eingeführt hatte und dann im Deutschen Philologenblatt jährlich über seine Erfahrungen berichtete ${ }^{1881}$, schrieb 1914 dazu:

„Wehe der deutschen Bildungsstätte, welcher die Zöglinge von heute später einmal, wenn schon längst das Gleichmaß der Friedenstätigkeit wiedergekehrt ist, den schweren Vorwurf zuschleudern können: du und deine Hüter, ihr habt uns in jenen unvergleichlichen Tagen, da unsere junge Seele brannte von vaterländischer Begeisterung und unser Geist lechzste nach verständnisvollem Mitschwingen und hungerte nach Sättigung mit nationalen Gemütswerten, nur Steine statt Brot gegeben und, wenn auch vielleicht in vermeintlich gewissenhafter Pflichterfüllung, aber doch im Sonne einer kleinzügigen Alltäglichkeit, den frischen Lufthauch des neuen Zeitalters von uns ferngehalten. “'1882

Am Beispiel eines Ulmer Gymnasiums sollen Organisation und Ablauf einer typischen „Kriegsstunde“ beschrieben und durch Beispiele anderer Schulen ergänzt werden. In Ulm versammelten sich die Schüler aller Klassen von Quarta bis Oberprima jeden Sonnabend in der letzten Stunde der Woche (11-12 Uhr) im Festsaal der Schule. Die Stunde, die stets unter

\footnotetext{
${ }^{1878}$ Brinkmann, Der Naturkundeunterricht zur Kriegszeit, in: Deutsche Schulpraxis 1916, S. 164.

${ }^{1879}$ Brinkmann, Der Naturkundeunterricht zur Kriegszeit, in: Deutsche Schulpraxis 1916, S. 164.

${ }^{1880}$ Schott, „Kriegsstunden“ in der Schule, in: Deutsches Deutsches Philologen-Blatt 1914, S. 698.

1881 Siehe: Schott, „Kriegsstunden“ in der Schule, in: deutsches Deutsches Philologen-Blatt 1914, S. 698f.; Schott, „Ein Jahr Kriegsstunden am Gymasium“, in: Deutsches Deutsches Philologen-Blatt 1915, S. 617- 619; Schott, „Das zweite Jahr Kriegsstunden“ in der Schule, in: Deutsches Deutsches Philologen-Blatt 917, S. 23-25; Schott, „Das dritte Jahr Kriegsstunden“ in der Schule, in: deutsches Deutsches Philologen-Blatt 1918, S. 4f.; Schott, „Zum Abschluss der Kriegsstunden“ in der Schule, in: deutsches Deutsches Philologen-Blatt 1918, S. 419.

${ }^{1882}$ Schott, „Kriegsstunden“ in der Schule, in: deutsches Deutsches Philologen-Blatt 1914, S. 697.
} 
der Leitung des Direktors stand, begann mit einem „vaterländischen Gesang“, der von einem Lehrer auf dem Klavier begleitet wurde, z. B. „Deutschland, Deutschland über alles“, „O Deutschland hoch in Ehren“ und der „Wacht am Rhein“. Daran schlossen sich die „Wochenberichte“ über die aktuellen Ereignisse auf den Kriegsschauplätzen an. In wechselnder Reihenfolge hielten Primaner oder Sekundaner, die die Aufgabe freiwillig übernommen hatten, einen kurzen Vortrag und erläuterten an großen Karten, die Tertianer vorbereitet hatten, die aktuellen militärischen Ereignisse. Im Anschluss daran trugen jüngere Schüler Kriegsgedichte vor, die sie selbst ausgesucht hatten und die vom Direktor genehmigt worden waren. Die Veranstaltung schloss dann mit einem patriotischen Lied. Während der Veranstaltung ließ man ein Kästchen herumgehen, in das die Schüler, um „damit dem Vaterland einen Dienst“ zu erweisen“, eine kleine Spende für die „Kriegswohltätigkeit“" werfen konnten.

Neben der aktuellen Kriegslage wurde in den „Kriegsstunden“ auch über „Einzelheldentaten“ der Soldaten im Felde, ihre „Standhaftigkeit im Tode“ und die „Opferfreudigkeiten aller Volksschichten“ gesprochen. Ferner erhielt jeder Kriegsfreiwillige beim Abschied „aus dem Munde des Schulvorstands den geleitenden Segenswunsch der Anstalt und der Schülerschaft “"1883. Zu Ehren von gefallenen Schülern und Lehrern hielt der Schulleiter ,ein kurzes Nachwort“ und außerdem wurde das Lied „Morgenrot, Morgenrot“" gesungen.

Häufig berichteten auch ehemalige Schüler und Lehrer oder Gäste über ihre Erfahrungen an der Front. Über den Besuch eines Offiziers, der vor dem Krieg selbst Schulleiter gewesen war, schrieb der Ulmer Direktor:

„(Er gab) der versammelten Schülerschar eine lebenswarme und bei aller Schlichtheit doch so ergreifende Erzählung des Selbsterlebten auf der Eisenbahnfahrt und dem Fußmarsch, im Kampfesgetümmel und im Lazarettdrangsal (...); in dieser Stunde ging in der Person des jungen, mit dem Eisernen Kreuze geschmückten Soldaten der Geist des Kriegsgottes durch unsere sonst den Musen geweihte Stätte und ließ unsere Knabenwelt einen starken Hauch dieses Geistes verspüren." 1884

Die Bilanz nach einem Jahr „Kriegsstunden“ fiel zwar insgesamt positiv aus, der Ulmer Schulleiter äußerte aber die Sorge, dass ,auch die herrlichsten Taten auf dem Schlachtfeld oder im Schützengraben allmählich (beginnen) die Herzen unserer Knaben kalt werden zu lassen““1885. Seiner Meinung gewöhnten sich die Kinder wegen der Länge des Krieges und „seines allgewaltigen Einflusses auf die verschiedensten Lebensgebiete“ an den Kriegszustand, der für viele fast zur Normalität geworden sei. In zunehmendem Maße wurde in den „Kriegsstunden“ auch über Aktionen an der „Heimatfront“ gesprochen: „Befand sich doch

\footnotetext{
1883 Schott, „Kriegsstunden“ in der Schule, in: deutsches Deutsches Philologen-Blatt 1914, S. 698.

${ }^{1884}$ Schott, „Kriegsstunden“ in der Schule, in: deutsches Deutsches Philologen-Blatt 1914, S. 698.

1885 Schott, „Ein Jahr Kriegsstunden am Gymnasium“, in: deutsches Deutsches Philologen-Blatt 1915, S. 618.
} 
unter dieser vielköpfigen Schulgemeinde sicherlich immer eine stattliche Anzahl von solchen, die dem, was aus dem Vielerlei des Krieges gerade zur Sprache kam, besonders offene Ohren und Herzen entgegenbrachten, dem Kriegsbrot und Kriegsmehl oder der Milliardenanleihe und Goldaufspeicherung, der Fremdwörterbekämpfung und der Kriegsschulausstellung. “1886 Um Zeit für diese Themen zu gewinnen, wurden die Wochenberichte über die aktuelle Kriegslage verkürzt und nur noch in Form einer kurzen Übersicht gegeben.

Mit Beginn des Schuljahrs 1915/16 wurden die „Kriegsstunden“ nur noch zwei Mal im Monat erteilt, und zwar getrennt für die Quinta bis Obertertia sowie die Untersekunda bis Oberprima. Die Kleinen versuchte man für die „Kriegsstunden“ dadurch zu begeistern, dass ihnen Preise und Auszeichnungen für besondere Leistungen, z. B. an der „Heimatfront“, öffentlich verliehen wurden. In den Stunden für die Großen wurde zwar auch weiter über die Kriegslage informiert, einen breiten Raum aber nahmen die verschiedenen Aktivitäten an der „Heimatfront“ ein. Es wurden z. B. Feldbriefe von „,vergessenen Soldaten““1887 und Antworten auf verschickte Liebespakete vorgelesen.

„Und endlich ließ sich wiederum in diesen Kriegsstunden, sowohl für die Ober- wie für die Jungstufe, alles da so bequem und planmäßig unterbringen, was die inhaltsvolle Gedankenverbindung ,Krieg und Schule' umfaßt, die Schülerzeichnungen für die Kriegsanleihe, die Altpapier- und Obstkernsammlung, das Verhalten bei Fliegerangriffen und das Grüßen der Schüler bei vorüberziehenden Soldatenbeerdigungen und vieles andere.“" ${ }^{\text {"1888 }}$

Der dritte Erfahrungsbericht aus dem Jahre 1918 machte den Stimmungsumschwung in der Schule sehr deutlich: „An die Stelle des Getragenseins von jener unvergleichlichen Gemütserhebung, von der die Anfangsmonate des Völkerringens durchflutet waren, ist schon lange das harte Pflichtbewußtsein unerschütterlichen Durchhaltens getreten, das uns immer neu und zahlreicher sich auftürmender Schwierigkeiten gegenüber vor einem Nachlassen und Müdewerden schützen soll durch eiserne Willensmahnung: Jetzt erst recht.“1889 Wie in Ulm wurde der Unterricht an nahezu allen Schulen durch die vielen Sammlungen, Hilfsdienste und Aktionen in erheblichem Maße beeinträchtigt: „Sammlungstätigkeit und Kriegsanleihewerbung, Hilfsdienstarbeit und Landwirtschaftsunterstützung sind - um nur die besonders anspruchsvollen Kriegseindringlinge zu nennen - Fremdkörper, welche die rauhe Notwendigkeit in unser stilles Wirken rücksichtslos hereinschleudert. “' ${ }^{1890}$ Wie sehr sich die Stimmung im letzten Kriegsjahr gewandelt hatte, geht auch aus der Tatsache hervor, dass sich am Ulmer Gymnasium und auch an vielen anderen Schulen sogar die jüngeren Schüler teilweise

\footnotetext{
${ }^{1886}$ Schott, „Ein Jahr Kriegsstunden am Gymnasium“, in: deutsches Deutsches Philologen-Blatt 1915, S. 618.

${ }^{1887}$ Siehe Kapitel 4.6.

1888 Schott, „Das zweite Kriegsstunden am Gymnasium“, in: deutsches Deutsches Philologen-Blatt 1917, S. 24.

1889 Schott, „Das dritte Kriegsstunden am Gymnasium“, in: deutsches Deutsches Philologen-Blatt 1918, S. 4.

${ }^{1890}$ Schott, „Das dritte Kriegsstunden am Gymnasium“, in: deutsches Deutsches Philologen-Blatt 1918, S. 4.
} 
weigerten, Kriegsgedichte zum Vortragen in den „Kriegsstunden“ auswendig zu lernen und vorzutragen.

An vielen Schulen wurden die Schüler nicht so stark in den Ablauf mit einbezogen wie am Ulmer Gymnasium. So hielten z. B. in den Gymnasien in Schwabach, Ingolstadt und Landshut (alle Kgr. Bayern) die jeweiligen Schulleiter bzw. deren Stellvertreter wöchentlich einen Vortrag über die Kämpfe der vergangenen Woche, und über das Gymnasium in Amberg (Kgr. Bayern) ist überliefert: „In der 9. und 8. Klasse hielt der Berichterstatter fortlaufende Vorträge über staatliche und wirtschaftliche Verhältnisse unseres Vaterlandes und seiner Verbündeten sowie der feindlichen Staaten ... Fast in allen Klassen wurden Wochenübersichten gegeben. “1891

Im Hofer Gymnasium (Kgr. Bayern) hatte man ein Klassenzimmer in einen „Lehrraum“ umgestaltet, in dem die Schüler der oberen Klassen sich täglich in der Zeit von 10-12 Uhr anhand von jeweils neuestem Kartenmaterial, zwei Tageszeitungen u. a. über die aktuelle Kriegssituation informieren konnten. ${ }^{1892}$ Viele Gymnasien verzichteten aber auf die Erteilung gesonderter „Kriegsstunden“, wie z. B. das Gymnasium in Iserlohn (Provinz Westfalen). Im Jahresbericht 1914/15 des Realgymnasiums ist vermerkt, dass das Lehrerkollegium sich zur Einrichtung von „Kriegsstunden“ nicht entschließen konnte, sondern die Besprechung kriegerischer Ereignisse den Klassenlehrern sowie den Geschichts- und Erdkundelehrern übertrug. Man war der Meinung, damit die Schüler altersgemäßer ansprechen zu können. ${ }^{1893}$ Auch für einige Lyzeen, Realschulen und Volksschulen sind „Kriegsstunden“ bezeugt. So werden beispielsweise im Jahresbericht der Rostocker Realschule für das Schuljahr 1915/16 eine Reihe von Themen genannt. ${ }^{1894}$ Da sie sich nicht von denen der Gymnasien unterscheiden, kann auf eine Nennung verzichtet werden. In der kleinen Volksschule in Drohne (Provinz Westfalen) versammelten die Schüler sich sogar sonntags, um „über die Kriegslage zu erfahren, vaterländische Lieder zu singen und Gedichte vorzutragen““1895. Dass die Zahl der Schulen, die „Kriegsstunden“ erteilten, recht groß gewesen sein muss, geht bereits aus der Tatsache hervor, dass den Lehrern wie für die regulären Fächer auch für diese Stunden entsprechende Verlagspublikationen mit Anregungen und Themen zur Verfügung standen. ${ }^{1896}$

\footnotetext{
1891 Kriegsjahresberichte der bayerischen höheren Lehranstalten mit Lateinunterricht 1915/16, in: Deutsches Deutsches Philologen-Blatt 1916, S. 754-756.

1892 Siehe Kriegsjahresberichte der bayerischen höheren Lehranstalten mit Lateinunterricht 1915/16, in: Deutsches Deutsches Philologen-Blatt 1916, S.755.

${ }^{1893}$ Siehe Jahres-Bericht über das Realgymnasium und die Realschule zu Iserlohn, http://www.lbz-rlp.de/ Schulprogramme/schulprogramm_iserlohn_1914.pdf (4.01.2011), S. 17.

${ }^{1894}$ Langer, Lernziel Krieg! (2000), S. 27, S. 50, ein Thema war z. B. „Die Liebestätigkeit in Rostock“.

${ }^{1895}$ Schulchronik Drohne; zitiert nach: Kammeier, Der Landkreis Lübbecke und der 1. Weltkrieg (1998), S. 205.

${ }^{1896}$ Zum Beispiel: Korsch, H.: Kriegsstunden. Stoffe und Darbietungen für die Schule, Leipzig 1915.
} 


\subsection{Schulleben (Ausflüge, Pausen, Räumlichkeiten u. a.)}

Nicht nur der Unterricht, sondern auch das gesamte sonstige Schulleben wurde in den Dienst der „Kriegspädagogik“ gestellt. Dieses soll an einigen ausgewählten Beispielen erläutert werden.

Bereits vom ersten Schultag an wurden die Schüler mit dem Krieg konfrontiert, denn teilweise kamen die Kinder mit einer Zuckertüte, die militärische Motive aufwies (z. B. Bilder von Hindenburg und dem Grafen Zeppelin sowie Kinder mit Papierhelmen und Holzschwertern), zur Einschulung. ${ }^{1897}$ In dem Museum „Villa Hügel“ in Essen ist sogar eine Zuckertüte in Form einer 42cm-Mörsergranate aus dem Jahre 1915 ausgestellt.

Auch in dem Schulgebäude wurden die Kinder ständig an den Krieg erinnert. Der Eingangsbereich, die Flure und die Räume waren meistens mit schwarz-weiß-roten Fahnen und den Fahnen der Verbündeten geschmückt, an den Wänden hingen Kriegskarten, Kriegswandzeitungen, Plakate, die für eine Aktion der „Heimatfront“ warben, sowie Bilder Hindenburgs ${ }^{1898}$ und anderer Feldherrn. Zur Illustration sei aus einem Bericht einer Schulchronik der kleinen Dorfschule Tonnenheide (Provinz Westfalen) zitiert: „An der Wand hängen die Karten der Kriegsschauplätze. Fähnchen in den Farben der streitenden Völker bezeichnen die Stellungen der Heere. Welch große Freude, wenn unsere schwarz-weiß-roten Fähnchen vorgerückt werden können! Wie leuchten dann die Augen der Kinder!“" ${ }^{1899}$ Auch in der Realschule in Iserlohn (Provinz Westfalen) hingen „Karten der Kriegsschauplätze ( . . ) in den meisten Klassen“1900. Dass gerade dem „Kriegsbild in der Schule“ für die Kriegserziehung eine große Bedeutung beigemessen wurde, verdeutlicht ein Aufsatz eines Gymnasiallehrers. Seiner Meinung nach trügen gerade „Kriegsbilder“ dazu bei, dass „unsere Kinder mit der (Kriegs-) Zeit leben und ihre Sprache verstehen lernen“1901.

Auch Sammelbüchsen, deren Erlös in der Regel der Kriegshilfe zugutekam, wurden in fast allen Schulen an zentraler Stelle aufgestellt, wie z. B. aus dem Kriegstagebuch eines Hamburger Schulleiters hervorgeht. Dort wurden bereits „am ersten Schultag“ nach Kriegsbeginn zwei Sammelbüchsen aufgestellt, „eine für das Rote Kreuz, eine für die Kriegshilfe“ ${ }^{\text {1902 }}$.

\footnotetext{
${ }^{1897}$ Siehe die Abbildungen einer „Zuckertüte mit militärischen und einigen zivilen Motiven“ aus dem Jahre 1915: http://www.dhm.de/datenbank/, GOS-Nr. 20013859 (8. 01.2010

${ }^{1898}$ In Jahresbericht eines Berliner Lyzeums ist vermerkt, dass bald nach Kriegsbeginn „Bildnisse , unseres großen Hindenburg ' hingen bald in allen Klassen.“ Zitiert nach: Wildhagen, „Laß dich gelüsten nach der Männer Bildung ..." (1994), S. 125).

${ }^{1899}$ Zitiert nach:Kammeier, Der Landkreis Lübbecke und der 1. Weltkrieg (1998), S. 208.

1900 Jahres-Bericht über das Realgymnasium und die Realschule zu Iserlohn, http://www.lbzrlp.de/Schulprogramme/schulprogramm_iserlohn_1914.pdf (4.01.2011), S. 17.

${ }_{1901}$ Stein, Das Kriegsbild in der Schule, in: Deutsches Deutsches Philologen-Blatt 1915, S. 167.

${ }^{1902}$ Loewenberg, Kriegstagebuch einer Mädchenschule (1916), S. 13.
} 
Viele Schulen begannen den Schultag mit einer „täglichen Schul- und Kriegsandacht“, andere mit einer entsprechenden Andacht zum Wochenbeginn. Über den Ablauf der Andacht in der Dorfschule Getmold (Provinz Westfalen) berichtete der Lehrer 1914 in der Schulchronik. ${ }^{1903}$ Nach dem Singen eines Kirchenliedes und einem gemeinsamen Gebet wurde ,ein Kriegsgesang gesungen“. Anschließend sprach der Lehrer ein „Kriegsgebet“, in dem er Gott ,in dieser Kriegsnot“" um Schutz für das Vaterland und die Soldaten bat. Nach dem Vaterunser betete der Lehrer zum Abschluss mit den Schulkindern für die Gefallenen, wobei der Text immer gleich war:

„Barmherziger Gott und Vater, es ist geschehen, unser lieber (...) ist auf dem Felde der Ehre gefallen. Wir wissen ja, daß viele Opfer für unser liebes teures Vaterland gebracht werden müssen, aber wir empfinden doch über den Verlust dieses tapferen und edlen tiefen Schmerz. Er war die Freude und Hoffnung seiner Eltern. Nun bitten wir Dich, lieber himmlischer Vater, laß uns stille sein und auch bei dieser Trauerkunde bedenken, daß Deine Wege auch dann Gnadenwege sind, wenn sie uns dunkel erscheinen. Laß` unseren lieben, guten (...), der den Heldentod für das Vaterland gestorben ist, in Frieden ruhen und laß" ihm leuchten das ewige Licht. Amen.“

Auch an Schulen anderer Schulformen gehörte die Kriegsschulandacht in der Regel zum Alltag der Schüler. Dass auch sie sich am Kriegsgeschehen orientierte, geht aus einem Aufsatz eines Lehrers aus Solingen (Provinz Westfalen) hervor, ${ }^{1904}$ in dem er den Ablauf einiger Andachten an verschiedenen Schulen beschreibt. U. a. heißt es dort: „In unserer nächsten Andacht stellten wir dem eindrucksvollen Bericht des bayerischen Dichters (M. K.: Ganghofer) ein Gedicht Reinhold Brauns zur Seite, welches zeigt, wie tief inneres Gottbewußtssein auch in dem einfachsten deutschen Soldaten lebt und gepflegt wird. “' ${ }^{1905}$

Immer wieder fiel an einzelnen Tagen zugunsten von Sammlungen und Aktionen für die „Heimatfront“ der gesamte Unterricht aus, wie z. B. in einem Hamburger Lyzeum, als im November 1914 ein „Feldpostpakettag“ durchgeführt wurde, an dem die Schülerinnen den ganzen Tag lang Liebespakete für die Soldaten packten. Nach Meinung des Schulleiters war das „der schönste Schultag des ganzen Winters“ („War das eine Freude, ein Leben, ein Zugreifen, ein Helfen“(1906). Da die Schulen oft allgemeine Sammelstellen waren und gesammelte Produkte (z. B. Liebesgaben ${ }^{1907}$, Laubheu ${ }^{1908}$, Altmetalle, Obst- und Gemüsespenden und Bücher in der „Reichsbuchwoche“(1909) oft vorübergehend in Aulen, Turnhallen und anderen

\footnotetext{
${ }^{1903}$ Siehe Kammeier, Der Landkreis Lübbecke und der 1. Weltkrieg (1998), S. 204 f.

1904 Thamhahn, Kriegsschulandachten, in: Deutsches Deutsches Philologen-Blatt 1918, S. 226- 228.

1905 Thamhahn, Kriegsschulandachten, in: Deutsches Deutsches Philologen-Blatt, 1918, Jg. 26, Heft 27/28, S. 227.

${ }^{1906}$ Loewenberg, Kriegstagebuch einer Mädchenschule (1916), S. 27.

${ }^{1907}$ Siehe Anhang, Seite 71, Bild 2.

1908 Siehe Anhang, Seite 49, Bild 3.

${ }^{1909}$ Siehe Anhang, Seite 72, Bild 1.
} 
Schulräumen gelagert wurden, waren die Schüler immer wieder mit der schwierigen Versorgungslage und den Bemühungen an der „Heimatfront“" konfrontiert.

In größeren Städten wurden häufig die Schulküchen zu „Kriegsküchen“ umgewandelt ${ }^{1910}$, in denen neben Lehrern auch ältere Schülerinnen beschäftigt waren. In der Mittagszeit begegneten dort die Schüler oft Menschen, die in wirtschaftlichem Sinne besonders unter dem Krieg litten, und wurden auch dadurch mit dem Kriegsalltag in der Heimat konfrontiert.

Immer wieder kam es auch vor, dass Uniformierte in der Schule waren - ehemalige Schüler, eingezogene Lehrer oder auch Verwundete. In einem Hamburger Lyzeum veranstaltete z. B. die Oberklasse einen Unterhaltungsnachmittag für 25 verwundete Soldaten aus dem Lazarett - mit Liedern, Gedichten und Tänzen bei Kaffee und Kuchen in einem mit Fähnchen und Blumen geschmückten Raum. ${ }^{1911}$

Auch die Gestaltung der Pausen wurde oft im Sinne der „Kriegspädagogik“ genutzt ${ }^{1912}$, was im Folgenden an zwei Beispielen erläutert werden soll. Ein Lehrer aus Hartau bei Chemnitz (Kgr. Sachsen) machte eine Reihe von Vorschlägen, wie Kinder „Krieg auf dem Schulhofe“ spielen könnten, z. B. durch Marschübungen, Bau eines Feldlagers mit Zelten im Sommer und eines Schützengrabensystems im Winter. Er war der Meinung, dass durch solche Spiele auf dem Schulhof ,die Kleinen der Schule auf ihre Art in den Krieg hineingestellt (werden).“1913 Das andere Beispiel stammt aus dem Kriegstagebuch eines Hamburger Schulleiters. Er ließ an einem Tag die Kinder sämtlicher Klassen sich in der Pause auf dem Schulhof aufstellen, wo ihnen ein Soldat die Fähigkeiten eines „Sanitätshundes“ demonstrierte, z. B. bei der Suche nach Verwundeten. ${ }^{1914}$

Wandertage und Schulausflüge wurden hauptsächlich genutzt, um Sammel- oder Verkaufsaktionen durchzuführen, militärische Anlagen oder Kriegsausstellungen zu besichtigen oder mitunter auch, um die Schüler durch „Ertüchtigungsmärsche“ ${ }^{1915}$ vormilitärisch auszubilden. Besonders beliebt bei den Kindern waren Besichtigungen von Exerzierplätzen mit Schützengräben oder „Musterkriegsschauplätzen““1916. Zwar wurden in der Regel Jungenschulen bei der Vergabe der Besichtigungszeiten bevorzugt, es gibt allerdings eine Reihe von Beispielen über

\footnotetext{
${ }^{1910}$ Siehe Kapitel 4.7.1.

1911 Siehe Loewenberg, Kriegstagebuch einer Mädchenschule (1916), S. 45f.

1912 Siehe auch: Lemmermann, Kriegserziehung im Kaiserreich (1984), S. 893 („,Kriegsspiel: Der kleine Kavallerist - Krieg auf dem Schulhofe“).

1913 Silbermann, Der Krieg auf dem Schulhofe, in: Deutsches Deutsches Philologen-Blatt 1916, S. 143. In der Kriegschronik der Stadt Münster ist ein Bild von so einem „Kriegsspiel“ abgedruckt, siehe: Schulte, Kriegschronik der Stadt Münster 1914-18, (1930), Anhang, S. 3.

${ }^{1914}$ Siehe Loewenberg, Kriegstagebuch einer Mädchenschule (1916), S. 115-118.

1915 Siehe Weis, Ertüchtigungsmärsche unserer Schuljugend in der Kriegszeit, in: Deutsche Schulpraxis 1916, S. 188.

${ }^{1916}$ Siehe Schneider, Das Vaterländische Museum in Hannover (2010), S. 147-149.
} 
Besichtigungen durch Mädchenschulklassen. ${ }^{1917}$ In Flensburg beispielsweise haben etwa 2.000 Jungen aus den drei oberen Klassen von 13 Schulen die Schützengräben auf dem Marineexerzierplatz besichtigt. ${ }^{1918}$ Und der „Musterkriegsschauplatz“ in Hannover (Vahrenwalder Heide) wurde ebenfalls von sehr vielen Schulklassen aufgesucht. ${ }^{1919}$ Auch die Kriegsausstellungen der Kommunen waren recht häufig Ziele von Klassenausflügen. ${ }^{1920}$

Viele Schulen richteten nach dem Vorbild der kommunalen Ausstellungen selbst Kriegsausstellungen und Kriegsmuseen ein, die dann im Rahmen des Unterrichts besucht wurden. Als Beispiel sei auf die Kriegsausstellung eines Gymnasiums in Segeberg (Provinz SchleswigHolstein) hingewiesen. ${ }^{1921}$ Sie war im Zeichensaal eingerichtet worden und enthielt verschiedene thematisch geordnete Abteilungen, und zwar 1. „führende deutsche Männer“, 2. „Unsere Flotte“, 3. Darstellungen der verschiedenen Kriegsschauplätze“ und 4. „Krieg und Karikatur“. Neben Abbildungen wurden auch Exponate wie ,deutsche, österreichische, englische, französische, belgische und russische Infanteriegeschosse, Dumdumgeschosse, Granatzünder und Granatsplitter aller Art, Uniformknöpfe ( ... ), Achselstücke, Schießabzeichen und vieles andere“ ${ }^{\text {1922 }}$ ausgestellt. Neben größeren Kriegsausstellungen wurden auch kleinere Kriegsmuseen eingerichtet, z. B. in der Dorfschule in Rodt-Müllenbach (Rheinprovinz). ${ }^{1923}$ In Lehrerzeitschriften war 1915 eine Aufforderung an ,jede Schule in Stadt und Land“ abgedruckt worden ${ }^{1924}$, „,ein heimatliches Schulmuseum für Kriegserinnerungen“ zu gründen, der offensichtlich eine beträchtliche Zahl gefolgt ist. Neben solchen permanenten Sammlungen gab es zudem immer wieder Ausstellungen, die nur für einen bestimmten Zeitraum zu sehen'waren, wie z. B. eine im Rahmen einer „Spielzeugwoche“, die von Schülerinnen eines Hamburger Lyzeums veranstaltet worden war. Sie enthielt hauptsächlich Puppen und das entsprechende Zubehör, das die Schülerinnen Ende 1915 gesammelt hatten. ${ }^{1925}$

In vielen Schulen wurden neben Räumen für „Kriegsstunden“ und Kriegssaustellungen auch Büchereien eingerichtet, die von einem Lehrer und älteren Schülern verwaltet wurden. Sie

\footnotetext{
${ }^{1917}$ Beispielsweise besuchte die 1. Klasse eines Hamburger Lyzeums den „Großborsteler Exerzierplatz“; siehe: Siehe Loewenberg, Kriegstagebuch einer Mädchenschule (1916), S. 114.

${ }^{1918}$ Hohnsbehn, Die Flensburger Schuljugend in der Zeit des ersten Weltkriegs (1996), S. 201.

${ }^{1919}$ Siehe Kapitel 7.3.4 (,Hannover“) und Schneider, Das Vaterländische Museum in Hannover (2010), S. 147149.

${ }^{1920}$ Siehe Kapitel 7.3.4. („Flensburg“). Dort werden konkrete Zahlen zum Besuch der „Deutsche(n) Kriegsausstellung für die Nordmark" in Flensburg genannt.

${ }^{1921}$ Siehe Georges, Eine Kriegsausstellung in der Schule, in: Deutsches Deutsches Philologen-Blatt 1915, S. 353-355.

${ }_{1922}$ Georges, Eine Kriegsausstellung in der Schule, in: Deutsches Deutsches Philologen-Blatt 1915, S. 355.

${ }^{1923}$ Siehe die Abbildung in: Führen, Lehrer im Krieg (1936), Tafel 55.

${ }^{1924}$ Gericke, Gustav, Schulmuseum, in: Die Lehrerin, Organ des Allgemeinen Deutschen Lehrerinnenvereins 1915, S. 78.

${ }^{1925}$ Siehe Loewenberg, Kriegstagebuch einer Mädchenschule (1916), S. $98 f$.
} 
enthielten gestiftete brauchbare Schulbücher, die von ärmeren Schülern ausgeliehen werden konnten und auch für „Lehrgänge hinter der Front gewährt werden konnten“1926.

Zum Abschluss soll noch auf einige weitere kriegsbezogene schulische Aktivitäten hingewiesen werden, und zwar auf das regelmäßige Führen von „Kriegstagebüchern“1927, „Schulkriegschroniken“1928 sowie die Herausgabe von „Kriegszeitungen“1929. Besonders verbreitet waren - vor allem an Mädchenschulen - die „Kriegstagebücher“, die an vielen Schulen von den Schülern geführt werden mussten, wie z. B. an einem Lyzeum in Essen (Rheinprovinz). Dort waren die Schülerinnen der Klassen I - VII verpflichtet, zweimal in der Woche zu von ihnen selbst gewählten Themen zusammenhängende Beiträge zu verfassen, die die zensierten Aufsätze ersetzten. Die meisten von ihnen beschäftigten sich nicht mit den Kämpfen an der Front, sondern mit der Situation an der „Heimatfront“, wie die Überschriften „Unser Kriegsliebesdienst“, „Unsere Weihnachtskisten“, „Packnachmittag“, „Alles strickt“, „Im Wolladen“, „Nur 225 g Brot!“, „,Winterhutkauf“, „,Kriegsbrot““, „Butter sparen““1930 u. v. a. belegen. Sicher sind die Schülerinnen insgesamt durch die intensive Auseinandersetzung mit solchen Themen zu eigenem Engagement an der „Heimatfront“ angeregt worden. Während die „Kriegstagebücher" hauptsächlich Selbsterlebtes enthielten, sollte die ebenfalls für den Deutschunterricht empfohlene „Schulkriegschronik“ in erster Linie den Verlauf des Krieges aus Sicht der Schulen dokumentieren. Ein Kreisschulinspektor entwickelte ein - recht detailliert ausgearbeitetes - Muster, das den Schulen die Führung solcher Chroniken erleichtern und dafür sorgen sollte, dass das Kriegsgeschehen möglichst breit erfasst wurde. ${ }^{1931} \mathrm{Zu}$ den Themen gehörten auch in großem Umfang die Maßnahmen der Schule an der „, Heimatfront“. So werden im Abschnitt „Die Zurückgebliebenen“ u. a. „Kriegshilfe und Liebestätigkeit, Rotes Kreuz, Bahnhofsdienst, Lazarette, Sammlungen an Geld, Gold, Naturalien, ( ... ) Zeichnungen für die Kriegsanleihen, Liebesgaben für die Kriegsbetstunden, Sieg- und Gedächtnisfeiern“ genannt. Außerdem sollte die Chronik Informationen über die ,zurückgebliebenen Lehrer und die Kriegswohlfahrtspflege“, die „Schuljugend und die Kriegshilfe“, „Siegesfeiern in der Schule“ und „Kriegsunterricht“ enthalten. Am Ende eines jeden Monats war die Chronik von den Schülern zu ergänzen, wobei Zeitungsausschnitte und Feldpostbriefe aufgenommen werden sollten. Durch die regelmäßige Beschäftigung mit der Chronik

\footnotetext{
${ }^{1926}$ Siehe Rausch, Heimatdienst und zwölf Artikel für Schulen, in: Deutsches Deutsches Philologen-Blatt 1918, S. 323-326.

${ }^{1927}$ Siehe Schulze, Kriegstagebücher, in: Deutsches Deutsches Philologen-Blatt 1915, S. 34-36.

1928 Siehe Bendele, Krieg, Kopf und Körper (1984), S. 159f.

${ }^{1929}$ Siehe Czasche, Schul-Kriegsschriften, in: Deutsches Deutsches Philologen-Blatt 1917, S. $285 \mathrm{f}$.

${ }^{1930}$ Schulze, Kriegstagebücher, in: Deutsches Deutsches Philologen-Blatt 1915,. S. 35.

1931 Amrehn, Der Weltkrieg im Unterricht (1916), S. 48f.; zitiert nach: Bendele, Krieg, Kopf und Körper (1984), S. $159 f$.
} 
versuchte man zudem die Begeisterung der Schüler für den Kampf an der „Heimatfront“ aufrechtzuerhalten oder sogar noch zu stärken.

Vor allem die Gymnasien gaben häufig „Schulkriegsschriften“ heraus, und zwar entweder als „Schulkriegszeitungen“ mit dem Schulleiter als Herausgeber (z. B. am König-GeorgGymnasium in Dresden oder an der Chemnitzer Reformschule) oder als „Schülerkriegszeitungen“ (z. B. am Lessing-Gymnasium zu Frankfurt a. M. oder an dem Friedrich-WilhelmGymnasium in Berlin), die von der Schülerschaft bearbeitet wurden. ${ }^{1932}$ Die Zeitungen beschäftigten sich hauptsächlich mit den Kriegsschicksalen der ehemaligen Schüler und berichteten auch über wichtige Vorgänge aus dem Schulleben. Ferner dienten sie der Sammlung von Adressen ehemaligen Schüler.

\subsection{Fazit}

Auch wenn die Beschreibung der Situation an den „Kriegsschulen“ nicht vollständig ist, so zeigt die Untersuchung doch, wie umfassend die ,Mobilmachung der Schule" war, von der die Schüler sowohl als zukünftige Soldaten als auch als Kämpfer an der „Heimatfront“ erfasst wurden. Karl Liebknecht hatte also recht, als er im März 1916 hinsichtlich der Situation der Schule im preußischen Abgeordnetenhaus klagte: „Krieg, Krieg und noch einmal Krieg ist die Losung der Schulen“1933 und ,(die Schule ist) ein politisches Propagandamittel für den Krieg, ein Hilfsmittel für die Kriegswirtschaft, ein Werkzeug für die Kriegsfinanzen““1934 geworden, denn nahezu der gesamte Unterrichtsbetrieb war tatsächlich den Bedürfnissen des Krieges untergeordnet. Der Einsatz der Kinder für die Kriegswirtschaft erfuhr seine Vorbereitung im Unterricht und der in den Lehrplänen vorgesehene Unterrichtsstoff trat zugunsten des „Kriegsunterrichts“ zurück. Im Deutschunterricht wurden „Kriegsdiktate“ und „Kriegsaufsät$z^{\text {“ }}$ geschrieben sowie „Kriegsgedichte“ besprochen und auch verfasst, in Rechnen waren „Kriegsaufgaben“ zu lösen, Zeichnen wurde zum „Kriegszeichnen“ und die naturkundlichen Fächer zu „Kriegsbiologie“, „Kriegsphysik“ und „Kriegschemie“. Anstelle der regulären Schulbücher wurden im Unterricht auf den Krieg ausgerichtete Lesehefte, Einlegeblätter und Schülermerkblätter benutzt, Lehrmittel der „Kriegspädagogik“ angepasst, wie es z. B. oft bei Geschichtsatlanten der Fall war. ${ }^{1935}$

Sicher war das entsprechende Engagement der Lehrer unterschiedlich, aber die große Mehrheit unterrichtete nach kriegspädagogischen Grundsätzen. Schulen, in denen dem Krieg nur wenig Beachtung geschenkt wurde, waren sehr selten. Dass es sie gegeben hat, zeigt die fol-

\footnotetext{
${ }^{1932}$ Siehe Czasche, Schul-Kriegsschriften, in: Deutsches Deutsches Philologen-Blatt 1917, S. 286.

${ }^{1933}$ Liebknecht, Gesammelte Werke und Schriften, Band 8 (1966); S: 531.

${ }^{1934}$ Liebknecht, Gesammelte Werke und Schriften, Band 8 (1966); S: 531.

1935 Jahnke, Die Einrichtung von Geschichtsatlanten, in: Deutsches Deutsches Philologen-Blatt 1916, S. 629f.
} 
gende Äußerung eines Zeitzeugen: „Über den Krieg wurde im Unterricht wenig gesprochen. Es war selbstverständlich, dass Deutschland gewinnen mußte und würde. “1936 Lehrer hingegen, die z. B. die Schulanfänger „Schulrekruten“ nannten, von Schülern als „Wehrpflichtigen” sprachen und mit ihnen „Ertüchtigungsmärsche“ durchführten, waren in keinem Fall die Ausnahme. Sehr viele handelten nach der Forderung eines Mathematiklehrers „Lassen wir den Krieg von der militärischen wie von der wirtschaftlichen Seite eintreten in die Schulstu-

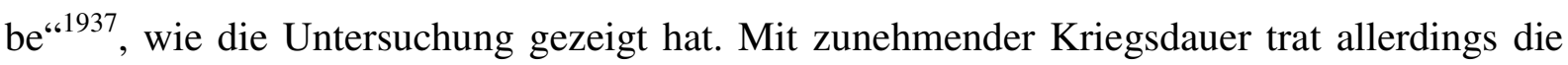
ideologische Mobilmachung immer mehr hinter der Aktivierung der Schüler für den Einsatz an der „Heimatfront“ zurück. Sätze wie „Jeder Deutsche muß Soldat sein auf wirtschaftlichem Gebiete“ oder im „wirtschaftlichen Kampfe muß sich die allgemeine Wehrplicht ausdehnen auf jeden Deutschen“ ${ }^{\text {1938 }}$ zeigen die gewandelte Zielsetzung. Die Schulpflicht wurde damals also durchaus auch als Wehrpflicht gesehen, und zwar unabhängig von der Schulform sowie dem Geschlecht und dem Alter der Schüler.

Anfangs profitierten die „Kriegspädagogen“ von der Ausrichtung des gesamten Schulbetriebs auf den Krieg. „Theorie und Praxis, Anspruch und Wirklichkeit klafften in der Schule im Krieg weniger weit auseinander als sonst. Ziele wie Ordnung, Gehorsam, Fleiß und Pflichtbewußtsein waren plötzlich keine hohlen Phrasen mehr, denn unter dem Einfluß des großen wirklichen Krieges endete der alltägliche Kleinkrieg zwischen Lehrern und Schülern.“1939 Dieser kehrte allerdings bald zurück, als die militärischen Erfolge seltener wurden und die wirtschaftliche Not sich vergrößerte. Hinzu kam, dass die Schüler durch die Ausrichtung des Unterrichts in allen Fächern und auch des Schullebens auf das Kriegsgeschehen der Thematik in zunehmendem Maße überdrüssig wurden. Neben vielen anderen Faktoren wie z. B. der Überalterung und der Erschöpfung der Lehrer, dem Nachmittagsunterricht, den übergroßen Klassen, der schlechten Ernährung und dem hohen Unterrichtsausfall war auch die Überfütterung mit Kriegsthemen eine Ursache für die Klagen vieler Lehrer über mangelnde Disziplin,fehlende Arbeitsmoral und vor allem unentschuldigte Unterrichtsversäumnisse. So erklärte z. B. im März 1918 die Flensburger Schuldeputation, dass sich einige Lehrkräfte „,den Anstrengungen des Dienstes nicht mehr gewachsen (fühlten)“", und die Lehrkräfte der St. Nikolaischule in Flensburg wurden im Sommer 1915 aufgefordert, „die Versäumnisse scharf zu

\footnotetext{
${ }^{1936}$ Gradl, Als Kreuzberg noch kaiserlich war; in: Pörtner, Kindheit im Kaiserreich (1997), S. 241.

${ }^{1937}$ Tussing, Der Krieg und der Unterricht im Rechnen, in: Die Mittelschule: Zeitschrift der Reichsfachschaft Mittelschule im Nationalsozialistischen Lehrerbund., 1916, S. 135.

${ }^{1938}$ Tussing, Der Krieg und der Unterricht im Rechnen, in: Die Mittelschule: Zeitschrift der Reichsfachschaft Mittelschule im Nationalsozialistischen Lehrerbund., 1916, S. 135.

${ }^{1939}$ Bendele, Krieg, Kopf und Körper (1984), S. 207.
} 
kontrollieren, da in der Kriegszeit ein Fehlen ohne Grund leicht möglich sei“ ${ }^{\text {1940 }}$. Beispielsweise stieg der Anteil der an Flensburger Jungenschulen bzw. Mädchenschulen unentschuldigt fehlenden Kinder von 7,5\% (5,0\%) im Schuljahr 1914/15 auf 13,3\% (8,4\%) ${ }^{1941}$ im Schuljahr 1917/18. Beklagt wurde ferner immer wieder, dass die häuslichen Arbeiten oft überhaupt nicht oder nur mangelhaft erledigt würden. Nach Hohnsbehn mussten die Lehrer und die unerfahrenen Hilfskräfte sich ,mit enormen Problemen herumschlagen ( . . ), denn die Kinder ertrotzten sich weitreichende Freiheiten und hoben die schulische Ordnung zumindest teilweise aus den Angeln“"1942 Auch aus vielen anderen Schulen dokumentieren Berichte negative Folgen des Krieges für den Unterricht, wie z. B. der offizielle Jahresbericht 1917/18 des Direktors der Realschule zu Schönberg (Ghzgt. Mecklenburg-Schwerin): „Die Schüler waren leicht zerstreut und zeigten vielfach wenig Interesse für die Schulangelegenheiten (... ); die Klassenziele wurden nicht erreicht, die Kenntnisse hatten Lücken bekommen und der Fleiß hatte nachgelassen. “ ${ }^{1943}$ Immer wieder gab es Klagen über die „durch die Kriegsverhältnisse hervorgerufene Zuchtlosigkeit der Jugendlichen““1944 (Regierungspräsident von Schleswig am 27. Mai 1916) und über die besondere Gefährdung der schulpflichtigen Jugend (Schulblatt der Provinz Sachsen 1916), wobei der Hauptgrund für die „Verrohung der Jugend““1945 in erster Linie in der „Not und Schwermut des vaterlosen Hauses“ gesehen wurde, in dem es an „Zucht und Aufsicht“ mangele, und nicht in der Schule. ${ }^{1946}$ Die Schule bemühte sich vielmehr, die erzieherischen Aufgaben der Eltern mitzuübernehmen ${ }^{1947}$. Auch wenn die Bemühungen der Lehrer, die Leistungen schwieriger Schüler zu verbessern, oft nicht besonders erfolgreich waren, so waren sie doch insofern wichtig, als „die Väter an der Front ihren schweren Dienst an der Front erfüllen (konnten) “ ${ }^{1948}$, da sie wussten, dass die Schulen sich um ihre Kinder kümmerten.

Abschließend kann festgestellt werden, dass die moralische und die wirtschaftliche „Mobilmachung“ der Schule einerseits zu einem Niveauverlust des Unterrichts führten, andererseits

\footnotetext{
${ }^{1940}$ Zitiert nach: Hohnsbehn, Die Flensburger Schuljugend in der Zeit des ersten Weltkriegs (1996), S. 268.

${ }^{1941}$ Hohnsbehn, Die Flensburger Schuljugend in der Zeit des ersten Weltkriegs (1996), S. 270.

${ }^{1942}$ Hohnsbehn, Die Flensburger Schuljugend in der Zeit des ersten Weltkriegs (1996), S. 275.

1943 Langer, Lernziel Krieg! (2000), S. 65.

1944 Zitiert nach: Führen, Lehrer im Krieg (1936), S. 43.

1945 Siehe dazu: Sellmann, Zur Verrohung der Jugend, in: Deutsches Deutsches Philologen-Blatt 1916, S. 168f.

${ }^{1946}$ Die Zitate stammen aus: Führen, Lehrer im Krieg (1936), S. 43.

1947 Z. B. erteilten viele Schulen, vor allem Gymnasien, speziell Jungen, deren Väter im Felde standen und deren Leistungen zurückgegangen waren, regelmäßig nachmittags zusätzlichen Unterricht, um einer ,drohenden Verwahrlosung“ entgegenzusteuern. Aber offensichtlich brachte diese Maßnahme in vielen Fälle ,nicht gleich alle Früchte, die die Eltern und Erzieher von ihr (erwarteten)“, wie ein Oberlehrer 1916 schrieb. Siehe Barth, Zur Einrichtung von Arbeitsstunden während des Krieges, in: Deutsches Philologen-Blatt 1916, S. 365f.

${ }^{1948}$ Siehe Barth, Zur Einrichtung von Arbeitsstunden während des Krieges, in: Deutsches Philologen-Blatt 1916, S. 366.
} 
jedoch die vaterländische Arbeit der Jugend an der „Heimatfront“ in erheblichem Maße stärkten. 


\section{Schlussbetrachtung}

Die Erziehung im Kaiserreich der Vorkriegszeit mit den Zielen ,Liebe zum Vaterland' und ,Vorbereitung auf den Krieg' war vor allem deshalb sehr erfolgreich, weil die Lehrer zu großen Teilen national und monarchisch eingestellt waren. Viele von ihnen begrüßten den Ausbruch des Krieges und stellten sich freiwillig für den Einsatz an der Front zur Verfügung. Nicht anders war es bei den Schülern. So meldeten sich die Abiturientenjahrgänge oft geschlossen zum Kriegsdienst. Aber auch die Schüler, die für den Militärdienst an der Front noch zu jung waren, die Schülerinnen und die aus verschiedenen Gründen nicht wehrfähigen Lehrer waren fast ausnahmslos bereit, sich für das bedrohte Vaterland (wie es die Propaganda verkündete) einzusetzen und im Rahmen der „Heimatfront“ zu kämpfen. Da mit dem Ersten Weltkrieg die Epoche ,totaler Kriege“ begann, war aufgrund der Industrialisierung des Krieges und der bis dahin kaum vorstellbaren Vernichtung von Menschen und Material eine patriotisch-nationale Mobilisierung von Soldaten und Zivilisten erforderlich, die zu einer weitgehenden Aufhebung der Grenzen zwischen militärischer Front und „Heimatfront“ führte. Neben den Frauen, die im Rahmen der „Heimatfront“ sich vor allem um die Betreuung der verwundeten Soldaten und die Kinderfürsorge kümmerten, wurden die Schulen mit zunehmender Kriegsdauer für den ,Kriegsdienst' in der Heimat immer bedeutsamer und zu einer der wichtigsten Bastionen der „Heimatfront“. Man sprach deshalb sogar von „schulischer Wehrpflicht“ und dem „Kampf an der Schulfront““.

Vom ersten Kriegstag an übernahmen Schüler und Lehrer eine Reihe von Hilfsdiensten. Die Schüler beispielsweise stellten sich als Post- und Telegrafenboten zur Verfügung, arbeiteten als Briefsortierer und Paketverteiler, befreiten im Winter die Bürgersteige von Schnee und Eis und halfen bei der Straßenreinigung. Noch stärker als die Schüler waren die Lehrkräfte durch Hilfsdienste belastet, denn sie mussten häufig ihre Schüler bei solchen Einsätzen begleiten und wurden darüber hinaus für viele andere Aufgaben herangezogen. Den weitaus größten Raum nahm neben Schreibdiensten dabei die Instruktion der Erwachsenen durch die Lehrerinnen und Lehrer ein. Aufgrund ihrer Stellung, ihrer Sprachfertigkeit und ihres Wissens waren die Lehrkräfte als Bindeglied zwischen Volk und politisch-militärischer Führung wichtige Multiplikatoren. Beispielsweise hielten sie Vorträge über Fragen der Ernährung, informierten über den Kriegsverlauf, versuchten die Siegeszuversicht der Menschen zu stärken und riefen zum Durchhalten auf. Vor allem die Volksschullehrer in Dörfern und kleineren Städten wurden zu wichtigen „Agents of Propaganda“1949, die auf „weite Volkskreise“(1950 einwirkten.

\footnotetext{
1949 Demm, Ostpolitik und Propaganda im Ersten Weltkrieg (2002), Seiten 61-70 (Kapitel 4: „Agents of Propaganda: German Teachers at War").
} 
Ohne die Schulen hätten die Kommunen schon aufgrund des Arbeitskräftemangels viele Aufgaben nicht wahrnehmen können.

Für die Versorgung der Bevölkerung mit Lebensmitteln waren die Arbeitseinsätze der älteren Schüler in der Landwirtschaft von Kriegsbeginn an außerordentlich wichtig. Mit zunehmender Kriegsdauer trugen sie in immer größerem Umfang zur Gesamtversorgung der Bevölkerung mit Lebensmitteln bei. Die schulische Erntehilfe konnte zwar den Mangel nicht beheben, ohne sie hätten sich die Menschen jedoch noch weiter einschränken und teilweise noch mehr hungern müssen. Demgegenüber waren die Erträge aus den Schul- und Schülergärten weit weniger wichtig und volkswirtschaftlich nahezu bedeutungslos, auch wenn sie vielen Familien der betroffenen Schülerinnen und Schüler und auch einigen Volksküchen geholfen haben. In erzieherischer Hinsicht waren die Aktionen allerdings insgesamt bedeutsamer, denn die beteiligte Schuljugend hat durch die Arbeit in den schuleigenen Gärten manches gelernt, z. B. im Gemüseanbau, in der Botanik und durch den Verkauf der Produkte auch in wirtschaftskundlicher Hinsicht. Außerdem hatten die Lehrer und die Schüler bei der Arbeit in den Schulgärten insgesamt das Gefühl, sie würden für das Vaterland etwas Gutes tun.

Von großer Bedeutung für die Volksernährung war hingegen die Einrichtung von ,Kriegsküchen' in den Städten, an der die Schulen aktiv beteiligt waren, denn viele wandelten ihre Schulküchen in Volksküchen um. In ihnen arbeiteten vor allem viele Hauswirtschaftslehrerinnen und oft auch ältere Schülerinnen. Während die Lehrerinnen Kochkurse abhielten, stellten die Mädchen der obersten Schulklassen unter deren Leitung das Essen her, das während der Dauer des Krieges an bedürftige Familien abgegeben wurde. Insgesamt waren die Schulen im Kampf gegen den Hunger der Kinder eine der wichtigsten Institutionen.

Bedeutsam für den Kampfeswillen der Soldaten waren die Briefe und die Liebesgabenpakete, die zu Hunderttausenden von Schülerinnen und Schülern an die Front geschickt worden sind, ob die Adressaten den Schülern nun bekannt waren oder ob es sich um „,vergessene Soldaten“ handelte. Durch sie haben die Schülerinnen und die Schüler mit dazu beigetragen, die Stimmung der Soldaten zu verbessern. Die Lehrerinnen und Lehrer hatten schon ziemlich früh die große Bedeutung der Feldpost für die Soldaten an der Front erkannt. Sie wussten, wie wichtig für jene das Gefühl war, von der „Heimatfront“ moralisch und materiell unterstützt zu werden. Deshalb initiierten sie nicht nur die Briefkontakte zwischen Schülern und Soldaten sowie Geschenksendungen, sondern richteten auch in allen Regionen des Reiches Kriegsschreibstuben ein. Dort halfen sie vielen im Schreiben Ungeübten und auch den vielen alten Menschen, Pakete an die Front richtig zu adressieren, oder ließen sich Briefe an Soldaten diktieren.

\footnotetext{
${ }^{1950}$ LAS, Abtlg. 302, Nr. 3178; siehe: Bericht des Provinzial-Schulkollegiums in Schleswig 1918, Abschnitt b („Einwirkung der Schule auf weitere Volkskreise“).
} 
Neben Volksküchen und Kriegsschreibstuben beherbergten viele Schulen auch Kriegsnähstuben und Strickschulen, in denen Schülerinnen Liebesgaben in sehr großer Zahl herstellten.

Sehr stark wurde das Schulleben von den aktuellen Kriegsereignissen beeinflusst, denn zu den traditionellen Schulfeiern, die auch im Krieg in formal etwas weniger aufwendigem Rahmen, aber inhaltlich in kräftig , aufgerüsteter' Form fortgesetzt wurden, traten zahlreiche Siegesfeiern und andere patriotische Veranstaltungen. Sie waren, unabhängig vom Anlass, ein wichtiges Element der Erziehung zum Patriotismus und gipfelten fast immer in einem feierlichen Bekenntnis zu Kaiser, Vaterland und Militär. Mit den Feiern sollten das patriotische Empfinden der Schuljugend gestärkt und die Schüler für eine opferfreudige Hingabe des eigenen Lebens begeistert werden. Durch die Einbeziehung von Gebeten und geistlichen Liedern glichen sie oft Gottesdiensten und förderten die religiöse Verklärung des Krieges. Die mit Festumzug, Marschmusik, Fahnenschmuck, patriotischen Reden und pseudoreligiösem Pathos meistens sehr aufwendig inszenierten Veranstaltungen übten besonders auf die Kinder und die Jugendlichen eine intensive Wirkung aus und beeinflussten sie stark und nachhaltig im Sinne der vaterländischen Kriegserziehung.

Mit zunehmender Dauer des Krieges fanden die Siegesfeiern immer seltener statt; die Gedenkfeiern für gefallene ehemalige Schüler und Lehrer hingegen wurden für das Schulleben vor allem der höheren Schulen ständig wichtiger. Angesichts der im Laufe des Krieges mehr und mehr ausbleibenden militärischen Erfolge und durch die zahlreichen Todesfälle, von denen die Schulgemeinschaft betroffen war, konnte man das zunächst vermittelte Bild, das das Kriegsgeschehen verharmloste, nicht weiter propagieren. Um dennoch die von Kriegsbeginn an vorhandene Kriegsbegeisterung der Jugend aufrechtzuerhalten und den allgemeinen Durchhaltewillen zu stärken, versuchte eine Reihe von Lehrern auch nach den großen Materialschlachten 1916 (Verdun, Somme), als in Teilen der Lehrerschaft die Kriegsbegeisterung geschwunden war und einem Skeptizismus Platz gemacht hatte, die Gefallenen pauschal zu vorbildhaften Helden zu stilisieren, die ihr Leben gern und uneigennützig für Kaiser und Vaterland gegeben hatten.

Neben den genannten patriotischen Feiern und Festen fand in den Schulen eine Reihe weiterer wichtiger Veranstaltungen statt, wie beispielsweise Weihnachtsfeiern, Vortragsabende und Unterhaltungsveranstaltungen. Meistens wurden Eintrittsgelder erhoben oder Spenden erbeten, um mit den Einnahmen die Kriegsfürsorge unterstützen zu können. Da die Erlöse häufig den örtlichen sozialen Einrichtungen zugutekamen, wurden die Veranstaltungen von den Kommunen begrüßt und unterstützt. So stellten sie ihnen geeignete Räumlichkeiten zur Verfügung, wenn die Schulen selbst keine besaßen. Die eingenommenen Gelder waren teilweise 
erheblich und stellten für die Wohlfahrtsverbände eine wichtige Einnahmequelle dar. Hinsichtlich der pädagogischen Zielsetzung und der Gestaltung unterschieden sie sich meist nicht von den allgemeinen Feiern. Sie waren durchgehend patriotisch ausgerichtet und somit Teil der nationalen Gesinnungsvermittlung. Herrscherverehrung, Vaterlandsliebe, Siegesgewissheit und Opferbereitschaft waren die angestrebten Erziehungsziele, die vor allem dadurch erreicht werden sollten und meistens auch erreicht worden sind, dass die Kinder und die Jugendlichen in die Veranstaltungen sehr oft als Akteure eingebunden wurden. Insofern dienten auch sie der Stabilisierung der „Heimatfront“.

$\mathrm{Zu}$ den Kriegsdienstleistungen in der Heimat, die den Unterricht und das Schulleben besonders belasteten, gehörten in erster Linie die vielen verschiedenen Sammelaktionen. Durchschnittlich acht solcher Aktionen wurden von den Schulen im Schuljahr bewältigt. Einerseits dokumentieren sie die große Leistung, die Schüler und Lehrer im Dienste ,kriegswichtiger Interessen' erbracht haben, andererseits jedoch verdeutlichen sie auch, dass angesichts der zahlreichen Aktionen, vor allem im letzten Kriegsjahr, regulärer Unterricht kaum noch möglich war. Dieses nahmen die Behörden jedoch billigend in Kauf.

Der volkswirtschaftliche Nutzen der einzelnen Sammlungen war allerdings recht unterschiedlich. Einige Sammlungen waren so wenig erfolgreich, dass sie als unwirtschaftlich eingestellt wurden. Andere hingegen wurden nicht abgebrochen, obwohl die erhofften Ergebnisse nicht erreicht wurden. Durch die Sammlung von ölhaltigen Früchten beispielsweise konnte die Versorgungslage der Bevölkerung nicht entscheidend verbessert werden, auch wenn die Schulen teilweise respektable Mengen abgeliefert haben. Bei der Sammlung anderer Naturerzeugnisse hingegen waren die Schulen sehr erfolgreich. So entsprachen die gesammelten Mengen von Laubheu beispielsweise den Erwartungen des Kriegsamtes. Noch größer waren die Erfolge der Schulen bei den vielen Geld- und Edelmetallsammlungen, die für die Kriegswirtschaft und die Finanzierung der Wohlfahrtsverbände von großer Bedeutung waren. Dieses trifft in besonderem Maße auf die Aktion „Gold-in-die-Reichsbank“ zu, bei der z. B. im Jahre 1915 die Schulen in Deutschland 152 Millionen Goldmark aufgebracht haben. Mit dieser Summe waren sie an der Zunahme des Goldvorrats der Reichsbank für das Jahr 1915 zu etwa 43 \% beteiligt.

Die Ergebnisse der Sammlungen zeigen insgesamt, dass die Schule für den „Abwehrkampf“ gegen die Wirtschaftsblockade erfolgreich mobilisiert und durchaus wirksam für die Kriegswirtschaft an der „Heimatfront“ eingesetzt wurde. Der Staat bediente sich erfolgreich sowohl der Schulkinder und der Lehrer als auch der kostenlos nutzbaren Organisationsstruktur der 
Schule. Ohne die Institution Schule hätten die Kriegssammlungen in dem erforderlichen Umfang nicht durchgeführt werden können.

Auch für die Finanzierung des Krieges war die Mobilisierung der Schüler und vor allem der Lehrer sehr wichtig, und zwar insbesondere bei den Kriegsanleihen. Dass die Anleihen, die für die Finanzierung des Krieges von großer Bedeutung waren, von ca. 75 \% der Bevölkerung gezeichnet wurden und finanziell so erfolgreich waren, ist in besonderem Maße auch das Verdienst der Lehrerschaft gewesen. Sie wurden als Multiplikatoren im Dienst der Volksaufklärung für eine flächendeckende Vortrags- und Werbetätigkeit verpflichtet. Über sie ist es gelungen, die Menschen auch im kleinsten und abgelegensten Dorf zu erreichen und sie dank ihrer Autorität zum Zeichnen zu bewegen, indem sie an das patriotisches Pflichtgefühl (,finanzielle Wehrpflicht““1951) appellierten. Dass sich auch Millionen von Schülern als Werber und Zeichner für die Kriegsanleihen engagierten, war ebenfalls in erster Linie das Verdienst der vom Staat instrumentalisierten Lehrer. Sie waren zusammen mit ihren Schülern ein wichtiger Teil der umfassenden staatlichen Werbeorganisation, die die Schulen immer aufforderte, sich durch das Zeichnen von Kriegsanleihen bei der „Mobilmachung der kleinen Beträge“،1952 an der „Heimatfront“ zu engagieren.

Neben dem Einsatz für die Kriegsanleihen engagierten die meisten Schulen sich bei vielen Spendenaktionen wie der „Ludendorff-Spende“ oder anderen Aktionen der Kriegsfürsorge. In der Regel war der Einsatz der Schulen regional durchaus wichtig, in volkswirtschaftlicher Hinsicht war seine Bedeutung jedoch gering. Auch wenn der finanzielle Erfolg häufig nicht dem großen Engagement der Schüler entsprach, so waren sie dennoch fast immer erfolgreich, da sie stets einen Beitrag zur patriotischen Indoktrinierung der Schulen leisteten.

Auch an der jeweiligen „Heimatfront“ der Kriegsgegner Deutschlands kämpften die Schüler und Lehrer, indem sie vor allem Hilfsdienste übernahmen, sich bei den diversen Sammlungen beteiligten, Spenden sammelten ${ }^{1953}$ und Liebespakete an die Front schickten. In Frankreich z. B. wurden in großem Umfang die Kinder in den Mittelpunkt der Propaganda gestellt. So

\footnotetext{
${ }^{1951}$ Michalka, Der Erste Weltkrieg (1994), S. 424.

1952 LAS, Abtl. 309, 13114; diese Forderung wurde in Flugblättern („Wer zahlt, hilft siegen“) erhoben, die der königlichen Schulinspektor Wißkott aus Trebnitz (Provinz Schlesien) jährlich an alle preußischen Landräte, Oberbürgermeister und Kreisschulinspektoren schickte. In ihnen wurde durchgehend das Engagement der Schulen als Kampf an der „Heimatfront“ betont, wie z. B. folgende Auszüge zeigen: „Jetzt gilt eine noch größere Schlacht, einen noch umfassenderen Sieg (zu erringen)“, „Wer zahlt, was er entbehren kann, hilft mit zu Sieg und Frieden. Wer nicht zahlt, was er entbehren kann, verlängert den Krieg.“, „Auf, Deutsches Volk! Die Septembergeldschlacht 1916 muss deinen finanziellen Vorsprung vor den Feinden nur noch größer machen!“

${ }^{1953}$ Siehe: Didier/Hirschfeld, In Papiergewittern (2008), siehe: z. B. die Seite 67; dort ist ein Plakat abgedruckt, auf dem ein Mädchen, das eine Krankenschwestertracht trägt, und ein Junge mit Medaillen auf der Brust zu sehen sind, die für einen vom Parlament veranstalteten „Journée du poilu“, der. Spendengelder für die Soldaten und ihre Angehörigen einbringen sollten, sammeln.
} 
waren einerseits etwa 30 von Victor Prouvé ab 1917 entworfene Plakate eigens für die Wände der Klassenzimmer bestimmt, während andererseits fünfzehn von Pariser Schülern angefertigte Zeichnungen in Form von Kleinplakaten gedruckt und in der Stadt in Geschäften und Postämtern aufgehängt: „Sie sollten die Sparmaßnahmen populär machen und an den Bürgersinn appellieren. ${ }^{61954}$ Auch in den Werbekampagnen für die vier Kriegsanleihen spielten die französischen Schulen eine wichtige Rolle. Kriegsnagelungen hingegen gab es ausschließlich in Deutschland und Österreich. Das ist insofern erstaunlich, als gerade diese Aktionen für den Kampf an der „Heimatfront“ von besonderer Bedeutung waren. Es kann davon ausgegangen werden, dass sich die große Mehrheit der Schüler und Lehrer im Deutschen Reich an den Kriegsnagelungen beteiligt ha; allein von der Firma Glasmachers wurden mehr als 30.000 Nagelschilde bezogen. Hinzu kommen die vielen schuleigenen Objekte und die Nagelbretter, die von anderen Herstellern vertrieben wurden. Auch an den über 1.000 Kriegsnagelungen der Gemeinden und Städte waren die Schulen in der Regel beteiligt.

Während sich über den finanziellen Anteil der Schulen an den kommunalen Nagelungen im Deutschen Reich insgesamt keine gesicherten Angaben machen lassen, liegen die Ergebnisse der von Lehrern gegründeten Vereine „Jugendspende für Kriegerwaisen e. V.“ und „Jugenddank für Kriegsbeschädigte e. V.“ teilweise vor. Der Reingewinn der Aktionen betrug mehr als 1.600.000 Mark. Auch wenn mit den Spenden, die unter den damaligen Bedingungen eine große Leistung der Schulen darstellten, vielen bedürftigen Menschen geholfen werden konnte, so war der finanzielle Erfolg in volkswirtschaftlicher Hinsicht eher gering und spielte auch im Vergleich mit den angestrebten pädagogischen Zielen eine untergeordnete Rolle. Den Schulkindern sollte vielmehr in erster Linie das Gefühl vermittelt werden, Mitglied der großen deutschen ,Volksgemeinschaft' zu sein und zusammen mit anderen an der „Heimatfront“ für den Sieg Deutschlands zu kämpfen. Angesichts der außerordentlichen Beliebtheit der Nagelaktionen bei den Kindern, die bis zum Ende des Krieges und in Einzelfällen sogar darüber hinaus anhielt, und begünstigt durch die oft wirkungsvollen Inszenierungen der Nagelungsfeiern konnten die patriotischen Erziehungsziele in der Regel auch erreicht werden.

Wie leicht es ist, Kinder und Jugendliche für Spendennagelungen zu begeistern, zeigen Nagelprojekte in unserer heutigen Zeit, wie z. B. das Schulprojekt „Friedenswahrzeichen“ des Gymnasiums Käthe-Kollwitz-Schule in Hannover. ${ }^{1955}$ Nach der entsprechenden Vorbereitung

\footnotetext{
${ }^{1954}$ Didier/Hirschfeld, In Papiergewittern (2008), siehe: z. B. die Seiten 63.

1955 Unter der Leitung des Verfassers wurde in einem Geschichtsleistungskurs 2005 das Projekt konzipiert und durchgeführt. Das $180 \mathrm{~cm}$ hohe dreieckige Friedenswahrzeichen, das vom Holzschnitzermeister Uwe Bormann aus Rieder (Harz) nach Plänen der Schüler hergestellt wurde, zeigt Käthe Kollwitz’ berühmtes Motiv „Nie wieder Krieg“, eine Friedenstaube und Angaben zur Schule. Im Sockelbereich ist umlaufend der Schriftzug „Nie wieder Krieg“ und „Käthe-Kollwitz-Schule“ flach eingeschnitzt worden, der auch als Nagelschablone dient.
} 
im Unterricht durch die Lehrer gelang es dort problemlos, die gesamte Schulgemeinschaft des Gymnasiums für die Nagelaktion zu gewinnen. Trotz der Begeisterung, mit der gerade die jüngeren Schüler die Nägel einschlugen und ihre Nagelsprüche in das ,Eiserne Buch' schrieben, war das Nageln frei von jener feierlichen und oft sogar weihevollen Stimmung, die die Aktionen im Ersten Weltkrieg auszeichnete.

Die Kriegsnagelungen, die bezeichnenderweise zu einem Zeitpunkt einsetzten, als sich nach der Siegeseuphorie der ersten Kriegsmonate ein Stimmungsumschwung im Volk bemerkbar machte, demonstrierten sowohl den inneren Zusammenhalt als auch die Verteidigungsbereitschaft nach außen und waren deshalb für den Staat ein besonders wichtiges Propagandasymbol. Zwar gab es im Krieg viele gemeinschaftsfördernde Aktionen, jedoch beeinflusste keine die Menschen mental so intensiv und nachhaltig wie die der Nagelungen. Während der feierlichen Veranstaltungen hatten viele Teilnehmer fast das Gefühl, in einer Schicksalsgemeinschaft aufzugehen - in der „Heimatfront“. Gesellschaftliche Gegensätze traten in den Hintergrund und soziale Harmonie wurde sichtbar. Man wollte an das „August-Erlebnis", das die Nation einte und die Klassengegensätze vergessen ließ, erinnern und den „Geist von 1914“ erneuern. Es scheint fast, als hätte man mit den Nagelaktionen jene „ganz große Idee“1956 gefunden, die in Robert Musils Roman „Der Mann ohne Eigenschaften“ zur 70. Wiederkehr des Regierungsantritts Kaiser Franz Josephs I. gesucht wird. Mit ihr wollte man die kulturelle Auflösung der gesellschaftlich heterogenen Donaumonarchie verhindern. In der sog. Parallelaktion hatte es sich eine Gruppe von Intellektuellen zum Ziel gesetzt, eine ,große patriotische Aktion“ ins Leben zu rufen, die ,,aus der Mitte des Volkes aufsteige(n sollte)“1957.

Es kann festgestellt werden, dass mit den Nagelungen 1915 weit mehr als ein originelles Mittel der Spendenbeschaffung gefunden worden ist. ${ }^{1958}$ Sie entsprachen dem Bedürfnis der Bevölkerung, sich ein bestimmtes Symbol zu schaffen, an dem jeder seinen Gemeinschaftssinn und seine Opferbereitschaft öffentlich zur Schau stellen konnte. Mit dem Nachlassen der anfänglichen Siegeseuphorie und der schwindenden Hoffnung auf ein baldiges Kriegsende wurde die Nagelungsbereitschaft der Bevölkerung trotz des großen propagandistischen Aufwands

\footnotetext{
Jeder Schüler, der einen Euro für einen Nagel spendete und einschlug, konnte sich in ein Nagelbuch eintragen und erhielt eine Nagelurkunde. Der Erlös der Aktionen wurde karitativen Einrichtungen zur Verfügung gestellt. Am 27. Januar 2006, dem Tag des Gedenkens an die Opfer des Nationalsozialismus, benagelte die gesamte Schulgemeinschaft, d. h. mehr als 1.000 Schüler, das Friedenswahrzeichen. Die Nagelung sollte sowohl gemeinschaftsstiftend wirken als auch zum Nachdenken über Frieden und Sicherheit anregen. In den folgenden Jahren nagelten dann jeweils die Schüler der 5. Klassen anlässlich ihrer Aufnahme in die Schule; siehe auch: Anhang, S. 112.

${ }^{1956}$ Musil, Der Mann ohne Eigenschaften (2007), Band 1, S. 93.

${ }^{1957}$ Musil, Der Mann ohne Eigenschaften (2207), Band 1, S. 171.

1958 Zur Funktion des Nagelns siehe u. a.: Schneider, "Der schöne Gedanke ins Groteske verkehrt"? In Korf, (Hrsg.), Alliierte im Himmel (2006), S. 328-337.
} 
Ende 1916 in zunehmendem Maße geringer, sodass die Nagelungen in einigen Orten sogar ganz eingestellt wurden.

In den Schulen hingegen hatte die Nagelungsbereitschaft in den letzten Kriegsjahren nicht nachgelassen, sondern war in der Regel noch größer geworden. Das Nageln übte bis zuletzt und teilweise sogar über das Kriegsende hinaus auf die Schulkinder jene besondere Faszination aus, die 1915 im gesamten Deutschen Reich zu der epidemieartigen Ausbreitung der Nagelaktionen geführt hatte. Sie fühlten sich als Mitglieder der großen Gemeinschaft „Heimatfront“" und waren der Überzeugung, einen Beitrag zur Verteidigung des Vaterlandes zu leisten. Voller Begeisterung bekannten sie durch den Akt des Nagelns, Nagelsprüche, Rezitationen und Gesangsbeiträge öffentlich ihre patriotische Gesinnung und legten - verbal oder symbolisch - ein persönliches Gelübde für Kaiser und Vaterland ab. Deshalb kam gerade den Schulnagelungen eine ganz besondere Bedeutung zu; sie wurden nahezu zum Symbol für den Kampf der Schulen an der „Heimatfront“. 1959

Der Krieg hatte nicht nur durch die vielen Sammelaktionen, Feiern und Sonderaufgaben schwerwiegende Beeinträchtigungen des Schulbetriebs zur Folge, sondern auch die personellen und materiellen Einschränkungen für die Schulen im gesamten Reichsgebiet waren dramatisch und führten zu mitunter unzumutbaren Rahmenbedingungen. Daran konnten auch die Sparappelle der Behörden, die Bemühungen der einzelnen Kommunen und sogar der patriotische Eifer der Lehrer kaum etwas ändern. Hinzu kam, dass die Schuldisziplin sich allmählich auflöste, da in vielen Familien die väterliche Autorität fehlte und die Kinder, vor allem in den Großstädten, teilweise verwahrlosten. Insgesamt hatten die Auswirkungen des Krieges einen deutlichen Niveauverlust des Unterrichts zur Folge.

Für den Kampf der Schulen an der „Heimatfront“ waren die Lehrer außerordentlich bedeutsam, und zwar als wichtige Multiplikatoren in der Öffentlichkeit und vor allem als Erzieher der Kinder. Ideologisch vom Staat gesteuert, sollten sie die Kinder zur Liebe zum Kaiser und zum Vaterland, zu Opfersinn und Kriegsbereitschaft sowie zur willigen Unterordnung unter die Befehle der Obrigkeit erziehen. Wie im Kapitel „Kriegsunterricht“ nachgewiesen worden ist, haben sie diese Aufgaben in den meisten Fällen im Sinne der „Kriegspädagogik mit Pflichtbewusstsein, Vaterlandsliebe und Verteidigungswillen erfüllt. Oft war ihnen dabei nicht bewusst, dass sie vom Staat für Kriegszwecke instrumentalisiert wurden. Wie wichtig die Rolle der Lehrer für den Kampf an der „Heimatfront“ war, zeigen auch Äußerungen von

\footnotetext{
1959 Auf dich kommt es an!, Schulblatt für die Herzogtümer Braunschweig und Anhalt 1917. In dem Aufruf zur Zeichnung von Kriegsanleihen heißt es: „Auf jede Mark kommt es an. Es ist wie bei der Nagelung unserer Kriegswahrzeichen; jeder einzelne der vielen Tausend Nägel ist winzig. Aber in der Gesamtheit umfangen sie das Gebilde mit einem ehernen Panzer. So muß auch unser deutsches Vaterland geschützt und gesichert werden durch das freudige Geldopfer der großen und kleinen Sparer.“
} 
Regierungsvertretern und Reichstagsabgeordneten. ${ }^{1960}$ Beispielsweise äußerte sich der Reichstagsabgeordnete v. Schulze-Gaevernitz am 12. Juli 1917: „Was unser Volk seit drei Jahren in unerhörtem Ringen in Erweisung geistiger Kraft und wunderbarem Heldentum jeglicher Art offenbart, verdankt es in grundlegender Weise der opferwilligen, pflichtgetreuen, hingebungsvollen Arbeit der Herren Jugendbildner.“1961

Auch wenn gegen Ende des Krieges durchaus eine Reihe von Lehrern desillusioniert und kriegsmüde war, so ,kämpfte' doch die große Mehrzahl bis zum Schluss zusammen mit ihren Schülern engagiert, erfolgreich und loyal daheim. Die schulische „Heimatfront“ desertierte also nicht, wie Hämmerle in „Kindheit im Ersten Weltkrieg“(1962, behauptet, allenfalls geriet sie nach den opferreichen Großschlachten im Jahre 1916 etwas „,ins Wanken“1963, als die Versorgungslage immer schlechter wurde und die Hoffnung auf einen baldigen Sieg bei vielen Lehrern allmählich schwand. Insgesamt jedoch entsprach die „Schulfront“ bis zum Schluss weitgehend den in sie gesetzten Erwartungen und trug damit - ohne es zu wollen - zu einer Verlängerung des Krieges bei. Das zeigen allein schon die Sammelergebnisse, die 1918 in vielen Fällen besser waren als die im Jahr zuvor. Die Schüler im Deutschen Reich fühlten sich bis zum Kriegsende als Kämpfer an der „Heimatfront“, teilweise sogar als Teilnehmer an einem „Kreuzzug“'1964, und erfüllten ihre Pflicht.

\section{Zusammenfassung}

Zwar ist der volkswirtschaftliche Nutzen der vielen schulischen Aktivitäten an der „Heimatfront“" insgesamt nicht exakt zu beurteilen, die Schule hat jedoch, wie ich meine nachgewiesen zu haben, einen wichtigen Beitrag zur Deckung der Kriegs- und zur Finanzierung der Kriegsfolgekosten geleistet. Wegen ihrer mit zunehmender Kriegsdauer immer größer werdenden Bedeutung für die Versorgung der Bevölkerung mit Lebensmitteln waren dabei die Arbeitseinsätze der älteren Schüler in der Landwirtschaft besonders wichtig. Hinzu kommt der im Ganzen recht hohe propagandistische Wert der Sammlungen, Hilfsdienste, Feiern und Nagelungen, und zwar sowohl für die Schülerinnen und Schüler als auch für die Gesamtbevölkerung. Indem es dem Staat gelang, die Schule umfassend für kriegswirtschaftliche Interessen zu instrumentalisieren und sie zu einem wichtigen Teil der staatlichen Werbeorganisation zu

\footnotetext{
1960 Siehe: Führen, Lehrer im Krieg (1936), S. 527-554.

1961 Führen, Lehrer im Krieg (1936), S. 547. Ähnlich äußerte sich auch Medizinalrat Dr. Abderhalden am 4. März 1918 in ,Leipziger Neueste Nachrichten’: „Der Krieg hat uns vieles Neue gelehrt und manches, was für weite Kreise im verborgenen blühte, ins hellste Licht gerückt. Dazu gehört in erster Linie die gewaltige Arbeit der deutschen Schule. Die gesamte Lehrerschaft hat Grundlagen gelegt, die jetzt die schwersten Lasten aushalten. Ihre Leistungen während des Krieges sind über jedes Lob erhaben“ (S. 548).

1962 Hämmerle, Kindheit im Ersten Weltkrieg (1993), S. 299.

1963 Schneider, Zur Mobilisierung der Heimatfront, Zeitschrift für Volkskunde, Bd. 32 (1999), S. 203.

${ }^{1964}$ Reich, Das Buch Michael (1917); siehe: Anschnitt 4: „Unserer Kinder Kreuzzeug““.
} 
machen, wurden die Menschen in allen Regionen des Deutschen Reiches erreicht und durch das Vorbild der Schulkinder und die patriotisches Appelle der Lehrer dazu gebracht, sich in hohem Maße durch Spenden sowie durch das Zeichnen der Kriegsanleihen an der Finanzierung des Krieges zu beteiligen.

Ferner hat die Schule durch das Verschicken von Liebespaketen die Kontakte zu den „Vergessenen Soldaten“ und die Lazarettbesuche nicht unerheblich den Durchhaltewillen der Soldaten an der militärischen Front gestärkt.

Insgesamt haben nationale Indoktrination und kriegsrelevante Instrumentalisierung der Schule in bedeutsamer Weise zur ideologischen und finanziellen Stärkung der „Heimatfront“ und damit zur Verlängerung des Ersten Weltkriegs beigetragen.

\section{Ausblick}

Die Schulen halfen also einerseits durch ihr umfassendes Engagement, die Niederlage des Deutschen Reiches hinauszuzögern, andererseits jedoch hatte die Mobilisierung über das Kriegsende hinaus weitreichende Folgen. Die damalige Schülergeneration, zu der auch Sebastian Haffner (*geb. 1907) gehörte, hat die Zeit von 1914-1918 hauptsächlich als ,großes aufregend-begeisterndes Spiel der Nationen (erlebt), das tiefere Emotionen beschert als irgendetwas, was der Frieden zu bieten hat ${ }^{\star 1965}$. Nach Haffners Meinung haben Hunger und selbst Schicksalsschläge wie die Verwundung oder der Tod von nahen Verwandten nicht die kriegerische „Traumwelt des großen Spiels“"1966, in der die Kinder lebten, zerstört. Deshalb fühlten sie sich mit der Kapitulation im November 1918 unsanft aus dem ,patriotisch-kriegerischen Rausch“1967 gerissen und um den immer wieder versprochenen Sieg betrogen. Diese frühen Erfahrungen haben die Entstehung des Nationalsozialismus und seinen Aufstieg begünstigt. Seine Wurzeln lagen nach Haffners Ansicht deshalb „nicht im ,Fronterlebnis’, sondern im Kriegserlebnis des deutschen Schuljungen“"1968.

Die Frontgeneration hatte die Schrecken des Krieges unmittelbar erfahren und war deshalb weit weniger anfällig für die NS-Ideologie als die Schuljugend, für die der Kampf an der „Heimatfront“ nur ein „großes Spiel“ gewesen war und die glaubte, man habe sie um den verdienten Sieg geprellt. Die Ergebnisse von Haffners hellsichtiger Analyse der Folgen der schulischen Kriegserziehung im Kaiserreich und der Erfahrungen der Schulkinder an der „Heimatfront", die zum Scheitern der Weimarer Republik beitrugen, entsprechen den Erkenntnissen der neueren historischen Forschung. So nennt Eberhard Demm beispielsweise die

\footnotetext{
${ }^{1965}$ Haffner, Geschichte eines Deutschen (2002), S. $21 \mathrm{f}$.

${ }^{1966}$ Haffner, Haffner, Geschichte eines Deutschen (2002), S. 89.

${ }^{1967}$ Haffner, Haffner, Geschichte eines Deutschen (2002), S. 25.

${ }^{1968}$ Haffner, Haffner, Geschichte eines Deutschen (2002), S. 22.
} 
Schuljugend der Jahre 1914-18, „eine Generation, die überwiegend die liberalen Werte zurückwies und schließlich die eifrigsten Anhänger Adolf Hitlers darstellte“61969, und Andrew Donson vertritt eine entsprechende Meinung. ${ }^{1970}$

Die Generation, die mit dem leitmotivischen Motto „Konnt ich auch nicht Waffen tragen, half ich doch die Feinde schlagen"1971 an der „Heimatfront“ gekämpft hatte, war nur zwei Jahrzehnte später mitverantwortlich für die Entfesselung des Zweiten Weltkriegs. Dort kämpften sie dann als Soldaten an der militärischen Front, wo - eben anders als im Ersten Weltkrieg Millionen von ihnen umkamen.

${ }^{1969}$ Demm, Ostpolitik und Propaganda im Ersten Weltkrieg (2002), S. 121.

${ }^{1970}$ Donson, Models for Young Nationalists and Militarists, German Studies Review, 2004, 579. Er schreibt z. B.: The reading experience of the war youth arguably prepared them for the nationalism and militarism of rightwing organisations after 1918" (S. 579).

${ }^{1971}$ Mit diesem Vers wurde in den Schulen für die Goldsammlungen geworben. 


\section{Quellen- und Literaturverzeichnis}

\section{Ungedruckte Quellen}

Geheimes Staatsarchiv Berlin

HA I, Rep. 76 VI, Sekt. I, Blatt 8 d A, Ministerium der geistlichen und Unterrichts-Angelegenheiten, Einsatz von Schülern in der Landwirtschaft, Einsatz von Schülern in der Landwirtschaft

\section{Niedersächsisches Hauptstaatsarchiv Hannover (NHStA)}

Hann. 122a, Nr. 380. Oberpräsident Hannover:Die Kriegsanleihen in den Jahren 1914-1918

Hann. 174, Hannover I, Nr. 195 (Sammel- und Spendenaufrufe aus dem ersten Kriegsjahr)

Hann. 180 Nr. 651, B1. 290. (Aufruf "Liebe Kinder! Meine fleißigen Freunde!"), Nr. 652 (Tätigkeitsbericht der Freiwilligen Kriegshilfe Hannover und Linden e. V. während der beiden Kriegsjahre 19141916), Blatt 40ff. Werbeprospekt der Nagelungsaktion vom März 1916

\section{Niedersächsisches Staatsarchiv Bückeburg (NStAB)}

Nr. 1038 (Enthält u. a. Festveranstaltung mit Nagelung des Wappens der Stadt Stadthagen zu Kriegsfürsorgezwecken)

Nr. 3650 (Deutsche Nationalstiftung für die Hinterbliebenen der im Kriege Gefallenen, Spendensammlung, Nagelung des Eisernen Kreuzes als "... Wahrzeichen an die große gewaltige Zeit ..."; Ludendorff-Spende für Kriegsbeschädigte)

X.C.26 (Enthält u. a. die Nagelung des Wappens).

\section{Niedersächsisches Staatsarchiv Osnabrück (NStAO)}

7/43 Nr. 31 (Enthält u. a. die Nagelung eines Standbildes Karls des Großen 1915)

\section{Niedersächsisches Staatsarchiv Wolfenbüttel (NStAW)}

34 N Nr. 4356 (Aufruf des Vereins Jugendspende für Kriegerwaisen, 1917 ; Flugblatt: auf zum Endkampf, Kriegspresseamt Berlin, 1917)

13 Nr. 37922 (Feier des 400. Jahrestages der Reformation: Festgottesdienste, Jubelfeier, Vorbereitungen dazu)

\section{Staatsarchiv Bremen (SAB)}

Nr. 3.M.2.h.Nr.29[59] der Akten der Senatsregistratur und Nr. 4,14/1-Kr.A.20. der Polizeidirektion (Nagelungen); Ausschnitte aus der Weserzeitung und der Bremer Kriegsschau

Landesarchiv Schleswig (LAS)

Abteilung 302 (Provinzial-Schulkollegium, Nr. 3178 (Sammlungen, Ernteeinsatz, Bericht des Provinzial-Schulkollegiums über die kriegswirtschaftlichen Leistungen der Schulen 1917 an das Preußische Abgeordnetenhaus)

Abteilung 309 (Königliche Regierung, II. Kirchen- und Schulsachsen), Nr. 13114 (Kriegsanleihen)

\section{Stadtarchiv Bad Homburg (StABH)}

A III, 7m, 23 (St. Michael in Eisen 1915/16); 24 („Gold gab ich für Eisen“ 1914/16); 25 (Spendensammlungen div.)

\section{Stadtarchiv Bamberg (StABA)}

BS 28723 B. u. T. 12/20m; K. S. D 217 (Nagelungen des „Eisernen Ritters)

C 56 KA; Nummer: 10/20m

\section{Stadtarchiv Bonn (StABO)}

Nr. 6086 a,b; 16209 a-d (Bilder von Nagelungen der Schulkinder)

\section{Stadtarchiv Braunschweig (StAB)}

D IV: C IX: 58a (Zirkularverfügungen des Herzoglichen Konsistoriums 1907-1931) 
Stadtarchiv Dresden (StAD)

Bestand des Schulamts, Akte Nr. 795, Blätter 1-2, 4-6, 8, 20ff, 27ff (Nagelung der Hindenburgsäule)

Stadtarchiv Eisfeld (StAEF)

Inventarverzeichnis Nr. 823;

Stadtarchiv Erfurt (StAE)

Zwei Bilder (24. Oktober 1915, Einweihung und Nagelung des „Eisernen Landsturmmannes“; 1916, Schulklasse zum Besuch im Angermuseum beim „Eisernen Landsturmmann“); Zeitungsausschnitte des „Erfurter Allgemeiner Anzeiger"), Oktober 1915.

\section{Stadtarchiv Flensburg (StAFL)}

IV C, Nr. 978; IV E, Nr. 34, 285, 289, 291, 301, 963; IV F 312 (Nachweis über die von unseren Volksschulen geleisteten kriegswirtschaftlichen Arbeiten);

XII HS Z. Bd.1 + 2; XII HS 1894, Bd.1, S. 40, S. 52 (Siegesfeiern); S. 8, 15, 82, 83.

\section{Stadtarchiv Greiz (StAG)}

Bestand B, Nr. 481 Seite 87

\section{Stadtarchiv Hannover (StAH)}

HR 16 (Schule im Krieg - Kriegsschule), Nr. 145 (Schülerhilfsdienst während des Krieges und nachher sowie Urlaub zu landwirtschaftlichen Arbeiten, Bd. 1 1916-1945, Nr. 200 (Laubheusammlungen), 239 (Unterrichtsbetrieb an den städtischen Lehranstalten während des Kriegszustandes 1914-1950), 496 (Feiern nationaler Gedenktage in den städtischen Schulen 1872-1943), Nr. 553 (Sammeltätigkeit) HR 39, Nr. 1 (Aufforderung zur Zahlung von Kriegsanleihen September 1916), 39, Nr. 15 (,Jugendspende“), 19 (Die Ludendorff-Spende für Kriegsbeschädigte), 42 (Reichswollwoche vom 18. bis 24. Januar 1915).

SB Nr. 277, Blatt 11 (H 6, S. 235), Blatt 4, Blatt 16 (Lutherschule).

\section{Stadtarchiv Kornwestheim (StAK)}

Signatur VA 2.

Stadtarchiv Peine (StAP)

AF 34, Nr.8).

\section{Stadtarchiv Mannheim (StAMA)}

Kleine Erwerbungen, Nr. 1068 (Nagelbuch);

S 2/A43, 536, S. 4/ (Zeitungsartikel).

Stadtarchiv Mühlhausen/Thüringen (StAMÜ)

11/425/18 (Das eiserne Ehrenmal 1916).

Stadtarchiv Offenbach (StAO)

M 41 (Der „Eiserne Mann“).

Stadtarchiv Reutlingen (StAR)

AZ 361-51-5 (Reutlinger Kriegswahrzeichen)

\section{Stadtarchiv Rudolstadt (StAR)}

BCf 3/7, 3/8, 3/9 (Bilder von der Nagelung des Eisernen Kreuzes).

Stadtarchiv Wismar (StAW)

XIV $1,26^{\mathrm{III}}$ (Vorbereitung und Durchführung der Nagelung in der Ratsakte)

\section{Stadtarchiv Zwickau (StAZ)}

I A 122 (Goldenes Buch des Zwickauer Hindenburg-Roland 1915-1916). 


\section{Gedruckte Quellen}

Alexan, Friedrich, Die Welt der kleinen Leute. Erinnerungen an eine Jugend im Ersten Weltkrieg, Mannheim 2008.

Amreihn, Hans, Der Weltkrieg im Unterricht. Beiträge zur Theorie und Praxis des Gegenwartsunterrichts, Bielefeld/Leipzig 1916.

Arbeit der Volkschullehrerinnen in Breslau, in: Die Lehrerin, Organ des Allgemeinen Deutschen Lehrerinnenverein 1914/15, S. 222f.

Auf dich kommt es an!, in: Schulblatt für die Herzogtümer Braunschweig und Anhalt, Jg. 30, 1917, S. 91.

Aufruf, Die Lehrerin, Organ des Allgemeinen Deutschen Lehrerinnenverein, 1915/16, S. $13 f$.

Aufruf an alle deutschen Schulen, Hannoversche Schulzeitung. Organ der Provinzial-Lehrervereins, der Bezirks- und Pestalozzivereine der Provinz Hannover, des Lehrer-Brandversicherungsvereins für Hannover, Bremen und das Fürstentum Lippe, 1915, S. 326

Aufruf an alle Schulen, Monatszeitschrift für höhere Schulen, 1915, S. 479/480.

Aufruf an die deutsche Lehrerschaft, Die Lehrerin, Organ des Allgemeinen Deutschen Lehrerinnenverein, 1915, S: $93 \mathrm{f}$.

Aufruf an die deutsche Lehrerschaft, Hannoversche Schulzeitung. Organ der Provinzial-Lehrervereins, der Bezirks- und Pestalozzivereine der Provinz Hannover, des Lehrer-Brandversicherungsvereins für Hannover, Bremen und das Fürstentum Lippe., 1915, S. 302.

Aufruf an die Jugend, Die Lehrerin, Organ des Allgemeinen Deutschen Lehrerinnenverein, 1914/15, S. 254.

Aufruf an die Schülerinnen, Die Lehrerin, Organ des Allgemeinen Deutschen Lehrerinnenverein, 1915/16, S. 35.

Aufruf zur Nagelung des Kriegswahrzeichens der Stadt Witten, in: Wittener Tageblatt, 18. Januar 1917.

Aufruf zur Nagelung eines Kriegswahrzeichens, in: Mühlhäuser Anzeiger, 08./15. April 1916.

Aus der Heimat, in: Eisenberger Nachrichtenblatt, 10. April 1916.

Aus der Stadt, in: Halberstädter Zeitung und Intelligenzblatt mit Berlin, 28. Januar/ 8. Februar1916.

Aus Nah und Fern, in: Kronacher Tagblatt, 18.Januar 1916.

Aus neuen Büchern, Deutsches Philologen-Blatt, Korrespondenz-Blatt für den akademisch gebildeten Lehrerstand, 1916, Beilage Nr. 1.

Aus Stadt und Land, Anzeiger von Weingarten, 22. November 1915.

Barth, Zur Einrichtung von Arbeitsstunden während des Krieges, in: Korrespondenz-Blatt für den akademisch gebildeten Lehrerstand, 1916, S. $365 f$.

Bäumer, Gertrud, Heimatchronik während des Weltkrieges, Quellenhefte zum Frauenleben in der Geschichte, Berlin 1930.

Bäumer, Gertrud, Eine Kriegspflicht der Schule, in: Die Lehrerin, Organ des Allgemeinen Deutschen Lehrerinnenverein, 1914/15, S. 241f.

Baumert, Hannover-Linden, Deutsches Philologen-Blatt, Korrespondenz-Blatt für den akademisch gebildeten Lehrerstand, 1916, S. 9.

Bayer, A., Eine Hindenburg-Ehrung, in: Deutsches Philologen-Blatt, Korrespondenz-Blatt für den akademisch gebildeten Lehrerstand, 1917, S. 546.

Bayer, A., Die "Vaterländische Kriegssammelstelle der höheren Schulen in Gotha", Deutsche Tageszeitung, 1918, S. 38f.

Becher, Der Krieg und die Schule, in: Deutsches Philologen-Blatt, Korrespondenz-Blatt für den akademisch gebildeten Lehrerstand, 1914, S. 668-670.

Bechtolsheimer, Karl, Der vaterländische Hilfsdienst der Schuljugend, Berlin-Lankwitz 2. Auflage 1917. 
Beisenherz, H., Leeret die Sammelbüchsen häufiger! In: Deutsches Philologen-Blatt, KorrespondenzBlatt für den akademisch gebildeten Lehrerstand, 1916, S. 707f.

Beispiel einer selbständigen Schülerarbeit im Anschluß an den Unterricht, in: Die Arbeitsschule, 1918, S. 108.

Beispiel einer Vortragsfolge, in: Die Arbeitsschule, 1918, S. 112.

Below, Georg von, Deutschland und die Hohenzollern. Eine Kriegsgedenkrede, Leipzig 1915.

Benagelung des Stadtlöwen, in: Wasserburger Anzeiger, 18. Dezember 1915.

Beteiligung der Schuljugend bei kriegswirtschaftlichen Arbeiten im Jahre 1917, in: Deutsches Philologen-Blatt, Korrespondenz-Blatt für den akademisch gebildeten Lehrerstand, 1918, S. $162 \mathrm{f}$.

Berger, H., Der Weltkrieg und die höheren Schulen Badens, in: Deutsches Philologen-Blatt, Korrespondenz-Blatt für den akademisch gebildeten Lehrerstand, 1915, S. $564 f$.

Beyte, Sophienschule Hannover, 1916, S. 153.

Biehl, W. (Hrsg. )., Deutsche Quellen zur Geschichte des Ersten Weltkriegs), Darmstadt 1991.

Biese, Alfred, Der Krieg und der Schulunterricht, Deutsches Philologen-Blatt, Korrespondenz-Blatt für den akademisch gebildeten Lehrerstand, 1914,. 562f.

Bilderbuch zum Besten kriegsverletzter Landsturmmänner, in: Amtliches Schulblatt für den Regierungsbezirk Hildesheim, 1917, Nr. 5.

Bis zum Beginn der Kämpfe um Verdun, Bielefeld [u. a.] 1916.

Blickmann, Th., Die Kriegsfürsorge der deutschen Lehrerschaft, Pädagogische Reform, 1915, S. 213.

Blömer, Ursula (Hrsg.), "Wir Kinder hatten ein herrliches Leben ...". Jüdische Kindheit und Jugend im Kaiserreich 1871-1918, Oldenburgische Beiträge zu jüdischen Studien, 5, Bibliotheks- und Informationssystem der Universität., Oldenburg

Blos, Anna, Krieg und Schule, Kriegsprobleme der Arbeiterklasse, 1915.

Bockmann, Blanche, Unsere Liebestätigkeit seit Kriegsbeginn (Wiesbaden), in: Die Lehrerin, Organ des Allgemeinen Deutschen Lehrerinnenverein 1915, S. $319 f$.

Bohm-Schuch, Clara, Die Kinder im Weltkriege, Kriegsprobleme der Arbeiterklasse, 1916

Bohnstedt, H., Die Kriegshilfe unserer Schuljugend, insbesondere im Hauswirtschaftsunterricht, Langensalza 1917.

Bongaertz, J., Zur Feier des Geburtstages Sr. Majestät Kaiser Wilhelm II. Ein Lebensbild unseres Kaisers, nebst einer reichhaltigen Sammlung vaterländischer Gedichte, Düsseldorf 9. Auflage 1909.

Böttger, W., Die Brennesselsammlung in Landsberg a. W., in: Deutsches Philologen-Blatt, Korrespondenz-Blatt für den akademisch gebildeten Lehrerstand, 1918, S. 39.

Braun, Reinold, Deutschlands Jugend in großer Zeit. Ein Buch vom Weltkriege für jung und alt, Rostock 2. Auflage 1916.

Brethfeld, M., Umgestaltung unserer Schulfeiern, in: Sächsische Schulzeitung, 1917, S. 541.

Briel, Scholastica, Aus der Chronik der Ursulinenschule, Saarbrücken, 1895-1938, Saarbrücken 1938.

Brill, Jever, in: Deutsches Philologen-Blatt, Korrespondenz-Blatt für den akademisch gebildeten Lehrerstand, 1916, S. 26.

Broßmer, Leitsätze über die zukünftigen Aufgaben des freiwilligen Schülerhilfsdienstes, in: Zentralblatt für die gesamte Unterrichtsverwaltung in Preußen, 1917, S. 253.

Broßmer, Der freiwillige Schülerhilfsdienst in der Landwirtschaft, in: Jahrbuch für Volks- und Jugendspiele, 1918.

Buchenau, Artur, Literatur zur Frage der Volksernährung, in: Deutsches Philologen-Blatt, Korrespondenz-Blatt für den akademisch gebildeten Lehrerstand, 1916, S. 196f.

Buchholz, Jahresbericht des Gymnasiums zu Hann. Münden. Schuljahr 1914/15, Hann.-Münden 1915.

Bünning, "Vergessene Krieger", in: Deutsches Philologen-Blatt, Korrespondenz-Blatt für den akademisch gebildeten Lehrerstand, 1916, S. 739.

Bürgel, G. J., Die Feier vaterländischer Gedenk- und Erinnerungstage in der Volksschule, Köln 2. Auflage 1894. 
Cartarius, Ulrich, Deutschland im Ersten Weltkrieg. Texte u. Dokumente 1914-1918, München 1982. Czasche, Rudolf, Schul-Kriegsschriften, in: Deutsches Philologenblatt, Korrespondenz-Blatt für den akademisch gebildeten Lehrerstand 1917, S. 285f.

Das Kreuz in Eisen, in: Anhalter Anzeiger, 22. Juni 1915.

Das Volk in Eisen. Kriegsgedichte der täglichen Rundschau (1914), Berlin 1914.

den Lindemann, Barbara/Jung, Wolfgang, Erinnerungen einer Freischülerin. Cläre Preissner erzählt aus der Zeit von 19071915, in: Beck, J./ Boehncke, H. (Hrsg.), Jahrbuch für Lehrer, Reinbeck 1981.

Denecke, Herford, in: Deutsches Philologen-Blatt, Korrespondenz-Blatt für den akademisch gebildeten Lehrerstand 1915, S. 740.

Den Vertrieb eines Bildes in den Schulen zum Besten der Nationalstiftung für die Hinterbliebenen der im Kriege Gefallenen betreffend, in: Schulblatt für die Herzogtümer Braunschweig und Anhalt, 1916, S. 298

Der "Eiserne Greif", in: Baden-Badener Badeblatt, 20. September 1915.

Der Eiserne Graf in Hamm. Ein Jahr der Opfertätigkeit, Hamm (Westfalen) 1916.

Der Eiserne Roland in Bremen, in: Bremer Nachrichten, 16. Juli 1915.

Der Eiserne Schmied von Hagen. Das erste Jahr seiner Geschichte, Hagen (Westf.) 1916.

Der Gelbe Verlag Walter Blumtritt, 13. Juli 1916.

Der Kronprinz an die Jungmannen, in: Deutsches Philologen-Blatt, Korrespondenz-Blatt für den akademisch gebildeten Lehrerstand, 1917, S. 646.

Der preußische Handelsminister Dr. Sydow über die Liebestätigkeit in den Schulen, in: Die Lehrerin, Organ des Allgemeinen Deutschen Lehrerinnenverein 1914, S. 183.

Der Schulleiter, Chronik der Wirgeser Schule, Wirges im Westerwald o. J.

Der Schulleiter, Bericht der Großherzoglichen Realschule über das Schuljahr 1915/16, Langen 1916.

Deutsche Kriegsausstellung 1916 in Hamburg, Berlin 1916.

Deutsche Kriegsausstellung für die Nordmark, Flensburg 1916.

Deutsche Kriegsausstellung 1916. Amtlicher Führer, Berlin 1916.

Deutsche Kriegsausstellung 1916-1917 in Hannover, Ausstellungsverzeichnis der Kriegsausstellung, Hannover-Stadthalle 1916/1917, Berlin 1916.

Deutschlands Jugend bei der vaterländischen Hilfsarbeit, in: Deutsches Philologen-Blatt, Korrespondenz-Blatt für den akademisch gebildeten Lehrerstand, 1917, S. 609

Deutschlands Jugend und der Weltkrieg, Heft 1, Cassel 1915.

Die "Kriegsbuchwoche", in: Deutsches Philologen-Blatt : Korrespondenz-Blatt für den akademisch gebildeten Lehrerstand, 1915, S. 364.

Die Fahrt des Heinsberger Kriegswahrzeichens, in: Heinsberger Volkszeitung, 1. August und 26. September/26. November 1917, 31. August und 2. September 1918.

Die Feier der Brunnennagelung in Wetzlar, in: Kreisblatt für den Kreis Wetzlar, 28. Januar 1916.

Die feierliche Einweihung des "Eisernen Kreuzes" von Schwarzburg-Rudolstadt, in: Rudolstädtische Landeszeitung, 15. August 1915/ 17. August 1917.

Die feierliche erste Benagelung des Ingolstädter Kriegswahrzeichens am Sonntag, den 16. Januar 1916, in: Ingolstädter Zeitung, 18. Januar 1918.

Die höhere Tochter als Landarbeiterin in: Die Lehrerin, Organ des Allgemeinen Deutschen Lehrerinnenverein 1917, S. 26.

Die höheren Schulen und die Frage der Volksernährung, in: Deutsches Philologen-Blatt, Korrespondenz-Blatt für den akademisch gebildeten Lehrerstand, 1915, S. 132.

Die Lebensmittelversorgung der Stadt Freiburg während des Krieges. Stadtgemeinde Freiburg im Breisgau. Ein Jahr Kriegsarbeit v. Aug. 1914/15, Walter, Freiburg i. B 1915.

Die Nagelung der eisernen Tür, in: Eberswalder Zeitung, 27. September 1915.

Die Nagelung des Eisernen Males, in: Mühlhausener Anzeiger, 24. April 1916. 
Die Nagelung des Landsberger Kriegswahrzeichens, in: Oberbayrischer Generalanzeiger, 1./3. April 1916.

Die Nagelung des Stadtwappens, in: Wertheimer Zeitung, 31. Januar/1. und 2. Februar 1916.

Die Schulfeier vor dem "Kreuz in Eisen" im Landesmuseum der Stadt Dessau, in: Anhaltinisches Tageblatt, 20. August 1915.

Die Weihe der Kriegs-Kirchtüre zu Borna, in: Tageblatt für den amtshauptmannschaftlichen Bezirks Borna, 25. Juni 1916/ 10 Januar 1917.

Die zwei Feldgrauen, in: Ludwigsburger Zeitung, 13., 14. und 15. Oktober 1916/17; 1993, Nr. 2 Beilage, März 1917.

"Diesmal wird es nichts!", in: Hannoversche Schulzeitung. Organ der Provinzial-Lehrervereins, der Bezirks- und Pestalozzivereine der Provinz Hannover, des Lehrer-Brandversicherungsvereins für Hannover, Bremen und das Fürstentum Lippe, 1917, Jg. 53, S. $318 \mathrm{f}$.

Diez, R., Die Werbetätigkeit der Schulen für die Kriegsanleihen, in: Südwestdeutsche Schulblätter, Organ des badischen Philologenvereins, des hessischen Oberlehrervereins sowie des württembergischen Philologenvereins, 1917, S. 200f.

Dihle, E., Ein beachtenswerter Versuch, in: Deutsches Philologen-Blatt, Korrespondenz-Blatt für den akademisch gebildeten Lehrerstand, 1917, S. 630.

Drenckhahn, Mobilmachung unserer Schulkinder, in: Die Mittelschule, Zeitschrift der Reichsfachschaft Mittelschule im Nationalsozialistischen Lehrerbund., 1915, S. 98.

Dresbach, Ewald, Kriegs-Chronik der Gemeinde Halver von 1914 bis 1919, Halver i. W. 1932.

Driesen, Gold in die Reichsbank!, in: Deutsches Philologen-Blatt, Korrespondenz-Blatt für den akademisch gebildeten Lehrerstand (Beilage), 1916, S. 33.

Driesen, $O$., Besonders erfolgreiche Schulen, in: Deutsches Philologen-Blatt, Korrespondenz-Blatt für den akademisch gebildeten Lehrerstand, 1916, S. 142.

Driesen, $O$., Das Gold auf dem Lande, in: Deutsches Philologen-Blatt, Korrespondenz-Blatt für den akademisch gebildeten Lehrerstand (Beilage), 1916, S. 68.

Driesen, $O$., Wo steckt noch Gold?, in: Deutsches Philologen-Blatt, Korrespondenz-Blatt für den akademisch gebildeten Lehrerstand (Beilage), 1916, S. 68.

Driesen, Otto, Der Goldschatz unserer Feinde und die Aussichten unserer Goldpolitik., in: Deutsches Philologen-Blatt, Korrespondenz-Blatt für den akademisch gebildeten Lehrerstand, 1915, S. 34.

Driesen, Otto, Die "Gold-in-die-Reichsbank!"-Organisationen der deutschen Philologen, Lehrer und Geistlichen, in: Deutsches Philologen-Blatt, Korrespondenz-Blatt für den akademisch gebildeten Lehrerstand, 1915, S. 161f.

Driesen, Otto, Die "Gold-in-die-Reichsbank!"-Organisationen der deutschen Philologen, Lehrer und Geistlichen, in: Deutsches Philologen-Blatt, Korrespondenz-Blatt für den akademisch gebildeten Lehrerstand, 1915, S. 199f.

Driesen, Otto, Die "Gold-in-die-Reichsbank!"-Organisationen der deutschen Philologen, Lehrer, Lehrerinnen und Geistlichen, in: deutsches Philologen-Blatt, Korrespondenz-Blatt für den akademisch gebildeten Lehrerstand, 1915, S. 209.

Driesen, Otto, Die "Gold-in-die-Reichsbank!"-Organisationen der deutschen Philologen, Lehrer, Lehrerinnen und Geistlichen, in: Deutsches Philologen-Blatt, Korrespondenz-Blatt für den akademisch gebildeten Lehrerstand, 1915, S. 232.

Driesen, Otto, Die "Gold-in-die-Reichsbank!"-Organisationen der deutschen Philologen, Lehrer, Lehrerinnen und Geistlichen, in: Deutsches Philologen-Blatt, Korrespondenz-Blatt für den akademisch gebildeten Lehrerstand, 1915, S. 248.

Driesen, Otto, Eine "Gold-in-die-Reichsbank!"-Organisation der deutschen Philologen, in: Deutsches Philologen-Blatt, Korrespondenz-Blatt für den akademisch gebildeten Lehrerstand, 1915, S. 122.

Ebel, Günther, Dorfchronik Becklingen 1916-1937. Schulchronik Bd. I, Bergen 1988.

Eberhard, Gisela, Die Neubrücker Schulchronik, Wendeburger Heimatkunde, 1996. 
Ebner, E., Die höheren realistischen Schulen Bayerns im Kriegsjahr 1914/15, in: Deutsches Philologen-Blatt, Korrespondenz-Blatt für den akademisch gebildeten Lehrerstand, 1915, S. 670.

Ebner, E., Das zweite Kriegsjahr der höheren realistischen Schulen in Bayern, in: Deutsches Philologen-Blatt, Korrespondenz-Blatt für den akademisch gebildeten Lehrerstand, 1916, S. 611f.

Eifelvereinsblatt Bonn 1915.

Ein Besuch in der Reichsbank, in: Deutsches Philologen-Blatt, Korrespondenz-Blatt für den akademisch gebildeten Lehrerstand (Beilage), 1916, S. $281 \mathrm{f}$.

Einweihung und Nagelung des Eisernen Kreuzes, in: Lauenburgische Zeitung, 6./ 19.September und. 1. November 1915.

Engel, Eduard, Entwelschung. Verdeutschungswörterbuch für Amt, Schule, Haus, Leben, Leipzig 1989.

Erbach, W., Die Schüler höherer Lehranstalten in der Landarbeit, in: Deutsches Philologen-Blatt, Korrespondenz-Blatt für den akademisch gebildeten Lehrerstand, 1917, S. 485f.

Ergebnisse der Schulzeichnungen im Herzogtum Braunschweig auf die VII. Kriegsanleihe 1917/18, Braunschweig 1918.

Ernst, H., Sammelt Obstkerne!, in: Deutsche Schulpraxis“, 1916, S. 311.

Erstnagelung des Chamer Kriegswahrzeichens, in: Amts-Blatt für den Bezirk Cham, 15. Mai 1915.

Exner, W. (Hrsg.), Die Nagelung von Kriegswahrzeichen. Beilage II, Berlin 1918.

Fahland, Marie, Vom Krieg und vom Religionsunterricht, in: Die Lehrerin, Organ des Allgemeinen deutschen Lehrerinnenverein 1917, S. 71-74.

Feier des Gedenktages der Reformation, in: Zentralblatt für die gesamte Unterrichtsverwaltung in Preußen, 1917, S. 103/104.

Feier in Berlin, in: Dresdner Anzeiger, 3. Oktober 1915.

Feldmann, Armin Zur Geschichte der Brehnaer Schule von ihren Anfängen bis 1945, München und Ravensburg 2004.

Feldpausch, Gelsenkirchen, in: Deutsches Philologen-Blatt, Korrespondenz-Blatt für den akademisch gebildeten Lehrerstand, 1916, S. 26.

Fischer, Aloys, Die höhere Schule im Lichte der Kriegserfahrung, in: Deutsches Philologen-Blatt, Korrespondenz-Blatt für den akademisch gebildeten Lehrerstand, 1915, S. 713-715.

Fischer, J., Mehr Lesestoffe für unsere Krieger in den Lazaretten!, in: Deutsches Philologen-Blatt, Korrespondenz-Blatt für den akademisch gebildeten Lehrerstand, 1915, S. 263.

Fischer, J., Kriegsarbeit in der Schule, 1916, S. 259.

Fitzke, Benno/Matzdorf, Paul, Eiserne Kreuz-Nagelungen zum Besten der Kriegshilfe und zur Schaffung von Kriegswahrzeichen; Gebrauchsfertiges Material f. vaterländ. Volksunterhaltung durch Feiern in Schulen, Leipzig 1916.

Floerke, Hanns, Die Kinder und der Krieg. Aussprüche, Taten, Opfer und Bilder, München 4. Auflage 1915.

Folkerts, Martin (Hrsg.), Die Schulchronik von Borchel Teil I: 1801-1945, Rotenburg 2005.

Förster, Friedrich Wilhelm, Die deutsche Jugend und der Weltkrieg, Deutschlands Jugend und der Weltkrieg, /H. 1 Kassel 1915.

Förster, Heinrich, der Kriegs-Schülergarten, Leipzig und Frankfurt a. M. 1916.

Forstreuter, Adalbert, Hat das neue Kriegsjahr neue Gebote? Eine Kriegsstunde mit Kindern, in: Kinderland, Blätter für ethische Jugenderziehung, 1916, S. 43f.

Frank, Dora, Erinnerungen aus dem 1. Jahrzehnt unserer Schule in 50 Jahre Schule an der Rechenflether Straße 1905-1955, Bremen 1955.

Freudenberg, Alwin, Matthäus 5,44 im Lichte des Krieges, in: Deutsche Schulpraxis“, 1916, S. 202 205. 
Friedeberg, E./Wronsky, S., Handbuch der Kriegsfürsorge im Deutschen Reich. Die wichtigsten Bestimmungen und Einrichtungen auf dem Gebiete der Kriegsfürsorge nebst einem Anhang: Die Kriegsfürsorge in Groß-Berlin, Berlin 1917.

Fürsorge der höheren Lehranstalten für die "vergessenen" Krieger, in: Deutsches Philologen-Blatt, Korrespondenz-Blatt für den akademisch gebildeten Lehrerstand, 1916, S.152.

Gärtner, Flora, Gartenarbeit mit Schulkindern, in: Die Lehrerin, Organ des Allgemeinen Deutschen Lehrerinnenverein 1917, S. 87.

Georges, K. A., Eine Kriegsausstellung in der Schule, in: Deutsches Philologen-Blatt, KorrespondenzBlatt für den akademisch gebildeten Lehrerstand, 1915, S. 353-355.

Gericke, Schulmuseum, in: Die Lehrerin, Organ des Allgemeinen deutschen Lehrerinnenverein 1915, S. 78.

Gerst, Heinrich, Das erste Kriegsjahr und die Schule, in: Lehrer-Zeitung für Ost- und Westpreußen, 1915, S. 391f.; 395-97; S. 401-403.

Göhl, Th., Ein Jahr Gartenarbeit im Kriege, in: Die Arbeitsschule, 1917, S. 268.

Göhrs, Fr., Kriegszeichnen, in: Deutsche Schulpraxis“, 1915, S. $101 f$.

Göhrs, Fr., Kriegszeichnen, in: Deutsche Schulpraxis“, 1915, S. 246-248.

Goldene Blätter zur Augsburger Kriegschronik. Kriegsjahr 1914/15, Augsburg 1914/15.

Gothura-Werk, Kriegs-Wahrzeichen zur Nagelung in bewährten Ausführungen, Gotha 1915.

Gotthardt, M., Die Nagelung von eisernen Wahrzeichen im Kreise Beeskow-Storkow 1915/16, Beeskow o. J.

Gruenweller, August, Krieg und Schule. Ein Mahnruf an unser evangelisches Deutschland und seine Lehrerschaft (1915), Elberfeld-Sonnborn.

Grünweller, August, Der Krieg als Volkserzieher und die Volksschule. Ein Wort für christliche Jugend- und Volkserzieher, Schul- und Volksfreunde, 1915, S. 21.

Grünwald, E., Bismarck, in: Deutsches Philologen-Blatt, Korrespondenz-Blatt für den akademisch gebildeten Lehrerstand, 1915, S. 185.

Grünwald, E., Totenfeier, in: Deutsches Philologen-Blatt, Korrespondenz-Blatt für den akademisch gebildeten Lehrerstand, 1917, S. 25.

Grünwald, Johann, Schule und militärische Jugendvorbereitung, in: Deutsches Philologen-Blatt, Korrespondenz-Blatt für den akademisch gebildeten Lehrerstand, 1917, Jg. 25, S. 560f.

Günther, A., Der Kriegerdank des Deutschen Lehrervereins, in: Pädagogische Reform, 1916, S. 57-59.

Günther, Anna, Von der Kriegsarbeit der Mädchenschulen, in: Jugenddank-Kalender, 1919, S. 72

Günther, Anna / Hildebrandt, Paul / Samuleit, Hans (Hrsg.), Jugenddank-Kalender. Herausgegeben im Auftrag des Jugenddanks für Kriegsbeschädigte, Charlottenburg 1919.

Gutzmann, W., Die Schüler der höheren Lehranstalten in der Landarbeit, in: Deutsches PhilologenBlatt, Korrespondenz-Blatt für den akademisch gebildeten Lehrerstand, 1917, S. 607f.

Gymnasialdirektor Grünwald, Krieg und Schule in Schäfer, Dietrich (Hrsg.), Der Krieg 1914/16, Leipzig und Wien 1916.

Gymnasiasten als Landarbeiter, in: Deutsches Philologen-Blatt, Korrespondenz-Blatt für den akademisch gebildeten Lehrerstand, 1917, S. 191f.

Gymnasiasten als Schneeschipper, in: Tageblatt für den amtshauptmannschaftlichen Bezirks Borna 1917.

H.-G. Nerlich, in: Historisches Kalenderblatt 2, 20.09.2007.

Hahn, i. A. Gemeinsames Archiv der Kreise Steinburg und der Stadt Itzehoe, "Der Eiserne Karl", Itzehoe, Schreiben vom 28.10.2004.

Der Eiserne Graf in Hamm. Ein Jahr der Opfertätigkeit, Hamm (Westfalen) 1916. 
Hanstein, R. v., Mitarbeit der Schulen bei der Vorbereitung der wirtschaftlichen Kriegsbereitschaft, in: Deutsches Philologen-Blatt, Korrespondenz-Blatt für den akademisch gebildeten Lehrerstand, 1915, S. 208.

Hantke, Max, Die Schule und der Krieg. Mit Anhang, in: Pädagogisches Magazin Heft 603, Langensalza 1915.

Harnack, Adolf von, Martin Luther und die Grundsteinlegung der Reformation. Martin Luther und die Grundlegung der Reformation. Festschrift der Stadt Berlin zum 31. Oktober 1917, Berlin 1917.

Hartmann, M., Kriegspädagogische Betrachtungen, in: Deutsches Philologen-Blatt, KorrespondenzBlatt für den akademisch gebildeten Lehrerstand, 1915, S. 42-45.

Haselbeck, Franz (Stadtarchivar), Nagelfiguren (als Kriegswahrzeichen), Traunstein, Schreiben vom11.10.2004.

Haupt, F., Schulchor im Kriegsdienst, in: Die höheren Mädchenschulen, 1915, S. 140.

Häußner, J., Der Weltkrieg und die höheren Schulen Badens im Schuljahr 191-1915. Beilage zu den Jahresberichten der höheren Schulen Badens, Karlsruhe o. J. (ca. 1915).

Hecker, Hilde, Die Lehrerin: Organ des Allgemeinen Deutschen Lehrerinnenverein 1915, S. 351f.

Hecker, R., Kriegspoesie 1914/16, IX. Poetische Stimmungsbilder aus großer stolzer Zeit, in: Deutsche Schulpraxis“, 1916, S. 229-231.

Hensold, K. , Ein Jahr Kriegspädagogik (1915), in: Deutsches Philologenblatt, 1915, Jg. 23, Heft 41, S. 633-636.

Heine. Gerhard, Die Mobilmachung der Schule, Leipzig 1916.

Herder, K., Vorschläge für die Jubelfeier der Reformation an höheren Schulen, in: Monatszeitschrift für höhere Schulen, 1917, S. 309.

Herrmann, F., Noch ein beachtenswerter Versuch, in: Deutsches Philologen-Blatt, KorrespondenzBlatt für den akademisch gebildeten Lehrerstand, 1918, S. 6.

Herrmann, Ulrike, Ausblick, in: Berg, Christa (Hrsg.). Handbuch der deutschen Bildungsgeschichte, München 1991.

Herstellung von Liebesgaben in der Schule, in: Die Lehrerin, Organ des Allgemeinen Deutschen Lehrerinnenverein 1914/15, S. 231.

Herzoglich Braunschweigisch-Lüneburgisches Konsistorium, Einsammeln von Brennesseln betreffend, in: Schulblatt für die Herzogtümer Braunschweig und Anhalt, 1916.

Heydt, Johann Daniel von der, Lutherlieder: ein Fest- und Schulbüchlein zur Feier des Jubeljahres der Reformation 1917, 1917.

Hildebrand, Friedrich, Jugenddank und Erziehung, in: Die Arbeitsschule, 1918, S. 177.

Hildebrand, Friedrich, Jugenddank-Arbeit, in: Die Arbeitsschule, 1918, S. 33.

Hildebrandt, Paul, Die Leitungen unserer Schüler im Kriege, in: Günther, Anna/Hildebrandt, Paul/ Samuleit, Hans (Hrsg.), Jugenddank-Kalender, Charlottenburg 1919.

Hindenburg-Feiern, in: Dresdner Anzeiger, 3. Oktober 1915.

Hindenburg-Tafel aus Sondernach, in: Eninger Tagblatt, 3. Januar 1916.

Hinrichs, Johanna/ Masemann, Gerhard, Schulchronik Ruschwedel von 1884-1972, Bliedersdorf o. J. Hitz, Arnold, Die Feier patriotischer Gedenktage in Schulen, Vereinen und in der Armee, Hamm 1909.

Höfler, Zum Kriegsgartenbau der höheren Schule., in: Deutsches Philologen-Blatt, KorrespondenzBlatt für den akademisch gebildeten Lehrerstand, 1917, S. $286 \mathrm{f}$.

Höhere Mädchen- und Frauenbildung, in: Die Lehrerin, Organ des Allgemeinen Deutschen Lehrerinnenverein 1917, S. 101f.

Höheres Mädchenschulwesen in Österreich, in: Die Lehrerin, Organ des Allgemeinen Deutschen Lehrerinnenverein A, 1915/16, S. 38f.

Holl, Ferdinand, Der Kriegsgarten des Kaiser-Karl-Gymnasiums zu Aachen, in: Die Arbeitsschule, 1917, S. 156.

Hözel, E., Reden und Ansprachen bei Schulfeierlichkeiten, Leipzig 1911. 
Hübner, Max, Vaterländische Gedenktage in der Schule. Ansprachen, Entwürfe und Gedichte, Breslau 1889.

Hübschmann, P., Die Tätigkeit der Goldankaufshilfsstelle Weida, in: Deutsches Philologen-Blatt, Korrespondenz-Blatt für den akademisch gebildeten Lehrerstand, 1918, S. 32.

Huckert, E., Förderung der Sparsamkeit in betreff der Lebensmittel durch die Lehrer der höheren Schulen, in: Deutsches Philologen-Blatt, Korrespondenz-Blatt für den akademisch gebildeten Lehrerstand, 1916, S.146f.

Ilgen, Paul, Eine dankbare Aufgabe für die höheren Lehranstalten, in: Deutsches Philologen-Blatt, Korrespondenz-Blatt für den akademisch gebildeten Lehrerstand, 1915, S. 624.

Ilgen, Paul, Spende für "vergessene Krieger', in: Deutsches Philologen-Blatt, Korrespondenz-Blatt für den akademisch gebildeten Lehrerstand, 1915, S. 719.

Ilgen, Paul, "Vergessene" Krieger, in: Deutsches Philologen-Blatt, Korrespondenz-Blatt für den akademisch gebildeten Lehrerstand, 1916, S. 315.

Jacobi, Uwe, Das war das 20. Jahrhundert, in: Heilbronner Stimme, 3. und 21. Januar 2001.

Jahnke, C., Kaiser-Geburtstagfeier in der Schule, Danzig 1893.

Jahnke, Richard, Die Einrichtung von Geschichtsatlanten, in: Deutsches Philologen-Blatt, Korrespondenz-Blatt für den akademisch gebildeten Lehrerstand, 1916, S. 629f.

Jahnke, Richard, Die höhere Schule und die Fremdwortfrage, in: Monatszeitschrift für höhere Schulen, 1918, S. 29.

Jahnow, Hedwig, Die Entwicklung der Staatsgesinnung unter den Hohenzollern. Festrede, gehalten am 21. Oktober 1915, in: Neue Jahrbücher für das klassische Altertum, Geschichte und deutsche Literatur, S. 512.

Jahresbericht der Oberrealschule zu Halberstadt, Halberstadt 1915.

Jahresbericht des Königlichen Kaiserin Auguste Victoria-Gymnasiums zu Linden. Schuljahr 19141915, Hannover 1915.

Jahresbericht über das Herzogliche Gymnasium zu Wolfenbüttel, Wolfenbüttel 1915.

Jahres-Bericht über das Königliche Friedrich-Wilhelm-Gymnasium zu Berlin, Berlin 1915.

Jahresbericht über das Königliche Joachimthalsche Gymnasium in Templin, Templin 1915.

Jeismann, Michael, Das Vaterland der Feinde. Studien zum nationalen Feindbegriff und Selbstverständnis in Deutschland und Frankreich, 1792-1918, Sprache und Geschichte, Bd. 19, Stuttgart 1992.

Johannessen, F., Die zweite Kriegsbuchwoche, in: Deutsches Philologen-Blatt, Korrespondenz-Blatt für den akademisch gebildeten Lehrerstand, 1916, S. $305 f$.

Jugenddank für Kriegsbeschädigte, in: Deutsches Philologen-Blatt, Korrespondenz-Blatt für den akademisch gebildeten Lehrerstand, 1916, S. 331.

Jugenddank für Kriegsbeschädigte e. V., Jahresberichte 1917 und 1918, Charlottenburg.

Jugendspende für Kriegerwaisen, in: Amtliches Schulblatt für den Regierungsbezirk Hildesheim, 1915, S. 138.

Jugendspende für Kriegerwaisen, in: Die Lehrerin, Organ des Allgemeinen Deutschen Lehrerinnenverein 1917, S.13.

Jünemann, Igna Maria, Kriegshilfe der Stadt Essen, M. Gladbach o. J.

Jungmannen bei der nächsten Frühjahrsbestellung, in: Deutsches Philologen-Blatt, KorrespondenzBlatt für den akademisch gebildeten Lehrerstand, 1918, S. 12.

Just, Einführung in das Verständnis des großen Krieges durch den Geschichtsunterricht der 1. Klasse des Lyzeums, in: Die Lehrerin, Organ des Allgemeinen deutschen Lehrerinnenverein 1915, S. 195201.

Kaufnicht, H., Laßt auch die Kleinen in die Lazarette gehen!, in: Die Lehrerin, Organ des Allgemeinen Deutschen Lehrerinnenverein 1916/17, S. 225.

Kaul, C., Ein Lutherbuch für die deutsche Jugend. Festschrift zur 400jährigen Gedenkfeier der deutschen Reformation im 31. Oktober 1917, Halle a. d. Saale 1917. 
Keller, Robert, Die Schule im Dienste der vaterländischen Erziehung, in: Zeitschrift für die österreichischen Gymnasien, 1917, S. 701.

Kennen Sie schon das Kriegsanleihe-Thermometer?, in: Deutsches Philologen-Blatt, KorrespondenzBlatt für den akademisch gebildeten Lehrerstand (Beilage), 1917, S. 556.

Kern, Reinold, Hohenzollernlieder, in: Monatszeitschrift für höhere Schulen, 1915, S. 563f.

Keyl, Fr, Unsere Feldpost. Aus der Liebig-Oberealschule in Frankfurt a. M., in: Deutsches PhilologenBlatt, Korrespondenz-Blatt für den akademisch gebildeten Lehrerstand, 1916, S. 121f.

Kinder- und Jugendfürsorge im Krieg, in: Die Lehrerin, Organ des Allgemeinen deutschen Lehrerinnenverein 1914, S. 170f.

Kiisbey, E., Das politische Gewissen der Lehrerin, in: Die Lehrerin, Organ des Allgemeinen Deutschen Lehrerinnenverein 1914, S. 9.

Kinder- und Jugendfürsorge im Krieg, in: Die Lehrerin, Organ des Allgemeinen Deutschen Lehrerinnenverein 1914, S. 170f.

Kießner, J., Gedanken zum Deutschen Unterricht in den Tagen des Großen Krieges, in: die Mädchenschule, 1915, S. 361-366.

Klatt, Nationale Rücksichten bei der Auswahl der fremdsprachlichen Lektüre, in: Deutsches Philologenblatt, 1915, Jg. 23, S. 231.

Klaube, Archivrat, Stadtarchiv Kassel, Nagelung des "Zaitenstocks", Kassel, Schreiben vom 07.10.2004.

Klindt, Jochen/Bubert, Ingo, 750 Jahre Stein. Dorfchronik von 1240 bis 1990, Schellhorn 1990.

Knabe, Karl, Der Weltkrieg und die deutsche Schule, Leipzig 1915.

Knebel, W., Unterricht in Kriegszeit, in: Biese, Der Krieg und der Schulunterricht, Deutsches Philologen-Blatt, Korrespondenz-Blatt für den akademisch gebildeten Lehrerstand, 1914, S. 638f.

Knoche, Magdeburg, in: Deutsches Philologen-Blatt, Korrespondenz-Blatt für den akademisch gebildeten Lehrerstand, 1916.

Koch, J., Schöne Ehrung für einen gefallenen Philologen, in: Deutsches Philologen-Blatt, Korrespondenz-Blatt für den akademisch gebildeten Lehrerstand, 1917, S. 511.

Koch-Weser, Erich/ Mühlhausen, Walter/ Papke, Gerhard, Kommunalpolitik im ersten Weltkrieg. Die Tagebücher Erich Koch-Wesers 1914 bis 1918, Schriftenreihe der Stiftung Reichspräsident-FriedrichEbert-Gedenkstätte, Nr.6, München 1999.

Koehler, L., Ausländisches Geld, in: Deutsches Philologen-Blatt, Korrespondenz-Blatt für den akademisch gebildeten Lehrerstand, 1915, S. 394.

Koehler, L., Ausländisches Geld, in: Deutsches Philologen-Blatt, Korrespondenz-Blatt für den akademisch gebildeten Lehrerstand, 1915, S. 412.

Koehler, L., Sammelt Gold!, in: Deutsches Philologen-Blatt, Korrespondenz-Blatt für den akademisch gebildeten Lehrerstand, 1915, S. 73f.

Koehler, L., Ausländisches Geld, in: Deutsches Philologen-Blatt, Korrespondenz-Blatt für den akademisch gebildeten Lehrerstand, 1916, S. 512.

Königliche Regierung für Ostpreußen, Abteilung für Kirchen und Schulwesen, Bestellung des Schullandes, in: Amtliches Schulblatt für den Regierungsbezirk Königsberg, 1915, S. 41.

Königliche Regierung für Ostpreußen, Abteilung für Kirchen und Schulwesen, Betrifft Schulfeiern aus Anlaß größerer Siege, in: Amtliches Schulblatt für den Regierungsbezirk Königsberg, 1915, S. 40.

Königliche Regierung für Ostpreußen, Abteilung für Kirchen und Schulwesen, Kriegsschreibstuben in den Schulen und Schreibunterricht, in: Amtliches Schulblatt für den Regierungsbezirk Königsberg, 1915, S. 50.

Königliche Regierung für Ostpreußen, Abteilung für Kirchen und Schulwesen, Schülergemüsegärten, in: Amtliches Schulblatt für den Regierungsbezirk Königsberg, 1918, S. 44f.

Königliche Regierung in Hildesheim, An die Lehrerschaft, in: Amtliches Schulblatt für den Regierungsbezirk Hildesheim, 1914. 
Königliche Regierung in Hildesheim, Pilztafeln und Merkblätter, in: Amtliches Schulblatt für den Regierungsbezirk Hildesheim, 1917, S. 168f.

Königliche Regierung in Hildesheim, Sammeln von Laub- und Reisigfutter, in: Amtliches Schulblatt für den Regierungsbezirk Hildesheim, 1918, S. 73.

Königliche Regierung in Hildesheim, Sammlung von einheimischen Arzneipflanzen, in: Amtliches Schulblatt für den Regierungsbezirk Hildesheim, 1918, S. 53

Königliche Regierung für Ostpreußen, Abteilung für Kirchen und Schulwesen, Verwendung der Schulkinder zu Erntearbeiten, in Amtliches Schulblatt für den Regierungsbezirk Königsberg, Nr. 13, 6. August 1914.

Königliche Regierung, Abteilung für Kirchen- und Schulwesen, Schülergemüsegärten, in: Amtliches Schulblatt für den Regierungsbezirk Königsberg, 1917, S. $26 f$.

Königliche Regierung, Abteilung für Kirchen- und Schulwesen Verhütung von Schädigungen infolge der Beteiligung der Schüler und Schülerinnen der höheren Schulen und der Lehrerbildungsanstalten an kriegswirtschaftlichen Arbeiten, in: Amtliches Schulblatt für den Regierungsbezirk Königsberg, 8. Januar 1918

Königliches Gymnasium mit Realschule zu Schneidemühl, Jahresbericht, Schneidemühl 1915.

Korff, Gottfried, Kriegs-Volks-Kunde. Zur Erfahrungsbindung durch Symbolbildung, Untersuchungen des Ludwig-Uhland-Instituts der Universität Tübingen, Bd. 98, Tübingen 2005.

Krakow, O., Gold in die Reichsbank!, in: Deutsches Philologen-Blatt, Korrespondenz-Blatt für den akademisch gebildeten Lehrerstand, 1915, S. 107

Kranzler, Wilhelm, Für Vaterland und Ehre. Wahrheitsgetreue Geschichte des großen Krieges 1914/15, Hansa-Verlag, Hamburg o. J.

"Kreuz-Pfennig"-Marken, in: Amtliches Schulblatt für den Regierungsbezirk Hildesheim, 1914, S. 189.

Krieger, Der Kaiser im Feld, in: Amtliches Schulblatt für den Regierungsbezirk Hildesheim, 1917, Nr. 6.

Jungmannen im landwirtschaftlichen Hilfsdienst und Jugendabteilungen für die militärische Vorbildung der Jugend, in: Zentralblatt für die gesamte Unterrichtsverwaltung in Preußen, 31. Oktober 1917. Jungmannenauszeichnung für Schulen höherer Lehranstalten für die männlichen Schüler, in: Zentralblatt für die gesamte Unterrichtsverwaltung in Preußen, 8. Oktober 1917.

Regelung der Vermittlungsfrage für die Jungmannenhilfe, in: Zentralblatt für die gesamte Unterrichtsverwaltung in Preußen, 15. November 1917.

Kriegsanleihe und Schule, in: Deutsches Philologen-Blatt, Korrespondenz-Blatt für den akademisch gebildeten Lehrerstand, 1916, S.175.

Kriegs-Ansichtspostkarten, in: Deutsches Philologen-Blatt, Korrespondenz-Blatt für den akademisch gebildeten Lehrerstand, 1915, S. 407.

Kriegsarbeit der Landwirtschaftskammer für die Provinz Pommern 1914-1918, in: Pommernblatt Sonderausgabe, Berlin 1918.

Kriegsbilderbogen-Woche, in: Amtliches Schulblatt für den Regierungsbezirk Hildesheim, 1916, S. $106 f$.

Kriegsbuch für die Jugend u. das Volk, Stuttgart 1915.

Kriegschronik des Württembergischen Landesvereins vom Roten Kreuz. Kriegschronik des Württembergischen Landesvereins vom Roten Kreuz Heilbronn 1921.

Kriegs-Erlebnisse der Ursulinen-Schule (1914/1917), Ursulinen-Schule, Saarbrücken 1917.

Kriegsfingerhut, in: Amtliches Schulblatt für den Regierungsbezirk Hildesheim, 1917, Nr. 7.

Kriegshelferdienst der Schülerinnen als Vorbereitung auf das weibliche Dienstjahr, in: Die Lehrerin, Organ des Allgemeinen Deutschen Lehrerinnenverein 1916, S. 179f.

Kriegshilfe der Schülerinnen, in: Die Lehrerin, Organ des Allgemeinen Deutschen Lehrerinnenverein 1914/15, S. 271. 
Kriegshilfe einer deutschen Mädchenschule, in: Die Lehrerin, Organ des Allgemeinen Deutschen Lehrerinnenverein 1914, S. 262.

Kriegshilfeleistung durch die Schule, in: Die Lehrerin, Organ des Allgemeinen Deutschen Lehrerinnenverein 1915, S. 100.

Kriegskartoffelacker des Kaiser-Friedrich-Realgymnasiums zu Neukölln 1914/1917, in: Deutsche Tageszeitung 1917.

Kriegsschreibstuben für Feldpostsendungen, in: Die Lehrerin, Organ des Allgemeinen Deutschen Lehrerinnenverein 1915/16, S. 63.

Kriegsschriften des Kaiser-Wilhelm-Danks, in: Amtliches Schulblatt für den Regierungsbezirk Königsberg, 23, 9. September 1915.

Kriegswahrzeichen, in: Oberfränkische Zeitung und Bayreuther Anzeiger, 28. Mai 1916.

Kriegs-Wahrzeichen zum Benageln. 69 Entwürfe aus einem Preiswettbewerb des Deutschen Werkbundes, München 1915.

Kuckhoff, J., Die Reichskriegswoche und Ähnliches, in: Deutsches Philologen-Blatt, KorrespondenzBlatt für den akademisch gebildeten Lehrerstand, 1915, S. 323f.

Kuckhoff, J., Wie können die höheren Schulen die wirtschaftliche Kriegsbereitschaft Deutschlands stützen helfen?, in: Deutsches Philologen-Blatt, Korrespondenz-Blatt für den akademisch gebildeten Lehrerstand, 1914, S. 745f.

Kuckhoff, J., Die dritte Kriegsanleihe und die Schule, in: Deutsches Philologen-Blatt, KorrespondenzBlatt für den akademisch gebildeten Lehrerstand, 1915, S. 520f.

Kuhn, Adam, Kriegs-Chronik der Stadtgemeinde Biberach (Weltkrieg 1914-1918), Höhn, BiberachRiß 1922.

Kuntz, O., Die Volksernährung im Kriege und in der Schule, in: Die Mittelschule, Zeitschrift der Reichsfachschaft Mittelschule im Nationalsozialistischen Lehrerbund., 1915, S. 98.

Lamath, G., Die Jungmannen des Kgl. Friedrich Wilhelm-Gymnasiums zu Cöln in der Eifel.,in: Deutsches Philologen-Blatt, Korrespondenz-Blatt für den akademisch gebildeten Lehrerstand, 1917, S. $642 \mathrm{f}$.

Lange, Erna, 1914 bis 1918 auf der Schulbank Berlin 1933.

Lange, Helene, Vorträge, in: Die Lehrerin, Organ des Allgemeinen Deutschen Lehrerinnenverein 1914/15, S. 299.

Langner, E., Nochmals: Das Gold!, in: Deutsches Philologen-Blatt, Korrespondenz-Blatt für den akademisch gebildeten Lehrerstand, 1915, S. 146f.

Leberecht, Migge, Jugendparks als Kriegerdank, in: Möller's deutsche Gärtner-Zeitung, 1916.

Lehm, Kurt, Zwei Siegesfeiern, in: Deutsche Schulpraxis, Wochenblatt für deutsche Lehrkunst, für Geschichte und Schrittum der Erziehung und des Unterrichts, 1915, S. 403-407.

Lehmann, Konrad (Hrsg.), Weltkriegs-Erinnerungen aus dem Kreise des Gymnasiums zu BerlinSteglitz. Ein kulturgeschichtliches Lesebuch, Berlin-Steglitz 1925.

Lehrerinnen als Vertreter von zum Heere einberufenen Lehrern, in: Die Lehrerin, Organ des Allgemeinen Deutschen Lehrerinnenverein 1914/15, S. 190.

Leitsätze über die zukünftigen Aufgaben des freiwilligen Schülerhilfsdienstes, in: Deutsches Philologen-Blatt, Korrespondenz-Blatt für den akademisch gebildeten Lehrerstand, 1918, S. 59f.

Leschhorn, Oskar, Deutschland, Deutschland über alles! Stoffe zur Feier des Sedantages, in: Leschhorn, Oskar (Hrsg.), Handbuch für Schulfeiern, Lissa i. P. 1913/14.

Leschhorn, Oskar, Heil, Kaiser, Dir! Stoffe zur Feier des Geburtstages Seiner Majestät des Kaisers in Leschhorn, Oskar (Hrsg.), Handbuch für Schulfeiern, Lissa i. P. 1913/14.

Leschhorn, Oskar, Nun zu guter Letzt! Stoffe zur Feier der Schülerentlassung in Leschhorn, Oskar (Hrsg.), Handbuch für Schulfeiern, Nr. 3, Lissa i. P. 1913/14.

Leupold, E., Mehr Gesangsstunden, in: 1916, S. 29.

Liebknecht, Karl ,Gesammelte Werke und Schriften, Band 8, Berlin1966; S: 531. 
Lier, Otto, III. Kriegsanleihe, in: Deutsches Philologen-Blatt, Korrespondenz-Blatt für den akademisch gebildeten Lehrerstand, 1915, S. 328.

Lindenau, M., Die Erntehilfe des Oranienburger Realprogymnasiums in Liebenberg, in: Deutsches Philologen-Blatt, Korrespondenz-Blatt für den akademisch gebildeten Lehrerstand, 1916, S. 781.

Linkenbach, Hans Ludwig, Das Kriegswahrzeichen der Stadt Mainz. Eine Erinnerungsschrift, Mainz 1916.

Loewenberg, Jakob, Kriegstagebuch einer Mädchenschule,Berlin 1916.

Löwenhaupt, V., Der große Krieg in Zahlen. Eine Ergänzung zu den Rechenbüchern, Leipzig o. J.

Lohmann, Wilhelmine, Die Abstinenz als patriotische Liebesstat, in: Die Lehrerin, Organ des Allgemeinen Deutschen Lehrerinnenverein 1914/15, S. $260 f$.

Lohmann, Wilhelmine, Deutscher Jugenddank 1915, in: Die Lehrerin, Organ des Allgemeinen Deutschen Lehrerinnenverein 1915/16, S. 278f.

Loth, P., Das Kriegswahrzeichen der Stadt Zweibrücken. Eine Erinnerungsschrift (1916), Zweibrücken 1916.

Lübke, Hans von, Nagelung von kirchlichen Kriegswahrzeichen, in : Die Dorfkirche (Hrsg. von Hans von Lüpke), 1916/17, S. 214-216.

Lunau, Karl Ferdinand, Kriegs-Chronik 1914-18, Bedburg 1976.

Mahle, Martha, Naturkunde im Gegenwartsunterricht, in: Die Lehrerin, Organ des Allgemeinen Deutschen Lehrerinnenverein 1916/17, S. 175f.

Maier, Jos., Der "eiserne Torschmied" das Kriegswahrzeichen von Neumarkt i. Opf., Vorgeschichte u. Eröffnungsfeier nebst Verzeichnis der edlen Spender, Neumarkt in der Oberpfalz 1916.

Mann, Friedrich, Die Schule und der Krieg. In: Pädagogisches Magazin Heft 603, Langensalza 1915.

Mannheim, in: General-Anzeiger (Badische Neueste Nachrichten), 24. Januar 1916.

Mappe mit Bildern des Kaisers und der Heerführer, in: Amtliches Schulblatt für den Regierungsbezirk Hildesheim, 1917, Nr. 6.

Marschall, Otto, Landshuter Stadtchronik; Bd. 2., 1909-1918, Landshut 1989.

Martín, M., Deutschland voran! Soldaten- und Jugendwehrlieder, München 1915.

Masche, Die Schul-Kriegs-Anleihe, in: Deutsches Philologen-Blatt, Korrespondenz-Blatt für den akademisch gebildeten Lehrerstand, 1915, S. 211 .

Masche, Die Schul-Kriegsanleihe, in: Deutsches Philologen-Blatt, Korrespondenz-Blatt für den akademisch gebildeten Lehrerstand, 1915, S. 378.

Masche, Die zweite Schulkriegsanleihe, in: Deutsches Philologen-Blatt, Korrespondenz-Blatt für den akademisch gebildeten Lehrerstand, 1915, S. 528.

Masche, Schul-Kriegsanleihe, in: Deutsches Philologen-Blatt, Korrespondenz-Blatt für den akademisch gebildeten Lehrerstand, 1915, S. $265 f$.

Masche, Goldsachenankauf, in: Deutsches Philologen-Blatt, Korrespondenz-Blatt für den akademisch gebildeten Lehrerstand (Beilage), 1916, S. 517.

Masche, Der Goldmünzenumtausch an den höheren Schulen im Jahre 1916, in: Deutsches PhilologenBlatt, Korrespondenz-Blatt für den akademisch gebildeten Lehrerstand, 1917, S. 86.

Masche, Goldsachen-Ankauf, in: Deutsches Philologen-Blatt, Korrespondenz-Blatt für den akademisch gebildeten Lehrerstand, 1917, S. $121 \mathrm{f}$.

Masche, W., Das Gold dem Vaterland!, in: Deutsches Philologen-Blatt, Korrespondenz-Blatt für den akademisch gebildeten Lehrerstand (Beilage), 1916, S. 571f.

Masche, W., Statistik der Sammelzeichnungen der höheren und mittleren Schulen des Deutschen Reiches auf die dritte Kriegsanleihe, in: Hannoversche Schulzeitung. Organ der Provinzial-Lehrervereins, der Bezirks- und Pestalozzivereine der Provinz Hannover, des Lehrer-Brandversicherungsvereins für Hannover, Bremen und das Fürstentum Lippe., 1916, S. 20.

Masche, W., Belohnungen für Gold sammelnde Schüler, in: Deutsches Philologen-Blatt, Korrespondenz-Blatt für den akademisch gebildeten Lehrerstand (Beilage), 1918, S. 32f. 
Matthias, Adolf, Krieg und Schule, in: Monatszeitschrift für höhere Schulen, 1915, S. $136 f$.

Meinardus, Schulfeiern, in: Monatszeitschrift für höhere Schulen, 1917, S. 546.

Meinhold, Paul, Hohenstaufen und Hohenzollern, in: Deutsches Philologen-Blatt, KorrespondenzBlatt für den akademisch gebildeten Lehrerstand, 1915, S. 601-603.

Mellmann, Die "Gold-in-die-Reichsbank!"-Organisationen der deutschen Philologen, in: Deutsches Philologen-Blatt, Korrespondenz-Blatt für den akademisch gebildeten Lehrerstand, 1915, S. 375 f.

Mellmann, Beschlüsse der Goldgeldkommission, in: Deutsches Philologen-Blatt, Korrespondenz-Blatt für den akademisch gebildeten Lehrerstand (Beilage), 1916, S. 33.

Merkblatt für Schulkinder, in: Die Lehrerin, Organ des Allgemeinen Deutschen Lehrerinnenverein 1914/15, S. 346.

Merling, B., Kopien des Stadtmuseums Jüterbog vom "Eisernen Roland", Jüterbog, Schreiben vom 5. 2. 2003.

Messing, O., Der Schützengrabenspiegel, in: Die Arbeitsschule, 1915, S. 319-321.

Meyer, E., Siebenunddreissigster Jahresbericht der städtischen Leibnizschule zu Hannover. Schulnachrichten über das Jahr 1914/15, Hannover 1915.

Meyer, Johannes, Wie in der Bürgerschule für Mädchen zu Crefeld während der verflossenen Kriegsmonate gearbeitet worden ist, in: Die Mittelschule, Zeitschrift der Reichsfachschaft Mittelschule im Nationalsozialistischen Lehrerbund., 1915-158, S. 154.

Mielke, Leo (Hrsg.), Kriegstagebücher des Heidedichters Diedrich Speckmann. 1915-1918, 2005.

Migge, Leberecht, Jugendparks als Kriegerdank, in: Möller's deutsche Gärtner-Zeitung, 1916, S. 213.

Mihaly, Jo, ... da gibt's ein Wiedersehn! Kriegstagebuch eines Mädchens, München 1986.

Ministerium der geistlichen und Unterrichts-Angelegenheiten, Abführen von Reichsgoldmünzen an die Reichsbank, in: Zentralblatt für die gesamte Unterrichtsverwaltung in Preußen, 1914, S. 732.

Ministerium der geistlichen und Unterrichts-Angelegenheiten, Anfertigung von Liebesgaben für das Heer in dem Handarbeitsunterricht für die weibliche Jugend., in: Zentralblatt für die gesamte Unterrichtsverwaltung in Preußen, 1914, S. 568f.

Ministerium der geistlichen und Unterrichts-Angelegenheiten, Beseitigung und Vermeidung fremdsprachlicher Ausdrück und Redeweisen, in: Zentralblatt für die gesamte Unterrichtsverwaltung in Preußen, 1914, S. $277 \mathrm{f}$.

Ministerium der geistlichen und Unterrichts-Angelegenheiten, Beurlaubung der größeren Beurlaubung von Schulkindern zum Viehhüten, in: Zentralblatt für die gesamte Unterrichtsverwaltung in Preußen, 19. August 1914.

Ministerium der geistlichen und Unterrichts-Angelegenheiten, Beurlaubung der größeren Schulkinder zur Teilnahme an den Erntearbeiten, in: Zentralblatt für die gesamte Unterrichtsverwaltung in PreuBen, 1914, S. 512.

Ministerium der geistlichen und Unterrichts-Angelegenheiten, Teilnahme von Schülern höherer Lehranstalten an den Erntearbeiten infolge der Mobilmachung, in: Zentralblatt für die gesamte Unterrichtsverwaltung in Preußen, 1914, S. 489.

Ministerium der geistlichen und Unterrichts-Angelegenheiten, Verwendung der Schulküchen für vaterländische Zwecke, in: Zentralblatt für die gesamte Unterrichtsverwaltung in Preußen, 1914, S. 746f.

Ministerium der geistlichen und Unterrichts-Angelegenheiten, Vorträge an die Lehrerschaft des Regierungsbezirks Hildesheim, in: Zentralblatt für die gesamte Unterrichtsverwaltung in Preußen, 1914, S. 644.

Ministerium der geistlichen und Unterrichts-Angelegenheiten, Abführung von Reichsgoldmünzen an die Reichsbank, in: Zentralblatt für die gesamte Unterrichtsverwaltung in Preußen, 1915, S. 375.

Ministerium der geistlichen und Unterrichts-Angelegenheiten, Bestellung der Schulgärten und des Dienstlandes der zum Kriegsdienste eingezogenen Volksschullehrer mit Kartoffel usw., in: Zentralblatt für die gesamte Unterrichtsverwaltung in Preußen, 1915, S. $386 f$.

Ministerium der geistlichen und Unterrichts-Angelegenheiten, Nutzbarmachung der Erzeugnisse des Waldes, in: Zentralblatt für die gesamte Unterrichtsverwaltung in Preußen, 1915, S. 521. 
Ministerium der geistlichen und Unterrichts-Angelegenheiten, Bekämpfung der Modeauswüchse, in: Zentralblatt für die gesamte Unterrichtsverwaltung in Preußen, 1916, S. 426f.

Ministerium der geistlichen und Unterrichts-Angelegenheiten, Die Heranziehung der Schuljugend zum Sammeln der Waldfrüchte und zur Kartoffelernte, in: Zentralblatt für die gesamte Unterrichtsverwaltung in Preußen, 1916, S. 502f.

Ministerium der geistlichen und Unterrichts-Angelegenheiten, Pflege des Strickens und anderer Nutzarbeiten im Nadelarbeitsunterricht der Mädchenschulen, in: Zentralblatt für die gesamte Unterrichtsverwaltung in Preußen, 1916, S. 580f.

Ministerium der geistlichen und Unterrichts-Angelegenheiten, Verringerung der Druckaufträge auf dem Gebiete des Schulwesens, in: Zentralblatt für die gesamte Unterrichtsverwaltung in Preußen, 1916, S. 420f.

Ministerium der geistlichen und Unterrichts-Ungelegenheiten, Beurlaubung von Schulkindern zur Teilnahme an den Erntearbeiten (26. August 1914), in: Zühlke, Raoul (Hrsg.), Bildpropaganda im Ersten Weltkrieg, Hamburg 2000, S. 609f.

Ministerium der geistlichen und Unterrichts-Angelegenheiten, Brennesselsammlung; Merkblätter, in: Zentralblatt für die gesamte Unterrichtsverwaltung in Preußen, 1917, S. 539-453.

Ministerium der geistlichen und Unterrichts-Angelegenheiten, Die Regelung der Vermittlungsfrage für die Jungmannenhilfe, in: Zentralblatt für die gesamte Unterrichtsverwaltung in Preußen, 1917, S. 782.

Ministerium der geistlichen und Unterrichts-Angelegenheiten, Gartenbauversuche an Lyzeen, in: Zentralblatt für die gesamte Unterrichtsverwaltung in Preußen, 1917, S. 322f.

Ministerium der geistlichen und Unterrichts-Angelegenheiten, Heranziehung der Schuljugend zu landwirtschaftlichen Arbeiten, in: Zentralblatt für die gesamte Unterrichtsverwaltung in Preußen, 18. Juni 1917.

Ministerium der geistlichen und Unterrichts-Angelegenheiten, Merkblatt für die Nesselernte", in:Zentralblatt für die gesamte Unterrichtsverwaltung in Preußen, 1917, S. 538.

Ministerium der geistlichen und Unterrichts-Angelegenheiten, Sammlung von Teeersatzmitteln, in: Amtliches Schulblatt für den Regierungsbezirk Hildesheim, 1917, S. $127 \mathrm{f}$.

Ministerium der geistlichen und Unterrichts-Angelegenheiten, Sparsamkeit im Gebrauch von Lederschuhzeug., in: Zentralblatt für die gesamte Unterrichtsverwaltung in Preußen, 1917, S. 38f.

Ministerium der geistlichen und Unterrichts-Angelegenheiten, Förderung des Gemüse- und Obstbaues, in: Zentralblatt für die gesamte Unterrichtsverwaltung in Preußen, 1918, S. 327.

Ministerium der geistlichen und Unterrichts-Angelegenheiten, Kriegshilfe der Schulen, in: Zentralblatt für die gesamte Unterrichtsverwaltung in Preußen, 1918, S. 410-413.

Mitteilungen aus den Kollegien, in: Deutsches Philologen-Blatt, Korrespondenz-Blatt für den akademisch gebildeten Lehrerstand, 1917, S. 489.

Mitteilungen und Nachrichten, in:Deutsche Tageszeitung, Jg. 23, Heft 36/37, S.575f.

Mitteilungen und Nachrichten, in: Deutsches Philologen-Blatt, Korrespondenz-Blatt für den akademisch gebildeten Lehrerstand, 1915, S. 642f.

Mohrmann, G., Noch ein Bildungsschaden durch die Fremdwörter, in: Monatszeitschrift für höhere Schulen, 1915, S. 321.

Moos, Josef, Stock im Eisen - eine Tradition lebt wieder auf, Cloppenburg, 4. Auflage 2000.

Mücke, Königliches Kaiser-Wilhelms-Gymnasium in Hannover. Schuljahr 1914-1915, Hannover 1915.

Müller, Fritz, Lissauers „Hassgesang auf England“, in: Deutsche Schulpraxis“, 1915, S. 35- 37.

Müller, Fritz, Schwert aus der Scheide, in: Deutsche Schulpraxis“, 1916, S. 381-394.

Müller, Fritz, Geschosse im Formenlehreunterricht, in: Deutsche Schulpraxis“, 1916, S. 126.

Muthesius, Hermann, Zur "Nagelung vom Kriegswahrzeichen", in: Tremona, Nr. 267, 29. September 1915.

Nachrichten, in: Die Lehrerin, Organ des Allgemeinen Deutschen Lehrerinnenverein 1918, S. 62. 
Nack, Jahresbericht des Königlichen Goethe-Gymnasiums Hannover für das Schuljahr von Ostern 1914-1915, Hannover 1915.

Nack, E., Der Krieg als Erzieher, in: Zeitschrift für die österreichischen Gymnasien, 1917, S. 715.

Nagelung der Domtür als Kriegswahrzeichen der Residenz, in: Mecklenburgische Zeitung, 1916, Heft 158.

Nagelung der Peiner Eule, in: Peiner Zeitung, 8. Mai 1916.

Nagelung des Eisernen Kreuzes in Pößneck, in: Pößnecker Zeitung, August 1915.

Nagelung des Eisernen Kreuzes in St. Georgsberg, in: Lauenburgische Zeitung, 1. November 1915.

Nagelung des Gedenkschildes, in: Heimatglocken. Gemeindeblatt für die Inspektionen Hardegsen und Uslar, 1917, S. 86.

Nagelung des Junggermanen, in: Münsterischer Anzeiger, 23. Januar 1916.

Nagelung des Kreuzes, in: Darmstädter Tageblatt, 23., 24., 26. und 28. April 1915.

Nagelung des Kriegswahrzeichens, in: Heinsberger Volkszeitung, 1. August und 26. November 1917, 2. September 1918.

Nagelung des Kriegswahrzeichens des Kreises Heinsberg, in: Heinsberger Volkszeitung, 31. August 1918.

Nagelung eines Wahrzeichens, in: Mecklenburger Tageblatt, 10. Und 19. Oktober 1915.

Nationaler Frauendank, An die deutschen Mädchen, in: Die Lehrerin, Organ des Allgemeinen Deutschen Lehrerinnenverein 1914/15, S. 284f.

Nationaler Frauendienst, in: Die Lehrerin, Organ des Allgemeinen Deutschen Lehrerinnenverein 1914/15, S. 284/285.

Nationalgabe, Entwürfe von Kriegs-Wahrzeichen zum Benageln, Berlin 1915.

Naue, Hanns, Gedenkblatt zur Benagelung des "Ehernen Wehrschildes" der Stadt Traunstein im Jahre 1915 (1915), Traunstein 1915.

Naumann, Friedrich / Bäumer, Gertrud, Kriegs- und Heimat-Chronik, Berlin o. J.

Niemann, A., Der Krieg und die Schule, in: Kinderland, Blätter für ethische Jugenderziehung, 1915,

S. 1.

Notstandsarbeiten für Frauen, in: Die Lehrerin, Organ des Allgemeinen Deutschen Lehrerinnenverein 1914/15, S. 156.

Nottnagel, O., Kriegsgartenbau der Schule, in: Deutsches Philologen-Blatt, Korrespondenz-Blatt für den akademisch gebildeten Lehrerstand, 1917, S. $236 f$.

Öffentliche Einladung, in: Meißner Tageblatt, 14.11.1915.

Ohmann, M., Schüler als Werber für die vierte Kriegsanleihe, in: Deutsches Philologen-Blatt, Korrespondenz-Blatt für den akademisch gebildeten Lehrerstand, 1916, S. 153.

Ohmann, M., Zur Statistik der Werbetätigkeit der Schulen für die vierte Kriegsanleihe, in: Deutsches Philologen-Blatt, Korrespondenz-Blatt für den akademisch gebildeten Lehrerstand, 1916, S. 381.

Ohmann, M., Die Kriegshilfe der deutschen Schule, in: Deutsches Philologen-Blatt, KorrespondenzBlatt für den akademisch gebildeten Lehrerstand, 1917, S. 99f.

Ohmann, M., Die deutsche Schulkriegshilfe - eine Statistik für das Jahr 1917, in: Monatszeitschrift für höhere Schulen, 1918, S. 376.

Ohmann, M., Ein besonderer Anreiz zur Nesselsammlung, in: Monatszeitschrift für höhere Schulen, 1918, S. 320.

Ohmann, M., Eine Gedenkmünze zur Kriegshilfe der Schulen für besonderes verdiente Helfer, in: Deutsches Philologen-Blatt, Korrespondenz-Blatt für den akademisch gebildeten Lehrerstand, 1918, S. 127.

Ohmann, M., Eine Statistik der Sammeltätigkeit der Schulen im Jahre 1917, in: Deutsches PhilologenBlatt, Korrespondenz-Blatt für den akademisch gebildeten Lehrerstand, 1918, S. 232.

Ohmann, M., Siebente Kriegsanleihe und Schule, in: Deutsches Philologen-Blatt,: Korrespondenz-

Blatt für den akademisch gebildeten Lehrerstand, 1918, S. 515. 
Ohmann, M., Statistik der Werbetätigkeit der Schulen für die sechste Kriegsanleihe, in: Deutsches Philologen-Blatt, Korrespondenz-Blatt für den akademisch gebildeten Lehrerstand, 1918, S. 155f.

Ohmann, M., Zur Förderung der neunten Kriegsanleihe durch die Schulen, in: Deutsches PhilologenBlatt, Korrespondenz-Blatt für den akademisch gebildeten Lehrerstand, 1918, S. 292.

Ohmann, M., Zur Statistik der Schulkriegshilfe, in: Deutsches Philologen-Blatt, Korrespondenz-Blatt für den akademisch gebildeten Lehrerstand, 1918, S. 109.

Ohnesorge, Franziska, Volkschularbeit im Kriege, in: Die Lehrerin, Organ des Allgemeinen deutschen Lehrerinnenverein 1914, S. 181.

Olszewski, Karl Ewald, Der Kriegs-Struwwelpeter. Lustige Bilder und Verse, München 1915.

Oppermann, Krieg. Aus der Schulchronik von Tiftlangerode 1914-1925, in: Monatsschrift des Eichsfeldes, 1995, S. 165.

Ostrowski, O., Eine neue Anregung, in: Deutsches Philologen-Blatt, Korrespondenz-Blatt für den akademisch gebildeten Lehrerstand, 1915, S. 538f.

Partenschmitt, Karl F., Dem Deutschen sei seine Sprache heilig! Ein FremdwortVerdeutschungsbuch, Leipzig o. J.

Pertsch, E., Kriegsanleihe und Schule, in: Deutsches Philologen-Blatt, Korrespondenz-Blatt für den akademisch gebildeten Lehrerstand, 1915, S. 574f.

Pfefferkorn, Else, Hinterm Pflug. Erlebnisse eines Stadtkindes (1916), Karlsruhe 1916.

Pflege der schulentlassenen Jugend in Verbindung mit Elternabenden usw., in: Zentralblatt für die gesamte Unterrichtsverwaltung in Preußen, 1916, S. 532.

Pesendorfer, Friedrich, Oberösterreich im Weltkrieg. Weltkriegs-Ehrenbuch des Kronlandes Oesterreich ob der Enns, Linz 1915.

Petzold, Gertrud, Eine notwendige Arbeit im Dienste der Kriegshilfe, in: Die Lehrerin, Organ des Allgemeinen deutschen Lehrerinnenverein 1914, S. 233-236.

Pigge, H., Schulfeste in Roloff, E. M. (Hrsg.), Lexikon der Pädagogik, Bd. 4, Freiburg1915.

Pohl, Max, Des Lebens Stückwerk. Erinnerungen eines Gymnasialdirektors - zwei Teile in einem Bande (1924), Wolfenbüttel 1924.

Pottag, A., Der Krieg als Erzieher zum Deutschtum. Vaterländische Abende, Heft 2, Berlin 1915.

Preisausschreiben des Jugenddanks für Kriegsbeschädigte zur Gewinnung von JugenddankPostkarten., in: Amtliches Schulblatt für den Regierungsbezirk Hildesheim, 1918, S. 124.

Programm, in: Oberfränkische Zeitung und Bayreuther Anzeiger, 26. Januar und 28. Mai 1915.

Programm für die vaterländische Feier und Schildnagelung am Sonntag, den 2. April 1916, in: Oberbayrischer Generalanzeiger, 3. April 1916.

Rathke, J., Der Weltkrieg in Liedern und Gedichten. Sammlung für Schulfeiern, Breslau 1915.

Rathke, J., Neue Kriegslieder für den Schulgebrauch, Breslau 1916.

Rathke, J., Merkbüchlein zum Weltkrieg. Für Lehrer und Schüler, Breslau 1918.

Rathke, J. (Hrsg.), Alte und neue Kriegslieder. Für den Schulgebrauch gesammelt, Breslau 1917.

Rattinger, Richard (Hrsg.), Bayrischer Heimatschutz 1915. Die Nagelung von Kriegswahrzeichen, Heft 5/6/7/8/9/10, München 1915.

Rauh, Sigismund, Der Weltkrieg in der Volksschule und in den Anfangsklassen höherer Schulen, Göttingen 1917.

Rausch, A., Heimatdient und zwölf Artikel für Schulen, in: Deutsches Philologenblatt, KorrespondenzBlatt für den akademisch gebildeten Lehrerstand, 1918, S. 323-326.

Richter, Johannes, Vom Kriegsthema in der deutschen Schule, in: Die Arbeitsschule, 1916, S. 353355 .

Reich, Hermann, Das Buch Michael, Berlin 2. Auflage 1917.

Reichert, Folker/Wolgast, Eike(Hrsg.), Karl Hampe, Kriegstagebuch 1914-1919, 2004.

Reichsbuchwoche, in: Deutsches Philologen-Blatt, Korrespondenz-Blatt für den akademisch gebildeten Lehrerstand, 1916, S. 267f. 
Reichsbuchwoche der deutschen Schuljugend: 28. Mai bis 3. Juni 1916, in: Die Lehrerin, Organ des Allgemeinen Deutschen Lehrerinnenverein 1916, S. 60f.

Reichsbuchwoche, 28. Mai bis 3. Juni 1916, in: Deutsches Philologen-Blatt, Korrespondenz-Blatt für den akademisch gebildeten Lehrerstand, 1916, S. $276 f$.

Reinartz, Manfred/Weber-Benzing, G. F., Schwenninger Bilddokumente. 1850-1930, Schriftenreihe der Stadt Villingen-Schwenningen, Heft 1, Schwenningen Villingen-Schwenningen 1977.

Reiniger, Max (Hrsg.), Der Weltkrieg im persönlichen Ausdruck der Kinder. 150 Schülerkriegsaufsätze, Langensalza 1915.

Riegelmann, Gotthold, Der Stock in Eisen. Praktische Ratschläge zur Errichtung einfacher Nagelholzmale, Berlin 1916.

Ritter, Falk, Goldspenden im Kreis Schleswig, in: Beiträge zur Schleswiger Stadtgeschichte, 47, S. 71.

Rohde, A., Die Schulfeste in der Volksschule, Osterwieck 2. Auflage 1894.

Röhl, Die Kriegshilfe der deutschen Schuljugend, in: Hannoversche Schulzeitung. Organ der Provinzial-Lehrervereins, der Bezirks- und Pestalozzivereine der Provinz Hannover, des LehrerBrandversicherungsvereins für Hannover, Bremen und das Fürstentum Lippe, S. 71 und S. 311.

Roloff, E. M. (Hrsg.), Lexikon der Pädagogik, Freiburg 1915.

Rosbund, M., Schülerhilfe in der Landwirtschaft, in: Deutsches Philologen-Blatt, Korrespondenz-Blatt für den akademisch gebildeten Lehrerstand, 1917, S. 449f.

Rotes Kreuz (Hrsg.), Das Rote Kreuz in Jena im Weltkriege 1914-1918, Jena 1919.

Rotes Kreuz, Mannheim, in: General-Anzeiger (Badische Neueste Nachrichten), 2. Oktober 1915.

Rundschau, In: Schulblatt für die Herzogtümer Braunschweig und Anhalt, 1916, S. 112.

Rundschau, In: Schulblatt für die Herzogtümer Braunschweig und Anhalt, 1917, S. 144.

Saathoff, Albrecht, Göttinger Kriegsgedenkbuch. 1914-1918, Göppingen 1935.

Sachs, Hans, Vom Hurrakitsch, Das Plakat, 1917, Nr. 3

Sammlung einer Jugendspende für Kriegerwaisen, in: Amtliches Schulblatt für den Regierungsbezirk Hildesheim, 1915, S. 83f.

Schädla, Gertrud, Die Tagebücher der Gertrud Schädla. 1914-1918, Verden (Aller) 2000.

Schäfer, Stadtarchiv, Eisernes Wappen, Andernach, Schreiben vom 20. 10. 2004.

Schäfer, Dietrich (Hrsg.), Der Krieg 1914/16. Werden und Wesen des Weltkriegs, dargestellt in umfassenderen Abhandlungen und kleineren Sonderartikeln, Leipzig und Wien 1916.

Scherer, J., Liebesgaben aus der Schülerwerkstatt, in: Die Arbeitsschule, 1915, S. 85f.

Silbermann, Der Krieg auf dem Schulhofe, in: Deutsches Philologenblatt, 1916, S. 142f.

Schmidt, Harry, Fürsorge für die "vergessenen Krieger", in: Deutsche Tageszeitung, Jg. 23, Nr. 47, 1915, S.739.

Schnoor, Neumünster, in: Deutsche Tageszeitung, Jg. 23, Nr. 47, 1915, S. 740.

Schoenichen, Schulleben in der Kriegszeit in Schule und Krieg, Berlin 1915.

Schön, F., Landwirtschaftliche Arbeit der Schüler, in: Deutsches Philologen-Blatt, KorrespondenzBlatt für den akademisch gebildeten Lehrerstand, 1915, S. 280.

Schön, F., Schule und Krieg, in: Deutsches Philologen-Blatt, Korrespondenz-Blatt für den akademisch gebildeten Lehrerstand, 1915, S. 312f.

Schön, F., Bebauung von Brachland als Kriegsarbeit der Schüler, in: Deutsches Philologen-Blatt, Korrespondenz-Blatt für den akademisch gebildeten Lehrerstand, 1916, S. 509f.

Schöppa, Gottlob/Schwartz, Hugo/Reinecke, Hermann, Die Bestimmungen über die Volks- und Mittelschule, die Vorbildung und die Prüfungen der Lehrer und Lehrerinnen in Preußen - nebst den wichtigsten dazu erlassenen Ministerial-Verfügungen, Berlin 1916.

Schott, E., Fürsorge der höheren Schulen für die "vergessenen Krieger", in: Deutsches PhilologenBlatt, Korrespondenz-Blatt für den akademisch gebildeten Lehrerstand, 1916, S. 135. 
Schott, E. „Kriegsstunden“ in der Schule, in: Deutsches Philologen-Blatt, Korrespondenz-Blatt für den akademisch gebildeten Lehrerstand 1914, Jg. 22, Heft 44, S. 697f.

Schott, E., Ein Jahr Kriegsstunden am Gymnasium, in: Deutsches Philologen-Blatt, KorrespondenzBlatt für den akademisch gebildeten Lehrerstand, 1915, S. 617.

Schott, E., Das zweite Jahr Kriegsstunden am Gymnasium, in: Deutsches Philologen-Blatt, Korrespondenz-Blatt für den akademisch gebildeten Lehrerstand, 1915, S. 23.

Schott, E., Das dritte Jahr Kriegsstunden am Gymnasium, in: Deutsches Philologen-Blatt, Korrespondenz-Blatt für den akademisch gebildeten Lehrerstand, 1917, S. 4f.

Schott, E. „Zum Abschluss der Kriegsstunden“ in der Schule, in: Deutsches Philologen-Blatt, Korrespondenz-Blatt für den akademisch gebildeten Lehrerstand, 1918, S. 419.

Schreck, Ernst, Zur Jubelfeier der Reformation: 1517-1917. Ausgeführte Schulfeier mit Ansprachen, Liedern und Vortagsstoffen, nebst Reden und Gedichten, 1917.

Schreiner-Arbeiten der Friedhofkunst. Grabkreuze, Särge, Postamente für Urnen, Kriegswahrzeichen, Ehrentafeln, Kriegstruhen usw.; 30 Taf. mit 100 ausgeführten Entwürfen. 8 Werkzeichen nebst Anleitung f. d. Ausführung, Stuttgart 1916.

Schröer, Gustav (Hrsg.), Die Kriegsanleihe der Jungen von Erbesbach und andere Erzählungen aus dem Weltkrieg, Schaffsteins blaue Bändchen, Nr. 79, Cöln am Rhein 1916.

Schulchronik der Volksschule zu Breinermoor (um 1970).

Schule und Krieg, in: Die Lehrerin, Organ des Allgemeinen Deutschen Lehrerinnenverein A, 1915/16, S. 6.

Schule und Krieg, Berlin 1915. Sonderausstellung im Zentralinstitut für Erziehung und Unterricht Berlin 1915.

Schulte, Eduard, Kriegschronik der Stadt Münster 191418. Quellen und Forschungen zur Geschichte der Stadt Münster, Münster 1930.

Schwarz, Bericht über eine Jugenddank-Veranstaltung der Lübecker Stadt- und Landschulen im Dezember 1917, in: Die Arbeitsschule, 1918, S. 110.

Schwarz, W., Sammelt Gold, in: Deutsches Philologen-Blatt, Korrespondenz-Blatt für den akademisch gebildeten Lehrerstand, 1915, S.107.

Schwellnus, Max, Vaterländische Festtage in der Schule. Festreden und Gedichte zur Kaisergeburtstags- und Sedanfeier, Breslau 1911.

Sechste Kriegsanleihe, in: Amtliches Schulblatt für den Regierungsbezirk Königsberg, 1917, S. 32.

Sellmann, Zur Verrohung der Jugend, in: Deutsches Philogen-Blatt, Korrenspondenz-Blatt für den akakdemisch gebildeten Lehrerstand, 1916, S. 168f.

Siegloch, Nicola/Stadtarchiv Isny, Nagelfiguren, Schreiben vom 28.09.2004.

Sofer, Emil, Die Schulen Niederösterreichs und die dritte österreichische Kriegsanleihe, in: Zeitschrift für die österreichischen Gymnasien, 1916.

Sohnrey, Heinrich, Kriegsarbeit auf dem Lande. Wegweiser für ländliche Wohlfahrts- und Heimatpflege in der Kriegszeit, Berlin1915.

Soziale Rundschau, in: Die Lehrerin, Organ des Allgemeinen Deutschen Lehrerinnenverein 1916,

S. 360.

Splett, F., Kaisers Geburtstag in der Volksschule, Breslau o. J.

Stadt und Kreis Goslar, in:Goslarsche Zeitung, 20. August 1915.

Stadtarchiv der Stadt Reutlingen,AZ 361-51-5, Reutlinger Kriegswahrzeichen, Schreiben vom 25.10.2004.

Stadtarchiv Zwickau, Nagelung des Hindenburg-Roland 1915-1916), Schreiben vom 4. Oktober 2004.

Stein, Walther, Das Kriegsbild in der Schule, 1915, S. 166f.

Steinecke, Gerhard, Ortschronist der Stadt Meißen, Nagelfigur in Meißen, Schreiben vom 3. November 2004. 
Stemplinger, Eduard, Kriegsjahresberichte1914/15 der bayrischen gymnasialen Anstalten, in: Deutsches Philologen-Blatt, Blatt für den akademisch gebildeten Lehrerstand 1915, S. 167.

Steinecke, Gerhard, Ortschronist der Stadt Meißen, Nagelfigur in Meißen, Schreiben vom 3. November 2004.

Stemplinger, Eduard, Kriegsjahresberichte1914/15 der bayrischen gymnasialen Anstalten, in: Deutsches Philologen-Blatt, Korrespondenz-Blatt für den akademisch gebildeten Lehrerstand, 1915,

S. 747.

Stiehler, Tagung für Jugenddankarbeit Dresden 1918, 27. und 28. September, in: Die Arbeitsschule, 1918, S. 201f.

Stiehler, Georg, Besondere Schularbeit in der Kriegszeit, in: Die Arbeitsschule, 1915, S. 2.

Störmer, K., Der Weltkrieg und die deutsche Schule, in: Die deutsche Schule [Weinheim], Zeitschrift für Erziehungswissenchaft und pädagogische Praxis, 1915, S. 562

Stranz, Helene, Reichsverband für Kriegspatenschaften, in: Die Lehrerin, Organ des Allgemeinen Deutschen Lehrerinnenverein 1917/18, S.268f.

Strater, Elisabeth, Wie in der Bürgerschule für Mädchen zu Crefeld während der verflossenen Kriegsmonate gearbeitet worden ist, in: Die Mittelschule, Zeitschrift der Reichsfachschaft Mittelschule im Nationalsozialistischen Lehrerbund., 1915, S. 154.

Strauch, Friedrich Wilhelm, Krieg und schulpflichtiges Alter, Halle 1917.

Sturm, Marie, Zur Fremdwörterfrage, in: Die Lehrerin, Organ des Allgemeinen Deutschen Lehrerinnenverein 1916/17, S: 333.

Stürzenacker, A., Über genagelte Kriegswahrzeichen, Karlsruhe1916.

Sz., Kriegswahrzeichen für jede Schule, in: Die Mittelschule, Zeitschrift der Reichsfachschaft Mittelschule im Nationalsozialistischen Lehrerbund., 1916, S. 526.

T. M., Vaterländischer Hilfsdienst für Schüler und Schülerinnen höherer Lehranstalten, in: Die Lehrerin, Organ des Allgemeinen Deutschen Lehrerinnenverein 1917, S. 398.

Tauscher, Edwin, Behandlung eines Kriegsgedichts, in: Deutsche Schulpraxis“, 1916, S. 100-103.

Teichert, Silva/ Stadtarchiv Zwickau, Die Nagelung des Eisernen Roland, Schreiben vom 26. 10. 2004.

Teichert, Silva/Stadtarchiv Zwickau, "Eiserner Roland" und andere Nagelfiguren, Schreiben vom 13. 02. 2003.

Terner, E., Unterhaltung in den Lazaretten, in: Deutsches Philologen-Blatt, Korrespondenz-Blatt für den akademisch gebildeten Lehrerstand, 1915, S. 294f.

Tews, $F$, Gedenkt der Kinder, in: Die Lehrerin, Organ des Allgemeinen deutschen Lehrerinnenverein 1914, S. 164f.

Thambahn, Solingen, in: Deutsches Philologen-Blatt, Korrespondenz-Blatt für den akademisch gebildeten Lehrerstand, 1916.

Thies, A., Ein Beitrag zur Lebensmittelstreckung, in: Deutsches Philologen-Blatt, Korrespondenz-Blatt für den akademisch gebildeten Lehrerstand, 1915, S. 198.

Thamhahn, W., Kriegsschulandachten, in: Deutsches Philologenblatt, 1918, Jg. 26, Heft 27/28, S. $226-228$.

Thomas, Adrienne/Scholdt, Günter, Aufzeichnungen aus dem Ersten Weltkrieg. Ein Tagebuch, Selbstzeugnisse der Neuzeit, Nr. 14, Köln 2004.

Thüringen und Nachbarstaaten, in: Ilm-Bote, 28. Juni 1919.

Töwe, E., Deutschen und fremdes Volkstum in der höheren Schule, in: Deutsches Philologenblatt, 1916, Jg. 24, S. 143f.

Trantow, E., Die Jungmannen bei der Landarbeit im Jahre 1918, in: Deutsches Philologen-Blatt, Korrespondenz-Blatt für den akademisch gebildeten Lehrerstand, 1918, S. 38.

Trautwein P., Zentrale Kriegshilfe der Schulen, in: Deutsches Philologen-Blatt, Korrespondenz-Blatt für den akademisch gebildeten Lehrerstand, 1917, S. 421f. 
Treuge, Margarete, Aus Bismarcks Kindheit und Schülerjahren, in: Die Lehrerin, Organ des Allgemeinen Deutschen Lehrerinnenverein 1914/15, S. 395f.

Treuge, Margarete, Weihnachten, der Krieg und die Jugend, in: Die Lehrerin, Organ des Allgemeinen Deutschen Lehrerinnenverein 1914, S. 273.

Treuge, Margarete, Was können wir Lehrerinnen tun?“, in:Die Lehrerin, Organ des Allgemeinen deutschen Lehrerinnenverein 1914, S. $175 f$.

Treuge, Margarete, Die Aufgaben der Schule bei der Aufklärungsarbeit über die deutsche Volksernährung, in: Die Lehrerin, Organ des Allgemeinen Deutschen Lehrerinnenverein 1915, S. 341.

Treuge, Margarete, "Lebenskunde" im Lyzeum, in: Die Lehrerin, Organ des Allgemeinen Deutschen Lehrerinnenverein 1915, S. 121f.

Treuge, Margarete, Der Kaiser und sein Reich, in: Die Lehrerin, Organ des Allgemeinen Deutschen Lehrerinnenverein 1918, S. 257-259.

Tussing,H., Der Krieg und der Unterricht im Rechnen, in: Die Mittelschule: Zeitschrift der Reichsfachschaft Mittelschule im Nationalsozialistischen Lehrerbund., 1916, S. 135.

Ungelenk, Ludwig, Coburg im Weltkrieg 1914-18; Ein Denk- u. Dankstein, von Heimatgenossen errichtet v. Ludwig Ungelenk, Coburg 1922.

Unter dem Schutze, in: Rostocker Anzeiger 2./3. September 1915.

Valentin Veit, Bismarck und seine Zeit, in: Monatszeitschrift für höhere Schulen, 1915, S. 210/211.

Vaterländische Kundgebung am Sedantag 1915, in: Hamelner Tageblatt, 4. September 1915.

Vaterländischer Hilfsdienst der Mädchen, in: Die Lehrerin, Organ des Allgemeinen Deutschen Lehrerinnenverein 1917/18, S. 94.

Veeck, O., Die Reformation in Bremen. Ein Gedenkbuch für 1917, Berlin 2. Auflage 1917.

Verbot des Verkaufs von Ansichtskarten durch Schulkinder, in: Amtliches Schulblatt für den Regierungsbezirk Hildesheim, 1916, S. 57.

Verein Jugendspende für Kriegerwaisen e. V., Kriegswahrzeichen, Essen 1916.

Verein Jugenddank für Kriegsbeschädigte e. V., Kriegswahrzeichen, Berlin 1918.

Vereinsnachrichten aus dem deutschen Lehrerverein, in: Hannoversche Schulzeitung. Organ der Provinzial-Lehrervereins, der Bezirks- und Pestalozzivereine der Provinz Hannover, des LehrerBrandversicherungsvereins für Hannover, Bremen und das Fürstentum Lippe., 1915, S. 326.

Verfügungen, in: Amtliches Schulblatt für den Regierungsbezirk Hannover, 1914-15/1916-18

Vermischtes, in: Die Mittelschule, Zeitschrift der Reichsfachschaft Mittelschule im Nationalsozialistischen Lehrerbund., 1915, S. 358f.

Versammlung von Vertretern der deutschen Schule, in: Deutsches Philologen-Blatt, KorrespondenzBlatt für den akademisch gebildeten Lehrerstand, 1915, S. 282f.

Vertrieb einer Wohlfahrtskarte, in: Zentralblatt für die gesamte Unterrichtsverwaltung in Preußen, 1917, S. 67.

Vertrieb von Postkarten für eine U-Bootspende, in: Amtliches Schulblatt für den Regierungsbezirk Hildesheim, 1918, S. 91f.

Vom eifrigen Kampf unserer Jugend, in: Die Lehrerin, Organ des Allgemeinen Deutschen Lehrerinnenverein 1914, S. 190.

Vom Eisernen Georg, in: Niederreinische Volkszeitung, 11. März 1916.

Vom Eisernen Landsturmmann, in: Erfurter Allgemeiner Anzeiger, 20. Oktober 1915.

Vom Eisernen Wehrmann, in: Halberstädter Zeitung und Intelligenzblatt mit Berlin, 8. Februar 1916.

Vondung, Klaus/Dilcher, Gerhard, Das wilhelminische Bildungsbürgertum. Zur Sozialgeschichte seiner Ideen, Kleine Vandenhoeck-Reihe, Nr. 1420, Göttingen 1976.

Voos, Paul, Kriegswahrzeichen für jede deutsche Schule, in: Die Mittelschule, Zeitschrift der Reichsfachschaft Mittelschule im Nationalsozialistischen Lehrerbund., 1916, S. 496.

Vorbildlich, in: Die Lehrerin, Organ des Allgemeinen Deutschen Lehrerinnenverein 1914/15, S. 203. 
Vorstand des Vaterländischen Frauenvereins, Liebesgaben, in: Zentralblatt für die gesamte Unterrichtsverwaltung in Preußen, 1914, S. 569.

Vorsteher, Dieter/Klotz, Katharina/Müller, Marianne/Sachs, Hans, Plakate des Ersten Weltkrieges. 1914-1918; [aus der Sammlung von Hans Sachs im Deutschen Historischen Museum], Diskus, 8, München 1996.

Wagler, B., Ein neues Werbemittel für die Kriegsanleihe, in: Deutsches Philologen-Blatt, Korrespondenz-Blatt für den akademisch gebildeten Lehrerstand, 1918, S. 116.

Wehrmann, M., Der Unterricht und der Krieg, in: Deutsches Philologen-Blatt, Korrespondenz-Blatt für den akademisch gebildeten Lehrerstand, 1914, S. 665.

Weidemann, Gerhard, Die Hohenzollern und die Schule. Zur 500jährigen Jubelfeier am 21. Oktober 1915, Halle an der Saale 1915.

Weihe und Nagelung des Eisernen Landsturmmannes, in: Erfurter Allgemeiner Anzeiger, 4. September 1915 .

Weihnachtsglückwunsch Seiner Majestät des Kaisers, in: Amtliches Schulblatt für den Regierungsbezirk Königsberg, 1916, S. 148.

Weihnachtsgruß der Heimat, in: Amtliches Schulblatt für den Regierungsbezirk Königsberg, 1916, S. 148.

Weis, Bruno, Ertïchtigungsmärsche unserer Schuljugend in der Kriegszeit, in: Deutsche Schulpraxis,

Wochenblatt für deutsche Lehrkunst, für Geschichte und Schrittum der Erziehung und des Unterrichts, 1916, S. 188.

Wettley, E., Zum landwirtschaftlichen Hilfsdienst unserer Schüler, in: Deutsches Philologen-Blatt, Korrespondenz-Blatt für den akademisch gebildeten Lehrerstand, 1917, S. 236.

Wettstein Richard von, Der Krieg und unsere Schulen, Zur Zeit- und Weltlage, Wien.1915.

Wilke, Edwin, „Der Kern des deutschen Geistes der Zukunft“ und der Deutschunterricht, in: Die deutsche Schule [Weinheim], Zeitschrift für Erziehungswissenchaft und pädagogische Praxis, 1916, S. 7786.

Wir alle wollen Streiter sein!“, ein Aufruf an Deutschlands Jugend, in: Deutsches Philologen-Blatt, Korrespondenz-Blatt für den akademisch gebildeten Lehrerstand, 1915, S. 197f.

Wißkirchen, Josef (Hrsg.), Schulchronik Stommelerbusch. 1870-1952, Pullheim 2002.

Wohlfahrtskarte Seiner Majestät des Kaisers, in: Amtliches Schulblatt für den Regierungsbezirk Hildesheim, S. 114f.

Wohlrab, E. H., Ein Tag. Ein Ausschnitt aus dem Schuljahre 1915/16, in: Deutsche Schulpraxis“, 1916, S. 169-174.

Wolbe, Eugen, Kriegsgeschichte 1914, Leipzig \& Wien 1915.

Wolde, E., Schulgärten und Schülergärten, in: Deutsches Philologen-Blatt, Korrespondenz-Blatt für den akademisch gebildeten Lehrerstand, 1916, S. 763.

Wöll, Bernhard, Stadtarchiv, Weilheim i. O., Schreiben vom 18. 10. 2004.

Wossidlo, R., Vorschläge zur Nagelung von Gedenkzeichen, in: Zeitschrift des Heimatbundes Mecklenburg, 1915, S. 84.

Wurthe, Wilhelm, Beiträge zur Kriegsnaturkunde. Eine Sammlung naturkundlicher Kriegsaufsätze, aktuelle Fragen aus der Pädagogik der Gegenwart, Nr. 15, Langensalza 1917.

Württ. Landesverein vom Roten Kreuz, in: Eßlinger Tagblatt, 4. Februar 1916.

Württembergische Landesausschuß für Natur- und Heimatschutz (Hrsg.), Richtlinien für die Erstellung von Kriegserinnerungszeichen, in: Blätter des Schwäbischen Albvereins, 1916.

Zenetti, L., Der Sammelhilfsdienst der Frankfurter Schuljugend und seine Ergebnisse am GoetheGymnasium, in: Deutsches Philologen-Blatt, Korrespondenz-Blatt für den akademisch gebildeten Lehrerstand, 1918, S. 7f.

Sonderausstellung Schule und Krieg. Frühjahr-Sommer 1915. Zentralinstitut für Erziehung und Unterricht, Sammelband Ausstellungen, Nr. 3, Berlin 1915. 
Zanther, E., Eine Sedanrede im Kriegsjahr 1916, in: Deutsche Schulpraxis, Wochenblatt für deutsche Lehrkunst, für Geschichte und Schrittum der Erziehung und des Unterrichts, 1916, S. 265-267.

Zeibig, M., Ein Fahnenstündlein zur Übung der deutschen Sprache in meiner Elementarklasse, in: Deutsche Schulpraxis“, 1915, S. 326f.

Zentralstelle für Fragen der Volksernährung, Wir alle wollen Streiter sein!, Deutsches PhilologenBlatt, Korrespondenz-Blatt für den akademisch gebildeten Lehrerstand, 1915, S. 197f.

Zentralstelle für Kriegswohlfahrt (Hrsg.), Ernährungsmerkblatt, in: Zentralblatt für die gesamte Unterrichtsverwaltung in Preußen, 1915, S. 426.

Ziegler, Th., Zehn Gebote der Kriegspädagogik, in: Deutsches Philologen-Blatt, Korrespondenz-Blatt für den akademisch gebildeten Lehrerstand, 1914, S. 594.

Ziermann, Christel/Leiterin Stadtmuseum/Stadtarchiv Pößneck, Schreiben vom 25. 10. 2004.

Zill, Fritz, Stolz weht die Fahne: Schwarz-Weiß-Rot. Anschließend das Brummergeschoss, in: Deutsche Schulpraxis“, 1915, S. 398f.

Zoozmann, Richard, Das ist der Krieg der Kriege!; Ernstes u. Heiteres f. Gesang u. Vortrag aus d. Weltkriege 1914 (1915), Berlin-Treptow: Winterfeld 1915.

Zum 27. Januar 1917, in: Deutsches Philologen-Blatt, Korrespondenz-Blatt für den akademisch gebildeten Lehrerstand, 1917, S. 2.

Zum Jahreswechsel, in: Monatszeitschrift für höhere Schulen, 1918, S. 2.

Zur Gedächtnisfeier der Reformation, in: Amtliches Schulblatt für den Regierungsbezirk Königsberg, 1917, S. 104.

Zur Nagelung des "Eisernen Kreuzes", in: Schwarzburg-Rudolstädtische Landeszeitung, 15. August 1915.

Zur Unterweisung und Herstellung nahrhafter und billiger Gerichte, in: Die Lehrerin, Organ des Allgemeinen Deutschen Lehrerinnenverein 1914, S. 211.

\section{Literatur}

Auer, Werner, Kriegskinder. Schule und Bildung in Tirol im Ersten Weltkrieg, Tirol im Ersten Weltkrieg, Nr. 7, Innsbruck 2008.

Biermann, Werner/Billstein Heinrich/Büschenfeld, Jürgen/Roerkohl, Anne/Stenner, Susanne/Trost, Gabriele (Hrsg.), Der Erste Weltkrieg. Das Buch zur ARD Serie, .Berlin 2004.

White, Hayden/Brinkmann-Siepmann, Brigitte/Siepmann, Thomas, Auch Klio dichtet oder Die Fiktion des Faktischen. Studien zur Topologie des historischen Diskurses, Stuttgart 1991.

3 Jahre Kriegsarbeit. 1914-1917; Nationaler Frauendienst Stettin, Stettin 1918.

50 Jahre Schule an der Rechenflether Straße 1905-1955, Bremen 1955.

Festschrift zum 65. Geburtstag von Jörn-Peter Leppien, 55. Jahrgang, Flensburg 2003.

Aereboe, Friedrich, Der Einfluß des Krieges auf die landwirtwirtschaftliche Produktion in Deutschland, Wirtschafts- und Sozialgeschichte des Weltkrieges, Stuttgart, Berlin Leipzig 1927.

Albisetti, James C., Höhere Knabenschulen, in: Berg, Christa (Hrsg.), Handbuch der deutschen Bildungsgeschichte, C. H. Beck, München 1991.

Alexander, Beatrix, Der Kölner Bauer, Kölnisches Stadt Museum, Köln 1987.

"Als der Krieg über uns gekommen war ..." Die Saarregion und der Erste Weltkrieg; Katalog des Regionalgeschichtlichen Museums im Saarbrückener Schloss, Saarbrücken 1993.

Ansichten vom Krieg. Vergleichende Studien zum Ersten Weltkrieg in Literatur und Gesellschaft, Hochschulschriften, Literaturwissenschaft, Königstein Ts. 1984. 
Audoin-Rouzeau, Stéphane, Die mobilisierten Kinder, in: Hirschfeld, Gerhard/Krumeich, Gerd/ Renz, Irina (Hrsg.), Keiner fühlt sich hier mehr als Mensch ..., Schriften der Bibliothek für Zeitgeschichte, Essen 1993.

Audoin-Rouzeau, Stéphane, La guerre des enfants (1914-1918), Paris 1993.

Audoin-Rouzeau, Stéphane, Kinder und Jugendliche, in: Hirschfeld, Gerhard u. a. (Hrsg.), Enzyklopädie Erster Weltkrieg, Paderborn 2. Auflage 2004.

Autorenkollektiv, Deutschland im Ersten Weltkrieg, Berlin 1968/69.

Bab, Julius, Die deutsche Kriegslyrik 1914-1918., Stettin 1920.

Battenberg, Friedrich/Franz, Eckhart G., Darmstadts Geschichte. Fürstenresidenz und Bürgerstadt im Wandel der Jahrhunderte, Studien zur Geschichte des Alltags; Nr.10, Darmstadt 1980.

Beck, J./Boehncke, H. (Hrsg.), Jahrbuch für Lehrer, Nr. 6, Reinbeck 1981.

Becker, Helmut/Kluchert, Gerhard, Die Bildung der Nation, Stuttgart 1993.

Beckett, Ian Frederick William, Home front, 1914-1918. How Britain survived the great war, National Archives, Kew 2006.

Beil, Christine, Der ausgestellte Krieg. Präsentationen des Ersten Weltkriegs 1914-1939, 2004.

Beiträge zur Heimatkunde der Städte Löhne und Bad Oeynhausen, 2006.

Bendele, Ulrich, Krieg, Kopf und Körper, Frankfurt/M. 1984.

Bendick, Rainer, Krieg in der Schule, in: Praxis Geschichte, 2001, Seite 35-39.

Bendick, Rainer, Kriegserwartung und Kriegserfahrung. Der Erste Weltkrieg in deutschen und französischen Schulgeschichtsbüchern (1900-1939/45), 2003.

Berg, Christa, Kinderwelten, Frankfurt am Main1994.

Berg, Christa (Hrsg), Familie, Kindheit, Jugend, in: Berg, Christa (Hrsg.), Handbuch der deutschen Bildungsgeschichte (1991), München 1991.

Berg, Christa (Hrsg.), Handbuch der deutschen Bildungsgeschichte. Von der Reichsgründung bis zum Ende des Ersten Weltkriegs, Bd. IV, München 1991.

Berg, Erika, Militär und Militarisierung, in: Berg, Christa (Hrsg.), Handbuch der deutschen Bildungsgeschichte, München 1991.

Berghahn, Volker, Das Kaiserreich, Stuttgart 10. Auflage 2003.

Bergmann, Klaus, Geschichtsdidaktik. In: Beiträge zu einer Theorie historischen Lernens, 1998.

Bergmann, Klaus/Schneider, Gerhard, Gegen den Krieg. Dokumente und Materialien, in: Geschichtsdidaktik. Studien, Materialien, 11-12, Düsseldorf 1982.

Bergmann, Klaus/Schneider, Gerhard (Hrsg.), Gesellschaft - Staat - Geschichtsunterricht, Beiträge zu einer Geschichte der Geschichtsdidaktik und des Geschichtsunterrichts 1500-1980, Düsseldorf 1982.

Blömer, Usula/Garz, Detlef (Hrsg.), „Wir Kinder hatten ein herrliches Leben“, in: Jüdische Kindheit und Jugend im Kaiserreich 1871-1918, Oldenburgische Beiträge zu jüdischen Studien, Nr. 5, Oldenburg 2000.

Blondet-Bisch, Thérèse/Krumeich, Gerd, Fotos, in: Didier, Christophe/ Hirschfeld, Gerhard (Hrsg.), In Papiergewittern, Somogy; Bibliothèque Nationale Universitaire, Straßburg 2008.

Böcke, Heinz, Altwulsdorfer Schule 125 Jahre. 1866-1991, Bremerhaven 1991.

Bockstiegel, Heiko, Der "Eiserne Burgmann" im Rathaussaal" zu Quakenbrück, in: Heimatjahrbuch "Osnabrücker Land", 1980, S. 54

Bohrmann, Hans/Malhotra, Ruth/Hagen, Manfred, Politische Plakate, Dortmund 1987.

Böke, Gerhard, Die Kriegswirtschaft im deutschen Reich während des Ersten Weltkriegs und deren privatrechtliche Folgen, 1997.

Bönisch, Monika/Bussemer, Herrad-Ulrike (Hrsg.), August 1914. Ein Volk zieht in den Krieg, Berliner Geschichtswerkstatt, Nr. 7, Berlin 1989.

Bracke, Gerhard (Hrsg.), 100 Jahre Wilhelm-Gymnasium Braunschweig 1885-1985. Festschrift zum 100jährigen Jubiläum des Wilhelm-Gymnasiums, Braunschweig 1995. 
Brakelmann, Günter, Der deutsche Protestantismus im Epochenjahr 1917, Witten 1974.

Brandt, Susanne, Kriegssammlungen im Ersten Weltkrieg, in: Hirschfeld/Krumeich/Renz (Hrsg.), Keiner fühlt sich hier mehr als Mensch (1993), S. 283-304.

Braun, Lothar R., Großherzog Ernst Ludwig nagelt, in: Offenbacher-Post, Nr. 179, 5./6. August 1989. Bräunche, Ernst Otto/Caroli, Michael, Geschichte im Plakat, Karlsruhe 2004.

Brinkmann, Matthias, Der Naturkundeunterricht zur Kriegszeit, in: Deutsche Schulpraxis“, 1916, S. 162-165.

Brocks, Christine, Die bunte Welt des Krieges. Bildpostkarten aus dem Ersten Weltkrieg 1914-1918, Frieden und Krieg, Nr. 10, Essen 2008.

Brudmann, F., Grosser Bilderatlas des Weltkrieges. mit 1600 Abbildungen, Bildnissen, Karten und Urkunden, München 1915ff.

Bruhns, Wibke, Meines Vaters Land. Geschichte einer deutschen Familie, München 2005.

Brune, Thomas, Staufertraditionalismus im Spiegel einer Göppinger Zeitung seit 1863, Stadtarchiv Göppingen, Veröffentlichungen Bd. 14, Göppingen 1977.

Budde, G., Krieg und höhere Schule! (1915), Hermann Beyer \& Söhne, Langensalza

Burkhardt, Johannes, Reformations- und Lutherfeiern. Die Verbürgerlichung der reformatorischen Jubliläumskultur in Düding, Dieter (Hrsg.), Öffentliche Festkultur, Rowohlts Enzyklopädie462 (1988), Rowohlt-Taschenbuch-Verlag, Reinbek bei Hamburg

Büttner, Ingeborg, Siegfried oder Gerechtigkeit für ein vaterländisches Denkmal, in: Wiesbadener Leben, 1982.

Chickering, Roger, The Great War and urban life in Germany. Freiburg, 1914-1918, Studies in the social and cultural history of modern warfare, 24, Cambridge 2009.

Chickering, Roger/Ameskamp, Simone, Das Deutsche Reich und der Erste Weltkrieg, Beck'sche Reihe, München 2005.

Chickering, Roger/Renz, Rudolf/Nicolai, Karl, Freiburg im Ersten Weltkrieg. Totaler Krieg und städtischer Alltag 1914-1918, Paderborn 2009.

Christa Setzer, Stadtarchiv Dorsten, Nagelfiguren, Schreiben vom 05. 10. 2004.

Christadler, Marieluise, Kriegserziehung im Jugendbuch. Literarische Mobilmachung in Deutschland und Frankreich vor 1914, Studien zur Kinder- und Jugendmedien-Forschung, Nr. 3, Frankfurt/Main 1979.

Chronik Hessens (1991), Dortmund 1991.

Ciment, James/Russell, Thaddeus, The home front encyclopedia. United States, Britain and Canada in World Wars I and II, Santa Barbara ( Californien) 2007.

Cossetto, Milena, Hinter den Fronten. Alltag im Krieg - Südtiroler Heimatfront im Ersten Weltkrieg., Bozen 2005.

Cuntz, Christoph, 60000 Nägel für Krieg und Frieden, in: Wiesbadener Kurier, 9. Mai 2007, S. 3.

Datzkow, Beate/Stadtarchiv im Gotischen Haus Bad Homburg, Schreiben (Materialien zur Nagelung des "St. Michael zu Bad Homburg v. d. Höhe") vom 14. Oktober 2004.

Davis, Belinda J., Heimatfront. Ernährung, Politik und Frauenalltag im Ersten Weltkrieg, 2002.

Demm, Eberhard, Ostpolitik und Propaganda im Ersten Weltkrieg (2002), Peter Lang; Europäischer Verlag der Wissenschaften; Frankfurt am Main; Berlin; Bern; Bruxelles; New York; Oxford, Wien 2002.

Denscher, Bernhard, Gold gab ich für Eisen. Österreichische Kriegsplakate 1914-1918, Wien 1987.

Der Krieg des kleinen Mannes. Eine Militärgeschichte von unten, Serie Piper (1992), Piper, München

Der Magistrat der Stadt Bad König, i.A. Herr Kraft / AZ IV/3-K, Nagelungen in Bad König (25.10.2004)

Der Tod als Maschinist. Der industrialisierte Krieg 1914-1918; eine Ausstellung des Museums Industriekultur Osnabrück im Rahmen des Jubiläums "350 Jahre Westfälischer Friede"; 17. Mai-23. August 1998; Katalog, Bramsche 1998. 
Deutsch, Karin / Drebning, Sarah / Korf, Britta, Die Nagelung des Eisernen Kreuzes 1915/16 in: Hann.-Münden (Wettbewerbsbeitrag. Hilfe für Bedürftige oder Aktion zur Kriegsfinanzierung (1996/97), Hann.-Münden 1996/97.

Didier, Christophe / Hirschfeld, Gerhard (Hrsg.), In Papiergewittern. Die Kriegssammlungen der Bibliotheken, 1914-1918, Bibliothèque Nationale Universitaire, Straßburg 2008.

Die Kaiserproklamation 1871 in Versailles im Vergleich zur Frankfurter Nationalversammlung 1848. Einheit und Freiheit als Ziele der deutschen Geschichte ; [Unterrichtsstunde in der Klasse 9c am Gymnasium Westerstede am 1. Juli 1985, Lehrer Herr Hoven], Hochsch.-Internes Fernsehen der Univ., Oldenburg 1985.

Die Ostpreußenhilfe im Ersten Weltkrieg, hrsg. vom Ostpreußischen Landesmuseum Lüneburg zur Ausstellung "Zum Besten der Ostpreußenhilfe" (23.9.2006-28.1.2007), Husum 2006.

Die Türe des Rathausturmes, in: Ludwigsburger Kreiszeitung, Nr.2 (Beilage), 1993.

Hoffmann, Detlef (Hrsg.), Ein Krieg wird ausgestellt. Die Weltkriegssammlung des Historischen Museums (1914-1918); Themen einer Ausstellung; Inventarkatalog, Kleine Schriften des Historischen Museums, Nr. 8, Frankfurt am Main 1976.

Diers, Michael, Schlagbilder. Zur politischen Ikonographie der Gegenwart, Frankfurt Main 1997.

Dix, Arthur, Wirtschaftskrieg und Kriegswirtschaft. Zur Geschichte des deutschen Zusammenbruchs, Berlin 1920.

Doffiné, Ernst, 120 Jahre Volksschule, in: Die Heimat, Nr. 25, 1986, S. 43-64.

Donson, Andrew, Models for Young Nationals and Militarists, German Studies Review, 2004, S. 579.

Döring, Edmund, Die Zeitereignisse der Jahre 1914-1920), Sondershausen o. J.

Dörnte, Günter, Katholische Schulen in Hamburg 1832 bis 1933. Ein Beitrag zur Geschichte des hamburgischen Unterrichtswesens (1984), Hamburg

Drüner, Hans, Im Schatten des Weltkrieges. Zehn Jahre Frankfurter Geschichte von 1914-1924, Frankfurt a. M. 1934.

Düding, Dieter (Hrsg.), Öffentliche Festkultur. Politische Feste in Deutschland von der Aufklärung bis zum 1. Weltkrieg, Rowohlts Enzyklopädie 462, Reinbeck bei Hamburg 1988.

Düding, Dieter, Politische Öffentlichkeit - politisches Fest - politische Kultur, in: Düding, Dieter (Hrsg.), Öffentliche Festkultur, Rowohlts Enzyklopädie, Reinbek bei Hamburg 1988, S. 10-24.

Dunkmann, Rudolf/Sauermann, Dietmar, Aus dem Leben eines Heuerlings und Arbeiters, in: Beiträge zur Volkskultur in Nordwestdeutschland, Nr. 23, Münster 1980.

Düwell, Kurt/Köllmann, Wolfgang, Rheinland-Westfalen im Industriezeitalter. Von der Reichsgründung bis zur Weimarer Republik, Rheinland-Westfalen im Industriezeitalter, Bd. 2, Wuppertal 1984.

Eberle, W., Das Kriegswahrzeichen am Fünfknotenturm, in: Kaufbeurer Geschichtsblätter, 1993/94, S. 59.

Ebermeier, Werner/Mayer-Mommertz, Wolfgang/Pfaffenzeller, Walter, Die Geschichte des HansCarossa-Gymnasiums Landshut 1629-2004, München 2004.

Ehrenmal und Ärgernis. Schüler erforschen Bergisch-Gladbacher Kriegsdenkmäler, Bergisch Gladbach 1997.

Eifert, Christiane, Frauenarbeit im Krieg - die Berliner Heimatfront 1914 bis 1918, 1985.

Eildermann, Wilhelm, Jugend im ersten Weltkrieg. Tagebücher, Briefe, Erinnerungen [von Dezember 1912 bis Oktober 1918], Berlin 1972.

Emminger, Eckhard, "... und der ganze Unterrichts muß auf die große Uhr des Weltkriegs eingestellt werden!" Die Auswirkungen des Ersten Weltkrieges auf die Volksschule im Königreich Bayern 1914 bis 1918, Augsburg 1987.

Ertheiler, August/Plohn, Robert, Das Sammeln in der Kriegswirtschaft, Beiträge zur Kriegswirtschaft; hrsg. von der Volkswirtschaftlichen Abteilung des Reichswirtschaftsministeriums, 1919.

Ewert, Malte, Die Schulchronik als Quelle historischer Bildungsforschung, Schriftenreihe der Stiftung Schulmuseum der Universität Hildesheim, Nr. 10, Alfeld 2009 
Festschrift zur 75-Jahrfeier des Oberlyzeums I mit Reform-Gymnasialer Studienanstalt zu Kiel, Kiel 1936.

Fiedler, Gudrun, Jugend im Krieg. Bürgerliche Jugendbewegung, Erster Weltkrieg und sozialer Wandel 1914-1923, Köln 1989.

Fink, Andrea, Der "Michel Mort in Eisen" von Hugo Cauer, in: Bad Kreuznacher Heimatblätter Beilage zum Oeffentlichen AnzeigerBad Kreuznach Nr. 12, 2000.

Fisch, Elisabeth, Die Paderborner "Heimatfront" 1914-1918, in: Westfälische Zeitschrift, 1992, S. 361.

Fischer, Fritz, Griff nach der Weltmacht. Die Kriegszielpolitik des kaiserlichen Deutschland 1914/18, Düsseldorf 1961.

Föllmer, Moritz, Die Verteidigung der bürgerlichen Nation. Industrielle und hohe Beamte in Deutschland und Frankreich 1900-1930, Kritische Studien zur Geschichtswissenschaft, Nr. 154, Göttingen 2002.

Frahm, Gerda, Geschichte der ersten städtischen höheren Mädchenschule in Altona. 1876-1926 Glückstadt und Hamburg o. J.

François, Etienne/Siegrist, Hannes/Vogel, Jakob, Die Nation. Vorstellungen, Inszenierungen, Emotionen, in: François, Etienne/Siegrist, Hannes/Vogel, Jakob (Hrsg.), Nation und Emotion, Kritische Studien zur Geschichtswissenschaft, Göttingen 1995.

Franke, Heidemarie/Ernst Ilse, 3. Die Kriegsgeneration, in: Blömer, Usula/ Garz, Detlef (Hrsg.), „Wir Kinder hatten ein herrliches Leben ... “, Oldenburgische Beiträge zu jüdischen Studien, Oldenburg 2000.

Frantzen, Allen J., Bloody good, Chicago 2004.

Franz, Eckhardt G. (Hrsg.), Chronik Hessen 1915, Dortmund 1991).

Frerichs, Holger, Zwischen Kriegsdienst und Wohlfahrtspflege. Das Rote Kreuz in Friesland 1870 bis 1955; eine Chronik von den Anfängen des Roten Kreuzes im Jeverland und in Varel / Friesische Wehde bis zum Neuaufbau nach dem II. Weltkrieg Jever 1999.

Friederich, Gerd, Die Volksschule im Württemberg im 19. Jahrhundert, in: Führ, Christoph/Mitter, Wolfgang (Hrsg.), Studien und Dokumentationen zur deutschen Bildungsgeschichte, Weinheim und Basel 1991.

Frisch, Werner/Obermeier, K. W., Brecht in Augsburg. Erinnerungen, Dokumente, Texte, Fotos, Berlin und Weimar 1986.

Fritz, Gerhard/Trefz, Bernhard, Backnanger Jahrbuch; Nr. 11, Backnang 2003.

Führ, Christoph/Mitter, Wolfgang (Hrsg.), Studien und Dokumentationen zur deutschen Bildungsgeschichte, Bd. 6, Weinheim und Basel 1991.

Führen, Franz, Lehrer im Krieg. Ein Ehrenbuch deutscher Volksschullehrer; die Kriegsarbeit deutscher Lehrer in der Heimat, Leipzig 1936.

Gailus, Michael, Nagelfiguren des Ersten Weltkriegs, Münster 2002.

Gebhard, Klemens, Ellwangen im 1. Weltkrieg. Eine fachwissenschaftliche Untersuchung zur Heimatfront 1914-1918 mit didaktisch-methodische Überlegungen zur Unterrichtspraxis an der Realschule, 2000.

Geertz, Clifford/Luchesi, Brigitte/Bindemann, Rolf, Dichte Beschreibung. Beiträge zum Verstehen kultureller Systeme, Frankfurt am Main 1983.

Giesbrecht, Sabine, Musikalische Kriegsrüstung. Zur Funktion populärer Musik im Ersten Weltkrieg. In: Populäre Musik im kulturwissenschaftlichen Diskurs, Beiträge zur Popularmusikforschung, Jg. 27/28, S. 161-184.

Giesbrecht, Sabine, "Lieb' Vaterland, magst ruhig sein" in: Lück, Hartmut/Senghaas Dieter (Hrsg.), Vom hörbaren Frieden, Frankfurt am Main2005.

Giese, Gerhardt, Quellen zur deutschen Schulgeschichte seit 1800, Quellensammlung zur Kulturgeschichte, Nr. 15, Göttingen [u. a.] 1961. 
Göbels, Hubert, Hundert alte Kinderbücher 1870-1945. Eine illustrierte Bibliographie, Dortmund 1981.

Goebel, Klaus, Des Kaisers neuer Geschichtsunterricht, in: GWU, 1974, S. 709.

Goebel, Stefan, "Kohle und Schwert". Zur Konstruktion der Heimatfront, Kriegswahrzeichen des Ruhrgebiets im Ersten Weltkrieg, in: Westfälische Forschungen, 2001, Nr. 257.

Goebel, Stefan, Schools, in: Winter, Jay/ Robert, Jean-Louis (Hrsg.), Capital Cities at War: Paris, London, Berlin 1914-1919, Cambridge 2007.

Goebel, Otto, Deutsche Rohstoffwirtschaft im Krieg, Stuttgart, Berlin und Leipzig, 1930.

Goldberg, Bettina, Schulgeschichte als Gesellschaftsgeschichte. Die höheren Schulen im Berliner Vorort Hermsdorf (1893-1945), Reihe Deutsche Vergangenheit, Stätten der Geschichte Berlins, Berlin 1994.

Grenz, Dagmar, Geschichte der Mädchenlektüre. Mädchenliteratur und die gesellschaftliche Situation der Frauen vom 18. Jahrhundert bis zur Gegenwart, Weinheim 1997.

Grimm, Stephan, Das Kriegswahrzeichen auf dem Rathausplatz 1915 bis 1917, in: Gütersloher Beiträge zur Heimat- und Landeskunde, 1993, S. 813.

Gross, Claus-Peter, ... verliebt ... verlobt ... verheiratet ... 1871-1918. Unter Adlers Fittichen [Begleitbuch zur gleichnamigen Ausstellung in Berlin und Bielefeld], Berlin1986.

Grotjahn, Karl-Heinz, Vaterlandsverteidiger bis zum Jüngsten hinab - die hannoversche Jugend zwischen Kriegsdienst und Disziplinierung, in: Mußmann, Olaf (Hrsg.), Leben abseits der Front, Hannover 1992.

Grotjahn, Karl-Heinz, Stahl und Steckrüben. Beiträge und Quellen zur Geschichte Niedersachsens im Ersten Weltkrieg (1914-1918), Bd. 2, Hameln 1993.

Grotjahn, Karl-Heinz, Als geheim gebuttert wurde, Schriften zur Stadtgeschichte, Garbsen 1995.

Gruber, Verena, Mobilisierung von Kindern und Jugendlichen im Vorfeld und im Ersten Weltkrieg, 2001.

Günnewig, Beatrix, Schulische Festkultur am Beispiel der Wilhelm-Raabe-Schule. Die Höhere Töchterschule I in Hannover, in: Landeshauptstadt Hannover (Hrsg.), Hannoversche Geschichtsblätter, Hannover 2003/2004).

Günther-Arndt, Hilke, Geschichtsunterricht, Oldenburg 1900-1930, in: Oldenburger Studien, Nr. 19, Oldenburg 1980.

Günther-Arndt, Hilke, Geschichtsunterricht und didaktische Rekonstruktion, Oldenburger VorDrucke, Oldenburg 1995.

Haacke, Ulrich/Schneider, Benno, Das Buch vom Kriege 1914-1918 - Briefe, Berichte, Erinnerungen, Urkunden, Ebenhausen bei München 1939.

Hackl, Othmar/Messerschmidt Manfred (Hrsg.), Militärgeschichtliche Mitteilungen, Nr. 34. 1983.

Haffner, Sebastian, Geschichte eines Deutschen. Die Erinnerungen 1914-1933, Stuttgart 2002.

Hagenow, Elisabeth von, Mit Gott für König, Volk und Vaterland. Die Bildpostkarten als Massen- und Bekenntnismedium, in: Zühlke, Raoul (Hrsg.), Bildpropaganda im Ersten Weltkrieg, Hamburg 2000.

Halbekam, Joachim J., Die "Burgschule" in Esslingen 1904-2004. Von der Mädchenschule zur GHS, Festvortrag anläßlich der Feier des 100jährigen Schuljubiläums, Esslingen 2004.

Hamann, Brigitte, Der Erste Weltkrieg. Wahrheit und Lüge in Bildern und Texten, München 2004.

Hammer, Karl, Der deutsche Protestantismus und der Erste Weltkrieg, Francia, 1974, S. 398-414.

Hämmerle, Christa, "Wir strickten und nähten Wäsche für Soldaten ...", in: L' Homme - Zeitschrift für feministische Geschichtswissenschaft, 1992, S. $107 \mathrm{ff}$.

Hämmerle, Christa (Hrsg.), Kindheit im Ersten Weltkrieg, Damit es nicht verloren geht, Wien-Böhlau 1993.

Hartung, Olaf, Pädagogische Überlegungen zu einer Geschichtsdidaktik des Reisens, in: Oldenburger Schriften zur Geschichtswissenschaft, Nr. 5 (1999), Oldenburg 1999. 
Haußmann, Andrea, Alltagsleben im Krieg. Freiburg 1914-1918, in: Stadt und Geschichte, Nr. 15, Freiburg 1994.

Häußner, J., Der Weltkrieg und die höheren Schulden Badens im Schuljahr 1914-1915, Karlsruhe

o. J.

Heimatfront und Kriegsalltag, in: Praxis Geschichte, 4/2004, Braunschweig 2004

Heinemann, Erich, Für Kaiser und Vaterland. Hildesheim im Ersten Weltkrieg, Hildesheim 1989.

Helfferich, Karl, Der Weltkrieg, Ullstein Berlin 1919.

Helming, Antonia/Fredeweß-Wenstrup, Stephanie, "Mutters Kriegstagebuch". Die Aufzeichnungen der Antonia Helming 1914-1922, in: Rückblick, Nr. 3, Münster 2005.

Hennig, Helmut, Die Heimat im Ersten Weltkrieg. Dargestellt am Beispiel der oberfränkischen Gemeinde Stammbach, Bezirksamt Münchberg, in: Oberfränkischer Schulanzeiger - Heimatbeilage, Bayreuth 2003.

Herbner, Detlef, Titisee-Neustadt. Eine Stadtgeschichte, Freiburg im Breisgau1995.

Hergenröder, Gerhard, Wendlingen am Neckar. Auf dem Weg zu einer Stadt, die Geschichte von Wendlingen, Unterboihingen und Bodelshofen, Wendlingen am Neckar 1992.

Herrlitz, Hans-Georg/Hopf, Wulf/Titze, Hartmut/Cloer, Ernst, Deutsche Schulgeschichte von 1800 bis zur Gegenwart. Eine Einführung, Weinheim 2005.

Herrmann, Ulrich $G$, Regionale Differenzierung und gesamtstaatliche Systembildung. Preußen und seine Provinzen - Deutsches Reich und seine Staaten, 1800-1945, Datenhandbuch zur deutschen Bildungsgeschichte. Höhere und mittlere Schulen, Bd. 2; Teil 2, Göttingen 2003.

Herzig, Arno, Die Lasalle-Feiern in der politischen Festkultur der frühen Arbeiterbewegung, in: Düding, Dieter (Hrsg.), Öffentliche Festkultur, Reinbek bei Hamburg 1988.

Hinnen, Werner, Die Kriegsanleihen Deutschlands, Englands, Frankreichs und die Mobilisationsanleihen der Schweizerischen Eidgenossenschaft unter Berücksichtigung der Emissionssysteme, 1923.

Hirschfeld, Gerhard (Hrsg.), Kriegserfahrungen. Studien zur Sozial- und Mentalitätsgeschichte des Ersten Weltkriegs, Schriften der Bibliothek für Zeitgeschichte, N. F., Nr. 5, Essen 1997.

Hirschfeld, Gerhard/Krumeich, Gerd/Renz, Irina (Hrsg.), „Keiner fühlt sich hier mehr als Mensch“. Erlebnis und Wirkung des Ersten Weltkriegs, Schriften der Bibliothek für Zeitgeschichte, N. F., Nr. 1, Essen 1993.

Hirschfeld, Gerhard u. a. (Hrsg.), Enzyklopädie Erster Weltkrieg, Paderborn 2. Auflage 2004.

Hirschmann, Wilhelm, Der Rückgang der Kriegsanleihe, seine Folgen und seine Bekämpfung, Hamburg 1919.

Historische Kommission für Niedersachsen und Bremen (Hrsg.), Niedersächsisches Jahrbuch für Landesgeschichte, Hannover 2000.

Hoegen, Jesko von, Der Held von Tannenberg, Stuttgarter, Historische Forschungen, Nr. 4, Böhlau, Köln, Wien u.a. 2007.

Höffler, Felix, Kriegserfahrungen in der Heimat: Kriegsverlauf, Kriegsschuld und Kriegsende in württembergischen Stimmungsbildern des Ersten Weltkriegs, in: Hirschfeld, Gerhard (Hrsg.), Kriegserfahrungen, Schriften der Bibliothek für Zeitgeschichte, Essen 1997.

Hohlfeld, Johannes, Zwanzig Jahre deutsches Ringen: vom Weltkrieg über Versailles zur nationalen Erneuerung, Berlin 1934.

Hohnsbehn, Harald, Die Flensburger Schuljugend in der Zeit des ersten Weltkriegs, Schriften der Gesellschaft für Flensburger Stadtgeschichte e. V., Nr. 49, Flensburg 1996.

Hornburg, Heinz, Vaterländische Nägel in Bützow, in: Mecklenburg-Magazin 1998, S. 26.

Hoßfeld, Adolf, Krieg an der "Heimatfront". Sonneberg im Ersten Weltkrieg, Sonneberg 2004.

Hoßfeld, Adolf, Sonneberg zu Beginn des 1.Weltkriegs im Jahr 1914, in: Jahrbuch des Landkreises Sonneberg,Tradition und Zukunft, 2004, S. 152.

Huegel, Arnulf, Kriegsernährungswirtschaft Deutschlands während des Ersten und Zweiten Weltkrieges im Vergleich, Konstanz 2003. 
Hüppauf, Bernd, Transformationen von Gewalt in Kriegsritualen der Moderne. Erinnerungen schwacher Täter, in: Korff, Gottfried (Hrsg.), Alliierte im Himmel, Untersuchungen des Ludwig-UhlandInstituts der Universität Tübingen, Tübingen 2006.

Hüppauf, Bernd (Hrsg), Ansichten vom Krieg. Vergleichende Studien zum Ersten Weltkrieg, in: Literatur und Gesellschaft, Forum Academicum (Hochschulschriften Literaturwissenschaft), Bd. 61, Köln, Wien u. a. 1984.

Iggers, Georg G., Geschichtswissenschaft im 20. Jahrhundert. Ein kritischer Überblick im internationalen Zusammenhang,, Göttingen 2007.

Irmisch, Rudolf, Geschichte der Stadt Itzehoe, Itzehoe 1960.

Jacobi, Uwe, "Ritter Eisenhart", in: Heilbronner Stimme, 3. Januar 2001.

Jeismann, Michael, Propaganda, in: Hirschfeld, Gerhard u. a. (Hrsg.), Enzyklopädie Erster Weltkrieg, Paderborn 2. Auflage 2004.

Jessen, Johannes, Aus der Kriegschronik des Kirchspiels Kosel. Erlebnisse daheim und draußen, Eckernförde1922.

Johann, Ernst, Innenansicht eines Krieges. Bilder, Briefe, Dokumente 1914-1918, Frankfurt am Main 1968.

Jung, Rainer, Der "Eiserne Ritter" der Ursulinenschule, in: "Als der Krieg über uns gekommen war ..." Die Saarregion und der Erste Weltkrieg; Katalog des Regionalgeschichtlichen Museums im Saarbrückener Schloss, Saarbrücken 1993.

Kaden, Stadtarchiv Dresden, Kriegskreuz 1914, Dresden, Schreiben vom 31. 12. 2004.

Kaeber, Ernst, Berlin im Weltkriege. Fünf Jahre städtischer Kriegsarbeit, Berlin 1921.

Kammeier, Heinz-Ulrich, Der Landkreis Lübbecke und der 1. Weltkrieg. Alltagserfahrungen in einem ländlichen Raum Ostwestfalens, Quellen und Schrifttum zur Kulturgeschichte des Wiehengebirgsraumes, Reihe A, Rahden/Westfalen 1998.

Karl, Willibald, Jugend, Gesellschaft und Politik im Zeitraum des Ersten Weltkriegs. Zur Geschichte der Jugendproblematik der deutschen Jugendbewegung im ersten Viertel des 20. Jhs. unter besonderer Berücksichtigung ihrer gesellschaftlichen und politischen Relationen und Entwicklungen in Bayern, in: Neue Schriftenreihe des Stadtarchivs, Nr.48, München.

Kaschura, Wolfgang, Die Nation als Körper. Zur symbolischen Konstruktion 'nationaler' Alltagswelten, in: François, Etienne/Siegrist, Hannes/Vogel, Jakob (Hrsg.), Nation und Emotion, Kritische Studien zur Geschichtswissenschaft, Göttingen 1995.

Kawerau, Siegfried, Alter und neuer Geschichtsunterricht, Entschiedene Schulreform, Oldenburg und Leipzig 1924.

Kempf-Oldenburg, Claudia, Orts- und Schulchronik. Schulalltag und Dorfleben in Westerbeck von den Anfängen bis 1974, Westerbeck 1990.

Kirchgässer, Bernhard/Scholz, Günther (Hrsg.), Stadt und Krieg, Sigmaringen 1989.

Kirschninck, Harald, 1685-1918, Die Geschichte der Juden in Elmshorn, Norderstedt 2005.

Klein Peter J., Ostfriesland und der Erste Weltkrieg. Projektskizze für den Kursunterricht der gymnasialen Oberstufe (Vor- und Kursstufe); erarbeitet im Rahmen des Projekts "Schule und Bibliothek" Aurich 1997.

Knoch, Peter, Kinder im Krieg 1914-18. Zwei Mädchen schreiben Kriegstagebuch, in: Knoch, Peter (Hrsg.), Varia historica, Plochingen 1998.

Knoch, Peter (Hrsg.), Varia historica, Plochingen 1998.

Knoch, Peter/Dines, Peter (Hrsg.), Kriegsalltag. Die Rekonstruktion des Kriegsalltags als Aufgabe der historischen Forschung und der Friedenserziehung, Didaktische Reihe der Landeszentrale für Politische Bildung Baden-Württemberg, Stuttgart 1989.

Knodt, Manfred, Ernst Ludwig. Großherzog von Hessen und bei Rhein; sein Leben und seine Zeit, Darmstadt 1997.

Koch, Christian, Bildpropaganda für die deutschen Kriegsanleihen im 1. Weltkrieg, München 2006. 
Koch, Elke, "Jeder tut, was er kann fürs Vaterland": Frauen und Männer an der Heilbronner "Heimatfront", in: Hirschfeld, Gerhard (Hrsg.), Kriegserfahrungen, Schriften der Bibliothek für Zeitgeschichte Essen 1997.

Koch, Herbert, Geschichte der Stadt Jena, Stuttgart 1996.

Kocka, Jürgen, Klassengesellschaft im Krieg. Deutsche Sozialgeschichte, 1914-1918, Frankfurt am Main 1998.

Koeppen, Wolfgang, Es war einmal in Masuren, Frankfurt am Main 1991.

Kohnle, Armin/Engehausen, Frank/Wolgast, Eike, Zwischen Wissenschaft und Politik. Studien zur deutschen Universitätsgeschichte; Festschrift für Eike Wolgast zum 65. Geburtstag, Stuttgart 2001.

König, Museum Dömitz, Dömitz, Schreiben vom 22. April 2006.

Korff, Gottfried (Hrsg.), Alliierte im Himmel. Populare Religiosität und Kriegserfahrung, Untersuchungen des Ludwig-Uhland-Instituts der Universität Tübingen, Bd. 99, Tübingen 2006.

Korsch, H.: Kriegsstunden. Stoffe und Darbietungen für die Schule, Leipzig 1915.

Korte, Barbara, Der Erste Weltkrieg in der populären Erinnerungskultur, Schriften der Bibliothek für Zeitgeschichte, N. F., Nr. 22, Essen 2008.

Koszyk, Kurt, Deutsche Pressepolitik im Ersten Weltkrieg, 1968.

Kramer, Hans, Deutsche Kultur zwischen 1871 und 1918, Handbuch der Kulturgeschichte, Abt. 1, Zeitalter deutscher Kultur, Frankfurt am Main 1971.

Kramer, Susanne, Die Schulgemeinde Marten. Ein Beispiel für westfälische Schulgeschichte, Schriftenreihe des Westfälischen Schulmuseums Dortmund, Band 1, Dortmund 1992.

Krämer, Werner, Die Nagelung des "Eisernen Mannes" in Aschaffenburg, Mitteilungen aus dem Stadt- und Stiftsarchiv Aschaffenburg, Aschaffenburg 1995, Bd. 4, Heft 6, S. 483-487.

Kraul, Margret, Höhere Mädchenschulen, in: Berg, Christa (Hrsg.), Handbuch der deutschen Bildungsgeschichte, München 1991.

Krumeich, Gerd, Kriegsfront - Heimatfront, in: Hirschfeld, Gerhard (Hrsg.), Kriegserfahrungen, Schriften der Bibliothek für Zeitgeschichte, Essen1997.

Krumeich, Gerd/Hirschfeld, Gerhard, Die Geschichtsschreibung zum Ersten Weltkrieg, in: Berg, Christa (Hrsg.), Handbuch der deutschen Bildungsgeschichte, München 1991.

Krumeich, Gerd/Hirschfeld, Gerhard, Die Geschichtsschreibung zum Ersten Weltkrieg, in: Hirschfeld, Gerhard u. a. (Hrsg.), Enzyklopädie Erster Weltkrieg, Paderborn 2. Auflage 2004.

Kuczinski, J., Geschichte des Alltags des deutschen Volkes. 1871-1918, Köln 1982.

Kuderer, Uschi/Schneider, Gerhard, Nageln für das Vaterland, Beiträge zur Heimatkunde der Städte Löhne und Bad Oeynhausen, 2006, S. 185-208.

Kuhlemann, Frank-Michael, Niedere Schulen, in: Berg, Christa (Hrsg.), Handbuch der deutschen Bildungsgeschichte, Bd. IV, München 1991.

Küppers, Paul, Kriegsarbeit der Stadt Bochum 1914-1918, Bochum 1926.

Lange, Britta, Einen Krieg ausstellen. Die "Deutsche Kriegsausstellung" 1916 in Berlin, Berlin 2003.

Lange, Dirk / Buckstegge, Eva-Maria, Politische Bildung an historischen Orten. Materialien zur Didaktik des Erinnerns, Baltmannsweiler 2006.

Langer, Hermann, Schulfrei für den Tod. Jugend unter Pickelhaube und Stahlhelm, Berlin 1988.

Langer, Hermann, Die Mobilmachung der Schule, in: Mecklenburg-Magazin, Nr. 10, Schwerin 1994.

Langer, Hermann, Schulfrei für den Krieg, in: Mecklenburg-Magazin, Nr.12, Schwerin 1994.

Langer, Hermann, Lernziel Krieg! Eine Dokumentation zur Geschichte der Schulen Mecklenburgs im Ersten und Zweiten Weltkrieg, Mecklenburgische Schulgeschichte, Schwerin 2000.

Langer, Hermann, Der Krieg als Erzieher. Zur Kriegserziehung an den Schulen Vorpommerns von 1900-1945; mit einer Dokumentation, Rostock 2004.

Lehberger, Reiner, Schule in Hamburg während des Kaiserreichs. Zwischen "Pädagogischer Reform" und „Vaterländischer Gesinnung", in: Stephan, Inge/ Winter, Hans-Gerd (Hrsg.), "Heil über dir, Hammonia", Hamburg 1992. 
Lehrer helfen siegen. Kriegspädagogik im Kaiserreich. Mit Beiträgen zur NS-Kriegspädagogik, Edition Diesterweg-Hochschule, Berlin 1987.

Leicht, Walter Herzog, Elisabeth, Unbekanntes Denkmal der Stadtgeschichte, in: Oberbayrisches Volksblatt, Nr. 3. November 1987.

Landeshauptstadt Hannover (Hrsg.), Hannoversche Geschichtsblätter, Nr.57, Hannover 2003/2004.

Lemm, Werner, Schulgeschichte in Berlin, Berlin 1987.

Lemmermann, Heinz, Kriegserziehung im Kaiserreich. Studien zur politischen Funktion von Schule und Schulmusik, 1890-1918, Lilienthal/Bremen 1984.

Lerch, Edith, Die Maifeiern der Arbeiter im Kaiserreich, in: Düding, Dieter (Hrsg.), Öffentliche Festkultur, Rowohlts Enzyklopädie 462, Reinbek bei Hamburg 1988.

Löher, Jochen, Mit Gott für König und Vaterland. Die Schule im Ersten Weltkrieg, in: Löher, Jochen/ Wulf, Rüdiger (Hrsg.), Furchtbar dräute der Erbfeind! Vaterländische Erziehung in den Schulen des Kaiserreichs 1871-1918,Schriftenreihe des Westfälischen Schulmuseums, Band 3, Dortmund.

Loidl, Tristan, Andenken aus Eiserner Zeit. Patriotische Abzeichen der österreichisch-ungarischen Monarchie von 1914 bis 1918,Wien 2004.

Ludewig, Hans-Ulrich, Das Herzogtum Braunschweig im Ersten Weltkrieg. Wirtschaft Gesellschaft Staat, Quellen und Forschungen zur braunschweigischen Geschichte, Braunschweig 1984.

Lück, Hartmut Senghaas Dieter (Hrsg.)., Vom hörbaren Frieden. Lieb“ Vaterland, magst ruhig sein“. Musik und Nationalismus im deutschen Kaiserreich, Frankfurt am Main 2005.

Lüdtke, Alf, Lebenswelten und Alltagswissen in Berg, Christa (Hrsg. ), Handbuch der deutschen Bildungsgeschichte, München 1991.

Lundgreen, Peter, Schulsystem. Bildungschancen und städtische Gesellschaft in Berg, Christa (Hrsg.), Handbuch der deutschen Bildungsgeschichte, München 1991.

Lurz, Meinhold, Kriegerdenkmäler in Deutschland. I. Weltkrieg, Bd. 3, Heidelberg 1985.

Madsen, P. L., Nachrichten über das Flensburger Volksschulwesen im Auftrag der städtischen Schuldeputation, Heft XV, Flensburg 1916.

Marquardsen, Ida, Festschrift des staatlichen Oberlyzeums zu Flensburg, 1886-1936, Flensburg 1936.

Martens, Matthias, Heimatbild und Feindbild. Werbung für Kriegsanleihen im Ersten Weltkrieg, in: Sauer, Michael (Hrsg.), Plakate, Geschichte lernen, Velber 2005.

Martens, Matthias, Heimatbild und Feindbild, in: Geschichte Lernen, Velber 2006, S. 22-27.

März, Eduard, Österreichische Bankpolitik in der Zeit der grossen Wende 1913-1923. Am Beispiel d. Creditanstalt für Handel u. Gewerbe, München 1981.

Materialsammlungen u.a., in: Luckauer Heimatblätter, Februar 1938.

Matthias, Adolf, Bismarck, sein Leben und Werk, in: Monatszeitschrift für höhere Schulen, Jg. 14, 1915, S. 146-148.

Maubach, Peter, Neubrandenburg im 1. Weltkrieg. August 1914 bis Nov. 1918, in: Allgemeiner Mecklenburger Anzeiger - Neubrandenburger Zeitung, 65-69. Jahrgang (1996), Neubrandenburg 1996.

Maurer, Catherine, Medien im Alltag. Maueranschläge und Plakate zur Mobilisierung der Zivilbevölkerung in Straßburg, in: Didier, Christophe/Hirschfeld, Gerhard (Hrsg.), In Papiergewittern, Straßburg 2008.

Maurer, Michael (Hrsg.), Neue Themen und Methoden der Geschichtswissenschaft, Reclam Universalbibliothek, Nr. 17033, Leipzig 2003.

Meerwarth, Rudolf/Günther, Adolf/Zimmermann, Waldemar, Die Einwirkung des Krieges auf Bevoelkerungsbewegung, Einkommen und Lebenshaltung in Deutschland, Stuttgart 1932.

Mehnert, Gottfried, Evangelische Kirche und Politik 1917-1919, Beiträge zur Geschichte des Parlamentarismus und der politischen Parteien, hrsg. von der. Kommission für Geschichte des Parlamentarismus und der Politischen Parteien, Düsseldorf 1959.

Meyer, Folkert, Schule der Untertanen. Lehrer und Politik in Preußen (1976), Hamburg 1976. 
Meyer, Hans-Joachim, Die Nagelungen des Eisernen Kreuzes 1915/16 in Hann.-Münden. Hilfe für Bedürftige oder Aktion zur Kriegsfinanzierung, Hannoversch-Münden 1997.

Michalka, Wolfgang (Hrsg.), Der Erste Weltkrieg. Wirkung, Wahrnehmung, Analyse, München und Zürich 1994.

Mielke, Robert, Gartenbau in der Großstadt, Heimatschutz in Brandenburg, 1917, S. 66-70.

Mommsen, Wolfgang Justin/Kocka, Jürgen/Gebhardt/Bruno/Häfele, Rolf, Die Urkatastrophe Deutschlands. Der Erste Weltkrieg, 1914-1918, 19. Jahrhundert (1806-1918), Stuttgart 2004.

Morling, B. Stadtmuseum Jüterbog, "Eiserner Hindenburg-Roland", Jüterbog, Schreiben vom 05. 02. 2003.

Müller, Detlef K./Zymek, Bernd/Herrmann, Ulrich, Datenhandbuch zur deutschen Bildungsgeschichte, Göttingen 1987.

Müller-Henning, Markus (Hrsg.), Kriegsalltag, Kriegswirklichkeit und Kriegsende im Urteil Wiesbadener Schüler. Dokumentation eines Studienprojektes im Hessischen Hauptstaatsarchiv; bearbeitet vom Leistungskurs Geschichte der Carl-von-Ossietzky-Schule unter besonderer Mitwirkung von Sascha König und Carsten Stork, Wiesbaden 1960.

Musil, Robert, Der Mann ohne Eigenschaften. Roman Band I; erstes und zweites Buch, Hamburg 2007.

Mußmann, Olaf (Hrsg.), Leben abseits der Front. Hannoverscher Alltag in kriegerischen Zeiten, Hannover 1992.

Mütter, Bernd, Entdeckendes Lernen im Geschichtsunterricht. Das Fallbeispiel "Geschichtsbuch" Bd. 4; Vortrag im Zentralinstitut für Fachdidaktik an der Freien Universität Berlin am 26. 10. 1995, Oldenburg 1996.

Nipperdey, Thomas, Wie modern war das Kaiserreich? Das Beispiel der Schule, Opladen 1986.

Nipperdey, Thomas, Deutsche Geschichte 1866-1918. Arbeitswelt und Bürgergeist, Bd. 1, München 1994.

Nipperdey, Thomas, Deutsche Geschichte. Machtstaat vor der Demokratie, Bd. 2, München 1995.

Nolte, Maik, Isern Hinnerk warb um Spenden, in: Nordwest-Zeitung, 21. Juli 2007.

Notstand zu wehren, Deutschland zu ehren, schlug ich den Nagel ein. Zur Erinnerung an meine Nagelung des eisernen Baumes am Schwabentor zu Freiburg i. B., Freiburg i. B. 1915.

Nübel, Christoph, Mobilisierung der Heimatfront und Selbstbehauptung im Feindesland, in: Rheinisch-westfälische Zeitschrift für Volkskunde, Nr. 52, 2007, S. 131-156.

Nübel, Christoph, Die Mobilisierung der Kriegsgesellschaft. Propaganda und Alltag im Ersten Weltkrieg in Münster, Münsteraner Schriften zur Volkskunde, Europäischen Ethnologie, Bd. 14, Münster 2008.

Oberschelp, Reinhard/Grotjahn, Karl-Heinz, Stahl und Steckrüben. Beiträge und Quellen zur Geschichte Niedersachsens im Ersten Weltkrieg (1914-1918), Veröffentlichungen der Niedersächsischen Landesbibliothek Hannover, Hameln 1993.

Nord-Ollnborg, Unterrichtshilfen, in: Oldenburgische Landschaft, Nr.2, Oldenburg 1983.

Oppelt, Ulrike, Film und Propaganda im Ersten Weltkrieg. Propaganda als Medienrealität im Aktualitäten- und Dokumentarfilm, Beiträge zur Kommunikationsgeschichte, Nr. 10, Stuttgart 2002.

Ottmann, Matthias, Schule im Krieg. Höhere Schulen in der Stadt Oldenburg im Ersten Weltkrieg,Oldenburg 1996.

Pandel, Hans-Jürgen (Hrsg.), Verstehen und Verständigen (1991), Pfaffenweiler 1991.

Paul, Bruno, Zeichnet Kriegsanleihe. Die Zeit ist hart, aber der Sieg ist sicher, Klett-Schulgalerie, Stuttgart 1974.

Paul, G. (Hrsg.), Visual history, Göttingen 2006.

Pörtner, Rudolf (Hrsg.), Kindheit im Kaiserreich. Erinnerungen an vergangene Zeiten, München 1990.

Pörtner, Rudolf (Hrsg.), Mein Elternhaus, ETB, Nr. 26057 (1996), Düsseldorf und Wien 1996.

Pust, Hans-Christian, „Eisern war die Zeit“. Nagelfiguren im Ersten Weltkrieg, in: Grenzfriedenshefte, 2002, S. 3-24. 
Pust, Hans-Christian, Schleswig-Holsteinische Nagelungsdenkmäler im Ersten Weltkrieg. Ein Überblick, in: Festschrift zum 65. Geburtstag von Jörn-Peter Leppien, 55. Jahrgang, Flensburg 2003.

Pust, Hans-Christian, "Vaterländische Erziehung" für "Höhere Mädchen". Soziale Herkunft und politische Erziehung von Schülerinnen an höheren Mädchenschulen in Schleswig-Holstein 1861-1918, Osnabrück 2004.

Pust, Hans-Christian, Kriegsbilder. Postkarten des Ersten Weltkriegs in Didier, Christophe/Hirschfeld, Gerhard (Hrsg.), In Papiergewittern, Straßburg 2008.

Putz, Petra, "Die heldenmutigen Truppen kämpfen siegreich an allen Fronten ...". Die Wirkung der Propaganda im Ersten Weltkrieg am Beispiel des Mädchentagebuchs von Anna H (1916/17), 2008.

Pyta, Wolfgang, Hindenburg - Herrschaft zwischen Hohenzollern und Hitler, Hamburg 2007.

Rabl, Erich/Stadtarchiv Horn, Nagelfiguren in Horn und Umgebung, Horn Schreiben vom 16. November 2004.

Raulff, Ulrich (Hrsg.), Mentalitäten-Geschichte. Zur historischen Rekonstruktion geistiger Prozesse, Berlin 1987.

Rauscher, Heinz, Das Volksschulwesen in Backnang 1880-1952 (2.Teil), in: Backnanger Jahrbuch, 2003, S. 106ff.

Redersborg, Eckart, Nagelung von sogenannten Kriegswahrzeichen im Ersten Weltkrieg, Informationen des Heimatvereins, Grevesmühlen 1996, S. 14-16.

Redersborg, Eckart, Nagelung von sogenannten Kriegswahrzeichen im Ersten Weltkrieg (Teil 2), 1996, S. 26-28.

Regulski, Christoph, Bibliographie zum Ersten Weltkrieg, Marburg 2005.

Reimann, Aribert, Der große Krieg der Sprachen, Schriften der Bibliothek für Zeitgeschichte, Essen 2000.

Reimann, Aribert, Der Erste Weltkrieg - Urkatastrophe oder Katalysator, Das Parlament (Beilage 'Aus Politik und Zeitgeschichte'), 2004.

Röder, Kerstin Bedeutung und Möglichkeiten von Rollenspielen im Geschichtsunterricht der Grundschule und der Orientierungsstufe, Oldenburger Vor-Drucke, Nr. Oldenburg 1997.

Roerkohl, Anne, Der Erste Weltkrieg in Westfalen, Westfalen im Bild, Reihe: Westfälische Wirtschafts- und Sozialgeschichte, 1987.

Roerkohl, Anne, Hungerblockade und Heimatfront. Die kommunale Lebensmittelversorgung in Westfalen während des Ersten Weltkrieges, Studien zur Geschichte des Alltags, Nr. 10, Stuttgart 1991.

Roerkohl, Anne, Schlachtfeld Heimat in: Schlanstein Beate/Wolter, Gudrun/Karwath, Gerolf (Hrsg.), Der Erste Weltkrieg, Berlin 2004.

Roseland, B., Aus meiner Schulzeit!, Heimatkalender für den Landkreis Verden, 1980.

Rößler, Thomas, "Als der Krieg über uns gekommen war ..." Saarbrücken 1993.

Rotes Kreuz (Hrsg.), Kriegs-Chronik des Württembergischen Landesvereins vom Roten Kreuz, Heilbronn 1921.

Rotes Kreuz (Hrsg.), Das Rote Kreuz in Mannheim 1914-1918 und in der Nachkriegszeit, Mannheim 1934.

Rother, Rainer, Der Weltkrieg 1914-1918. Ereignis und Erinnerung [Ausstellung im Deutschen Historischen Museum, Berlin 13. Mai bis 16. August 2004], Berlin 2004.

Rürup, Ingeborg, 'Es entspricht nicht dem Geist der Zeit, daß die Jugend müßig gehe.' Kriegsbegeisterung, Schulalltag und Bürokratie in den höheren Lehranstalten Preußens, in: Bönisch, Monika/ Bussemer, Herrad-Ulrike (Hrsg.), August 1914, Berlin 1989.

Rürup, Reinhard, Der 'Geist' von 1914 in Deutschland. Kriegsbegeisterung und Ideologisierung des Kriegs im Ersten Weltkrieg, in: Hüppauf, Bernd (Hrsg.), Ansichten vom Krieg, Forum Academicum (Hochschulschriften Literaturwissenschaft), Köln, Wien u. a. 1984.

Rumpf, Fritz, Nagelung, Heimatschutz in Brandenburg, 1917, S. 76-81.

Sabellek, Reiner (Hrsg.), Hannovers Übergang vom Königreich zur preußischen Provinz 1866, Hannover 1995. 
Sauer, Michael, Die Entwicklung des höheren Schulwesens in Hannover vom 19. Jahrhundert bis nach dem 2. Weltkrieg. Sonderdruck in Stadtarchiv Hannover (Hrsg.), Hannoversche Geschichtsblätter, Nr. 43, Hannover 1989.

Sauer, Michael, Vom "Schulehalten" zum Unterricht. Preußische Volksschule im 19. Jahrhundert (1998), Böhlau und Köln 1998.

Sauer, Michael (Hrsg.), Plakate, Geschichte lernen, Heft 114, Velber 2006.

Sauer, Michael, Auffällig, verbreitet und meinungsmachend. Plakate als Quelle im Geschichtsunterricht, in: Sauer Michael (Hrsg.), Plakate, Geschichte Lernen,, Heft 114, Velber 2006, S. 2-11.

Sauermann, Eberhard, Literarische Kriegsfürsorge. Österreichische Dichter und Publizisten im Ersten Weltkrieg, Literaturgeschichte, in: Studien und Quellen, Nr. 4, Böhlau und, Wien 2000.

Saul, Klaus, Jugend im Schatten des Krieges. Vormilitärische Ausbildung - Kriegswirtschaftlicher Einsatz - Schulalltag in Deutschland 1914-1918, in: Hackl, Othmar/ Messerschmidt Manfred (Hrsg.), Militärgeschichtliche Mitteilungen, Nr. 34, 1983, S. 91-185.

Sauvage, Anne-Marie/Renz, Irina, Der Krieg der Plakate, in: Didier, Christophe/Hirschfeld, Gerhard (Hrsg.), In Papiergewittern, Straßburg 2008.

Schellack, Fritz, Sedan- und Kaisergeburtstagsfeste, in Düding, Dieter (Hrsg.), Öffentliche Festkultur, Rowohlts Enzyklopädie Nr. 462, Reinbek bei Hamburg 1988.

Schellack, Fritz, Nationalfeiertage in Deutschland von 1871 bis 1945, Europäische Hochschulschriften-Reihe 3, Frankfurt am Main 1990.

Schlanstein Beate/Wolter, Gudrun/Karwath, Gerolf(Hrsg.), Der Erste Weltkrieg. Das Buch zur ARDFernsehserie, Berlin 2004.

Schmid, Hans-Dieter, Einführung: Feste und Feiern als Gegenstand der Kulturgeschichte in Schmid, Hans-Dieter (Hrsg.), Feste und Feiern in Hannover, in: Hannoversche Schriften zur Regional- und Lokalgeschichte, Nr. 10, Bielefeld 1995.

Schmid, Hans-Dieter, Reformations- und Lutherfeiern in Hannover 1617-1883, in: Schmid, HansDieter (Hrsg.), Feste und Feiern in Hannover, Hannoversche Schriften zur Regional- und Lokalgeschichte, Bielefeld 1995.

Schneider, Dorit (Landeshauptarchiv Schwerin), Nagelung eines Kreuzes in Schwerin, Schwerin, Schreiben vom 18. Februar 2008.

Schneider, Gerhard, Über hannoversche Nagelfiguren im Ersten Weltkrieg, in: Landeshauptstadt Hannover (Hrsg.), Hannoversche Geschichtsblätter, Bd. 50, Hannover, S. 207-258.

Schneider, Gerhard, Der Geschichtsunterricht in der Ära Wilhelms II. vornehmlich in Preußen, in: Bergmann, Klaus/Schneider, Gerhard (Hrsg.), Gesellschaft - Staat - Geschichtsunterricht, Düsseldorf 1982.

Schneider, Gerhard, "... nicht umsonst gefallen"? Kriegerdenkmäler und Kriegstotenkult in Hannover, Hannoversche Geschichtsblätter; N. F., Sonderband, Hannover 1991.

Schneider, Gerhard, "Patriotische Schulfeste" und Schulunterricht im Kaiserreich, vorwiegend in Preußen (1871-1914), in: Pandel, Hans-Jürgen (Hrsg.), Verstehen und Verständigen, Pfaffenweiler 1991, S. 165-195.

Schneider, Gerhard, Die Märzfeiern der hannoverschen Arbeiterbewegung, in: Schmid, Hans-Dieter (Hrsg.), Feste und Feiern in Hannover, Hannoversche Schriften zur Regional- und Lokalgeschichte, Bielefeld 1995, S. 125-146.

Schneider, Gerhard, Herrschergeburtstagsfeiern in der preußischen Provinz 1867-1971, in: Sabellek, Reiner (Hrsg.), Hannovers Übergang vom Königreich zur preußischen Provinz 1866, Hannover 1995.

Schneider, Gerhard, Politische Feste der Arbeiter, Hannoversche Studien, Nr. 3 (1995), Hannover 1995.

Schneider, Gerhard, Nagelung von sogenannten Kriegswahrzeichen im Ersten Weltkrieg (Teil 1), in: Heimatverein 1996, S. 15-17.

Schneider, Gerhard, Ein Photofund und über die Arbeit der "Freiwilligen Kriegshilfe Hannover und Linden" im Ersten Weltkrieg, Hannoversche Geschichtsblätter, Nr. 53, Hannover 1999, S. 201-213. 
Schneider, Gerhard, Serbien muß sterben! Kriegspropaganda auf Postkarten des Ersten Weltkriegs; [Begleitheft zur Ausstellung 3. August bis 28. September 1999], Kleine Schriften des Stadtarchivs Hannover, 1999, Hannover 1999.

Schneider, Gerhard, Zur Mobilisierung der Heimatfront, Zeitschrift für Volkskunde, 1999, S. 32-64.

Schneider, Gerhard, Über politische Feste der Bürger in Hannover (1866-1918), in: Historische Kommission für Niedersachsen und Bremen (Hrsg.), Niedersächsisches Jahrbuch für Landesgeschichte, Band 72, Hannover 2000.

Schneider, Gerhard, Nagelungen in Niedersachsen im Ersten Weltkrieg, in: Niedersächsisches Jahrbuch für Landesgeschichte, Nr. 76, 2004, 245-284.

Schneider, Gerhard, "Der schöne Gedanke ins Groteske verkehrt"? Die kultisch-rituelle Funktion des Nagelns sog. Porträtstatuen im Ersten Weltkrieg, in: Korff, Gottfried (Hrsg.), Alliierte im Himmel, Untersuchungen des Ludwig-Uhland-Instituts der Universität Tübingen (2006), Tübinger Vereinigung für Volkskunde, Tübingen 2006, S. 311-346.

Schneider, Gerhard, Der Erste Weltkrieg als erster industrialisierter Krieg, Schwalbach/Ts 2000.

Schneider, Gerhard, Wie der Krieg in die Heimat kam, in: Ulrich, Volker (Hrsg.), Erster Weltkrieg, Praxis Geschichte, Heft 3, 1995, S. 10-15.

Schneider, Gerhard, Das Vaterländische Museum Hannover im Ersten Weltkrieg, in: Historisches Museum Hannover (Hrsg.), Deutungen, Bedeutungen - Beiträge zu Hannovers Stadt- und Landesgeschichte, Hannover 2010, S. 124-173.

Schneider, Jörg, Der Krieg an der Heimatfront; Reutlingen 1914-1918. Eine lokalgeschichtliche Studie mit Überlegungen zur Fachdidaktik, 1998.

Schnyder, Caroline, Reformation, UTB Profile, Nr. 3022, Stuttgart 2008.

Schöllkopf, Chr., Vom "Helfensteiner Ritter" im Heimatmuseum, in: Geschichtliche Mitteilungen von Geislingen und Umgebung, 1933, S. 52f.

Schröder, Helge, "Spare Seife". Propagandaplakate für die deutsche "Heimatfront" 1915-1918, in:

Schröder, Helge, "Spare Seife!", Geschichte Lernen, 2006, S. 16-21.

Schroeder, Ulrich, Funktion und Gestalt des patriotischen Schulfestspiels in der Wilhelminischen Kaiserzeit (1871-1914), 1990.

Schröer, Gustav, Der Held daheim, in: Schröer, Gustav (Hrsg.), Die Kriegsanleihe der Jungen von Erbesbach und andere Erzählungen aus dem Weltkrieg, Schaffsteins blaue Bändchen, Cöln am Rhein o. J.

Schubert-Weller, Christoph, Vormilitärische Jugenderziehung, in: Berg, Christa (Hrsg.), Handbuch der deutschen Bildungsgeschichte München 1991.

Schubert-Weller, Christoph, „Kein schönrer Tod...“, Die Militarisierung der männlichen Jugend und ihr Einsatz im Ersten Weltkrieg 1890-1918, Weinheim und München 1998.

Schulze, Winfried, Sozialgeschichte, Alltagsgeschichte, Mikro-Historie. Eine Diskussion, Kleine Vandenhoeck-Reihe, Nr. 1569, Göttingen 1994.

Schütt, Hans Heinz, Vom "Stierkopfwappen" zum "Koggenwappen". Die Wappen der Hansestadt Wismar, in: Mecklenburgische Jahrbücher, in Schwerin 1999, S. 361-371.

Schütze, Karl R., Der eiserne Hindenburg, Berlin 2007.

Schwarte, Max, Der Weltkrieg in seiner Einwirkung auf das Deutsche Volk, Leipzig 1918.

Schwarzwälder, Herbert, Geschichte der Freien Hansestadt Bremen, Hamburg 1987.

Seeger, Christine, Die Sedanfeiern in Hannover. Integration oder Ausgrenzung im Kaiserreich, Hannoversche Geschichtsblätter, Hannover 1992, S. 212-148.

Seeger, Christine, Hannoversche Maifeiern und Gewerkschaftsfeste als Stimmungsbarometer im Kaiserreich, in: Schmid, Hans-Dieter (Hrsg.), Feste und Feiern in Hannover, Hannoversche Schriften zur Regional- und Lokalgeschichte, Bielefeld 1995, S. 212-248.

Sicken, Bernhard, Die Festungs- und Garnisonstadt Wesel im Ersten Weltkrieg. Kriegsauswirkungen und Versorgungsprobleme, in: Kirchgässer, Bernhard/Scholz, Günther (Hrsg.), Stadt und Krieg (1989), Sigmaringen 1989. 
Sinne, Heinz/Motz, Johannes, Solingen im 1. Weltkrieg. Dokumentation, Schriftenreihe des Bergischen Geschichtsvereins, Solingen 1981.

Skalweit, August, Die deutsche Kriegsernährungswirtschaft. Wirtschafts- und Sozialgeschichte des Weltkriegs, Deutsche Serie, Stuttgart u.a. 1927.

Sölle, Dorothea, Heimatfront - wir überlebten. Frauen berichten, 1985.

Sommer, Michael, Heilbronn im 1. Weltkrieg. Eine fachwissenschaftliche Untersuchung zur 'Heimatfront'; 1914-1918 und didaktisch-methodische Überlegungen zu deren Behandlung im Unterricht, 1998.

Spindler, Max, Handbuch der bayrischen Geschichte. Das neue Bayern 1800-1970, 1. Teilband, München 1979.

Spittler, Botho, Das höhere Schulwesen in der "polnischen Ecke" Westpreußens im Spannungsfeld der Nationalitätenpolitik, Veröffentlichungen der Forschungsstelle Ostmitteleuropa an der Universität Dortmund-Reihe A, Nr. 45, Dortmund 1986.

Spuren des 1. Weltkriegs im Landkreis Lüchow-Dannenberg, Schriften des Museums Wustrow, Wustrow 1986.

Stahr, Henrik, Liebesgaben für den Ernstfall. Das Rote Kreuz in Deutschland zu Beginn des Ersten Weltkrieg, in: Bönisch, Monika / Bussemer, Herrad-Ulrike (Hrsg.), August 1914, Berliner Geschichtswerkstatt, Berlin 1989.

Stephan, Inge/Winter, Hans-Gerd (Hrsg.), "Heil über dir, Hammonia", Hamburg 1992.

Stöber, Rudolf, Die erfolgverführte Nation. Deutschlands öffentliche Stimmungen 1866 bis 1945, Stuttgart 1998.

Strahl, Antje, Rostock im Ersten Weltkrieg. Bildung Kultur und Alltag in einer Seestadt zwischen 1914 und 1918, Kleine Stadtgeschichte, Berlin und Münster 2007.

Sturm, J., Buntes Kaleidoskop. Aus dem Leben eines Volksschullehrers, Regensburg 1968.

Tausche, Gerhard, Landshuter Stadtchronik. 1909-1918, Band II, Landshut 1989.

Thalmann, Heinrich, Die Pfalz im Ersten Weltkrieg. Der ehemalige bayerische Regierungskreis bis zur Besetzung Anfang Dezember 1918, Beiträge zur pfälzischen Geschichte, Nr. 2, Kaiserslautern 1990.

Theile, Alfred, Zur Geschichte des Lyzeums I mit Oberlyzeum zu Kiel (1911-1936), in: Festschrift zur 75-Jahrfeier des Oberlyzeums I mit Reform-Gymnasialer Studienanstalt zu Kiel, Kiel 1936.

Theurerer, W./Archivamtmann, Stadt Archiv Bamberg, Kriegswahrzeichen (27.10.2004), Bamberg

Thier, Dietrich, Das Kriegswahrzeichen von Wetter (Ruhr): die Nagelspende, das Eiserne Schwert, Schriftenreihe der Friedrich-Harkort-Gesellschaft Wetter (Ruhr) und des Stadtarchivs Wetter (Ruhr), S. 212-227.

Tilemann, Heinrich, Geschichte und Geschichtsunterricht. Vortrag, gehalten am 22. März 1922 in der Vereinigung der Freunde des humanistischen Gymnasiums zu Oldenburg, Oldenburg 1922.

Timm, Willy, Unnaer benagelten Krupp-Granate, Heimatbuch Kreis Unna, Unna 1992, S. 86-89.

Titze, Hartmut, Lehrerbildung und Professionalisierung, in Berg, Christa (Hrsg.), Handbuch der deutschen Bildungsgeschichte, München 1991.

Überegger, Oswald, Leben im Krieg. Die Tiroler Heimatfront im Ersten Weltkrieg, Bozen 2004.

Überegger, Oswald, Heimatfronten. Dokumente zur Erfahrungsgeschichte der Tiroler Kriegsgesellschaft im Ersten Weltkrieg, Tirol im Ersten Weltkrieg, Innsbruck 2006.

Uhle, $P$., Chemnitz in großer und schwerer Zeit. 1914-1919 Chemnitz 1919.

Ulbricht, Otto, Mikrogeschichte: Versuch einer Vorstellung, in: Geschichte in Wissenschaft und Unterricht, 1994, S. 347-367.

Ullmann, Hans-Peter, Kriegswirtschaft, in: Hirschfeld, Gerhard u. a. (Hrsg.), Enzyklopädie Erster Weltkrieg, Paderborn 2004, S. 220-232.

Ullrich, Volker, Kriegsalltag. Hamburg im 1. Weltkrieg (1982), Köln 1982.

Ulrich, Volker, Heimatfront und Schützengraben, in: Wollschläger, Antonius (Hrsg.) ,Praxis Geschichte, Heft 3, 1995, 4-9. 
van Laak, Dirk, Alltagsgeschichte, in: Maurer, Michael (Hrsg.), Neue Themen und Methoden der Geschichtswissenschaft, Reclam Universalbibliothek, Leipzig 2003.

Vechtel, Christian, Nagelungen. Die fast vergessenen Kriegswahrzeichen, in: Zühlke, Raoul (Hrsg.), Bildpropaganda im Ersten Weltkrieg, Hamburg 2000.

Vogel, Jakob, Militärfeiern in Deutschland und Frankreich als Rituale der Nation (1871-1914), in: François, Etienne /Siegrist, Hannes/Vogel, Jakob (Hrsg.), Nation und Emotion, Kritische Studien zur Geschichtswissenschaft, Göttingen 1995, S. 199-215.

Vogel, Jakob, Nationen im Gleichschritt. Der Kult der Nation in Waffen; in Deutschland und Frankreich, 1871-1914, Göttingen 1997.

Vogeler, Adolf, Kriegschronik der Stadt Hildesheim, Hildesheim und Leipzig 1929.

Vondung, Klaus (Hrsg.), Kriegserlebnis. Der 1. Weltkrieg in der. literarischen. Gestaltung und symbolischen. Deutung der Nationen, Göttingen 1980.

Wacker, Armin, Der Erste Weltkrieg an der "Heimatfront". Heidelberg 1914-1918. Eine lokalgeschichtliche Untersuchung mit Überlegungen zur Fachdidaktik und Unterrichtspraxis, 2000.

Wegener, Heinz Friedrich Ernst, Das Joachimsthalsche Gymnasium - die Landesschule Templin. Ein Berlin-Brandenburgisches Gymnasium im Mahlstrom der deutschen Geschichte 1607-2007, Berlin 2007.

Wehler, Hans-Ulrich, Das Deutsche Kaiserreich. 1871-1918, Kleine Vandenhoeck-Reihe, Nr. 1380, Göttingen 1973.

Wehrmann, Volker, Die Schule in Lippe. Von 1800-1945in Bildern, Dokumenten und grafischen Darstellungen, Detmold 1991.

Schubert-Weller, Christoph, "Kein schönrer Tod ...". Die Militarisierung der männlichen Jugend und ihr Einsatz im Ersten Weltkrieg 1890-1918, Materialien zur historischen Jugendforschung, Weinheim 1998.

Weichardt, Jürgen, Von der Lateinschule zum Alten Gymnasium Oldenburg. 1573-1973, Oldenburgische Monographien, Oldenburg 1993.

Weimar, Wolfgang, Geschichte des Gymnasiums in Schleswig-Holstein, Rendsburg 1987.

Weise, Niels, Der "lustige" Krieg, Historische Studien der Universität Würzburg; Nr. 3, Rahden/Westfalen 2004.

Wien, Ulrich Andreas, Friedrich Müllers pädagogische und publizistische Anfänge, in: Zeitschrift für Siebenbürger Landeskunde, Heft 1, 1998, S. 38-59.

Wiesmann, Gerd, Die geistige Mobilisierung der Heimatfront' im Ersten Weltkrieg in der Stadt Emmendingen. Lokalgeschichtliche Befunde und Überlegungen zur Unterrichtspraxis, 1997.

Wildhagen, Harald, "Laß dich gelüsten nach der Männer Bildung ...". Mädchenbildung in Preußen; die Marie-Curie-Oberschule in Berlin-Wilmersdorf als Beispiel für die Geschichte einer höheren Mädchenschule in einem bürgerlichen Wohnbezirk, Berlin 1994.

Winter, Jay/Parker, Geoffrey/Habeck, Mary R., (Hrsg.), Der Erste Weltkrieg und das 20. Jahrhundert, Hamburg 2002.

Winter, Jay/Robert, Jean-Louis (Hrsg.), Capital Cities at War: Paris, London, Berlin 1914-1919, Cambridge 2007.

Wolfgruber, Renate, Die sogenannte Heimatfront. Eine Ergänzung zur Darstellung des Ersten Weltkrieges im Geschichtsunterricht, in: Zeitgeschichte, Nr. 4, 1977, S. 346-358.

Wulf, Rüdiger, Hurra, heut ist ein froher Tag, des Kaisers Wiegenfest! Schulfeiern zum Kaisersgeburtstag und zum Sedantag unter Wilhelm II., in: Löher,Jochen/Wulf, Rüdiger (Hrsg.), Furchtbar dräute der Erbfeind!, Schriftenreihe des Westfälischen Schulmuseums, Dortmund

Zeidler, Manfred, Die deutsche Kriegsfinanzierung 1914 bis 1918 und ihre Folgen, in: Michalka, Wolfgang (Hrsg.), Der Erste Weltkrieg, München und Zürich 1994, S. 415-433.

Ziemann, Benjamin, Front und Heimat. Ländliche Kriegserfahrungen im südlichen Bayern 1914-1923, Veröffentlichungen des Instituts zur Erforschung der Europäischen Arbeiterbewegung. Schriftenreihe A, Darstellungen, Nr. 8, Essen 1987.

Ziemann, Benjamin War experiences in rural Germany 1914-1923, Oxford 2007. 
Ziessow, Karl-Heinz, Der Erste Weltkrieg. Materialien \& Studien zur Alltagsgeschichte und Volkskultur Niedersachsens, hrsg. im Auftrag der Stiftung Museumsdorf Cloppenburg, Cloppenburg 2009.

Zühlke, Raoul (Hrsg.), Bildpropaganda im Ersten Weltkrieg, Hamburg 2000.

Zwach, Eva, Deutsche und englische Militärmuseen im 20. Jahrhundert. Eine kulturgeschichtliche Analyse des gesellschaftlichen Umgangs mit Krieg, Museen - Geschichte und Gegenwart, Nr. 4, Münster 1999.

\section{Online verfügbare Dokumente}

1. Weltkrieg http://www.schule-hausbruch.de/?Wir:Chronik:1. Weltkrieg (20.03.2008).

12000 Jahre Niederrhein - 800 Jahre Kleve, http://www.heimat-kleve.de/geschichte/chronik/15.htm (17.09.2009).

1914-1918 - Der erste Weltkrieg und was unsere Schulchronik dazu sagt,

http://www.du.nw.schule.de/grimm/grimmold3.htm (21.07.2008).

75 Jahre Knaben-Mittelschule Augustplatz/ Realschule John.F.-Kennedy-Platz in Braunschweig, http://www.nibis.de/ rskennedyplatz/schulgeschichte/schulgeschichte.html (19.07.2008).

Adler, Horst, Chronologischer Abriß der Stadt Schweidnitz von 1243 bis 1918, http://www.horstadler.de/Schweidnitz 1243-1918.pdf (08.07.2008).

Andresen, Knud, Gab es in Eckernförde eine Kriegsbegeisterung? http://www.beirat-fuergeschichte.de/fileadmin/pdf/band 17/Demokratische Geschichte Band 17_Essay_2.pdf (14.09.2009.).

Arntz, Hans-Dieter, Chronik des Gymnasiums Marienschule Euskirchen, http://www.hans-dieterarntz.de/100_jahre_marienschule.html (15.12.2008).

Asmuth, Heike, Frauen im Widerstand, http://www.gedenkstaette-moringen.de/geschichte/frauen/ pol_wid/pol_wid.html (17.08.2008).

Audoin-Rouzeau, Stéphane, Die mobilisierten Kinder: Die Erziehung zum Krieg an französischen Schule, http://www.erster-weltkrieg.clio-online.de/_Rainbow/documents/ keiner\%20f\%C3\%BChlt \%20sich\%202/audoin-rouzeau.pdf (18.01.2009).

Aus der "Schul-, Dorf- und Kirchenchronik" St. Willibrord Wardt, http://www.xanten-web.de/ Domstadt/ WardtChro5.html (03.04.2008).

Aus der Geschichte der Antoniusschule, http://www.antoniusschule.homepage.t-online.de/chronik.htm (25.04.2008).

Auszüge aus der Überherrner Schulchronik, http://www.erweiterte-realschule-ueberherrn.de/ chronik.htm (25.04.2008).

Auszüge aus Schulchronik und Schultagebüchern der Evang. Volksschule zu Daufenbach, http://www.duerrholz.com/arbeitsgruppen/Chronik/Chronikseite43bis56.pdf (04.04.2008).

Barmer Nagelung, http://www.eugen-langen-schule.de/1_weltkrieg.htm (14.11.2007).

Bösch, Frank, Das Zeremoniell der Kaisergeburtstage http://www.ruhr-uni-bochum.de/iga/isb/isbhauptframe/forschung/Tagung\%20Kaiserreich/B\%F6sch.pdf (21.01.2010).

Boldt, M., Borsflether Kirchenschätze, http://www.borsflether-zeitung.de/web\%2044.htm.

Böse, Günther, Das Staatliche Gymnasium, http://www.litzigerlay.de/traben trarbach/k21k25/k21.htm (01.03.2010).

Brandt, Rainer, Die Weltkriege und die Zeit dazwischen, http://www.kkbz.de/augusten/weltkriege.htm (25.03.2009).

Bremens Geschichte http://www2.bremen.de/info/history/WK1.html, (07.04.2008).

Brenner, Die Oberrealschule zu Bad Oldesloe während des Weltkrieges (1914 bis 1918), http://de.tmsod.de/ (15.07.2007),

Buchinger, Franz, Auszug aus der Schulchronik der Volksschule Altenburg, http://schulen.asnnoe.ac.at/vsaltenburg/Chronik\%20Teil\%208.rtf. (14. 01.2008). 
Buchkremer, Richard, Chronik der "Schule Hülhoven", http://www.unserortsring.de/pdf/schulchronik.pdf (25.03.2009).

Burmester, Helmut/Rühle, Klaus, Die Kaiserzeit (1887-1918), http://www.emil-nolde-schule.de/ altschul/inhalt.htm $(9.10 .2009)$.

Buschmann, Nikolaus, Der verschwiegene Krieg, http://www.erster-weltkrieg.clio-online.de/ Rainbow/ documents/Kriegserfahrungen/buschmann.pdf (11.12.2009).

Chronik der Schule Marienberg nach den vorhandenen Unterlagen, http://www.erzbistumkoeln.de/export/sites/erzbistum/schule/marienberg/_galerien/download/Chronik_der_Schule_Marienb erg_nach den_vorhandenen_Unterlagen.pdf (13.11.2007).

Chronik der Stadt Kyllburg 800-2000, http://www.mueller-kyllburg.de/weltkrieg_eins/ kriegsanleihen.html (10.09.2008).

Das Dorf Elze während des Kriegs 1914-18, http://www.wedemark.de/dorfelze/schulchronik1.htm (06.04.2008).

Der Erste Weltkrieg in Oberösterreich,

http://www.ooegeschichte.at/Erster_Weltkrieg_in_Oberoesterreich.1326.0.html (21.11.2009).

Die ersten 50 Jahre der "Sophie", http://www.sophienschule.de/impressum/pdf-version/schrift_131242.pdf (15.07.2008).

Die Geschichte der Städtischen Realschule Nortorf. http://www.realschule-nortorf.lernnetz.de/ geschi_3.php?group=4 (17.06.2008).

Die jüdischen Schülerinnen der ehemaligen Höheren Töchterschule, heute Elisabethschule (1878 bis 1938), http://www.elisabethschule.de/schueler/schuelerzeitung/experiment_sonder.html (15.07.2008).

Dohm, Winfried, Aus der Chronik der alten Brücker Volksschule, http://www.koeln-brueck.de/ geschich/alteschu.htm (22.04.2008).

Dohse, Rainer, Nagelbretter im Johann-Heinrich-Voß-Gymnasium Eutin, http://www.vossschule.de/wir/nagelbretter/index.htm (01.06.2009).

Dorn, Ernst, Sammelt Obstkerne zur Ölgewinnung, http://www.lwl.org/westfaelische-geschichte/ portal/Internet/ (21.03.2008).

Ebert, Hans, 75 Jahre Menzel-Oberschule (1902-1977),

http://www.schule.de/schulen/menzel/allg/hist_ebert/ebert_3.html (29.01.2009).

Eckert, Reinhard, Gemeinde- und Schulchronik von Lowkowitz, http://www.schloss-ellguth.de/ lowkowitz2.htm (05.04.2008).

Eugen-Lange-Schule, http://www.eugen-langen-schule.de/1_weltkrieg.htm (01.09.2008).

Evertz, Marlies, Oberweis im Wandel der Geschichte, http://www.oberweis.de/historie.html (06.04.2008).

Feges Sebastian/Weber, Lukas/Weirauch, Lukas (Nikolaus-von-Weis-Gymnasium), Belagerungswappen Speyer, http://www.1000xheimat.de/index.php?id=11\&detail=1285 (20.02.2008).

Fischer-Feldsee, W., 100 Jahre Geschwister-Scholl-Gymnasium Velbert, www.gsgvelbert.de/joomla/media/flyer_festschrift.pdf (18.07.2008).

Friedel, Johannes, Chronik der Martinschule, www.cappelpower.de/martinschule /geschichte/ geschichte/_oo1.htm $(03.10 .2008)$.

Friesack, http://www.awo-friesack.de/ge/ge3.html. (28.09.2010)

Fuckner, Franziskus, Gemeinde- und Schulchronik von Lobkowitz, http://www.schlossellguth.de/lowkowitz2.htm (19.06.2008).

Gemeinde Rondeshagen, Pächter und Verwalter auf Gut Rondeshagen \& Bauernvögte des Dorfes

Rondeshagen, http://www.rondeshagen.com/Verwalter_Paechter.html (08.04.2008).

Geschichtswerkstatt, Spuren jüdischen Lebens in Düren, http://www.geschichtswerkstatt-dueren.de/ (04.12.2008).

Grützbach, Irmgard/Meinhof, Thomas, Die Geschichte der Kirche in Gadegast,

http://www.seyda.de/Nachbarn\&Partner/Gadegast/Geschichte.htm (03.09.2008).

Hamester, Dietrich, Emil Duborg, http://www.fwk-f.de/emilduborg.htm (14.12.2008). 
Harling, Sabine, Schulen in der Bonner Nordstadt: Nordschule - Marienschule - Karlschule, http://www.bonner-geschichtswerkstatt.de/schule.html (18.11.2008).

Hartwig, Klaus und Gabi, Chronik der Schule zu Hammoor, http://www.fincaverde.net/uns_doerp_2.htm (13.12.2008).

Heimatmuseum Münchingen, "Sonst geht es mit gut" - Korntal und Münchingen im Ersten Weltkrieg, http://www.korntal-muenchingen.de/kultur_veranst/heimatmuseum.htm. (07.10.2007).

Heimatverein Wehrstedt e.V., Die Dorfchronik, http://www.heimatverein-wehrstedt.de/drei. html\#titelanker15 (03.04.2008).

Heinken, Ilse, Das Schulsystem im Kaiserreich, http://docserver.bis.uni-oldenburg.de/_publikationen/ bisverlag/2000/blowir00/pdf/heinken.pdf (27.02.2009).

Hemme, Otto, Das Dorf Elze während des Krieges 1914-1918, http://www.dorf-elze.de/ schulchronik1.htm $(15.12 .2008)$.

Heneke, Cornelia, Chronik der Giesensdorfer Grundschule, http://www.giesensdorfer-grundschule.de/ schulchronik/chronik.html (18.12.2009).

Hoghe, Raimund, Ein Kinde erlebt den Krieg, http://www.zeit.de/1982/25/Ein-Kind-erlebt-den-Krieg (11.07.2008).

Honikel, Karl, "Die Begeisterung für den Krieg war groß", http://www.hersfelder-zeitung.de/ netcontentmedia/office/http.www.hersfelder-zeitung.de/heimatland/43/7htm.pdf (21.03.2008).

Hube, Gerhard, Chronik Zaasch, http://www.zaasch.de/pdf/Chronik Zaasch.pdf (14.11.2008).

Huber, Franz, Gedenkbuch der Gemeinde Irritz, http://www.europas-mitte.de/Heimatbuch irritz.htm\#DER\%20ERSTE\%20WELTKRIEG (21.03.2008).

Immanuel-Kant-Schule Rüsselsheim, http://www.iks-ruesselsheim.de/44.html (02.10.2007).

Jaensch, Karl, Boostedt und der Erste Weltkrieg, http://www.forgottenplaces.de/boostedt03g.htm (16.11.2004).

Jahres-Bericht über das Realgymnasium und die Realschule zu Iserlohn (Reformanstalt nach dem Frankfurter System), für die Zeit von Ostern 1914 bis Ostern 1915, http://www.lbz-rlp.de/ Schulprogramme/schulprogramm_iserlohn_1914.pdf (4.01.2011).

Jensch, Hugo, Pirna im Ersten Weltkrieg, http://www.geschichte-pirna.de/Pirna\%20im \%201.\% 20Weltkrieg.pdf (22.01.2010).

Johann, Traugott / Tchech, Friedrich / Schicha, Gottlieb / Zwikirsch, Josef / Matzel, Gerhard / Rosemann, Erich, Schulchronik der Schule zu Mittel-Podiebrad, http://petertscherny.pe. funpic.de /strehlen/podiebrad/chronp.pdf. (19.09.2009).

Kammelar, Roob, Spijkeren voor het vaderland, http://www.wereldoorlog1418.nl/spijkeren/index.html (14.09.2009).

Kamp, Willi, Chronik der katholischen Schule Bergneustadt

,http://www.gm.nw.schule.de/ kgsb/links/Chronik\%20der\%20katholischen\%20Schule\%20Bergneusta dt.pdf (15.12.2008).

Kiendl, Gerald, Nessis Tagebuch aus dem Ersten Weltkrieg, http://www.zenker.se/History/nessi_tagebuch.shtml (01.12.2009).

Kracht, Peter, Nageln gegen Hunger und Krieg, http://www.werner-linie.de/G_Nagelbild.pdf (14.09.2009).

Kremer, Armin / Rieß, Falk, Mobilmachung im Umterricht. Die Instrumentaliserung der Physikpädagogik für Nation und Krieg im Kaiserreich, http://wanderforschung.de/files/ kaiserreich1267643749.pdf (5.01.2011).

Kriegswahrzeichen der Stadt Speyer, http://www.museum.speyer.de/sammlungen/neuzeit/sammlungen neuzeit kriegszeichen (12.09.2009).

Kuleßa, J., Mittelschule "Johann Heinrich Pestalozzi" in Pirna, http://www.mspesta.com/page63.html (15.07.2008). 
Landesarchivverwaltung Rheinland-Pfalz, Vor 85 Jahren,

http://www.landeshauptarchiv.de/blick/archiv.html?31.10.2 (08.07.2008).

Landzettel, Ute, Der Schriftsteller Wolfgang Weyrauch (1904-1980), http://deposit.ddb.de/cgi-bin/ dokserv?idn=973877707 \&dok_var=d1\&dok_ext= pdf\&filename=973877707.pdf $(15.07 .2008)$.

Leitsätze zur Aufklärung über Volksernährungsfragen im Ersten Weltkrieg für den Regierungsbezirk Arnsberg, http://www.lwl.org/westfaelische-geschichte/portal/Internet/finde/einfache_suche/ recherche go.php (05.02.1010).

Rother, Rainer, Sammelt Obstkerne, http://www.dradio.de/dlr/sendungen/wk1/287779/ (20.03.2008).

Lersch, Heinrich, Weihnachten im Schützengraben, http://www.uibk.ac.at/brenner-archiv/editionen/ ged_wk1/links/lersch_gr6.html (14.11.2008).

„Lieber Herr Pastor!“", http://www.beepworld.de/members3/seydaaktuell/heimatstube.htm (15.07.2008).

Matthaei, Rolf-Fredrik, Kaufkraftumrechner, http://fredriks.de/HVV/kaufkraft.htm (21.02.2008).

Mehlis, E., Festschrift zur 50-Jahr-Feier der Stormarnschule Ahrensburg im Mai 1977.

http://stormarnschule.lernnetz.de/archiv/buch1977/mehlis.htm (14.02.2008).

Meinhard, Günther, Atzenhausen bis 1933, http://www.dr-ulonska.homepage.t-online.de/html/ body_atzenhausen_bis_1933.html (16.12.2008).

Müller, Werner, Schulgeschichte von 1821 bis 1959, http://hgt.bildung-rp.de/seiten/chronik1.htm (24. September 2009).

Müller, Wolfgang, Die Chronik der Schule zu Grunewald, http://www.mueller-nuembrecht.de/chronik/ chronik1.htm (02.03.2009).

Nägel für Kriegsopfer, http://www.zeitung.org/onetz/760742-118,1,0.html (09.02.2008).

Nageln für einen sozialen Zweck (1915).

http://www.goeppingen.de/servlet/PB/menu/1101628_pcontent_11/navigate1195566625218.html (18.01.2008).

Nagelungen, Oberschlesien - Zeitung für die Oberschlesier in Ost und West, http://www.oberschlesien-aktuell.de/presse/presse/oberschlesien/051013.pdf (03.01.2010).

Nerlich, Ruth, Aus der Gebersdorfer Schulchronik, 1911-1920 http://www.gebersdorf-mark.de/ kalenderblatt.htm.

Neuhaus, H., Chronik der Hauptschule Süd (Gütersloh), http://www.helmut-neuhaus.de/archivchronik3.html (4.Februar 2010).

Neuhaus, Helmut, Janusz-Korczak-Gesamtschule, http://www.jkg-gt.de/schule/stadtteil/abschnitt-ikriegschronik-1914-1918.html (14.12.2008).

Oelkers, A., Chronologie der Schule, http://www.haste.de/chronik.html (15.07.2008).

Online-Redaktion, Vor 90 Jahren wurde der "Eiserne Mann" auf dem Aliceplatz enthüllt, http://www02.offenbach.de/Themen/Rathaus/Aktuelles_\&_Medien/Pressearchiv/2005/news/p1eiserne rmann0310.html (11.02.2008).

Oskar-von-Miller-Gymnasium, Chronik, http://www.ovmg.de/index.php?page=chronik (20.01.2010).

Owen, Wilfred, best known poem of the First World War, http://www.warpoetry.co.uk/owen1.html (13.08.2009).

Plümpe, Kaspar, Hauptschule Gütersloh, http://www.helmut-neuhaus.de/archiv-chronik3.html (26.11.2008).

Prellwitz, Jens (Betreuer), Sachkatalog der Staatsbibliothek, http://ark.staatsbibliothek-berlin.de/ index.php?ebene $=002.015 .008 \& A C T=\& I K T=\& T X=\& S E T=\& N S I=S Y S(15.12 .2009)$.

Prof. Dr. Brenner, Die Oberrealschule zu Bad Oldesloe während des Weltkrieges (1914 bis 1918), http://de.tms-od.de/ (14.02.2008).

Rasch, Ilse, Der Weltkrieg 1914-1918: Berichte eines Zeitzeugen, http://hersfelder-zeitung.de/ heimatland/40_1.htm (21.03.2008).

Reichert, Folker, Heidelberger Hochschullehrer im Ersten Weltkrieg, http://www.uni-heidelberg.de/ presse/news/2110reichert.html (11.02.2008). 
Reinhold, Klaus, Chronik Arnstadt (Band II), http://www.arnstadt.de/content/chronik/teil5.pd (20.01.2010).

Reyher, Ulrich, Die Schwanheimer Schulchronik, www.schulserver.hessen.de/.../Die\%20Schwanheimer\%20Volksschule\%20im\%201.Weltkrieg.doc (29.02.2008).

Sauer, Wolfgang D., Geschichte des Schloß-Gymnasiums, http://www.schloss-gymnasium.de/ geschichte.htm\#Im\%20Ersten\%20Weltkrieg (15.07.2008).

Scharnhorstgymnasium Hildesheim, Die Chronik des Scharnhorstgymnasiums http://66023.nibis.de/website/index.php?id=35 (21.02.2008).

Schepp, Schule und Krieg, http://www.zum.de/psm/1wk/schule.php.(11. November 2009).

Schiffler, Horst, Der 1. Weltkrieg und die Schule, http://www.schulmuseum,ottweiler.net/ mason/ site/view.html? section $=$ kaiser-6\&language $=(20.03 .2008)$.

Schiller, Adolf, Geschichte der Stadt Beuten, http://www.glogauerheimatbund.de/pages/NGAArtikel/2006/NGA06 08GeschichteBeuthen VI.html (03.09.2008).

Schleicher, Gabriele, Bingersbrücker und Rupertsberger Geschichte(n), http://www.bingerbrueck.de/pdf/schulchronik.pdf (15.07.2008).

Schmidt, Roland, Der Sedantag am Plauener Gymnasium, http://www.schulgeschichte.de/dersedantag-am-plauener-gymnasium.html (6.12.2010).

Schmitz, Burckhard, Die Geschichte des Schiller-Gymnasiums Köln 1899-2006, http://www.schillergymnasium-koeln.de/schule/geschichte/grafik/geschichte-1.pdf (11.03.2009).

Schmitz, Martin/Popp, Susanne, "Ein Markstein des Dankes aus Eiserner Zeit", http://www.europe1418.eu/preview_site/telechargements02/zeit_aallll.doc (14.09.2009).

Schulchronik, http://www.badliebenwerda.de/prieschka/schule.htm (21.10.2003).

Schulchronik, http://www.vg-katzenelnbogen.de/buch2/15.htm (10.10.2007).

Schulchronik "Die Schule im Ersten Weltkrieg 1914-1918", http://www.vikilu.de/ vikilu/ index. php?id=61 (06.03.2009).

Schulchronik, (1913/14) http://www.eugen-langen-schule.de/1_weltkrieg.htm (22.07.2007; am 18.02.2008 war die Seite nicht mehr aufrufbar).

Schule in Gesmold, http://www.schule-gesmold.de/modules/info/index.php?id=2:14 (15.12.2008).

Schule im Kaiserreich - Erziehung zum Patriotismus, http://www.uni-protokolle.de/ Lexikon/ Schwienkuhl.html (01.03.2010).

Schweidnitz/Geschichte 1914-1918, http://wiki-de.genealogy.net/Schweidnitz/ Geschichte 19141918 (19.06.2008).

Seggern, Andreas von, "Bismarck Heil!" - Kanzlerkult in der Festkultur des Kaiserreiches, http://www.ruhr-uni-bochum.de/iga/isb/isb-hauptframe/forschung/Tagung\%20Kaiserreich/ von\% 20seggern.pdf (11.07.2008).

Stadt Mainz, Kur für die Nagelsäule, http://www.mainz.de/WGAPublisher/online/html/default/ehon6p8jyf.de.html (05.09.2007).

Stadt Peine (Hrsg.), Die Peiner Eule, http://www.peinemarketing.de/pema/ img/pdf/peiner Eule 2002.pdf (11.02.2008).

Stadtarchiv Augsburg - Archiv und Schule, http://www.stadtarchiv.augsburg.de/index.php?id=17256 (01.01.2009).

Stadtarchiv Frankfurt (Oder), Vom "Eisernen Kreuz" von Rosengarten, http://www.frankfurt-oder.de/ data/stadtarchiv/aktuell/ablage/nagelbld/nbld1.htm (25.03.2009).

Ständer, Manfred, Der "Eiserne Michael" an der Südwestecke des Ohrdrufer Rathauses, http://82.165.28.118/akgeschichtendetails.php4?codered=\&lang=us\&nr=30 $(08.02 .2008)$.

Stehle, Ludwig, Vorgeschichte der Berger Volksschule, http://www.berg-pfalz.de/historie/ his5 chronik.html (15.01.2008). 
Stock, Uwe, Schule und Erster Weltkrieg,

http://www.sandermielke.de/www/homepage3/mybb/showthread.php?tid=34 (07.07.2008).

Thomale, Franz, Die schlesische Festungsstadt Festenberg, http://www.gross-wartenberg.de/ sukgw/s081.html (28.12.2008).

Vor 90 Jahren, http://www.lugau-erzgebirge.de/A-200626/a-hist.pdf (25.01.2009).

Walther, Franziska, Das Königliche Humanistische Gymnasium Rosenheim im Ersten Weltkrieg http://www.stadtarchiv.de/fileadmin/fuerschueler/Facharbeit_Walther.pdf (14.09.2009).

Weber, Bernd, Zur Geschichte des Annette-von-Droste-Hülshoff-Gymnasiums Münster 1690-1945, http://www.muenster.org/annette/ (28.01.2009).

Weggel, Renate, Alltag im 1.Weltkrieg, www.augsburg.de/Seiten/augsburg_d/bildung/stadtarchiv/archiv_schule/alltag.shtml (24.09.2005).

Weyer, Rüdiger, EXPERIMENT-Sonderheft, http://www.elisabethschule.de/schueler/schuelerzeitung/experiment sonder.html (98.07.2008).

Weyrauch, Max, Das Dürener Realgymnasium mit Realschule, http://www.wirteltor-gymnasium.de /828/index.html (15.12.2008).

Wieferink, Hermann, Schulchronik der Volksschule Neuenhaus, http://www.gbiu.de/Chroniken/02nhs.htm (15.07.2009).

Wuppertal Vohwinkel, http://www.agvv.org/160.htm (27.12.2008).

Wojtecki, Wolfram, Kriegsalltag an der Front und in der Heimat, http://www.erster-weltkrieg.clioonline.de/_Rainbow/Documents/einzelne/krieg-1914-wojtecki.pdf (11.12.2009).

„Zuckertüte mit militärischen und einigen zivilen Motiven“, http://www.dhm.de/datenbank/, GOS-Nr. 20013859 (8.01.2010). 


\section{Abkürzungsverzeichnis}

Frst. Fürstentum

Ghzgt. Großherzogtum

GWU Geschichte in Wissenschaft und Unterricht

Hrzgt. Herzogtum

Jb. Jahresbericht

kgl. königlich

Kgr. Königreich

MGM Militärgeschichtliche Mitteilungen

ZB Zentralblatt für das gesamte Unterrichtswesen in Preußen

Archive:

GSTA Geheimes Staatsarchiv

StABH Stadtarchiv Bad Homburg

StABA Stadtarchiv Bamberg

StABO Stadtarchiv Bonn

StAB Stadtarchiv Braunschweig

NStAB Niedersächsisches Staatsarchiv Bückeburg

SAB Staatsarchiv Bremen

StAD Stadtarchiv Dresden

StAE Stadtarchiv Erfurt

StAEF Stadtarchiv Eisfeld

StAG Stadtarchiv Greiz

NHStA Hauptstaatsarchiv Hannover

StAFL Stadtarchiv Flensburg

StAK Stadtarchiv Kornwestheim

StAMA Stadtarchiv Mannheim

StAMÜ Stadtarchiv Mühlhausen/Thüringen

StAO Stadtarchiv Offenbach

NStAO Niedersächsisches Staatsarchiv Osnabrück

StAP Stadtarchiv Peine

StAR Stadtarchiv Reutlingen

StAR Stadtarchiv Rudolstadt

LAS Landesarchiv Schleswig 
StAW Stadtarchiv Wismar

NStAW Niedersächsisches Staatsarchiv Wolfenbüttel

StAZ Stadtarchiv Zwickau 


\section{Versicherung}

Hiermit versichere ich an Eides statt, dass ich die eingereichte Dissertation „Die Bedeutung der Schule für die ,Heimatfront’ im Ersten Weltkrieg - Sammlungen, Hilfsdienste, Feiern und Nagelungen im Deutschen Reich“ selbständig und ohne unerlaubte Hilfe verfasst habe. Anderer als der von mir angegebenen Hilfsmittel und Schriften habe ich mich nicht bedient. Alle wörtlich oder sinngemäß den Schriften anderer Autorinnen und Autoren entnommenen Stellen habe ich kenntlich gemacht. Die Abhandlung ist noch nicht veröffentlicht worden und noch nicht Gegenstand eines Promotionsverfahrens gewesen.

Hannover, den 


\section{Anhang}




\section{Übersicht der Bild- und Texttafeln}

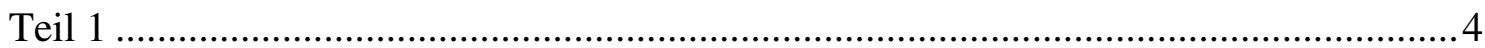

Übersichten, Texte, Gedichte u.a. ........................................................................ 4

Zentralblatt für die gesamte Unterrichtsverwaltung in Preußen ............................5

Amtliches Schulblatt für dem Regierungsbezirk Hildesheim .............................. 8

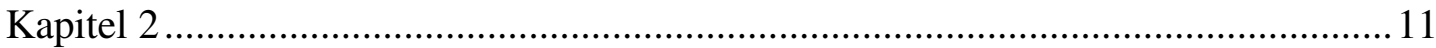

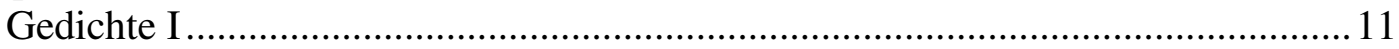

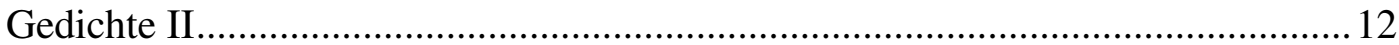

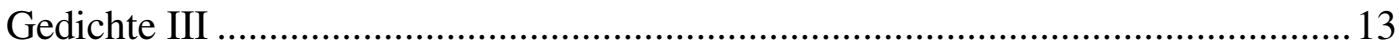

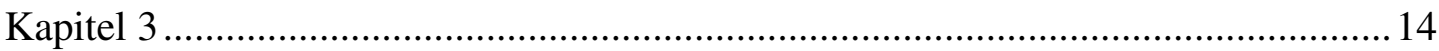

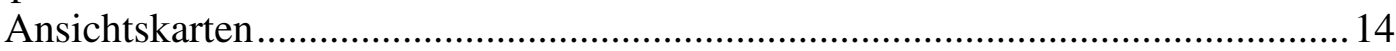

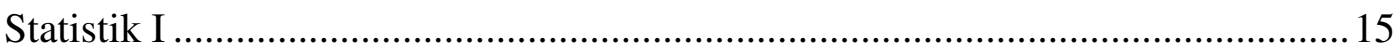

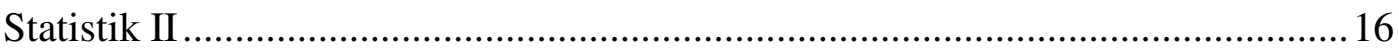

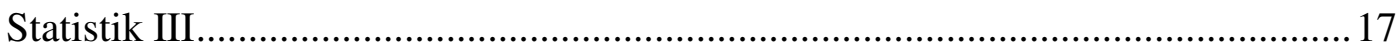

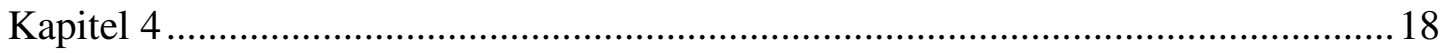

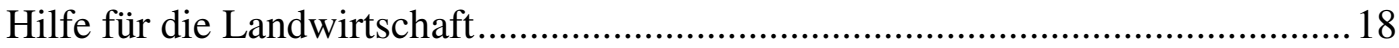

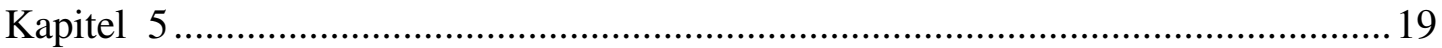

Programm einer nationalen Schulfeier I ........................................................... 19

Texte zur Geburtstagsfeier des Kaisers am Schiller-Gymnasium .........................20

Programm einer nationalen Schulfeier II ...................................................... 21

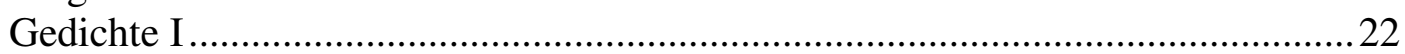

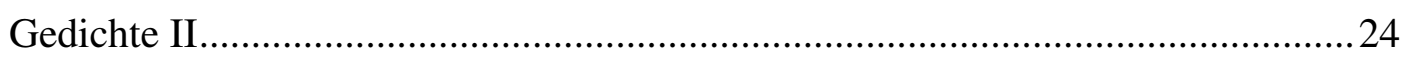

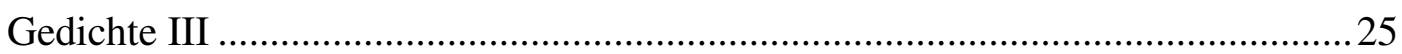

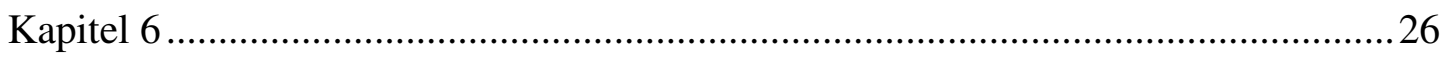

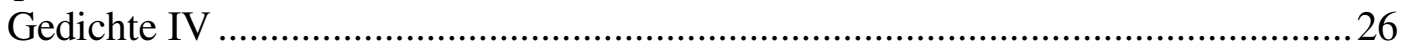

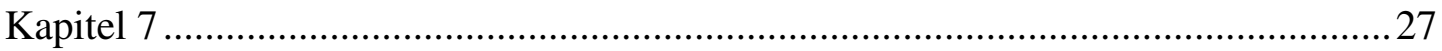

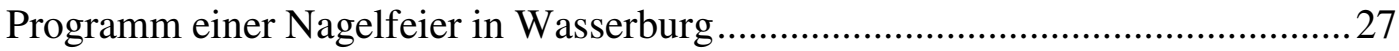

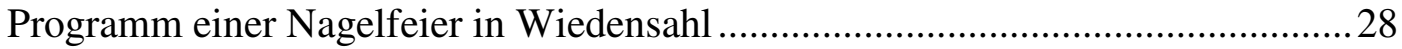

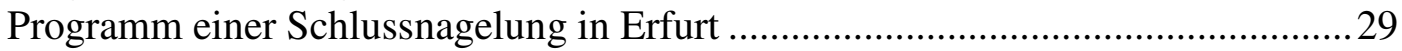

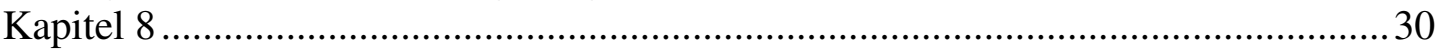

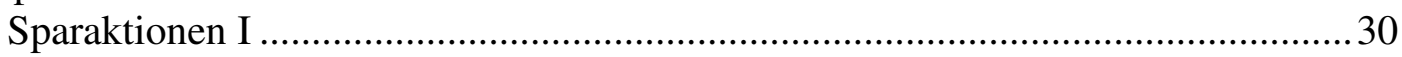

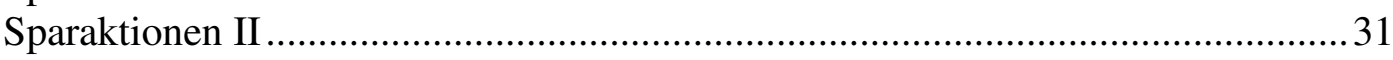

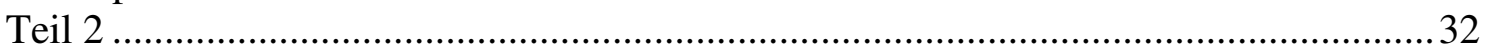

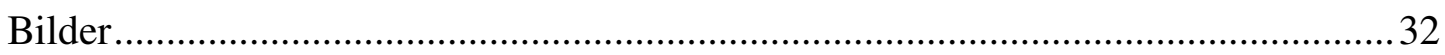

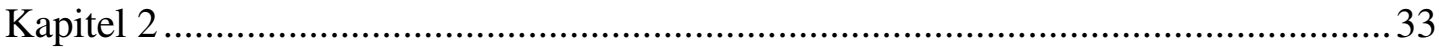

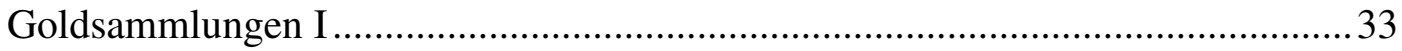

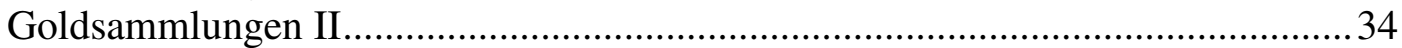

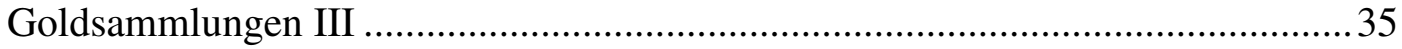

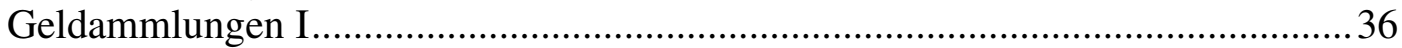

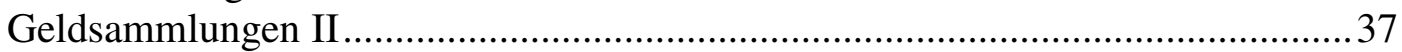

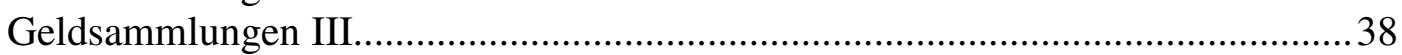

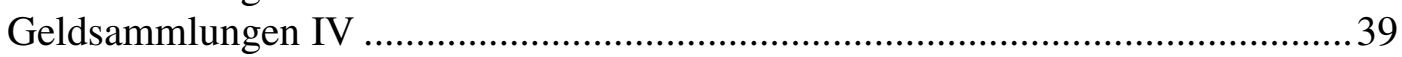

Sammlung von Altmaterialien I................................................................. 40

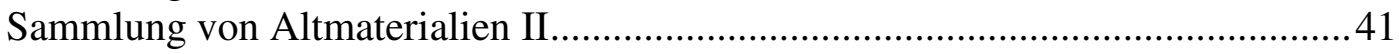

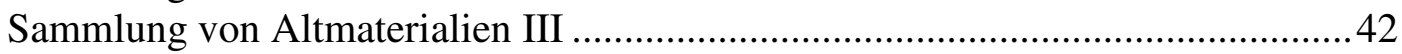

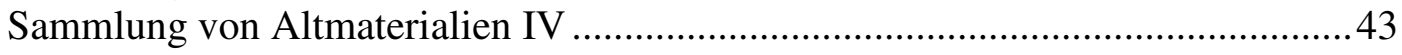

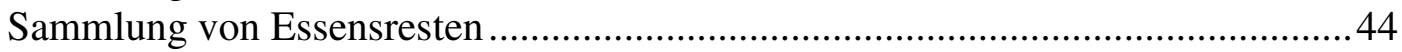

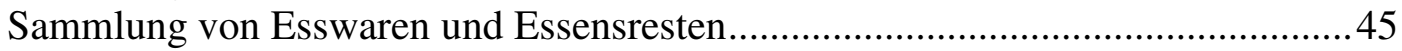

Sammlung Essensresten, Bucheckern und Kastanien ........................................46

Sammlung von Obstkernen ..................................................................................4 4

Sammlung von Brennnesseln ...................................................................... 48

Sammlung von Eicheln und Laubheu ........................................................... 49 


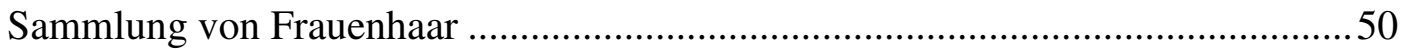

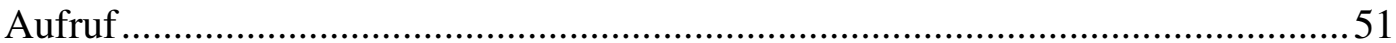

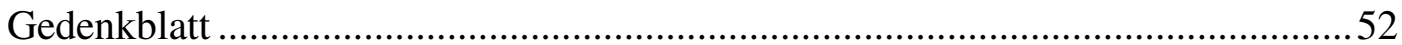

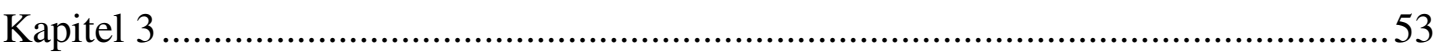

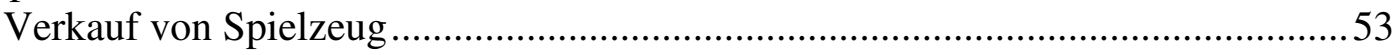

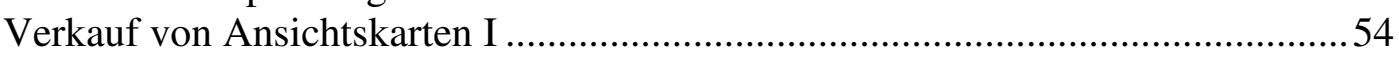

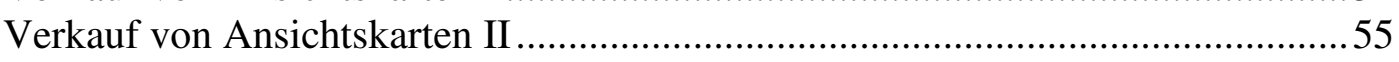

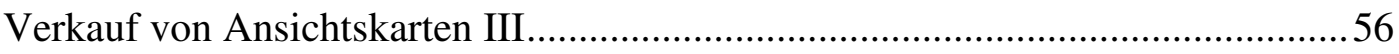

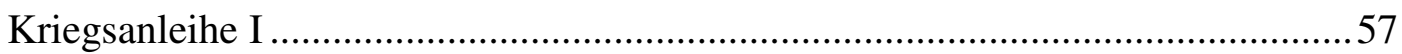

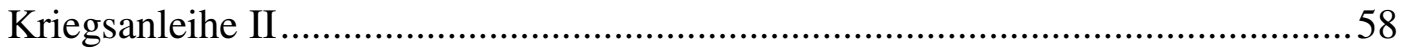

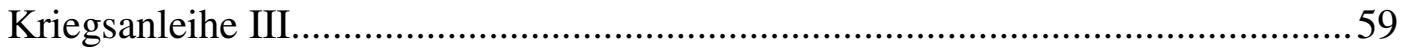

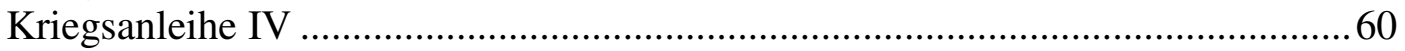

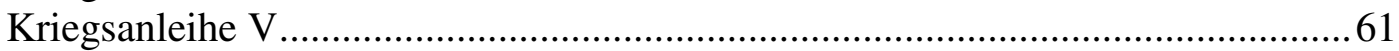

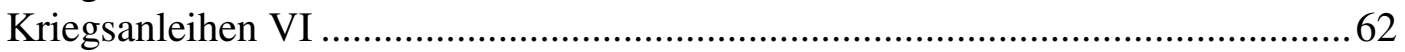

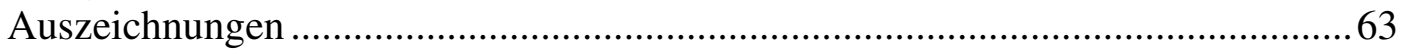

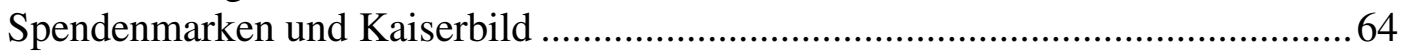

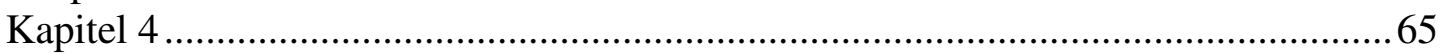

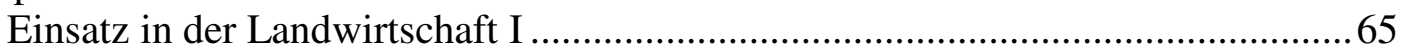

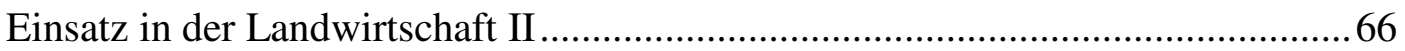

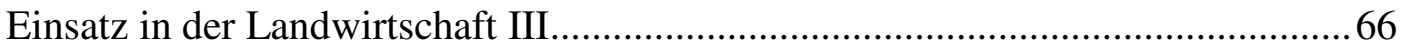

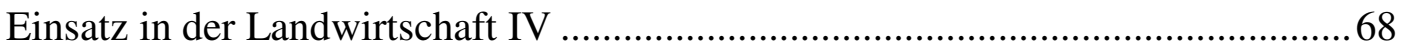

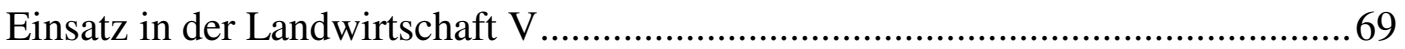

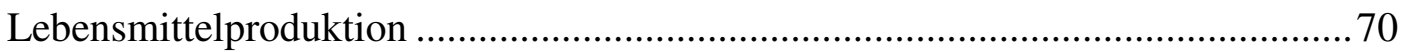

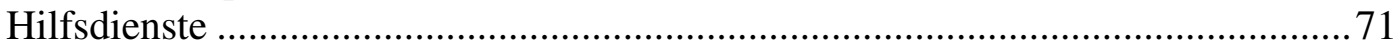

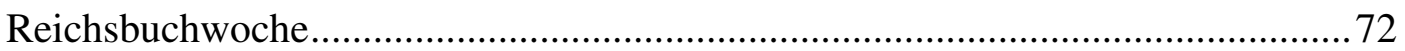

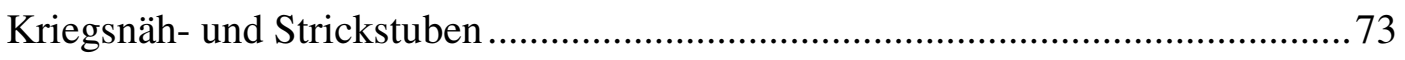

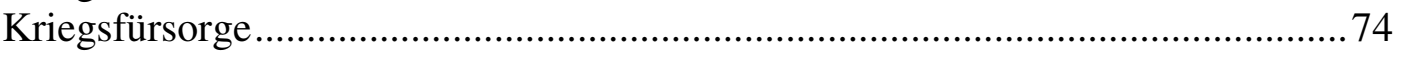

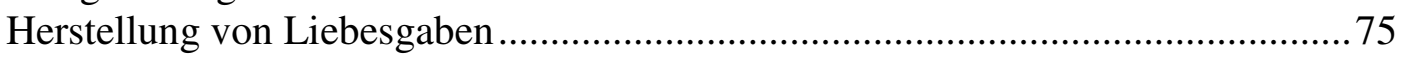

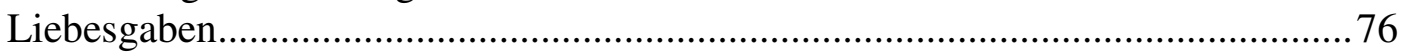

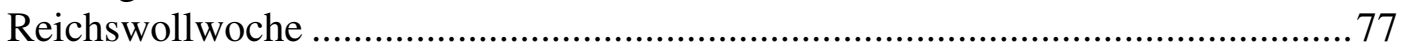

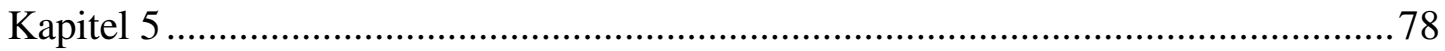

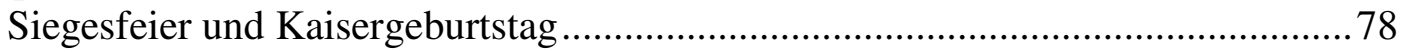

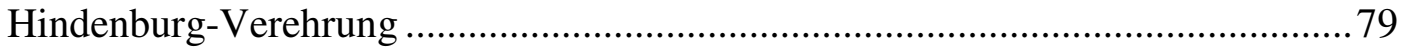

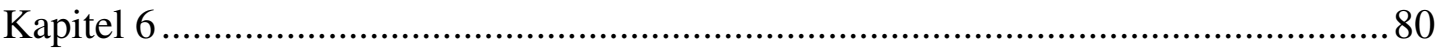

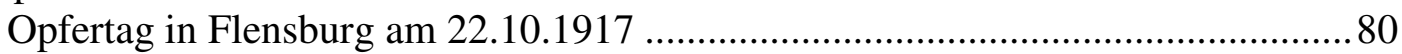

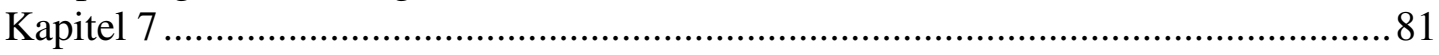

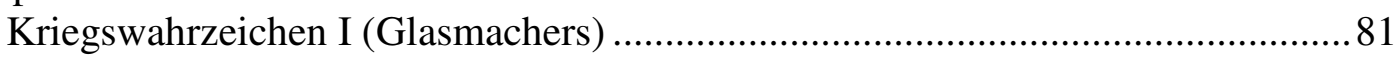

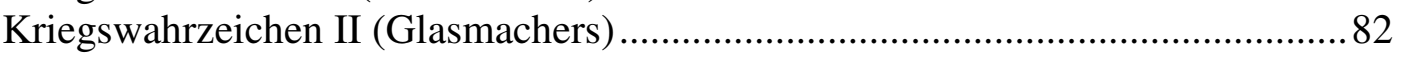

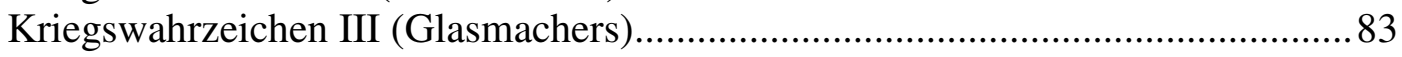

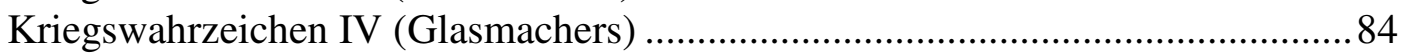

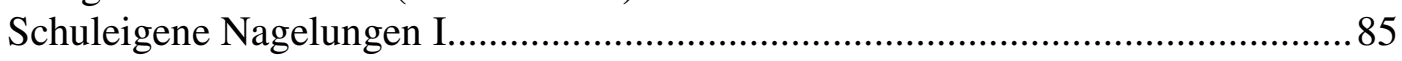

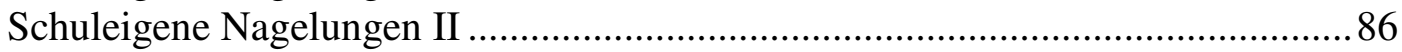

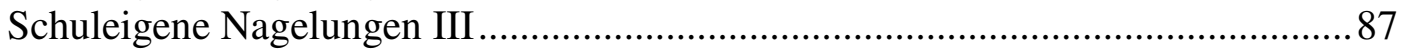

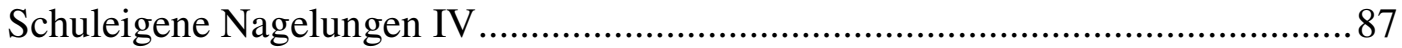

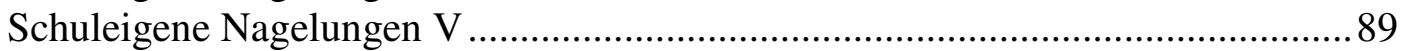

Schuleigene Nagelungen VI..................................................................... 90

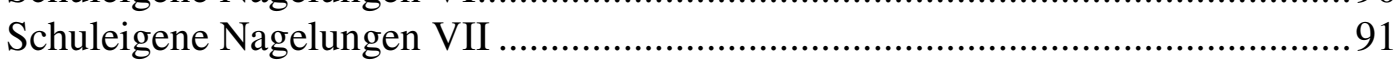

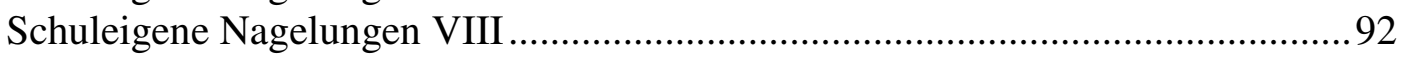

Schuleigene Nagelungen IX ......................................................................... 93

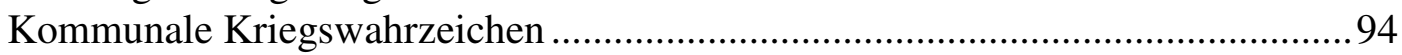

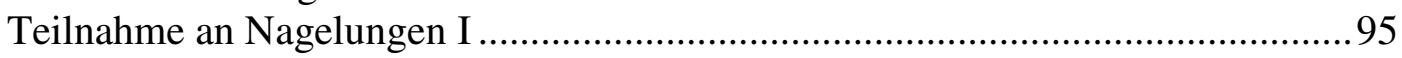

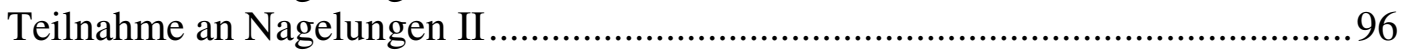

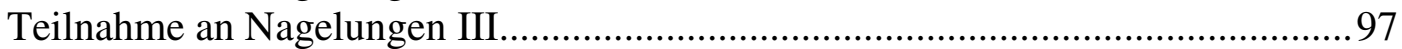




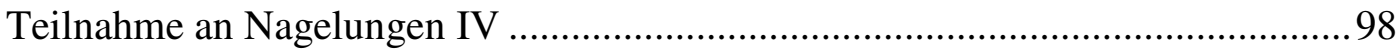

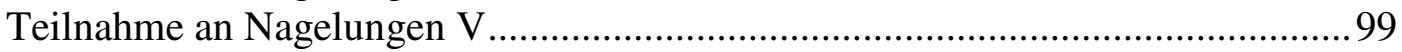

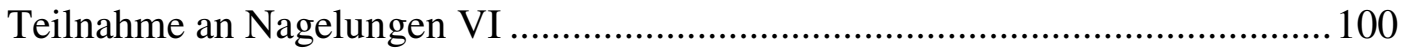

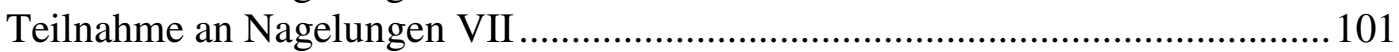

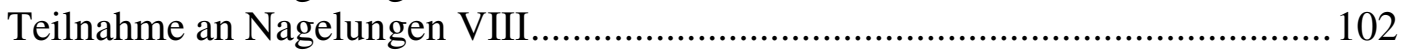

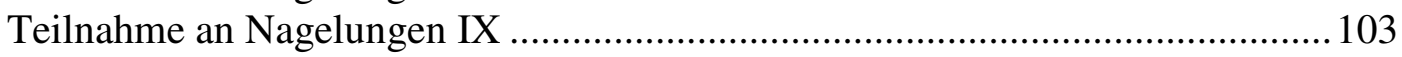

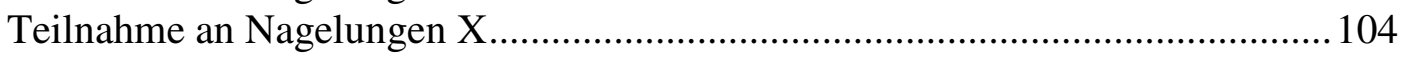

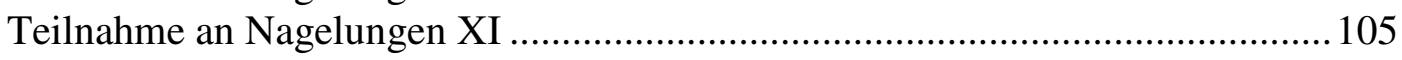

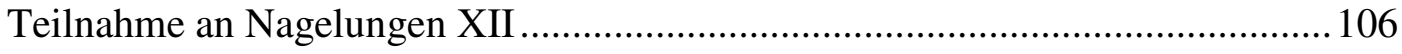

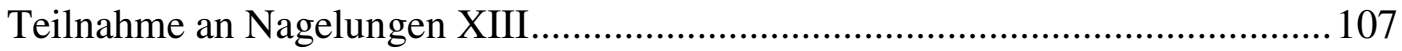

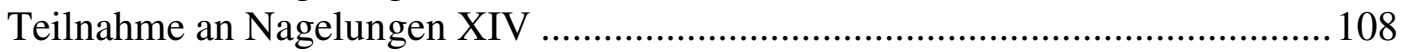

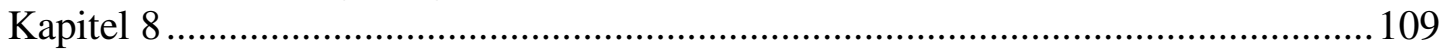

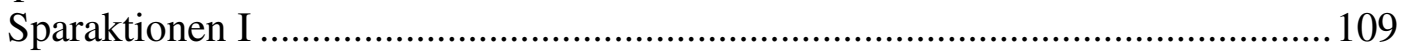

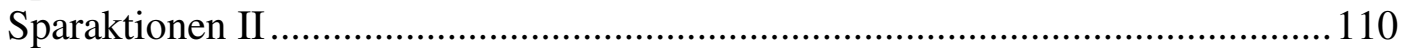

Sparaktionen III.......................................................... 111

Die Nagelung des Friedenswahrzeichens.............................. 112 


\section{$\underline{\text { Teil } 1}$}

Übersichten, Texte, Gedichte u.a. 


\section{Zentralblatt für die gesamte Unterrichtsverwaltung in Preußen}

Hier: Erlasse für den ,Kampf an der Heimatfront'

\begin{tabular}{|c|c|c|}
\hline 1914 & & \\
\hline Beschaffung von Tinten & 3. August 1914 & Heft 8, S. 483 \\
\hline $\begin{array}{l}\text { Teilnahme von Schülern der höheren Lehranstalten an den } \\
\text { Erntearbeiten infolge der Mobilmachung }\end{array}$ & 1. August 1914 & Heft 8, S. 498 \\
\hline $\begin{array}{l}\text { Beurlaubung der größeren Schulkinder zur Teilnahme an den } \\
\text { Erntearbeiten }\end{array}$ & 3. August 1914 & Heft 8, S. 512 \\
\hline $\begin{array}{l}\text { Anfertigung von Liebesgaben für das Heer in dem } \\
\text { Handarbeitsunterricht für die weibliche Jugend }\end{array}$ & 18. August 1914 & Heft 9, S. 568 \\
\hline Beurlaubung von Schulkindern zum Viehhüten & 19. August 1914 & Heft 10, S. 609 \\
\hline $\begin{array}{l}\text { Beurlaubung von Schulkindern zur Teilnahme an den } \\
\text { Erntearbeiten }\end{array}$ & 26. August 1914 & Heft 10, S. 609 \\
\hline $\begin{array}{l}\text { Militärische Vorbereitung der Jugend während des mobilen } \\
\text { Zustandes }\end{array}$ & 4. September 1914 & Heft 10, S. 629 \\
\hline $\begin{array}{l}\text { Anfertigung von Liebesgaben für das Heer in dem } \\
\text { Handarbeitsunterricht für die weibliche Jugend }\end{array}$ & 28. September 1914 & Heft 11, S. 693 \\
\hline $\begin{array}{l}\text { Militärische Vorbereitung der Jugend während des mobilen } \\
\text { Zustandes }\end{array}$ & 9. Oktober 1914 & Heft 11, S. 693 \\
\hline Abführung von Reichsgoldmünzen an die Reichsbank & 21. November 1914 & Heft 12, S. 732 \\
\hline $\begin{array}{l}\text { Pflege vaterländischer Begeisterung bei den höheren } \\
\text { Lehranstalten }\end{array}$ & 6. November 1914 & Heft 12, S. 740 \\
\hline 1915 & & \\
\hline Einschränkung des Bargeldverkehrs & 16. Dezember 1914 & Heft 2, S. 258 \\
\hline $\begin{array}{l}\text { Beseitigung und Vermeidung fremdsprachlicher Ausdrücke und } \\
\text { Redewendungen }\end{array}$ & 27. August 1915 & Heft 2, S. 277 \\
\hline Militärische Vorbereitung der Jugend & 9. Dezember 1914 & Heft 2, S. 279 \\
\hline $\begin{array}{l}\text { Versicherung gegen Unfall und Haftpflicht bei Übungen zur } \\
\text { militärischen Vorbereitung der Jugend }\end{array}$ & 9. Dezember 1914 & Heft 2, S. 283 \\
\hline Jahresberichte der höheren Lehranstalten für das Jahr 1914/15 & 17. Dezember 1914 & Heft 2, S. 284 \\
\hline $\begin{array}{l}\text { Beurlaubung von Schulkindern für landwirtschaftliche Arbeiten } \\
\text { usw. }\end{array}$ & 5. März 1915 & Heft 3, S. 385 \\
\hline $\begin{array}{l}\text { Ablieferung von aufgefundenen Munitionsteilen an die } \\
\text { Artilleriedepots }\end{array}$ & 19. Dezember 1914 & Heft 3, S: 286 \\
\hline $\begin{array}{l}\text { Bestellung der Schulgärten und des Dienstlandes der zum } \\
\text { Kriegsdienste eingezogenen Volksschullehrer mit Kartoffeln }\end{array}$ & 13. März 1915 & Heft 3, S. 386 \\
\hline Ernährungsblatt, Ratschläge für die Kriegszeit & 13. Februar 1915 & Heft 4, S. 452 \\
\hline Ernährung der Schulkinder & 12. März 1915 & Heft 4, S. 454 \\
\hline Verwendung von Zeichenpapier usw. deutschen Ursprungs & 30. März 1915 & Heft 4, S. 456 \\
\hline $\begin{array}{l}\text { Portofreiheit für Postsendungen aus Anlaß der militärischen } \\
\text { Jugendvorbereitung }\end{array}$ & 30. März 1915 & Heft 5, S. 486 \\
\hline Die Volksernährung im Krieg & 30. März 1915 & Heft 5, S. 496 \\
\hline Text des Liedes „Die Wacht am Rhein“ & 21. April 1915 & Heft 6, S. 518 \\
\hline $\begin{array}{l}\text { Bekämpfung der Obst- und Gemüseschädlinge durch die } \\
\text { Schuljugend - Nutzbarmachung des Waldes }\end{array}$ & 15. Mai 1915 & Heft 6, S. 521 \\
\hline Heimatschutz bei Bodenarbeiten & 17. Mai 1915 & Heft 7, S. 582 \\
\hline Beurlaubung von Schulkindern für die Obsternte & 12. Juni 1915 & Heft 7, S. 583 \\
\hline Ährenlesen für schulpflichtige Kinder & 3. Juli 1915 & Heft 8, S. 618 \\
\hline Zulassung zum Dienste in der freiwilligen Krankenpflege & 3. Juli 1915 & Heft 8, S. 620 \\
\hline Unterbringung von Kriegswaisen & & \\
\hline $\begin{array}{l}\text { Die Nutzbarmachung der Eicheln und Bucheln usw. und die } \\
\text { Verwendung der Schulkinder zum Einsammeln dieser } \\
\text { Waldfrüchte während des Krieges }\end{array}$ & 16. September 1915 & Heft 10, S. 685 \\
\hline Förderung der Handarbeit während und nach der Schulzeit & 6. November 1915 & Heft 12, S. 774 \\
\hline 1916 & & \\
\hline Papierersparnis in den Schulen & 18. März 1916 & Heft 4, S. 335 \\
\hline Verkauf von Altpapier & 26. April 1916 & Heft 5, S. 357 \\
\hline $\begin{array}{l}\text { Beurlaubung von Schulkindern für die Obsternte - Bekämpfung } \\
\text { der Obst- und Gemüseschädlinge und Verwertung der } \\
\text { Erzeugnisse des Waldes }\end{array}$ & 8. April 1916 & Heft 5, S. 382 \\
\hline
\end{tabular}




\begin{tabular}{|c|c|c|}
\hline Kleinkinderfürsorge & 1916 & Heft 6, S. 386 \\
\hline Gebrauch von Schulheften mit nicht ganz leimfesten Papier & 17. Mai 1916 & Heft 7, S. 419 \\
\hline Ährenlese durch Schulkinder & 18. Mai 1916 & Heft 7, S. 420 \\
\hline Richtlinien für die Erhaltung der diesjährigen Obsternte & 6. Junin 1916 & Heft 7, S. 422 \\
\hline Bekämpfung der Modeauswüchse & 24. Mai 1916 & Heft 7, S. 4 \\
\hline Wanderungen zur Verbreitung der Pilzkunde & 17. Juni 1916 & Heft 7, S. 431 \\
\hline Beurlaubung von Schulkinder für landwirtschaftliche Arbeiten & 9. Juni 1916 & Heft 7, S. 435 \\
\hline $\begin{array}{l}\text { Sammlung von Obstkernen durch die Schuljugend zur } \\
\text { Ölgewinnung }\end{array}$ & 10. Juni 1916 & Heft 7, S. 437 \\
\hline Unterricht in der Nadelarbeit an Lyzeen und Frauenfachschulen & 1. Juli 1916 & Heft 8, S. 460 \\
\hline $\begin{array}{l}\text { Die Heranziehung der Schuljugend zum Sammeln der } \\
\text { Waldfrüchte und zur Kartoffel- usw. Ernte }\end{array}$ & 20. September 1916 & Heft 10, S. 502 \\
\hline $\begin{array}{l}\text { Pflege der schulentlassenen Jugend in Verbindung mit } \\
\text { Elternabenden usw. }\end{array}$ & 5. Oktober 1916 & Heft 11, S. 532 \\
\hline $\begin{array}{l}\text { Pflege des Strickens und anderer Nutzarbeiten im } \\
\text { Nadelhandarbeitsunterricht der Mädchenschulen }\end{array}$ & 7. Dezember 1916 & Heft 12, S. 580 \\
\hline \multicolumn{3}{|l|}{1917} \\
\hline Vaterländischer Hilfsdienst & 11. Januar 1917 & Heft 2, S. 242 \\
\hline Vaterländischer Hilfsdienst & 11. Januar 1917 & Heft 2, S. 250 \\
\hline $\begin{array}{l}\text { Sammlung von Obstkernen durch die Schuljugend zur } \\
\text { Ölgewinnung }\end{array}$ & 17 Februar 1917 & Heft 3, S. 291 \\
\hline $\begin{array}{l}\text { Heranziehung der Schuljugend zu kriegswirtschaftlichen, } \\
\text { insbesondere landwirtschaftlichen Arbeiten }\end{array}$ & 21. Februar 1917 & Heft 3, S. 293 \\
\hline Unkrautvernichtung durch die Schuljugend & 6. März 1917 & Heft 3, S. 299 \\
\hline $\begin{array}{l}\text { Aufnahme von Kindern der städtischen und } \\
\text { Industriebevölkerung in ländlichen Familien }\end{array}$ & 12. März 1917 & Heft 3, S. 303 \\
\hline Gartenbauversuche an Lyzeen & 14. Februar 1917 & Heft 3, S. 322 \\
\hline Vaterländischer Hilfsdienst & 14. März 1917 & Heft 3, S.329 \\
\hline Mithilfe der Schuljugend bei der Frühjahrsbestellung & 16. März 1917 & Heft 4, S. 349 \\
\hline Beteiligung der Schüler an landwirtschaftlichen Hilfsarbeiten & 22. März 1917 & Heft 4, S. 352 \\
\hline Vaterländischer Hilfsdienst & 30. März 1917 & Heft 4, S. 353 \\
\hline $\begin{array}{l}\text { Vorbereitung der evangelischen Schuljugend auf den } \\
\text { Gedenktag der Reformation }\end{array}$ & 27. März 1917 & Heft 5, S. 378 \\
\hline Herausgabe eines Reichskriegsblattes & 21. April 1917 & Heft 6, S. 405 \\
\hline Dichter des Liedes „O Deutschland hoch in Ehren & 1917 & Heft 6, S. 414 \\
\hline $\begin{array}{l}\text { Merk- bzw. Flugblätter des Kaiserin Auguste Victoria-Hauses } \\
\text { zu Charlottenburg zur Bekämpfung der Säuglingssterblichkeit }\end{array}$ & 1917 & Heft 6, S.445 \\
\hline Feldschutz & 2. Juni1917 & Heft 7, S. 457 \\
\hline $\begin{array}{l}\text { Zusammenstellung der bei der Beeren- und Pilzernte des Jahres } \\
1916 \text { gemachten Erfahrungen }\end{array}$ & 5. Juni 1917 & Heft 7, S. 458 \\
\hline $\begin{array}{l}\text { Merkblatt zur Sammlung und Aufbewahrung von Obstkernen } \\
\text { für die Ölgewinnung }\end{array}$ & 6. Juni 1917 & Heft 7, S. 464 \\
\hline Heranziehung der Schuljugend zu landwirtschaftlichen Arbeiten & 18. Juni 1917 & Heft 7, S. 468 \\
\hline Heranziehung der Schuljugend zum vaterländischen Hilfsdienst & 24. Mai 1917 & Heft 7 S. 470 \\
\hline Annahme von Hartgeld zum Umtausch in Scheine & 2. Juli 1917 & Heft 8, S. 493 \\
\hline Mitwirkung der Schulen zur Verhütung von Brandschäden & 25. Juni 1917 & Heft 8, S. 496 \\
\hline Lehrgang für Kleinkinderfürsorge & 1917 & Heft 8, S. 508 \\
\hline Verdeutschung von Fremdwörtern & 9. Juni 1917 & Heft 9, S. 516 \\
\hline Ersparung von Brennstoffen & 14. Juli 1917 & Heft 9, S. 525 \\
\hline Brennesselsammlung & 23. Juli 1917 & Heft 9, S. 538 \\
\hline Sparsamkeit im Gebrauch von Lederschuhzeug & 23. Juli 1917 & Heft 9, S. 542 \\
\hline Feier des Gedenktages der Reformation & 28. Julin 1917 & Heft 9, S. 543 \\
\hline Sparsamkeit im Papierverbrauch & 6. Juli 1917 & Heft 10, S. 574 \\
\hline Sammlung von Arzneikräutern & 10. August 1917 & Heft 10, S. 594 \\
\hline $\begin{array}{l}\text { Sammeln von Beeren, Pilzen und Wildgemüse in den } \\
\text { Staatsforsten }\end{array}$ & 14. September 1917 & Heft 10, S. 603 \\
\hline $\begin{array}{l}\text { Heranziehung der Schüler höherer Lehranstalten zu } \\
\text { landwirtschaftlichen Arbeiten }\end{array}$ & 15. September 1917 & Heft 10, S. 604 \\
\hline Beschäftigung der Jungmannen (Schüler höherer Lehranstalten) & 22. September 1917 & Heft 10, S. 608 \\
\hline Steigerung der Obstkernsammlung & 27. August 1917 & Heft 10, S. 612 \\
\hline $\begin{array}{l}\text { Jungmannenauszeichnung für Schüler höherer Lehranstalten für } \\
\text { die männliche Jugend }\end{array}$ & 6. November 1917 & Heft 11, S. 733 \\
\hline
\end{tabular}




\begin{tabular}{|c|c|c|}
\hline Vorträge über Kleinkinderfürsorge & 1917 & Heft 11, S. 687 \\
\hline Ablieferung alter Wandkarten durch die Schulen & 20. Oktober 1917 & Heft 11, S. 710 \\
\hline Jungmannenauszeichnung für Schüler höherer Lehranstalten & 6. November 1917 & Heft 11, S. 717 \\
\hline Pflanzenschutz & 7. November 1917 & Heft 11, S. 749 \\
\hline $\begin{array}{l}\text { Jungmannen im landwirtschaftlichen Hilfsdienst und } \\
\text { Jugendabteilungen für die militärische Vorbildung der Jugend }\end{array}$ & 24. November 1917 & Heft 12, S. 756 \\
\hline Verwendung des Jungmannenfonds & 4. Dezember 1917 & Heft 12, S. 758 \\
\hline Verwendung gebrauchter Schulbücher bei Versetzungen & 4. Dezember 1917 & Heft 12, S. 759 \\
\hline \multicolumn{3}{|l|}{1918} \\
\hline Sammlung von Altpapier und Papierersparnis & 6. Februar 1918 & Heft 2, S. 233 \\
\hline $\begin{array}{l}\text { Vermittlung von Jungmannen (Schüler höherer Lehranstalten) } \\
\text { für den Hilfsdienst in der Provinz Brandenburg }\end{array}$ & 12. Dezember 1917 & Heft 2, S. 239 \\
\hline Beteiligung der Schulen bei der Knochensammlung & 14. Dezember 1917 & Heft 2, S. 240 \\
\hline Zweites Merkblatt zur Sammlung von Knochen durch Schulen & 1918 & Heft 2, S. 240 \\
\hline $\begin{array}{l}\text { Deutsche Lichtbilder-Zentrale für den landwirtschaftlichen } \\
\text { Schülerhilfsdienst }\end{array}$ & 4. Dezember 1917 & Heft 1, S. 246 \\
\hline $\begin{array}{l}\text { Lichtbilderzentrale für den landwirtschaftlichen } \\
\text { Schülerhilfsdienst }\end{array}$ & 29. Dezember 1917 & Heft 1, S. 247 \\
\hline $\begin{array}{l}\text { Verhütung von Schädigungen infolge der Beteiligung der } \\
\text { Schüler und Schülerinnen der höheren Schulen und der } \\
\text { Lehrerbildungsanstalten an kriegswirtschaftlichen Arbeiten }\end{array}$ & 8. Januar 1918 & Heft 1, S. 250 \\
\hline $\begin{array}{l}\text { Heranziehung der Schuljugend zur Vertilgung schädlicher } \\
\text { Nager usw. }\end{array}$ & 11. Dezember 1917 & Heft 1, S. 251 \\
\hline $\begin{array}{l}\text { Leitsätze über die zukünftigen Aufgaben des freiwilligen } \\
\text { Schülerhilfsdienstes von Professor Broßmer, Referent beim } \\
\text { Stabe des Kriegsamtes }\end{array}$ & 13. Dezember 1917 & Heft 1, S. 253 \\
\hline Ausbildung im Morsealphabet & 23. Januar 1918 & Heft 2, S. 257 \\
\hline Ersparung von Papier bei den Schulschreibheften & 2. Februar 1918 & Heft 2, S. 258 \\
\hline $\begin{array}{l}\text { Einschränkung des Verbrauchs von Zeichenpapier an den } \\
\text { Unterrichtsanstalten }\end{array}$ & 6. Februar 1918 & Heft 2, S. 260 \\
\hline $\begin{array}{l}\text { Jungmannenauszeichnung für Zöglinge an den } \\
\text { Lehrerbildungsanstalten }\end{array}$ & 10. Dezember 1917 & Heft 2, S. 287 \\
\hline Förderung des Kartoffelanbaus & 18. Februar 1918 & Heft 3, S. 304 \\
\hline $\begin{array}{l}\text { Heranziehung von Studierenden und Schülern zum } \\
\text { vaterländischen Hilfsdienst }\end{array}$ & 22. Februar 1918 & Heft 3, S. 305 \\
\hline $\begin{array}{l}\text { Heranziehung von jüdischen Schülern zum landwirtschaftlichen } \\
\text { Hilfsdienst }\end{array}$ & 8. März 1918 & Heft 4, S. 326 \\
\hline Förderung des Gemüse- und Obstanbaus & 18. März 1918, & Heft 4, S. 327 \\
\hline Sammeln von Laub- und Reisigfutter & 28. März 1918 & Heft 5, S. 375 \\
\hline Kriegshilfe der Schulen & 24. April 1918 & Heft 6, S. 410 \\
\hline Sammeln von Laub- und Reisigfutter & 3. Juni 1918 & Heft 7, S. 5457 \\
\hline Koloniale Wanderausstellung & 2. Juli 1918 & Heft 9, S. 542 \\
\hline Schulkriegsanleihen & 12. Oktober 1918 & Heft 10, S. 591 \\
\hline
\end{tabular}

Insgesamt 113 Erlasse 


\section{Amtliches Schulblatt für den Regierungsbezirk Hildesheim}

Hier: Verfügungen für den ,Kampf an der Heimatfront'

\begin{tabular}{|c|c|c|}
\hline 1914 & & \\
\hline 12.11 .1914 & Hildesheim & Umtausch von Gold gegen Reichsbanknoten (Nr. 22, S. 188) \\
\hline 02.11 .1914 & Berlin & "Kreuz-Pfennig"-Marken (Nr.22, 189) \\
\hline 21.11.1914 & Berlin & $\begin{array}{l}\text { Umtausch von Gold gegen Reichsbanknoten (Nr.23, S. 195/196), S. } \\
\text { 195/96) }\end{array}$ \\
\hline 27.11.1914 & Hildesheim & $\begin{array}{l}\text { Herstellung der Strümpfe für die im Felde stehenden Krieger (Nr. 23, } \\
\text { S. 196/97) }\end{array}$ \\
\hline 28.12 .1914 & Hildesheim & Deutschlands Brotversorgung (Nr.1, S. 1-3) \\
\hline 28.12.1914 & Hildesheim & Sammlung von Patronenhülsen und Patronen (Nr. 1, S. 3) \\
\hline 30.12 .1914 & Hildesheim & Der Weltkrieg in der Schulchronik (Nr. 2, S. 14/15) \\
\hline 20.12 .1914 & Berlin & Ernährung im Krieg (Nr. 3, S. 14/15) \\
\hline \multicolumn{3}{|l|}{1915} \\
\hline 28.01.1915 & Berlin & $\begin{array}{l}\text { Beteiligung der Lehrer bei der Aufnahme der Getreide- und } \\
\text { Mehlvorräte (Nr. 3, S. 31) }\end{array}$ \\
\hline 12.02.1915 & Hildesheim & $\begin{array}{l}\text { Mithilfe der Lehrerschaft bei den Maßnahmen zur Regelung des } \\
\text { Verbrauchs der Lebensmittelvorräte (Nr. 4, S. 1-2) }\end{array}$ \\
\hline 24.02.1915 & Hildesheim & Kriegsernährung (Nr. 5, S. 39/40) \\
\hline 05.03 .1915 & Berlin & $\begin{array}{l}\text { Beurlaubung von Schulkindern zur Durchführung } \\
\text { landwirtschaftlicher Arbeiten (Nr. 6, S. 46/47) }\end{array}$ \\
\hline 22.03.1915 & Berlin & Sammlung von altem Metall für Kriegszwecke (Nr. 7, S. 54/55) \\
\hline 12.03.1915 & Berlin & Teilnahme von Lehrern an Viehzählungen (Nr. 7, S. 54) \\
\hline 23.03 .1915 & Berlin & Abführung des Goldes an die Reichsbank (Nr. 8, S. 63/64) \\
\hline 18.04 .1915 & Berlin & Flugblatt über Notgemüse oder Kriegsgemüse (Nr. 8, S. 62/63) \\
\hline 29.04.1915 & Hildesheim & Merkbüchlein "Wilde Gemüse" (Nr. 10, S. 72) \\
\hline 07.05 .1915 & Berlin & Ausstellung "Schule und Krieg" (Nr. 10, S. 74) \\
\hline 15.05.1915 & Berlin & $\begin{array}{l}\text { Bekämpfung der Obst- und Gemüseschädlinge. - Sammeln von Pilzen } \\
\text { (Nr. 11, S. 77/78) }\end{array}$ \\
\hline 11.05.1915 & Berlin & $\begin{array}{l}\text { Sammlung von entbehrlichen Gold- und Silbergegenständen (Nr. 11, } \\
\text { S.78) }\end{array}$ \\
\hline 11.05 .1915 & Hildesheim & Beurlaubung von Schulkindern für die Obsternte (Nr. 11, S. 83) \\
\hline 27.02.1915 & Berlin & Sammlung einer Jugendspende für Kriegerwaisen (Nr. 12, S. 83/84) \\
\hline 18.06.1915 & Berlin & $\begin{array}{l}\text { Merkblätter und Plakate des Vaterländischen Frauenvereins (Nr. 13, } \\
\text { S. 90) }\end{array}$ \\
\hline 18.08.1915 & Hildesheim & $\begin{array}{l}\text { Lichtspielaufführungen zum Besten des "Invalidendanks" (Nr. 13, S. } \\
\text { 91) }\end{array}$ \\
\hline 03.07 .1915 & Berlin & Ährenlesen (Nr. 14,S. 94/95) \\
\hline 05.07 .1915 & Berlin & Gummisammlung (Nr. 14, S. 95) \\
\hline 26.07 .1915 & Cassel & Schonung von Sonnenblumen (Nr. 15, S. 101) \\
\hline 07.08.1915 & Berlin & $\begin{array}{l}\text { Sammlung von "Weidenröschen" zum Ersatz von Rohjute (Nr. 16, S. } \\
\text { 107/108) }\end{array}$ \\
\hline 15.08.1915 & Berlin & Dritte Kriegsanleihe (Nr. 18, S. 119/120) \\
\hline 06.08 .1915 & Hildesheim & Bilder der gefallenen Lehrer in den Schulen (Nr. 18, S.122) \\
\hline 16.09 .1915 & Berlin & Nutzbarmachung der Eicheln und Bucheln (Nr. 18, S. 122) \\
\hline 14.09.1915 & Berlin & $\begin{array}{l}\text { Der Verwertung von Eicheln, Bucheln, Roßkastanien, Linden-, } \\
\text { Ahornfrüchten und getrockneten Vogelbeeren als Vieh- und } \\
\text { Hühnerfutter sowie zur Ölbereitung (Nr. 20, S. 132-137) }\end{array}$ \\
\hline 06.09 .1915 & Hannover & Jugendspende für Kriegerwaisen (Nr. 20, S. 138/139) \\
\hline 29.09 .1915 & Berlin & Goldsammlungen (Nr. 21, S. 145/146) \\
\hline 25.10.1915 & Berlin & $\begin{array}{l}\text { Verwertung von Brennesseln für die Zwecke der Hanf- und } \\
\text { Juteindustrie (Nr. 21, 146/147) }\end{array}$ \\
\hline \multicolumn{3}{|l|}{1916} \\
\hline 26.01 .1916 & Hildesheim & Goldsammlung (Nr. 3, S. 12/13) \\
\hline 21.01.1916 & Berlin & Beurlaubung älterer Schüler (Nr. 3, S. 15/16) \\
\hline 17.02.1917 & Berlin & Kriegsanleihe (Nr. 5, S. 19/20) \\
\hline 18.02 .1916 & Berlin & Ausnutzung von Kartoffeln (Nr. 5, S. 20) \\
\hline
\end{tabular}




\begin{tabular}{|c|c|c|}
\hline 09.02 .1916 & Berlin & Anpflanzung von Sonnenblumen (Nr.6, S. 23-27) \\
\hline 18.03 .1916 & Berlin & Papierersparnis in den Schulen (Nr. 7, S. 31) \\
\hline 22.03 .1916 & Hannover & Sammlung von Zeitungspapier (Nr. 7, S. 32) \\
\hline 22.03 .1916 & Berlin & Anpflanzung von Sonnenblumen (Nr. 7, S: 32-35) \\
\hline 18.03 .1916 & Berlin & Sammlung von nicht mehr gebrauchten Tauen (Nr. 7, S. 36) \\
\hline 08.04 .1916 & Berlin & Beurlaubung älterer Schulkinder für die Obsternte (Nr. 8, S. 43) \\
\hline 06.05 .1916 & Berlin & $\begin{array}{l}\text { Verbot des Verkaufs von Ansichtskarten durch Schulkinder (Nr. 10, } \\
\text { S. 57) }\end{array}$ \\
\hline 08.05 .1916 & Berlin & Maikäfer als Hühner- und Schweinefutter (Nr. 10, S. 58) \\
\hline 10.05 .1916 & Berlin & Bekämpfung des Kartoffelkäfers (Nr. 10, S. 58) \\
\hline 19.05.1916 & Berlin & Papierersparnis (Nr. 11, S. 61/62) \\
\hline 13.05 .1916 & Berlin & Goldsammlung (Nr. 11, S. 62/63) \\
\hline \multicolumn{3}{|l|}{1917} \\
\hline 17.03.1917 & Berlin & Landwirtschaftliche Arbeiten der Schuljugend (Nr. 7, S.61) \\
\hline 16.03.1917 & Berlin & Anbau von Sonnenblumen (Nr. 7, S. 61) \\
\hline 25.03 .1917 & Berlin & Frühgemüse (Nr. 8, S. S. 75/76) \\
\hline 12.04 .1917 & Hildesheim & Pilzbestimmungsstelle (Nr. 8, S: 76/77) \\
\hline \multirow[t]{2}{*}{01.05 .1917} & Hildesheim & Aufruf zur Landarbeit durch General Groener (Nr. 9, S. 81) \\
\hline & Berlin & $\begin{array}{l}\text { Beurlaubung von Schulkindern zur Vertilgung der Raupennester zur } \\
\text { Pflege Baumscheiben usw. (Nr. 9, S. 82/83) }\end{array}$ \\
\hline 25.04 .1917 & Berlin & U-Boot-Spende (Nr. 10, S. 90) \\
\hline 27.04 .1917 & Berlin & Beihilfen zur Förderung der Obstbauzucht (Nr. 10, S. 91) \\
\hline 27.02.1917 & Berlin & $\begin{array}{l}\text { Sammlung kleinerer Gegenstände aus Sparmetallen (Nr. 11, S. } \\
\text { 103/104) }\end{array}$ \\
\hline 06.06 .1917 & Berlin & Sammlung von Obstkernen; mit Merkblatt (Nr. 11, S. 104/105) \\
\hline 16.06 .1917 & Hildesheim & $\begin{array}{l}\text { Beurlaubung der Schulkinder zu dringenden landwirtschaftlichen } \\
\text { Arbeiten (Nr. 12, S. 107/8) }\end{array}$ \\
\hline 25.05 .1917 & Berlin & Wohlfahrtskarte Seiner Majestät des Kaisers (Nr. 12, S. 118/119) \\
\hline 16.06 .1917 & Berlin & $\begin{array}{l}\text { Volksspende zum Ankauf von Lesestoff für Heer und Flotte (Nr. 13, } \\
\text { S. 121) }\end{array}$ \\
\hline 05.06 .1917 & Berlin & $\begin{array}{l}\text { Nutzbarmachung der Beeren und Pilze u. wildwachsendem Gemüse } \\
\text { (Nr.13, S: 121-127) }\end{array}$ \\
\hline 08.06 .1917 & Berlin & Sammlung von Teeersatzmittel (Nr. 13, S. 127/128) \\
\hline 05.07 .1917 & Hildesheim & Pilztafel (Nr. 14, S: 133/134) \\
\hline \multirow[t]{2}{*}{ 11.07.1917 } & Berlin & $\begin{array}{l}\text { Sammlung der Früchte des Weißdorns zur Gewinnung eines } \\
\text { Kaffeersatzmittel }\end{array}$ \\
\hline & & (Nr. 15, S. 143/44) \\
\hline 23.07 .1917 & Berlin & Brennesselsammlung; mit Merkblatt (Nr. 15, S. 144/146) \\
\hline 10.08 .1917 & Berlin & Sammlung von Arzneipflanzen (Nr. 16, S: 155-157) \\
\hline 17.08.1917 & Hildesheim & Beurlaubungen für die Obsternte (Nr. 16, S. 158) \\
\hline 23.07 .1917 & Berlin & Sparsamkeit im Gebrauch von Lederzeug (Nr. 16, S.162) \\
\hline 23.07 .1917 & Hildesheim & Sammlung von Teeersatzmitteln (Nr. 16, S. 162/163) \\
\hline 20.08 .1917 & Berlin & Siebte Kriegsanleihe (Nr. 17, S. 165/166) \\
\hline 14.08 .1917 & Hildesheim & Pilztafeln und Merkblätter (Nr. 17, S. 168/169) \\
\hline 26.08 .1917 & Berlin & Papierersparnis bei Schulversäumnislisten (Nr. 18, S. 179) \\
\hline 20.09 .1917 & Hildesheim & Hindenburgfeier (Nr. 19, S.190/191) \\
\hline 25.09.1917 & Berlin & $\begin{array}{l}\text { Beteiligung der Schulkinder an der Kartoffelernte (Nr, 20, S. } \\
\text { 193/194) }\end{array}$ \\
\hline 28.09 .1917 & Berlin & Abgabe von Knochenbrühwürfeln für Obstkerne (Nr. 20, S. 194/195) \\
\hline 08.10 .1917 & Hannover & $\begin{array}{l}\text { Weihnachtsgaben für die Hannoverschen Truppen (Nr. 21, S. } \\
\text { 203/204) }\end{array}$ \\
\hline 20.11 .1917 & Berlin & Beteiligung der Lehrer an der Volkszählung (Nr. 23, S. 229/230) \\
\hline \multicolumn{3}{|l|}{1918} \\
\hline 14.12.1917 & Berlin & Sammlung von Knochen; mit Merkblatt (Nr. 1, S.8-13) \\
\hline 18.01 .1918 & Berlin & Achte Kriegsanleihe (Nr. 3, S. 23) \\
\hline \multirow[t]{2}{*}{ 11.12.1917 } & Berlin & $\begin{array}{l}\text { Heranziehung der Schuljugend zur Vertilgung der Mäuse, Hamster } \\
\text { und Raupen }\end{array}$ \\
\hline & & (Nr. 3, S. 24/25) \\
\hline 06.02 .1918 & Berlin & $\begin{array}{l}\text { Einschränkung des Papierverbrauchs im Zeichenunterricht (Nr. 5, S. } \\
\text { 39/40) }\end{array}$ \\
\hline 18.01 .1918 & Berlin & Anregung zur Vermehrung des Kartoffelverbrauchs (Nr. 5, S. 41) \\
\hline
\end{tabular}




\begin{tabular}{|c|c|c|}
\hline 24.01 .1918 & Berlin & Sammlung von Weißblech- und Zinngegenständen (Nr. 5, S. 41/42) \\
\hline 03.12 .1917 & Berlin & Petroliummangel (Nr. 5, S. 42-44) \\
\hline 02.02 .1918 & Berlin & Schulschreibhefte (Nr. 5, S. 45/46) \\
\hline 12.03 .1918 & Hildesheim & Sammlung von einheimischen Arzneipflanzen (Nr.6, S. 53-55) \\
\hline 06.03 .1918 & Hildesheim & Sammlung von Knospenreisig als Futterersatz (Nr. 6, S: 55) \\
\hline 19.03.1918 & Hildesheim & Achte Kriegsanleihe (Nr.7, S. 61/62) \\
\hline 27.03 .1918 & Berlin & Erhebung über Anbauflächen (Nr. 8, S. 68/89) \\
\hline 18.03 .1918 & Berlin & Gemüse- und Obstanbau (Nr. 8, S. 69-72) \\
\hline 16.03 .1918 & Berlin & Deutsche wilde Gemüse (Nr. 8, S. 72/73) \\
\hline 28.03 .1918 & Berlin & Sammeln von Laub- und Reisigfutter (Nr. 8, S. 73/74) \\
\hline 22.03 .1918 & Berlin & Einschränkung des Handarbeitsunterrichts (Nr. 8, S. 74/75) \\
\hline 24.04 .1918 & Berlin & $\begin{array}{l}\text { Beteiligung der Schuljugend an kriegswirtschaftlichen Arbeiten und } \\
\text { Samml. (Nr.10, S. 85-88) }\end{array}$ \\
\hline 30.04 .1918 & Berlin & Ludendorff-Spende (Nr. 10, S. 90/91) \\
\hline 04.05 .1918 & Berlin & Vertrieb von Postkarten für eine U-Bootspende (Nr. 10, S. 91/92) \\
\hline 08.06 .1918 & Hildesheim & Laubgewinnung für das Feldheer (Nr. 11a, S. 107-113) \\
\hline 31.05 .1918 & Berlin & Ludendorff-Spende für Kriegsbeschädigte (Nr. 11a, S. 113/114) \\
\hline 13.06 .1918 & Hildesheim & Sammlung von Wildfrüchten (Nr. 12, S. 122/123) \\
\hline 12.06 .1918 & Hildesheim & Sammlung von Knochen (Nr. 12, S. 123) \\
\hline 29.06 .1918 & Hildesheim & $\begin{array}{l}\text { Preisausschreiben des Jugenddank für Kriegsbeschädigte zur } \\
\text { Gewinnung von Jugenddank-Postkarten (Nr.12, S. 124) }\end{array}$ \\
\hline 27.06 .1918 & Berlin & Laubheugewinnung (Nr. 13, S. 127/128) \\
\hline 08.07 .1918 & Hildesheim & Sammeln von Laubheu (Nr. 14, S: 131/132) \\
\hline 10.06 .1918 & Berlin & $\begin{array}{l}\text { Fahrpreisermäßigung für Schulkinder zum Sammeln von Laubheu } \\
\text { (Nr. 14, S: 133-137) }\end{array}$ \\
\hline 22.06 .1918 & Berlin & Kolonialkriegerspende (Nr.14, S. 138) \\
\hline 22.07 .1918 & Hannover & Brennesselsammlung (Nr. 14, S. 146/147) \\
\hline 24.07 .1918 & Berlin & Papierersparnis bei Schulheften (Nr. 15, S. 148) \\
\hline 06.08 .1918 & Hannover & Laubheu (Nr. 16, S. 151/152) \\
\hline 31.08 .1918 & Hildesheim & Laubheusammlung (Nr. 17, S. 159) \\
\hline 26.08 .1918 & Hildesheim & Brennesselsammlung (Nr. 17, S. 159) \\
\hline 24.08 .1918 & Hildesheim & $\begin{array}{l}\text { Sammlung von Bucheckern, Eicheln und Kastanien (Nr.17, S. 159- } \\
\text { 161) }\end{array}$ \\
\hline 16.09 .1918 & Hildesheim & Aufruf an die Lehrer zur neunten Kriegsanleihe (Nr.18, S. 163/164) \\
\hline 12.09 .1918 & Hannover & Neunte Kriegsanleihe. Nationalzeichnungstag (Nr. 19, S. 169-171) \\
\hline 23.08 .1918 & Hildesheim & Militärische Vorbereitung der Jugend (Nr. 19, S. 172) \\
\hline 15.08 .1918 & Berlin & Ernte von Eicheln und Kastanien \\
\hline 11.10 .1918 & Berlin & Beurlaubungen zur Kartoffel- und Rübenernte \\
\hline 23.09 .1918 & Hannover & $\begin{array}{l}\text { Ablieferung von gesammeltem Frauenhaar an die Deutsche } \\
\text { Frauenhaarsammlung }\end{array}$ \\
\hline & & Roten Kreuz in Magdeburg (Nr. 20, S. 177/178) \\
\hline 30.09 .1918 & Berlin & Sammlung von Hopfenstengeln (Nr. 20, S. 179 \\
\hline 30.09 .1918 & Berlin & Laubheusammlung (Nr. 20, S. 182) \\
\hline 18.10 .1918 & Hildesheim & Bucheckernsammlung (Nr. 20, S. S. 183) \\
\hline 05.10 .1918 & Hildesheim & Brennesselsammlung (Nr. 20, S: 183) \\
\hline 20.10 .1918 & Hildesheim & Beurlaubung von Schulkindern zu Erntearbeiten (Nr. 21, S. 184) \\
\hline 17.10 .1918 & Hildesheim & Brennesselsammlung (Nr.21, S. 184) \\
\hline 04.10 .1918 & Berlin & $\begin{array}{l}\text { Beteiligung der Schuljugend an kriegswirtschaftlichen Arbeiten (Nr. } \\
\text { 22, S. 190/191) }\end{array}$ \\
\hline 13.11 .1918 & Hildesheim & Schulschließungen für landwirtschaftliche Arbeiten (Nr. 22, S. 191) \\
\hline 12.10 .1918 & Berlin & $\begin{array}{l}\text { Anlegung von Sammelzeichnungen für die Kriegsanleihen (Nr. 22, } \\
\text { S. 193-196) }\end{array}$ \\
\hline
\end{tabular}

Insgesamt 181 Verfügungen 


\section{Kapitel 2}

\section{Gedichte I}

\section{Alt-Metalltag in der Schule}

Gebt acht, ihr Knaben:

Ihr werdet wohl selbst schon überall

den Aufruf ,Sammel Alt-Metall!“

an Säulen und Wänden gelesen haben.

So stöbert denn i h $\mathrm{r}$ auch unterm Dach

in Kisten und Truhen fleißig nach

und schleppt, was ihr findet an Zinn und Blei,

an Nickel, Messing und Kupfer herbei!

Bringt alles! Es ist zu dieser Zeit

Die kleinste Gabe von Wichtigkeit. -

Wer will sich nun Mühen fürs Vaterland?

Der hebe die Hand!

Und fünf Dutzend Finger flitzen empor:

Ich! Ich erklingt es im Jubelchor.

Und nachmittag's: auf der Treppe schon umsummt's mich wie eifriger Bienenton. Ich trete ins surrende Zimmer - und jeder Der Sammler stürmt jauchzend zum Katheder Und breitet, was er erbeutet im Haus

Erbettelt, erschmeichelt, voll Stolz nun aus. -

Bald deckte den Tisch ein stattlicher Hauf

Gerät' und Gerümpels - wer zählt es auf?

Auch vielerlei Spielzeug aus Messing und Zinn

Ward fröhlich gespendet mit selbstlosem Sinn, und manchem der Stücke sah man's an, wie sie ihm künstlich Gewalt angetan:

Wie sie lachend, mit reinstem Bubengewissen, von „Lokomotiven“ die Räder gerissen; wie sie Bleisoldaten, so lieb so teuer, rasch umgeschmolzen am Ofenfeuer.

Kurzum, wie sie alle, heilig durchglüht, zu köstlichem Opfer sich redlich bemüht.

Doch als ich nun so sonder Zaudern und Beben

Sie sah ihr Geliebtes und Bestes geben, das wurde mit seltsam ums Herz - und leis stieg's auf in die Augen, feucht und heiß und selig sang ich in mich hinein:

Lieb Vaterland magst ruhig sein...!

Josef Rauscher

Quelle: Deutschlands Jugend in großer Zeit - ein Buch vom Weltkriege für jung und alt, Reinold Braun, Stiftungsverlag in Potsdam 1916, S.100/101 


\section{Gedichte II}

\section{„Eine Laub-Heu-Sammelfahrt““}

Was rennt das Volk, was wälzt sich dort

Die Billiger Straße brausend fort?

Stürzt Billig unter Feuersflammen?

Es rottet sich ein Sturm zusammen.

Und hoch beglückt, den Strang

berührt zu haben,

Der Karren zieht, begleiten frohe Knaben

Mit hellen Liedern die verehrte Last,

Ihnen stürzt in dicht geschlossenen Gliedern

Die ganze Schar der Freunde nach . . .

... Und der Professor mit frohem Blick

Von des Hügels weitschauender Spitze

Überzählet vom luftigen Sitze

der Säcke gefüllte Bäuche (. . .)

Wanderer, kommst du nach Billig,

verkündige dorten,

Du habest sie hier liegen gesehen,

Wo steil der Fahrweg herabstürzt . . ."

Das damals bekannte Euskirchener Gedicht war im Volksblatt vom 16. 8. 1918 abgedruckt.

Quelle: http://www.hans-dieter-arntz.de/100_jahre_marienschule.html 


\section{Gedichte III}

Ein Begleitschreiben seiner Klasse aus Gundershofen hatte der Lehrer in folgendes Gedicht umgeformt:

„Die Mädchen können Socken stricken

Und andere warme Sachen

Und sie dann an Soldaten schicken

Und ihnen Freude machen,

Was haben sie auch brav getan schon haben.-

Was aber tun wir Knaben?

Da haben wir denn so gedacht:

Eine Sparbüchse ist ja schnell gemacht.

Dann wollen wir jeden Pfennig sparen,

Den wir, wenn wir fleißig waren,

Von Eltern und Nachbarn bekommen haben.

So können helfen Mädchen und Knaben.

Schnell machten wir ein Kistchen leer

Und stellten eine Sparbüchse her.

In der Schule wurde sie aufgestellt,

Wir warfen hinein das verdiente Geld,

Sooft wir in die Schule kamen.

Bald schon war eine hübsche Summe beisammen.

Wir schauten, ob wir genug bald hätten.

Es reichte. Wir kauften Zigaretten.

Zwei Radler taten's. Sie kamen zurück.

Und hatten ein Kistchen mit tausend Stück.

Das senden wir nun den Soldaten ins Feld

Und hoffen, daß es dort allen gefällt.

Und denken, es hat das rechte getroffen

Die Oberstufe von Gundershofen.

Grüß Gott, ihr Soldaten, raucht fröhlich und heiter,

Es kommt bald ein zweites, wir sammeln weiter.“

Quelle: Führen, Lehrer im Krieg, S. 64 


\section{Kapitel 3}

\section{Ansichtskarten}

Karten der Serie "Unsere Kinder im Krieg"
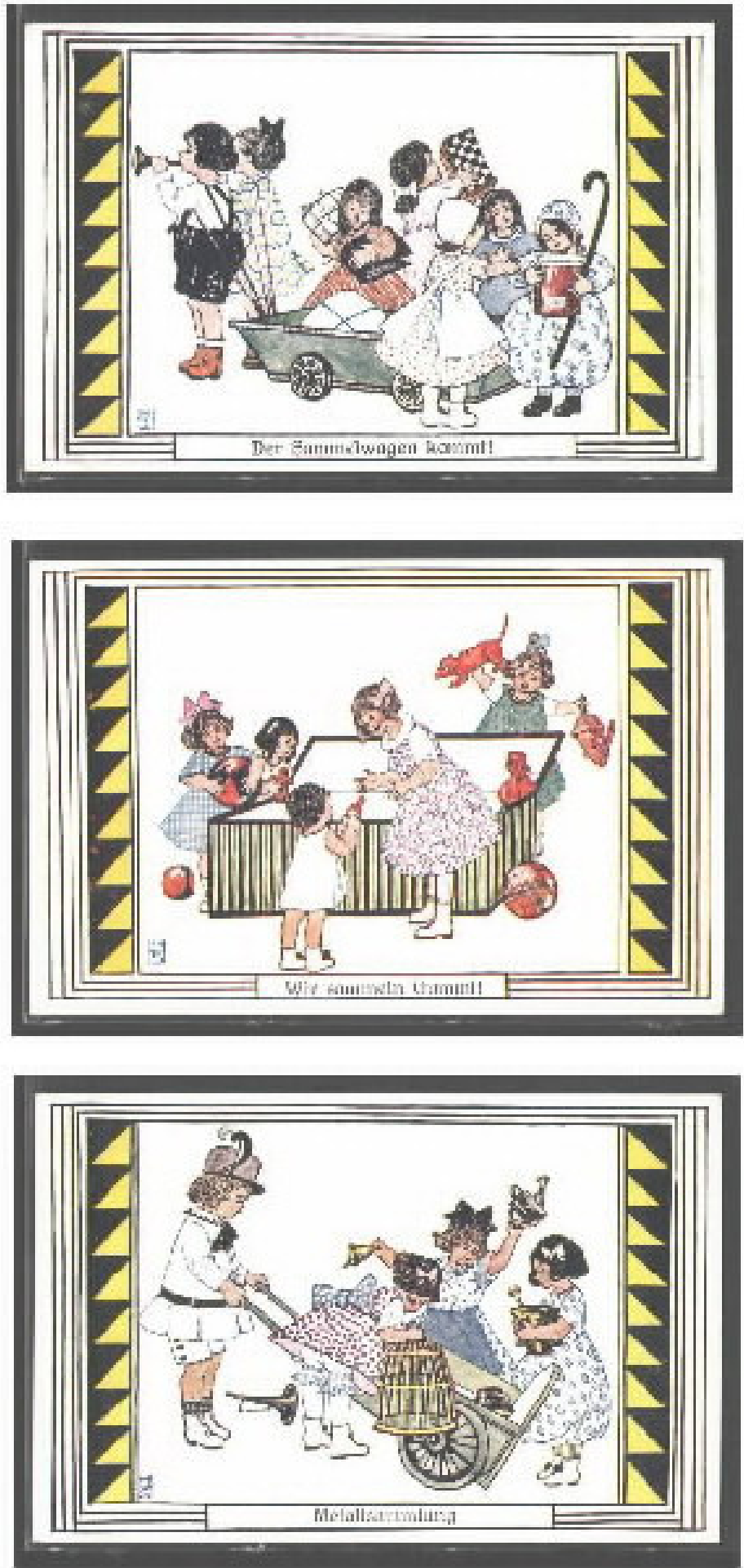

Quelle: Sammlung Kronenberg 


\section{Statistik I}

Ergebnisse der 4. Kriegsanleihe

Tafer 1.

\begin{tabular}{|c|c|c|c|c|c|c|c|c|c|c|}
\hline \multirow{2}{*}{ Frovinz } & \multirow{2}{*}{ 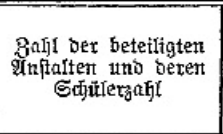 } & \multirow{2}{*}{ 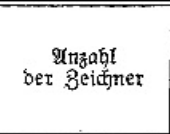 } & \multirow{2}{*}{ 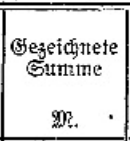 } & \multirow{2}{*}{ 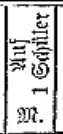 } & \multicolumn{2}{|c|}{ Dabon uttter 100 Matz } & & \multirow{2}{*}{ 焉 } & \multirow{2}{*}{ 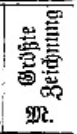 } \\
\hline & & & & & $\begin{array}{l}\text { getrag } \\
\text { me. }\end{array}$ & $\begin{array}{c}\text { Yutzaki } \\
\text { Der Betwiter }\end{array}$ & Betrag & 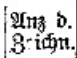 & & \\
\hline 1 & 2 & 3 & 4 & 5 & 6 & 7 & 8 & 9 & 10 & 21 \\
\hline 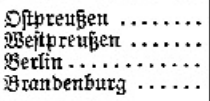 & 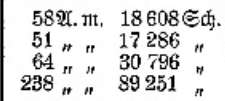 & 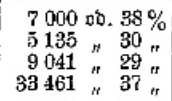 & $\begin{array}{r}1118294 \\
930563 \\
1304899 \\
4037006\end{array}$ & $\begin{array}{l}160 \\
181 \\
144 \\
121\end{array}$ & 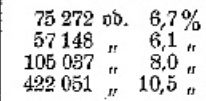 & $\begin{array}{r}3081 \text { ⿰D. } 44 \% \\
1977 " 39 " \\
3314 " 37 " \\
14801 " 44 "\end{array}$ & $\begin{array}{r}9668 \\
9291 \\
4703 \\
33973\end{array}$ & $\begin{array}{r}1266 \\
570 \\
538 \\
3937\end{array}$ & $\begin{array}{l}1 \\
1 \\
1 \\
1\end{array}$ & $\begin{array}{r}5650 \\
10000 \\
30000 \\
12000\end{array}$ \\
\hline 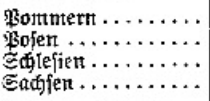 & 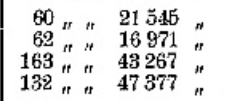 & 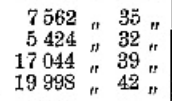 & $\begin{array}{r}881091 \\
703480 \\
1786675 \\
2345486\end{array}$ & $\begin{array}{l}117 \\
130 \\
10.5 \\
118\end{array}$ & 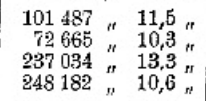 & 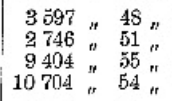 & $\begin{array}{r}882 \theta \\
8711 \\
28032 \\
33202\end{array}$ & $\begin{array}{l}1062 \\
1043 \\
3592 \\
4608\end{array}$ & {$\left[\begin{array}{l}1 \\
1 \\
1 \\
1\end{array}\right]$} & $\begin{array}{l}20000 \\
10000 \\
10000 \\
10000\end{array}$ \\
\hline 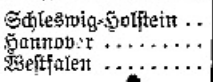 & $\begin{array}{l}101 " \text { " } 34816 " \\
129 " \text { " } 44385 " ~ \\
159 " \text { " } 41022 "\end{array}$ & 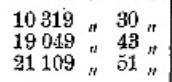 & $\begin{array}{l}1478332 \\
2197050 \\
2875604\end{array}$ & $\begin{array}{l}148 \\
115 \\
136\end{array}$ & 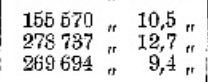 & $\begin{array}{l}4758,46 " \\
9117 " 48 " \\
9908,47 "\end{array}$ & $\begin{array}{l}10056 \\
20342 \\
25145\end{array}$ & $\begin{array}{l}1035 \\
2434 \\
3312\end{array}$ & $\begin{array}{c}1 \\
1 \\
1 / 2\end{array}$ & $\begin{array}{l}10000 \\
10000 \\
20000\end{array}$ \\
\hline 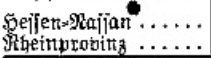 & $\begin{array}{r}66 " \text { " } 21698 \text { " } \\
253 " \text { " } 84414 \text { " } \\
\end{array}$ & $\begin{array}{r}9160 " \\
39197 " 42 "\end{array}$ & $\begin{array}{r}995380 \\
\text { ธ779 945 } \\
\end{array}$ & $\begin{array}{l}109 \\
147 \\
\end{array}$ & $\begin{array}{r}108987 " 10,9 n \\
467721 " 7,99_{n}^{n} \\
\end{array}$ & $\begin{array}{r}4703 " \text { ว1" } \\
16950 " 43 " \\
\end{array}$ & $\begin{array}{l}13950 \\
45681\end{array}$ & $\begin{array}{r}2100 \\
5342 \\
\end{array}$ & $\begin{array}{l}1 \\
1 \\
\end{array}$ & $\begin{array}{l}10000 \\
32000\end{array}$ \\
\hline & $1536 \mathfrak{4}, 111.611936$ ङक. & $203499.00 .40 \%$ & 26433805 & 130 & 2589586 00. $9,8 \%$ & 95065 vD. $47 \%$ & 48083 & & & \\
\hline
\end{tabular}

Tafel 2.

\begin{tabular}{|c|c|c|c|c|c|c|c|c|c|c|}
\hline Stat & $\begin{array}{l}\text { Baby ber beteifigtent } \\
\text { Writalter unt berent } \\
\text { હdifletzabl. }\end{array}$ & $\begin{array}{c}\text { Mnzahr } \\
\text { Der Betwermer }\end{array}$ & $\begin{array}{l}\text { OStzeidnete } \\
\text { Entritte } \\
\text { פ⿰冫. }\end{array}$ & 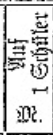 & $\begin{array}{l}\text { Dawon urter } \\
\text { Setrog } \\
\text { sh. }\end{array}$ & 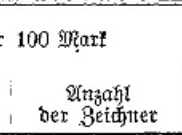 & $\begin{array}{c}\text { Unter } 20 \\
\text { Wetrag! } \\
\text { Oi. }\end{array}$ & 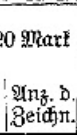 & 㱐 & 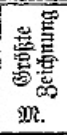 \\
\hline 1 & 2 & 3 & 4 & 5 & 6 & 7 & 8 & 9 & 10 & 11 \\
\hline 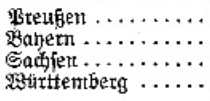 & 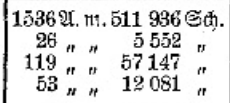 & 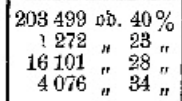 & \begin{tabular}{|r|}
26433805 \\
199198 \\
1515815 \\
511730
\end{tabular} & $\left|\begin{array}{r}130 \\
157 \\
94 \\
126\end{array}\right|$ & $\mid \begin{array}{rrr}2589085 \text { c5. } & 9,8 \% \\
10610 & 5,3 \% \\
200374 & 13,2 \\
47345 & 0, & 9,3\end{array}$ & 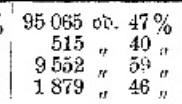 & $\mid \begin{array}{r}248083 \\
2055 \\
34643 \\
5389\end{array}$ & $\begin{array}{r}30839 \\
270 \\
4809 \\
677\end{array}$ & & $\begin{array}{r}32000 \\
3000 \\
12000 \\
3000\end{array}$ \\
\hline 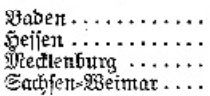 & 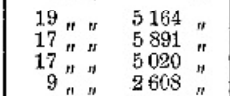 & 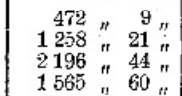 & & $\begin{array}{l}288 \\
138 \\
115 \\
115\end{array}$ & 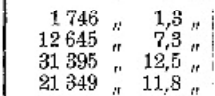 & $\mid \begin{array}{lll}128 & 37 & 37 \\
466 & 37 & 37 \\
887 & 40 \\
762 " & 49 "\end{array}$ & $\mid \begin{array}{r}606 \\
1269 \\
945 \\
2099\end{array}$ & $\begin{array}{r}98 \\
164 \\
92 \\
220\end{array}$ & $\begin{array}{r}2 \\
1 \\
10 \\
1\end{array}$ & $\begin{array}{l}5000 \\
5000 \\
1200 \\
5000\end{array}$ \\
\hline 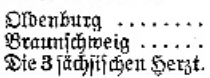 & 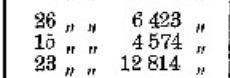 & $\begin{array}{l}3575 " 56 " \\
1152 " \text { " } 54 " \\
2297 " 18 "\end{array}$ & & $\begin{array}{l}129 \\
134 \\
124\end{array}$ & 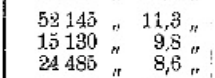 & $\begin{array}{r}1526 " 43 " \\
457 " \\
827 " 40 " \\
86 "\end{array}$ & $\begin{array}{r}2478 \\
750 \\
1620\end{array}$ & $\begin{array}{r}277 \\
77 \\
226\end{array}$ & & $\begin{array}{l}5000 \\
3100 \\
4000\end{array}$ \\
\hline 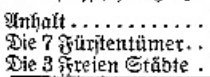 & $\begin{array}{rrr}20 & & 7705 \\
21 " & 6554 & \\
27 & \prime \prime & 12476 . "\end{array}$ & 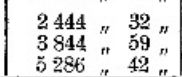 & $\begin{array}{l}222788 \\
367664 \\
56: 068\end{array}$ & $\begin{array}{r}91 \\
96 \\
106 \\
\end{array}$ & $\begin{array}{l}32447 " 14,6 " \\
49301 \text { " } 13,4 " \\
91616 " 16,3,\end{array}$ & 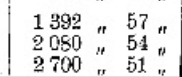 & $\begin{array}{l}3993 \\
6988 \\
5422\end{array}$ & $\begin{array}{l}639 \\
929 \\
655\end{array}$ & $\left|\begin{array}{l}1 \\
1 \\
1\end{array}\right|$ & $\begin{array}{l}1500 \\
7000 \\
5000\end{array}$ \\
\hline
\end{tabular}

Tafel 3.

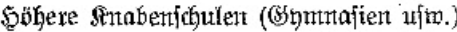

\begin{tabular}{|c|c|c|c|c|c|c|c|}
\hline ßrobing & \multicolumn{4}{|c|}{ 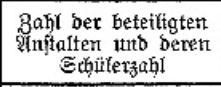 } & $\begin{array}{c}\text { 2ftzatil ber } \\
\text { 3eichner }\end{array}$ & $\begin{array}{l}\text { (3) zeidyt. } \\
\text { ङumme } \\
\text { m. }\end{array}$ & $\mid \begin{array}{l}\mathbb{W}=11 \\
1 \\
1 \\
\text { Sta. } \\
\mathfrak{M}\end{array}$ \\
\hline 1 & & 3 & 4 & 5 \\
\hline 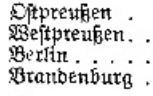 & \multicolumn{4}{|c|}{ 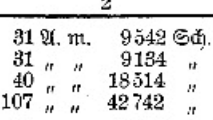 } & $\begin{array}{r}373500.39 \% \\
3344 " 37 \% \\
5042 " 27 \% \\
17384 " 41 \%\end{array}$ & $\begin{array}{r}71.5800 \\
627500 \\
804500 \\
2256300\end{array}$ & $\begin{array}{l}192 \\
188 \\
160 \\
130\end{array}$ \\
\hline 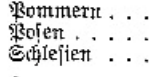 & \multicolumn{4}{|c|}{$\begin{array}{rllrl}30 & \prime \prime & 8567 & \prime \prime \\
26 & \prime \prime & 8280 & " \prime \\
77 & \prime \prime & 22297 & " \prime\end{array}$} & $\begin{array}{lll}3729 & 44 \% \\
3044 & 37 \% \\
8855 & 40 \% & 40 \%\end{array}$ & $\begin{array}{r}521000 \\
472100 \\
1087100\end{array}$ & $\begin{array}{l}140 \\
155 \\
123\end{array}$ \\
\hline 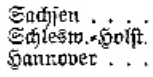 & \multicolumn{4}{|c|}{$\begin{array}{lllll}49 & \prime \prime & 13864 & \\
32 & \prime \prime & 12038 & " \prime \\
51 & \prime \prime & 17417 & " \prime\end{array}$} & $\begin{array}{l}7296 \text { " } 53 \% \\
4157 " 35 \% \\
8911 " \\
\text { " } 51 \%\end{array}$ & $\begin{array}{r}1316200 \\
712900 \\
1214900\end{array}$ & $\begin{array}{l}180 \\
171 \\
136\end{array}$ \\
\hline 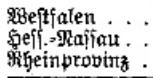 & \multicolumn{4}{|c|}{ 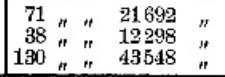 } & $\begin{array}{rl}11156 & " 51 \% \\
5116 & " 42 \% \\
20002 & " 46 \%\end{array}$ & $\begin{array}{r}1830600 \\
671400 \\
3474200\end{array}$ & $\begin{array}{l}164 \\
131 \\
174\end{array}$ \\
\hline & \multicolumn{4}{|c|}{ 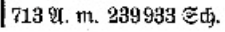 } & 10177100.42 & $15704500 \mid$ & 15 \\
\hline
\end{tabular}

Tafel 4.

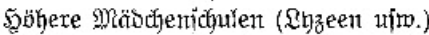

\begin{tabular}{|c|c|c|c|c|c|c|}
\hline Frobing & \multicolumn{3}{|c|}{ 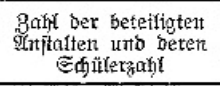 } & 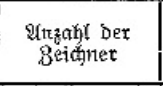 & $\begin{array}{c}\text { Bezeiditt. } \\
\text { Sitmmte } \\
\text { s. }\end{array}$ & 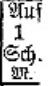 \\
\hline 1 & \multicolumn{3}{|c|}{2} & 3 & 4 & 5 \\
\hline 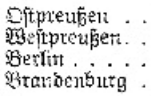 & $\begin{array}{l}20 \text { भ. n. } \\
13 " n " \\
21 " n \\
83 " n "\end{array}$ & $\begin{array}{r}6645 \\
5053 \\
\mathbf{1 1 1 1 1} \\
\mathbf{3 0 9 3 4}\end{array}$ & $\begin{array}{c}\text { 巨ள. } \\
" \\
" \\
"\end{array}$ & $\begin{array}{r}251300.38 \% \\
1258 \text { " } 25 \% \\
3805 " 34 \% \\
12057 \% 39 \%\end{array}$ & $\begin{array}{r}368400 \\
212200 \\
488100 \\
1424500\end{array}$ & $\begin{array}{l}147 \\
169 \\
128 \\
118\end{array}$ \\
\hline 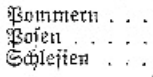 & 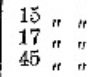 & $\begin{array}{r}4377 \\
4879 \\
11026\end{array}$ & & $\begin{array}{l}2096 " 48 \% \\
1402 " 29 \% \\
4693 " 43 \%\end{array}$ & & $\begin{array}{r}108 \\
120 \\
99\end{array}$ \\
\hline 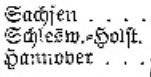 & $\begin{array}{lll}27 & " \prime \prime \\
18 " & " \prime \\
39 & " \prime\end{array}$ & $\begin{array}{r}8948 \\
6419 \\
12675\end{array}$ & & $\begin{array}{l}4251 " 48 \% \\
2418 " 38 \% \\
6498 . " 51 \%\end{array}$ & $\begin{array}{l}541300 \\
334700 \\
649700\end{array}$ & $\begin{array}{l}127 \\
139 \\
100\end{array}$ \\
\hline 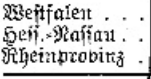 & $\begin{array}{ll}37 & " \prime \\
20 & " \prime \\
87 " \prime \prime \\
\end{array}$ & $\begin{array}{r}10803 \\
5675 \\
28712 \\
\end{array}$ & & $\begin{array}{r}5710 \text { " } 53 \% \\
2712 " 48 \% \\
14262 \% 50 \% \\
\end{array}$ & $\begin{array}{r}732100 \\
278600 \\
1868200 \\
\end{array}$ & $\begin{array}{l}128 \\
103 \\
131 \\
\end{array}$ \\
\hline & 42 भ. m. & 957 & & 63670 00. 43 & 9800 & 122 \\
\hline
\end{tabular}




\section{Statistik II}

\section{Ergebnisse der 4. Kriegsanleihe}

Material 1

\begin{tabular}{|c|c|c|c|c|}
\hline & 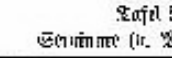 & โท. 2 . & & \\
\hline $4=0 \mathrm{t}=3$ & 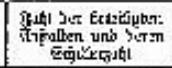 & 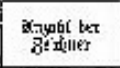 & 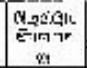 & 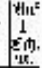 \\
\hline 1 & $B$ & 5 & 4 & 6. \\
\hline 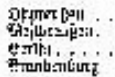 & 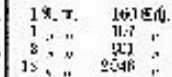 & 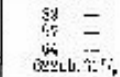 & 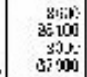 & $=$ \\
\hline 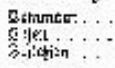 & : & 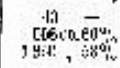 & 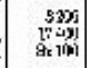 & $\sum_{63}$ \\
\hline 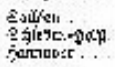 & 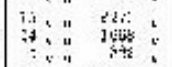 & 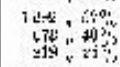 & 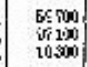 & 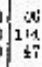 \\
\hline 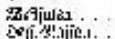 & 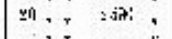 & Ezere, $1 i ?$ & 20190 & i \\
\hline 9: & 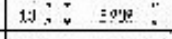 & 493,319 & I18:40, & $\underline{n}$ \\
\hline$q \pi \mathrm{rf} ; \mathrm{x}^{\circ}$ & |رyx & 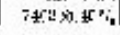 & akrions & 1) 7 \\
\hline & 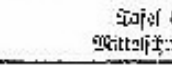 & & & \\
\hline nwotis & 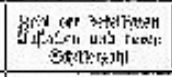 & 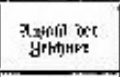 & 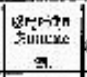 & 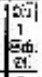 \\
\hline 1 & 2 & 3 & $\div$ & 15 \\
\hline 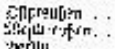 & 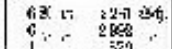 & 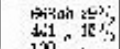 & s10 & 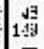 \\
\hline 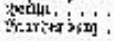 & 秎: & $\log _{200}$ & $\begin{array}{l}180 \\
23+40\end{array}$ & $\bar{s}$ \\
\hline 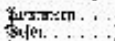 & 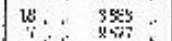 & 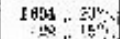 & 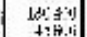 & $i_{10}^{77}$ \\
\hline sithriti $\ldots$ & 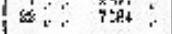 & =1\%: & 1,00000 & 71 \\
\hline 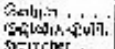 & 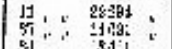 & 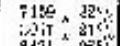 & $\frac{149000}{\sin 3 \times 10}$ & $\infty_{\infty}^{\infty}$ \\
\hline & $51 \ldots=3.11$ & $\begin{array}{ll}8121 \\
99=35\end{array}$ & 323300 & \\
\hline . & M $: \therefore$ & ist: & 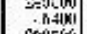 & 3 \\
\hline 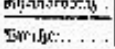 & $6-1, \ldots=121$, & $-4 \div 11 n_{n} 238$ & Estriki & 3 \\
\hline $1158 \div \ldots$ & ושS & 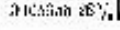 & $|24, \operatorname{lin} \sin |$ & $\$ 1$ \\
\hline & & & & \\
\hline
\end{tabular}

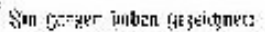

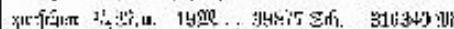

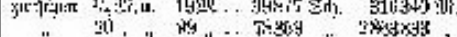

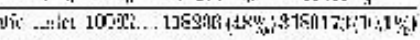

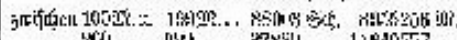

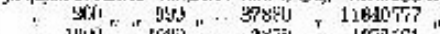

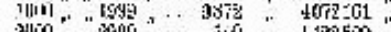

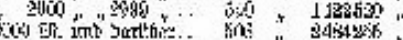

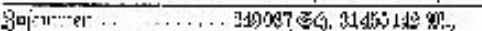

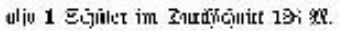

Ergebnisse der 3. - 8. Kriegsanleihe

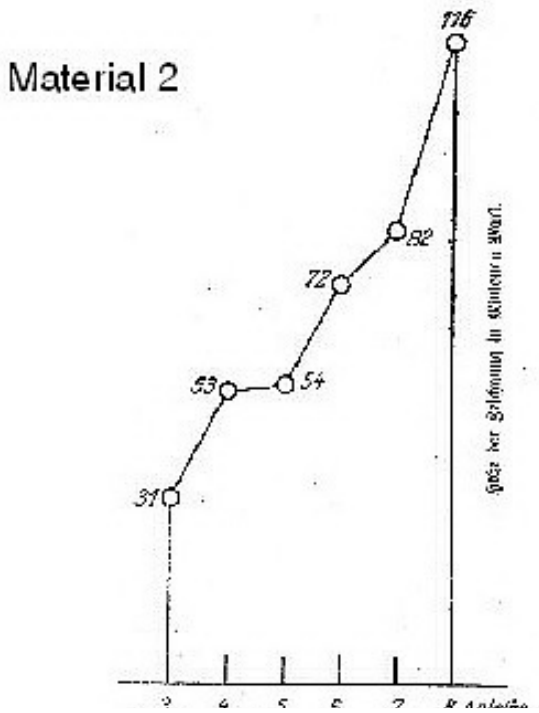

Quelle: Masche, Deutsches-Philologenblatt 1916, S. 23 
Statistik III

Ergeb nis der neun deutschen Kriegsanleihen in Mill Mark:

Kriegsanleihe Monat Jahr $5 \%$ ige Reichs-

anleihe $5 \%$ ige Schatz-

anleihe 4,5\% ige Schatz-

anweis ungen Nennbetrag Erbis

$\begin{array}{llllllll}\text { I. } & \text { September } & 1914 & 3491,9 & 1000 & - & 4491,9 & 4351\end{array}$

II. Mär $1915 \quad 8330,3 \quad 776,1 \quad-\quad 9106,4 \quad 8920,9$

$\begin{array}{llllll}\text { III. September } & 1915 & 12161,6 & - & 12161,6 & 11980,8\end{array}$

IV. März $1916 \quad 9194,2 \quad-\quad 1571,9 \quad 10766,1 \quad 10502,4$

$\begin{array}{llllllll}\text { V. } & \text { September } & 1916 & 9622,4 & - & 1074,3 & 10696,8 & 10403,9\end{array}$

VI. März $1917 \quad 11,747,2-1850 \quad 13597,2 \quad 12790,3$

$\begin{array}{lllllll}\text { VI. September } & 1917 & 11304,9 & - & 1369,2 & 12674,1 & 12252,6\end{array}$

VIII. Mär $1918 \quad 13532,3-1593,3 \quad 15125,6 \quad 14635,1$

$\begin{array}{llllllll}\text { LX. September } & 1918 & 9194 & - & 1376 & 10569,9 & 10118,8\end{array}$

$\begin{array}{llllll}\text { b esondere Begeb ungen } & 19,8 & 800 & 1400 & 2200 & 973,1\end{array}$

$\begin{array}{lllll}\text { Summe* } & 88578,8 & 2576,1 & 10234,8 & 101389,6\end{array}$

*: Kleine D ifferenxen durch R und ung der Zahlen

Quelle: Lotz, Walther, Die deutsche Staatsfinanxwirtschaft in Kriege,

Stuttgart/Berlin/L eip zig 1927 , S.120 


\section{Kapitel 4}

\section{Hilfe für die Landwirtschaft}

Für die Mitarbeit der Schuljugend auf dem I.ande kommen folgende Arbciten in Becracht:

A. Auf dem Acker und auf dem I Iofe:

1. Ablesen von Steinen auf Klecfeldern.

2. Ebnen wor. Maulwurfshägeln aul Klec-urd Gerreideäckern.

3. Ablesen von Unkräutern wie Queken, Wurzelsiöcken der Gänsedistel, Winden usw, auf gepflügtem und geeggrcm oder gegrubbertcm Land.

4. Auszichen und Ausstechen von. Disteln auf Winter- und Sommergetreide.

5. Kartoffellegen beim P'flanzen in die Furchen.

6. Tegen von Runkelribensamen-

7. Verziehen der Zucke:- und Runkelrüben.

8. Auslegen der Sctzlinge beim Pflanzen von Runkelrüben.

9. Angießen mit $\mathbb{W}$ asser bei großer Trockenheit.

1C. Vertcilen yon Jauche an die Pflanzen.

11. Antragen von Getreide beim Binden.

12. Hilfe beim Aufstellen der Getreidepuppen.

13. Zusammenrechen der Getreidehalme nach dem Aufbinden und Aufladen des Getreides.

14. Aufsammeln der Kartoffeln bei der lirnter und beim Pflugen und Eggen der Kartoffelfelder.

15. Hilfe beim Futterholen durch Aufladen und Nachrechen

16. Ausnehmen, Abschnciden und Zusammentragen der Runkelrüben.

17. IXilfc bcim Aufladen und Abladen samtlicher Wurzelgewächse.

18. Führen der Zugtiere beim Säen, dem Hacken und Häufeln dex Kartoffeln, dem Hacken der Rüben, Mohren, Erbsen, Bohnen und Gemüse.

19. Zutragen von Essen und Kaffee nacli dem. Felde bei größerer Entfernung der Arbeitsstelle vom Wohnort.

20. Abtragen von Stroh und Streu beim Dreschen.

21. Sammein und Ordaen der Bindestricke.

22. Zählen der Getrcidesäcke und Aufschreiben der Sackgewichte.

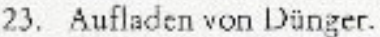

24. Wenden des Gerreides auf dem Schüttboden.

B. Auf Wiesen und Weiden.

1. Abrechen aller Verunreinigungen im Frühahr.

2. Ebnen von Maulwats- und Amcisenhügeln.

3. Ausbreiten des Cirases beim Schnitt mit der Sense.

4. Wendes des Heurs und Grummets.

5. Zusammenrechen in Schwaden

6. Nachrecheo beim Aufladen.

7. II iife beim Abladen.

8. Beaufsichtiģung der Weidetiere.

C. In Garter.

1. Jätcen von Unkraut.

2. Dilngerfahien auf die Beete.

3. Legen von Erbsen und Bohneu.

4. Begief́en der Saaten und Pllanzen.

5. Auflegen und Ablegen der Matten für die Ferusucr.

6. Bestrejchen der Fens.er mit. Kalkmilch.

7. Offnen und Schließen der Fenster.

8. Ablesen der Schnecken und Raupen von Gemüsen.

9. Pflücken von Becren aller Art

10. I Iilfe bei der Ernte sämtlicher Erzeuğnisse.

D. Im Oastbau

1. Abkratzen abgestorbener Rinde, des Mooses und der Flechten.

2. Bestreichen der Stämme und stärkeren Äste mit Kalkmilch.

3. Anlegen von Schutzgürteln gegen tierjsche Schädlinrre.

4. Begieficr der Bäume mi Wasser ind flïssizem Dïnger.

5. Pelüicken des Obstes.

L. Samtetarlueit jeder Aut.

Vor allem kom nr es daraul an. das Intercsse cer Schuljugend für die vacerländische Mit arbeit zu wecken. Wird es der Jugend klar, wieviel von ihwer tätigen Mithilfe für die Siche-

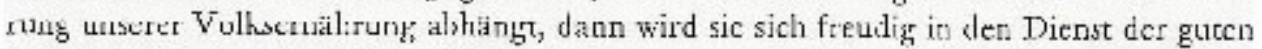
Si:che stcllen. Jede freiwillige Arbeil ist aber umso niitzliche; je freudiger sie greleistet wrd 
Kapitel 5

Programm einer nationalen Schulfeier I

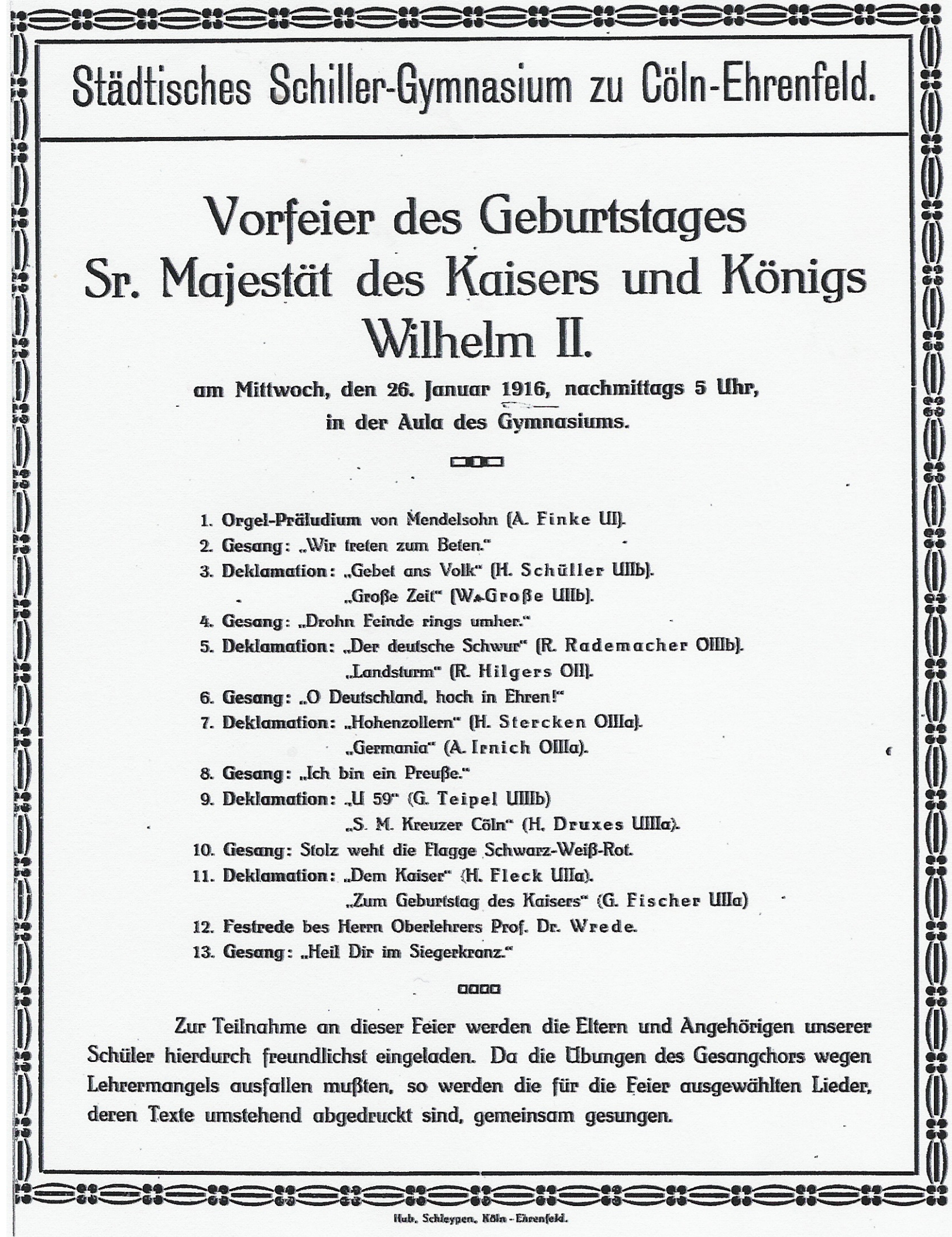

Quelle: Schmitz, Geschichte des Schiller-Gymnasiums, S. 16 


\section{Texte zur Geburtstagsfeier des Kaisers am Schiller-Gymnasium}

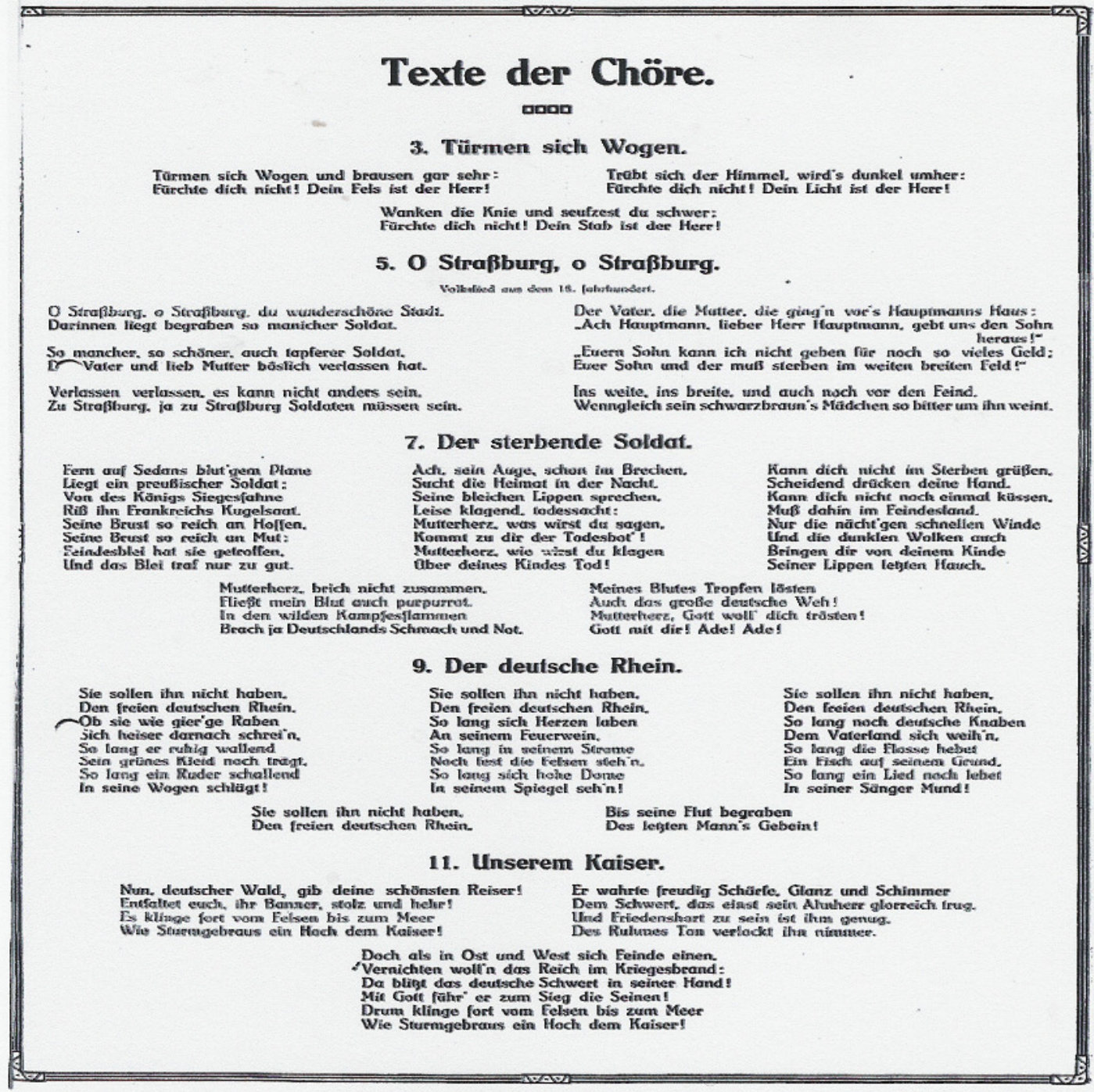

Chöre bei einer Schulfeier 1916

Quelle: Schmitz, Geschichte des Schiller-Gymnasiums, S. 15 


\section{Programm einer nationalen Schulfeier II}

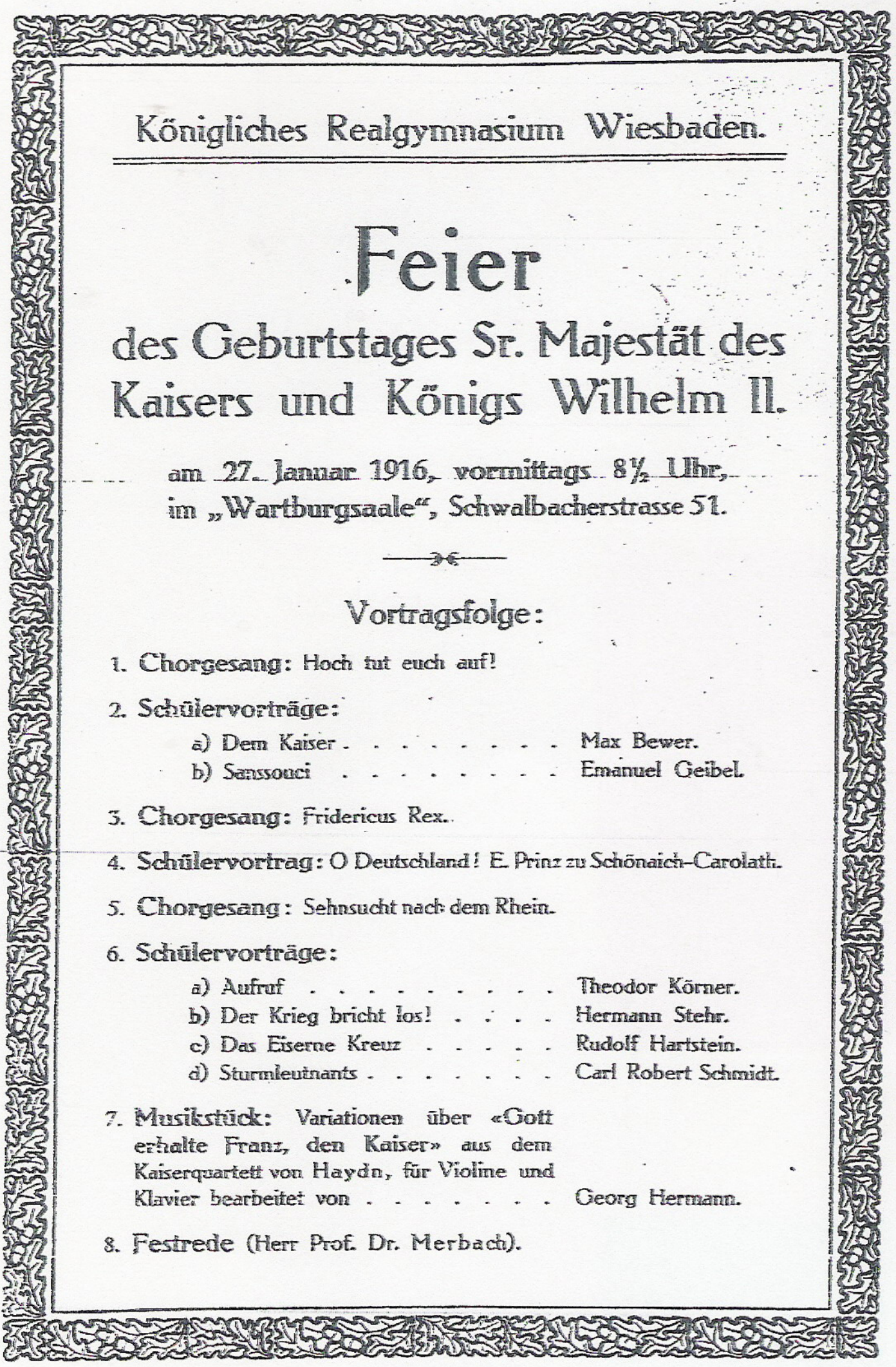

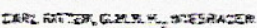

Quelle: Löher/Wulf, Furchtbar dräute..., S. 73 


\section{Gedichte I}

\section{Für euch!}

Ihr, die ihr jammert, die ihr klagt, Wie schwer und hart die Zeit, Und die ihr beinah' ganz verzagt, Weil noch der Friede weit,

Und die ihr matt die Hände ringt, Und mürrisch seid und flucht, Weil noch nicht die Erlösung winkt,

Die ihr ersehnt und sucht, Bedenkt doch, in der weiten Welt, Stirbt irgendwo ein deutscher Held Für Euch!

Ihr, die Ihr frech zu wuchern wagt, Und blutet auch das Land,

Die ihr Gewinn und Gut erjagt,

Mit gierig-geiz'ger Hand,

Die ihr des grimm'gen Elends lacht

Und die ihr schamlos-kalt

Auf schnöden Reichtum nur bedacht, Den Beutel füllt, - umkrallt,

Bedenkt doch, in der weiten Welt, Stirbt irgendwo ein deutscher Held Für Euch!

Und ihr, des Großen nicht bewußt,

Das durch die Zeit jetzt schwingt,

Die ihr in eitler Sinnenlust

Des Lebens Wonnen trinkt,

Die ihr im Rausch, in Freuden lebt,

Betäubt der Zeiten Not

Und nichts dem Vaterlande gebt,

Nichts wissen wollt vom Tod,

Bedenkt doch, in der weiten Welt,

Stirbt irgendwo ein deutscher Held Für Euch! 
Für Euch! (Fortsetzung)

Fällt er in vollem Siegeslauf, Vom Schlachtenlärm umtost, Schwebt seine Seele sanft hinauf, Von Träumen mild umkost, Verschmachtet er im dorn'gen Strauch, Auf's Herz gepreßt die Hand, Sein letztes Wort, sein letzter Hauch Ist: Deutschland - Vaterland.

Und überall in weiter Welt

Stirbt ach! Wie mancher deutsche Held Für Euch!

Sei's nun im schönen Frankenreich, Auf Polens weitem Feld, Er blutet und er stirbt für euch Als Held, als tapf' rer Held, Verdurstet in der Wüste Sand, Ertrinkt auf hoher Flut,

Stirbt für sein Volk und Vaterland Mit ungebeugtem Mut.

$\mathrm{Ja}$, in der weiten, weiten Welt

Stirbt irgendwo ein deutscher Held Für Euch!

Otto Bangert, 15 J., Schüler eines Gymnasiums

Quelle: Weltzin, Otto, Kriegsnagelungen in Niederdeutschland, S. 43 


\section{Gedichte II}

Für uns!

Ferne, ferne im Osten, da gähnt ein Grab,

Da senkt man zu tausend die Toten hinab.

Für uns!

Im Westen, da ragt manch Kreuz schlicht und klein,

Da liegen sie stumm in langen Reih'n -

Für uns!

Und wo im Winde rauscht das Meer,

Da gaben sie freudig ihr Leben her -

Für uns!

Sie opferten Zukunft und Jugendglück,

Sie kehren nie wieder zur Heimat zurück -

Für uns!

Sie gaben Ihr Alles, ihr Leben, ihr Blut,

Sie gaben es hin mit heiligem Mut -

Für uns!

Und wir? Wir können nur weinen und beten

Für sie, die da liegen bleich, blutig, zertreten -

Für uns!

Denn es gibt kein Wort, für das Opfer zu danken,

Und es gibt keinen Dank für sie, die da sanken -

Für Uns!

Das Gedicht wurde in ein 1917 vom Pestalozzi-Verein herausgegebenes Schulbuch aufgenommen und ,als Requiem für die Gefallenen“ sogar vertont.

Quelle: Vogeler, Adolf, Kriegschronik der Stadt Hildesheim, S. 114/115 


\section{Gedichte III}

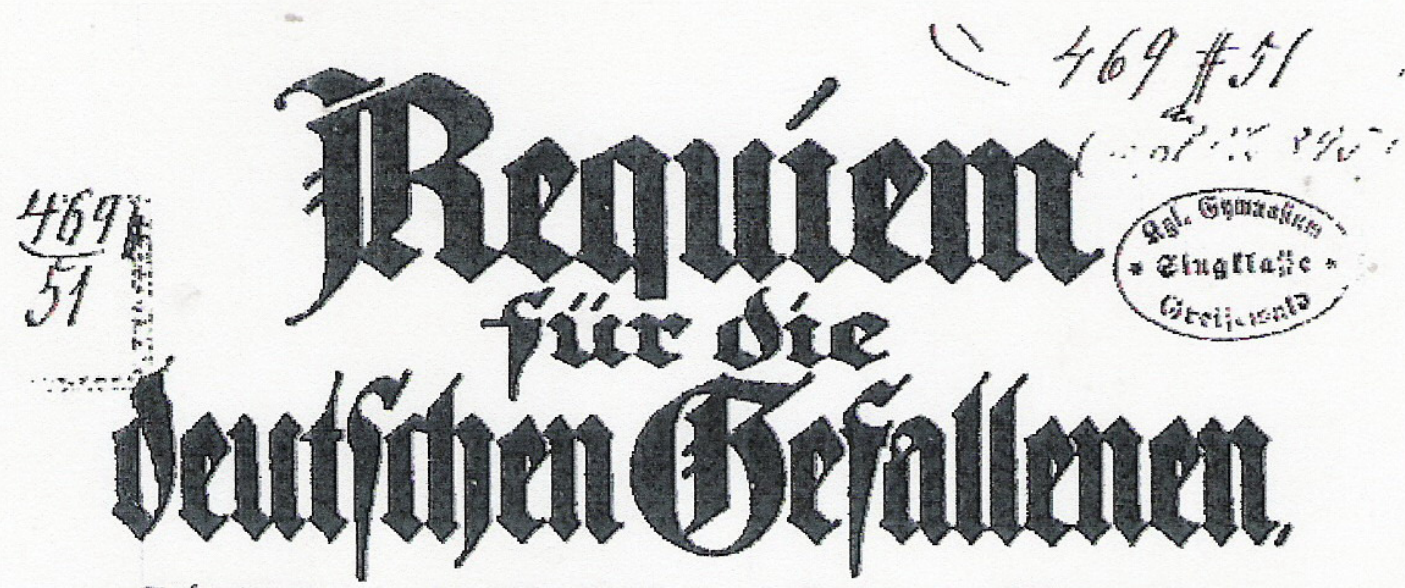

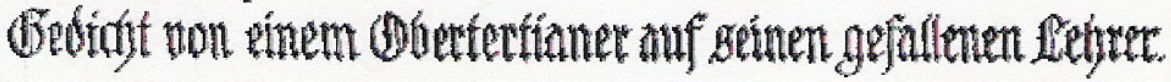

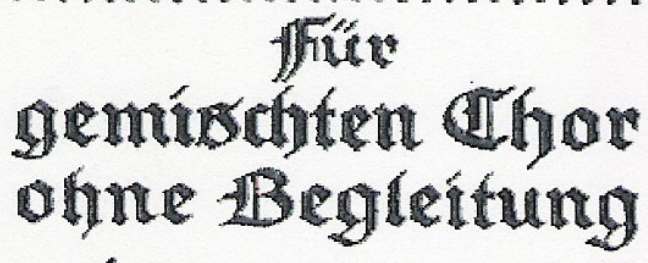

: Romponiert oon

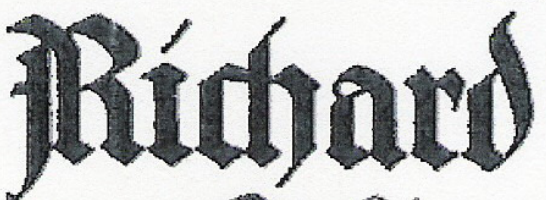

(11) p, 61 .

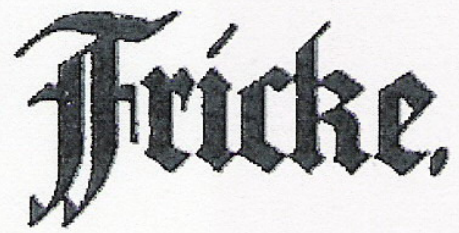

Ausgabe fur gemischten (Thoo

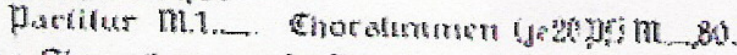

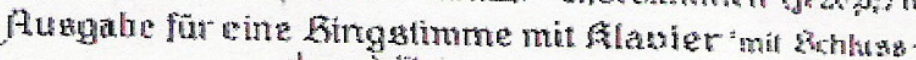
chur ato tib.

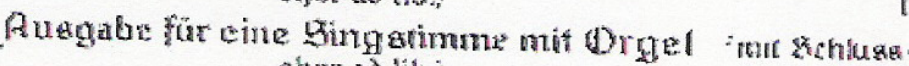
chor ad lib:

Teipzig,

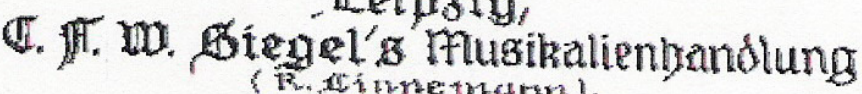

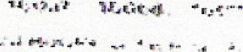

Gedichtvertonung eines Schülers aus Charlottenburg

Quelle: Langer, Lernziel Krieg, S. 27 


\section{Kapitel 6}

\section{Gedichte IV}

Gedicht eines 13jährigen Jungen

Von E. von Katinsky

Wir lassen uns nicht unterkriegen, wir siegen!

Herbei, ihr Feinde all, ihr frechen, wir rächen!

Ihr Gegner all sollt unterliegen, wir fliegen!

Wir kämpfen um gerechte Sachen, wir lachen!

In uns ist frohes, mut'ges Klingen, wir singen!

Russen, Franzosen, Engländer, Serben, wir erben!

Mit Lüttich haben wir begonnen gewonnen!

Was kämpft ihr gegen uns?! Welch Spott!

Wir sind „Mit Gott!“

Quelle: Das Volk in Eisen, S. 51 
Kapitel 7

Programm einer Nagelfeier in Wasserburg

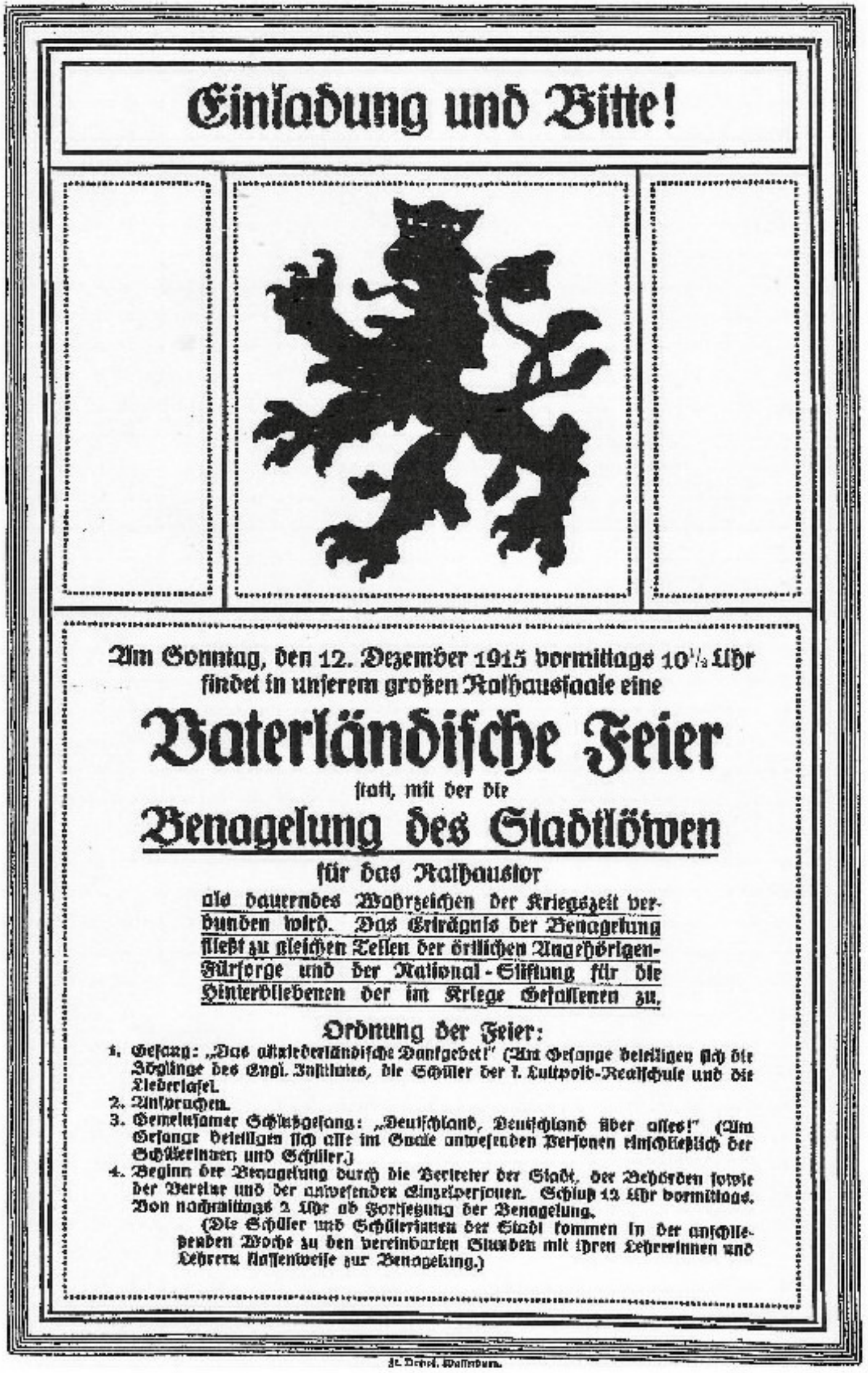

Quelle: Stadtarchiv Wasserburg in Oberbayern 


\section{Programm einer Nagelfeier in Wiedensahl}

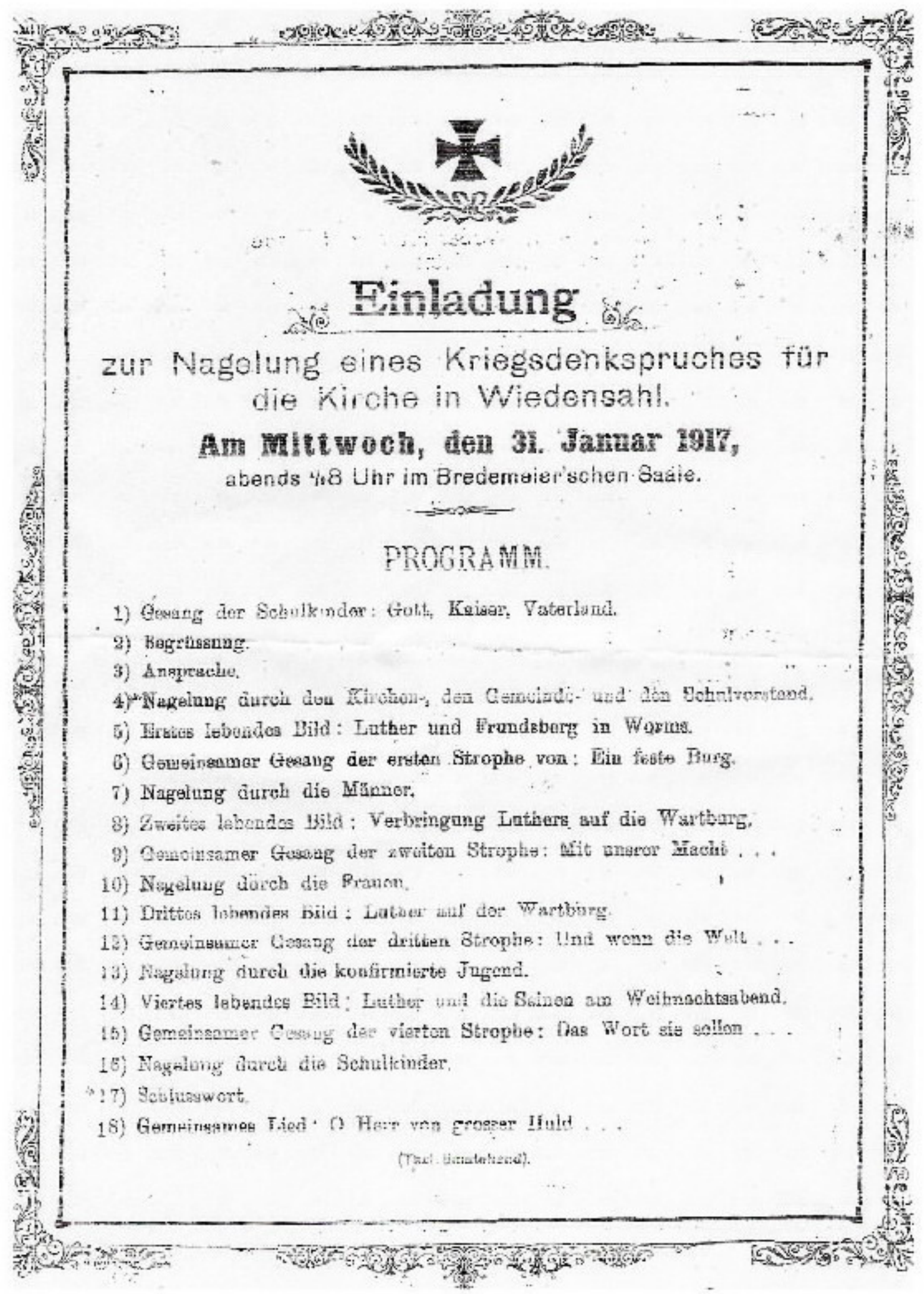

Quelle: Heimatmuseum Wiedensahl 


\section{Programm einer Schlussnagelung in Erfurt}

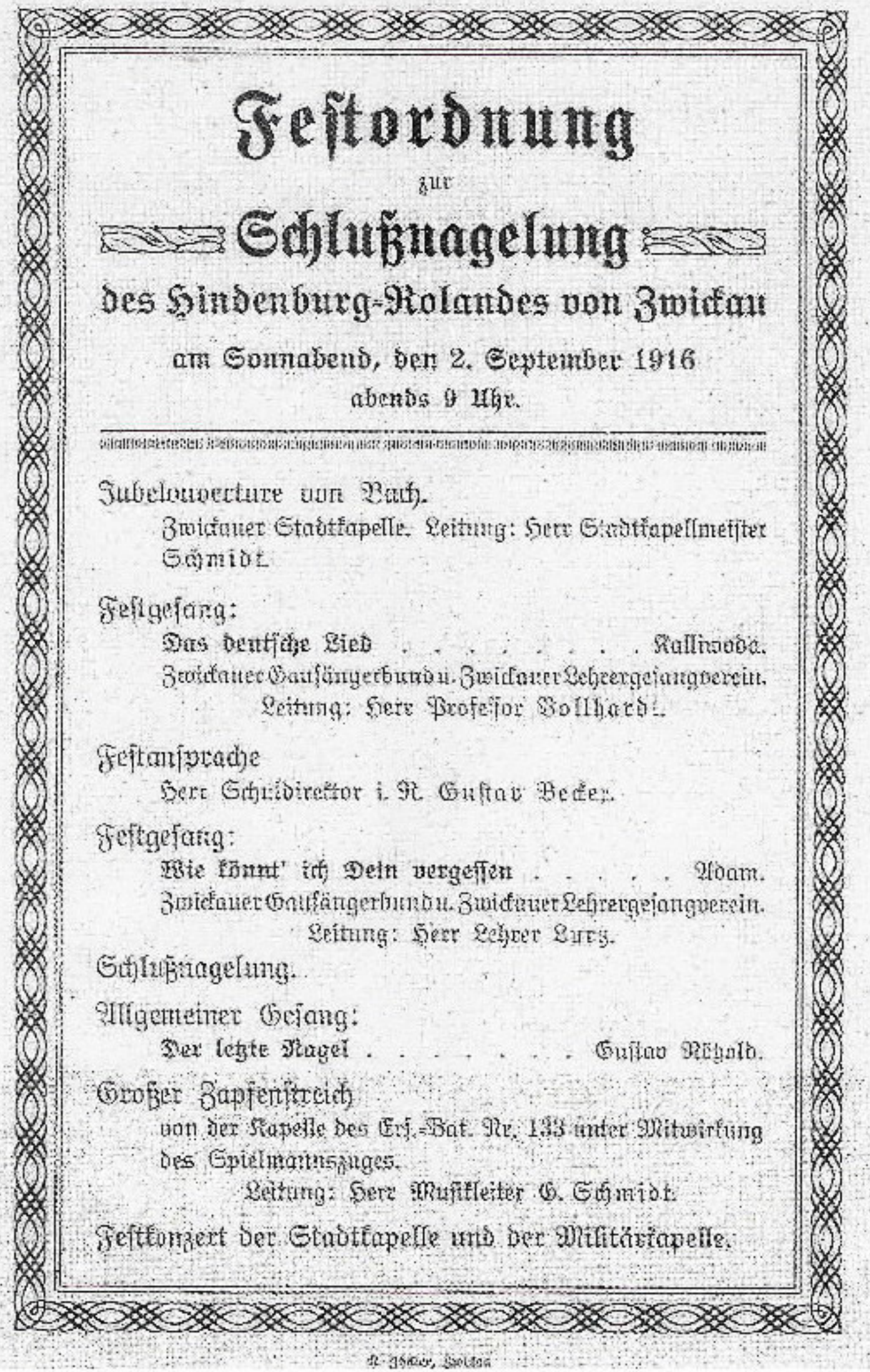




\section{Kapitel 8}

\section{Sparaktionen I}

Nahrung

\section{Zeitschrift}

fữr

\section{Untersuchung der Nahrungs- und Genußmittel,}

sowie der Gebrauchsgegenstände.

\section{Der Nachweis von Kartoffelzusatz im Kriegsbrot, $\left.{ }^{1}\right)$ Vom}

\section{A. Lüngelsheim.}

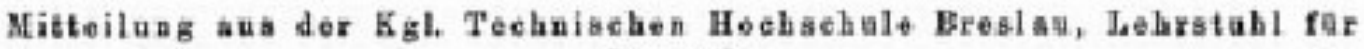
Botanik.

[Eingegangew am 10. März 1915.]

Die Bandestatsperondnung, betr, die Beteitung pon Backware von 5. Jah. 1915²)

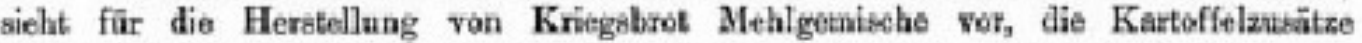
oder als deren Eratz Gerotenmehl, Hafermobl, Reiamehl oder Geretenechrot enthalten mu็̆asen.

Ua eine wirksame Streskenge dex Getreidevorrâte zu gowahben, tritt mōglicher-

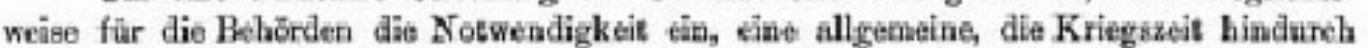
andauarnde Kontrolle des fertigen Brotes bezüglich jener Zasätzà einzuführon. Im folgenden berichto ich aber die Ergebniase meiner Benuhungen zar Gewinnung einer

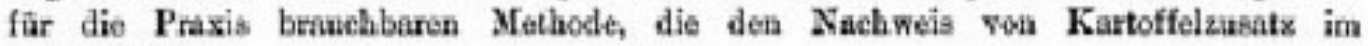
Bnot betrifft.

Wăkrend die mikroakopiache Prüfung anf die Anwesenheit bestimmter Getreidearten in Mehlgemischen vor allem mach dem bekannten, ziemlich zeitraubenden Ver-

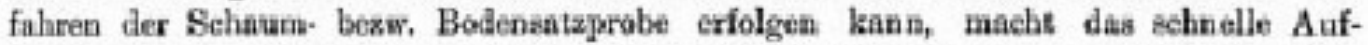
finden der Kartoffelstärke in Mehl bei der gänzlich abweichenenden Grỏle und Struktur

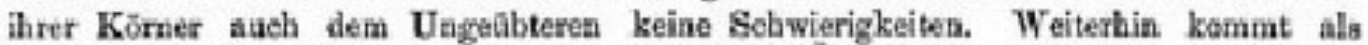
Zusatz zum Mehl ein Kartiffelmahlprodukt aus den gekochtén, getrockneten Knollen in Betracht, das als Kartoffelnalzmehl oder Putentwalzmichl bezelchinet wird. Dieses ânerlich an Grielfonehl erinaternde Eraugnis stelt ein grob snzufühlendes, gellbliechweißes Palver dar, in welchem reichlich brïnuliche Partikel, der Kartoffelechale entstammend (bei Herstellung ans ungeachalter Kartoffel), werteilt siudd.

Ein Zusatz deesos Mehles zi einer Getreidemehlmigchung iat ebenfalls unschwer featruatellen. Im mikroskopischen Bilde fallen die in Wasser etras quellenden Koraplexe noch zusammenhingender bie zn $300 \mu$ grober, rundlicher eder etwas polygonialer Zellen stark auf; dieselben enthalten deformierte Stärkekörner, deren Grenzen

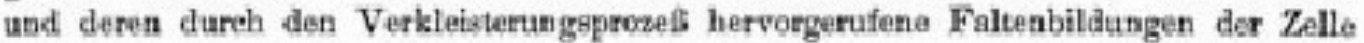
ein "marmoriertes" Augsehen perbeihen. Das Bild der einzelnen Zellen deckt sich wollstăndig mît dem in Fig, 6 dargestellten, welches Zellen sus gekochter Kartoffel

1) Enter diegem Titel erachien eine am 18. Februar eingereichte, in der Nammer vam

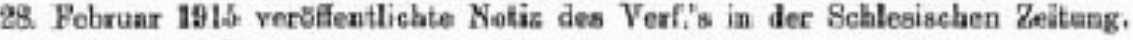

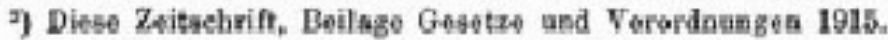




\title{
Sparaktionen II
}

\author{
Nahrung
}

\section{Merfliratt fint Edurfinder.}

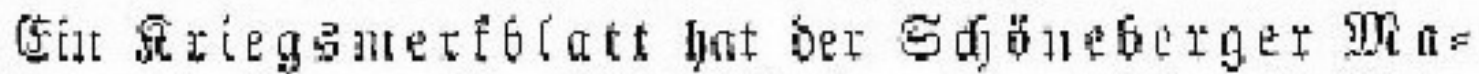

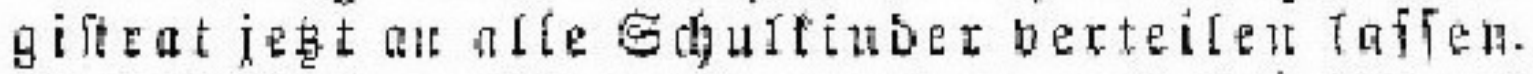

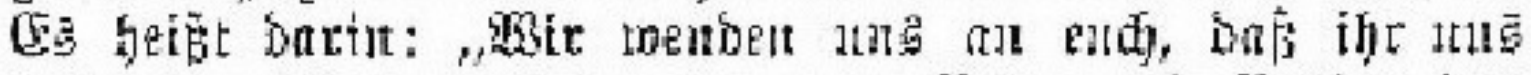

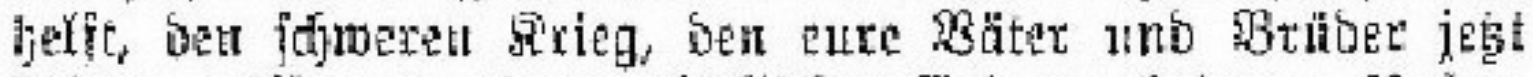

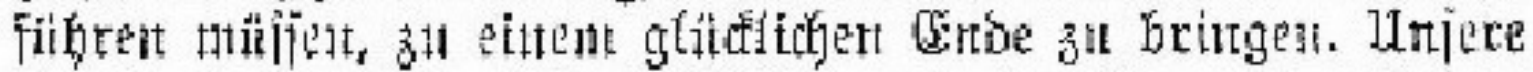

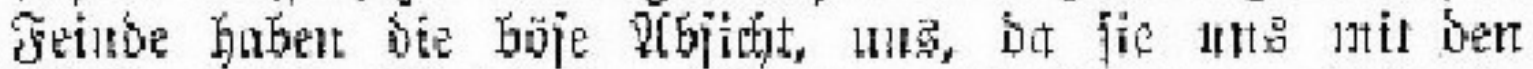

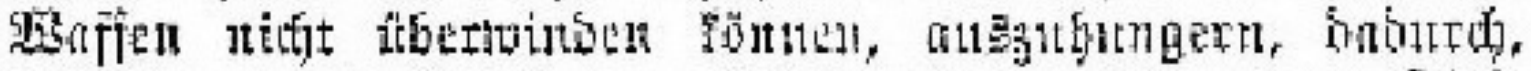

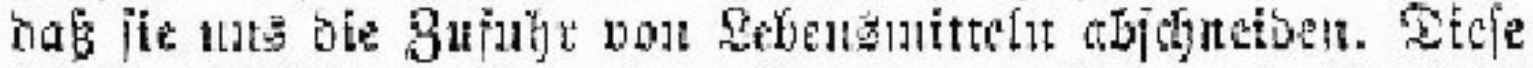

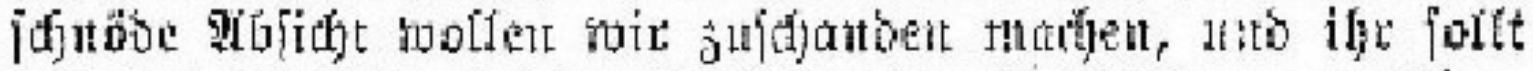

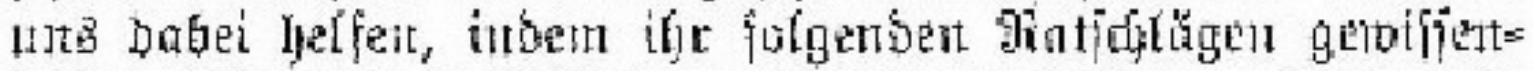

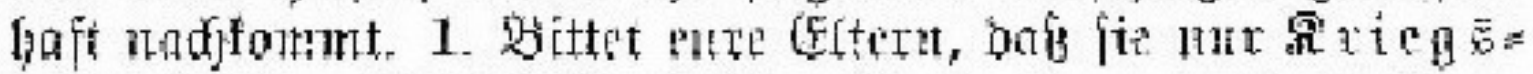

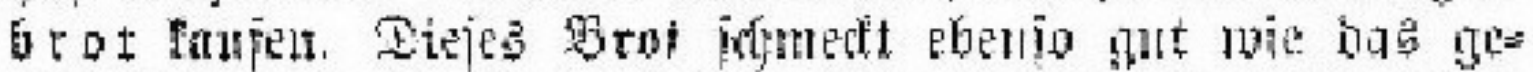

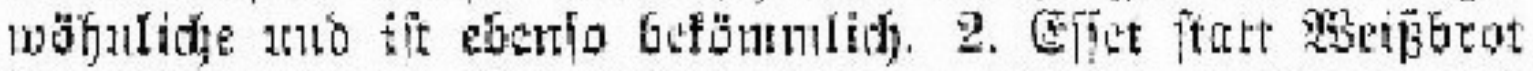

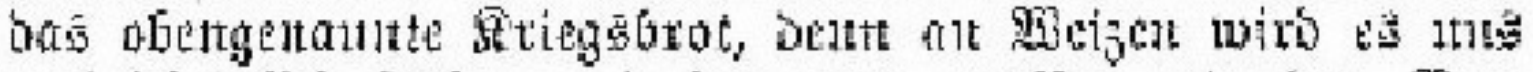

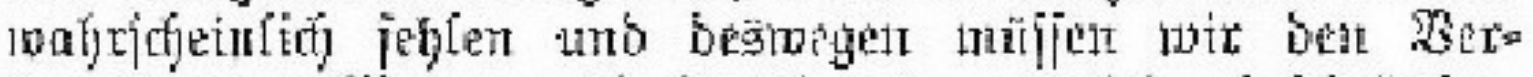

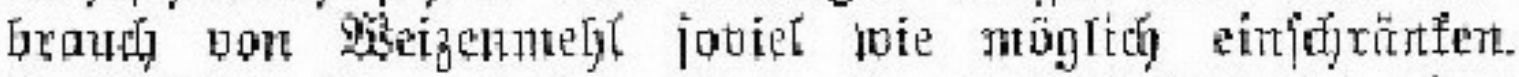

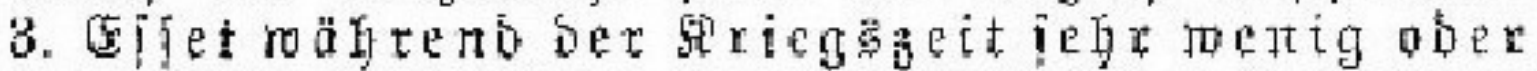

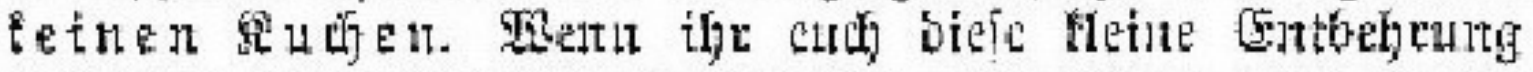

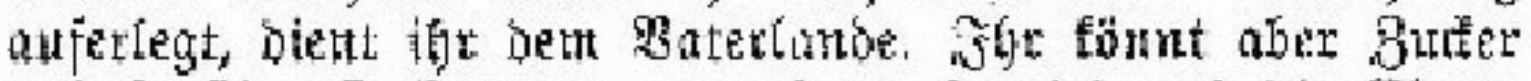

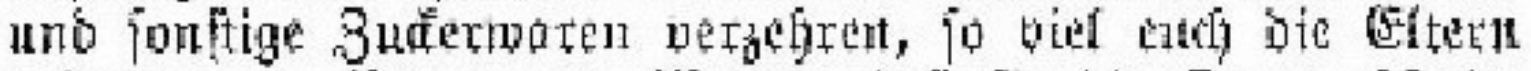

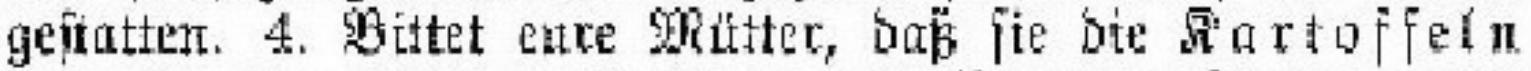

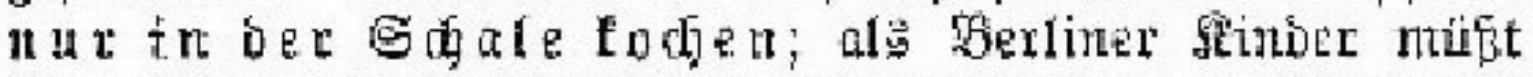

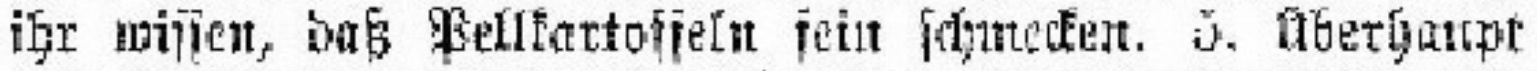

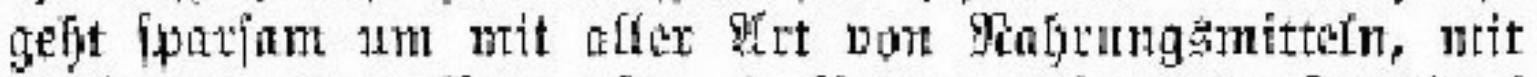

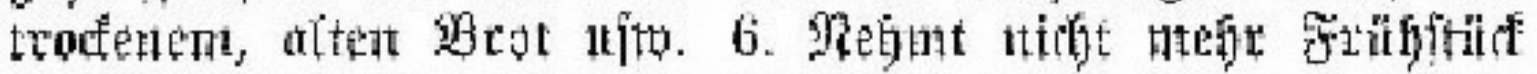

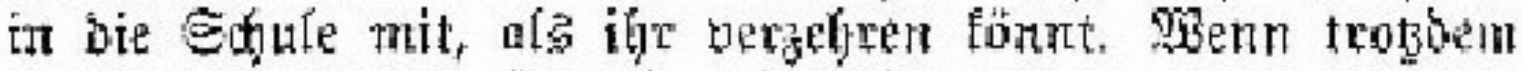

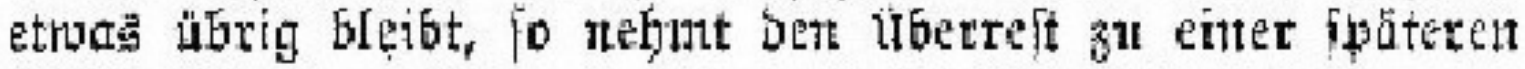

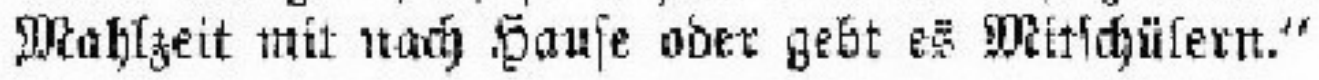




\section{$\underline{\text { Teil } 2}$}

Bilder 


\section{Kapitel 2}

\section{Goldsammlungen I}

Bild 1

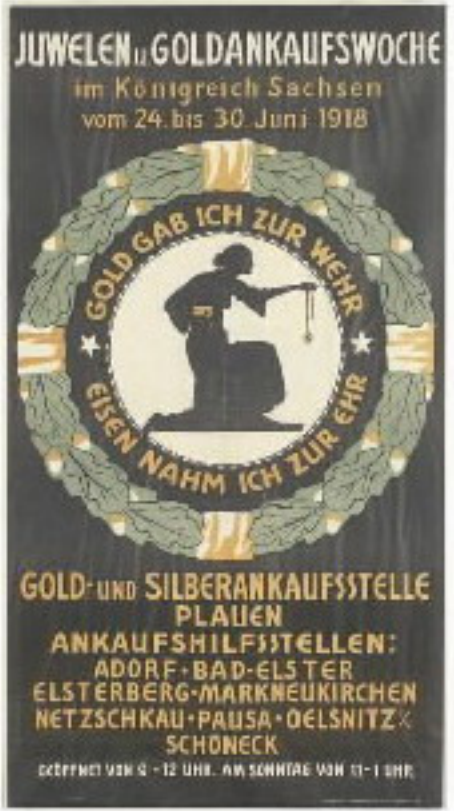

Bild 2

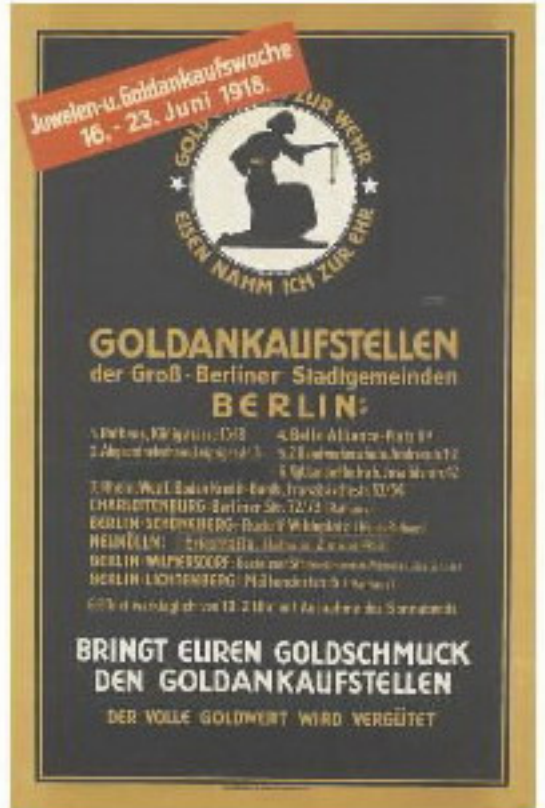

Werbeplakate
Bild 3

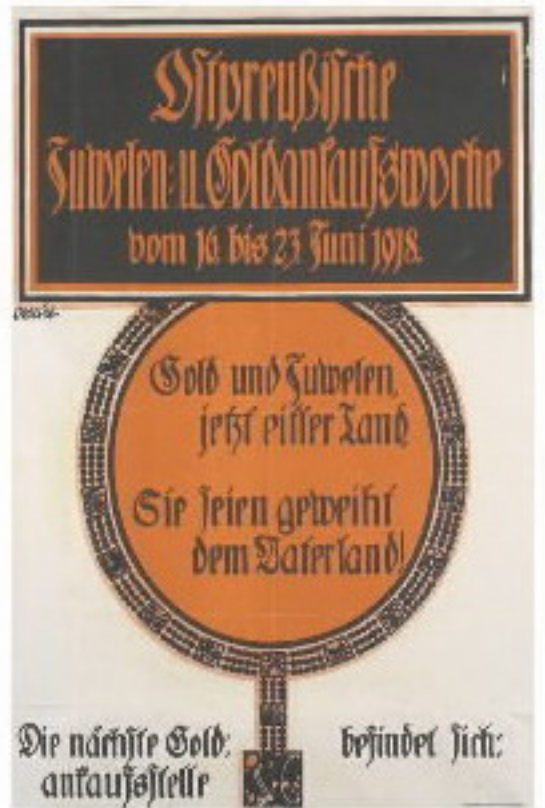

Foto einer Sammelstelle in einer Berliner Schule

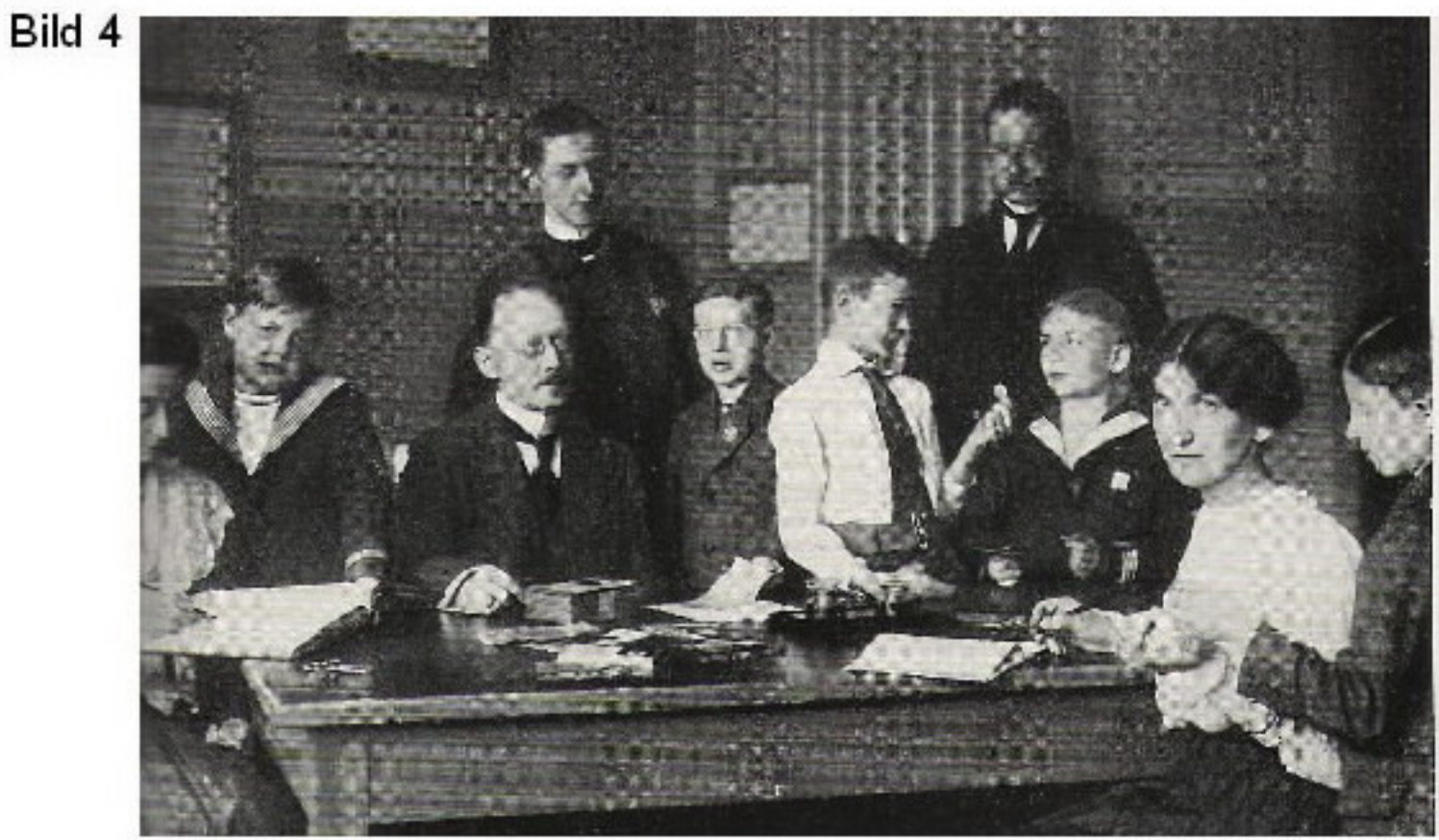

Ablieferung des gesammelten Goldes 


\section{Goldsammlungen II}

Bild 1

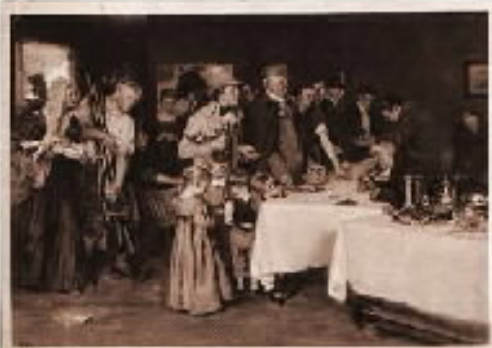

Goldsammlung 1813

\section{Bild 2}

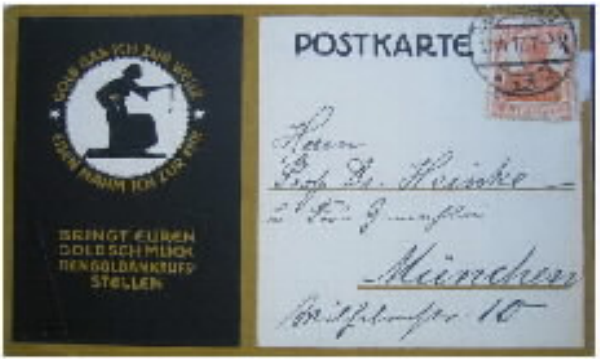

Postkarte

\section{Bild 3}

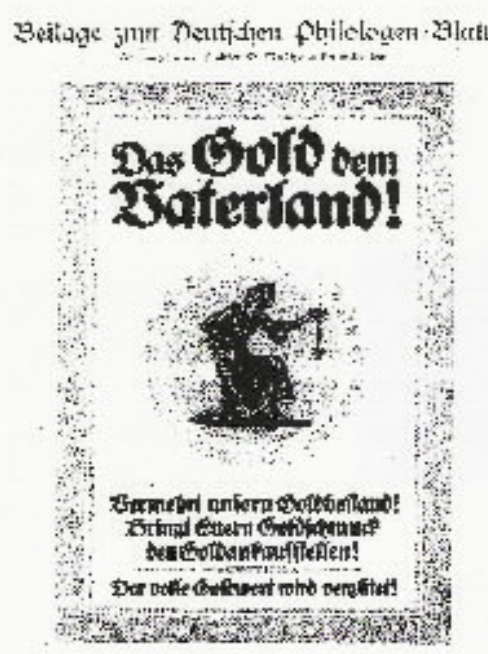

Aufruf

\section{Bild 4}

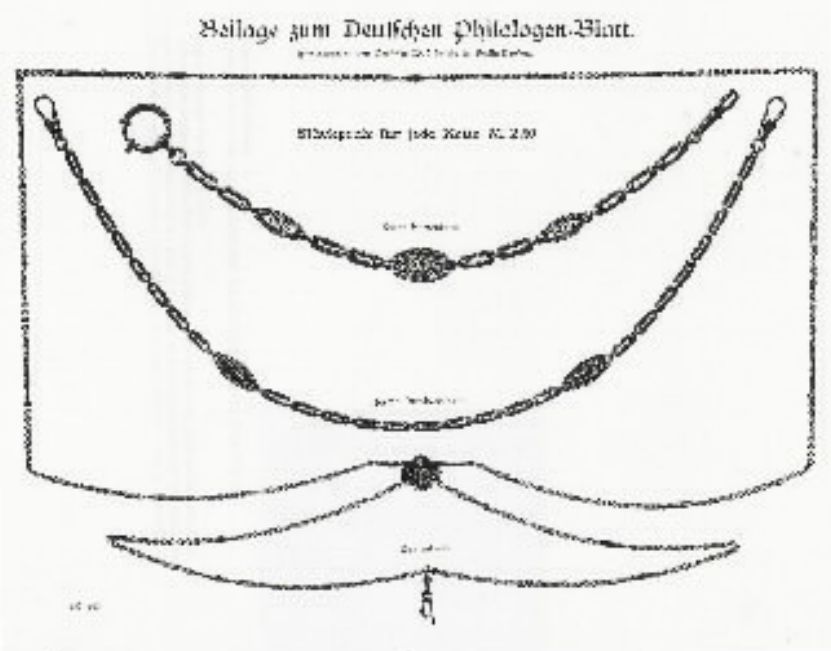

Eisenschmuck

"Gold gab ich für Eisen"

Bild 5b

\section{Bild 5a}

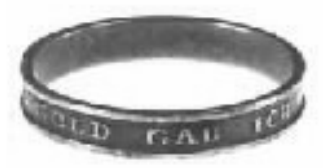

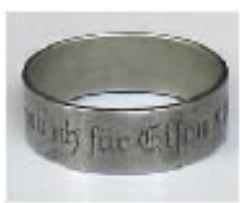

\section{Bild 5c}

Spendenringe und Spendennadel

Bild 6a

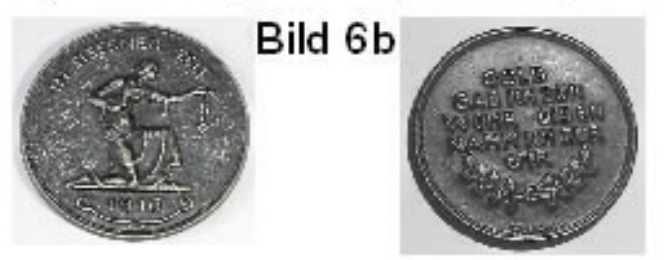

Bild 5d

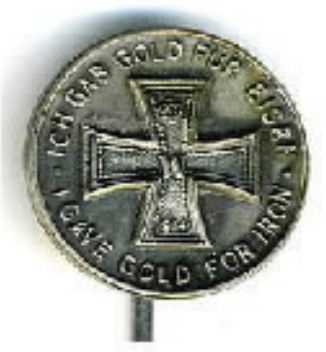




\section{Goldsammlungen III}

\section{Bild 1}

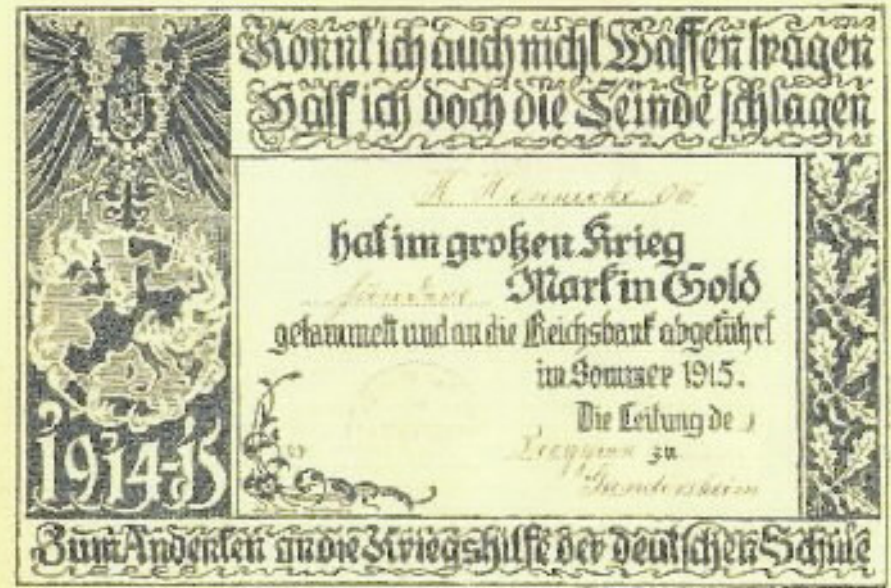

Bild 2

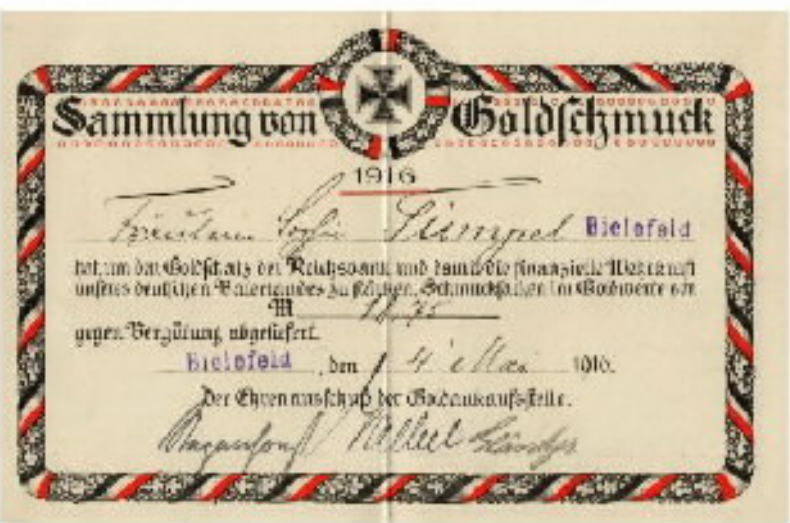

\section{Bild 3}

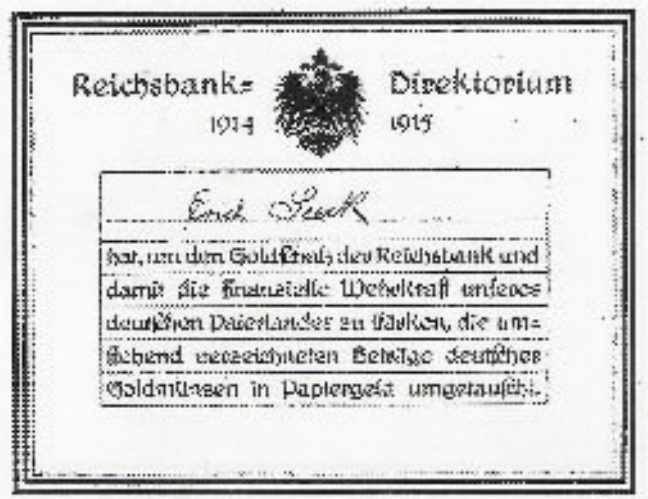

Bild 4

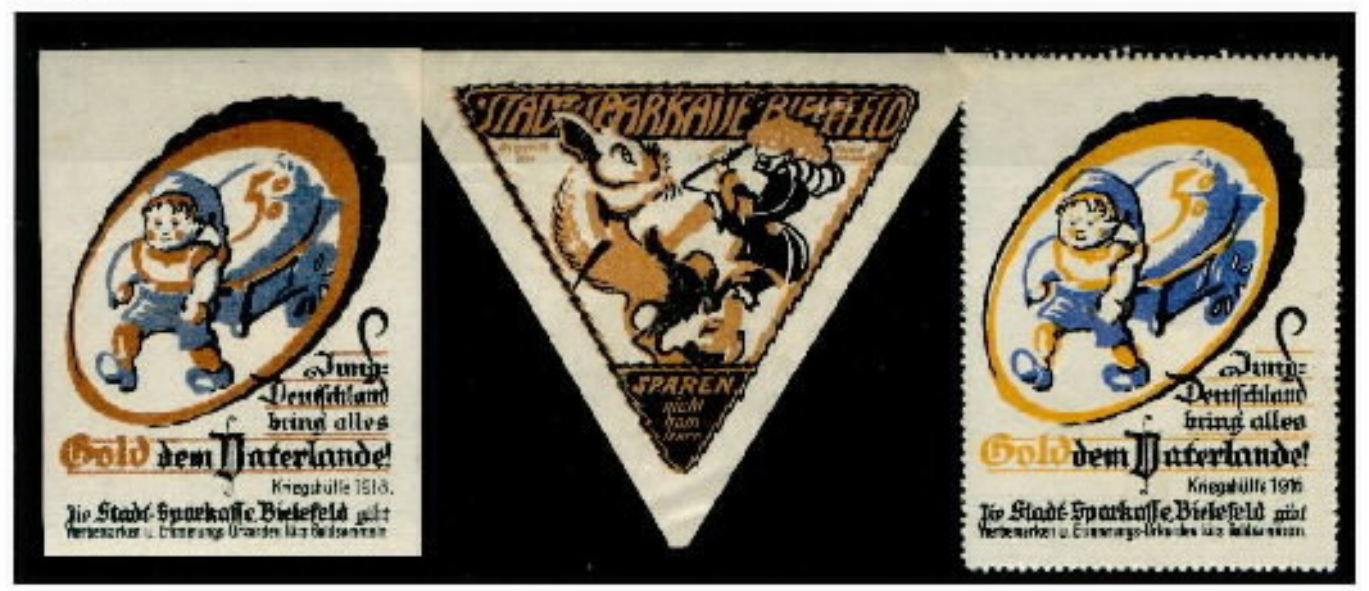

Spendenmarken

Quelle: Sammlung Kronenberg $(1,2,4)$; Philologen-Blatt, 1915, S. 640 (3) 
Geldammlungen I

Bild 1

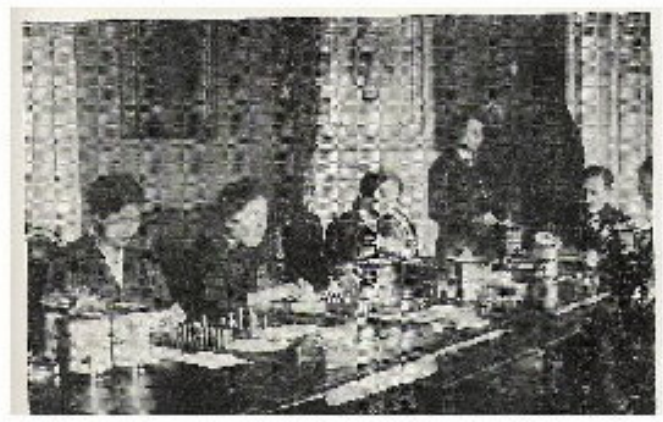

Opfertage: Öffnen der Sammelbüchsen
Bild 2

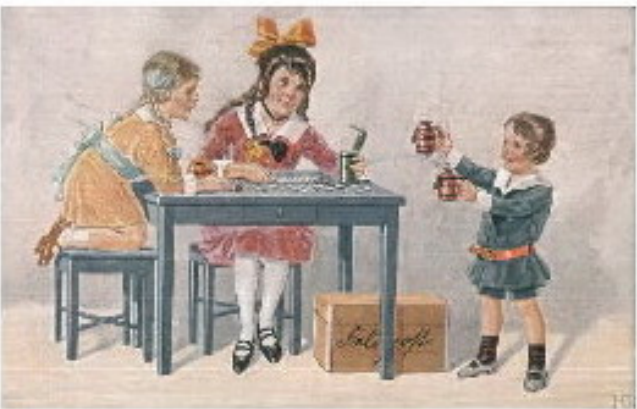

Ansichtskarte

\section{Bild 3}

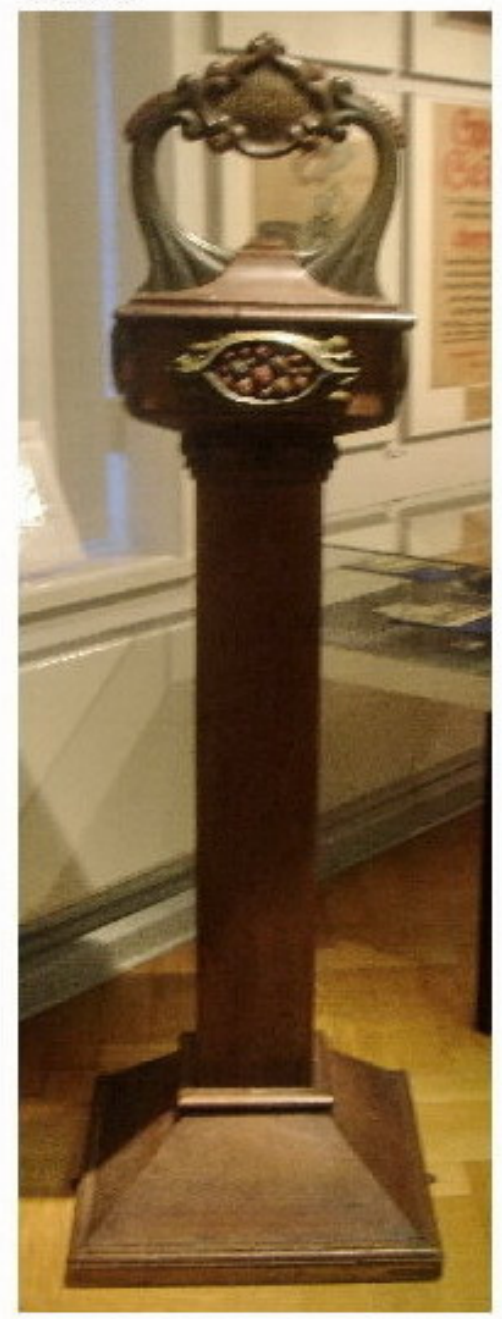

Opterstock in Schleswig

\section{Bild 4}

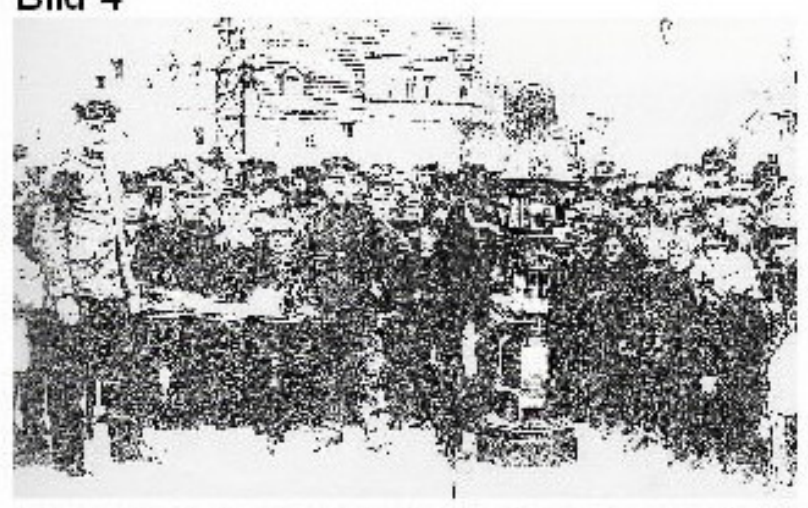

Nagelung des Opferstocks in Schwenningen

Bild 5

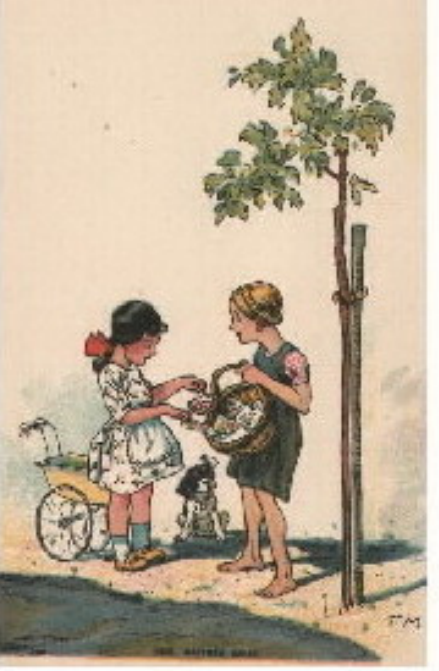

Geldspende für hungernde Kinder

Quellen: Sammlung Kronenberg (2,3,5,); Führen, Lehrer im Krieg, Tafel 23 (1); Reinartz, S. $31 / 32$ (4) 


\section{Geldsammlungen II}

\section{Bild 1}

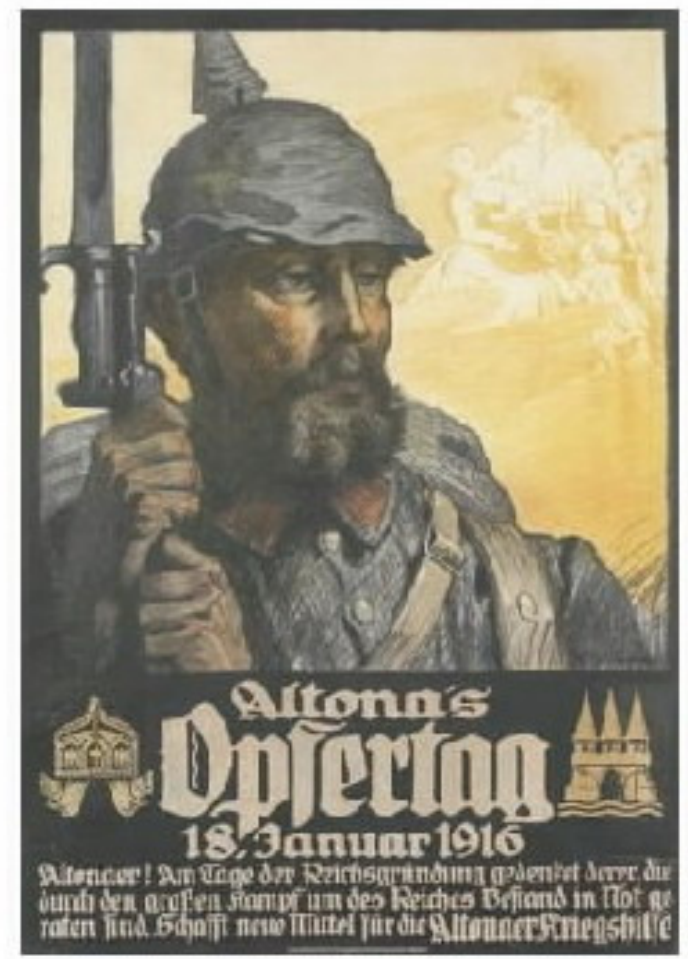

\section{Bild 3}

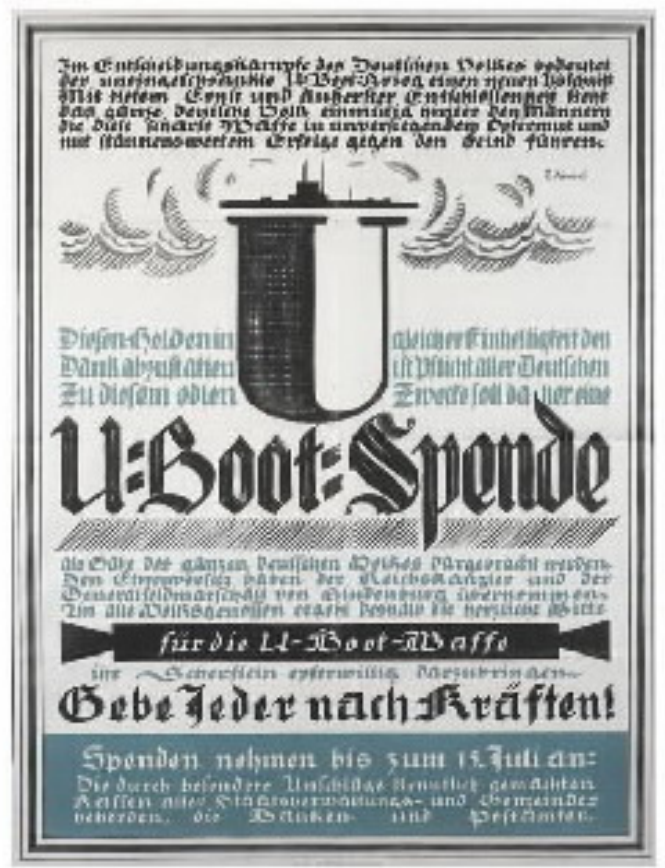

Bild 2

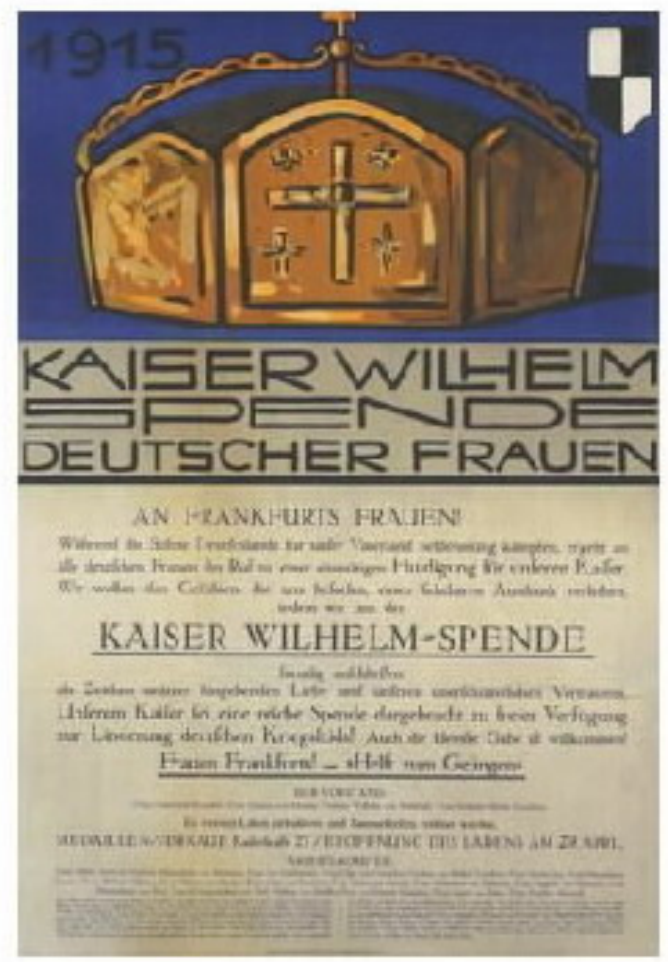

Bild 4

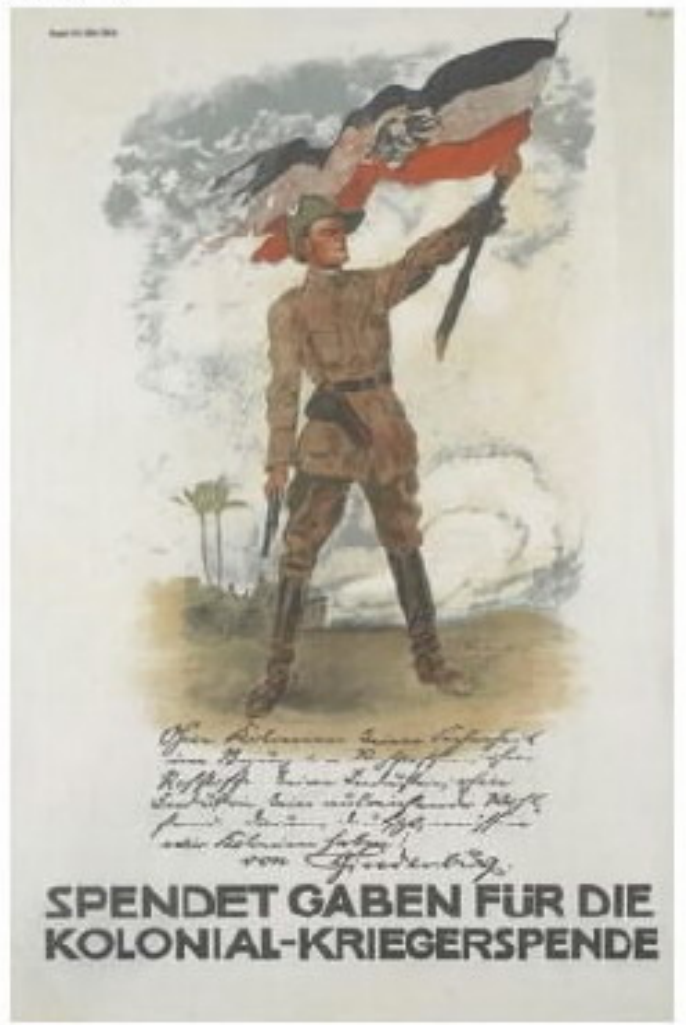




\section{Geldsammlungen III}

Bild 1

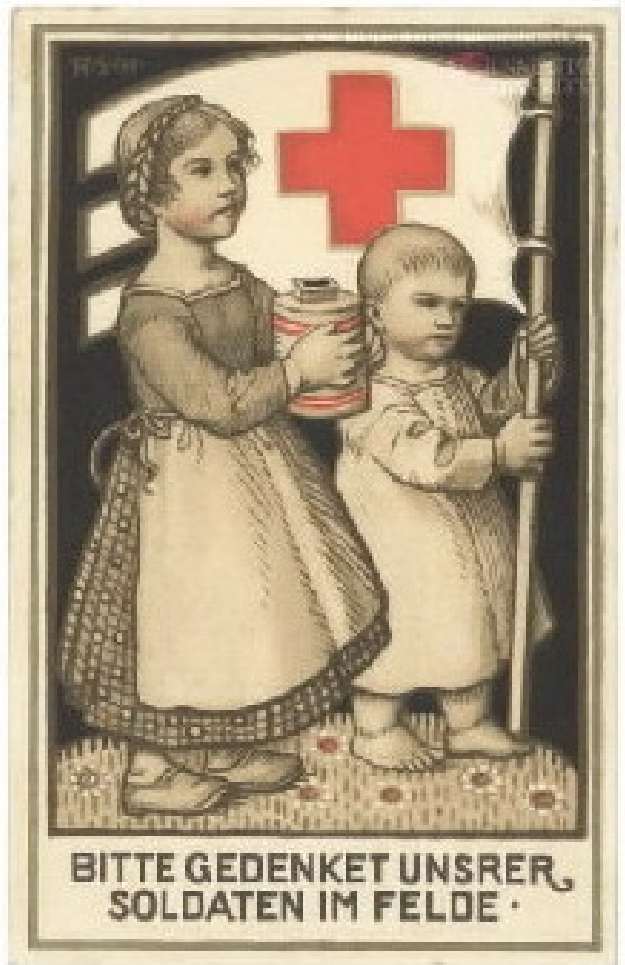

Bild 2

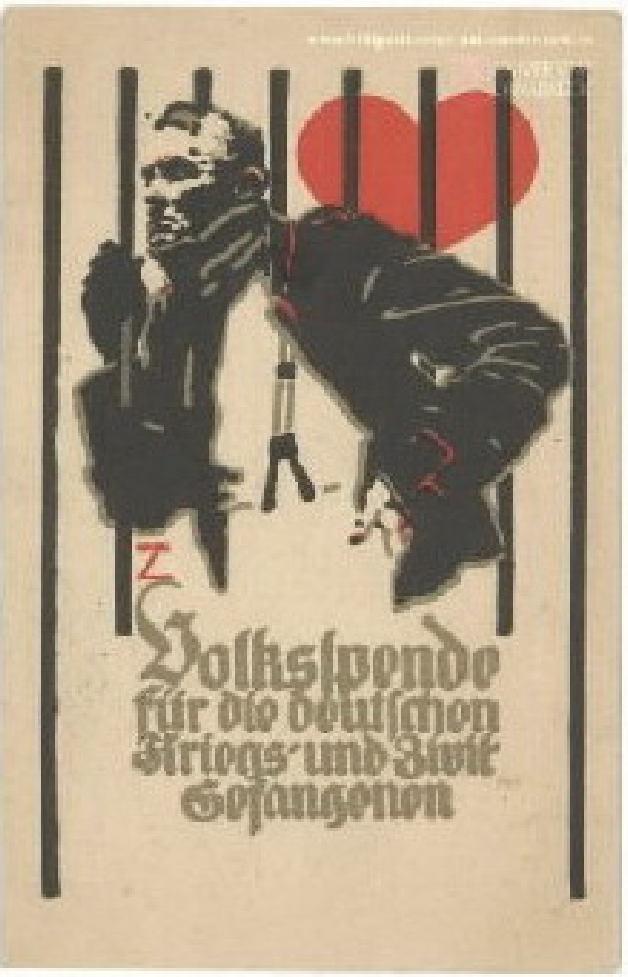

\section{Bild 3}

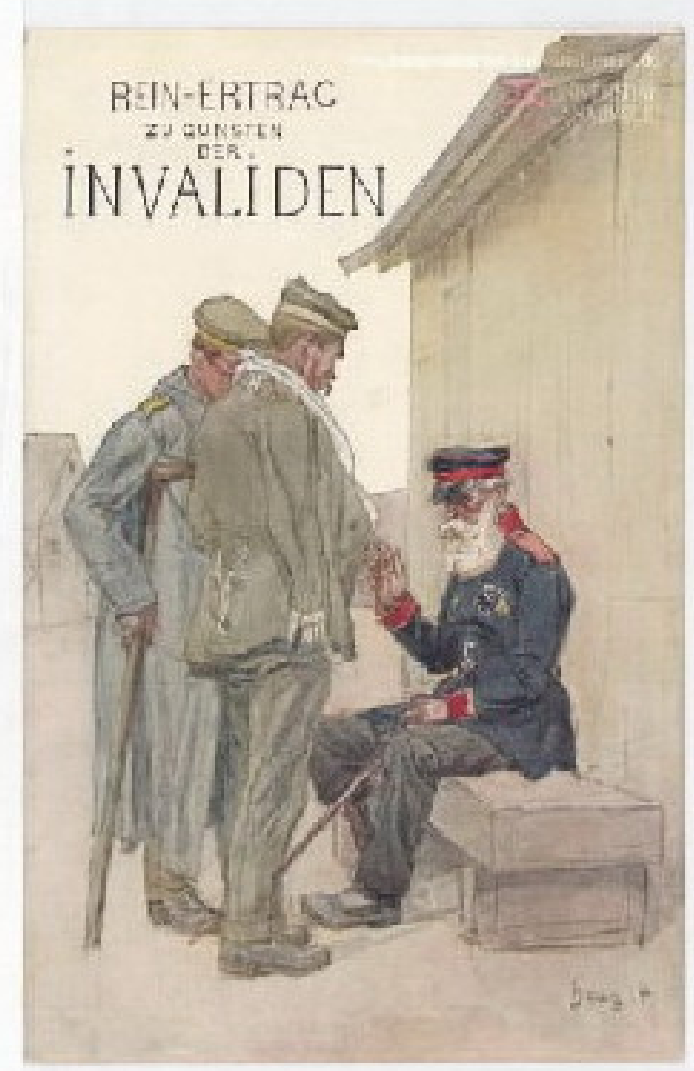




\section{Geldsammlungen IV}

Bild 1

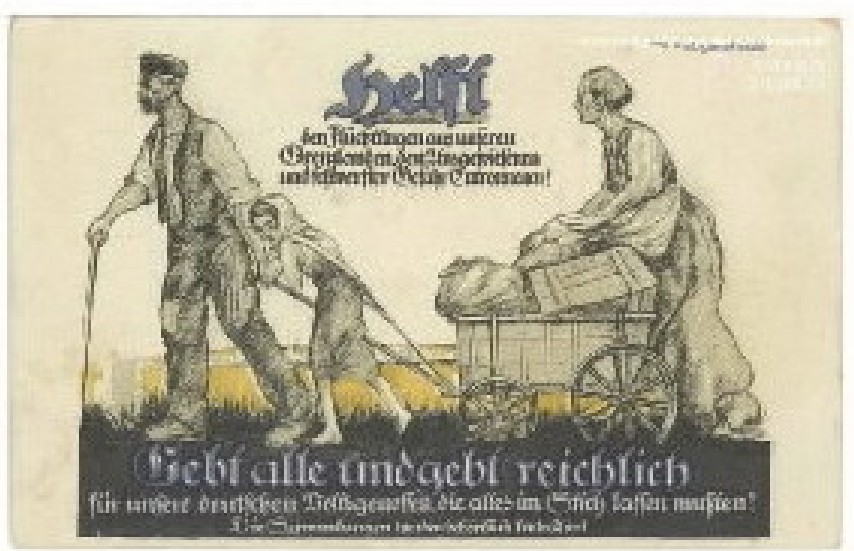

\section{Bild 2}

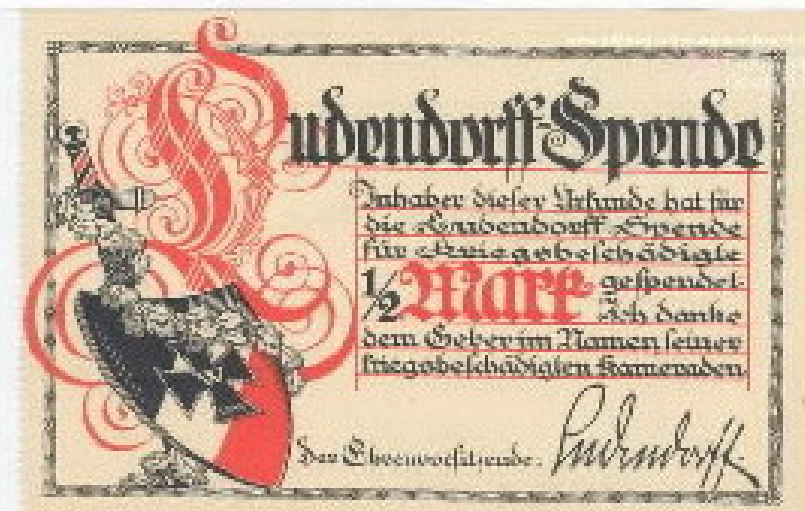

\section{3}

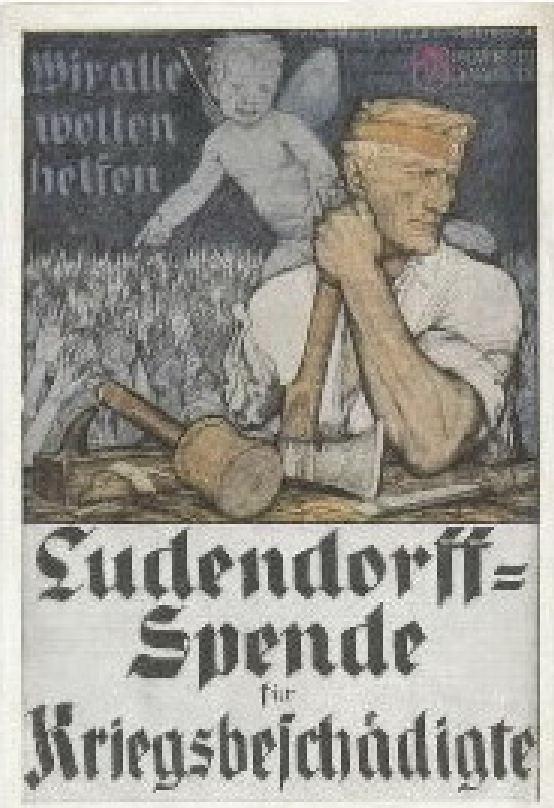

\section{Bild 4}

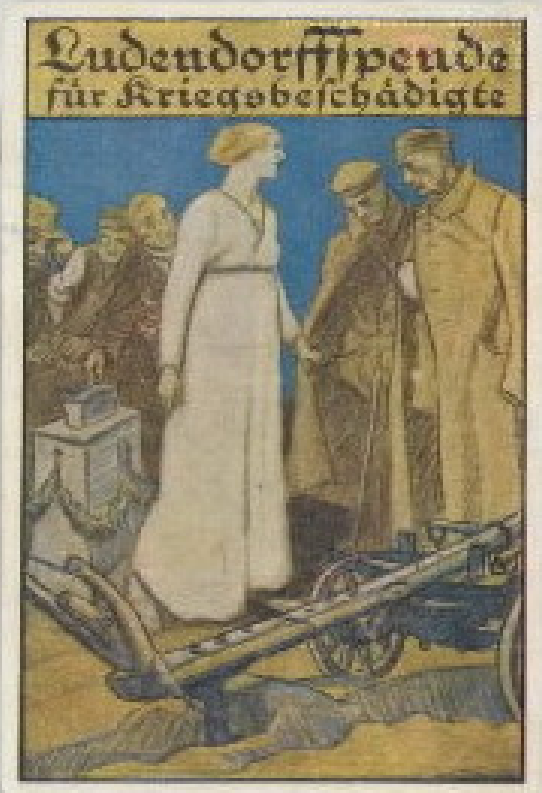




\section{Sammlung von Altmaterialien I}

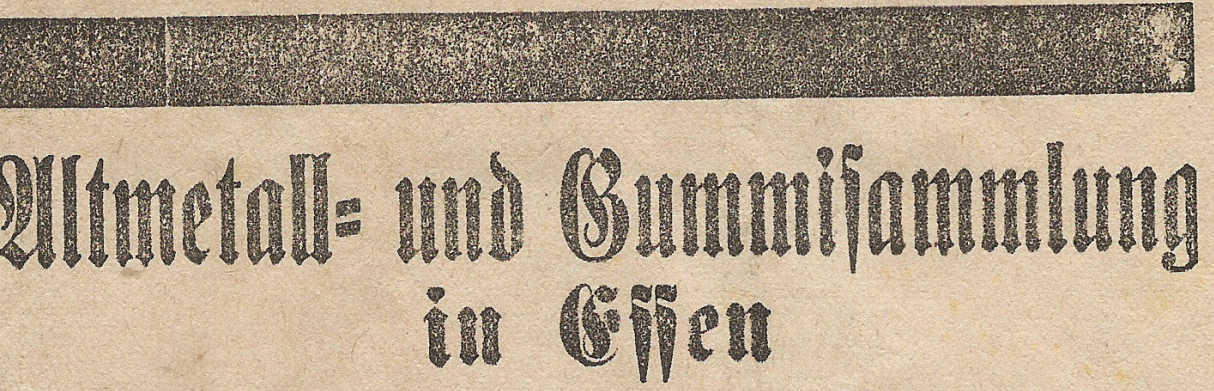

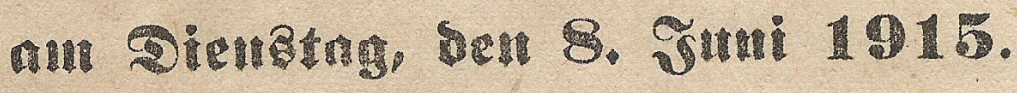

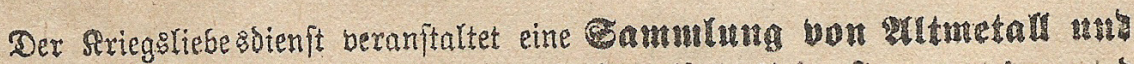

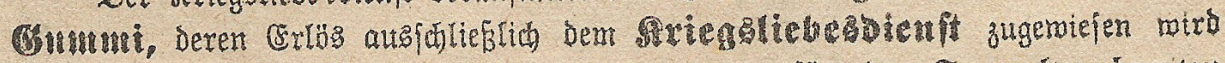
Unjere Ditbürger merben Dafer freunotidjt gebeten, für den EnmnteItag bereitzl ftellen, was an alten Dietallgegenftünden ober (Sumni borhanden ift.

(s) merden ramentlich erbeten:

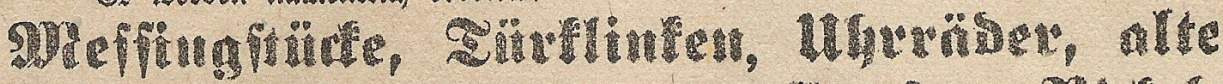

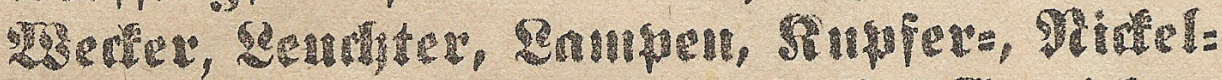

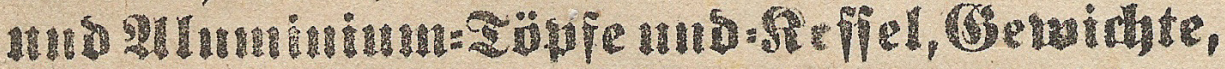

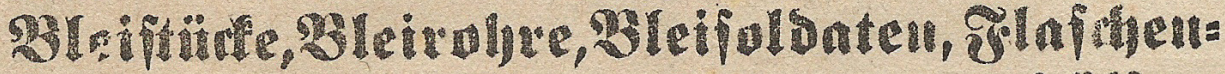

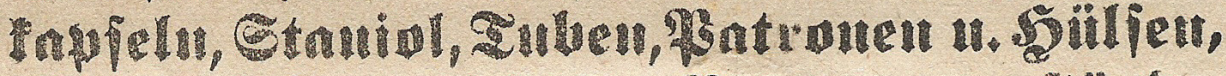

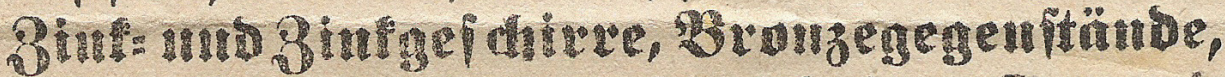

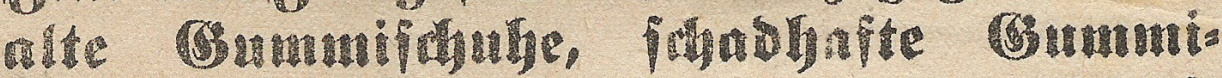

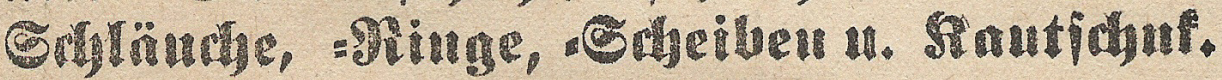

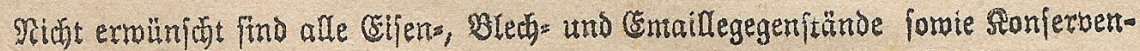
Eürugen.

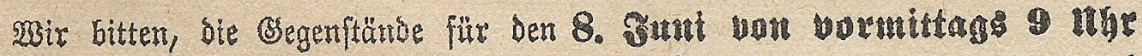

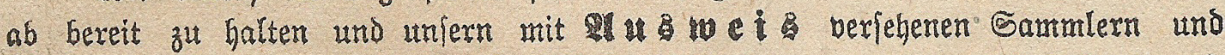
Sammlexinten auszufündigen. Der थusmeis befteht in einer fleinen Starte mit

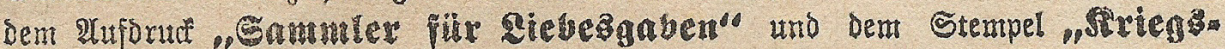

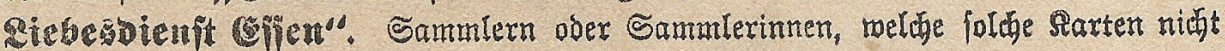
porseigen tomen, bitten mix oxingento nidbts auszuliejern.

Die Samntler und Sammlerinnen fügren mit bem gleichen Stempel ber-

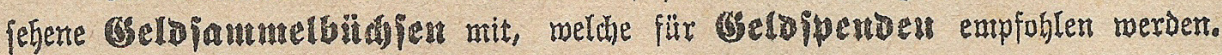

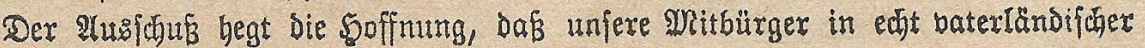
Befinmung bereitrillig fir in Den Dienft der guten Sache ftellen und durdi Lebax raeifung fonjt arfitlos meggenorfener Dinge nach Siräften dazu beitragen, neue Mittel futr Den Strieggliebesoienft zu befijaffen.

(F) f

Der Riebeลีg 


\section{Sammlung von Altmaterialien II}

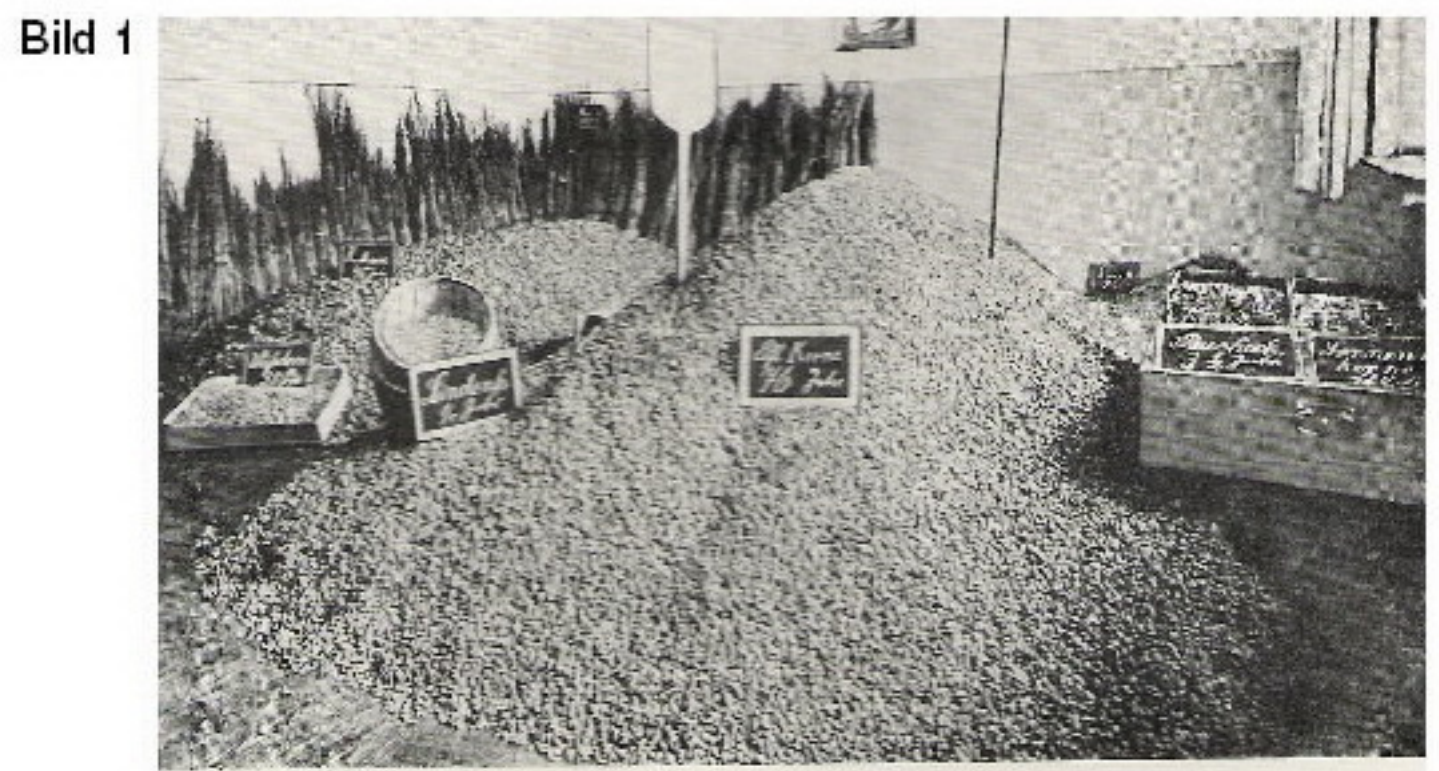

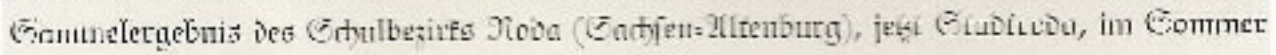
Igt6

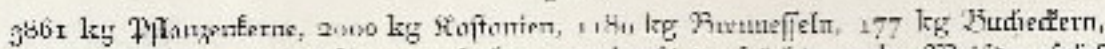

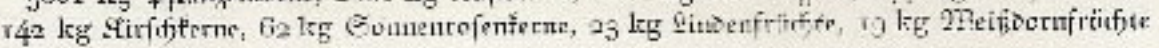

Bild 2

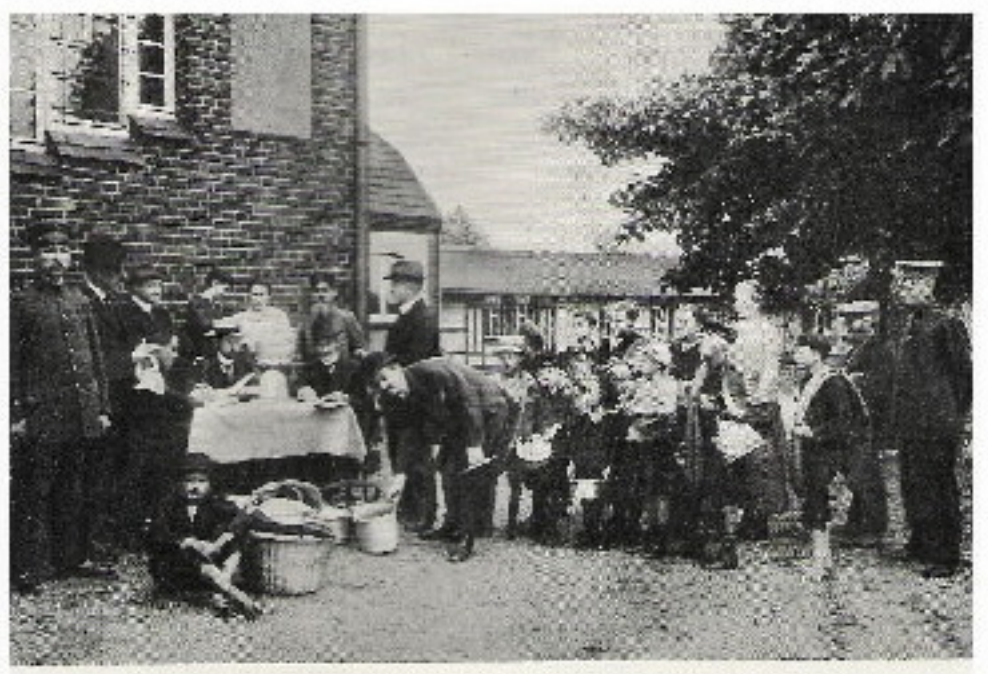

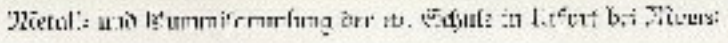

Bild 3

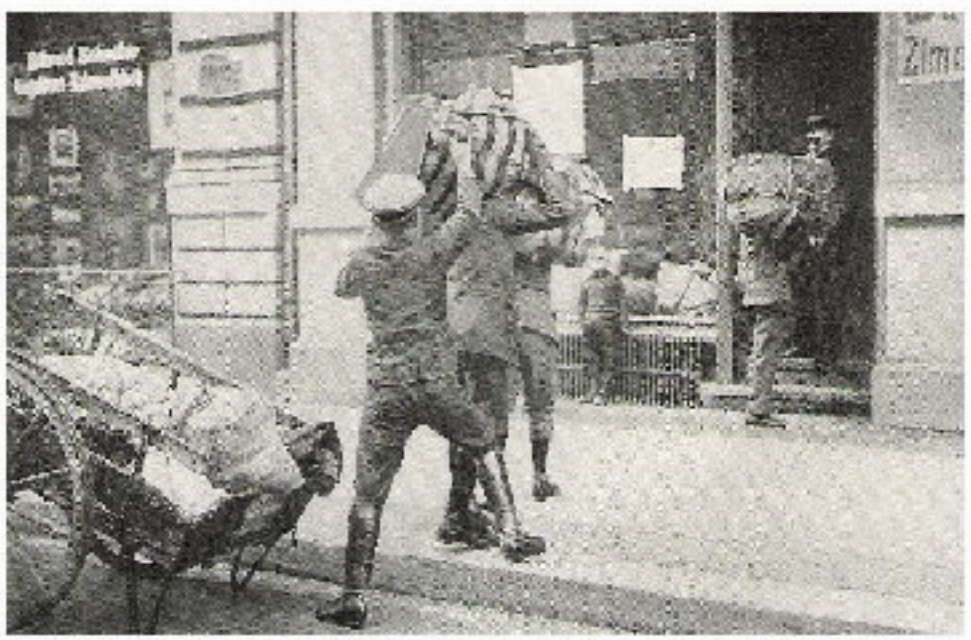


Sammlung von Altmaterialien III
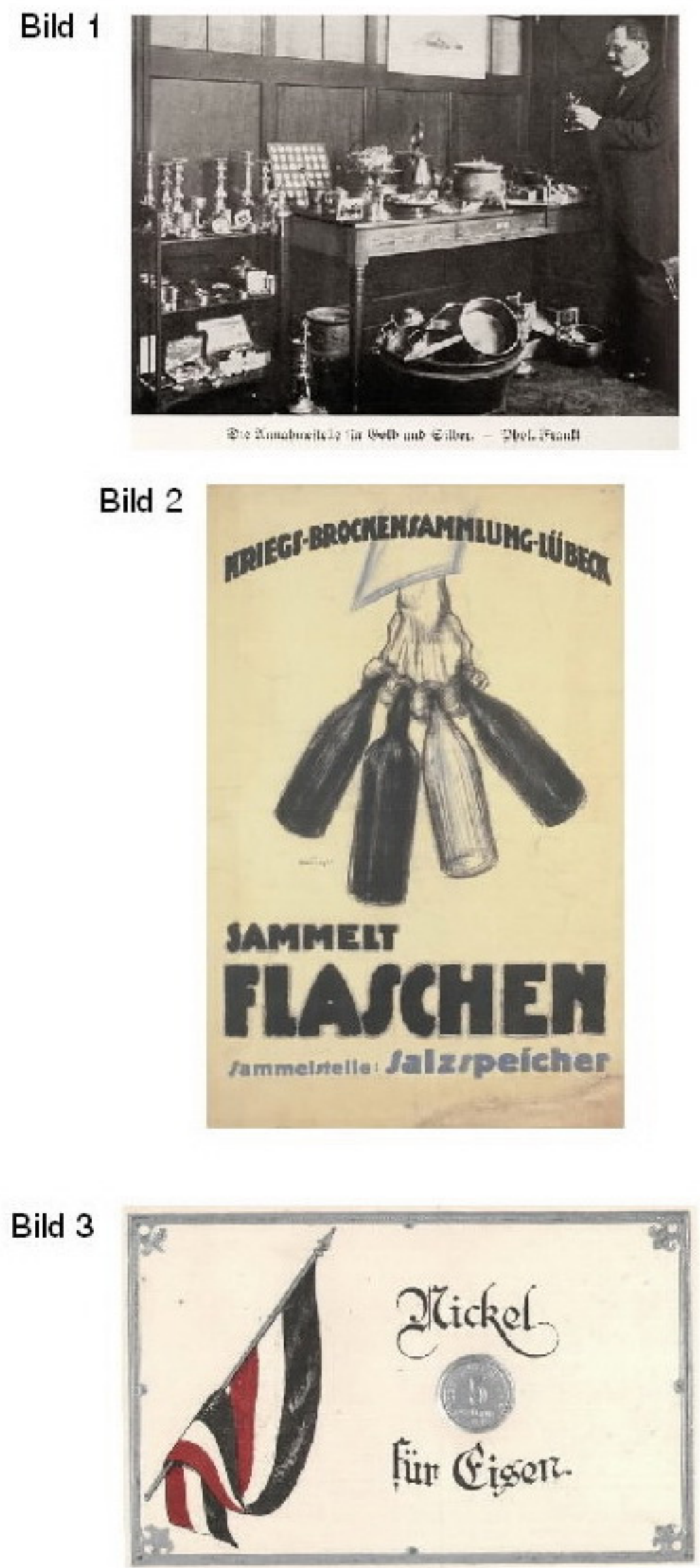

Quelle: Sammlung Kronenberg 
Sammlung von Altmaterialien IV

Bild 1

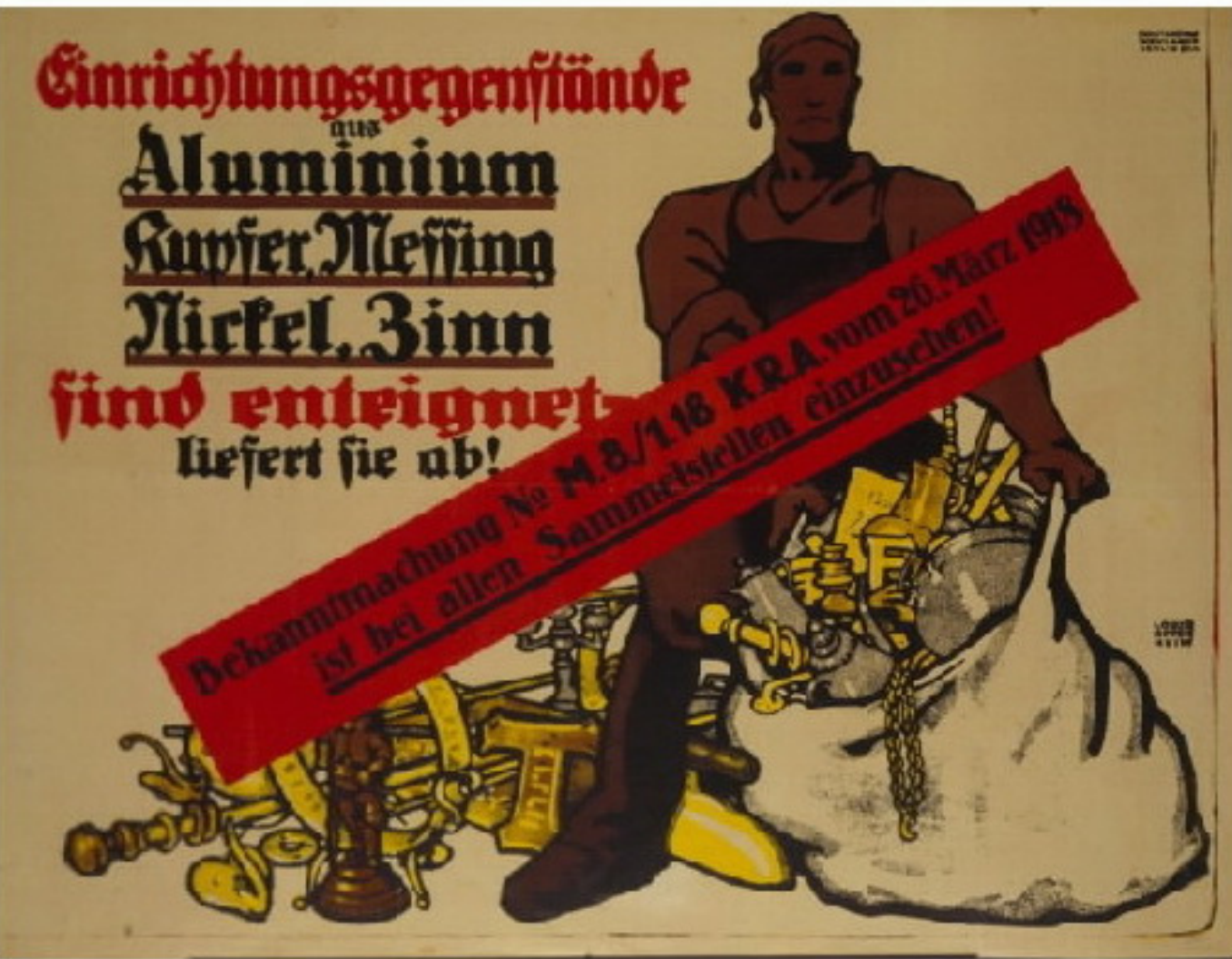

ild 2

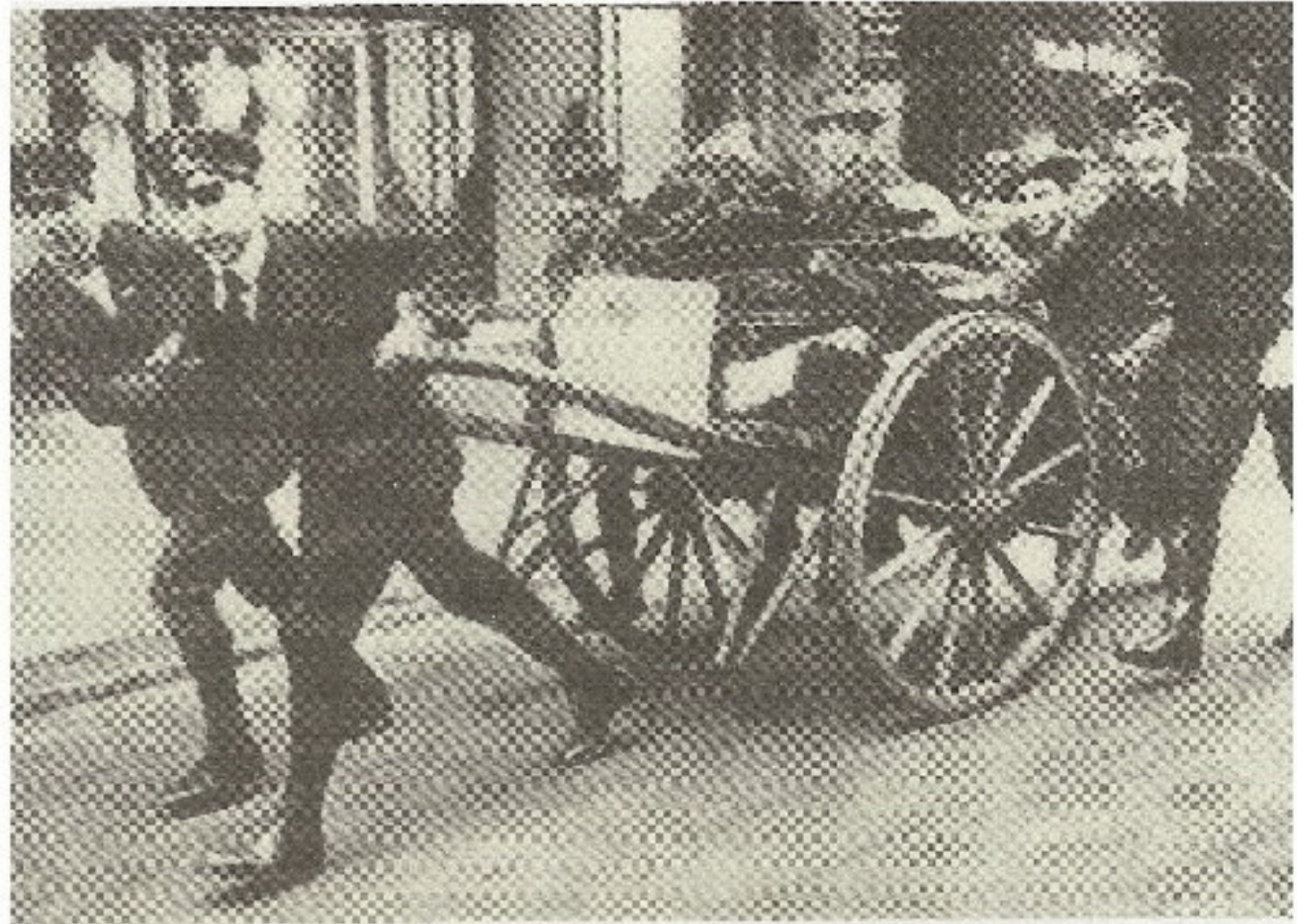

Quellen: Sammlung Kronenberg (1); Lemm, Schulgeschichte in Berlin, S. 107 


\section{Sammlung von Essensresten}

Bild 1

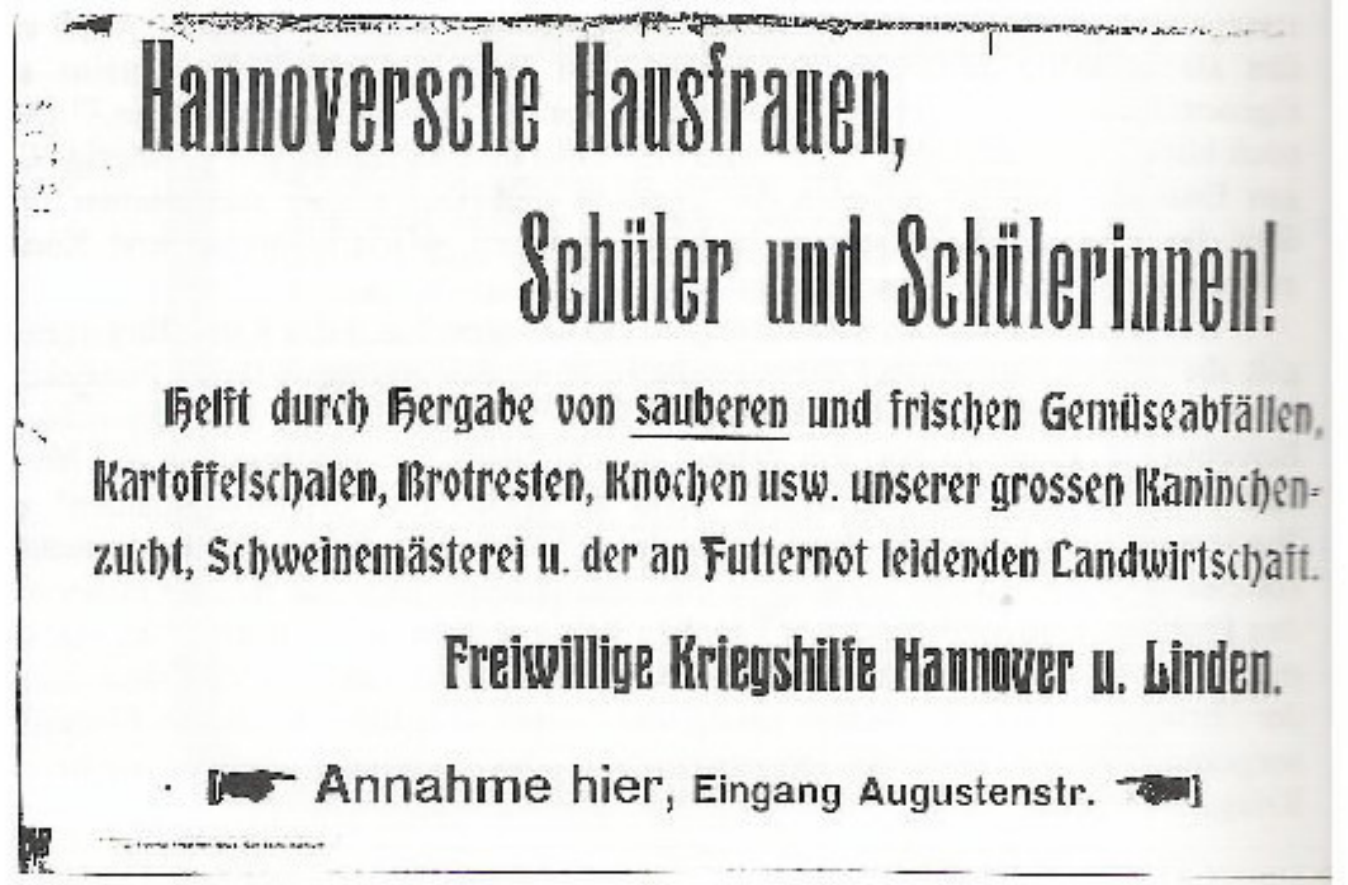

A ffruf der Freiwill. Kriesghilfe. Hannower-Linden zur Abgabe von Kachenabfillen. Quelie: NHSt/H Hann. S80 Hann., Nr. 651

Bild 2

\section{Aufruf}

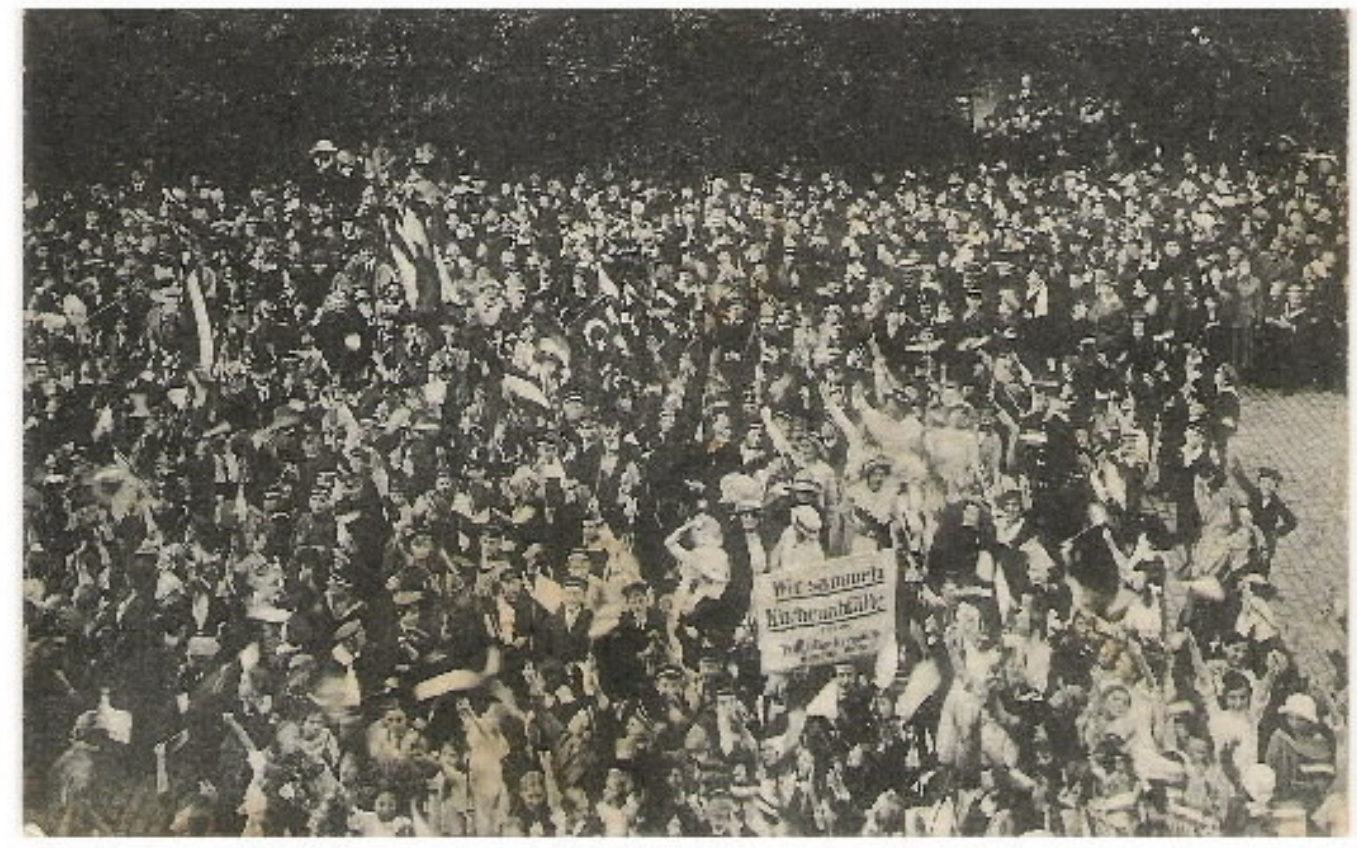

4000 Schulkinder bringen in Hannover Hindenburg die gesammelten Küchenabfälle. 


\section{Sammlung von Esswaren und Essensresten}

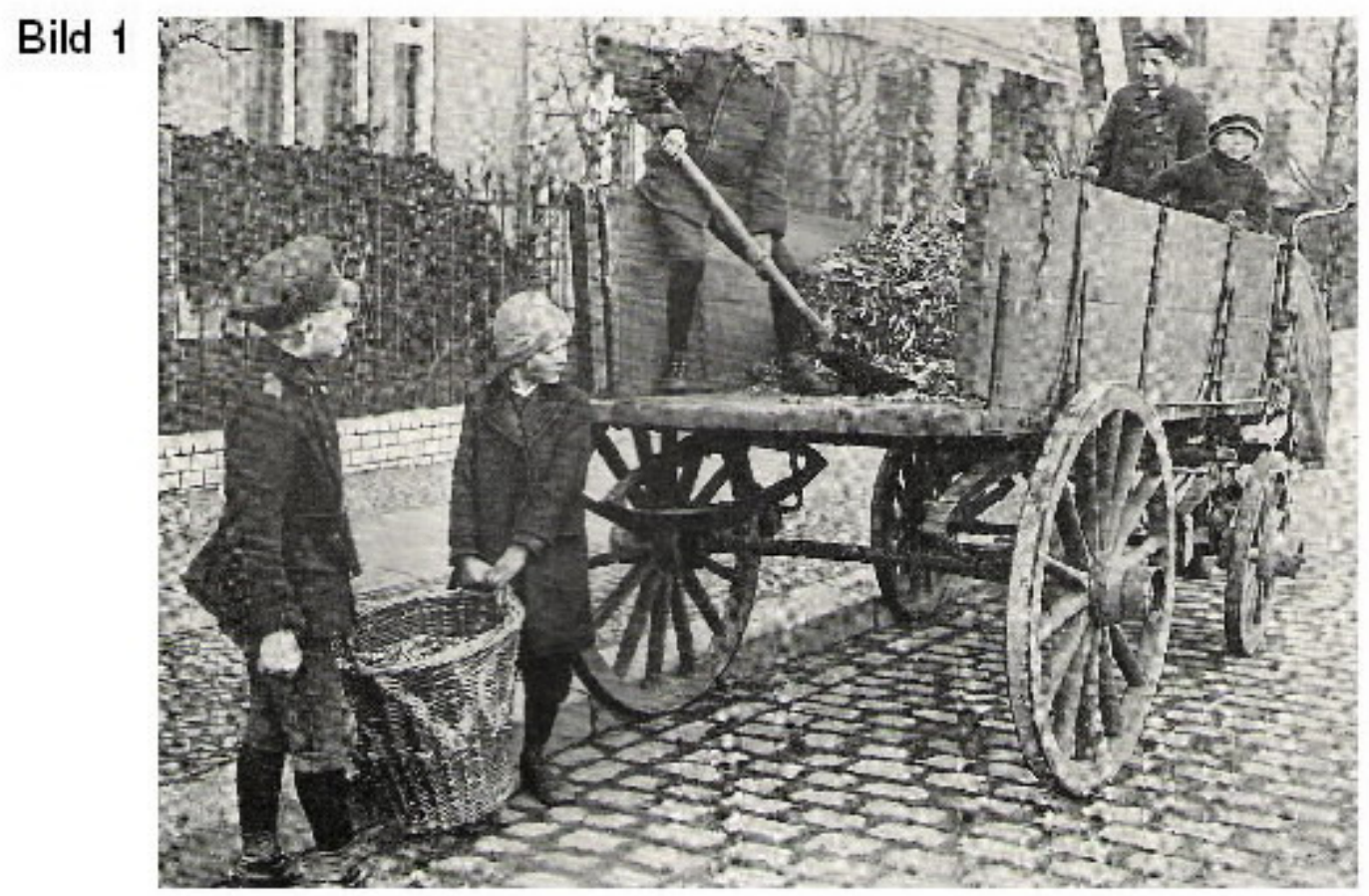

Berliner Schüler holen Kartoffelschalen ab.

Bild 2

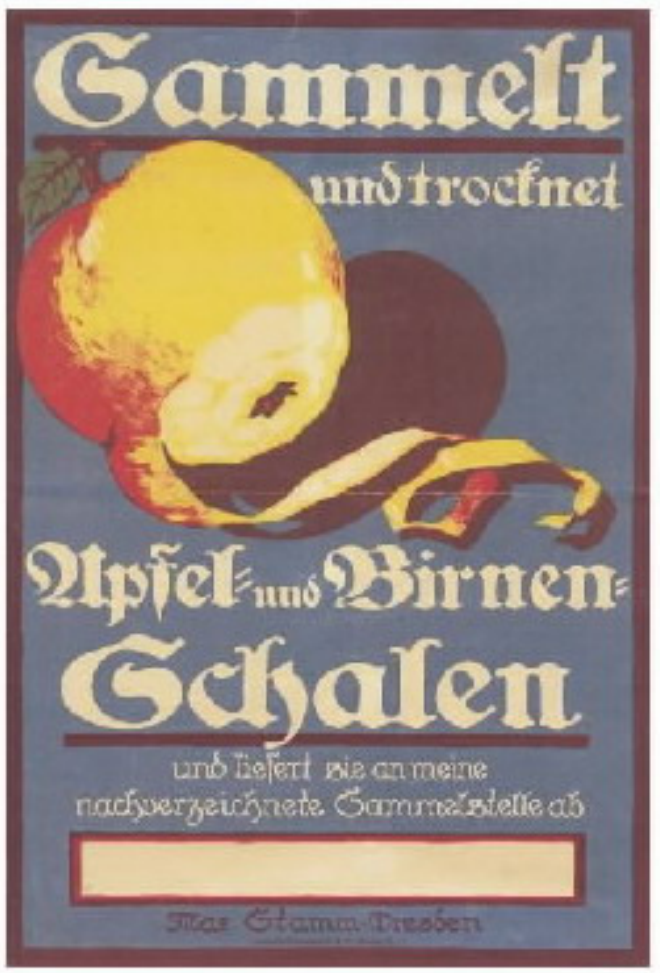

Bild 3

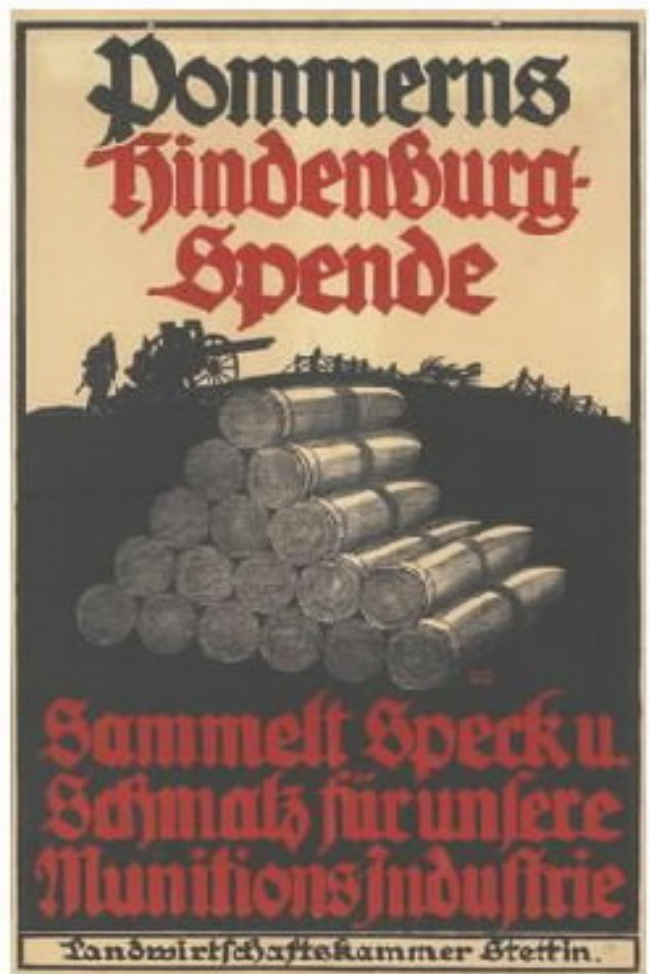

Quellen: Führen, Lehrer im Krieg, Ta,fel 1(1); Sammlung Kronenberg $(2,3)$ 
Sammlung von Essensresten, Bucheckern und Kastanien
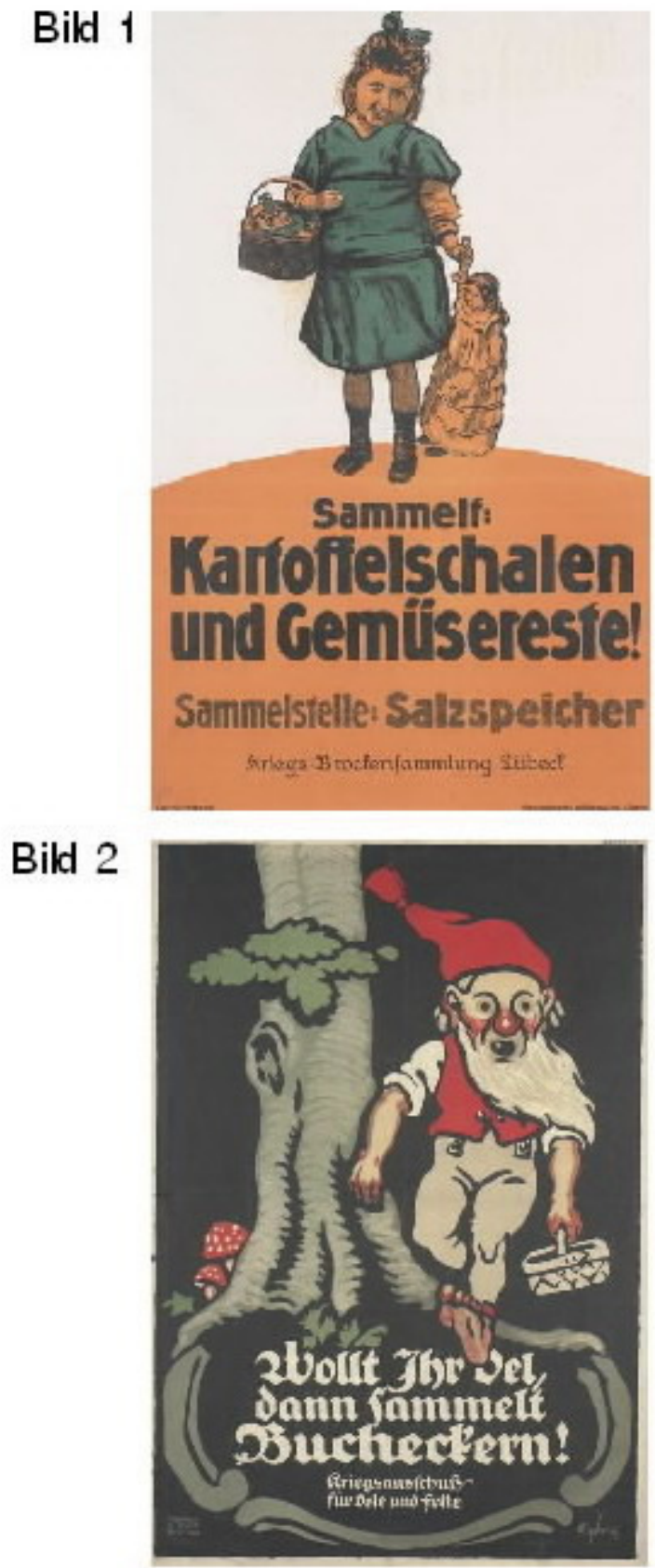

Bild 3

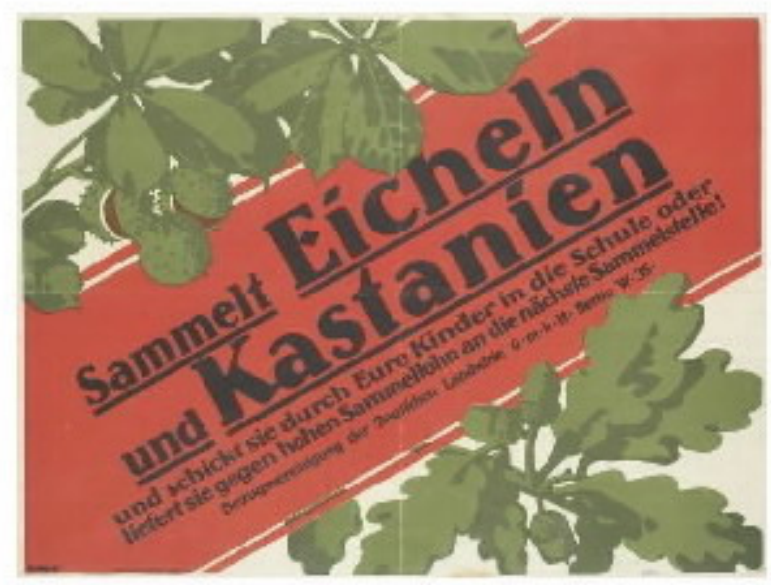




\section{Sammlung von Obstkernen}

Bild 1

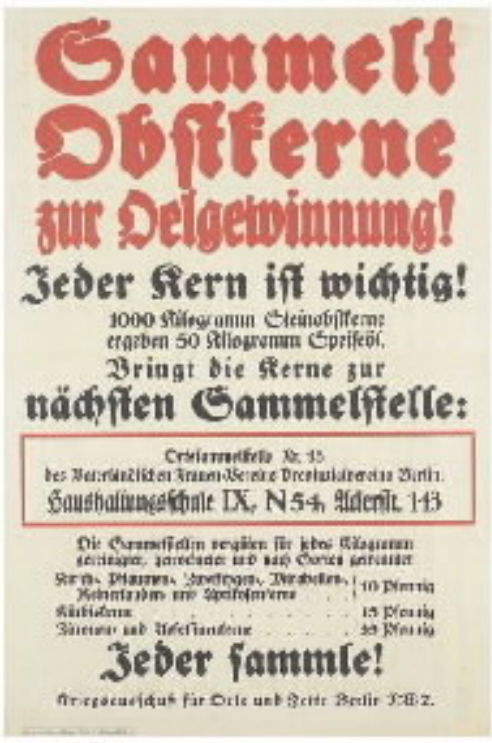

Bild 2

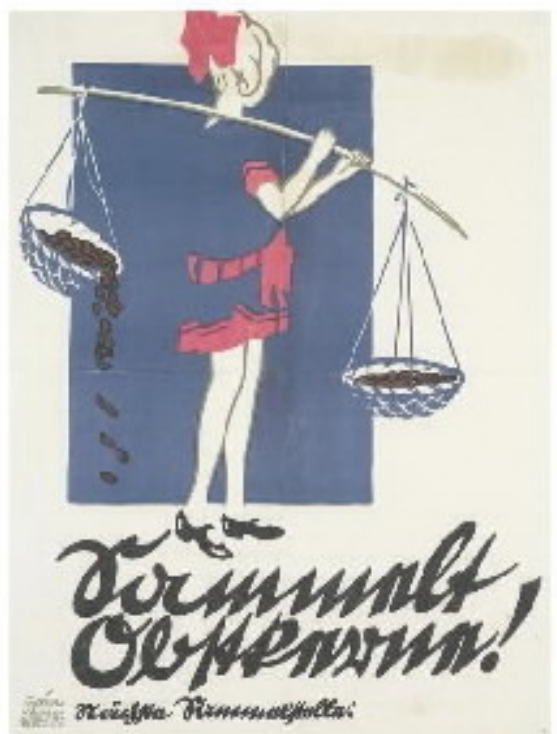

Bild 3

Bild 4

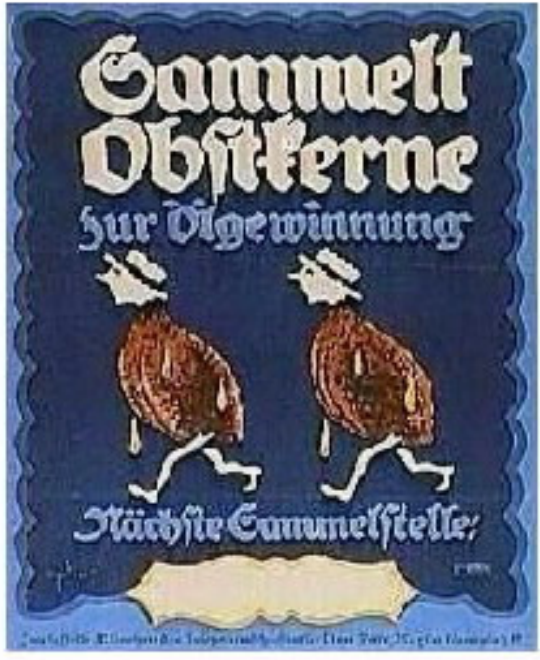

Bild 5

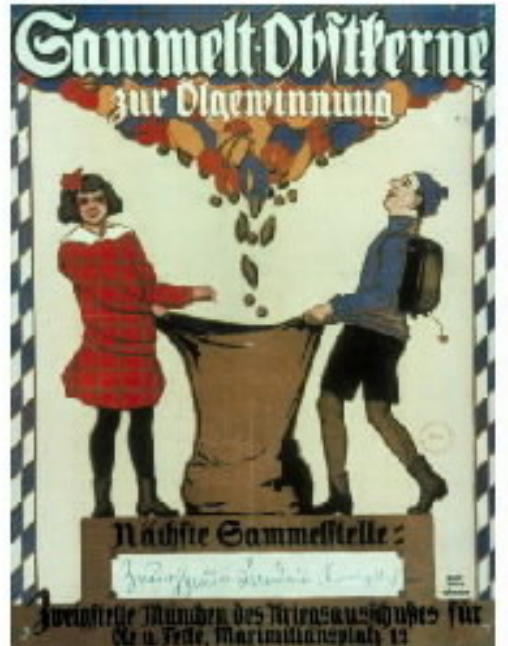

Quelle: http./Nads.ands.ac.uk/arge.php?pic=IWMPG11300\&cmd=search\&pag (1-4); Sammlung Kronenberg (5) 


\section{Sammlung von Brennnesseln}

Bild 1

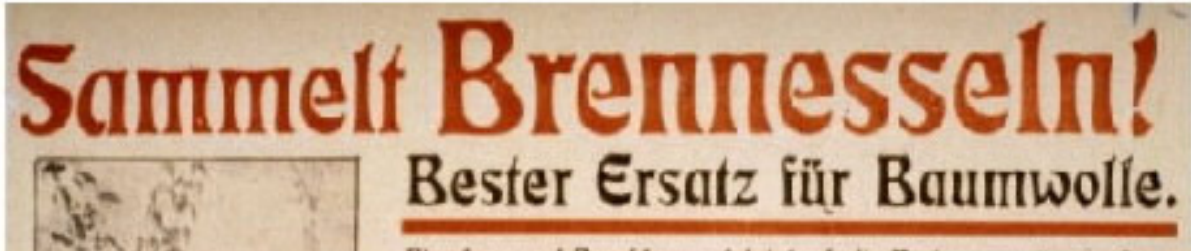

Abnohme und Bezahlumg erfolgh turdt die Deriruuensmalnaer, derea Hidressen jon den stđdiffscten und IAnflidien Behörden zi erircgen sind. Wo keine Derinatensmdnner sind, wende mon sidr an ille unter* zeldnete gemeinnahige Kriecsgesalisdialt, die wdirend des Krieges * das clleinige Rectit des Ankauls und der Verwertung hat.

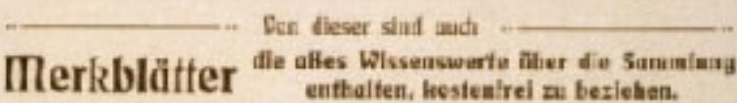
enthalten, hestemlrei za beziehan.

Fît $100 \mathrm{ky}$ irosane llesselstenget werden Miark 28, - gezobitt Fur jeden Heitar Habaulladio werden IItch 400 - vergitiott

Пlessel-Anbau-Gesellsthait m. b. .

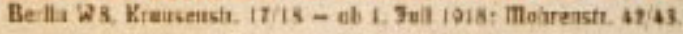
Fand: tothe เรเด, sos.

Zarme as, seme * * 대

Bild 2

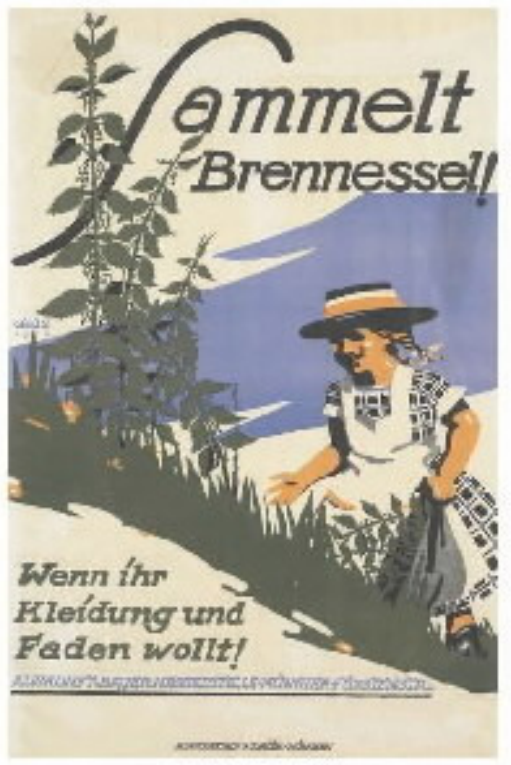

Bild 3

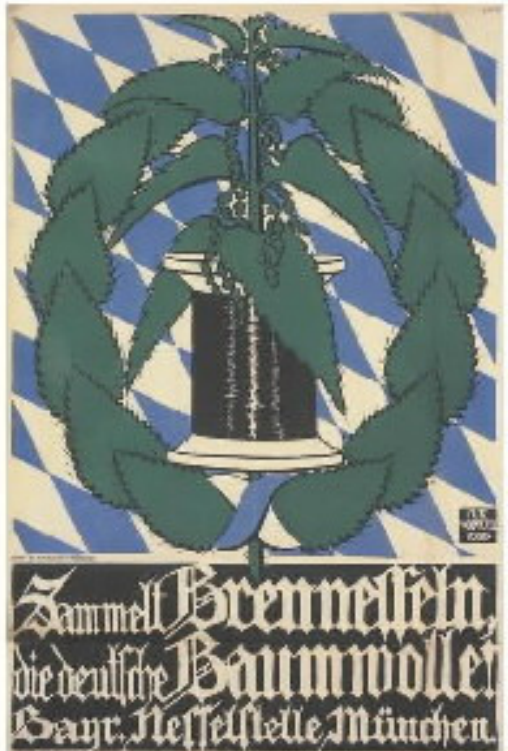

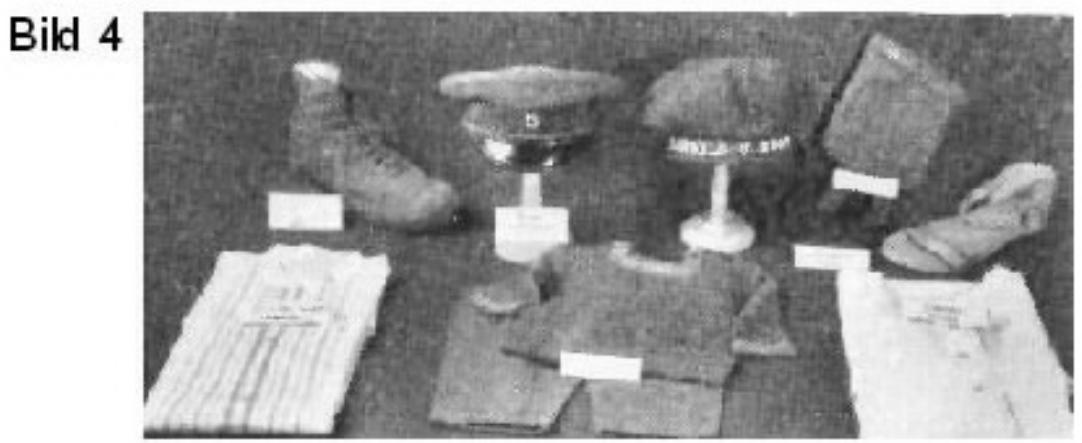

Kleidungsstücke aus Nesselstoff 


\section{Sammlung von Eicheln und Laubheu}

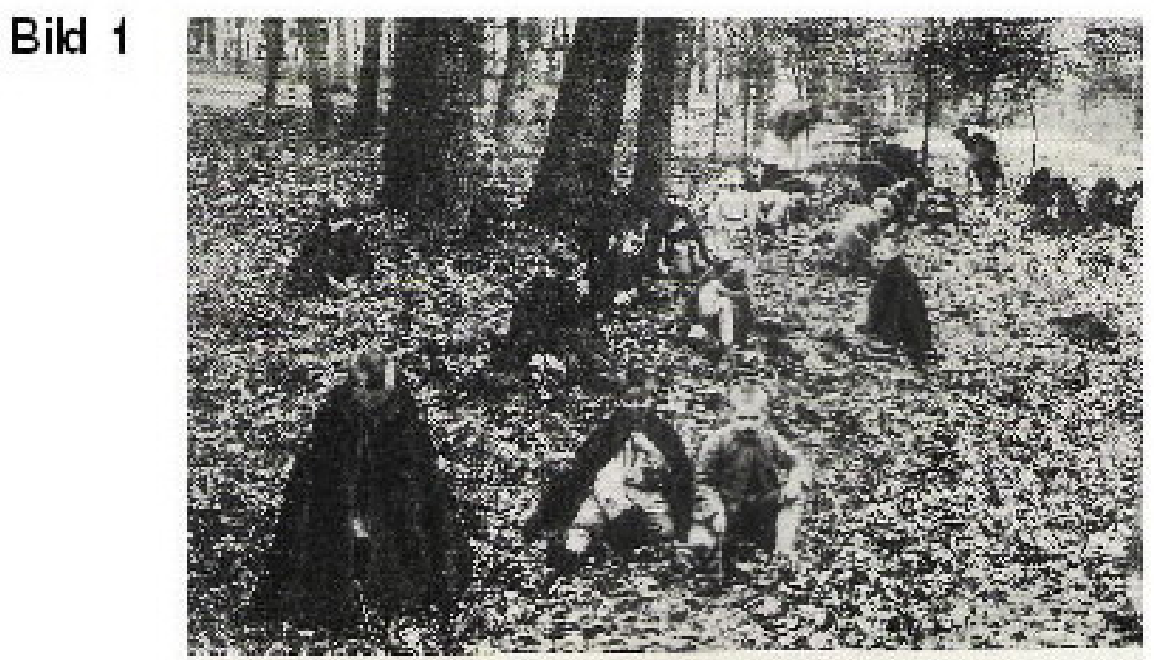

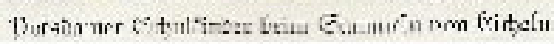

Sammeln von Eicheln

Bild 2

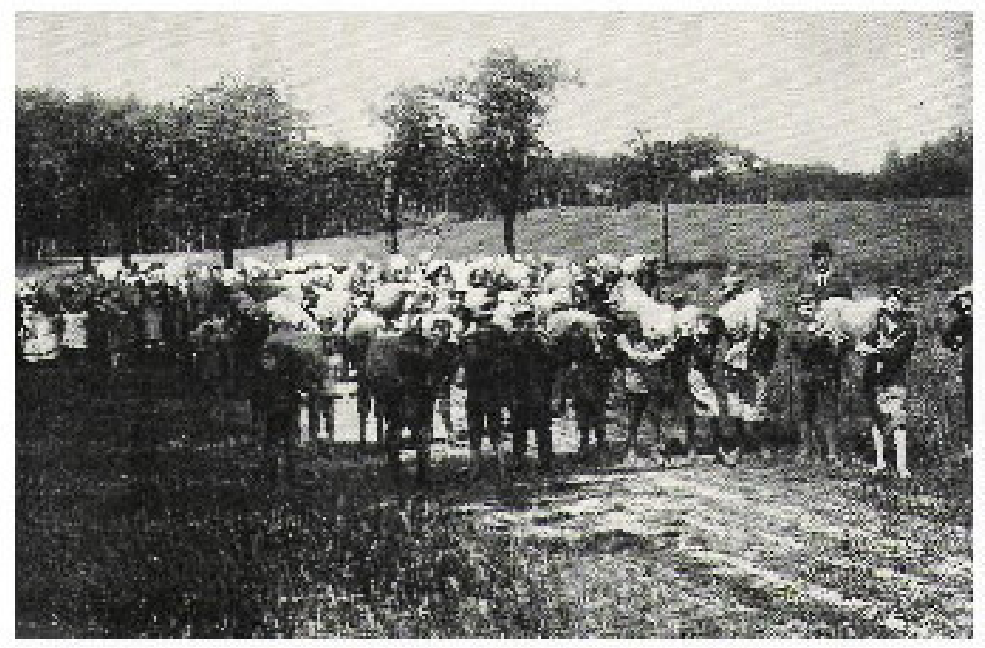

Laubernte

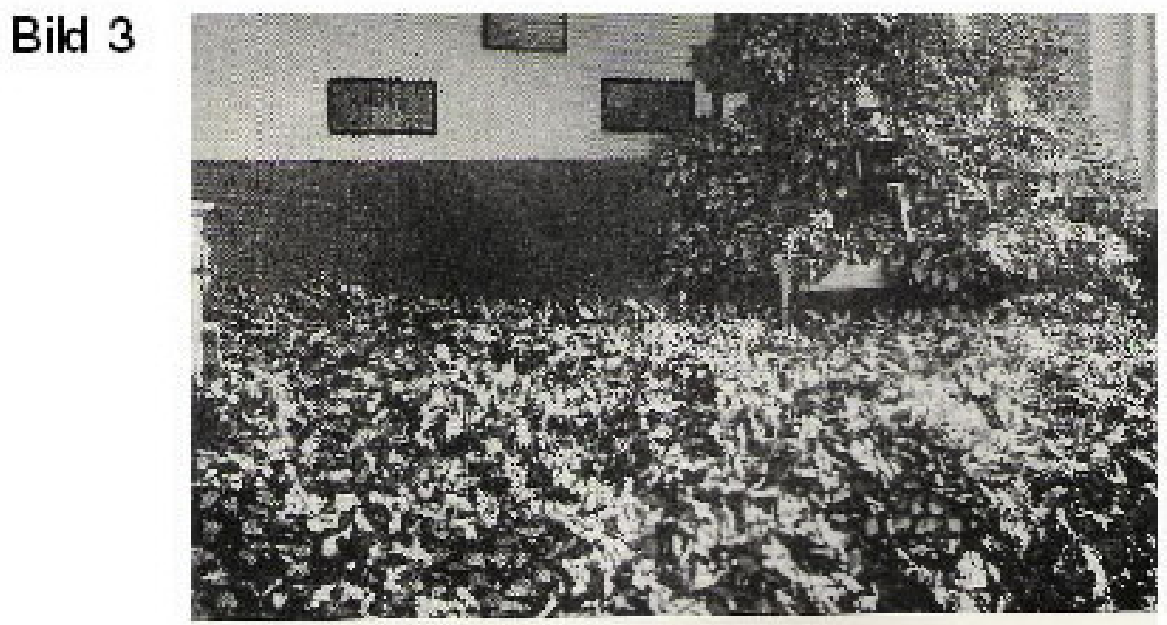

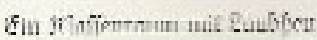




\section{Sammlung von Frauenhaar}

Bild 1

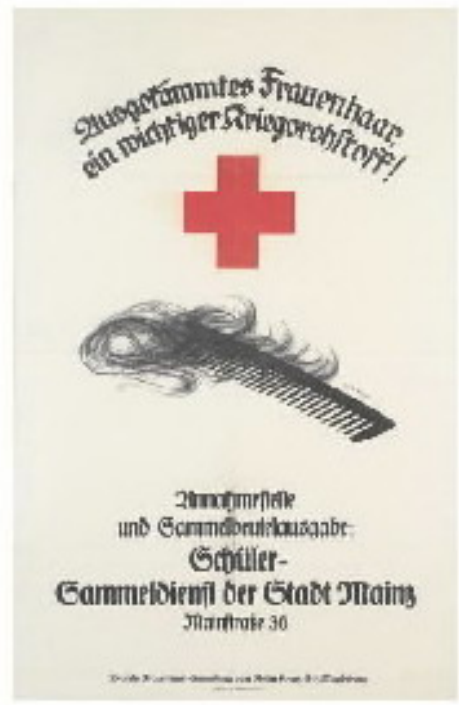

Bild 2

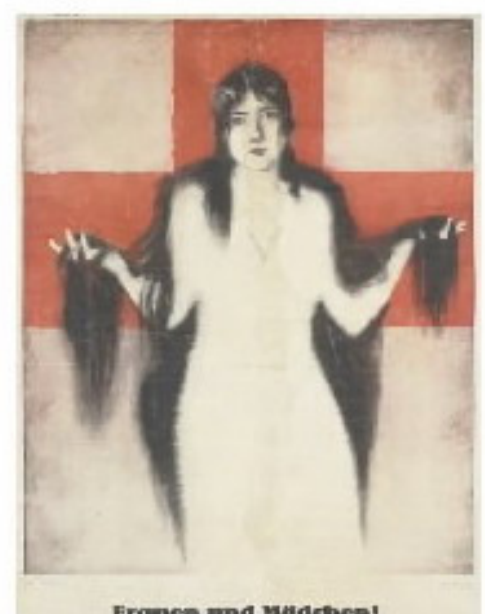

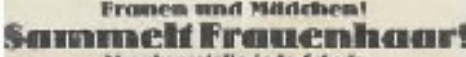

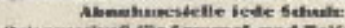

Bild 3

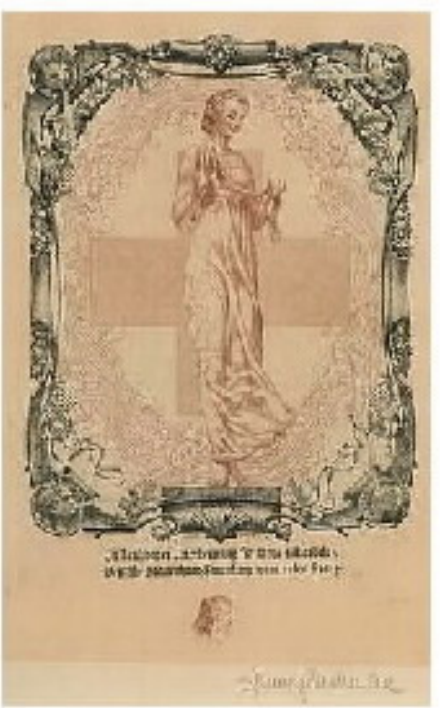

Bild 4

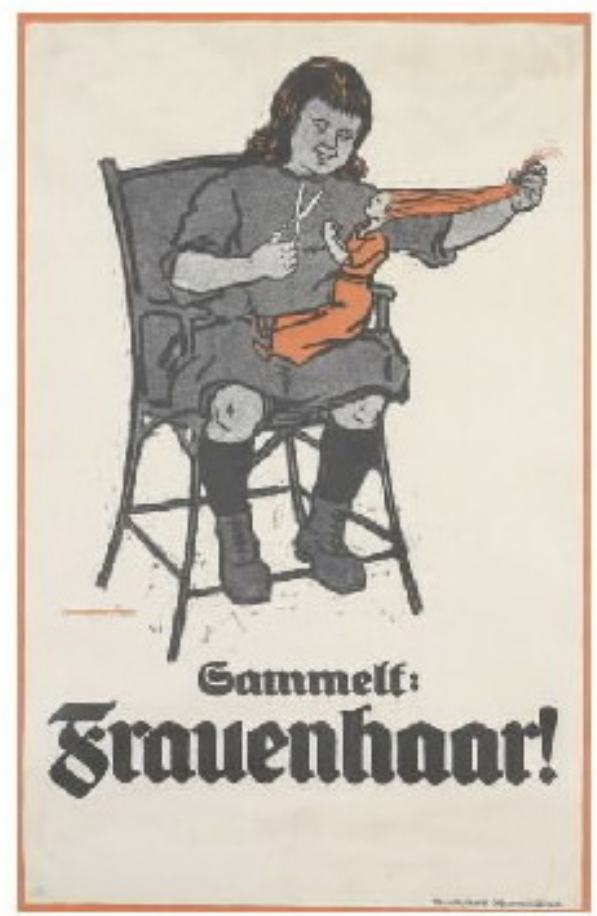

Bild 5

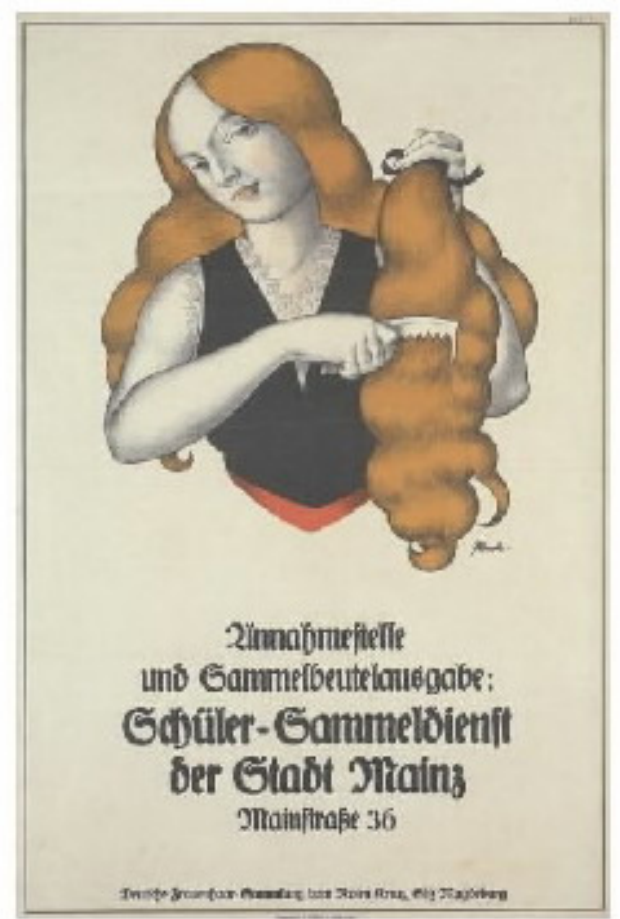

Quellen:VADS, http:/Nads.ahds.ac.uk/arge php?pic=IWMFG $11300 \& \mathrm{cmd}=5$ earch $\&$ pag $(1,2,4,5$; Sammlung Kronenberg (3) 


\section{Aufruf}

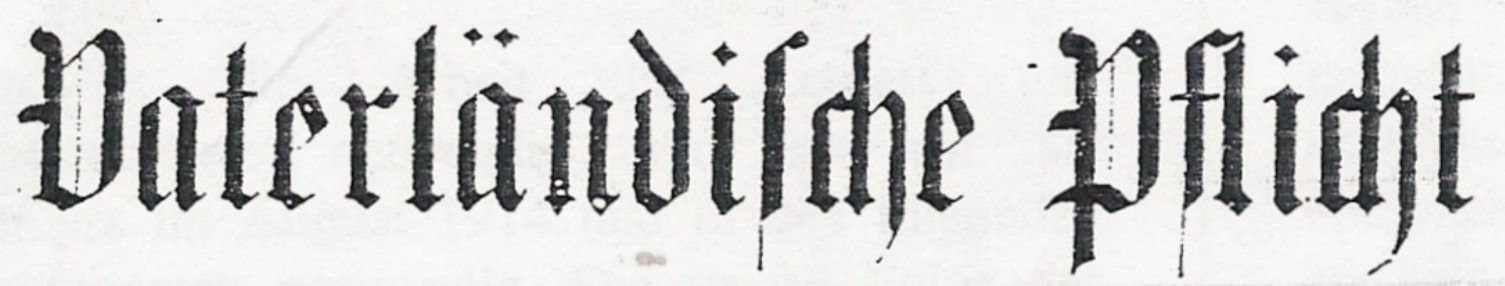 eincs jeden Sdjülers ifl es, bei den folgenden Sammlungen nad) beften keäften mitzumirken:}

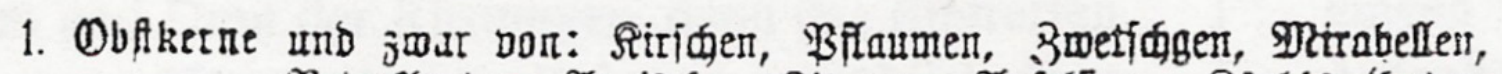

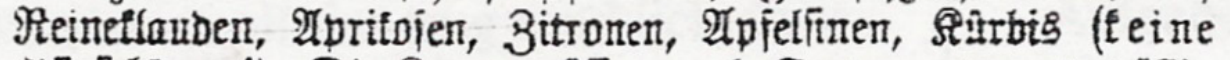

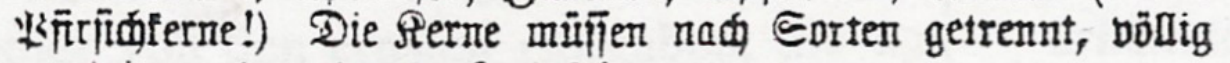
getremigt und gut getrofinet fein.

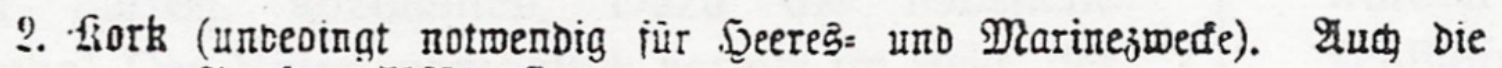
flemịter ${ }^{2}$ bịâlle jino mertboll.

3. Wummi (un jeder Form).

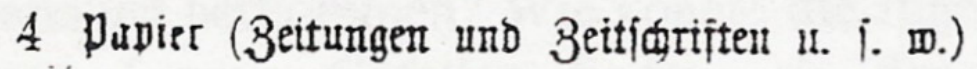

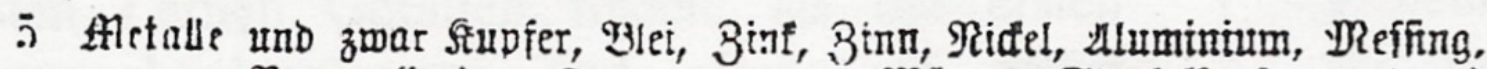

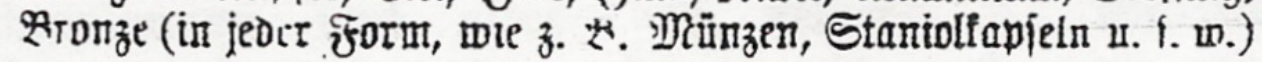

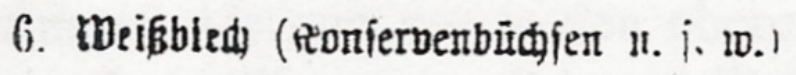

7. efteniduenhaar.

8. Enomen (gefout uno gejäubert).

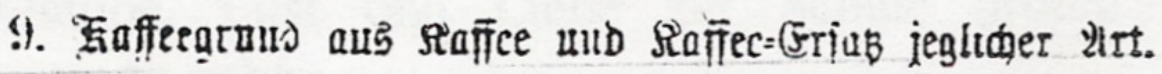

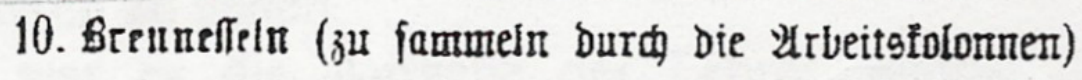

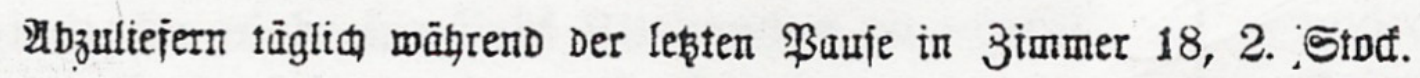

Vour neuten witb bie (Jolinegenfäänden bringend in Erinnerung gebramt.

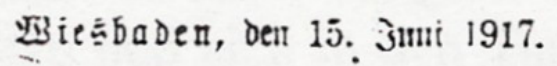




\section{Gedenkblatt}

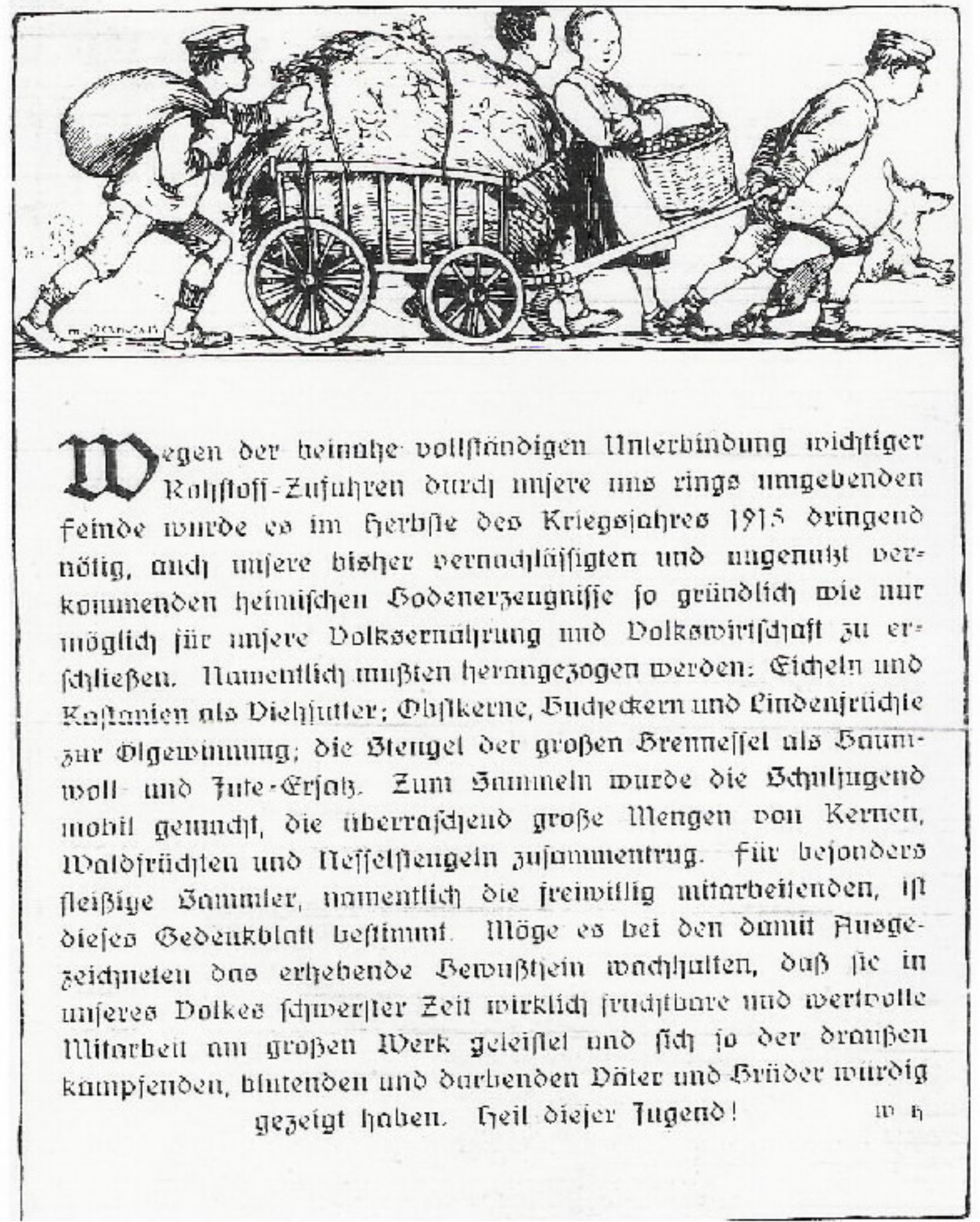

Quelle: Bundesa,rchiv Koblenz, Rep. 319, R 86, Nr. 3286 


\section{Kapitel 3}

Verkauf von Spielzeug

\section{Bastelanleitungen des 'Sächsischen Jugenddanks'}

Bild 1

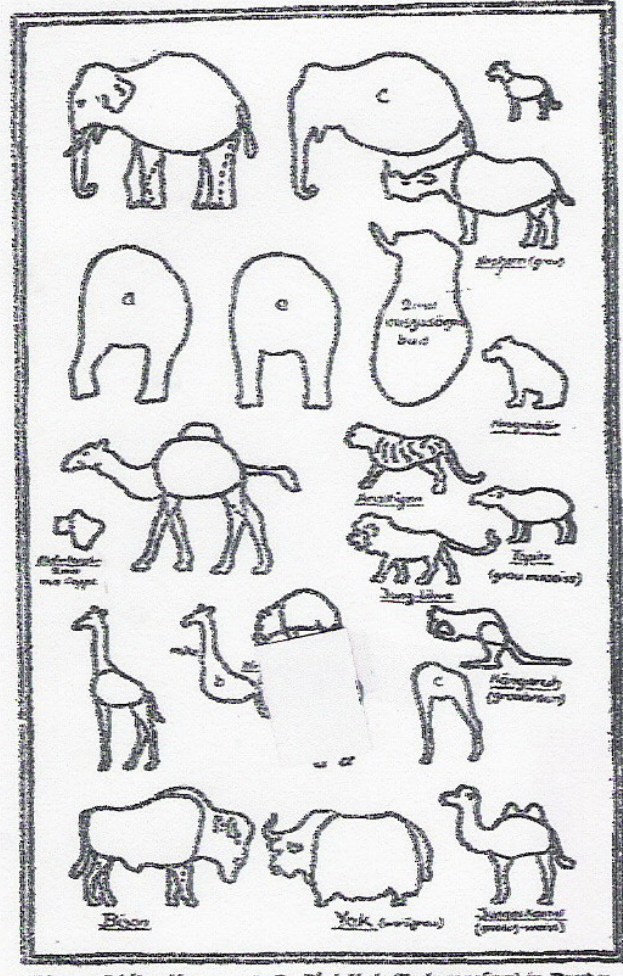

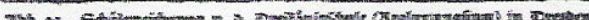

Bild 2

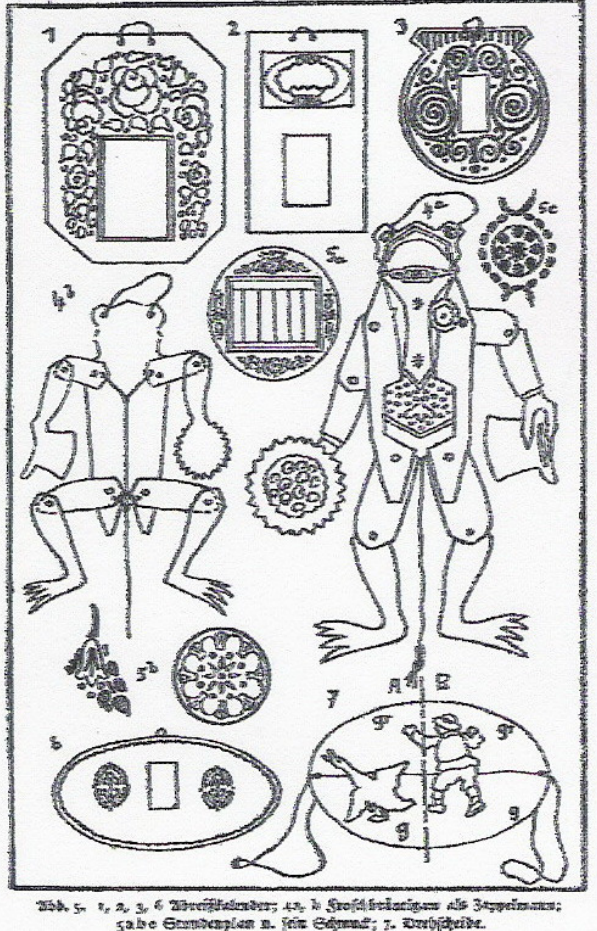




\section{Verkauf von Ansichtskarten I}

Bild 1

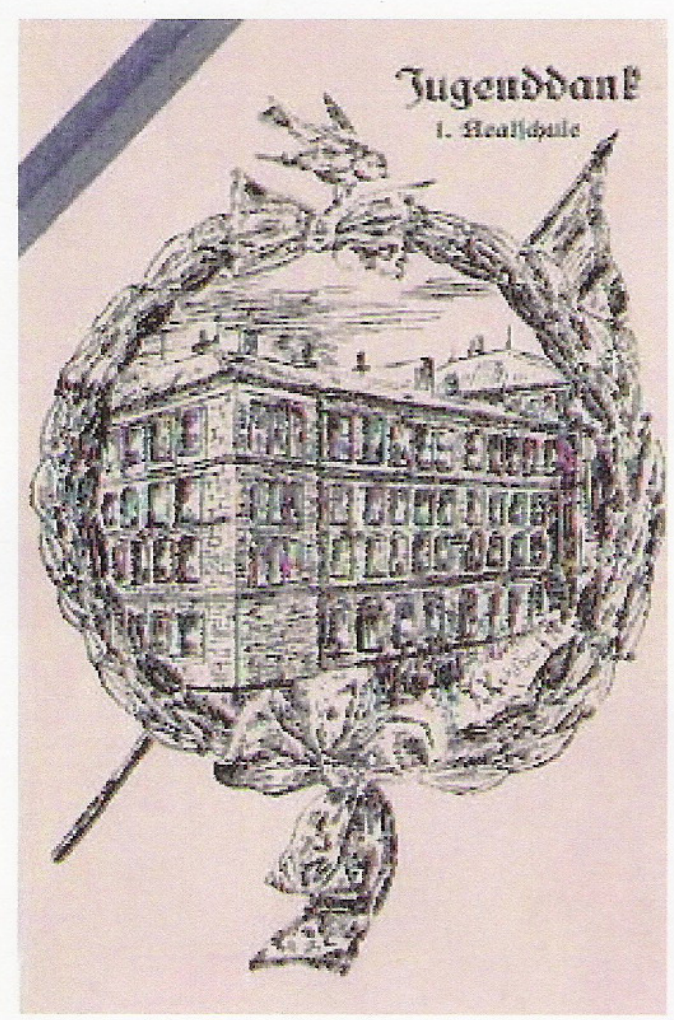

Bild 2

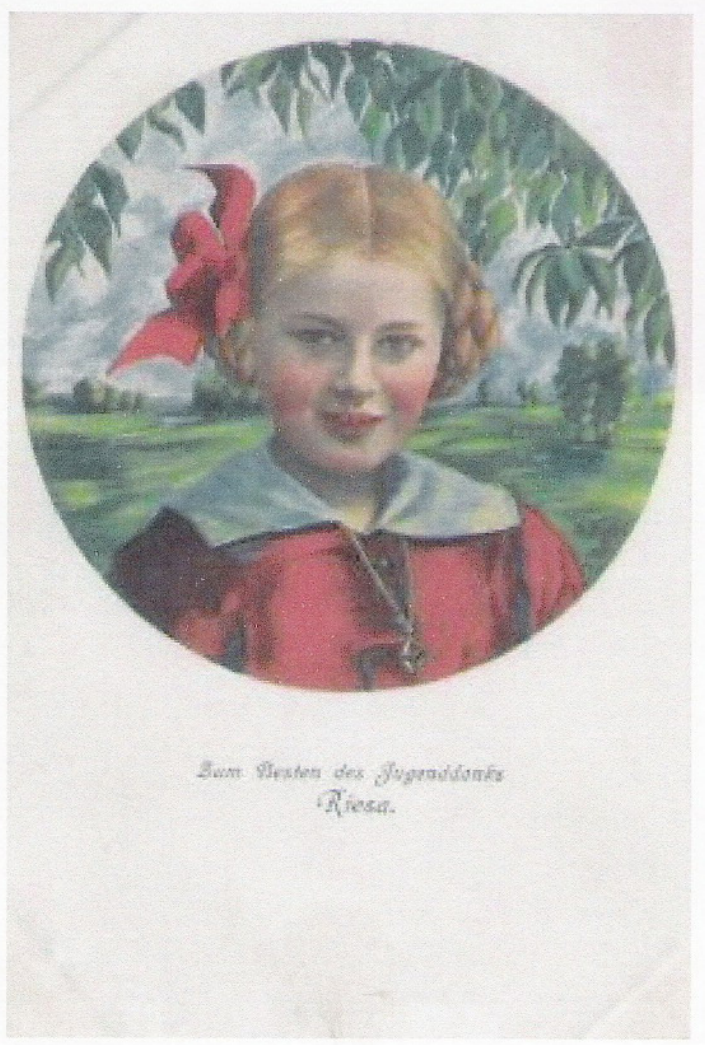

Quelle: Sammlung Kronenberg 


\section{Verkauf von Ansichtskarten II}

Von den Schülern der Fontaneschule gestaltete Kriegspostkarten

Bitdt

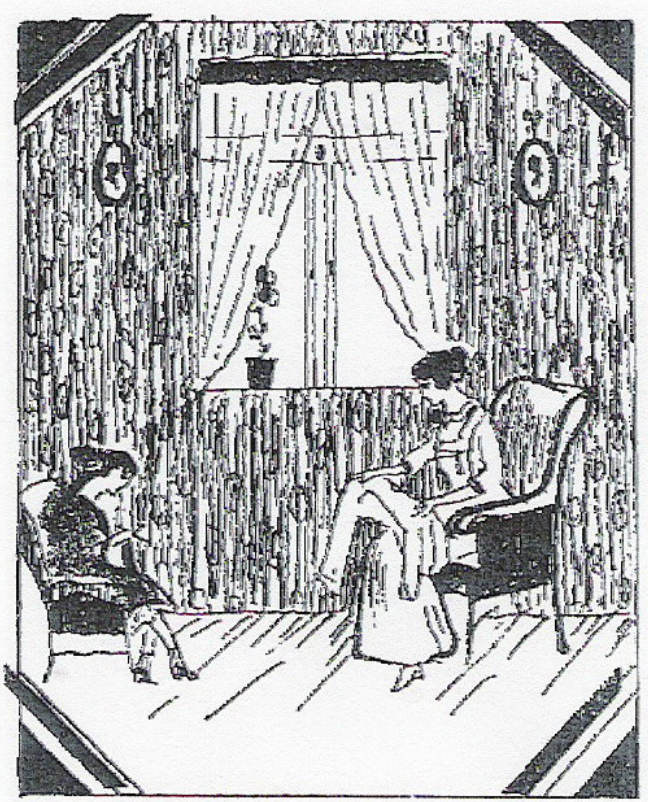

atuch soir wollen belfen?
Bild 2

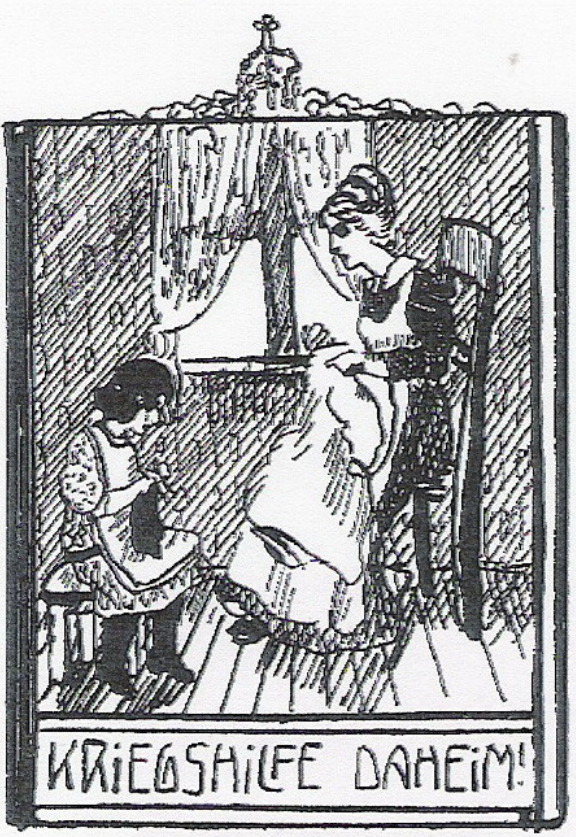

\section{Bild 3}

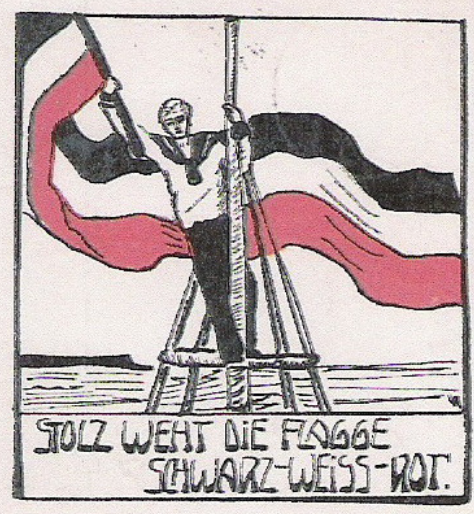


Verkauf von Ansichtskarten III

Von Schülern gestaltete Kriegspostkarten

\section{Bild 1}

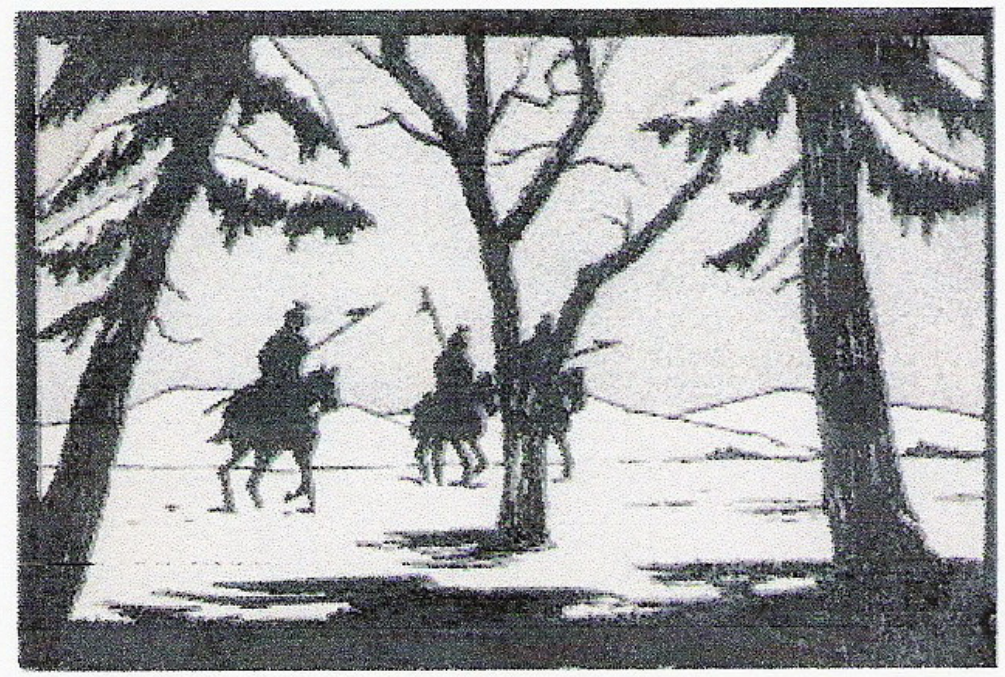

Bild 2

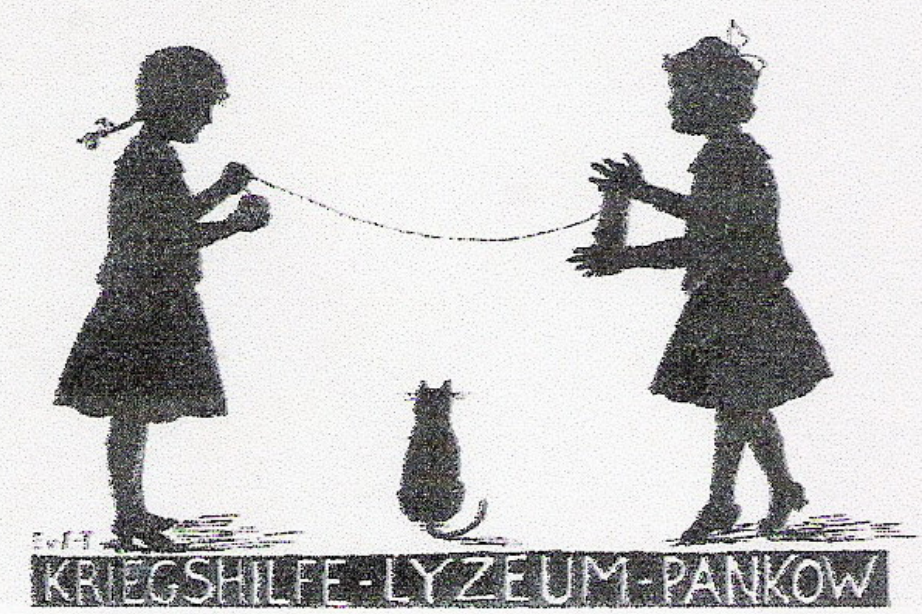

Bild 3

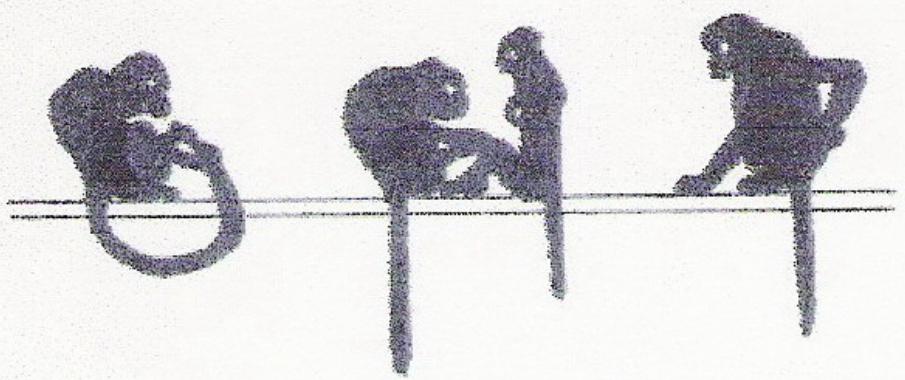

Quelle: Sammlung Kronenberg 


\section{Kriegsanleihe I}

\section{Aufruf zur 4. Kriegsanleihe}

\section{gentethes bhilologeniblatt

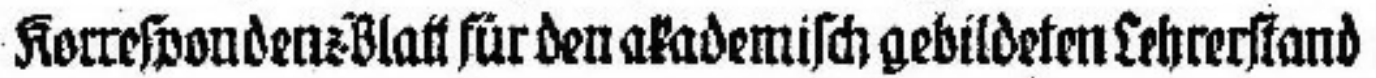

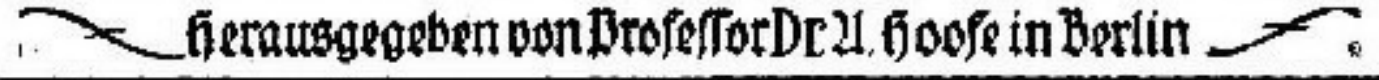

\section{B̧eidanet die vierte Rriegganleibe!}

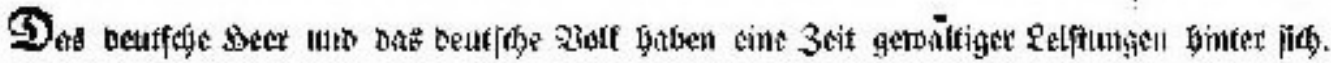

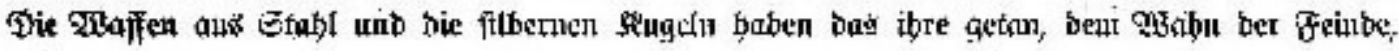

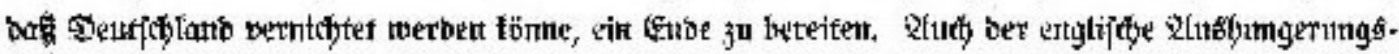

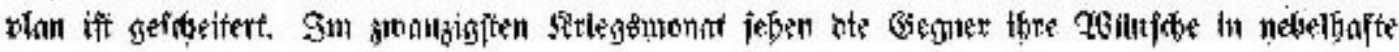

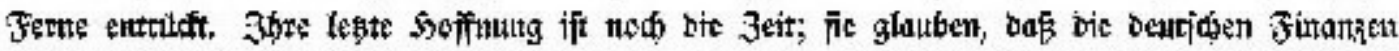

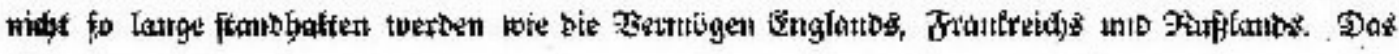

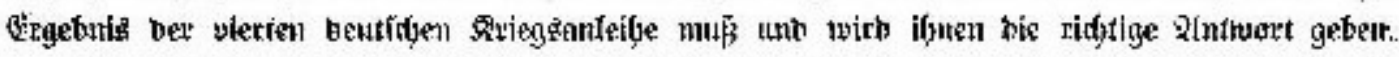

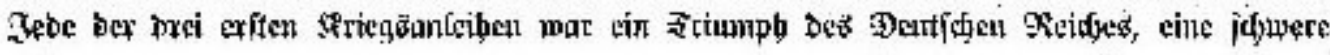

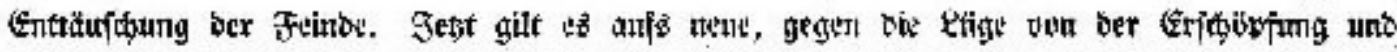

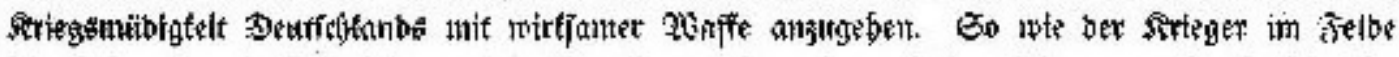

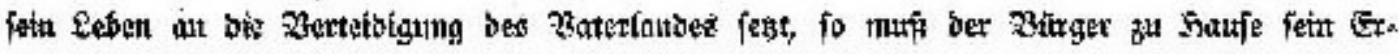

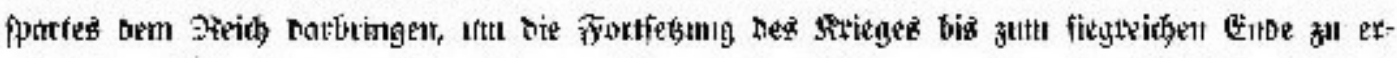

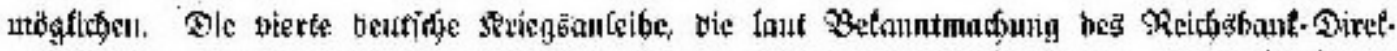

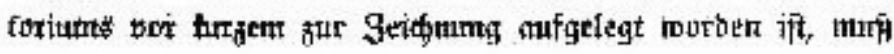

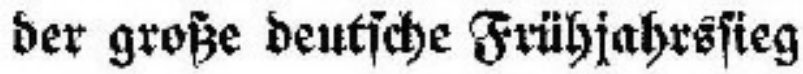 aú bemt fintanziellen Bablachtfelde}

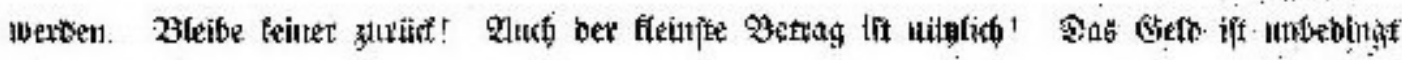

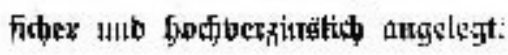




\section{Kriegsanleihe II}

Dankesurkunde des Kaisers (1915)

Bild 1

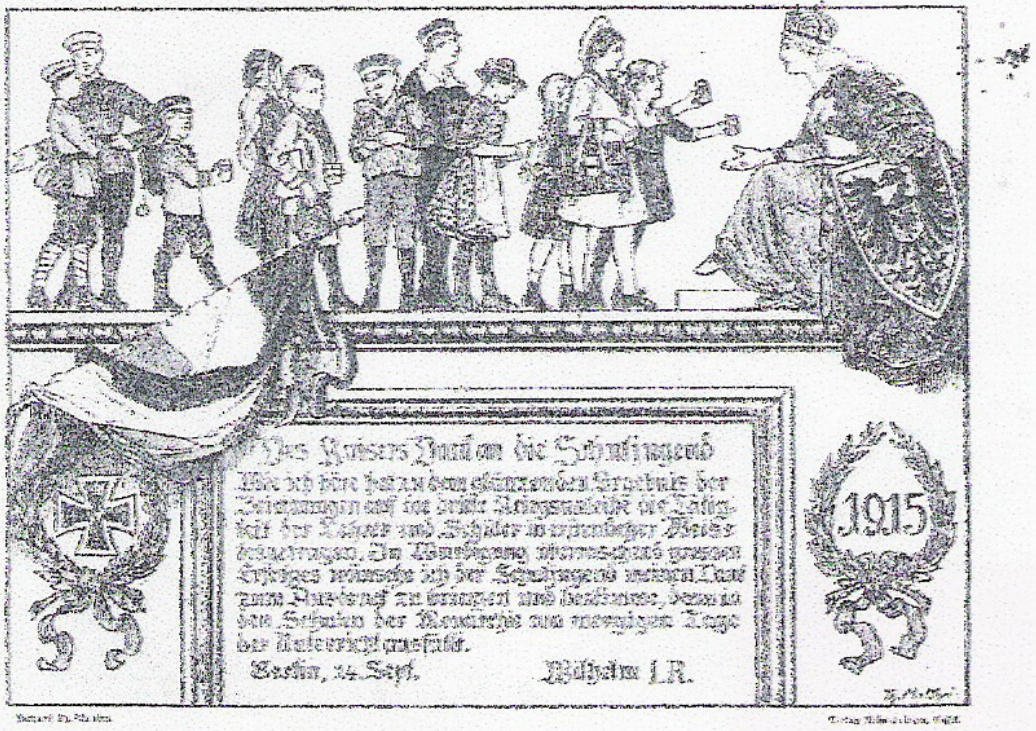

Sparen bei Kriegssparkassen

Bild 2

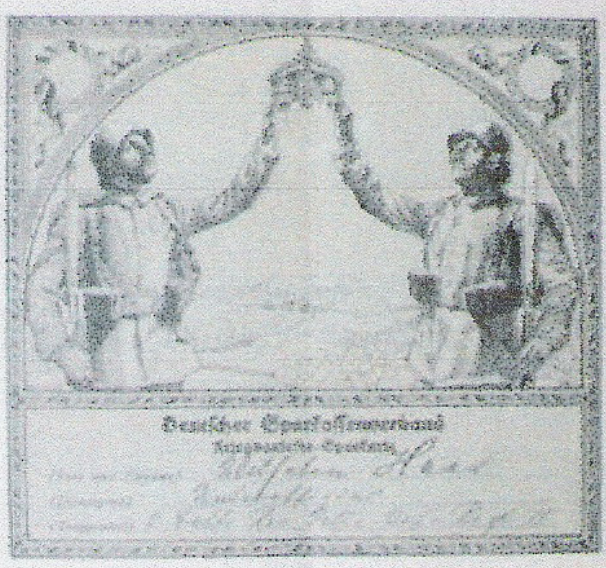

Bild 3

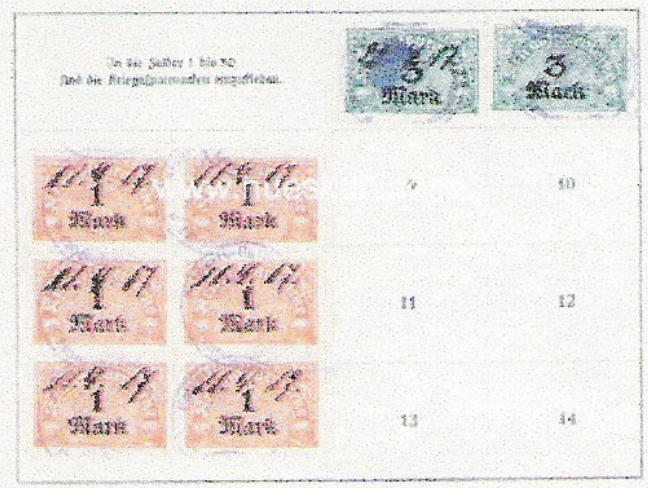

Quelle: Sammlung Kronenberg 


\section{Kriegsanleihe III}

\section{Werbeaktion Berliner Schüler}

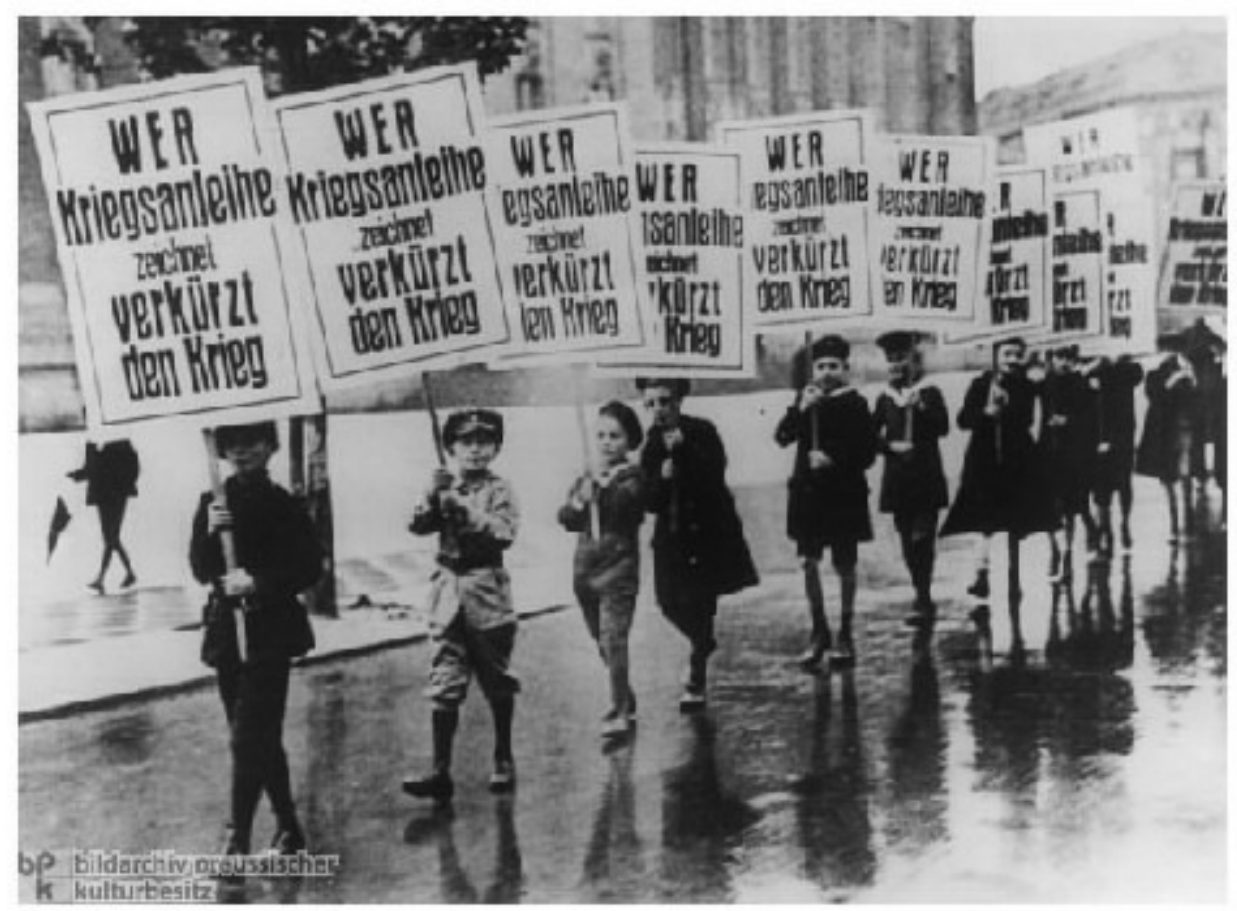

\section{Bild 2}

\section{Renten Gie fojon bas

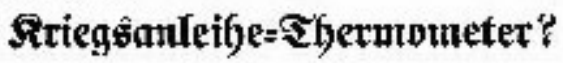

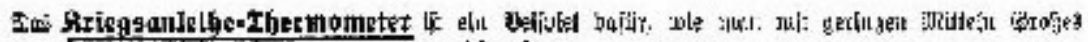
tereificen loar.

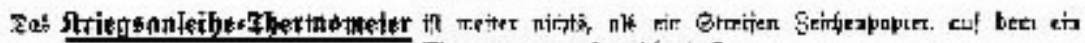

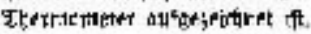

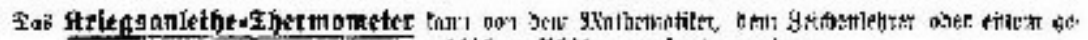

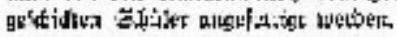

xins fritegsmicihe

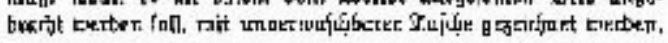

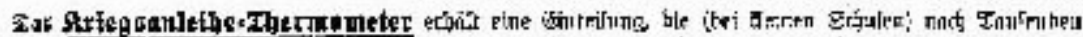

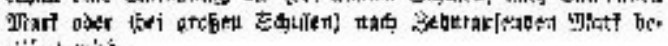
jififat aiź.

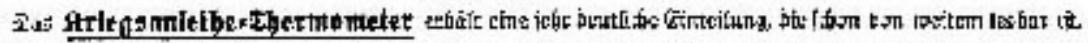

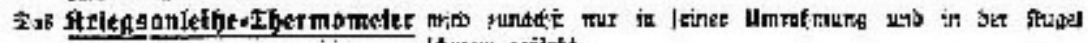

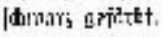

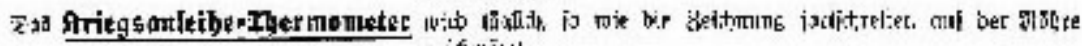

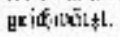

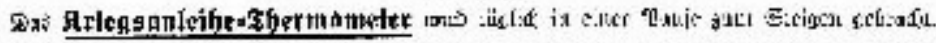

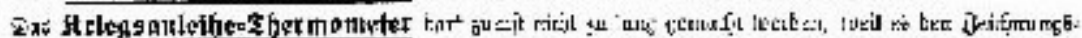

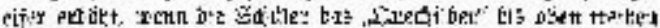

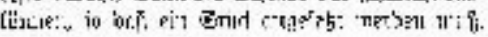

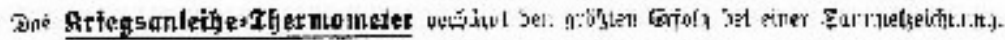

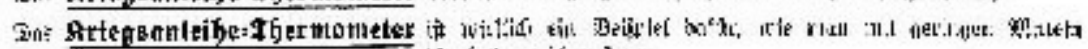

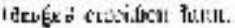




\section{Kriegsanleihe IV}

\section{Kriegsanleihe-Kalender}

Bild 1

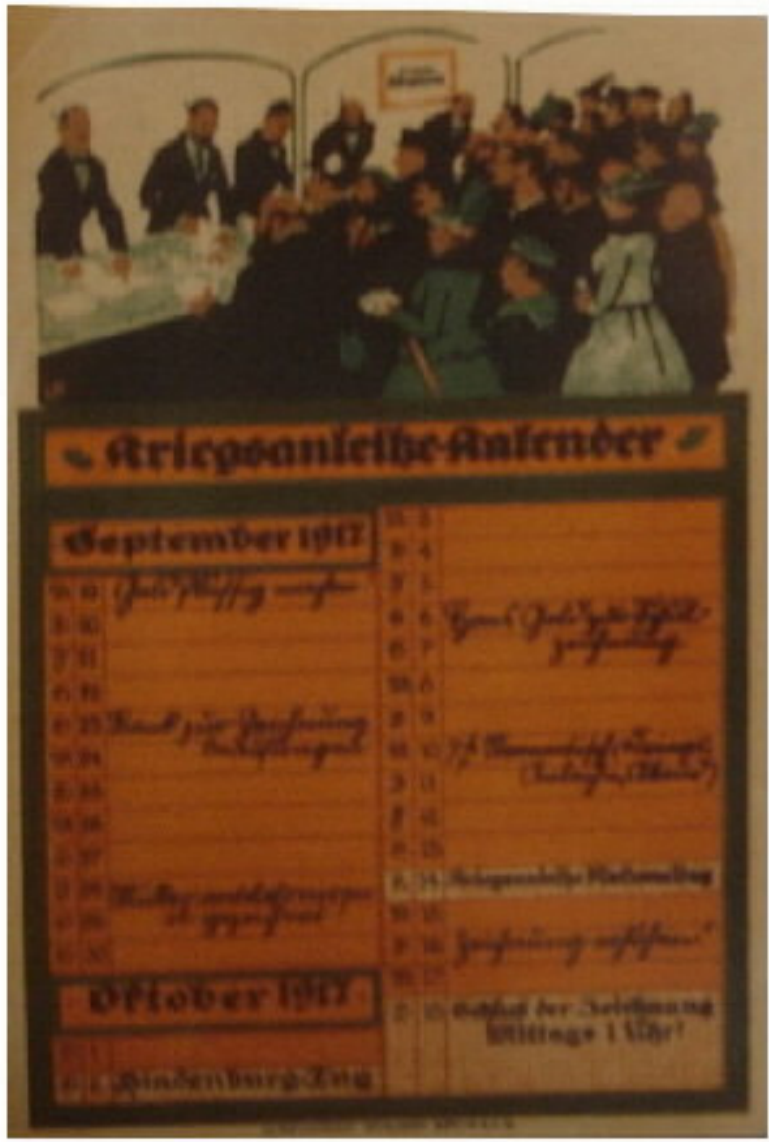

Bild 2

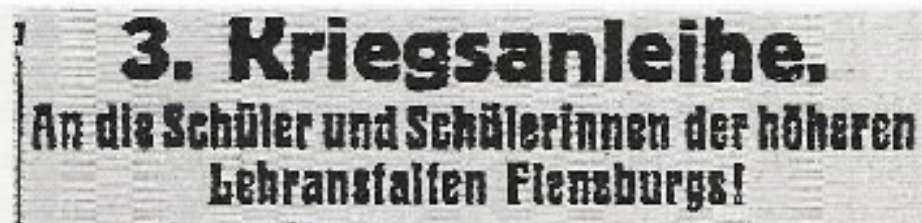

Die bohuren Schulen Deutschlands Iahlen dic freudige Vetpllichtung, wic bei den verschicdenen Samminngen wahrend der Kriegszeil, so such bei der 3. Kriegsanleihe, sich und die Krâfte ihrer Sebiler in der Dienst des Vaterlandes 24 stelien. Um diesen bohen Zweck auch in unserer Stadt zu erreichen, werden alfe Schaler und Schalerinnen der hơheren Lehranstalten Flensburge (auch der Vorschulklassen) aulgcfordert, am Domnerseta9, 9. September, is Uhn morgens, in dor Aula ihrer Austatt sich einzulinden, wo ihuen das Nahere milgeteitt werten wird. Dic amswäntigen Schtier werdei aufgeforfert, wonn es ihnen irgend moglich ist, cbenfalts zu cr. scheinen.

Kgl. Gymnasium und Realgymnamism.

St5dtiveto Oberrealechmia 1.

Staditieche Oberrealischule II.

Städtisohes Lyzewm und Oberlyzeurm. 
Kriegsanleihe V

Anerkennungsurkunden

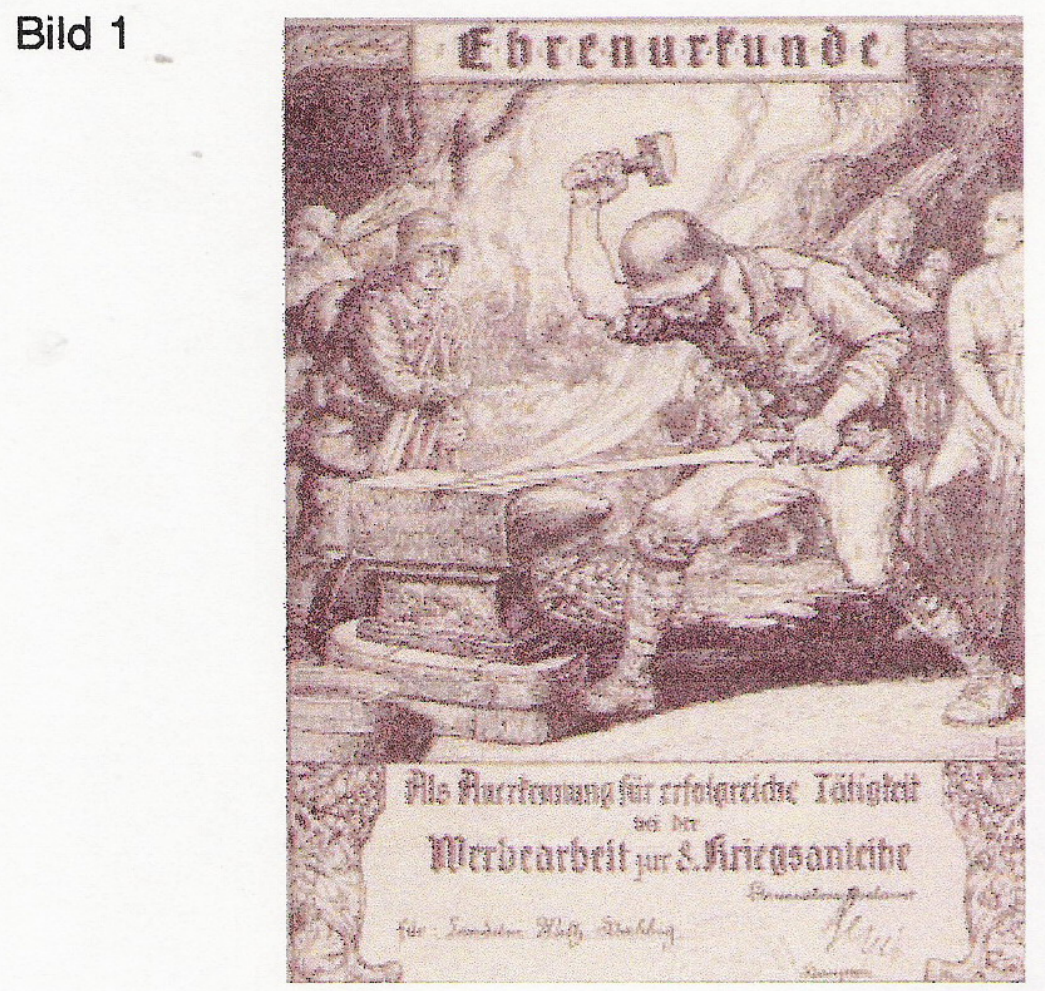

Bild 2

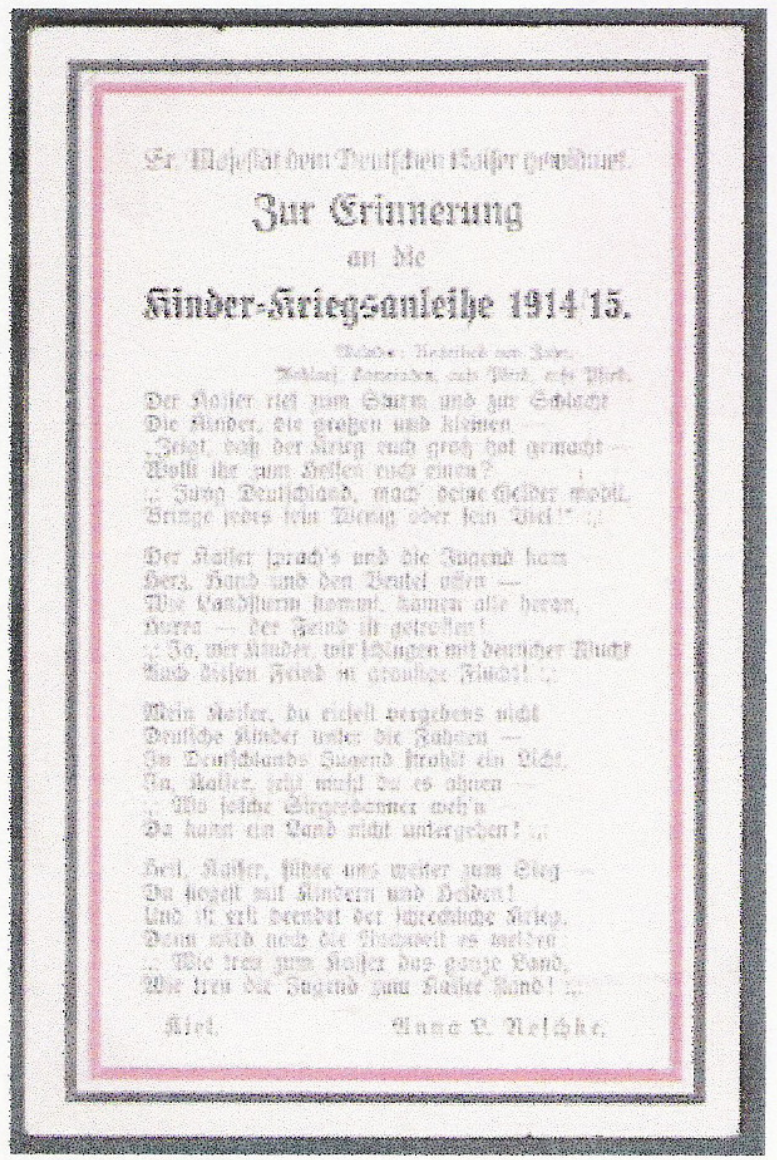

Quelle: Sammlung Kronenberg 


\section{Kriegsanleihen VI}

Bild 1

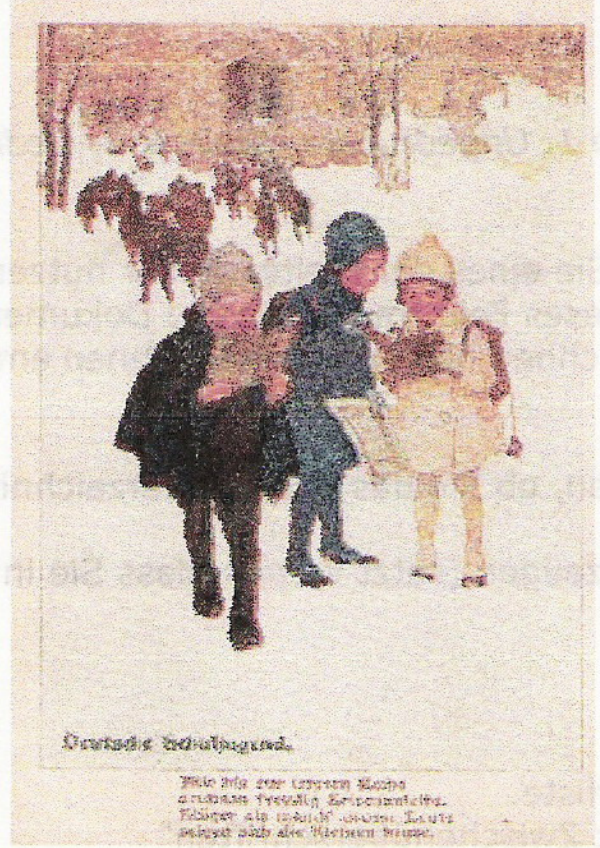

Bild 2

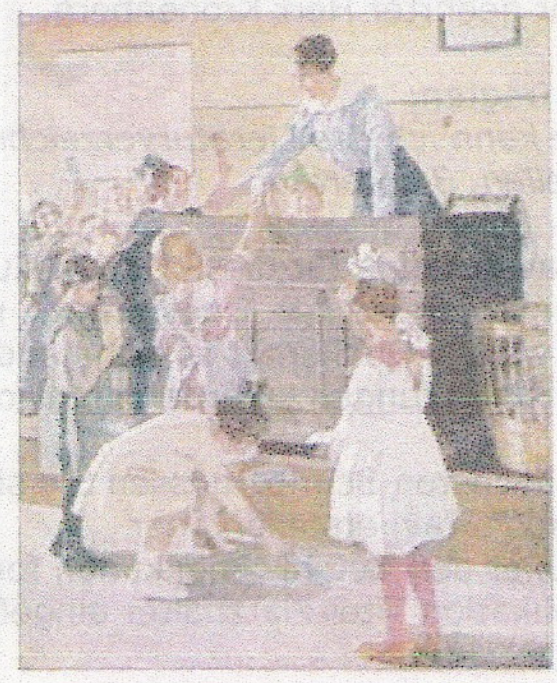

Gertien stante.
Bild 3

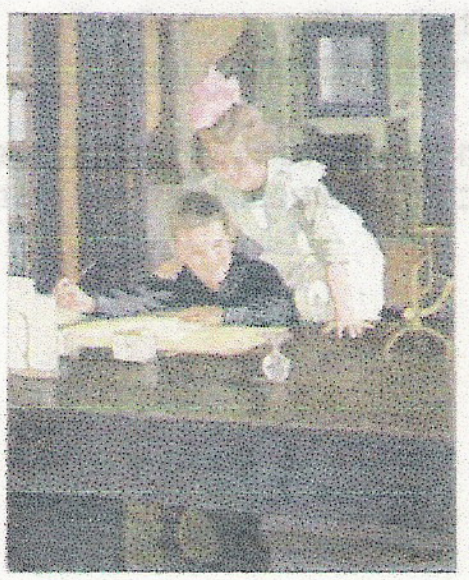

Dic atuth statr:
Bild 4

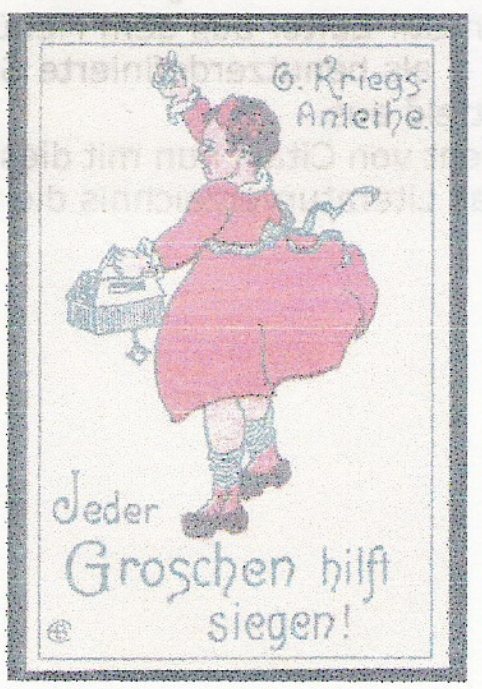

Bild 5

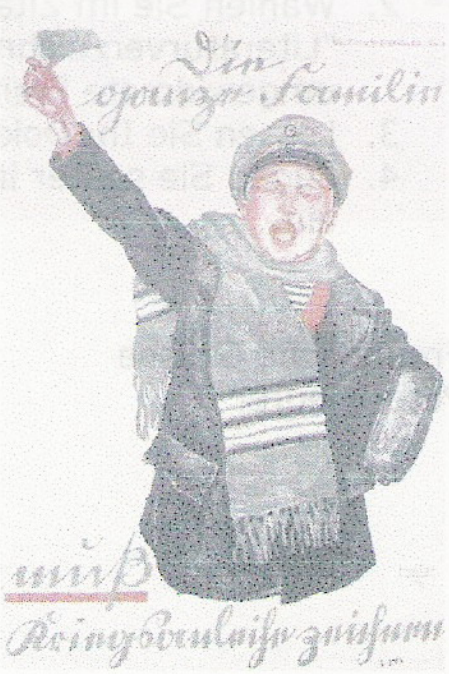

Quelle: Sammlung Kronenberg 


\section{Auszeichnungen}

\section{Verdienstkreuze für Kriegshilfe}

\section{Königreich Preußen}

Bild 1a

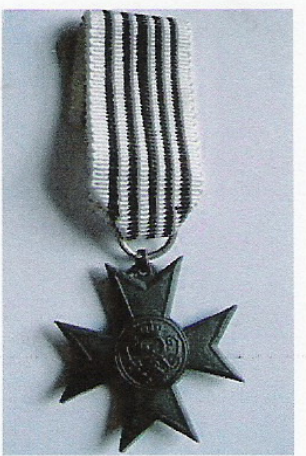

Bild 1b

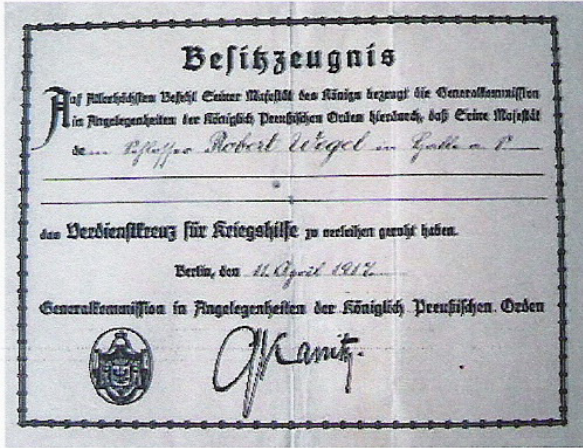

Besitzurkunde

Großherzogtum Baden

Bild 2a

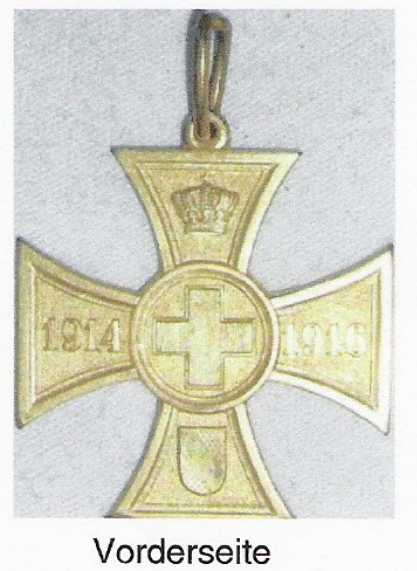

Bild 2b

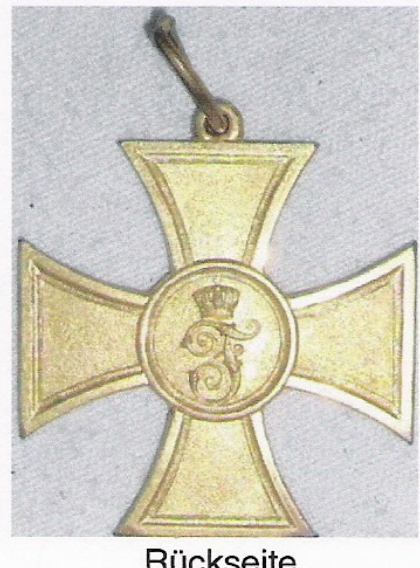

Rückseite

Königreich Sachsen

Bild 3a

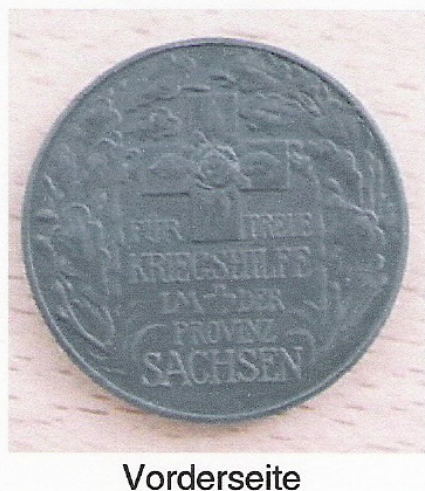

Bild 3b

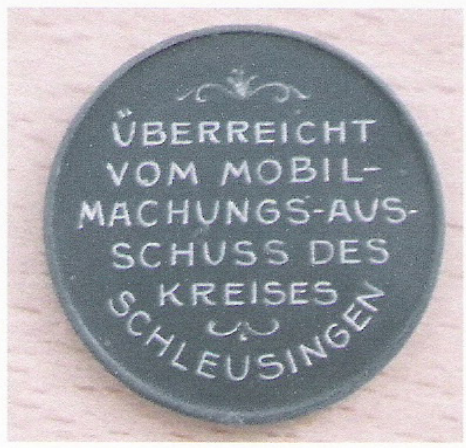

Rückseite

Quelle: Sammlung Kronenberg 


\section{Spendenmarken und Kaiserbild}

Spendenmarken der 'Jugendspende'

Bild 1

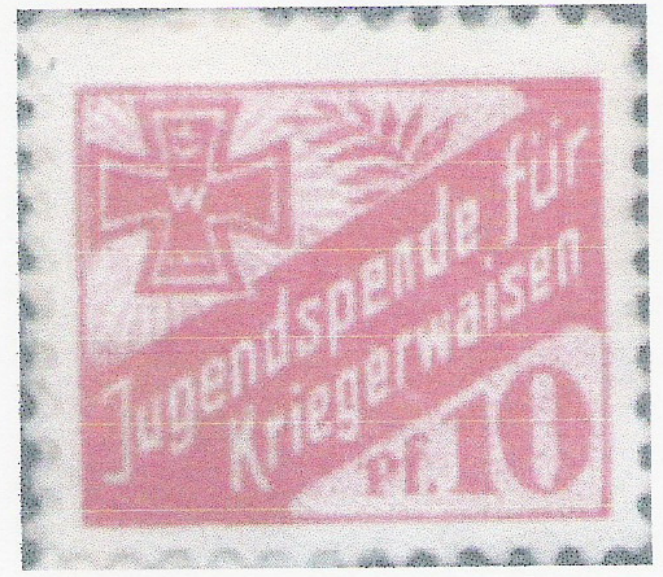

Bild 2

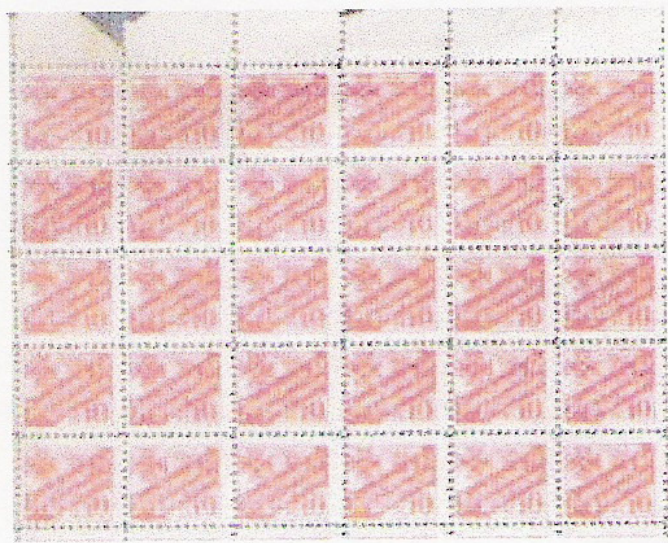

Bild "Kaiser und Hindenburg"'

\section{Bild 3}

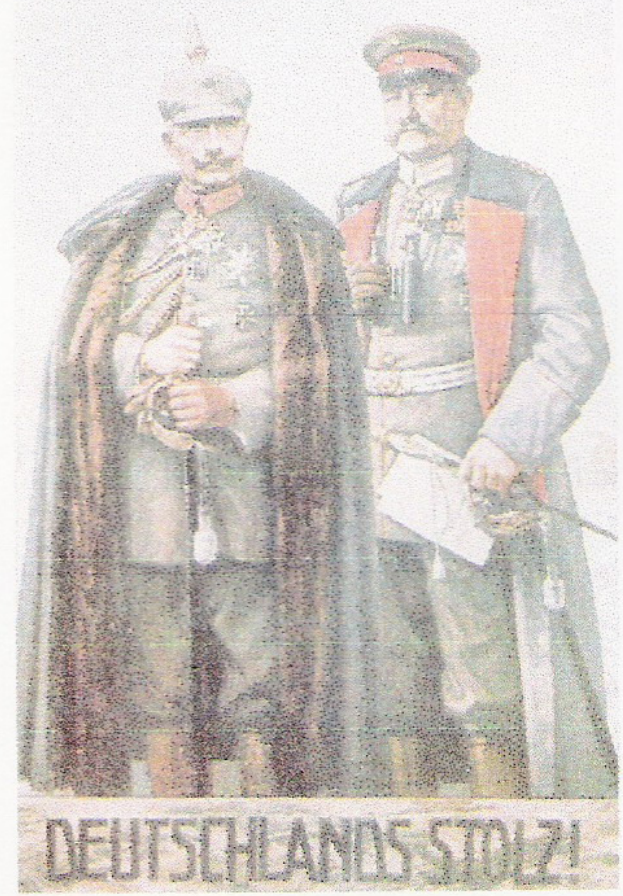

Quelle: Sammlung Kronenberg 


\section{Kapitel 4}

\section{Einsatz in der Landwirtschaft I}

\section{Ansichtskarten}

\section{Bild 1}

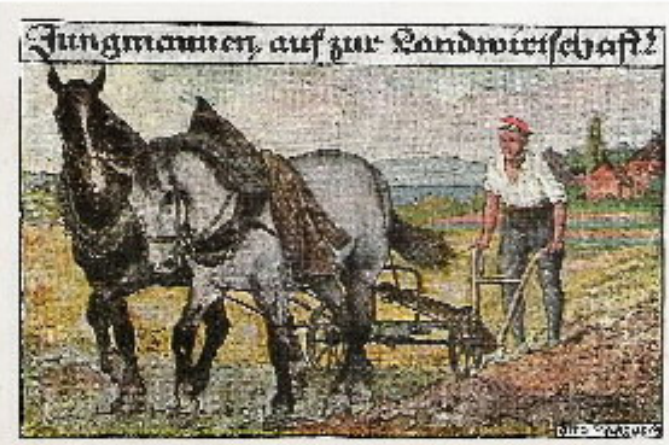

Bild 2

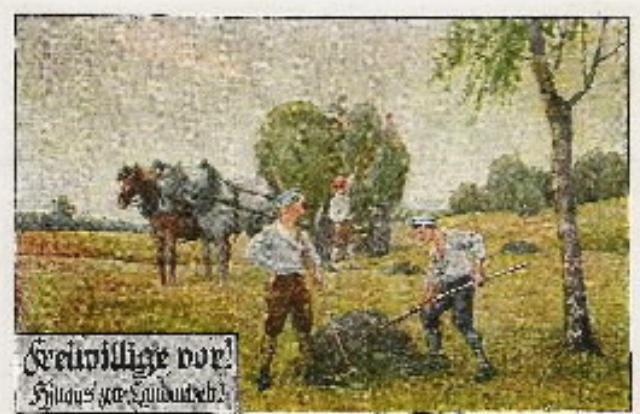

Bild 3

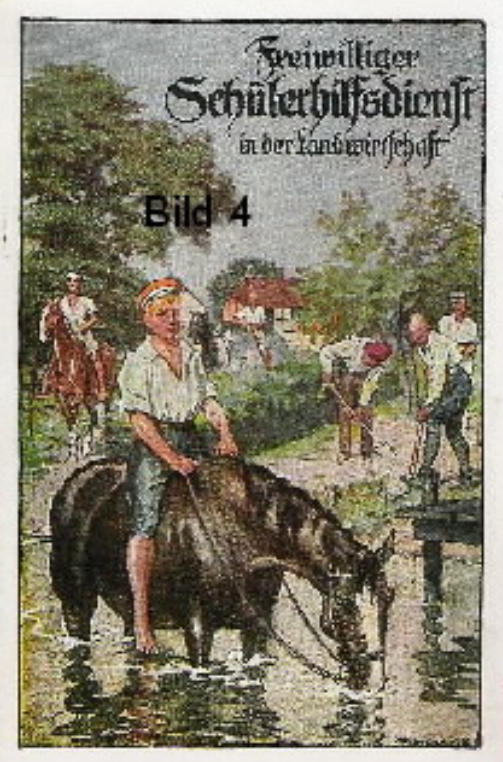

Bild 4

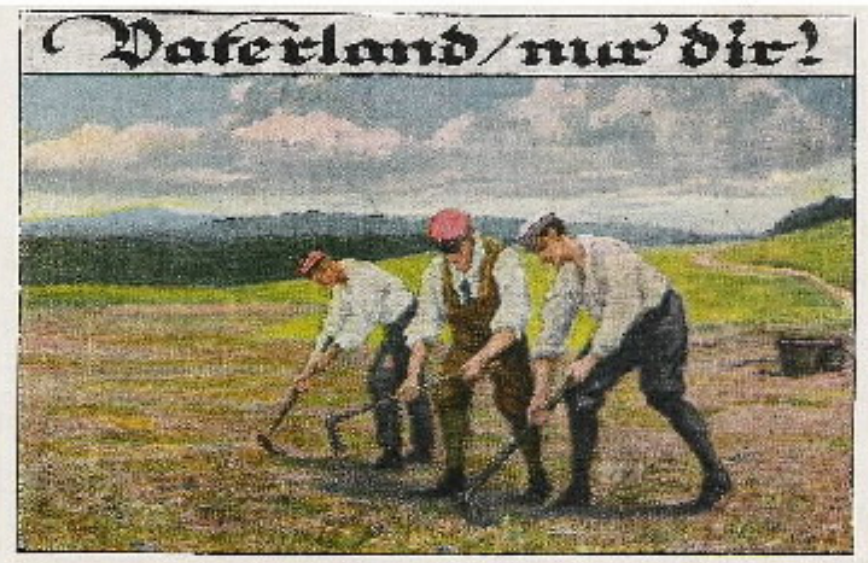

Quelle: Sammlung Kronenberg (1-4) 


\section{Einsatz in der Landwirtschaft II}

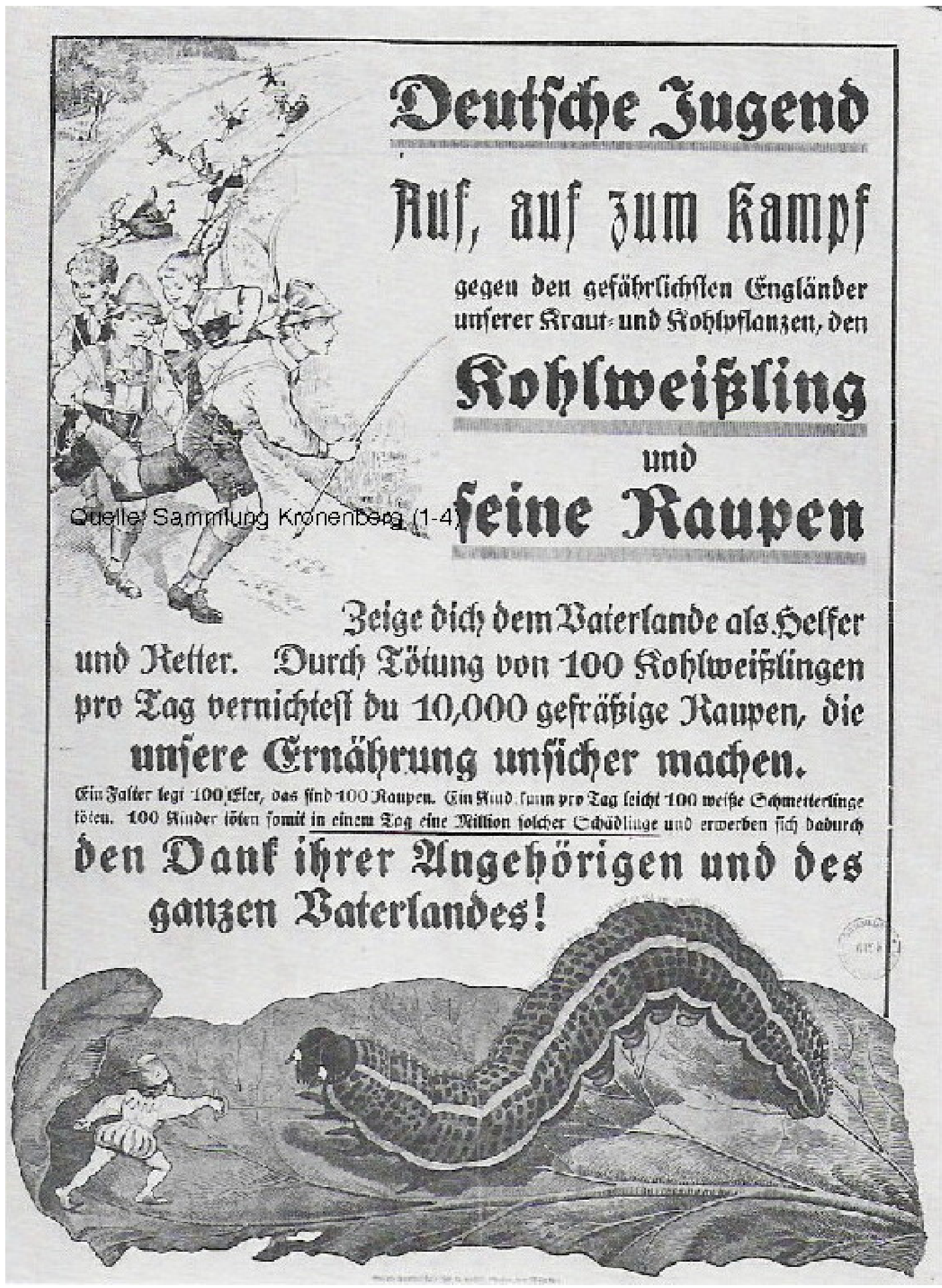




\section{Einsatz in der Landwirtschaft III}

\section{Fotos}

\section{Bild 1}

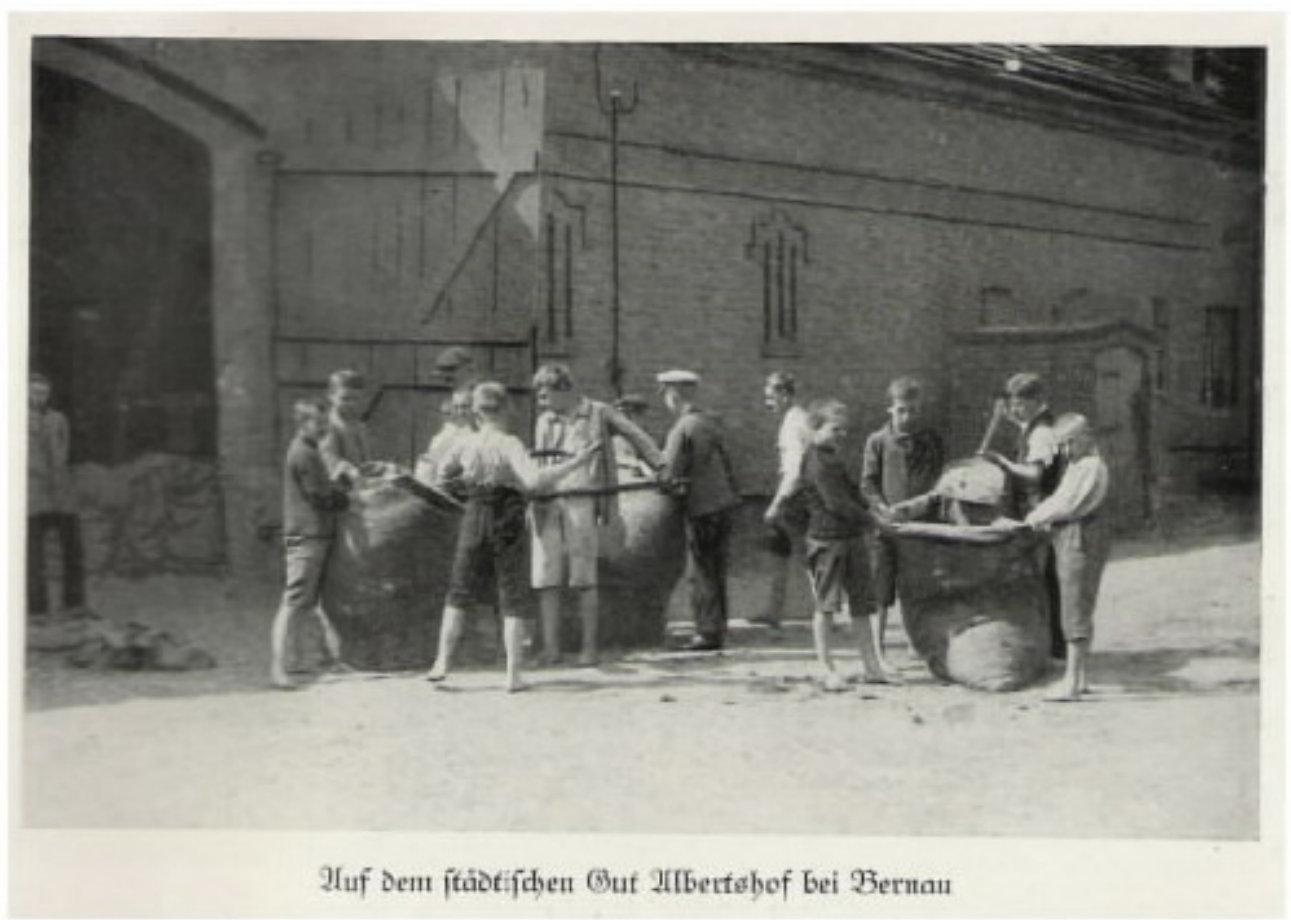

Bild 2

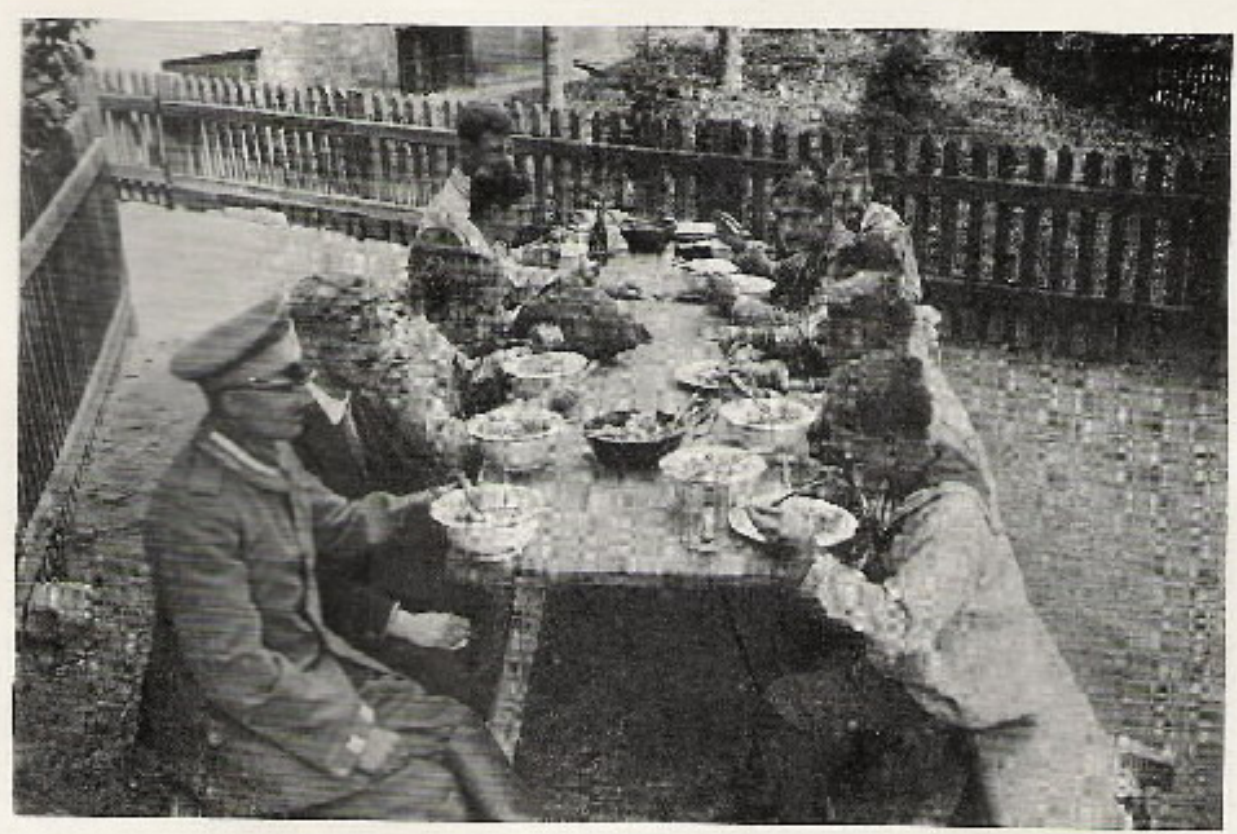

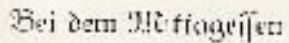




\section{Einsatz in der Landwirtschaft IV}

\section{Ansichtskarten}

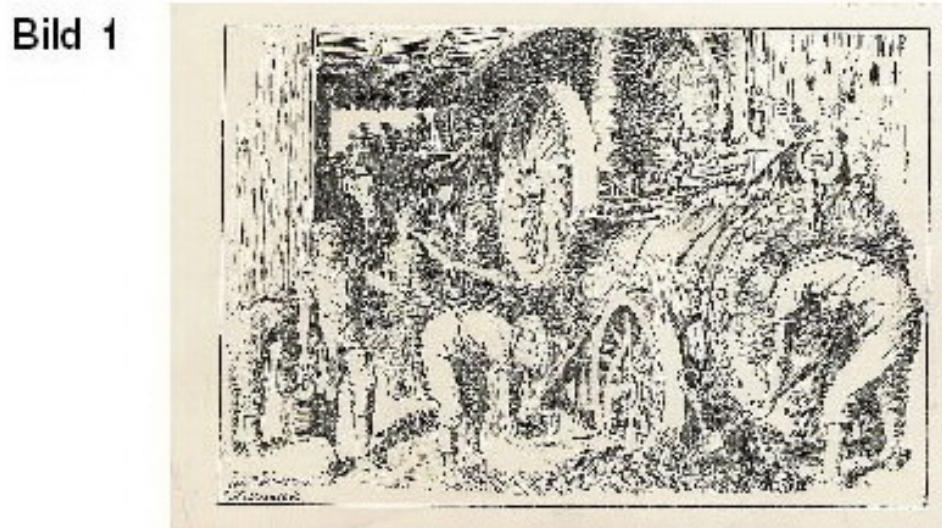

Bild 2

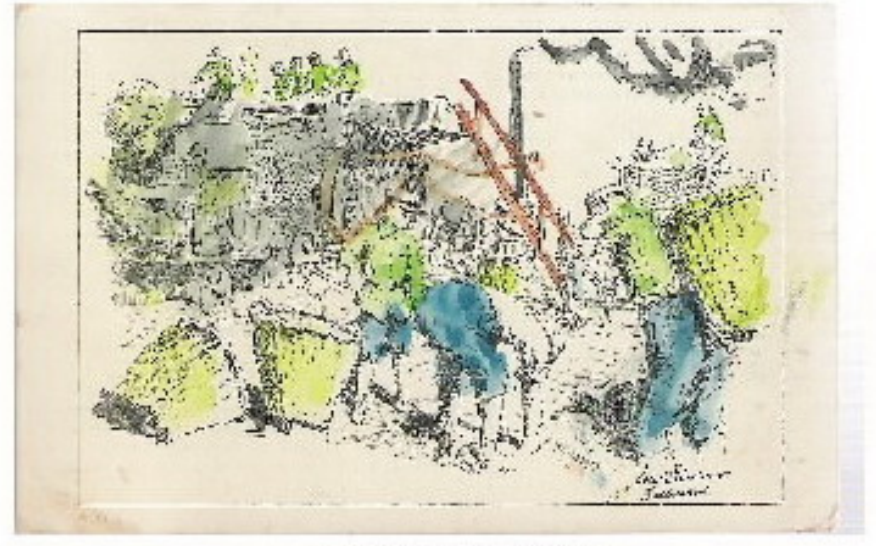

IMO Magdeburg

Schüler höherer Lehranstalten, Seminare u. Präparande

Bild 3

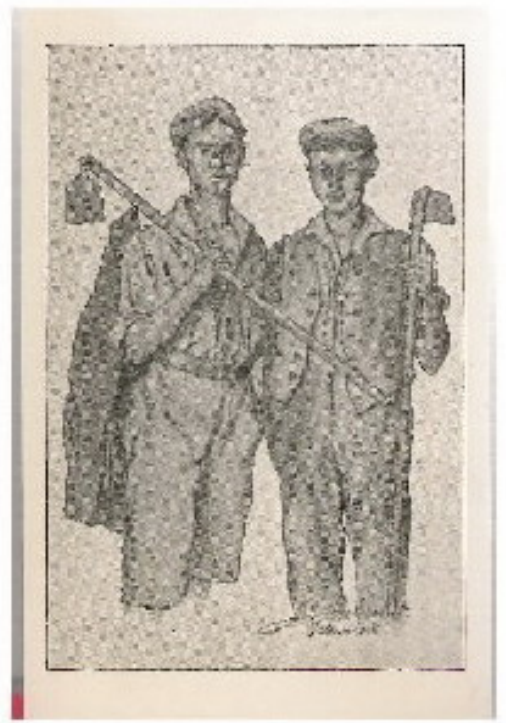

IMO Königreich Sachsen

Schüler höherer Lehranstalten

Quelle: Sammlung Kronenberg 


\section{Einsatz in der Landwirtschaft V}

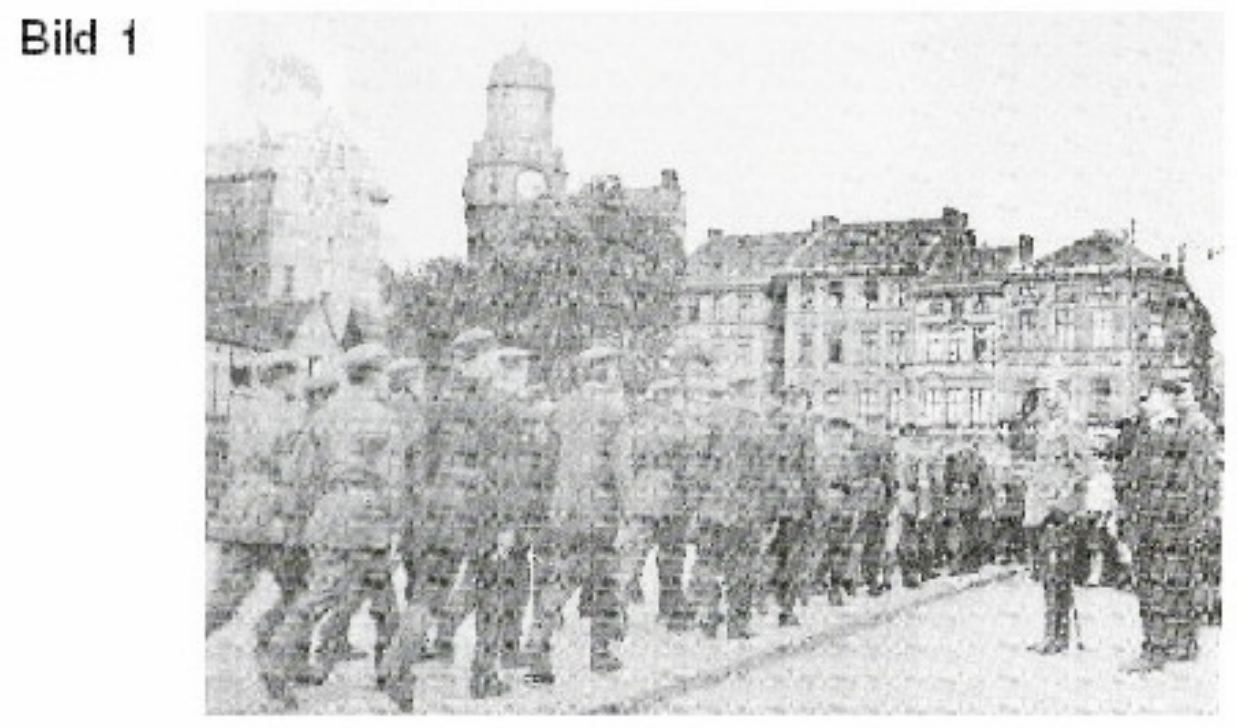

Dortmunder Jungmannen auf dem Weg zum Ernteeinsatz in Eelgien 1915

Bild 2

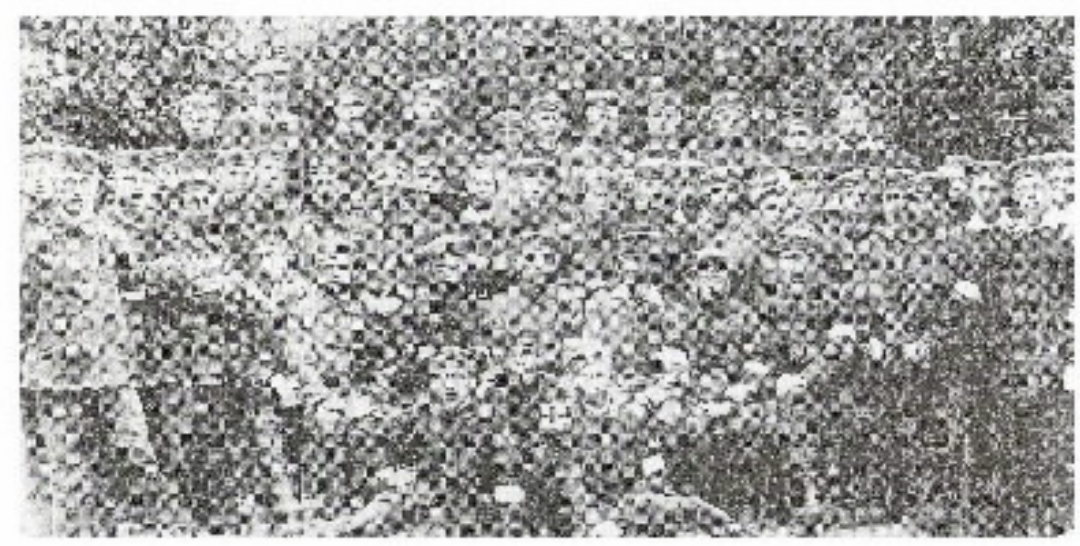

Dortmunder Jungmannen

\section{Bild 3}

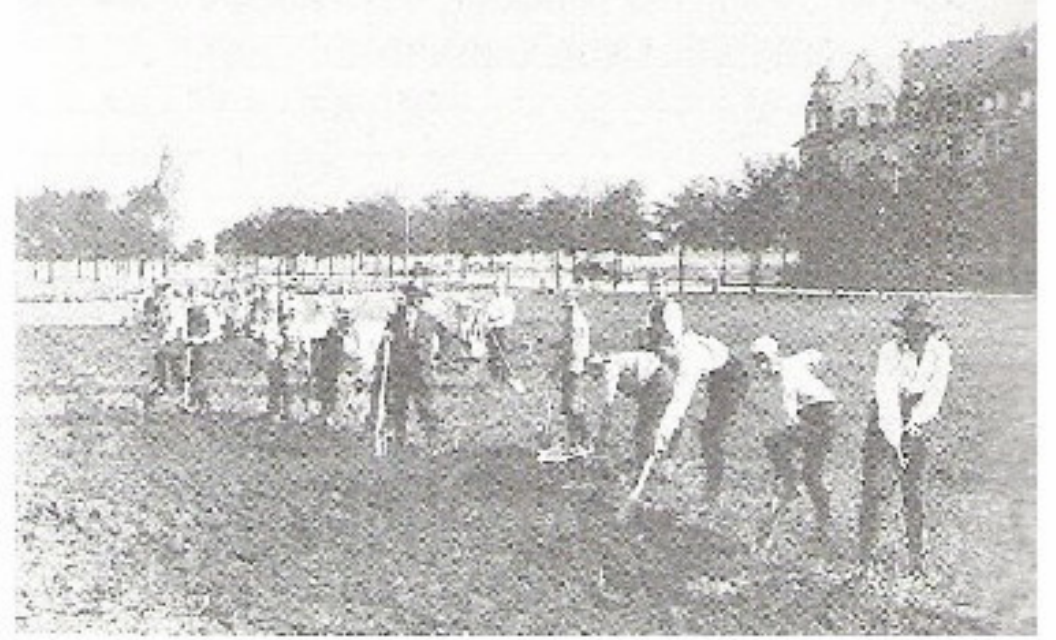

Ein Lehrer mit seinen Schülern auf dem Feld

Quellen: Löher, Jochen, Furchtbar..., S. 111 (1), 89 (2); Sammlung Kronenberg (3) 


\section{Lebensmittelproduktion}

\section{Schulgarten / Schülergarten (Kaiser-Karl-Gymnasium Aachen)}

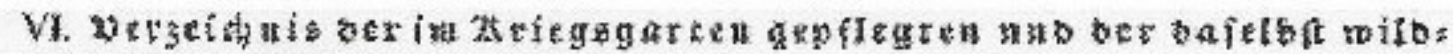
xad) frubes Wflanjen.

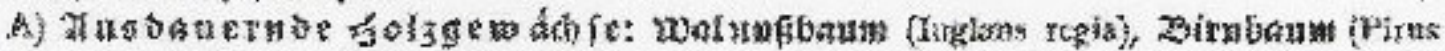

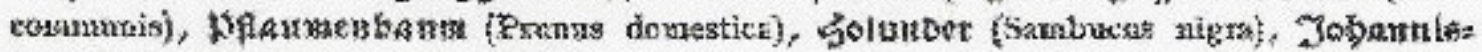

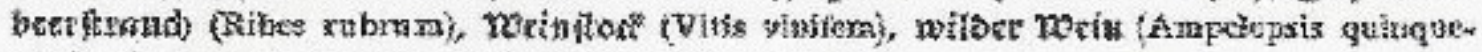

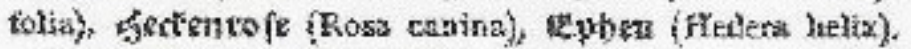

3) दattex

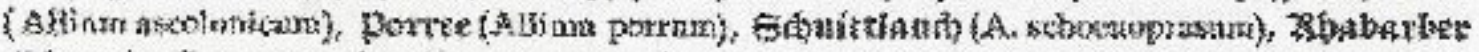

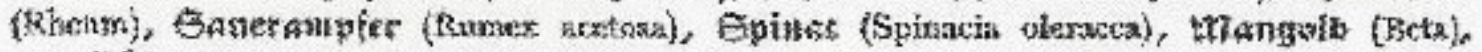

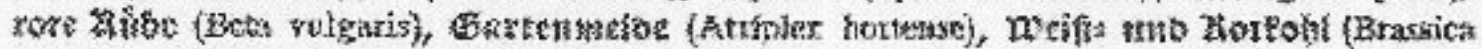

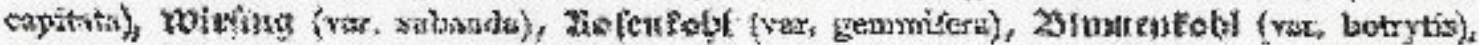

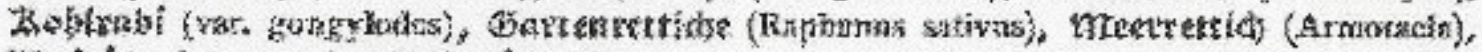

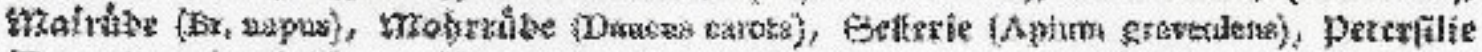

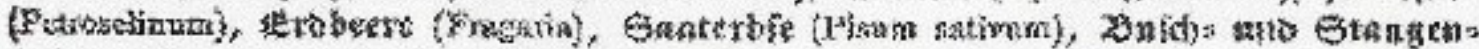

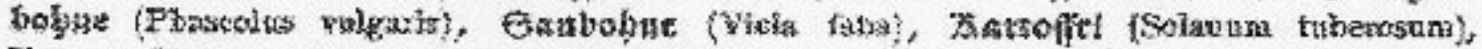

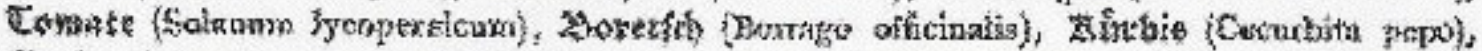

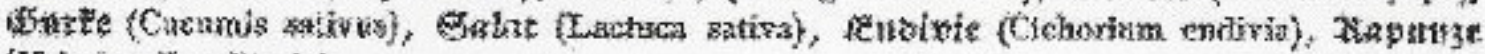
(Vaturisnmilla othtoria).

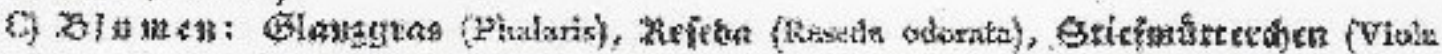

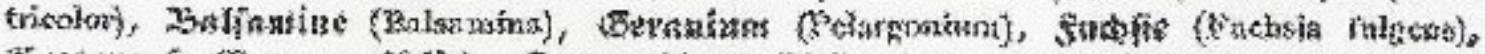

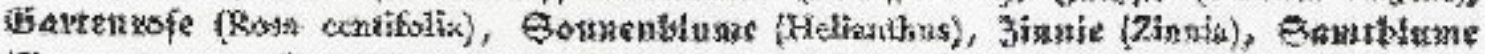

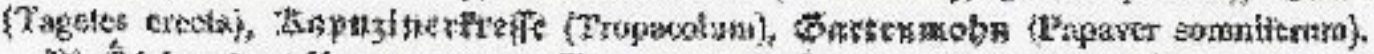

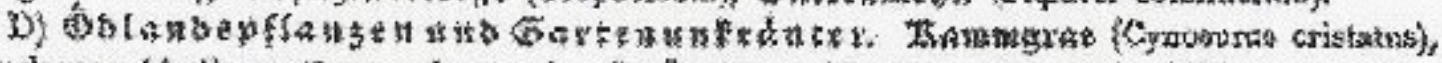

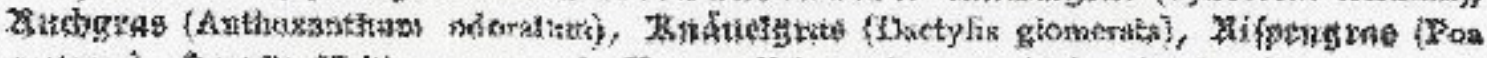

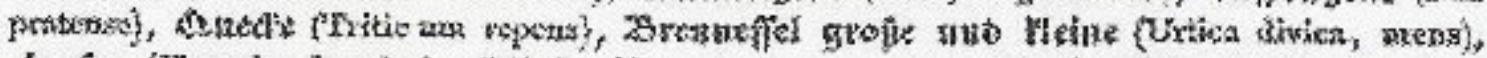

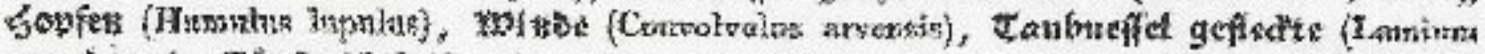

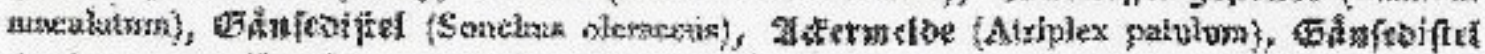

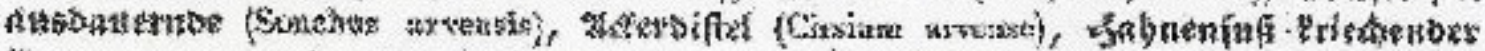

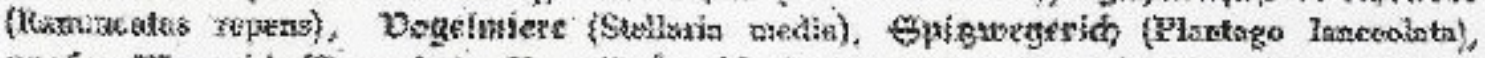

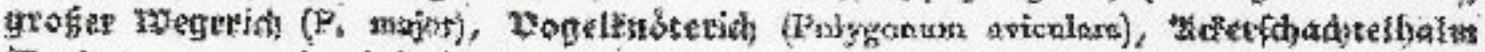

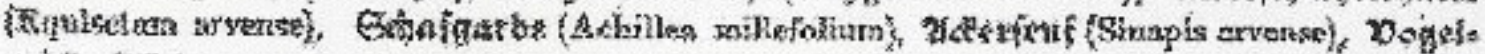

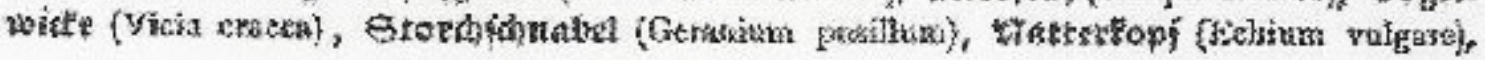

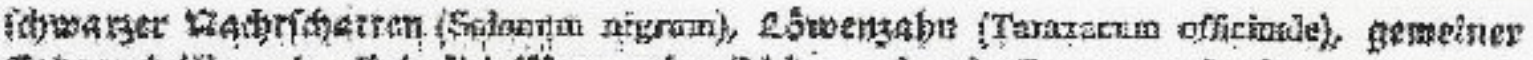

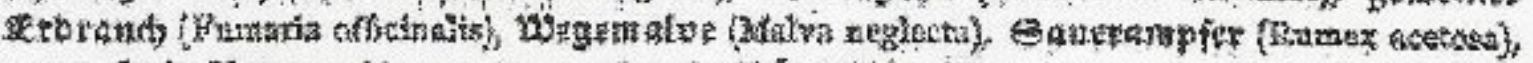

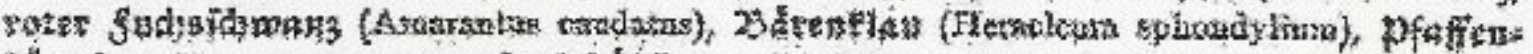

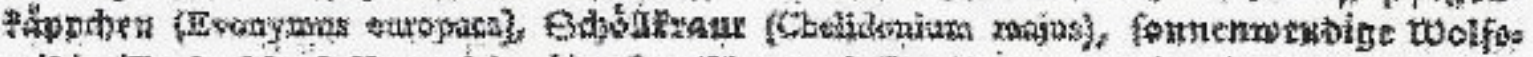

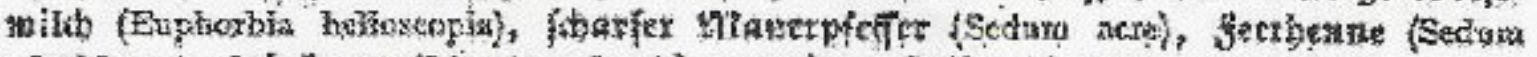

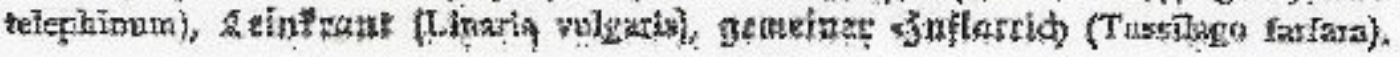

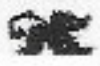

Quelle: Holl, Ferdinand, Der Kriegsgarten..., S. 161/162 


\section{Hilfsdienste}

\section{Bild 1}

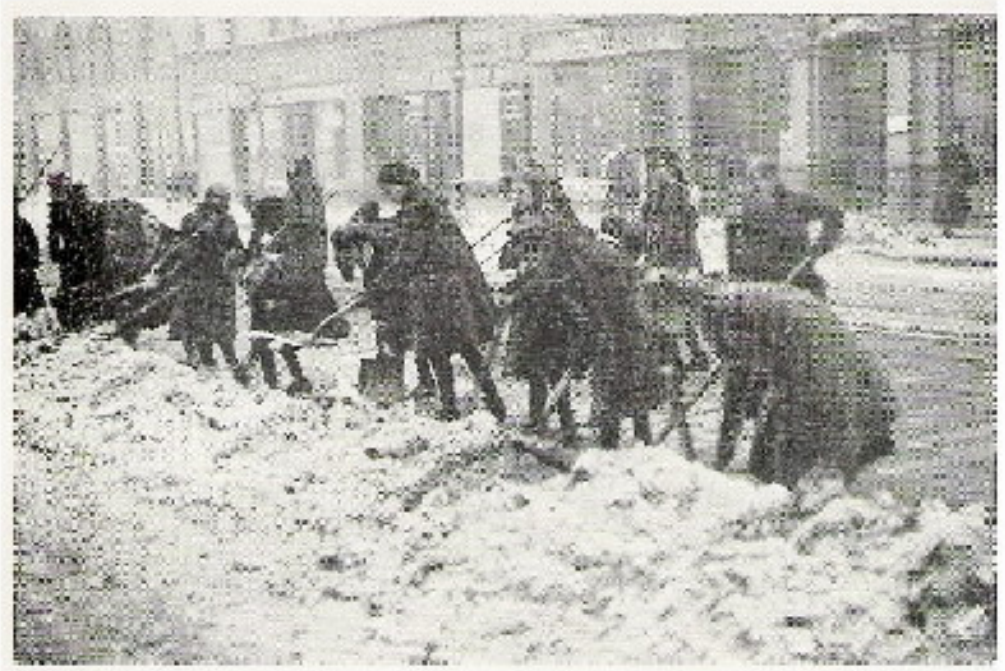

Schülerinnen beim Schneeschippen

Bild 2

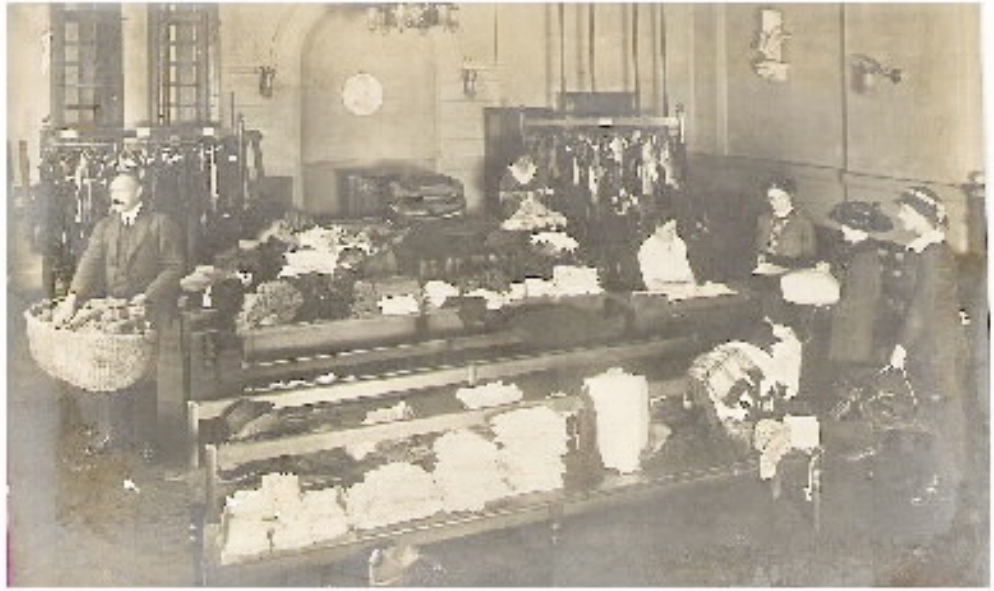

Annahmestelle Liebesgaben in einer Schule

\section{Bild 3}

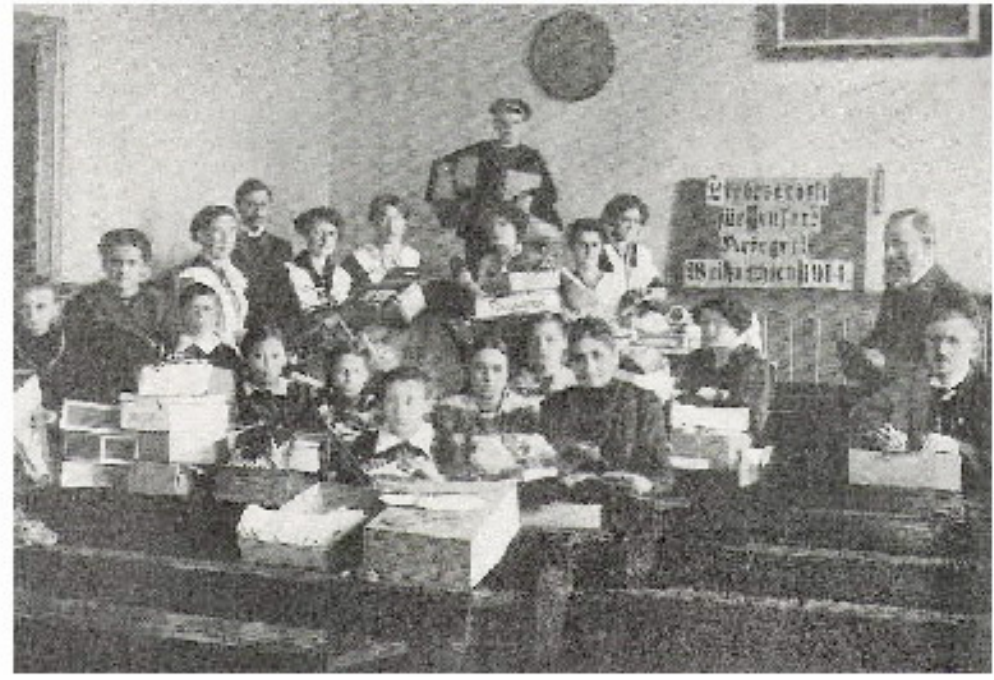

Verpacken der Liebesgaben

Zweiklassige ev. Volksschule in Wesel-Feldmark

Quelle: Führen, Lehrer im Krieg, Tafeln 9 (3), 22 (1); Sammlung Kronenberg (3) 


\section{Reichsbuchwoche}

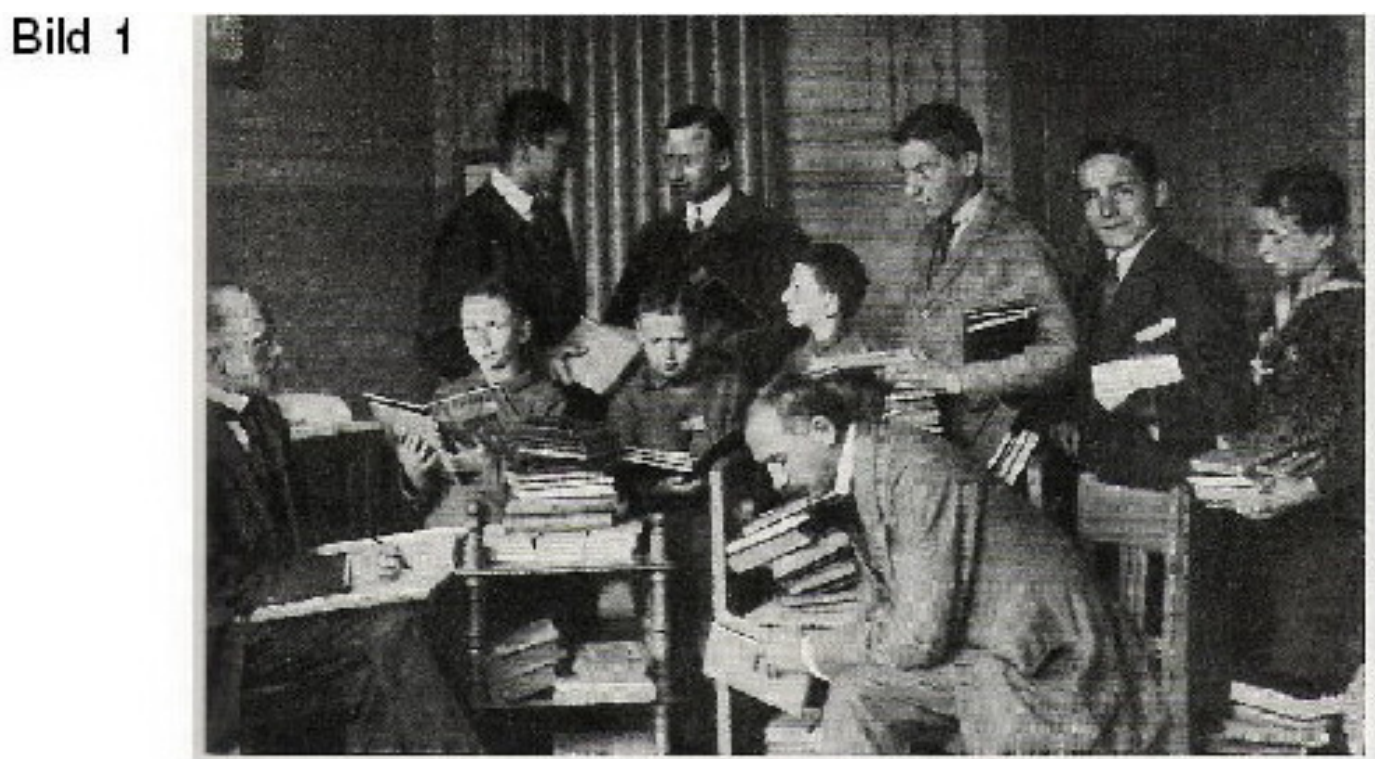

\section{Bild 2}

\section{Büinet fuir verwundete}

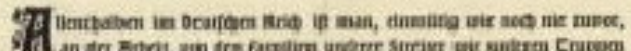

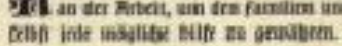

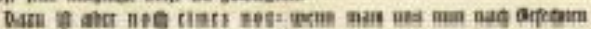

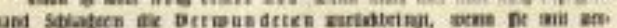

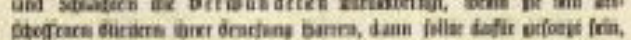

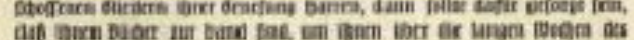

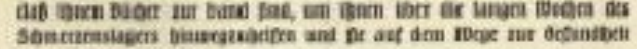

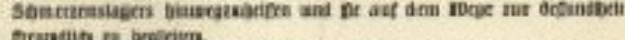
Ancustith an beperiem.

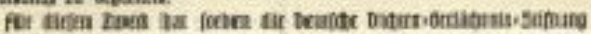

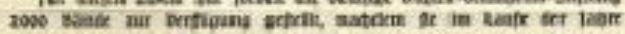

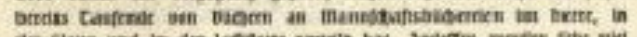

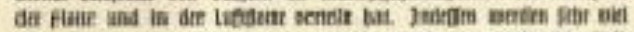

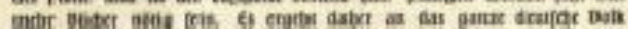

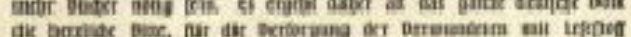

Spenden in Biinern oder 6eld

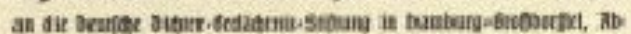

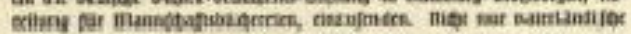

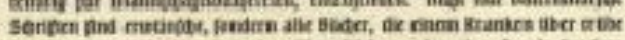

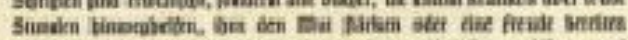

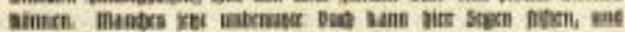

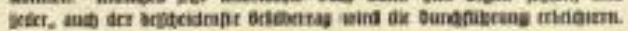

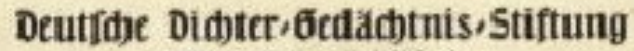

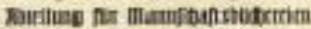

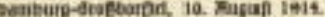

riskatia

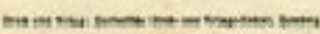

Plakat zur Reichsbuchwoche 
Kriegsnäh- und Strickstuben

Bild 1

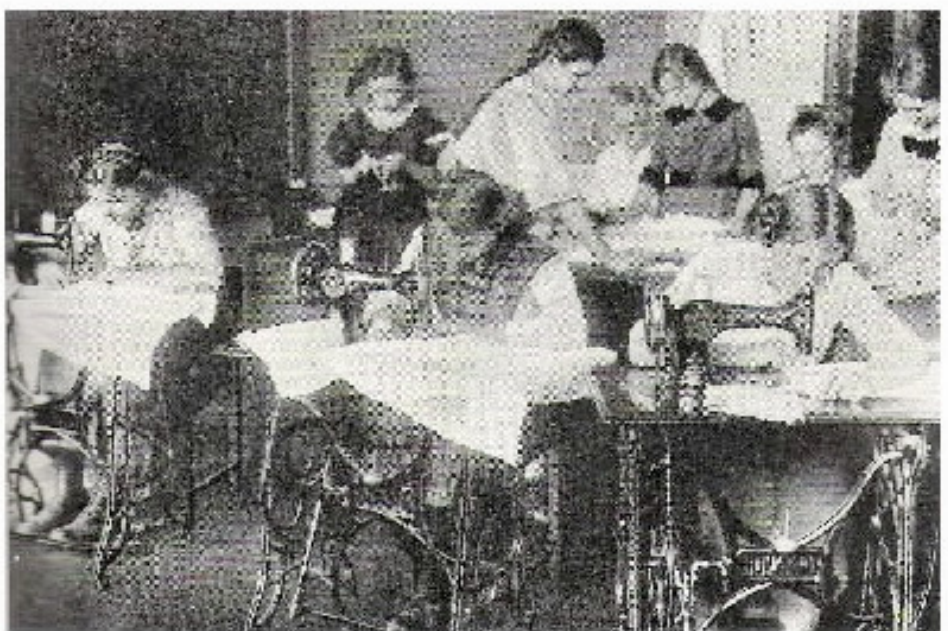

In einer Kriegsnähstube

Bild 2

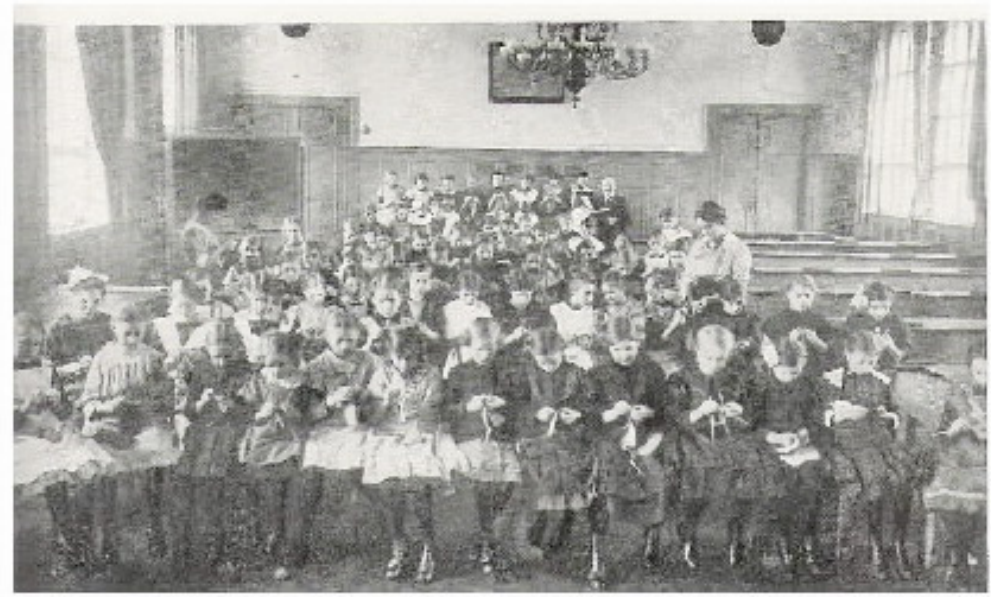

Strickstunde in einer Berliner Schule

Bild 3

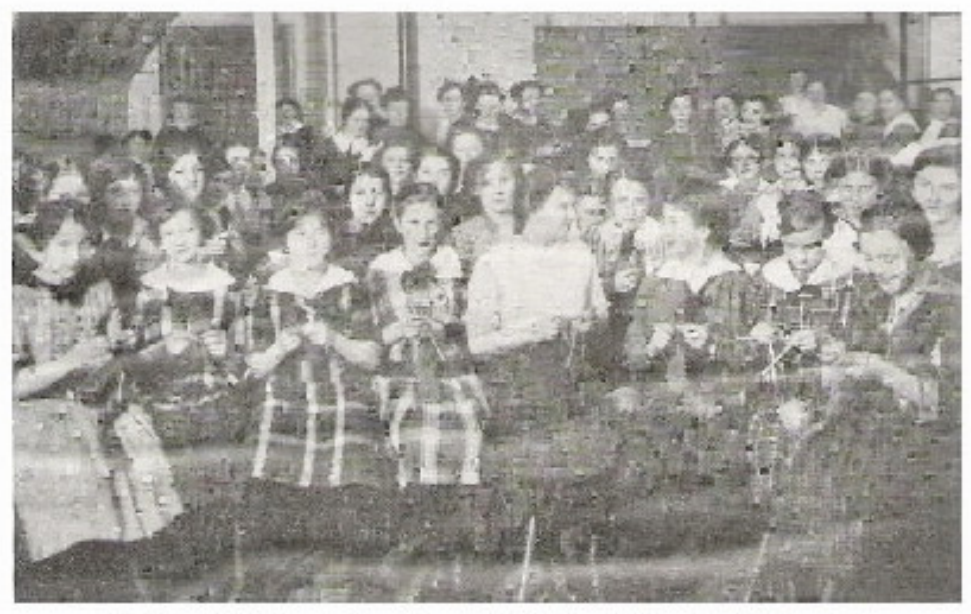

Eeim Stricken in einer Mittelschule in Münster

Quellen: Führen im Krieg, Tafeln 57 (1), 9 (2); Sammlung Kronenberg (3) 


\section{Kriegsfürsorge}

\section{Bild 1}

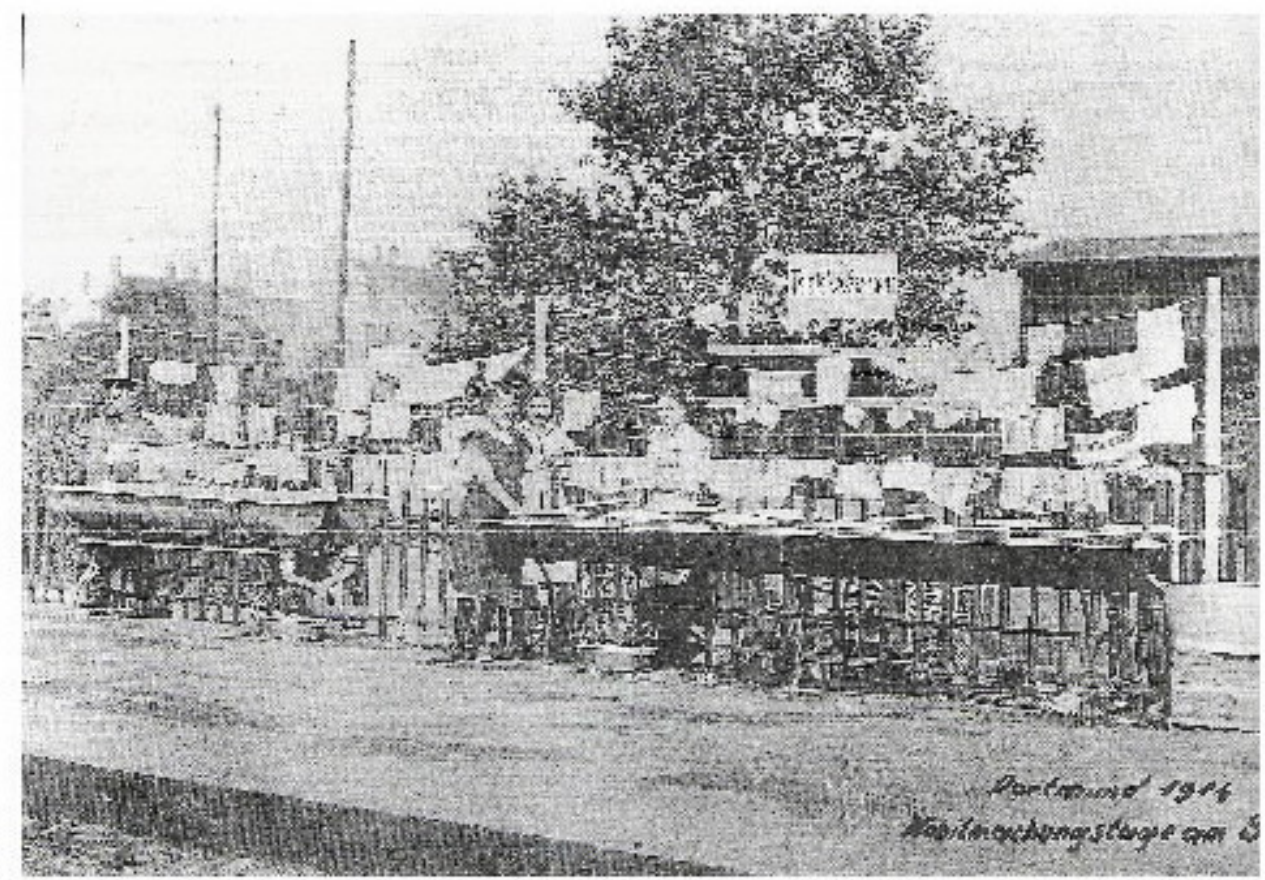

Schülerinnen am Versorgungsstand während der Mobilmachung 1914 in Dortmund

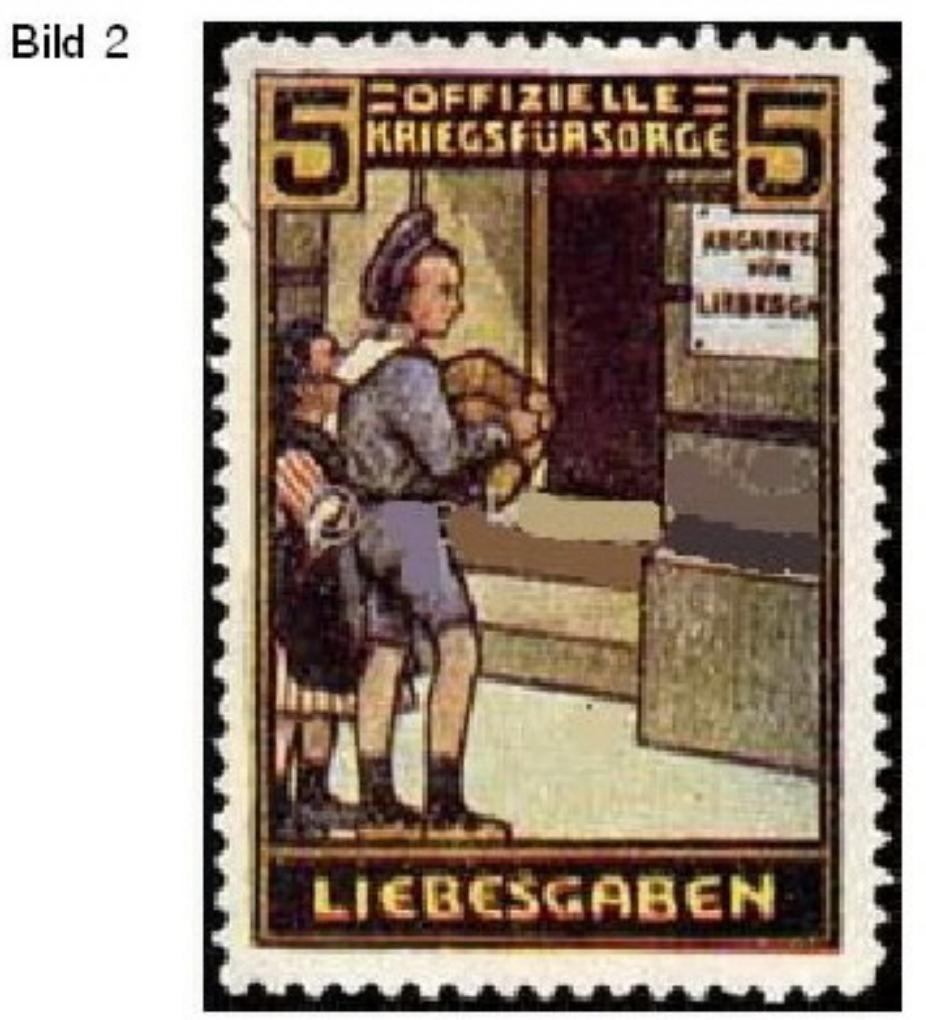

Spendenmarke für abgelieferte Liebesgaben

Quellen: Löher, Jochen, Furchtbar dräute..., S. 107 (1); Sammlung Kronenberg (2) 
75

Herstellung von Liebesgaben

Ansichtskarten

Bild 1

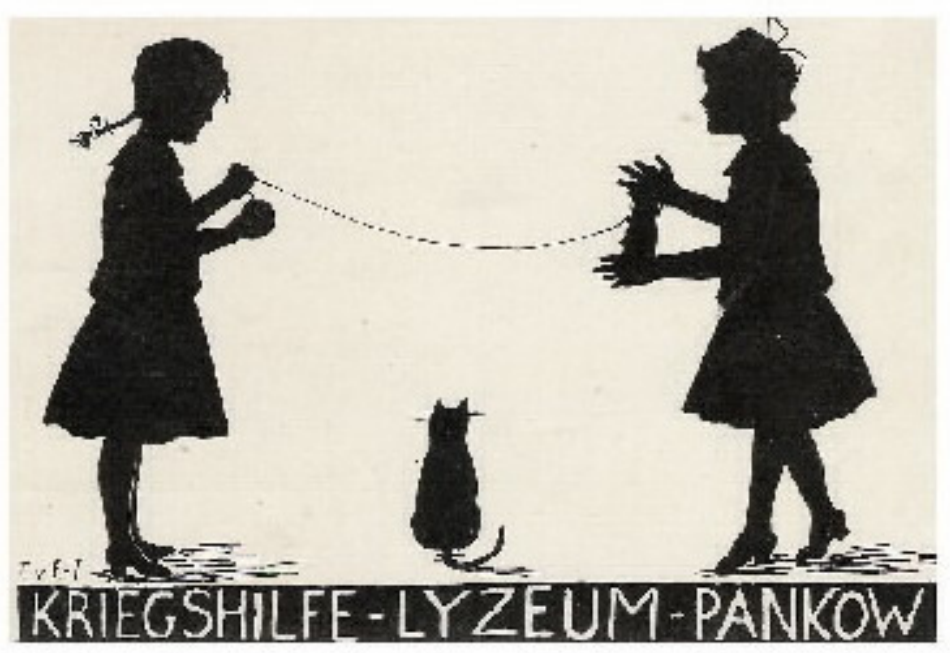

Bild 2

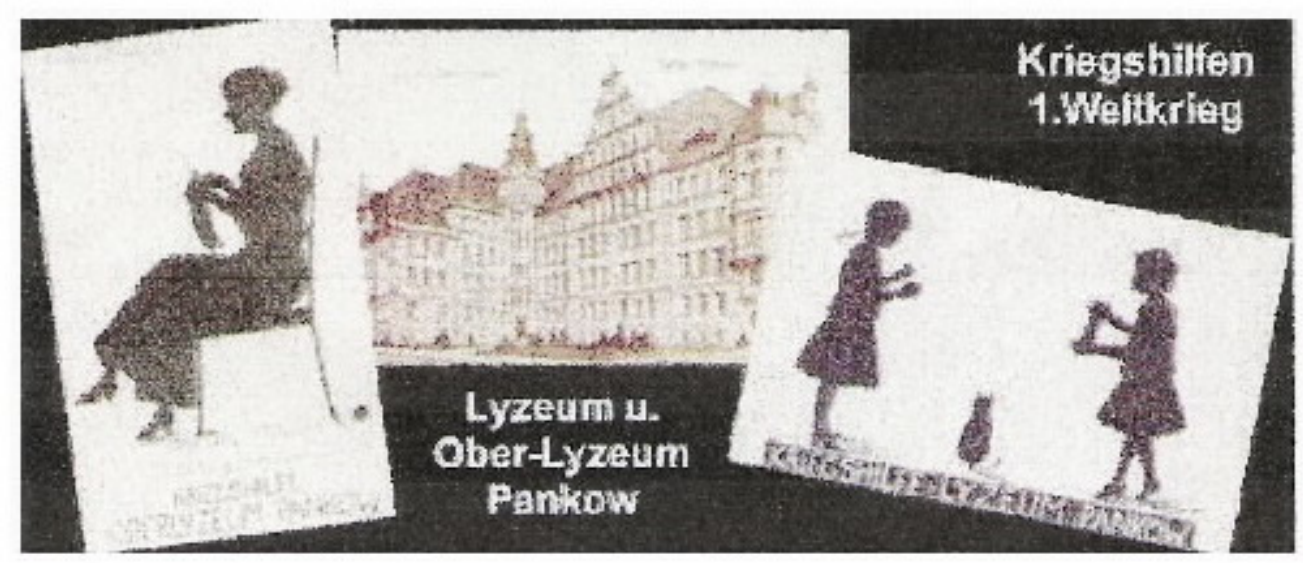

Bild 3

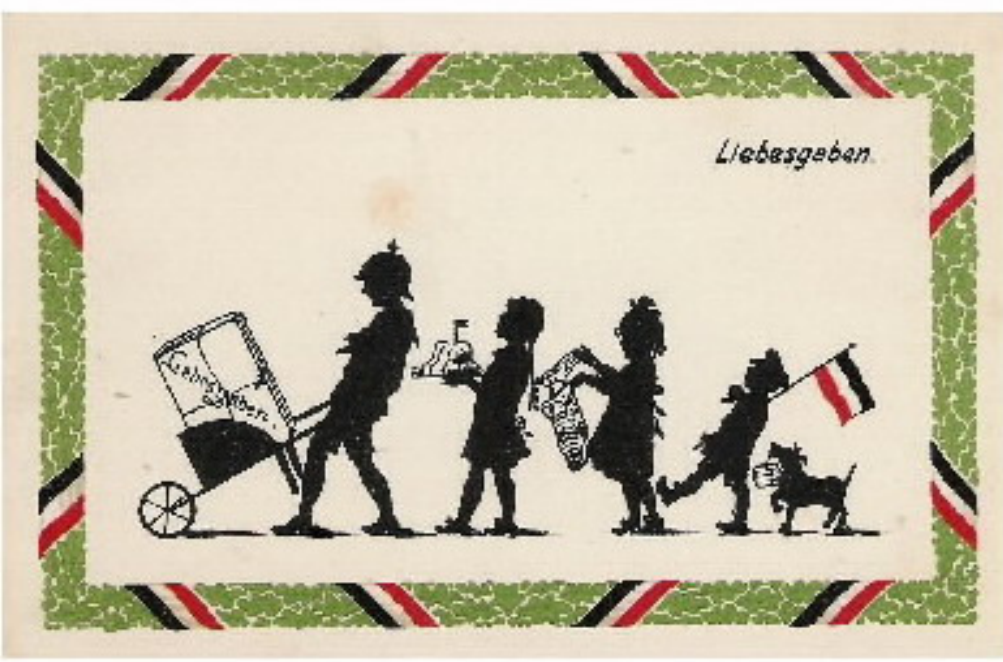

Quelle: Sammlung Kronenberg (1-3) 


\section{Liebesgaben}

Bild 1

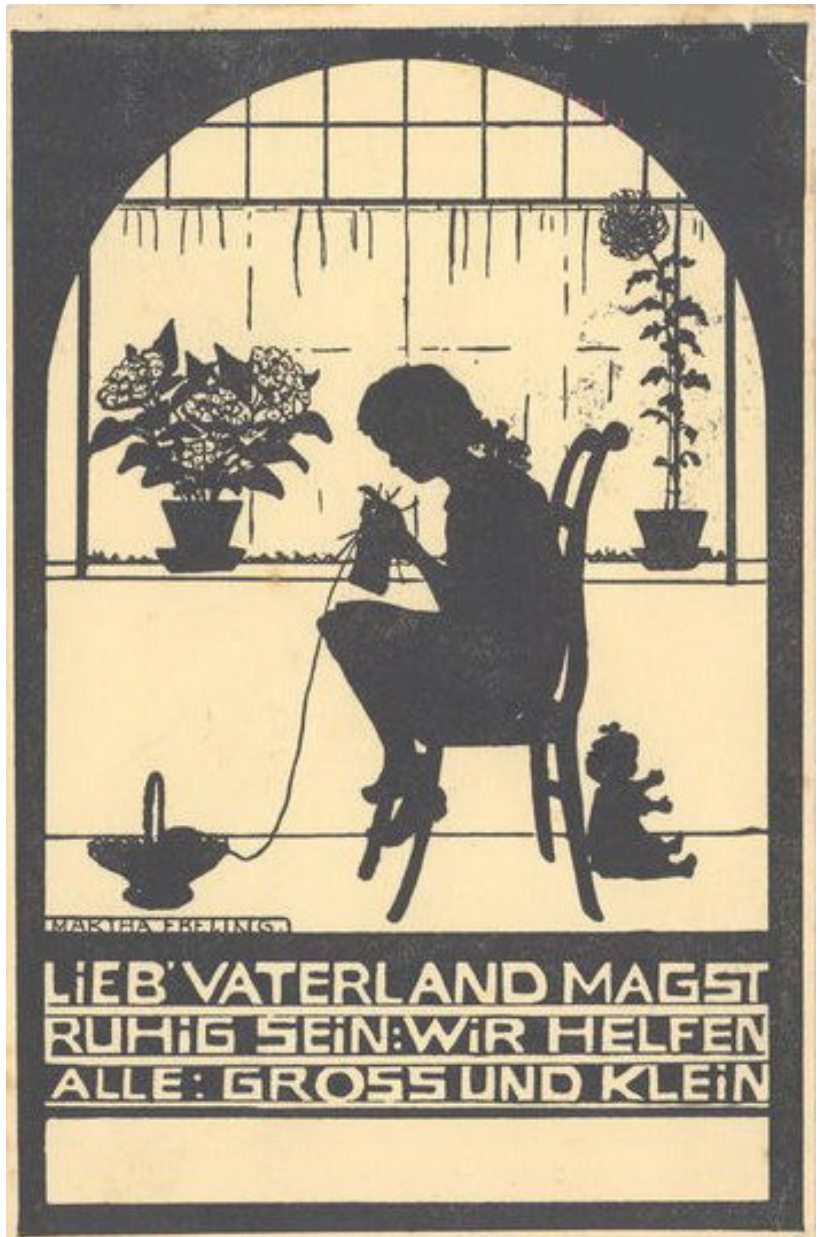

Bild 2

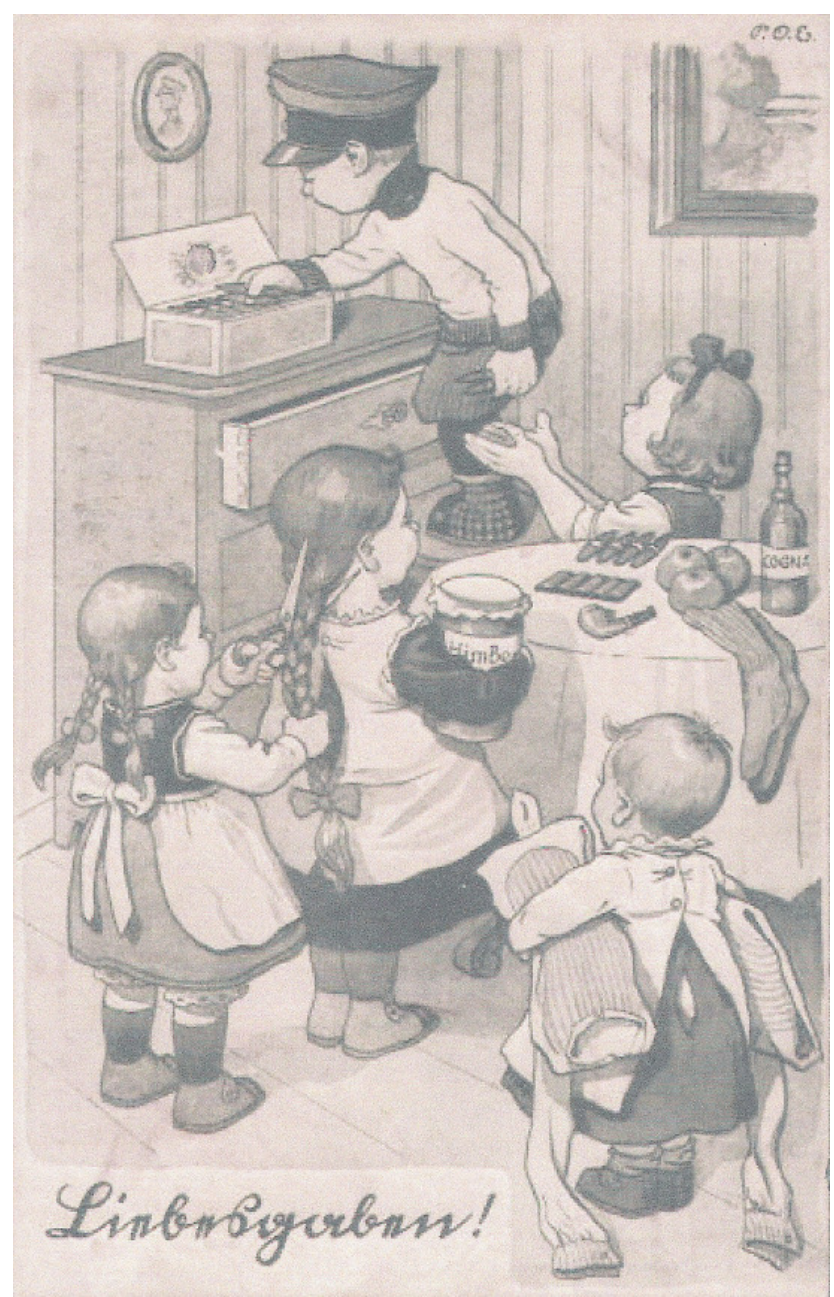

Quelle: Sammlung Kronenberg 


\section{Reichswollwoche}

\section{Bild 1}

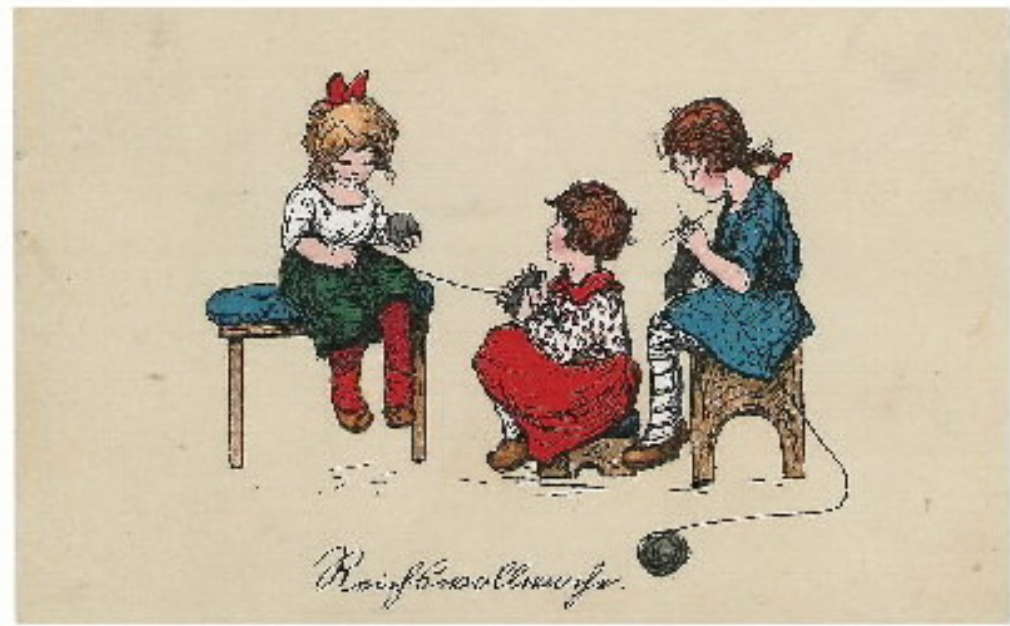

Ansichtskarte

\section{Bild 2}

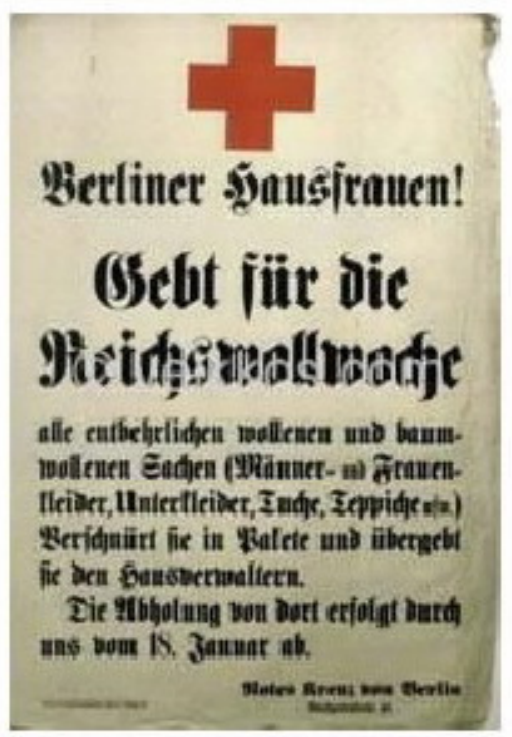

Plakat

\section{Bild 3}

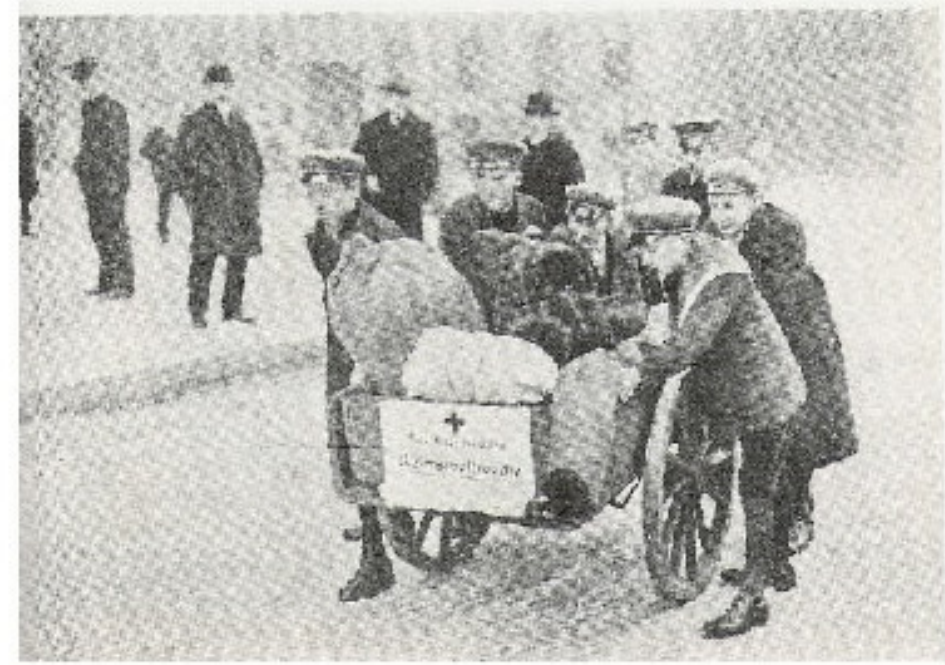

Foto 


\section{Kapitel 5}

\section{Siegesfeier und Kaisergeburtstag}

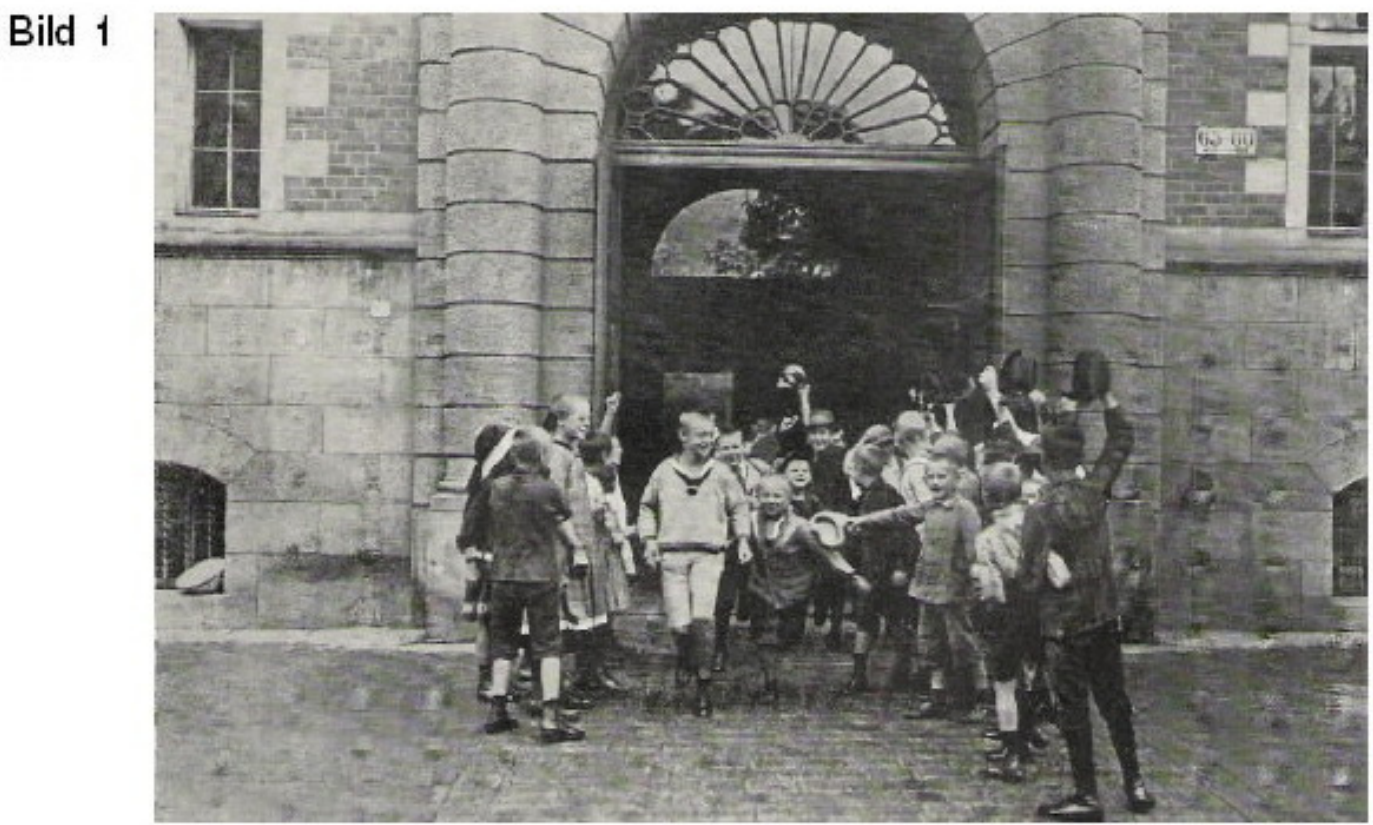

"Hurra, siegfrei!"

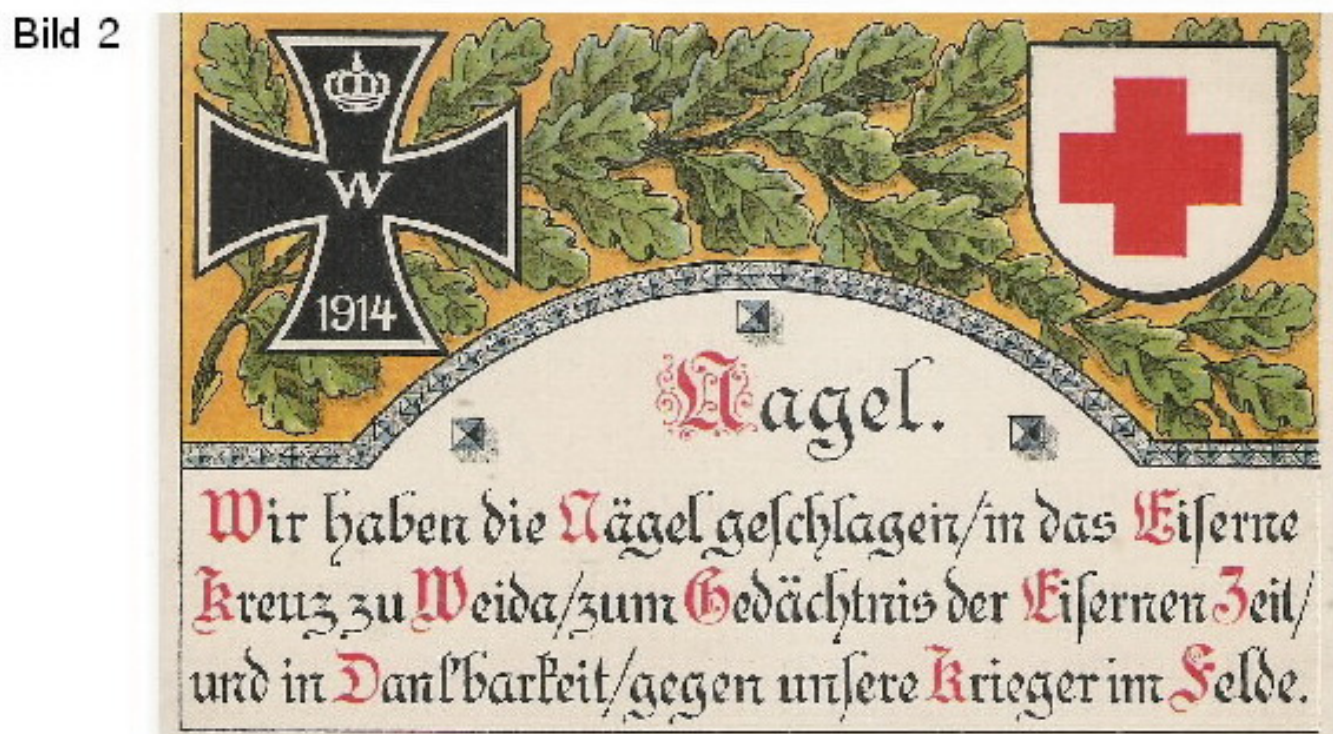

\section{Schulpostkarte}

Quellen: Führen, Lehrer im Krieg, Tafeln 57 (1), 9 (2); Sammlung Kronenberg (3) 
Hindenburg-Verehrung

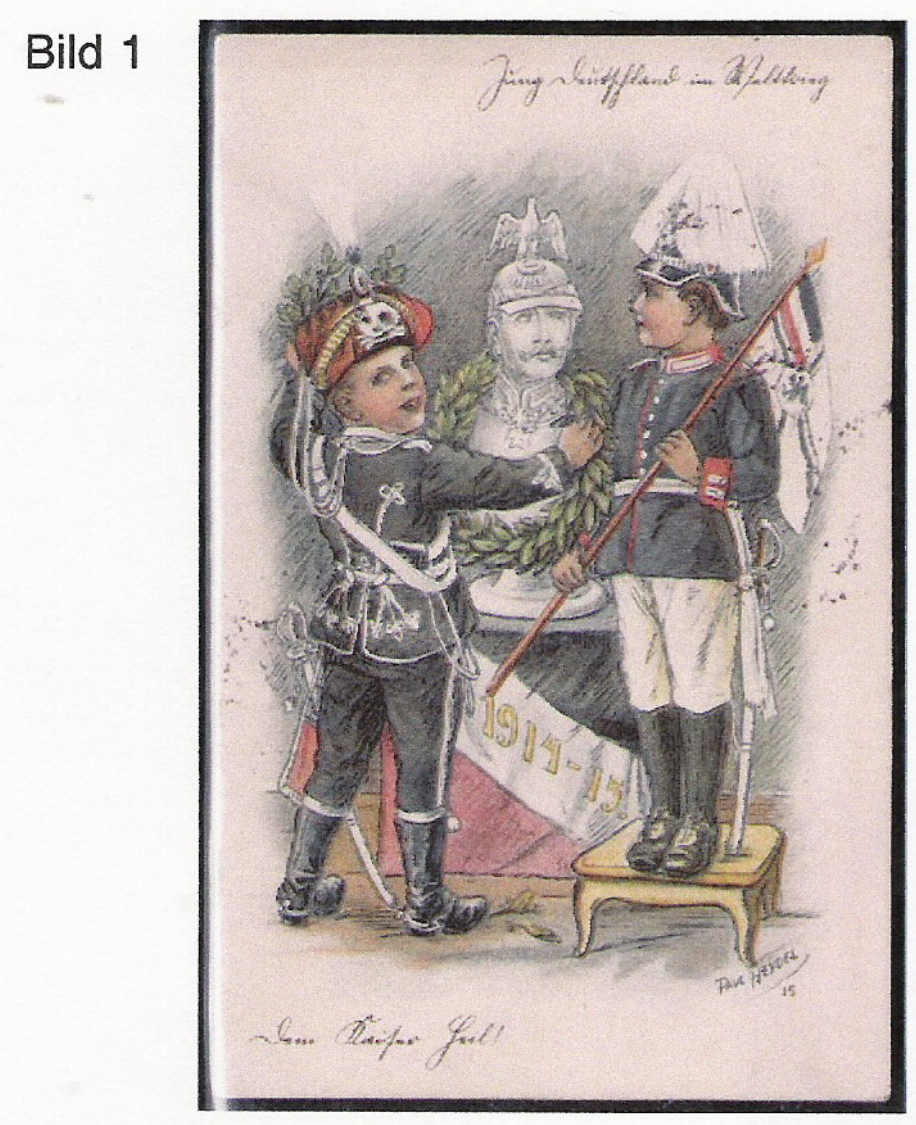

Bild 2

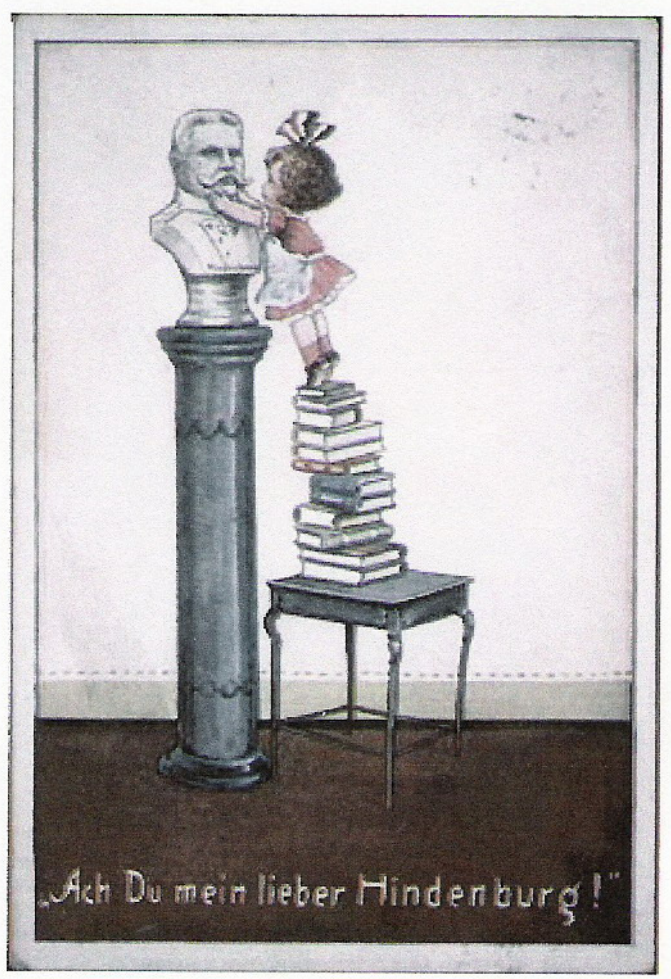

Bild 3

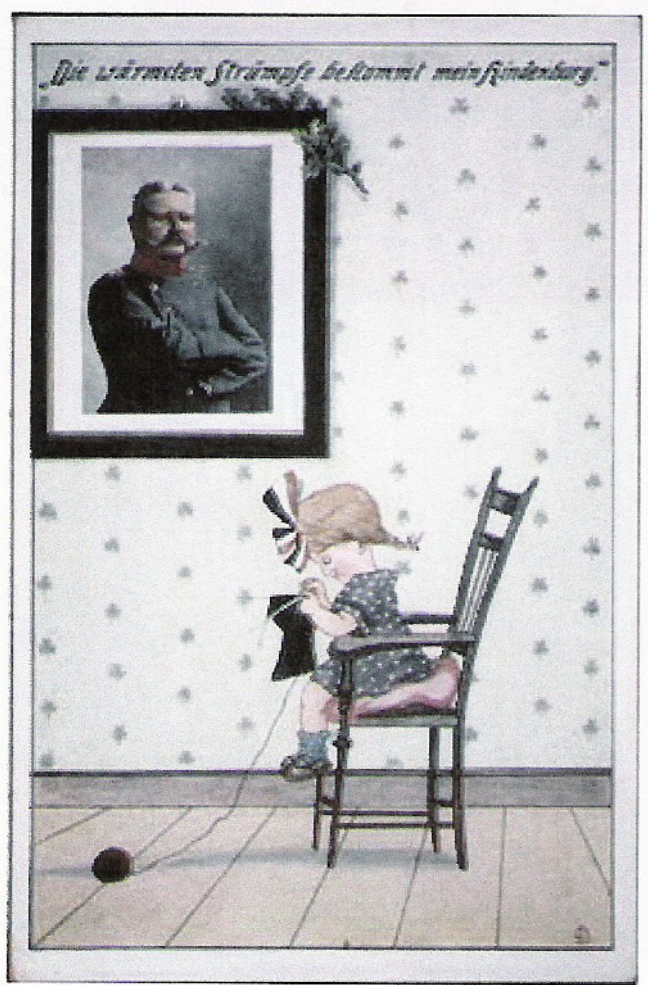




\section{Kapitel 6}

\section{Opfertag in Flensburg am 22.10.1917}

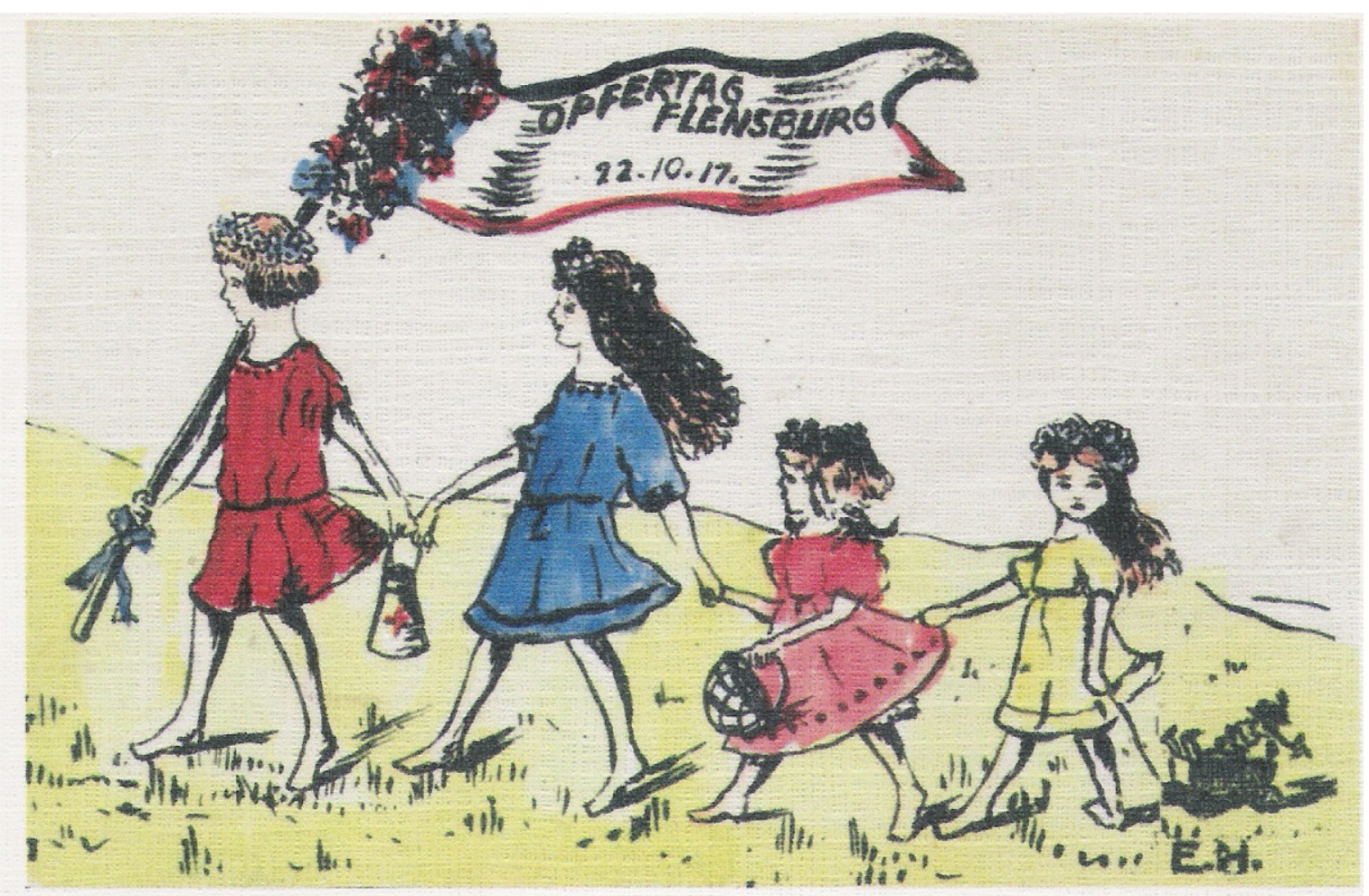

Von einer Schülerin des Oberlyzeums Flensburg gezeichnete Postkarte

Quelle: Pust, Vaterländische Erziehung, Deckblatt 


\section{Kapitel 7}

\section{Kriegswahrzeichen I (Glasmachers)}

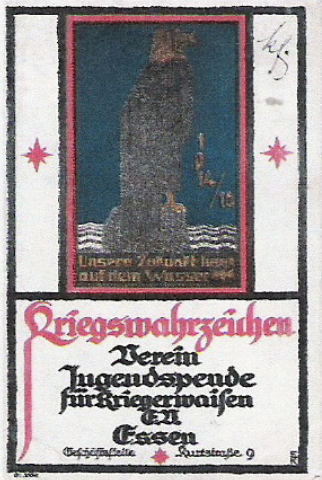

Deckblatt

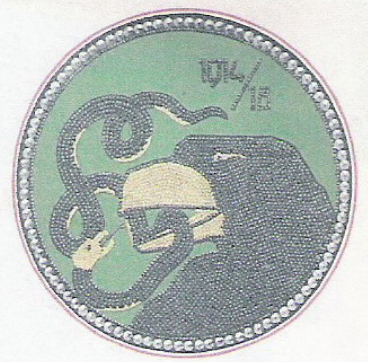

"Adlerkopf"

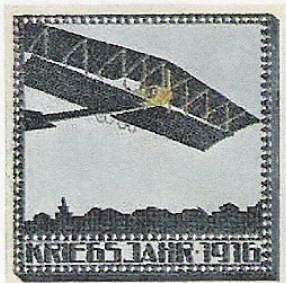

"Flugzeug"

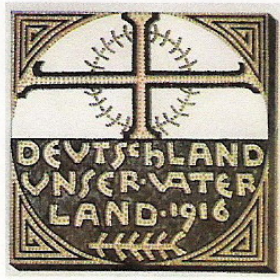

"Kreuz"

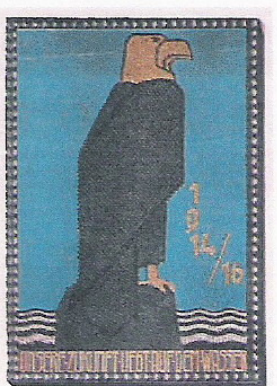

"Adler"

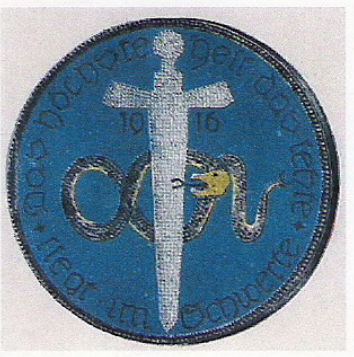

"Schwert"

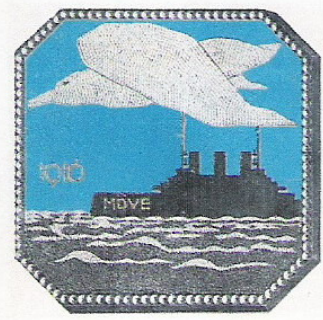

"Möve"

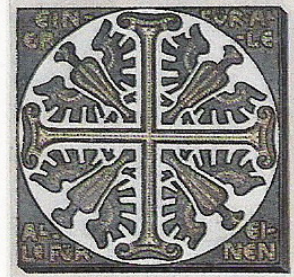

"Vier Adler"

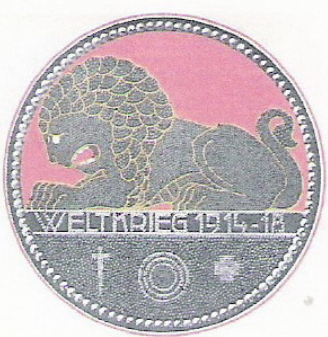

"Löwe"

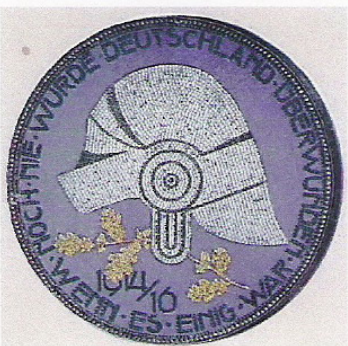

"Helm"

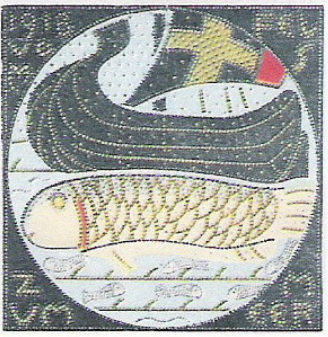

"Schiff"

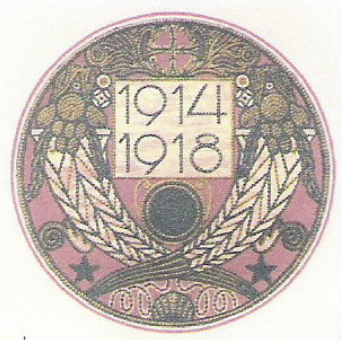

"Füllhorn" 
Kriegswahrzeichen II (Glasmachers)

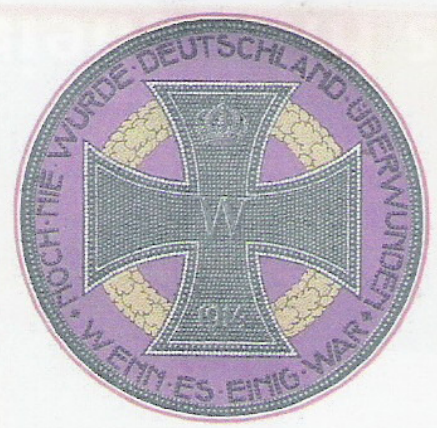

Eisernes Kreuz (mit Kranz)

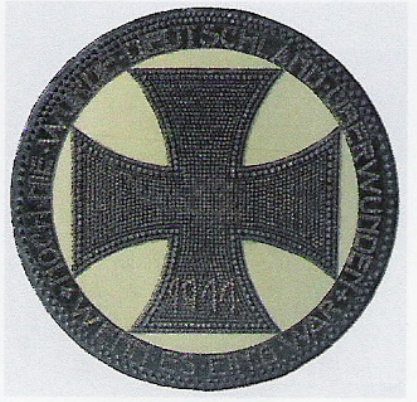

Eisernes Kreuz

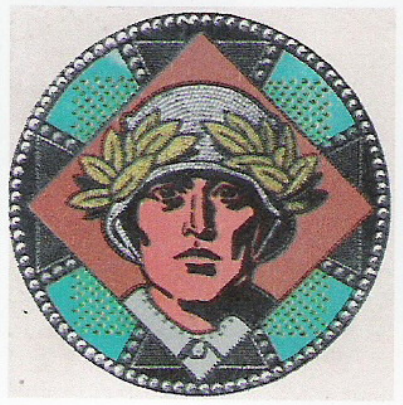

Kopf

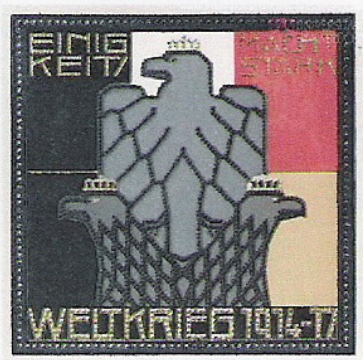

Doppeladler

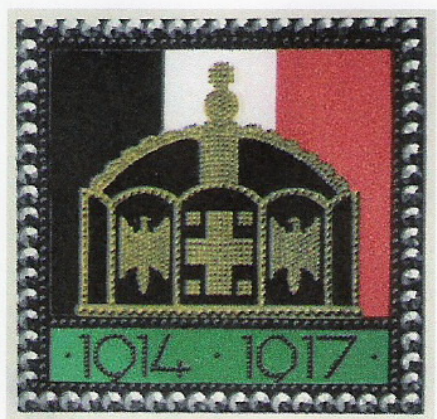

Krone

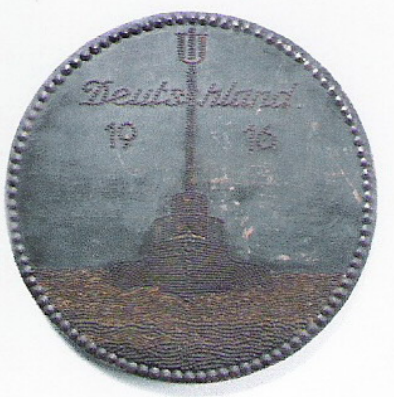

U-Deutschland

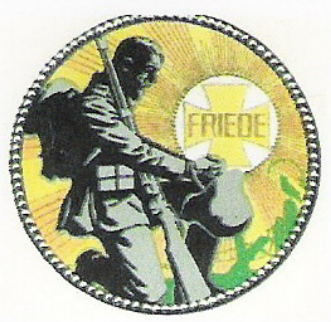

Friede

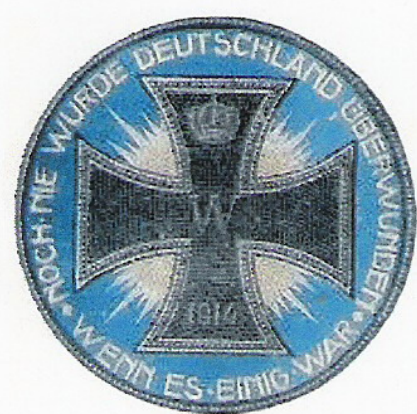

Eisernes Kreuz (mit Sonne)

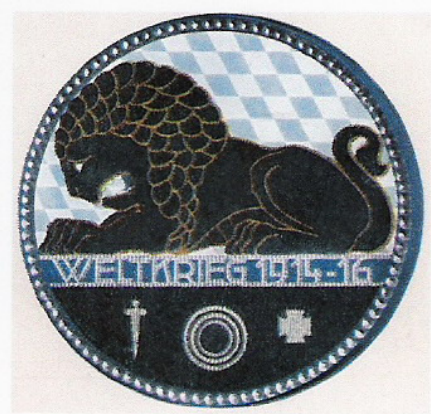

Bayrischer Löwe

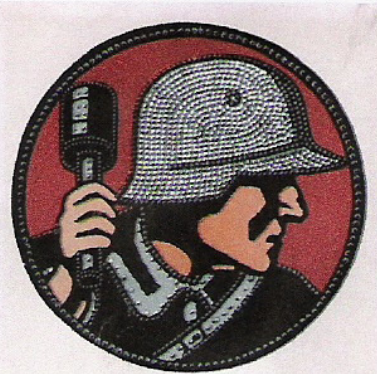

Soldat 


\section{Kriegswahrzeichen III (Glasmachers)}

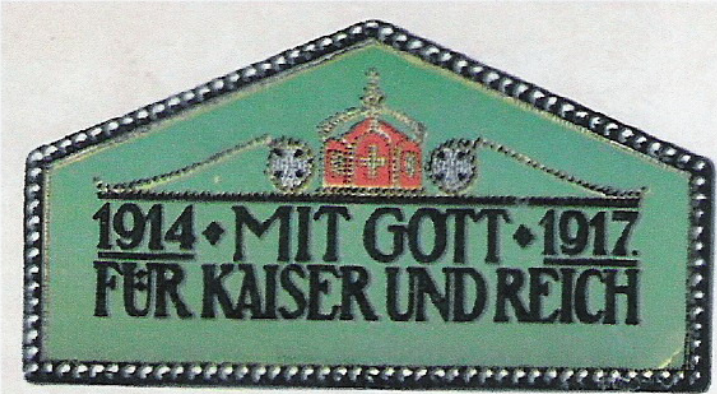

Spruch I

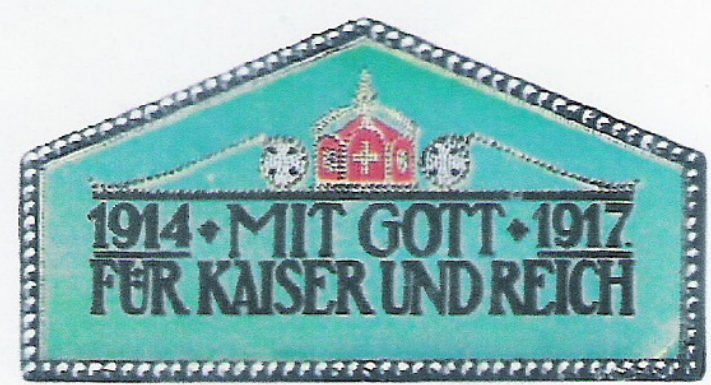

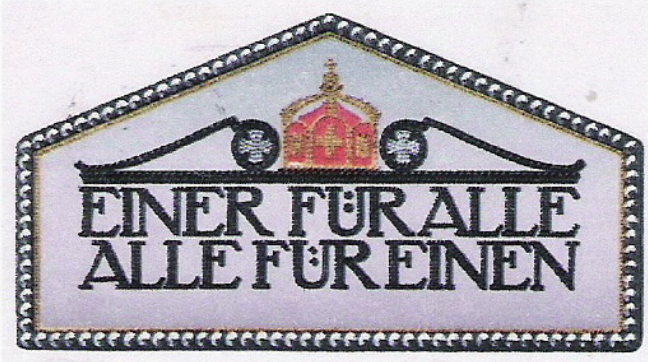

Spruch II

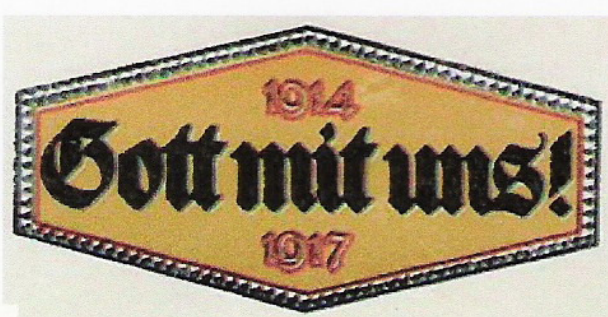

Spruch III

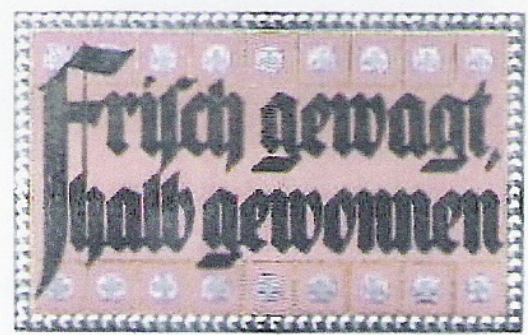

Spruch VI

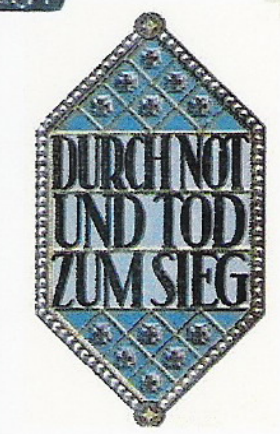

Spruch V

\section{Spruch IV}

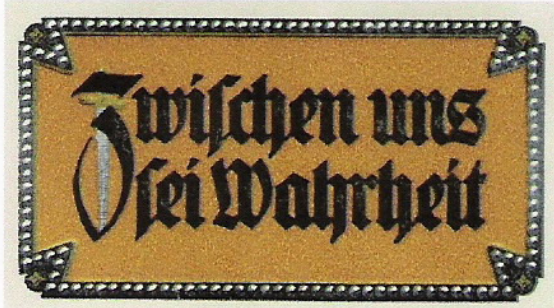

Spruch VII

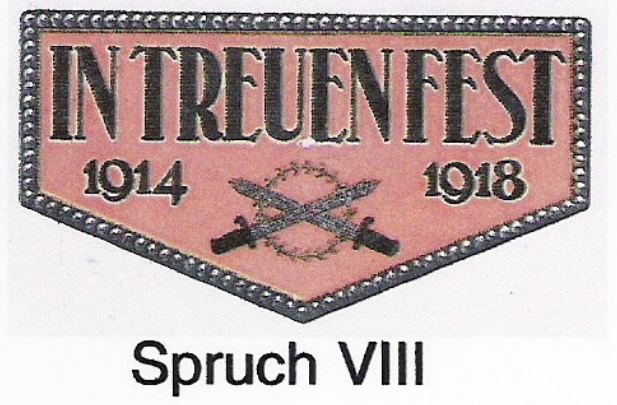




\section{Kriegswahrzeichen IV (Glasmachers) \\ Gedenkschilde für gefallene Lehrer}

\section{Bild 1}

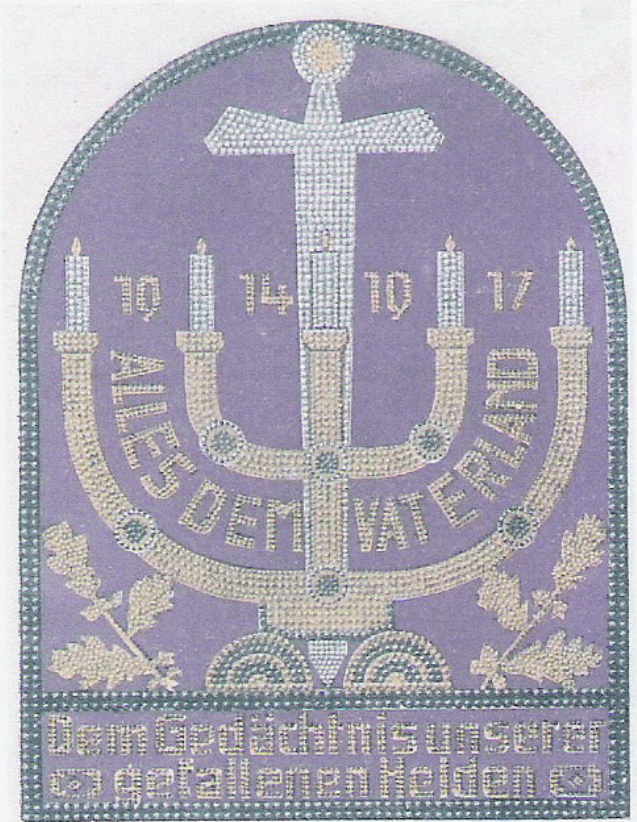

Gedenkschild

für den gefallenen Lehrer Meyer zu Düte genagelt zum Besten der Kriegerwaisen von der Mittelschule Badbergen

\section{Bild 2}

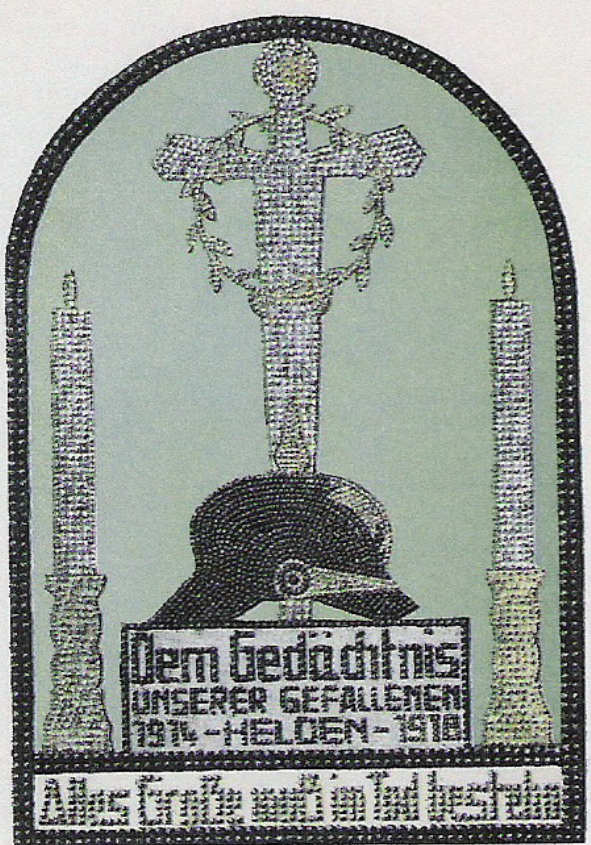

Gedenkschild

genagelt zum Besten des Jugenddanks für Kriegsheschădigte von der Luisenstaditischen Oberrealschule Drasdenarstrabie 113, Berlin

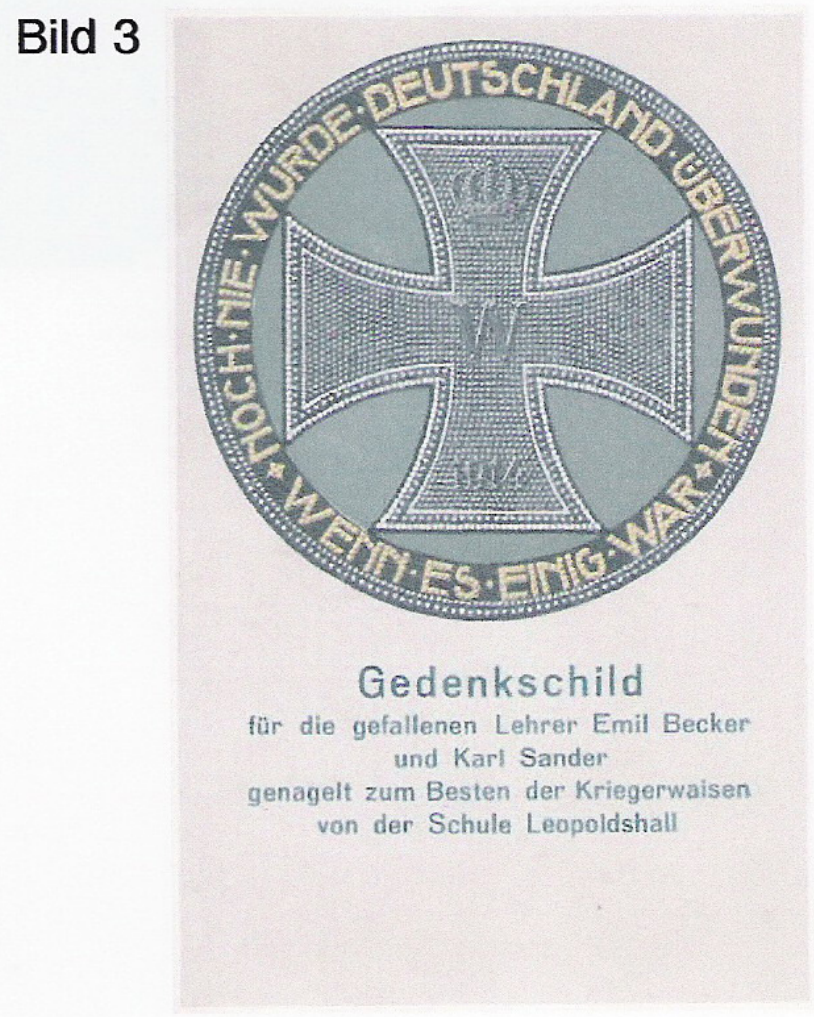

Quelle: Sammlung Kronenberg 


\section{Schuleigene Nagelungen I}

Bild 1

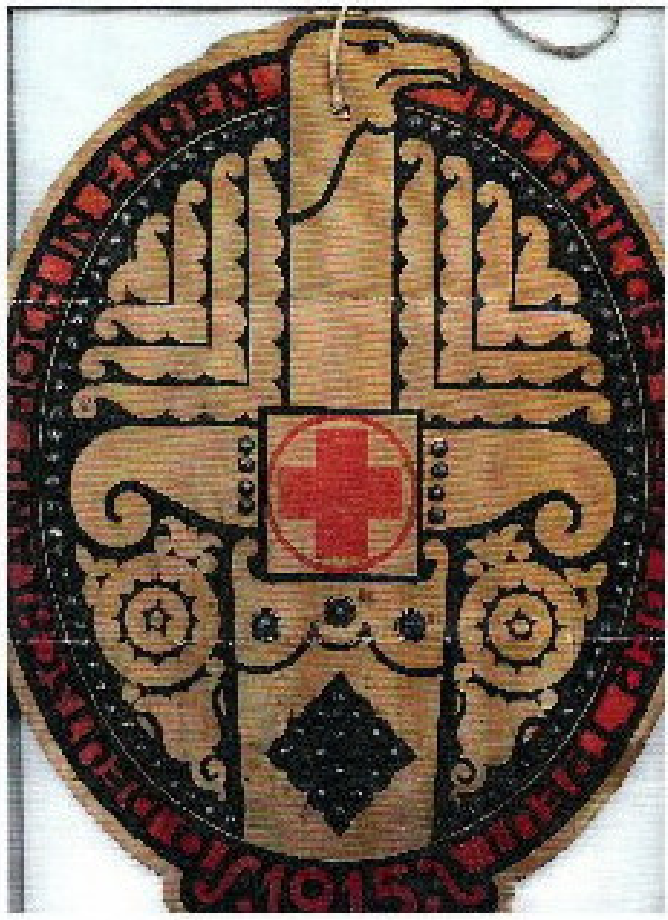

Bild 2

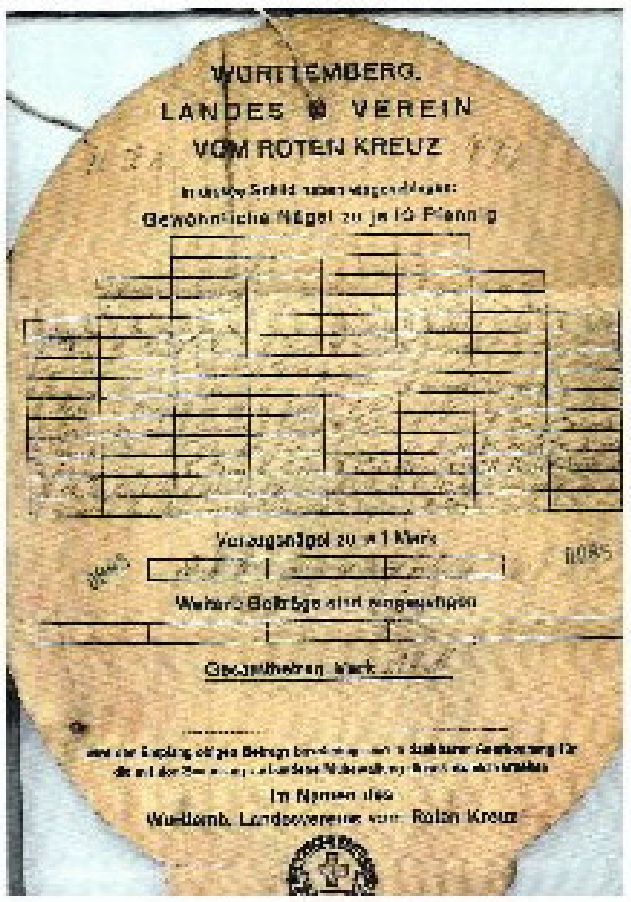

Höhere Töchterschule in Reutlingen

(vor- und Rückseite)

\section{Bild 3}

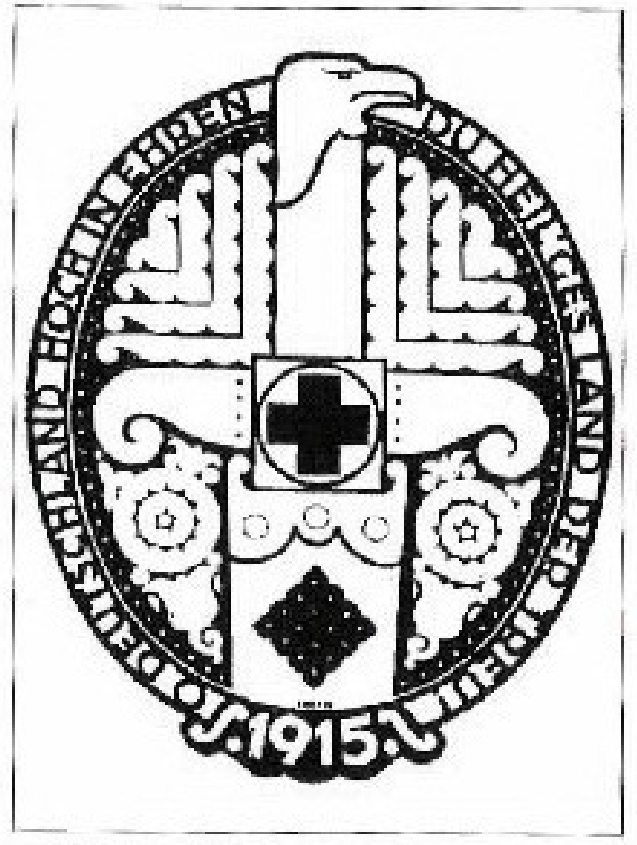

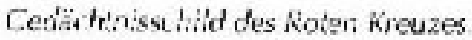

Bild 4

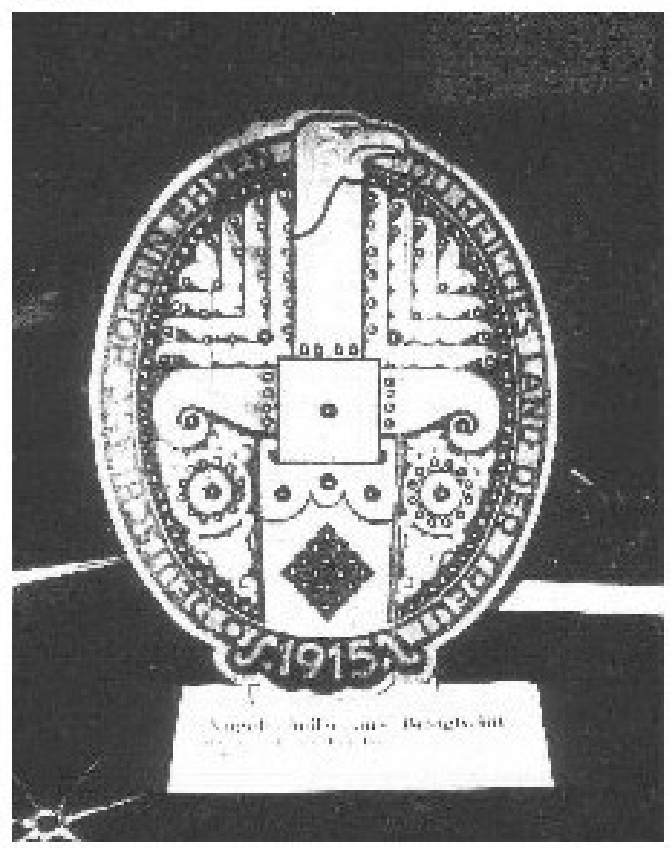

Besigheim 


\section{Schuleigene Nagelungen II}

\section{Nagelbretter der Firma Gothura}

\section{Bild 1}

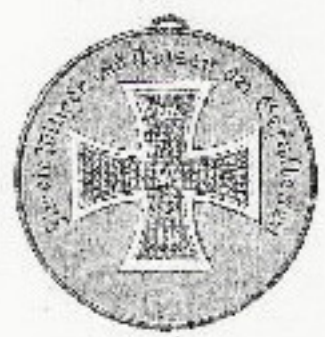

Virsen Sr

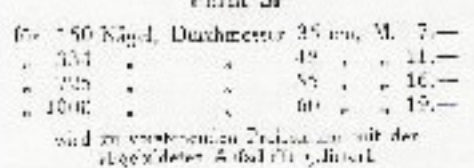

Schild 1

\section{Bild 3}

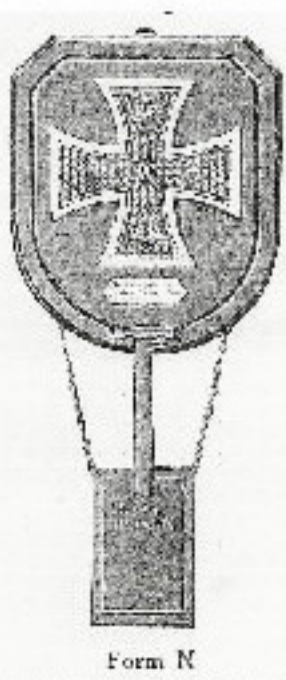

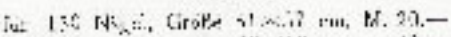

- SE, , , ,

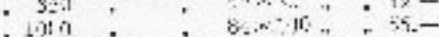

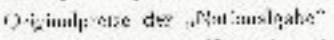

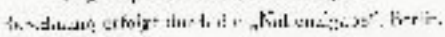

\section{Bild 2}

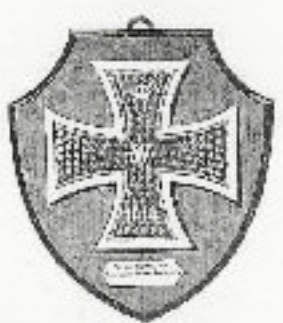

Viom 5 ;

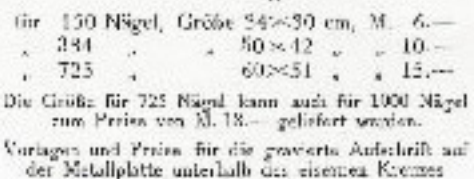

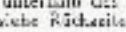

\section{Schild 2}

\section{Bild 4}

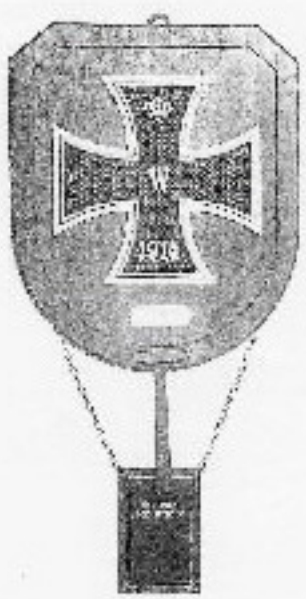

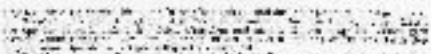

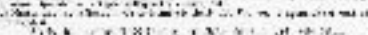
… W.

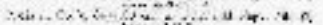

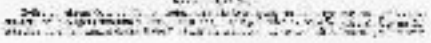




\section{Schuleigene Nagelungen III}

Entwürfe des Deutschen Werkbundes

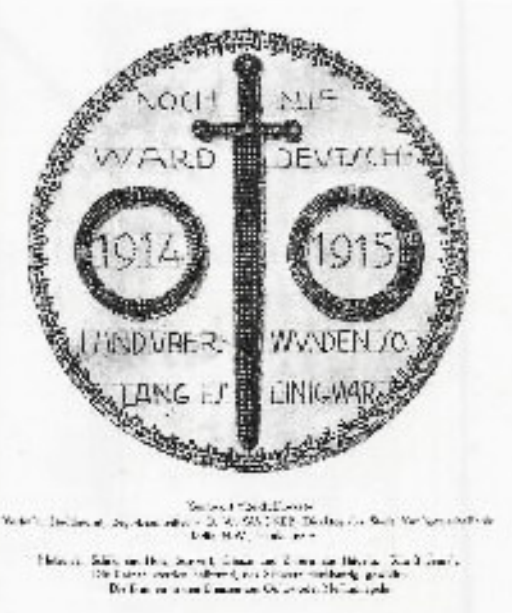

Entwurf 1

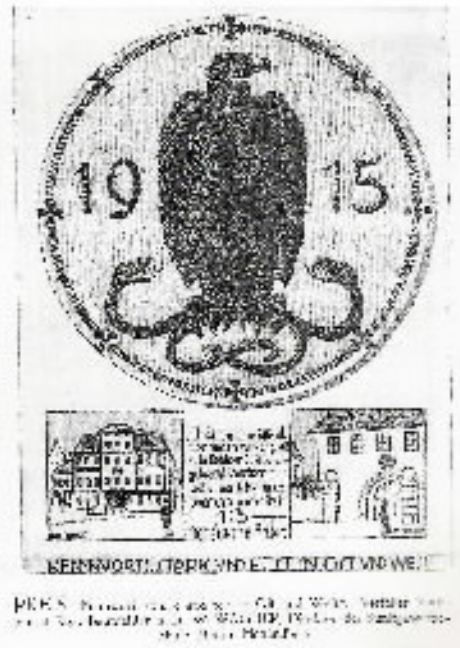

Entwurf 2

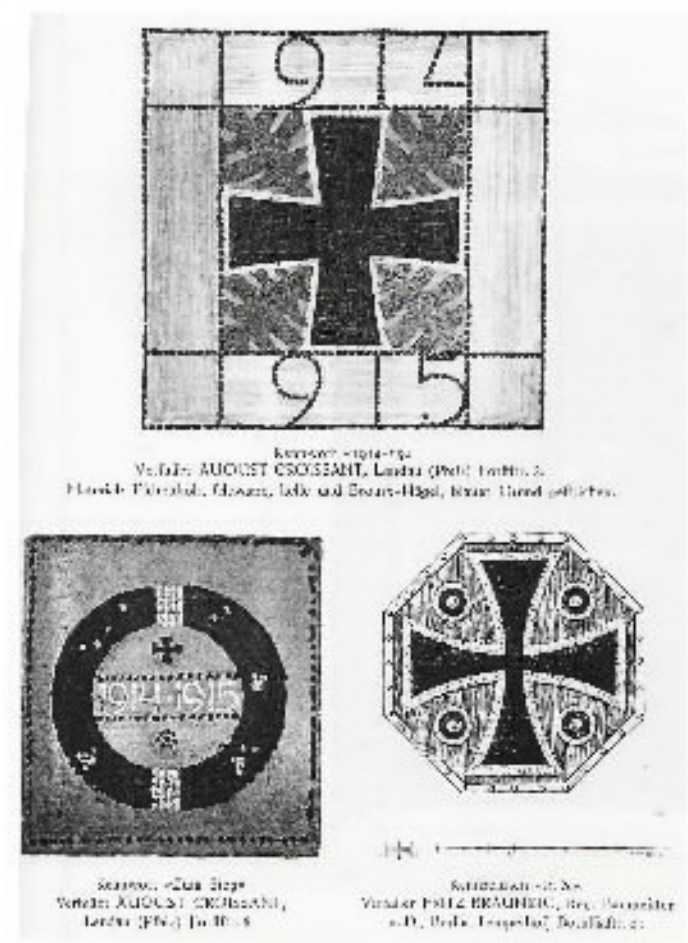

Entwürfe 3, 4 und 5

Quelle: Entwürfe des Deutschen Werkbundes 


\section{Schuleigene Nagelungen IV}

Schildnagelungen

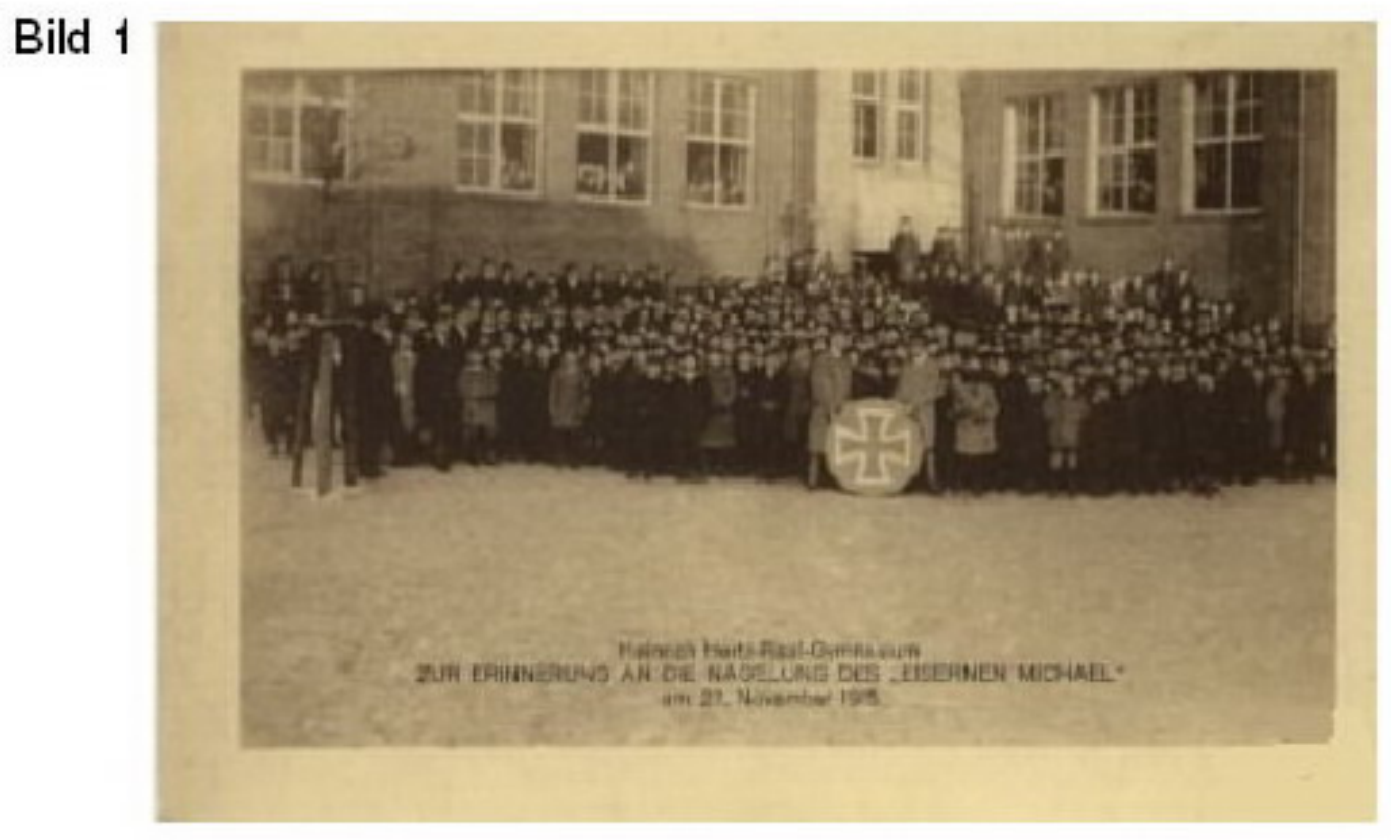

\section{Heinrich-Hertz-Oberrealschule Hamburg}

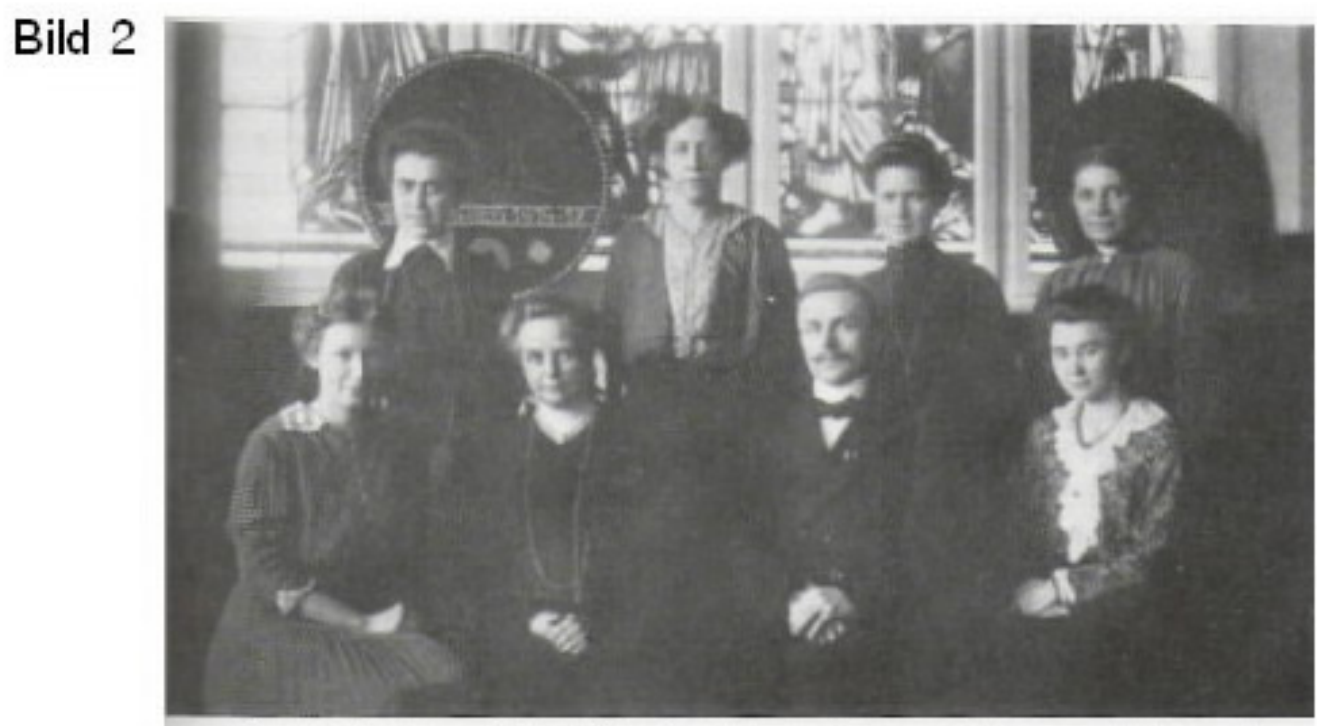

Das Kollegium der Luisenschule 1918 in der Aula, im Hintergrund sind cwei runde NagetBilder erkennbar (aus: Festschrift zur Einweihung des Neubaues der Luisenschule, 1966)

\section{Lyzeum Luisenschule Bad Oeynhausen}

Quellen: Sammlung Kronenberg (1); Kuderer/Schneider, Nageln fur das Vaterland (2) 


\section{Schuleigene Nagelungen V}

Bild 1

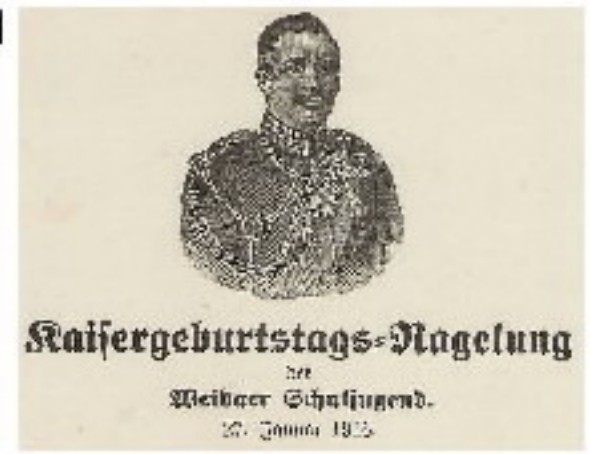

Bild 2

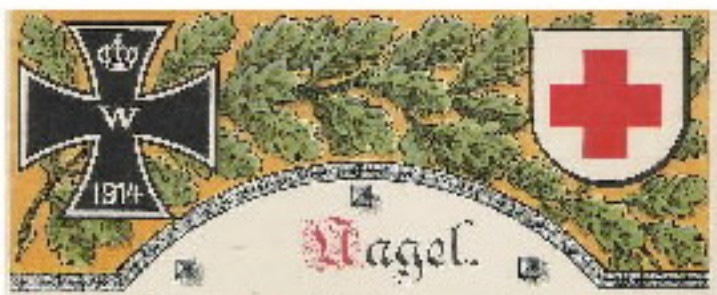

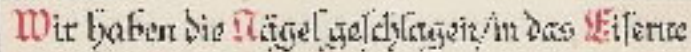

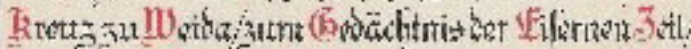

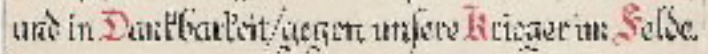

Weida - Vor-und Rückseite

Bild 3
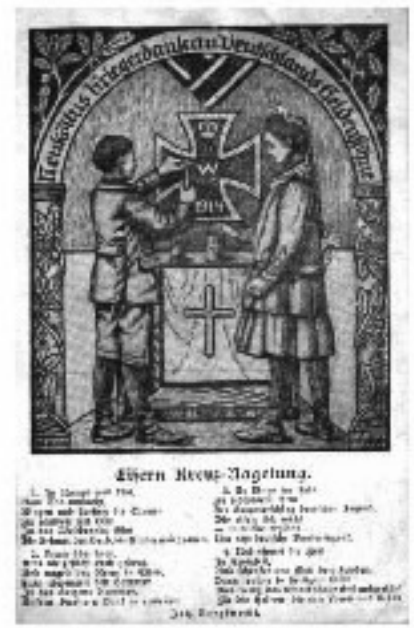

Neukölln

\section{Bild 4}

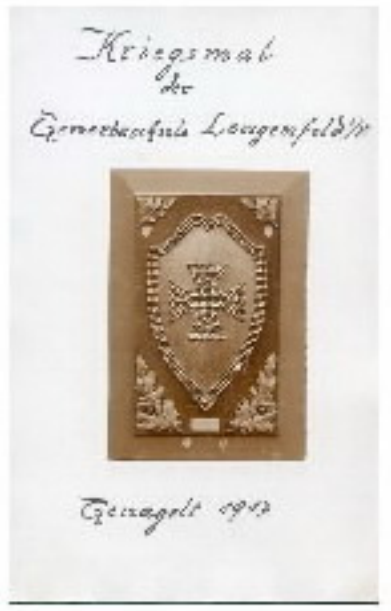

Lengenfeld i.OF
Bild 5
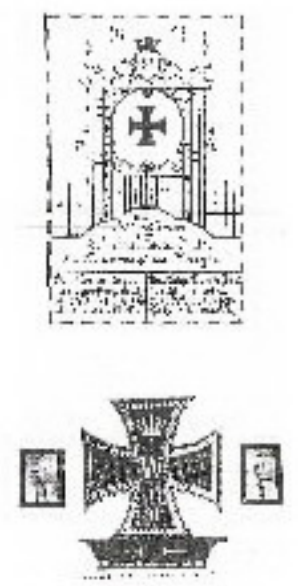

Zella St. BI.
Bild 6

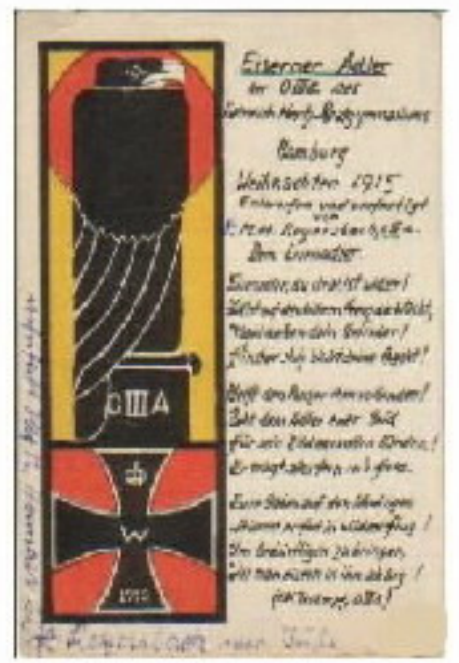

Heinrich-Hertz-Oberrealschule Hamburg
Bild 7

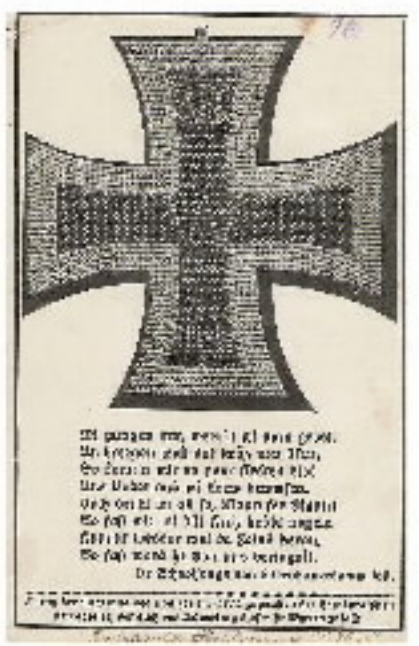

Schule am Steinhauerdamm Hamburg 
Schuleigene Nagelungen VI

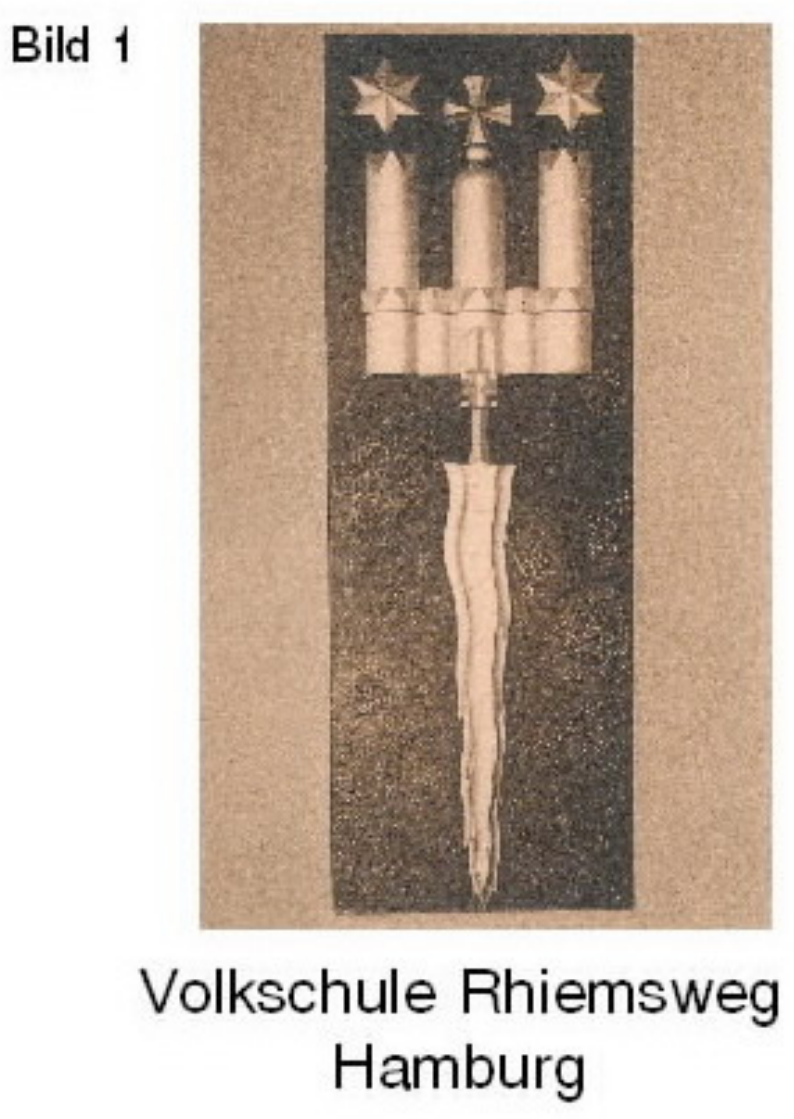

Bild 2

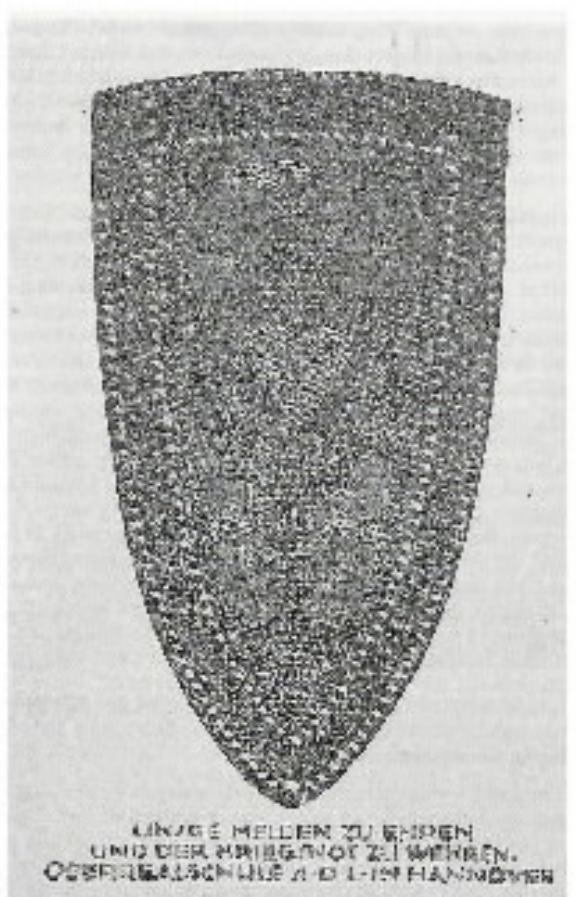

Lutherschule Hannover

Quellen: Sammlung Kronenberg (1); Schneider, Über Hannoversche Nagel figuren, S. 250 (2) 


\section{Schuleigene Nagelungen VII}

\section{Königliche Schillerschule in Jüterbog}

Bild 1

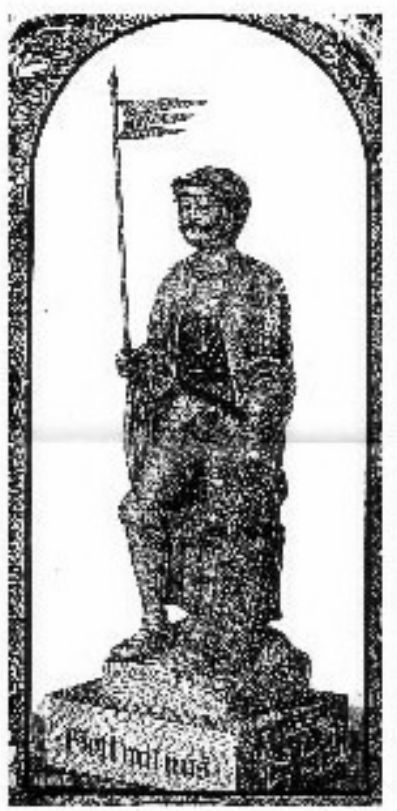

Bild 2

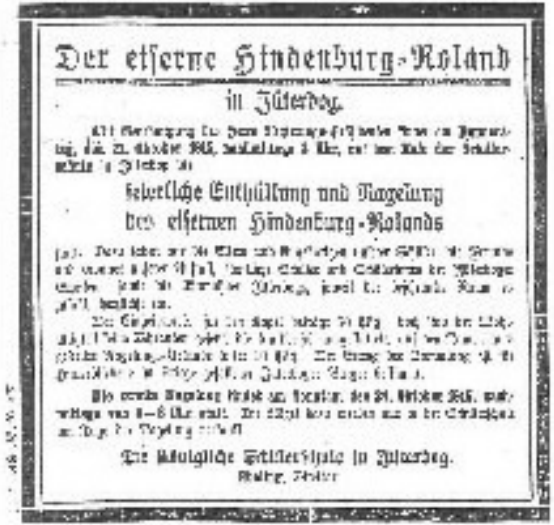

Einladung der Schule
Bild 3

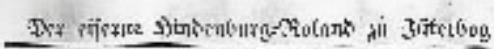

รั)

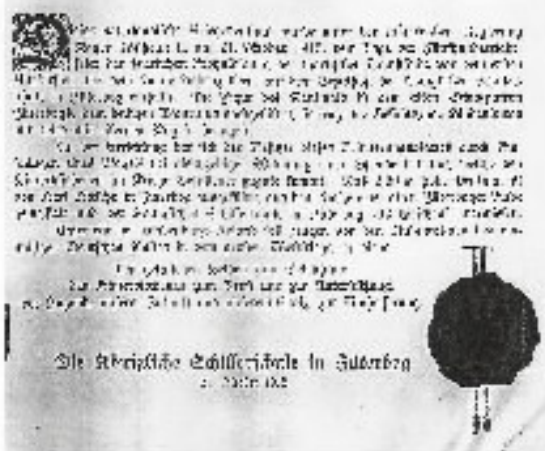

Nagelungsurkunde

\section{Bild 4 Ursulinenschule in Saarbrücken Bild 5}

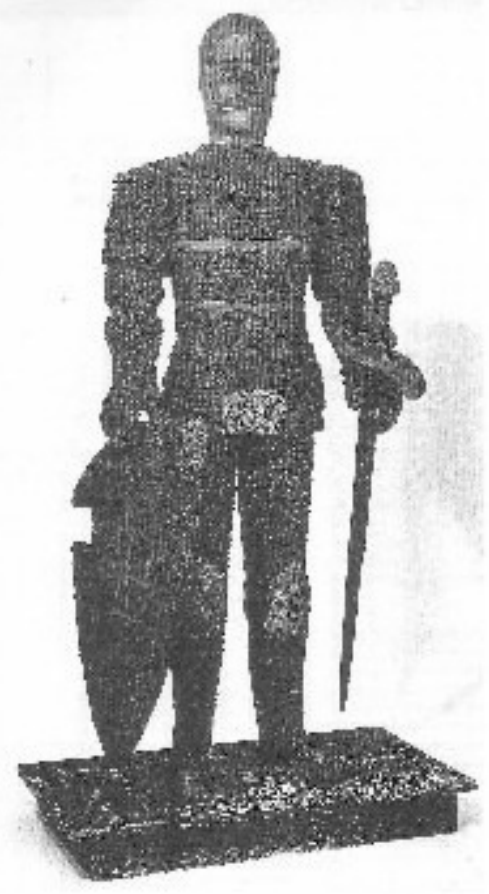

"Eiserner Ritter"

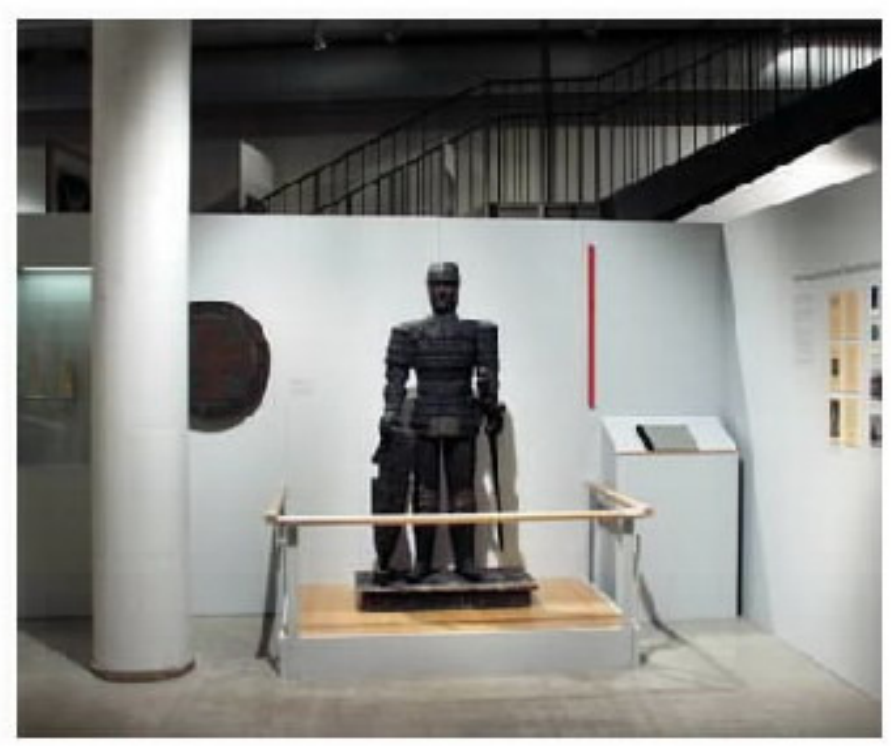

Ausstellung 1993 Museum Saarbrücker Schloss

Quellen: Stadtmuseum Jüterbog (1,2,3); Regionalgeschichtliches Museum Saarbrücken (4,5) 


\title{
Schuleigene Nagelungen VIII
}

\author{
- Österreich I -
}

\section{Bild 1}

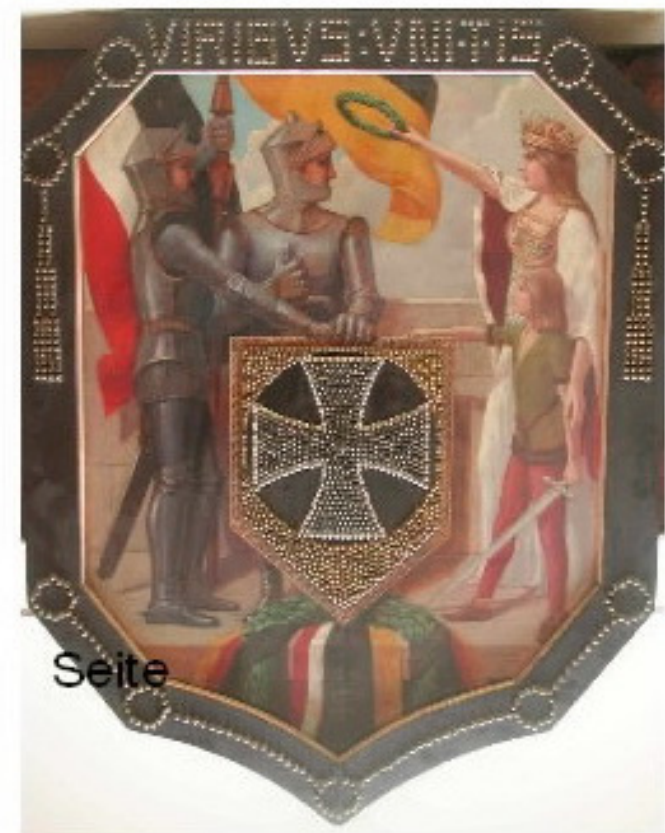

Nagelschild des Gymnasiums in Ried im Inntal
Bild 2

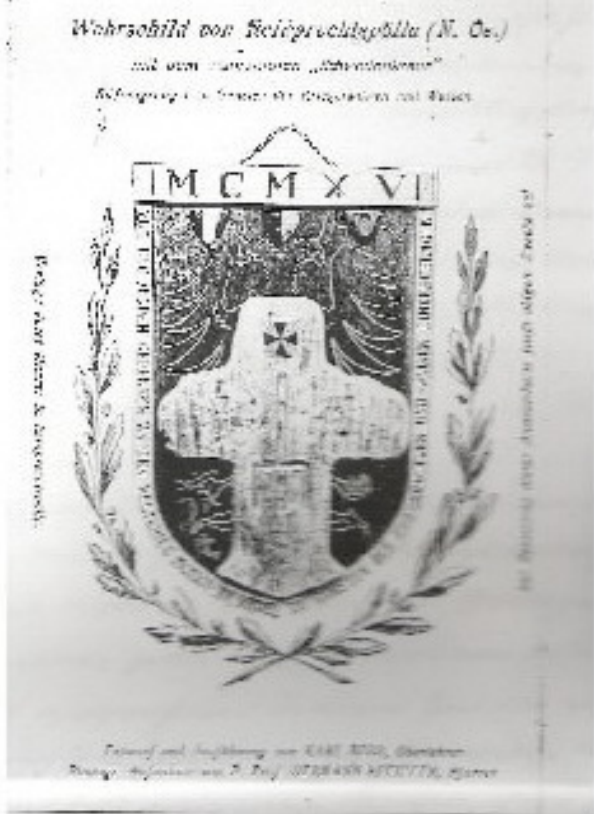

'Schwedenkreuz' von

Reinprechtspölla

\section{Bild 3}

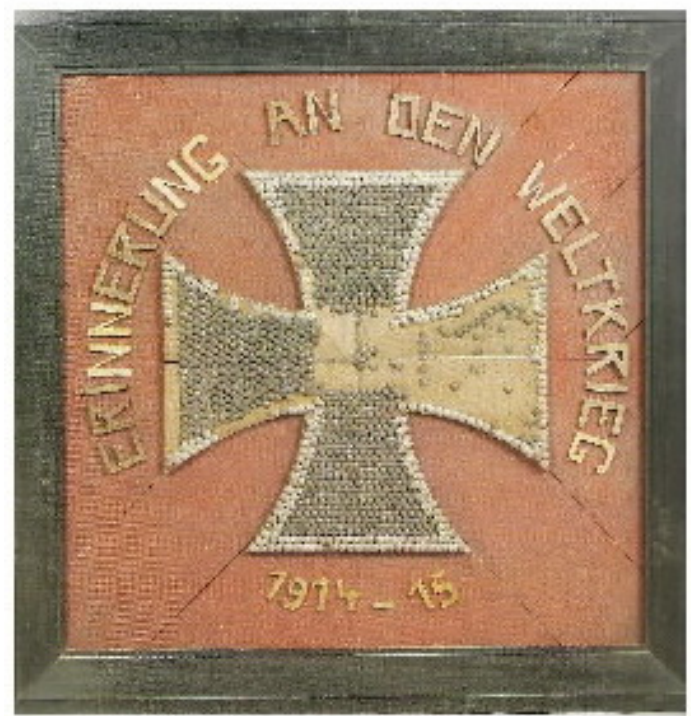

Eisernes Kreuz von Hallein

\section{Bild 4}

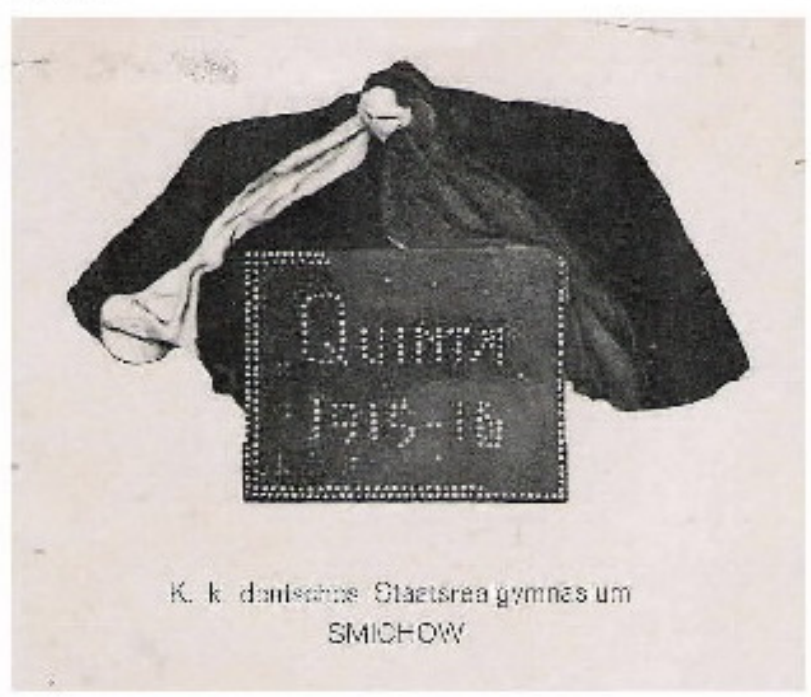

K. k. deutsches Gymnasium SMICHOW 


\section{Schuleigene Nagelungen IX}

Österreich II -

Bild 1

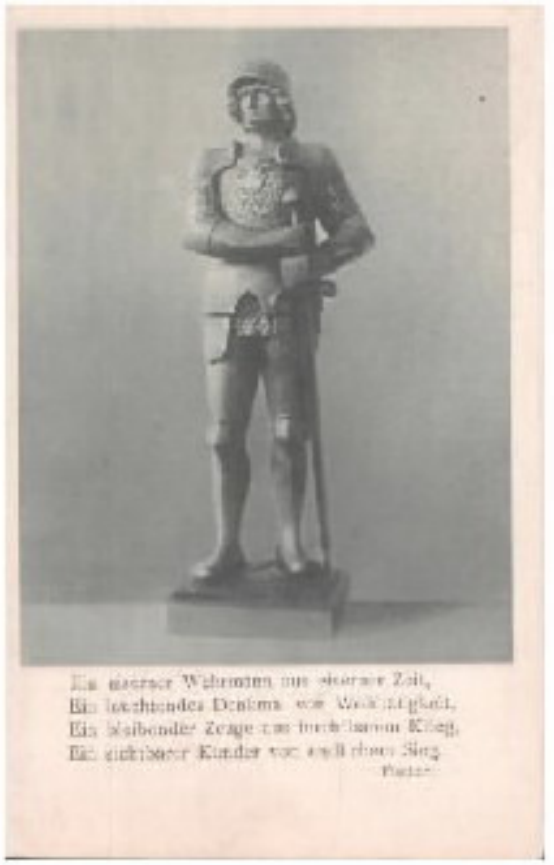

Ansichtskarte
Bild 2

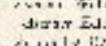

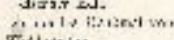

कusi.unt...

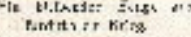

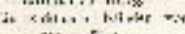

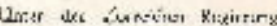

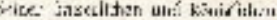

aprowieden Bavest:

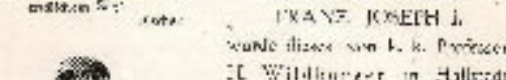

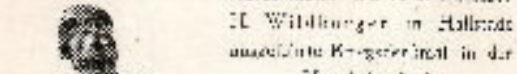
Ehadilxsinule

fis welis Nidit.. Wern

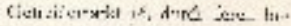

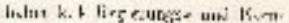

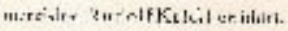

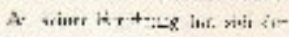

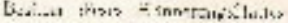

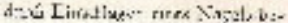

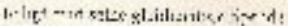

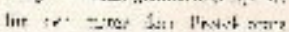

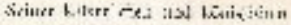

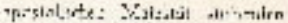
K K ASTERKCIOI ISCAIIN

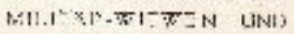

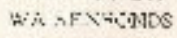
ces dred.
TW] KR:F:T:Z]AHK

Wehrmann in Eisen

Handelsschule Alois Weiß Nachfolger in Wien

Bild 3

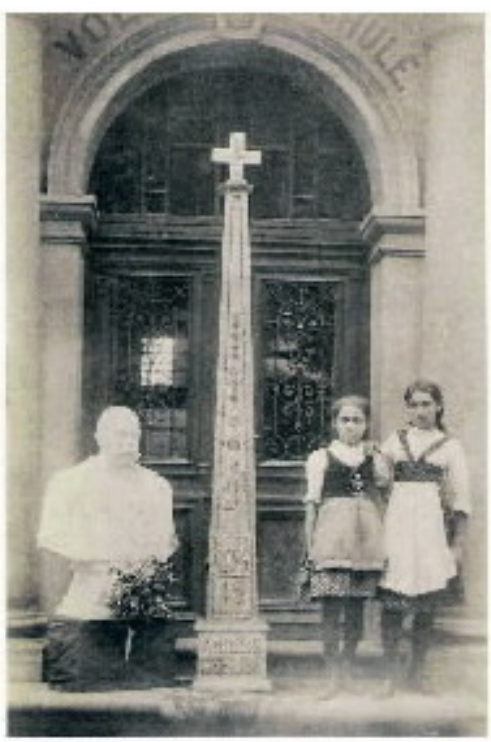

Kriegs-Obelisk der Volksschule in Saaz (Bōhmen)
Bild 4

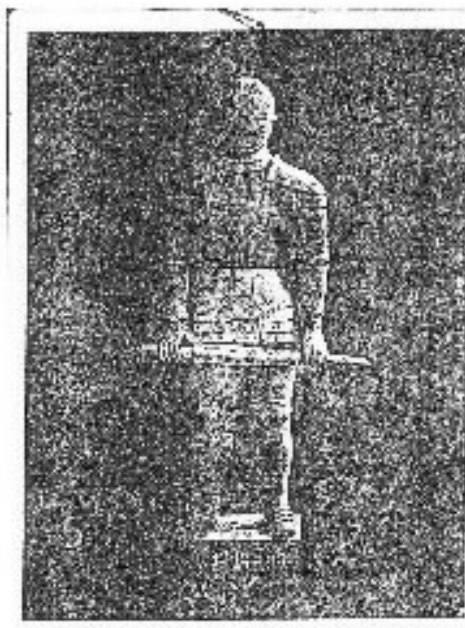

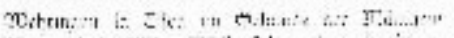

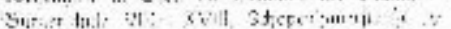

Wehrmann in Eisen Bürgerschule, Wien XVIII 


\section{Kommunale Kriegswahrzeichen}

Von Lehrern gestaltete Objekte

\section{Bild 1}

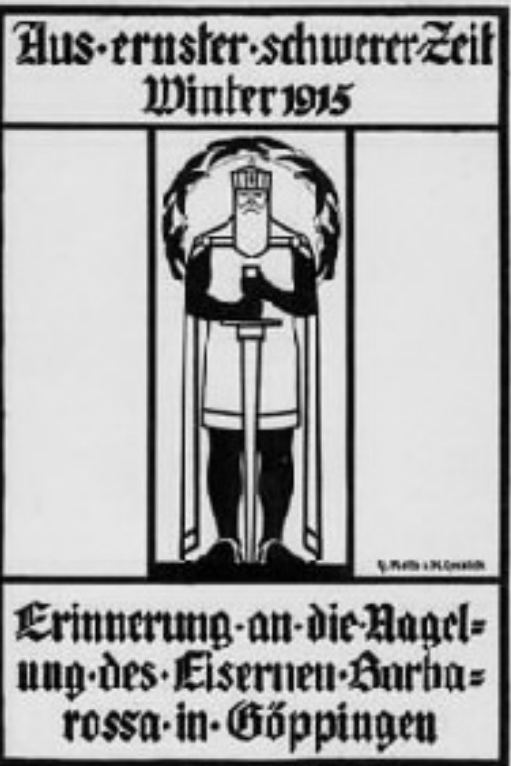

"Eiserner Barbarossa" Göppingen

\section{Bild 2}

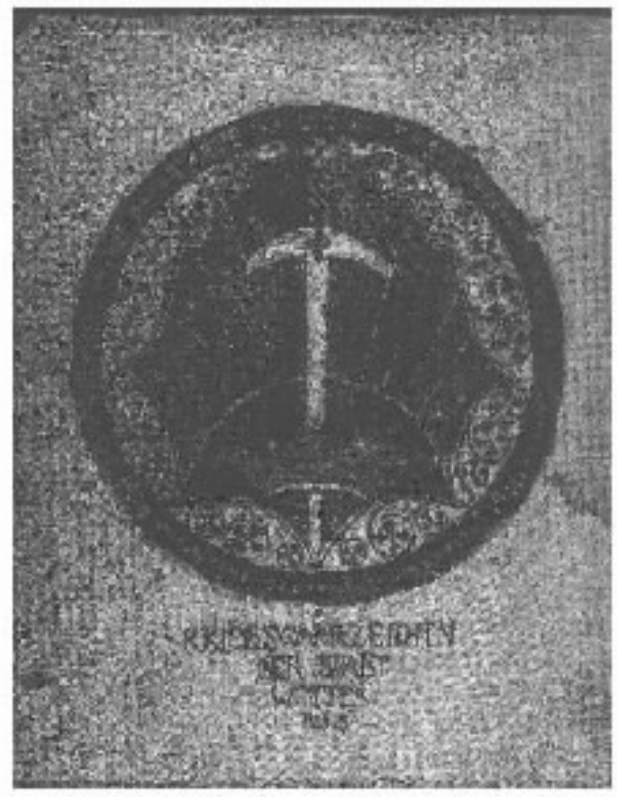

'Das Eiserne Schwert" Wetter (Ruhr)

Bild 4

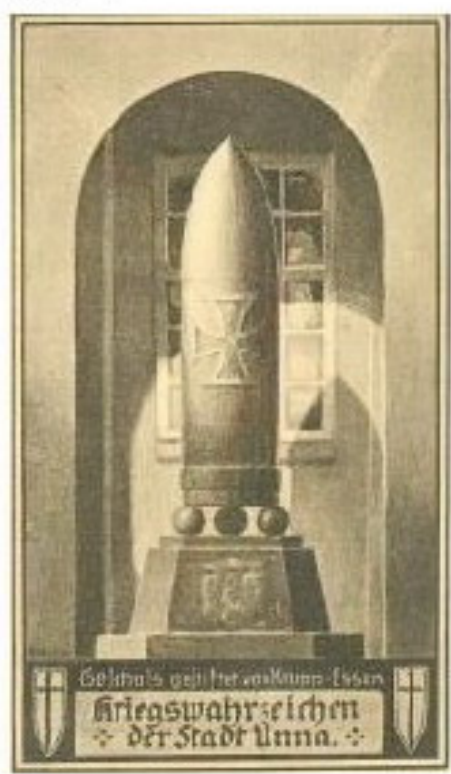

"Eiserne Granate" Ansichtskarte Unna 
Teilnahme an Nagelungen I

Stadt Weilheim am 18. Juni 1916

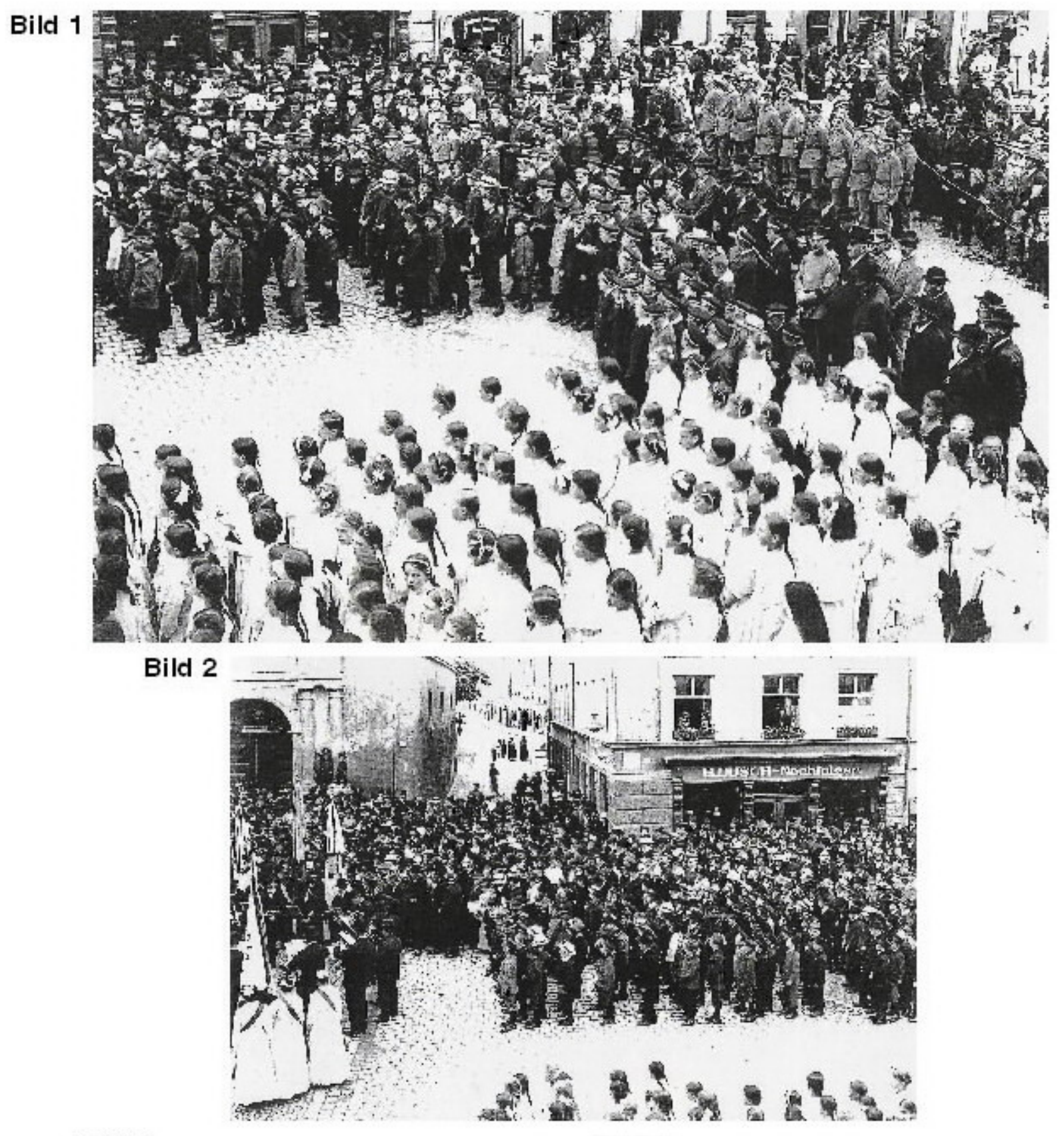

Bild 3

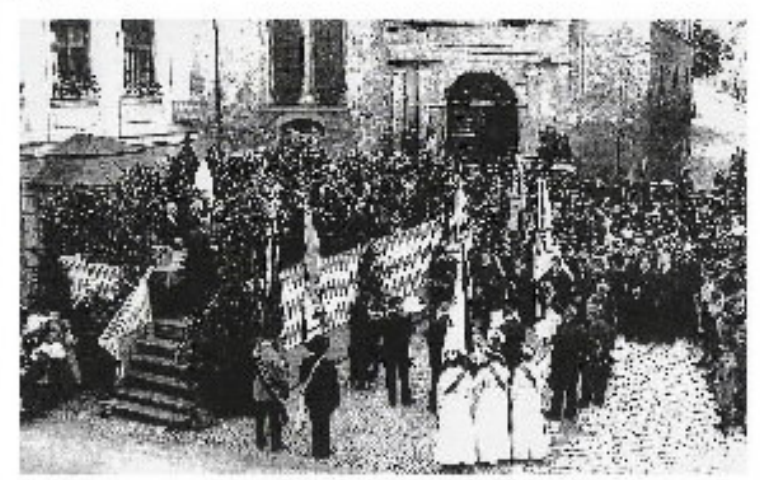

\section{Bild 4}

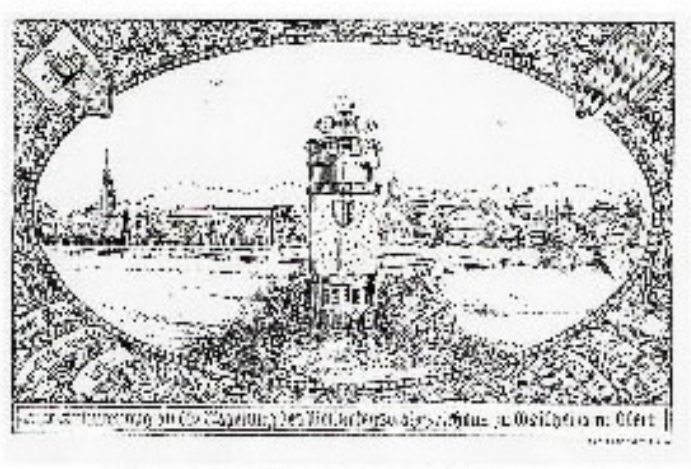

Kriegswahrzeichen

Quelle: Stadtarchiv Weilheim in Oberbayern 
Teilnahme an Nagelungen II

Offenbach am 3. Oktober 1915

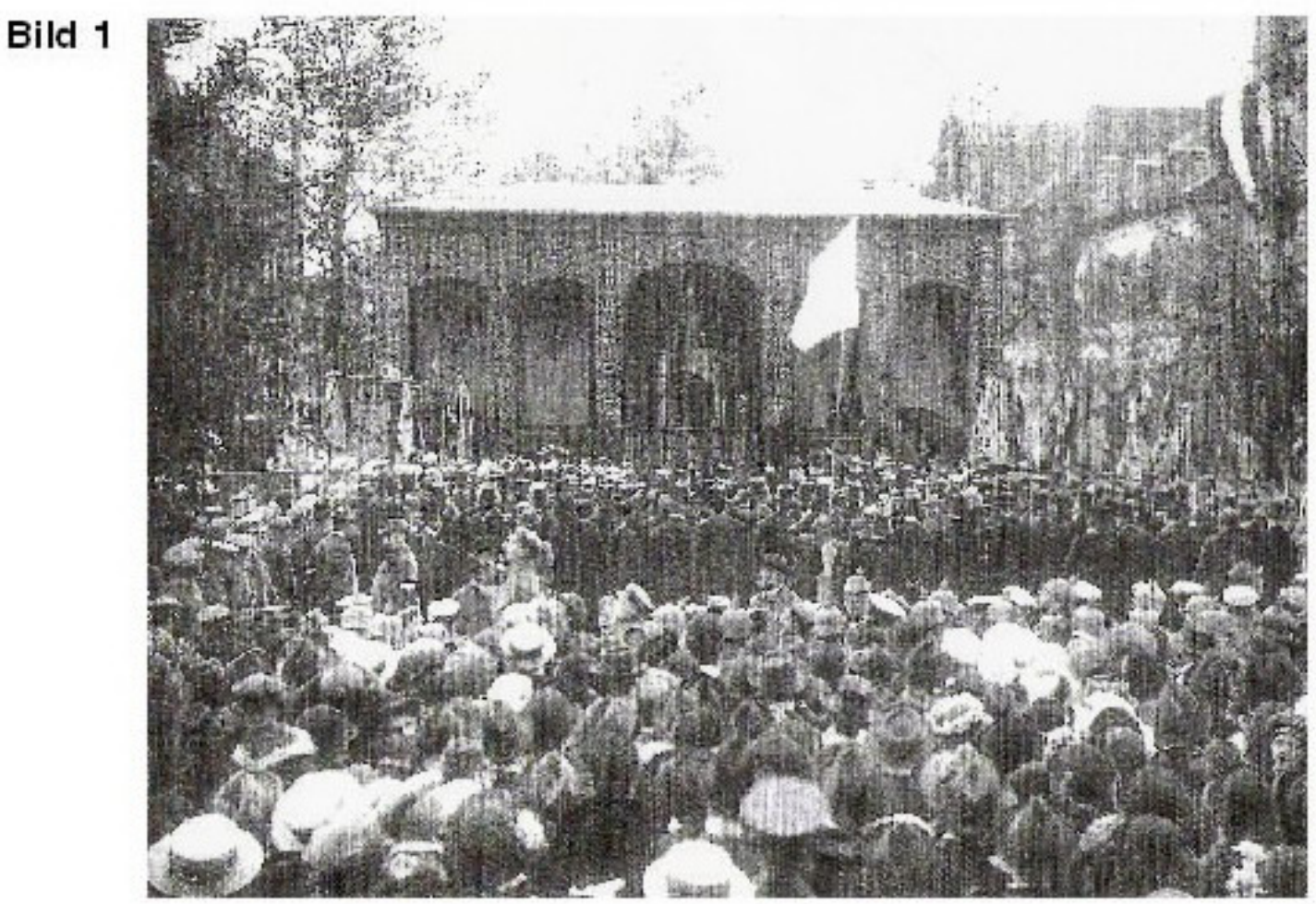

Enthüllung des "Eisernen Mannes" (Götz von Berlichingen)

\section{Erfurt am 24. April 1915}

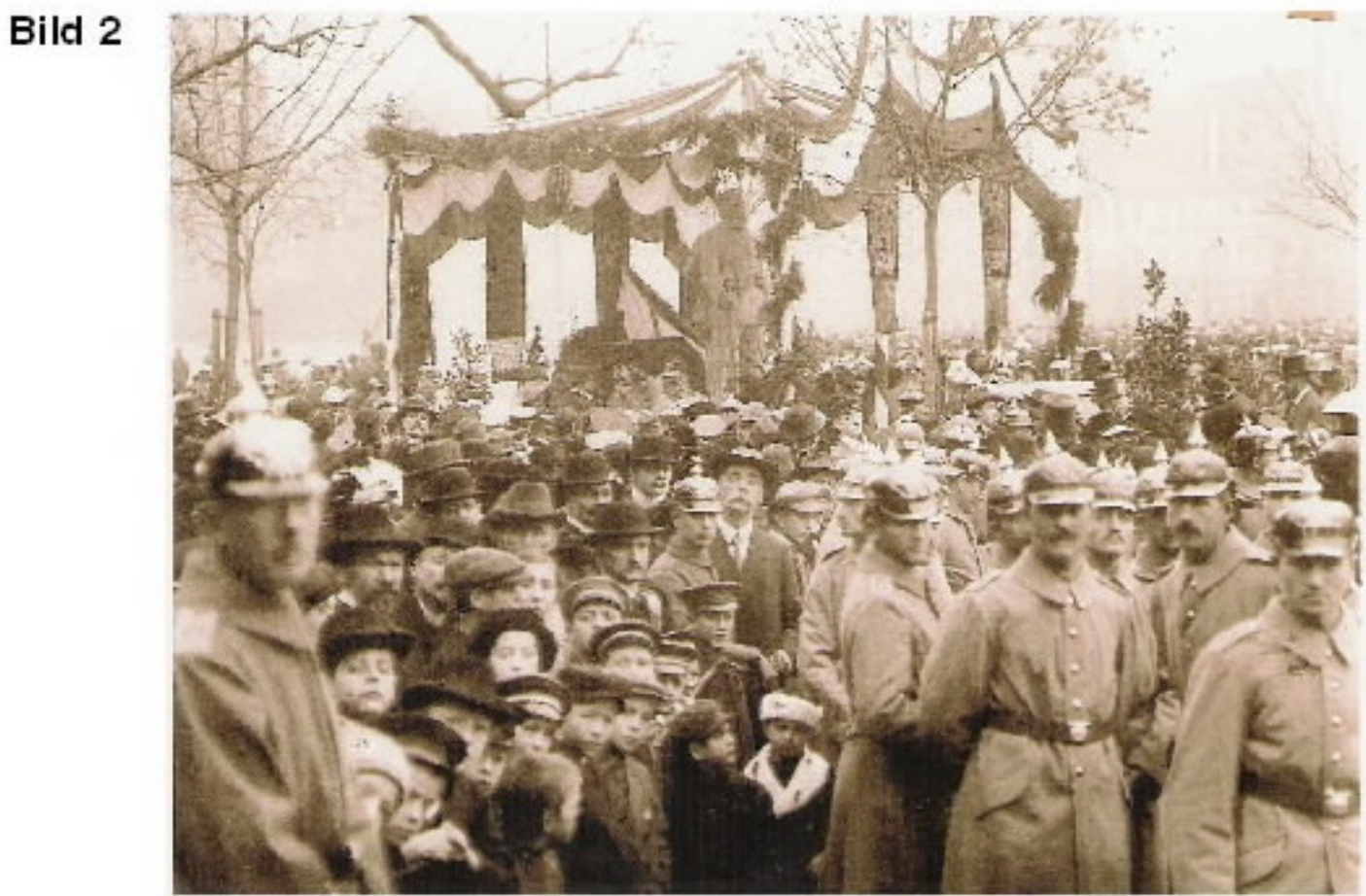

Einweihung des "Eisernen Landsturmmannes" 
Teilnahme an Nagelungen III

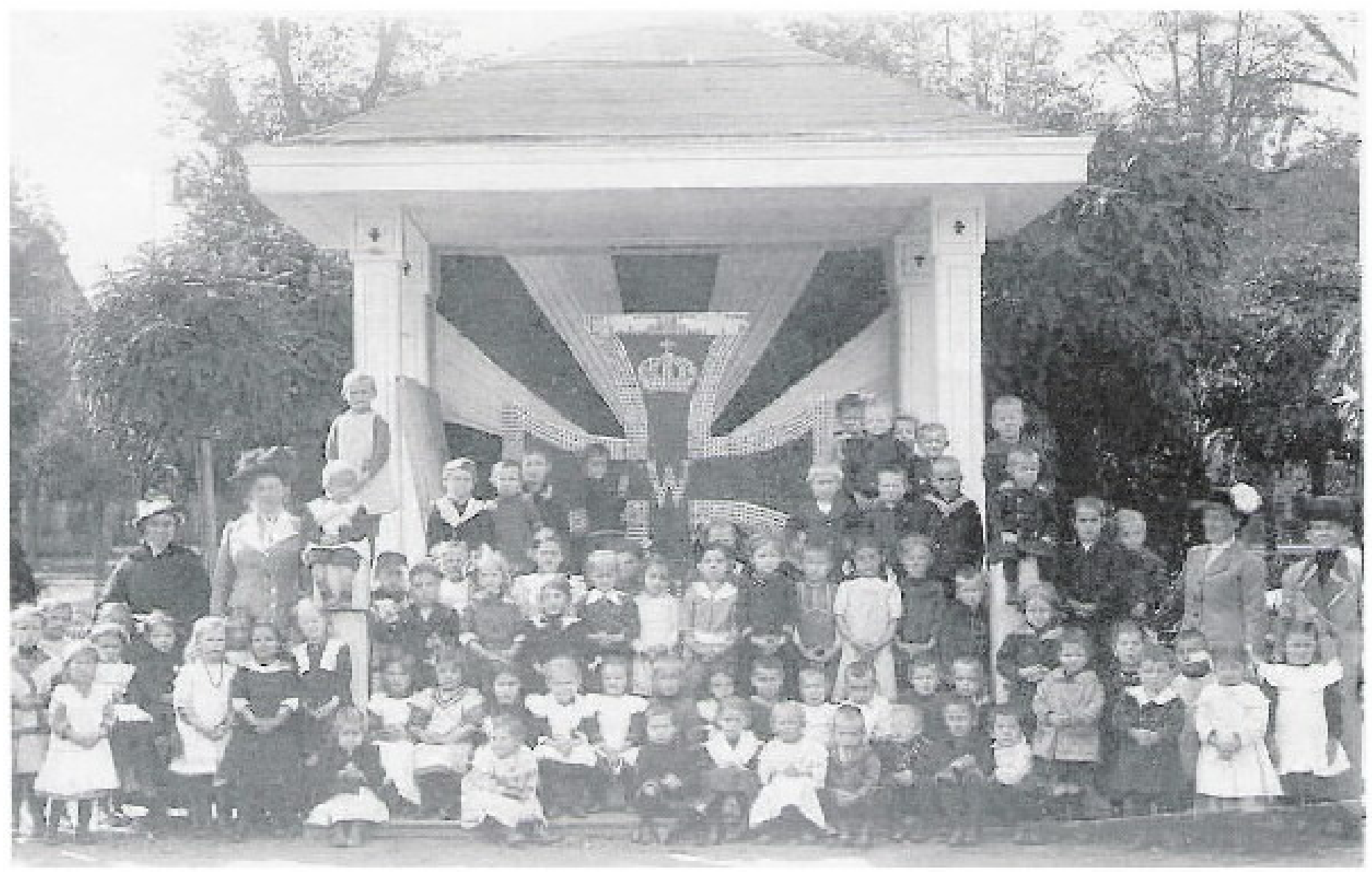

Nagelung des Eisernen Kreuzes in Rudolstadt am 23.09.1915

Quelle: Stadtarchiv Rudolstadt 
Teilnahme an Nagelungen IV

Schulen am „Eisernen Schmied“ in Hagen (1)

\section{Bild 1}

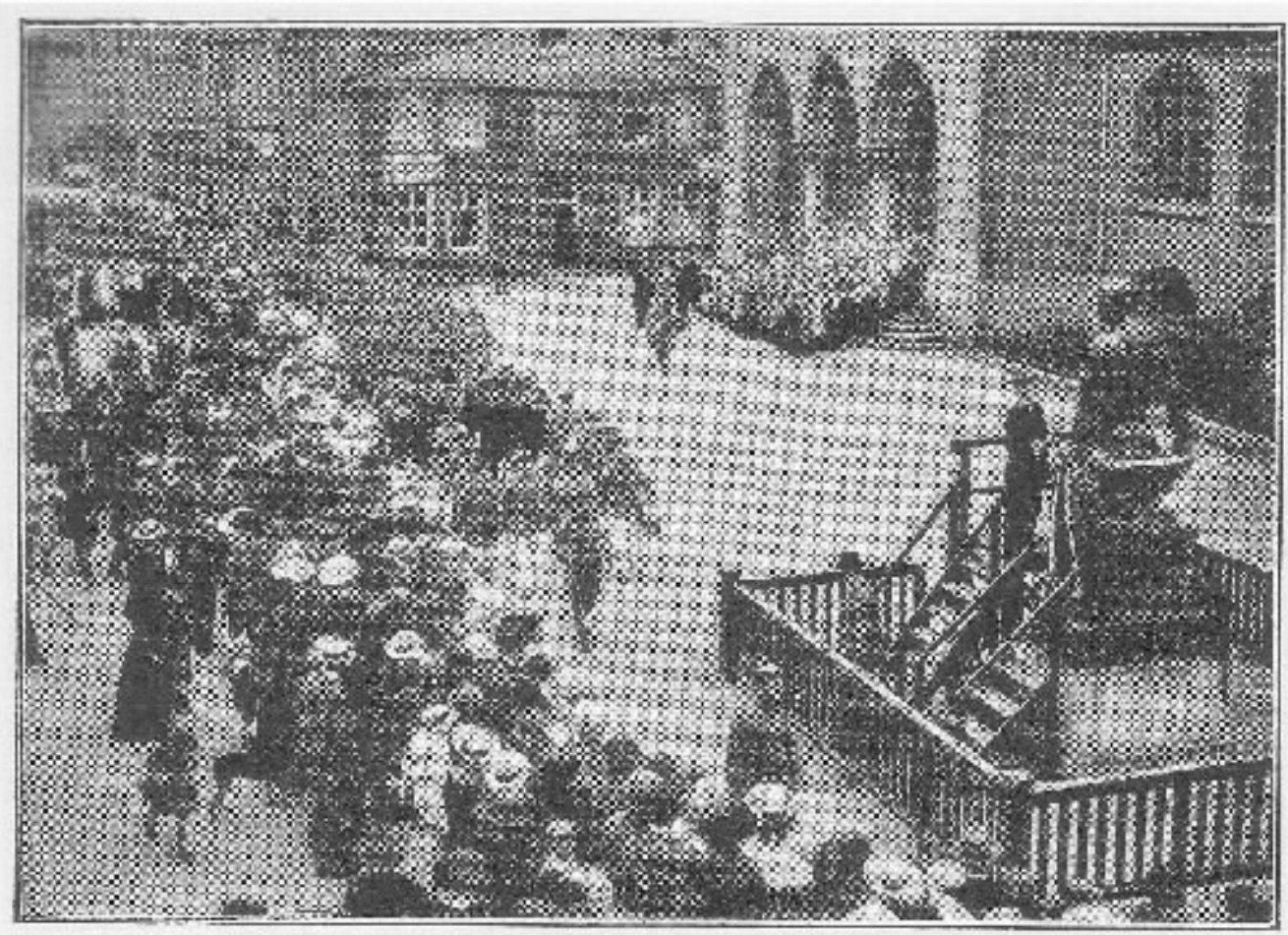

Attonarsci zur Nagelfeier.

\section{Bild 2}

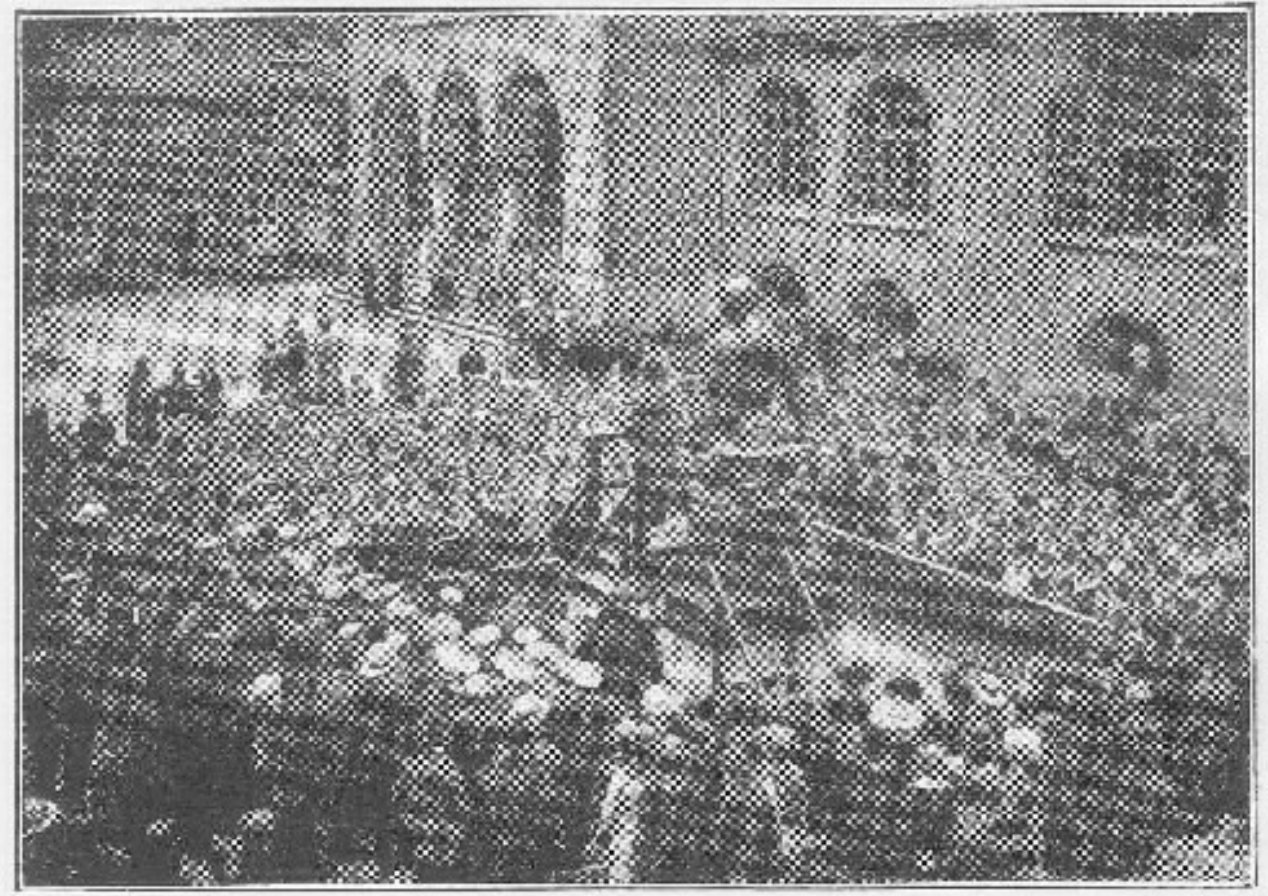

Sthïlcrchar am Eiscrncn Sdomiec.

Quelle: Der Eiserne Schmied von Hagen, S. 35 u. 37 


\section{Teilnahme an Nagelungen $\mathbf{V}$}

Schulen am „Eisernen Schmied“ in Hagen (2)

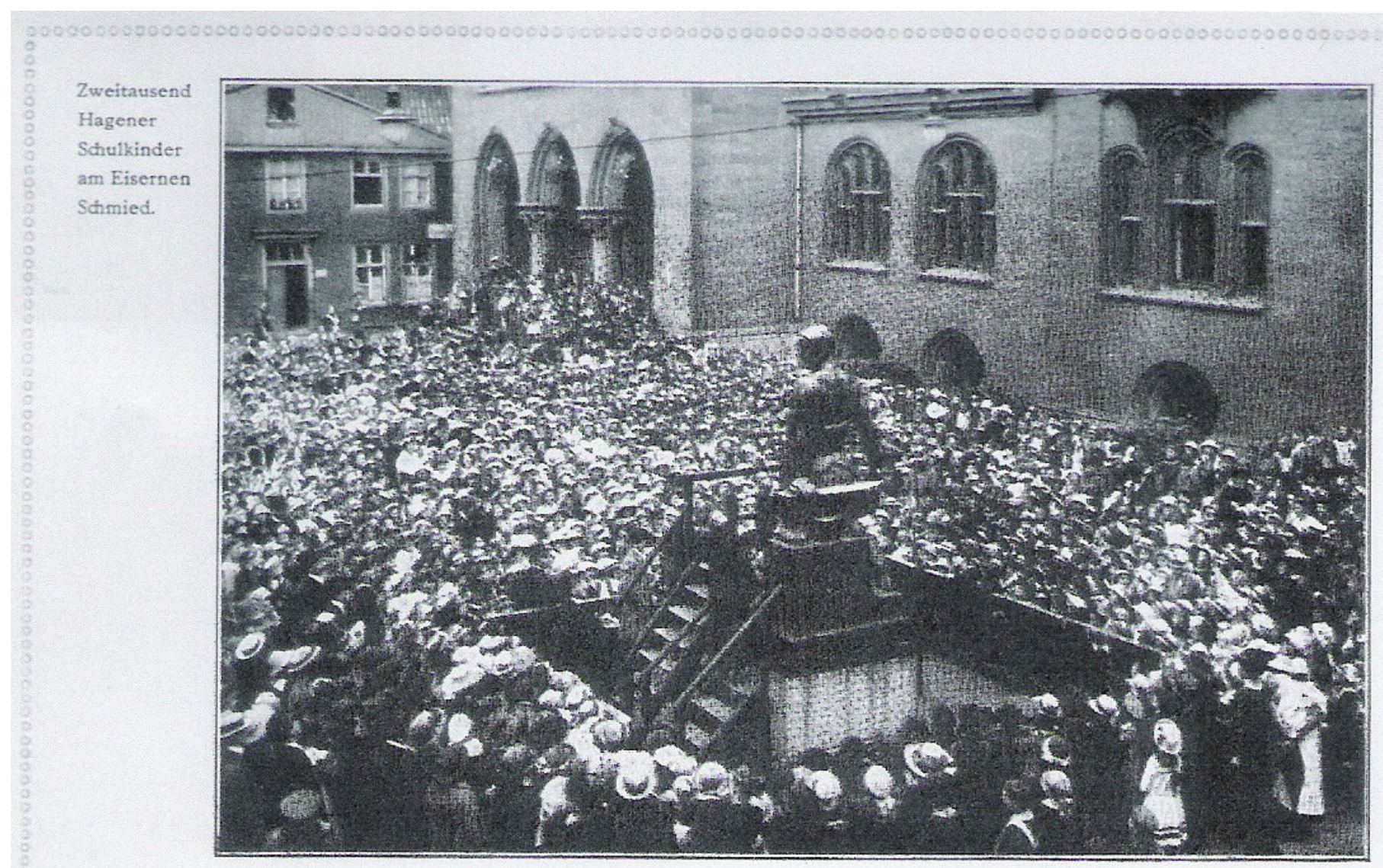

Quelle: Der „Eiserne Schmied von Hagen“, S. 37 


\section{Teilnahme an Nagelungen VI}

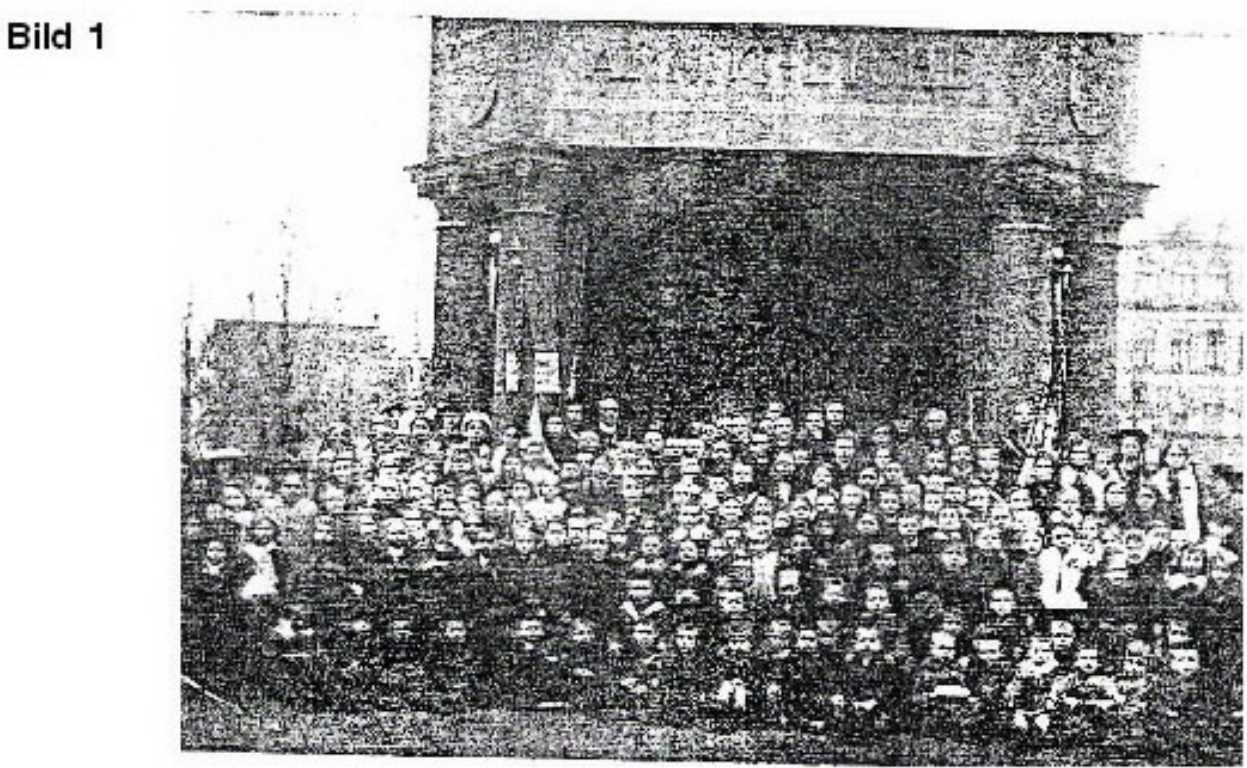

Nagelung der Arndt-Eiche in Bonn

Bild 2
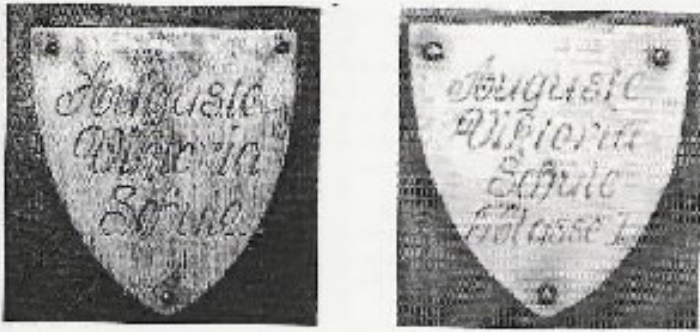

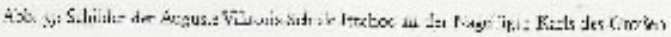

Nagelschilder der Auguste-Viktoria-Schule in Itzehoe

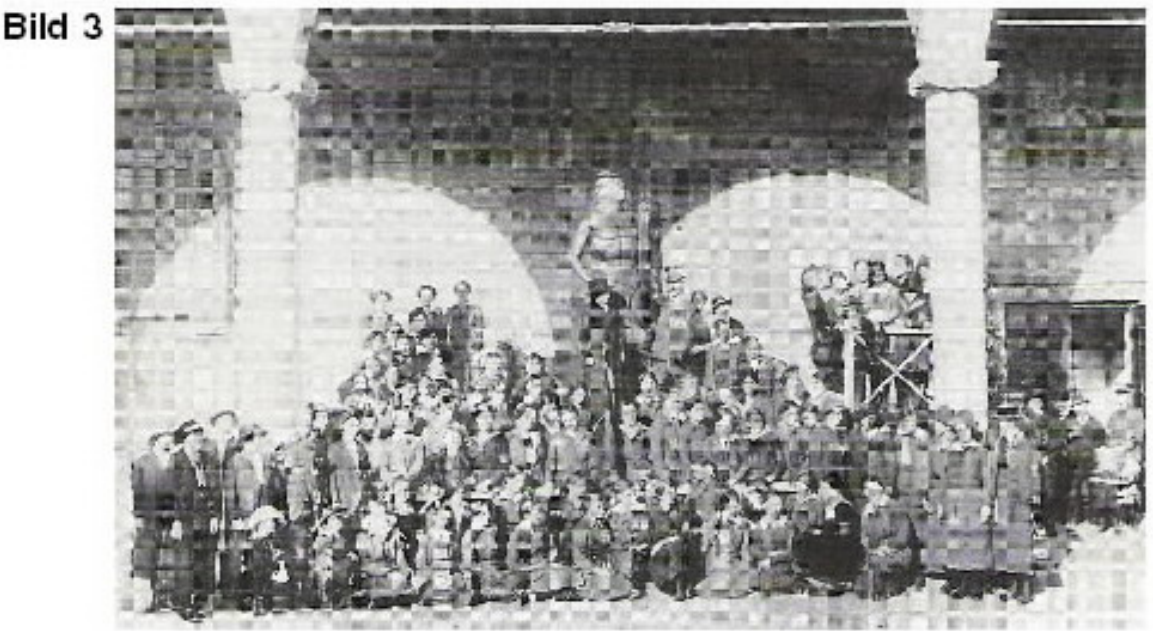

Nagelung des 'Eisernen Schwaben' in Stuttgart

Quellen: Stadtarchiv B onn (1); Pust, Vaterländische Etziehung, S. 408 (2); Sammlung Kronenberg (3) 


\section{Teilnahme an Nagelungen VII}

Der "Eiserne Mann" von Cleve - Nagelung des Königl. Gymnasiums am 26. März 1915

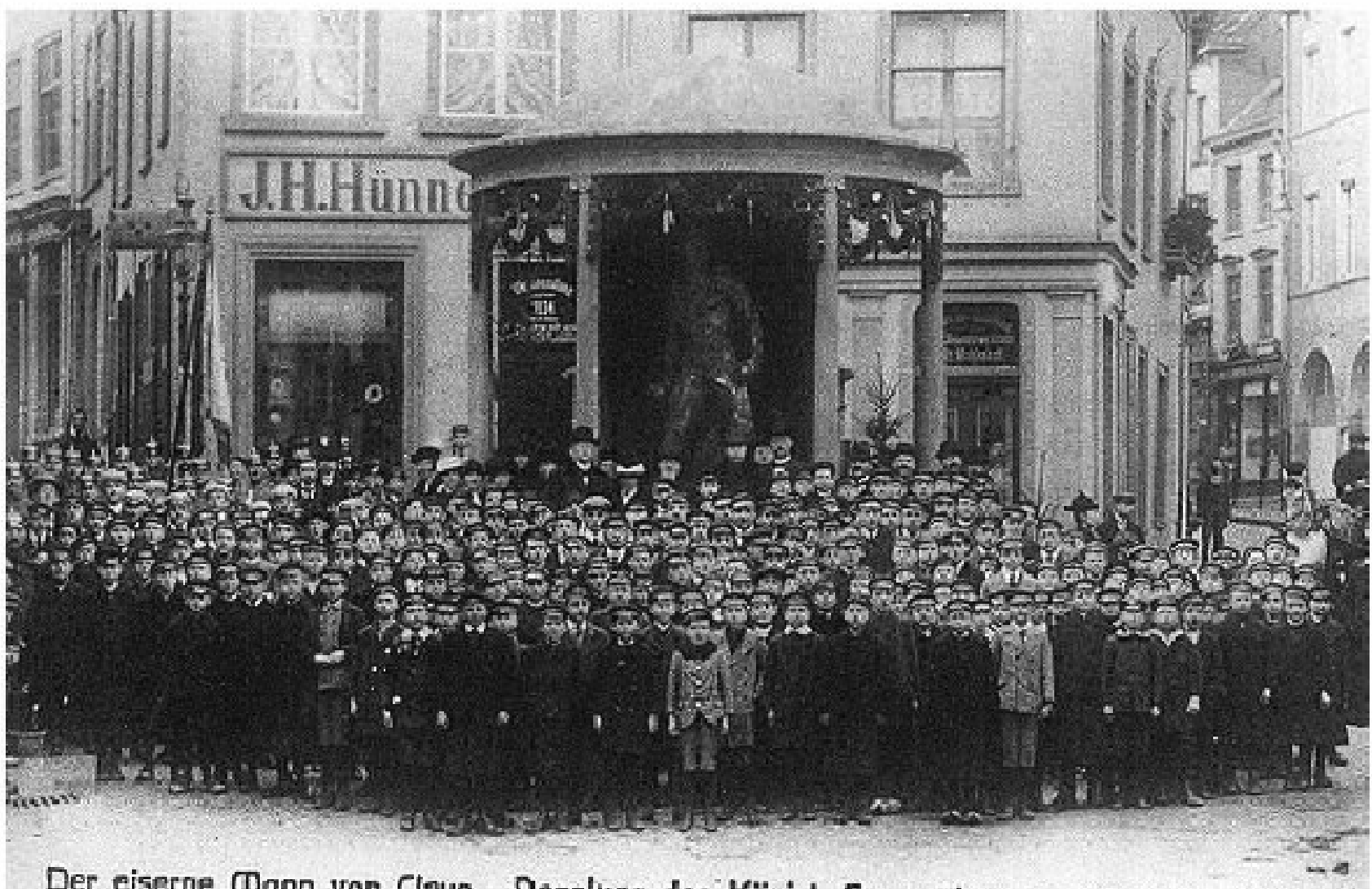

Der eiserne Thann von Cleve. Magelung des Königl. Gymnasium an 28. März 1916. -

Quelle:http:/www.heimat-kleve.de/geschichte/chronik/15.htm 


\section{Teilnahme an Nagelungen VIII}

\section{Bild 1}

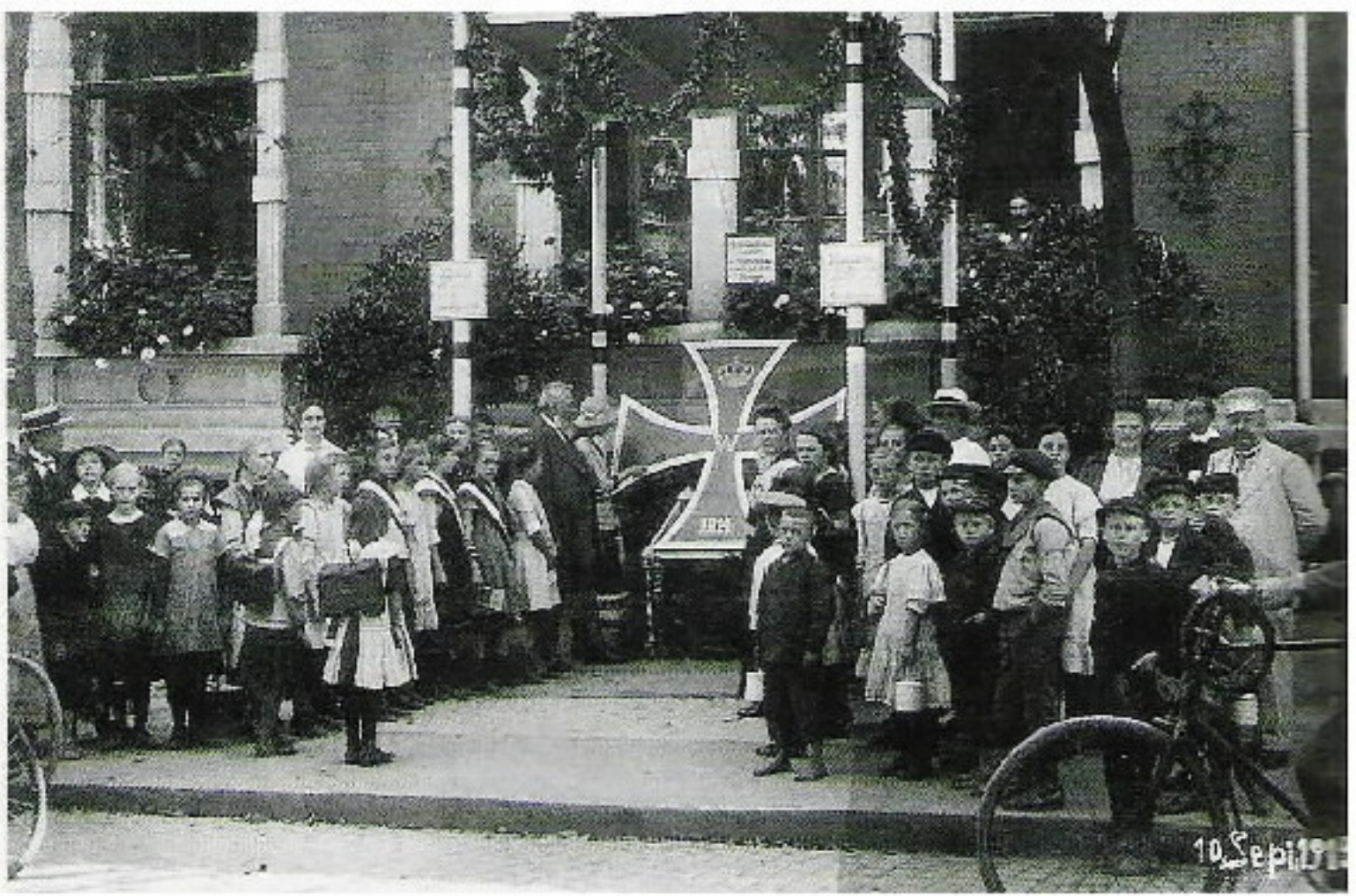

\section{Bild 2}

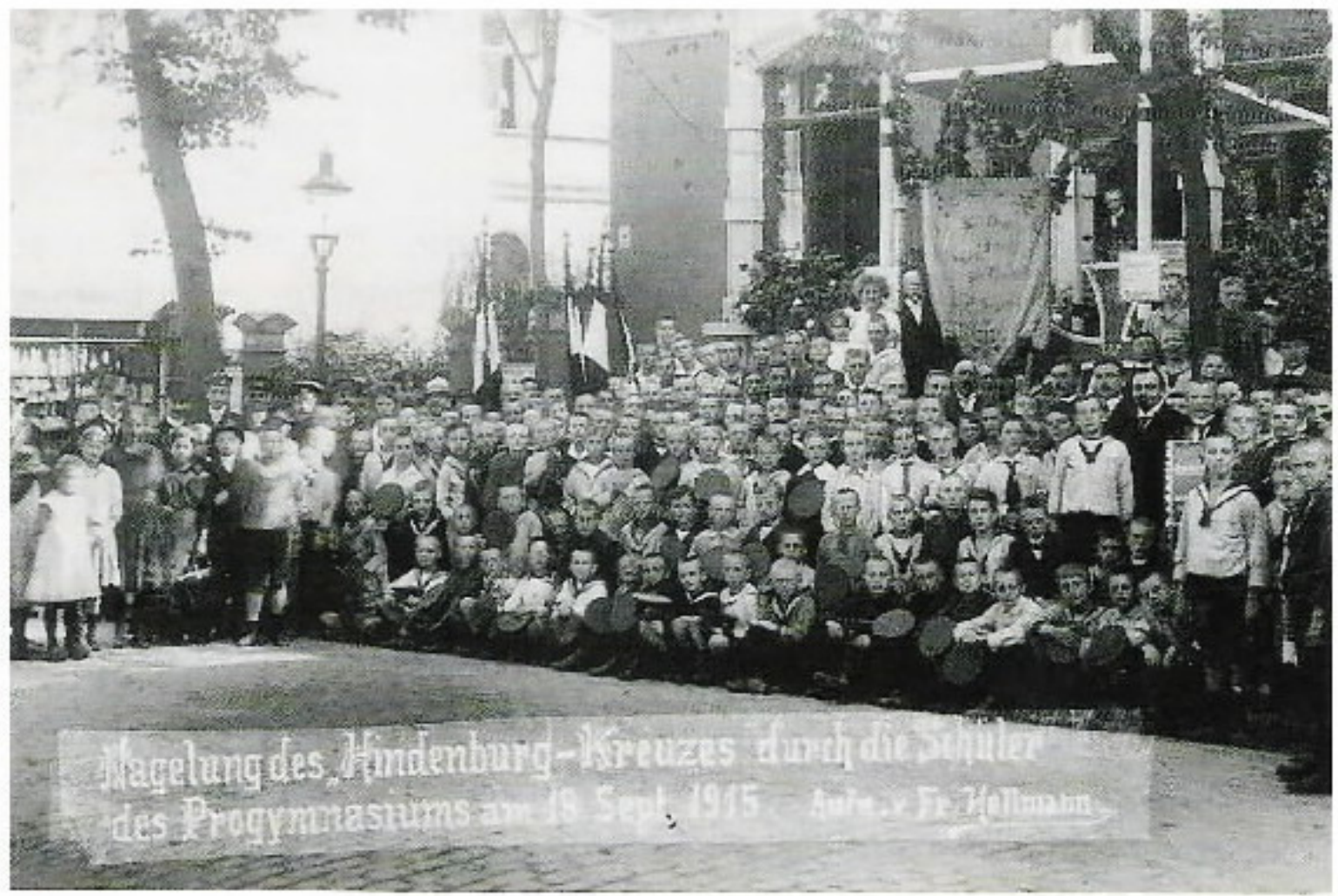

Quelle: Kuderer/Schneider, Nageln für das Vatefland, S.196 


\section{Teilnahme an Nagelungen IX}

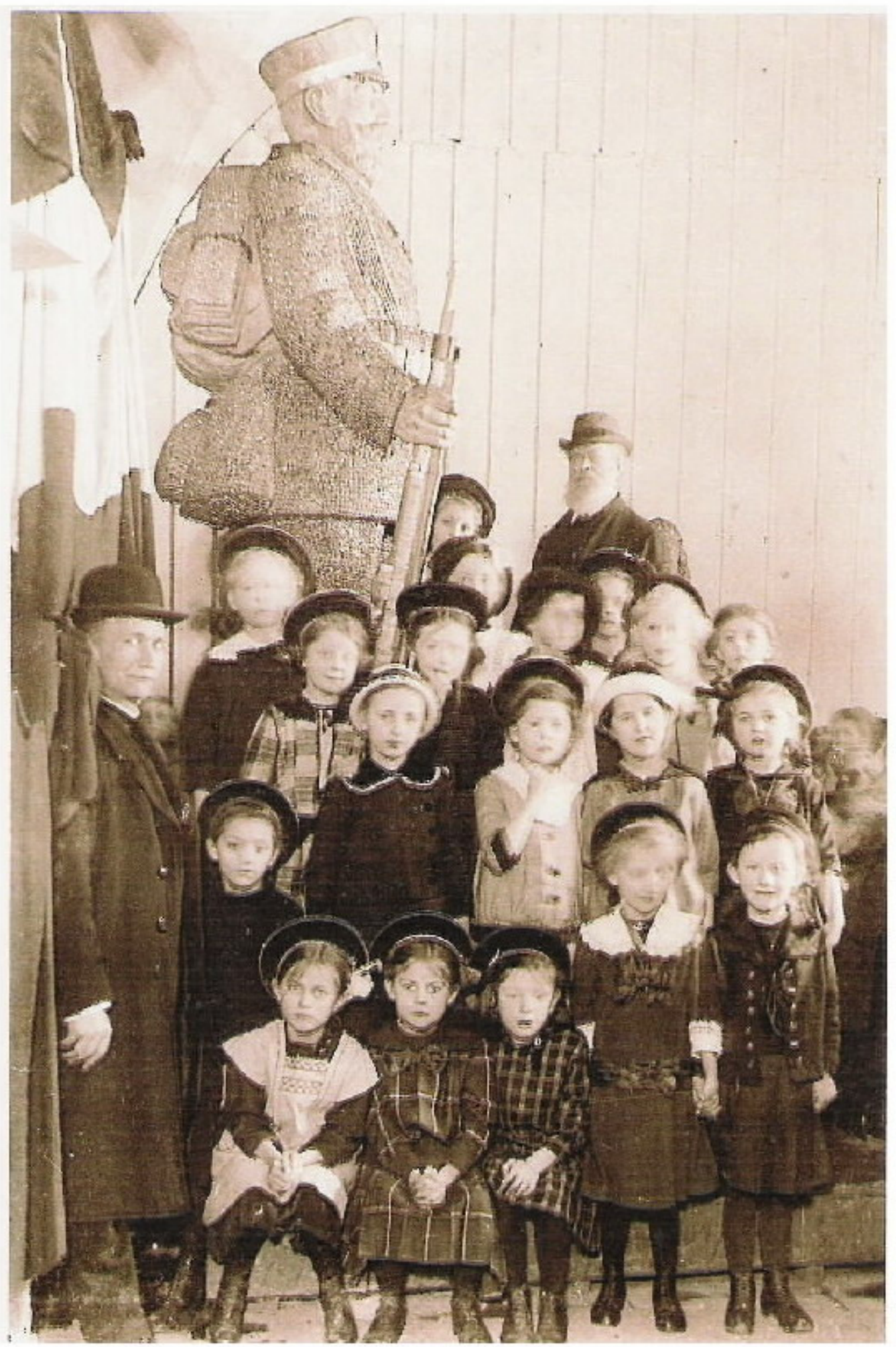

Eine Mädchenklasse vor dem "Eisernen Landsturmmann" in Erfurt 


\section{Teilnahme an Nagelungen $X$}

\section{Bild 1}

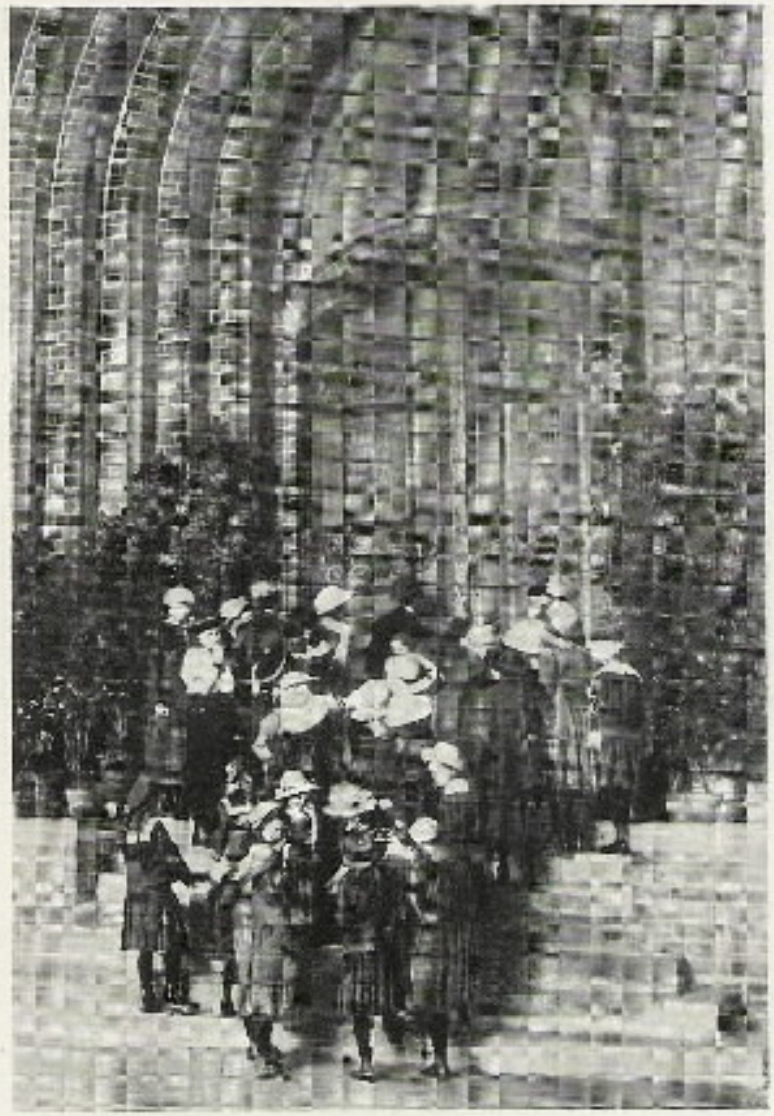

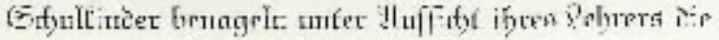

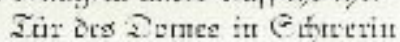

Eine Mädchenklasse nagelt die Domtür in Schwerin

Bild 2

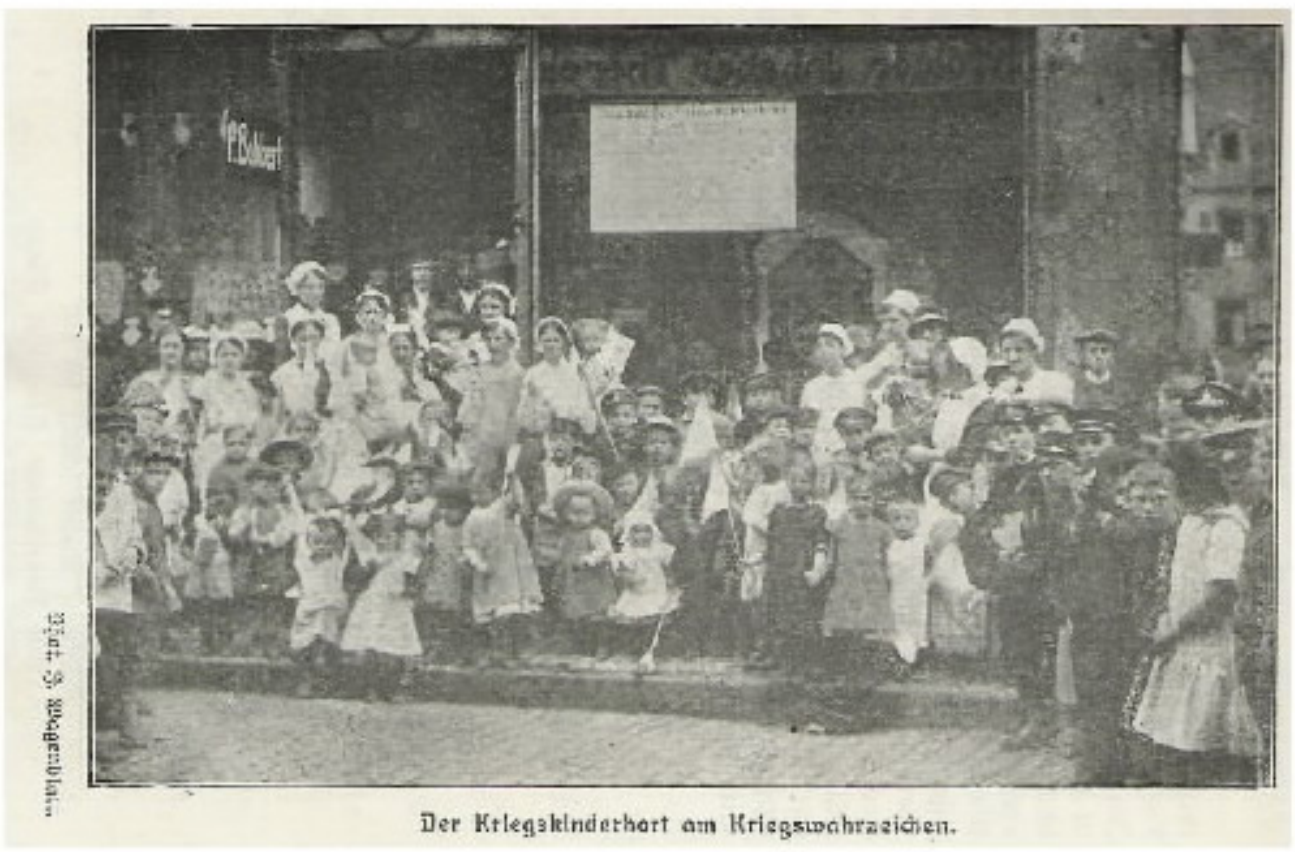

Die Kinder des Kriegskinderhortes nageln das Kriegswahrzeichen in Zweibrücken Quellen: Führen, Lehrer im Krieg, Tafel 24 (1); Loth, Das Kriegswahrzeichen der Stadt Zweibrücken (2) 
Teilnahme an Nagelungen XI

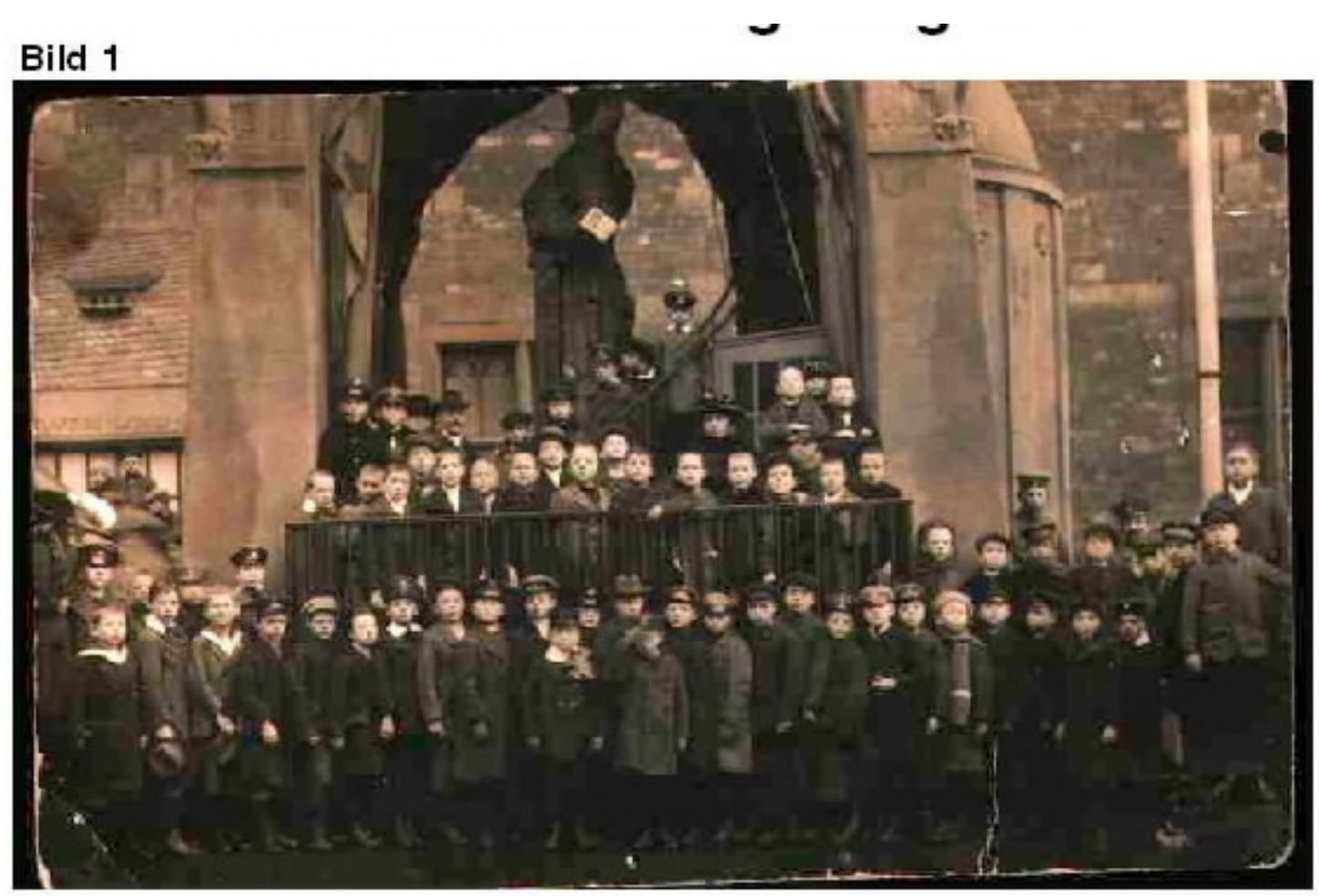

Nagelung des "Isern Boor" in Köln

\section{Bild 2}

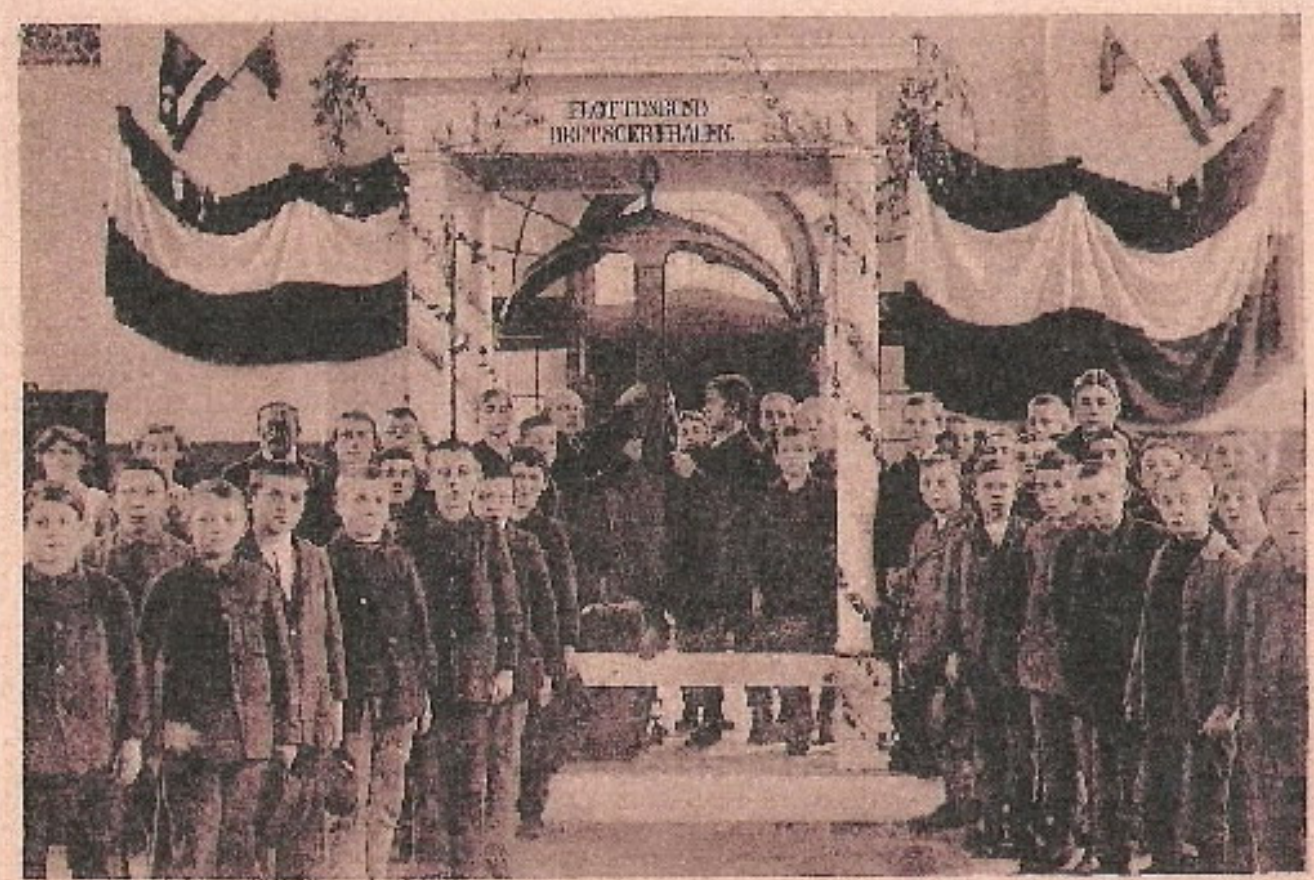

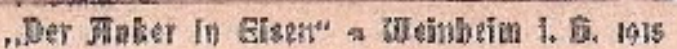

Nagelung des "Eisernen Ankers" in Weinheim 
Teilnahme an Nagelungen XII

Nagelung des „Eisernen Hindenburg“ in Berlin (1)

\section{Bild 1}

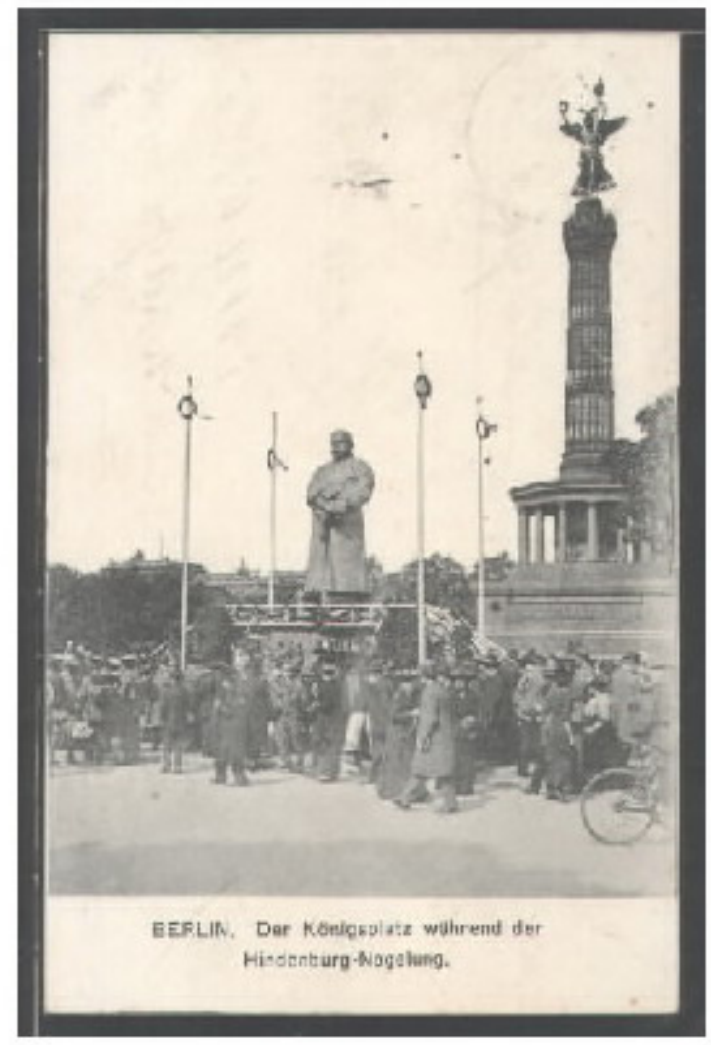

Bild 2

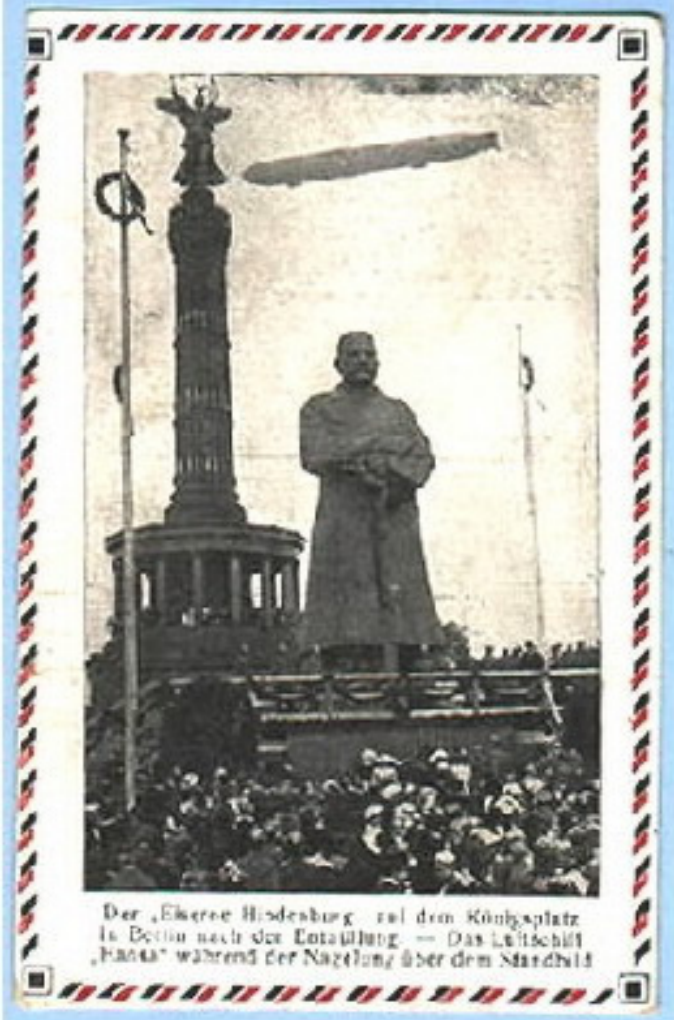

Der "Eiserne Hindenburg" mit Siegessäule und Luftschiff Quelle: Sammlung Kronenberg 
Teilnahme an Nagelungen XIII

Nagelung des „Eisernen Hindenburg“ in Berlin (2)

Bild 1

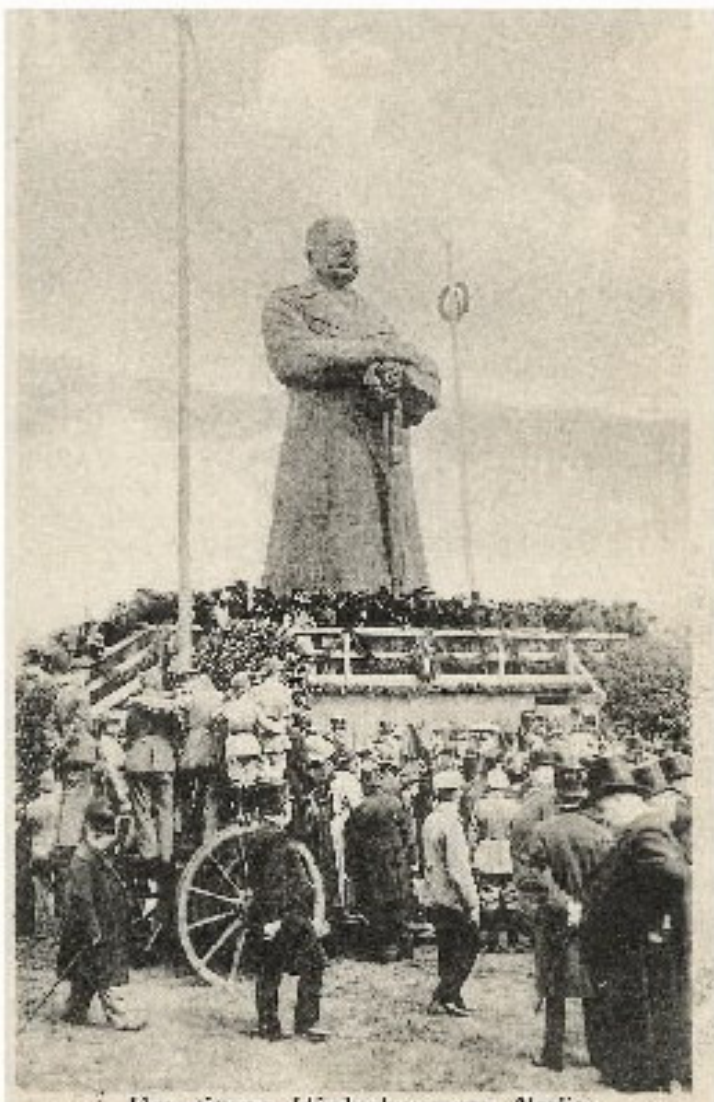

Uher eisene Hindeuburz yon Heslin.

Bild 2

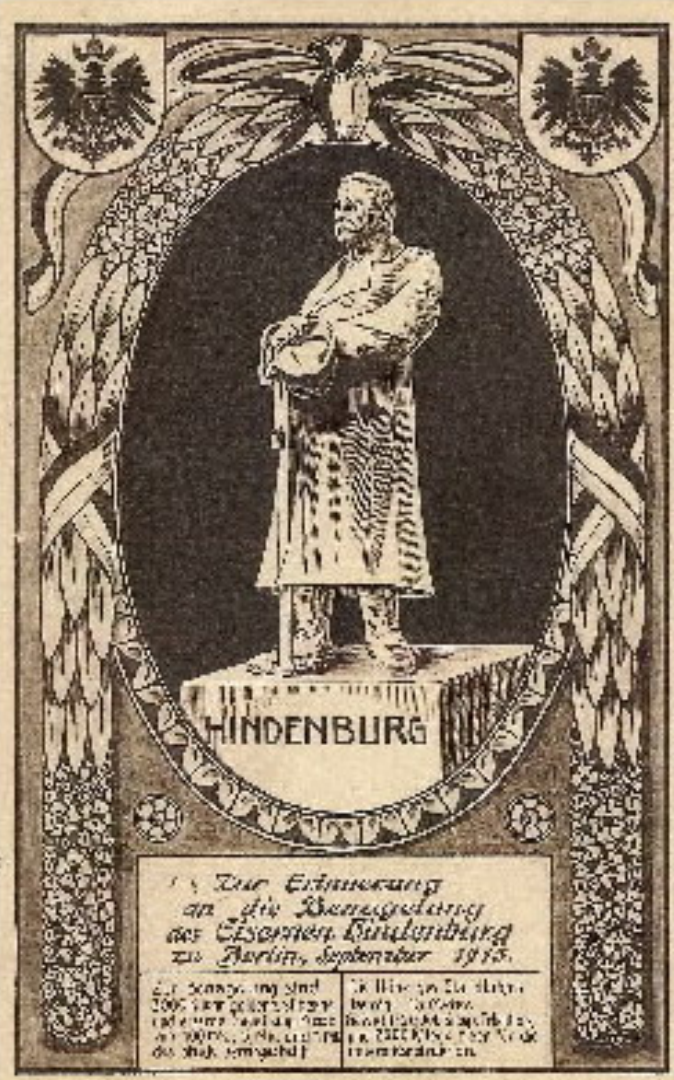




\section{Teilnahme an Nagelungen XIV \\ - Österreich -}

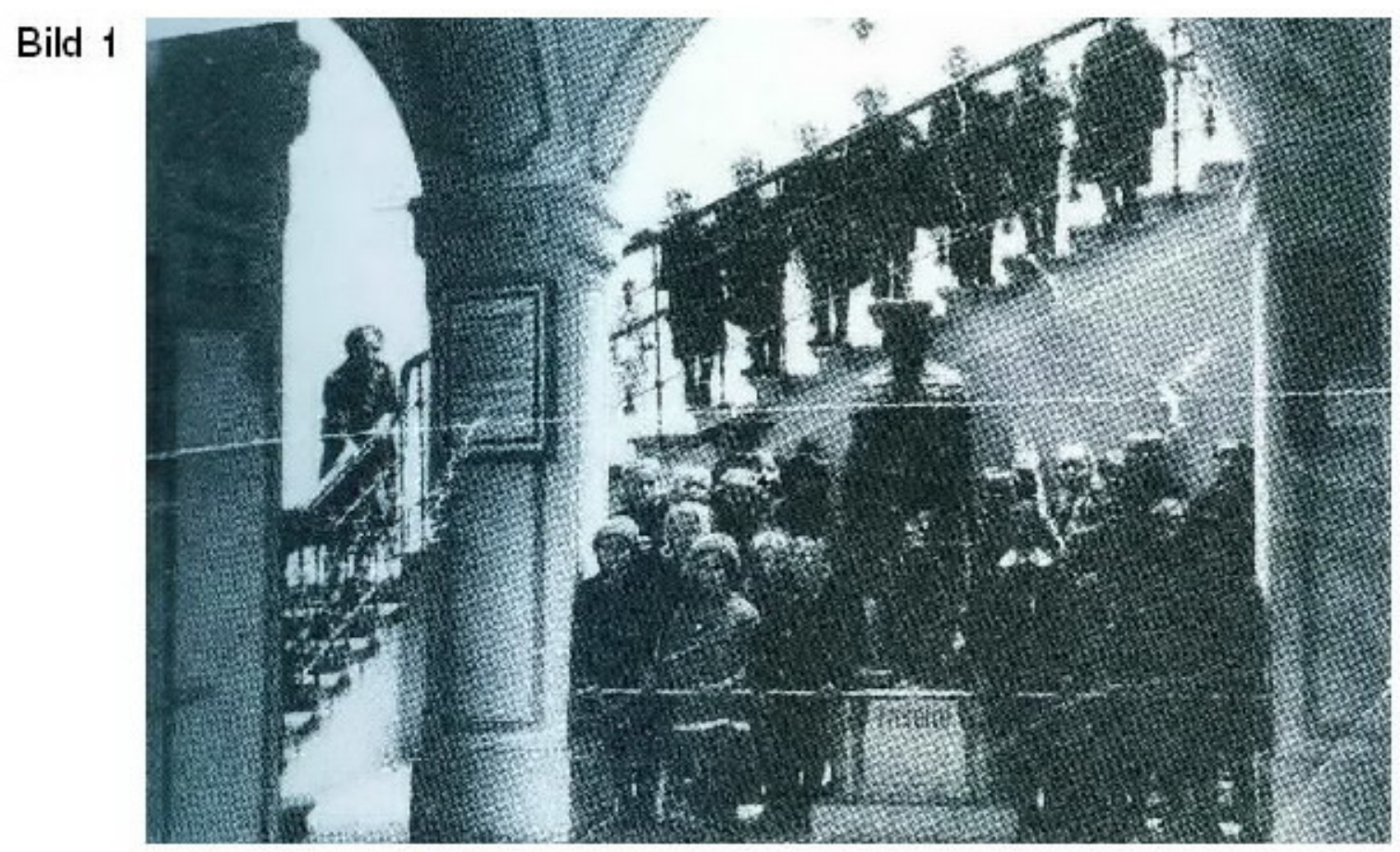

Schulkinder nageln 1915 den 'Eisernen Tassilo" im Kurhaus von Bad Hall

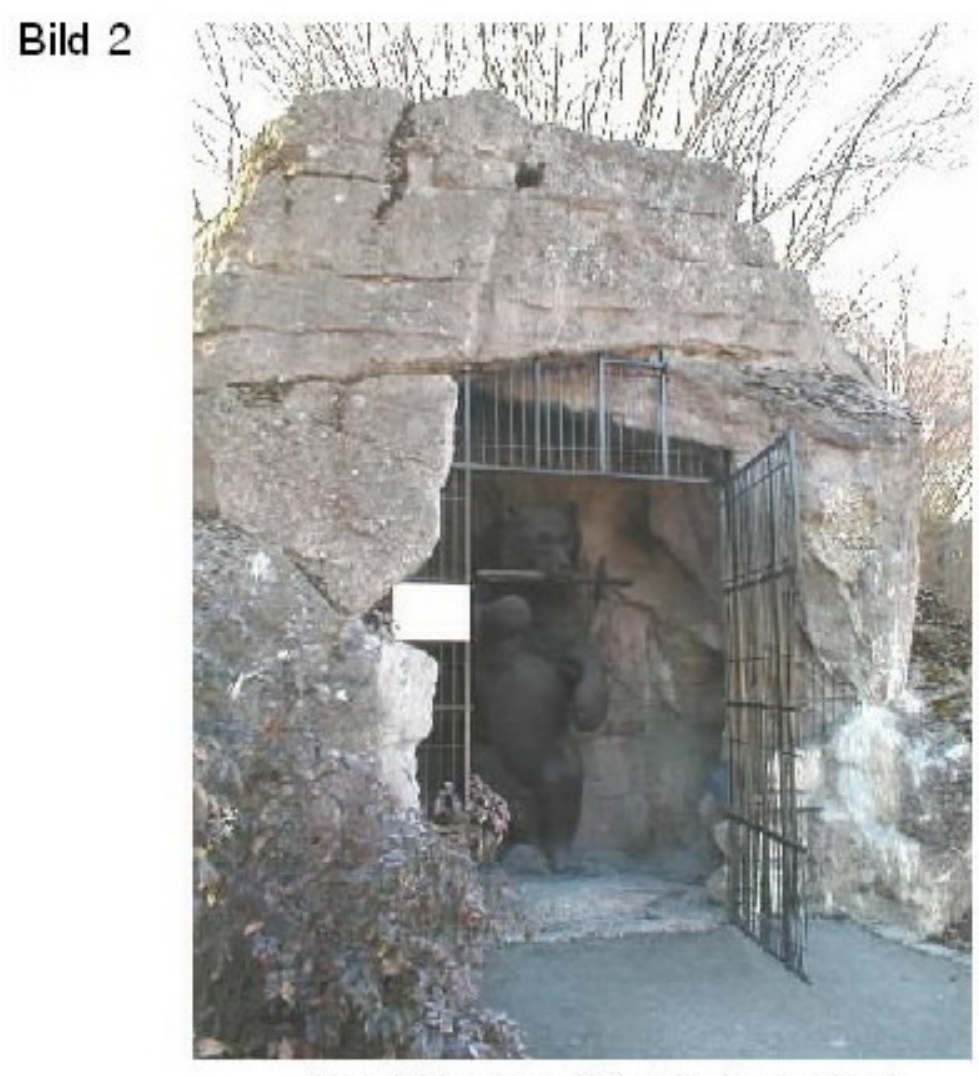

Der "Eiserne Bār" in Berndorf

Stadtarchive in Bad Hall (1) und Berndorf (2) 


\section{Kapitel 8}

\section{Sparaktionen I}

Nahrung

\section{Bild 1}

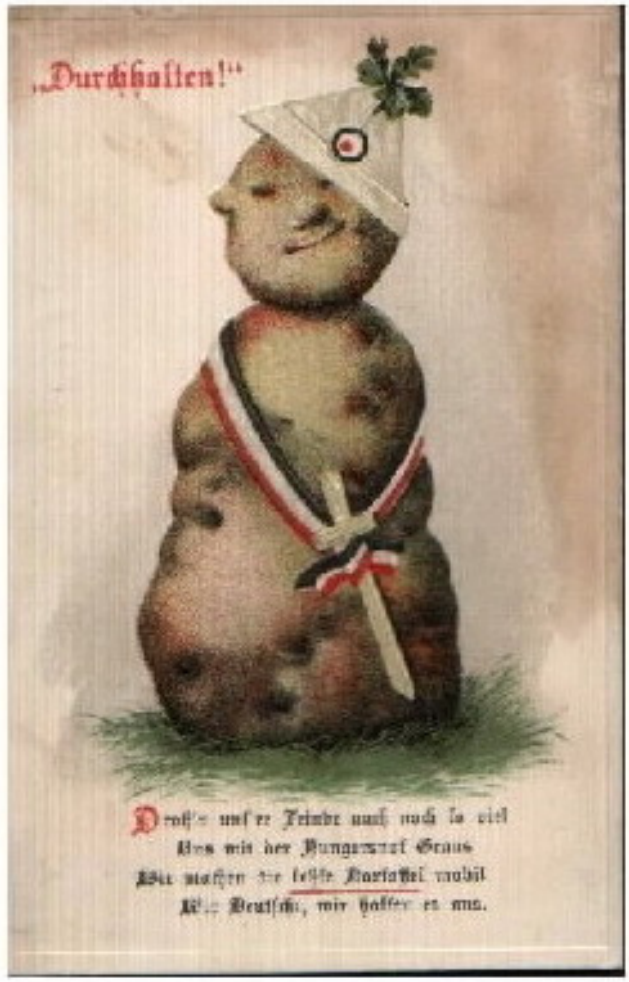

Bild 2

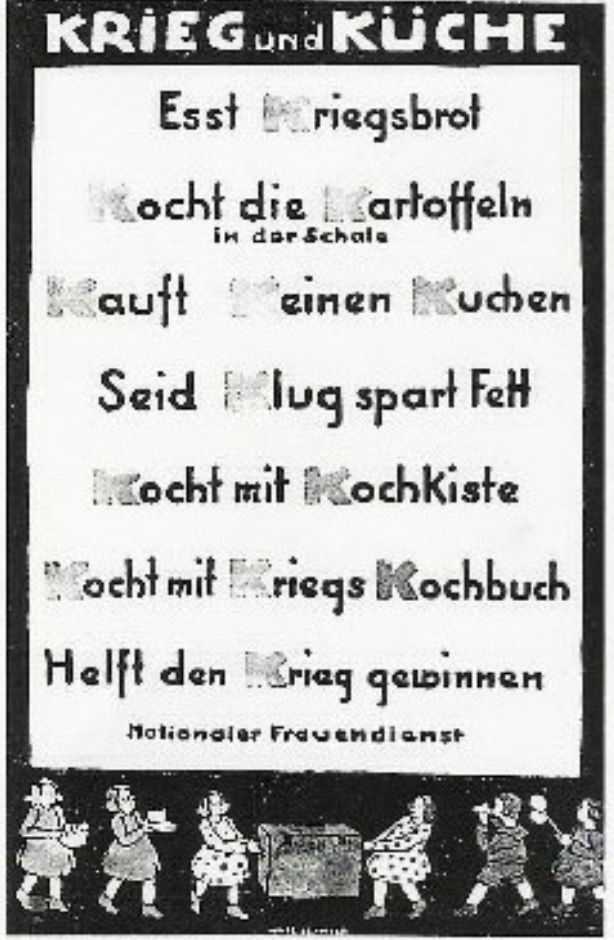

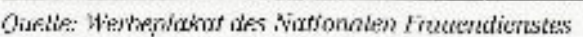

\section{Bild 3}

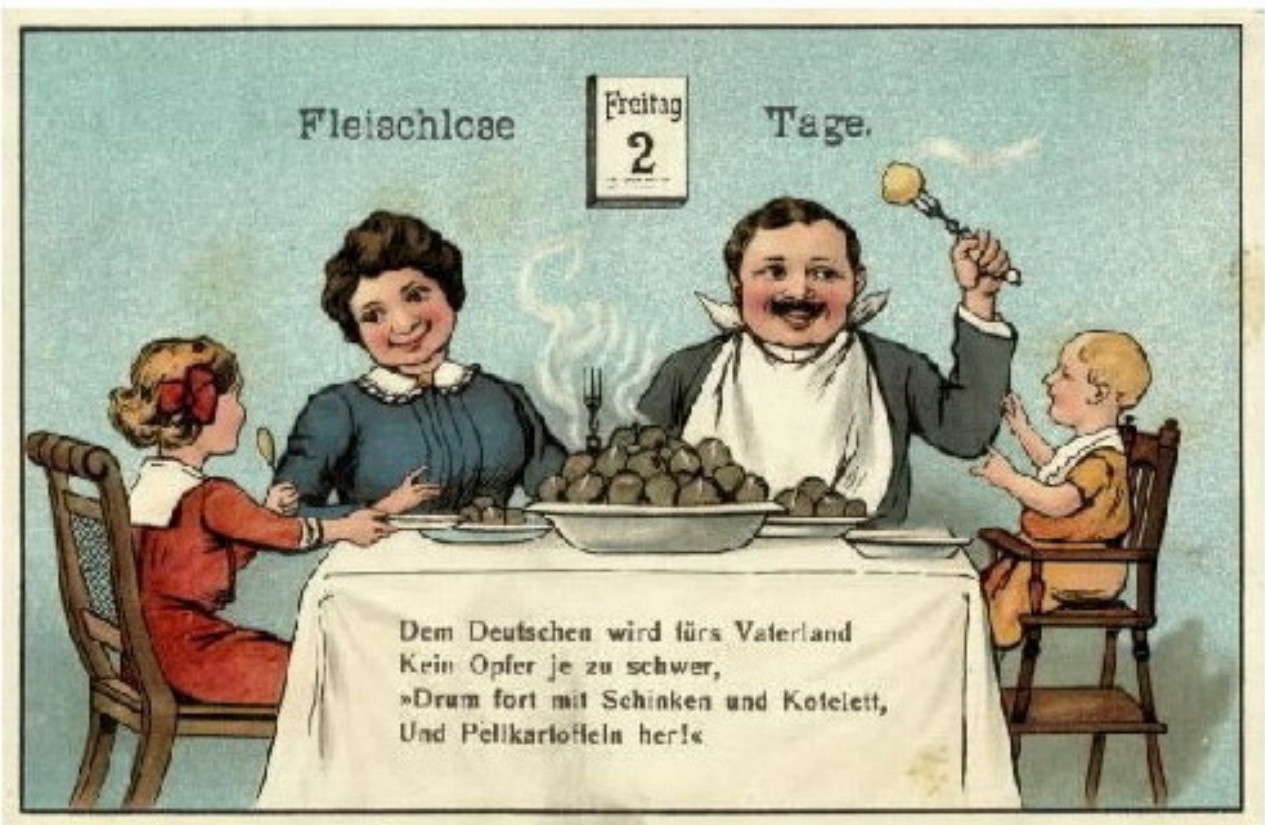

Quellen: Sammlung Kronenberg (1, 3); Oberschelp, Stahl und Steckrüben (2), S. 244 


\section{Sparaktionen II}

Schuhe

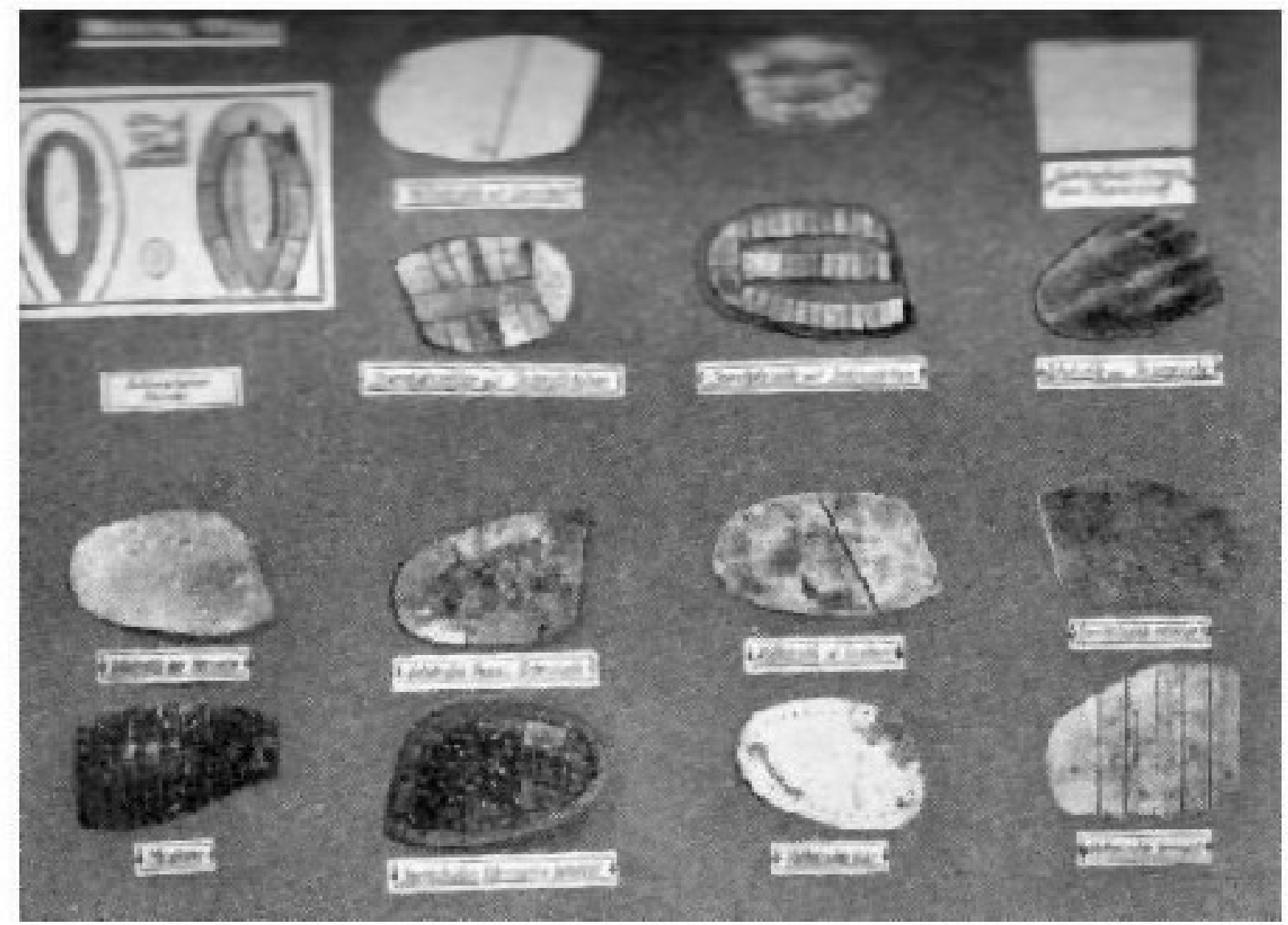

Schuhsohlenersatz

Quelle: Stadtarchiv Bielefeld 
Sparaktionen III

Bild 1

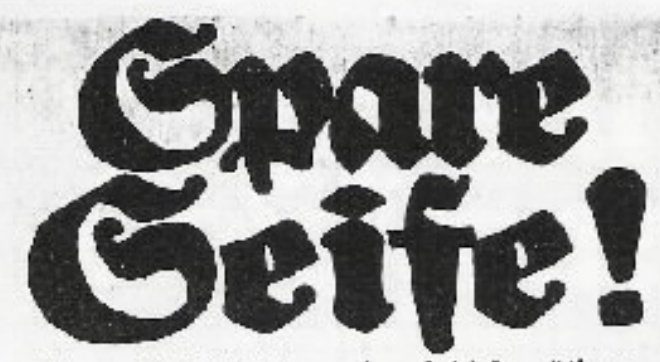

Denu fic belieht aus beu jeht fo nötigen unb tnapven Setten und Oefen.

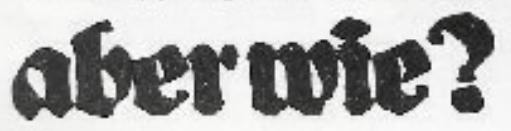

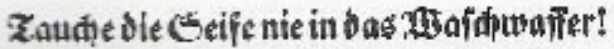

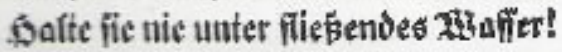

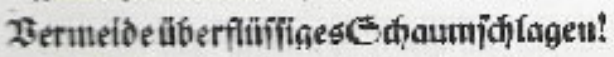
Safte den Seifennapf fiets troden! abiref bie Seifenrefic uidit weg?

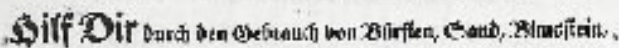

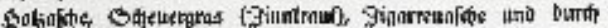

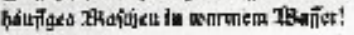

Gitiegsaugfútup für Dele unb Sette Berlin $x$ th $\pi$

tast

\section{Kampf gegen Fremdwörter}

Bild 2

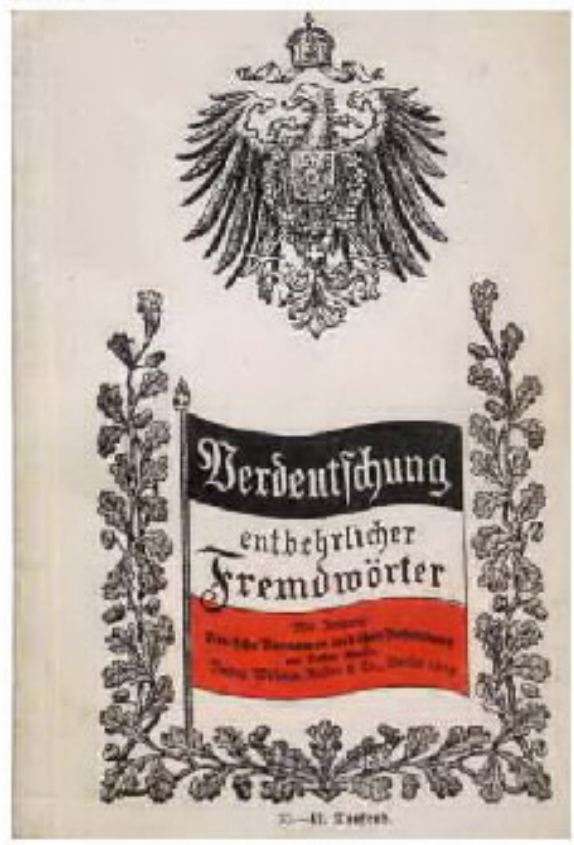

Bild 3

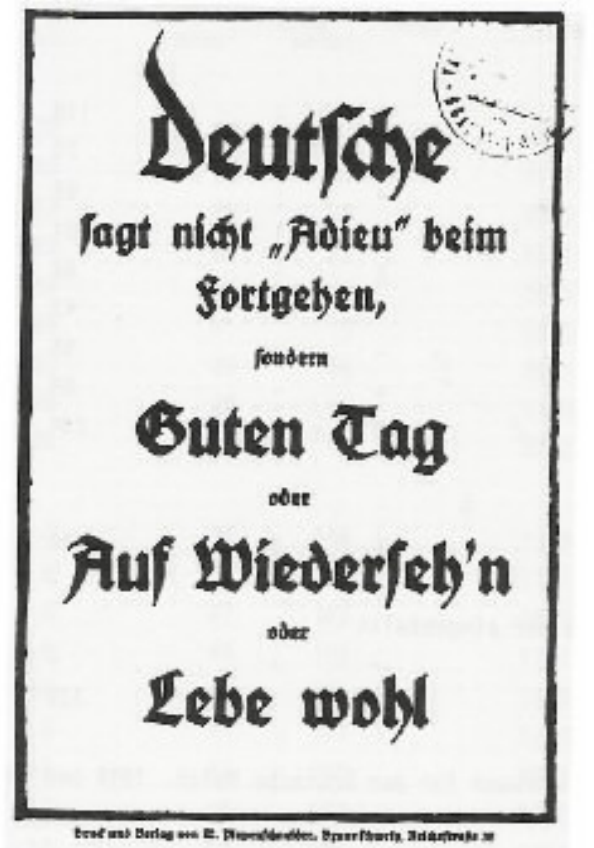




\section{Schlussbetrachtung}

\section{Die Nagelung des Friedenswahrzeichens}

Schulprojekt der Käthe-Kollwitz-Schule Hannover

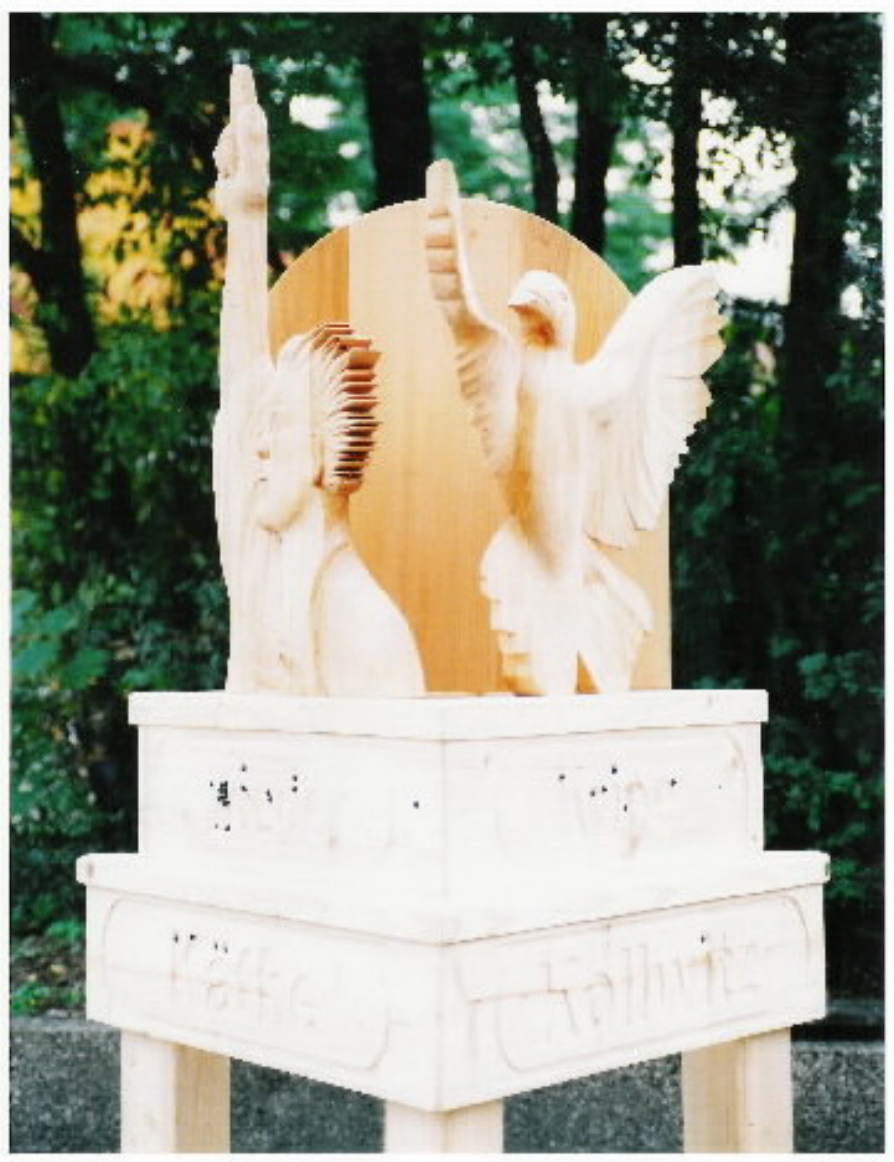

Das Wahrzeichen wurde vom Holzschnitzer Uwe Bormann (Rieder) nach Schülerentwürfen 2005 hergestellt.

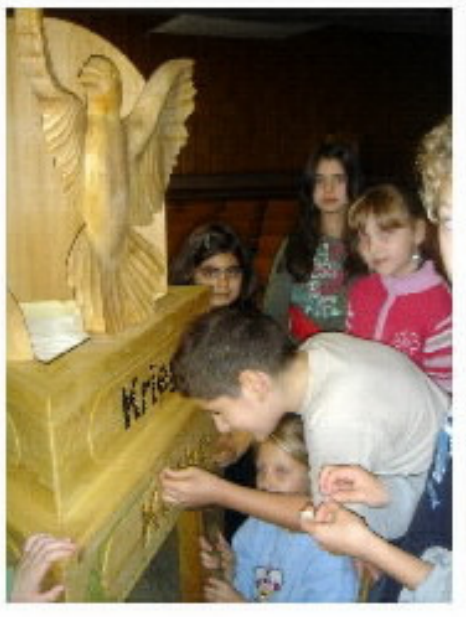

Schüler einer 5 . Klasse beim Nageln

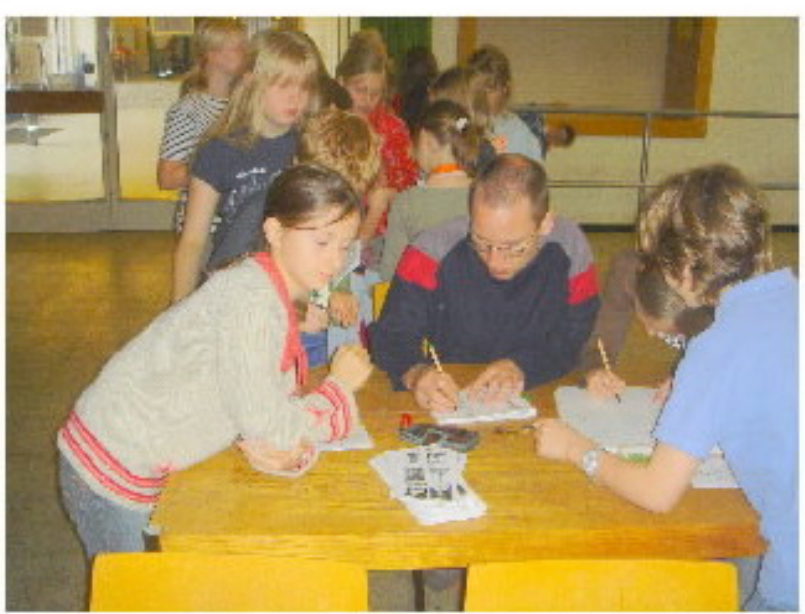

Eintrag ins Nagel buch und Ausgabe der Nagel urkunde 